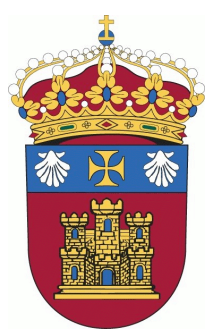

UNIVERSIDAD DE BURGOS

\title{
2,3-Dihalofenoles: Sustratos de partida versátiles para la síntesis de heterociclos funcionalizados regioselectivamente
}

VERÓNICA GUILARTE MORENO

Tesis Doctoral

Burgos, 2012 



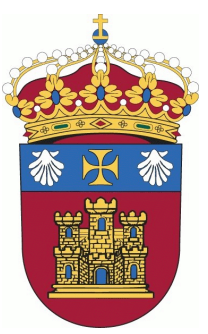

BEGOÑA GARCÍA RUIZ, Directora del Departamento de Química de la Universidad de Burgos.

\section{INFORMA:}

Que habiéndose recibido en este Departamento la memoria presentada por la licenciada Verónica Guilarte Moreno titulada "2,3-Dihalofenoles: Sustratos de partida versátiles para la síntesis de heterociclos funcionalizados regioselectivamente”, dirigida por el Catedrático Roberto Sanz Diez, con la que opta al grado de Doctor por la Universidad de Burgos, y que no habiéndose presentado ninguna objeción de los miembros del Consejo del Departamento, extiende, por la presente, el preceptivo informe favorable, a fin de que prosiga su trámite ante la Comisión de Doctorado de la Universidad de Burgos.

Burgos, Marzo de 2012

Fdo.: Begoña García Ruiz 

ROBERTO SANZ DIEZ, Catedrático de Química Orgánica del Departamento de Química de la Universidad de Burgos.

\section{CERTIFICA:}

Que la presente memoria titulada "2,3-Dihalofenoles: Sustratos de partida versátiles para la síntesis de heterociclos funcionalizados regioselectivamente”, ha sido realizada en el Departamento de Química de la Universidad de Burgos, bajo su dirección, por la licenciada Verónica Guilarte Moreno y autoriza su presentación para que sea calificada como Tesis Doctoral.

Burgos, 31 de Enero de 2012

Fdo.: Dr. Roberto Sanz Diez 

"A mi familia,

por estar siempre a mi lado" 



\section{AGRADECIMIENTOS:}

En primer lugar, quisiera agradecer a mi director de Tesis, Roberto Sanz, el haberme dado la oportunidad de formar parte de su grupo de investigación durante estos años. Quisiera darle las gracias por su esfuerzo, dedicación, paciencia y total disponibilidad para ayudarme en cualquier momento. Gran parte de lo aprendido durante estos años se lo debo a él, por contagiarme su afán de superación y su gran pasión por la Síntesis Orgánica.

A todos mis compañeros de trabajo, con los que he compartido la mayor parte de mi vida durante estos años, gracias por estar siempre dispuestos a echarme una mano siempre que lo he necesitado. A todos ellos querría además agradecerles la amistad que hemos compartido y todos los momentos que hemos vivido. Aparte de las experiencias profesionales, hemos estado juntos en numerosas cenas, fiestas, congresos y viajes, de los cuales guardo un grato recuerdo. A Pilar, por ayudarme a dar mis primeros pasos en el laboratorio. Gracias por todos tus consejos, paciencia y enseñanzas, y por intentar resolver todas mis dudas siempre con una sonrisa. A Delia y Alberto, por contagiar con su alegría el ambiente del laboratorio y hacer más llevadero el trabajo diario. A Manu, Patricia y Elsa por su ayuda, especialmente en los últimos meses, al igual que por su trabajo en el estudio de la síntesis de benzo[b]tiofenos. Al resto de mis compañeros de "labo": Nuria, Pedro, Noelia, Ana, Mukut, Estela, Silvia, Dani, Balles, Bea, Miriam... con quienes he compartido largas jornadas de trabajo pero también momentos de diversión. Muchas gracias a todos vosotros por hacer de estos años una de las mejores etapas de mi vida.

A Jacinto y Marta, por su gran efectividad y profesionalidad en el trabajo. Gracias por vuestra ayuda y colaboración siempre que la he necesitado. A Jacinto quisiera además agradecer su apoyo moral y paciencia en todo momento.

Professor Paul Wentworth and Anita, thank you for giving me the opportunity to work in your group in The Scripps Research Institute in San Diego. Thank you for your welcome and for being so kind with me. I also would like to thank my lab mates during these months, specially Rajesh and Brian, thank you for your help and support in any moment.

Dr. Matthew J. Gaunt, thank you for giving me the opportunity to join to your group in the University of Cambridge. I learned too many things about $\mathrm{C}-\mathrm{H}$ activation using metal 
catalysis. Many thanks to all the Gaunt group members, specially to Christoph, Qiaoyan and Rafael, for being so nice with me. Thank you for your company and for all the time we have shared during these months.

A mis nuevos compañeros del CENIEH, especialmente a Fernando, Mathieu, Isabel, Ana, Carlos Saiz, Carlos Pérez... por su ánimo y apoyo en estos últimos meses. Gracias por estar siempre dispuestos a soportar mis continuas conversaciones mono-temáticas con amabilidad. A Fernando me gustaría agradecer todas esas charlas "químicas" que hemos compartido. A Mathieu quisiera además darle las gracias por su paciencia y comprensión durante este año, por saber entender que tenía que dividir mi tiempo entre dos mundos distintos: la geocronología y la síntesis orgánica.

A mis amig@s, Loreto, Elsa, Celia, María, Marina, Elena... por todos los momentos que hemos compartido durante todos los años que os conozco. Por la confianza y ánimos que me habéis dado para seguir adelante, y por saber hacerme sonreir en los malos momentos. Durante este último año habéis recibido un "no" a muchas de vuestras propuestas por mi falta de tiempo, así que os debo un montón de viajes, cenas, etc... que por fin podré disfrutar con vosotr@s.

A mi madre, para la que no tengo suficientes palabras para agradecer todo su esfuerzo y apoyo incondicional. Eres mi otra parte, la mitad sin la que no hubiera conseguido esto, mi punto de apoyo, la que me ve caer y siempre está ahí para ayudarme a levantar, la que me conoce tal y como soy, y así me quiere con mis múltiples defectos. Mamá, muchísimas gracias por estar siempre ahí y creer en mí, apoyándome en todas las decisiones que he tomado. A mi hermano, por su alegría, optimismo y apoyo, especialmente en estos últimos meses. Sois lo más importante de mi vida y con vuestra ayuda he podido conseguir las metas que me he ido proponiendo. 


\section{ÍNDICE DE ABREVIATURAS}

\begin{tabular}{|c|c|}
\hline Ac & acetilo \\
\hline Alq & alquilo \\
\hline $\mathrm{aq}$ & acuoso \\
\hline Ar & arilo \\
\hline BINAP & 2,2'-bis(difenilfosfino)-1,1'-binaftilo \\
\hline $\mathrm{Bn}$ & bencilo \\
\hline Boc & $t$-butoxicarbonilo \\
\hline cat. & catalítico \\
\hline CIPE & efecto de proximidad inducido por complejo \\
\hline CG-EM & cromatografía de gases-espectrometría de masas \\
\hline Cod & ciclooctadieno \\
\hline $\mathrm{Cp}$ & ciclopentadienilo \\
\hline $\mathrm{CyPF} t-\mathrm{Bu}$ & 1-diciclohexilfosfino-2-di-t-butilfosfinoetilferroceno \\
\hline DavePhos & 2-diciclohexilfosfino-2',2'-dimetilaminobifenilo \\
\hline $\mathrm{dba}$ & dibencilidenacetona \\
\hline DBDMH & 1,3-dibromo-5,5-dimetilhidantoína \\
\hline $\mathrm{DBU}$ & 1,8-diazabiciclo[5.4.0]undec-7-eno \\
\hline DEAD & azodicarboxilato de dietilo \\
\hline DiPPF & bis(diisopropilfosfino)ferroceno \\
\hline DMA & $N, N$-dimetilacetamida \\
\hline DME & 1,2-dimetoxietano \\
\hline DMF & $N, N$-dimetilformamida \\
\hline DMPU & $N, N^{\prime}$-dimetil- $N, N^{\prime}$-propilenurea \\
\hline DMSO & dimetilsulfóxido \\
\hline dppf & bis(difenilfosfino)ferroceno \\
\hline equiv. & equivalente \\
\hline HetAr & heteroarilo \\
\hline JohnPhos & 2-(bifenil)-di-t-butilfosfina \\
\hline LDA & diisopropilamiduro de litio \\
\hline
\end{tabular}




\begin{tabular}{|c|c|}
\hline LiHMDS & hexametildisilazida de litio \\
\hline LiTMP & amiduro de litio de la 2,2,6,6,-tetrametilpiperidina \\
\hline$\% \mathrm{~mol}$ & porcentaje en moles \\
\hline MOM & metoximetil \\
\hline MW & microondas \\
\hline NBS & $\mathrm{N}$-bromosuccinimida \\
\hline NMP & $N$-metilpirrolidona \\
\hline NOE & efecto nuclear Overhauser \\
\hline OTf & trifluorometano sulfonato \\
\hline PCC & clorocromato de piridinio \\
\hline PEG & polietilenglicol \\
\hline PPA & ácido polifosfórico \\
\hline PTSA & ácido $p$-toluensulfónico \\
\hline Py & piridina \\
\hline SPhos & 2-diciclohexilfosfino-2',6'-dimetoxibifenilo \\
\hline$t$-BuXPhos & 2-di-t-butilfosfino-2',4',6'-triisopropil-1,1'-bifenilo \\
\hline TBAF & fluoruro de tetrabutil amonio \\
\hline TIPS-SH & triisopropilsilil tiol \\
\hline TFA & ácido trifluoroacético \\
\hline Th & tienilo \\
\hline THF & tetrahidrofurano \\
\hline THP & tetrahidropirano \\
\hline TMEDA & $N, N, N^{\prime}, N^{\prime}$-tetrametiletilendiamina \\
\hline TMP & 2,2,6,6,-tetrametilpiperidina \\
\hline TMP-zincato & dialquil $(2,2,6,6$, -tetrametilpiperiduro)zincato de litio \\
\hline TMS & trimetilsililo \\
\hline Ts & $p$-toluenosulfonilo \\
\hline Xantphos & 4,5-bis(difenilfosfino)-9,9-dimetilxanteno \\
\hline XPhos & 2-diciclohexilfosfino-2', 4',6'-triisopropilbifenilo \\
\hline
\end{tabular}


INTRODUCCIÓN 1

ANTECEDENTES BIBLIOGRÁFICOS GENERALES.................................................................

A REACCIONES DE orto-METALACIÓN DIRIGIDA..............................................................

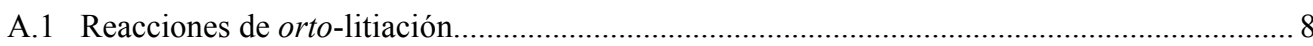

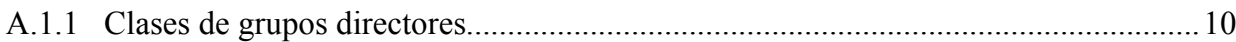

A.1.2 Reacciones de metalación dirigida en carbamatos de $O$-arilo................................15

A.1.3 Reacciones de metalación dirigida en carbamatos de $N$-arilo y anilidas................... 23

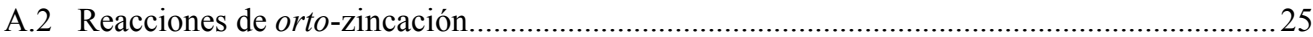

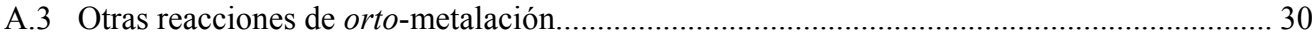

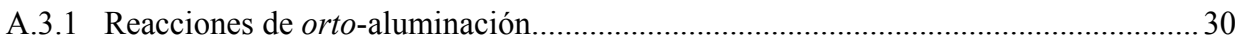

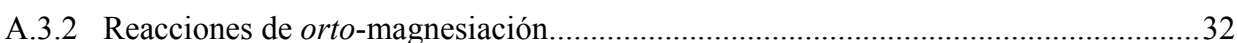

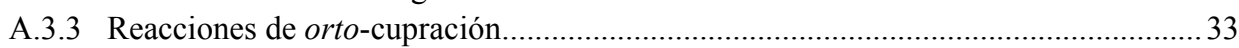

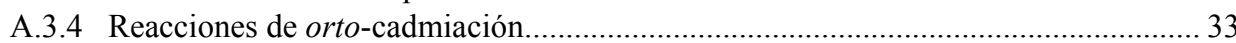

B REACCIONES DE ACOPLAMIENTO C-C CATALIZADAS POR COMPLEJOS

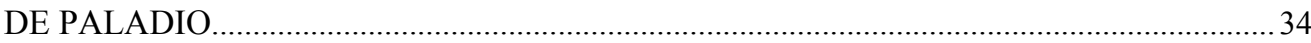

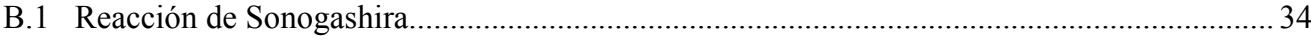

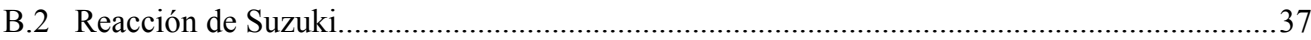

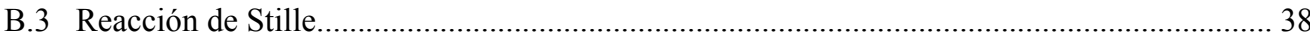

\section{CAPÍTULO 1: "Aproximaciones a la síntesis de 2,3-dihaloanilinas. Precursores de indoles}

1.1 INTRODUCCIÓN

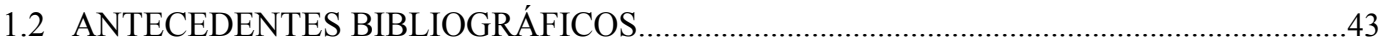

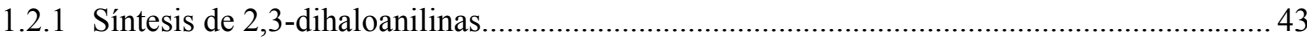

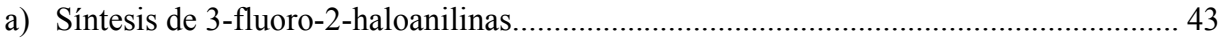

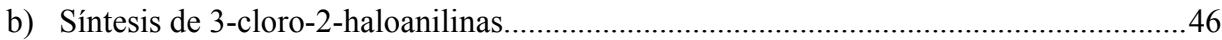

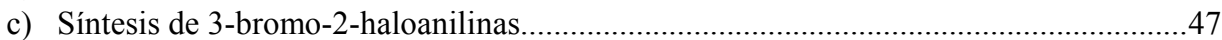

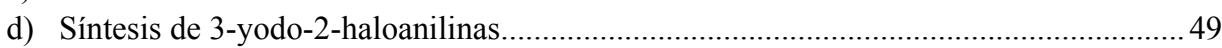

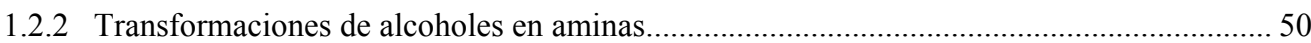

a) Transformación de alcoholes alifáticos en aminas.........................................................50

b) Transformación de alcoholes aromáticos en anilinas.................................................... 51

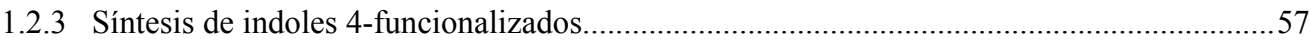

a) Introducción de sustituyentes en la posición 4 del núcleo indólico..................................58

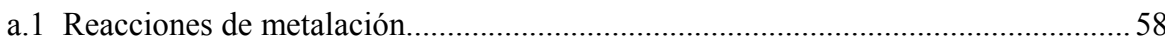

a.2 Activación del enlace C-H en 4-acetoxi-6,7-dihidroindoles..................................60

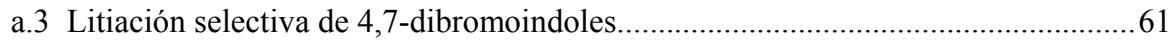

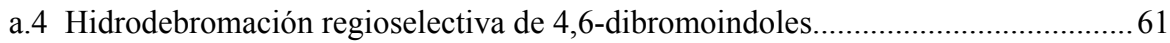

b) Reacciones de ciclación en sustratos previamente funcionalizados.............................. 61

b.1 Reacciones de ciclación con formación del enlace C3-C3a....................................... 61

b.2 Reacciones de ciclación con formación del enlace C2-C3 ....................................63 
b.3 Reacciones de ciclación con formación del enlace N-C2 ó N-C7a...................... 64

1.2.4 Síntesis de indoles 2-sustituidos mediante heterociclación de orto-alquinilanilinas............ 68

a) Procedimientos basados en catálisis con metales de transición........................................68

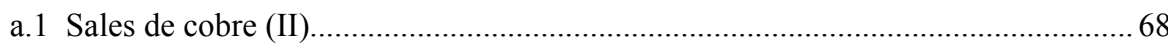

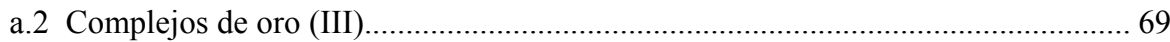

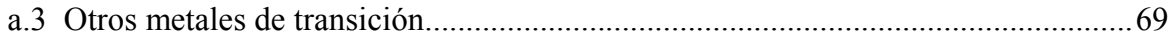

b) Métodos de ciclación basados en el empleo de alcóxidos metálicos...............................71

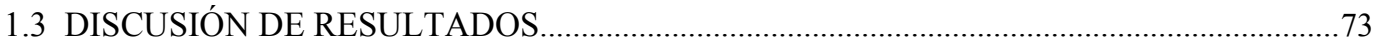

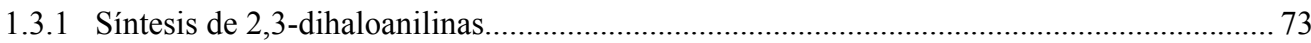

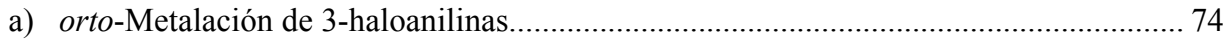

a.1 Estudio de la reacción de orto-litiación en derivados de 3-haloanilinas................. 74

a.2 Estudio de la reacción de orto-zincación en derivados de 3-haloanilinas................. 77

b) Reacción de metalación en 3-halonitrobencenos.............................................................. 79

c) Preparación de 2,3-dihaloanilinas a partir de 2,3-dihalofenoles........................................ 81

c.1 Preparación de los $N, N$-dietilcarbamatos de 2,3-dihalofenilo 17.......................... 82

c.2 Síntesis de las $N$-(2,3-dihalofenil)-2-hidroxi-2-metilpropanamidas 25.

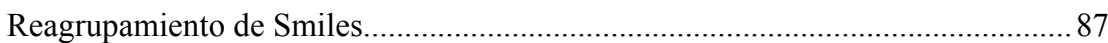

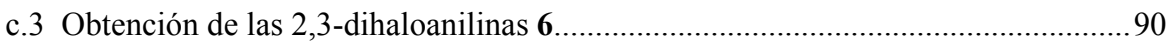

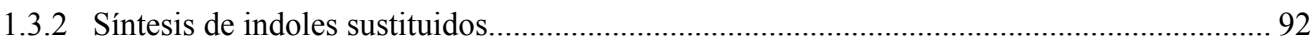

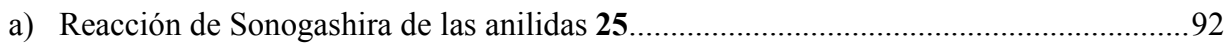

b) Estudio de las condiciones de ciclación de las 2-alquinil-3-haloanilidas 27..................94

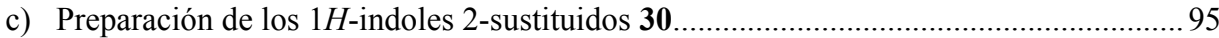

d) Preparación de nitro- y amino-indoles $\mathbf{3 5}$ y $\mathbf{3 6}$ a partir de las 2-halonitroanilinas 34.. 103

e) Reducción selectiva de 5,7-dinitroindoles 2-sustituidos 38........................................ 108

1.3.3 Síntesis regioselectiva de 4-haloindoles 28................................................................... 112

a) Preparación de los 4-haloindoles 28 a partir de las alquinilanilidas 27....................... 112

b) Preparación de los 4-haloindoles 28 a partir de las 2,3-dihaloanilidas 25.................... 113

c) Síntesis de los 4-fluoro- $1 H$-indoles 28aa,aj y $\mathbf{4 1}$ a partir de la trifluoroacetamida

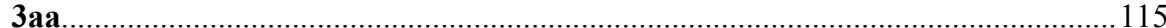

d) Síntesis de los 3-feniltio-4-halo- $1 H$-indoles 2-sustituidos 43 .....................................118

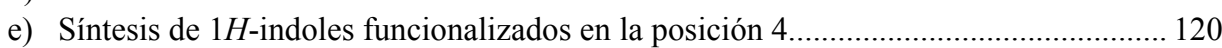

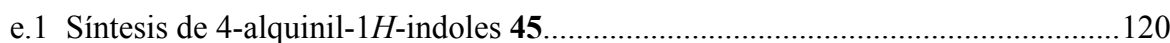

e.2 Síntesis de 4-heteroaril-1H-indoles 2-sustituidos $\mathbf{4 6}$ mediante la reacción de

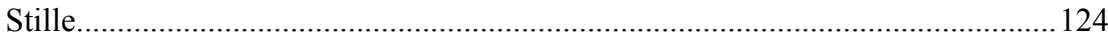

e.3 Síntesis de 4-aril-1H-indoles 2-sustituidos 47 mediante la reacción de Suzuki... 124

e.4 Síntesis del 4-bromo-2-fenil-3-((Z)-1,3-difenil-4-metil-penta-1,3-dienil)-

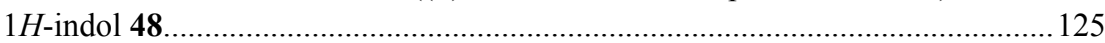

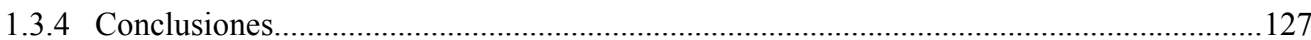

CAPÍTULO 2: "Reacciones de orto-zincación en derivados de 3-bromoanisoles.

Aplicaciones a la síntesis de benzo[b]furanos alcoxi-funcionalizados".

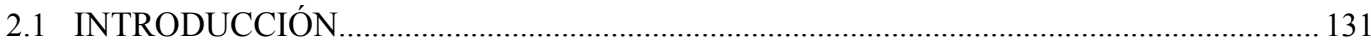


2.2.1 Síntesis de benzo[b]furanos oxígeno-funcionalizados................................................... 133

a) Reacciones de ciclación en derivados de furano........................................................ 133

b) Reacciones de ciclación en derivados bencénicos funcionalizados.................................134

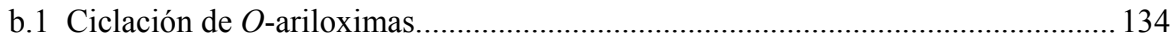

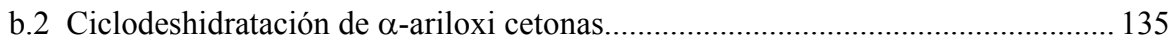

b.3 Reagrupamiento [3,3] de Claisen en fenil propargil y alil fenil éteres.................. 136

b.4 Ciclación de aril-(2,2-dietoxietil) éteres.............................................................. 137

b.5 Ciclación de derivados de resorcinol y salicilaldehído...........................................137

b.6 Reacción tándem acoplamiento de Sonogashira / heterociclación........................... 138

b.7 Ciclación oxidante de $o$-vinilfenoles...................................................................... 138

2.2.2 Reacciones de formación de fenoles a partir de haluros de arilo..................................... 139

a) Reacciones de hidroxilación catalizadas por complejos de paladio.............................139

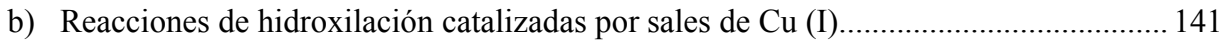

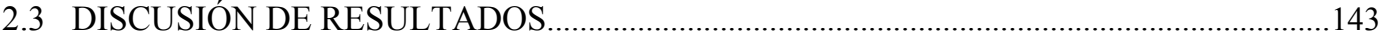

2.3.1 Síntesis de alcoxi y dialcoxibenzo[b]furanos a partir de derivados de 2,3-dihalofenoles.....143

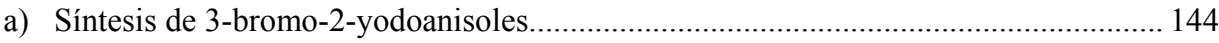

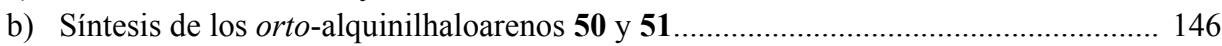

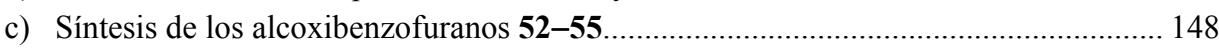

d) Transformaciones sintéticas de los metoxibenzo[ $b]$ furanos......................................... 152

2.3.2 Intento de síntesis de 4-halobenzo[b]furanos 3-funcionalizados...................................... 154

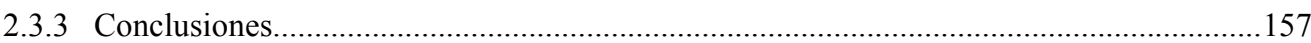

\section{CAPÍTULO 3: "Reacciones de orto-metalación combinadas con acoplamientos catalizados} por paladio. Síntesis de benzo[b]tiofenos regioselectivamente funcionalizados"

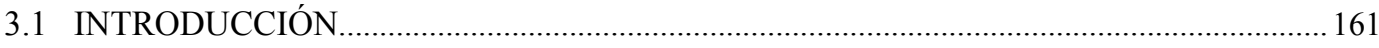

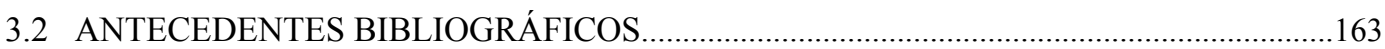

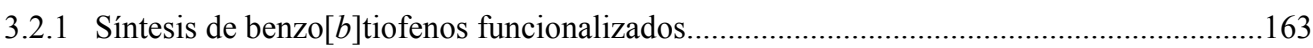

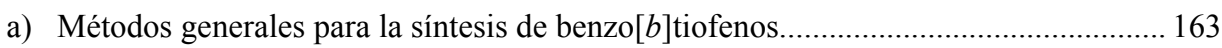

a.1 Reacciones de ciclación en derivados de tiofenoles alquilados.............................. 163

a.2 Ciclodeshidratación de $\alpha$-ariltio cetonas.............................................................. 164

a.3 Ciclación de derivados de orto-halobenzaldehído.................................................. 164

a.4 Reacciones catalizadas por complejos de metales de transición............................ 165

a.5 Reacciones de ciclación en derivados de orto-alquinilaril tioéteres........................ 166

a.6 Reacciones que implican la formación de complejos de bencinozirconoceno...... 166

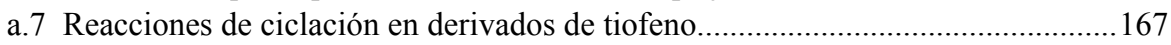

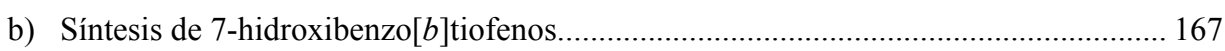

b.1 Reacción de ciclación en derivados de tiofeno......................................................... 167

b. 2 Reacciones de ciclación en derivados de benceno funcionalizados........................ 168

3.2.2 Reacciones de ciclación electrofílica: Aplicación a la síntesis de heterociclos benzofusionados de 5 miembros... 
3.2.3 Reacciones de formación de enlaces $\mathrm{C}-\mathrm{S}$ a partir de halogenuros de arilo 173

a) Reacciones de formación del enlace $\mathrm{C}-\mathrm{S}$ empleando complejos de $\mathrm{Pd}$ como catalizadores.

a.1 Reacciones de acoplamiento de haluros de arilo y tioles

a.2 Reacciones de acoplamiento $\mathrm{C}-\mathrm{S}$ empleando fuentes de azufre equivalentes al $\mathrm{H}_{2} \mathrm{~S}$.......

b) Reacciones de formación del enlace $\mathrm{C}-\mathrm{S}$ empleando sales de cobre

b.1 Reacciones de acoplamiento $\mathrm{C}-\mathrm{S}$ empleando haluros de arilo y fuentes de azufre.

b.2 Reacciones de acoplamiento de haluros de arilo y tioles

3.3.1 Síntesis de benzo[b]tiofenos 7-oxígeno funcionalizados.

180

a) Síntesis de los $N, N$-dietilcarbamatos de $O$-3-halo-2-sulfanilfenilo 61

b) Síntesis de los $N, N$-dietilcarbamatos de $O$-3-alquinil-2-(metiltio)fenilo 62 a partir del carbamato de $O-3$-halofenilo $61 \mathrm{ca}$

c) Síntesis de los benzo[b]tiofenos 7-oxígeno-funcionalizados 2,3-disustituidos 63-66.

d) Síntesis de 7-hidroxibenzo[b]tiofenos 2,3-disustituidos 67

e) Síntesis de los 3-halobenzo[b]selenofenos 7-oxígeno-funcionalizados 2-sutituidos 68

f) Aplicaciones sintéticas de los 7-(N,N-dietilcarbamoiloxi)-3-halobenzo[b]tiofenos 63 y 64.

f.1 Intercambio halógeno-litio en los 7-(N,N-dietilcarbamoiloxi)-3-yodo benzo[ $b]$ tiofenos 2-sustituidos $\mathbf{6 3 b}, \mathbf{e}$

f.2 Síntesis de benzo[b]tiofenos 3-sustituidos empleando reacciones catalizadas por complejos de paladio.

3.2.2 Síntesis de benzo[b]tiofenos a partir de orto-alquinilbromobencenos.............................. 195

a) Preparación de los derivados de 2-alquinil-3-bromofenoles 51 y $\mathbf{7 8}$..............................195

b) Intento de síntesis de los benzo[b]tiofenos 4-oxígeno funcionalizados $\mathbf{8 0}$ y $\mathbf{8 1}$ empleando sulfuros alcalinos.

c) Síntesis de benzo[b]tiofenos oxígeno-funcionalizados mediante acoplamientos $\mathrm{C}-\mathrm{S}$ catalizados por complejos de paladio.

c.1 Tiourea como fuente de azufre. 198

c.2 Tioacetato potásico como fuente de azufre...........................................................199

c.3 Triisopropilsilil tiol (TIPS-SH) como fuente de azufre....................................... 203

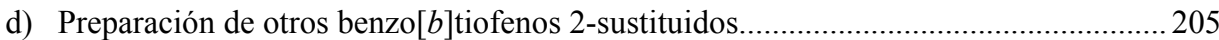

d.1 Método A: Síntesis de $\mathbf{8 4}$ empleando tioacetato potásico........................................ 206

d.2 Método B: Síntesis de 84 empleando triisopropilsilil tiol..................................... 208

e) Preparación de los benzo[b]tiofenos 3-funcionalizados 88......................................210

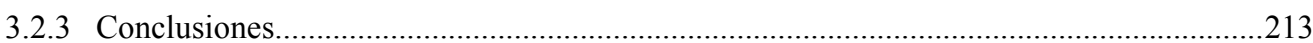


0. GENERALIDADES 221

1. APROXIMACIONES A LA SÍNTESIS DE 2,3-DIHALOANILINAS. PRECURSORES DE INDOLES 4-FUNCIONALIZADOS.

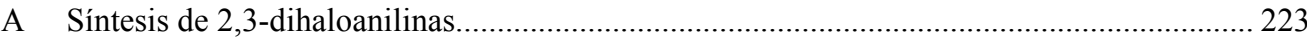

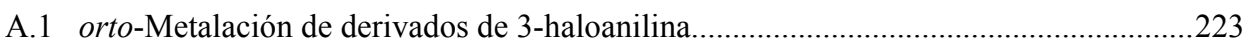

A.2 Reacción de metalación en 3-halonitrobencenos.......................................................... 230

A.3 Preparación de 2,3-dihaloanilinas a partir de derivados de 2,3-dihalofenoles.............. 231

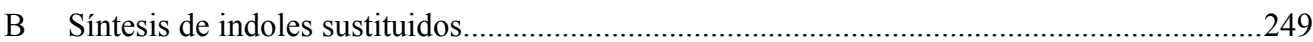

B.1 Reacción de Sonogashira de las anilidas 25 .............................................................. 249

B.2 Síntesis de los $1 H$-indoles 2-sustituidos 30 ............................................................. 253

B.3 Preparación de los nitro y amino-indoles 35 y $\mathbf{3 6}$ a partir de las 2-halonitroanilinas

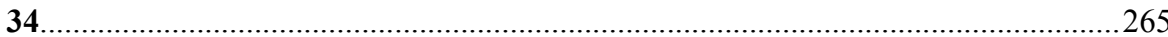

B.4 Reducción selectiva de 5,7-dinitroindoles 2-sustituidos 38_.................................... 273

C Síntesis regioselectiva de 4-haloindoles 28.................................................................. 278

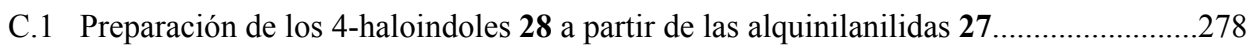

C.2 Preparación de los 4-haloindoles 28 a partir de las 2,3-dihaloanilidas 25.................. 281

C.3 Síntesis de los 4-fluoro- $1 H$-indoles 28aa,aj y $\mathbf{4 1}$ a partir de la trifluoroacetamida 3aa...283

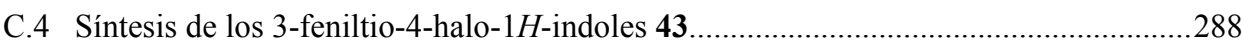

C.5 Síntesis de $1 H$-indoles funcionalizados en la posición 4 .............................................291

2. REACCIONES DE orto-ZINCACIÓN EN DERIVADOS DE 3-BROMOANISOLES. APLICACIÓN A LA SÍNTESIS DE BENZO[b]FURANOS ALCOXIFUNCIONALIZADOS

A Síntesis de alcoxi y dialcoxibenzo[b]furanos a partir de derivados de 2,3-dihalofenoles......299

A.1 Preparación de 3-bromo-2-yodoanisoles....................................................................299

A.2 Procedimiento general para la preparación de los $o$-alquinilhaloarenos $\mathbf{5 0}$ y $\mathbf{5 1} \ldots \ldots \ldots . . . .300$

A.3 Procedimiento general para la preparación de los alcoxibenzo[b]furanos 52-55.........306

A.4 Transformaciones sintéticas de los metoxibenzo $[b]$ furanos...................................... 311

B Intentos de síntesis de 4-halobenzo[b]furanos 3-funcionalizados......................................... 312

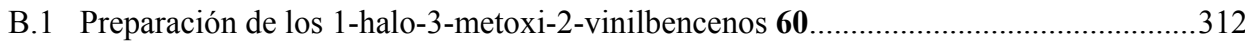

3. REACCIONES DE orto-METALACIÓN COMBINADAS CON ACOPLAMIENTOS CATALIZADOS POR PALADIO. SÍNTESIS DE BENZO[$b]$ TIOFENOS REGIOSELECTIVAMENTE FUNCIONALIZADOS............................................................ 314

A Síntesis de benzo[b]tiofenos 7-oxígeno-funcionalizados................................................... 314

A.1 Preparación de los $N, N$-dietilcarbamatos de $O$-3-halo-2-sulfanilfenilo 61 .................... 314

A.2 Síntesis de los $N, N$-dietilcarbamatos de $O$-3-alquinil-2-(metiltio)fenilo 62 ................. 317

A.3 Síntesis de los benzo[b]tiofenos 7-oxígeno-funcionalizados 2,3-disustituidos 63-66.....320

A.4 Síntesis de los 7-hidroxibenzo[b]tiofenos 2,3-disustituidos 67 y del 7-hidroxi2-pentil-3-yodobenzo[b]selenofeno $\mathbf{7 2}$. 
A.5 Síntesis de los 3-halobenzo[b]selenofenos 7-oxígeno-funcionalizados 2-sustituidos 70 y 71.

A.6 Aplicaciones sintéticas de los 7-(N,N-dietilcarbamoiloxi)-3-halobenzo[ $b]$ tiofenos 63 y 64 . .333

B Síntesis de benzo[ $b]$ tiofenos a partir de $o$-alquinilbromobencenos...................................... 337

B.1 Preparación de los derivados de 2-alquinil-3-bromofenoles 51, 78 y $82 \ldots \ldots \ldots \ldots \ldots \ldots . . . . . . .337$

B.2 Procedimiento general para la síntesis de los tioacetatos de $S$-2-alquinilfenilo 83....... 342

B.3 Síntesis de los benzo[b]tiofenos 80a, 81, 84 y 85 mediante acoplamientos $\mathrm{C}-\mathrm{S}$

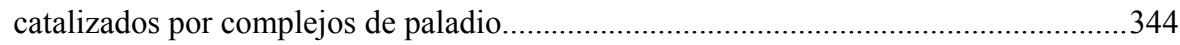

B.4 Procedimiento general para la síntesis de los benzo[b]tiofenos 3-funcionalizados $\mathbf{8 8}$..... 351 


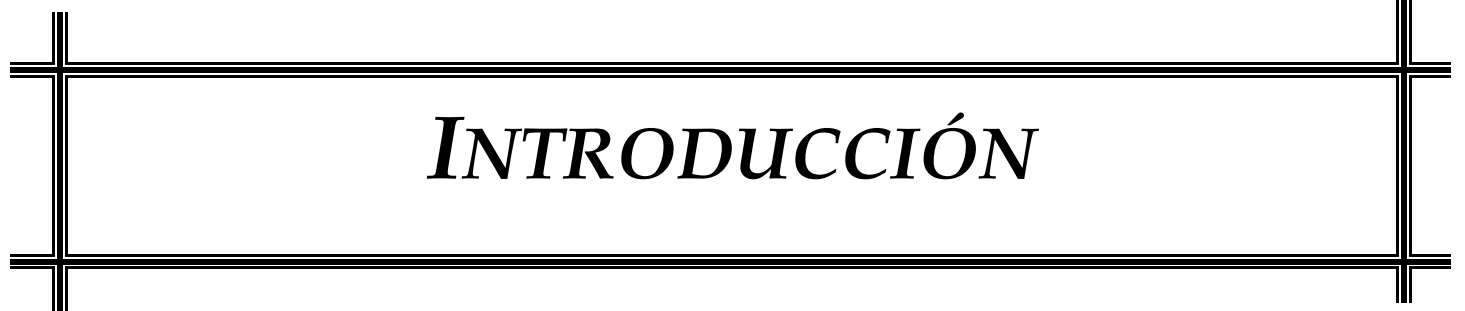

"Quiero compartir con ustedes el secreto que me ha llevado a alcanzar todas mis metas: mi fuerza reside únicamente en mi tenacidad". Louis Pasteur 

La preparación de compuestos heterocíclicos funcionalizados presenta un especial atractivo dentro de la Síntesis Orgánica debido a las interesantes propiedades que manifiestan este tipo de compuestos. Muchos de estos heterociclos presentan actividad biológica y/o farmacológica lo que ha contribuído, por ejemplo, al desarrollo de nuevos fármacos. Además, algunos de ellos muestran propiedades adecuadas para la preparación de materiales con interés desde el punto de vista electrónico y óptico.

En los últimos años, nuestro grupo de investigación ha estado involucrado en el desarrollo de metodologías adecuadas para la síntesis de compuestos heterocíclicos funcionalizados. ${ }^{\alpha}$

Uno de los retos en Síntesis Orgánica es la introducción de distintos sustituyentes en una posición determinada de un anillo aromático. En este contexto, las reacciones de ortometalación dirigida han sido ampliamente empleadas como un método eficiente para la funcionalización regioselectiva de compuestos aromáticos. Estas reacciones permiten la obtención de compuestos organometálicos por desprotonación de derivados aromáticos sustituidos. Tradicionalmente se han utilizado bases fuertes como alquillitio o dialquilamiduros de litio para llevar a cabo este proceso de desprotonación aunque, más recientemente, también han empezado a surgir otros compuestos más suaves basados en la combinación de más de un centro metálico. Las reacciones de orto-metalación constituyen un método alternativo a la sustitución electrofílica aromática clásica, permitiendo la funcionalización de una posición concreta del anillo aromático y evitando así la obtención de distintos regioisómeros.

Por otro lado, las reacciones de acoplamiento catalizadas por complejos de metales de transición, fundamentalmente por paladio, son posiblemente uno de los procedimientos más empleados en Síntesis Orgánica para la construcción de nuevos enlaces $\mathrm{C}-\mathrm{C}$ ó C-heteroátomo. De esta forma, estos acoplamientos permiten la elaboración de moléculas con un alto grado de funcionalización a partir de reactivos sencillos.

Con estas premisas, nos planteamos como objetivo de este trabajo de investigación el desarrollo de rutas sintéticas sencillas y eficaces con el fin de preparar distintas familias

a a) J. Barluenga, F. J. Fañanás, R. Sanz, C. Marcos, Chem. Eur. J. 2005, 11, 5397. b) R. Sanz, M. P. Castroviejo, Y. Fernández, F. J. Fañanás, J. Org. Chem. 2005, 70, 6548. c) R. Sanz, D. Miguel, A. Martínez, A. Pérez, J. Org. Chem. 2006, 71, 4024. d) R. Sanz, Y. Fernández, M. P. Castroviejo, A. Pérez, F. J. Fañanás, J. Org. Chem. 2006, 71, 6291. e) R. Sanz, J. Escribano, M. R. Pedrosa, R. Aguado, F. J. Arnáiz, Adv. Synth. Catal. 2007, 349, 713. f) R. Sanz, D. Miguel, F. Rodríguez, Angew. Chem., Int. Ed. 2008, 47, 7354. 
de heterociclos funcionalizados de forma regioselectiva. Para ello se ha empleado, fundamentalmente, la combinación de la estrategia de orto-metalación con diferentes reacciones de acoplamiento catalizadas por complejos de paladio.

Este trabajo se ha centrado en la síntesis de tres tipos de heterociclos benzofusionados de gran interés: indoles, benzo $[b]$ furanos y benzo $[b]$ tiofenos.

Los resultados recogidos en la presente memoria se han organizado en tres capítulos, cada uno de los cuales se centra en la preparación de un tipo de estos heterociclos. En primer lugar se describe la síntesis de indoles 4-funcionalizados a partir de derivados de 2,3-dihaloanilinas. Para ello también se ha desarrollado una estrategia sintética adecuada para la preparación de estas anilinas. En el segundo Capítulo se han preparado los heterociclos análogos de oxígeno. Concretamente se puso a punto la síntesis de benzo $[b]$ furanos alcoxi- y dialcoxi-funcionalizados. Finalmente, el último Capítulo se centra en los heterociclos análogos de azufre, los benzo[b]tiofenos. Se han desarrollado metodologías para la preparación de distintos benzo[b]tiofenos oxígeno-funcionalizados de forma regioselectiva.

Previamente a la exposición de estos resultados se procederá a realizar una breve revisión bibliográfica de los principales tipos de reacciones involucradas en este trabajo: reacciones de orto-metalación y acoplamientos catalizados por paladio. 


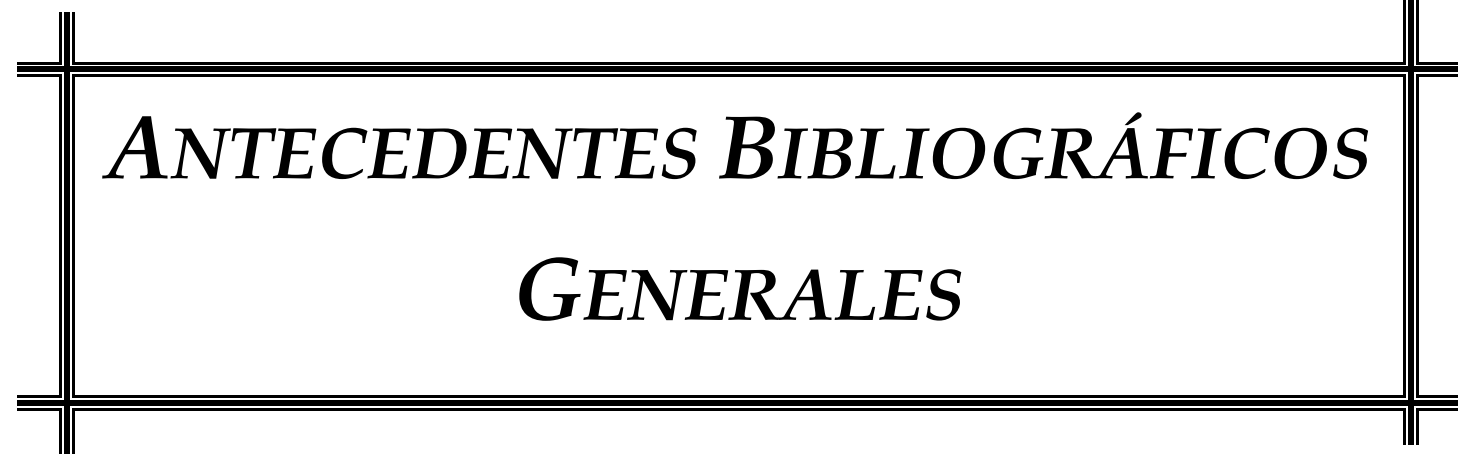

"Nuestro conocimiento es una pequeña isla en el enorme océano del desconocimiento". Isaac Basgevis Singer" 

En este apartado de "Antecedentes Bibliográficos" se van a tratar los principales aspectos generales relacionados con el trabajo de investigación realizado:

- Inicialmente se describirán las reacciones de orto-metalación dirigida. Se comenzará explicando brevemente en qué consisten las reacciones de orto-litiación, así como los principales grupos directores de las mismas, y se continuará con una exposición de otros tipos de reacciones de orto-metalación, descritas más recientemente en la literatura, centrándonos en las reacciones de orto-zincación.

- En un segundo apartado se comentarán algunos de los acoplamientos catalizados por complejos de paladio, de gran utilidad en síntesis orgánica, y que han sido empleados a lo largo del presente trabajo.

\section{A REACCIONES DE orto-METALACIÓN DIRIGIDA}

Las reacciones de orto-metalación son aquellas que resultan de la desprotonación de compuestos aromáticos sustituidos mediante la utilización de un compuesto organometálico. ${ }^{1}$ Desde el trabajo pionero de Gilman y Wittig, las reacciones de ortometalación dirigida han sido ampliamente utilizadas como un método eficiente para la funcionalización regioselectiva de compuestos aromáticos ${ }^{2}$ y constituyen una ruta alternativa a la sustitución electrofílica aromática clásica. Estas reacciones están favorecidas por la presencia de grupos funcionales denominados grupos directores. Los reactivos que han sido empleados tradicionalmente para llevar a cabo este proceso de desprotonación son bases fuertes tales como alquillitios o dialquilamiduros de litio. Sin embargo, su aplicación a la preparación de moléculas orgánicas complejas ha estado generalmente limitada debido a que presentan una baja tolerancia hacia ciertos grupos funcionales, como por ejemplo ésteres o nitrilos, ${ }^{3}$ y a las bajas temperaturas requeridas normalmente para llevar a cabo dichas reacciones. Por ello, en los últimos años han empezado a emerger una nueva clase de

1 a) J. Clayden, Organolithiums: Selectivity for Synthesis; Pergamon Press: Amsterdam, 2002; Cap. 2; p. 9. b) C. G. Hartung, V. Snieckus, en Modern Arene Chemistry; D. Astruc, Ed.; Wiley-VCH: New York, 2002; p. 330. c) T. Macklin, V. Snieckus, en Handbook of C-H Transformations; G. Dyker, Ed.; Wiley-VCH: New York, 2005; p. 106. d) M. C. Whisler, S. MacNeil, V. Snieckus, P. Beak, Angew. Chem., Int. Ed. 2004, 43, 2206.

2 a) H. W. Gschwend, H. R. Rodríguez, Org. React. 1979, 26, 1. b) P. Beak, V. Snieckus, Acc. Chem. Res. 1982, 15, 306. c) V. Snieckus, Chem. Rev. 1990, 90, 879.

3 C. J. Upton, P. Beak, J. Org. Chem. 1975, 40, 1094. 
agentes de metalación denominados complejos "ato", formados por diferentes ligandos (variables en naturaleza y número) y dos centros metálicos: el primer centro metálico suele ser un átomo de magnesio, zinc o aluminio y el segundo un metal alcalino como litio o sodio. Así, se ha empezado a desarrollar una química basada en la utilización de estos complejos heterometálicos, los cuales presentan alta quimioselectividad en las reacciones de orto-metalación dirigida de compuestos aromáticos en condiciones suaves. Los complejos "ato" son bases de gran versatilidad que exhiben una química sinérgica que no puede ser explicada por complejos homometálicos de magnesio, zinc o aluminio. ${ }^{4}$

\section{A.1 Reacciones de orto-litiación}

En los años 1939-1940 Gilman y Wittig introdujeron el término "orto-litiación" al descubrir de forma independiente que el anisol era desprotonado en posición orto al grupo metoxilo por tratamiento con $n$-BuLi.

La reacción de benceno con $n$-BuLi en hexano es termodinámicamente favorable, sin embargo, resulta ser cinéticamente lenta debido al estado de agregación hexámerico que presenta el $n$-BuLi en disolución. ${ }^{6}$ Para conseguir la ruptura de los agregados de $n$-BuLi es necesario adicionar $N, N, N^{\prime}, N$ '-tetrametiletilendiamina (TMEDA) o THF que actúan como agentes coordinantes externos aumentando la reactividad del $n$-BuLi y favoreciendo así la litiación (Esquema I). ${ }^{7}$

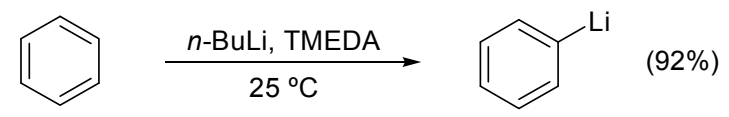

\section{Esquema I}

Cuando el compuesto aromático presenta como sustituyentes heteroátomos o grupos funcionales capaces de interaccionar con el reactivo organolítico, la metalación se ve favorecida en posición orto- al sustutituyente. Estos grupos funcionales se denominan

4 a) R. E. Mulvey, Organometallics 2006, 25, 1060. b) R. E. Mulvey, Acc. Chem. Res. 2009, 42, 743. c) D. R. Armstrong, L. Balloch, E. Hevia, A. R. Kennedy, R. E. Mulvey, C. T. O'hara, S. D. Robertson, Beilstein J. Org. Chem. 2011, 7, 1234.

5 a) H. Gilman, R. L. Bebb, J. Am. Chem. Soc. 1939, 61, 109. b) G. Wittig, G. Fuhrmann, Ber. Dtsch. Chem. Ges. 1940, 73, 1197.

6 H. L. Lewis, T. L. Brown, J. Am. Chem. Soc. 1970, 92, 4664

7 M. D. Rausch, D. J. Ciappenelli, J. Organomet. Chem. 1967, 10, 127. 
grupos directores y permiten introducir sustituyentes de forma regioselectiva en anillos aromáticos. Se pueden distinguir tres tipos de sustituyentes activantes:

- Sustituyentes que proporcionan un punto de coordinación al alquillitio, favoreciendo la aproximación del compuesto organolítico al protón en orto al sustituyente y facilitando, así, la desprotonación de esta posición.

- Sustituyentes que presentan un efecto inductivo electrón atractor, aumentado la acidez de los hidrógenos en posición orto.

- Sustituyentes que ejercen simultáneamente ambos efectos.

\section{a) Influencia coordinativa}

La reacción de $N, N$-dimetilbencilamina con $n$-BuLi es un ejemplo de este tipo de influencia. ${ }^{8}$ La $N, N$-dimetilbencilamina, con protones no más ácidos que el benceno, es desprotonada más rápidamente que éste y de manera regioselectiva en la posición 2 , la más cercana al grupo director. El mecanismo de orto-litiación se considera que funciona proporcionando al alquillitio un punto de coordinación, incrementando de este modo la reactividad específicamente en las proximidades del sitio de coordinación del sustrato y dirigiendo así la desprotonación (Esquema II).

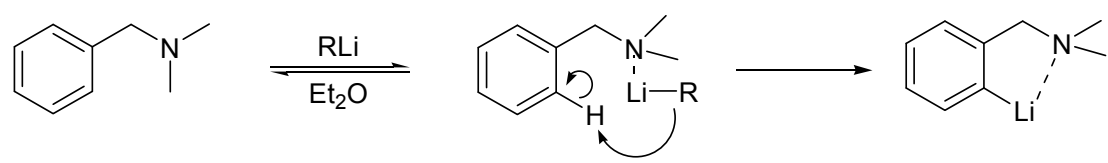

Esquema II

\section{b) Influencia inductiva}

Cuando la coordinación al heteroátomo resulta ser electrónica o geométricamente imposible, el incremento de la acidez de los protones en orto- al grupo director por el efecto electrón atractor que éste ejerce puede ser causa suficiente para conducir a una reacción de orto-litiación regioespecífica. Por ejemplo, el fluorobenceno experimenta orto-litiación reaccionando con $n$-BuLi en THF a temperaturas inferiores a $-50{ }^{\circ} \mathrm{C}$ (Esquema III). ${ }^{9}$

8 F. N. Jones, M. F. Zinn, C. R. Hauser, J. Org. Chem. 1963, 28, 663.

9 H. Gilman, T. S. Soddy, J. Org. Chem. 1957, 22, 1715. 


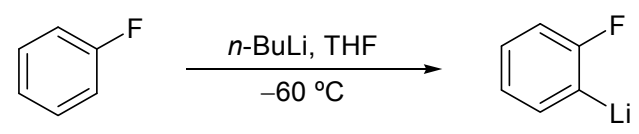

Esquema III

\section{c) Influencia coordinativa e inductiva}

Los sustituyentes con mayor capacidad para dirigir la litiación en posición orto suelen presentar una combinación de ambos efectos: influencia coordinativa e inductiva. Este tipo de sustituyentes tienen una mezcla de propiedades básicas, necesarias para la buena coordinación al litio, y de propiedades ácidas, requeridas para una desprotonación rápida y eficiente. Dentro de estos sustituyentes estarían, por ejemplo, el grupo carbamato o las sulfonamidas (Esquema IV). ${ }^{10}$

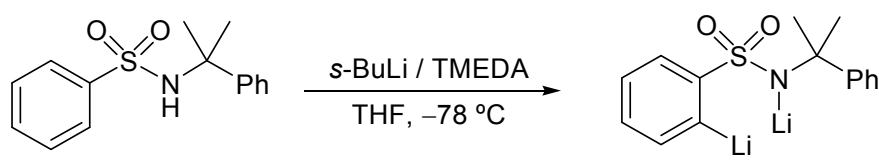

\section{Esquema IV}

Se puede concluir que la reacción de orto-litiación tiene lugar en dos etapas: coordinación del agregado $(\mathrm{RLi})_{\mathrm{n}}$ al heteroátomo del grupo director y desprotonación en la posición orto- a dicho grupo director. La regioselectividad y la velocidad de la reacción de litiación vienen controladas por la coordinación entre el organolítico y el heteroátomo, y por la acidez del protón a abstraer. Los mejores grupos directores se coordinan de forma eficaz al átomo de litio y aumentan la acidez del protón en orto- favoreciendo su abstracción.

\section{A.1.1 Clases de grupos directores}

En 1990 Snieckus ${ }^{2 c}$ dividió los grupos directores más comunes para llevar a cabo una reacción de orto-litiación en diferentes clases, de acuerdo a su habilidad para dirigir la metalación y a sus aplicaciones en síntesis. Así los grupos directores se pueden clasificar según la secuencia mostrada en el Esquema V, donde se especifican las condiciones

10 a) B. Chauder, L. Green, V. Snieckus, Pure Appl. Chem. 1999, 8, 1521. b) J. Blanchet, T. Macklin, P. Ang, C. Metallinos, V. Snieckus, J. Org. Chem. 2007, 72, 3199. 
requeridas por cada grupo funcional para llevar a cabo una reacción de orto-litiación (Esquema V). ${ }^{1 \text { a }}$

Dada la gran variedad de grupos directores nos centraremos en los más importantes de cada clase, destacando los empleados en el presente trabajo.

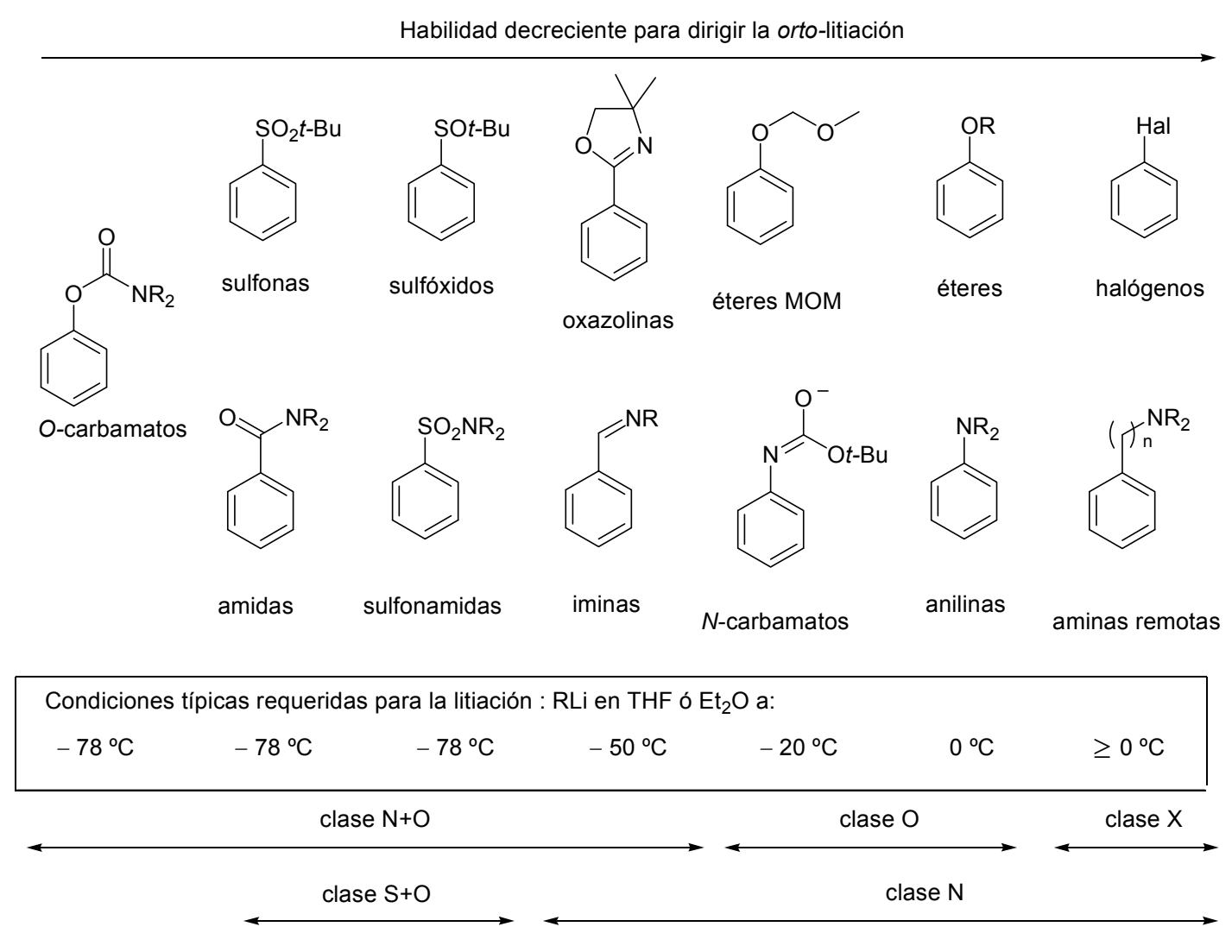

Esquema $\mathbf{V}$

- Clase $N+O$

Comprende ácidos carboxílicos y funciones carbonadas que contienen nitrógeno y oxígeno, como amidas secundarias y terciarias, ${ }^{11}$ carbamatos $^{2 \mathrm{c}}$ y oxazolinas. ${ }^{12}$ Son los grupos más eficaces para dirigir la orto-litiación debido a su naturaleza anfótera: todos ellos contienen un heteroátomo básico, que favorece la coordinación al reactivo organolítico, y

11 P. Beak, A. Tse, J. Hawkins, C. W. Chen, S. Mills, Tetrahedron 1983, 39, 1983.

12 T. G. Gant, A. I. Meyers, Tetrahedron 1994, 50, 2297. 
muchos son grupos electrón atractores que incrementan la acidez de los protones del anillo. Por otro lado, son grupos funcionales susceptibles de posteriores transformaciones, lo que favorece sus posibilidades sintéticas. Sin embargo, como inconveniente, presentan un grupo tipo carbonilo que puede verse afectado por el reactivo organolítico.

Dentro de esta clase se encuentra el grupo funcional empleado para dirigir las reacciones de orto-litiación llevadas a cabo en el presente trabajo: los $O$-carbamatos. Snieckus y Sibi fueron los primeros en describir la reacción de orto-metalación dirigida en $O$-carbamatos de arilo. ${ }^{13}$ Los $N, N$-dietilcarbamatos de $O$-arilo son los compuestos que con más facilidad experimentan una reacción de $o$-litiación dentro de esta clase. Sin embargo son difíciles de hidrolizar requiriéndose condiciones básicas enérgicas, ${ }^{13}$ aunque en ocasiones la cercanía de un grupo funcional puede facilitar la hidrólisis. Alternativamente, también es posible llevar a cabo su reducción empleando $\mathrm{LiAlH}_{4}\left(\right.$ Esquema VI). ${ }^{14}$

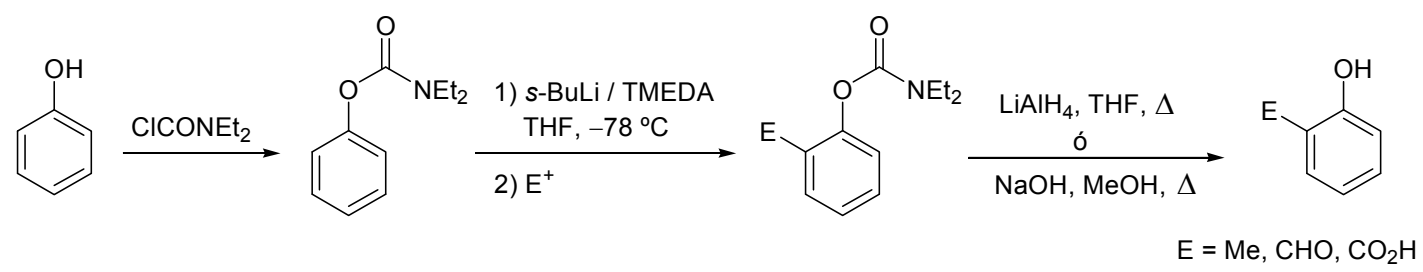

\section{Esquema VI}

- Clase $\mathrm{S}+\mathrm{O}$

Las sulfonas y sulfonamidas presentan una fuerte capacidad directora ${ }^{15}$ y no sufren ataque electrofílico al azufre, aunque son menos utilizadas debido a que sus aplicaciones sintéticas son más limitadas. Los $t$-butilsulfóxidos de arilo son también buenos grupos directores (Esquema VII), ${ }^{16}$ aunque los diarilsulfóxidos con menor impedimento estérico son susceptibles del ataque por parte del organolítico al átomo de azufre. ${ }^{17}$

13 M. P. Sibi, V. Snieckus, J. Org. Chem. 1983, 48, 1935.

14 R.-J. De Lang, M. J. C. M. van Hooijdonk, L. Brandsma, Tetrahedron 1998, 54, 2953.

15 a) J. Clayden, M. Julia, J. Chem. Soc., Chem. Commun. 1993, 1682. b) J. Clayden, J. J. A. Cooney, M. Julia, J. Chem. Soc., Perkin Trans. 1 1995, 7.

16 C. Quesnelle, T. Iihama, T. Aubert, H. Perrier, V. Snieckus, Tetrahedron Lett. 1992, 33, 2625.

17 J. P. Lockard, C. W. Schroeck, C. R. Johnson, Synthesis 1973, 485. 

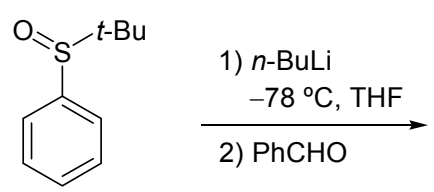<smiles>CC(C)(C)c1ccccc1C(O)c1ccccc1S(=O)C(C)(C)C</smiles>

\section{Esquema VII}

- Clase Ny clase O

Menos importantes con respecto a su capacidad directora pero con un alto valor sintético son los grupos que sólo contienen oxígeno (éteres, acetales, carboxilatos,...), que pertenecen a la clase $O$, y aquellos que sólo contienen nitrógeno (aminas, iminas, nitrilos,...), que pertenecen a la clase $N$. Los compuestos con estos grupos experimentan la reacción de litiación más lentamente y a temperaturas más elevadas, pero en muchos casos presentan la ventaja de que no pueden ser atacados por los reactivos organolíticos.

En la clase $N$ los grupos que mejor dirigen la reacción de orto-litiación son aquellos que pueden utilizar el par de electrones solitario para coordinarse al reactivo organolítico, es decir todos excepto las anilinas (Esquema VIII). ${ }^{18}$
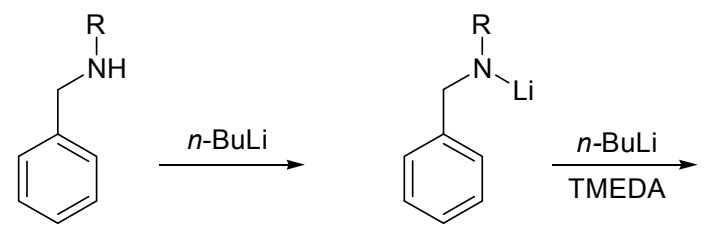<smiles></smiles><smiles>[R]NCc1ccccc1C(O)(c1ccccc1)c1ccccc1</smiles>

\section{Esquema VIII}

Dentro de la clase $O$, los mejores grupos directores son los que presentan el átomo de oxígeno unido al anillo aromático, acidificando así los protones que se encuentran próximos a él. También son buenos grupos directores los que contienen un segundo átomo de oxígeno (por ejemplo, los acetales) para coordinarse al átomo de litio (Esquema IX). ${ }^{19}$

18 R. E. Ludt, C. R. Hanser, J. Org. Chem. 1971, 36, 1607.

19 E. Marzi, M. Schlosser, Tetrahedron 2005, 61, 3393. 


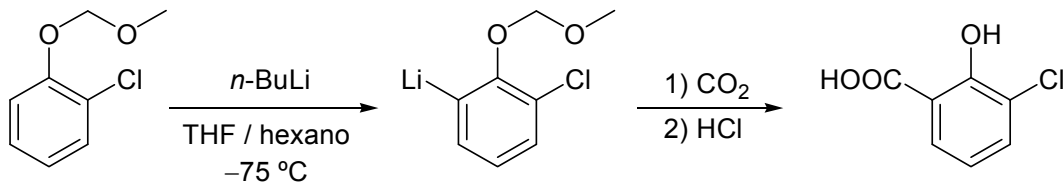

$(74 \%)$

\section{Esquema IX}

- Clase $X$

Los halógenos dirigen únicamente por efecto inductivo incrementando la acidez de los protones a abstraer.

El flúor es mejor grupo director que el cloro y éste, a su vez, mejor que el bromo. Por lo tanto, la desprotonación del fluorobenceno ${ }^{9}$ (Esquema III) es más fácil que la del clorobenceno. La reacción de litiación del clorobenceno ${ }^{20} \mathrm{a}-105^{\circ} \mathrm{C}$ es lenta y no se puede completar, sin embargo, el empleo de temperaturas superiores conduce a la formación de bencino. $^{2 \mathrm{a}}$

Un factor limitante en el empleo de haluros arílicos orto-litiados es su facilidad para generar bencinos. Además, bromuros y yoduros de arilo experimentan preferentemente intercambio halógeno-metal a la desprotonación cuando se enfrentan a reactivos organolíticos. Como consecuencia, las condiciones deben de ser cuidadosamente controladas para evitar reacciones laterales y utilizar preferentemente bases como LDA ó LiTMP, ${ }^{20,21}$ y no compuestos organolíticos.

Como hemos descrito anteriormente, cuando un compuesto aromático que contiene un grupo director experimenta una reacción de metalación, ésta ocurre con preferencia en la posición orto a dicho grupo. En el caso de que el mismo compuesto aromático presente más de un grupo director pueden ocurrir diferentes situaciones:

- Los dos sustituyentes dirigen la reacción de orto-metalación en la misma posición (efecto cooperativo) (Esquema X). ${ }^{22}$

20 a) M. Iwao, J. Org. Chem. 1990, 55, 3622. b) F. Mongin, M. Schlosser, Tetrahedron Lett. 1997, $38,1559$.

21 a) F. Mongin, O. Desponds, M. Schlosser, Tetrahedron Lett. 1996, 37, 2767. b) F. Mongin, M. Schlosser, Tetrahedron Lett. 1996, 37, 6551. c) R. J. Mattson, C. P. Sloan, C. C. Lockhart, J. D. Catt, Q. Gao, S. Huang, J. Org. Chem. 1999, 64, 8004. d) M. Dabrowski, J. Kubicka, S. Lulinski, J. Serwatowski, Tetrahedron Lett. 2005, 46, 4175 .

22 P. Beak, R. A. Brown, J. Org. Chem. 1982, 47, 34. 
<smiles>CCNC(=O)c1cccc(Cl)c1</smiles><smiles>[NH3+]C(=O)c1cccc(Cl)c1Cl</smiles><smiles>COC</smiles><smiles>[2H]c1c(Cl)cccc1C(=O)NCC</smiles>

Esquema $X$

- Los dos sustituyentes del compuesto aromático favorecen la orto-metalación en distintas posiciones. En este caso la desprotonación tendrá lugar en la posición que esté favorecida por el mejor grupo director. Un ejemplo de este tipo de situación ocurre en la metalación del $N, N$-dietilcarbamato de 4-metoxifenilo con $s$-BuLi donde la desprotonación tiene lugar en la posición orto al grupo carbamato (Esquema XI). ${ }^{13}$<smiles>CCNC(=O)Oc1ccc(OC)cc1</smiles>

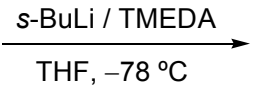<smiles>CCNC(=O)Oc1ccc(OC)cc1Cl</smiles><smiles>CC(=O)O</smiles><smiles>CCNC(=O)Oc1ccc(OC)cc1C(=O)O</smiles>

\section{Esquema XI}

\section{A.1.2 Reacciones de metalación dirigida en carbamatos de $O$-arilo}

A continuación se comentarán con más detalle las reacciones de metalación en las que participan carbamatos de $O$-arilo, por ser éste el grupo director que ha sido empleado en el presente trabajo, y se describirá su utilidad en síntesis orgánica.

\section{a) Reacciones de orto-metalación}

Como se ha comentado anteriormente, los $O$-carbamatos son excelentes grupos directores para la preparación de compuestos aromáticos que presentan un sustituyente en la posición orto del anillo arílico. Así, el tratamiento de distintos carbamatos de $O$-arilo con un reactivo organolítico, tal como $s$-BuLi en presencia de TMEDA, seguido de la reacción con un electrófilo ${ }^{2 c}$ permite la introducción de una gran variedad de sustituyentes en el anillo aromático (Esquema XII), como por ejemplo: 
- Halógenos: $\mathrm{I}, \mathrm{Br}$ ó $\mathrm{Cl}$ por reacción con yodo, 1,2-dibromoetano o percloroetano, respectivamente.

- Grupos alquilo tales como metilo por reacción con agentes alquilantes.

- Grupos hidroxialquilo o carbamoílo por reacción con electrófilos carbonados: aldehídos, cetonas o cloruros de carbamoílo, respectivamente.

- Grupos trimetilsililo por reacción con cloruro de trimetilsililo.

Además, la presencia de sustituyentes en el anillo arílico tales como grupos metilo, metoxilo, aminas terciarias o cloro son compatibles con las fuertes condiciones básicas requeridas en la reacción de orto-litiación.<smiles>[R][X]c1ccc(OC(=O)NCC)cc1</smiles>

$\mathrm{R}=\mathrm{H}, \mathrm{Me}, \mathrm{NMe}_{2}, \mathrm{OMe}, \mathrm{Cl}, \mathrm{TMS}$

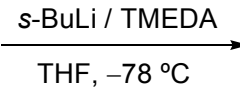<smiles>[R][X]C(C)(C)C(=O)Oc1cccc(Cl)c1</smiles><smiles>[R][R]1ccc(OC(=O)NCC)c(F)c1</smiles>

$\mathrm{E}=\mathrm{I}, \mathrm{Br}, \mathrm{Cl}$ $\mathrm{Me}, \mathrm{TMS}, \mathrm{Ph}_{2} \mathrm{C}(\mathrm{OH}), \mathrm{CONEt}_{2}, \ldots$

Esquema XII

b) Procesos de orto-metalación iterativos.

Los procesos de orto-metalación dirigida de forma iterativa, aunque no han sido estudiados exhaustivamente, muestran un gran potencial para acceder de forma rápida a diversos compuestos aromáticos polisustituidos. Este concepto implica la introducción secuencial de electrófilos que a su vez sirven de grupos orto-directores para la siguiente metalación. Las reacciones de orto-litiación tienen lugar de forma sucesiva en las distintas posiciones alrededor del anillo. Un ejemplo de este tipo de procesos se muestra en el Esquema XIII. Así, la secuencia de metalación / sililación y metalación / carbamoilación conduce a un derivado trisustituido. Éste experimenta una segunda reacción de metalación / carbamoilación para generar el derivado tetrasustituido que se muestra en el Esquema XIII. $^{2 \mathrm{c}}$ 


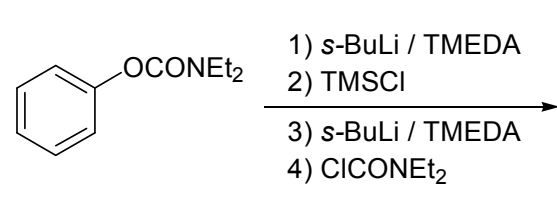

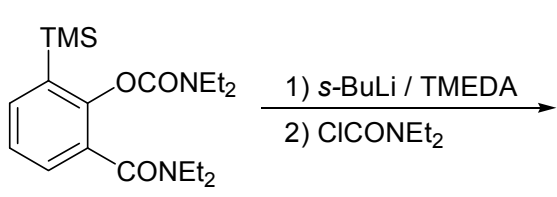

$(54 \%)$<smiles>CCOC(=O)c1ccc(S(C)(=O)=O)c(OCC)c1C(=O)OCC</smiles>

$(75 \%)$

\section{Esquema XIII}

c) Reagrupamiento aniónico de orto-Fries

Los $N, N$-dimetilcarbamatos de $O$-arilo son inestables una vez litiados, sufriendo rápidamente un reagrupamiento de tipo orto-Fries, mediante un mecanismo de transferencia de un grupo carbamoílo. ${ }^{2 \mathrm{c}}$ En el caso de los $N, N$-dietilcarbamatos es posible controlar este reagrupamiento ya que el carbamato orto-litiado es estable a $-78{ }^{\circ} \mathrm{C}$, aunque al subir la temperatura también experimenta la transferencia del grupo carbamoílo para generar una 2hidroxiamida (Esquema XIV). ${ }^{13}$

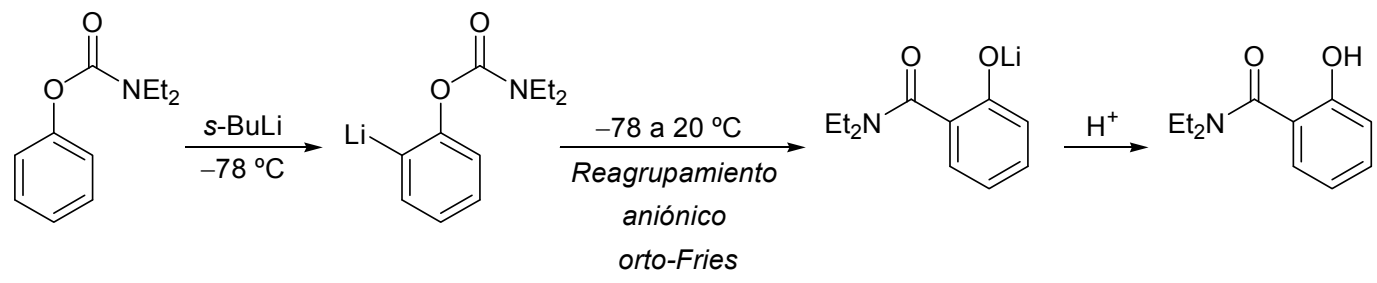

\section{Esquema XIV}

El reagrupamiento de orto-Fries en combinación con reacciones de orto-litiación ha sido de utilidad para la preparación de compuestos aromáticos polisustituidos de forma regioselectiva. Los carbamatos de $O$-arilo pueden experimentar un reagrupamiento de este tipo conduciendo a una amida, la cual ofrece nuevas posibilidades de funcionalización por litiación. Este hecho se pone de manifiesto en la síntesis de la "ocratoxina $A$ " ${ }^{23}$ Una reacción de orto-litiación del $\mathrm{N}, \mathrm{N}$-dietilcarbamato de 4-clorofenilo ha permitido introducir un grupo amido para generar el compuesto I, el cual tras un reagrupamiento de orto-Fries seguido de reacción con MeI da lugar a II (Esquema XV). La diamida simétrica II experimenta una reacción de $o$-litiación y alilación seguida de una ciclación en medio ácido,

${ }^{23}$ M. P. Sibi, S. Chattopadhyay, J. W. Dakwardt, V. Snieckus, J. Am. Chem. Soc. 1985, 107, 6312. 
al hidrolizarse los grupos amida. La desprotección del fenol conduce al intermedio de benzopiranona que se muestra en el Esquema XV, precursor de la "ocratoxina A".<smiles>CCOC(=O)Oc1ccc(Cl)cc1</smiles><smiles>CCNC(=O)c1cc(Cl)cc(C(=O)NCC)c1OC</smiles>

1) $s$-BuLi / TMEDA

$-78{ }^{\circ} \mathrm{C}$

2) $\mathrm{MgCl}_{2}$

3) Bromuro de alilo<smiles>C=CCc1c(Cl)cc(C(=O)NCC)c(OC)c1C(=O)NCC</smiles>

\section{Esquema XV}

Este reagrupamiento aniónico también se ha observado en compuestos heteroaromáticos, como la piridina. Así se ha podido preparar la 3-hidroxipiridina que se muestra en el Esquema XVI con un rendimiento moderado. ${ }^{24}$<smiles>CCNC(=O)Oc1cccnc1</smiles>

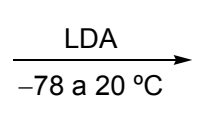<smiles>CCNC(=O)c1nccc(SCC(C)(C)C)c1O</smiles>

\section{Esquema XVI}

${ }^{24}$ M. Tsukazaki, V. Snieckus, Heterocycles 1992, 33, 533. 


\section{d) Reacciones de orto-metalación remota}

En los carbamatos de $O$-arilo, cuando las posiciones orto están bloqueadas, el grupo director puede dirigir la litiación en otra posición diferente, lo que se conoce como litiación remota. Por ejemplo, el carbamato biarílico mostrado en el Esquema XVII experimenta por tratamiento con LDA en THF a reflujo una litiación en una posición remota, seguida de un reagrupamiento de Fries por migración del grupo carbamoílo a dicha posición. La posterior reacción de ciclación del intermedio III en medio ácido conduce a la lactona IV con un rendimiento del $70 \%$ (Esquema XVII). ${ }^{25}$ Esta estrategia sintética de metalación remota-reagrupamiento de Fries-ciclación ha permitido preparar diferentes derivados de dibenzopiranonas y varios productos naturales. ${ }^{1 \mathrm{~d}, 26}$

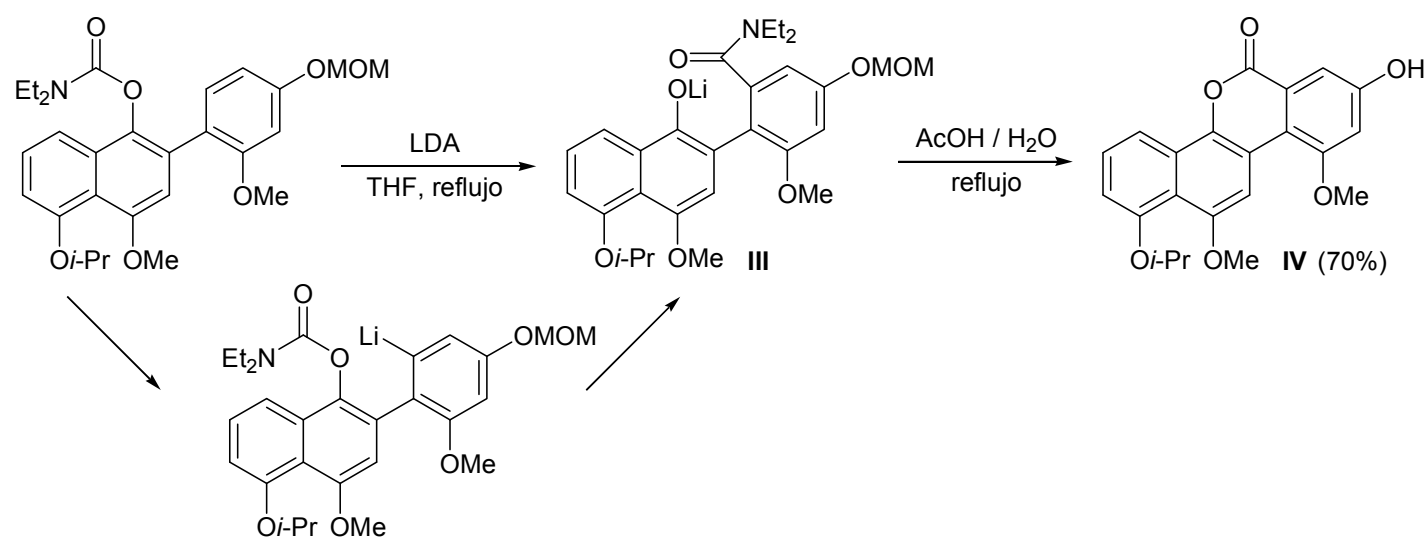

\section{Esquema XVII}

El biarilo que se muestra en el Esquema XVIII experimenta, bajo las mismas condiciones de reacción, una litiación remota y un reagrupamiento aniónico de Fries, obteniéndose la amida intermedia $\mathbf{V}$. Esta amida dirige una reacción de litiación remota en la posición bencílica al reaccionar con el exceso de LDA. Finalmente, la ciclación del organolítico bencílico VI conduce al fenantreno que se muestra en el Esquema XVIII. ${ }^{27}$

25 C. A. James, V. Snieckus, J. Org. Chem. 2009, 74, 4080.

26 a) C. A. James, V. Snieckus, Tetrahedron Lett. 1997, 38, 8149. b) C. A. James, A. L. Coelho, M. Gevaert, P. Forgione, V. Snieckus, J. Org. Chem. 2009, 74, 4094.

27 X. Wang, V. Snieckus, Tetrahedron Lett. 1991, 32, 4879. 


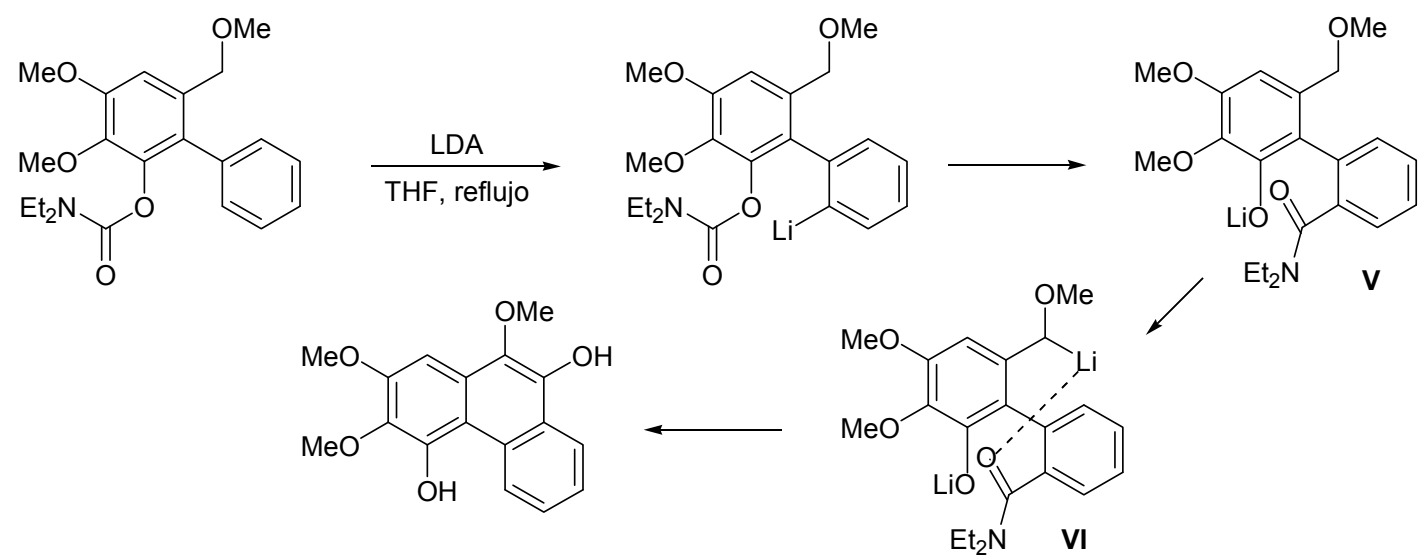

Esquema XVIII

e) Intercambio de halógenos ("Halogen Dance")

El intercambio de halógenos ("halogen dance") es un reagrupamiento en el cual un átomo de halógeno se mueve a una nueva posición del anillo aromático. Es conocido que algunos bromuros o yoduros de arilo pueden experimentar este reagrupamiento mediante tratamiento con amiduros alcalinos.

Snieckus y colaboradores han empleado la secuencia de reacción de ortometalación-intercambio de halógenos-reacción con electrófilos para la obtención de piridinas trisustituidas. Así la reacción de los carbamatos de $O$-piridilo con LDA a baja temperatura seguida de la adición del electrófilo ha permitido obtener piridinas trifuncionalizadas con rendimientos entre moderados y buenos (Esquema XIX). ${ }^{28}$

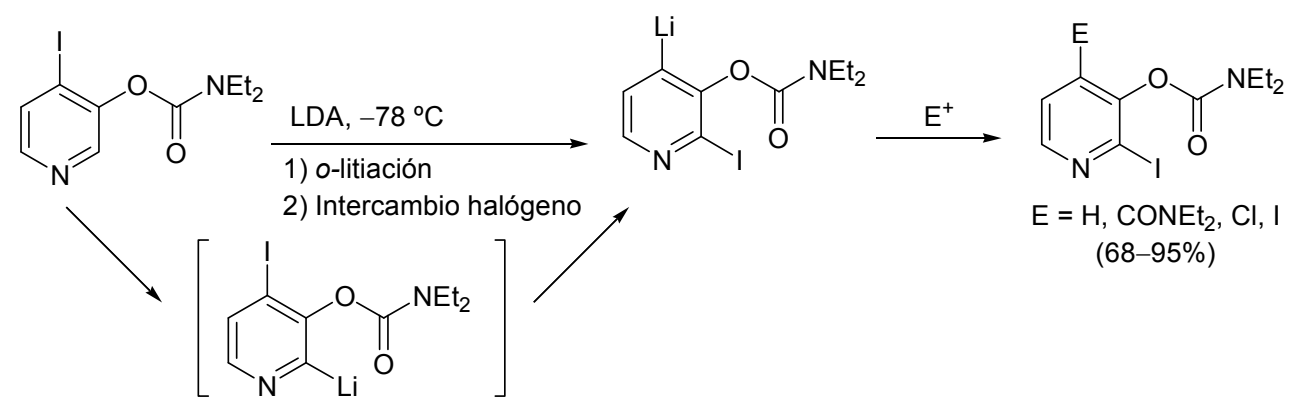

Esquema XIX

${ }^{28}$ R. E. Miller, T. Rantanen, K. A. Ogilvie, U. Groth, V. Snieckus, Org. Lett. 2010, 12, 2198. 
Estos mismos autores han combinado las reacciones de ortometalación-intercambio de halógeno-reagrupamiento aniónico de orto-Fries con el objetivo de obtener los carbamatos de $O$-arilo tetrasustituidos que se muestran en el Esquema XX. ${ }^{28}$

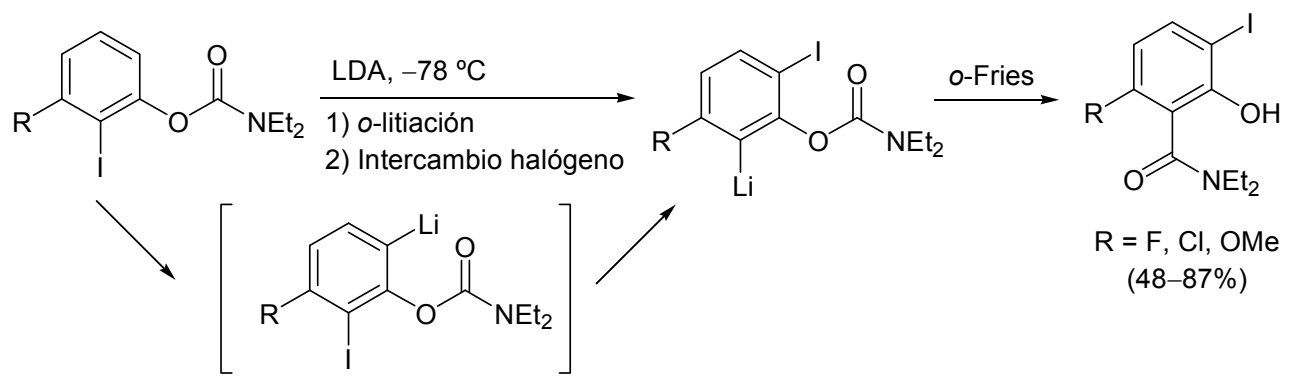

Esquema $X X$

\section{f) Combinación de reacciones de orto-metalación / acoplamiento de Suzuki}

La combinación de la reacción de orto-metalación con el acoplamiento de Suzuki ha sido ampliamente utilizada en síntesis orgánica para la introdución de grupos arilo en la posición orto al grupo director. ${ }^{29}$ Así, por ejemplo, se ha descrito la orto-litiación de $O$ carbamatos de 3,4-dihidro-2H-pirano por tratamiento con $t$-BuLi en THF a baja temperatura seguida de la adición de trimetilborato como electrófilo. Posteriormente, el ácido borónico obtenido experimenta un acoplamiento de Suzuki al reaccionar con un yoduro de arilo en presencia de cantidades catalíticas de $\mathrm{PdCl}_{2}\left(\mathrm{PPh}_{3}\right)_{2}$ y $\mathrm{Na}_{2} \mathrm{CO}_{3}$ como base (Esquema XXI). ${ }^{29 b}$

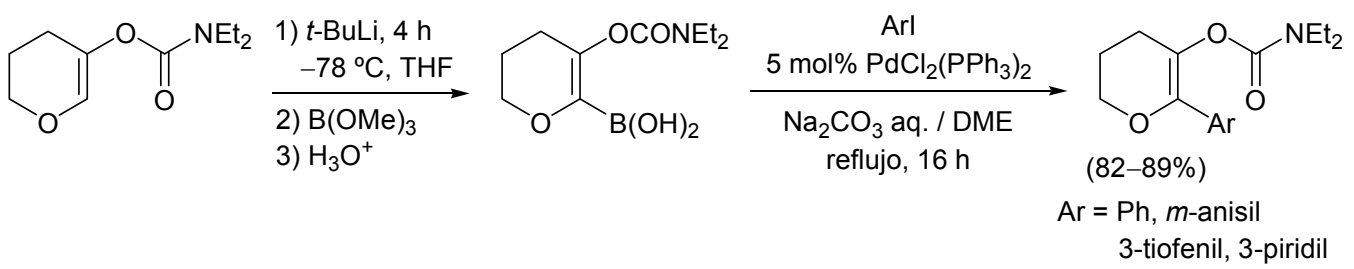

\section{Esquema XXI}

\footnotetext{
29 a) M. J. Sharp, W. Cheng, V. Snieckus, Tetrahedron Lett. 1987, 43, 5093. b) J. F. Bower, D. Guillaneux, T. Nguyen, P. L. Wong, V. Snieckus, J. Org. Chem. 1998, 63, 1514. c) T. E. Hurst, T. K. Macklin, M. Becker, E. Hartmann, W. Kügel, J.-C. Parisienne-La Salle, A. S. Batsanov, T. B. Marder, V. Snieckus, Chem. Eur. J. 2010, 16,8155 .
} 
Snieckus y colaboradores han puesto a punto una secuencia de ortometalación-acoplamiento de Suzuki, seguida de una reacción de metalación remota y posterior ciclación. De esta forma han preparado lactonas tetracíclicas con rendimientos entre moderados y buenos (Esquema XXII). ${ }^{26 \mathrm{~b}}$

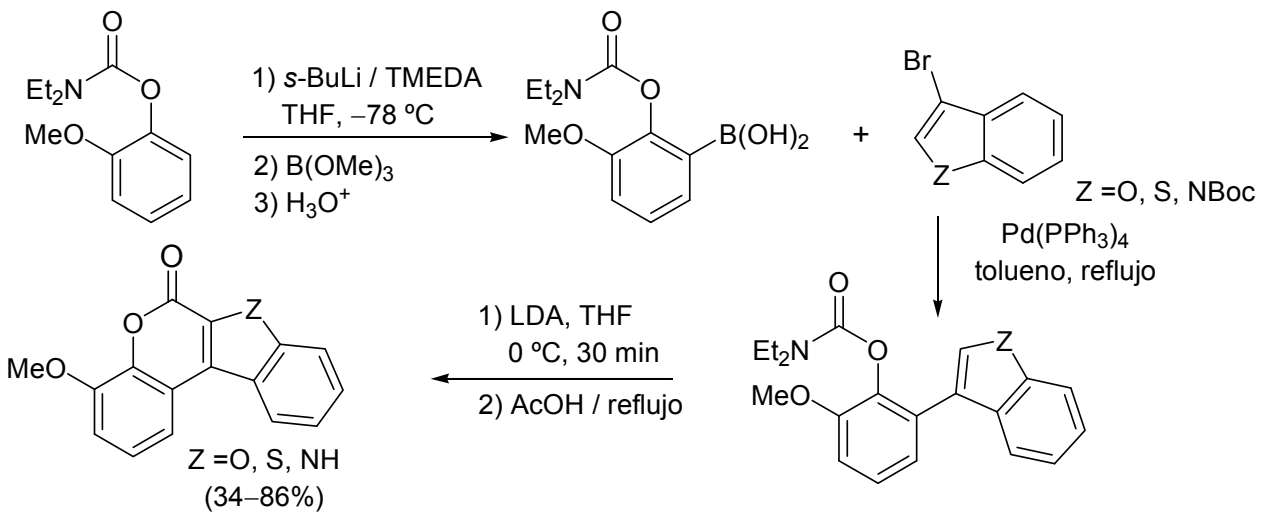

\section{Esquema XXII}

g) Generación de bencinos

Kobayashi descubrió que los triflatos de arilo que contienen un grupo trimetilsililo en posición orto son precursores de bencinos al reaccionar con una fuente de fluoruro. ${ }^{30 \mathrm{a}}$ Este hecho en combinación con las reacciones de $o$-metalación de carbamatos de arilo ha sido empleado por Snieckus para generar un intermedio bencínico, el cual en presencia de dienófilos permite obtener el producto resultante de la cicloadición con buenos rendimientos (Esquema XXIII). ${ }^{30 \mathrm{~b}}$

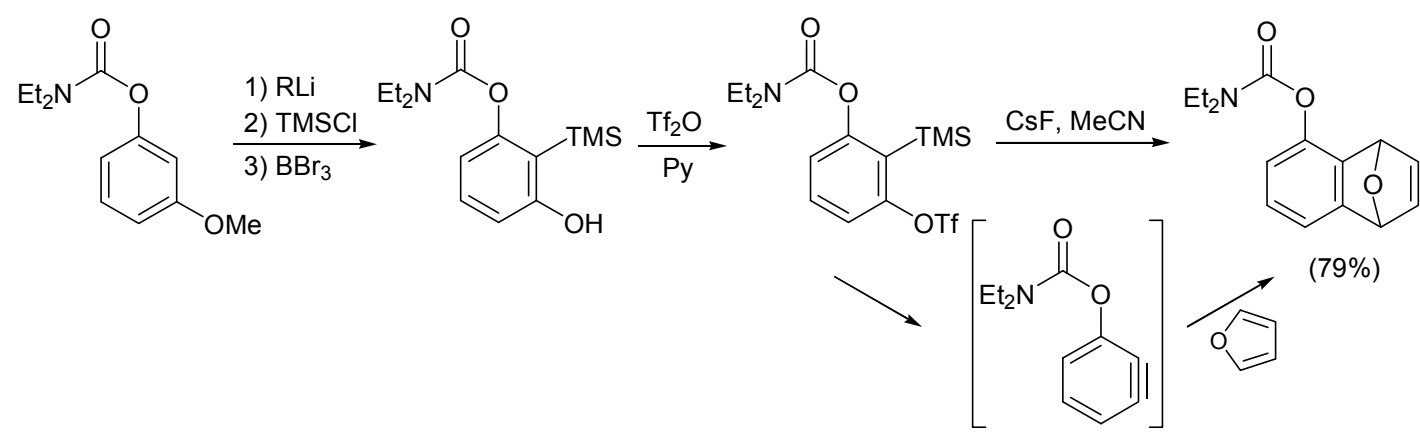

\section{Esquema XXIII}

30 a) Y. Himeshima, T. Sonoda, H. Kobayashi, Chem. Lett. 1983, 1211. b) K. Shankaran, V. Snieckus, Tetrahedron Lett. 1984, 25, 2827. 


\section{A.1.3 Reacciones de metalación dirigida en carbamatos de $N$-arilo y anilidas}

A continuación se describirán las reacciones de orto-litiación descritas en la literatura empleando carbamatos de $N$-arilo y anilidas, grupos que también han sido empleados en este trabajo de investigación.

Como se ha comentado anteriormente, las anilinas son grupos directores pobres: el par de electrones del nitrógeno es menos básico que el de las correspondientes aminas $\mathrm{y}$, además, posee un débil efecto acidificante. Sin embargo, la $N, N$-dimetilanilina puede ser litiada por tratamiento con $n$-BuLi a reflujo en hexano. ${ }^{31}$ La mejor solución a este problema para litiar anillos aromáticos con sustituyentes amino es acilar la anilina con el fin de obtener una pivalamida o un carbamato con un grupo $t$-butoxicarbonilo (Boc). Es necesario emplear dos equivalentes del reactivo organolítico, un equivalente para desprotonar el átomo de nitrógeno y el segundo para llevar a cabo la reacción de orto-litiación (Esquema XXIV). ${ }^{32}$

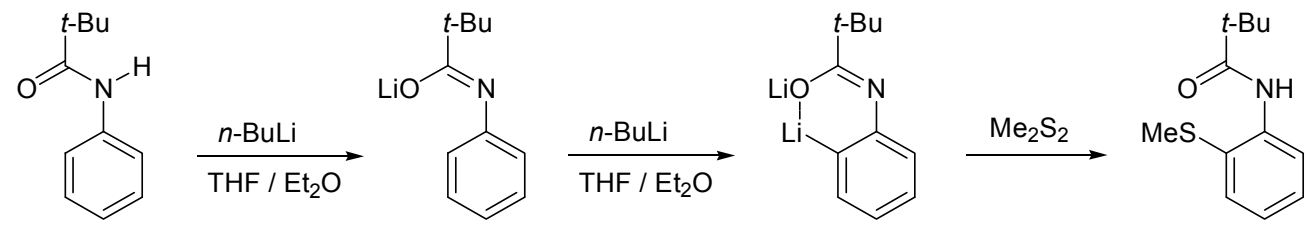

\section{Esquema XXIV}

Con las anilinas que contienen un grupo $N$-Boc en su estructura, las mejores condiciones para llevar a cabo la litiación son 2.2 equivalentes de $t$-BuLi en éter a $-10{ }^{\circ} \mathrm{C}$ (Esquema XXV). ${ }^{33}$

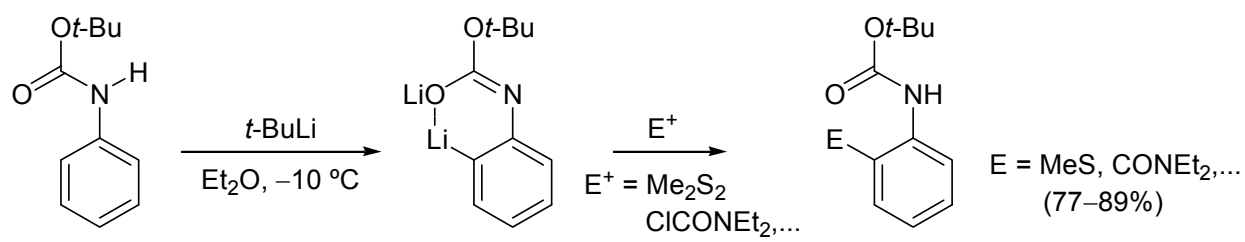

Esquema XXV

\footnotetext{
31 a) A. P. Lepley, W. A. Khan, A. B. Giumanini, A. G. Giumanini, J. Org. Chem. 1966, 31, 2047. b) D. W. Slocum, G. Bock, C. A. Jennings, Tetrahedron Lett. 1970, 3443.

32 W. Fuhrer, H. W. Gschwend, J. Org. Chem. 1979, 44, 1133.

33 a) J. M. Muchowski, M. C. Venuti, J. Org. Chem. 1980, 45, 4798. b) P. Stanetty, H. Koller, M. Mihovilovic, J. Org. Chem. 1992, 57, 6833.
} 
Las amidas derivadas de aminopiridinas también han sido ampliamente utilizadas para dirigir la litiación. La reacción de metalación resulta más efectiva cuando se emplea $n$ BuLi en ausencia de TMEDA (Esquema XXVI). ${ }^{34}$<smiles>CC(C)(C)C(=O)Nc1ccccn1</smiles><smiles>CCC(=O)OC(C)(C)C</smiles><smiles>CC(C)(C)C(=O)Nc1ncccc1C(=O)O</smiles>

\section{Esquema XXVI}

Barker y colaboradores han llevado a cabo la funcionalización en posición 2 de $N$-Boc pirrolidinas empleando $s$-BuLi a $-30{ }^{\circ} \mathrm{C}$ en THF (Esquema XXVII). ${ }^{35}$
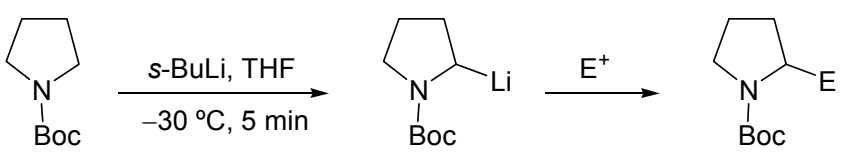
$\mathrm{E}=\mathrm{Me}, \mathrm{CH}_{2}=\mathrm{CHCH}_{2}, \mathrm{COOH}$
$\mathrm{CHO}, \mathrm{PhCO}, \mathrm{SiMe}_{3}, \ldots$

$\mathrm{E}^{+}=\mathrm{Me}_{2} \mathrm{SO}_{4}, \mathrm{CH}_{2}=\mathrm{CHCH}_{2} \mathrm{Br}, \mathrm{CO}_{2}$ $(51-73 \%)$ $\mathrm{DMF}, \mathrm{PhCONMe}, \mathrm{Me}_{3} \mathrm{SiCl}, \ldots$

\section{Esquema XXVII}

La orto-litiación de $N$-Boc anilinas con un átomo de halógeno en posición 3, como flúor o cloro, ha sido empleada para la construcción de benzoxazoles. El grupo $N$-Boc dirige la litiación a la posición orto del anillo generándose, tras la eliminación del haluro de litio, un intermedio bencínico que cicla y puede reaccionar con un electrófilo (Esquema XXVIII). ${ }^{36}$

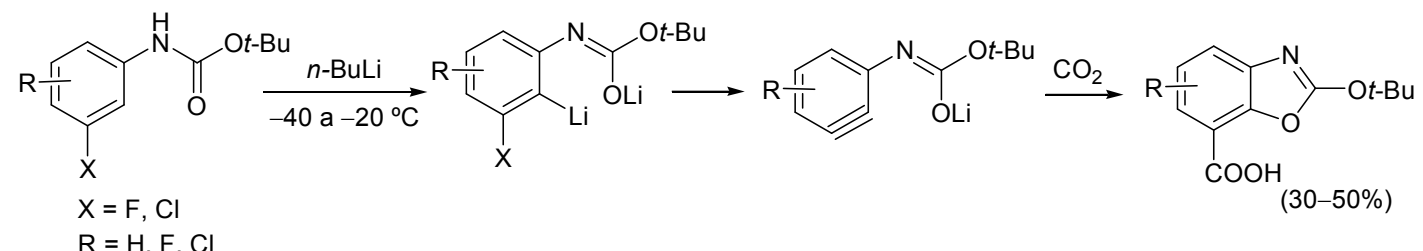

\section{Esquema XXVIII}

${ }^{34}$ G. Quéguiner, F. Marsais, V. Snieckus, J. Epsztajn, Adv. Heterocycl. Chem. 1991, 52, 187.

${ }^{35}$ G. Barker, P. O’Brien, K. R. Campos, Org. Lett. 2010, 12, 4176.

36 D. R. Reavill, S. K. Richardson, Synth. Commun. 1990, $20,1423$. 
De un modo análogo, la orto-litiación de tioanilidas se ha utilizado para la construcción de anillos de benzotiazol vía formación de bencinos (Esquema XXIX). ${ }^{37}$

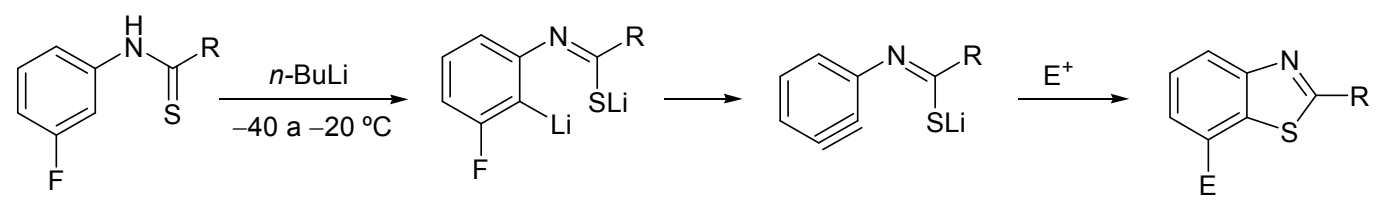

\section{Esquema XXIX}

Por otro lado, McKittrick y colaboradores han descrito la orto-metalación de la 2,2,2-trifluoro- $N$-(3-fluorofenil)acetamida empleando $t$-BuLi en presencia de TMEDA a $-78{ }^{\circ} \mathrm{C}$. La combinación del átomo de flúor (electrón atractor) y del grupo trifluoroacetamida permite la litiación a baja temperatura, evitándose la formación de bencino. La posterior reacción de la especie orto-litiada con bromo o dimetilsulfuro conduce a las 3fluorotrifluoroacetanilidas 2-sustituidas (Esquema XXX). ${ }^{38}$

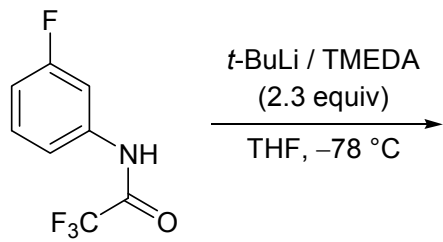<smiles>OC(=Nc1cccc(F)c1Cl)C(F)(F)F</smiles><smiles>CCCC</smiles><smiles>O=C(Nc1cccc(F)c1F)C(F)(F)F</smiles>

Esquema $\mathrm{XXX}$

\section{A.2 Reacciones de orto-zincación}

En los últimos años se han desarrollado nuevos procedimientos sintéticos para la desprotonación de compuestos aromáticos y heteroaromáticos utilizando zincatos de metales alcalinos. Estos agentes metalantes han permitido llevar a cabo la metalación orto-dirigida de diferentes sustratos aromáticos funcionalizados. ${ }^{39}$

P. Stanetty, B. Krumpak, J. Org. Chem. 1996, 61, 5130.

38 B. McKittrick, A. Failli, R. J. Steffan, R. M. Soll, P. Hughes, J. Schmid, A. A. Asselin, C. C. Shaw, R. Noureldin, G. Gavin, J. Heterocycl. Chem. 1990, 27, 2151.

${ }^{39}$ a) R. E. Mulvey, F. Mongin, M. Uchiyama, Y. Kondo, Angew. Chem., Int. Ed. 2007, 46, 3802. b) E. Hevia, An. Quím. 2011, 107, 335. 
Kondo y colaboradores describieron por primera vez la desprotonación de compuestos arílicos utilizando di-t-butil(tetrametilpiperiduro)zincato de litio. Esta base permite llevar a cabo reacciones de orto-metalación con gran quimioselectividad y ha sido empleada en la funcionalización de distintas series de arenos. Por ejemplo, benzoatos de alquilo, $N, N$-diisopropilbenzamidas y benzonitrilo han sido metalados con este TMP-zincato a temperatura ambiente y, tras la adición de yodo, han dado lugar a los correspondientes 2-yodo derivados (Esquema XXXI). ${ }^{40}$

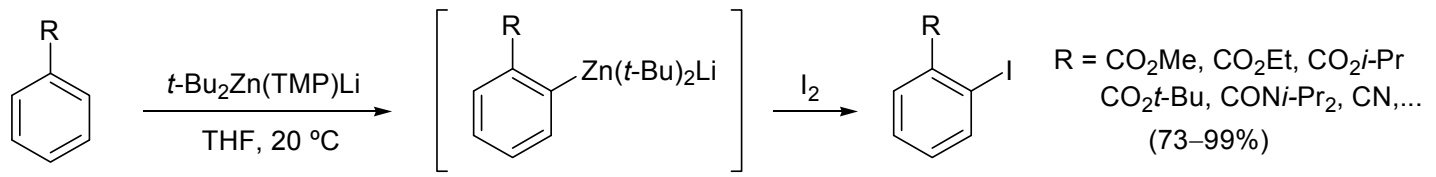

\section{Esquema XXXI}

El $t$ - $\mathrm{Bu}_{2} \mathrm{Zn}(\mathrm{TMP}) \mathrm{Li}$ necesario para estas reacciones se prepara por adición de di-tbutilzinc a una disolución del amiduro de litio de la 2,2,6,6-tetrametilpiperidina (LiTMP) en THF a baja temperatura (Esquema XXXII). ${ }^{40}$

$$
\mathrm{ZnCl}_{2}+t \text {-BuLi (2 equiv) } \frac{\mathrm{THF}}{-78 \text { a } 20^{\circ} \mathrm{C}} \quad(t-\mathrm{Bu})_{2} \mathrm{Zn}
$$

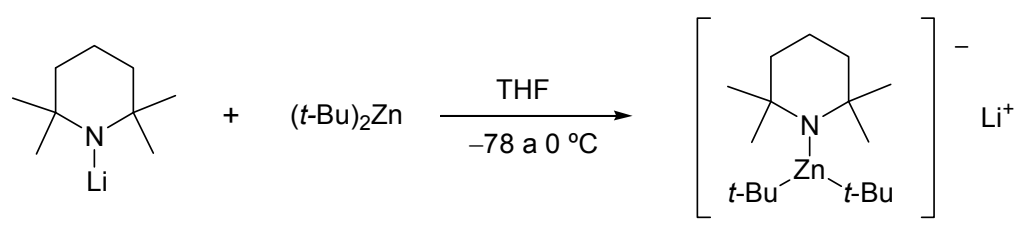

\section{Esquema XXXII}

Además, estos mismos autores observaron que el tratamiento de alquilbenzoatos con LiTMP, seguida de la adición de $t-\mathrm{Bu}_{2} \mathrm{Zn}$, no conducía a la formación de los mismos arilzincatos, lo que pone de manifiesto la formación previa del complejo de $t$ $\mathrm{Bu}_{2} \mathrm{Zn}(\mathrm{TMP}) \mathrm{Li}$ al paso de zincación. También comprobaron que si se elimina el metal alcalino, el $t-\mathrm{Bu}_{2} \mathrm{Zn}$ es incapaz de producir la reacción de zincación de amidas aromáticas terciarias, lo que demuestra la actividad sinérgica de ambos metales.

${ }^{40}$ Y. Kondo, M. Shilai, M. Uchiyama, T. Sakamoto, J. Am. Chem. Soc. 1999, 121, 3539. 
También se ha investigado la orto-zincación de varios bromobencenos 3-sustituidos variando la naturaleza de los TMP-zincatos. Cuando los bromobencenos funcionalizados en posición meta con grupos tales como: $\mathrm{OMe}, \mathrm{Cl}, \mathrm{F}, \mathrm{CN}$ ó $\mathrm{CON} i-\mathrm{Pr}_{2}$ se trataron con $t$ $\mathrm{Bu}_{2} \mathrm{Zn}$ (TMP)Li, la reacción de metalación tuvo lugar quimio y regioselectivamente en la posición 2, como puso de manifiesto el aislamiento de los correspondientes productos yodados. ${ }^{41}$ Sin embargo, cuando se sustituyó el $t$-Bu $2 \mathrm{Zn}(\mathrm{TMP}) \mathrm{Li}$ por su análogo con ligandos metilo, el $\mathrm{Me}_{2} \mathrm{Zn}(\mathrm{TMP}) \mathrm{Li}$, al llevar a cabo la desprotonación de los bromobencenos 3-sustituidos fue imposible evitar la formación de bencinos. Y así, incrementando la temperatura de la mezcla de reacción en presencia de un isobenzofurano, se aislaron los correspondientes aductos de Diels Alder (Esquema XXXIII). ${ }^{41}$<smiles>[R]c1cccc(Br)c1I</smiles>

$(77-96 \%)$<smiles>[R]c1cccc(Br)c1[Ge](C)(CCC)C(C)(C)C</smiles>

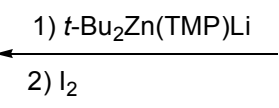

$\mathrm{R}=\mathrm{OMe}, \mathrm{Cl}, \mathrm{F}, \mathrm{CN}, \mathrm{CONi}-\mathrm{Pr}_{2}$<smiles>[R][R]([R])c1c(Br)cccc1I</smiles>
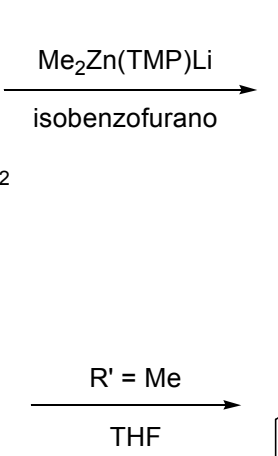<smiles>[R]c1cccc2c1OC1(c3ccccc3)OC2(c2ccccc2)c2ccccc21</smiles>

\section{Esquema XXXIII}

Por otro lado, se ha observado que al tratar la 2- y la 3-bromopiridina con complejos de estructura $t-\mathrm{Bu}_{2} \mathrm{Zn}(\mathrm{R}) \mathrm{Li}$ la regioselectividad de la metalación dependía de la naturaleza del resto $\mathrm{R}$ y de las condiciones de reacción (temperatura y disolvente). Se utilizaron dos complejos ato, el $t$ - $\mathrm{Bu}_{2} \mathrm{Zn}(\mathrm{TMP}) \mathrm{Li}$ y el $t-\mathrm{Bu}_{2} \mathrm{Zn}\left(i-\mathrm{Pr}_{2} \mathrm{~N}\right) \mathrm{Li}$, obteniéndose los resultados que se muestran en el Esquema XXXIV. ${ }^{42}$

\footnotetext{
${ }^{41}$ M. Uchiyama, T. Miyoshi, Y. Kajihara, T. Sakamoto, Y. Otani, T. Ohwada, Y. Kondo, J. Am. Chem. Soc. 2002, 124, 8514.

42 T. Imahori, M. Uchiyama, T. Sakamoto, Y. Kondo, Chem. Commun. 2001, 2450.
} 


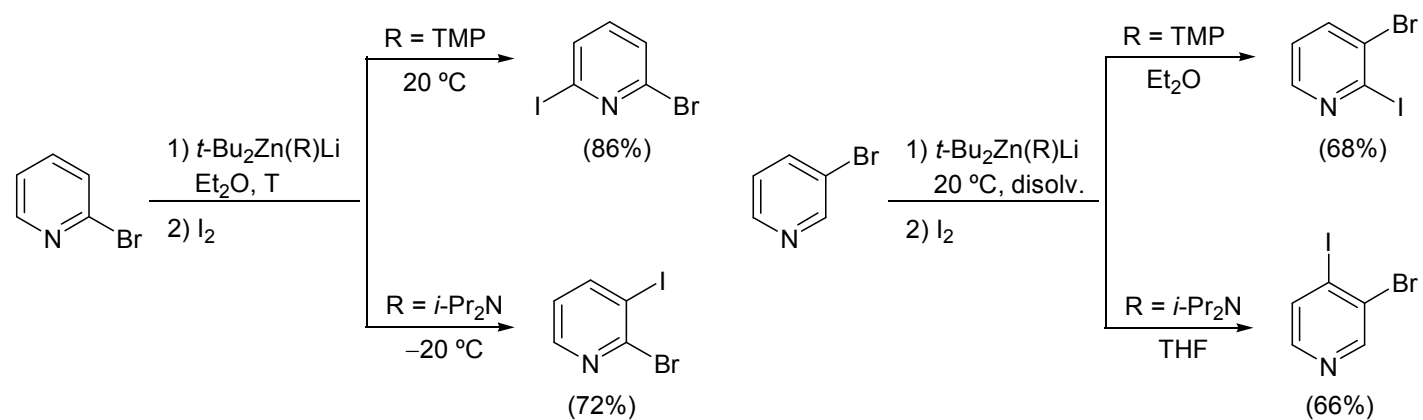

Esquema XXXIV

También se ha descrito la desprotonación de benzoxazol, benzotiazol, benzo[b]tiofeno, benzo[ $b]$ furano y el $N$-Boc-indol, empleando una mezcla "in situ" de $\mathrm{ZnCl}_{2} \cdot$ TMEDA y LiTMP en THF a temperatura ambiente. ${ }^{43}$ La posterior reacción con yodo permitió preparar los derivados yodo funcionalizados de forma regioselectiva (Esquema $\mathrm{XXXV}){ }^{43 \mathrm{a}}$<smiles>[X]1cnc2ccccc12</smiles><smiles>[X]O[S]</smiles><smiles>[X]c1cccc2ccccc12</smiles>
$\mathrm{X}=\mathrm{O}, \mathrm{S}, \mathrm{NBoC}$
1) $\mathrm{ZnCl}_{2} \cdot \mathrm{TMEDA}(0.5$ equiv)

$$
+\operatorname{LiTMP}(1.5 \text { equiv) }
$$

2) $\mathrm{I}_{2}$

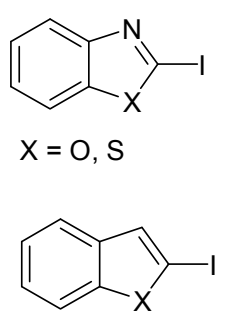

$X=O, S, N B o c$

\section{Esquema XXXV}

En los últimos años se han realizado un gran número de estudios con el objetivo de conocer el mecanismo por el que transcurren las reacciones de orto-metalación dirigida que emplean como agentes metalantes complejos ato heterometálicos. ${ }^{39 b, 44}$

43 a) J.-M. L'Helgoual'ch, A. Seggio, F. Chevallier, M. Yonehara, E. Jeanneau, M. Uchiyama, F. Mongin, $J$. Org. Chem. 2008, 73, 177. b) F. Mongin y col. Chem. Eur. J. 2011, 17, 13284.

44 a) W. Clegg, S. H. Dale, A. M. Drummond, E. Hevia, G. W. Honeyman, R. E. Mulvey, J. Am. Chem. Soc. 2006, 128, 7434. b) W. Clegg, S. H. Dale, E. Hevia, G. W. Honeyman, R. E. Mulvey, Angew. Chem., Int. Ed. 2006, 45, 2370. c) D. R. Armstrong, W. Clegg, S. H. Dale, E. Hevia, L. M. Hogg, G. W. Honeyman, R. E. Mulvey, Angew. Chem., Int. Ed. 2006, 45, 3775. d) W. Clegg, S. H. Dale, E. Hevia, L. M. Hogg, G. W. Honeyman, R. E. Mulvey, Angew. Chem., Int. Ed. 2006, 45, 6548. e) M. Uchiyama, Y. Matsumoto, S. Usui, Y. Hashimoto, K. Morokuma, Angew. Chem., Int. Ed. 2007, 46, 926. f) Y. Kondo, J. V. Morey, J. C. Morgan, H. Naka, D. Nobuto, P. R. Raithby, M. Uchiyama, A. E. H. Wheatley, J. Am. Chem. Soc. 2007, 129, 12734. 
Estos compuestos heterometálicos que combinan dos centros metálicos: un metal alcalino (normalmente $\mathrm{Li}, \mathrm{Na}$, ó $\mathrm{K}$ ) y un átomo de $\mathrm{Zn}$ ó $\mathrm{Al}$ permiten efectuar con éxito reacciones que no pueden ser reproducidas por los correspondientes compuestos homometálicos de metales alcalinos, de zinc o aluminio (efecto sinérgico). El $t$ $\mathrm{Bu}_{2} \mathrm{Zn}(\mathrm{TMP}) \mathrm{Li}$ en THF como disolvente forma un complejo en el que ambos metales se encuentran conectados a través de un ligando amiduro TMP (Esquema XXXVI).

El mecanismo de estas reacciones se considera más complejo que el de las ortolitiaciones y se cree que el efecto CIPE $^{45}$ (Complex-Induced Proximity Effect) juega un papel muy importante. Este mecanismo ha sido estudiado empleando diferentes técnicas (resonancia magnética nuclear, espectrofotometría de infrarrojo con transformada de Fourier, difracción de rayos X) y por numerosos estudios teóricos (basados en cálculos DFT). Se cree que la reacción tiene lugar mediante la formación de un aducto inicial entre el complejo ato y el compuesto aromático, seguida de la formación del compuesto aromático metalado por desprotonación (Esquema XXXVI).

En los complejos ato formados por distintos tipos de ligandos, como por ejemplo el $t$ $\mathrm{Bu}_{2} \mathrm{Zn}(\mathrm{TMP}) \mathrm{Li}$, se ha observado que tanto el ligando alquilo como el ligando amido pueden actuar como base. Una de las primeras moléculas para la cual se investigó sus reacciones de desprotonación empleando el complejo $t$ - $\mathrm{Bu}_{2} \mathrm{Zn}(\mathrm{TMP}) \mathrm{Li}$ fue el anisol. ${ }^{39,44 a}$ Experimentalmente se observa que I (caractizado por rayos X) ha actuado como una base de tipo alquilo, donde el grupo $t$-butilo puente entre los dos metales es sustituido en el producto final por el correspondiente areno desprotonado (Esquema XXXVI).

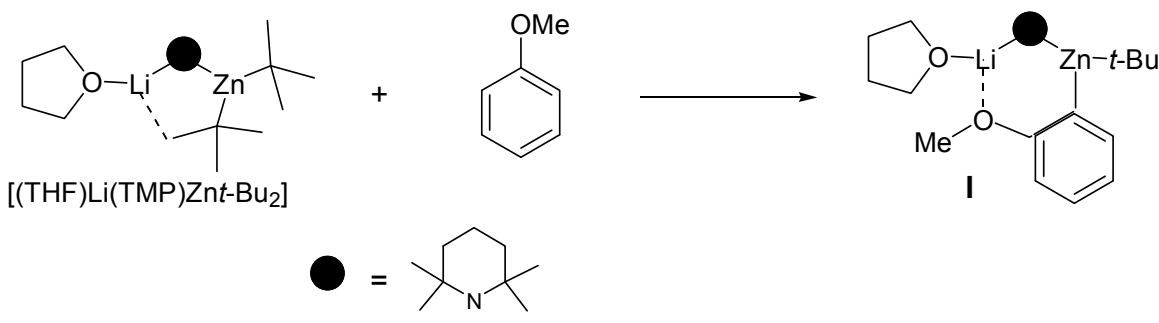

\section{Esquema XXXVI}

45 a) P. Beak, A. I. Meyers, Acc. Chem. Res. 1986, 19, 356. b) W. Bauer, P. V. R. Scheler, J. Am. Chem. Soc. 1989, 111, 7191. c) D. R. Anderson, N. C. Faibish, P. Beak, J. Am. Chem. Soc. 1999, 121, 7553. 


\section{A.3 Otras reacciones de orto-metalación}

\section{A.3.1 Reacciones de orto-aluminación}

Los primeros autores en estudiar las reacciones de orto-aluminación fueron Uchiyama y colaboradores en 2004. Describieron la funcionalización regio y quimioselectiva de una serie de arenos empleando como agente metalante el complejo heteroléptico triisobutil(tetrametilpiperiduro)aluminato de litio. ${ }^{46}$ Este complejo se prepara por adición de triisobutilaluminio a una disolución de LiTMP en THF (Esquema XXXVII).

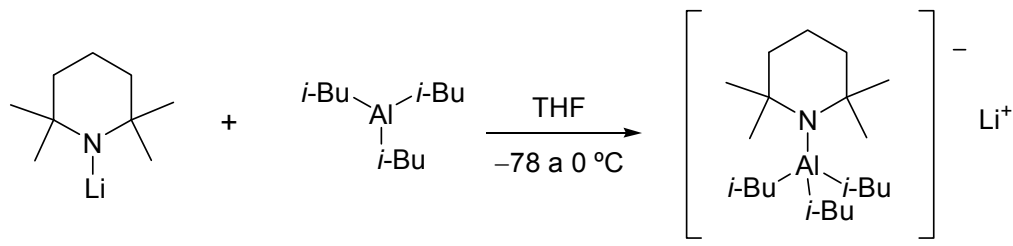

\section{Esquema XXXVII}

Este agente orto-metalante permite desprotonar una gran variedad de compuestos aromáticos. Es compatible tanto con grupos electrón dadores, metoxilo; como con grupos electrón atractores, ciano o amido (Esquema XXXVIII).

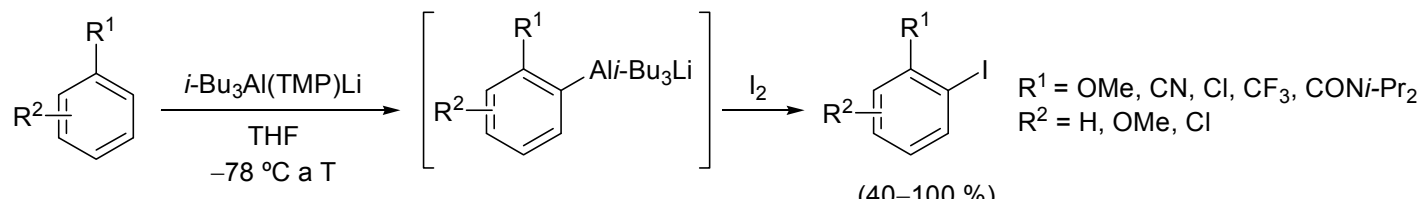

\section{Esquema XXXVIII}

Estos mismos autores también han descrito la orto-aluminación regioselectiva de compuestos heteroaromáticos tales como piridinas, indoles, benzofuranos y benzoxazoles por tratamiento con $i$ - $\mathrm{Bu}_{3} \mathrm{Al}(\mathrm{TMP}) \mathrm{Li}$ (Esquema XXXIX). ${ }^{47}$

46 M. Uchiyama, H. Naka, Y. Matsumoto, T. Ohwada, J. Am. Chem. Soc. 2004, 126, 10526.

${ }^{47}$ H. Naka, M. Uchiyama, Y. Matsumoto, A. E. H. Wheatley, M. McPartlin, J. V. Morey, Y. Kondo, J. Am. Chem. Soc. 2007, 129, 1921. 


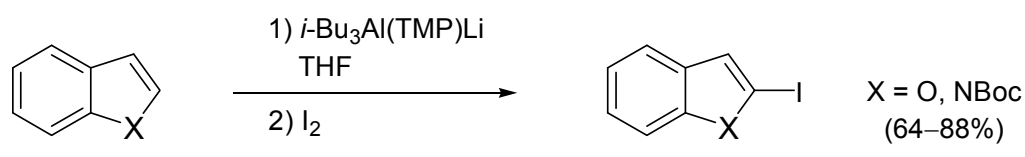

Esquema XXXIX

La desprotonación del anillo arílico por parte del aluminato tiene lugar sin producirse la adición nucleófila a los grupos carbonilo o ciano. Además, tampoco tiene lugar el intercambio halógeno-metal en compuestos que presentan átomos de yodo adicionales. Esta quimioselectividad es considerada como única de estos aluminatos debido a que ni las bases metálicas (tales como alquillitio o reactivos de Grignard) ni incluso los TMP-zincatos pueden coexistir con yoduros de arilo. Así el $p$-yodoanisol o el $p$ yodobenzonitrilo se pueden orto-metalar sin que se produzca la reacción de intercambio halógeno-metal (Esquema XL). ${ }^{39 a, 46}$

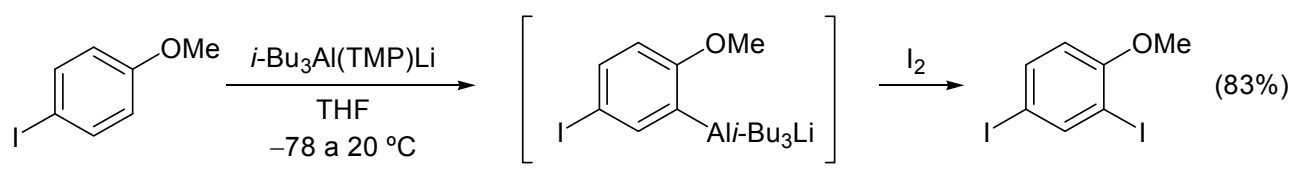

Esquema XL

En las reacciones de aluminación, la generación de bencinos se puede favorecer o evitar controlando la temperatura a la que se lleva a cabo la reacción. Así, el intermedio arilaluminato que se genera al desprotonarse el compuesto aromático puede reaccionar con un electrófilo, si la reacción transcurre a baja temperatura. Sin embargo, si la reacción se deja evolucionar hasta temperatura ambiente se forma el correspondiente bencino, el cual reacciona con dienos tales como 1,3-difenilisobenzofurano para dar el correspondiente aducto de Diels-Alder con rendimientos prácticamente cuantitativos (Esquema XLI). ${ }^{46}$<smiles>O=C(N[P+](=O)[O-])c1cccc(Br)c1I</smiles>

$(65 \%)$

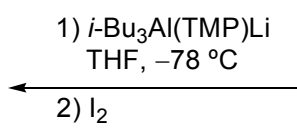<smiles>O=C(N=[Nb])c1cccc(Br)c1</smiles>

Esquema XLI
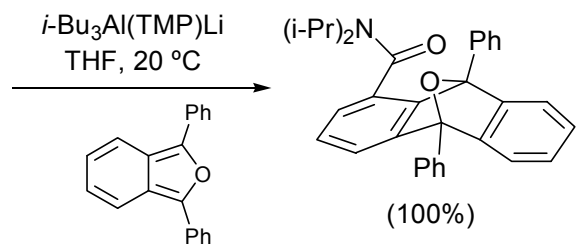


\section{A.3.2 Reacciones de orto-magnesiación}

El primer uso de un magnesiato como agente metalante para desprotonar compuestos aromáticos fue descrito en 1992. Castaldi y Borsotti ${ }^{48}$ describieron la metalación de sustratos activados, tales como derivados de trifluorometilbenceno que contenían un segundo grupo ( $N, N$-dimetilamino, metoxilo o trifluorometilo) en el $\mathrm{C}-3$, empleando tributilmagnesiato de litio (Esquema XLII).

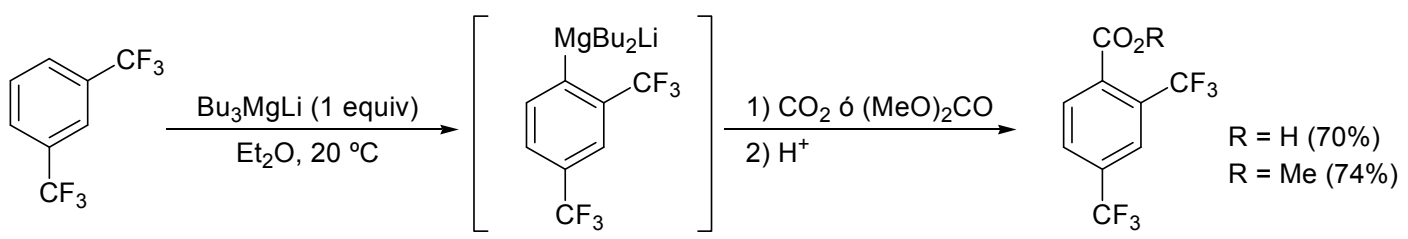

Esquema XLII

Tradicionalmente, las bases de magnesio han sido poco empleadas como agentes metalantes en reacciones de orto-metalación debido a su baja solubilidad y basicidad. Sin embargo, en los últimos años Knochel y colaboradores han estudiado amidas de magnesio complejadas con cloruro de litio del tipo $\mathrm{R}_{2} \mathrm{NMgCl} \cdot \mathrm{LiCl}^{49}$ y $\left(\mathrm{R}_{2} \mathrm{~N}\right)_{2} \mathrm{Mg} \cdot \mathrm{LiCl}^{50}$ que han demostrado ser buenos agentes orto-metalantes de compuestos aromáticos y heteroaromáticos. Así, la reacción de (TMP) $\mathrm{MgCl} \cdot \mathrm{LiCl}$ con isoquinolina, 2,6-dicloropiridina, furano, tiofeno, benzotiofeno, tiazol o benzotiazol a temperatura ambiente, y su posterior reacción con distintos electrófilos permitió la funcionalización de estos heterociclos con buenos rendimientos. También se demostró que los complejos ato de magnesio toleraban la presencia de grupos como éster, nitrilo o carbonilo en el compuesto aromático (Esquema XLIII). ${ }^{49 \mathrm{~b}}$

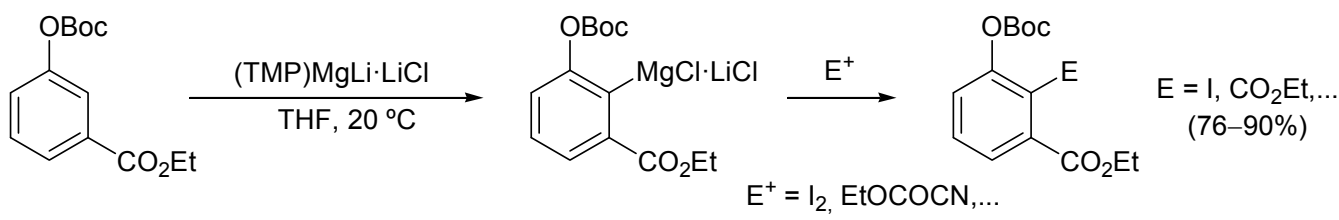

\section{Esquema XLIII}

48 G. Castaldi, G. Borsotti. Eur. Patent 491326A2, 1992 [Chem. Abstr. 1992, 117, 150667].

49 a) A. Krasovskiy, V. Krasovskaya, P. Knochel, Angew. Chem., Int. Ed. 2006, 45, 2958. b) W. Lin, O. Baron, P. Knochel, Org. Lett. 2006, 8, 5673. c) G. Monzon, P. Knockel, Synlett 2010, 304. d) S. H. Wunderlich, C. J. Rohbogner, A. Unsinn, P. Knochel, Org. Process Res. Dev. 2010, 14, 339.

50 G. C. Clososki, C. J. Rohbogner, P. Knochel, Angew. Chem., Int. Ed. 2007, 46, 7681. 


\section{A.3.3 Reacciones de orto-cupración}

También se ha demostrado que los organoamidocupratos son agentes metalantes con utilidad en reacciones de orto-cupración de compuestos aromáticos y heteroaromáticos. Estos agentes metalantes toleran la presencia de grupos metoxilo, ciano, amido y halógeno durante el transcurso de la reacción. Además, los arilcupratos intermedios que se forman pueden experimentar reacciones de metilación, alilación, sililación, sin la presencia de un catalizador de paladio o cobre, a diferencia de los zincatos o aluminatos (Esquema XLIV). ${ }^{51}$
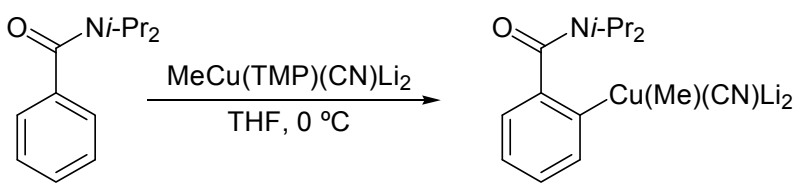

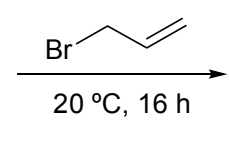<smiles>C=CCc1ccccc1C(=O)NC(=O)c1ccccc1</smiles>

\section{Esquema XLIV}

\section{A.3.4 Reacciones de orto-cadmiación}

Los agentes metalantes de cadmio también son útiles para funcionalizar de forma regio y quimioselectiva compuestos aromáticos y heteroaromáticos. La principal desventaja que presenta este método es la elevada toxicidad del cadmio (Esquema XLV). ${ }^{52}$<smiles>[R]c1ccccc1</smiles>

1) $\mathrm{CdCl}_{2} \cdot \operatorname{TMEDA}(0.5$ equiv) + LiTMP (1.5 equiv) THF, $20^{\circ} \mathrm{C}, 2 \mathrm{~h}$

2) $I_{2}$<smiles>[R]c1ccccc1I</smiles>

$\mathrm{R}=\mathrm{OMe}, \mathrm{CN}, \mathrm{CONEt}_{2}, \mathrm{COPh}, \ldots$ (60-97\%)

Esquema XLV

51 S. Usui, Y. Hashimoto, J. V. Morey, A. E. H. Wheatley, M. Uchiyama, J. Am. Chem. Soc. 2007, 129, 15102.

52 a) J.-M. L'Helgoual'ch, G. Bentaved-Ababsa, F. Chevallier, M. Yonehara, M. Uchiyama, A. Derdour, F. Mongin, Chem. Commun. 2008, 5375. b) K. Snégaroff, J.-M. L'Helgoual'ch, G. Bentabed-Ababsa, T. T. Nguyen, F. Chevallier, M. Yonehara, M. Uchiyama, A. Derdour, F. Mongin, Chem. Eur. J. 2009, 15, 10280. 


\section{B REACCIONES DE ACOPLAMIENTO C-C CATAlizAdAS POR COMPLEJOS DE PALADIO}

Las reacciones de acoplamiento catalizadas por metales de transición constituyen uno de los métodos más importantes para la construcción de enlaces $\mathrm{C}-\mathrm{C} .^{53} \mathrm{~A}$ esta clase de reacciones pertenecen las de Sonogashira, Heck, Suzuki, Stille, Negishi, etc. En este apartado se van a describir brevemente los acoplamientos que han sido empleados en este trabajo.

\section{B.1 Reacción de Sonogashira}

Sonogashira describió por primera vez en 1975 el acoplamiento de alquinos terminales con yoduros de arilo, bromoalquenos y bromopiridinas en presencia de cantidades catalíticas de dicloro[bis(trifenilfosfina)]paladio (II) y yoduro de cobre (I) en dietilamina como disolvente bajo condiciones suaves de reacción (Esquema XLVI). ${ }^{54}$

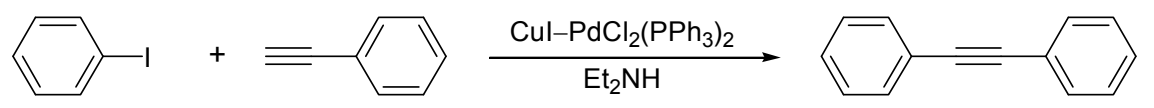

\section{Esquema XLVI}

La reacción de Sonogashira consiste en un acoplamiento $s p-s p^{2}$ de alquinos terminales con halogenuros o triflatos de arilo o vinilo, ${ }^{55} \mathrm{y}$ se ha convertido en el método más empleado para preparar arilalquinos y eninos conjugados. Ello es debido, en gran medida, a las suaves condiciones en las que se lleva a cabo, así como a la gran tolerancia que muestra hacia grupos funcionales presentes tanto en el haluro como en el alquino.

El acoplamiento en los haluros o triflatos de arilo electrónicamente pobres se produce más fácilmente que en los que presentan una elevada densidad electrónica en el anillo aromático y, además, la reacción de acoplamiento es muy sensible al impedimento estérico que presenta el haluro o triflato de partida.

53 a) M. Beller, C. Bolm, Transition Metals for Organic Synthesis; Wiley-VCH: Weinheim, 1998. b) A. De Meijere, F. Diederich, Metal Catalyzed Cross-coupling Reactions, 2nd ed.; Wiley-VCH: New York, 2004.

54 K. Sonogashira, Y. Tohda, N. Hagihara, Tetrahedron Lett. 1975, 50, 4467.

55 a) P. Siemsen, R. C. Livingston, F. Diederich, Angew. Chem., Int. Ed. 2000, 39, 2632. b) H. Doucet, J.-C. Hierso, Angew. Chem., Int. Ed. 2007, 46, 834. c) R. Chinchilla, C. Nájera, Chem. Rev. 2007, 107, 874. d) M. Pal, Synlett 2009, 2896. 
La mayoría de los ejemplos de esta reacción descritos en la bibliografía se basan en la utilización de un catalizador de paladio, un cocatalizador de cobre y una amina. La reacción transcurre por el mecanismo que se muestra en el Esquema XLVII. En primer lugar se reduce el complejo de paladio (II) por reacción con disolventes, aditivos y / o ligandos, para dar la especie activa de Pd (0) que entra en el ciclo catalítico. Se pueden distinguir tres pasos una vez generada la especie de $\operatorname{Pd}(0)$ : a) adición oxidante del halogenuro de arilo o vinilo $(\mathrm{R}-\mathrm{X})$ al $\mathrm{Pd}(0)$ para generar un intermedio de 16 electrones de $\mathrm{Pd}$ (II); b) transmetalación de este intermedio con un acetiluro de cobre, formado por reacción del correspondiente alquino terminal y una sal de cobre en presencia de una amina y; c) isomerización trans / cis del intermedio, seguida de una eliminación reductora que conduce al producto final, regenerándose el catalizador de Pd (0) y completándose así el ciclo catalítico (Esquema XLVII).

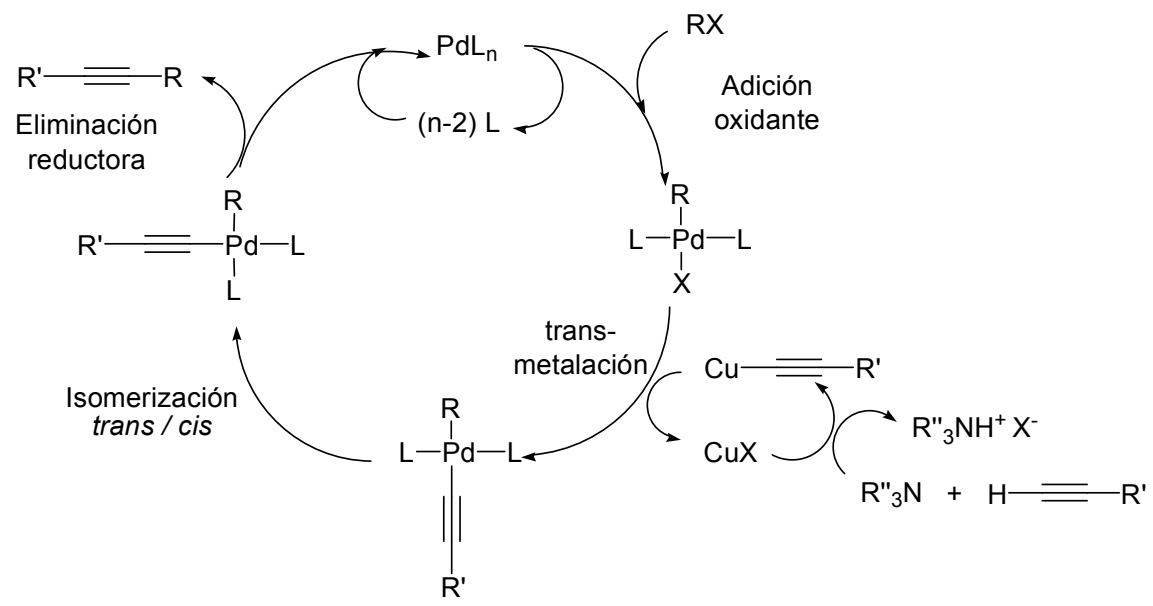

Esquema XLVII

La generación "in situ" de acetiluros de cobre bajo las condiciones de reacción puede dar lugar al homoacoplamiento del alquino terminal (acoplamiento de Glasser). Este hecho provoca una disminución del rendimiento de la reacción, especialmente en el caso de sustratos impedidos estéricamente. La utilización de atmósfera reductora, ${ }^{56} \mathrm{o}$ la adición lenta del alquino ${ }^{57}$ puede minimizar esta reacción lateral de homoacoplamiento del alquino. De la

56 A. Elanfovan, Y.-H. Wang, T.-I. Ho, Org. Lett. 2003, 5, 1841.

57 S. Thorand, N. Krauser, J. Org. Chem. 1998, 63, 8551. 
misma forma, se han desarrollado diferentes variantes de la reacción de Sonogashira que evitan el uso de sales de cobre como cocatalizadores. ${ }^{58}$

Los complejos de paladio para llevar a cabo esta reacción en ausencia de sales de cobre son los mismos que los utilizados en las condiciones estándar, destacando $\mathrm{PdCl}_{2}\left(\mathrm{PPh}_{3}\right)_{2}$, $\mathrm{PdCl}_{2}\left(\mathrm{CH}_{3} \mathrm{CN}\right)_{2}, \mathrm{Pd}(\mathrm{OAc})_{2}$ y $\mathrm{Pd}\left(\mathrm{PPh}_{3}\right)_{4}$, entre otros. Sin embargo, se suele requerir la presencia de bases distintas, destacando el uso de fluoruro y acetato de tetrabutil amonio, ${ }^{58 \mathrm{c}}$ así como de otras bases tales como $\mathrm{K}_{2} \mathrm{CO}_{3},{ }^{58 b, \mathrm{f}}$ pirrolidina, ${ }^{58 \mathrm{e}}$ o piridina. Además, algunas de estas variantes requieren la presencia de activadores, ${ }^{58 \mathrm{a}} \mathrm{o}$ de distintos ligandos voluminosos, fundamentalmente fosfinas. ${ }^{58, d, f}$ Li y colaboradores han descrito la reacción de Sonogashira en ausencia de cocatalizadores de cobre, aminas y disolventes. Así, el tratamiento de haluros de arilo (yoduros, bromuros y cloruros) con alquinos terminales en presencia de cantidades catalíticas de $\mathrm{PdCl}_{2}\left(\mathrm{PPh}_{3}\right)_{2}$ y exceso de fluoruro de tetrabutilamonio trihidrato (TBAF· $\left.3 \mathrm{H}_{2} \mathrm{O}\right)$ permite obtener arilalquinos con buenos rendimientos (Esquema XLVIII). ${ }^{59}$

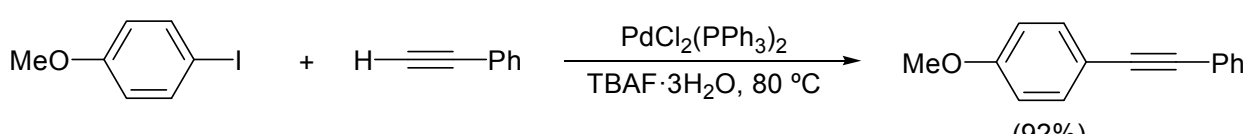

Esquema XLVIII

En los últimos años han aparecido nuevos procedimientos más beneficiosos para el medio ambiente que emplean agua ${ }^{60}$ o líquidos iónicos como disolventes. ${ }^{61}$ También se han empleado catalizadores alternativos al paladio tales como complejos de oro (Esquema XLIX) ${ }^{62}$ plata, ${ }^{63}$ hierro, ${ }^{64}$ etc.

58 a) A. Mori, J. Kawashima, T. Shimada, M. Suguro, K. Hirabayashi, Y. Nishihara, Org. Lett. 2000, 2, 2935. b) M. Feuerstein, H. Doucet, M. Santelli, Tetrahedron Lett. 2004, 45, 8443. c) S. Urgaonkar, J. G. Verkade, J. Org. Chem. 2004, 69, 5752. d) J. Cheng, Y. Sun, F. Wang, M. Guo, J.-H. Xu, Y. Pan, Z. Zhang, J. Org. Chem. 2004, 69, 5428. e) B. Liang, M. Dai, J. Chen, Z. Yang, J. Org. Chem. 2005, 70, 391. f) A. Komáromi, Z. Novák, Chem. Commun. 2008, 4968. g) J. Mao, M. Wu, G. Xie, S. Ji, Adv. Synth. Catal. 2009, 351, 2101 h) S. J. Shirbin, B. A. Boughton, S. C. Zammit, S. D. Zanatta, S. M. Marcuccio, C. A. Hutton, S. J. Williams, Tetrahedron Lett. 2010, 51, 2971.

59 Y. Liang, Y.-X. Xie, J.-H. Li, J. Org. Chem. 2006, 71, 379.

60 a) L. Ray, S. Barman, M. M. Shaikh, P. Ghosh, Chem. Eur. J. 2008, 14, 6646. b) B. H. Lipshutz, D. W. Chung, B. Rich, Org. Lett. 2008, 10, 3793. c) C. A. Fleckenstein, H. Plenio, Green. Chem. 2008, 10, 563.

61 T. Fukuyama, M. Shinmen, S. Nishitani, M. Sato, I. Ryu, Org. Lett. 2002, 4, 1691.

62 a) C. González-Arellano, A. Abad, A. Corma, H. García, M. Iglesias, F. Sanchez, Angew. Chem., Int. Ed. 2007, 46, 1536. b) P. Li, L. Wang, M. Wang, F. You, Eur. J. Org. Chem. 2008, 5946.

63 P. Li, L. Wang, Synlett 2006, 2261.

64 a) M. Carril, A. Correa, C. Bolm, Angew. Chem., Int. Ed. 2008, 47, 4862. b) X. Xie, Xu, H. Li, X. Xu, J. Yang, Y. Li, Adv. Synth. Catal. 2009, 351, 1263. 


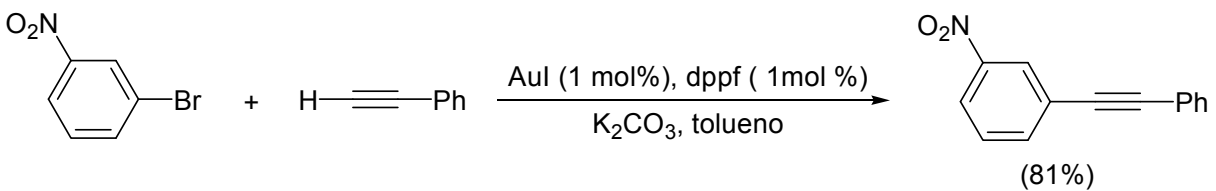

\section{Esquema XLIX}

El orden de reactividad de los haluros en acoplamientos con alquinos terminales resulta ser: yoduros de vinilo $>$ triflatos de vinilo $>$ bromuros de vinilo $>$ yoduros de arilo $>$ triflatos de arilo $>$ bromuros de arilo $>>$ cloruros de arilo. De este modo, el acoplamiento de cloruros de arilo con alquinos terminales requiere, normalmente, la presencia en el medio de reacción de distintos ligandos, tales como fosfinas voluminosas, y de otras bases tipo $\mathrm{Cs}_{2} \mathrm{CO}_{3}$ (Esquema L). ${ }^{65}$

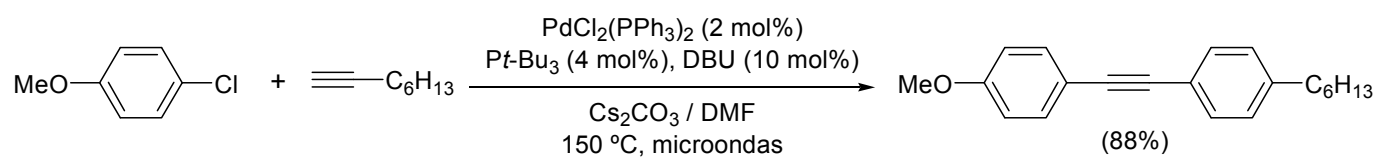

Esquema $\mathbf{L}$

\section{B.2 Reacción de Suzuki}

La reacción de Suzuki consiste en el acoplamiento entre un compuesto orgánico de boro (ácidos borónicos, ésteres borónicos o boranos) y un haluro o triflato catalizado por un complejo de paladio. ${ }^{66}$ También se ha descrito este tipo de acoplamiento empleando otros metales de transición como níquel, ${ }^{67}$ cobre o hierro. ${ }^{68}$

La reacción de Suzuki requiere normalmente el empleo de una base debido a que el enlace $\mathrm{C}-\mathrm{B}$ es prácticamente covalente $\mathrm{y}$, por ello, es necesaria la coordinación del átomo

65 a) D. Gelman, S. L. Buchwald, Angew. Chem., Int. Ed. 2003, 42, 5993. b) C. Yi, R. Hua, J. Org. Chem. 2006, 71, 2535. c) H. Huang, H. Liu, H. Jiang, K. Chen, J. Org. Chem. 2008, 73, 6037.

66 a) N. Miyaura, A. Suzuki, Chem. Rev. 1995, 95, 2457. b) B. Witulski, J. R. Alayrac, A. Arnautu, V. Collot, S. Rault, Synthesis 2005, 771. c) L. Liu, Y. Zhang, B. Xin, J. Org. Chem. 2006, 71, 3994. d) K. L. Billingsley, T. E. Barder, S. L. Buchwald, Angew. Chem., Int. Ed. 2007, 46, 5359. e) Y. Yamamoto, M. Takizawa, X.-Q. Yu, N. Miyaura, Angew. Chem., Int. Ed. 2008, 47, 928.

67 a) Z.-Y. Tang, Q.-S. Hu, J. Am. Chem. Soc. 2004, 126, 3058. b) X.-H. Fan, L.-M. Yang, Eur. J. Org. Chem. $2010,2457$.

68 a) J.-H. Li, J.-L. Li, D.-P. Wang, S.-F. Pi, Y.-X. Xie, M.-B. Zhang, X.-C. Hu, J. Org. Chem. 2007, 72, 4586. b) D. Bézier, C. Darcel, Adv. Synth. Catal. 2009, 351, 1732. 
de boro a una base para que tenga lugar la transferencia del resto orgánico del compuesto de boro al complejo metálico en la etapa de transmetalación (Esquema LI). ${ }^{69}$

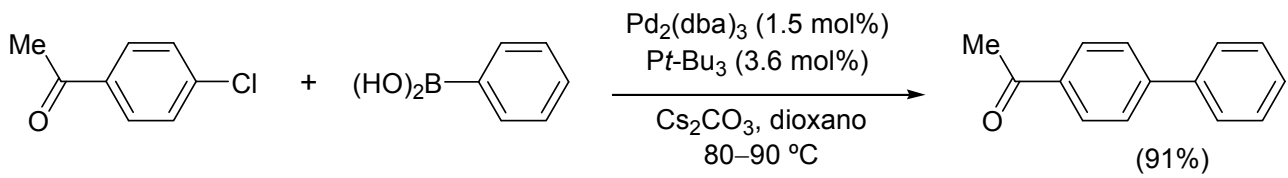

\section{Esquema LI}

El acoplamiento de Suzuki es uno de los métodos más empleados para la formación de enlaces $\mathrm{C}-\mathrm{C}$ debido a que esta reacción tiene lugar en condiciones suaves, no se ve afectada por pequeñas cantidades de agua y tolera una amplia variedad de grupos funcionales.

\section{B.3 Reacción de Stille}

La reacción de Stille se puede definir como el acoplamiento de un organoestannano y un haluro o triflato catalizada por un complejo de paladio. ${ }^{70}$ Este método es considerado uno de los más versátiles en reacciones de acoplamiento de halogenuros con reactivos organometálicos ya que se toleran una gran variedad de grupos funcionales. El principal inconveniente de este proceso es la toxicidad de los estannanos.

Al igual que ocurre con la reacción de Sonogashira, los cloruros de arilo son menos reactivos que los correspondientes bromuros o yoduros. Sin embargo, han aparecido procedimientos útiles para el acoplamiento de cloruros de arilo con estannanos. Así, Littke y $\mathrm{Fu}$ han descrito la reacción de distintos cloruros de arilo, incluso cloruros electrónicamente ricos, con tributilvinilestannano empleando $\mathrm{Pd}_{2}(\mathrm{dba})_{3}$, una fosfina voluminosa y $\mathrm{CsF}$ como base (Esquema LII). ${ }^{71}$

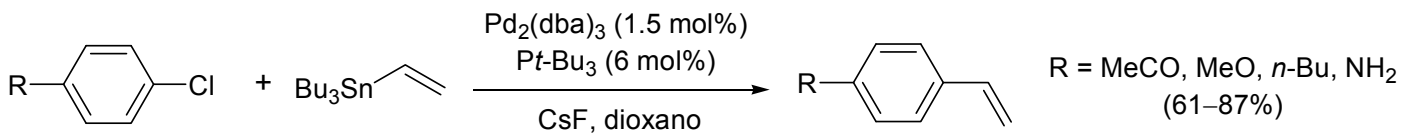

\section{Esquema LII}

69 A. F. Littke, G. C. Fu, Angew. Chem., Int. Ed. 1998, 37, 3387.

70 a) J. K. Stille, Angew. Chem., Int. Ed. Engl. 1986, 25, 508. b) J. R. Naber, S. L. Buchwald, Adv. Synth. Catal. 2008, 350, 957. c) W.-J. Zhou, K.-H. Wang, J.-X. Wang, Adv. Synth. Catal. 2009, 351, 1378. d) D.-H. Lee, A. Taher, W.-S. Ahn, M.-J. Jin, Chem. Commun. 2010, 46, 478.

71 A. F. Littke, G. C. Fu, Angew. Chem., Int. Ed. 1999, 38, 2411. 


\section{CAPÍTULO 1}

Aproximaciones a la sintesis de

2,3-dihaloanilinas. Precursores de indoles

4-funcionalizados

"Nunca consideres el estudio como una obligación

sino como una oportunidad para penetrar en el

bello y maravilloso mundo del saber". Einstein 



\subsection{INTRODUCCIÓN}

En nuestro grupo de investigación se ha descrito un nuevo método para la síntesis de 2,3-dihalofenoles, basado en una reacción de orto-litiación de carbamatos de 3halofenilo, funcionalización y posterior desprotección del grupo director (Esquema 1.1). ${ }^{72}$ Además, los 2,3-dihalofenoles han demostrado ser compuestos de utilidad para acceder a benzo[b]furanos funcionalizados regioselectivamente. ${ }^{72}$<smiles>[X]c1cccc(OC(=O)N(CC)CC)c1</smiles>

\section{Esquema 1.1}

Por otro lado, dentro de los diferentes heterociclos funcionalizados, los derivados indólicos se pueden considerar estructuras privilegiadas por presentar una excelente capacidad de interacción con numerosos receptores, puesta de manifiesto por su presencia en el esqueleto de numerosos productos biológicamente activos. ${ }^{73}$ Este hecho ha provocado el desarrollo de numerosas rutas sintéticas prácticas y eficientes con el propósito de obtener indoles con una amplia variedad de patrones de sustitución, siendo esta búsqueda un continuo desafío para los químicos orgánicos. ${ }^{74}$ Aunque existen numerosos métodos para la síntesis de indoles, la obtención de compuestos funcionalizados regioselectivamente en la posición 4 continúa siendo un problema sin resolver completamente. La principal dificultad radica en que dicha posición del anillo indólico es menos rica electrónicamente que el resto, por lo que reacciones convencionales de sustitución electrofílica aromática suelen ser poco

\footnotetext{
72 a) M. P. Castroviejo: Tesis Doctoral (Universidad de Burgos, 2009). b) R. Sanz, M. P. Castroviejo, Y. Fernández, F. J. Fañanás, J. Org. Chem. 2005, 70, 6548.

73 a) M. Somei, F. Yamada, Nat. Prod. Rep. 2005, 22, 73. b) K. Higuchi, T. Kawasaki, Nat. Prod. Rep. 2007, 24, 843. c) M. Ishikura, K. Yamada, Nat. Prod. Rep. 2009, 26, 803.

74 a) S. Cacchi, G. Fabrizi, Chem. Rev. 2005, 105, 2873. b) G. R. Humphrey, J. T. Kuethe, Chem. Rev. 2006, 106, 2875. c) J. Barluenga, F. Rodríguez, F. J. Fañanás, Chem. Asian J. 2009, 4, 1036. d) R. Vicente, Org. Biomol. Chem. 2011, 9, 6469. e) S. Cacchi, G. Fabrizi, A. Goggiamani, Org. Biomol. Chem. 2011, 9, 641.
} 
efectivas. Debido a estas razones, nos planteamos como uno de los objetivos del presente trabajo el diseño de una nueva ruta sintética para acceder a estos interesantes compuestos.

De acuerdo al análisis retrosintético planteado en el Esquema 1.2, una posible ruta para acceder a indoles 4-funcionalizados podría implicar un acoplamiento de Sonogashira con derivados de 2,3-dihaloanilinas, seguido de una reacción de heteroanulación. No obstante, esta sencilla aproximación a los 4-haloindoles no había sido descrita con anterioridad, probablemente debido a la inexistencia de rutas directas para acceder a las 2,3dihaloanilinas.

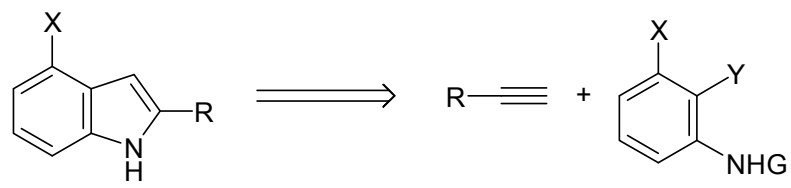

Esquema 1.2

Los métodos descritos en la literatura para la preparación de 2,3-dihaloanilinas son muy escasos, tediosos y generalmente conducen a mezclas de productos, los cuales son difíciles de separar. Por lo tanto, un segundo objetivo que nos planteamos en este Capítulo fue poner a punto una nueva y eficiente síntesis de 2,3-dihaloanilinas. Como se muestra en el Esquema 1.3 se proponen tres posibles estrategias retrosintéticas. Una primera, ruta $(a)$, implicaría una reacción de orto-metalación seguida de funcionalización en un derivado apropiado de 3-haloanilina. Alternativamente, las 2,3-dihaloanilinas se podrían obtener por metalación y funcionalización de 3-halonitrobencenos seguida de posterior reducción (Esquema 1.3, ruta $(b)$ ). Finalmente, otra posible ruta podría consistir en utilizar 2,3dihalofenoles como productos de partida, a partir de los cuales obtener los análogos nitrogenados (Esquema 1.3, ruta (c)).<smiles>[X]c1cccc(NO)c1</smiles><smiles>c1ccccc1</smiles><smiles>[X]c1cccc(N)c1[X]</smiles>

(c)<smiles>[X]c1cccc(O)c1[X]</smiles>

Esquema 1.3 


\subsection{ANTECEDENTES BIBLIOGRÁFICOS}

En este apartado se van a tratar los aspectos más generales relacionados con el trabajo de investigación realizado en este Capítulo. Inicialmente, se describirán los métodos existentes en la bibliografía para la preparación de las 2,3-dihaloanilinas. A continuación, se hará una breve revisión de las estrategias para la transformación de alcoholes aromáticos en anilinas.

Por otro lado, se hará una selección de las principales rutas sintéticas desarrolladas para la síntesis de $1 H$-indoles 4 -funcionalizados. Por último, se comentarán los métodos más habituales para llevar a cabo la ciclación 5-endo-dig de orto-alquinilanilinas con el fin de obtener indoles 2-sustituidos.

\subsubsection{SÍNTESIS DE 2,3-DIHALOANILINAS}

Las 2-halo-3-yodoanilinas son desconocidas, excepto la 2-bromo-3-yodoanilina. Entre las 3-halo-2-yodoanilinas, sólo ha sido descrita la 3-bromo-2-yodoanilina. Asimismo, la 3-bromo-2-cloroanilina no ha sido sintetizada anteriormente a este trabajo. Para el resto de 2,3-dihaloanilinas los métodos descritos en la literatura para su preparación son muy escasos y, generalmente, conducen a mezclas de productos, los cuales suelen ser difíciles de separar. La mayoría de estos procedimientos consisten en reacciones descritas hace más de cincuenta años y basadas en la introducción del segundo halógeno mediante diazotación de halonitroanilinas y posterior reducción del grupo nitro.

\section{a) Síntesis de 3-fluoro-2-haloanilinas}

La 2,3-difluoroanilina es la única 3-fluoro-2-haloanilina comercial. Un método descrito para su preparación consiste en una secuencia multipaso que implica: a) intercambio del sustituyente $-\mathrm{Cl}$ por $-\mathrm{F}$ en el 1,2,3-triclorobenceno empleando $\mathrm{CsF}$, y b) aminólisis de la mezcla de clorodifluoroderivados (Esquema 1.4). ${ }^{75}$

75 R. G. Pews, J. A Gall, J. Fluorine Chem. 1991, 53, 379. 


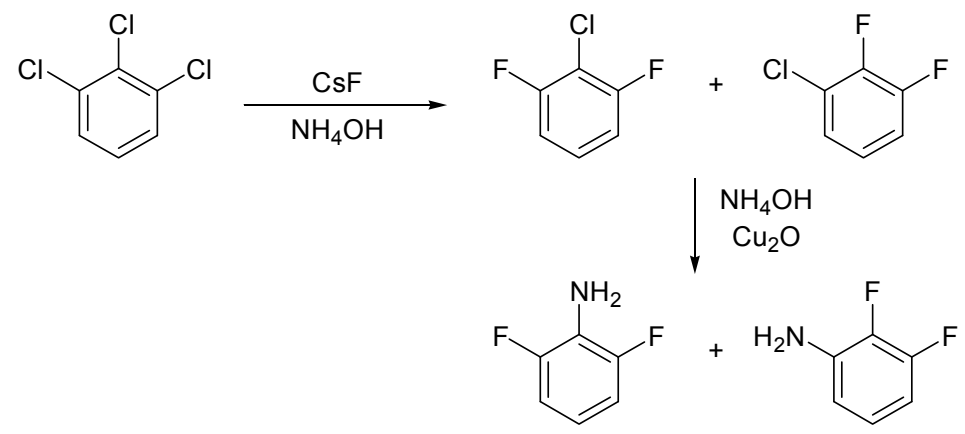

Esquema 1.4

El único método recogido en la bibliografía para la preparación de la 2-cloro-3fluoroanilina supone la diazotación de 2,3-dinitroanilina en $\mathrm{HCl}$, seguido de su tratamiento con $\mathrm{NaBF}_{4}$ para generar la sal de diazonio, la cual descompone al calentar, para dar el 2 cloro-1-fluoro-3-nitrobenceno. La posterior reducción del nitroderivado con $\mathrm{SnCl}_{2}$ en medio ácido conduce a la 3-fluoro-2-cloroanilina (Esquema 1.5). ${ }^{76 \mathrm{~b}} \mathrm{La} 2,3$-dinitroanilina se prepara a su vez mediante nitración de $m$-nitroacetanilida seguida de desprotección del grupo acetamida en medio ácido. ${ }^{76 a}$<smiles>Nc1cccc([N+](=O)[O-])c1[N+](=O)[O-]</smiles>

$\stackrel{\text { 1) } \mathrm{NaNO}_{2}, \mathrm{HCl}}{\text { 2) } \mathrm{NaBF}_{4}}$<smiles>[NH3+]c1cccc([N+](=O)[O-])c1Cl</smiles><smiles>[Tl]</smiles><smiles>O=[N+]([O-])c1cccc(F)c1Cl</smiles>

$(15 \%)$<smiles>C[SnH3]</smiles><smiles>Nc1cccc(F)c1Cl</smiles>

$(77 \%)$

\section{Esquema 1.5}

El paso clave en la síntesis de la 2-bromo-3-fluoroanilina implica la preparación del 2-bromo-3-fluorobenzonitrilo a partir de 3-fluorobenzonitrilo, existiendo dos rutas alternativas:

1. Orto-metalación del 3-fluorobenzonitrilo mediante tratamiento con LDA y B(Oi$\mathrm{Pr})_{3}$, seguida de la bromodeboración del ácido arilborónico intermedio por adición

76 a) K. H. Pausacker, J. G. Scroggie, J. Chem. Soc. 1955, 1897. b) J. M. Blunck, P. E. Hughes, J. G. Scroggie, J. Med. Chem. 1969, 12, 195. 
de 1,3-dibromo-5,5-dimetilhidantoína (DBDMH) en presencia de $\mathrm{NaOMe}$ (Esquema 1.6). ${ }^{77}$

2. Reacción de orto-metalación utilizando el complejo $t$ - $\mathrm{Bu}_{2} \mathrm{Zn}(\mathrm{TMP}) \mathrm{Li}$, seguida de la adición de bromo (Esquema 1.6). ${ }^{40}$

La hidrólisis del 2-bromo-3-fluorobenzonitrilo y un posterior reagrupamiento de Hofmann conducen a la 2-bromo-3-fluoroanilina (Esquema 1.6). ${ }^{78}$

${ }_{C N}^{F}$
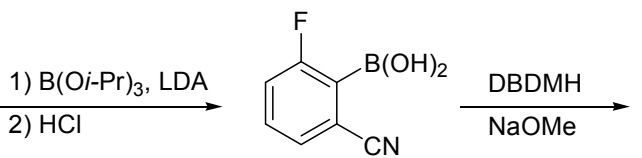<smiles>N#Cc1cccc(F)c1Br</smiles><smiles>C[13CH3]</smiles><smiles>N#Cc1cccc(F)c1</smiles>
Hidrólisis<smiles>Nc1cccc(F)c1Br</smiles>

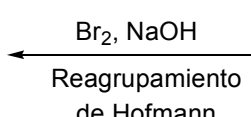<smiles>NC(=O)c1cccc(F)c1Br</smiles>

\section{Esquema 1.6}

Otro método descrito en la bibliografía para la síntesis de la 2-bromo-3fluoroanilina consiste en una reacción de orto-litiación sobre la 3-fluorotrifluoroacetanilida a baja temperatura, seguida de su reacción con bromo. La posterior hidrólisis de la acetanilida en medio básico permite obtener la 2-bromo-3-fluoroanilina (Esquema 1.7). ${ }^{38}$
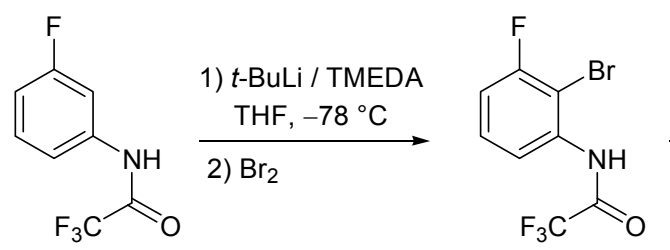

$\mathrm{NaOH}$ acuoso<smiles></smiles>

Esquema 1.7

77 R. H. Szumigala, Jr., P. N. Devine, D. R. Gauthier, Jr., R. P. Volante, J. Org. Chem. 2004, 69, 566

78 C. R. Hauser, W. B. Renfrow Jr., J. Am. Chem. Soc. 1937, 59, 121. 


\section{b) Síntesis de 3-cloro-2-haloanilinas}

La 3-cloro-2-fluoroanilina y la 2,3-dicloroanilina son productos comerciales. Por otra parte, la preparación de la 2-bromo-3-cloroanilina se basa en la síntesis de la 2-cloro-6nitroanilina como intermedio, siguiendo distintas rutas:

1. Cloración de la 2-nitroanilina utilizando hipoclorito de $t$-butilo. Se obtiene así, una mezcla de la 4-cloro-2-nitroanilina y la 6-cloro-2-nitroanilina, siendo minoritario $(38 \%)$ el compuesto de interés (Esquema 1.8). ${ }^{79}$

2. Acetilación de la 2-cloroanilina y posterior nitración, dando lugar a una mezcla de isómeros difíciles de separar (Esquema 1.8). ${ }^{80}$<smiles>Nc1ccccc1[N+](=O)[O-]</smiles><smiles>CC(C)(C)OCl</smiles><smiles>Nc1ccccc1Cl</smiles><smiles>CC(C)(C)[N+](=O)[O-]</smiles><smiles>Nc1ccc(Cl)cc1[N+](=O)[O-]</smiles><smiles>Nc1c(Cl)cccc1[N+](=O)[O-]</smiles>

1) Separación isómeros 2) $\mathrm{H}_{3} \mathrm{O}^{+}$<smiles>CC(=O)Nc1ccc([N+](=O)[O-])cc1Cl</smiles><smiles>CC(=O)Nc1c(Cl)cccc1[N+](=O)[O-]</smiles>

\section{Esquema 1.8}

3. Aminación del 2,3-dicloronitrobenceno, obteniéndose la 2-cloro-6-nitroanilina por tratamiento con amoniaco en etanol (Esquema 1.9). ${ }^{81}$

Una vez preparada la 2-cloro-6-nitroanilina, su halogenación se lleva a cabo mediante una reacción de diazotación seguida del tratamiento de la sal de diazonio formada con $\mathrm{CuBr}$ en $\mathrm{HBr}$ acuoso. Finalmente, la reducción del grupo nitro conduce a la 2-bromo-3cloroanilina tal como se muestra en el Esquema 1.9. ${ }^{82}$

\footnotetext{
79 H. Pausacker, J. G. Scroggie, Aust. J. Chem. 1959, 12, 430.

80 B. Lamm, B. Liedholm, Acta Chem. Scand. 1967, 21, 2679.

81 L. De Bruyn, Recl. Trav. Chim. Pays-Bas. 1917, 36, 139.

82 T. Tuccinardi, S. Bertini, A. Martinelli, F. Minutolo, J. Med. Chem. 2006, 49, 5001.
} 


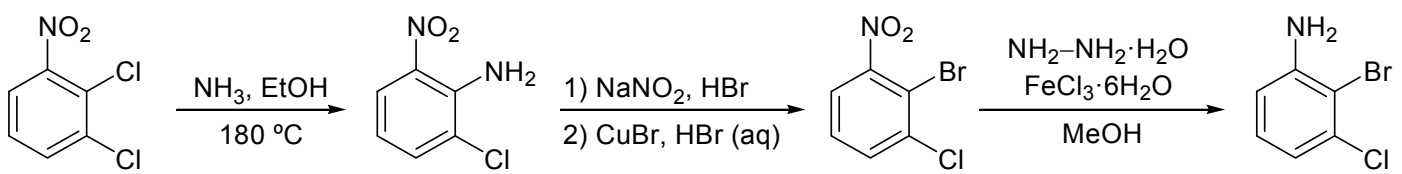

\section{Esquema 1.9}

\section{c) Síntesis de 3-bromo-2-haloanilinas}

La 3-bromo-2-cloroanilina no ha sido descrita previamente a este trabajo. Sin embargo, todos los métodos existentes para la preparación de las demás 3-bromo-2haloanilinas pasan por la obtención del 2,3-dibromonitrobenceno o la 2-bromo-6nitroanilina como productos intermedios en la síntesis de las 3-bromo-2-haloanilinas.

La preparación del 2,3-dibromonitrobenceno se puede llevar a cabo mediante dos rutas sintéticas diferentes:

1. Nitración del 1,2-dibromobenceno, que da lugar a una mezcla de isómeros, siendo minoritario el compuesto de interés (Esquema 1.10). ${ }^{83}$<smiles>Brc1ccccc1Br</smiles>

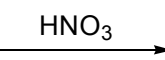<smiles>[B]c1ccc([N+](=O)[O-])cc1[B]</smiles><smiles>[11CH3]</smiles>

$(84 \%)$<smiles>O=[N+]([O-])c1cccc(Br)c1Br</smiles>

$(16 \%)$

\section{Esquema 1.10}

2. Bromación del 2-bromonitrobenceno, mediante tratamiento con $\mathrm{Fe} \mathrm{y}$ bromo. ${ }^{84} \mathrm{Al}$ igual que en el caso anterior se obtiene una mezcla de dos dibromobencenos isómeros, siendo complicada y tediosa su separación (Esquema 1.11).

Una vez llevada a cabo la separación de los distintos isómeros, el 2,3dibromonitrobenceno se reduce por reacción con $\mathrm{PtO}_{2}$ en ácido fórmico. ${ }^{83}$ Esta reducción también se puede llevar a cabo empleando Fe en etanol acidificado con $\mathrm{HCl}^{85}$

83 R. Singh, G. Just, J. Org. Chem. 1989, 54, 4453.

84 A. L. Holleman, Recl. Trav. Chim. Pays-Bas. 1906, 25, 202.

85 B. Liedholm, Acta Chem. Scand. B 1984, 38, 877. 


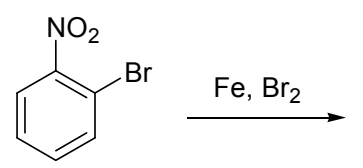<smiles>Nc1cccc(Br)c1Br</smiles>

\section{Esquema 1.11}

Los métodos descritos para la preparación de la 3-bromo-2-yodoanilina implican la síntesis de la 2-bromo-6-nitroanilina, para lo cual existen distintas alternativas:

1. Aminación del 2,3-dibromonitrobenceno por reacción con amoniaco en disolución alcohólica (Esquema 1.12). ${ }^{86}$

2. Nitración de la 2-bromoacetanilida, que conduce a una mezcla de isómeros, seguida de la hidrólisis del grupo amida por tratamiento con $\mathrm{HCl}$ (Esquema 1.12, (a)). ${ }^{87}$

3. Nitración de la 2-bromoanilina por reacción con 2,3,5,6-tetrabromo-4-metil-4-nitro2,5-ciclohexadienona. La reacción no es regioselectiva produciéndose la nitración en posiciones orto- y para- al grupo amino, aislándose un 26 y un $45 \%$ de los correspondientes isómeros, respectivamente, siendo minoritario el compuesto de interés (Esquema 1.12, (b)). ${ }^{88}$

(a)<smiles>CC(=O)Nc1ccccc1Br</smiles><smiles>CC(=O)Nc1ccc([N+](=O)[O-])cc1Br</smiles>
$+$<smiles>CC(=O)Nc1c(Br)cccc1[N+](=O)[O-]</smiles>

(b)<smiles>Nc1ccccc1Br</smiles>

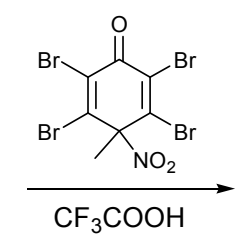<smiles>Nc1ccc([N+](=O)[O-])cc1Br</smiles><smiles>Nc1c(Br)cccc1[N+](=O)[O-]</smiles>

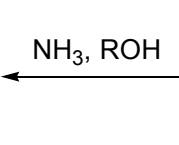<smiles>O=[N+]([O-])c1cccc(Br)c1Br</smiles>

\section{Esquema 1.12}

${ }^{86}$ Koerner, Contardi, Atti Accad. Naz. Lincei Cl. Sci. Fis. Mat. Nat. Rend. 1906, 5, 526.

${ }^{87}$ M. Macleod, J. Chem. Soc. 1928, 3092.

88 M. Lemaire, A. Guy, P. Boutin, J. P. Guette, Synthesis 1989, 761. 
Una vez preparada la 2-bromo-6-nitroanilina, su diazotación y posterior introducción de yodo mediante tratamiento con $\mathrm{KI},{ }^{89}$ seguida de la reducción con $\mathrm{Fe}$ del 3 bromo-2-yodonitrobenceno permite obtener la 3-bromo-2-yodoanilina (Esquema 1.13). ${ }^{90}$<smiles>Nc1c(Br)cccc1[N+](=O)[O-]</smiles><smiles>O=[N+]([O-])c1cccc(Br)c1I</smiles>

$(72 \%)$

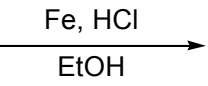<smiles>Nc1cccc(Br)c1I</smiles>

$(76 \%)$

\section{Esquema 1.13}

\section{d) Síntesis de 3-yodo-2-haloanilinas}

La 2-bromo-3-yodoanilina es la única 2-halo-3-yodoanilina que ha sido descrita en la literatura. La bromación de la 3-yodoanilina con 2,4,4,6-tetrabromo-2,5-ciclohexadien-1ona conduce a una mezcla de los isómeros: 2-bromo-5-yodoanilina, 4-bromo-3-yodoanilina y 2-bromo-3-yodoanilina. La bromación tiene lugar fundamentalmente en posición para respecto al grupo amino (Esquema 1.14), ${ }^{91}$ obteniéndose la 2-bromo-3-yodoanilina con tan solo un $8 \%$ de rendimiento.

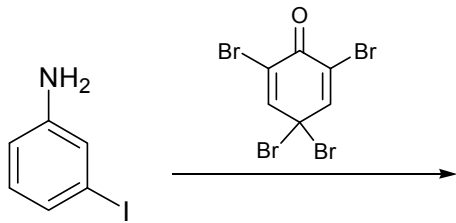<smiles>Nc1cc(I)ccc1Br</smiles>

$(15 \%)$<smiles>Cc1cc(N)ccc1Br</smiles>

$(77 \%)$<smiles>Nc1cccc(I)c1Br</smiles>

$(8 \%)$

Esquema 1.14

89 J. F. Corbett, J. F. Holt, J. Chem. Soc. 1961, 5029.

90 B. Liedholm, Acta Chem. Scand. 1993, 47, 701.

91 J. H. Markgraf, G. T. Marshall, M. A. Greeley, Chem. Ind. 1987, 8, 298. 


\subsubsection{TRANSFORMACIÓN DE ALCOHOLES EN AMINAS}

\section{a) Transformación de alcoholes alifáticos en aminas}

La mayoría de las reacciones existentes se basan en procesos de sustitución nucleofílica. Sin embargo, en general, los alcoholes no reaccionan directamente con nucleófilos, al ser el grupo hidroxilo un mal grupo saliente, por lo que es necesario su previa conversión en un buen grupo saliente, como por ejemplo, un halogenuro o un tosilato. A continuación, la reacción del haluro o tosilato de alquilo con distintos nucleófilos nitrogenados tales como azidas, amoniaco (este último con limitaciones para obtener aminas primarias), o ftalimida, seguida de posteriores transformaciones, conduciría a las aminas buscadas (Esquema 1.15).

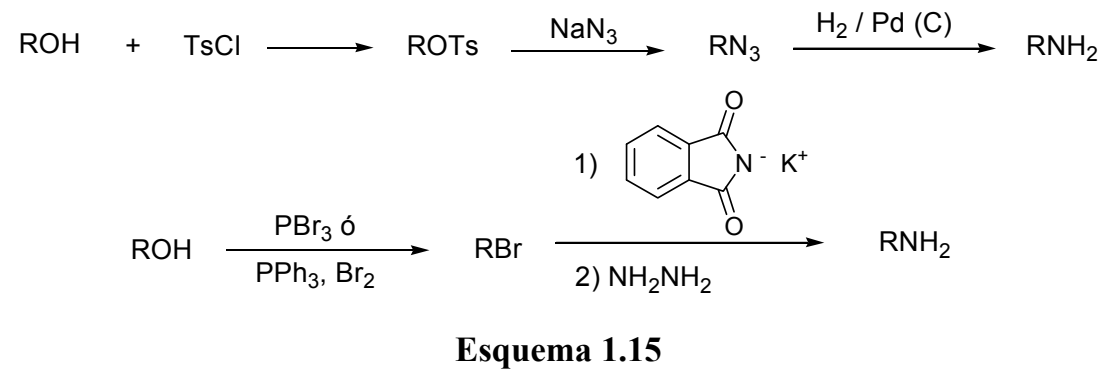

Otra posible alternativa para llevar a cabo la síntesis de aminas a partir de alcoholes se basa en la reacción de Mitsunobu, obteniéndose una sulfonamida por tratamiento del correspondiente alcohol con $p$-toluensulfonamida, trifenilfosfina y azodicarboxilato de dietilo (DEAD). La hidrólisis de la sulfonamida conduciría a la amina buscada (Esquema 1.16).

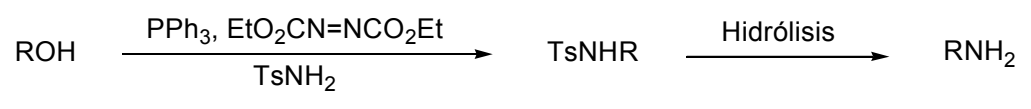

\section{Esquema 1.16}

En los últimos años, se han desarrollado numerosas metodologías para la sustitución directa de alcoholes ${ }^{92 a, b}$ por distintos nucleófilos, incluidos aminas. Estas reacciones suelen estar catalizadas por metales de transición que, o bien son caros o bien precisan de varios

92 a) F. Kabalka, M.-L. Yao, Curr. Org. Synth. 2008, 5, 28. b) A. J. M. Caffin, K. M. Nicholas, en Comprehensive Organometallic Chemistry II, E. W. Abel, G. A. Stone, G. Wilkinson, Eds; Pergamon: New York, 1995; Vol 12, Cap 7.1. c) R. Sanz, A. Martínez, J. M. Álvarez-Gutiérrez, F. Rodríguez, Eur. J. Org. Chem. 2006, 1383. d) R. Sanz, A. Martínez, D. Miguel, J. M. Álvarez-Gutiérrez, F. Rodríguez, Adv. Synth. Catal. 2006, 348, 1841. 
pasos para su síntesis. En este contexto, en nuestro grupo de investigación se ha desarrollado una metodología para las reacciones de sustitución nucleofílica directa de una gran variedad de alcoholes propargílicos, alílicos y bencílicos utilizando como catalizadores ácidos de Brønsted sencillos, tales como el ácido $p$-toluensulfónico monohidrato (PTSA) ${ }^{92 c, d}$ En el Esquema 1.17 se muestra la reacción de alcoholes alílicos y progargílicos con nucleófilos tales como anilinas o sulfonamidas.<smiles>OC(/C=C/P)c1ccccc1</smiles><smiles>Nc1ccc([N+](=O)[O-])cc1</smiles>
$\underset{\mathrm{MeCN}, 80^{\circ} \mathrm{C}}{\stackrel{\mathrm{PTSA}}{\longrightarrow}}$<smiles>[R]C#CC(O)c1ccccc1</smiles>
$\mathrm{R}=\mathrm{H}, n-\mathrm{Bu}, \mathrm{Ph}$

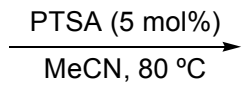
$\mathrm{MeCN}, 80^{\circ} \mathrm{C}$<smiles>NS(=O)(=O)c1ccccc1</smiles>

Esquema 1.17<smiles>O=[N+]([O-])c1ccc(NC(/C=C/c2ccccc2)c2ccccc2)cc1</smiles><smiles>[R]C#CC(NS(=O)(=O)c1ccccc1)c1ccccc1</smiles>

\section{b) Transformación de alcoholes aromáticos en anilinas}

Mientras que en la literatura existen numerosos métodos para la conversión de alcoholes alifáticos en aminas, sin embargo, las rutas existentes para la preparación de anilinas a partir de fenoles son escasas y con un alcance limitado.

\section{b.1 Métodos particulares para la conversión de fenoles en anilinas}

La reacción de Bücherer consiste en el tratamiento de fenoles con sulfito amónico y se limita generalmente a naftoles, así como a hidroxi- y amino-fenoles (Esquema 1.18). ${ }^{93}$ Esta reacción también se puede llevar a cabo empleando hidróxido amónico y dióxido de azufre. ${ }^{93 d}$

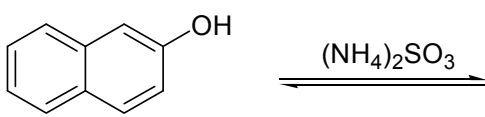<smiles>Nc1ccc2ccccc2c1</smiles>

$(95 \%)$

Esquema 1.18

93 a) R. J. Lindsay, en Comprehensive Organic Synthesis; B. M. Trost, I. Fleming, Eds.; Pergamon Press: Oxford, 1991; Vol 2, p. 131. b) H. T. Bucherer, J. Prakt. Chem. 1904, 69, 49. c) N. L. Drake, Org. React. 1942, 1, 105. d) M. S. Newman, R. H. B. Galt, J. Org. Chem. 1960, 25, 214. 
Generalmente, el grupo hidroxilo debe ser convertido en otro grupo funcional antes de poder acceder a la amina. Algunas de estas transformaciones se describen a continuación:

- Los fenoles pueden ser transformados en un éster de dietilfosfato, por tratamiento con clorofosfato de dietilo en medio básico. La posterior adición de amiduro potásico y potasio metálico en amoniaco líquido conduce a la correspondiente amina (Esquema 1.19). ${ }^{94}$

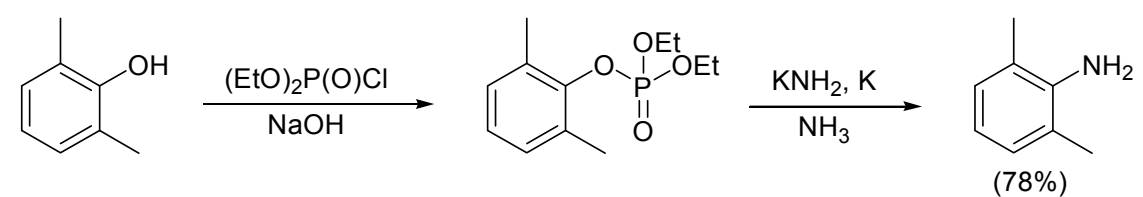

Esquema 1.19

- Preparación de 4-ariloxi-2-fenilquinazolinas por tratamiento del fenóxido correspondiente con 4-cloro-2-fenilquinazolina. Por calentamiento, la quinazolina sufre un reagrupamiento y, tras su hidrólisis, se obtiene la anilina buscada (Esquema 1.20). ${ }^{95}$ Como inconveniente de esta metodología, se requieren temperaturas extremadamente altas y condiciones fuertemente básicas.

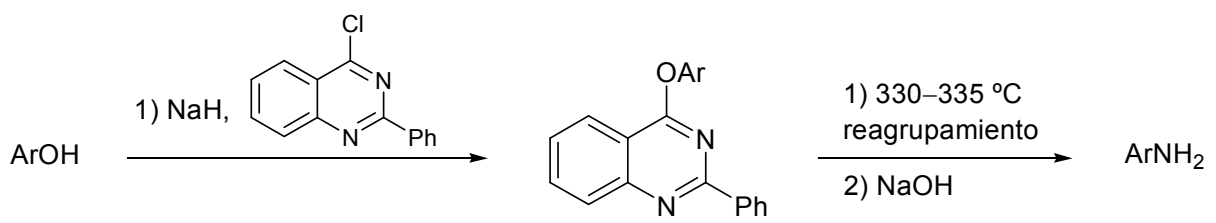

Esquema 1.20

Estos métodos son poco generales y, únicamente, permiten acceder a una escasa variedad de anilinas.

94 a) A. R. Katrizky, O. Meth-Cohn, C. W. Rees, Comprehensive Organic Fuctional Groups Transformations Pergamon Press: Oxford, 1995; Vol 2, p. 752. b) R. A. Rossi, J. F. Bunnett, J. Org. Chem. 1972, 37, 3570.

95 a) D. F. Morrow, R. M. Hofer, J. Med. Chem. 1966, 9, 249. b) R. A. Scherrer, H. R. Beatty, J. Org. Chem. 1972, 37, 1681. 


\section{b.2 Reacciones de aminación de aril sulfonatos}

En los últimos años se han descrito acoplamientos de aminas con triflatos o tosilatos de arilo catalizados por complejos de paladio. ${ }^{96,97}$ Estas reacciones implican la transformación previa del fenol en el correspondiente sulfonato. Buchwald ha descrito este acoplamiento empleando $\mathrm{Pd}(\mathrm{OAc})_{2}$ ó $\mathrm{Pd}_{2}(\mathrm{dba})_{3}$ en cantidades catalíticas y fosfinas voluminosas como la 2-(bifenil)-di-t-butilfosfina (JohnPhos) ${ }^{96 \mathrm{c}}$ o ligandos quelantes, especialmente el 2,2'-bis(difenilfosfino)-1,1'-binaftilo (BINAP) (Esquema 1.21). ${ }^{96 a, b}$

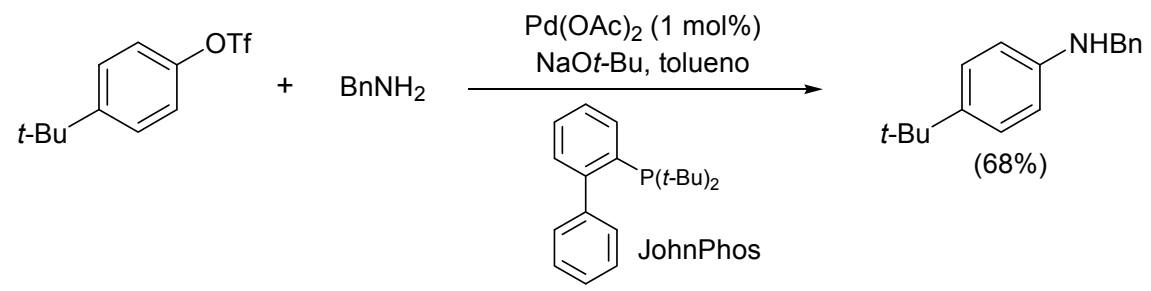

\section{Esquema 1.21}

También se puede llevar a cabo la reacción de nonaflatos de arilo con distintas anilinas empleando $\mathrm{Pd}_{2}(\mathrm{dba})_{3}$, 2-diciclohexilfosfino-2',4',6'-triisopropilbifenilo (XPhos) o $t$ BuXPhos (con dos grupos $t$-butilo en lugar de grupos ciclohexilo unidos al átomo de fósforo) como fosfinas, y DBU como base (Esquema 1.22). ${ }^{96 \mathrm{~d}}$
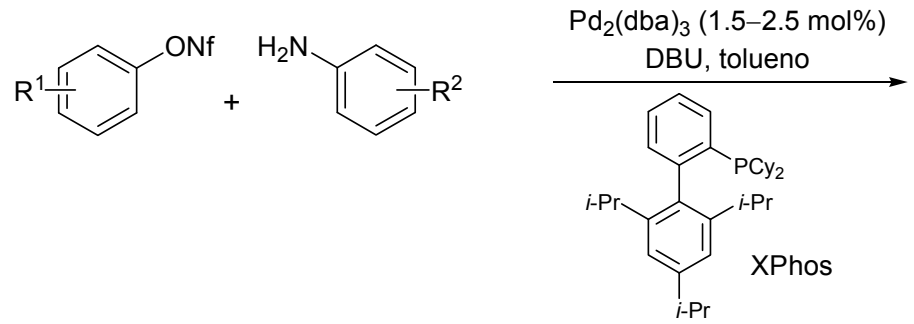

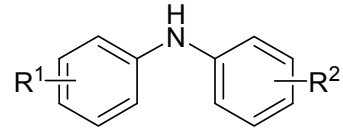

$(81-99 \%)$

\section{Esquema 1.22}

96 a) P. J. Wolfe, S. L. Buchwald, J. Org. Chem. 1997, 62, 1264. b) H. B. Yang, S. L. Buchwald, J. Organometal. Chem. 1999, 576, 125. c) P. J. Wolfe, H. Tomiri, J. P. Sadighi, J. Yin, S. L. Buchwald, J. Org. Chem. 2000, 65, 1158. d) D. S. Surry, S. L. Buchwald, Chem. Sci. 2011, 2, 27.

97 a) J. Louie, M. S. Driver, B. C. Hamann, J. F. Hartwig, J. Org. Chem. 1997, 62, 1268. b) L.-C. Campeau, M. Parisien, A. Jean, K. Fagnou, J. Am. Chem. Soc. 2006, 128, 581. c) T. Ogata, J. F. Hartwig, J. Am. Chem. Soc. 2008, 130, 13848. d) C. M. So, Z. Zhou, C. P. Lau, F. Y. Kwong, Angew. Chem., Int. Ed. 2008, 47, 6402. e) G. D. Vo, J. F. Hartwig, J. Am. Chem. Soc. 2009, 131, 11049. 
Por su parte, Hartwig ha descrito la reacción de aminación de tosilatos con aminas $\operatorname{primarias}^{97 \mathrm{c}}$ o amoniaco ${ }^{97 \mathrm{e}}$ empleando el sistema catalítico $\mathrm{Pd}\left[\mathrm{P}(o-\mathrm{tol})_{3}\right]_{2} / \mathrm{CyPF}-t-\mathrm{Bu}(1-$ diciclohexilfosfino-2-di-t-butilfosfinoetilferroceno) y $\mathrm{NaO} t$-Bu como base (Esquema 1.23).

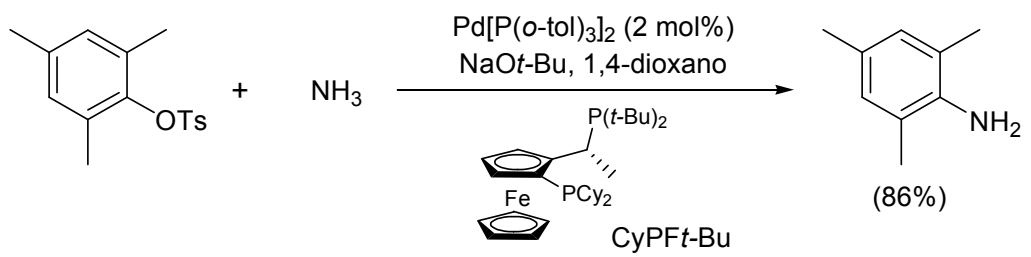

\section{Esquema 1.23}

Otros autores también han estudiado el acoplamiento de mesilatos o triflatos con anilinas empleando $\mathrm{Pd}(\mathrm{OAc})_{2}$, distintas fosfinas voluminosas y $\mathrm{K}_{3} \mathrm{PO}_{4}$ ó $\mathrm{K}_{2} \mathrm{CO}_{3}$ como bases (Esquema 1.24). ${ }^{97 b, \mathrm{~d}}$

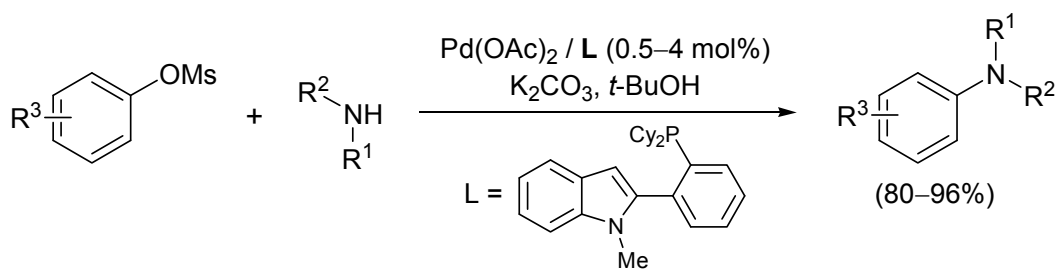

\section{Esquema 1.24}

Como inconveniente de esta metodología estaría el hecho de que si hay presentes halógenos en el compuesto aromático, éstos podrían competir en la reacción de aminación del correspondiente sulfonato.

\section{b.3 Reagrupamiento de Smiles}

Un método que no ha sido ampliamente utilizado pero con gran utilidad para la preparación de anilinas a partir de fenoles es el reagrupamiento de Smiles, el cual funciona especialmente bien con fenoles que contienen grupos electrón atractores. ${ }^{98}$ Esta metodología

98 a) I. G. C. Coutts, M. R. Southcott, J. Chem. Soc., Perkin Trans 1 1990, 767. b) C. Bonini, M. Funicello, R. Scialpi, P. Spagnolo, Tetrahedron 2003, 59, 7515. c) C. Bonini, G. Cristiani, M. Funicello, L. Viggiani, Synth. Commun. 2006, 36, 1983. d) O.-I. Patriciu, A.-L. Finaru, S. Massip, J.-M. Leger, C. Jarry, G. Guillaumet, Org. Lett. 2009, 11, 5502. e) H. Yang, Z.-B. Li, D.-S. Shin, L.-Y. Wang, J.-Z. Zhou, H.-B. Qiao, X. Tian, X.-Y. Ma, H. Zuo, Synlett 2010, 483. 
implica la conversión inicial del correspondiente fenol en una ariloxiacetamida, en la cual los átomos de oxígeno y nitrógeno están separados por un grupo $\operatorname{COC}(\mathrm{R})_{2}$. La eterificación del fenol por tratamiento con 2-bromo-2-metilpropanamida da lugar a una 2-ariloxi-2metilpropanamida, la cual experimenta un reagrupamiento por tratamiento en medio básico y calor conduciendo a la correspondiente $N$-aril-2-hidroxi-2-metilpropanamida. ${ }^{99}$ Posteriormente, la hidrólisis de la anilida formada permite obtener la correspondiente anilina (Esquema 1.25).

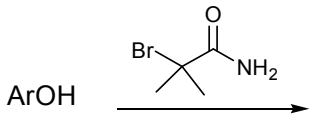<smiles>CC(C)(O[Al])C(N)=O</smiles><smiles>CC(C)(O)C(=O)N[Ga]Cl</smiles>

\section{Esquema 1.25}

El mecanismo mediante el cual parece transcurrir el reagrupamiento de Smiles se muestra en el Esquema 1.26. ${ }^{100 a}$ De acuerdo con este esquema, la abstracción de un primer protón en la 2-ariloxipropanamida I produce el anión IIa que puede atacar al núcleo aromático para dar lugar al anión espiránico IIb. La ruptura del enlace carbono-nitrógeno regeneraría el anión IIa sin avance de la reacción. Sin embargo, la ruptura del enlace carbono-oxígeno en IIb conduce al alcóxido IIc. El exceso de base puede abstraer el protón de la amida en IIc produciendo el dianión IId, el cual ya no puede regresar a IIb. La hidrólisis final de IId da lugar al producto de Smiles reagrupado III.

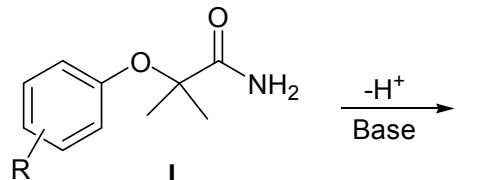<smiles>[R]c1ccc(OC(C)(C)C(N)=O)cc1</smiles><smiles>[R]C=CC12C=CC=CC1(C=CC)OC(C)(C)C(=O)N2</smiles><smiles>[R][X]1ccc(NC(=O)C(C)(C)O)cc1</smiles><smiles>[R]c1ccc(NC(=O)C(C)(C)[O-])cc1</smiles><smiles>CCCCCC</smiles><smiles>[R]c1ccc(NC(=O)C(C)(C)[O-])cc1</smiles>

Esquema 1.26

99 R. Bayles, M. C. Johnson, R. F. Maisey, R. W. Turner, Synthesis 1977, 31.

100 a) J. Weidner, P. M. Weintraub, R. A. Schnettler, N. P. Peet, Tetrahedron 1997, 53, 6303. b) M. Mizuno, M. Yamano, Org. Lett. 2005, 7, 3629. 
Utilizando esta estrategia general, Bonini y colaboradores describieron la conversión de 4-hidroxibenzo[b]tiofenos en los 4-aminoderivados empleando $\mathrm{NaH}$ como base y una mezcla DMF / DMPU ( $N, N^{\prime}$-dimetil- $N, N^{\prime}$-propilenurea) como disolvente (Esquema 1.27). ${ }^{98 \mathrm{~b}}$ La presencia de DMPU favorece el reagrupamiento, fundamentalmente en sustratos aromáticos desactivados con grupos electrón dadores. Estos mismos autores también estudiaron el reagrupamiento de Smiles en otros compuestos heterocíclicos, como los 4 y 5hidroxibenzo[b]furanos, empleando $\mathrm{NaH}$ en DMF como disolvente a $150{ }^{\circ} \mathrm{C} .{ }^{98 \mathrm{c}}$

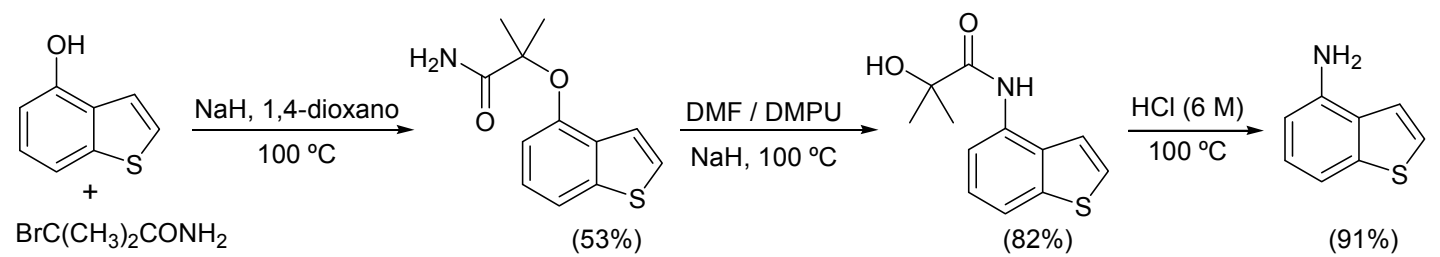

\section{Esquema 1.27}

Algunos ejemplos encontrados en la bibliografía describen la posibilidad de llevar a cabo la secuencia de alquilación del fenol-reagrupamiento de Smiles, sin necesidad de tener que aislar el intermedio 2-ariloxi-2-metilpropanamida (Esquema 1.28). ${ }^{100 a}$

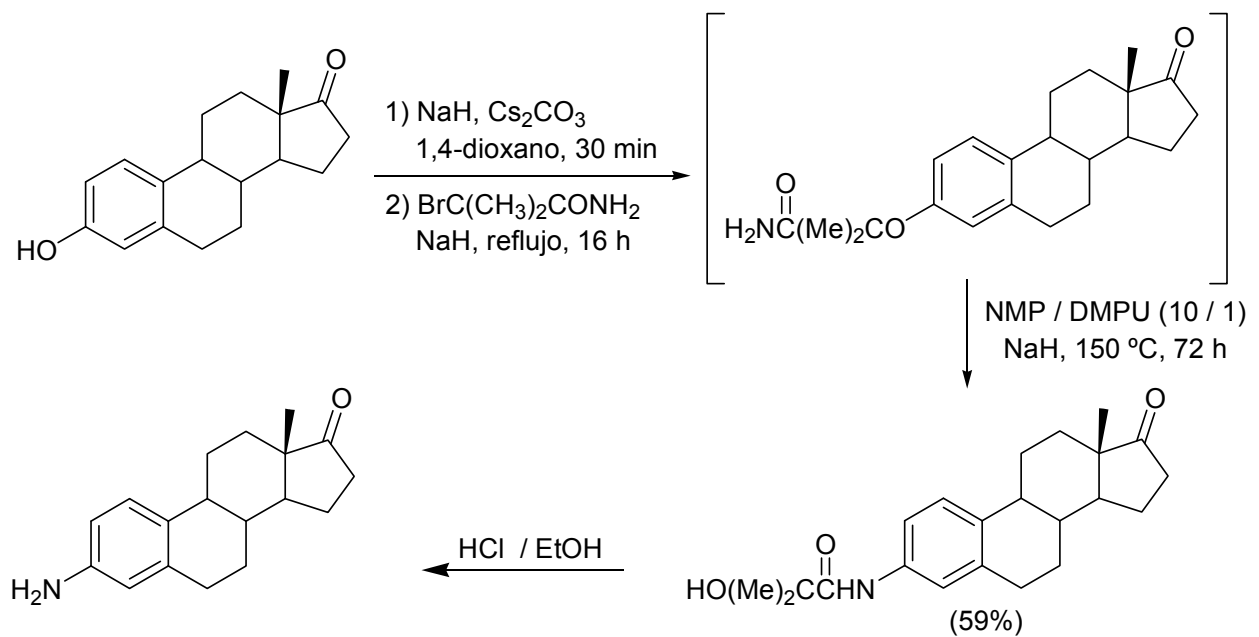

\section{Esquema 1.28}


Mizuno y colaboradores han descrito la conversión de fenoles en anilinas empleando $\mathrm{NaOH}$ como base, en lugar de $\mathrm{NaH}$, mediante un proceso "one pot". El paso final de hidrólisis de la $\mathrm{N}$-aril-2-hidroxipropanamida con el fin de obtener la anilina se suele llevar a cabo en condiciones fuertemente ácidas, sin embargo, estos autores han propuesto su hidrólisis "in situ" sin más que adicionar agua y calentar la mezcla de reacción. ${ }^{100 \mathrm{~b}}$ Así, han preparado la tetralona que se muestra en el Esquema 1.29 mediante el empleo de $\mathrm{NaOH}$ en $N, N$-dimetilacetamida (DMA) como disolvente.<smiles>CC(C)(C)[C@H]1CCc2cc(O)ccc2C1=O</smiles>

Esquema 1.29

\subsubsection{SÍNTESIS DE INDOLES 4-FUNCIONALIZADOS}

Como se ha comentado en la introducción de este Capítulo, aunque existen numerosos métodos para la síntesis de indoles, la obtención de compuestos funcionalizados regioselectivamente en la posición 4 continúa siendo un objetivo no totalmente resuelto en Síntesis Orgánica. Se han desarrollado diferentes aproximaciones para la obtención de estos interesantes derivados, las cuales se han clasificado en las siguientes categorías:

Introducción de sustituyentes en la posición 4 del núcleo indólico ya formado o modificación selectiva de los sustituyentes presentes en el anillo indólico. Algunas de estas aproximaciones implican la metalación de indoles funcionalizados 
adecuadamente en posición 3, hidrodebromación regioselectiva de 4,6dibromoindoles, o la activación del enlace $\mathrm{C}-\mathrm{H}$ en 4-acetoxi-6,7-dihidroindoles.

Reacciones de ciclación de sustratos de partida previamente funcionalizados. Se van a describir algunos métodos de preparación de indoles sustituidos en la posición 4 basados en reacciones de ciclación que implican la formación del enlace entre C3-C3a, C2-C3 ó C-N. La principal desventaja de esta aproximación es la necesidad de preparar previamente los correspondientes derivados bencénicos funcionalizados.

\section{a) Introducción de sustituyentes en la posición 4 del núcleo indólico.}

\section{a.1 Reacciones de metalación}

La introducción de sustituyentes en el anillo carbocíclico del indol se puede llevar a cabo mediante reacciones de metalación. Sin embargo, las posiciones 2 y 3 del núcleo indólico presentan gran reactividad por lo que, en general, se requiere que estas posiciones estén protegidas o impedidas estéricamente. Por otro lado, la metalación regioselectiva en la posición 4 necesita normalmente la presencia de sustituyentes en el esqueleto indólico que favorezcan la reacción de metalación en esta posición. A continuación se describen algunos ejemplos basados en esta aproximación.

\section{a.1.1 Reacciones de taliación}

Un método para obtener derivados de 4-yodoindol consiste en una reacción de taliación de indoles 3-sustituidos, como el 3-formilindol y posterior yodación (Esquema 1.30). ${ }^{101}$ El sustituyente en posición 3 favorece la taliación en la posición 4 del anillo indólico. También se ha descrito la taliación regioselectiva de un cetoindol empleando tristrifluoroacetato de talio seguida de tratamiento con $\mathrm{CuI}$ y yodo (Esquema 1.30).

${ }^{101}$ a) M. Somei, F. Yamada, M. Kunimoto, C. Kaneko, Heterocycles 1984, 22, 797. b) P. Wipf, F. Yokokawa, Tetrahedron Lett. 1998, 39, 2223. c) R. A. Hollins, L. A. Colnago, M. Vera, M. C. Seidl, J. Heterocycl. Chem. 1979, 16, 993. 
<smiles>O=Cc1c[nH]c2ccccc12</smiles><smiles>CC(C)(C)NCNCC(=O)c1c[nH]c2c(I)ccc(I)c12</smiles>

Esquema 1.30

\section{a.1.2 Reacciones de mercuriación}

Brown y Kerr han obtenido derivados de 4-yodoindol mediante mercuriación y posterior yodación de indoles 3-funcionalizados que presentaban el átomo de nitrógeno protegido con un grupo tosilo (Esquema 1.31). ${ }^{102}$

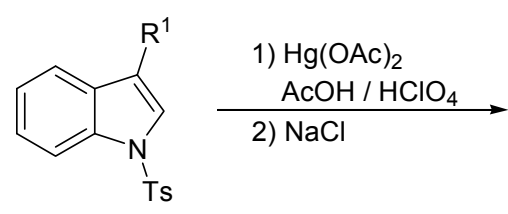

$\mathrm{R}^{1}=\mathrm{Me}, \mathrm{Br}, \mathrm{CHO}, \mathrm{CO}_{2} \mathrm{Me}$<smiles>[R]c1cn([3H])c2cccc(Cl)c12</smiles>

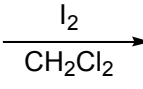<smiles>[R]c1cn([As])c2cccc(I)c12</smiles>

\section{Esquema 1.31}

\section{a.1.3 Reacciones de litiación}

Los derivados de gramina han sido los esqueletos indólicos más empleados para su funcionalización en la posición 4 . Se ha conseguido la litiación regioselectiva en la posición 4 del anillo indólico gracias a la combinación de dos efectos: la capacidad orto-directora del grupo $N, N$-dimetilaminometilo en posición 3 , unida al impedimento estérico provocado por el grupo $N$-triisopropilsililo, que dificulta la litiación de la posición 2 del indol. De esta

\footnotetext{
${ }^{102}$ M. A. Brown, M. A. Kerr, Tetrahedron Lett. 2001, 42, 983.
} 
forma, Iwao y Snieckus han preparado una amplia variedad de productos indólicos funcionalizados en el C-4 (Esquema 1.32). ${ }^{103}$

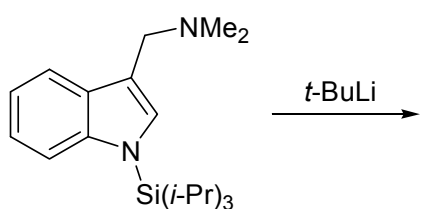

$\mathrm{Si}(i-\mathrm{Pr})_{3}$<smiles>CN1[CH]c2cccc3c2c(cn3[AlH2])C1</smiles><smiles>[CH+]C</smiles>

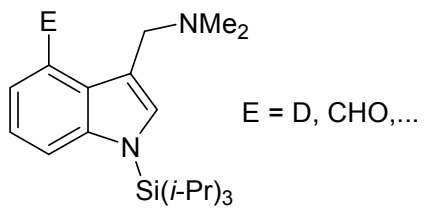

Esquema 1.32

\section{a.2 Activación del enlace $\mathrm{C}-\mathrm{H}$ en 4-acetoxi-6,7-dihidroindoles}

También se han podido preparar indoles 4-funcionalizados a partir de 4-acetoxi-6,7dihidroindoles mediante la combinación de una reacción de activación del enlace $\mathrm{C}-\mathrm{H}$, utilizando un prolinato de rodio $\mathrm{Rh}_{2}(\mathrm{~S}-\mathrm{DOSP})_{4}$ en cantidades catalíticas, con un reagrupamiento de Cope y una posterior reacción de eliminación (Esquema 1.33). ${ }^{104}$<smiles>[R]C=CC(=N)C(C)=O</smiles>

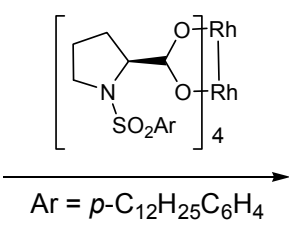<smiles>[R]C(/C=C/C(C)=O)C1(OC(C)=O)C=CCc2c1ccn2C(=O)OCc1ccccc1</smiles><smiles>[R]C(C=CC(C)=O)c1cccc2c1ccn2C(=O)O</smiles>

\section{Esquema 1.33}

Los ejemplos que se describirán en el apartado a.3 y a.4 se basan en la modificación selectiva de los sustituyentes presentes en el núcleo indólico y no en la introducción de un sustituyente en la posición 4 del anillo.

${ }^{103}$ a) M. Iwao, Heterocycles 1993, 36, 29. b) M. Iwao, O. Motoi, Tetrahedron Lett. 1995, 36, 5929. c) B. Chauder, A. Larkin, V. Snieckus, Org. Lett. 2002, 4, 815. d) T. Fukuda, H. Akashima, M. Iwao, Tetrahedron 2005, 61, 6886.

${ }^{104}$ H. M. L. Davies, J. R. Manning, J. Am. Chem. Soc. 2006, 128, 1060. 


\section{a.3 Litiación selectiva de 4,7-dibromoindoles}

Se ha desarrollado una ruta para acceder a indoles 4-sustituidos basada en una reacción de litiación selectiva en la posición 7 de 4,7-dibromoindoles mediante tratamiento con $t$-BuLi en éter seguida de la hidrólisis de la mezcla de reacción (Esquema 1.34). ${ }^{105}$<smiles>[R1]n1c2c(c3c(Br)ccc(Br)c31)CCC2</smiles>

$\mathrm{R}^{1}=\mathrm{H}, \mathrm{Me}, \mathrm{SEM}$

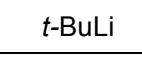<smiles>[R1]n1c2c(c3c(Br)ccc(Cl)c31)CCC2</smiles>

Esquema 1.34

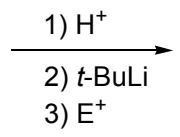<smiles>[R1]n1c2c(c3c(F)cccc31)CCC2</smiles>

$62-77 \%)$

\section{a.4 $\underline{\text { Hidrodebromación regioselectiva de 4,6-dibromoindoles }}$}

Buchwald y Chae han descrito la hidrodebromación selectiva de 4,6-dibromoindoles empleando $\mathrm{NaBH}_{4}$ como agente reductor y el sistema catalítico $\mathrm{Pd}(\mathrm{OAc})_{2} / \mathrm{BINAP}$, en presencia de TMEDA como base. De esta manera, se obtienen selectivamente 4bromoindoles (Esquema 1.35). ${ }^{106}$<smiles>[R]c1[nH]c2cc(Br)c([R])c(Br)c2c1[R]</smiles><smiles>[R]c1ccc2[nH]c([R])c([R])c2c1Br</smiles>

$(73-87 \%)$
$\mathrm{R}^{1}=\mathrm{H}, \mathrm{Me}, \mathrm{OMe}, \mathrm{NMe}_{2}$

$\mathrm{R}^{2}=\mathrm{Me}, \mathrm{Et}, \mathrm{CO}_{2} \mathrm{Et}$

$\mathrm{R}^{3}=\mathrm{Me}, n-\mathrm{Bu}, \ldots$

\section{Esquema 1.35}

\section{b) Reacciones de ciclación en sustratos previamente funcionalizados}

\section{b.1 Reacciones de ciclación con formación del enlace C3-C3a}

\section{b.1.1 Reacciones de ciclación catalizadas por metales de transición}

El desarrollo de métodos basados en catálisis con metales de transición, sobre todo paladio, ha conducido a diferentes rutas para la síntesis de indoles. Una de ellas está basada en

${ }^{105}$ L. Li, A. Martins, Tetrahedron Lett. 2003, 44, 5987.

${ }^{106}$ J. Chae, S. L. Buchwald, J. Org. Chem. 2004, 69, 3336. 
una reacción de Heck intramolecular, en la cual una $o$-haloanilino enamina se cicla formando el anillo de indol, por tratamiento con una especie de paladio y una base (Esquema 1.36). ${ }^{107}$<smiles>C/C=C(/Nc1cccc(COP)c1I)C(=O)OCc1ccccc1</smiles>

\section{Esquema 1.36}<smiles>COC(=O)c1cccc2[nH]c(C(=O)OCc3ccccc3)c(C)c12</smiles>

\section{b.1.2 Reacciones de ciclación sobre arinos}

La adicción intramolecular de enolatos de imina ${ }^{108}$ o vinil-litios ${ }^{109}$ (metodología desarrollada por el grupo) sobre arinos permite obtener derivados indólicos funcionalizados en posición 4 (Esquema 1.37).<smiles>[R]N(CC(=C)I)c1ccccc1F</smiles>

$$
\begin{aligned}
& \text { 1) } t \text {-BuLi, THF } \\
& -110 \text { a } 20^{\circ} \mathrm{C} \\
& \hline \text { 2) } \mathrm{E}^{+}
\end{aligned}
$$<smiles>C[CH-]CC</smiles><smiles>[R]N(CC(=C)C)c1c#cccc1</smiles><smiles>[R]n1cc(C)c2c(F)ccc(C)c21</smiles>

$\mathrm{R}=\mathrm{Me}$, alilo $\mathrm{E}=\mathrm{Br}, \mathrm{SnBu}_{3}, \mathrm{CO}_{2} \mathrm{Et}, \ldots$ $(51-64 \%)$

Otra posibilidad sintética para la obtención de indoles funcionalizados regioselectivamente consiste en una reacción de carbometalación intramolecular de una olefina por un complejo bencinozirconoceno seguida de la reacción con yodo, DBU y enófilos. Así se han preparado indoles 3,4-difuncionalizados (Esquema 1.38). ${ }^{110}$

\footnotetext{
${ }^{107}$ a) K. Koerber-Plé, G. Massiot, Synlett 1994, 759. b) N. Charrier, E. Demont, R. Dunsdon, G. Maile, A. Naylor, A. O'Brien, S. Redshaw, P. Theobald, D. Vesey, D. Walter, Synthesis 2006, 3467.

${ }^{108}$ C. Caubère, P. Caubère, S. Ianelli, M. Nardelli, B.-J. Gregoire, Tetrahedron 1994, 50, 11903.

${ }^{109}$ J. Barluenga, F. J. Fañanás, R. Sanz, Y. Fernández, Chem. Eur. J. 2002, 8, 2034.

110 J. H. Tidwell, S. L. Buchwald, J. Am. Chem. Soc. 1994, 116, 11797.
} 


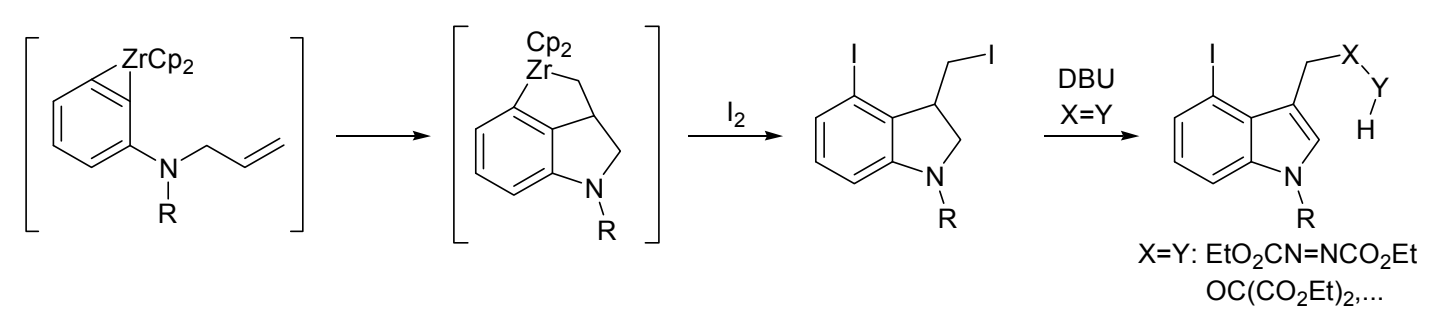

Esquema 1.38

\section{b. 2 Reacciones de ciclación con formación del enlace $\mathrm{C} 2-\mathrm{C} 3$}

b.2.1 Reacciones de ciclación de carbenos de Fischer

Una cicloadición intramolecular [2+2] de $N$-arilamino carbenos de Fischer que presentan un sustituyente vinílico en la posición orto del anillo aromático, permite obtener indoles sustituidos en posición 4 . Se propone una reacción de metátesis que transcurre a través de un metalaciclobutano que, finalmente, permite obtener dichos indoles (Esquema 1.39). ${ }^{111}$<smiles>C=Cc1c(N/C(C)=C(\C)C([O-])([O-])[O-])cccc1C(C)=O</smiles>

\section{b.2.2 Reacciones de ciclación en derivados de orto-nitrotolueno}

Una alternativa a la síntesis de Leimgruber-Batcho (apartado b.3.1) para la preparación de 4-nitroindoles consiste en el tratamiento de algunos derivados de 3nitroanilina con oxalatos de dialquilo en medio básico. La reacción intramolecular de ciclación del anión intermedio ha permitido obtener 4-nitroindoles (Esquema 1.40). ${ }^{112}$

\footnotetext{
111 a) B. C. G. Söderberg, E. S. Helson, L. R. Austin, H. H. Odens, J. Org. Chem. 1993, 58, 5589. b) B. C. G. Söderberg, J. A. Shiver, S. H. Cooper, T. L. Shrout, E. S. Helson, L. R. Austin, H. H. Odens, B. R. Hearn, P. C. Jones, T. N. Kouadio, T. H. Ngi, R. Baswell, H. J. Caprara, M. D. Meritt, T. Mai, Tetrahedron 2003, 59, 8775 .

112 J. Bergman, P. Sand, U. Tilsman, Tetrahedron Lett. 1983, 24, 3665.
} 
<smiles>[R][C@H](OCC)c1cccc([N+](=O)[O-])c1C</smiles>

Esquema 1.40

\section{b.3 Reacciones de ciclación con formación del enlace N-C2 ó N-C7a}

b.3.1 Reacciones de ciclación reductora en derivados de orto-nitrotolueno y 2nitroestirenos

Leimgruber y Batcho introdujeron una síntesis eficiente de indoles basada en la condensación de orto-nitrotolueno con el dimetilacetal de la $N, N$-dimetilformamida seguida de la reducción y posterior ciclación del trans- $\beta$-dimetilamino-2-nitroestireno resultante (Esquema 1.41). ${ }^{113}$<smiles>[R]c1cccc([N+](=O)[O-])c1C</smiles>

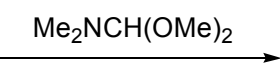<smiles>[R]c1cccc([N+](=O)[O-])c1/C=C/NC</smiles><smiles>[R20]#[13CH]</smiles>

$\mathrm{R}=\mathrm{Cl}, \mathrm{OMe}, \mathrm{OBn}, \mathrm{NH}_{2}, \mathrm{NO}_{2}, \mathrm{CN}, \ldots$ (33-84\%)

\section{Esquema 1.41}

Por otro lado, se ha preparado una amplia familia de indoles mediante heteroanulación reductora de 2-nitroestirenos catalizada por $\mathrm{Pd}(\mathrm{OAc})_{2} / \mathrm{PPh}_{3}$, en presencia de monóxido de carbono (Esquema 1.42). ${ }^{114}$<smiles>[R]c1cccc([N+](=O)[O-])c1C=C</smiles><smiles>[R]c1cccc2[nH]ccc12</smiles>

$\mathrm{R}=\mathrm{OH}, \mathrm{OMe}, \mathrm{OTf}, \mathrm{NO}_{2}, \mathrm{CO}_{2} \mathrm{Me}$ $(40-100 \%)$

\section{Esquema 1.42}

113 a) M. Somei, M. Tsuchiya, Chem. Pharm. Bull. 1981, 29, 3145. b) R. D. Clark, D. B. Repke, Heterocycles 1984, 22, 195.

114 B. C. Söderberg, J. A. Shiver, J. Org. Chem. 1997, 62, 5838. 
En nuestro grupo de investigación se ha descrito la ciclación reductora de 2nitroestirenos catalizada por un complejo de dioxomolibdeno (VI), como una estrategia sintética interesante para obtener indoles sustituidos regioselectivamente. Este procedimiento es una versión catalítica de la reacción de Cadogan-Sundberg. ${ }^{115}$ Esta metodología se complementó poniendo a punto una reacción "one-pot" para sintetizar indoles con un amplio patrón de sustitución a partir de derivados de 2-nitrobenzaldehídos, incluyendo 4-cloroindoles (Esquema 1.43). ${ }^{116}$<smiles>O=Cc1c(Cl)cccc1[N+](=O)[O-]</smiles>

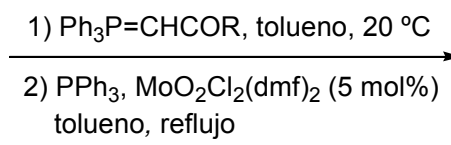<smiles>[R]C([R])c1cc2c(Cl)cccc2[nH]1</smiles>

\section{Esquema 1.43}

\section{b.3.2 Heteroanulación de Larock}

Larock ha descrito la preparación regioselectiva de indoles polisustituidos en un único paso de reacción, ${ }^{117}$ partiendo de orto-yodoanilinas y alquinos internos. La reacción está catalizada por complejos de paladio y transcurre en presencia de una base. Esta metodología ha sido empleada por ejemplo en la síntesis de la psilocina, una molécula que presenta gran interés biológico (Esquema 1.44). ${ }^{118}$

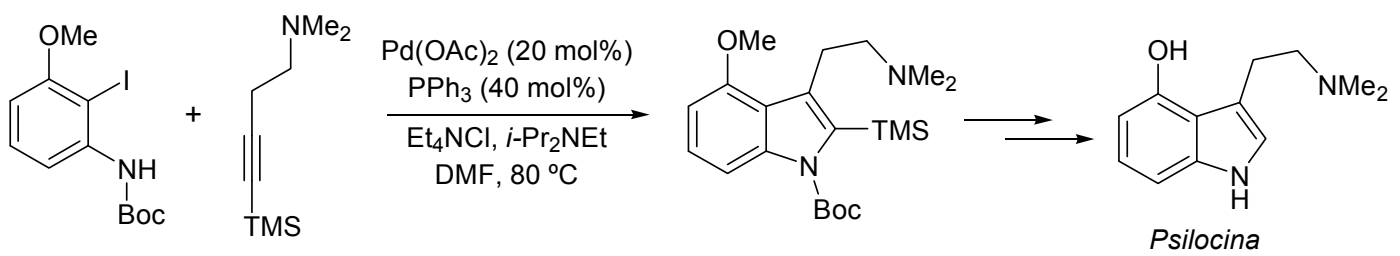

Esquema 1.44

115 a) J. I. G. Cadogan, M. Cameron-Wood, Proc. Chem. Soc. 1962, 361. b) J. I. G. Cadogan, M. CameronWood, R. K. Mackie, R. J. G. Searle, J. Chem. Soc. 1965, 4831. c) R. J. Sundberg, J. Org. Chem. 1965, 30, 3604. d) R. J. Sundberg, T. Yamazaki, J. Org. Chem. 1967, 32, 290.

${ }^{116}$ R. Sanz, J. Escribano, M. R. Pedrosa, R. Aguado, F. J. Arnáiz, Adv. Synth. Catal. 2007, 349, 713.

${ }_{117}^{1}$ R. C. Larock, E. K. Yun, J. Am. Chem. Soc. 1991, 113, 6689.

${ }^{118}$ N. Gathergood, P. J. Scammells, Org. Lett. 2003, 5, 921 


\section{b.3.3 Otras reacciones de ciclación catalizadas por complejos de paladio}

Se pueden obtener indoles sustituidos regioselectivamente en la posición 4 mediante una ciclación intramolecular de hidrazonas $N, N$-disustituidas de $o$-cloroarilacetaldehído, catalizada por un complejo de paladio y en presencia de un ligando fosfina como la tri-tbutilfosfina o el 2-(dimetilaminometil)-1-(di-t-butilfosfanil)ferroceno (Esquema 1.45). ${ }^{119}$
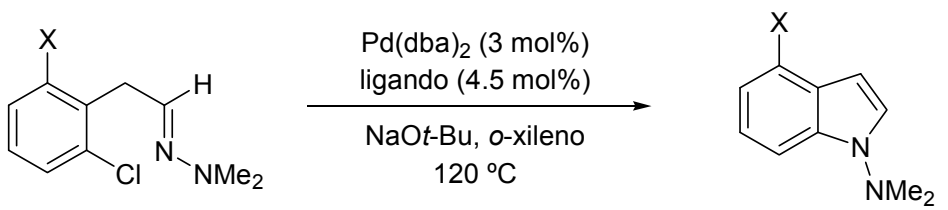

$$
\mathrm{X}=\mathrm{F}, \mathrm{Cl}
$$

\section{Esquema 1.45}

Una reacción tándem de aminación / ciclación intramolecular de haluros de haloalquenilfenilo, catalizada por $\operatorname{Pd}_{2}(\mathrm{dba})_{3}$ y una fosfina impedida, como DavePhos (2diciclohexilfosfino-2',2'-dimetilaminobifenilo) conduce a la formación de derivados de indol 4-halosustituidos (Esquema 1.46). ${ }^{120}$

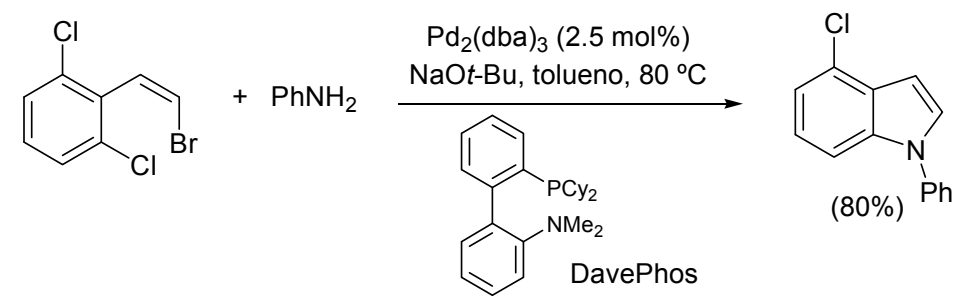

\section{Esquema 1.46}

Barluenga y colaboradores han descrito una aproximación al esqueleto indólico mediante una reacción en cascada de 1,2-dihaloarenos e iminas. ${ }^{121}$ El proceso implica una $\alpha$ arilación de la imina seguido de una reacción intramolecular de formación del enlace $\mathrm{C}-\mathrm{N}$ (Esquema 1.47). ${ }^{121 \mathrm{a}}$

\footnotetext{
${ }^{119}$ M. Watanabe, T. Yamamoto, M. Nishiyama, Angew. Chem., Int. Ed. 2000, 39, 2501.

${ }^{120}$ M. C.Willis, G. N. Brace, T. J. K. Findlay, I. P. Holmes, Adv. Synth. Catal. 2006, 348, 851.

121 a) J. Barluenga, A. Jiménez-Aquino, F. Aznar, C. Valdés, J. Am. Chem. Soc. 2009, 131, 4031. b) J. Barluenga, A. Jiménez-Aquino, F. Aznar, C. Valdés, Chem. Eur. J. 2010, 16, 11707.
} 


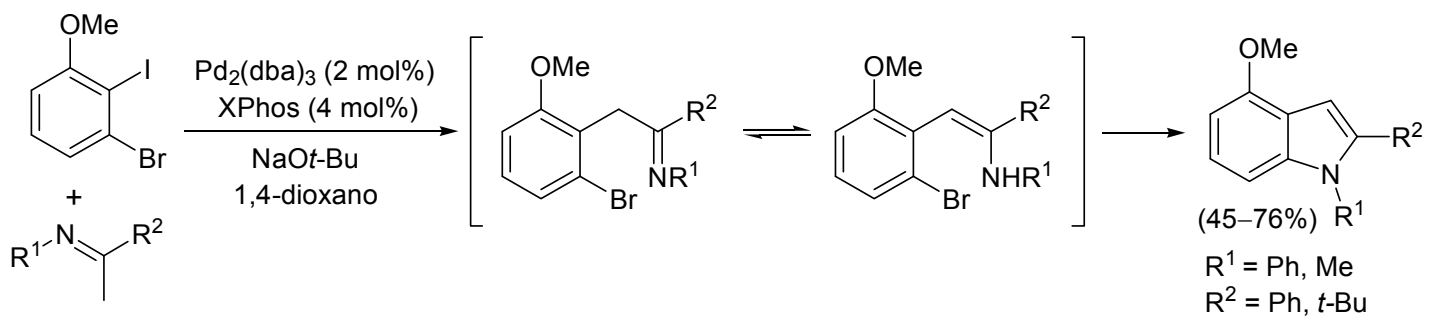

Esquema 1.47

También se ha desarrollado un método para la síntesis de indoles catalizado por el sistema $\mathrm{Pd}(\mathrm{OAc})_{2}$ / SPhos a partir de gem-dibromovinilanilinas y ácidos borónicos a través de un proceso tándem de acoplamientos $\mathrm{C}-\mathrm{N}$ (aminación de Buchwald-Hartwig) / C-C (Suzuki-Miyaura) (Esquema 1.48). ${ }^{122}$<smiles>[R]c1cccc(N)c1C=C(Br)Br</smiles>

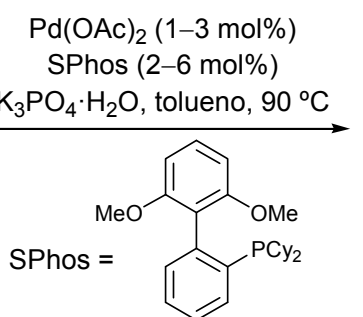<smiles>[R]c1cccc2[nH]c(-c3ccccc3)cc12</smiles>
$(77-88 \%)$

\section{Esquema 1.48}

\section{b.3.4 Reacciones de ciclación de $\alpha$-arilazirinas}

Las $\alpha$-arilcetonas se pueden transformar en $\alpha$-arilazirinas mediante una reacción de Neber. Un posterior reagrupamiento termolítico de la $\alpha$-arilazirina conduce al correspondiente indol (Esquema 1.49). ${ }^{123}$

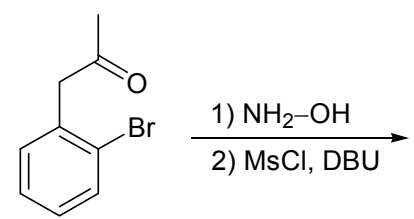<smiles></smiles><smiles>Cc1cc2c(Br)cccc2[nH]1</smiles>

\section{Esquema 1.49}

122 a) Y.-Q. Fang, M. Lautens, Org. Lett. 2005, 7, 3549. b) Y.-Q. Fang, M. Lautens, J. Org. Chem. 2008, 73, 538.

123 a) P. W. Neber, G. Huh, Justus Liebigs Ann. Chem. 1935, 515, 283. b) P. W. Taber, W. Tian, J. Am. Chem. Soc. 2006, 128, 1058. 


\section{b.3.5 Reacción de ciclación de azidas}

El tratamiento de 2-arilvinil azidas con perfluorobutirato de rodio (II) genera un nitrenoide de rodio, el cual evoluciona con formación del enlace $\mathrm{C}-\mathrm{N}$ dando lugar al esqueleto de indol (Esquema 1.50). ${ }^{124}$

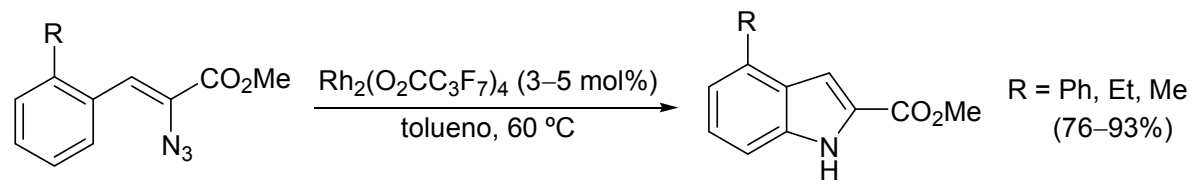

\section{Esquema 1.50}

\subsubsection{SÍNTESIS DE INDOLES 2-SUSTITUIDOS MEDIANTE HETEROCICLACIÓN DE ORTO-ALQUINILANILINAS}

Entre los numerosos estrategias sintéticas descritas en la bibliografía para la síntesis del anillo indólico, las reacciones de ciclación en derivados de 2-alquinilanilinas son unos de los procedimientos más utilizados. Estas reacciones se pueden clasificar fundamentalmente en dos categorías:

a) Procedimientos que emplean sistemas catalíticos basados en metales de transición, como cobre, oro, indio,...

b) Procedimientos basados en alcóxidos metálicos, fundamentalmente de metales alcalinos.

\section{a) Procedimientos basados en catálisis con metales de transición ${ }^{74 b}$}

\section{a.1 Sales de cobre (II)}

La ciclación de 2-alquinilanilinas empleando sales de cobre (II) en cantidades catalíticas ha sido demostrada por Hiroya y colaboradores. Esta reacción se aplicó a sulfonamidas y derivados de anilinas primarias y secundarias, donde el catalizador elegido

\footnotetext{
${ }^{124}$ B. J. Stokes, H. Dong, B. E. Leslie, A. L. Pumphrey, T. G. Driver, J. Am. Chem. Soc. 2007, 129, 7500.
} 
fue $\mathrm{Cu}(\mathrm{OAc})_{2}$ para 2-alquinilanilinas $N$-sustituidas y $\mathrm{Cu}\left(\mathrm{OCOCF}_{3}\right)_{2}$ para 2-alquinilanilinas (Esquema 1.51). ${ }^{125}$<smiles>[R]C#Cc1cc([R])c([R])cc1N[R]</smiles>

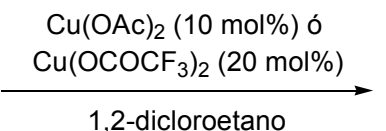

$\mathrm{R}^{1}=\mathrm{H}, \mathrm{Me}, \mathrm{Br}, \mathrm{CN}$

$\mathrm{R}^{2}=\mathrm{H}, \mathrm{OMe}, \mathrm{CN}$

$\mathrm{R}^{3}=\mathrm{H}, \mathrm{Ph},\left(\mathrm{CH}_{2}\right)_{4} \mathrm{OTBS}$

$\mathrm{R}^{4}=\mathrm{H}, \mathrm{Ms}, 4-\mathrm{MeOC}_{6} \mathrm{H}_{4}, i-\mathrm{Pr}$<smiles>[R]c1cc2cc([R])n([R])c2cc1[R]</smiles>

$(84-100 \%)$

\section{Esquema 1.51}

\section{a.2 Complejos de oro (III)}

En este campo también se ha descrito la síntesis de indoles mediante ciclación de 2alquinilanilinas catalizada por complejos de oro (III) ${ }^{126}$ en EtOH, $i$-PrOH o mezclas de $\mathrm{EtOH} / \mathrm{H}_{2} \mathrm{O}$ a temperatura ambiente (Esquema 1.52). ${ }^{126 \mathrm{a}}$
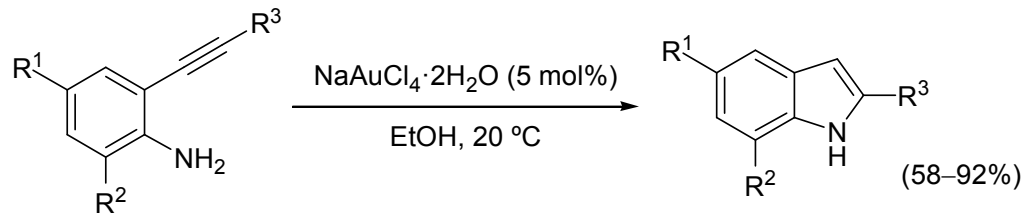

$$
\begin{aligned}
& \mathrm{R}^{1}=\mathrm{H}, \mathrm{Ph}, \mathrm{HetAr} \text {, vinilo } \\
& \mathrm{R}^{2}=\mathrm{H}, \mathrm{F}, \mathrm{Cl}, \mathrm{NO}_{2} \\
& \mathrm{R}^{3}=\mathrm{H}, \mathrm{F}, \mathrm{Cl}, \mathrm{CF}_{3}
\end{aligned}
$$

\section{Esquema 1.52}

\section{a.3 Otros metales de transición}

Nishizawa y colaboradores estudiaron la cicloisomerización de 2-alquinil- $N$ tosilanilinas catalizada por $\mathrm{Hg}(\mathrm{OTf})_{2}$ y consiguieron preparar una familia de $\mathrm{N}$-tosilindoles con buenos rendimientos (Esquema 1.53). ${ }^{127}$

\footnotetext{
${ }^{125}$ a) K. Hiroya, S. Itoh, M. Ozawa, Y. Kanamori, T. Sakamoto, Tetrahedron Lett. 2002, 43, 1277. b) K. Hiroya, S. Itoh, T. Sakamoto, J. Org. Chem. 2004, 69, 1126.

${ }^{126}$ a) M. Alfonsi, A. Arcadi, M. Aschi, G. Bianchi, F. Marinelli, J. Org. Chem. 2005, 70, 2265. b) J. P. Brand, C. Chevalley, J. Waser, Beilstein J. Org. Chem. 2011, 7, 565.
} 


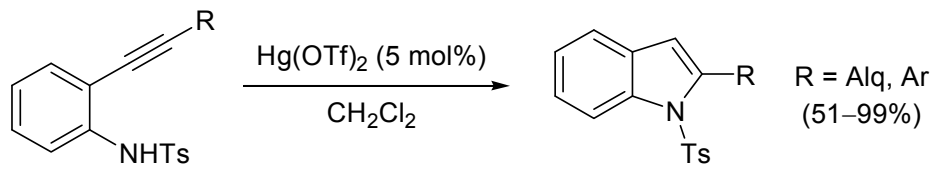

\section{Esquema 1.53}

También se ha utilizado $\mathrm{InBr}_{3}$ en tolueno a reflujo para ciclar distintos derivados de 2-alquinilanilinas obteniéndose indoles polisustituidos (Esquema 1.54). ${ }^{128}$<smiles>[R]C#Cc1cc([R])c([R])cc1N[R]</smiles>

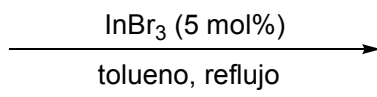

$\mathrm{R}^{1}=\mathrm{H}, \mathrm{Me}, \mathrm{F}, \mathrm{CN}, \mathrm{NO}_{2}$

$\mathrm{R}^{2}=\mathrm{H}, \mathrm{Me}$

$\mathrm{R}^{3}=\mathrm{Ph}, \mathrm{C}_{6} \mathrm{H}_{13}, t-\mathrm{Bu}$

$\mathrm{R}^{4}=\mathrm{H}, \mathrm{Bn}, \mathrm{Ac}$<smiles>[R]c1cc2cc([R])n([Z2])c2cc1[R]</smiles>

$(52-98 \%)$

\section{Esquema 1.54}

En este mismo sentido, otros autores han empleado complejos de rodio con $\mathrm{PPh}_{3}$ ó $\left(4-\mathrm{FC}_{6} \mathrm{H}_{4}\right)_{3} \mathrm{P}$ para llevar a cabo la heterociclación sobre derivados de $o$-alquinilanilinas (Esquema 1.55). ${ }^{129}$<smiles>[R]Nc1ccc([R])cc1C#C</smiles>

$\left[\mathrm{Rh}(\operatorname{cod}) \mathrm{Cl}_{2}(1 \mathrm{~mol} \%)\right.$ $\underset{\mathrm{DMF}, 85^{\circ} \mathrm{C}}{\stackrel{\mathrm{Ph}_{3} \mathrm{P} \text { ó }\left(4-\mathrm{FC}_{6} \mathrm{H}_{4}\right)_{3} \mathrm{P}(5 \mathrm{~mol} \%)}{\longrightarrow}}$<smiles>[R]c1ccc2c(ccn2[R])c1</smiles>

$\mathrm{R}^{1}=\mathrm{Me}, \mathrm{Cl}, \mathrm{CO}_{2} \mathrm{Et}, \mathrm{CN}$, $\mathrm{NO}_{2}, \mathrm{COCH}_{3}$ $\mathrm{R}^{2}=\mathrm{H}, \mathrm{Bn}$

$(52-92 \%)$

\section{Esquema 1.55}

${ }^{127}$ T. Kurisaki, T. Naniwa, H. Yamamoto, H. Imagawa, M. Nishizawa, Tetrahedron Lett. 2007, 48, 1871.

${ }^{128}$ N. Sakai, K. Annaka, T. Konakahara, Tetrahedron Lett. 2006, 47, 631.

${ }^{129}$ B. M. Trost, A. Mc Clory, Angew. Chem., Int. Ed. 2007, 46, 2074. 


\section{b) Métodos de ciclación basados en el empleo de alcóxidos metálicos}

En la bibliografía se ha descrito la síntesis de indoles 2-sustituidos empleando alcóxidos metálicos para promover la ciclación sobre derivados de 2-alquinilanilinas como uno de los métodos más sencillos e interesantes. Algunos ejemplos de esta metodología implican la utilización de $\mathrm{NaOEt}^{130}$ ó $\mathrm{KO} t-\mathrm{Bu}^{131}$ con anilinas $N$-sustituidas, normalmente carbamatos.

De este modo, la ciclación de carbamatos de 2-alquinilfenilo en presencia de $\mathrm{NaOEt}$ ó $\mathrm{NaOMe}$ ha permitido obtener una amplia variedad de $1 H$-indoles (Esquema 1.56). ${ }^{130 \mathrm{a}, \mathrm{d}}$

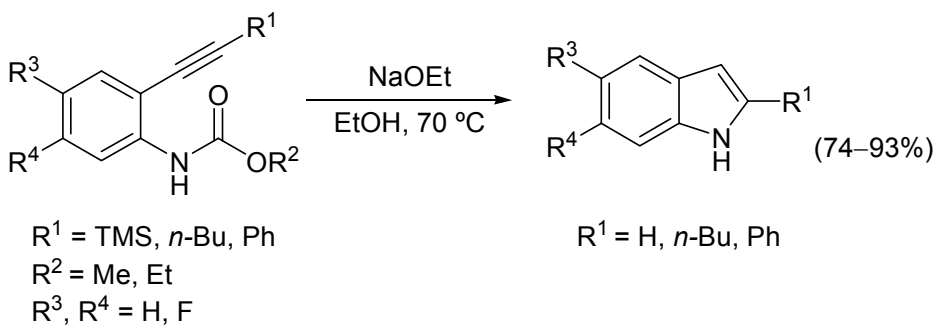

\section{Esquema 1.56}

También se ha ensayado este mismo tipo de ciclaciones empleando $\mathrm{KO} t$ - $\mathrm{Bu}$ en lugar de NaOEt y así, por ejemplo, se han podido preparar indoles con sustituyentes metoxilo y triisopropilsililoxilo en diferentes posiciones de su estructura (Esquema 1.57). ${ }^{131}$

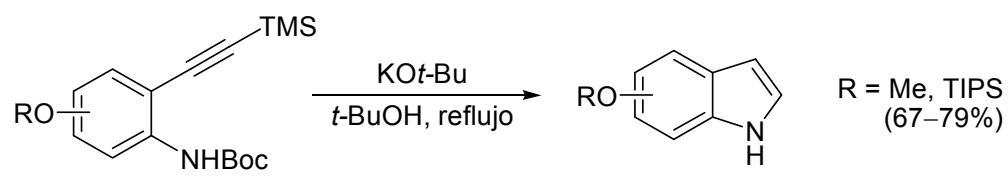

\section{Esquema 1.57}

En este contexto, Knochel y colaboradores estudiaron la ciclación de 2alquinilanilinas empleando distintas bases: $\mathrm{NaH}, \mathrm{NaOEt}, \mathrm{KO} t$-Bu, $\mathrm{KH}, \mathrm{CsOH}$ ó $\mathrm{CsO} t$-Bu y

\footnotetext{
130 a) T. Sakamoto, Y. Kondo, H. Yamanaka, Heterocycles 1986, 24, 31. b) K. Shin, K. Ogasawara, Synlett 1995, 859. c) Y. Kondo, S. Kojima, T. Sakamoto, Heterocycles 1996, 43, 2741. d) K. Shin, M. Moriya, K. Ogasawara, Tetrahedron Lett. 1998, 39, 3765. e) J. Wang, N. Soundarajan, N. Liu, K. Zimmermann, B. N. Naidu, Tetrahedron Lett. 2005, 46, 907.

${ }^{131}$ Y. Kondo, S. Kojima, T. Sakamoto, J. Org. Chem. 1997, 62, 6507.
} 
NMP ( $N$-metilpirrolidona) como disolvente, llegando a la conclusión que bases como $\mathrm{KO} t$ $\mathrm{Bu}$ ó $\mathrm{KH}$ junto con el empleo de disolventes polares eran las condiciones óptimas para la reacción de heterociclación (Esquema 1.58). ${ }^{132}$<smiles>[R]C#Cc1cc([R])cc([R])c1N</smiles>

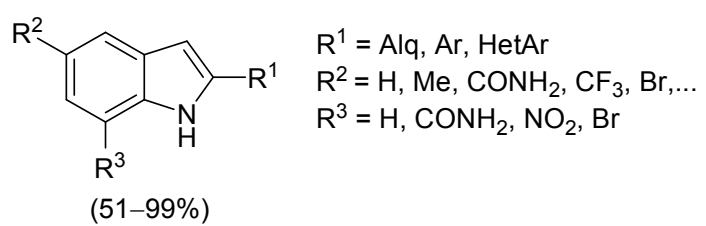

\section{Esquema 1.58}

Este mismo procedimiento también ha sido utilizado para llevar a cabo la ciclación de distintos derivados de 2-alquinilanilida (Esquema 1.59). ${ }^{133}$ Asimismo, otros autores han descrito la preparación de azaindoles (Esquema 1.59), ${ }^{134}$ o 2-alquinilindoles empleando esta misma metodología. ${ }^{135}$<smiles>[R]C#CC1=C(NC([R7])=O)C#[R]C[R]1[R]</smiles>

$\mathrm{R}^{1}=\mathrm{Ph}, n-\mathrm{Pr}$<smiles>[R]C#Cc1ncc[R3]([R10])c1N[R1]</smiles><smiles>[R][R]1ccc2cc([R])n(C(=O)[PH2+])c2c1</smiles>

$(72-86 \%)$<smiles>[R][R]1ccnc2cc([R])n([R])c12</smiles>

$\mathrm{R}^{1}=\mathrm{Bn}, 4-\mathrm{MeOC}_{6} \mathrm{H}_{4} \mathrm{CH}_{2}, \mathrm{C}_{6} \mathrm{H}_{11}, \ldots$ $\mathrm{R}^{2}=\mathrm{Ph}$, ciclohexenilo, $n$-Bu $\mathrm{R}^{3}=\mathrm{Me}, \mathrm{NO}_{2}, \mathrm{~F}$

$\mathrm{R}^{2}=\mathrm{H}, \mathrm{Me}$

$\mathrm{R}^{3}=\mathrm{H}, \mathrm{Me}, \mathrm{Cl}, \mathrm{SO}_{2} \mathrm{Et}, \mathrm{NO}_{2}$ $\mathrm{R}^{2}, \mathrm{R}^{3}=5,6-\left(\mathrm{CH}_{2}\right)_{4}$

$(50-91 \%)$

\section{Esquema 1.59}

\footnotetext{
132 a) A. L. Rodríguez, C. Koradin, W. Dohle, P. Knochel, Angew. Chem., Int. Ed. 2000, 39, 2488. b) C. Koradin, W. Dohle, A. L. Rodríguez, B. Schmid, P. Knochel, Tetrahedron 2003, 59, 1571. c) A. H. Stoll, P. Knochel, Org. Lett. 2008, 10, 113.

133 a) W.-M. Dai, D.-S. Guo, L.-P. Sun, Tetrahedron Lett. 2001, 42, 5275. b) L.-P. Sun, X.-H. Huang, W.-M. Dai, Tetrahedron 2004, 60, 10983.

${ }^{134}$ M. Mc Laughlin, M. Palucki, I. W. Davies, Org. Lett. 2006, 8, 3306.

${ }^{135}$ V. Fiandanese, D. Bottalico, G. Marchese, A. Punzi, Tetrahedron 2008, 64, 53.
} 


\subsection{DISCUSIÓN DE RESULTADOS}

\subsubsection{SÍNTESIS DE 2,3-DIHALOANILINAS}

Como se ha descrito en la Introducción de este Capítulo, el primer objetivo del presente trabajo consistió en el diseño de una ruta sintética eficiente para la obtención de 2,3-dihaloanilinas. Inicialmente, nos planteamos tres posibles alternativas para acceder a estos interesantes compuestos (Esquema 1.60):

- Ruta (a), que implicaría una reacción de orto-metalación seguida de funcionalización en un derivado de 3-haloanilina.

- Por otro lado, las 2,3-dihaloanilinas se podrían obtener por reducción de 2,3dihalonitrobencenos, a los cuales se podría acceder mediante una reacción de metalación y posterior funcionalización de 3-halonitrobencenos, ruta $(b)$.

- Otra posible ruta consistiría en utilizar los 2,3-dihalofenoles como productos de partida a partir de los cuales obtener los análogos nitrogenados, mediante un reagrupamiento de Smiles como paso clave del proceso, ruta $(c)$.
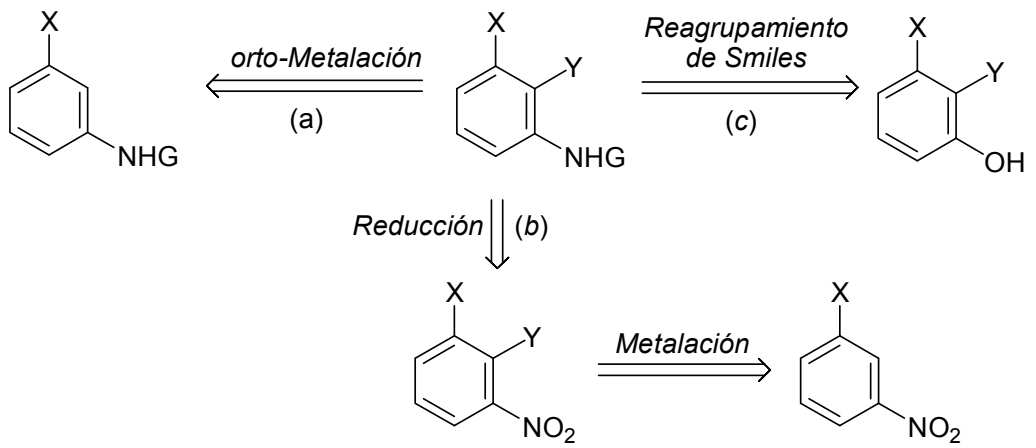

\section{Esquema 1.60}

A continuación se describirán los resultados obtenidos empleando cada una de las tres estrategias sintéticas propuestas. Asimismo, se analizará el alcance de las distintas alternativas y las dificultades encontradas en la preparación de las 2,3-dihaloanilinas. 


\section{a) orto-Metalación de 3-haloanilinas}

\section{a.1 Estudio de la reacción de orto-litiación en derivados de 3-haloanilinas}

Como se ha comentado en los Antecedentes Bibliográficos Generales, se había descrito la orto-litiación de la 2,2,2-trifluoro- $N$-(3-fluorofenil)acetamida 1a mediante su tratamiento con $t$-BuLi en presencia de TMEDA para generar el intermedio organolítico 2a que, posteriormente, era atrapado con disulfuro de metilo o bromo ${ }^{38}$ Esta reacción no ha sido empleada posteriormente en síntesis a pesar del potencial interés de estos derivados de anilina 2,3-funcionalizados para la preparación de indoles que contengan flúor en su estructura. Por lo tanto, decidimos aplicar esta estrategia a la obtención de la 3-fluoro-2yodotrifluoroanilida 3aa partiendo de la acetamida 1a, empleando yodo como electrófilo. Usando un pequeño exceso de $t$-BuLi / TMEDA en THF a $-78{ }^{\circ} \mathrm{C}$ fuimos capaces de generar la especie dilitiada $\mathbf{2 a}$, la cual reaccionó con yodo permitiendo aislar 3aa con un $63 \%$ de rendimiento (Esquema 1.61). De forma análoga, la adición de bromo o hexacloroetano como electrófilos al intermedio $\mathbf{2 a}$ condujo a las correspondientes 3-fluoro2-halo-trifluoroanilidas 3ab y 3ac con rendimientos del 45\% y 30\%, respectivamente. Además, la hidrólisis básica de algunas de estas trifluoroacetanilidas 3 dio lugar a las 3fluoro-2-haloanilinas 6aa y 6ab con altos rendimientos (Esquema 1.61).

También comprobamos que hay que tener un especial cuidado en el control de la temperatura en la reacción de orto-metalación debido a la eliminación competitiva de LiF que tiene lugar a temperaturas superiores a $-60{ }^{\circ} \mathrm{C}$. Por encima de esa temperatura se genera el intermedio bencínico $5,{ }^{136}$ que reacciona intramolecularmente dando lugar, tras su reacción con el electrófilo, al benzoxazol 4 con un rendimiento moderado (Esquema 1.61). Este tipo de reactividad había sido observada previamente por Clark y Caroon en la metalación directa de las 3-fluoroanilinas que contenían los grupos pivaloílo, $N$-Boc, o benzoílo como grupos directores. ${ }^{137}$

\footnotetext{
${ }^{136}$ Para una revisión sobre las aplicaciones sintéticas de arinos, ver: R. Sanz, Org. Prep. Proced. Int. 2008, 40, 215.

${ }^{137}$ R. D. Clark, J. M. Caroon, J. Org. Chem. 1982, 47, 2804.
} 


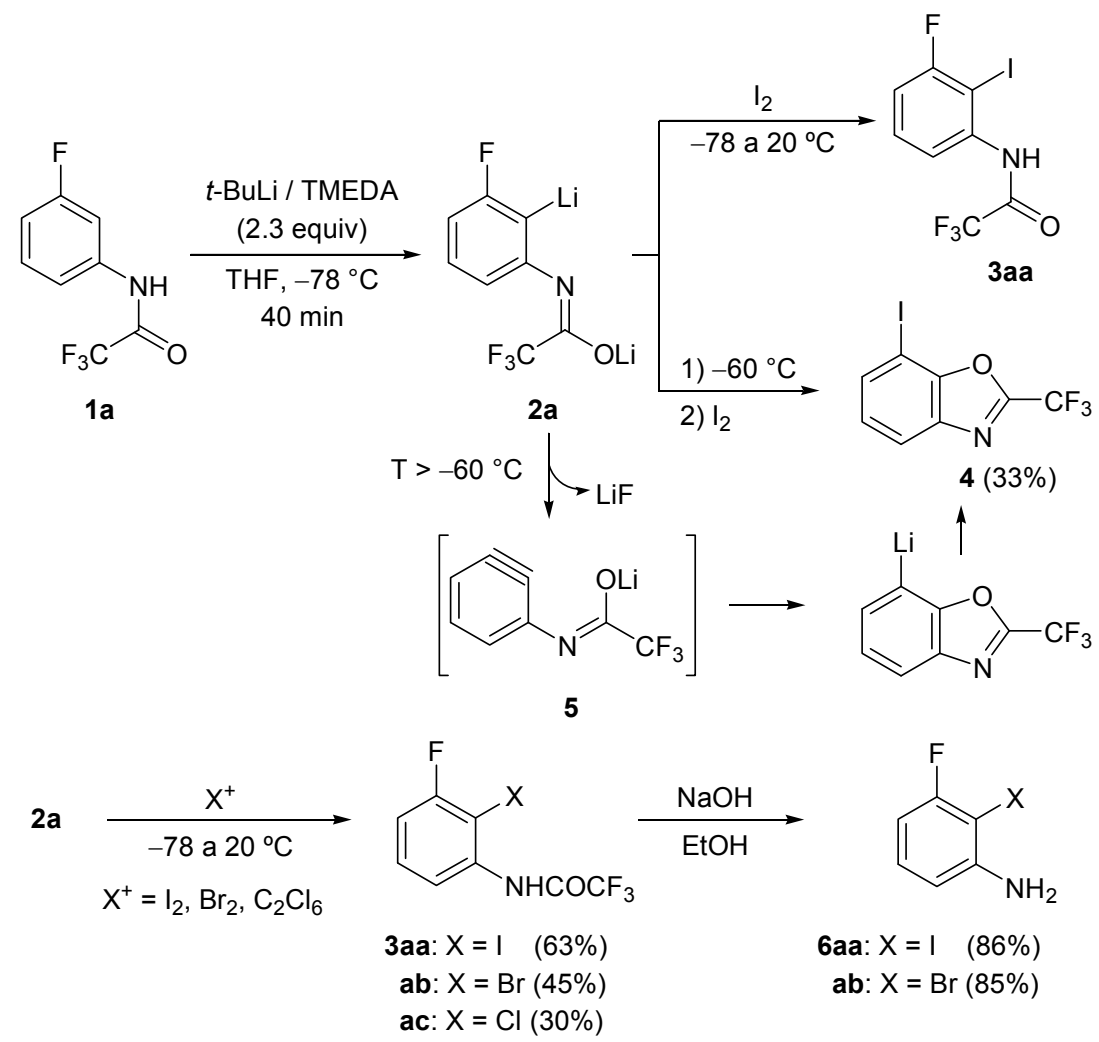

Esquema 1.61

Sin embargo, cuando se intentó aplicar esta estrategia de orto-litiación a la 3clorotrifluoroacetanilida $\mathbf{1 b}$ no se pudo acceder al correspondiente derivado de la 3-cloro-2yodoanilina. Bajo las mismas condiciones de reacción empleadas en la metalación de 1a $(t$ BuLi / TMEDA, THF, $-78{ }^{\circ} \mathrm{C}$ ) únicamente se recuperó el sustrato de partida. Además, cuando se permitió que la mezcla de reacción alcanzara temperaturas superiores a $-40{ }^{\circ} \mathrm{C}$, se observó la adición de $t$-BuLi al grupo trifluoroacetamido aislándose la $N$-(3-cloro)fenil pivalamida 7 con un rendimiento del $35 \%$ (Esquema 1.62). ${ }^{138}$ El empleo de $n$-BuLi en lugar de $t$-BuLi evitó el ataque a la amida pero no se observó la metalación hasta $-30{ }^{\circ} \mathrm{C} .{ }^{139}$ Por otro lado, la utilización de LDA como agente metalante tampoco condujo a resultados

\footnotetext{
${ }^{138}$ A $0{ }^{\circ} \mathrm{C}$ se obtuvo una mezcla $1: 1$ de 7 y $\mathbf{1 b}$.

${ }^{139}$ Por encima de esta temperatura se esperaría la formación de bencino si se formasen las correspondientes especies dilitiadas 2b. Ver: D. R. Reavill, K. Richardson St., Synth. Commun. 1990, 20, 1423.
} 
satisfactorios. Así la reacción de metalación de $\mathbf{1 b}$ no tuvo lugar por debajo de $-40{ }^{\circ} \mathrm{C}$, mientras que al permitir que la mezcla de reacción alcanzase temperaturas más altas se obtuvieron productos de descomposición. A $0{ }^{\circ} \mathrm{C}$ se observó conversión completa del sustrato de partida en el crudo de reacción, probablemente debido a una orto-litiación y posterior formación de bencino que condujo a una mezcla difícil de tratar (Esquema 1.62).

Posteriormente, intentamos aplicar la conocida capacidad directora del grupo Boc ${ }^{33}$ a la síntesis de la 3-cloro-2-yodoanilina empleando la $N$-(Boc)-3-cloroanilina 8a como sustrato de partida. En este caso, el tratamiento con LDA en THF condujo a un resultado distinto. A baja temperatura el sustrato de partida permaneció intacto, mientras que al calentar la mezcla de reacción empezó a formarse la $N$-(Boc)anilina 9 , y al alcanzarse $0{ }^{\circ} \mathrm{C}$ se pudo aislar esta última anilina con un $75 \%$ de rendimiento (Esquema 1.62). La formación de 9 a partir de 8a, mediante una reducción formal, podría ser justificada por la generación de una especie bencínica intermedia y un posterior ataque de un hidruro derivado de la $i$ $\mathrm{Pr}_{2} \mathrm{NH}$.

Es conocido que el $t$-BuLi es capaz de abstraer un protón de una posición doblemente activada en los isómeros meta de las $N$-(Boc)fluoro- y cloroanilinas, incluso a baja temperatura, y también se ha descrito que la posterior eliminación del haluro de litio correspondiente genera un intermedio bencínico que da lugar a derivados del 7litiobenzoxazol. ${ }^{140} \mathrm{Sin}$ embargo, debido a que esta reacción no había sido llevada a cabo con $\mathbf{8 a}$, decidimos ensayar su metalación con $t$-BuLi y posterior reacción con yodo como electrófilo. Así, se adicionó $t$-BuLi sobre una disolución de 8a en THF a $-78{ }^{\circ} \mathrm{C}$ y se dejó evolucionar la mezcla de reacción a $-20{ }^{\circ} \mathrm{C}$ durante 1 hora, seguida del tratamiento con yodo a baja temperatura. Como era de preveer en base a resultados previos, no se pudo evitar la formación del intermedio arínico 12, obteniéndose finalmente los yodobenzoxazoles 10 y 11, los cuales fueron aislados con rendimientos del $18 \%$ y $38 \%$, respectivamente (Esquema 1.62). Se propone el siguiente mecanismo para explicar la formación de 10 y 11 a partir del intermedio bencínico 12. Una primera ciclación aniónica intramolecular en el intermedio $\mathbf{1 2}$ daría lugar al intermedio litiado 2-t-butoxi-7litiobenzoxazol. Posteriormente, el ataque nucleofílico del exceso de base $(t$-BuLi) presente

${ }^{140}$ Ver referencias (137) y (139). Ver también: a) L. E. Fisher, J. M. Caroon, Synth. Commun. 1989, 19, 233. b) S. Takagishi, G. Katsoulos, M. Schlosser, Synlett 1992, 360. Para información relativa a los derivados de 7 litiobenzotiazol, ver: c) P. Stanetty, B. Krumpak, J. Org. Chem. 1996, 61, 5130. d) R. A. Fairhurst, D. Janus, A. Lawrence, Org. Lett. 2005, 7, 4697. 
en el medio de reacción a este intermedio conduciría a $\mathbf{1 0}$ tras la reacción con el electrófilo. La formación de $\mathbf{1 1}$ podría ser debida a la eliminación de $t$-BuOH en el compuesto 10, bajo las condiciones de reacción (Esquema 1.62).
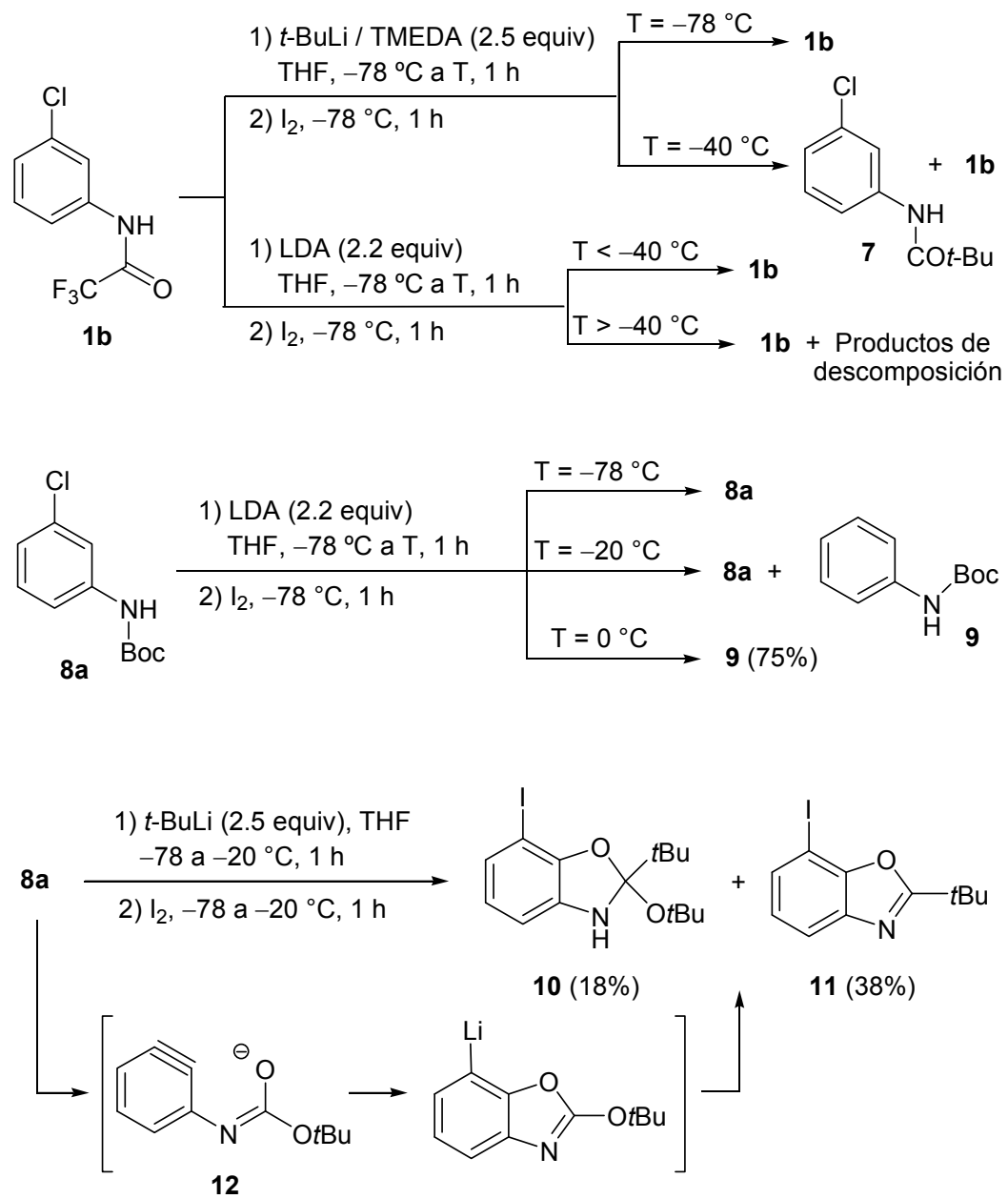

Esquema 1.62

\section{a.2 Estudio de la reacción de orto-zincación en derivados de 3-haloanilinas}

Como se ha descrito en los Antecedentes Bibliográficos Generales, en los últimos años se ha desarrollado una química basada en el empleo de complejos "ato" heterometálicos de $\mathrm{Zn}, \mathrm{Al}$, ó Mg para llevar a cabo reacciones de orto-metalación en compuestos aromáticos polifuncionalizados bajo condiciones suaves y con alta quimioselectividad. Este hecho nos 
llevó a proponer una posible ruta sintética para la obtención de derivados de 3-cloro-2yodoanilina consistente en una reacción de orto-zincación sobre derivados de 3-cloroanilina que contuvieran un grupo director en su estructura, seguida de la adición de yodo como electrófilo.

Se emplearon la $N$-(Boc)-3-cloroanilina $8 \mathbf{8 a}$, la $N, N$-di-t-butoxicarbonil-3cloroanilina 8b y la 3-cloro- $N, N$-dimetilanilina $8 \mathbf{c}$ como sustratos de partida siguiendo el procedimiento que se describe a continuación. ${ }^{40} \mathrm{El}$ primer paso consistió en la preparación del organozincato $t$ - $\mathrm{Bu}_{2} \mathrm{Zn}$ (TMP)Li por adición de di-t-butilzinc a una disolución de LiTMP en THF a baja temperatura. Una vez formado el reactivo organozíncico, se adicionó 8 a la mezcla de reacción y transcurrido un tiempo (t), yodo como electrófilo (Esquema 1.63).

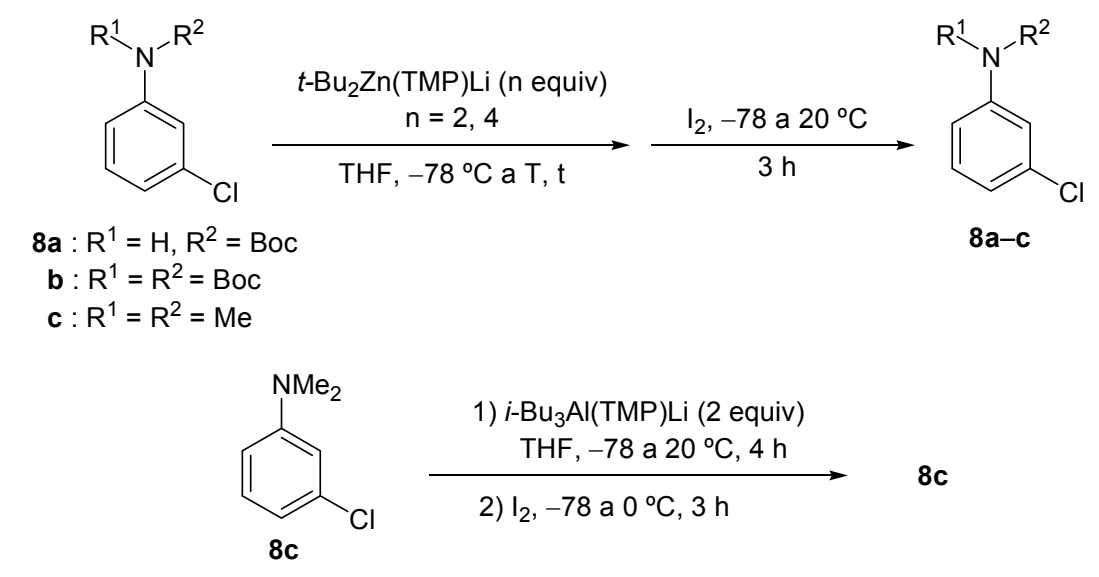

Esquema 1.63

En general, la utilización de compuestos organozíncicos como agentes metalantes requiere el uso de temperaturas más altas y de mayores tiempos de reacción que los necesarios en el caso de emplear reactivos organolíticos. Se ensayaron temperaturas entre -45 y $20^{\circ} \mathrm{C}$, tiempos de entre 3 y 18 horas y exceso de agente metalante entre 2 y 4 equiv. En todas las experiencias llevadas a cabo en este estudio, tras el tratamiento con yodo y posterior hidrólisis de la mezcla de reacción, se aislaron los productos de partida $\mathbf{8 a}-\mathbf{c}$, sin detectarse la formación de los derivados de las 3-cloro-2-yodoanilinas buscados (Esquema 1.63). Por último, también se ensayó la reacción de la amina $8 \mathrm{c}$ con el aluminato (i$\mathrm{Bu}_{3} \mathrm{Al}(\mathrm{TMP}) \mathrm{Li}$ ), análogo al de zinc, aunque en este caso la metalación tampoco fue efectiva. 
En todos los ensayos realizados se recuperó el reactivo de partida sin experimentar cambio alguno (Esquema 1.63).

Tras nuestro estudio podemos concluir que la metodología de orto-litiación aplicada a derivados de 3-haloanilina sólo es eficiente para la preparación de 3-fluoro-2-haloanilinas, no siendo una estrategia de utilidad para la síntesis del resto de 2,3-dihaloanilinas. Por otro lado también hemos comprobado que, bajo las condiciones ensayadas, los organozincatos de litio no son agentes metalantes lo suficientemente fuertes para llevar a cabo la ortometalación en derivados de 3-haloanilina.

\section{b) Reacción de metalación en 3-halonitrobencenos}

Habiendo visto que la estrategia de orto-metalación aplicada a la síntesis de 2,3dihaloanilinas sólo nos permite acceder a 3-fluoro-2-haloanilinas, a continuación nos centramos en la posibilidad de poder preparar 2,3-dihalonitrobencenos (ruta b, Esquema 1.60). Daugulis y colaboradores publicaron la halogenación de compuestos con hidrógenos ácidos en condiciones básicas y describieron la síntesis del 2-bromo-1-fluoro-3-nitrobenceno 14ab por tratamiento del 1-fluoro-3-nitrobenceno 13a con $t$-butóxido de litio y tetrabromuro de carbono en DMF. ${ }^{141}$ Nosotros fuimos capaces de reproducir este resultado y, además, intentamos extender esta metodología a la preparación de otros 2,3-dihalonitrobencenos 14. Aunque pudimos obtener el 2-cloro-1-fluoro-3-nitrobenceno 14ac con alto rendimiento empleando hexacloroetano como electrófilo, al usar yodo como electrófilo, con el fin de preparar el 1-fluoro-3-nitro-2-yodobenceno 14aa, bajo las mismas condiciones de reacción se observó una conversión muy pequeña $(<10 \%)$ (Esquema 1.64). Una vez preparados los 2,3-dihalonitrobencenos 14ab y 14ac, a partir del 1-fluoro-3-nitrobenceno 13a (disponible comercialmente), se pudieron sintetizar las correspondientes anilinas 6ab y 6ac con altos rendimientos, por reducción con $\mathrm{Fe}$ en etanol acidificado con $\mathrm{HCl}$ (Esquema 1.64). ${ }^{90,142}$

\footnotetext{
141 a) H.-Q. Do, O. Daugulis, Org. Lett. 2009, 11, 421. b) I. Popov, H.-Q. Do, O. Daugulis, J. Org. Chem. 2009, 74,8309 .

${ }^{142}$ Y. Liu, Y. Lu, M. Prashad, O. Repic, T. J. Blacklock, Adv. Synth. Catal. 2005, 347, 217.
} 
Sin embargo, cuando se intentó extender esta metodología al 1-cloro-3-nitrobenceno 13b, su tratamiento con $\mathrm{LiO} t$-Bu y tetrabromuro de carbono, bajo las mismas condiciones de reacción, permitió aislar únicamente un $13 \%$ del 2-bromo-1-cloro-3-nitrobenceno $\mathbf{1 4 b b},{ }^{143}$ demostrándose así que la desprotonación de 13b no era tan eficiente como la de 13a (Esquema 1.64). Además, también intentamos metalar 13b empleando (TMP) ${ }_{2} \mathrm{Zn} \cdot 2 \mathrm{MgCl}_{2} \cdot 2 \mathrm{LiCl}$ como base, reactivo que había sido descrito por Knochel y colaboradores para llevar a cabo una zincación selectiva de arenos y heteroarenos, tales como el 2-nitrobenzo[b]furano. ${ }^{144} \mathrm{Sin}$ embargo, la zincación de $\mathbf{1 3 b}$ no fue posible con esta base, incluso a temperaturas de $0{ }^{\circ} \mathrm{C}$ (Esquema 1.64).<smiles>O=[N+]([O-])c1cccc(F)c1</smiles>

$13 a$<smiles>[X]c1c(F)cccc1[N+](=O)[O-]</smiles>
$\mathrm{X}^{+}=\mathrm{I}_{2}, \mathrm{CBr}_{4}, \mathrm{C}_{2} \mathrm{Cl}_{6}$

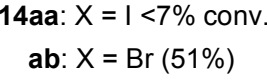

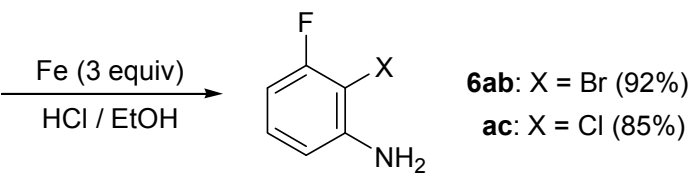<smiles>N#[N+]c1cccc(Cl)c1</smiles>

$13 b$

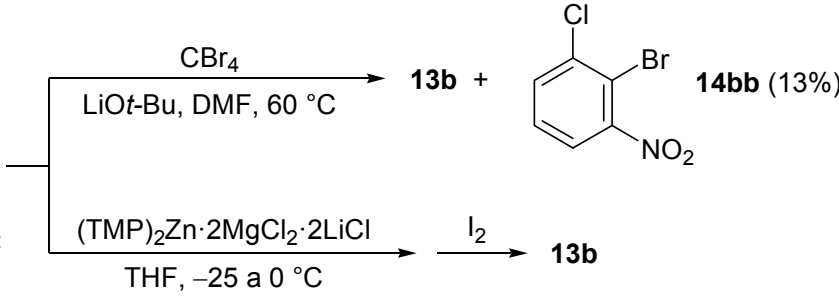

Esquema 1.64

\footnotetext{
${ }^{143}$ El 2-bromo-1-cloro-3-nitrobenceno también ha sido preparado por diazotación a partir de la 2-cloro-6nitroanilina, la cual fue obtenida como isómero minoritario (14\% de rendimiento) en la cloración de $o$ nitroanilina. Ver: B. Liedholm, Acta Chem. Scand. 1969, 23, 3175.

${ }^{144}$ S. H. Wunderlich, P. Knochel, Angew. Chem., Int. Ed. 2007, 46, 7685.
} 
Por lo tanto, la reacción de metalación del 1-fluoro-3-nitrobenceno 13a empleando $\mathrm{LiO}$ - $\mathrm{Bu}$, seguida de la adición del correspondiente electrófilo halogenado condujo a la preparación de los dihalonitroderivados 14, los cuales permitieron sintetizar, tras su posterior reducción, las 3-fluoro-2-haloanilinas 6ab y 6ac. Sin embargo, en el caso de partir del 1-cloro-3-nitrobenceno 13b, que contiene hidrógenos menos ácidos en su estructura, su metalación no resultó eficiente de cara a la preparación de 1-cloro-2-halo-3-nitrobencenos.

\section{c) Preparación de 2,3-dihaloanilinas a partir de derivados de 2,3-dihalofenoles}

Teniendo en cuenta que sólo se han podido preparar las 2-halo-3-fluoroanilinas 6aa-ac mediante las dos primeras aproximaciones (Esquema 1.60, rutas (a) y (b)) y, aprovechando la metodología puesta a punto por nuestro grupo de investigación para la síntesis de 2,3-dihalofenoles, ${ }^{72}$ nos planteamos utilizar estos compuestos como sustratos de partida para acceder a las 2,3-dihaloanilinas 6 (Esquema 1.60, ruta (c)).

Como se ha comentado en los Antecedentes Bibliográficos de este Capítulo, la conversión directa de fenoles en anilinas representa una transformación compleja y se han descrito pocos métodos generales para llevar a cabo esta reacción. En los últimos años, los acoplamientos de aminas con triflatos de arilo o tosilatos, catalizados por paladio, han supuesto un importante avance en este campo. Sin embargo, los haluros de arilo también participan en las reacciones de formación de enlaces $\mathrm{C}-\mathrm{N}$ catalizadas por metales de transición, ${ }^{145}$ por lo tanto, el empleo de esta estrategia no sería posible para nuestros 2,3dihalofenoles. Además de los procedimientos catalizados por paladio y cobre, el reagrupamiento de Smiles puede ser considerado una buena alternativa para la preparación de $N$-arilaminas a partir de fenoles, especialmente si se emplean fenoles con grupos electrón atractores en su estructura como sustratos de partida. Así pensamos que este reagrupamiento podría ser una estrategia adecuada a partir de la cual desarrollar una ruta sintética eficiente para obtener las 2,3-dihaloanilinas (Esquema 1.65).

${ }^{145}$ D. S. Surry, S. L. Buchwald, Angew. Chem., Int. Ed. 2008, 47, 6338. 


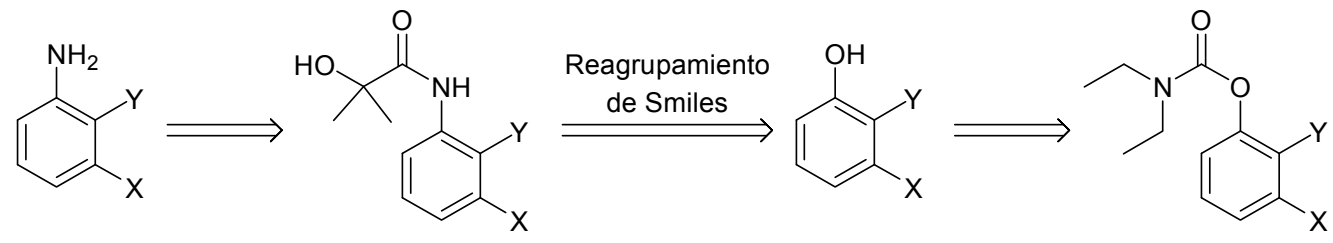

\section{Esquema 1.65}

De acuerdo con este análisis retrosintético, las 2,3-dihaloanilinas podrían ser accesibles mediante la desprotección de las correspondientes 2,3-dihaloanilidas, las cuales se podrían preparar a partir de los carbamatos de 2,3-dihalofenilo utilizando un reagrupamiento de Smiles como paso clave del proceso. Por lo tanto, la ruta sintética propuesta implicaría tres pasos diferenciados que se describirán a continuación:

\section{c.1 Preparación de los N,N-dietilcarbamatos de 2,3-dihalofenilo 17}

Una reacción de orto-litiación sobre los carbamatos de $O$-3-halofenilo 15, seguida de la adición del correspondiente electrófilo, permitió obtener los carbamatos de 2,3dihalofenilo 17. Inicialmente, para este proceso se empleaban distintos agentes de metalación dependiendo del carbamato 15 de partida. Así, para los carbamatos de 3-fluoro y 3 -clorofenilo 15a y 15b la $o$-litiación se realizaba por tratamiento con exceso de $s$-BuLi en THF utilizando TMEDA como codisolvente. Sin embargo, las condiciones óptimas para llevar a cabo la $o$-litiación de los carbamatos de 3-bromo y 3-yodofenilo $\mathbf{1 5 c}$ y $\mathbf{1 5 d}$ eran el empleo de 1.1 equiv. de LDA a $-78{ }^{\circ} \mathrm{C}$ durante 30 minutos. ${ }^{72}$ Una reducción de los tiempos de reacción conducía a una metalación de $\mathbf{1 5 c}$ y $\mathbf{1 5 d}$ incompleta.

Como novedad en este trabajo, encontramos que estas últimas condiciones (LDA, $-78{ }^{\circ} \mathrm{C}$ durante 30 minutos) pueden ser empleadas para todos los $O$-carbamatos $\mathbf{1 5}$, independientemente del átomo de halógeno de la posición 3 (Tabla 1.1). Esta modificación del procedimiento presenta ventajas desde el punto de vista experimental debido a que no es necesario utilizar TMEDA como codisolvente, evitándose así su proceso de secado y destilado. 
Tabla 1.1 Preparación de los carbamatos de $O-2,3$-dihalofenilo 17

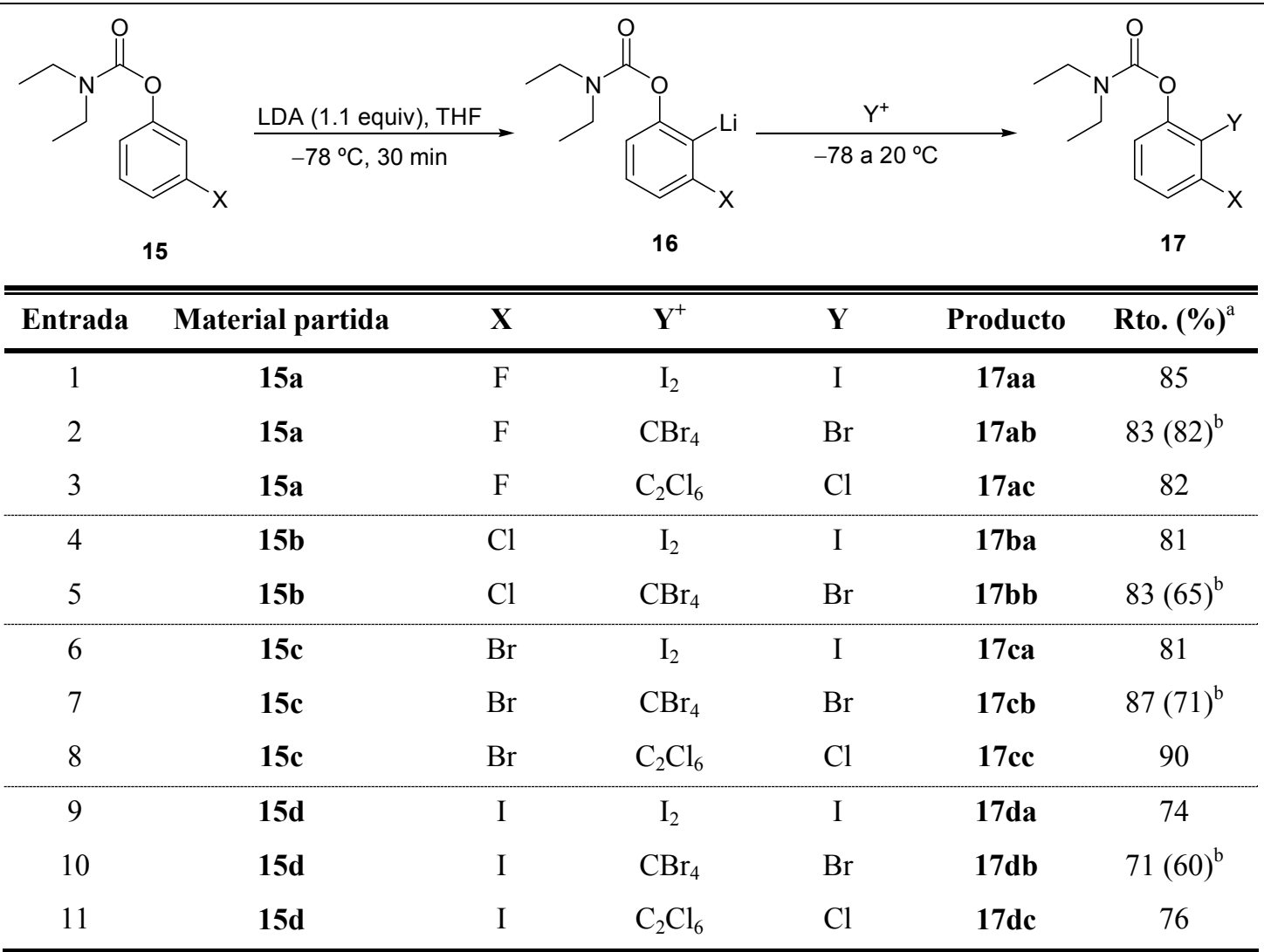

${ }^{\mathrm{a}}$ Rendimiento en producto aislado referido a los carbamatos de partida 15. ${ }^{\mathrm{b}} \mathrm{El}$ rendimiento entre paréntesis se refiere al rendimiento de $\mathbf{1 7}$ empleando 1,2-dibromoetano como electrófilo.

Además, también comprobamos que para la introducción de bromo como electrófilo se obtenían mejores resultados empleando tetrabromuro de carbono como reactivo electrofílico comparado con el 1,2-dibromoetano, el cual había sido utilizado anteriormente en nuestro grupo. Los rendimientos para la síntesis de los $O$-2-bromo-3-halofenilcarbamatos $17 \mathbf{b b}, \mathbf{1 7} \mathbf{c b}$ y $17 \mathbf{d b}$ fueron mejorados hasta el $83 \%, 87 \%$ y $71 \%$, respectivamente, mediante el empleo de tetrabromuro de carbono (Tabla 1.1, entradas 5, 7 y 10). Esta mejora en el rendimiento puede ser explicada teniendo en cuenta que cuando se utiliza 1,2-dibromoetano como electrófilo puede tener lugar un proceso competitivo de protonación del intermedio litiado 16, obteniéndose así una mezcla de los correspondientes carbamatos 15 y 17. Este hecho podría deberse al alto impedimento estérico del anión intermedio $\mathbf{1 6}$ que puede 
preferir reaccionar con el hidrógeno (camino a) que con el átomo de bromo (camino b) (Esquema 1.66).

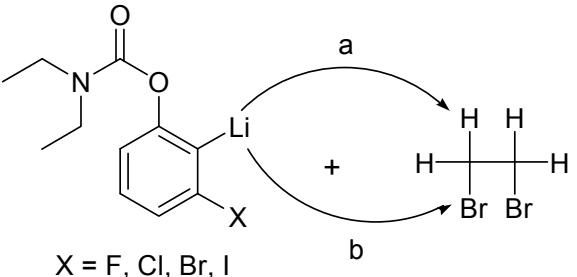

16

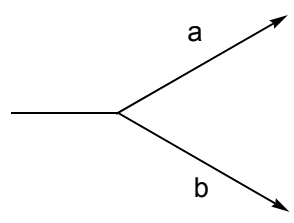

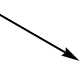<smiles>[X]c1cccc(OC(=O)N(CC)CC)c1[1H]</smiles>

15<smiles>[X]c1cccc(OC(=O)N(CC)CC)c1Br</smiles>

17

\section{Esquema 1.66}

\section{c.1.1 Estudio de la estabilidad de los carbamatos orto-litiados $\mathbf{1 6}$}

Como se ha descrito en los Antecedentes Generales los $N, N$-dimetilcarbamatos de $\mathrm{O}$-arilo orto-litiados son inestables, teniendo lugar rápidamente un reagrupamiento aniónico de tipo orto-Fries. ${ }^{2 c}$ En el caso de los $N, N$-dietilcarbamatos se puede evitar este reagrupamiento controlando la temperatura (Esquema 1.67). ${ }^{13}$<smiles>CCNC(=O)Oc1ccccc1</smiles><smiles>CCNC(=O)Oc1ccccc1-c1ccc(OC)c(Cl)c1</smiles><smiles>[3H]CNC(=O)c1ccccc1OCC</smiles><smiles>CCNC(=O)c1ccccc1O</smiles>

\section{Esquema 1.67}

Por lo tanto, nos planteamos el estudio de la estabilidad de los carbamatos ortolitiados 16. En primer lugar tratamos los carbamatos de 3-fluoro y 3 -clorofenilo $\mathbf{1 5 a}$ y $\mathbf{1 5 b}$ con LDA. La adición se llevó a cabo a $-78{ }^{\circ} \mathrm{C}$ y tras 10 minutos a esta temperatura se dejó que la mezcla de reacción evolucionara hasta temperatura ambiente durante 3 horas, seguida de su posterior hidrólisis. La purificación del crudo de reacción permitió aislar 
exclusivamente los fenoles 18a y $\mathbf{1 8 b}$. Esto nos indica que los correspondientes aniones 16a,b son inestables al subir la temperatura experimentando el reagrupamiento de orto-Fries (Esquema 1.68).

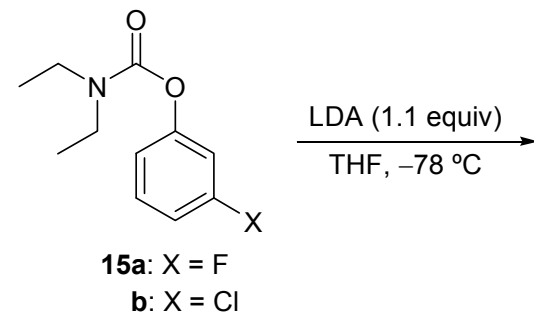

b: $\mathrm{X}=\mathrm{Cl}$

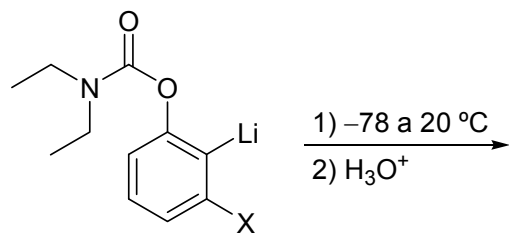

$16 a, b$

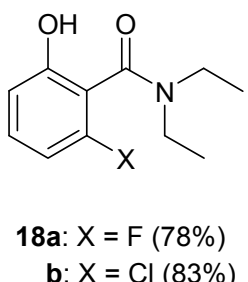

b: $\mathrm{X}=\mathrm{Cl}(83 \%)$

\section{Esquema 1.68}

Sin embargo, la metalación de los carbamatos de 3-bromo y 3-yodofenilo 15 c y $\mathbf{1 5 d}$ bajo las mismas condiciones de reacción anteriormente descritas condujo a un resultado diferente.

Así, para el carbamato de 3-bromofenilo $15 \mathrm{c}$ se adicionó la LDA a $-78^{\circ} \mathrm{C}$ y tras 10 minutos a esta temperatura se dejó que la mezcla de reacción evolucionase hasta temperatura ambiente durante 3 horas, seguida de su posterior hidrólisis. En estas condiciones se observó, por análisis de una alícuota del crudo de reacción por cromatografía de gases acoplada con espectrometría de masas (CG-EM), la formación de un nuevo producto 20 que presentaba un $\mathrm{M}^{+}=462$. La purificación por cromatografía de columna permitió aislar un $20 \%$ del producto orto-Fries $18 c$ y un $30 \%$ del nuevo compuesto 20 . Su formación se podría explicar por reacción del carbamato orto-litiado $\mathbf{1 6 c}$ con el correspondiente arino, formado por eliminación de $\mathrm{LiBr}$ a partir del propio anión 16c, generándose así un intermedio biarílico litiado 19. A continuación, un reagrupamiento ortoFries conduciría al compuesto finalmente aislado 20 (Esquema 1.69). Este resultado pone de maniesto que la temperatura a la cual el carbamato orto-litiado 16c experimenta el reagrupamiento de $o$-Fries es del mismo orden que la temperatura a la cual $\mathbf{1 6 c}$ elimina $\mathrm{LiBr}$, conduciendo a la formación del correspondiente bencino.

En el caso de partir del carbamato de 3-yodofenilo 15d, y llevando a cabo la reacción de $o$-litiación en las mismas condiciones de reacción, se obtuvo una mezcla en una proporción aproximada (1/1) del compuesto 21 y del bifenilo 22 . La formación de 21 se explicaría por adición de LDA al derivado de bencino, proveniente de la eliminación de LiI 
en el carbamato $o$-litiado 16d, seguido de un reagrupamiento de $o$-Fries. El bifenilo 22 presentaría una estructura análoga al obtenido al emplear el carbamato de 3-bromofenilo 15c. Tras purificación de la mezcla se aisló por cromatografía de columna un $25 \%$ de 21 y un $25 \%$ de 22 (Esquema 1.69). La obtención de los productos 21 y 22, sin observarse la formación de 18d, nos indica que la temperatura a la cual 16d experimenta la formación de bencino es inferior que la temperatura a la cual se produce el reagrupamiento de $o$ Fries.
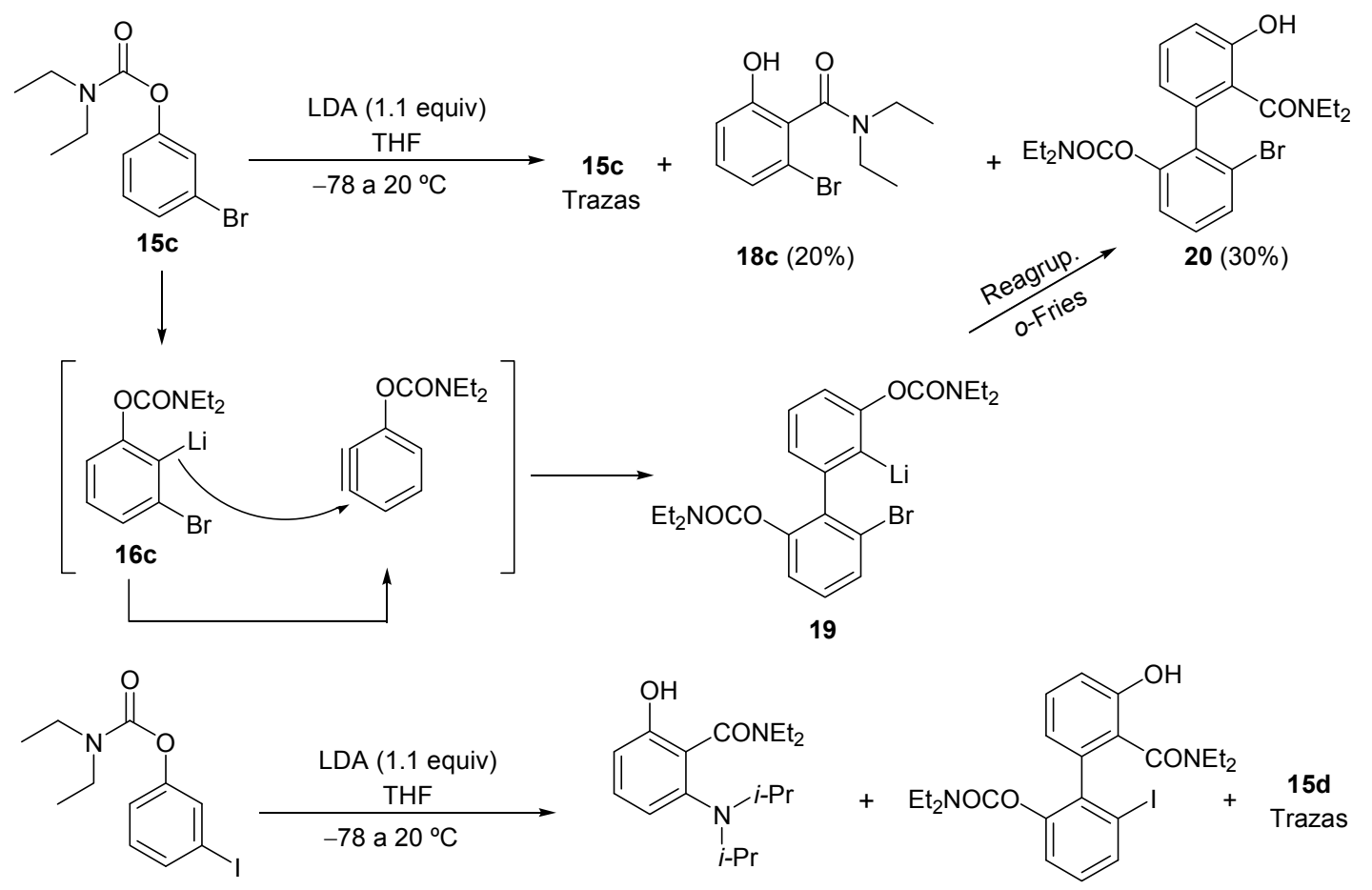

$15 d$<smiles>[3H][3H]</smiles><smiles></smiles><smiles>CCOc1cccc(N(C(C)C)C(C)C)c1Cl</smiles>

Esquema 1.69 
Este estudio demuestra la gran importancia del control de la temperatura de reacción en la metalación de los carbamatos de $O$-3-halofenilo 15 para evitar otras posibles reacciones competitivas.

c.2 Síntesis de las $N$-(2,3-dihalofenil)-2-hidroxi-2-metilpropanamidas $\mathbf{2 5}$. $\underline{\text { Reagrupamiento de Smiles }}$

Una vez sintetizados los carbamatos de 2,3-dihalofenilo 17, éstos se utilizaron como productos de partida en la obtención de las $N$-(2,3-dihalofenil)-2-hidroxi-2metilpropanamidas 25 empleando el reagrupamiento de Smiles. El primer paso consistió en la obtención de los 2,3-dihalofenoles 23 por hidrólisis básica de los carbamatos 17 con $\mathrm{NaOH}$ en exceso. El final de la hidrólisis se determinó mediante el análisis de alícuotas de reacción por CG-EM. Tras un proceso de extracción, dichos fenoles no fueron posteriormente purificados debido a que su pureza era suficiente para continuar el proceso sintético (Esquema 1.70).

A continuación, se llevó a cabo la alquilación de los correspondientes 2,3dihalofenoles 23 por tratamiento con exceso de $\mathrm{NaOH}$, en DMF como disolvente, seguido de la adición de un exceso de la 2-bromo-2-metilpropanamida. ${ }^{146}$ Tras 2 horas de reacción a temperatura ambiente se aislaron las 2-ariloxi-2-metilpropanamidas $\mathbf{2 4}$ con altos rendimientos mediante simple adición de agua a la mezcla de reacción y filtración del compuesto cristalizado (Esquema 1.70 y Tabla 1.2).

Hay que destacar que, sin necesidad de aislar los compuestos 24, la adición de un exceso de $\mathrm{NaOH}$ a la mezcla de reacción y posterior calentamiento a $60{ }^{\circ} \mathrm{C}$ durante 2 horas permitió obtener las $\mathrm{N}$-(2,3-dihalofenil)-2-hidroxi-2-metilpropanamidas $\mathbf{2 5}$ con altos rendimientos referidos a los carbamatos de partida 17 (Esquema 1.70 y Tabla 1.2). De esta forma, las 2,3-dihaloanilidas $\mathbf{2 5}$ pudieron ser sintetizadas de forma eficiente a partir de los 2,3-dihalofenilcarbamatos 17 en un proceso "two pot" en tres pasos (hidrólisis del carbamato-alquilación del fenol-reagrupamiento). Además, la simple adición de agua al final de la reacción provocó la cristalización de las anilidas $\mathbf{2 5}$ de la mezcla de reacción, las cuales se aislaron con pureza suficiente por simple filtración, evitándose así una posterior purificación cromatográfica.

\footnotetext{
${ }^{146}$ Se preparó a partir de bromuro de 2-bromo-2-metilpropanoílo por adición de hidróxido amónico acuoso (25\%).
} 


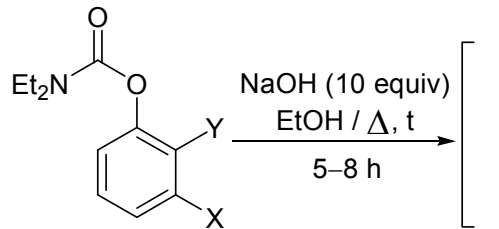

17

$\mathrm{X}=\mathrm{F}, \mathrm{Cl}, \mathrm{Br}, \mathrm{I}$

$\mathrm{Y}=\mathrm{Cl}, \mathrm{Br}, \mathrm{I}$<smiles>[X]c1cccc(O)c1I</smiles>

1) $\mathrm{NaOH}$ (3 equiv), DMF, $20^{\circ} \mathrm{C}, 1 \mathrm{~h}$ 2) $\mathrm{BrC}(\mathrm{Me})_{2} \mathrm{CONH}_{2}$ (3 equiv), $2 \mathrm{~h}$

3) $\mathrm{NaOH}$ (9 equiv), $60^{\circ} \mathrm{C}, 2 \mathrm{~h}$

23

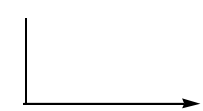<smiles>[X]c1cccc(NC(=O)C(C)(C)O)c1[X]</smiles>

25<smiles>[X]c1cccc(OC(C)(C)C(N)=O)c1[X]</smiles>

Esquema 1.70

Tabla 1.2. Preparación de las propanamidas 24 y dihaloanilidas 25

\begin{tabular}{|c|c|c|c|c|c|c|c|}
\hline Entrada & 17 & $\mathbf{X}$ & $\mathbf{Y}$ & 24 & Rto. $(\%)^{\mathrm{a}}$ & 25 & Rto. $(\%)^{\mathrm{c}}$ \\
\hline 1 & $17 \mathbf{a a}$ & F & I & $24 a a$ & 86 & $25 a a$ & 83 \\
\hline 2 & $17 \mathbf{a b}$ & $\mathrm{F}$ & $\mathrm{Br}$ & $24 a b$ & 83 & $25 a b$ & 77 \\
\hline 3 & $17 \mathrm{ac}$ & $\mathrm{F}$ & $\mathrm{Cl}$ & $24 a c$ & 82 & $25 a c$ & 76 \\
\hline 4 & $-{ }^{\mathrm{b}}$ & $\mathrm{Cl}$ & I & $24 \mathrm{ba}$ & 86 & $25 \mathrm{ba}$ & 82 \\
\hline 5 & $17 \mathrm{bb}$ & $\mathrm{Cl}$ & $\mathrm{Br}$ & $24 \mathrm{bb}$ & 80 & $25 \mathrm{bb}$ & 78 \\
\hline 6 & $17 \mathrm{bc}$ & $\mathrm{Cl}$ & $\mathrm{Cl}$ & $24 b c$ & 87 & $25 \mathrm{bc}$ & 84 \\
\hline 7 & $17 \mathrm{ca}$ & $\mathrm{Br}$ & I & $24 \mathrm{ca}$ & 85 & $25 \mathrm{ca}$ & 81 \\
\hline 8 & $17 \mathrm{cb}$ & $\mathrm{Br}$ & $\mathrm{Br}$ & $24 \mathrm{cb}$ & 86 & $25 \mathrm{cb}$ & 83 \\
\hline 9 & $17 \mathrm{cc}$ & $\mathrm{Br}$ & $\mathrm{Cl}$ & $24 \mathrm{cc}$ & 82 & $25 \mathrm{cc}$ & 77 \\
\hline 10 & $17 \mathrm{da}$ & I & I & $24 \mathrm{da}$ & 83 & $25 \mathrm{da}$ & 79 \\
\hline 11 & $17 \mathrm{db}$ & I & $\mathrm{Br}$ & $24 d b$ & 80 & $25 \mathrm{db}$ & 77 \\
\hline 12 & $17 \mathrm{dc}$ & I & $\mathrm{Cl}$ & $24 d c$ & 79 & $25 \mathrm{dc}$ & 75 \\
\hline
\end{tabular}

${ }^{a}$ Rendimiento en producto aislado referido a los carbamatos de partida 17. ${ }^{b}$ Se empleó el 2,3-diclorofenol comercial como producto de partida en lugar del correspondiente carbamato. ${ }^{\mathrm{c}}$ Rendimiento en producto aislado referido a los carbamatos de partida $\mathbf{1 7}$ sin aislar el intermedio 24 .

Por otro lado, y de acuerdo a la metodología desarrollada por Uchiyama y colaboradores, ${ }^{41}$ pensamos que otra alternativa sintética a la preparación de 2,3- 
dihalofenoles, podría consistir en la síntesis de los 3-halo-2-yodoanisoles 26a y 26b empleando una reacción de orto-zincación en los correspondientes 3-haloanisoles. Así, el 3cloroanisol y el 3-bromoanisol se adicionaron sobre una disolución de $t$ - $\mathrm{Bu}_{2} \mathrm{Zn}(\mathrm{TMP}) \mathrm{Li}$ en THF a $-78{ }^{\circ} \mathrm{C}$, preparado como se ha descrito anteriormente (apartado 1.3.1a.2, pág. 78),

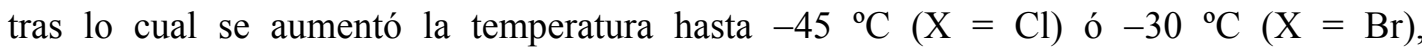
manteniéndose la agitación durante 12 horas. El tratamiento con yodo del arilzincato generado $^{147}$ condujo a los 3-halo-2-yodoanisoles 26a y 26b con buenos rendimientos, tras purificación por cromatografía de columna. Cabe destacar que se ha comprobado la reproducibilidad de estos resultados a una escala de 12 mmoles (Esquema 1.71).

Estos 2,3-dihaloanisoles $\mathbf{2 6}$ también resultaron ser materiales de partida útiles para preparar las 2,3-dihaloanilidas 25 ba y $25 \mathbf{c a}$ con altos rendimientos mediante un proceso "two pot" en tres pasos, análogo al ya descrito (desprotección mediada por $\mathrm{BBr}_{3}$-alquilación del fenol-reagrupamiento) (Esquema 1.71).

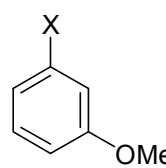

$$
\text { 1) } t \text { - } \mathrm{Bu}_{2} \mathrm{Zn}(\mathrm{TMP}) \mathrm{Li}, \mathrm{THF},-78^{\circ} \mathrm{C} \text { a T }
$$$$
\mathrm{T}=-45^{\circ} \mathrm{C}(\mathrm{X}=\mathrm{Cl})
$$$$
\mathrm{T}=-30^{\circ} \mathrm{C}(\mathrm{X}=\mathrm{Br})
$$

2) $I_{2}$, THF<smiles>[X]c1cccc(OC)c1I</smiles>

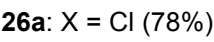<smiles>[X]c1cccc(OC)c1I</smiles>

26

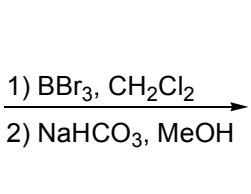
Me

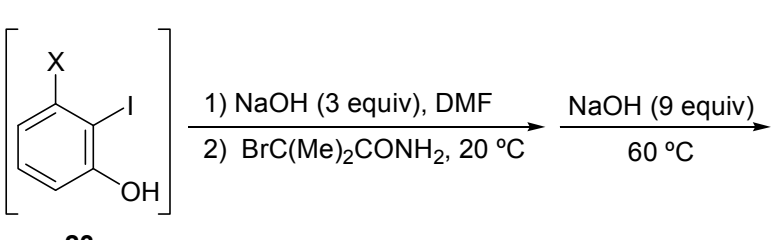

23

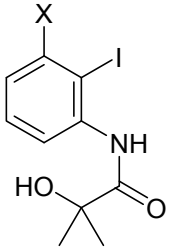

25ba: $\mathrm{X}=\mathrm{Cl}(86 \%)$ ca: $X=\operatorname{Br}(85 \%)$

\section{Esquema 1.71}

Se puede concluir que se ha desarrollado una estrategia sintética para la preparación de las anilidas 25 a partir de los carbamatos de $O-2,3$-dihalofenilo 17, basándonos en el reagrupamiento de Smiles como paso clave del proceso. Por otro lado, algunas de las anilidas $\mathbf{2 5}$ también se pudieron sintetizar empleando una secuencia análoga a partir de 3halo-2-yodoanisoles.

${ }^{147}$ R. Sanz, M. P. Castroviejo, V. Guilarte, A. Pérez, F. J. Fañanás, J. Org. Chem. 2007, 72, 5113. 


\section{c.3 Obtención de las 2,3-dihaloanilinas $\mathbf{6}$}

Una vez establecido un procedimiento viable y eficiente para acceder a las 2,3dihaloanilidas 25, y debido a la escasez de métodos para preparar las 2,3-dihaloanilinas, intentamos llevar a cabo su síntesis mediante hidrólisis de las correspondientes anilidas $\mathbf{2 5}$. Esta hidrólisis requiere de condiciones enérgicas al poseer un grupo amida en su estructura. ${ }^{148}$

Tabla 1.3. Síntesis de las 2,3-dihaloanilinas 6

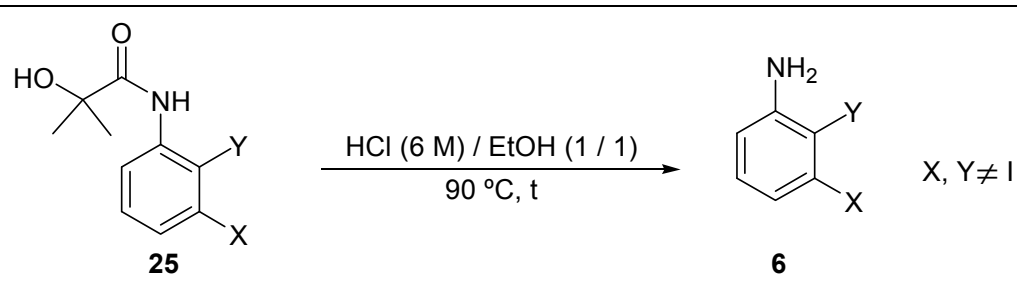

\begin{tabular}{ccccccc}
\hline \hline Entrada & Material partida & $\mathbf{X}$ & $\mathbf{Y}$ & $\mathbf{t}(\mathbf{h})$ & Producto & ${\text { Rto. }(\%)^{\mathrm{a}}}^{\mathrm{a}}$ \\
\hline 1 & $\mathbf{2 5 a b}$ & $\mathrm{F}$ & $\mathrm{Br}$ & 6 & $\mathbf{6 a b}$ & 89 \\
2 & $\mathbf{2 5 a c}$ & $\mathrm{F}$ & $\mathrm{Cl}$ & 6 & $\mathbf{6 a c}$ & $66^{\mathrm{b}}$ \\
\hline 3 & $\mathbf{2 5 b b}$ & $\mathrm{Cl}$ & $\mathrm{Br}$ & 6.5 & $\mathbf{6 b b}$ & 94 \\
4 & $\mathbf{2 5 b c}$ & $\mathrm{Cl}$ & $\mathrm{Cl}$ & 5 & $\mathbf{6 b c}$ & 90 \\
\hline 5 & $\mathbf{2 5 c b}$ & $\mathrm{Br}$ & $\mathrm{Br}$ & 5.5 & $\mathbf{6 c b}$ & 89 \\
6 & $\mathbf{2 5 c c}$ & $\mathrm{Br}$ & $\mathrm{Cl}$ & 6 & $\mathbf{6 c c}$ & 95 \\
\hline
\end{tabular}

${ }^{\mathrm{a}}$ Rendimiento en producto aislado referido a las anilidas de partida 25. ${ }^{\mathrm{b}}$ Rendimiento menor debido probablemente a su alta volatilidad.

Aprovechando que la reacción de preparación de las anilidas 25 se había llevado a cabo en medio básico, se ensayó su desprotección "in situ" tras el reagrupamiento de Smiles, sin más que adicionar una pequeña cantidad de agua a la mezcla de reacción y calentar a reflujo. Sin embargo, en tales condiciones básicas, incluso con tiempos de reacción de más de 20 horas, se recuperaron las anilidas $\mathbf{2 5}$ sin sufrir transformación alguna. Entonces decidimos ensayar condiciones fuertemente ácidas y encontramos que el tratamiento de las anilidas 25 con una mezcla de $\mathrm{HCl}(6 \mathrm{M}) / \mathrm{EtOH}(1 / 1)$ a $90{ }^{\circ} \mathrm{C}$ permitía obtener las anilinas 6 con altos rendimientos (Tabla 1.3). Desafortunadamente, las amidas

${ }^{148}$ J. Clayden, N. Greeves, S. Warren, P. Wothers, Organic Chemistry; Oxford University Press, 2001; p. 279. 
reagrupadas 25 que contenían yodo en su estructura no condujeron de forma limpia a las haloyodoanilinas esperadas debido a una pérdida parcial del átomo de yodo durante el transcurso de la reacción. Por ejemplo la 2,3-diyodoanilida 25da condujo a una mezcla de 2,3-diyodoanilina 6da y 3-yodoanilina en una proporción $1 / 2$ con un rendimiento global del $71 \%$ (Esquema 1.72). Por su parte, se obtuvo una mezcla en proporción aproximada $1 / 1.5$ de 3-cloro-2-yodoanilina 6ba y 3-cloroanilina, con un rendimiento global del $80 \%$, cuando se llevo a cabo la hidrólisis de la 3-cloro-2-yodoanilida 25ba (Esquema 1.72).<smiles>CC(C)(O)C(=O)Nc1cccc(I)c1I</smiles>

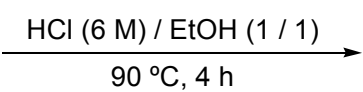<smiles>Nc1cccc(I)c1</smiles>
6da $(1 / 2)$

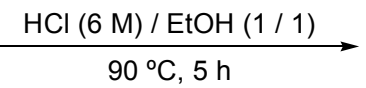<smiles>Nc1cccc(Cl)c1</smiles>
$6 \mathrm{ba}$

$(1 / 1.5)$

\section{Esquema 1.72}

Por lo tanto, hemos puesto a punto una nueva metodología, práctica y eficiente, para la preparación de 2,3-dihaloanilinas. Esta estrategia sintética supone una mejora cualitativa con respecto a los métodos descritos en la bibliografía para su preparación, basados en su mayoría en reacciones de sustitución aromática clásicas y poco selectivas. Además, se han podido obtener algunas de las 2,3-dihaloanilinas que no habían sido descritas en la bibliografía con anterioridad a este trabajo de investigación. 


\subsubsection{SÍNTESIS DE INDOLES SUSTITUIDOS}

Considerando el análisis retrosintético que habíamos planteado en la introducción del Capítulo para la síntesis de 4-haloindoles (Esquema 1.2), y habiendo desarrollado rutas adecuadas para acceder a las 2,3-dihaloanilidas 3 y $\mathbf{2 5}$, nuestro siguiente objetivo fue afrontar la preparación de una amplia variedad de 4-haloindoles. Así, los indoles 4funcionalizados se podrían obtener por ciclación de 2-alquinil-3-haloanilinas, las cuales se prepararían por un acoplamiento de Sonogashira selectivo de 2,3-dihaloanilinas con alquinos terminales (Esquema 1.73).<smiles>[R]c1cc2c([X])cccc2[nH]1</smiles><smiles>[R]C#Cc1c([X])cccc1N</smiles><smiles></smiles>

Esquema 1.73

\section{a) Reacción de Sonogashira de las anilidas 25}

Debido a las dificultades encontradas en la hidrólisis de las 2,3-dihaloanilidas 25 que contienen un átomo de yodo en su estructura, y a que el orden de reactividad de los halogenuros de arilo en acoplamientos con alquinos terminales resulta ser: $\mathrm{ArI}>\mathrm{ArBr}>>\mathrm{ArCl}$, se decidió llevar a cabo la reacción de Sonogashira empleando las 2-yodoanilidas $25 \mathbf{b a}$ y $\mathbf{2 5} \mathbf{c a}$, en lugar de las 2,3-dihaloanilinas 6 con otros halógenos distintos de yodo en su estructura.

En la bibliografía se han destrito numerosos ejemplos de la reacción de Sonogashira sobre diferentes halogenuros arílicos, pudiéndose considerar como condiciones estándar el empleo de un sistema catalítico formado por un complejo de paladio y $\mathrm{CuI}$ como cocatalizador, en presencia de una base. ${ }^{54}$

Estas condiciones estándar $\mathrm{PdCl}_{2}\left(\mathrm{PPh}_{3}\right)_{2}(5 \mathrm{~mol} \%) / \mathrm{CuI}(3 \mathrm{~mol} \%)$, sin necesidad de utilizar ligandos fosfina especiales, resultaron ser adecuadas para el acoplamiento selectivo con alquinos terminales a través del átomo de yodo en las 3-halo-2-yodoanilidas $25 \mathbf{b a}$ y $\mathbf{2 5} \mathbf{c a}$, a pesar de la presencia de un átomo de halógeno adicional y de que la posición ocupada por el yodo sea la más impedida estéricamente. Sin embargo, para evitar procesos de dialquinilación, en el caso de emplear la acetanilida $\mathbf{2 5 c a}$, la cual contiene un átomo de bromo en su estructura, se deben de controlar cuidadosamente las condiciones de reacción (Tabla 1.4). Se observó que 
cuando se llevaba a cabo el acoplamiento de Sonogashira de la anilida $25 \mathrm{ca}$ con 1.5 equiv. de distintos alquinos terminales, con sustituyentes tanto arílicos como alquílicos, a una temperatura de $80{ }^{\circ} \mathrm{C}$ y empleando el sistema catalítico $\mathrm{PdCl}_{2}\left(\mathrm{PPh}_{3}\right)_{2} / \mathrm{CuI}$, en todas estas experiencias se formaban pequeñas cantidades del producto resultante de la dialquinilación junto con la 2alquinil-3-bromoanilida esperada 27. Esto puede ser explicado considerando que una vez formado el compuesto $\mathbf{2 7}$, este puede acoplarse a través del átomo de bromo con el exceso de alquino presente en el medio de reacción. Después de realizar distintos experimentos variando la temperatura de reacción y la cantidad de alquino empleada, comprobamos que llevando a cabo la reacción a $50{ }^{\circ} \mathrm{C}$ con 1.2 equiv. de alquino se obtenía exclusivamente el compuesto 27 , evitándose así el proceso de dialquinilación (Tabla 1.4).

Tabla 1.4. Acoplamiento selectivo de las 3-halo-2-yodoanilidas 25

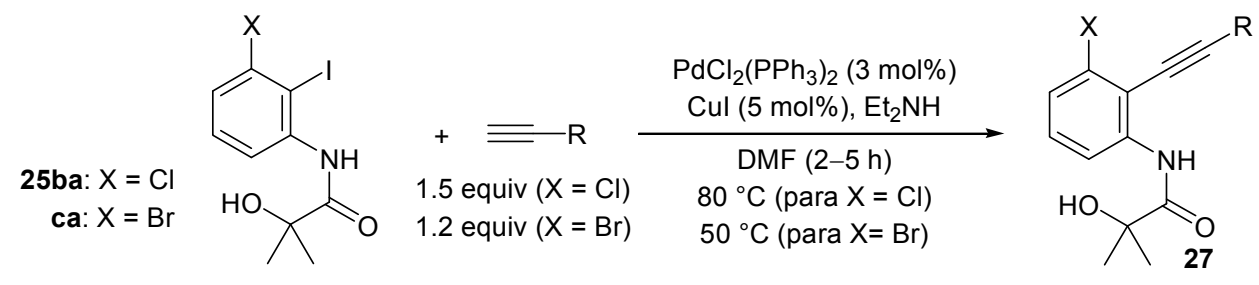

\begin{tabular}{ccccccc}
\hline \hline Entrada & Anilida partida & $\mathbf{X}$ & Alquino (R) & t (h) & Producto & ${\text { Rto. }(\mathbf{\%})^{\mathrm{a}}}^{\text {(h) }}$ \\
\hline 1 & $\mathbf{2 5 b a}$ & $\mathrm{Cl}$ & $\mathrm{Ph}$ & 2 & $\mathbf{2 7 b a}$ & 86 \\
2 & $\mathbf{2 5 b a}$ & $\mathrm{Cl}$ & $n-\mathrm{Bu}$ & 2.5 & $\mathbf{2 7 b b}$ & 90 \\
3 & $\mathbf{2 5 b a}$ & $\mathrm{Cl}$ & $n-\mathrm{C}_{5} \mathrm{H}_{11}$ & 2.5 & $\mathbf{2 7 b c}$ & 81 \\
4 & $\mathbf{2 5 b a}$ & $\mathrm{Cl}$ & $c-\mathrm{C}_{6} \mathrm{H}_{9}{ }^{\mathrm{b}}$ & 3 & $\mathbf{2 7 b d}$ & 80 \\
5 & $\mathbf{2 5 b a}$ & $\mathrm{Cl}$ & $\mathrm{SiMe}_{3}$ & $5.5^{\mathrm{c}}$ & $\mathbf{2 7 b e}$ & 81 \\
6 & $\mathbf{2 5 b a}$ & $\mathrm{Cl}$ & $\mathrm{Si}\left(i-\mathrm{Pr}_{3}\right.$ & $6^{\mathrm{c}}$ & $\mathbf{2 7 b f}$ & 80 \\
\hline 7 & $\mathbf{2 5 c a}$ & $\mathrm{Br}$ & $\mathrm{Ph}$ & 3.5 & $\mathbf{2 7 c a}$ & 80 \\
8 & $\mathbf{2 5 c a}$ & $\mathrm{Br}$ & $n-\mathrm{Bu}$ & 3.5 & $\mathbf{2 7 c b}$ & 85 \\
9 & $\mathbf{2 5 c a}$ & $\mathrm{Br}$ & $n-\mathrm{C}_{5} \mathrm{H}_{11}$ & 3.5 & $\mathbf{2 7 c c}$ & 79 \\
10 & $\mathbf{2 5 c a}$ & $\mathrm{Br}$ & $c-\mathrm{C}_{6} \mathrm{H}_{9}{ }^{\mathrm{b}}$ & 5 & $\mathbf{2 7 c d}$ & 86 \\
11 & $\mathbf{2 5 c a}$ & $\mathrm{Br}$ & $\mathrm{SiMe}_{3}$ & $3^{\mathrm{c}}$ & $\mathbf{2 7 c e}$ & 71 \\
12 & $\mathbf{2 5 c a}$ & $\mathrm{Br}$ & $3-\mathrm{Th}^{\mathrm{d}}$ & 3.5 & $\mathbf{2 7 c g}$ & 74 \\
\hline
\end{tabular}

${ }^{\mathrm{a}}$ Rendimiento en producto aislado referido a las acetanilidas de partida $25 .{ }^{\mathrm{b}} 1$-Ciclohexenilo. ${ }^{\mathrm{c}}$ Llevada a cabo a $40{ }^{\circ} \mathrm{C}$ debido a la volatilidad del trialquilsililacetileno. ${ }^{\mathrm{d}} 3$-Tienilo. 
Una amplia variedad de alquinos terminales, incluyendo alquinos aril-, alquil-, y trialquilsililsustituidos, pudieron ser acoplados con las anilidas $\mathbf{2 5}$ dando lugar a las 2alquinil-3-haloanilidas 27 con altos rendimientos (Tabla 1.4). En el caso de emplear trimetilsililacetileno o triisopropilsililacetileno como alquinos, la temperatura de reacción fue de $40{ }^{\circ} \mathrm{C}$ debido a la volatilidad que presentan estos compuestos (Tabla 1.4, entradas 5, 6 y 11). Una vez preparadas estas 2-alquinil-3-haloanilidas 27 nuestro siguiente objetivo fue la búsqueda de las condiciones óptimas de reacción para llevar a cabo la ciclación de $\mathbf{2 7}$ que conducirían a los 4-haloindoles 28.

\section{b) Estudio de las condiciones de ciclación de las 2-alquinil-3-haloanilidas 27}

De acuerdo con los métodos descritos en la literatura para la ciclación de derivados de 2-alquinilanilinas (ver Antecedentes de este Capítulo) pensamos que la ciclación de las alquinilanilidas 27 promovida por una base podría conducir a los 4-haloindoles. Así, nos planteamos realizar un estudio con el fin de optimizar la base, el disolvente y la temperatura de reacción para la ciclación de 27. Se tomó como sustrato modelo la $N$-[3-cloro-2(feniletinil)fenil]-2-hidroxi-2-metilpropanamida $\mathbf{2 7 b a}$ y se estudió su ciclación al 4-cloro-2fenil-1 $H$-indol 28ba (Tabla 1.5).

Tabla 1.5. Optimización de la reacción de ciclación de $\mathbf{2 7 b a}$

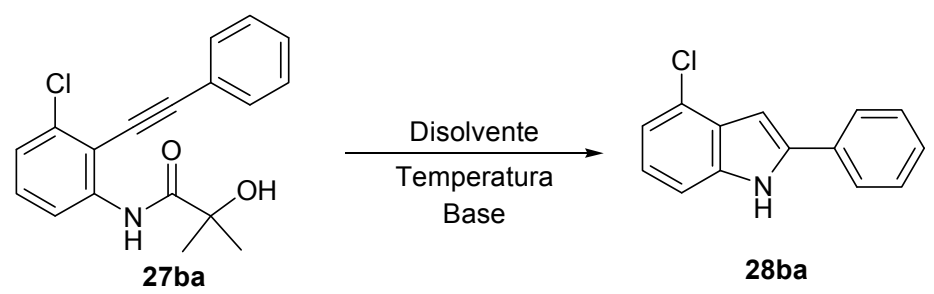

\begin{tabular}{cccccc}
\hline \hline Entrada & Disolvente & ${\text { Temperatura }\left({ }^{\circ} \mathbf{C}\right)}$ & Tiempo (h) & Base (5 equiv) & Rto. (\%) ${ }^{\mathrm{a}}$ \\
\hline 1 & Tolueno & 110 & 24 & $\mathrm{KO} t$ - $\mathrm{Bu}$ & 20 \\
2 & DMF & 110 & 24 & $\mathrm{KO} t-\mathrm{Bu}$ & 31 \\
3 & $\mathrm{DMF}$ & 120 & 24 & $\mathrm{KO} t-\mathrm{Bu}$ & 36 \\
4 & $\mathrm{DMF}$ & 140 & 24 & $\mathrm{KO} t$ - $\mathrm{Bu}$ & 40 \\
5 & $\mathrm{DMF}$ & 140 & 8 & $\mathrm{NaOH}$ & 86 \\
\hline
\end{tabular}

${ }^{\mathrm{a}}$ Rendimiento en producto aislado referido a la alquinilanilida de partida $\mathbf{2 7} \mathbf{b a}$. 
En primer lugar utilizamos $\mathrm{KO}$ - $\mathrm{Bu}$ como base, debido a que era el alcóxido metálico más empleado en la literatura en reacciones de heterociclación para la síntesis de indoles (ver Antecedentes Bibliográficos, apartado 1.2.4 b). Con esta base, estudiamos la influencia del disolvente y observamos que el empleo de DMF conducía a un rendimiento del 4-cloro-2-fenil-1 $H$-indol 28ba ligeramente superior que cuando se empleaba tolueno (entradas 1 y 2). A continuación, con DMF como disolvente estudiamos el efecto de la temperatura de reacción y comprobamos que se obtenían rendimientos ligeramente mayores al llevar a cabo la reacción a $130-140{ }^{\circ} \mathrm{C}$ (entradas 2,3 y 4). Como el rendimiento de esta ciclación no era muy alto (40\%), se ensayó el empleo de bases tipo hidróxido observándose que, gratamente, un exceso de $\mathrm{NaOH}$ permitía obtener $\mathbf{2 8 b a}$ con un $86 \%$ de rendimiento.

\section{c) Preparación de los $1 \mathrm{H}$-indoles 2-sustituidos 30}

Debido a la simplicidad y efectividad que presenta la reacción de ciclación de $\mathbf{2 7 b a}$, y al bajo coste y fácil manejo del $\mathrm{NaOH}$, decidimos extender esta metodología a la ciclación de una amplia variedad de 2-alquinilanilinas 29, con el fin de poner a punto un nuevo método para la síntesis de indoles 2-sustituidos. Las anilinas $\mathbf{2 9}$ fueron preparadas mediante un acoplamiento de Sonogashira de la 2-yodoanilina (comercialmente disponible) con distintos alquinos terminales, empleando catálisis de $\mathrm{Pd} / \mathrm{Cu}$ y dietilamina como base, en DMF como disolvente a temperatura ambiente.

Una vez preparadas estas anilinas, nuestro estudio comenzó con la optimización de la temperatura de reacción y la cantidad de base utilizada en la reacción de ciclación de las orto-alquinilanilinas 29. Se estudió la reacción modelo de la $o$-(1-hexinil)anilina 29a con $\mathrm{NaOH}$ en polvo, en DMF anhidra como disolvente, y bajo diferentes condiciones de reacción. Como se muestra en la Tabla 1.6 (entradas 1-3), la ciclación requiere de $140{ }^{\circ} \mathrm{C}$ para la conversión completa de la anilina 29a al 2-butilindol 30a. A esta temperatura la cantidad de base requerida puede ser reducida a 3 equiv., manteniéndose una conversión completa de 29a (Tabla 1.6, entrada 5). Sin embargo, una mayor reducción conduce a la presencia de 29a en el crudo de reacción, junto con el indol 30a (Tabla 1.6, entrada 4). Por lo tanto, las condiciones óptimas fueron la utilización 3 equiv. de $\mathrm{NaOH}$ a $140{ }^{\circ} \mathrm{C}$, aislándose un $85 \%$ de 30a (entrada 5). A continuación, debido a que el calentamiento empleando radiación de microondas ha comenzado a emerger como un método versátil para acelerar numerosos procesos químicos, consiguiendo reacciones más limpias y dando lugar 
a altos rendimientos en pocos minutos, ${ }^{149}$ decidimos ensayar esta ciclación bajo irradiación de microondas (Tabla 1.6, entradas 6-9). En estas condiciones la utilización de la $N, N$ dimetilacetamida anhidra (DMA) como disolvente condujo a una reacción más limpia que la DMF y, de esta forma, la ciclación completa de 29a tuvo lugar en tan sólo 8 minutos empleando 1.5 equiv. de $\mathrm{NaOH}$ a $170{ }^{\circ} \mathrm{C}$ (Tabla 1.6, entrada 9). Así, tras purificación por cromatografía de columna se aisló un $89 \%$ de 30a, rendimiento similar al obtenido empleando calentamiento convencional (entradas 5 y 9). Hay que destacar que el uso de microondas como método de calentamiento permitió una considerable reducción de la cantidad de base y tiempo necesario para esta ciclación. Todas estas reacciones fueron llevadas a cabo con 0.5 mmol de 29a en $2 \mathrm{~mL}$ de DMF o DMA anhidra.

Tabla 1.6. Optimización de las condiciones de ciclación de la $o$-1-hexinilanilina 29a

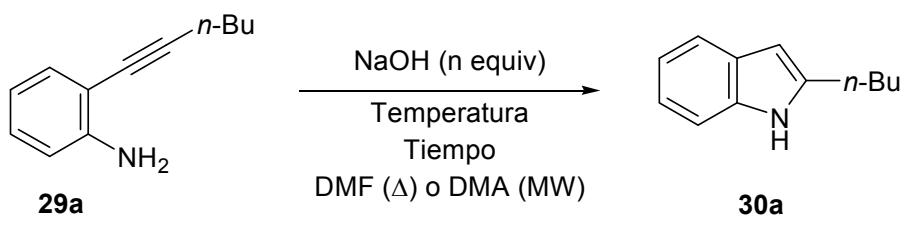

\begin{tabular}{ccccccc}
\hline \hline Entrada & $\begin{array}{c}\text { NaOH } \\
\text { (equiv.) }\end{array}$ & $\begin{array}{c}\text { Método } \\
\text { Calentamiento }\end{array}$ & T $\left({ }^{\circ} \mathbf{C}\right)$ & Tiempo & $\begin{array}{c}\text { Relación }^{\mathrm{a}} \\
\mathbf{3 0 a} / \mathbf{2 9 a}\end{array}$ & Rto. $(\%)^{\mathrm{b}}$ \\
\hline 1 & 6 & $\Delta$ & 20 & $2 \mathrm{~h}$ & $0 / 1$ & $-^{\mathrm{c}}$ \\
2 & 6 & $\Delta$ & 120 & $4 \mathrm{~h}$ & $2 / 1$ & $-^{\mathrm{c}}$ \\
3 & 6 & $\Delta$ & 140 & $2.5 \mathrm{~h}$ & $1 / 0$ & $-^{\mathrm{c}}$ \\
4 & 1.3 & $\Delta$ & 140 & $3 \mathrm{~h}$ & $3 / 1$ & $-^{\mathrm{c}}$ \\
5 & 3 & $\Delta$ & 140 & $2.5 \mathrm{~h}$ & $1 / 0$ & 85 \\
6 & 6 & MW & 140 & $10 \mathrm{~min}$ & $6 / 1$ & $-^{\mathrm{c}}$ \\
7 & 6 & $\mathrm{MW}$ & 170 & $7 \mathrm{~min}$ & $1 / 0$ & $-^{\mathrm{c}}$ \\
8 & 1 & $\mathrm{MW}$ & 170 & $14 \mathrm{~min}$ & $20 / 1$ & $-^{\mathrm{c}}$ \\
9 & 1.5 & $\mathrm{MW}$ & 170 & $8 \mathrm{~min}$ & $1 / 0$ & 89 \\
\hline
\end{tabular}

${ }^{\mathrm{a}}$ Determinado por análisis de los espectros de ${ }^{1} \mathrm{H}$ RMN del crudo de reacción. ${ }^{\mathrm{b}}$ Rendimiento de 30a aislado referido a la alquinilanilina 29a después de purificación mediante cromatografía de columna. ${ }^{\circ}$ No determinado.

149 J. P. Tierney, P. Lidström, Microwave Assisted Organic Synthesis; Blackwell: Oxford, 2005. 
Habiendo establecido las mejores condiciones de reacción para la ciclación de 29a, tanto utilizando calentamiento convencional como bajo radiación de microondas, pensamos en explorar el alcance de esta síntesis de indoles con respecto a los distintos sustituyentes en la posición $\mathrm{C}-2$ del indol final $\mathbf{3 0}$.

Así, la reacción de las correspondientes anilinas 29 empleando un exceso de $\mathrm{NaOH}$ (3 equiv. bajo condiciones térmicas o 1.5 equiv. bajo irradiación de microondas) en DMF anhidra (condiciones térmicas) o DMA anhidra (microondas) como disolvente y a la temperatura de $140{ }^{\circ} \mathrm{C}$ (condiciones térmicas) ó $170{ }^{\circ} \mathrm{C}$ (microondas), permitió preparar los indoles 2-sustituidos 30a-f con altos rendimientos (Tabla 1.7).

Tabla 1.7. Síntesis de los $1 H$-indoles 2 -sustituidos 30a-f mediante ciclación mediada por $\mathrm{NaOH}$ de las $o$-alquinilanilinas $\mathbf{2 9}^{\mathrm{a}}$<smiles>[R]C#Cc1ccccc1N</smiles>

29

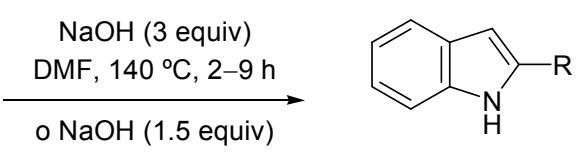

30

\begin{tabular}{ccccccc}
\hline \hline Entrada & Anilina partida & $\mathbf{R}$ & Calentamiento & Tiempo & Producto & Rto. (\%) \\
\hline 1 & $\mathbf{2 9 a}$ & $n-\mathrm{Bu}$ & $\Delta$ & $2.5 \mathrm{~h}$ & $\mathbf{3 0 a}$ & 85 \\
2 & $\mathbf{2 9 a}$ & $n-\mathrm{Bu}$ & $\mathrm{MW}$ & $8 \mathrm{~min}$ & $\mathbf{3 0 a}$ & 89 \\
3 & $\mathbf{2 9 b}$ & $\mathrm{Ph}$ & $\Delta$ & $9 \mathrm{~h}$ & $\mathbf{3 0 b}$ & 74 \\
4 & $\mathbf{2 9 b}$ & $\mathrm{Ph}$ & $\mathrm{MW}$ & $20 \mathrm{~min}$ & $\mathbf{3 0 b}$ & 81 \\
5 & $\mathbf{2 9 c}$ & $c-\mathrm{C}_{6} \mathrm{H}_{9}{ }^{\mathrm{c}}$ & $\Delta$ & $2 \mathrm{~h}$ & $\mathbf{3 0 c}$ & 87 \\
6 & $\mathbf{2 9 c}$ & $c-\mathrm{C}_{6} \mathrm{H}_{9}{ }^{\mathrm{c}}$ & $\mathrm{MW}$ & $7 \mathrm{~min}$ & $\mathbf{3 0 c}$ & 91 \\
7 & $\mathbf{2 9 d}$ & $3-\mathrm{Th}^{\mathrm{d}}$ & $\Delta$ & $6 \mathrm{~h}$ & $\mathbf{3 0 d}$ & 77 \\
8 & $\mathbf{2 9 d}$ & $3-\mathrm{Th}^{\mathrm{d}}$ & $\mathrm{MW}$ & $40 \mathrm{~min}$ & $\mathbf{3 0 d}$ & 78 \\
9 & $\mathbf{2 9 e}$ & $c-\mathrm{C}_{6} \mathrm{H}_{11}$ & $\Delta$ & $5 \mathrm{~h}$ & $\mathbf{3 0 e}$ & 72 \\
10 & $\mathbf{2 9 e}$ & $c-\mathrm{C}_{6} \mathrm{H}_{11}$ & $\mathrm{MW}$ & $20 \mathrm{~min}$ & $\mathbf{3 0 e}$ & 76 \\
11 & $\mathbf{2 9 f}$ & $n-\mathrm{C}_{5} \mathrm{H}_{11}$ & $\Delta$ & $2.5 \mathrm{~h}$ & $\mathbf{3 0 f}$ & 83 \\
\hline
\end{tabular}

${ }^{\mathrm{a}}$ Las reacciones fueron llevadas a cabo con la anilina $29(1 \mathrm{mmol})$ en DMF anhidra $(4 \mathrm{~mL})$ utilizando calentamiento convencional o con $29(0.5 \mathrm{mmol})$ en DMA anhidra $(2 \mathrm{~mL})$ bajo irradiación de microondas.

${ }^{\mathrm{b}}$ Rendimiento aislado del indol 30 referido a la $o$-alquinilanilina 29. ${ }^{\mathrm{c}} 1$-Ciclohexenilo. ${ }^{\mathrm{d}} 3$-Tienilo. 
En general, se obtuvieron rendimientos ligeramente superiores empleando radiación de microondas como método de calentamiento (Tabla 1.7, entradas 2, 4, 6, 8 y 10), aunque el hecho más destacable fue la significativa reducción del tiempo de reacción, normalmente desde varias horas a 10-20 minutos. También se observó que, en general, las ciclaciones son más rápidas cuando $\mathrm{R}$ es un grupo alifático que cuando es un grupo aromático (Tabla $1.7)$.

Aunque las anilinas de partida 29 se sintetizaron con facilidad empleando la reacción de Sonogashira entre la 2-yodoanilina 31a y diferentes alquinos terminales, en este punto nos planteamos si los indoles 2-sustituidos 30 podrían ser preparados mediante un procedimiento "one-pot" en dos pasos a partir de la o-yodoanilina 31a. Con este propósito, esta anilina fue tratada en primer lugar con 1-hexino bajo las condiciones estándar de Sonogashira (catálisis con $\mathrm{PdCl}_{2}\left(\mathrm{PPh}_{3}\right)_{2} / \mathrm{CuI}$ ) a temperatura ambiente (la desaparición de 31a se siguió por CG-EM) y, a continuación, se añadió un exceso de $\mathrm{NaOH}$ a la mezcla de reacción calentándose a $140{ }^{\circ} \mathrm{C}$ durante varias horas. Para determinar el exceso de base necesario para llevar a cabo este proceso "one pot" de manera efectiva, se ensayó la reacción entre 31a y 1-hexino empleando distintas cantidades de base, comprobándose que era necesario utilizar una mayor cantidad de $\mathrm{NaOH}$ que en el procedimiento por pasos para conseguir un buen rendimiento del indol 30a en tiempos razonablemente cortos. Tras este estudio se llegó a la conclusión que las condiciones óptimas de reacción eran el empleo de 10 equiv. de $\mathrm{NaOH}$. Así, la reacción de 31a con 1-hexino en las condiciones óptimas descritas permitió obtener el indol 30a con un $78 \%$ de rendimiento global y sin necesidad de aislar el intermedio 29a (Tabla 1.8, entrada 1). Este procedimiento "one pot" para la síntesis del indol 30a también pudo llevarse a cabo mediante el empleo de radiación de microondas. En este caso, hay que destacar una disminución considerable del tiempo de reacción. El acoplamiento de Sonogashira tuvo lugar en tan solo 10 minutos. ${ }^{150}$ Además, se redujeron tanto la cantidad necesaria de $\mathrm{NaOH}$ (de 10 a 4 equiv.) como el tiempo de reacción (de varias horas a 10 minutos) para la ciclación del intermedio 29a (Tabla 1.8, entrada 2).

Con este procedimiento puesto a punto se sintetizaron los indoles 2-sustituidos 30a-k, a partir de 31a y una amplia variedad de alquinos. En estas reacciones se empleó tanto calentamiento térmico (Tabla 1.8, entradas $1,3,5,8,10-12$ ) como por microondas

150 a) M. Erdélyi, A. Gogoll, J. Org. Chem. 2001, 66, 4165. b) O. G. Schramm, T. Oeser, M. Kaiser, R. Brun, T. J. J. Müller, Synlett 2008, 359. 
(Tabla 1.8, entradas 2, 4, 6, 7, 9, 13-15). Como se muestra en la Tabla 1.8, alquinos con sustituyentes alifáticos (entradas 1, 2, 8-10), alquenilo (entradas 5 y 6), arílicos (entradas 3 , 4, y 12), heteroarílicos (entradas 7 y 11), así como arilos funcionalizados (entradas 13-15) resultaron sustratos apropiados para llevar a cabo este proceso sintético.

Tabla 1.8 Preparación de los $1 H$-indoles 2-sustituidos 30 mediante acoplamiento de Sonogashira / ciclación mediada por $\mathrm{NaOH}$ a partir de la $o$-yodoanilina $\mathbf{3 1 a ^ { \mathrm { a } }}$

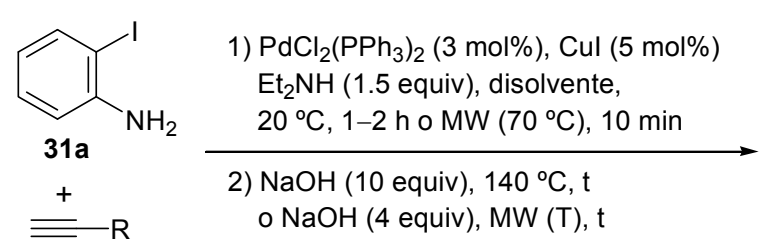

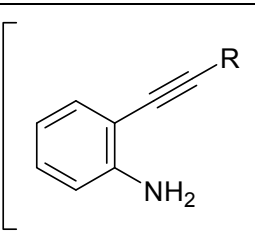

29<smiles>[R]c1cc2ccccc2[nH]1</smiles>

30

\begin{tabular}{|c|c|c|c|c|c|c|}
\hline Entrada & Alquino (R) & Disolvente & Calentamiento & Tiempo (t) & Producto & Rto. $(\%)^{b}$ \\
\hline 1 & $n-\mathrm{Bu}$ & DMF & $\Delta\left(140^{\circ} \mathrm{C}\right)$ & $3.5 \mathrm{~h}$ & $30 \mathbf{a}$ & 78 \\
\hline 2 & $n-\mathrm{Bu}$ & DMA & $\mathrm{MW}\left(170^{\circ} \mathrm{C}\right)$ & $10 \mathrm{~min}$ & $30 \mathbf{a}$ & 81 \\
\hline 3 & $\mathrm{Ph}$ & DMA & $\Delta\left(140^{\circ} \mathrm{C}\right)$ & $6 \mathrm{~h}$ & $30 \mathrm{~b}$ & 76 \\
\hline 4 & $\mathrm{Ph}$ & DMA & $\mathrm{MW}\left(190^{\circ} \mathrm{C}\right)$ & $20 \mathrm{~min}$ & $30 \mathrm{~b}$ & 77 \\
\hline 5 & $c-\mathrm{C}_{6} \mathrm{H}_{9}{ }^{\mathrm{c}}$ & $\mathrm{DMF}$ & $\Delta\left(140^{\circ} \mathrm{C}\right)$ & $2 \mathrm{~h}$ & $30 \mathrm{c}$ & 82 \\
\hline 6 & $c-\mathrm{C}_{6} \mathrm{H}_{9}{ }^{\mathrm{c}}$ & DMA & $\mathrm{MW}\left(170^{\circ} \mathrm{C}\right)$ & $10 \mathrm{~min}$ & $30 \mathrm{c}$ & 88 \\
\hline 7 & $3-T h^{d}$ & DMA & $\mathrm{MW}\left(180^{\circ} \mathrm{C}\right)$ & $40 \mathrm{~min}$ & 30d & 60 \\
\hline 8 & $c-\mathrm{C}_{6} \mathrm{H}_{11}$ & DMA & $\Delta\left(140^{\circ} \mathrm{C}\right)$ & $6 \mathrm{~h}$ & $30 \mathrm{e}$ & 69 \\
\hline 9 & $c-\mathrm{C}_{6} \mathrm{H}_{11}$ & DMA & $\mathrm{MW}\left(180^{\circ} \mathrm{C}\right)$ & $40 \mathrm{~min}$ & $30 \mathrm{e}$ & 50 \\
\hline 10 & $n-\mathrm{C}_{5} \mathrm{H}_{11}$ & $\mathrm{DMF}$ & $\Delta\left(140^{\circ} \mathrm{C}\right)$ & $4.5 \mathrm{~h}$ & $30 f$ & 68 \\
\hline 11 & $2-\mathrm{Py}^{\mathrm{e}}$ & $\mathrm{DMF}$ & $\Delta\left(140^{\circ} \mathrm{C}\right)$ & $2.5 \mathrm{~h}$ & $30 \mathrm{~g}$ & 76 \\
\hline 12 & 4- $\mathrm{MeC}_{6} \mathrm{H}_{4}$ & DMA & $\Delta\left(140^{\circ} \mathrm{C}\right)$ & $4 \mathrm{~h}$ & 30h & 70 \\
\hline 13 & $2-\mathrm{NH}_{2} \mathrm{C}_{6} \mathrm{H}_{4}$ & DMA & $\mathrm{MW}\left(180^{\circ} \mathrm{C}\right)$ & $50 \mathrm{~min}$ & $30 \mathrm{i}$ & 40 \\
\hline 14 & $4-\mathrm{F}-3-\mathrm{MeC}_{6} \mathrm{H}_{3}$ & DMA & $\mathrm{MW}\left(180^{\circ} \mathrm{C}\right)$ & $40 \mathrm{~min}$ & $\mathbf{3 0 j}$ & 71 \\
\hline 15 & $3-\mathrm{ClC}_{6} \mathrm{H}_{4}$ & DMA & $\mathrm{MW}\left(180^{\circ} \mathrm{C}\right)$ & $40 \mathrm{~min}$ & $30 \mathrm{k}$ & 74 \\
\hline
\end{tabular}

${ }^{a}$ Las reacciones fueron llevadas a cabo con 31a $(1 \mathrm{mmol})$ en DMF o DMA anhidra $(5 \mathrm{~mL})$ utilizando calentamiento convencional o con 31a $(0.5 \mathrm{mmol})$ en DMA anhidra $(2 \mathrm{~mL})$ bajo irradiación de microondas. ${ }^{\mathrm{b}}$ Rendimiento aislado del indol 30 referido a la $o$-yodoanilina 31a. ${ }^{\mathrm{c}}$ 1-Ciclohexenilo. ${ }^{\mathrm{d}} 3$-Tienilo. ${ }^{\mathrm{e}} 2$-Piridilo. 
En general, se obtuvieron rendimientos entre moderados y altos. Además, cabe destacar que este procedimiento se pudo aplicar a la síntesis de los indoles 2-sustituidos a escala multi-gramo y así, por ejemplo, se prepararon $2.31 \mathrm{~g}$ del indol 30a $(67 \%$ de rendimiento aislado) a partir de $4.38 \mathrm{~g}(20 \mathrm{mmol})$ de la 2-yodoanilina $31 \mathrm{a}$.

Una vez que habíamos comprobado la generalidad de este procedimiento "one-pot" para la síntesis de los indoles 2-sustituidos 30 con respecto a una amplia variedad de alquinos terminales, decidimos estudiar el alcance de esta estrategia sintética con respecto a las $o$-yodoanilinas de partida 31 (Tabla 1.9).

De nuevo, las reacciones se llevaron a cabo empleando tanto calentamiento convencional como por microondas. En primer lugar, comprobamos que la $N$-acetil-2yodoanilina 31b se comportaba como un equivalente sintético de la 2-yodoanilina 31a, debido a que bajo las condiciones de reacción tenía lugar una $N$-deacetilación (Tabla 1.9, entradas 1-3). Esta metodología no está restringida al empleo de anilinas primarias (31a y 31d-h), y así la $N$-bencil-2-yodoanilina 31c permitió obtener los correspondientes $N$ bencilindoles 301 y $\mathbf{3 0 m}$ con altos rendimientos (Tabla 1.9, entradas 4 y 5). Además, las halo-2-yodoanilinas 31d,e y las dihalo-2-yodoanilinas 31f,g permitieron la síntesis de los derivados indólicos halogenados regioselectivamente $\mathbf{3 0 n}-\mathbf{v}$ con rendimientos entre moderados y altos (Tabla 1.9, entradas 6-15). Finalmente, la 2-yodoanilina 31h, que contenía un grupo ciano, también condujo al correspondiente indol funcionalizado 30w (Tabla 1.9, entrada 16) demostrando que grupos funcionales sensibles son tolerados bajo las condiciones de reacción. 
Tabla 1.9 Preparación de indoles funcionalizados 30 mediante acoplamiento de Sonogashira / ciclación mediada por $\mathrm{NaOH}$ a partir de las $\boldsymbol{o}$-yodoanilinas $\mathbf{3 1}{ }^{\mathrm{a}}$

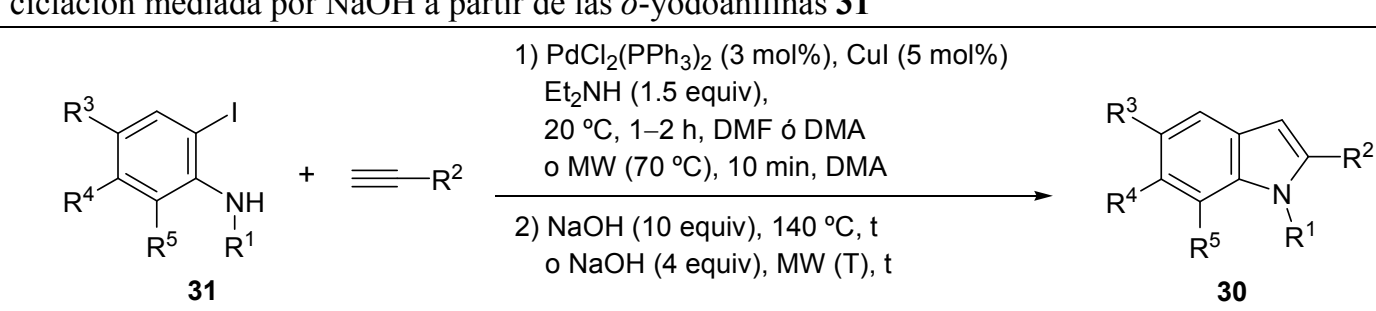

\begin{tabular}{|c|c|c|c|c|c|c|c|c|c|c|}
\hline Entrada & Anilina & $\mathbf{R}^{1}$ & $\mathbf{R}^{3}$ & $\mathbf{R}^{4}$ & $\mathbf{R}^{5}$ & $\begin{array}{c}\text { Alquino } \\
\mathbf{R}^{2}\end{array}$ & Calentamiento & $\begin{array}{c}\text { Tiempo } \\
\text { (t) }\end{array}$ & Producto & $\begin{array}{l}\text { Rto. } \\
(\%)^{b}\end{array}$ \\
\hline 1 & 31b & Ac & $\mathrm{H}$ & $\mathrm{H}$ & $\mathrm{H}$ & $n-\mathrm{Bu}$ & $\Delta\left(140^{\circ} \mathrm{C}\right)$ & $2.5 \mathrm{~h}$ & $\begin{array}{c}30 \mathbf{a}\left(\mathrm{R}^{1}\right. \\
=\mathrm{H})\end{array}$ & 89 \\
\hline 2 & 31b & Ac & $\mathrm{H}$ & $\mathrm{H}$ & $\mathrm{H}$ & $c-\mathrm{C}_{6} \mathrm{H}_{9}{ }^{\mathrm{c}}$ & $\Delta\left(140^{\circ} \mathrm{C}\right)$ & $3.5 \mathrm{~h}$ & $\begin{array}{c}\text { 30c }\left(\mathrm{R}^{1}\right. \\
=\mathrm{H})\end{array}$ & 75 \\
\hline 3 & 31b & Ac & $\mathrm{H}$ & $\mathrm{H}$ & $\mathrm{H}$ & $n-\mathrm{C}_{5} \mathrm{H}_{11}$ & $\operatorname{MW}\left(180^{\circ} \mathrm{C}\right)$ & $20 \mathrm{~min}$ & $\begin{array}{c}\text { 30f } \\
\left(\mathrm{R}^{1}=\mathrm{H}\right)\end{array}$ & 74 \\
\hline 4 & 31c & $\mathrm{Bn}$ & $\mathrm{H}$ & $\mathrm{H}$ & $\mathrm{H}$ & $n-\mathrm{Bu}$ & $\Delta\left(140^{\circ} \mathrm{C}\right)$ & $3.5 \mathrm{~h}$ & 301 & 80 \\
\hline 5 & $31 \mathrm{c}$ & $\mathrm{Bn}$ & $\mathrm{H}$ & $\mathrm{H}$ & $\mathrm{H}$ & $c-\mathrm{C}_{6} \mathrm{H}_{9}{ }^{\mathrm{c}}$ & $\operatorname{MW}\left(170^{\circ} \mathrm{C}\right)$ & $20 \mathrm{~min}$ & $30 \mathrm{~m}$ & 75 \\
\hline 6 & 31d & $\mathrm{H}$ & $\mathrm{H}$ & $\mathrm{Cl}$ & $\mathrm{H}$ & $n$-Bu & $\Delta\left(140^{\circ} \mathrm{C}\right)$ & $3 \mathrm{~h}$ & 30n & 88 \\
\hline 7 & 31d & $\mathrm{H}$ & $\mathrm{H}$ & $\mathrm{Cl}$ & $\mathrm{H}$ & $c-\mathrm{C}_{6} \mathrm{H}_{9}{ }^{\mathrm{c}}$ & $\Delta\left(140^{\circ} \mathrm{C}\right)$ & $3 \mathrm{~h}$ & 300 & 75 \\
\hline 8 & $31 \mathrm{e}$ & $\mathrm{H}$ & $\mathrm{H}$ & $\mathrm{F}$ & $\mathrm{H}$ & $n$-Bu & $\Delta\left(140^{\circ} \mathrm{C}\right)$ & $3 \mathrm{~h}$ & $30 p$ & 74 \\
\hline 9 & $31 \mathrm{e}$ & $\mathrm{H}$ & $\mathrm{H}$ & $\mathrm{F}$ & $\mathrm{H}$ & $\mathrm{Ph}$ & $\operatorname{MW}\left(180^{\circ} \mathrm{C}\right)$ & $40 \min$ & $30 q$ & 66 \\
\hline 10 & 31e & $\mathrm{H}$ & $\mathrm{H}$ & $\mathrm{F}$ & $\mathrm{H}$ & $c-\mathrm{C}_{6} \mathrm{H}_{9}{ }^{\mathrm{c}}$ & $\Delta\left(140^{\circ} \mathrm{C}\right)$ & $3 \mathrm{~h}$ & $30 r$ & 61 \\
\hline 11 & $31 f$ & $\mathrm{H}$ & $\mathrm{Cl}$ & $\mathrm{H}$ & $\mathrm{Cl}$ & $c-\mathrm{C}_{6} \mathrm{H}_{9}{ }^{\mathrm{c}}$ & $\Delta\left(140^{\circ} \mathrm{C}\right)$ & $2.5 \mathrm{~h}$ & $30 \mathrm{~s}$ & 68 \\
\hline 12 & 31f & $\mathrm{H}$ & $\mathrm{Cl}$ & $\mathrm{H}$ & $\mathrm{Cl}$ & $c-\mathrm{C}_{6} \mathrm{H}_{9}{ }^{\mathrm{c}}$ & $\operatorname{MW}\left(180^{\circ} \mathrm{C}\right)$ & $20 \mathrm{~min}$ & $30 \mathrm{~s}$ & 66 \\
\hline 13 & $31 f$ & $\mathrm{H}$ & $\mathrm{Cl}$ & $\mathrm{H}$ & $\mathrm{Cl}$ & $n-\mathrm{C}_{5} \mathrm{H}_{11}$ & $\Delta\left(140^{\circ} \mathrm{C}\right)$ & $2.5 \mathrm{~h}$ & $30 t$ & 78 \\
\hline 14 & $31 \mathrm{~g}$ & $\mathrm{H}$ & $\mathrm{Cl}$ & $\mathrm{H}$ & $\mathrm{F}$ & $\mathrm{Ph}$ & $\Delta\left(140^{\circ} \mathrm{C}\right)$ & $3 \mathrm{~h}$ & $30 u$ & 81 \\
\hline 15 & $31 \mathrm{~g}$ & $\mathrm{H}$ & $\mathrm{Cl}$ & $\mathrm{H}$ & $\mathrm{F}$ & $n-\mathrm{C}_{5} \mathrm{H}_{11}$ & $\Delta\left(140^{\circ} \mathrm{C}\right)$ & $3 \mathrm{~h}$ & $30 v$ & 83 \\
\hline 16 & 31h & $\mathrm{H}$ & $\mathrm{CN}$ & $\mathrm{H}$ & $\mathrm{H}$ & $\mathrm{Ph}$ & $\Delta\left(140^{\circ} \mathrm{C}\right)$ & $3 \mathrm{~h}$ & 30w & 85 \\
\hline
\end{tabular}

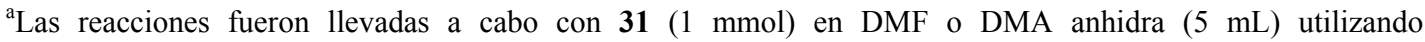
calentamiento convencional o con $31(0.5 \mathrm{mmol})$ en DMA anhidra $(2 \mathrm{~mL})$ bajo irradiación de microondas. ${ }^{\mathrm{b}}$ Rendimiento aislado de $\mathbf{3 0}$ referido a la anilina de partida $31 .{ }^{\mathrm{c}} 1$-Ciclohexenilo. 
Por otro lado, cabe destacar que empleando esta metodología también fue posible preparar los 3-ariltioindoles 2-sustituidos 32, debido a que el grupo ariltio se pudo introducir en la posición $\mathrm{C}-3$ de forma selectiva bajo las mismas condiciones básicas requeridas para el paso de ciclación (Tabla 1.10). ${ }^{151}$ De nuevo, este procedimiento "one pot" en tres pasos se llevó a cabo tanto utilizando calentamiento térmico, como radiación de microondas. En el caso de emplear radiación de microondas, los tiempos de reacción se vieron, de nuevo, reducidos considerablemente. Como se muestra en la Tabla 1.10 se obtuvieron los derivados indólicos polifuncionalizados 32a-c con rendimientos entre moderados y buenos a partir de productos de partida comercialmente disponibles tales como 31a,d.

Tabla 1.10. Preparación de los 3-ariltio- $1 H$-indoles funcionalizados 32

\begin{tabular}{|c|c|c|c|c|c|}
\hline $31 \mathrm{a}, \mathrm{d}$ & $\mathrm{NH}_{2}+\equiv \mathrm{R}^{2}$ & $\begin{array}{r}\text { 1) } \mathrm{PdC} \\
\mathrm{Et}_{2} \mathrm{~N} \\
20^{\circ} \\
\text { 2) } \mathrm{NaO} \\
\mathrm{O} \mathrm{Na} \\
\text { 3) } \mathrm{Ph}_{2} \\
\mathrm{O} \mathrm{Ml}\end{array}$ & $\begin{array}{l}3 \mathrm{~mol} \% \text { ), C } \\
\text { iv), DMA } \\
\left.\text { AW (70 }{ }^{\circ} \mathrm{C}\right) \\
\text { v), } 140^{\circ} \mathrm{C} \text {, } \\
\text { iv), } \mathrm{MW}(17 \\
\text { iv), } 140^{\circ} \mathrm{C} \\
20 \mathrm{~min}\end{array}$ & $\underset{20 \text { min }}{\stackrel{\text { ol\%) }}{\longrightarrow}}$ & $\approx C_{\mathrm{H}}^{\prime}$ \\
\hline Entrada & Anilina partida & $\mathbf{R}^{1}$ & $\mathbf{R}^{2}$ & Producto & Rendimiento (\%) \\
\hline 1 & $31 \mathrm{a}$ & $\mathrm{H}$ & $n-\mathrm{Bu}$ & 32a & 68 \\
\hline 2 & $31 \mathrm{a}$ & $\mathrm{H}$ & $\mathrm{Ph}$ & $32 b$ & 72 \\
\hline 3 & 31d & $\mathrm{Cl}$ & $n-\mathrm{C}_{5} \mathrm{H}_{11}$ & $32 c$ & 81 \\
\hline
\end{tabular}

${ }^{a}$ Rendimiento en producto aislado referido a la 2-yodoanilina de partida 31a ó 31d.

Podemos concluir que hemos desarrollado una ruta sintética eficiente para acceder a indoles 2-sustituidos a partir de 2-yodoanilinas y alquinos terminales en un proceso que implica un acoplamiento de Sonogashira seguido de una ciclación 5-endo-dig mediada por $\mathrm{NaOH}$, siendo este último el paso clave del proceso. Esta metodología también permite introducir selectivamente un grupo ariltio en la posición $\mathrm{C}-3$ sin necesidad de aislar ningún intermedio de reacción. Por último, hay que destacar que todas estas reacciones pueden llevarse a cabo empleando calentamiento convencional o bajo radiación de microondas, con una reducción considerable en los tiempos de reacción.

${ }^{151}$ J. G. Atkinson, P. Hamel, Y. Girard, Synthesis 1988, 480. 


\section{d) Preparación de nitro- y amino-indoles 35 y 36 a partir de las 2- halonitroanilinas 34}

Cuando en el proceso "one pot" de acoplamiento-ciclación se empleaba la yodoanilina 31a y fenilacetileno como sustratos de partida, en DMF como disolvente, se observaba la formación de la 2-(2-feniletil)anilina 33 (48\% de rendimiento) junto con el derivado indólico esperado 30b (25\% de rendimiento). En base a este resultado, pensamos que la formación de $\mathbf{3 3}$ podría deberse a la hidrogenación competitiva de la $o$-alquinilanilina intermedia 29b bajo las condiciones de reacción. Sin embargo, observamos con satisfacción que un cambio de disolvente, de DMF a DMA, evitaba por completo la formación del subproducto 33, permitiendo en este caso aislar un $84 \%$ de 30b (Esquema 1.74).

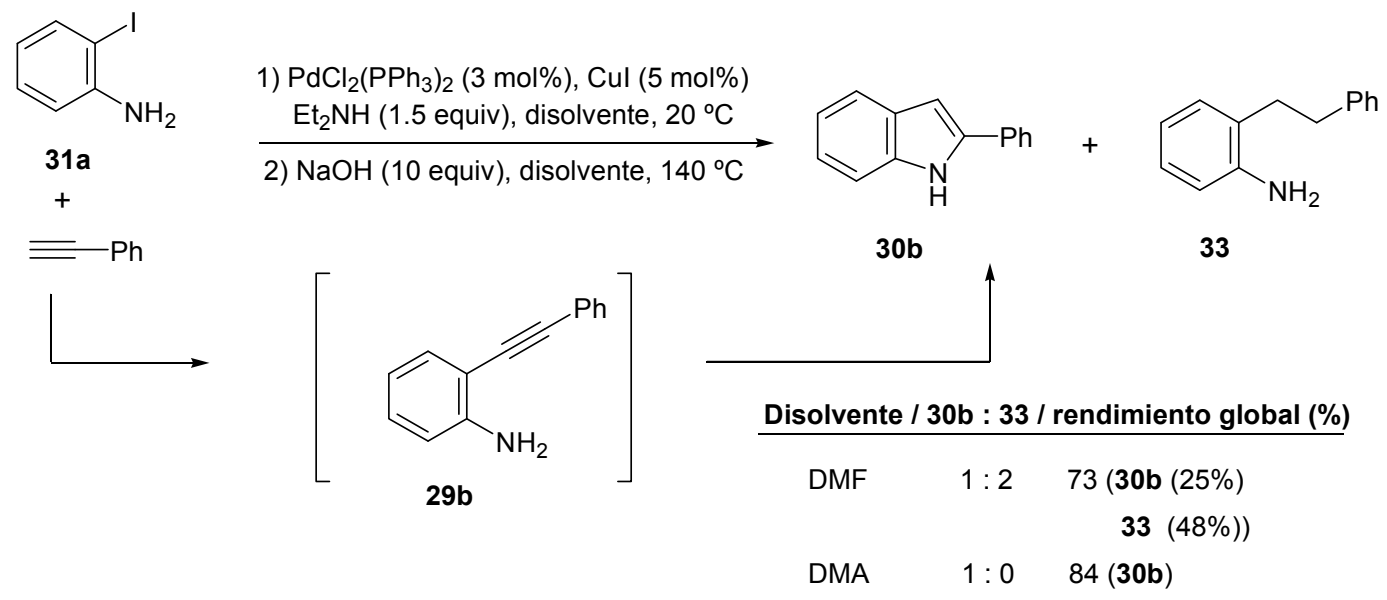

Esquema 1.74

Este resultado sugiere que cuando se utilizaba DMF como disolvente, probablemente se generaba algún derivado de formiato, el cual podría actuar como fuente de hidrógeno. ${ }^{152}$ En este mismo sentido, Wang y colaboradores habían observado la reducción de un grupo nitro al correspondiente grupo amino durante el transcurso de una reacción de Suzuki catalizada por complejos de paladio y empleando una mezcla DMF / $\mathrm{H}_{2} \mathrm{O}(5 / 1)$ como disolvente. ${ }^{153}$ Teniendo en cuenta que se debe de generar algún tipo de fuente de

\footnotetext{
${ }^{152}$ R. Nacario, S. Kotakonda, D. M. D. Fouchard, L. M. Viranga Tillekeratne, R. A. Hudson, Org. Lett. 2005, 7, 471.

${ }^{153}$ H.-S. Wang, Y.-C. Wang, Y.-M. Pan, S.-L. Zhao, Z.-F. Chen, Tetrahedron Lett. 2008, 49, 2634.
} 
hidrógeno bajo nuestras condiciones de reacción cuando se emplea DMF como disolvente, pensamos que se podrían sintetizar de forma selectiva nitro y aminoindoles a partir de las mismas 2-halonitroanilinas 34, mediante una simple selección del disolvente de la reacción.

Con estas premisas, se ensayó el proceso de acoplamiento de Sonogashira / ciclación que habíamos puesto a punto $\left(\mathrm{PdCl}_{2}\left(\mathrm{PPh}_{3}\right)_{2}-\mathrm{CuI} / \mathrm{NaOH}\right)$, empleando una nitroyodoanilina como sustrato de partida. Así, se hizo reaccionar la 4-nitro-2-yodo-anilina 34a con fenilacetileno. En primer lugar se empleó DMA como disolvente (camino A) obteniéndose el 5-nitroindol 35aa, el cual conservaba el grupo nitro intacto. A continuación se ensayó la misma reacción pero cambiando el disolvente, DMA por DMF (camino B). En este caso observamos la reducción simultánea del grupo nitro después de 15 horas de reacción tras el tratamiento con $\mathrm{NaOH}$, siendo posible aislar el 5-aminoindol 36aa con un rendimiento moderado (Esquema 1.75).

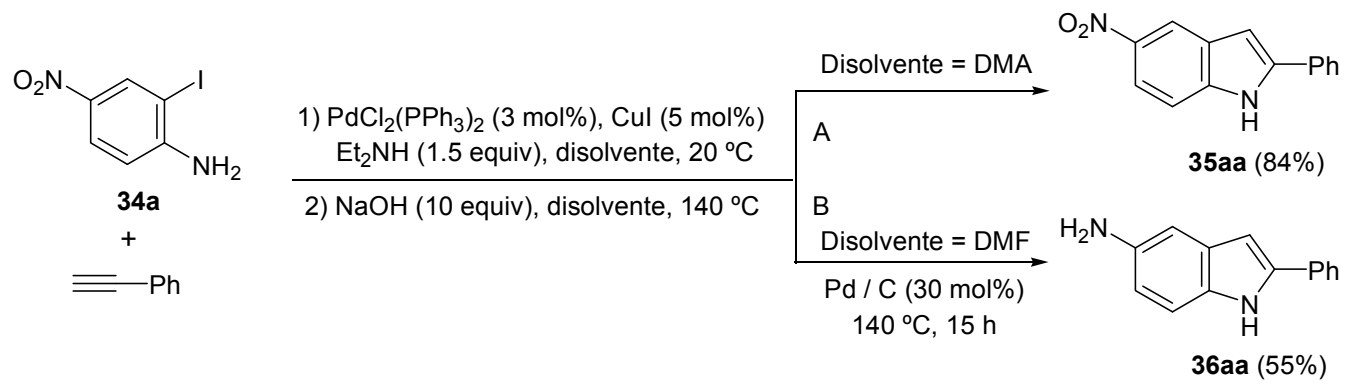

\section{Esquema 1.75}

Cuando se empleaba DMF como disolvente, se pudo comprobar por CG-EM que la reducción del grupo nitro en el nitroindol intermedio 35aa tenía lugar lentamente. Sin embargo, la adición de $\mathrm{Pd} / \mathrm{C}(30 \mathrm{~mol} \%)$ a la mezcla de reacción permitió la reducción completa de este nitroindol 35aa en tiempos razonables (Esquema 1.75).

Una vez confirmada nuestra premisa, comprobamos la generalidad de este procedimiento aplicándolo a distintas nitroyodoanilinas de partida y alquinos terminales. De este modo, se pudieron sintetizar los indoles 35 y 36 con grupos arilo-, alquilo-, y alquenilo en la posición $\mathrm{C}-2$ del anillo indólico partiendo de una amplia variedad alquinos terminales (Tablas $1.11,1.12$ y 1.13 ). 
Se consideraron distintas 2-halonitroanilinas 34, con el grupo nitro en diferentes posiciones del anillo de benceno, como sustratos de partida. Así, el empleo de la 4-nitro-2yodoanilina 34a, comercialmente disponible, permitió la síntesis de los 5-nitroindoles 35aa-ad con altos rendimientos, cuando se empleaba DMA como disolvente (Tabla 1.11, entradas 1-4). De la misma forma se obtuvieron los 5-aminoindoles 36aa-ae con rendimientos moderados al utilizar DMF como disolvente (Tabla 1.11, entradas 5-10). Este proceso de acoplamiento / ciclación mediada por $\mathrm{NaOH}$ y reducción simultánea también se pudo llevar a cabo empleando radiación de microondas, reduciéndose el tiempo de reacción a 20 minutos para el paso de ciclación y a 30 minutos para el paso de reducción (Tabla 1.11, entradas 3,9 y 10$)$.

Tabla 1.11. Síntesis de 5-nitroindoles 35aa-ad y 5-aminoindoles 36aa-ae a partir de la nitroanilina 34a

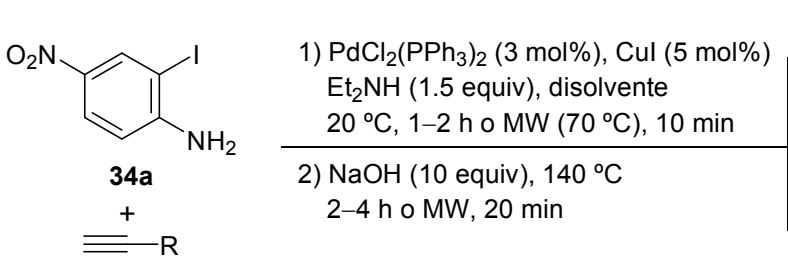

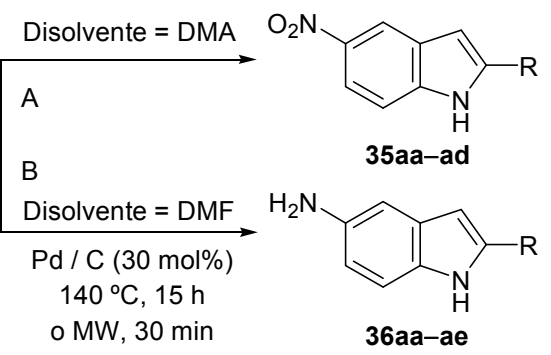

\begin{tabular}{|c|c|c|c|c|}
\hline Entrada & $\mathbf{R}$ & Método & Producto & Rto. $(\%)^{\mathrm{a}}$ \\
\hline 1 & $\mathrm{Ph}$ & A & 35aa: $\mathrm{R}=\mathrm{Ph}$ & 84 \\
\hline 2 & $c-\mathrm{C}_{6} \mathrm{H}_{9}{ }^{\mathrm{b}}$ & A & 35ab: $\mathrm{R}=c-\mathrm{C}_{6} \mathrm{H}_{9}$ & 76 \\
\hline 3 & $n-\mathrm{Bu}$ & A & 35ac: $\mathrm{R}=n-\mathrm{Bu}$ & $89^{c}$ \\
\hline 4 & $n-\mathrm{C}_{5} \mathrm{H}_{11}$ & A & 35ad: $\mathrm{R}=n-\mathrm{C}_{5} \mathrm{H}_{11}$ & 81 \\
\hline 5 & $\mathrm{Ph}$ & B & 36aa: $\mathrm{R}=\mathrm{Ph}$ & 55 \\
\hline 6 & $c-\mathrm{C}_{6} \mathrm{H}_{9}{ }^{\mathrm{b}}$ & B & 36ab: $\mathrm{R}=c-\mathrm{C}_{6} \mathrm{H}_{9}$ & 48 \\
\hline 7 & $n-\mathrm{Bu}$ & B & 36ac: $\mathrm{R}=n-\mathrm{Bu}$ & 65 \\
\hline 8 & $n-\mathrm{C}_{5} \mathrm{H}_{11}$ & B & 36ad: $\mathrm{R}=n-\mathrm{C}_{5} \mathrm{H}_{11}$ & 66 \\
\hline 9 & $n-\mathrm{C}_{5} \mathrm{H}_{11}$ & B & 36ad: $\mathrm{R}=n-\mathrm{C}_{5} \mathrm{H}_{11}$ & $62^{c}$ \\
\hline 10 & 4-F-3- $\mathrm{MeC}_{6} \mathrm{H}_{3}$ & B & 36ae: $\mathrm{R}=4-\mathrm{F}-3-\mathrm{MeC}_{6} \mathrm{H}_{3}$ & $44^{\mathrm{c}}$ \\
\hline
\end{tabular}

${ }^{a}$ Rendimiento aislado referido a la 4-nitro-2-yodoanilina 34a. ${ }^{\mathrm{b}}$ 1-Ciclohexenilo. ${ }^{\mathrm{c}}$ Llevada a cabo bajo radiación de microondas. 
Los indoles nitrógeno-sustituidos en el C-6 35ba-bd y 36ba-bf se sintetizaron a partir de 2-bromo-5-nitroanilina 34b con rendimientos moderados (Tabla 1.12).

Tabla 1.12. Síntesis de 6-nitroindoles 35ba-bd y 6-aminoindoles 36ba-bf a partir de la 2-bromo-5nitroanilina 34b

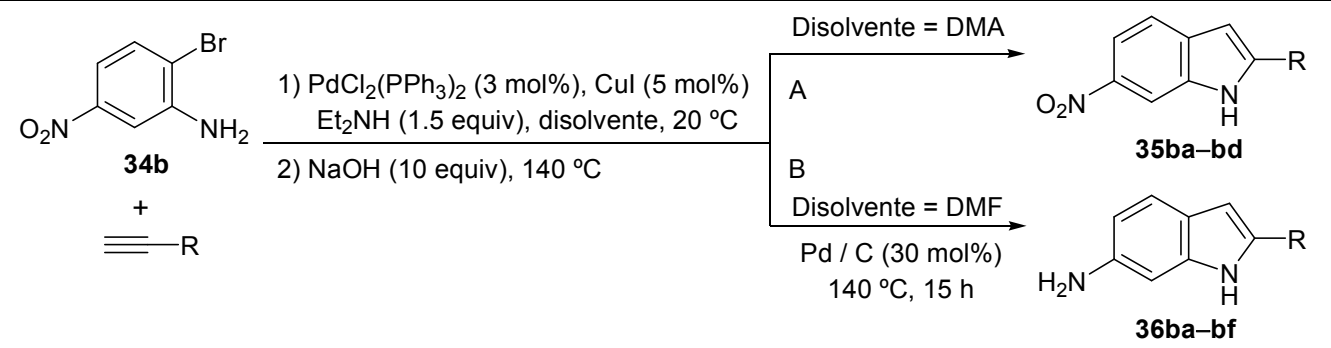

\begin{tabular}{|c|c|c|c|c|}
\hline Entrada & $\overline{\mathbf{R}}$ & "Método & Producto & Rto. (\%) \\
\hline 1 & $\mathrm{Ph}$ & A & 35ba: $\mathrm{R}=\mathrm{Ph}$ & 60 \\
\hline 2 & $n-\mathrm{Bu}$ & A & 35bc: $\mathrm{R}=n-\mathrm{Bu}$ & 45 \\
\hline 3 & $n-\mathrm{C}_{5} \mathrm{H}_{11}$ & A & 35bd: $\mathrm{R}={ }^{-}-\mathrm{C}_{5} \mathrm{H}_{11}$ & 47 \\
\hline 4 & $\mathrm{Ph}$ & B & 36ba: $\mathrm{R}=\mathrm{Ph}$ & 45 \\
\hline 5 & $n-\mathrm{C}_{5} \mathrm{H}_{11}$ & B & 36bd: $\mathrm{R}=n-\mathrm{C}_{5} \mathrm{H}_{11}$ & 32 \\
\hline 6 & 4- $\mathrm{MeC}_{6} \mathrm{H}_{4}$ & B & 36bf: $\mathrm{R}=4-\mathrm{MeC}_{6} \mathrm{H}_{4}$ & 43 \\
\hline
\end{tabular}

${ }^{a}$ Rendimiento aislado referido a la 2-bromo-5-nitroanilina $\mathbf{3 4 b}$.

Las anilinas 34c y 34d, necesarias para la obtención de los 7-nitro- y 7aminoindoles $\mathbf{3 5 c c - d d ~ y ~} \mathbf{3 6} \mathbf{c b}-\mathbf{d b}$ se prepararon por yodación de la 4-cloro-2-nitroanilina y la 4-metil-2-nitroanilina, respectivamente, empleando $\mathrm{ICl}$ en $\mathrm{AcOH} .{ }^{154}$ La reacción de estas anilinas 34c y 34d con diferentes alquinos permitió obtener los 7-nitroindoles 35cc,cg y 35da,dd (Tabla 1.13, entradas 1, 2, 6 y 7), además de los 7-aminoindoles 36cb-cd y 36db con rendimientos moderados (Tabla 1.13, entradas 3-5 y 8). Hay que destacar que de nuevo los tiempos de reacción del proceso de ciclación mediado por $\mathrm{NaOH}$ y la simultánea reducción del grupo nitro se redujeron considerablemente cuando las reacciones se llevaron a cabo empleando radiación de microondas.

${ }^{154}$ J. T. Manka, F. Guo, J. Huang, H. Yin, J. M. Farrar, M. Sienkowska, V. Benin, P. Kaszynski, J. Org. Chem. 2003, 68, 9574. 
Tabla 1.13. Síntesis de 7-nitroindoles 35 y 7-aminoindoles 36 a partir de las 2 -yodoanilinas 34c y 34d

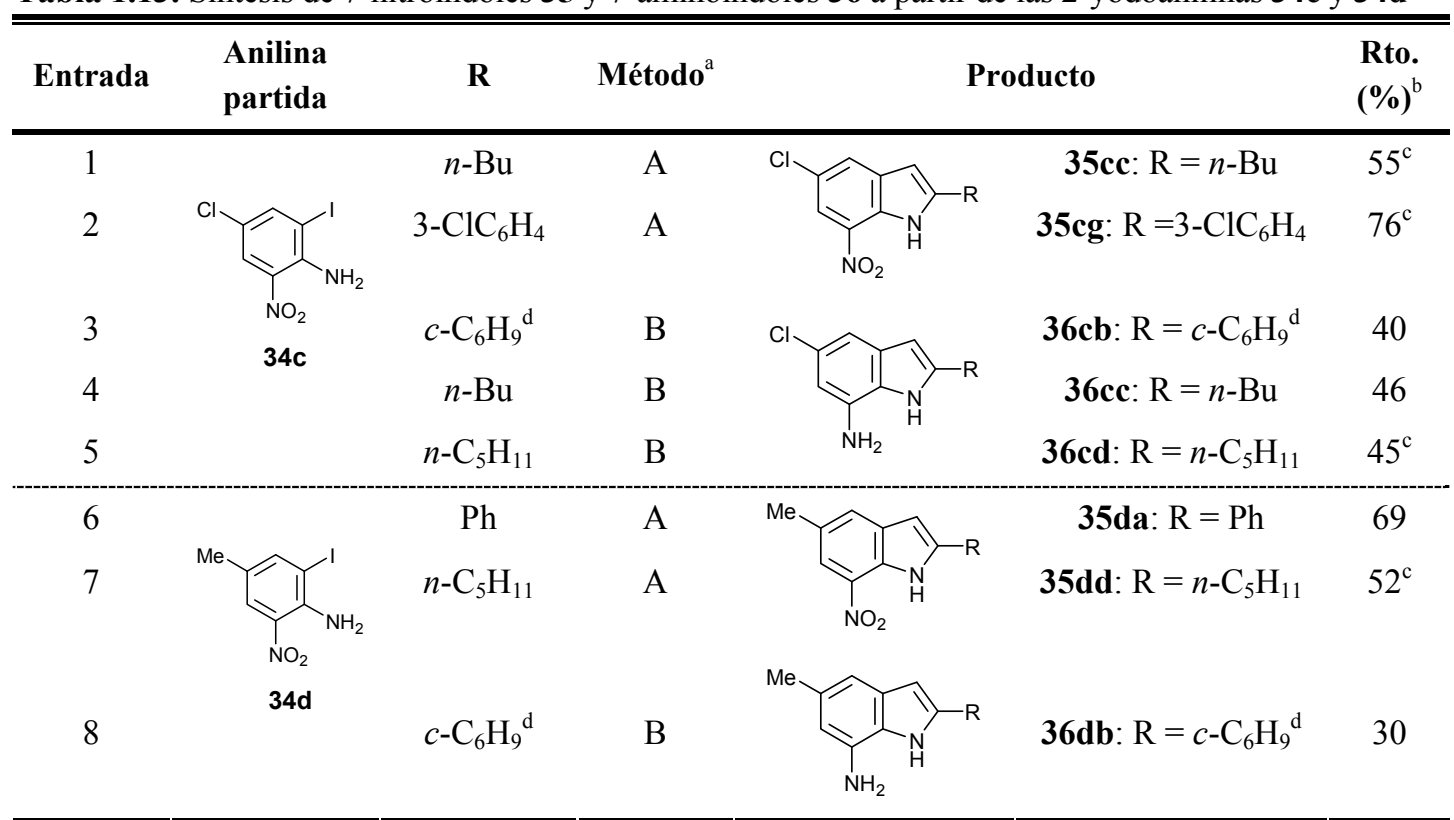

aétodo A: Reacción llevada a cabo empleando $\mathrm{PdCl}_{2}\left(\mathrm{PPh}_{3}\right)_{2}$ (3 mol\%), CuI (5 mol\%), $\mathrm{Et}_{2} \mathrm{NH}$ (1.5 equiv.) en DMA como disolvente a $20^{\circ} \mathrm{C}(1-2 \mathrm{~h})$ o $\mathrm{MW}\left(70{ }^{\circ} \mathrm{C}, 10 \mathrm{~min}\right)$ seguida de la adición de $\mathrm{NaOH}$ y calentamiento a $140^{\circ} \mathrm{C}(2-4 \mathrm{~h})$ o $\mathrm{MW}\left(140^{\circ} \mathrm{C}, 20 \mathrm{~min}\right)$. Método B: Reacción llevada a cabo empleando $\mathrm{PdCl}_{2}\left(\mathrm{PPh}_{3}\right)_{2}(3 \mathrm{~mol} \%)$, $\mathrm{CuI}(5 \mathrm{~mol} \%), \mathrm{Et}_{2} \mathrm{NH}$ (1.5 equiv.) en DMF como disolvente a $20^{\circ} \mathrm{C}$ o MW $\left(70{ }^{\circ} \mathrm{C}, 10 \mathrm{~min}\right)$ seguida de la adición de $\mathrm{NaOH}$ y calentamiento a $140{ }^{\circ} \mathrm{C}(2-4 \mathrm{~h})$ o $\mathrm{MW}\left(140{ }^{\circ} \mathrm{C}, 20 \mathrm{~min}\right)$. Adición de $\mathrm{Pd} / \mathrm{C}(30 \mathrm{~mol} \%)$ y calentamiento a $140{ }^{\circ} \mathrm{C}$ durante $15 \mathrm{~h}$ o MW $\left(140{ }^{\circ} \mathrm{C}, 30 \mathrm{~min}\right) .{ }^{\mathrm{b}}$ Rendimiento aislado referido a la nitroyodoanilina de partida 34c ó 34d. ${ }^{c}$ Llevada a cabo bajo irradiación de microondas. ${ }^{\mathrm{d}} 1$-Ciclohexenilo.

Por último, los indoles 35ec,ef se prepararon a partir de la anilina 34e. Cuando se aplicaron las mismas condiciones de reacción previamente descritas para la preparación de 34c y 34d (1.1 equiv. de $\mathrm{ICl}$ en $\mathrm{AcOH}$ ) a la yodación de la 4-cloro-3-nitroanilina, se obtuvo una mezcla de 4-cloro-5-nitro-2-yodoanilina y 4-cloro-3-nitro-2-yodoanilina. Tras ensayar diferentes condiciones de reacción se comprobó que el tratamiento de la 4-cloro-3nitroanilina con yodo en presencia de $\mathrm{HIO}_{3}, \mathrm{CCl}_{4}$ y $\mathrm{H}_{2} \mathrm{SO}_{4}$, empleando $\mathrm{AcOH}$ como disolvente, ${ }^{154}$ conducía al compuesto diyodado $34 \mathbf{e}$ que se muestra en el siguiente esquema con un rendimiento del $60 \%$.

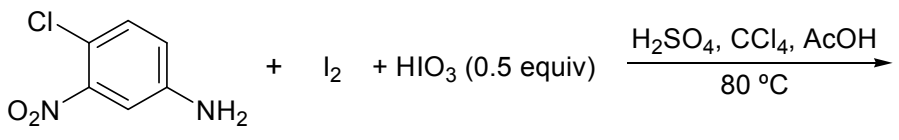<smiles>Nc1c(I)cc(Cl)c([N+](=O)[O-])c1I</smiles>

\section{Esquema 1.76}


La posterior reacción de 34e con alquinos terminales seguida del paso de ciclación permitió obtener los 6-nitroindoles 35ec,ef con rendimientos moderados (Esquema 1.77). Hay que señalar que en el paso del acoplamiento de Sonogashira, la diyodoanilina 34e pierde el átomo de yodo más impedido estéricamente de su estructura (Esquema 1.77). Así, la reacción de Sonogashira tiene lugar selectivamente sobre el otro átomo de yodo debido, probablemente, a su menor congestión estérica.

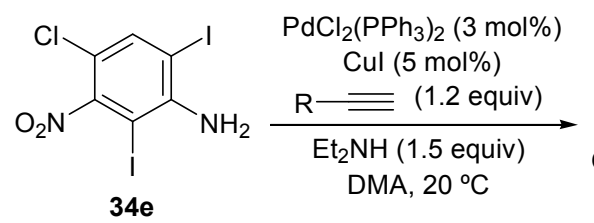<smiles>[R]C#Cc1cc(Cl)c([N+](=O)[O-])cc1N</smiles>

Esquema 1.77

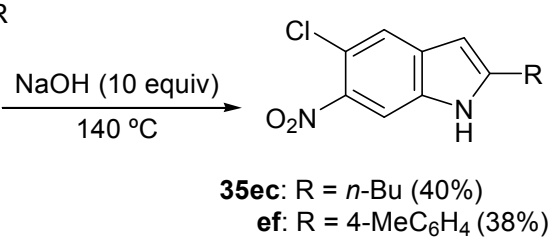

\section{e) Reducción selectiva de 5,7-dinitroindoles 2-sustituidos 38}

A continuación nos planteamos estudiar la reacción de acoplamiento / heterociclación empleando anilinas de partida con dos grupos nitro en su estructura. Se decidió partir de la 2-bromo-4,6-dinitroanilina 34f, comercialmente disponible. Así cuando se hizo reaccionar esta dinitroanilina $\mathbf{3 4 f}$ con alquinos terminales, bajo las condiciones estándar de Sonogashira y, tras 30 minutos bajo irradiación de microondas a $100{ }^{\circ} \mathrm{C}$, se consiguieron aislar los 5,7-dinitroindoles $\mathbf{3 8}$ con buenos rendimientos. Hay que destacar que se obtuvieron los indoles $\mathbf{3 8}$ sin necesidad de adicionar $\mathrm{NaOH}$ al medio de reacción, debido al fuerte efecto electrón atractor que ejercen los dos grupos nitro que posee la $o$ alquinilanilina intermedia 37 en su estructura (Esquema 1.78).

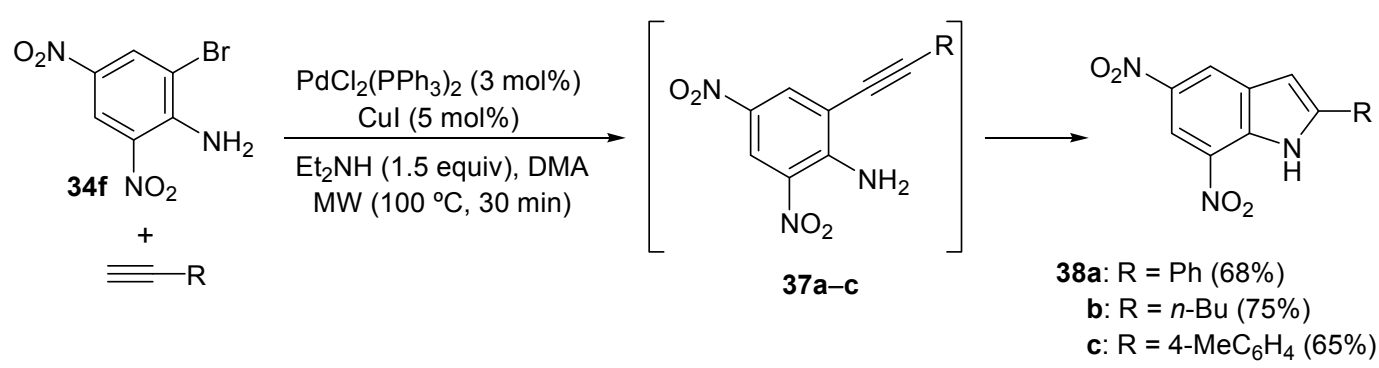

Esquema 1.78 
Sorprendentemente, cuando se ensayó la misma reacción entre 34f y distintos alquinos terminales bajo las condiciones de reacción ya descritas para la síntesis de los aminoindoles 36, (es decir empleando DMF como disolvente en lugar de DMA y con la adición de $\mathrm{NaOH}$ después del acoplamiento de Sonogashira), se obtuvieron los derivados indólicos 39, en los que únicamente uno de los dos grupos nitro se había reducido al correspondiente grupo amino (Tabla 1.14). En este caso la reacción no requirió un tratamiento adicional con $\mathrm{Pd} / \mathrm{C}$ para que la reducción se completara en un tiempo razonable y, tras sólo 2-4 horas de reacción con $\mathrm{NaOH}$, se pudieron aislar los 7-amino-5nitroindoles 39 con rendimientos moderados (Tabla 1.14). Este resultado es de gran interés debido a que no existía ningún método descrito en la literatura para la síntesis de 7-amino-5nitroindoles.

Tabla 1.14. Síntesis de 7-amino-5-nitroindoles 2 -sustituidos $\mathbf{3 9}$ a partir de $\mathbf{3 4 f} \mathbf{y}$ alquinos terminales

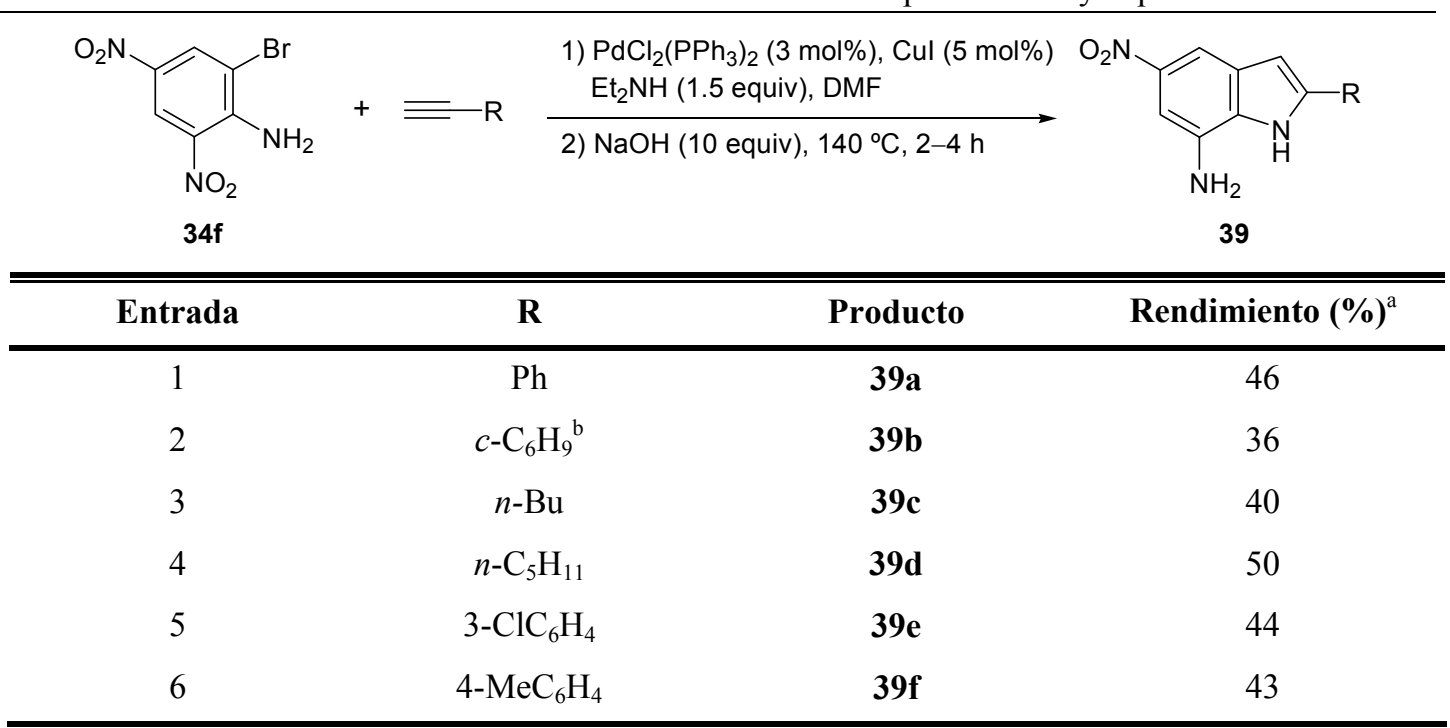

${ }^{a}$ Rendimiento en producto aislado referido a la 2-bromo-4,6-dinitroanilina 34f. ${ }^{\mathrm{b}}$ 1-Ciclohexenilo.

Hay que destacar que, en un primer momento, solo conocíamos que había tenido lugar una reducción selectiva de uno de los dos grupos nitro, sin embargo desconocíamos si esta reducción la había experimentado el grupo nitro en posición $\mathrm{C}-5$ o el localizado en la posición $\mathrm{C}-7$ del anillo. Intentamos determinar mediante análisis de los espectros de resonancia magnética nuclear (RMN) de los compuestos 39b y 39c qué grupo nitro había experimentado la reducción durante el transcurso de la reacción. Para ello realizamos 
experimentos bidimensionales de RMN: COSY, HMQC, HMBC y NOESY con el fin de poder realizar esta determinación. Sin embargo, tras estudio cuidadoso de estos espectros fue imposible asignar con total seguridad cuál de los dos grupos nitro (el de la posición $5 \mathrm{o}$ el de la posición 7) había sufrido el proceso de reducción.

Por lo tanto nuestro siguiente objetivo fue la preparación de algún derivado de estos aminonitroindoles 39 que nos pudiera ayudar a establecer su estructura sin ambigüedad. En primer lugar, la desprotonación del aminonitroindol 39b por tratamiento con $\mathrm{KOH}$, seguida de su reacción con exceso de MeI, permitió aislar el derivado 40a con tres grupos metilo (Esquema 1.79). Sin embargo, el estudio de los espectros bidimensionales de RMN tampoco nos permitió determinar su estructura.<smiles>Nc1cc([N+](=O)[O-])cc2cc(C3=CCCCC3)[nH]c12</smiles>

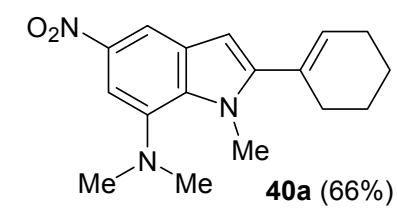

Esquema 1.79

A la vista de estos resultados decidimos preparar un derivado del indol 39f con un grupo sulfonamida, con el objetivo de conseguir un compuesto más fácilmente cristalizable. Así, el tratamiento del aminonitroindol 39f con cloruro de tosilo en piridina permitió obtener el derivado indólico $\mathbf{4 0 b}$ con un rendimiento del 70\% (Esquema 1.80).

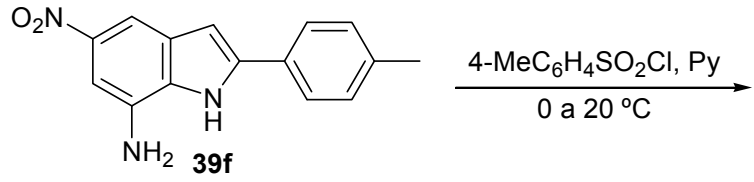

\section{Esquema 1.80}<smiles>Cc1ccc(-c2cc3cc([N+](=O)[O-])cc(NS(=O)(=O)c4ccc(C)cc4)c3[nH]2)cc1</smiles>

40b $(70 \%)$

Hay que resaltar que la estructura del producto 40b pudo ser confirmada por la técnica de difracción de rayos X (Figura 1.1), obteniéndose monocristales del 5-nitro-2-ptolil-7-( $N$-tosilamino)- $1 H$-indol $\mathbf{4 0 b}$ adecuados para su resolución estructural por 
evaporación lenta de una disolución de 40b en una mezcla de dietilamina y hexano como disolventes. La molécula 40b cristalizó junto con una molécula de dietilamina. ${ }^{155}$

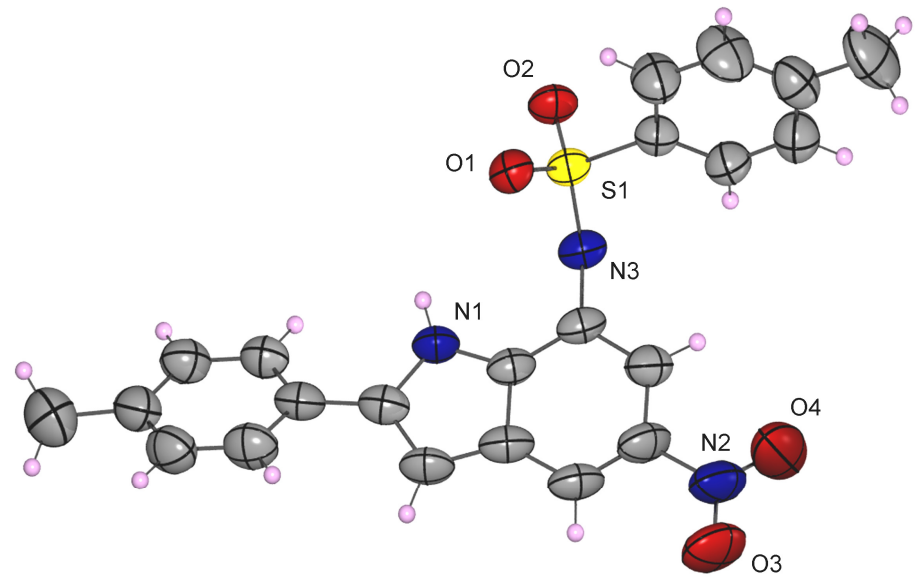

Figura 1.1. Estructura cristalina del compuesto $40 \mathrm{~b}$ (se omite una molécula de $\mathrm{Et}_{2} \mathrm{NH}$ por claridad). Elipsoides térmicos al 50\%.

La relevancia de esta nueva síntesis de los 7-amino-5-nitroindoles 39 también resultó avalada por el hecho de que la reducción del 5,7-dinitroindol 38a empleando condiciones convencionales $\left(\mathrm{H}_{2}\right.$ con $\mathrm{Pd} / \mathrm{C}$ en $\left.\mathrm{EtOH}\right)$ condujo al correspondiente derivado 5,7-diaminoindólico con un rendimiento del $84 \% .{ }^{156}$

Por lo tanto, se ha descrito una nueva aproximación para la síntesis de indoles 2sustituidos que contienen un grupo amino o nitro en el anillo bencénico basada en un proceso de acoplamiento de Sonogashira / heterociclación, y redución simultánea de un grupo nitro a un grupo amino, cuando se emplea DMF como disolvente. Esta metodología ha permitido la preparación regioselectiva de indoles nitrógeno-funcionalizados en un proceso "one-pot" a partir de anilinas comerciales o fáciles de preparar. Además, es interesante destacar que se ha desarrollado una nueva síntesis selectiva de 7-amino-5-nitroindoles a partir de la 2-bromo-4,6dinitroanilina. Los 7-amino-5-nitroindoles son compuestos que no habían sido preparados con anterioridad a este trabajo.

${ }^{155} \mathrm{CCDC} 725042$ contiene los datos cristalográficos del compuesto $\mathbf{4 0 b} \cdot \mathrm{Et}_{2} \mathrm{NH}$. Estos datos pueden ser obtenidos de The Cambridge Crystallographic Data Centre a través de www.ccdc.cam.ac.uk/data_request/cif.

${ }^{156}$ S. Saleha, A. A. Siddiqui, N. H. Khan, Indian J. Chem. 1980, 19B, 81. 


\subsubsection{SÍNTESIS REGIOSELECTIVA DE 4-HALOINDOLES 28}

\section{a) Preparación de los 4-haloindoles 28 a partir de las alquinilanilidas 27}

Una vez optimizado el proceso de ciclación de las orto-alquinilanilinas 29 con respecto a la cantidad de $\mathrm{NaOH}$, temperatura y disolvente a emplear, decidimos aplicar este procedimiento a la síntesis de los 4-haloindoles $\mathbf{2 8}$ a partir de las orto-alquinilanilidas 27. Así, el tratamiento de las anilidas $27 \mathbf{b a}-\mathbf{c g}$ con 3 equiv. de $\mathrm{NaOH}$ en polvo, en DMF como disolvente a $140{ }^{\circ} \mathrm{C}$, condujo a los 4-cloro y 4-bromoindoles 28 con buenos rendimientos (Tabla 1.15).

Tabla 1.15. Síntesis de los 4-halo- $1 H$-indoles 28 a partir de las 2-alquinil-3-haloanilidas 27
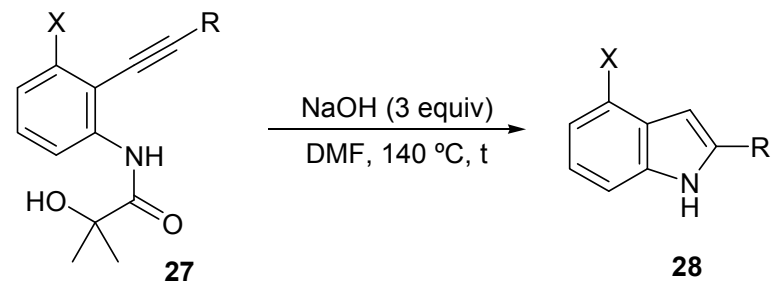

\begin{tabular}{|c|c|c|c|c|c|c|}
\hline Entrada & Material partida & $\mathbf{X}$ & Alquino (R) & Tiempo (h) & Producto & Rto. $(\%)^{\mathrm{a}}$ \\
\hline 1 & $27 \mathrm{ba}$ & $\mathrm{Cl}$ & $\mathrm{Ph}$ & 4 & $28 b a$ & 79 \\
\hline 2 & $27 \mathrm{bb}$ & $\mathrm{Cl}$ & $n-\mathrm{Bu}$ & 2.5 & $28 \mathrm{bb}$ & 86 \\
\hline 3 & $27 \mathrm{bc}$ & $\mathrm{Cl}$ & $n-\mathrm{C}_{5} \mathrm{H}_{11}$ & 2.5 & $28 \mathrm{bc}$ & 84 \\
\hline 4 & 27bd & $\mathrm{Cl}$ & $c-\mathrm{C}_{6} \mathrm{H}_{9}{ }^{\mathrm{b}}$ & 2.5 & 28bd & 81 \\
\hline 5 & $27 \mathrm{be}$ & $\mathrm{Cl}$ & $\mathrm{SiMe}_{3}$ & 4 & $28 b e^{c}$ & 73 \\
\hline 6 & $27 \mathrm{bf}$ & $\mathrm{Cl}$ & $\mathrm{Si}(i-\operatorname{Pr})_{3}$ & 3 & $28 b e^{c}$ & 75 \\
\hline 7 & $27 \mathrm{ca}$ & $\mathrm{Br}$ & $\mathrm{Ph}$ & 5 & $28 \mathrm{ca}$ & 83 \\
\hline 8 & $27 \mathrm{cb}$ & $\mathrm{Br}$ & $n$-Bu & 3 & $28 \mathrm{cb}$ & 80 \\
\hline 9 & $27 \mathrm{cc}$ & $\mathrm{Br}$ & $n-\mathrm{C}_{5} \mathrm{H}_{11}$ & 2.5 & $28 \mathrm{cc}$ & 82 \\
\hline 10 & $27 \mathrm{~cd}$ & $\mathrm{Br}$ & $c-\mathrm{C}_{6} \mathrm{H}_{9}{ }^{\mathrm{b}}$ & 4 & $28 \mathrm{~cd}$ & 76 \\
\hline 11 & 27ce & $\mathrm{Br}$ & $\mathrm{SiMe}_{3}$ & 5 & $28 \mathrm{ce}^{\mathrm{d}}$ & 75 \\
\hline 12 & $27 \mathrm{cg}$ & $\mathrm{Br}$ & $3-T h^{\mathrm{e}}$ & 3 & $28 \mathrm{cg}$ & 71 \\
\hline
\end{tabular}

${ }^{\mathrm{a}}$ Rendimiento en producto aislado referido a las $o$-alquinilanilidas de partida 27. ${ }^{\mathrm{b}}$ 1-Ciclohexenilo. ${ }^{\mathrm{c}}$ 4-Cloro-1Hindol $(\mathrm{R}=\mathrm{H}) .{ }^{\mathrm{d}}$ 4-Bromo- $1 H$-indol $(\mathrm{R}=\mathrm{H}) .{ }^{\mathrm{e}}$ 3-Tienilo 
Hay que señalar que, bajo las condiciones básicas en las que se llevó a cabo la ciclación, también se produjo la desprotección del átomo de nitrógeno en las anilidas $\mathbf{2 7}$ conduciendo a los derivados $\mathbf{2 8}$ con el nitrógeno indólico libre. Además, cuando se emplearon los $o$-trialquilsilil derivados $27 \mathbf{b e}, 27 \mathbf{b f}$ y $27 \mathbf{c e}$ como productos de partida, se obtuvieron los 4-halo- $1 H$-indoles $\mathbf{2 8}$ sin sustituir en la posición 2 del anillo indólico, debido a la ruptura del grupo sililo bajo las condiciones de reacción (Tabla 1.15, entradas 5, 6 y 11).

\section{b) Preparación de los 4-haloindoles 28 a partir de las 2,3-dihaloanilidas 25}

Anteriormente hemos demostrado que los indoles 2-sustituidos podían ser preparados mediante un procedimiento "one-pot" a partir de derivados de orto-yodoanilinas y alquinos terminales, a través de un acoplamiento de Sonogashira seguido de una ciclación mediada por $\mathrm{NaOH}$, y $\sin$ necesidad de aislar la correspondiente orto-alquinilanilina intermedia. Decidimos aplicar esta estrategia a la síntesis de los 4-haloindoles 28. Así, la reacción de las 3-halo-2-yodoanilidas 25aa-ca con una selección de alquinos terminales, de acuerdo a este procedimiento "one pot" de acoplamiento / ciclación 5-endo-dig, permitió sintetizar los 4-fluoro, 4-cloro y 4-bromo- $1 H$-indoles 28. Debido a la experiencia previa en la síntesis de los indoles 2-sustituidos 30, se decidió emplear DMA como disolvente en lugar de DMF para llevar a cabo este proceso. De esta forma se evitó una posible reducción del triple enlace en las $o$-alquinilanilidas intermedias 27. Con este procedimiento se obtuvieron los 4-fluoroindoles 28aa-ae (Tabla 1.16, entradas 1-4) y los 4-cloroindoles 28ba-bi (Tabla 1.16, entradas 5-10) con buenos rendimientos referidos a las anilidas de partida 25. Sin embargo, la 3-bromo-2-yodoanilida 25ca condujo a rendimientos más moderados de los correspondientes 4-bromoindoles 28ca-ch (Tabla 1.16, entradas 11-15). Este hecho podría deberse a que los complejos de paladio no fueron eliminados después del acoplamiento de Sonogashira, lo que puede dar lugar a procesos competitivos catalizados por paladio que implicarían el enlace $\mathrm{C}-\mathrm{Br}$, conduciendo a diferentes subproductos y justificando el menor rendimiento obtenido para la síntesis de los 4-bromoindoles $\mathbf{2 8}$. Por lo tanto, un proceso en dos pasos, con aislamiento del intermedio 27 , resulta ser más apropiado para acceder a los 4-bromoindoles 28.

Por otro lado, hay que descatar que esta metodología permitió la preparación 4haloindoles con una amplia variedad de sustituyentes en la posición $\mathrm{C}-2$ del anillo indólico (Tabla 1.16). Así, se demostró que el empleo de alquinos con sustituyentes tanto alquilo 
(entradas 2, 6 y 12), trialquilsililo (entradas 4 y 8 ) o alquenilo (entradas 3,7 y 13), como arilo (entradas 1, 5, 9, 10, 11 y 15) o heteroarilo (entrada 14) son compatibles con estas condiciones de reacción. Este procedimiento permitió incluso la utilización de alquinos arílicos con sustituyentes electrón atractores (entradas 9, 10 y 15).

Tabla 1.16. Síntesis de los 4-halo- $1 H$-indoles 28 a partir de las 2,3-dihaloanilidas 25

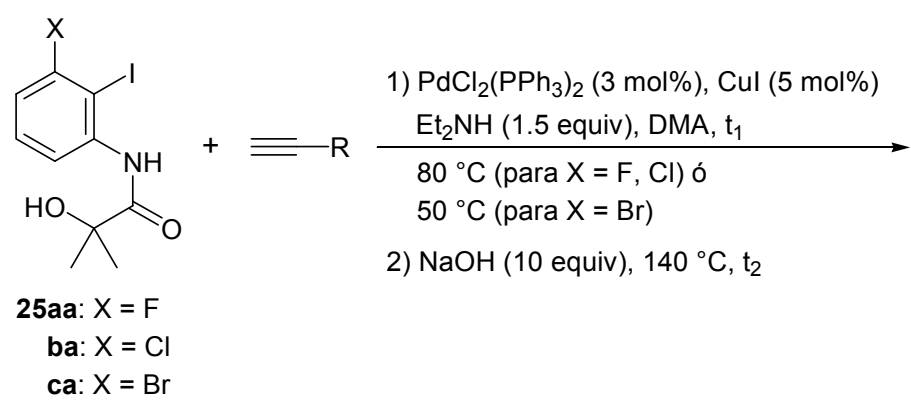<smiles>[R]c1cc2c([X])cccc2[nH]1</smiles>

28

\begin{tabular}{|c|c|c|c|c|c|c|c|}
\hline Entrada & 25 & $\mathbf{X}$ & $\mathbf{R}$ & $\mathbf{t}_{1}(\mathrm{~h})$ & $t_{2}(h)$ & Producto & Rto. $(\%)^{\mathrm{a}}$ \\
\hline 1 & $25 a a$ & $\mathrm{~F}$ & $\mathrm{Ph}$ & 3 & 4 & 28aa & 85 \\
\hline 2 & $25 a a$ & $\mathrm{~F}$ & $n-\mathrm{Bu}$ & 3 & 3 & $28 a b$ & 77 \\
\hline 3 & $25 a a$ & $\mathrm{~F}$ & $c-\mathrm{C}_{6} \mathrm{H}_{9}{ }^{\mathrm{b}}$ & 3 & 4 & 28ad & 65 \\
\hline 4 & $25 a a$ & $\mathrm{~F}$ & $\mathrm{SiMe}_{3}$ & $3^{c}$ & 3 & $28 \mathbf{a} e^{d}$ & 56 \\
\hline 5 & $25 \mathrm{ba}$ & $\mathrm{Cl}$ & $\mathrm{Ph}$ & 3 & 4 & $28 b a$ & 81 \\
\hline 6 & $25 \mathrm{ba}$ & $\mathrm{Cl}$ & $n-\mathrm{Bu}$ & 2.5 & 3 & $28 b b$ & 71 \\
\hline 7 & $25 \mathrm{ba}$ & $\mathrm{Cl}$ & $c-\mathrm{C}_{6} \mathrm{H}_{9}{ }^{\mathrm{b}}$ & 2 & 3 & $28 b d$ & 82 \\
\hline 8 & $25 \mathrm{ba}$ & $\mathrm{Cl}$ & $\mathrm{SiMe}_{3}$ & $5.5^{\mathrm{c}}$ & 3 & $28 b e^{e}$ & 61 \\
\hline 9 & $25 \mathrm{ba}$ & $\mathrm{Cl}$ & $3-\mathrm{ClC}_{6} \mathrm{H}_{4}$ & 2 & 3 & $28 \mathrm{bh}$ & 75 \\
\hline 10 & $25 \mathrm{ba}$ & $\mathrm{Cl}$ & $4-\mathrm{F}-3-\mathrm{MeC}_{6} \mathrm{H}_{3}$ & 2 & 4 & $28 b i$ & 72 \\
\hline 11 & $25 \mathrm{ca}$ & $\mathrm{Br}$ & $\mathrm{Ph}$ & 3 & 4 & $28 c a$ & 49 \\
\hline 12 & $25 \mathrm{ca}$ & $\mathrm{Br}$ & $n-\mathrm{Bu}$ & 2 & 3 & $28 \mathrm{cb}$ & 55 \\
\hline 13 & $25 \mathrm{ca}$ & $\mathrm{Br}$ & $c-\mathrm{C}_{6} \mathrm{H}_{9}{ }^{\mathrm{b}}$ & 2.5 & 2.5 & $28 \mathrm{~cd}$ & 48 \\
\hline 14 & $25 \mathrm{ca}$ & $\mathrm{Br}$ & $3-T h^{f}$ & 2.5 & 12 & $28 \mathrm{cg}$ & 55 \\
\hline 15 & $25 \mathrm{ca}$ & $\mathrm{Br}$ & $3-\mathrm{ClC}_{6} \mathrm{H}_{4}$ & 2 & 4 & $28 \mathrm{ch}$ & 50 \\
\hline
\end{tabular}

${ }^{\mathrm{a}}$ Rendimiento en producto aislado referido a las acetanilidas de partida $\mathbf{2 5} .{ }^{\mathrm{b}} 1$-Ciclohexenilo. ${ }^{\mathrm{c}}$ Llevada a cabo a $40{ }^{\circ} \mathrm{C}$ debido a la volatilidad del trimetilsililacetileno. ${ }^{\mathrm{d}}$ 4-Fluoro- $1 H$-indol $(\mathrm{R}=\mathrm{H}) .{ }^{\mathrm{e}}$ 4-Cloro- $1 H$-indol $(\mathrm{R}=\mathrm{H})$. 3-Tienilo. 
Se puede concluir que el procedimiento "one pot" de acoplamiento / heterociclación promovido por $\mathrm{NaOH}$ es una estrategia sintética sencilla y eficiente para la preparación de $1 H$-indoles funcionalizados regioespecíficamente en la posición 4 del anillo con buenos rendimientos y sin necesidad de aislar la alquinilanilida intermedia $\mathbf{2 7}$.

\section{c) Síntesis de los 4-fluoro-1H-indoles 28aa,aj y 41 a partir de la trifluoroacetamida 3aa}

Aprovechando el sencillo procedimiento puesto a punto para la preparación de la 3fluoro-2-yodotrifluoroacetanilida 3aa, a partir de la 2,2,2-trifluoro- $N$-(3-fluorofenil) acetamida 1a, mediante una reacción de $o$-litiación y posterior tratamiento con yodo (págs. 74 y 75), así como el interés y novedad que presentan los 4-fluoroindoles, decidimos emplear la acetamida 3aa como sustrato de partida en la síntesis de una familia de estos compuestos. Así logramos preparar de forma eficiente los 4-fluoro- $1 H$-indoles 2 -sustituidos 28aa,aj, por tratamiento de 3aa con alquinos terminales a través de un proceso tándem de acoplamiento catalizado por Pd / Cu-heterociclación (Esquema 1.81). ${ }^{157}$

Se emplearon $\mathrm{PdCl}_{2}\left(\mathrm{PPh}_{3}\right)_{2}$ y CuI como catalizadores y dietilamina como base para llevar a cabo la reacción de Sonogashira. Es interesante destacar que se obtuvieron los correspondientes indoles $\mathbf{2 8}$ con buenos rendimientos sin necesidad de adicionar $\mathrm{NaOH}$ tras el acoplamiento de 3aa con el correspondiente alquino terminal, debido al fuerte efecto electrón atractor del grupo trifluoroacetamido en la $o$-alquinilanilida intermedia (Esquema $1.81)$.

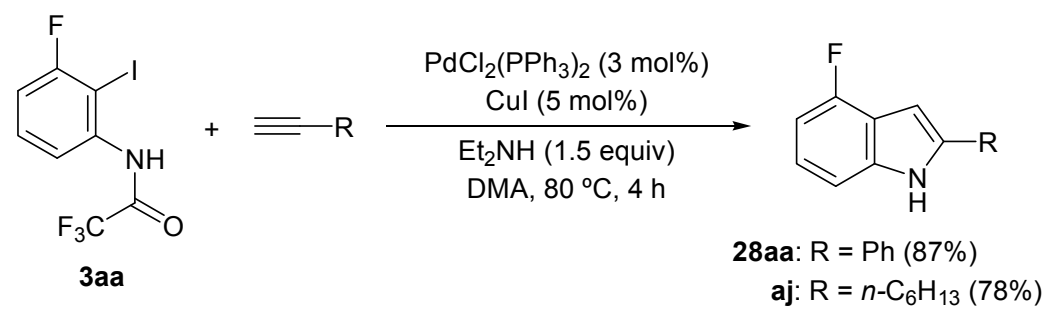

Esquema 1.81

157 a) H. A. Oskooie, M. M. Heravi, F. K. Behbahani, Molecules 2007, 12, 1438. b) M. M. Heravi, S. Sadjadi, Tetrahedron 2009, 65, 7761. 
Por otro lado, la reacción dominó de aminopaladación-eliminación reductora desarrollada fundamentalmente por Cacchi y colaboradores, ${ }^{158}$ ha sido empleada como una estrategia muy útil para la construcción regioselectiva de anillos indólicos 2,3-disustituidos a partir de orto-alquiniltrifluoroacetanilidas (Esquema 1.82).

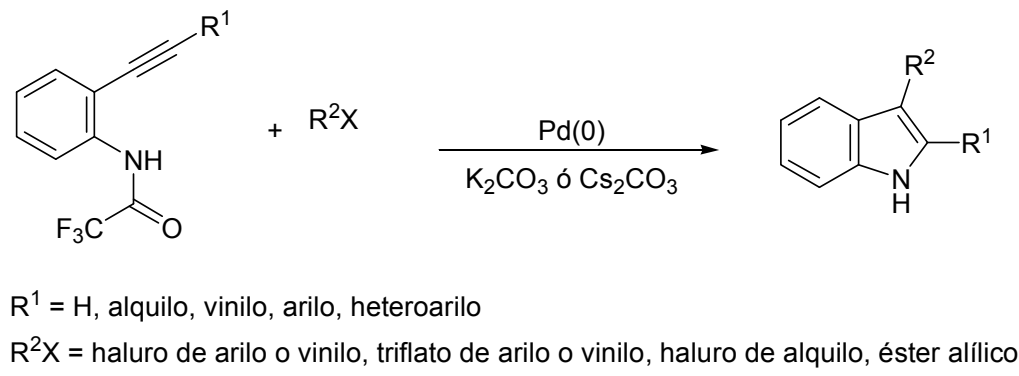

\section{Esquema 1.82}

Hay que resaltar que también se ha descrito la síntesis de $1 H$-indoles 2,3disustituidos mediante procesos "one pot" de tres componentes (o-haloanilida, alquino terminal y haluro de arilo). ${ }^{159}$ Basándonos en la estrategia descrita por Lu y colaboradores, ${ }^{159 \mathrm{~b}}$ nos planteamos sintetizar 4-fluoroindoles 2,3-disustituidos y así, fuimos capaces de preparar una amplia variedad de 3-aril-4-fluoro- $1 H$-indoles 2 -sustituidos 41 a partir de la 3-fluoro-2-yodotrifluoroacetanilida 3aa, alquinos terminales y bromuros de arilo en un proceso "one-pot" a través de reacciones tándem Sonogashira-Cacchi (Tabla 1.17). Se obtuvieron en general buenos rendimientos de 41 (Tabla 1.17), teniendo en cuenta que éstos se refieren a la trifluoroacetanilida de partida 3aa. Desde un punto de vista experimental también encontramos que los bromuros de arilo podían ser añadidos bien después de que la yodoanilida 3aa de partida se consumiera en el primer acoplamiento (monitorizado por CG-EM) (Tabla 1.17, entradas 1,2, 5-8), o bien desde el principio de la reacción (Tabla 1.17, entradas 3 y 4 ).

\footnotetext{
158 a) G. Battistuzzi, S. Cacchi, G. Fabrizi, Eur. J. Org. Chem. 2002, 2671. b) A. Arcadi, S. Cacchi, G. Fabrizi, F. Marinelli, L. M. Parisi, J. Org. Chem. 2005, 70, 6213. c) S. Cacchi, G. Fabrizi, A. Goggiamani, Adv. Synth. Catal. 2006, 348, 1301. d) S. Cacchi, G. Fabrizi, A. Goggiamani, A. Perboni, A. Sferrazza, P. Stabile, Org. Lett. 2010, 12, 3279.

159 a) J. H. Chaplin, B. L. Flynn, Chem. Commun. 2001, 1594. b) B. Z. Lu, W. Zhao, H.-X. Wei, M. Dufour, V. Farina, C. H. Senanayake, Org. Lett. 2006, 8, 3271. c) Y. Chen, N. A. Markina, R. C. Larock, Tetrahedron 2009, 65, 8908 .
} 
Tabla 1.17. Síntesis de 3-aril-4-fluoro- $1 H$-indoles 2 -sustituidos 41

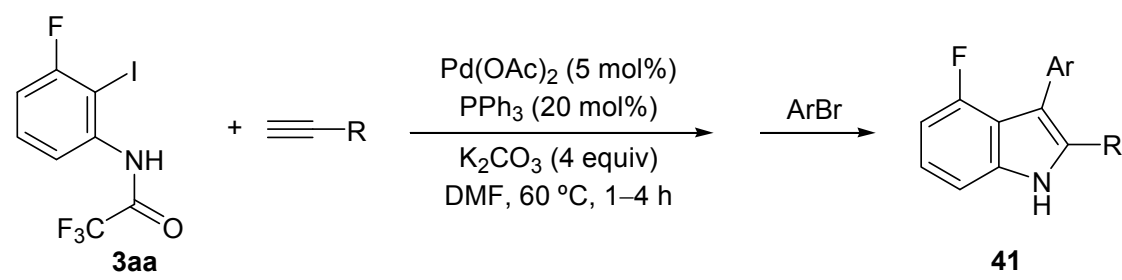

\begin{tabular}{ccccc}
\hline \hline Entrada & $\mathbf{R}$ & $\mathbf{A r}$ & Producto & Rto. (\%) $)^{\mathrm{a}}$ \\
\hline 1 & $\mathrm{Ph}$ & $2-\mathrm{NO}_{2} \mathrm{C}_{6} \mathrm{H}_{4}$ & $\mathbf{4 1 a}$ & 72 \\
2 & $n-\mathrm{Bu}$ & $2-\mathrm{NO}_{2} \mathrm{C}_{6} \mathrm{H}_{4}$ & $\mathbf{4 1 b}$ & 80 \\
$3^{\mathrm{b}}$ & $\mathrm{Ph}$ & $3-\mathrm{MeOC}_{6} \mathrm{H}_{4}$ & $\mathbf{4 1 c}$ & 84 \\
$4^{\mathrm{b}}$ & $n-\mathrm{C}_{6} \mathrm{H}_{13}$ & $4-\mathrm{MeO}^{\mathrm{c}}-\mathrm{MeC}_{6} \mathrm{H}_{3}$ & $\mathbf{4 1 d}$ & 56 \\
5 & $3-\mathrm{Th}^{\mathrm{c}}$ & $3-\mathrm{CNC}_{6} \mathrm{H}_{4}$ & $\mathbf{4 1 e}$ & 86 \\
6 & $c-\mathrm{C}_{6} \mathrm{H}_{9}{ }^{\mathrm{d}}$ & $4-\mathrm{NO}_{2} \mathrm{C}_{6} \mathrm{H}_{4}$ & $\mathbf{4 1 f}$ & 85 \\
7 & $4-\mathrm{MeOC}_{6} \mathrm{H}_{4}$ & $3-\mathrm{CNC}_{6} \mathrm{H}_{4}$ & $\mathbf{4 1 g}$ & 90 \\
8 & $n-\mathrm{C}_{6} \mathrm{H}_{13}$ & $2-\mathrm{CNC}_{6} \mathrm{H}_{4}$ & $\mathbf{4 1 h}$ & 46 \\
\hline
\end{tabular}

${ }^{a}$ Rendimiento en producto aislado referido a la acetanilida de partida 3aa. ${ }^{b}$ El bromuro de arilo se añadió desde el principio de la reacción. ${ }^{\mathrm{c}} 3$-Tienilo. ${ }^{\mathrm{d}} 1$-Ciclohexenilo.

Por otro lado, también preparamos los indoles trisustituidos $4 \mathbf{4} \mathbf{i}$ y $\mathbf{4 1 \mathbf { j }}$ mediante un procedimiento "one pot" en dos pasos desarrollado por Larock y colaboradores, ${ }^{159 \mathrm{c}}$ basado en la reacción de Cacchi. En esta alternativa sintética se empleó radiación de microondas como método de calentamiento y un yoduro de arilo, en lugar del correspondiente bromuro, para la introducción del grupo arilo en la posición C-3 del anillo indólico. Así, la reacción de 3aa con alquinos terminales empleando el sistema catalítico $\mathrm{PdCl}_{2}\left(\mathrm{PPh}_{3}\right)_{2} / \mathrm{CuI}$, en presencia de trietilamina como disolvente a $60{ }^{\circ} \mathrm{C}$ condujo al intermedio oalquiniltrifluoroacetamida correspondiente, cuya formación se detectó mediante CG-EM. A continuación, y sin necesidad de aislar este intermedio, la adición del yoduro de arilo y acetonitrilo al medio de reacción permitió obtener los 4-fluoroindoles 41i y 41j tras 30 minutos a $90{ }^{\circ} \mathrm{C}$. Ambos pasos de reacción se llevaron a cabo mediante el empleo de radiación de microondas, disminuyéndose así los tiempos de reacción. Hay que señalar que, aunque normalmente se requiere la adición de una base inorgánica tal como $\mathrm{K}_{2} \mathrm{CO}_{3}$ ó 
$\mathrm{Cs}_{2} \mathrm{CO}_{3}$ para llevar a cabo la reacción de Cacchi, en nuestro caso el proceso funcionó de forma eficiente bajo la influencia exclusiva de $\mathrm{Et}_{3} \mathrm{~N}$ como base (Esquema 1.83).

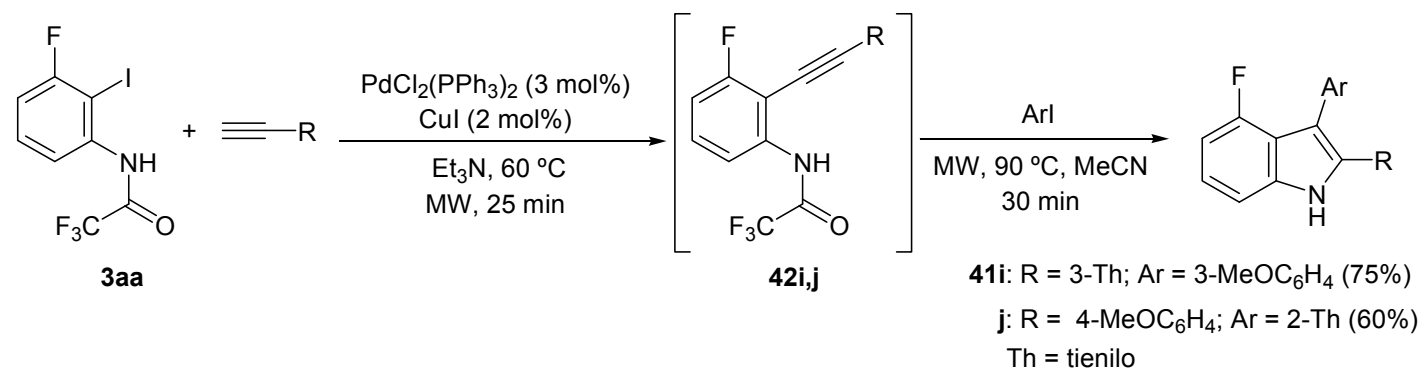

Esquema 1.83

Estos resultados demuestran que la 3-fluoro-2-yodotrifluoroacetamida 3aa es un material de partida muy interesante para acceder a 4-fluoroindoles funcionalizados de forma sencilla y eficaz.

\section{d) Síntesis de los 3-feniltio-4-halo-1 $\mathrm{H}$-indoles 2-sustituidos 43}

Nuestro siguiente objetivo fue la preparación de otros derivados indólicos polifuncionalizados a partir de las 2,3-dihaloanilidas 25. Nos planteamos introducir un grupo ariltio en la posición $\mathrm{C}-3$ en las mismas condiciones de reacción empleadas para la síntesis de los 3-ariltioindoles 32 (pág. 102). ${ }^{151}$ Así, se pudieron preparar los 4-halo-3feniltio- $1 H$-indoles 2 -sustituidos 43 , a partir de las 3-halo-2-yodoanilidas 25aa y 25ba y dos alquinos terminales distintos, en un proceso "one pot" en tres pasos que implicaba la adición de disulfuro de difenilo después del paso de ciclación mediado por $\mathrm{NaOH}$. Es interesante resaltar que estos derivados indólicos 2,3,4-trifuncionalizados $\mathbf{4 3}$ se prepararon con altos rendimientos a partir de las 2,3-dihaloanilidas 25 y sin necesidad de aislar ningún intermedio de reacción (Esquema 1.84). 


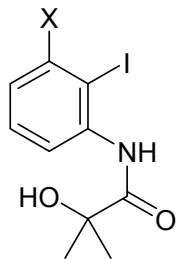

25aa: $X=F$

ba: $X=C$

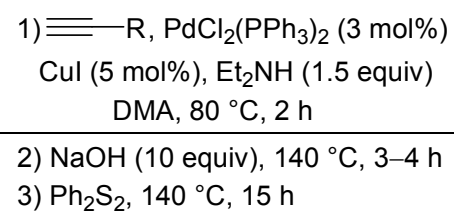

2) $\mathrm{NaOH}$ (10 equiv), $140{ }^{\circ} \mathrm{C}, 3-4 \mathrm{~h}$

3) $\mathrm{Ph}_{2} \mathrm{~S}_{2}, 140{ }^{\circ} \mathrm{C}, 15 \mathrm{~h}$<smiles></smiles>

43a: $X=F ; R=n-C_{5} \mathrm{H}_{11}(74 \%)$

b: $\mathrm{X}=\mathrm{Cl} ; \mathrm{R}=n-\mathrm{Bu}(78 \%)$

\section{Esquema 1.84}

También se pudo acceder a estos mismos indoles trisustituidos $\mathbf{4 3}$ a partir de las 2alquinil-3-haloanilidas 27 por tratamiento con $\mathrm{NaOH}$ y posterior adición del disulfuro (Tabla 1.18). El disulfuro (2- $\left.\mathrm{NH}_{2} \mathrm{C}_{6} \mathrm{H}_{4}\right)_{2} \mathrm{~S}_{2}$, no asequible comercialmente, se preparó por oxidación de 2-aminobencenotiol empleando el complejo de molibdeno $\mathrm{MoO}_{2} \mathrm{Cl}_{2}(\mathrm{DMSO})_{2}$ ( $2 \mathrm{~mol} \%$ ) en DMSO como disolvente a temperatura ambiente. ${ }^{160}$

Tabla 1.18 Síntesis de los 3-feniltio-4-halo- $1 H$-indoles 2-sustituidos $\mathbf{4 3}$ a partir de las 2-alquinil-3haloanilidas $27 \mathbf{b a}, \mathbf{c a}-\mathbf{c b}$.<smiles>[R]C#Cc1c([X])cccc1NC(=O)C(C)(C)O</smiles>

27ba,ca-b

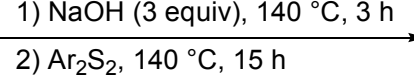<smiles>[R]c1[nH]c2cccc([X])c2c1[Se]</smiles>

$43 c-f$

\begin{tabular}{ccccccc}
\hline \hline Entrada & Anilida partida & $\mathbf{X}$ & $\mathbf{R}$ & $\mathbf{A r}$ & Producto & Rto. $(\%)^{\text {a }}$ \\
\hline 1 & $\mathbf{2 7 b a}$ & $\mathrm{Cl}$ & $\mathrm{Ph}$ & $\mathrm{Ph}$ & $\mathbf{4 3 c}$ & 79 \\
2 & $\mathbf{2 7 c a}$ & $\mathrm{Br}$ & $\mathrm{Ph}$ & $\mathrm{Ph}$ & $\mathbf{4 3 d}$ & 73 \\
3 & $\mathbf{2 7 c b}$ & $\mathrm{Br}$ & $n-\mathrm{Bu}$ & $\mathrm{Ph}$ & $\mathbf{4 3 e}$ & 75 \\
4 & $\mathbf{2 7 c b}$ & $\mathrm{Br}$ & $n-\mathrm{Bu}$ & $2-\mathrm{NH}_{2} \mathrm{C}_{6} \mathrm{H}_{4}$ & $\mathbf{4 3 f}$ & 60 \\
\hline
\end{tabular}

${ }^{\mathrm{a}}$ Rendimiento en producto aislado referido a la correspondiente alquinilanilida de partida 27.

${ }^{160}$ R. Sanz, R. Aguado, M. R. Pedrosa, F. J. Arnáiz, Synthesis 2002, 856. 


\section{e) Síntesis de $1 \mathrm{H}$-indoles funcionalizados en la posición 4}

Una vez desarrollada una nueva síntesis para acceder a las 2,3-dihaloanilidas 25 y a los 4-halo-1 $H$-indoles $\mathbf{2 8}$, el siguiente objetivo que nos propusimos fue demostrar que estos sustratos eran útiles para la obtención de $1 H$-indoles funcionalizados regioselectivamente en la posición 4 del anillo. A continuación se detallan las diferentes reacciones llevadas a cabo sobre algunas de las 2,3-dihaloanilidas 25 y de los 4-haloindoles 28.

\section{e.1 Síntesis de 4-alquinil-1H-indoles $\mathbf{4 5}$}

\section{e.1.1 Partiendo de la 2,3-dicloroanilida 25bc}

Aunque los acoplamientos de Sonogashira pudieron llevarse a cabo de forma selectiva en el átomo de yodo en las 3-halo-2-yodoanilidas 25aa-ca (Tabla 1.4 y Tabla 1.16), la presencia de un segundo átomo de halógeno en las anilidas 25 nos permitió plantearnos la idea de obtener 4-alquinil- $1 H$-indoles 2 -sustituidos, a través de un proceso de dialquinilación sobre ambos átomos de halógeno presentes en la dihaloanilida $\mathbf{2 5}$, seguido de la posterior ciclación de la 2,3-dialquinilanilida intermedia. En primer lugar, se escogió la 2,3-dicloroanilida 25bc como material de partida, debido a su más facil accesibilidad por ser el 2,3-diclorofenol un producto comercial, y se ensayó la reacción de dialquinilación usando el sistema catalítico descrito por Buchwald y Gelman para el acoplamiento de Sonogashira con cloruros de arilo. ${ }^{65 a}$ Así, el acoplamiento de 25 bc con exceso de diferentes alquinos terminales en presencia del sistema catalítico $\mathrm{PdCl}_{2}(\mathrm{MeCN})_{2} / \mathrm{XPhos}, \mathrm{Cs}_{2} \mathrm{CO}_{3}$ como base y acetonitrilo como disolvente a $80{ }^{\circ} \mathrm{C}$ condujo a las 2,3-dialquinilanilidas 44 (Tabla 1.19). La posterior reacción de ciclación de $\mathbf{4 4}$ en condiciones básicas, de acuerdo al procedimiento mediado por $\mathrm{NaOH}$ que habíamos puesto a punto, permitió obtener los 4-alquinil-1Hindoles 45 con buenos rendimientos. Estos indoles 45 poseen el mismo sustituyente tanto en la posición terminal del triple enlace como en la posición C-2 del anillo indólico (Tabla $1.19)$. 
Tabla 1.19. Preparación de los 4-alquinil- $1 H$-indoles 2 -sustituidos 45 a partir de la 2,3-dicloroanilida 25bc

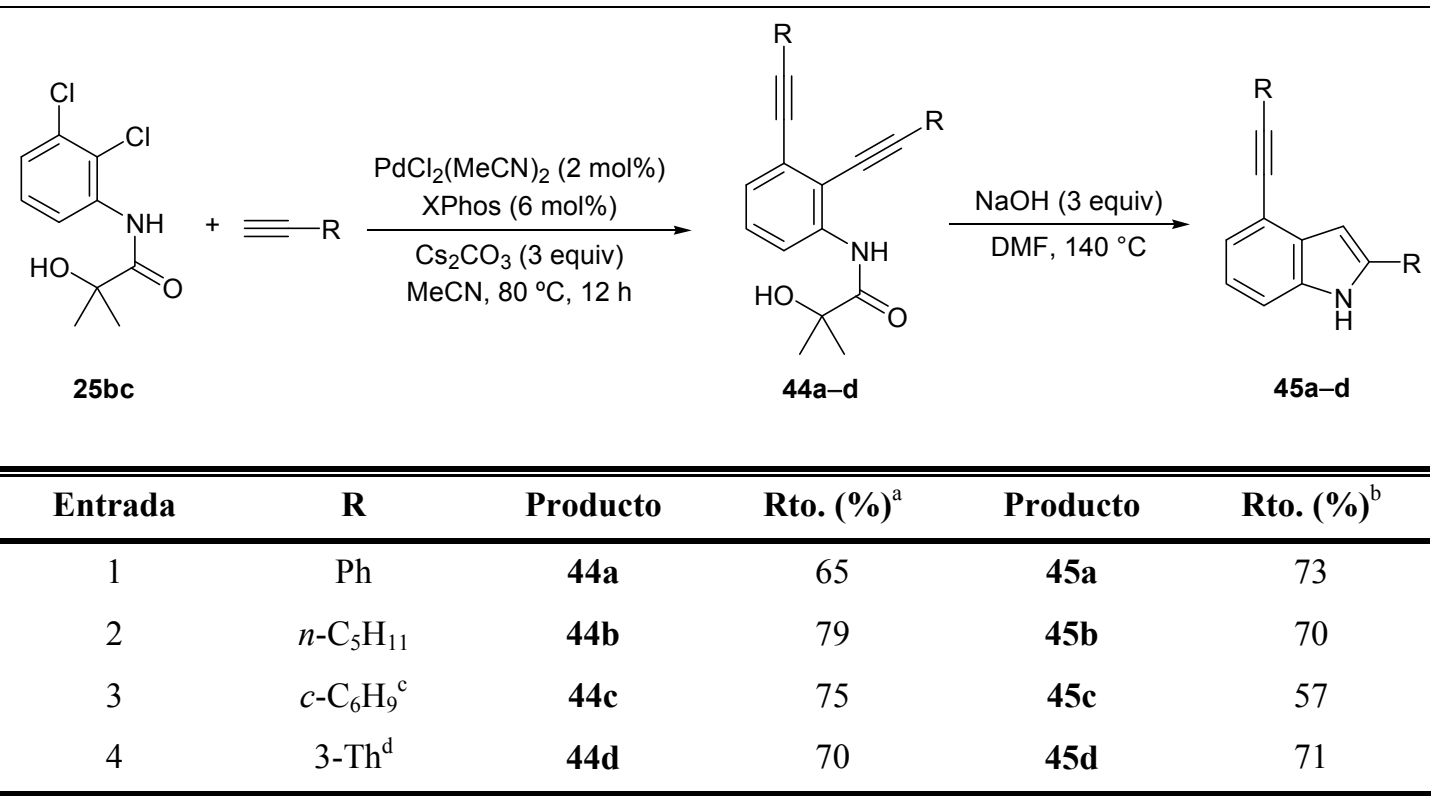

${ }^{\mathrm{a}}$ Rendimiento en producto aislado referido a la 2,3-dicloroanilida $25 \mathbf{b c}$. ${ }^{\mathrm{b}}$ Rendimiento en producto aislado referido a la correspondiente 2,3-dialquinilanilida de partida $44 a-d .{ }^{c} 1$-Ciclohexenilo. ${ }^{\mathrm{d}} 3$-Tienilo.

También se ensayó esta reacción de Sonogashira empleando únicamente 1.2 equiv. de 1-etinilciclohexeno como alquino terminal con el fin de comprobar si este acoplamiento podría ser regioselectivo y poder así obtener la 2-alquinil-3-cloroanilida $\mathbf{2 7 b d}$. Sin embargo, bajo las condiciones ensayadas se observó que la reacción no era selectiva y se obtuvo una mezcla en proporción aproximada (1 / 1) del isómero que presentaba la unidad de alquinilo sobre la posición $\mathrm{C}-2$ y del que la contenía en el carbono $\mathrm{C}-3$, junto con pequeñas cantidades de la anilida de partida 25bc (Esquema 1.85). El hecho de que se formasen estos dos isómeros con el grupo alquinilo en posiciones $\mathrm{C}-2$ y $\mathrm{C}-3$, respectivamente, desde el principio de la reacción y, antes de que se consumiera completamente la anilida de partida 25bc, pone de manifiesto la imposibilidad de obtener selectivamente uno de estos isómeros, al menos, bajo las condiciones ensayadas. 

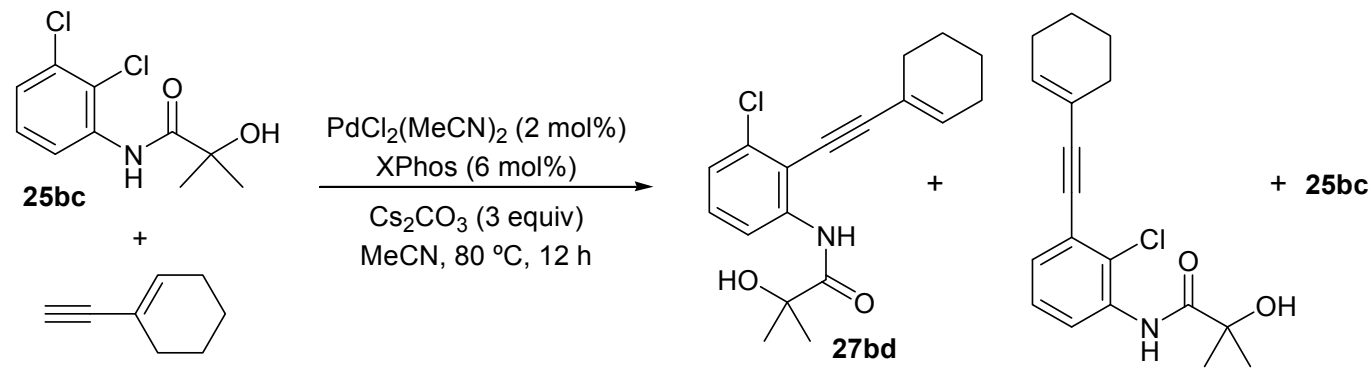

Esquema 1.85

\section{e.1.2 Partiendo de la 2,3-diclorotrifluoroacetamida $3 \mathbf{b c}$}

Debido a que la 2,3-dicloroanilina es un compuesto disponible comercialmente, decidimos comprobar la utilidad de la trifluoroacetamida 3bc en la síntesis del mismo tipo de indoles 45. La trifluoroacetamida 3bc se preparó por tratamiento de la 2,3-dicloroanilina con anhídrido trifluoroacético en presencia de $\mathrm{Na}_{2} \mathrm{CO}_{3}$ como base.

El acoplamiento de $\mathbf{3 b c}$ con distintos alquinos terminales de acuerdo a las condiciones empleadas para la síntesis de 44a-d condujo a los indoles 45e,f con rendimientos moderados. Debido a la presencia del grupo trifluoroacetamido sobre el átomo de nitrógeno, no se pudieron aislar las correspondientes 2,3-dialquiniltrifluroacetamidas 44

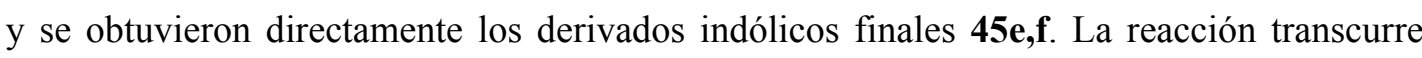
mediante un proceso "one-pot", aunque con un rendimiento global similar comparado al obtenido en el procedimiento en dos pasos cuando se empleaba la anilida $25 \mathbf{b c}$ como sustrato de partida (Esquema 1.86).<smiles>[R]C#C[CH]C(=O)Nc1cccc(Cl)c1Cl</smiles>
$\mathrm{PdCl}_{2}(\mathrm{MeCN})_{2}(2 \mathrm{~mol} \%)$ $\mathrm{MeCN}, 80^{\circ} \mathrm{C}, 12 \mathrm{~h}$ $3 b c$<smiles>[R]C#Cc1cccc2[nH]c([R])cc12</smiles>

45e: $\mathrm{R}=4-\mathrm{MeC}_{6} \mathrm{H}_{4}(44 \%)$ f: $\mathrm{R}=n-\mathrm{C}_{6} \mathrm{H}_{13}(51 \%)$

\section{Esquema 1.86}




\section{e.1.3 Partiendo de la 3-bromo-2-yodoacetanilida $25 \mathrm{ca}$}

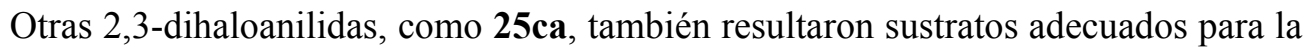
preparación de 4-alquinilindoles 45. En este caso, se sintetizó 45a empleando una metodología para el acoplamiento de Sonogashira libre de sales de cobre y en ausencia de disolvente (Esquema 1.87). ${ }^{59}$ Así, la reacción de 25 ca con fenilacetileno en presencia de $\mathrm{PdCl}_{2}\left(\mathrm{PPh}_{3}\right)_{2}$ en cantidades catalíticas y TBAF $3 \mathrm{H}_{2} \mathrm{O}$ a $60{ }^{\circ} \mathrm{C}$, seguida de la adición de $\mathrm{NaOH}$, una vez comprobada por CG-EM la formación de la dialquinilanilida intermedia, condujo al 4-alquinilindol 45a con un rendimiento moderado (Esquema 1.87).
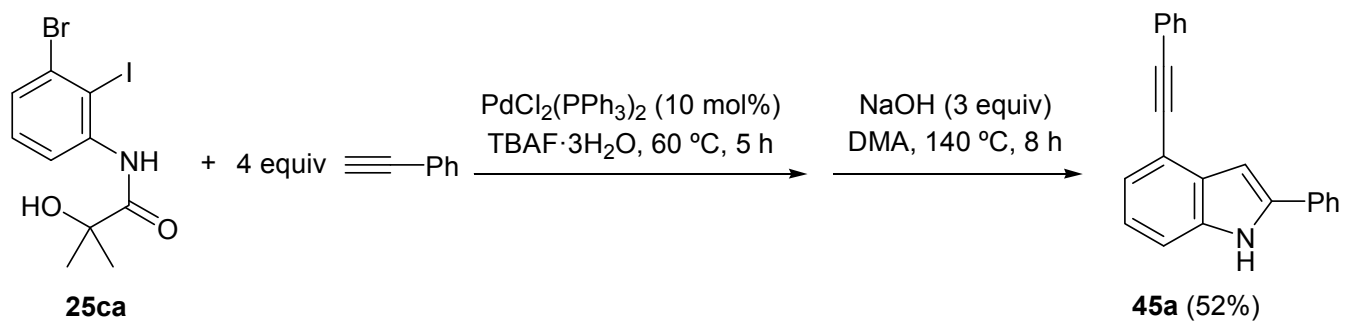

\section{Esquema 1.87}

\section{e.1.4 Partiendo del 4-bromo-2-fenilindol 28ca}

Aunque hemos descrito la preparación de 4-alquinil-1 $H$-indoles con el mismo sustituyente en la posición C-2 del indol y sobre el triple enlace de la posición C-4 (Tabla 1.19 y Esquemas 1.86 y 1.87), parece interesante poder acceder a 4-alquinil- $1 H$-indoles con distintos sustituyentes en el carbono $\mathrm{C}-2$ y en la posición terminal del triple enlace. Con este objetivo, se trató el 4-bromoindol 28ca con 1-hexino bajo las condiciones estándar de Sonogashira obteniéndose el 4-(1-hexinil)-2-fenil-1 $H$-indol 45g con buen rendimiento (Esquema 1.88).<smiles>Brc1cccc2[nH]c(-c3ccccc3)cc12</smiles>

28ca<smiles>CCCC#Cc1cccc2[nH]c(-c3ccccc3)cc12</smiles>

$45 g(77 \%)$

\section{Esquema 1.88}


e.2 Síntesis de 4-heteroaril-1H-indoles 2-sustituidos 46 mediante la reacción de $\underline{\text { Stille }}$

También decidimos estudiar la utilidad sintética de los 4-haloindoles 28 como precursores de otros $1 H$-indoles 4 -funcionalizados empleando acoplamientos catalizados por paladio. Así, decidimos preparar $1 H$-indoles que presentasen un sustituyente heteroarílico en la posición 4 utilizando para ello la reacción de Stille. ${ }^{70 a}$ Con este fin, se trataron los 4 cloroindoles 28ba,bb con 2-tributilestannilfurano en presencia del sistema catalítico $\mathrm{Pd}(\mathrm{OAc})_{2} / \mathrm{Xphos}, \mathrm{CsF}$ como base y 1,2-dimetoxietano (DME) como disolvente. ${ }^{70 b}$ Después de 3 horas a $80{ }^{\circ} \mathrm{C}$, se aislaron los 4-heteroarilindoles 46 con excelentes rendimientos (Esquema 1.89).

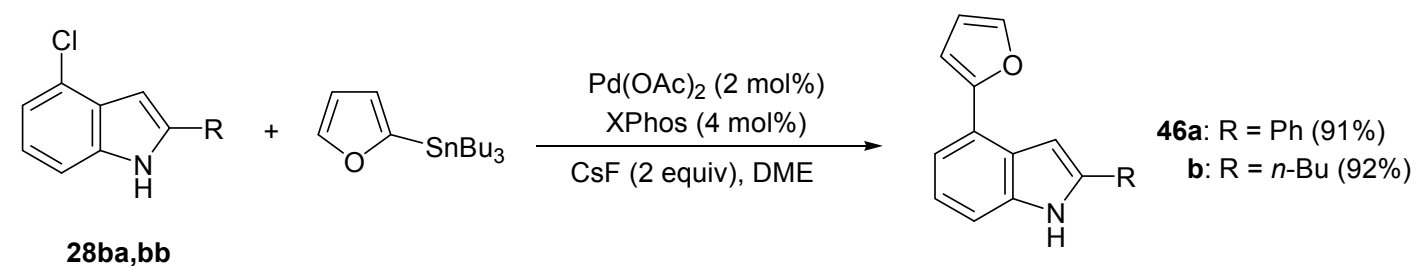

\section{Esquema 1.89}

\section{e.3 Síntesis de 4-aril-1H-indoles 2-sustituidos 47 mediante la reacción de Suzuki}

Como siguiente objetivo nos propusimos preparar $1 H$-indoles que presentasen un sustituyente arílico en la posición 4 del anillo indólico y para ello empleamos el acoplamiento de Suzuki. ${ }^{66 b}$ Así, se hicieron reaccionar los 4-bromo- $1 H$-indoles $\mathbf{2 8 c a}$ y $\mathbf{2 8 c b}$ con ácido fenilborónico, en presencia de cantidades catalíticas de $\mathrm{Pd}\left(\mathrm{PPh}_{3}\right)_{4}$, exceso de $\mathrm{Na}_{2} \mathrm{CO}_{3}$ y una mezcla de DME / $\mathrm{H}_{2} \mathrm{O}(2 / 1)$ como disolvente. De esta manera, se obtuvieron los 4-fenil-1H-indoles 2-sustituidos 47 con buenos rendimientos (Esquema 1.90).
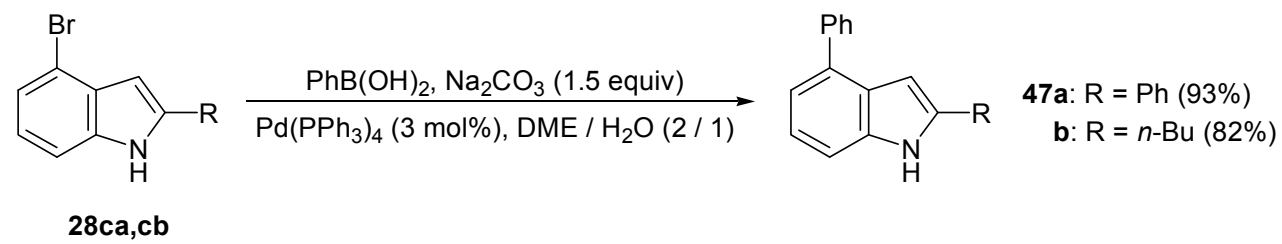

\section{Esquema 1.90}




\section{e.4 Síntesis del 4-bromo-2-fenil-3-((Z)-1,3-difenil-4-metil-penta-1,3-dienil)-1H- indol 48}

En nuestro grupo de investigación se ha puesto a punto recientemente un procedimiento para la alenilación de 2-arilindoles con alcoholes propargílicos terciarios empleando cantidades catalíticas de ácido $p$-toluensulfónico y acetonitrilo como disolvente. ${ }^{161}$ Se decidió ensayar estas condiciones utilizando el 4-bromo-2-fenil- $1 H$-indol 28ca y 1,3difenil-4-metilpent-1-in-3-ol como alcohol. Así, se obtuvo el producto resultante de la alenilación en la posición 3 del anillo indólico, el cual se isomeriza en las condiciones de reacción dando lugar al dienil indol 48 (Esquema 1.91).<smiles>[PH2+]c1cc2c(Br)cccc2[nH]1</smiles>

28ca<smiles>CC(C)C(O)(C#CC#P)c1ccccc1</smiles>

Esquema 1.91<smiles></smiles>

$48(80 \%)$ Hay que resaltar que la estructura de este indol se confirmó por la técnica de difracción de rayos X (Figura 1.2) obteniéndose monocristales del 4-bromo-2-fenil-3-((Z)-1,3-difenil-4metil-penta-1,3-dienil)-1H-indol $\mathbf{4 8}$ adecuados para su resolución estructural. ${ }^{162}$

\footnotetext{
${ }^{161}$ R. Sanz, M. Gohain, D. Miguel, A. Martínez, F. Rodríguez, Synlett 2009, 1985.

${ }^{162}$ CCDC 7297401 contiene los datos cristalográficos del compuesto 48. Estos datos pueden ser obtenidos de The Cambridge Crystallographic Data Centre a través de www.ccdc.cam.ac.uk/data_request/cif.
} 


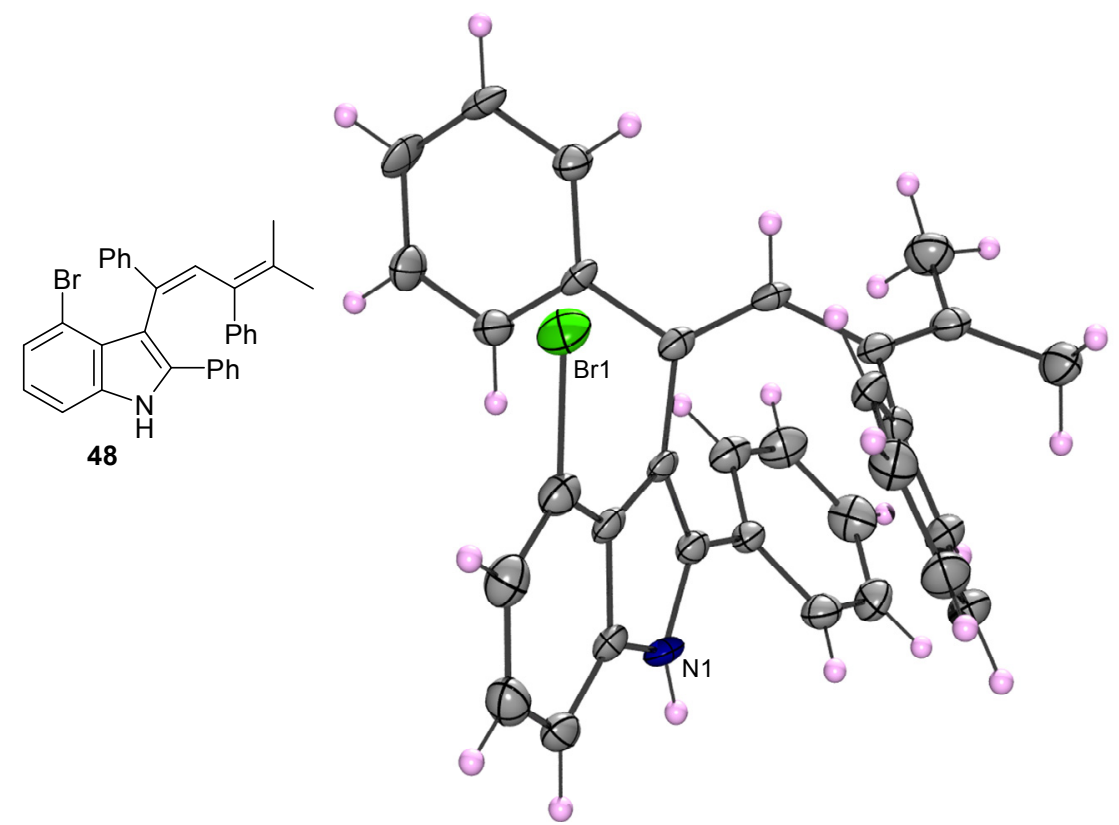

Figura 1.2. Estructura cristalina del compuesto 48 (se omite una molécula de tetrahidrofurano por claridad). Elipsoides térmicos al 50\%.

Podemos concluir que las 2,3-dihaloanilidas $25 \mathbf{b c}$,ca y 3bc, así como los 4-cloro o 4-bromo- $1 H$-indoles $\mathbf{2 8}$, son reactivos de partida útiles para la preparación de $1 H$-indoles funcionalizados regioespecíficamente en la posición 4 del anillo, mediante distintas reacciones de acoplamiento catalizadas por complejos de paladio. De esta forma, se han llevado a cabo reacciones de Sonogashira con alquinos terminales, así como reacciones de 4-haloindoles con estannanos o ácidos borónicos, demostrándose la utilidad de las 2,3dihalonilidas y los 4-haloindoles en diversas transformaciones sintéticas. 


\subsubsection{CONCLUSIONES}

Como resumen de los resultados expuestos en el Capítulo 1 se pueden extraer las siguientes conclusiones:

$>$ Se han estudiado tres posibles rutas sintéticas para acceder a las 2,3-dihaloanilinas demostrando el alcance de cada una de estas aproximaciones.

Se ha descrito un nuevo y eficiente método para la síntesis de 2,3-dihaloanilinas a partir de 2,3-dihalofenoles mediante una secuencia que implica la reacción de estos fenoles con 2-bromo-2-metilpropanamida, seguida de un reagrupamiento de Smiles y posterior hidrólisis de las correspondientes 2,3-dihaloanilidas.

Se ha desarrollado una nueva metodología para la síntesis de $1 H$-indoles 2sustituidos basada en un proceso "one pot", y consistente en un acoplamiento de Sonogashira sobre 2-yodoanilinas seguido de una heterociclación mediada por una base de fácil manejo como es el $\mathrm{NaOH}$. Además, la elección de las condiciones de reacción ha permitido la preparación selectiva de amino- y nitro- $1 H$-indoles.

Se ha aplicado la metodología anterior a la síntesis de 4-haloindoles a partir de diferentes 2,3-dihaloanilidas. De esta forma se han conseguido preparar una gran variedad de 4-haloindoles con buenos rendimientos. Además, también se han podido obtener derivados indólicos 2,3,4-trisustituidos de forma sencilla y eficaz, a partir de los mismos sustratos de partida por combinación de diferentes estrategias sintéticas.

$>$ Se ha demostrado la utilidad de las 2,3-dihaloanilidas y los 4-halo- $1 H$-indoles como productos de partida en la preparación de $1 H$-indoles funcionalizados regioespecíficamente en la posición 4 del anillo utilizando reacciones de acoplamiento catalizadas por complejos de paladio. 



\section{CAPÍTULO 2}

Reacciones de orto-zincación en derivados de 3-bromoanisoles. Aplicaciones a la sintesis de benzo[b]furanos alcoxi-funcionalizados 



\section{$2.1 \quad$ INTRODUCCIÓN}

Un objetivo importante en Síntesis Orgánica consiste en la preparación de benzo[ $b]$ furanos funcionalizados, debido a que un gran número de compuestos que contienen el esqueleto benzofuránico en su estructura presentan propiedades de interés. En consecuencia, se ha dedicado un gran esfuerzo al desarrollo de métodos sintéticos ${ }^{163}$ generales y versátiles, para la síntesis de estos heterociclos. El anillo de benzo[b]furano está presente en una gran variedad de productos naturales ${ }^{164} \mathrm{y}$, en particular, los derivados de benzo[b]furano con sustituyentes oxigenados, tales como grupos hidroxilo o alcoxilo, en la unidad de benceno son conocidos por su actividad biológica (Esquema 2.1). ${ }^{165}$ Por otra parte, algunos derivados de benzofurano también han resultado útiles para la construcción de materiales orgánicos con propiedades ópticas o electrónicas. ${ }^{166}$<smiles></smiles>

Gnetumelina B<smiles>COc1cc(O)c(C(=O)CCc2ccccc2)c2oc(-c3cc(C(C)=O)ccc3O)cc12</smiles>

Longicaudatina<smiles>C=C(C)c1cc2c(O)c(C(C)=O)ccc2o1</smiles>

Isoeuparina

Esquema 2.1

Como se ha comentado anteriormente, en nuestro grupo de investigación estamos interesados en el desarrollo de rutas sintéticas eficaces para la preparación de distintos

\footnotetext{
163 a) X. L. Hou, Z. Yang, K.-S. Yeung, H. N. C. Wong, Prog. Heterocycl. Chem. 2009, 21, 179. b) K.-S. Yeung, Z. Yang, X.-S. Peng, X.-L. Hou, Prog. Heterocycl. Chem. 2011, 22, 181.

${ }^{164}$ L. De Luca, G. Nieddu, A. Porcheddu, G. Giacomelli, Curr. Med. Chem. 2009, 16, 1.

165 a) Calebertina y Calepruninas: A. G. Ober, F. R. Fronczek, N. H. Fischer, J. Nat. Prod. 1985, 48, 242. b) Isoeuparina: F. J. Parodi, N. H. Fischer, J. Nat. Prod. 1988, 51, 594. c) Gnetumelina B: L.-Q. Wang, Y.-X. Zhao, J. M. Hu, A.-Q. Jia, J. Zhou, Helv. Chim. Acta 2008, 91, 159. d) Longicaudatina: A. S. Joshi, X.-C. Li, A. C. Nimrod, H. N. ElSholy, L. A. Walker, A. M. Clark, Planta Med. 2001, 67, 186.

${ }^{166}$ J. R. Hwu, K.-S. Chuang, S. H. Chuang, S.-C. Tsay, Org. Lett. 2005, 7, 1545.
} 
compuestos heterocíclicos funcionalizados. Así, en el Capítulo 1 nos hemos centrado en la síntesis de indoles 4-funcionalizados.

Por otro lado, en el grupo de investigación se había puesto a punto un método para la preparación de 4-halobenzo[b]furanos mediante una reacción tándem acoplamiento de Sonogashira / heterociclación de 3-halo-2-yodofenoles con distintos alquinos terminales (Esquema 2.2). ${ }^{72}$

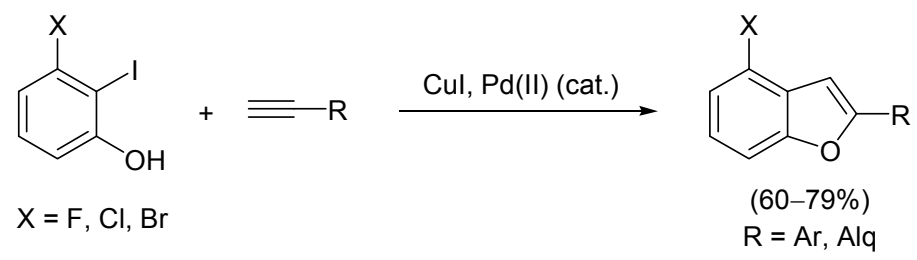

Esquema 2.2

En este contexto, y debido a las interesantes propiedades que presentan los derivados de benzo[ $[b]$ furano con sustituyentes oxigenados, nos propusimos como objetivo de este Capítulo el desarrollo de una estrategia sintética eficiente para la preparación de benzo[b]furanos 4- y 4,n-alcoxi-funcionalizados. Con esta idea, planteamos el análisis retrosintético que se muestra en el Esquema 2.3.<smiles>[R]Oc1ccc2oc([R])cc2c1O[R]</smiles><smiles>[R]Oc1ccc([X])c(I)c1O[R]</smiles>

Esquema 2.3

Los alcoxi y dialcoxibenzo[b]furanos se podrían preparar a partir de 3-halo-2yodofenil éteres por combinación de dos procesos catalizados por paladio, un acoplamiento selectivo de Sonogashira seguido de una reacción tándem de hidroxilación / heterociclación. 


\subsection{ANTECEDENTES BIBLIOGRÁFICOS}

En este apartado se hará una breve revisión de las principales metodologías descritas en la bibliografía para la preparación de benzo[b]furanos alcoxi e hidroxifuncionalizados. Como segundo tema de este apartado, se discutirán brevemente los acoplamientos catalizados por complejos de metales de transición de haluros de arilo con hidróxidos alcalinos con el fin de formar enlaces $\mathrm{C}-\mathrm{O}$.

\subsubsection{SÍNTESIS DE BENZO $[b \mid$ FURANOS OXÍGENO-FUNCIONALIZADOS}

Los principales procedimientos para la preparación de benzo[b]furanos están basados en la ciclación de compuestos aromáticos previamente funcionalizados y se pueden dividir en dos grupos distintos:

$>$ Métodos que emplean derivados de furano para construir la unidad bencenoide en varios pasos.

$>$ Métodos que implican la formación del anillo de furano por ciclación de derivados bencénicos previamente funcionalizados.

\section{a) Reacciones de ciclación en derivados de furano}

Una reacción de ciclocarbonilación en derivados de acetato de 3-(furan-2-il)alilo, catalizada por un complejo de paladio en presencia de trietilamina y anhídrido acético, permite sintetizar benzo[b]furanos 4-oxígeno-sustituidos (Esquema 2.4). ${ }^{167}$

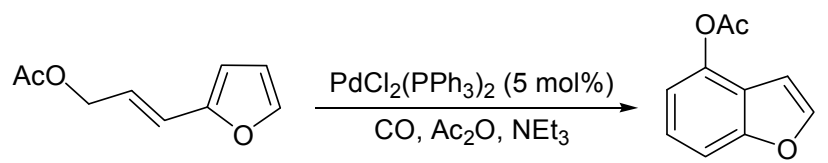

Esquema 2.4

\footnotetext{
${ }^{167}$ M. Iwasaki, Y. Kobayashi, J. P. Li, H. Matsuzaka, Y. Ishii, M. Hidai, J. Org. Chem. 1991, 56, 1922.
} 
Por otra parte, la bromación y posterior reacción de Suzuki de 2alquilidentetrahidrofuranos, los cuales se pueden preparar por ciclación de dianiones 1,3dicarbonílicos con 1,2-dielectrófilos, ${ }^{168}$ da lugar a 1'-(2','n'-dimetoxifenil)-2alquilidentetrahidrofuranos. El tratamiento de estos intermedios con $\mathrm{BBr}_{3}$ y adición de agua permite preparar hidroxibenzo[b]furanos funcionalizados regioselectivamente con buenos rendimientos (Esquema 2.5). ${ }^{169}$

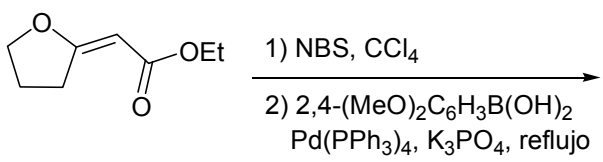
2) 2,4-(MeO $)_{2} \mathrm{C}_{6} \mathrm{H}_{3} \mathrm{~B}(\mathrm{OH})_{2}$
$\mathrm{Pd}\left(\mathrm{PPh}_{3}\right)_{4}, \mathrm{~K}_{3} \mathrm{PO}_{4}$, reflujo<smiles>CCOC(=O)c1c(CCCBr)oc2cc(O)ccc12</smiles>

$(97 \%)$

Esquema 2.5

\section{b) Reacciones de ciclación en derivados bencénicos funcionalizados}

En este apartado se describirán los principales métodos para la preparación de alcoxi e hidroxibenzo $[b]$ furanos basados en la ciclación de derivados bencénicos, haciendo un mayor hincapié en la síntesis de benzo[b]furanos 4-funcionalizados.

Los benzo[b]furanos oxígeno-funcionalizados en posiciones 5 y 7 se pueden preparar fácilmente por ciclación en derivados de fenoles sustituidos en las posiciones para y orto respectivamente. Sin embargo, los correspondientes benzo[b]furanos sustituidos en la posición 4 del anillo son difíciles de obtener de forma selectiva por ciclación de los fenoles análogos sustituidos en meta.

\section{b.1 Ciclación de $O$-ariloximas}

Las $O$-ariloximas han sido utilizadas para la síntesis de alcoxibenzofuranos a través de un reagrupamiento similar a la síntesis de Fischer de indoles. En el caso de pretender obtener el isómero 4-alcoxi-funcionalizado, este tipo de reacción suele conducir a mezclas

\footnotetext{
${ }^{168}$ P. Langer, W. Freiberg, Chem. Rev. 2004, 104, 4125.

${ }^{169}$ E. Bellur, P. Langer, J. Org. Chem. 2005, 70, 7686.
} 
de los benzo[b]furanos con el sustituyente en las posiciones 4 y 6 del anillo, siendo minoritario el compuesto 4-funcionalizado (Esquema 2.6). ${ }^{170}$

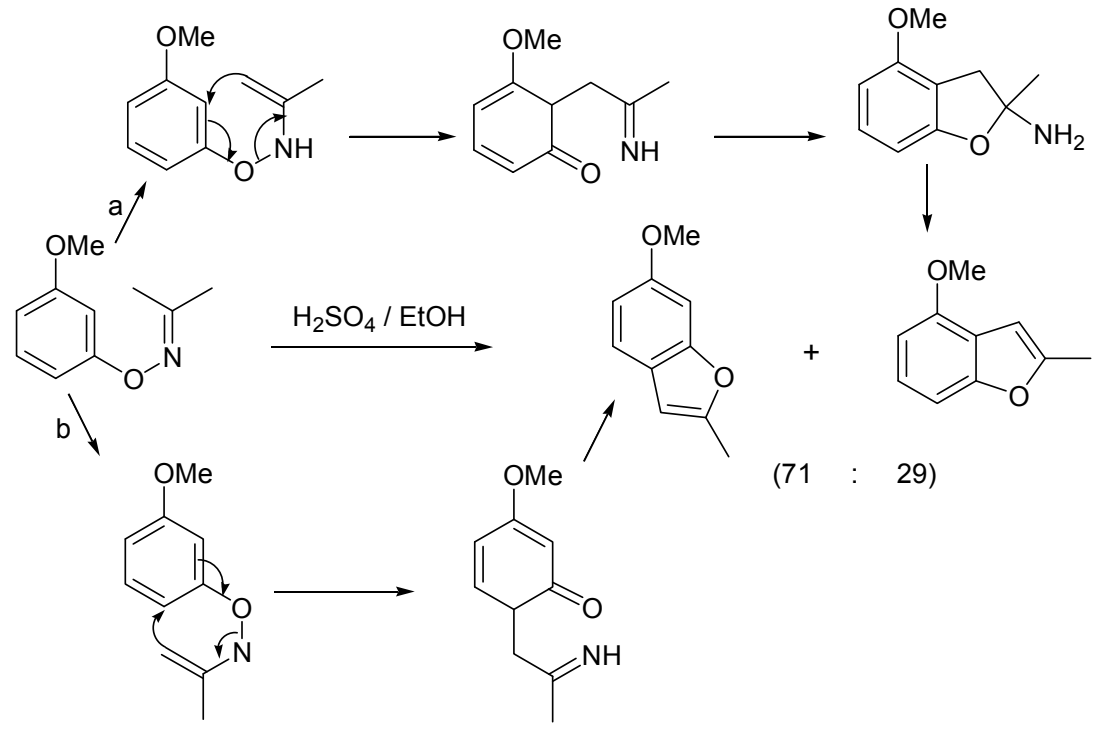

Esquema 2.6

\section{b. 2 Ciclodeshidratación de $\alpha$-ariloxi cetonas}

Una secuencia de ciclación-deshidratación en $\alpha$-ariloxi cetonas catalizada por tricloruro de boro ${ }^{171}$ permite obtener alcoxibenzo $[b]$ furanos regioselectivamente y con buenos rendimientos (Esquema 2.7). Estos autores obtienen únicamente el benzo[b]furano 6-metoxifuncionalizado en el caso de partir de $\alpha$-ariloxi cetonas con un grupo metoxilo en posición meta.
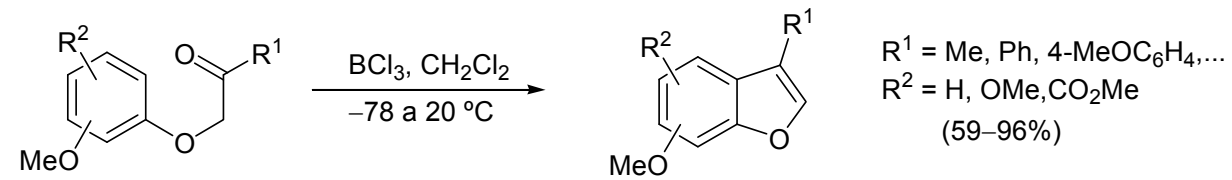

Esquema 2.7

\footnotetext{
170 a) A. J. Castellino, H. Rapoport, J. Org. Chem. 1984, 49, 4399. b) A. Alemagna, C. Baldoli, P. Del Buttero, E. Licandro, S. Maiorana, J. Chem. Soc., Chem. Commun. 1985, 417. c) Y. Endo, K. Namikawa, K. Shudo, Tetrahedron Lett. 1986, 27, 4209.

${ }^{171}$ I. Kim, S.-H. Lee, S. Lee, Tetrahedron Lett. 2008, 49, 6579.
} 
El empleo de un complejo de iridio ${ }^{172}$ también permite llevar a cabo esta secuencia de ciclación-deshidratación. La presencia de un resto acetilo, que actúa como grupo director, facilita la formación de un enlace carbono-iridio en la posición orto más impedida estéricamente, evitando la formación de mezclas de regioisómeros (Esquema 2.8).

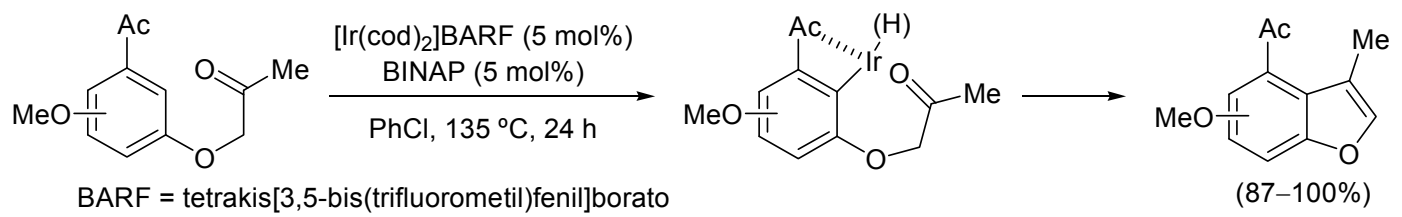

Esquema 2.8

\section{b.3 Reagrupamiento [3,3] de Claisen en fenil propargil y alil fenil éteres}

El reagrupamiento de Claisen de fenil propargil y alil fenil éteres adecuadamente sustituidos, seguido de la ciclación de los intermedios obtenidos, permite la síntesis de alcoxibenzo[b]furanos. Este reagrupamiento puede ser promovido térmicamente, ${ }^{173}$ por la presencia de una base, ${ }^{174} \mathrm{o}$ bien, de un complejo de paladio. ${ }^{175}$ Cuando se pretenden preparar 4-alcoxibenzo[b]furanos, es necesario el bloqueo de una de las posiciones en orto respecto al grupo éter para evitar que la ciclación tenga lugar en las dos posiciones orto, lo que conduciría a una mezcla de productos funcionalizados en posiciones 4 y 6 en lugar de obtener un único regioisómero (Esquema 2.9).

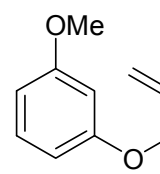
$\frac{\mathrm{PdCl}_{2}(\mathrm{MeCN})_{2}(20 \mathrm{~mol} \%), \mathrm{Na}_{2} \mathrm{CO}_{3}}{\text { 1,4-benzoquinona, 1,4-dioxano }}$ 1,<smiles>COc1cc(C=O)ccc1OCC#CPc1ccccc1</smiles><smiles>CCNCC(=O)c1cc(C=O)cc2c(-c3ccccc3)c(C)oc12</smiles>
$(51 \%)$
$(12$<smiles>COc1ccc2cc(C)oc2c1</smiles>
88)

\section{Esquema 2.9}

\footnotetext{
${ }^{172}$ K. Tsuchikama, Y.-k. Hashimoto, K. Endo, T. Shibata, Adv. Synth. Catal. 2009, 351, 2850.

${ }^{173}$ V. G. S. Box, P. C. Meleties, Heterocycles 1998, 48, 2173.

${ }^{174}$ V. S. P. R. Lingam, R. Vinodkumar, K. Mukkanti, A. Thomas, B. Gopalan, Tetrahedron Lett. 2008, 49, 4260.

${ }^{175}$ S. W. Youn, J. I. Eom, Org. Lett. 2005, 7, 3355.
} 


\section{b.4 Ciclación de aril-(2,2-dietoxietil) éteres}

En la bibliografía se ha descrito la preparación de 5-metoxibenzo[b]furano mediante una reacción de alquilación de 4-metoxifenol con el dietil acetal del 2-bromoacetaldehído seguida de la ciclocondensación intramolecular del aril-(2,2-dietoxietil) éter al tratarlo con ácido polifosfórico (PPA) (Esquema 2.10). ${ }^{176}$

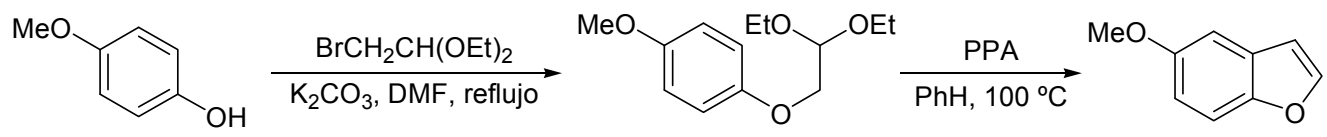

\section{Esquema 2.10}

\section{b.5 Ciclación de derivados de resorcinol y salicilaldehído}

Un procedimiento para sintetizar 4-hidroxibenzo[b]furanos consiste en la monoalquilación de derivados de resorcinol seguida de la ciclación del intermedio formado mediante fotólisis, ${ }^{177}$ catálisis ácida ${ }^{178} \mathrm{o}$ básica (Esquema 2.11). ${ }^{179}$

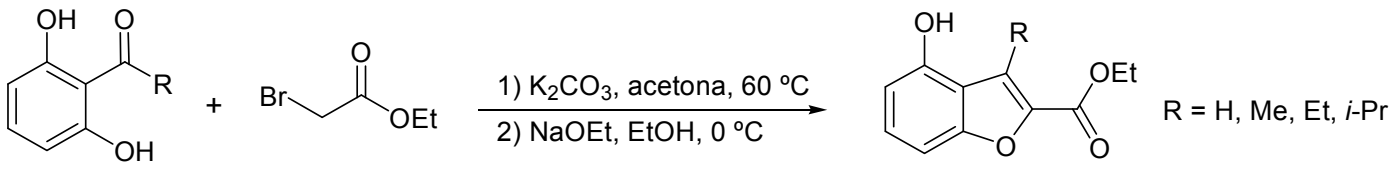

\section{Esquema 2.11}

Otros autores han llevado a cabo la $O$-alquilación de metoxi derivados de salicilaldehído empleando bromoacetonitrilo ${ }^{180 \mathrm{c}}$ o 2-bromoacetato de etilo ${ }^{180} \mathrm{y}$, así, se han preparado benzo[b]furanos 7-metoxi-funcionalizados en un único paso de reacción (Esquema 2.12).

176 a) P. Barker, P. Finke, K. Thompson, Synth. Commun. 1989, 19, 257. b) C. Bonini, G. Cristiani, M. Funicello, L. Viggiani, Synth. Commun. 2006, 36, 1983.

177 G. A. Kraus, P. J. Thomas, M. D. Schwinden, Tetrahedron Lett. 1990, 31, 1819.

${ }^{178}$ C. K. Lau y col. J. Med. Chem. 1989, 32, 1190.

${ }^{179}$ M. Masubuchi, K. Kawasaki, H. Ebiike, Y. Ikeda, S. Tsujii, S. Sogabe, T. Fujii, K. Sakata, Y. Shiratori, Y. Aoki, T. Ohtsuka, N. Shimma, Bioorg. Med. Chem. Lett. 2001, 11, 1833.

${ }^{180}$ a) K. Hagihara, H. Kashima, K. Iida, J. Enokizono, S.-i. Uchida, H. Nonaka, M. Kurokawa, J. Shimada, Bioorg. Med. Chem. Lett. 2007, 17, 1616. b) K. Ando, Y. Kawamura, Y. Akai, J.-i. Kunitomo, T. Yokomizo, M. Yamashita, S. Ohta T. Ohishi, Y. Ohishi, Org. Biomol. Chem. 2008, 6, 296. c) O. Saku, M. Saki, M. Kurokawa, K. Ikeda, T. Takizawa, N. Uesaka, Bioorg. Med. Chem. Lett. 2010, 20, 1090. 
<smiles>COc1ccc(Br)c(C=O)c1O</smiles>

Esquema 2.12

\section{b.6 Reacción tándem acoplamiento de Sonogashira / heterociclación}

El acoplamiento de orto-halofenoles y alquinos terminales, seguido de una ciclación 5-endo-dig del correspondiente arilalquino intermedio es uno de los procedimientos más empleados para la construcción del anillo de benzo[b]furano. ${ }^{181}$ En general, esta metodología permite obtener benzo[b]furanos sustituidos en la posición 2 del anillo. Además, también se ha podido aplicar a la construcción de benzofuranos 2-sustituidos que contengan un grupo alcoxilo en otra posición del anillo partiendo de $o$-halofenoles adecuadamente sustituidos (Esquema 2.13). ${ }^{166}$

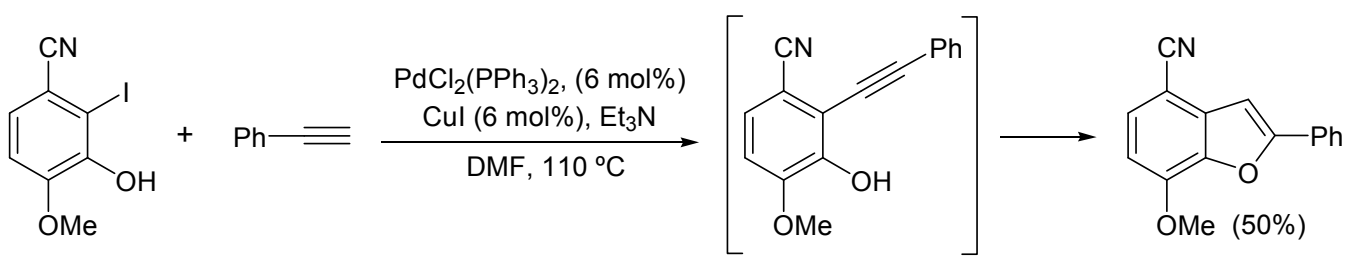

\section{Esquema 2.13}

\section{b.7 Ciclación oxidante de $o$-vinilfenoles}

Duan y colaboradores han descrito la preparación del producto antimicrobiano Cicerfurano mediante un acoplamiento selectivo de McMurry de un salicilaldehído alcoxisustituido con un aldehído aromático. Tras una ciclación oxidante del $o$-vinilfenol resultante, empleando $\mathrm{K}_{2} \mathrm{CO}_{3}$ y yodo, la posterior desprotección del grupo bencilo permite obtener el Cicerfurano (Esquema 2.14). ${ }^{182}$

181 a) G. W. Kabalka, L. Wang, R. M. Pagni, Tetrahedron 2001, 57, 8017. b) W.-M. Dai, K. W. Lai, Tetrahedron Lett. 2002, 43, 9377. c) M. Pal, V. Subramanian, K. R. Yeleswarapu, Tetrahedron Lett. 2003, 44, 8221. d) M. W. Khan, M. J. Alam, M. A. Rashid, R. Chowdhury, Bioorg. Med. Chem. 2005, 13, 4796. e) J.-R. Wang, K. Manabe, J. Org. Chem. 2010, 75, 5340. f) E. A. Jaseer, D. J. C. Prasad, G. Sekar, Tetrahedron, 2010, 66, 2077. g) A. Arcadi, F. Blesi, S. Cacchi, G. Fabrizi, A. Goggiamani, Tetrahedron Lett. 2011, 52, 5149.

${ }^{182}$ X.-F. Duan, J. Zeng, Z.-B. Zhang, G.-F. Zi, J. Org. Chem. 2007, 72, 10283. 


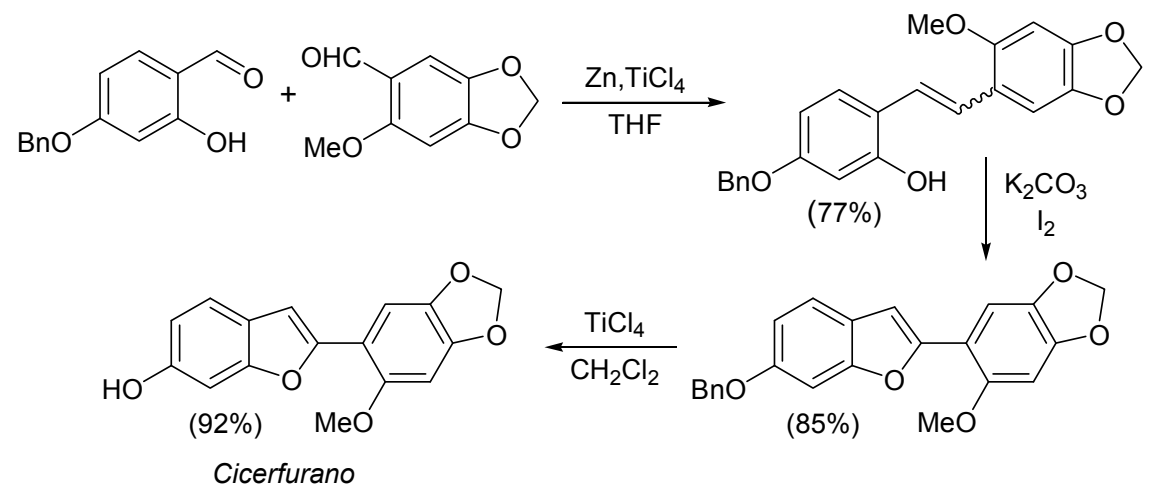

Esquema 2.14

\subsubsection{REACCIONES DE FORMACIÓN DE FENOLES A PARTIR DE HALUROS DE ARILO}

En los últimos años se han descrito en la literatura numerosos ejemplos de reacciones de acoplamiento entre haluros de arilo y alcoholes o fenoles catalizadas por complejos de metales de transición. ${ }^{183,184}$ Este tipo de acoplamientos son similares a las reacciones de aminación, estudiadas fundamentalmente por Buchwald y Hartwig, pero empleando alcoholes en lugar de aminas.

La formación del enlace $\mathrm{C}-\mathrm{O}$ también ha permitido la preparación de fenoles mediante la reacción de haluros aromáticos con hidróxidos, fundamentalmente de metales alcalinos. En este apartado nos centraremos en estos últimos estudios ya que ésta será la metodología empleada en nuestro trabajo de investigación. Estas reacciones de acoplamiento pueden estar catalizadas por distintos metales de transición, aunque principalmente se emplean complejos de paladio y, más recientemente, sales de $\mathrm{Cu}(\mathrm{I})$.

\section{a) Reacciones de hidroxilación catalizadas por complejos de paladio}

El acoplamiento de cloruros o bromuros de arilo con $\mathrm{KOH}$, empleando $\operatorname{Pd}_{2}\left(\mathrm{dba}_{3}\right.$ y fosfinas voluminosas como sistema catalítico, conduce a fenoles con buenos rendimientos

${ }^{183}$ C. H. Burgos, T. E. Barder, X. Huang, S. L. Buchwald, Angew. Chem., Int. Ed. 2006, 45, 4321.

184 a) J. F. Hartwig, Angew. Chem., Int. Ed. 1998, 37, 2046. b) S.-i. Kuwabe, K. E. Torraca, S. L. Buchwald, J. Am. Chem. Soc. 2001, 123, 12202. c) A. V. Vorogushin, X. Huang, S. L. Buchwald, J. Am. Chem. Soc. 2005, 127,8146 . d) S. Gowrisankar, A. G. Sergeev, P. Anbarasan, A. Spannenberg, H. Neumann, M. Beller, J. Am. Chem. Soc. 2010, 132, 11592. 
(Esquema 2.15). ${ }^{185}$ Estas condiciones de reacción permiten utilizar cloruros de arilo impedidos estéricamente o ricos electrónicamente. Esta metodología también ha sido esbozada para la síntesis de benzo[b]furanos sustituidos a partir de $o$-alquinilhaloarenos (Esquema 2.15). ${ }^{185 a}$<smiles>Cc1cccc(C)c1Cl</smiles>

1) $\mathrm{Pd}_{2}(\mathrm{dba})_{3}(2 \mathrm{~mol} \%)$ L (8 mol\%) $\mathrm{H}_{2} \mathrm{O} /$ 1,4-dioxano 2) $\mathrm{HCl}$<smiles>Oc1ccccc1C#Cc1ccccc1Cl</smiles>

$$
\mathrm{Pd}_{2}(\mathrm{dba})_{3}(2 \mathrm{~mol} \%)
$$
L $(8 \mathrm{~mol} \%)$

$\mathrm{H}_{2} \mathrm{O} /$ 1,4-dioxano $100^{\circ} \mathrm{C}$<smiles>CC(C)c1cc(C(C)C)c(-c2ccccc2P(C)(=O)c2cccnc2)c(C(C)C)c1</smiles><smiles>Cc1cccc([N+](=O)[O-])c1O</smiles><smiles>CCCCCCc1cc2ccccc2o1</smiles>

$(83 \%)$

\section{Esquema 2.15}

Por su parte, se ha descrito la preparación de fenoles por reacción de cloruros y bromuros de arilo con $\mathrm{KOH}$ ó $\mathrm{CsOH}$, empleando $\mathrm{Pd}(\mathrm{cod})\left(\mathrm{CH}_{2} \mathrm{SiMe}_{3}\right)_{2}{ }^{186 \mathrm{a}}$ ó $\mathrm{Pd}_{2}(\mathrm{dba})_{3}{ }^{186 \mathrm{~b}} \mathrm{y}$ una dialquil-2-( $N$-arilimidazoíl) fosfina como ligando. Estas condiciones de reacción toleran la presencia de distintos grupos funcionales como nitro, ciano, cetonas,... en el haluro de arilo (Esquema 2.16).

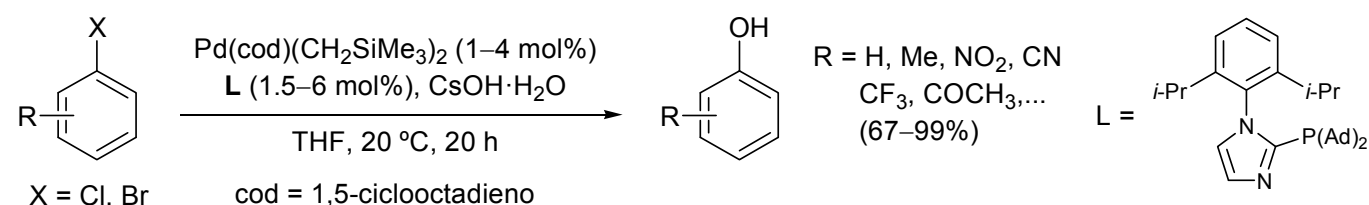

\section{Esquema 2.16}

La reacción de $o$-halonitroarenos con $\mathrm{K}_{3} \mathrm{PO}_{4} \cdot \mathrm{H}_{2} \mathrm{O}$ empleando el sistema catalítico $\mathrm{Pd}_{2}(\mathrm{dba})_{3} / t-\mathrm{Bu}_{3} \mathrm{P}$ ha permitido la síntesis de una variedad de $o$-nitrofenoles con distintos grupos funcionales en su estructura (Esquema 2.17). ${ }^{187}$

185 a) K. W. Anderson, T. Ikawa, R. E. Tundel, S. L. Buchwald, J. Am. Chem. Soc. 2006, 128, 10694. b) M. C. Willis, Angew. Chem., Int. Ed. 2007, 46, 3402.

186 a) A. G. Sergeev, T. Schulz, C. Torborg, A. Spannenberg, H. Neumann, M. Beller, Angew. Chem., Int. Ed. 2009, 48, 7595. b) T. Schulz, C. Torborg, B. Schäffner, J. Huang, A. Zapf, R. Kadyrov, A. Börner, M. Beller, Angew. Chem., Int. Ed. 2009, 48, 918.

${ }^{187}$ G. Chen, A. S. C. Chan, F. Y. Kwong, Tetrahedron Lett. 2007, 48, 473. 


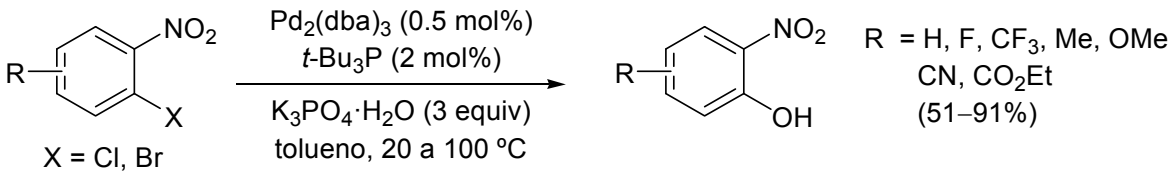

\section{Esquema 2.17}

En este mismo contexto, Diaconescu y colaboradores han estudiado el acoplamiento de haluros de arilo con $\mathrm{KOH}$ utilizando nanopartículas de paladio soportado sobre nanofibras de polianilina (PANI) (Esquema 2.18). ${ }^{188}$

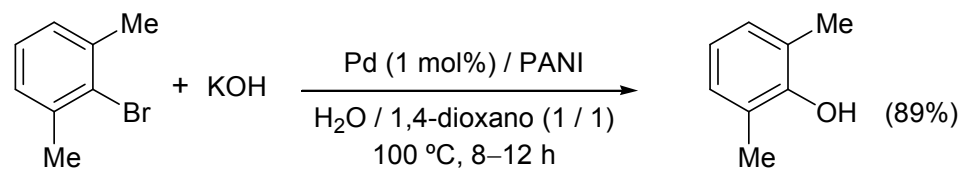

Esquema 2.18

\section{b) Reacciones de hidroxilación catalizadas por sales de $\mathrm{Cu}$ (I)}

En general, las reacciones de hidroxilación catalizadas por $\mathrm{Cu}$ (I) requieren el empleo de yoduros de arilo o bromuros con sustituyentes electrón atractores, no siendo eficientes con los correspondientes cloruros, los cuales suelen ser más abundantes y asequibles comercialmente.

Así, el tratamiento de yoduros de arilo o bromuros activados con hidróxidos de metales alcalinos $(\mathrm{KOH}$ ó $\mathrm{CsOH})$, en presencia de $\mathrm{CuI}$ y cantidades catalíticas elevadas de distintos ligandos como dicetonas o 1,10-fenantrolina ha permitido preparar una gran variedad de fenoles. ${ }^{189}$ Se suele emplear agua o mezclas DMSO / $\mathrm{H}_{2} \mathrm{O}$ como disolvente. Un ejemplo de este tipo de acoplamiento se muestra en el Esquema 2.19. ${ }^{189 a}$

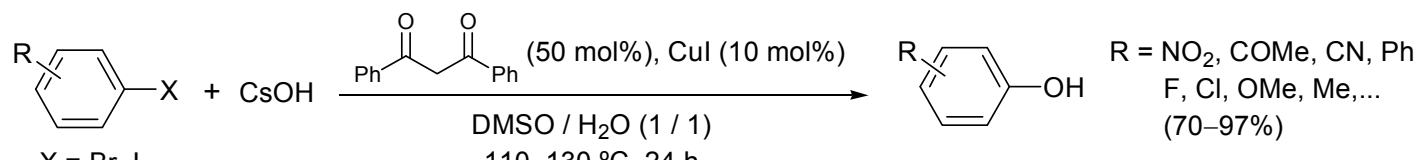

Esquema 2.19

${ }^{188}$ B. J. Gallon, R. W. Kojima, R. B. Kaner, P. L. Diaconescu, Angew. Chem., Int. Ed. 2007, 46, 7251

189 a) A. Tlili, N. Xia, F. Monnier, M. Taillefer, Angew. Chem., Int. Ed. 2009, 48, 8725. b) D. Zhao, N. Wu, S. Zhang, P. Xi, X. Su, J. Lan, J. You, Angew. Chem., Int. Ed. 2009, 48, 8729. 
Otros autores han descrito la reacción de yoduros y bromuros de arilo con $\mathrm{KOH}^{190 a}$ ó $\mathrm{Bu}_{4} \mathrm{NOH}^{190 \mathrm{~b}}$ empleando una hidroxiquinolina y $\mathrm{CuI}$ en cantidades catalíticas (Esquema 2.20).

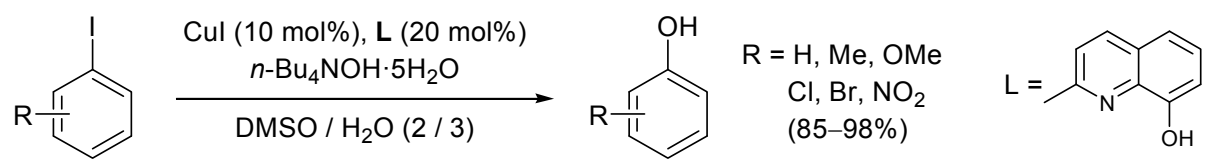

\section{Esquema 2.20}

La hidroxilación de yoduros o bromuros de arilo, con $\mathrm{CsOH}$, en presencia de cantidades catalíticas de $\mathrm{Cu}_{2} \mathrm{O}$, bromuro de tetrabutilamonio y piridin-2-aldoxima, utilizando agua como disolvente, ha permitido la preparación de una amplia variedad de fenoles con buenos rendimientos (Esquema 2.21). ${ }^{191}$ Las condiciones de reacción toleran la presencia de diferentes grupos funcionales tales como nitro o carboxilo en el haluro de arilo.

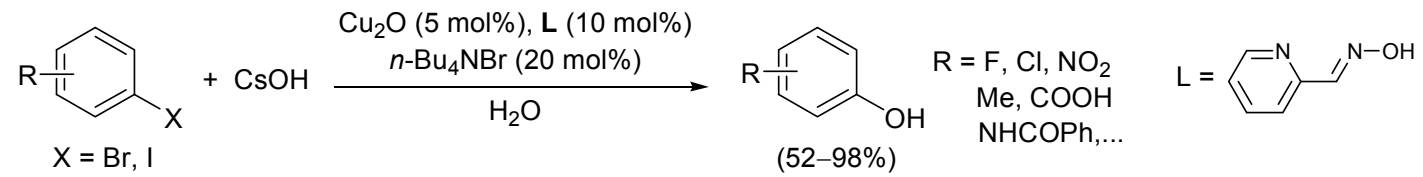

Esquema 2.21

También se ha descrito la reacción de diferentes haluros de arilo, incluyendo bromuros con grupos electrón dadores, con $\mathrm{NaOH}$ catalizado por una combinación de $\mathrm{CuI}$ y pipecolinato de litio, en agua como disolvente (Esquema 2.22). ${ }^{192}$

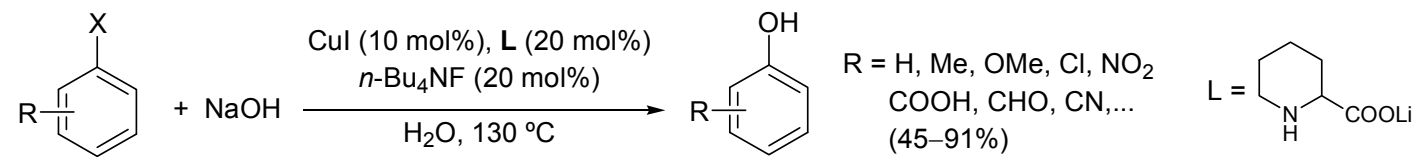
$\mathrm{X}=\mathrm{Br}, \mathrm{I}$

\section{Esquema 2.22}

En general, estas reacciones de hidroxilación precisan de mayores cantidades de catalizador y ligando en comparación con aquellas en las que se emplean complejos de paladio.

\footnotetext{
190 a) M. Stefan, W. Liu, X. Zhang, Y. Jiang, D. Ma, Synlett 2010, 976. b) R. Paul, Md. A. Ali, T. Punniyamurthy, Synthesis 2010, 4268.

${ }^{191}$ D. Yang, H. Fu, Chem. Eur. J. 2010, 16, 2366.

${ }^{192}$ L. Jing, J. Wei, L. Zhou, Z. Huang, Z. Li, X. Zhou, Chem. Commun. 2010, 46, 4767.
} 


\subsection{DISCUSIÓN DE RESULTADOS}

La estrategia de orto-metalación dirigida, en combinación con diferentes reacciones de acoplamiento catalizadas por paladio, ha demostrado ser una buena aproximación a la construcción de compuestos aromáticos y heteroaromáticos polisustituidos. ${ }^{25,193}$ En este contexto, nos planteamos el diseño de una ruta sintética eficiente para obtener benzo[b]furanos 4-alcoxi y 4,n-dialcoxi-funcionalizados.

\subsubsection{SíNTESIS DE ALCOXI Y DIALCOXIBENZO[b]FURANOS A PARTIR DE DERIVADOS DE 2,3-DIHALOFENOLES}

En el Capítulo 1 se ha descrito como los 2,3-dihalofenoles y sus derivados pueden ser empleados como sustratos de partida en la síntesis de 4-haloindoles. El objetivo de este segundo Capítulo consistió en la preparación de benzo[b]furanos 4-alcoxi y 4,n-dialcoxifuncionalizados a partir de derivados de 2,3-dihalofenoles. Para ello planteamos el siguiente análisis retrosintético.<smiles>COc1ccc2oc(F)cc2c1OC</smiles><smiles>[R]C#CC(O)O</smiles>

Esquema 2.23

De esta forma, los alcoxi y dialcoxibenzo[b]furanos se podrían sintetizar a partir de 3-bromo-2-yodofenil éteres mediante la combinación de dos procesos catalizados por paladio, un acoplamiento de Sonogashira selectivo y una reacción tándem de hidroxilación /

193 a) M. Alessi, A. L. Larkin, K. A. Ogilvie, L. A. Green, S. Lai, S. López, V. Snieckus, J. Org. Chem. 2007, 72, 1588. b) S. Nerdinger, C. Kendall, X. Cai, R. Marchart, P. Riebel, M. R. Johnson, C.-F. Yin, N. Hénaff, L. D. Eltis, V. Snieckus, J. Org. Chem. 2007, 72, 5960. c) S. L. MacNeil, M. Gray, D. G. Gusev, L. E. Briggs, V. Snieckus, J. Org. Chem. 2008, 73, 9710. 
heterociclación. Los 3-bromo-2-yodofenil éteres se podrían a su vez preparar mediante una reacción de orto-metalación regioselectiva en 3-bromofenil éteres, seguida de tratamiento con yodo como electrófilo.

En este apartado se describirán con detalle cada uno de los pasos indicados en el esquema anterior y que permiten la preparación regioselectiva de 4-alcoxi y 4,ndialcoxibenzo[b]furanos.

\section{a) Síntesis de 3-bromo-2-yodoanisoles}

De acuerdo al análisis retrosintético planteado en el Esquema 2.23, el primer paso para acceder a alcoxibenzo[b]furanos consistiría en la preparación de los 3-bromo-2yodoanisoles.

En el Capítulo anterior (apartado 1.3.1 c.2, pág. 89) hemos puesto a punto una síntesis eficiente del 3-cloro-2-yodoanisol 26a y del 3-bromo-2-yodoanisol 26b mediante una reacción de orto-zincación del correspondiente 3-haloanisol por tratamiento con $t$ $\mathrm{Bu}_{2} \mathrm{Zn}(\mathrm{TMP}) \mathrm{Li}$, seguida de la reacción del zincato intermedio con yodo (Esquema $1.71 \mathrm{y}$ Tabla 2.1, entrada 1).

Considerando estos resultados previos obtenidos en las reacciones de ortozincación, decidimos ensayar esta misma metalación con dimetoxibromobencenos disponibles comercialmente. De esta forma, diferentes 3-bromoanisoles se adicionaron a una disolución del $t$ - $\mathrm{Bu}_{2} \mathrm{Zn}(\mathrm{TMP}) \mathrm{Li}$ en THF a $-78{ }^{\circ} \mathrm{C}$. A continuación, se aumentó la temperatura hasta $-30{ }^{\circ} \mathrm{C}$, manteniéndose así durante 12 horas, para finalmente adicionar yodo. Tras el tratamiento y purificación de la reacción se obtuvieron los derivados de 3 bromo-2-yodoanisol 49 con buenos rendimientos (Tabla 2.1, entradas 2-4). Como ya se ha comentado con anterioridad, el $t-\mathrm{Bu}_{2} \mathrm{Zn}(\mathrm{TMP}) \mathrm{Li}$ se preparó por reacción de di-t-butilzinc, previamente formado, con LiTMP en THF a baja temperatura.

Analizando los resultados que se muestran en la Tabla 2.1 se puede concluir que es posible llevar a cabo, de forma regioselectiva, la orto-zincación de 3-bromoanisoles que presentan un grupo metoxilo adicional. Además, es interesante destacar que el sustrato que contiene dos grupos metoxilo en posición relativa meta, experimenta regioselectivamente la reacción de metalación en la posición entre el grupo metoxilo y el haluro, no detectándose el 
producto derivado de la metalación en la posición activada por los dos grupos metoxilo que, a priori, podría competir en este tipo de procesos.

Tabla 2.1 Síntesis de los 3-bromo-2-yodoanisoles 26 b y $49 a-c$

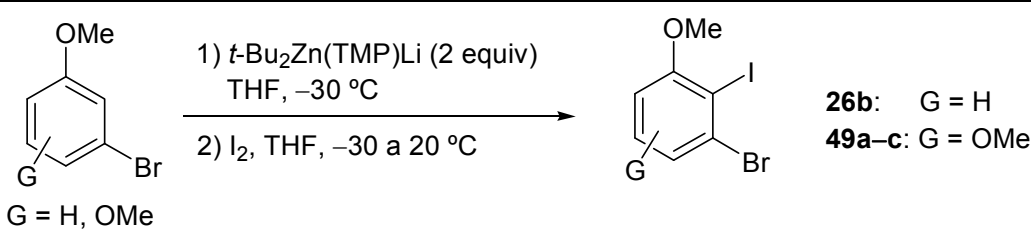

Entrada Anisol partida 40 Rendimiento (\%) ${ }^{\mathrm{a}}$

${ }^{a}$ Rendimiento en producto aislado referido a los 3-bromoanisoles de partida.

Hay que señalar que los dihaloanisoles $49 \mathbf{a}-\mathbf{c}$ son compuestos regioselectivamente funcionalizados con gran interés. Además, el compuesto 49a no ha sido descrito previamente a este trabajo, y los procedimientos encontrados en la bibliografía para la síntesis de 49b y 49c se basan normalmente en reacciones de sustitución aromáticas clásicas poco efectivas. ${ }^{194}$

\footnotetext{
${ }^{194}$ El compuesto 49c había sido sintetizado a partir de la 3,6-dimetoxi-2-nitroanilina en tres pasos de reacción. Ver: D. L. J. Clive, A. G. Anjoh, S. M. Bennet, J. Org. Chem. 1987, 52, 1339.
} 


\section{b) Síntesis de los orto-alquinilhaloarenos 50 y 51}

Con este protocolo eficiente para la síntesis de $26 \mathbf{b}$ y $49 \mathbf{a}-\mathbf{c}$ y, considerando el análisis retrosintético del Esquema 2.23, nuestro siguiente objetivo fue la preparación de los $o$-alquinilbromoarenos 50 y 51 mediante un acoplamiento de Sonogashira. Hay que tener en cuenta que los éteres $26 \mathrm{~b}$ y $\mathbf{4 9}$, presentan dos halógenos diferentes en posición relativa orto, lo que en principio puede originar problemas de selectividad al llevar a cabo la reacción de acoplamiento. Con el fin de lograr una reacción selectiva en el átomo de yodo se ensayaron dos procedimientos distintos.

Considerando el impedimento estérico que presenta la posición ocupada por el átomo de yodo ( $o, o^{\prime}$-disustituida) decidimos emplear una metodología libre de sales de cobre y en ausencia de disolvente, ${ }^{59}$ con el fin de evitar el posible homoacoplamiento del alquino, el cual podría verse favorecido por el elevado impedimento estérico del sustrato de partida. Así, el tratamiento de $\mathbf{2 6} \mathbf{b}$ con distintos alquinos terminales, utilizando TBAF $3 \mathrm{H}_{2} \mathrm{O}$ como base y cantidades catalíticas de $\mathrm{PdCl}_{2}\left(\mathrm{PPh}_{3}\right)_{2}$, permitió obtener los correspondientes $o$ alquinilbromoarenos 50a-e con rendimientos que oscilaron entre moderados y buenos (Procedimiento 1, Tabla 2.2).

Tabla 2.2 Preparación de $o$-alquinilbromoarenos 50a-e

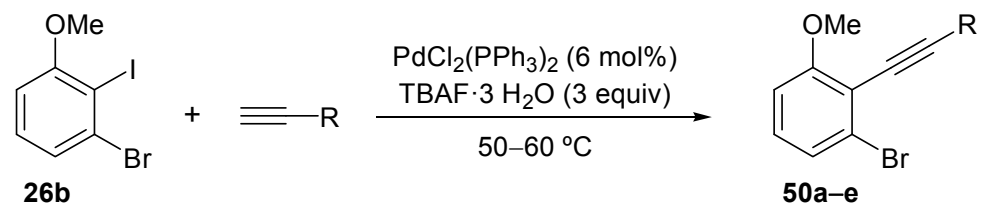

\begin{tabular}{ccccc}
\hline \hline Entrada & Alquino (R) & Tiempo (h) & Producto & Rto. $(\%)^{\text {a }}$ \\
\hline 1 & $n-\mathrm{C}_{5} \mathrm{H}_{11}$ & 3 & $\mathbf{5 0 a}$ & 65 \\
2 & $n-\mathrm{C}_{6} \mathrm{H}_{13}$ & 2 & $\mathbf{5 0 b}$ & 62 \\
3 & $c-\mathrm{C}_{6} \mathrm{H}_{9}{ }^{\mathrm{b}}$ & 2 & $\mathbf{5 0 c}$ & 78 \\
4 & $\mathrm{Ph}$ & 7 & $\mathbf{5 0 d}$ & 68 \\
5 & $3-\mathrm{FC}_{6} \mathrm{H}_{4}$ & 4.5 & $\mathbf{5 0 e}$ & 60 \\
\hline
\end{tabular}

${ }^{a}$ Rendimiento en producto aislado referido al anisol de partida $\mathbf{2 6}$. ${ }^{\mathrm{b}} 1$-Ciclohexenilo.

Posteriormente, se comprobó que el acoplamiento selectivo también se podía llevar a cabo empleando las condiciones estándar de Sonogashira (catálisis $\mathrm{PdCl}_{2}\left(\mathrm{PPh}_{3}\right)_{2}-\mathrm{CuI}$ ), 
mediante un control cuidadoso de la temperatura de reacción, evitando que ésta excediera de $50{ }^{\circ} \mathrm{C}$, y empleando únicamente un ligero exceso (1.2 equiv.) del correspondiente alquino (Procedimiento 2, Esquema 2.24). Con este segundo procedimiento se obtuvieron excelentes rendimientos de los 2-alquinil-3-bromoanisoles 50a y 50d.

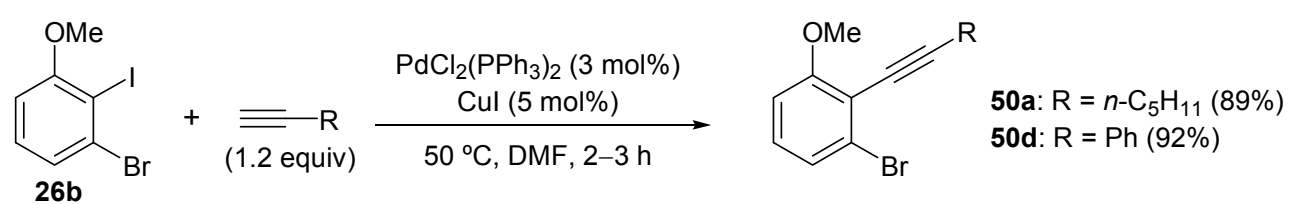

\section{Esquema 2.24}

También se observó que cuando se empleaba el procedimiento 1 (Pd / TBAF) partiendo del anisol 26b, se formaban pequeñas cantidades del producto resultante de la dialquinilación (alquinilación en ambos átomos de halógeno) junto con el $o$-alquinilanisol de interés 50. Por el contrario, se comprobó que el empleo del procedimiento 2 (catálisis Pd / $\mathrm{Cu}$ ) permitía obtener los 2-alquinil-3-bromoanisoles $\mathbf{5 0}$ de forma totalmente selectiva y con mejores rendimientos (Esquema 2.24).

Por lo tanto, el procedimiento 2 fue el elegido para llevar a cabo el acoplamiento selectivo de los 3-bromo-2-yodoanisoles, sustituidos con un grupo metoxilo adicional 49a-c, con distintos alquinos terminales. De este modo, se obtuvieron los correspondientes $o$-alquinilbromoarenos $\mathbf{5 1}$ aa-cd con buenos rendimientos (Tabla 2.3).

En la Tabla 2.3 se observa que el acoplamiento de 49a-c, de acuerdo a las condiciones descritas, es efectivo tanto utilizando alquinos con sustituyentes alquilo (entradas 1, 5, 6 y 9) y alquenilo (entrada 2), como con sustituyentes aromáticos (entradas 3 , 4, 7, 8, 10 y 11). Sin embargo, cuando se llevó a cabo el acoplamiento de 49c con 2propinilbenceno se obtuvo el 2-bromo-3-(3-fenilpropa-1,2-dienil)-1,4-dimetoxibenceno, en lugar del alquino esperado, con rendimiento moderado y derivado de un proceso de isomerización del triple enlace al correspondiente aleno (entrada 12).

Los resultados obtenidos también muestran que es posible preparar los $o$ alquinilbromoarenos 51aa-cd con un segundo grupo metoxilo en el anillo de benceno, tanto en posición orto (Tabla 2.3, entradas 1-4), meta (Tabla 2.3, entradas 5-8), como en posición para (Tabla 2.3, entradas 9-12), con respecto al grupo metoxilo contiguo al grupo alquinilo. 
Tabla 2.3 Síntesis de los $o$-alquinilbromoarenos dimetoxisustituidos 51aa-51cd

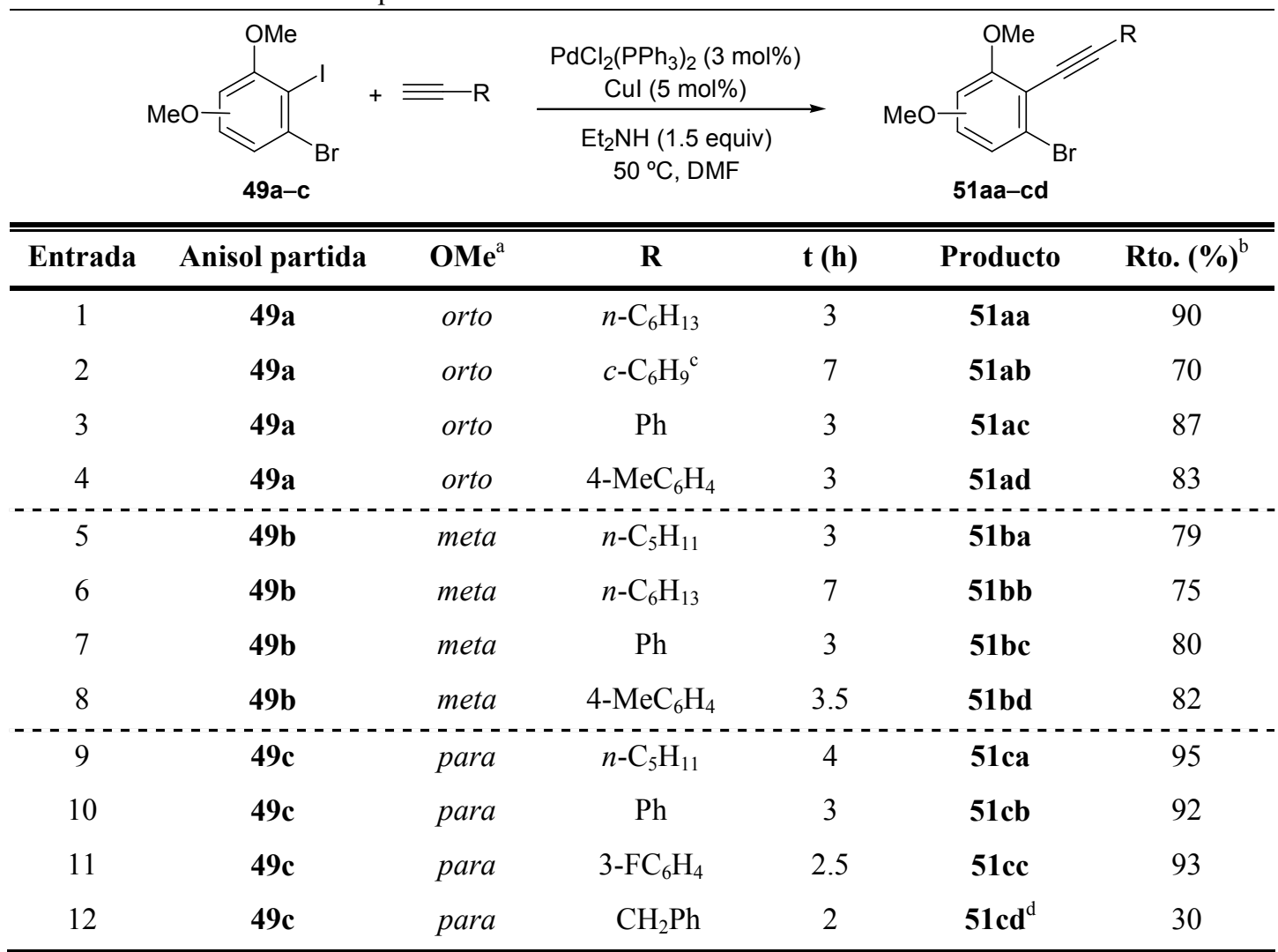

${ }^{a}$ Posición del grupo metoxilo adicional referido al ya existente. ${ }^{b}$ Rendimiento en producto aislado referido al anisol de partida 49a-c. ${ }^{\mathrm{c}} 1$-Ciclohexenilo. ${ }^{\mathrm{d}} \mathrm{Se}$ aisló el 2-bromo-3-(3-fenilpropa-1,2-dienil)-1,4-dimetoxibenceno en lugar del alquino esperado.

Estos resultados ponen de manifiesto la posibilidad de obtener eficientemente los $o$ alquinilbromoarenos 50 y 51, que contienen uno o dos grupos metoxilo en el anillo aromático, mediante acoplamiento de los 3-bromo-2-yodoanisoles 26b y 49a-c con distintos alquinos terminales.

\section{c) Síntesis de los alcoxibenzofuranos 52-55}

De acuerdo con nuestra propuesta de análisis retrosintético (Esquema 2.23), el paso final para obtener los derivados de benzo[b]furano debería ser la incorporación de un grupo hidroxilo seguido de una heterociclación "in situ". Tal como se describió en los Antecedentes Bibliográficos de este Capítulo, varios grupos de investigación han 
desarrollado métodos para la hidroxilación de haluros de arilo empleando catálisis de paladio o cobre. Mientras que las reacciones que utilizan catalizadores de cobre dan buenos resultados fundamentalmente cuando se emplean yoduros de arilo, ${ }^{189,190}$ la hidroxilación catalizada por paladio también funciona con bromuros y cloruros de arilo. ${ }^{185-188}$ En este contexto, Buchwald y colaboradores habían descrito la preparación del 2octilbenzo[b]furano y del 5-(trifluorometil)-2-(tiofen-3-il)benzo[b]furano a partir de los correspondientes $o$-alquinilhaloarenos por tratamiento con $\mathrm{KOH} .{ }^{185 a}$ Por lo tanto, se decidió ensayar este procedimiento para intentar la preparación de los 4-alcoxibenzo[b]furanos $\mathbf{5 2}$.

Así, el tratamiento de los 3-bromo-2-alquinilanisoles 50a-e, previamente preparados, con un exceso de $\mathrm{KOH}$, en presencia de cantidades catalíticas del sistema $\mathrm{Pd}_{2}(\mathrm{dba})_{3} / t$-BuXPhos a $100{ }^{\circ} \mathrm{C}$ en una mezcla de agua / 1,4-dioxano $(1 / 2)$, dio lugar a los correspondientes derivados de benzo[b]furano $\mathbf{5 2}$ con rendimientos moderados (método A, Tabla 2.4, entradas $1,3,5$ y 6 ).

Tabla 2.4 Preparación de los 4-metoxibenzo[b]furanos $\mathbf{5 2}$<smiles>COc1cccc(Br)c1C#CP</smiles>

50a-e

$$
+\mathrm{KOH} \frac{\begin{array}{c}
\mathrm{Pd}_{2}(\mathrm{dba})_{3}(2 \mathrm{~mol} \%) \\
t \text {-BuXPhos (8 mol\%) }
\end{array}}{\mathrm{H}_{2} \mathrm{O} / \text { 1,4-dioxano (1 / 2) }}
$$

A: $100^{\circ} \mathrm{C}, 12 \mathrm{~h}$

B: $\mathrm{MW}\left(150^{\circ} \mathrm{C}\right), 12 \mathrm{~min}$<smiles>[R]c1cc2c(OC)cccc2o1</smiles>

52

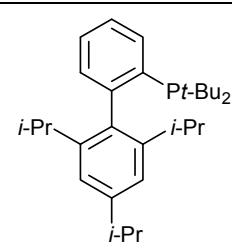

$t$-BuXPhos

\begin{tabular}{cccccc}
\hline \hline \multirow{2}{*}{ Entrada } & $\begin{array}{c}\text { Alquino } \\
\text { partida }\end{array}$ & $\mathbf{R}$ & Producto & Método $^{\mathrm{a}}$ & Rto. (\%) $^{\mathrm{b}}$ \\
\hline 1 & $\mathbf{5 0 a}$ & $n-\mathrm{C}_{5} \mathrm{H}_{11}$ & $\mathbf{5 2 a}$ & $\mathrm{A}$ & 65 \\
2 & $\mathbf{5 0 b}$ & $n-\mathrm{C}_{6} \mathrm{H}_{13}$ & $\mathbf{5 2 b}$ & $\mathrm{B}$ & 60 \\
3 & & & & $\mathrm{~A}$ & 52 \\
4 & $\mathbf{5 0 c}$ & $c-\mathrm{C}_{6} \mathrm{H}_{9}{ }^{\mathrm{c}}$ & $\mathbf{5 2 c}$ & $\mathrm{B}$ & 49 \\
5 & & & $\mathbf{5 2 d}$ & $\mathrm{A}$ & 63 \\
6 & $\mathbf{5 0 d}$ & $\mathrm{Ph}$ & $\mathbf{5 2 e}$ & $\mathrm{A}$ & 57 \\
\hline
\end{tabular}

${ }^{\mathrm{a}}$ Método A: Calentamiento convencional $\left(100^{\circ} \mathrm{C}, 12 \mathrm{~h}\right)$. Método B: MW (150 ${ }^{\circ} \mathrm{C}, 12 \mathrm{~min}$.) ${ }^{\mathrm{b}}$ Rendimiento en producto aislado referido a los 2-alquinil-3-bromoanisoles de partida 50a-e. ${ }^{\mathrm{c}} 1$-Ciclohexenilo. 
Además, debido a los largos tiempos de reacción necesarios para la desaparición completa de los alquinilanisoles de partida $\mathbf{5 0}$ (alrededor de 12 horas), se puso a punto un procedimiento alternativo empleando radiación de microondas como método de calentamiento. Se observó una considerable reducción de los tiempos de reacción necesarios para el acoplamiento a tan sólo unos minutos (método B, Tabla 2.4, entradas 2 y 4), conduciendo a los correspondientes 4-metoxibenzo[b]furanos $\mathbf{5 2}$ con rendimientos similares a los obtenidos cuando se empleaba calentamiento convencional (método A).

Teniendo en cuenta que los 4-metoxibenzo[b]furanos 52a-e se han obtenido con facilidad a partir de los 2-alquinil-3-bromoanisoles 50a-e, nos planteamos extender esta metodología al resto de $o$-alquinilhaloarenos de partida cuya síntesis se ha descrito en el apartado anterior y, así, obtener una amplia variedad de benzo[b]furanos 4,n-dimetoxifuncionalizados.

De este modo, se trataron los $o$-alquinilbromoarenos 51aa-ce con exceso de $\mathrm{KOH}$, en las mismas condiciones descritas anteriormente. Se empleó tanto calentamiento térmico tradicional (método A) como radiación de microondas (método B), obteniéndose, tras purificación por cromatografía de columna, los correspondientes dimetoxibenzo[ $b]$ furanos 53-55 (Tabla 2.5).

Analizando los resultados de la Tabla 2.5 se pueden realizar las siguientes observaciones. Los 4,5-, 4,6- y 4,7-dimetoxibenzo[b]furanos 53a-d, 54a-d y 55a-c se pudieron preparar a partir de los correspondientes $o$-bromoaril alquinos 51aa-ad (Tabla 2.5, entradas 1-6), 51 ba-bd (Tabla 2.5, entradas 7-11) y 51ca-cc (Tabla 2.5, entradas 12-15), respectivamente, con rendimientos que oscilaron entre moderados y buenos. Además, también se observó que los mejores rendimientos se alcanzaron para los derivados de benzofurano 54 (Tabla 2.5, entradas 7-11), los cuales se obtuvieron a partir de los $o$ alquinilbromobencenos $\mathbf{5 1} \mathbf{b a}-\mathbf{b d}$ que contenían dos grupos metoxilo en posiciones relativas 3,5- referido al átomo de bromo.

Como se muestra en la Tabla 2.5, alquinos 51 con sustituyentes tanto alifáticos (entradas 1, 7-9 y 12) como alquenilo (entradas 2 y 3 ) y arilo (entradas 4-6, 10, 11 y 13-15), resultaron sustratos adecuados para este proceso. Hay que volver a resaltar que el uso de radiación de microondas como método de calentamiento supuso una considerable 
reducción de los tiempos de reacción obteniéndose rendimientos similares que cuando se empleaba calentamiento convencional (Tabla 2.5, entradas 1, 3, 5, 8, 14 y 15).

Tabla 2.5 Síntesis de los benzo[b]furanos dimetoxi-sustituidos 53-55<smiles>[R]C#Cc1c([X])ccc(OC)c1OC</smiles>

$51 \mathrm{aa}-\mathrm{cc}$
$+\mathrm{KOH} \underset{\mathrm{H}_{2} \mathrm{O} / \text { 1,4-dioxano }(1 / 2)}{\stackrel{t \text {-BuXPhos }(8 \mathrm{~mol} \%)}{\mathrm{Pd}_{2}(\mathrm{dba})_{3}(2 \mathrm{~mol} \%)} \mathrm{MeO}}$

A: $100{ }^{\circ} \mathrm{C}, 12 \mathrm{~h}$

B: $\operatorname{MW}\left(150^{\circ} \mathrm{C}\right), 12 \mathrm{~min}$
$53\left[4,5-(\mathrm{MeO})_{2}\right]$

$54\left[4,6-(\mathrm{MeO})_{2}\right]$

$55\left[4,7-(\mathrm{MeO})_{2}\right]$

\begin{tabular}{|c|c|c|c|c|c|c|c|}
\hline Entrada & $\begin{array}{l}\text { Alquino } \\
\text { partida }\end{array}$ & $\mathbf{X}$ & $\mathbf{R}$ & Producto & $O M e^{a}$ & Método $^{\mathrm{b}}$ & Rto. $(\%)^{\mathrm{c}}$ \\
\hline 1 & 51 aa & $\mathrm{Br}$ & $n-\mathrm{C}_{6} \mathrm{H}_{13}$ & $53 \mathbf{a}$ & $4,5-(\mathrm{OMe})_{2}$ & B & 55 \\
\hline 2 & \multirow{2}{*}{$51 \mathrm{ab}$} & \multirow{2}{*}{$\mathrm{Br}$} & \multirow{2}{*}{$c-\mathrm{C}_{6} \mathrm{H}_{9}{ }^{\mathrm{d}}$} & \multirow{2}{*}{$53 \mathrm{~b}$} & \multirow{2}{*}{$4,5-(\mathrm{OMe})_{2}$} & A & 50 \\
\hline 3 & & & & & & B & 68 \\
\hline 4 & \multirow{2}{*}{$51 \mathrm{ac}$} & \multirow{2}{*}{$\mathrm{Br}$} & \multirow{2}{*}{$\mathrm{Ph}$} & \multirow{2}{*}{$53 \mathrm{c}$} & \multirow{2}{*}{$4,5-(\mathrm{OMe})_{2}$} & A & 50 \\
\hline 5 & & & & & & B & 55 \\
\hline 6 & $51 \mathrm{ad}$ & $\mathrm{Br}$ & 4- $\mathrm{MeC}_{6} \mathrm{H}_{4}$ & 53d & $4,5-(\mathrm{OMe})_{2}$ & A & 49 \\
\hline 7 & \multirow{2}{*}{$51 \mathrm{ba}$} & \multirow{2}{*}{$\mathrm{Br}$} & \multirow{2}{*}{$n-\mathrm{C}_{5} \mathrm{H}_{11}$} & \multirow{2}{*}{$54 a$} & \multirow{2}{*}{$4,6-(\mathrm{OMe})_{2}$} & A & 70 \\
\hline 8 & & & & & & B & 61 \\
\hline 9 & $51 \mathrm{bb}$ & $\mathrm{Br}$ & $n-\mathrm{C}_{6} \mathrm{H}_{13}$ & $54 b$ & $4,6-(\mathrm{OMe})_{2}$ & A & 64 \\
\hline 10 & $51 \mathrm{bc}$ & $\mathrm{Br}$ & $\mathrm{Ph}$ & $54 c$ & $4,6-(\mathrm{OMe})_{2}$ & A & 81 \\
\hline 11 & $51 \mathrm{bd}$ & $\mathrm{Br}$ & $4-\mathrm{MeC}_{6} \mathrm{H}_{4}$ & $54 d$ & $4,6-(\mathrm{OMe})_{2}$ & A & 75 \\
\hline 12 & $51 \mathrm{ca}$ & $\mathrm{Br}$ & $n-\mathrm{C}_{5} \mathrm{H}_{11}$ & $55 a$ & $4,7-(\mathrm{OMe})_{2}$ & A & 64 \\
\hline 13 & \multirow{2}{*}{$51 \mathrm{cb}$} & \multirow{2}{*}{$\mathrm{Br}$} & \multirow{2}{*}{$\mathrm{Ph}$} & \multirow{2}{*}{$55 b$} & \multirow{2}{*}{$4,7-(\mathrm{OMe})_{2}$} & A & 71 \\
\hline 14 & & & & & & B & 72 \\
\hline 15 & $51 \mathrm{cc}$ & $\mathrm{Br}$ & $3-\mathrm{FC}_{6} \mathrm{H}_{4}$ & $55 c$ & $4,7-(\mathrm{OMe})_{2}$ & B & 65 \\
\hline
\end{tabular}

${ }^{\mathrm{a}}$ Posición del grupo metoxilo referida a la unidad de benzo[b]furano. ${ }^{\mathrm{b}}$ Método A: Calentamiento convencional $\left(100{ }^{\circ} \mathrm{C}, 12 \mathrm{~h}\right)$. Método B: MW $\left(150{ }^{\circ} \mathrm{C}, 12 \mathrm{~min}\right.$. $){ }^{\mathrm{c}}$ Rendimiento en producto aislado referido a los 2-alquinil-3bromoanisoles de partida 51aa-cc. ${ }^{\mathrm{d}} 1$-Ciclohexenilo.

Estos resultados muestran que es posible llevar a cabo una reacción tándem de hidroxilación / heterociclación sobre los $o$-alquinilbromoanisoles $\mathbf{5 1}$ permitiendo el acceso a los benzo[b]furanos 53-55. 


\section{d) Transformaciones sintéticas de los metoxibenzo[b]furanos}

\section{d.1 $\underline{\text { Síntesis de los hidroxibenzo[b]furanos } \mathbf{5 6}, \mathbf{5 7} \text { y } \mathbf{5 8}}$}

La desprotección del grupo metoxilo en los 4-metoxibenzo[b]furanos 52a y 52d por tratamiento con $\mathrm{BBr}_{3}$ permitió preparar los 4-hidroxibenzo[b]furanos 56a y 56b con buenos rendimientos (Esquema 2.25).

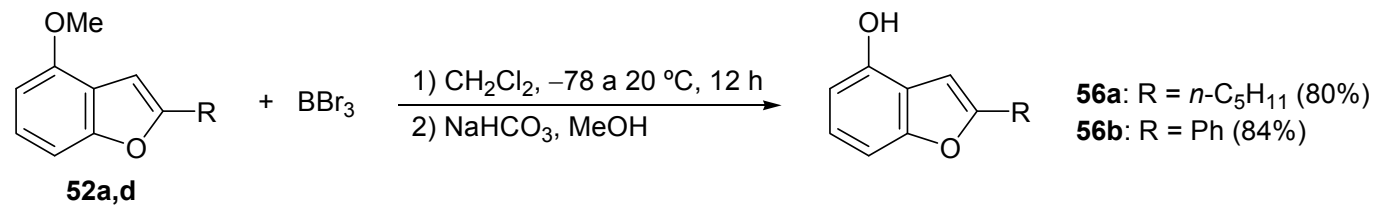

\section{Esquema 2.25}

También se decidió ensayar la desprotección de los grupos metoxilo empleando un dimetoxibenzo[ $b]$ furano como sustrato de partida. Así, cuando se trató el 4,5-dimetoxi-2- $p$ tolilbenzo $[b]$ furano $53 \mathrm{~d}$ con exceso de $\mathrm{BBr}_{3}$ se pudo obtener el correspondiente dihidroxibenzo[b]furano 57 con buen rendimiento (Esquema 2.26).<smiles>COc1ccc2oc(-c3ccc(C)cc3)cc2c1OC</smiles>

53d

\section{$+\mathrm{BBr}_{3} \underset{\mathrm{CH}_{2} \mathrm{Cl}_{2},-78 \text { a } 20^{\circ} \mathrm{C}, 12 \mathrm{~h}}{\longrightarrow}$}

\section{Esquema 2.26}

A continuación, se quiso comprobar si la desprotección de los grupos metoxilo presentes en un dimetoxibenzo[b]furano podría ser selectiva. Para ello, se hizo reaccionar el $2-$ (3-fluorofenil)-4,7-dimetoxibenzo[b]furano $\mathbf{5 5 c}$ con 1.8 equiv. de $\mathrm{BBr}_{3}$. El análisis por CG-EM de una alícuota del crudo de reacción y de los espectros de $\mathrm{RMN}$ de ${ }^{1} \mathrm{H}$ y ${ }^{13} \mathrm{C}$ nos indicó que se había formado una mezcla de isómeros correspondiente al 2-(3-fluorofenil)-4-hidroxi-7metoxibenzo[ $b]$ furano 58a y al 2-(3-fluorofenil)-7-hidroxi-4-metoxibenzo[ $b]$ furano $\mathbf{5 8 b}$, además de pequeñas cantidades del dimetoxibenzo $[b]$ furano de partida $55 \mathrm{c}$. La posterior purificación por cromatografía de columna permitió la separación de ambos isómeros, aislándose 58a y 58b con rendimientos del 50 y 35\%, respectivamente (Esquema 2.27). 
<smiles>COc1ccc(OC)c2oc(-c3cccc(F)c3)cc12</smiles>

$55 \mathrm{c}$

$$
\begin{aligned}
& \text { 1) } \mathrm{BBr}_{3}, \mathrm{CH}_{2} \mathrm{Cl}_{2} \\
& -78 \mathrm{a} 20{ }^{\circ} \mathrm{C}, 12 \mathrm{~h} \\
& \text { 2) } \mathrm{NaHCO}_{3}, \mathrm{MeOH}
\end{aligned}
$$<smiles>COc1ccc(O)c2cc(-c3cccc(F)c3)oc12</smiles>

$58 \mathbf{a}(50 \%)$<smiles>COc1ccc(O)c2oc(-c3cccc(F)c3)cc12</smiles>

58b $(35 \%)$

\section{Esquema 2.27}

Por otro lado, aunque el estudio de los espectros de ${ }^{1} \mathrm{H}$ y ${ }^{13} \mathrm{C}$-RMN de cada uno de los isómeros no permitió identificarlos, la realización de distintos experimentos de RMN bidimensionales permitió llevar a cabo esta asignación, tal como muestra el espectro NOESY de 58b (Figura 2.1).

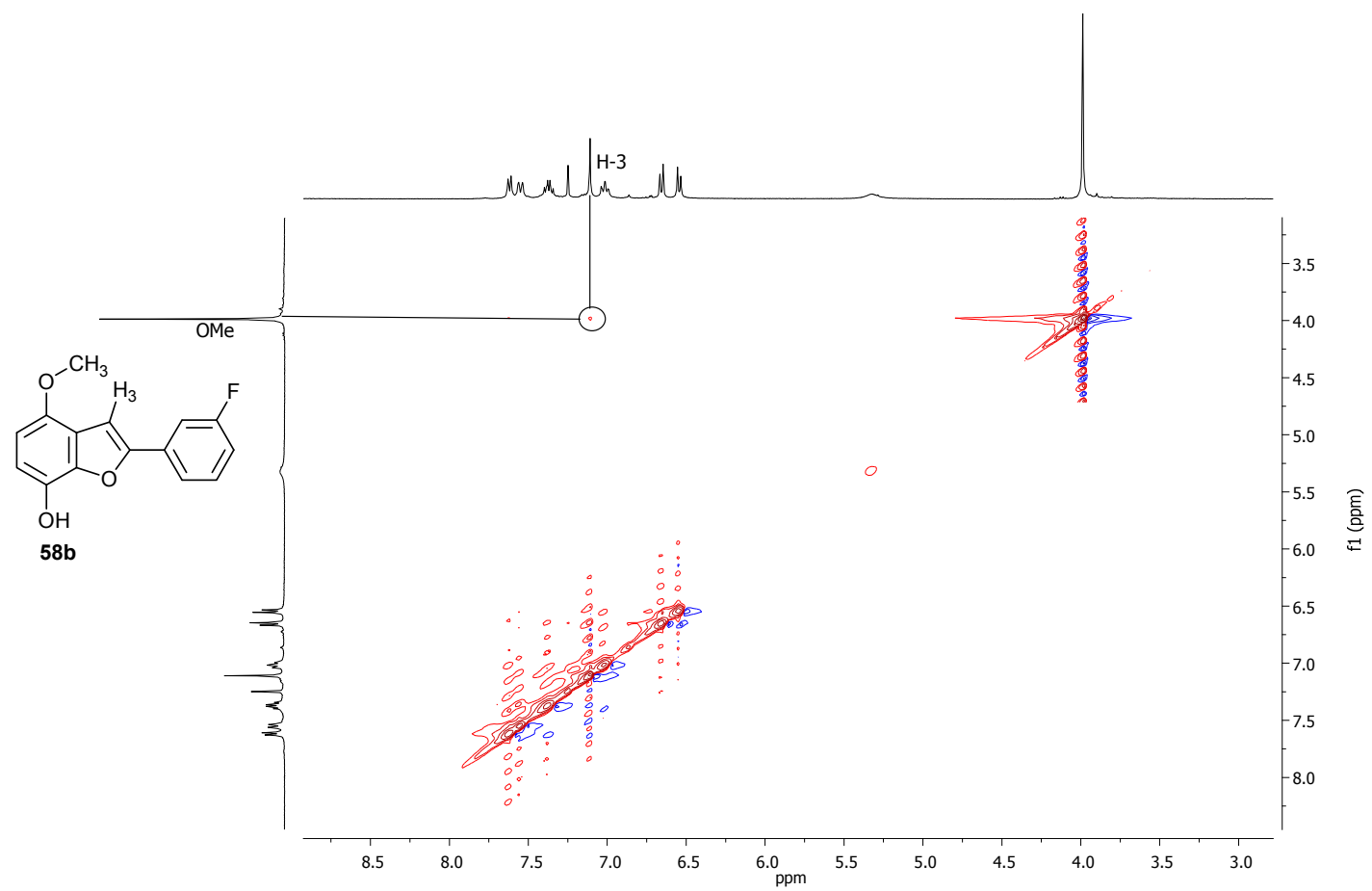

Figura 2.1. Espectro bidimensional NOESY ${ }^{1} \mathrm{H}-{ }^{1} \mathrm{H}(400 \mathrm{MHz})$ para $\mathbf{5 8 b}$ registrado en $\mathrm{CDCl}_{3}$ a $20^{\circ} \mathrm{C}$.

Analizando el espectro NOESY del 2-(3-fluorofenil)-7-hidroxi-4-metoxi benzo[b]furano $\mathbf{5 8 b}$, se puede observar un pico de cruce entre el singlete que aparece a 7.11 
ppm, asignable al hidrógeno $\mathrm{H}-3$, y el singlete correspondiente al grupo metoxilo situado a 3.94 ppm. Sólo sería posible observar NOE entre el H-3 y los hidrógenos del grupo metoxilo cuando estos se encuentran próximos en el espacio, lo que sólo puede ocurrir cuando el grupo metoxilo está unido al carbono C-4 (Figura 2.1).

\subsubsection{INTENTO DE SÍNTESIS DE 4-HALOBENZO[b]FURANOS-3-FUNCIONALIZADOS}

En la literatura se ha descrito la preparación regioselectiva de benzo[ $b]$ furanos sustituidos en las posiciones 2 y 3 mediante una reacción de ciclación electrofílica de $o$ alquinilanisoles, empleando distintos electrófilos tales como $\mathrm{I}_{2}, \mathrm{ICl}, \mathrm{NBS}, \mathrm{PhSeCl}$, etc. (Esquema 2.28). ${ }^{195}$ Se propone un mecanismo por pasos para esta reacción que implicaría una activación electrofílica del triple enlace en el $o$-alquinilanisol de partida, un ataque nucleofílico intramolecular al intermedio catiónico y, finalmente, una dealquilación dando lugar al correspondiente benzo[b]furano (Esquema 2.28).

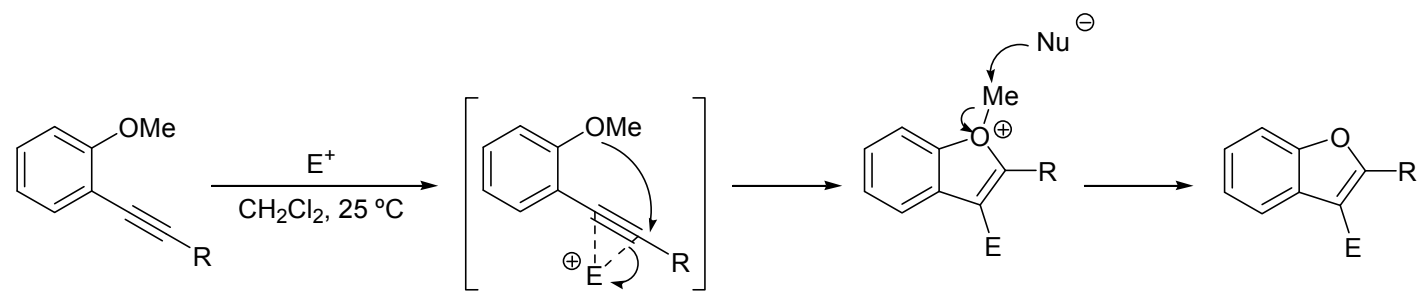

Esquema 2.28

En este contexto, nos propusimos aplicar esta metodología a la preparación de 3,4dihalobenzo[b]furanos 2-sustituidos. Con este objetivo, se trató el orto-alquinilhaloareno 50f con yodo como electrófilo en $\mathrm{CH}_{2} \mathrm{Cl}_{2}$. El avance de la reacción se siguió mediante el análisis de alícuotas por CG-EM a distintos tiempos, pero se observó que la reacción no avanzaba, recuperándose el anisol de partida tras 24 horas. La utilización de dicloroetano a $70{ }^{\circ} \mathrm{C}$ tampoco dio lugar a conversión alguna del producto de partida.

195 a) D. Yue, T. Yao, R. C. Larock, J. Org. Chem. 2005, 70, 10292. b) S. Mehta, J. P. Waldo, R. C. Larock, J. Org. Chem. 2009, 74, 1141. c) M. Jacubert, A. Hamze, O. Provot, J.-F. Peyrat, J.-D. Brion, M. Alami, Tetrahedron Lett. 2009, 50, 3588. 
A continuación se ensayó el empleo de monocloruro de yodo ( $\mathrm{ICl}$ ) como agente electrofílico. El producto esperado de una reacción de yodociclación sería el 4-cloro-2-fenil-3yodobenzo[b]furano. Sin embargo, cuando se hizo reaccionar 50f con $\mathrm{ICl}$ en $\mathrm{CH}_{2} \mathrm{Cl}_{2}$ a temperatura ambiente durante 2 horas se obtuvo, como único producto de reacción, el 1-cloro-2[(E)-1-cloro-2-fenil-2-yodovinil]-3-metoxibenceno 60a con alto rendimiento (Esquema 2.29).

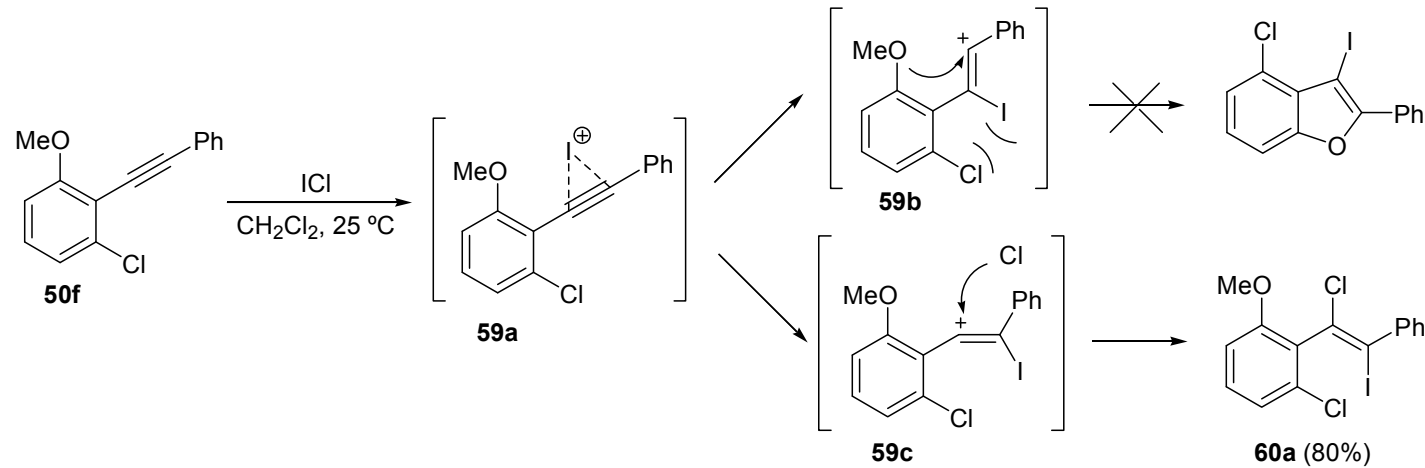

Esquema 2.29

La formación del producto 60a se podría explicar por adición electrofílica del $\mathrm{ICl}$ al triple enlace de acuerdo a la regla Markovnikov a través del intermedio 59c. Para justificar la formación del compuesto 60a en lugar del yodobenzo[ $b]$ furano, hay que considerar los dos posibles cationes intermedios 59b y 59c. El hecho de no obtener el yodobenzo[ $b]$ furano podría deberse a que existen interacciones estéricas desestabilizantes en el carbocatión 59b entre los átomos de yodo y cloro. Estas interacciones no existen en 59c que, además, está estabilizado electrónicamente por el grupo metoxilo (Esquema 2.29).

Análogamente, cuando esta misma reacción se ensayó con el orto-alquinilhaloareno 50d, se obtuvo el 1-bromo-2-[(E)-1-cloro-2-fenil-2-yodovinil]-3-metoxibenceno 60b con muy buen rendimiento (Esquema 2.30).<smiles>COc1cccc(Br)c1C#Cc1ccccc1</smiles>

50d

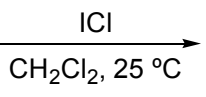

Esquema 2.30<smiles>COc1cccc(Br)c1/C(Cl)=C(\I)c1ccccc1</smiles>

60b $(87 \%)$ 
Bellina y colaboradores ${ }^{196}$ habían llevado a cabo un estudio de la reacción de adición electrofílica de $\mathrm{ICl}$ a distintos alquinos. Comprobaron que la regioquímica de la reacción venía determinada por la regla Markonikov. Además realizaron un exhaustivo análisis de los espectros bidimensionales NOESY ${ }^{1} \mathrm{H}-{ }^{1} \mathrm{H}$ con el fin de determinar la estereoquímica de los productos resultantes y llegaron a la conclusión de que la adición de $\mathrm{ICl}$ al triple enlace era anti.

Larock y colaboradores ${ }^{195 b}$ también han observado una reacción de adición de $\mathrm{ICl}$ al triple enlace cuando se empleaban $o$-alquinilmetoxibencenos que contenían otro grupo adicional en la otra posición en orto al grupo alquinilo. Ellos obtuvieron el producto resultante de la adición de ICl al 1-fenil-2-(feniletinil)-3-metoxibenceno, en lugar del producto de yodociclación (Esquema 2.31).

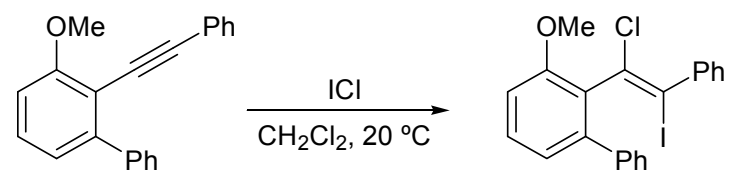

\section{Esquema 2.31}

Posteriormente, se decidió comprobar si la adición al triple enlace de otros reactivos electrofílicos también tenía lugar de un modo análogo al ICl. Así, cuando se hizo reaccionar el orto-alquinilhaloareno 50f con $\mathrm{PhSeCl}$ se obtuvo el producto 60c, resultante de la adición al triple enlace, en lugar del correspondiente benzofurano (Esquema 2.32).

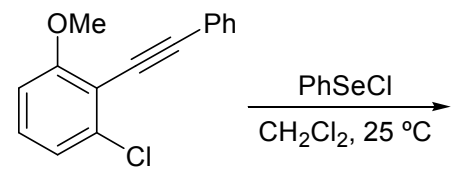

$50 f$<smiles>COc1cccc(Cl)c1C(Cl)=C(c1ccccc1)c1ccccc1</smiles>

60c $(85 \%)$

\section{Esquema 2.32}

${ }^{196}$ F. Bellina, F. Colzi, L. Mannina, R. Rossi, S. Viel, J. Org. Chem. 2003, 68, 10175. 
Aunque no se han podido preparar los 3,4-dihalobenzo[b]furanos buscados, la reacción de los $o$-alquinilhaloarenos $\mathbf{5 0 d , f}$ con distintos electrófilos ha permitido la síntesis de los productos $60 \mathbf{a}-\mathbf{c}$ altamente funcionalizados y con buenos rendimientos, resultantes de la adición al triple enlace.

\subsubsection{CONCLUSIONES}

Como resumen de los resultados expuestos en el Capítulo 2 se puede extraer la siguiente conclusión:

Se ha desarrollado una ruta sintética para acceder de forma regioselectiva a 4metoxi y 4,n-dimetoxibenzo[b]furanos a través de una combinación de reacciones de ortometalación dirigida / acoplamientos catalizados por paladio. La orto-zincación de una variedad de 3-bromoanisoles seguida de su reacción con yodo como electrófilo permite la preparación directa y regioselectiva de metoxi- y dimetoxidihalobencenos. A continuación, un acoplamiento selectivo de Sonogashira con alquinos terminales, seguido de la hidroxilación directa de los $o$-bromoaril alquinos resultantes con $\mathrm{KOH}$ y una heterociclación 5-endo-dig "in situ", permite obtener los derivados de benzo[b]furano. Además, se ha puesto a punto un nuevo procedimiento para la reacción de hidroxilación, el cual permite que el acoplamiento tenga lugar en tan sólo unos minutos empleando radiación de microondas. 



\section{CAPÍTULO 3}

Reacciones de orto-metalación combinadas con acoplamientos catalizados por paladio. Sintesis de benzo[b]tiofenos regioselectivamente funcionalizados 



\subsection{INTRODUCCIÓN}

En los últimos años, nuestro grupo de investigación se ha interesado por el desarrollo de metodologías adecuadas para la síntesis de compuestos heterocíclicos funcionalizados. Un tipo de heterociclos muy interesantes en Química Orgánica son los benzo[b]tiofenos.

Las moléculas que contienen el núcleo de benzo[b]tiofeno muestran un amplio espectro de actividades biológicas. ${ }^{197}$ De hecho, este esqueleto es un componente esencial de importantes fármacos tales como el raloxifeno, ${ }^{198}$ empleado para tratar la osteoporosis en mujeres tras la menopausia, o el zileuton ${ }^{199}$ (Ziflo), con buenas propiedades para el tratamiento del asma (Esquema 3.1). Por otro lado, compuestos que presentan este anillo heteroaromático también son útiles para la fabricación de dispositivos con propiedades ópticas y electrónicas. ${ }^{200}$

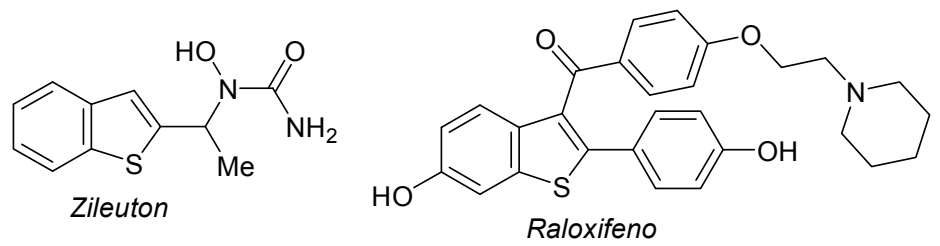

Esquema 3.1

En este contexto, el desarrollo de metodologías selectivas y eficaces para la construcción de benzotiofenos funcionalizados regioselectivamente es de considerable importancia en Síntesis Orgánica. En concreto, es conocido que la preparación de derivados de 7-hidroxibenzo[$[b]$ tiofenos es complicada, habiéndose descrito unos pocos procedimientos, los cuales emplean derivados de tiofeno para construir la unidad bencenoide en varios pasos.

197 a) C. Wu, E. R. Decker, N. Blok, H. Bui, T. J. You, J. Wang, A. R. Bourgoyne, V. Knowles, K. L. Berens, G. W. Holland, T. A. Brock, R. A. F. Dixon, J. Med. Chem. 2004, 47, 1969. b) H. F. Guo, H. Y. Shao, Z. Y. Yang, S. T. Xue, X. Li, Z. Y. Liu, X. B. He, J. D. Jiang, Y. Q. Zhang, S. Y. Si, Z. R. Li, J. Med. Chem. 2010, 53, 1819. c) S. Wang y col., J. Med. Chem. 2010, 53, 1473. d) K. Nakagawa-Goto y col. J. Med. Chem. 2011, 54, 1244.

198 a) L. Yu, H. Liu, W. Li, F. Zhang, C. Luckie, R. B. van Breemen, G. R. J. Thatcher, J. L. Bolton, Chem. Res. Toxicol. 2004, 17, 879. b) Z. Qin, I. Kasrati, R. E. P. Chandrasena, H. Liu, P. Yao, P. A. Petukhov, J. L. Bolton, G. R. J. Thatcher, J. Med. Chem. 2007, 50, 2682.

${ }^{199}$ X. Guinchard, J. N. Denis, J. Org. Chem. 2008, 73, 2028.

200 a) H. Ebata, E. Miyazaki, T. Yamamoto, K. Takimiya, Org. Lett. 2007, 9, 4499. b) Y. Zhou, W.-J. Liu, Y. Ma, H. Wang, L. Qi, Y. Cao, J. Wang, J. Pei, J. Am. Chem. Soc. 2007, 129, 12386. c) M. Funahashi, F. Zhang, N. Tamaoki, Adv. Mater. 2007, 19, 353. d) I. F. Perepichka, D. F. Perepichka Handbook of Thiophene-Based Materials: Applications in Organic Electronics and Photonics; John Wiley \& Sons: West Sussex, UK, 2009. 
En el Capítulo precedente se ha desarrollado una estrategia eficiente para la obtención de alcoxibenzo[b]furanos. En este sentido, considerando el interés en la síntesis de benzo $[b]$ tiofenos y la escasez de métodos para preparar 7-hidroxibenzo[b]tiofenos, nos propusimos como primer objetivo de este Capítulo la preparación de benzo[b]tiofenos oxígeno-funcionalizados regioselectivamente en la posición 7 del anillo. Con este objetivo en mente nos planteamos que derivados de 2-alquiltio-3-halofenoles podrían ser sustratos de partida muy interesantes para la síntesis de estos heterociclos 7-oxígeno-sustituidos empleando una combinación de acoplamientos catalizados por complejos de paladio y reacciones de ciclación electrofílica (Esquema 3.2).

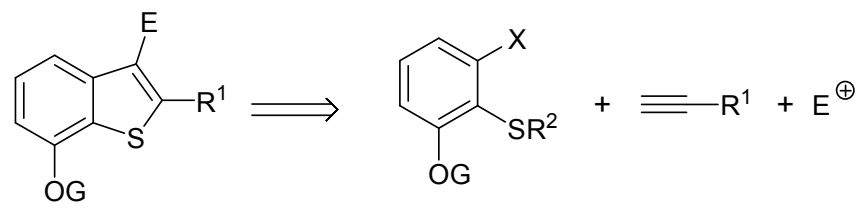

Esquema 3.2

Como segundo objetivo en este Capítulo nos propusimos poner a punto una estrategia sintética para la síntesis de benzo[b]tiofenos 2-sustituidos oxígenofuncionalizados de forma eficiente y sencilla, mediante el acoplamiento de derivados de $o$ alquinilbromoarenos y distintos equivalentes sintéticos del $\mathrm{H}_{2} \mathrm{~S}$ (Esquema 3.3).<smiles>[R]C#Cc1c(Br)ccc([R20])c1O[R]</smiles>

Esquema 3.3

Antes de exponer los resultados de este Capítulo, se va a proceder a hacer una breve revisión bibliográfica de algunos métodos descritos en la bibliografía que permiten la síntesis de benzo[b]tiofenos, así como de las reacciones de acoplamiento $\mathrm{C}-\mathrm{S}$ a partir de haluros de arilo catalizadas por metales de transición, fundamentalmente paladio. 


\subsection{ANTEDEDENTES BIBLIOGRÁFICOS}

En este apartado se van a tratar los aspectos más generales relacionados con el trabajo desarrollado en este Capítulo. En primer lugar, se describirán algunos de los principales métodos descritos en la bibliografía para la síntesis de benzo[b]tiofenos. Además, se detallarán los escasos procedimientos existentes para la preparación de 7 hidroxibenzo[$[b]$ tiofenos. A continuación, se presentarán las reacciones de ciclación electrofílica como método para la obtención de heterociclos de 5 miembros 2,3-disustituidos. Finalmente, se expondrán los acoplamientos de haluros de arilo con distintos sulfuros y tioles, catalizados por complejos de metales de transición, para la formación de enlaces $\mathrm{C}-\mathrm{S}$.

\subsubsection{SÍNTESIS DE BENZO $[b]$ TIOFENOS FUNCIONALIZADOS}

\section{a) Métodos generales para la síntesis de benzo $[b \mid$ tiofenos}

En este apartado se describirán los principales procedimientos para la preparación de benzo[b]tiofenos funcionalizados, la mayoría de los cuales están basados en la ciclación de derivados bencénicos previamente funcionalizados. Algunos de estos métodos, como la ciclodeshidratación de $\alpha$-ariltio cetonas, son análogos a los empleados para la síntesis de benzo[b]furanos.

\section{a.1 Reacciones de ciclación en derivados de tiofenoles alquilados}

La alquilación de distintos tiofenoles con el dietilacetal del 2-bromoacetaldehído, seguida de la ciclación del intermedio 2,2-dietoxietil-arilsulfuro en presencia de $\mathrm{BF}_{3} \cdot \mathrm{Et}_{2} \mathrm{O}^{201} \mathrm{o}$ PPA $^{202}$ permite preparar benzo[b]tiofenos funcionalizados (Esquema 3.4).

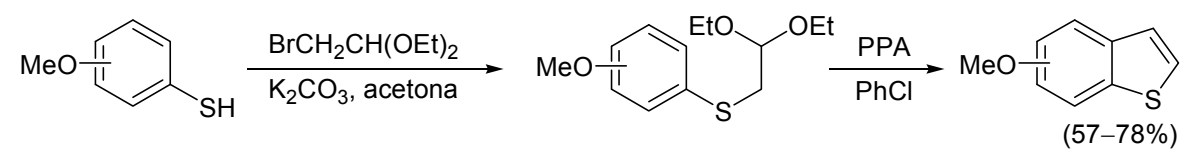

\section{Esquema 3.4}

${ }^{201}$ S. L. Graham y col., J. Med. Chem. 1989, 32, 2548.

${ }^{202}$ K. Takeuchi, T. J. Kohn, D. J. Sall, M. L. Denney, J. R. McCowan, G. F. Smith, D. S. Gifford-Moore, Bioorg. Med. Chem. Lett. 1999, 9, 759. 
Cuando se emplean tiofenoles 3-funcionalizados se observan problemas de selectividad, obteniéndose mezclas de los benzo[b]tiofenos 4 y 6 -funcionalizados.

\section{a.2 Ciclodeshidratación de $\alpha$-ariltio cetonas}

Se han preparado benzo[b]tiofenos funcionalizados mediante una secuencia de ciclación-deshidratación en $\alpha$-ariltio cetonas ${ }^{198 a, 203}$ (Esquema 3.5).<smiles>COc1ccc(C(=O)CSc2cccc(OC)c2OC)cc1</smiles>

\section{Esquema 3.5}

\section{a.3 Ciclación de derivados de orto-halobenzaldehído}

Se ha descrito la síntesis regioselectiva de benzo $[b]$ tiofenos mediante la reacción de $o$-fluorobenzaldehídos, adecuadamente sustituidos, con 2-mercaptoacetato de metilo ${ }^{204}$ o 2 mercaptoacetonitrilo, ${ }^{197 \mathrm{c}}$ seguida de la ciclación del intermedio formado (Esquema 3.6).

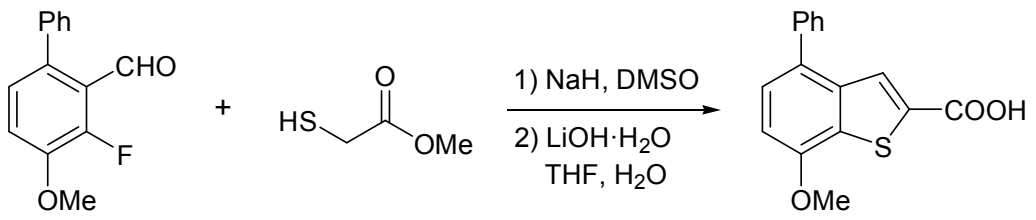

\section{Esquema 3.6}

Por su parte, la reacción de 2-clorobenzaldehídos con benciltioles, en presencia de $\mathrm{KOH}$ y PEG, ha permitido preparar 2-arilbenzo[b]tiofenos con buenos rendimientos (Esquema 3.7). ${ }^{205}$

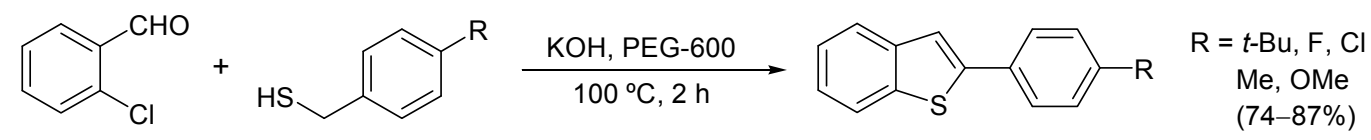

\section{Esquema 3.7}

${ }^{203}$ E. Campaigne, R. B. Rogers, J. Heterocyclic. Chem. 1973, 10, 963.

${ }^{204}$ O. Saku, M. Saki, M. Kurokawa, K. Ikeda, T. Takizawa, N. Uesaka, Bioorg. Med. Chem. Lett. 2010, 20, 1090.

${ }^{205}$ Z. Duan, S. Ranjit, X. Liu, Org. Lett. 2010, 12, 2430. 


\section{a.4 Reacciones catalizadas por complejos de metales de transición}

Una estrategia importante para la construcción del anillo de benzo[b]tiofeno se basa en reacciones de acoplamiento intramolecular $\mathrm{C}-\mathrm{S}$ de $o$-haloalqueniltiofenoles.

En este contexto, Lautens y colaboradores han desarrollado un método para la síntesis de benzo[b]tiofenos, catalizado por el sistema $\mathrm{PdCl}_{2} / \mathrm{SPhos}$, a partir de gemdibromoviniltiofenoles y ácidos borónicos mediante un proceso tándem de acoplamientos $\mathrm{C}-\mathrm{S} / \mathrm{C}-\mathrm{C}$ (Suzuki-Miyaura) (Esquema 3.8). ${ }^{206}$
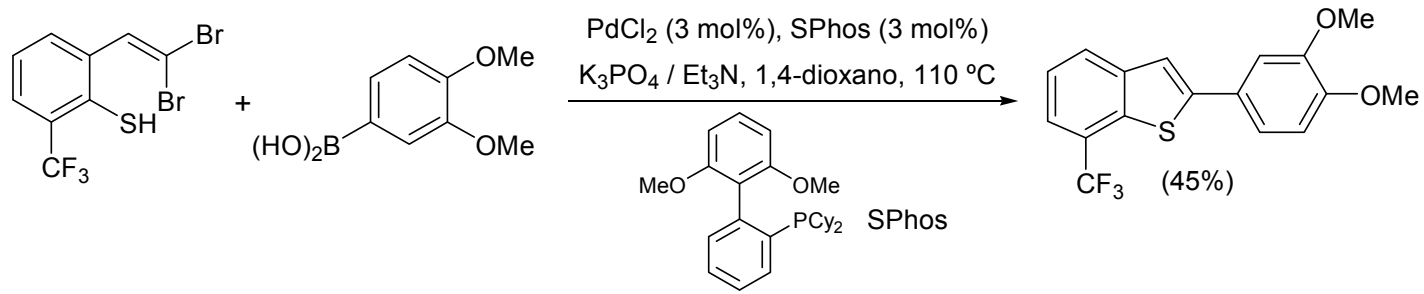

\section{Esquema 3.8}

También se han preparado derivados de 2-carbonilbenzo[b]tiofeno a partir de 2gem-dihaloviniltiofenoles en presencia de cantidades catalíticas de $\mathrm{Pd}(\mathrm{OAc})_{2}$ y una fosfina voluminosa ${ }^{207}$ Este procedimiento implica una secuencia en cascada de acoplamiento $\mathrm{C}-\mathrm{S}$ intramolecular / carbonilación (Esquema 3.9).

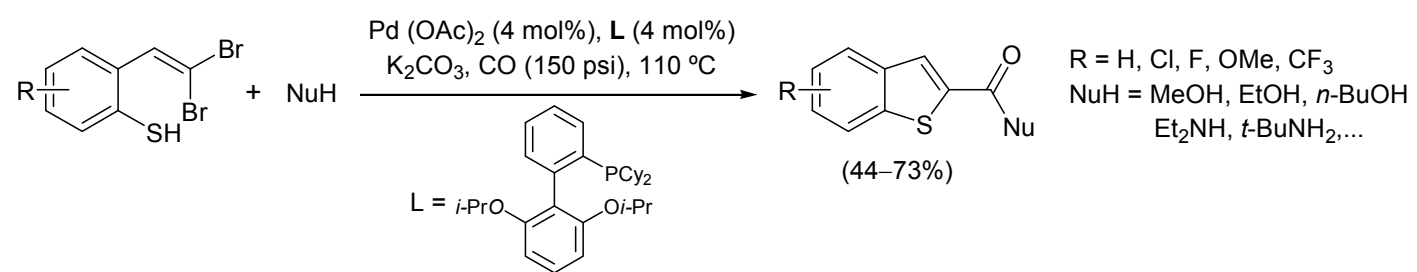

Esquema 3.9

Otros autores han descrito la síntesis de derivados de benzo $[b]$ tiofenos mediante una reacción tándem tiolación / ciclación intramolecular sobre haluros de haloalquenilfenilo con $\mathrm{Na}_{2} \mathrm{~S}$, catalizada por $\mathrm{CuI}$ (Esquema 3.10). ${ }^{208}$

${ }^{206}$ C. S. Bryan, J. A. Braunger, M. Lautens, Angew. Chem., Int. Ed. 2009, 48, 7064.

${ }^{207}$ F. Zeng, H. Alper, Org. Lett. 2011, 13, 2868.

${ }^{208}$ C.-L. Li, X.-G. Zhang, R.-Y. Tang, P. Zhong, J.-H. Li, J. Org. Chem. 2010, 75, 7037. 
Este proceso permite incluso la utilización de cloruros de cloroalquenilarilo, aunque obteniéndose rendimientos más moderados.

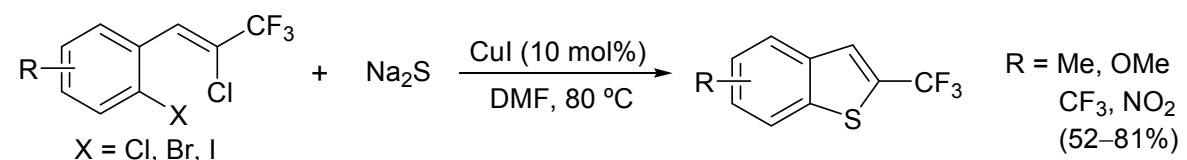

\section{Esquema 3.10}

\section{a.5 Reacciones de ciclación en derivados de orto-alquinilaril tioéteres}

Una de las aproximaciones más útiles para la construcción del anillo de benzo $[b]$ tiofeno implica una reacción de ciclación 5-endo-dig en $o$-alquinilaril tioéteres. Esta ciclación puede estar mediada por un ácido de Brønsted, ${ }^{209}$ en el caso particular de alquinos sustituidos con grupos aromáticos ricos (Esquema 3.11).
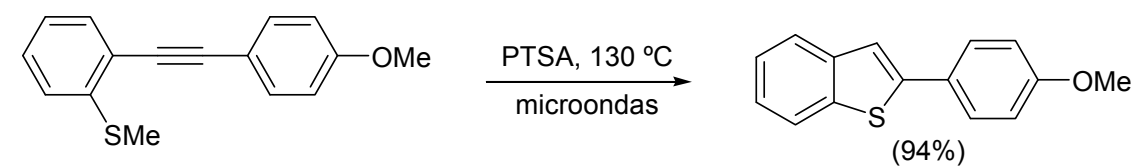

Esquema 3.11

\section{a.6 $\underline{\text { Reacciones que implican la formación de complejos bencinozirconoceno }}$}

Buchwald ha descrito un procedimiento para la transformación de bromuros de arilo, alquinos internos y dicloruro de azufre en benzo $[b]$ tiofenos polisustituidos con altos rendimientos empleando $\mathrm{MeZrCp}_{2} \mathrm{Cl}$. El método implica la generación de un complejo de bencinozirconoceno, seguida de la carbozirconación del alquino y una posterior transmetalación $\mathrm{Zr}-\mathrm{S}$ (Esquema 3.12). ${ }^{210}$

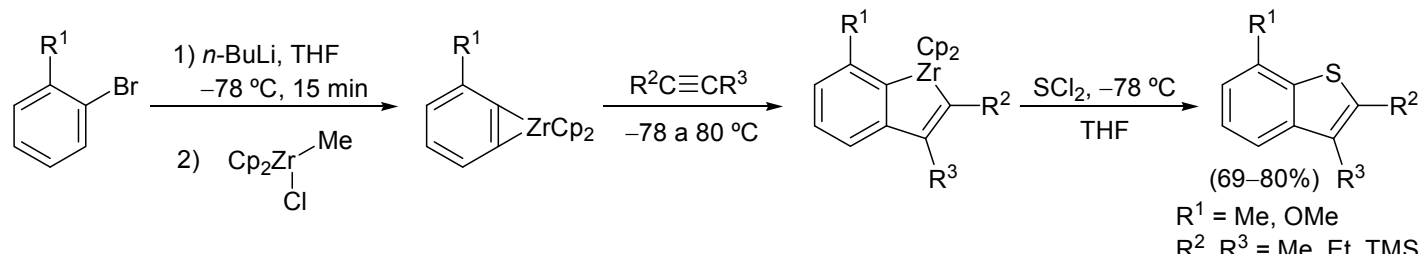

Esquema 3.12

${ }^{209}$ M. Jacubert, A. Hamze, O. Provot, J.-G. Peyrat, J.-D. Brion, M. Alami, Tetrahedron Lett. 2009, 50, 3588. ${ }^{210}$ S. L. Buchwald, Q. Fang, J. Org. Chem. 1989, 54, 2793. 


\section{a.7 Reacciones de ciclación en derivados de tiofeno}

Por otro lado, la reacción del tiofeno-2-carbaldehído con un reactivo de Wittig dihalogenado, seguida de una reacción de Sonogashira con alquinos terminales y una posterior ciclación regioespecífica 6-endo en medio básico, conduce a 6fluorobenzo[b]tiofenos 4-funcionalizados (Esquema 3.13). ${ }^{211}$

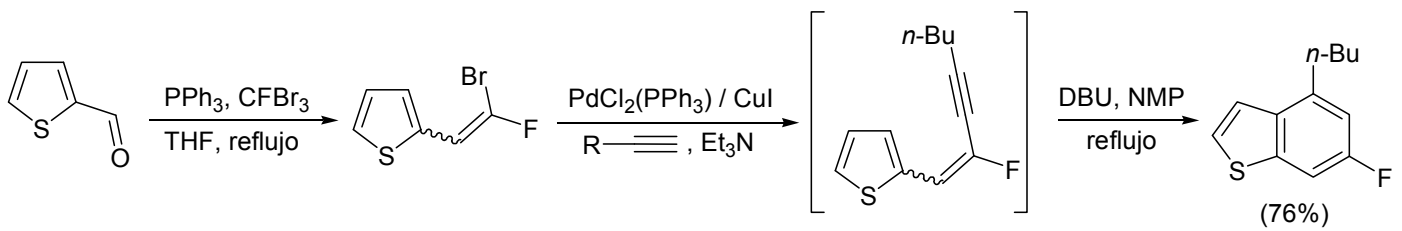

\section{Esquema 3.13}

\section{b) Síntesis de 7-hidroxibenzo[b]tiofenos}

En este apartado se comentarán las principales estrategias para la síntesis de 7hidroxibenzo $[b]$ tiofenos. Los procedimientos descritos en la bibliografía son reducidos y la mayoría de ellos implican varios pasos de reacción.

b.1 Reacción de ciclación en derivados de tiofeno

De y colaboradores han estudiado la ciclación del 4-(2-tienil)-4-oxobutanal III promovida por $\mathrm{BF}_{3} \cdot \mathrm{MeOH}$ que conduce al 7 -metoxibenzo[b]tiofeno con un $40 \%$ de rendimiento. ${ }^{212}$ El ceto-aldehído III fue preparado mediante la apertura y descarboxilación en medio básico de la lactona I seguida de la oxidación de II con PCC (Esquema 3.14).

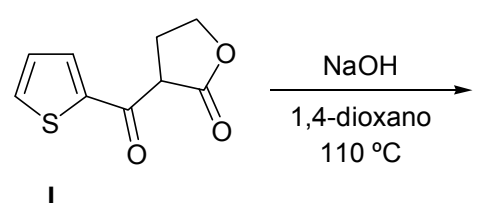<smiles>O=C(CCCO)c1cccs1</smiles>

Esquema 3.14

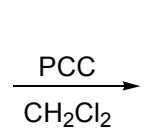<smiles>O=CCCC(=O)c1cccs1</smiles>
$\underset{\mathrm{MeOH}}{\stackrel{\mathrm{BF}_{3} \cdot \mathrm{MeOH}}{\longrightarrow}}$<smiles>COc1cccc2ccsc12</smiles>

$(40 \%)$

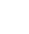


Estos mismos autores han sintetizado 7-hidroxibenzo[b]tiofenos a partir de derivados de tiofeno empleando una secuencia que implica una reacción de o-litiación seguida de una transmetalación y posterior reacción con bromuro de alilo. A continuación, la desprotonación de la posición alílica del derivado de 3-aliltiofeno con LDA seguida de la ciclación condujo al correspondiente benzo[b]tiofeno 7-hidroxifuncionalizado (Esquema 3.15). ${ }^{212 a}$

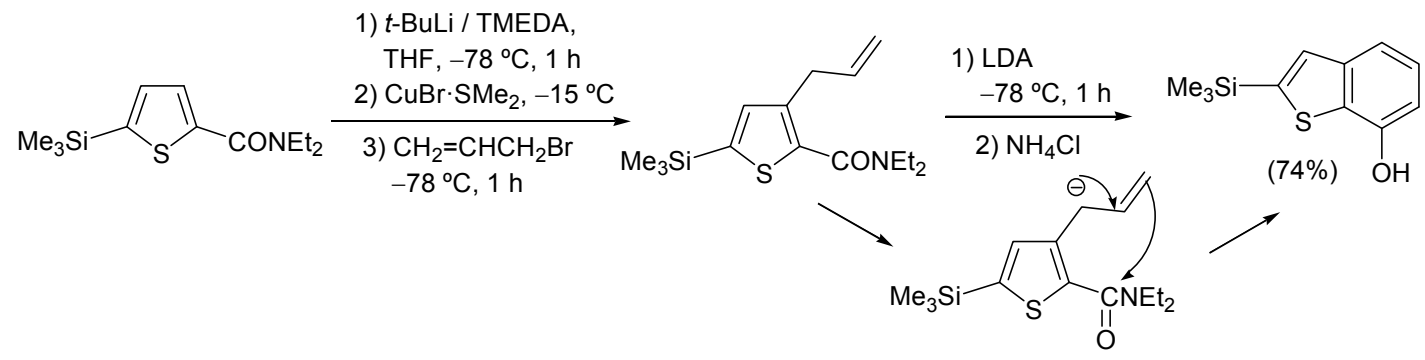

\section{Esquema 3.15}

\section{b.2 Reacciones de ciclación en derivados de benceno funcionalizados}

Chapman y colaboradores han descrito la preparación de 7-hidroxibenzo[b]tiofenos a partir de los correspondientes 7-halo derivados. Así, han preparado el 7-cloro-3metilbenzo $[b]$ tiofeno por ciclación de la (o-clorofeniltio) propanona promovida por PPA. ${ }^{213 a}$ El posterior desplazamiento nucleofílico del átomo de cloro, utilizando $\mathrm{NaOH}$ acuoso a elevada temperatura, ha permitido obtener el derivado de 7-hidroxibenzo $[b]$ tiofeno (Esquema 3.16). ${ }^{213 b}$<smiles>CC(C)CC(=O)CSc1ccccc1Cl</smiles><smiles>Cc1csc2c(Cl)cccc12</smiles>

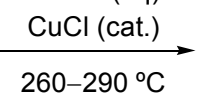
$260-290^{\circ} \mathrm{C}$<smiles>Cc1csc2c(O)cccc12</smiles>

$(63 \%)$

\section{Esquema 3.16}

Por otra parte, el tratamiento de una disolución alcalina de 2-mercapto-3metoxibenzaldehído con cloroacetato de sodio condujo al ácido 7-metoxibenzo[b]tiofen-2-

\footnotetext{
213 a) N. B. Chapman, K. Clarke, S. N. Sawhney, J. Chem. Soc. (C) 1968, 518. b) N. B. Chapman, K. Clarke, A. Manolis, J. Chem. Soc., Perkin Trans. 1 1972, 1404.
} 
carboxílico que, tras posterior desprotección del grupo metoxilo seguida de descarboxilación, ha permitido preparar el 7-hidroxibenzo[b]tiofeno (Esquema 3.17). ${ }^{214}$

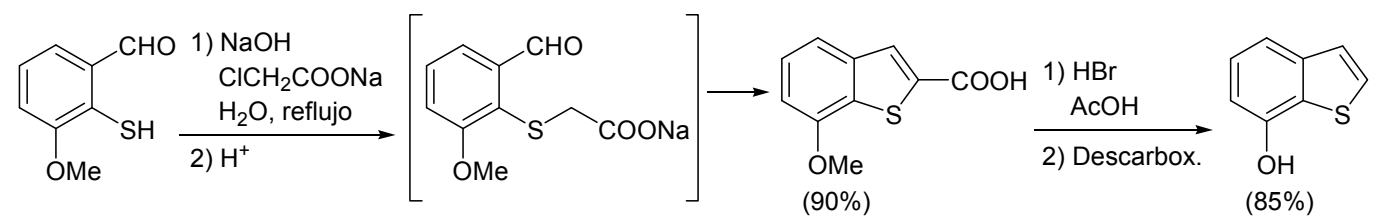

Esquema 3.17

\subsubsection{REACCIONES DE CICLACIÓN ELECTROFÍliCA: APLICACIÓN A LA SÍNTESIS DE HETEROCICLOS BENZOFUSIONADOS DE 5 MIEMBROS}

Larock y colaboradores han realizado numerosos estudios relacionados con las reacciones de ciclación electrofilica sobre derivados de alquinilbenceno que presentan en posición orto un nucleófilo heteroatómico. Así han podido preparar indoles, ${ }^{215}$ benzo[b]furanos, ${ }^{195 a, b}$ benzo[b]tiofenos ${ }^{215 b, 216}$ y benzo $[b]$ selenofenos, ${ }^{215 b, 217}$ entre otros compuestos heteroaromáticos (Esquema 3.18).

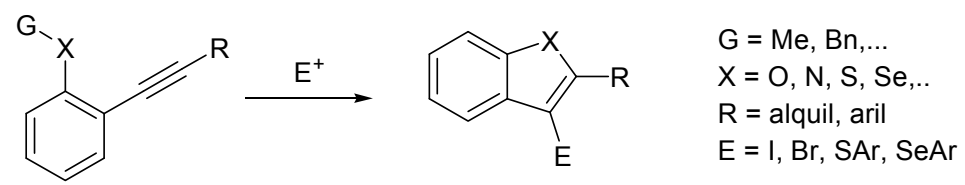

Esquema 3.18

Por ejemplo, la reacción de $o$-alquinil- $N, N$-dialquilanilinas en presencia de una amplia variedad de electrófilos, tales como halógenos y haluros de arilsulfenilo, permite obtener indoles 2,3-disustituidos (Esquema 3.19). ${ }^{215}$

${ }^{214}$ L. K. A. Rahman, R. M. Scrowston, J. Chem. Soc., Perkin Trans. 1 1983, 2973.

215 a) D. Yue, R. C. Larock, Org. Lett. 2004, 6, 1037. b) D. Yue, T. Yao, R. C. Larock, J. Org. Chem. 2006, 71, 62.

216 a) R. C. Larock, D. Yue, Tetrahedron Lett. 2001, 42, 6011. b) D. Yue, R. C. Larock, J. Org. Chem. 2002, 67, 1905. c) S. Mehta, R. C. Larock, J. Org. Chem. 2010, 75, 1652.

${ }^{217}$ T. Kesharwani, S. A. Worlikar, R. C. Larock, J. Org. Chem. 2006, 71, 2307. 


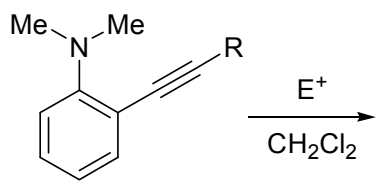<smiles>[R]c1c(F)c2ccccc2n1C</smiles>

Esquema 3.19

En relación a la síntesis de benzo $[b]$ tiofenos y benzo $[b]$ selenofenos, estos mismos autores han descrito la ciclación de orto-alquiniltioanisoles y 1-(1-alquinil)-2(metilseleno)arenos empleando una gran variedad de reactivos electrofílicos: bromo, yodo, $\mathrm{ICl}$, NBS, $\mathrm{PhSeCl}, \ldots$ en $\mathrm{CH}_{2} \mathrm{Cl}_{2}$ como disolvente y condiciones suaves de reacción (Esquema 3.20). ${ }^{216 b, 217}$ Este método tolera la presencia de una amplia variedad de grupos funcionales, tales como alcohol, éster, nitrilo, nitro y trialquilsililo en el alquino de partida.

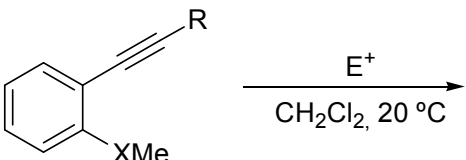

$\mathrm{X}=\mathrm{S}, \mathrm{Se}$<smiles>[R]c1[X]c2ccccc2c1F</smiles>

$(43-100 \%)$

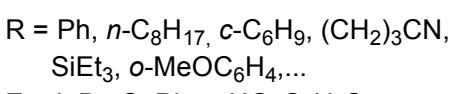

Esquema 3.20

Por otro lado estos autores también han puesto de manifiesto el mayor carácter nucleofílico del átomo de selenio comparado con el de azufre (Esquema 3.21). ${ }^{195 b}$

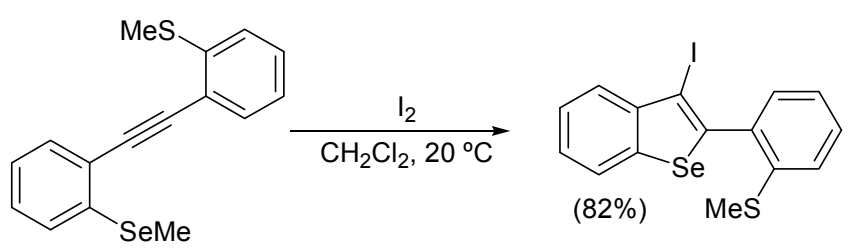

Esquema 3.21

En este contexto, la reacción de yodociclación ha sido empleada de forma iterativa en combinación con el acoplamiento de Sonogashira para preparar compuestos poliheterocíclicos (Esquema 3.22). ${ }^{216 \mathrm{c}}$ 


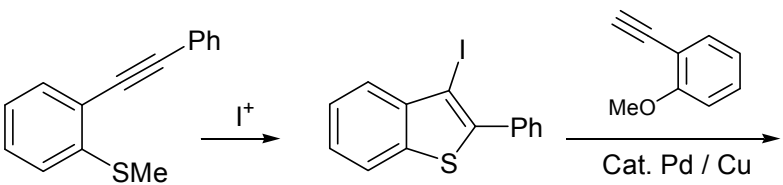

$(99 \%)$

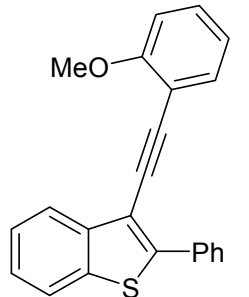

$(65 \%)$

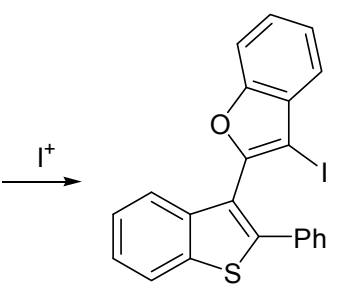

$(67 \%)$

\section{Esquema 3.22}

Otros autores también han descrito la yodociclación de diferentes tioéteres tales como los (o-alquinilaril)bencil tioéteres, obteniéndose los 3-yodobenzo[ $b]$ tiofenos 2-funcionalizados con buenos rendimientos. Estos yoduros pueden experimentar transformaciones posteriores, empleando acoplamientos catalizados por paladio (Esquema 3.23). ${ }^{218}$<smiles>[R]C#CC1=CC=C[R]C=C1Br</smiles><smiles>[C+][Co]</smiles><smiles>[R]c1sc2ccccc2c1I</smiles><smiles></smiles>

\section{Esquema 3.23}

Lu y Wu han sintetizado 3-cloro y 3-bromobenzo[b]tiofenos 2-funcionalizados mediante reacciones de halociclación promovidas por haluros de cobre (Esquema 3.24). ${ }^{219}$ Se propone un ataque anti del átomo de azufre al alquino para generar una sal de sulfonio. La posterior eliminación del grupo metilo mediante un desplazamiento $\mathrm{S}_{\mathrm{N}} 2$ conduciría al benzo[b]tiofeno.<smiles>[R]C#Cc1ccccc1C</smiles>

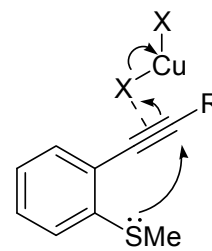

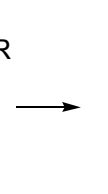<smiles></smiles><smiles>C1CCCC1</smiles><smiles>[R]c1sc2ccccc2c1[X]</smiles>

(65-99\%)

\section{Esquema 3.24}

${ }^{218}$ B. L. Flynn, P. Verdier-Pinard, E. Hamel, Org. Lett. 2001, 3, 651.

${ }^{219}$ W.-D. Lu, M.-J. Wu, Tetrahedron 2007, 63, 356. 
También se han desarrollado ciclaciones de orto-alquinilfeniltioéteres catalizadas por otros metales de transición. En este contexto, Nakamura ha descrito la migración de distintos grupos unidos al átomo de azufre, tales como alilo, propargilo, acilo o $\alpha$ alcoxialquilo a la posición 3 del anillo de benzo[b]tiofeno, durante el proceso de ciclación catalizado por $\mathrm{AuCl}$ (Esquema 3.25). ${ }^{220 \mathrm{a}}$

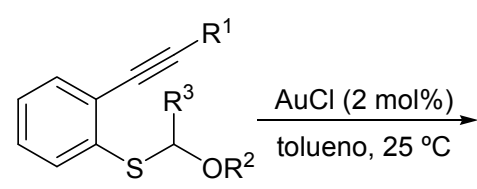<smiles>[R]C#Cc1ccccc1SC([R])O[R]</smiles><smiles>[R]c1c([C]Cl)c2ccccc2[s+]1C([R])[R9]</smiles><smiles>[R]c1sc2ccccc2c1C([R])[R]</smiles>

$\mathrm{R}^{1}=\mathrm{Ph}, n-\mathrm{Pr}, t-\mathrm{Bu}, c-\mathrm{C}_{6} \mathrm{H}_{9}$ $\mathrm{R}^{2}=\mathrm{Me}, \mathrm{Et}, \ldots$ $\mathrm{R}^{3}=\mathrm{H}, \mathrm{Me}$

\section{Esquema 3.25}

Estos mismos autores también han preparado 3-trialquilsililbenzo[b]tiofenos 2funcionalizados mediante ciclación de orto-alquinilfeniltiosilanos catalizada por la misma sal de oro. La reacción transcurre a través de un ataque nucleofílico intramolecular del átomo de azufre al triple enlace deficiente en electrones de la especie I para generar II, que tras una migración [1,3] conduce al correspondiente 3-sililbenzo[b]tiofeno (Esquema $3.26){ }^{220 b}$

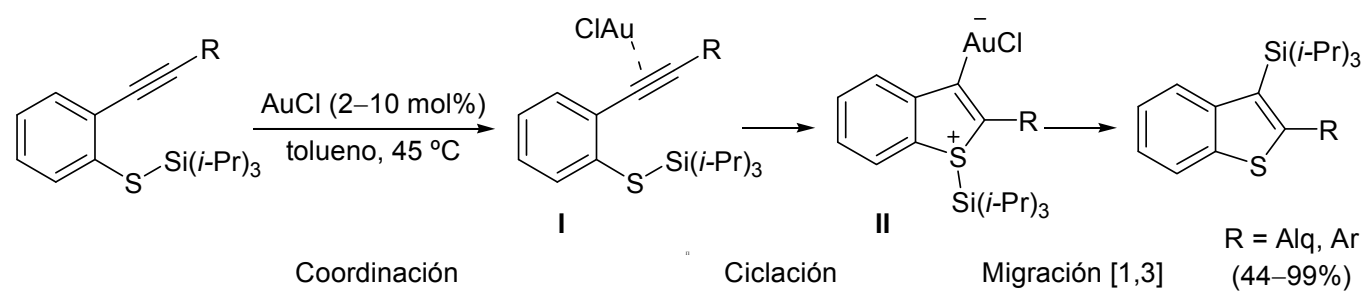

\section{Esquema 3.26}

\footnotetext{
${ }^{220}$ a) I. Nakamura, T. Sato, Y. Yamamoto, Angew. Chem., Int. Ed. 2006, 45, 4473. b) I. Nakamura, T. Sato, M. Terada, Y. Yamamoto, Org. Lett. 2007, 9, 4081.
} 


\subsubsection{REACCIONES DE FORMACIÓN DE ENLACES C-S A PARTIR DE HALOGENUROS DE ARILO}

En la literatura se han descrito numerosos ejemplos de reacciones de acoplamiento entre haluros de arilo y una amplia variedad de sulfuros o tioles catalizadas por metales de transición. ${ }^{221}$ Estos acoplamientos se han convertido en uno de los principales métodos que permiten la formación de nuevos enlaces $\mathrm{C}-\mathrm{S}$. Entre los metales de transición más empleados en estas reacciones destacan los complejos de paladio, aunque más recientemente también han aparecido procedimientos que utilizan sales de $\mathrm{Cu}$ (I) o complejos de níquel en cantidades catalíticas.

\section{a) Reacciones de formación del enlace $\mathrm{C}-\mathrm{S}$ empleando complejos de Pd como catalizadores}

\section{a.1 Reacciones de acoplamiento de haluros de arilo y tioles}

Una de las aplicaciones de las reacciones de acoplamiento $\mathrm{C}-\mathrm{S}$ es la preparación de tioéteres. Migita y colaboradores fueron los primeros en describir el acoplamiento de bromo y yodoarenos con tioles en presencia de $\mathrm{Pd}\left(\mathrm{PPh}_{3}\right)_{4}$ como catalizador. ${ }^{222}$ Con el inicio del siglo XXI han aparecido diferentes sistemas catalíticos más eficaces, la mayoría de los cuales emplean fosfinas voluminosas.

La reacción de acoplamiento de haluros de arilo y tioles ha sido estudiada fundamentalmente por Hartwig y colaboradores. Una de las limitaciones de este acoplamiento se debe a la fuerte avidez de los compuestos de azufre por el paladio. Los catalizadores más activos para llevar a cabo este proceso deben de contener ligandos que se enlacen lo suficientemente fuerte al metal como para prevenir la formación de los complejos tiolato aniónicos I o puente II, mientras que al mismo tiempo favorezcan la adición oxidante y la eliminación reductora (Esquema 2.27). ${ }^{223}$ Así, bisfosfinas voluminosas fuertemente electrón dadoras son buenas candidatas.

\footnotetext{
${ }^{221}$ I. P. Beletskaya, V. P. Ananikov, Chem. Rev. 2011, 111, 1596.

${ }^{222}$ a) K. Kosugi, T. Shimizu, T. Migita, Chem. Lett. 1978, 13. b) T. Migita, T. Shimizu, Y. Asami, J. Shiobara, Y. Kato, M. Kosugi, Bull. Chem. Soc. Jpn. 1980, 53, 1385.

${ }^{223}$ M. A. Fernández-Rodríguez, Q. Shen, J. F. Hartwig, Chem. Eur. J. 2006, 12, 7782.
} 


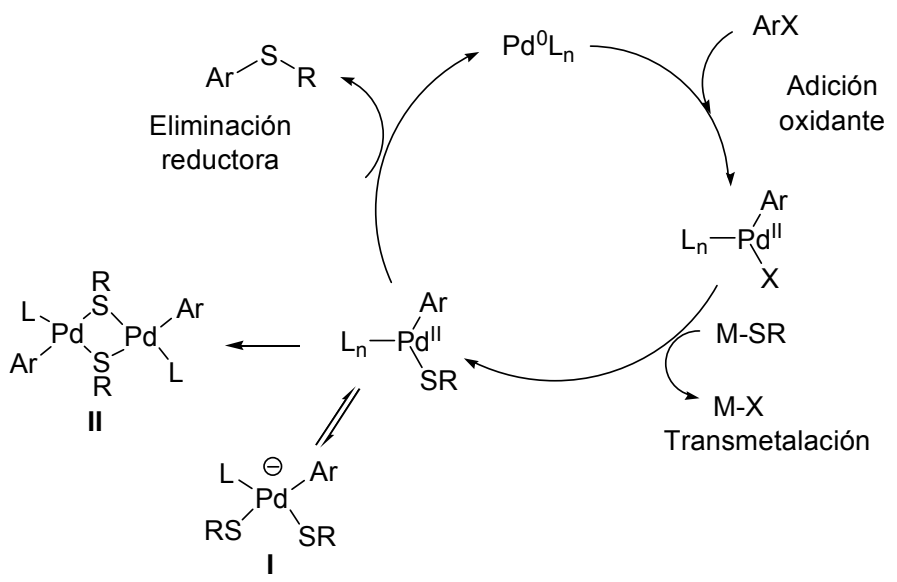

Esquema 3.27

En este contexto, Buchwald y Murata han empleado la bisfosfina DiPPF para llevar a cabo el acoplamiento de cloruros y bromuros de arilo con tioles y tiofenoles (Esquema 3.28). ${ }^{224}$

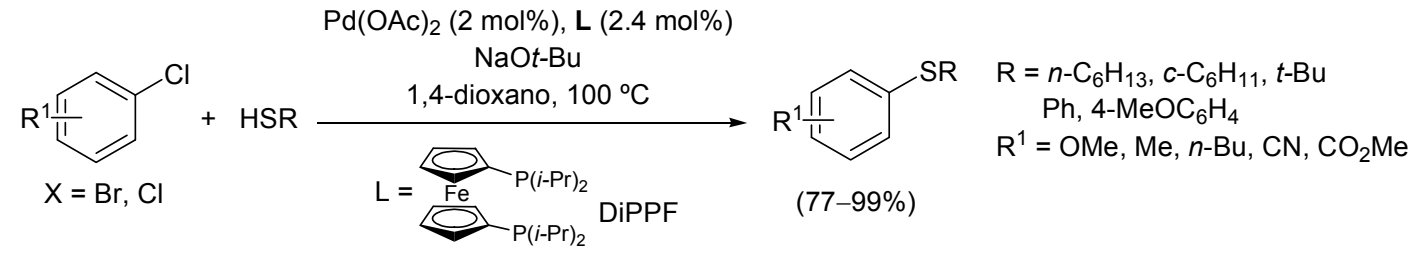

\section{Esquema 3.28}

Posteriormente y tras varios estudios, ${ }^{223,225}$ Hartwig mejoró las condiciones descritas por Buchwald demostrando que el ligando $\mathrm{CyPF} t$-Bu es el que permite llevar a cabo este tipo de acoplamientos con mayor efectividad. Así, el tratamiento de una amplia variedad de haluros de arilo (incluyendo cloruros de arilo) con tioles o tiofenoles, en presencia de $\mathrm{Pd}(\mathrm{OAc})_{2}$ ó $\mathrm{Pd}_{2}(\mathrm{dba})_{3}$ y $\mathrm{CyPF} t$-Bu en cantidades extremadamente bajas (normalmente $0.01-0.5 \mathrm{~mol} \%$ ), permite la síntesis de tioéteres con buenos rendimientos (Esquema 3.29). ${ }^{225 a}$ Generalmente, se utilizan $\mathrm{NaO} t$-Bu ó KOt-Bu como bases, en DME o tolueno como disolventes.

${ }^{224}$ M. Murata, S. L. Buchwald, Tetrahedron 2004, 60, 7397.

225 a) M. A. Fernández-Rodríguez, Q. Shen, J. F. Hartwig, J. Am. Chem. Soc. 2006, 128, 2180. b) J. F. Hartwig, Acc. Chem. Res. 2008, 41, 1534. c) M. A. Fernández-Rodríguez, J. F. Hartwig, J. Org. Chem. 2009, 74, 1663. d) E. Alvaro, J. F. Hartwig, J. Am. Chem. Soc. 2009, 131, 7858. 


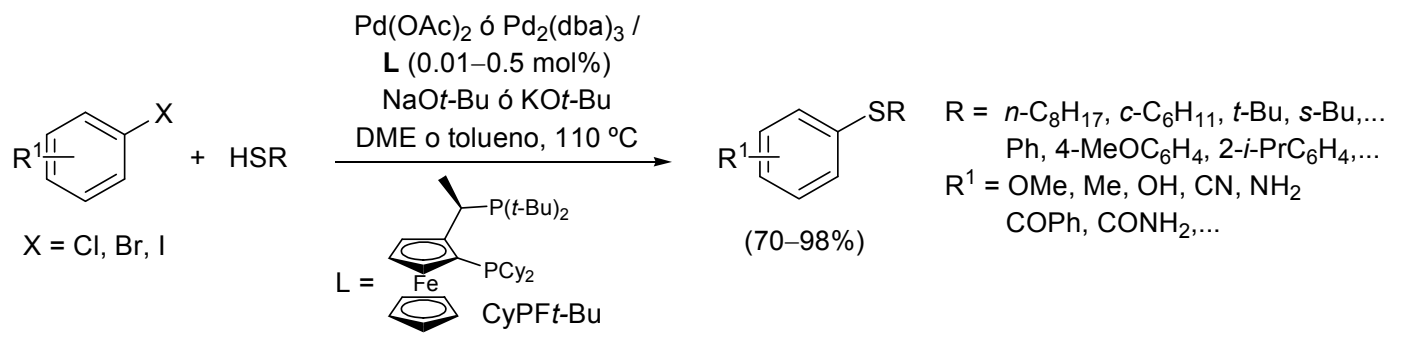

Esquema 3.29

Además, este tipo de procesos tolera la presencia de una gran variedad de grupos funcionales en el haluro de arilo, tales como fluoro, ciano, ceto, carboxilato, amido,...

\section{a.2 Reacciones de acoplamiento $\mathrm{C}-\mathrm{S}$ empleando fuentes de azufre equivalentes al $\mathrm{H}_{2} \underline{\mathrm{S}}$}

Otra de las aplicaciones de las reacciones de acoplamiento $\mathrm{C}-\mathrm{S}$ es la preparación de tiofenoles. Como se ha descrito en los Antecedentes Bibliográficos del Capítulo 2, los métodos existentes en la bibliografía para la síntesis de los análogos oxigenados, es decir, para la preparación de fenoles implican la reacción de haluros de arilo con hidróxidos de metales alcalinos. Sin embargo, muchos tiofenoles son inestables a la oxidación por lo que, en muchas ocasiones, es preferible la preparación de sus derivados protegidos. Y así, generalmente, la síntesis de tioles aromáticos implica la reacción de los correspondientes haluros o triflatos de arilo con compuestos que actúan como equivalentes sintéticos del $\mathrm{H}_{2} \mathrm{~S}$, tales como tiourea, tioacetato potásico o triisopropilsilil tiol, lo que permite obtener tiofenoles con el grupo mercapto protegido.

\section{- Tioacetato potásico}

El tratamiento de bromuros o triflatos de arilo con tioacetato potásico en presencia de cantidades catalíticas de $\mathrm{Pd}_{2}(\mathrm{dba})_{3}$ y fosfinas voluminosas, tales como 4,5bis(difenilfosfino)-9,9-dimetilxanteno (Xantphos) ${ }^{226}$ o $\quad \mathrm{CyPF} t-\mathrm{Bu}^{227}$ ha permitido la preparación de tioacetatos de $S$-arilo (Esquema 3.30). Es posible llevar a cabo este acoplamiento empleando radiación de microondas como método de calentamiento, reduciéndose considerablemente los tiempos de reacción.

${ }^{226}$ C. Lai, B. J. Backes, Tetrahedron Lett. 2007, 48, 3033.

${ }^{227}$ A. v. d. Hoogenband, J. H. M. Lange, R. P. J. Bronger, A. R. Stoit, J. W. Terpstra, Tetrahedron Lett. 2010, 51, 6877. 


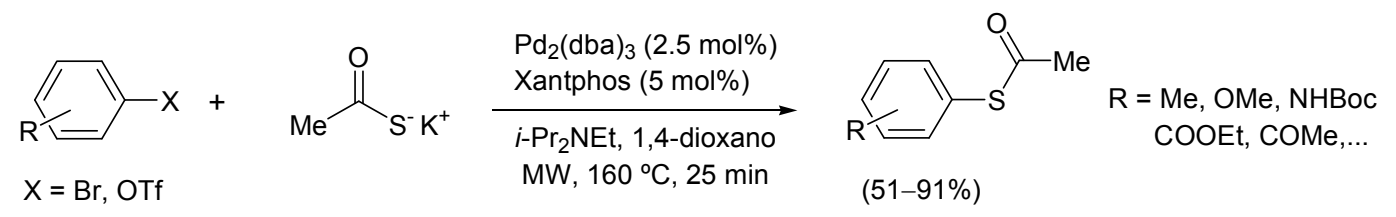

Esquema 3.30

Park y colaboradores han desarrollado un proceso "one pot" para la síntesis de sulfuros de diarilo no simétricos mediante el acoplamiento de tioacetato potásico con un yoduro y un bromuro de arilo empleando $\mathrm{Pd}(\mathrm{dba})_{2}$ y 1,1'-bis(difenilfosfino)ferroceno (dppf) en cantidades catalíticas elevadas. La variación de la temperatura de reacción permite el acoplamiento selectivo $\left(70{ }^{\circ} \mathrm{C}\right.$ para el yoduro de arilo y $110{ }^{\circ} \mathrm{C}$ para el correspondiente bromuro) (Esquema 3.31). ${ }^{228}$

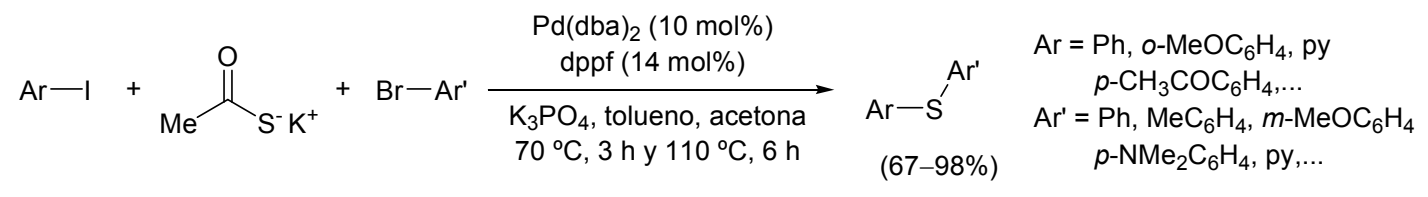

Esquema 3.31

- Tiourea

Muy recientemente, y simultáneamente a nuestra investigación, se ha descrito la preparación de benzo $[b]$ tiofenos 2 -funcionalizados por reacción de $o$-alquinilbromoarenos con tiourea, empleando $\mathrm{Pd}_{2}(\mathrm{dba})_{3}$ y un ligando tridentado (triphos), seguida de la ciclación intramolecular del ariltiolato intermedio (Esquema 3.32). ${ }^{229}$

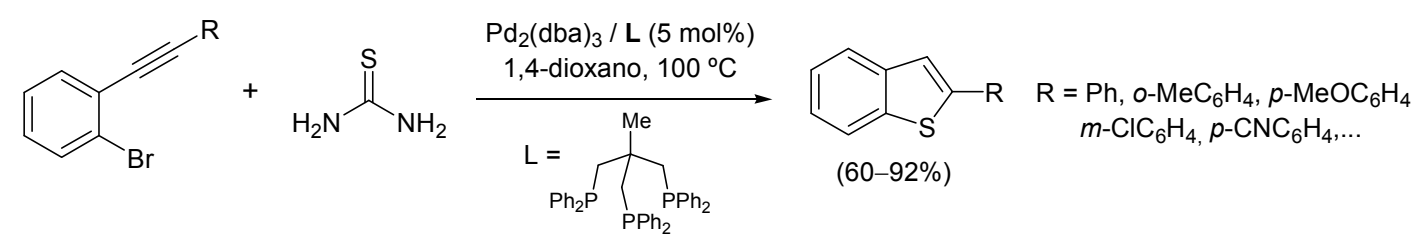

\section{Esquema 3.32}

${ }^{228}$ N. Park, K. Park, M. Jang, S. Lee, J. Org. Chem. 2011, 76, 4371.

${ }^{229}$ M. Kuhn, F. C. Falk, J. Paradies, Org. Lett. 2011, 13, 4100. 


\section{- Trialquilsilil tiol}

Se ha desarrollado la síntesis de arenotioles protegidos por un grupo sililo ${ }^{230}$ a partir haluros o triflatos de arilo y el triisopropilsilil tiol (TIPS-SH) empleando $\mathrm{Pd}(\mathrm{OAc})_{2}$ y cantidades catalíticas elevadas de $\mathrm{PPh}_{3}$ (Esquema 3.33). ${ }^{230 a}$

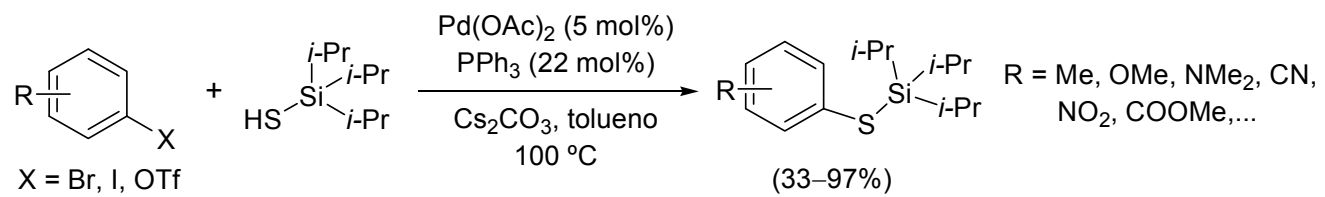

\section{Esquema 3.33}

Hartwig mejoró las condiciones anteriores reduciendo considerablemente las cantidades de catalizador y ligando, mediante el empleo de la bisfosfina CyPFt-Bu y hexametildisilazida de litio (LiHMDS) como base. Además, preparó diaril tioéteres no simétricos por acoplamiento del TIPS-SH con dos haluros de arilo distintos. El CyPFt-Bu permite llevar a cabo el segundo acoplamiento en presencia de CsF (Esquema 3.34). ${ }^{230 \mathrm{~b}}$<smiles>COc1ccc(Br)cc1</smiles>

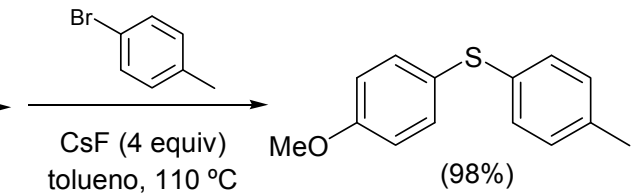

\section{Esquema 3.34}

Ambos procedimientos toleran la presencia de una gran variedad de grupos funcionales en el haluro de arilo tales como metoxilo, hidroxilo, aldehído, nitro,...

\section{- Tiosulfato sódico}

La reacción de bromuros, cloruros o triflatos de arilo con tiosulfato sódico empleando $\mathrm{Cs}_{2} \mathrm{CO}_{3}$ como base y en presencia de $\mathrm{Pd}_{2}(\mathrm{dba})_{3} /$ XPhos en cantidades catalíticas, seguida del tratamiento de la mezcla de reacción con $\mathrm{Zn} / \mathrm{HCl}$, ha permitido obtener una gran variedad de tioles con buenos rendimientos (Esquema 3.35). ${ }^{231}$ Estas condiciones de

\footnotetext{
${ }^{230}$ a) M. Kreis, S. Bräse, Adv. Synth. Catal. 2005, 47, 313. b) M. A. Fernández-Rodríguez, J. F. Hartwig, Chem. Eur. J. 2010, 16, 2355.

${ }^{231}$ J. Yi, Y. Fu, B. Xiao, W.-C. Cui, Q.-X. Guo, Tetrahedron Lett. 2011, 52, 205.
} 
reacción permiten el acoplamiento incluso utilizando cloruros de arilo ricos electrónicamente.

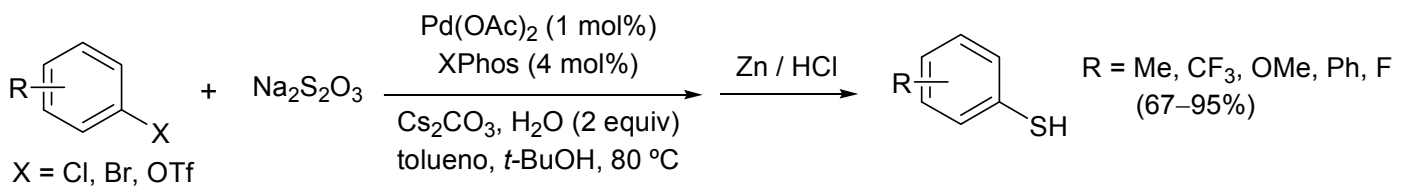

\section{Esquema 3.35}

\section{b) Reacciones de formación del enlace $\mathrm{C}-\mathrm{S}$ empleando sales de cobre}

En los últimos años se han desarrollado distintos procedimientos para llevar a cabo reacciones de acoplamiento $\mathrm{C}-\mathrm{S}$ entre haluros de arilo y tioles o sulfuros catalizados por compuestos de cobre. Generalmente, sólo tienen lugar con yoduros de arilo, aunque el empleo de los correspondientes bromuros ${ }^{232,233}$ también es posible en algunos casos. Sin embargo, estos acoplamientos no son efectivos cuando se utilizan cloruros de arilo debido a su menor reactividad.

\section{b.1 Reacciones de acoplamiento $\mathrm{C}-\mathrm{S}$ empleando haluros de arilo y fuentes de azufre}

En la literatura se ha descrito la reacción de distintas fuentes de azufre con haluros de arilo. Así por ejemplo, una doble reacción de acoplamiento de haluros de arilo con KSCN, empleando cloruro de cobre (II), 1,10-fenantrolina y TBAF en cantidades catalíticas, y $\mathrm{Cs}_{2} \mathrm{CO}_{3}$ como base en agua, ha permitido sintetizar diarilsulfuros simétricos. Se han obtenido mejores rendimientos al emplear yoduros de arilo en vez de los correspondientes bromuros como sustratos de partida (Esquema 3.36). ${ }^{234}$

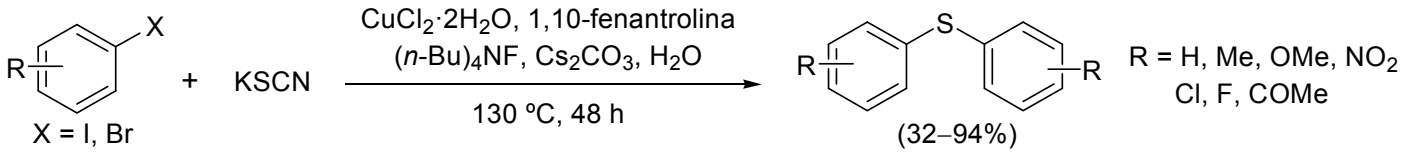

Esquema 3.36

\footnotetext{
${ }^{232}$ L. L. Joyce, G. Evindar, R. A. Batey, Chem. Commun. 2004, 446.

${ }^{233}$ S. Murru, H. Ghosh, S. K. Sahoo, B. K. Patel, Org. Lett. 2009, 11, 4254.

${ }^{234}$ F. Ke, Y. Qu, Z. Jiang, Z. Li, D. Wu, W. Zhou, Org. Lett. 2011, 13, 454.
} 
La reacción de acoplamiento $\mathrm{C}-\mathrm{S}$ también es efectiva partiendo de yoduros de vinilo en lugar de haluros de arilo. De esta forma, se ha desarrollado un proceso de $S$ alquenilación de 1,4-diyodo-1,3-dienos con $\mathrm{K}_{2} \mathrm{~S}$ que permite la preparación de tiofenos polisustituidos con buenos rendimientos (Esquema 3.37). ${ }^{235}$<smiles>[R]C1=C([R])C([R])=C([R])I=[Sn]1</smiles>

Esquema 3.37

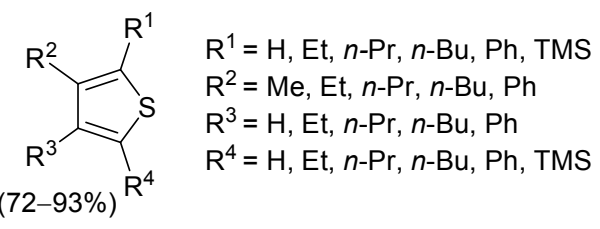
$\mathrm{R}^{3}=\mathrm{H}$, Et, $n-\mathrm{Pr}, n-\mathrm{Bu}, \mathrm{Ph}$ $=\mathrm{H}, \mathrm{Et}, n-\mathrm{Pr}, n-\mathrm{Bu}, \mathrm{Ph}, \mathrm{TMS}$

\section{b. 2 Reacciones de acoplamiento de haluros de arilo y tioles}

La reacción de acoplamiento de yoduros de arilo con tiofenoles ha sido estudiada por diferentes grupos. De este modo, se ha descrito la preparación de diarilsulfuros por tratamiento de haluros de arilo con tioles aromáticos empleando haluros de cobre (I) en cantidades catalíticas y distintos ligandos tipo $\beta$-cetoésteres (Esquema 3.38), ${ }^{236}$ cetofenoles ${ }^{237}$ o incluso en ausencia de ligandos. ${ }^{238}$, Como bases se han utilizado $\mathrm{Cs}_{2} \mathrm{CO}_{3}$ ó $\mathrm{K}_{2} \mathrm{CO}_{3}$ en DMSO ó NMP como disolventes. Este tipo de procesos también permite el acoplamiento de yoduros de arilo con alquiltioles. ${ }^{239}$

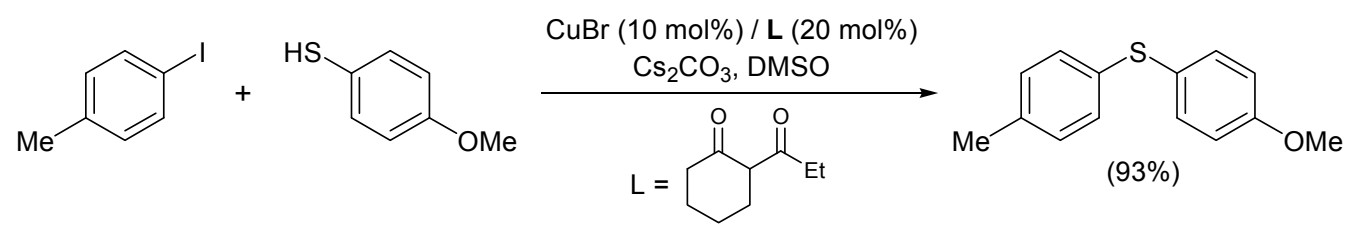

\section{Esquema 3.38}

En general, los acoplamientos de haluros de arilo con tioles empleando sales de cobre requieren la presencia de mayores cantidades de ligando y catalizador que los acoplamientos $\mathrm{C}-\mathrm{S}$ en los que se utilizan complejos de paladio.

${ }^{235}$ W. You, X. Yan, Q. Liao, C. Xi, Org. Lett. 2010, 12, 3930.

${ }^{236}$ X. Lv, W. Bao, J. Org. Chem. 2007, 72, 3863.

${ }^{237}$ R. Xu, J.-P. Wan, H. Mao, Y. Pan, J. Am. Chem. Soc. 2010, 132, 15531.

${ }^{238}$ E. Sperotto, G. P. M. v. Klink, J. G. de Vries, G. v. Koten, J. Org. Chem. 2008, 73, 5625.

${ }^{239}$ F. Y. Kwong, S. L. Buchwald, Org. Lett. 2002, 4, 3517. 


\subsection{DISCUSIÓN DE RESULTADOS}

En los Capítulos anteriores se han desarrollado rutas sintéticas con el fin de obtener indoles y benzo $[b]$ furanos regioselectivamente funcionalizados. Este Capítulo se centra en los heterociclos análogos de azufre, es decir en la síntesis de benzo[b]tiofenos.

\subsubsection{SÍNTESIS DE BENZO[b]TIOFENOS 7-OXÍGENO-FUNCIONALIZADOS}

Como se ha comentado en la Introducción y Antecedentes de este Capítulo, la preparación de derivados de 7-hidroxibenzo[b]tiofenos es complicada, y se han descrito escasos procedimientos para su síntesis. Considerando esta falta de métodos, nos propusimos como primer objetivo de este Capítulo el desarrollo de una nueva ruta sintética para acceder a los benzo[b]tiofenos oxígeno-funcionalizados en el $\mathrm{C}-7$. Con este propósito se planteó el siguiente análisis retrosintético.

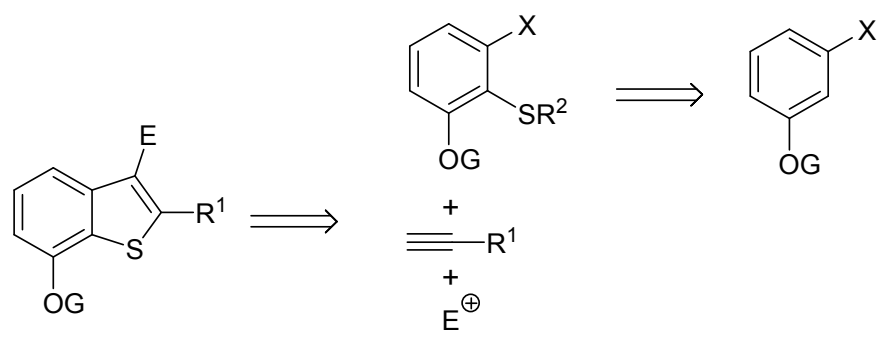

Esquema 3.39

Los benzo[b]tiofenos 7-oxígeno-funcionalizados se podrían obtener mediante la combinación de dos procesos, un acoplamiento de Sonogashira seguido de una reacción de ciclación electrofílica sobre derivados de 2-alquiltio-3-halofenoles. Estos intermedios podrían ser sintetizados mediante una reacción de orto-metalación dirigida en derivados de 3-halofenoles que contuvieran un grupo director, seguida del tratamiento con disulfuros como electrófilos (Esquema 3.39).

A continuación, se describirán con detalle cada uno de los pasos indicados en el esquema anterior y que permitirán preparar los benzo[b]tiofenos 7-oxígeno-funcionalizados. 


\section{a) Síntesis de los $\mathrm{N}, \mathrm{N}$-dietilcarbamatos de $\mathrm{O}$-3-halo-2-sulfanilfenilo 61}

De acuerdo con el esquema retrosintético planteado en el Esquema 3.39, el primer paso para la preparación de los benzo[b]tiofenos consistiría en la síntesis de los derivados de 2-alquiltio-3-halofenoles.

En el Capítulo 1 se empleó el grupo $O$-carbamato como grupo director para llevar a cabo la reacción de orto-metalación sobre los carbamatos de $O$-3-halofenilo a baja temperatura (apartado 1.3.1c.1, pág. 82). Empleando esta misma estrategia se ensayó la preparación de los derivados de 3-halo-2-(metiltio)fenol 61, utilizando dimetildisulfuro como modelo de agente electrofílico que contiene azufre. Así, la reacción de los carbamatos de $O$-3-halofenilo 15 con LDA a $-78{ }^{\circ} \mathrm{C}$ durante 30 minutos, seguida de la adición de dimetildisulfuro condujo a los derivados de benceno 1,2,3-trifuncionalizados 61aa-da con buenos rendimientos (Tabla 3.1, entradas 1-4). Mientras que se observaron reacciones limpias para los carbamatos $\mathbf{1 5 a}-\mathbf{c}$, en el caso de emplear el carbamato de $O$-3-yodofenilo 15d se aisló 61da junto con un 10\% del $N, N$-dietilcarbamato de $O$-2-(metiltio)fenilo, el cual había perdido el átomo de yodo (Tabla 3.1, entrada 4). Por lo tanto, se decidió emplear el carbamato de $O$-3-bromofenilo 15 c como material de partida, debido a su posibilidad para participar en posteriores transformaciones sintéticas a través del átomo de bromo.

A continuación se investigó el alcance de este proceso con respecto a la unidad de disulfuro empleando el carbamato de $O$-3-bromofenilo 15c. De esta forma, se comprobó que el carbamato orto-litiado 16c, además de con dimetildisulfuro, reaccionaba con disulfuros bencílicos y aromáticos permitiendo acceder a los correspondientes carbamatos funcionalizados con grupos benciltio y ariltio con buenos rendimientos (Tabla 3.1, entradas $5-8)$.

Los disulfuros empleados como electrófilos fueron adquiridos comercialmente, excepto el bis(2-bromofenil)disulfuro que se preparó con un $84 \%$ de rendimiento por oxidación de 2-bromotiofenol empleando el complejo de molibdeno $\mathrm{MoO}_{2} \mathrm{Cl}_{2}(\mathrm{DMSO})_{2}(2$ mol\%) en DMSO como disolvente a temperatura ambiente. ${ }^{160}$ 
Tabla 3.1 Síntesis de los $N, N$-dietilcarbamatos de $O$-3-halo-2-sulfanilfenilo 61

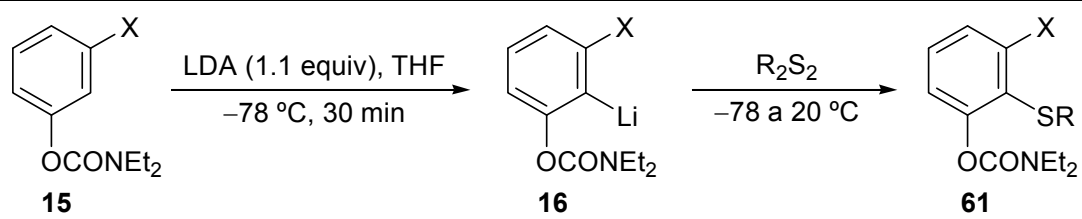

\begin{tabular}{|c|c|c|c|c|c|}
\hline Entrada & Material partida & $\mathbf{X}$ & Disulfuro (R) & Producto & Rto. $(\%)^{\mathrm{a}}$ \\
\hline 1 & $15 \mathbf{a}$ & $\mathrm{F}$ & $\mathrm{Me}$ & $61 \mathrm{aa}$ & 79 \\
\hline 2 & $15 b$ & $\mathrm{Cl}$ & $\mathrm{Me}$ & $61 \mathrm{ba}$ & 83 \\
\hline 3 & $15 c$ & $\mathrm{Br}$ & $\mathrm{Me}$ & 61ca & 81 \\
\hline 4 & 15d & I & $\mathrm{Me}$ & $61 d a$ & $70^{\mathrm{b}}$ \\
\hline 5 & $15 c$ & $\mathrm{Br}$ & $\mathrm{PhCH}_{2}$ & $61 \mathrm{cb}$ & 79 \\
\hline 6 & $15 \mathrm{c}$ & $\mathrm{Br}$ & $\left(4-\mathrm{MeOC}_{6} \mathrm{H}_{4}\right) \mathrm{CH}_{2}$ & $61 \mathrm{cc}$ & 77 \\
\hline 7 & $15 \mathrm{c}$ & $\mathrm{Br}$ & $\mathrm{Ph}$ & $61 \mathrm{~cd}$ & 77 \\
\hline 8 & $15 c$ & $\mathrm{Br}$ & $2-\mathrm{BrC}_{6} \mathrm{H}_{4}$ & 61ce & 82 \\
\hline
\end{tabular}

${ }^{\mathrm{a}}$ Rendimiento en producto aislado referido a los $O$-carbamatos de partida 15 . ${ }^{\mathrm{b}}$ Aislado junto con un $10 \%$ de $N, N$ dietilcarbamato de $O$-2-metiltiofenilo.

Por lo tanto, es posible llevar a cabo la preparación de los carbamatos de $O$-3-halo2-sulfanilfenilo 61aa-ce con buenos rendimientos mediante orto-litiación regioselectiva de los carbamatos de $O$-3-halofenilo 15 seguida de su reacción con distintos disulfuros como agentes electrofílicos.

\section{b) Síntesis de los $N, N$-dietilcarbamatos de $O$-3-alquinil-2-(metiltio)fenilo 62 a partir del carbamato de $O$-3-halofenilo $61 \mathrm{ca}$}

Teniendo el cuenta el análisis retrosintético del Esquema 3.39 para la síntesis de los benzo $[b]$ tiofenos 7-oxígeno-funcionalizados, el siguiente objetivo consistió en la introducción de la unidad alquinilo mediante una reacción de Sonogashira.

Tras el estudio de distintas condiciones de reacción para llevar a cabo el acoplamiento del carbamato de $O$-3-bromo-2-(metiltio)fenilo 61ca con alquinos terminales se decidió emplear las condiciones descritas por Buchwald y Gelman. ${ }^{65 a}$ Así, el tratamiento de 61ca con una gran variedad de alquinos terminales empleando el sistema catalítico 
$\mathrm{PdCl}_{2}(\mathrm{MeCN})_{2}(2 \mathrm{~mol} \%) / \mathrm{XPhos}(3 \mathrm{~mol} \%), \mathrm{Cs}_{2} \mathrm{CO}_{3}$ como base en acetonitrilo como disolvente a $80{ }^{\circ} \mathrm{C}$, permitió obtener los carbamatos de $O$-3-alquinil-2-(metiltio)fenilo $\mathbf{6 2 a}-\mathbf{h}$ con buenos rendimientos (Tabla 3.2).

Examinando los resultados de la Tabla 3.2 se pueden realizar las siguientes observaciones. La reacción de acoplamiento de 61ca, de acuerdo a las condiciones descritas, es efectiva tanto utilizando alquinos con sustituyentes alquilo (entradas 1 y 2 ) o alquenilo (entrada 3), como con sustituyentes aromáticos (entradas 6-8) o heteroaromáticos (entrada 9). Aunque el acoplamiento del carbamato 61 ca con etiniltriisopropilsilano se realizó a 45 ${ }^{\circ} \mathrm{C}$ en lugar de a $80{ }^{\circ} \mathrm{C}$, debido a la volatilidad del alquino, se obtuvo el correspondiente $o$ alquiniltioanisol $\mathbf{6 2 d}$ con buen rendimiento tras 45 horas de reacción (Tabla 3.2, entrada 4).

Tabla 3.2 Síntesis de los $o$-alquiniltioanisoles 62a-h a partir del carbamato de $O$-3-bromo-2(metiltio)fenilo 61 ca

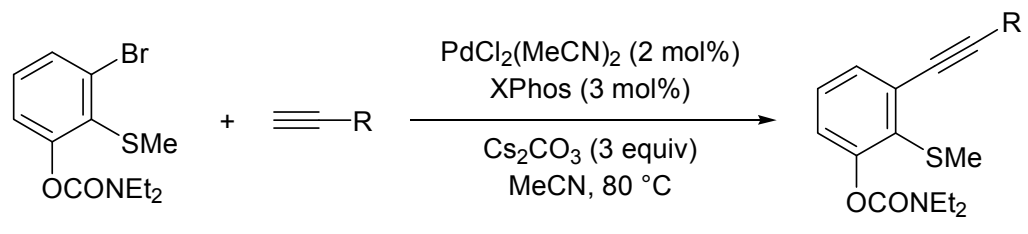

$61 \mathrm{ca}$

\begin{tabular}{ccccc}
\hline \hline Entrada & $\mathbf{R}$ & Tiempo (h) & Producto & ${\text { Rto. }(\%)^{\mathrm{a}}}^{\mathrm{a}}$ \\
\hline 1 & $n-\mathrm{C}_{5} \mathrm{H}_{11}$ & 2.5 & $\mathbf{6 2 a}$ & 91 \\
2 & $n-\mathrm{C}_{6} \mathrm{H}_{13}$ & 3 & $\mathbf{6 2 b}$ & 86 \\
3 & $c-\mathrm{C}_{6} \mathrm{H}_{9}{ }^{\mathrm{b}}$ & 2 & $\mathbf{6 2 c}$ & 71 \\
$4^{\mathrm{c}}$ & $i-\mathrm{Pr}_{3} \mathrm{Si}$ & 45 & $\mathbf{6 2 d}$ & 77 \\
5 & $\mathrm{CH}_{2} \mathrm{OH}$ & 19 & $-{ }^{\mathrm{d}}$ & - \\
6 & $\mathrm{Ph}$ & 2 & $\mathbf{6 2 e}$ & 77 \\
7 & $4-\mathrm{MeOC}_{6} \mathrm{H}_{4}$ & 2 & $\mathbf{6 2 f}$ & 72 \\
8 & $3-\mathrm{FC}_{6} \mathrm{H}_{4}$ & 3 & $\mathbf{6 2 g}$ & 73 \\
9 & $3-\mathrm{Th}^{\mathrm{e}}$ & 3 & $\mathbf{6 2 h}$ & 70 \\
\hline
\end{tabular}

${ }^{\mathrm{a}}$ Rendimiento en producto aislado referido al carbamato de $O$-3-bromofenilo 61ca. ${ }^{\mathrm{b}} 1$-Ciclohexenilo. ${ }^{\mathrm{c}} \mathrm{La}$ reacción se llevo a cabo a $45^{\circ} \mathrm{C}$. ${ }^{\mathrm{d}} \mathrm{Se}$ obtuvo 3-bromo-2-(metiltio)fenol (71\%) en lugar del carbamato esperado. ${ }^{\mathrm{e}}$ 3-Tienilo. 
También cabe destacar que en el caso de emplear alquinos con sustituyentes alquilo (Tabla 3.2, entradas 1 y 2) se alcanzaron rendimientos ligeramente superiores que cuando se utilizaban alquinos con sustituyentes alquenilo o aromáticos (Tabla 3.2, entradas 3,6-9).

Por otro lado, también se observó que cuando se hacía reaccionar 61 ca con 2propin-1-ol como alquino terminal, en lugar de la reacción de acoplamiento se producía la hidrólisis del grupo carbamato promovida, probablemente, por el alquinol y el $\mathrm{Cs}_{2} \mathrm{CO}_{3}$ presentes en el medio de reacción. De este modo, tras purificación por cromatografía de columna, se aisló un 71\% del 3-bromo-2-(metiltio)fenol en lugar del carbamato de $o$ alquinil(metiltio)fenilo esperado (Tabla 3.2, entrada 5).

Además hay que reseñar que se ha comprobado la reproducibilidad de la reacción a escala multigramo. Así, cuando se hizo reaccionar el carbamato 61ca (8 mmoles, $2.54 \mathrm{~g})$ con 1-octino se pudieron aislar $1.94 \mathrm{~g}$ de $\mathbf{6 2} \mathbf{b}$ ( $70 \%$ rendimiento).

c) Síntesis de los benzo[b]tiofenos 7-oxígeno-funcionalizados-2,3-disustituidos 63-66

Una vez puesto a punto un procedimiento para acceder a los carbamatos de 3-alquinil-2-metiltiofenilo 62, el último paso de acuerdo con el Esquema 3.39 para la obtención de los benzo[b]tiofenos 7-oxígeno-funcionalizados 63-66 consistiría en llevar a cabo una reacción de ciclación electrofílica sobre los carbamatos 62.

En primer lugar, se decidió estudiar la facilidad de los carbamatos $\mathbf{6 2} \mathbf{b}-\mathbf{h}$ para experimentar una reacción de halociclación promovida por yodo como electrófilo. Así, encontramos que el tratamiento de $\mathbf{6 2} \mathbf{b}-\mathbf{h}$ con un ligero exceso de yodo (1.5 equiv.) en $\mathrm{CH}_{2} \mathrm{Cl}_{2}$ conducía a los 7-(N,N-dietilcarbamoiloxi)-3-yodobenzo[b]tiofenos 2-sustituidos 63b-h (Tabla 3.3). Tras 3-4 horas a temperatura ambiente se obtuvieron buenos rendimientos de $\mathbf{6 3 b}-\mathbf{h}$, excepto para los alquinos que presentan un grupo 1-ciclohexenilo ó 3-fluorofenilo (Tabla 3.3, entradas 2 y 6), donde los rendimientos fueron moderados. 
Tabla 3.3 Ciclación electrofílica de los carbamatos 62b-h a los 7-(N,N-dietilcarbamoiloxi)-3yodobenzo[b]tiofenos 2-sustituidos $\mathbf{6 3 b} \mathbf{b}-\mathbf{h}$

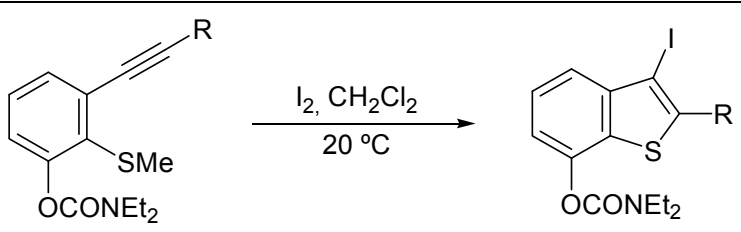

62

63

\begin{tabular}{cccccc}
\hline \hline Entrada & Material partida & $\mathbf{R}$ & Tiempo (h) & Producto & Rto. (\%) $^{\text {a }}$ \\
\hline 1 & $\mathbf{6 2 b}$ & $n-\mathrm{C}_{6} \mathrm{H}_{13}$ & 3 & $\mathbf{6 3 b}$ & 92 \\
2 & $\mathbf{6 2 c}$ & $c-\mathrm{C}_{6} \mathrm{H}_{9}{ }^{\mathrm{b}}$ & 3 & $\mathbf{6 3 c}$ & 56 \\
3 & $\mathbf{6 2 d}$ & $i-\mathrm{Pr}_{3} \mathrm{Si}$ & 3 & $\mathbf{6 3 d}$ & 83 \\
4 & $\mathbf{6 2 e}$ & $\mathrm{Ph}$ & 4 & $\mathbf{6 3 e}$ & 90 \\
5 & $\mathbf{6 2 f}$ & $4-\mathrm{MeOC}_{6} \mathrm{H}_{4}$ & 3 & $\mathbf{6 3 f}$ & 91 \\
6 & $\mathbf{6 2 g}$ & $3-\mathrm{FC}_{6} \mathrm{H}_{4}$ & 3 & $\mathbf{6 3 g}$ & 55 \\
7 & $\mathbf{6 2 h}$ & $3-\mathrm{Th}^{\mathrm{c}}$ & 3 & $\mathbf{6 3 h}$ & 77 \\
\hline
\end{tabular}

${ }^{\mathrm{a}}$ Rendimiento en producto aislado referido al $o$-alquiniltioanisol $\mathbf{6 2} \mathbf{b}-\mathbf{h}$ de partida. ${ }^{\mathrm{b}}$ 1-Ciclohexenilo. ${ }^{\mathrm{c}} 3$-Tienilo.

A continuación, se pensó en generalizar la reacción de ciclación electrofílica mediante la utilización de otros electrófilos. En primer lugar, se decidió introducir un átomo de bromo en la posición 3 del anillo de benzo[b]tiofeno. Con este objetivo se ensayó la reacción del carbamato de $O$-3-(feniletinil)-2-(metiltio)fenilo 62e con bromo molecular. Sin embargo, se detectó por CG-EM la presencia de dos compuestos con $\mathrm{M}^{+}=481 \mathrm{y}$, tras purificación por cromatografía de columna, se aislaron dos isómeros, cada uno de los cuales contenía dos átomos de bromo en distintas posiciones del anillo de benzo[b]tiofeno. A continuación, se ensayó la reacción de bromociclación de 62e empleando $\mathrm{N}$ bromosuccinimida (NBS) como agente electrofílico, observándose la introducción del átomo de bromo exclusivamente en la posición 3 del anillo. De la misma forma, la exposición de diferentes alquinos 62 a NBS permitió obtener los 3-bromo-7- $(N, N-$ dietilcarbamoiloxi)benzo[b]tiofenos 2-sustituidos 64 con buenos rendimientos (Tabla 3.4, entradas 1-5). Al emplear NBS como electrófilo son necesarios mayores tiempos de reacción (unas 16 horas) en comparación con las yodociclaciones (3-4 horas). 
También hay que comentar que mientras que el carbamato silil-funcionalizado 62d, experimentaba la reacción de yodociclación sin ruptura del grupo triisopropilsililo (Tabla 3.3, entrada 3), al tratarlo con NBS se recuperó el carbamato de partida 62d sin sufrir transformación alguna (Tabla 3.4, entrada 3). Por otro lado, hay que reseñar que se ha comprobado la reproducibilidad de la reacción de ciclación electrofílica a escala multigramo. Y así, al hacer reaccionar el carbamato 62e (8 mmoles, $2.7 \mathrm{~g}$ ) con NBS se obtuvieron $2.5 \mathrm{~g}$ (78\% rendimiento) del 3-bromo-7-( $N, N$-dietilcarbamoiloxi)-2-fenil benzo $[b]$ tiofeno $64 \mathbf{e}$.

Tabla 3.4 Ciclación electrofílica de los carbamatos 62a-h a los 7-(N,N-dietilcarbamoiloxi) benzo[b]tiofenos 2,3-disustituidos 64-65

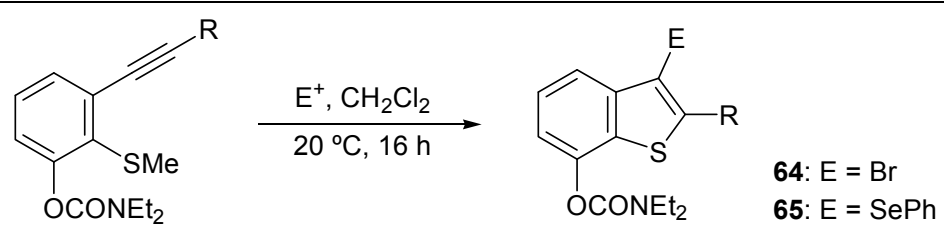

62

\begin{tabular}{ccccccc}
\hline \hline Entrada & Material partida & $\mathbf{R}$ & $\mathbf{E}^{+}$ & Producto & $\mathbf{E}$ & Rto. (\%) $^{\mathbf{a}}$ \\
\hline 1 & $\mathbf{6 2 a}$ & $n-\mathrm{C}_{5} \mathrm{H}_{11}$ & $\mathrm{NBS}$ & $\mathbf{6 4 a}$ & $\mathrm{Br}$ & 76 \\
2 & $\mathbf{6 2 c}$ & $c-\mathrm{C}_{6} \mathrm{H}_{9}{ }^{\mathrm{b}}$ & $\mathrm{NBS}$ & $\mathbf{6 4 c}$ & $\mathrm{Br}$ & $50^{\mathrm{c}}$ \\
3 & $\mathbf{6 2 d}$ & $i-\mathrm{Pr}{ }_{3} \mathrm{Si}$ & $\mathrm{NBS}$ & $\mathbf{6 4 d}$ & $\mathrm{Br}$ & - \\
4 & $\mathbf{6 2 e}$ & $\mathrm{Ph}$ & $\mathrm{NBS}$ & $\mathbf{6 4 e}$ & $\mathrm{Br}$ & 91 \\
5 & $\mathbf{6 2 h}$ & $3-\mathrm{Th}^{\mathrm{e}}$ & $\mathrm{NBS}$ & $\mathbf{6 4 h}$ & $\mathrm{Br}$ & 80 \\
6 & $\mathbf{6 2 a}$ & $n-\mathrm{C}_{5} \mathrm{H}_{11}$ & $\mathrm{PhSeCl}$ & $\mathbf{6 5 a}$ & $\mathrm{SePh}$ & 74 \\
7 & $\mathbf{6 2 e}$ & $\mathrm{Ph}$ & $\mathrm{PhSeCl}$ & $\mathbf{6 5 e}$ & $\mathrm{SePh}$ & 79 \\
8 & $\mathbf{6 2 h}$ & $3-\mathrm{Th}^{\mathrm{e}}$ & $\mathrm{PhSeCl}$ & $\mathbf{6 5 h}$ & $\mathrm{SePh}$ & 75 \\
\hline
\end{tabular}

${ }^{\mathrm{a}}$ Rendimiento en producto aislado referido al $o$-alquiniltioanisol $\mathbf{6 2} \mathbf{a}-\mathbf{h}$ de partida. ${ }^{\mathrm{b}}$ 1-Ciclohexenilo. ${ }^{\mathrm{c}}$ Impurificado con pequeñas cantidades de un isómero. ${ }^{\mathrm{d}} \mathrm{Se}$ recuperó el material de partida 62d. ${ }^{\mathrm{e}}$ 3-Tienilo.

A continuación, se ensayó el empleo de reactivos electrofílicos basados en selenio. De este modo, la reacción de los carbamatos 62 con $\mathrm{PhSeCl}$ en las mismas condiciones de reacción anteriormente descritas, es decir $\mathrm{CH}_{2} \mathrm{Cl}_{2}$ a temperatura ambiente, condujo a buenos rendimientos de los 3-fenilselenilbenzo[b]tiofenos 65 (Tabla 3.4, entradas 6-8). Las 
reacciones también fueron más lentas (aproximadamente 16 horas) que en el caso de las yodociclaciones.

De cara a la introducción de un átomo de cloro en la posición 3 del anillo de benzo $[b]$ tiofeno, el tratamiento de los $o$-alquiniltioanisoles 62a y 62e con $\mathrm{CuCl}_{2}$, en acetonitrilo a reflujo, ${ }^{219}$ permitió obtener los 3-cloro-7-( $N, N$-dietilcarbamoiloxi) benzo[b]tiofenos 2-sustituidos 66a y 66e con excelentes rendimientos (Esquema 3.40).<smiles>[R]C#Cc1cccc(OCC)c1OCCO</smiles>

$62 a, e$

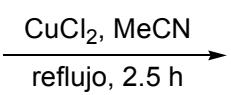<smiles>[R]c1sc2c(OCC)cccc2c1Cl</smiles>

66a: $\mathrm{R}=n-\mathrm{C}_{5} \mathrm{H}_{11}(87 \%)$ 66e: $\mathrm{R}=\mathrm{Ph}(90 \%)$

\section{Esquema 3.40}

Una vez que se ha demostrado la generalidad de esta estrategia para la síntesis de 7( $N, N$-dietilcarbamoiloxi)-3-halobenzo[b]tiofenos con distintos sustituyentes en la posición C-2 de anillo, también se pudo preparar el derivado de benzo[b]tiofeno 63i sin sustituyentes en la posición $\mathrm{C}-2$ mediante la desililación de $\mathbf{6 3 d}$ por tratamiento con TBAF a temperatura ambiente (Esquema 3.41).<smiles>CCOc1cccc2c(I)c([AlH]c3ccccc3)sc12</smiles>

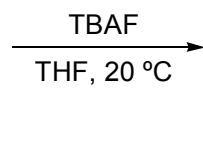

\section{Esquema 3.41}

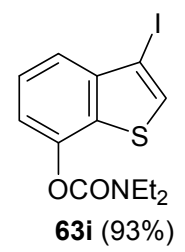

63i $(93 \%)$

Con el propósito de introducir funcionalización adicional en el anillo de benzo[b]tiofeno, el alquino silil-funcionalizado 62d se sometió a desililación con TBAF, obteniéndose así el alquino terminal $\mathbf{6 2} \mathbf{i}$ con un rendimiento prácticamente cuantitativo (Esquema 3.42). 


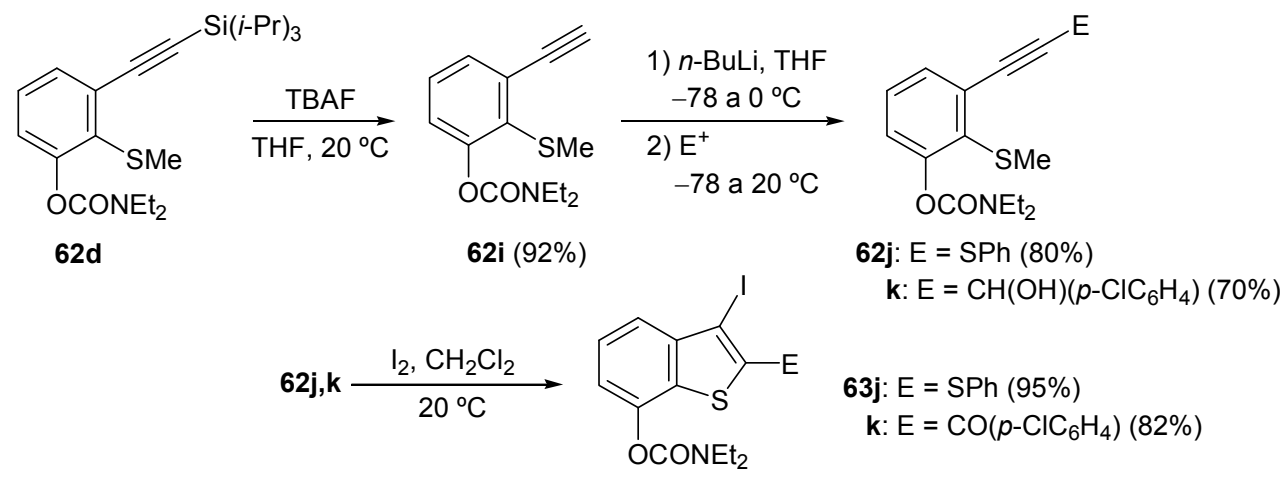

Esquema 3.42

A continuación, su tratamiento con $n$-BuLi seguido de la adición de difenildisulfuro ó $p$-clorobenzaldehído condujo a los alquinos $\mathbf{6 2} \mathbf{j}$ y $\mathbf{6 2} \mathbf{k}$, respectivamente (Esquema 3.42). Estos carbamatos $6 \mathbf{2} \mathbf{j}, \mathbf{k}$ también experimentaron eficientemente la reacción de yodociclación lo que permitió obtener los 7-(N,N-dietilcarbamoiloxi)-3-yodobenzo[b]furanos 2-sustituidos 63j y 63k con buenos rendimientos (Esquema 3.42). Hay que reseñar que durante la reacción de yodociclación de $\mathbf{6 2 k}$ se produjo la oxidación simultánea del grupo alcohol a la correspondiente cetona (Esquema 3.42).

Por otro lado, cuando se hizo reaccionar el carbamato de 3-etinil-2-(metiltio)fenilo 62i con $n$-BuLi, seguido de la adición de yodo como electrófilo, se obtuvo el alquino yodofuncionalizado esperado 621 con un $51 \%$ de rendimiento. Este moderado rendimiento se debe a que en esta reacción también se formó el 7-(N,N-dietilcarbamoiloxi)-2,3diyodobenzo[b]tiofeno 631, el cual se aisló con un $20 \%$ de rendimiento. Su formación se podría explicar considerando que, una vez formado 621, este compuesto experimentase una posterior yodociclación debida al exceso de yodo presente en el medio de reacción (Esquema 3.43).<smiles>C#Cc1cccc(OCC)c1C(C)(C)C</smiles>

$62 \mathrm{i}$

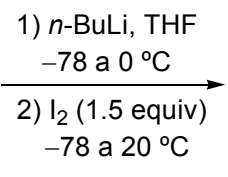

\begin{tabular}{l}
-78 a $20^{\circ} \mathrm{C}$ \\
\hline
\end{tabular}

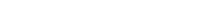

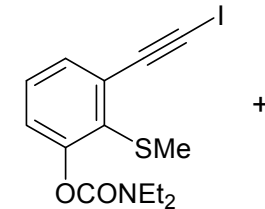

62I $(51 \%)$<smiles>CCOc1cccc2c(I)c(I)sc12</smiles>

$631(20 \%)$

Esquema 3.43 
Como resumen de los resultados expuestos en este apartado se puede concluir que se ha descrito una síntesis regioselectiva de una amplia variedad de benzo[b]tiofenos 7 oxígeno-funcionalizados 2,3-disustituidos mediante una reacción de ciclación electrofílica en los correspondientes carbamatos de $O$-3-alquinil-2-(metiltio)fenilo.

\section{d) Síntesis de los 7-hidroxibenzo[b]tiofenos 2,3-disustituidos 67}

El siguiente objetivo que nos planteamos fue preparar 7-hidroxibenzo[b]tiofenos por desprotección del grupo carbamato. Teniendo en cuenta que el grupo carbamato puede ser fácilmente eliminado mediante hidrólisis alcalina, ${ }^{240} \mathrm{el}$ tratamiento de algunos de los 7( $N, N$-dietilcarbamoiloxi)-3-halobenzo[b]tiofenos 2-sustituidos 63, 64 y 66, preparados con anterioridad, con un exceso de $\mathrm{NaOH}$ en etanol a reflujo permitió aislar los 3-halo-7hidroxibenzo[b]tiofenos 67 con buenos rendimientos (Esquema 3.44).

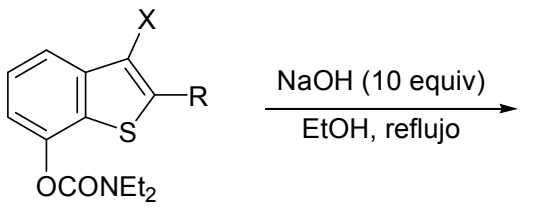

$63,64,66$<smiles>[R]c1sc2c(O)cccc2c1[X]</smiles>

67a: $\mathrm{R}=n-\mathrm{C}_{6} \mathrm{H}_{13} ; \mathrm{X}=\mathrm{I}(86 \%)$ b: $\mathrm{R}=\mathrm{Ph} ; \mathrm{X}=\mathrm{Br}(82 \%)$ c: $\mathrm{R}=n-\mathrm{C}_{5} \mathrm{H}_{11} ; \mathrm{X}=\mathrm{Cl}(89 \%)$

\section{Esquema 3.44}

\section{e) Síntesis de los 3-halobenzo[b]selenofenos 7-oxígeno-funcionalizados 2-sustituidos 68}

Como se ha comentado en los Antecedentes de este Capítulo (Esquema 3.20, pág. 170), también se ha descrito la preparación de benzo[b]selenofenos mediante ciclación electrofílica de $o$-alquinil(metilseleno)arenos. ${ }^{217}$ Sin embargo, los 2-yodoselenoanisoles que se necesitan como materiales de partida habían sido preparados con bajos rendimientos mediante una aproximación en dos pasos a partir de $o$-yodoanilinas. ${ }^{241}$

A la vista de estos resultados y habiendo puesto a punto un procedimiento para la síntesis de benzo[b]tiofenos 7-oxígeno-funcionalizados, se decidió comprobar su efectividad en la preparación de los benzo[b]selenofenos análogos.

\footnotetext{
${ }^{240}$ S. Mabic, L. Vaysse, C. Benezra, J.-P. Lepoittevin, Synthesis 1999, 1127.

${ }^{241}$ A. Luxen, L. Christiaens, Tetrahedron Lett. 1982, 23, 3905.
} 
Con este objetivo, ensayamos nuestra estrategia de orto-metalación-acoplamiento de Sonogashira-halociclación partiendo del $N, N$-dietilcarbamato de $O$-3-bromofenilo 15 c. Así su metalación con LDA, seguida de la adición de $\mathrm{Me}_{2} \mathrm{Se}_{2}$, condujo al $N, N$ dietilcarbamato de $O$-3-bromo-2-(metilseleno)fenilo $\mathbf{6 8}$ con buen rendimiento (Esquema 3.45). Su acoplamiento con diferentes alquinos terminales bajo las mismas condiciones de reacción empleadas para los carbamatos análogos 61, es decir, utilizando el sistema catalítico $\mathrm{PdCl}_{2}(\mathrm{MeCN})_{2}(2 \mathrm{~mol} \%) / \mathrm{XPhos}\left(3 \mathrm{~mol} \%\right.$ ) y $\mathrm{Cs}_{2} \mathrm{CO}_{3}$ como base, permitió obtener los carbamatos de $O$-3-alquinil-2-metilselenofenilo 69 (Esquema 3.45).

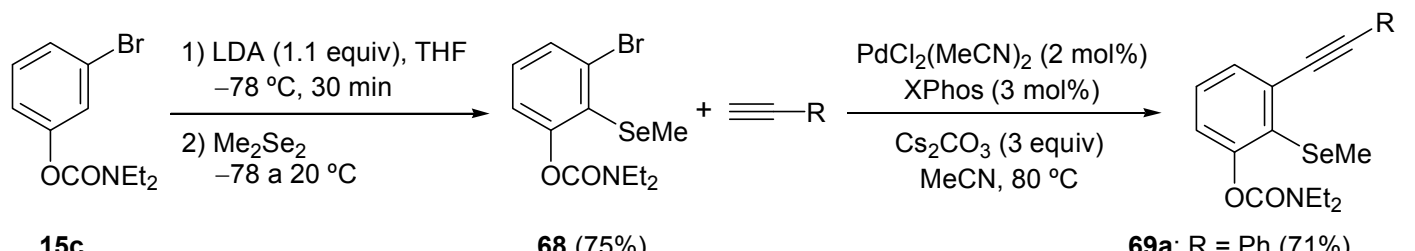

$68(75 \%)$

69a: $\mathrm{R}=\mathrm{Ph}(71 \%)$

b: $\mathrm{R}=n-\mathrm{C}_{5} \mathrm{H}_{11}(75 \%)$

\section{Esquema 3.45}

A continuación, se ensayó la reacción de yodociclación sobre 69 por tratamiento con yodo en $\mathrm{CH}_{2} \mathrm{Cl}_{2}$ a temperatura ambiente. De esta forma, se aislaron los 3yodobenzo[b]selenofenos $\mathbf{7 0}$, funcionalizados con un grupo $N, N$-dietilcarbamoiloxi en la posición C-7 del anillo, con altos rendimientos (Esquema 3.46).<smiles>[R]C#Cc1cccc(OCC)c1S(C)(=O)=O</smiles>

69

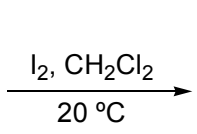<smiles>[R]c1[se]c2c(OCC)cccc2c1I</smiles>

70a: $\mathrm{R}=\mathrm{Ph}(91 \%)$ b: $\mathrm{R}=n-\mathrm{C}_{5} \mathrm{H}_{11}(80 \%)$

\section{Esquema 3.46}

Además, se hizo reaccionar el carbamato de 3-feniletinil-2-(metilseleno)fenilo 69a con NBS, pudiéndose así preparar el 3-bromo-7-( $N, N$-dietilcarbamoiloxi)-2fenilbenzo $[b]$ selenofeno 71 también con buen rendimiento (Esquema 3.47). 
<smiles>CCOc1cccc(C#Cc2ccccc2)c1OCC</smiles>

$69 a$

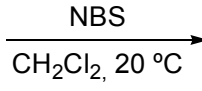

$\frac{\mathrm{NaOH} \text { (10 equiv) }}{\mathrm{EtOH} \text {, reflujo }}$

$70 \mathrm{~b}$

Esquema 3.47
$\mathrm{OCONEt}_{2}$<smiles></smiles><smiles>CCOc1cccc2c(Br)c(-c3ccccc3)[se]c12</smiles>

$71(72 \%)$

Por último, se preparó el 7-hidroxi-2-pentil-3-yodobenzo[b]selenofeno 72 mediante hidrólisis básica del grupo carbamato de 70b (Esquema 3.48).

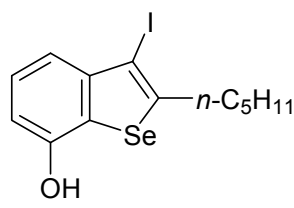

$72(72 \%)$

\section{Esquema 3.48}

Por lo tanto, también se ha comprobado la idoneidad de esta estrategia sintética basada en una secuencia de orto-litiación-acoplamiento de Sonogahira-halociclación, para la síntesis de 3-halobenzo[b]selenofenos 7-oxígeno-funcionalizados 2-sustituidos.

\section{f) Aplicaciones sintéticas de los 7-(N,N-dietilcarbamoiloxi)-3-halo- benzo[b]tiofenos 63 y 64}

Finalmente, nos propusimos estudiar la utilidad sintética de los derivados de 3halobenzo[b]tiofeno 63 y $\mathbf{6 4}$ como precursores de otros benzo[ $b]$ tiofenos 3-funcionalizados. Con este fin decidimos emplear tanto reacciones de intercambio halógeno-litio, como distintas reacciones de acoplamiento catalizadas por complejos de paladio.

\section{f.1 Intercambio halógeno-litio en los 7-( $N, N$-dietilcarbamoiloxi)-3-yodo benzo $[b]$ tiofenos 2-sustituidos $63 \mathbf{b}, \mathbf{e}$}

La reacción del 3-yodobenzo[b]tiofeno $63 \mathbf{b}$ con 1.1 equiv. de $n$-BuLi, a $-78{ }^{\circ} \mathrm{C}$ en THF durante 1 hora, condujo al organolítico resultante del intercambio halógeno-litio, el cual se pudo atrapar por reacción con MeOD, generando el producto 73a con un grado de 
deuteración del $90 \%$. Sin embargo, al cambiar el disolvente y emplear $\mathrm{Et}_{2} \mathrm{O}$ en lugar de THF, la reacción de intercambio yodo-litio sobre el 3-yodobenzo[b]tiofeno 63e permitió obtener el benzo $[b]$ tiofeno 3-deuterado 73b con buen rendimiento y una deuteración prácticamente completa (Esquema 3.49).<smiles>CCOc1cccc2c(I)c(OCCCCCCCO)sc12</smiles>

63b<smiles>CCOc1cccc2c(I)c(-c3ccccc3)sc12</smiles>

$63 \mathrm{e}$

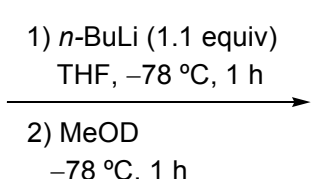

$-78^{\circ} \mathrm{C}, 1 \mathrm{~h}$

1) $n$-BuLi (1.1 equiv) $\mathrm{Et}_{2} \mathrm{O},-78^{\circ} \mathrm{C}, 1 \mathrm{~h}$

2) $\mathrm{MeOD}$ $-78^{\circ} \mathrm{C}, 1 \mathrm{~h}$

Esquema 3.49<smiles>CCOc1cccc2c(O)c(-c3ccccc3)sc12</smiles>

73a $(77 \%)$<smiles>[2H]c1c(-c2ccccc2)sc2c(OCC)cccc12</smiles>

73b $(78 \%)$

f.2 Síntesis de benzo[b]tiofenos 3-sustituidos empleando reacciones catalizadas por complejos de paladio

A continuación se detallarán las distintas reacciones llevadas a cabo sobre algunos de los 3-halobenzo[b]tiofenos 63 y 64.

f.2.1 Preparación de los 3-arilbenzo[b]tiofenos 74 y 75 mediante los acoplamientos de Suzuki y Stille

Debido al interés que presentan los benzo[b]tiofenos arilados en diferentes posiciones del anillo, ${ }^{242}$ se decidió sintetizar los 2,3-diarilbenzo[b]tiofenos $\mathbf{7 4}$ y $\mathbf{7 5}$ empleando los acoplamientos de Suzuki y Stille, respectivamente.

De esta manera, la reacción del 3-bromo-7-( $N, N$-dietilcarbamoiloxi)-2-fenil benzo $[b]$ tiofeno $64 \mathbf{e}$ con ácido fenilborónico, en presencia de cantidades catalíticas de $\mathrm{Pd}\left(\mathrm{PPh}_{3}\right)_{4}$, exceso de $\mathrm{Na}_{2} \mathrm{CO}_{3}$ y una mezcla de DME / $\mathrm{H}_{2} \mathrm{O}(2 / 1)$ como disolvente, ${ }^{66 b}$ permitió obtener el derivado de 2,3-difenilbenzotiofeno 74 con excelente rendimiento (Esquema 3.50).

${ }^{242}$ M. Miyasaka, K. Hirano, T. Satoh, M. Miura, Adv. Synth. Catal. 2009, 351, 2683. 
Este mismo 3-bromobenzo[b]tiofeno 64e se trató con 2-tributilestannilfurano empleando el sistema catalítico $\mathrm{Pd}(\mathrm{OAc})_{2} / \mathrm{XPhos}$, CsF como base en DME como disolvente. ${ }^{70 b}$ Después de 4 horas a $80^{\circ} \mathrm{C}$, se aisló el derivado de 3-(2-furil)benzo[b]tiofeno 75 (Esquema 3.50).

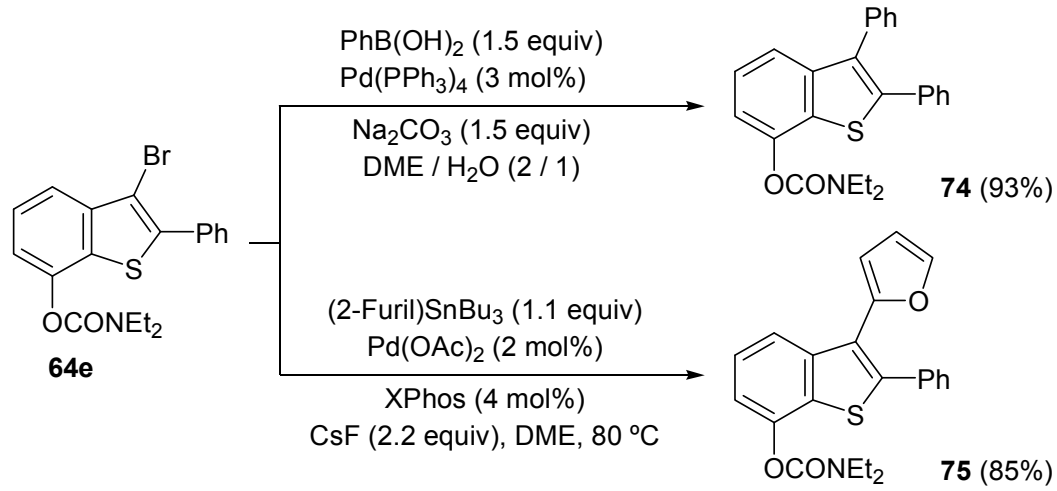

\section{Esquema 3.50}

\section{f.2.2 Preparación de los 3-alquinilbenzo[b]tiofenos 76 mediante el} acoplamiento de Sonogashira

También se sintetizaron los derivados de 3-alquinilbenzo[b]tiofenos $\mathbf{7 6}$ con buenos rendimientos al hacer reaccionar los 7-(N,N-dietilcarbamoiloxi)-3-yodobenzo[b]tiofenos 63b,f con distintos alquinos terminales, con sustituyentes tanto arílicos como alifáticos, bajo las condiciones estándar de Sonogashira $\left(\mathrm{PdCl}_{2}\left(\mathrm{PPh}_{3}\right)_{2} / \mathrm{CuI}\right)$ (Esquema 3.51).<smiles>[R]c1sc2c(OCC)cccc2c1I</smiles>

$63 b, f$

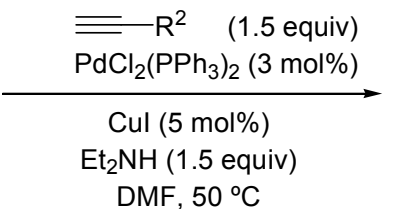

$$
\begin{aligned}
\text { 76a: } \mathrm{R}^{1} & =n-\mathrm{C}_{6} \mathrm{H}_{13} ; \mathrm{R}^{2}=\mathrm{Ph}(78 \%) \\
\text { b: } \mathrm{R}^{1} & =n-\mathrm{C}_{6} \mathrm{H}_{13} ; \mathrm{R}^{2}=n-\mathrm{C}_{5} \mathrm{H}_{11}(90 \%) \\
\text { c: } \mathrm{R}^{1} & =4-\mathrm{MeOC}_{6} \mathrm{H}_{4} ; \mathrm{R}^{2}=\mathrm{Ph}(77 \%)
\end{aligned}
$$

\section{Esquema 3.51}




\section{f.2.3 Sintesis de benzo[b]tiofenos 3-ciano sustituidos}

Weissman y colaboradores habían descrito un procedimiento para la cianación de bromuros de arilo mediante el empleo de ferricianuro potásico en presencia de cantidades catalíticas de $\mathrm{Pd}(\mathrm{OAc})_{2}$ y sin necesidad de ligandos. ${ }^{243}$ Decidimos ensayar estas condiciones con el fin de introducir un grupo ciano en la posición C-3 del anillo de benzo[b]tiofeno. Así, la reacción del 3-yodobenzo[b]tiofeno 63e, en las condiciones descritas, permitió sintetizar el 3-ciano-7-( $N, N$-dietilcarbamoiloxi)-2-fenilbenzo[b]tiofeno 77 con elevado rendimiento (Esquema 3.52).

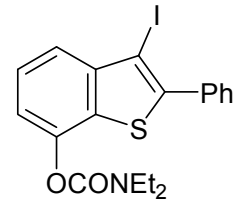

$63 e$

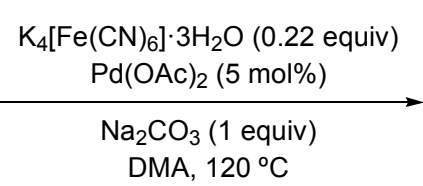

DMA, $120^{\circ} \mathrm{C}$

Esquema 3.52

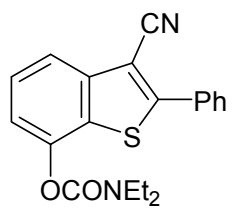

$77(89 \%)$

Podemos concluir que los 7-(N,N-dietilcarbamoiloxi)-3-halobenzo[b]tiofenos son precursores útiles para la preparación de benzo[b]tiofenos 7-oxígeno-funcionalizados que contengan distintos sustituyentes en la posición 3 del anillo, tales como grupos alquinilo, arilo, heteroarilo o ciano, mediante reacciones de acoplamiento catalizadas por complejos de paladio.

Como resumen del apartado 3.3.1, podemos decir que hemos desarrollado una ruta eficiente para la síntesis de benzo[b]tiofenos 7-oxígeno-funcionalizados basándonos en una combinación de las metodologías de orto-metalación y halociclación, como pasos clave del proceso. Además, hay que destacar que la unidad de benzotiofeno hidroxi-funcionalizada es un núcleo base importante en numerosos compuestos biológicamente activos.

${ }^{243}$ S. A. Weissman, D. Zewge, C. Chen, J. Org. Chem. 2005, 70, 1508. 


\subsubsection{SíNTESIS DE BENZO [b]TIOFENOS A PARTIR DE orto- ALQUINILBROMOBENCENOS}

Considerando que en el Capítulo 2 se había puesto a punto una síntesis de 4,ndialcoxibenzo[b]furanos y que, por otra parte, en la primera parte de este Capítulo se ha desarrollado una metodología para la preparación de benzo[b]tiofenos 7-oxígeno funcionalizados, en este punto nos propusimos como segundo objetivo de este Capítulo el diseño de una ruta sintética que nos permitiera acceder a benzo[ $b]$ tiofenos 4-oxígenofuncionalizados. Con este propósito, y en concordancia con lo desarrollado en el Capítulo 2 para el caso de los benzo $[b]$ furanos, se planteó el siguiente análisis retrosintético:

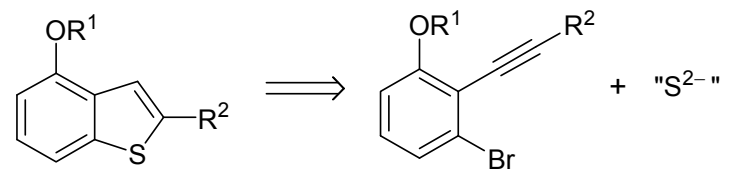

Esquema 3.53

De acuerdo al Esquema 3.53, estos benzo[b]tiofenos 4-oxígeno-funcionalizados podrían ser accesibles a partir de derivados de 2-alquinil-3-bromofenoles, mediante una secuencia tándem de acoplamiento $\mathrm{C}-\mathrm{S}$ / heterociclación, empleando un equivalente sintético del $\mathrm{H}_{2} \mathrm{~S}$.

\section{a) Preparación de los derivados de 2-alquinil-3-bromofenoles 51 y 78}

De acuerdo al esquema retrosintético planteado en el Esquema 3.53, el primer paso para acceder a los benzo[b]tiofenos 4-oxígeno funcionalizados consistiría en la preparación de 2-alquinil-3-bromofenil éteres. En el Capítulo 2 se ha descrito la síntesis de los 3-bromo2-yodoanisoles 26b y 49 mediante una reacción de orto-zincación en derivados de 3haloanisoles y posterior adición de yodo como electrófilo. Además, se han preparado una gran variedad de 2-alquinil-3-bromoanisoles 50 y 51aa-cd mediante un acoplamiento selectivo de los correspondientes anisoles $26 \mathbf{b}$ y 49 con diferentes alquinos, con sustituyentes tanto alifáticos como aromáticos, empleando el sistema catalítico $\mathrm{PdCl}_{2}\left(\mathrm{PPh}_{3}\right)_{2}$ / CuI, y controlando cuidadosamente la temperatura de reacción (Capítulo 2, apartado 2.3.1b). Por lo tanto, decidimos emplear algunos de estos 2-alquinil-3-bromofenil éteres $\mathbf{5 0}$ 
y 51 como sustratos de partida para la síntesis de los 4-alcoxibenzo[b]tiofenos. Además, también sintetizamos algún 2-alquinil-3-bromoanisol adicional, de acuerdo a las condiciones de reacción previamente descritas (Tabla 3.5, entradas 1-3). Por otro lado, también se preparó el $\mathrm{N}, \mathrm{N}$-dietilcarbamato de $\mathrm{O}$-3-bromo-2-(feniletinil)fenilo $\mathbf{7 8}$ como otro sustrato potencialmente interesante para acceder a benzo[b]tiofenos 4-oxígeno funcionalizados (Tabla 3.5, entrada 4).

Tabla 3.5 Síntesis de los $o$-alquinilbromoarenos 51ae-ce y 78

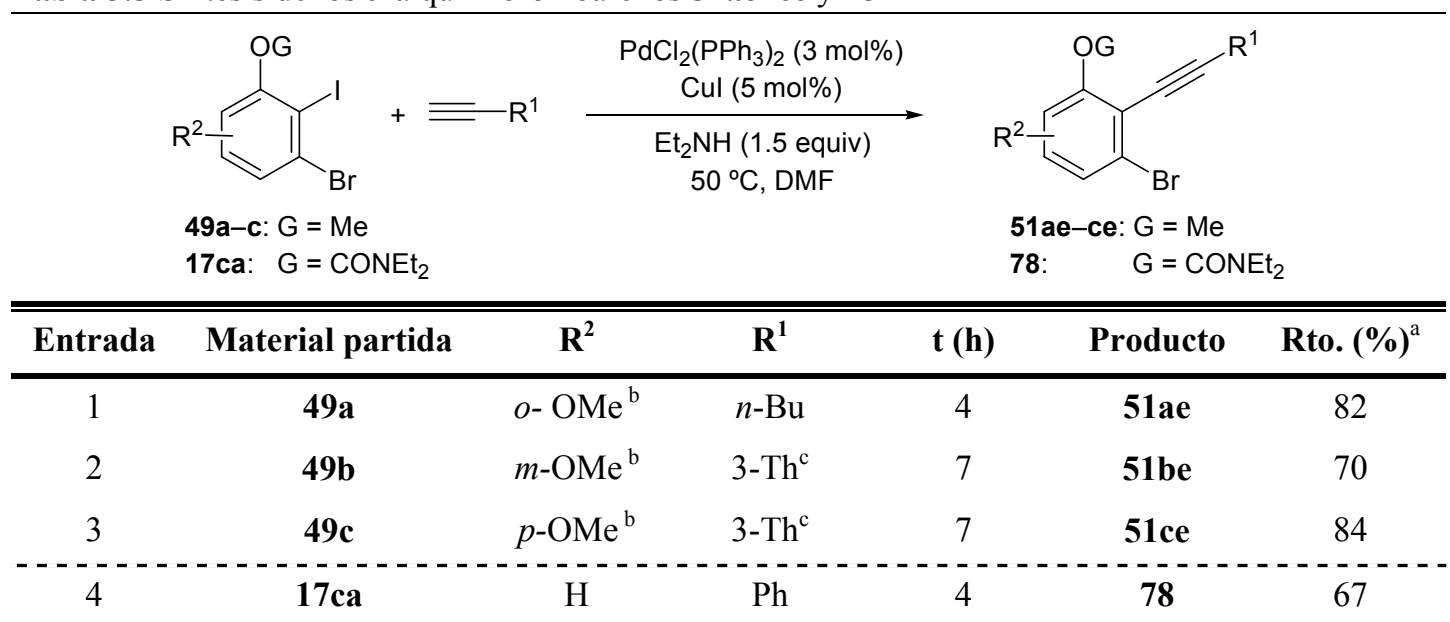

${ }^{a}$ Rendimiento en producto aislado referido a $49 a-c$ y 17 ca. ${ }^{b}$ Posición del grupo metoxilo adicional referido al ya existente ${ }^{\mathrm{c}} 3$-Tienilo.

\section{b) Intento de síntesis de los benzo[b]tiofenos 4-oxígeno funcionalizados 80 y 81 empleando sulfuros alcalinos}

Teniendo en mente el análisis retrosintético planteado en el Esquema 3.53, el paso clave en la síntesis de los benzo[b]tiofenos debería ser la incorporación del grupo tiol, seguido de una heterociclación "in situ” del correspondiente derivado de 3-alcoxi-2alquiniltiofenol.

Takimiya y colaboradores habían descrito la preparación de benzo[b]tiofenos mediante la reacción de $o$-alquinilhalobencenos con $\mathrm{Na}_{2} \mathrm{~S}$ en NMP seguida de la ciclación del feniltiolato intermedio (Esquema 3.54). ${ }^{244}$

244 a) T. Kashiki, S. Shinamura, M. Kohara, E. Miyazaki, K. Takimiya, M. Ideda, H. Kuwabara, Org. Lett. 2009, 11, 2473. b) S. Shinamura, E. Miyazaki, K. Takimiya, J. Org. Chem. 2010, 75, 1228. 


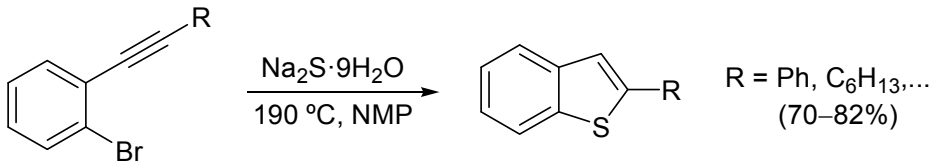

Esquema 3.54

En primer lugar, se consideró el empleo de este procediemiento utilizando el 3bromo-2-(feniletinil)anisol 50d como alquino modelo. Sin embargo, bajo estas condiciones de reacción, se obtuvo el 3-bromo-2-(feniletinil)fenol 79 como producto mayoritario, acompañado de pequeñas cantidades $(<10 \%)$ del 2-fenil-4-metoxibenzo[b]tiofeno buscado 80a. Este resultado nos indicó que lo que había tenido lugar preferentemente era la desprotección del grupo metoxilo en 50d (Esquema 3.55). ${ }^{245}$ Asimismo, cuando ensayamos estas mismas condiciones de reacción empleando $\mathbf{7 8}$ como alquino de partida, también se produjo de forma muy mayoritaria la ruptura del grupo $O$-protector (Esquema 3.55).<smiles>O=[N+]([O-])c1cccc(Br)c1C#Cc1ccccc1</smiles>

50d: $\mathrm{G}=\mathrm{Me}$ 78: $\mathrm{G}=\mathrm{CONEt}_{2}$

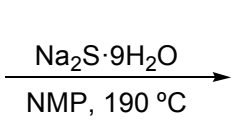<smiles>Oc1cccc(Br)c1C#Cc1ccccc1</smiles>

79<smiles>Oc1cccc2sc(-c3ccccc3)cc12</smiles>

80a: $\mathrm{G}=\mathrm{Me}(<10 \%)$ 81: $G=$ CONEt $_{2}(<10 \%)$

\section{Esquema 3.55}

\section{c) Síntesis de benzo $[b]$ tiofenos oxígeno-funcionalizados mediante acoplamientos $\mathbf{C}-\mathrm{S}$ catalizados por complejos de paladio}

Ante la imposibilidad de llevar a cabo una reacción de sustitución nucleofílica aromática con sulfuros sobre nuestros alquinos de partida modelo $\mathbf{5 0 d}$ y 78, se pensó en el empleo de acoplamientos $\mathrm{C}-\mathrm{S}$ catalizados por complejos de paladio. De esta forma, en principio, la reacción de un $o$-alquinilbromoarilo con un equivalente sintético del $\mathrm{H}_{2} \mathrm{~S}$ permitiría obtener el $o$-alquiniltiofenol protegido, el cual, tras la eliminación del grupo protector podría experimentar una reacción de ciclación 5-endo-dig conduciendo al correspondiente benzo $[b]$ tiofeno.

\footnotetext{
${ }^{245}$ Para la desprotección de grupos metoxilo con tiolatos, ver: J. R. Vyvyan, C. L. Holst, A. J. Johnson, C. M. Schwenk, J. Org. Chem. 2002, 67, 2263.
} 
Con esta idea, se ensayó la utilización de distintos equivalentes sintéticos del $\mathrm{H}_{2} \mathrm{~S}$ y condiciones de reacción con el fin de preparar los benzo[b]tiofenos 4-funcionalizados 80a, 81 y 85 de forma eficiente.

\section{c.1 Tiourea como fuente de azufre}

En primer lugar, se ensayó el acoplamiento del 3-bromo-2-(feniletinil)anisol 50d con tiourea, empleando el sistema catalítico $\mathrm{Pd}(\mathrm{OAc})_{2}$ (1 mol\%) / CyPFt-Bu (1 mol\%) descrito por Hartwig, ${ }^{230 \mathrm{~b}}$ y utilizando $\mathrm{NaO} t$-Bu como base en tolueno a reflujo. La reacción se monitorizó por CG-EM, observándose que no avanzaba y, tras 21 horas a reflujo, se recuperó el alquino de partida 50d. Se duplicó la carga catalítica hasta un $2 \mathrm{~mol} \%$ aunque, de nuevo, estas condiciones tampoco resultaron efectivas. Por lo tanto, se decidió variar el sistema catalítico. El empleo de $\mathrm{Pd}_{2}(\mathrm{dba})_{3} /$ Xantphos tampoco condujo a resultados completamente satisfactorios y, tras varios ensayos, solo se consiguió aislar un 51\% del 2fenil-4-metoxibenzo[b]tiofeno buscado 80a observándose además la formación de un subproducto minoritario, cuya estructura no pudo ser determinada (Esquema 3.56).

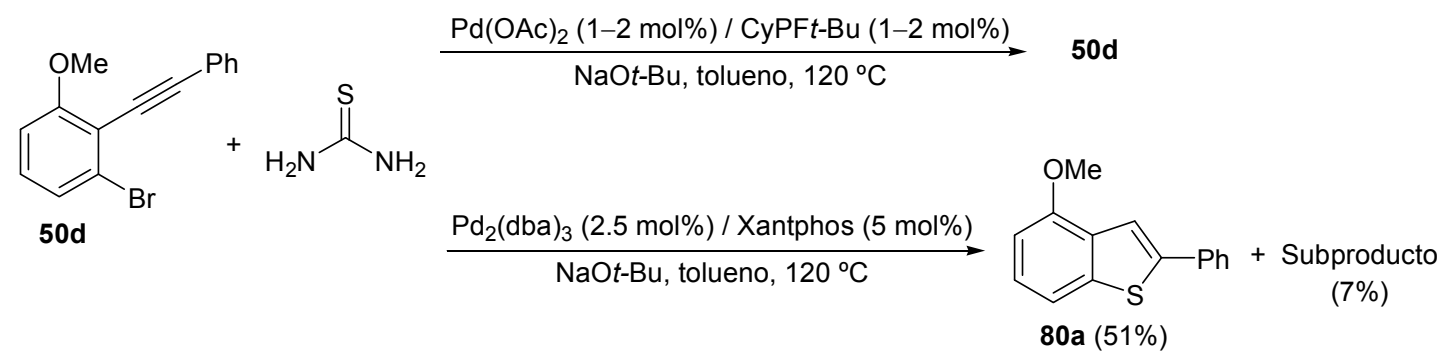

\section{Esquema 3.56}

Hay que señalar que las condiciones descritas por Kuhn y colaboradores ${ }^{229}$ (Antedecentes de este Capítulo, pág 176), es decir el empleo de $\operatorname{Pd}_{2}(\mathrm{dba})_{3}$ y un ligando tridentado (triphos) en 1,4-dioxano, no fueron ensayadas, ya que dicho trabajo fue publicado posteriormente a nuestras investigaciones. 


\section{c.2 Tioacetato potásico como fuente de azufre}

\section{c.2.1 Optimización de las condiciones de reacción}

A continuación, se estudió el empleo de tioacetato potásico como equivalente sintético del $\mathrm{H}_{2} \mathrm{~S}$. Se decidió utilizar el o-bromo(feniletinil)benceno 82a como sustrato modelo ya que puede ser preparado muy fácilmente a partir del 1-bromo-2-yodobenceno, comercialmente disponible, mediante un acoplamiento selectivo de Sonogashira. ${ }^{246}$ Realizamos un análisis de las siguientes variables: fosfina, catalizador de paladio, disolvente y equivalentes de tioacetato (Tabla 3.6).

En primer lugar, se estudió la reacción modelo de 82a con 3 equiv. de tioacetato potásico a $120^{\circ} \mathrm{C}$, en tolueno como disolvente, y en ausencia de catalizador, recuperándose el $o$-alquinilbromobenceno 82a de partida (Tabla 3.6, entrada 1).

En segundo lugar, se emplearon distintos ligandos fosfina: Xantphos, $\mathrm{CyPF}$-Bu, XPhos, PhDavePhos, manteniendo el resto de las condiciones fijas: $\mathrm{Pd}_{2}(\mathrm{dba})_{3}(2.5 \mathrm{~mol} \%)$, tioacetato potásico (3 equiv.) y tolueno como disolvente (Tabla 3.6, entradas 2-5). Analizando los resultados se observó que tanto el ligando Xantphos como el CyPFt-Bu promovían el acoplamiento, aunque únicamente se alcanzó conversión completa con Xantphos, pudiéndose aislar un 78\% de 83a (Tabla 3.6, entrada 2). A continuación, se estudió el efecto de las fuentes de paladio, $\mathrm{Pd}_{2}(\mathrm{dba})_{3}$ ó $\mathrm{Pd}(\mathrm{OAc})_{2}$, comprobándose que era necesario el empleo de una fuente de Pd (0) (Tabla 3.6, entradas 2 y 6). Posteriormente, se analizó el efecto del disolvente en esta reacción, manteniendo el resto de variables fijas, concluyendo que el tolueno era el único disolvente que daba lugar a una conversión completa (Tabla 3.6, entradas 2,7-9). Con 1,4-dioxano como disolvente se alcanzó una baja conversión (Tabla 3.6, entrada 7) y otros disolventes, como DMF ó 1,4-dioxano / $\mathrm{H}_{2} \mathrm{O}$ (2 / 1), no fueron efectivos. Por último, se estudió la cantidad de tioacetato necesaria en esta reacción. Se comprobó que el empleo de 1.5 equiv. de tioacetato potásico era suficiente y conducía a rendimientos similares que el uso de 3 equiv. (Tabla 3.6, entradas 2 y 10). Sin embargo, una mayor reducción de esta cantidad condujo a una menor conversión de 82a (entrada 11).

\footnotetext{
${ }^{246}$ El $o$-bromo(feniletinil)benceno 82a se preparó por reacción de 1-bromo-2-yodobenceno con fenilacetileno (1.2 equiv.) en presencia de $\mathrm{PdCl}_{2}\left(\mathrm{PPh}_{3}\right)_{2}$ (3 mol\%), CuI $(5 \mathrm{~mol} \%)$ y $\mathrm{Et}_{2} \mathrm{NH}$ (1.5 equiv.) en $\mathrm{DMF}$ a temperatura ambiente.
} 
Tabla 3.6 Optimización de las condiciones de reacción para la síntesis del tioacetato 83a

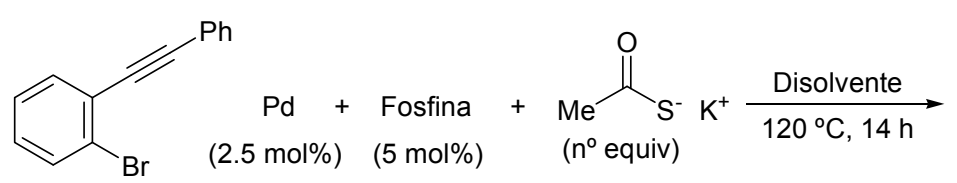

$82 a$

$(2.5 \mathrm{~mol} \%) \quad(5 \mathrm{~mol} \%)$

( ${ }^{\circ}$ equiv)<smiles>CC(=O)Sc1ccccc1C#Cc1ccccc1</smiles>

$83 a$

\begin{tabular}{|c|c|c|c|c|c|c|}
\hline Entrada & Fosfina & $\begin{array}{l}\text { Fuente de } \\
\text { paladio }\end{array}$ & Disolvente & $\begin{array}{c}\text { Equiv. } \\
\text { tioacetato }\end{array}$ & $\begin{array}{c}\text { Conversión } \\
(\%)^{\mathrm{a}}\end{array}$ & $\begin{array}{l}\text { Rto. } \\
(\%)^{b}\end{array}$ \\
\hline 1 & - & - & tolueno & 3 & 0 & - \\
\hline 2 & & $\mathrm{Pd}_{2}(\mathrm{dba})_{3}$ & tolueno & 3 & 100 & 78 \\
\hline 3 & & $\mathrm{Pd}_{2}(\mathrm{dba})_{3}$ & tolueno & 3 & 40 & 30 \\
\hline 4 & & $\mathrm{Pd}_{2}(\mathrm{dba})_{3}$ & tolueno & 3 & 0 & - \\
\hline 5 & & $\mathrm{Pd}_{2}(\mathrm{dba})_{3}$ & tolueno & 3 & 0 & - \\
\hline 6 & Xantphos & $\mathrm{Pd}(\mathrm{OAc})_{2}$ & tolueno & 3 & 0 & - \\
\hline 7 & Xantphos & $\mathrm{Pd}_{2}(\mathrm{dba})_{3}$ & 1,4-dioxano & 3 & 30 & - \\
\hline 8 & Xantphos & $\mathrm{Pd}_{2}(\mathrm{dba})_{3}$ & DMF & 3 & 0 & - \\
\hline 9 & Xantphos & $\mathrm{Pd}_{2}(\mathrm{dba})_{3}$ & $\begin{array}{c}\text { 1,4-dioxano / } \\
\mathrm{H}_{2} \mathrm{O}(2 / 1)\end{array}$ & 3 & 5 & - \\
\hline 10 & Xantphos & $\mathrm{Pd}_{2}(\mathrm{dba})_{3}$ & tolueno & 1.5 & 100 & 75 \\
\hline 11 & Xantphos & $\mathrm{Pd}_{2}(\mathrm{dba})_{3}$ & tolueno & 1.2 & 80 & - \\
\hline 12 & Xantphos & $\mathrm{Pd}_{2}(\mathrm{dba})_{3}$ & tolueno & 1.5 & 100 & $73^{\mathrm{c}}$ \\
\hline
\end{tabular}

${ }^{\mathrm{a}}$ Determinada por análisis de los espectros de ${ }^{1} \mathrm{H}$ RMN del crudo de reacción. ${ }^{\mathrm{b}}$ Rendimiento en producto aislado referido al 1-bromo-2-(feniletinil)benceno 82a. ${ }^{c}$ Llevada a cabo por calentamiento MW a $130{ }^{\circ} \mathrm{C}$ durante $30 \mathrm{~min}$. 
Por otro lado, también se comprobó que la reacción de 82a con tioacetato potásico (1.5 equiv.), empleando las condiciones óptimas, es decir $\operatorname{Pd}_{2}(\mathrm{dba})_{3}(2.5 \mathrm{~mol} \%) /$ Xantphos ( $5 \mathrm{~mol} \%$ ) en tolueno se podía llevar a cabo bajo radiación de microondas como método de calentamiento, reduciéndose el tiempo de reacción a tan solo 30 minutos, con rendimientos muy similares (73\%) (Tabla 3.6, entrada 12).

Una vez optimizadas las condiciones de reacción para obtener el tioacetato de $S$-2(feniletinil)fenilo 83a, el paso final para preparar el benzo[b]tiofeno consistiría en una heterociclación en 83a. Así se ensayó su ciclación empleando distintas bases que promovieran la hidrólisis del grupo acetilo. Se estudió la utilización de $\mathrm{KO} t-\mathrm{Bu}, \mathrm{K}_{3} \mathrm{PO}_{4} \mathrm{y}$ de carbonatos alcalinos tales como $\mathrm{K}_{2} \mathrm{CO}_{3}$ ó $\mathrm{Cs}_{2} \mathrm{CO}_{3}$, en tolueno a $120^{\circ} \mathrm{C}$, y se comprobó que tanto el $\mathrm{Cs}_{2} \mathrm{CO}_{3}$ como el $\mathrm{K}_{2} \mathrm{CO}_{3}$ conducían a buenos rendimientos del 2fenilbenzo[b]tiofeno 84a (89\% con $\mathrm{Cs}_{2} \mathrm{CO}_{3}$ y $86 \%$ con $\mathrm{K}_{2} \mathrm{CO}_{3}$ ) (Esquema 3.57).

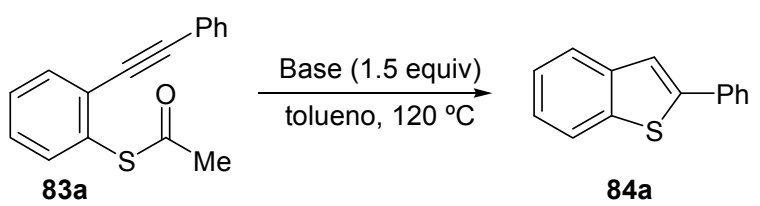

Esquema 3.57

A continuación, nos propusimos desarrollar una metodología one-pot para la síntesis del benzo[b]tiofeno 84a, sin necesidad de aislar el tioacetato 83a. De esta manera, tratamos el $o$-alquinilbromobenceno 82a con tioacetato potásico, en las condiciones optimizadas y empleando radiación de microondas. Monitorizamos el avance de la reacción mediante análisis por CG-EM y, una vez observada la formación del tioacetato 83a, se llevó a cabo la adición de los carbonatos alcalinos $\mathrm{K}_{2} \mathrm{CO}_{3}$ ó $\mathrm{Cs}_{2} \mathrm{CO}_{3}$, comprobándose que el $\mathrm{Cs}_{2} \mathrm{CO}_{3}$ conducía a mejores resultados en este proceso one-pot. También se ensayó la adición del $\mathrm{Cs}_{2} \mathrm{CO}_{3}$ desde el principio de la reacción, aunque en este caso se observó que la reacción se ralentizaba y, además, aparecían pequeñas cantidades de un subproducto cuya estructura no se logró determinar. Por lo tanto, se decidió adicionar el $\mathrm{Cs}_{2} \mathrm{CO}_{3}$ tras comprobar por CG-EM la desaparición completa del $o$-alquinilbromobenceno 82a. De esta manera, la reacción de 82a con tioacetato potásico durante 30 minutos a $130^{\circ} \mathrm{C}$, empleando radiación de microondas, seguida de la adición de 1.5 equiv. de $\mathrm{Cs}_{2} \mathrm{CO}_{3}$ y calentamiento bajo radiación de microondas a $130{ }^{\circ} \mathrm{C}$ durante 15 minutos, permitió obtener el 2-fenilbenzo[b]tiofeno 84a con un 70\% de rendimiento (Esquema 3.58). 


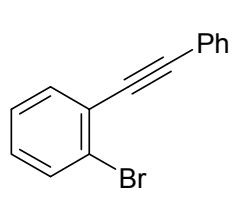

$82 a$

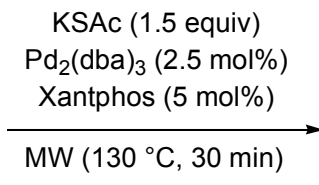

$\operatorname{MW}\left(130^{\circ} \mathrm{C}, 30 \mathrm{~min}\right)$

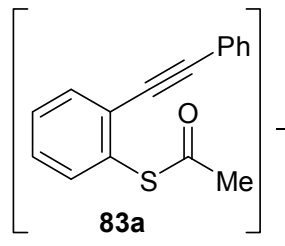

$\underset{\mathrm{MW}\left(130^{\circ} \mathrm{C}, 15 \mathrm{~min}\right)}{\stackrel{\mathrm{Cs}_{2} \mathrm{CO}_{3}(1.5 \text { equiv })}{\longrightarrow}}$

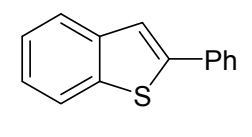

$84 a(70 \%)$

\section{Esquema 3.58}

\section{c.2.2 Aplicación a la síntesis de los benzo[b] tiofenos 80a, 81 y 85}

Una vez desarrollada una estrategia sintética eficiente para preparar el 2fenilbenzo[b]tiofeno 84a empleando tioacetato potásico como equivalente sintético del $\mathrm{H}_{2} \mathrm{~S}$, se retomó el objetivo inicial de sintetizar benzo[b]tiofenos 4-oxígeno funcionalizados. De esta forma, se hicieron reaccionar los 3-bromo-2-alquinilanisoles 50d y 51 y el carbamato de $\mathbf{O}$-3-bromo-2-(feniletinil)fenilo $\mathbf{7 8}$ con tioacetato potásico en presencia de cantidades catalíticas del sistema $\mathrm{Pd}_{2}(\mathrm{dba})_{3} /$ Xantphos en tolueno a $130{ }^{\circ} \mathrm{C}$. Tras la desaparición del $o$ alquinil bromoareno de partida, se adicionó $\mathrm{Cs}_{2} \mathrm{CO}_{3}$ lo que condujo a los benzo[b]tiofenos 4-metoxi, 4-n-dimetoxi y 4-carbamoiloxi funcionalizados 80a, 85 y 81, respectivamente, con rendimientos entre moderados y buenos considerando que se refieren a los bromoalquinos de partida (Tabla 3.7).

Tabla 3.7 Síntesis de benzo[b]tiofenos 4-oxígeno funcionalizados 80a, 81 y $\mathbf{8 5}$.

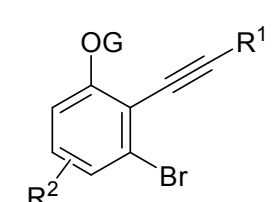

50d, 51: $\mathrm{G}=\mathrm{Me}$

78:

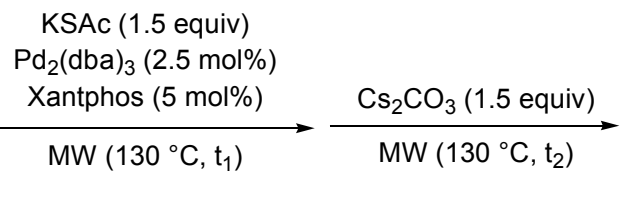
$\mathrm{Pd}_{2}(\mathrm{dba})_{3}(2.5 \mathrm{~mol} \%)$ Xantphos $(5 \mathrm{~mol} \%)$

$\mathrm{G}=\mathrm{CONEt}_{2}$<smiles>[R][X]c1ccc([O-])c2cc([R])sc12</smiles>

80a, 85: $\mathrm{G}=\mathrm{Me}$

81: $\mathrm{G}=\mathrm{CONEt}_{2}$

\begin{tabular}{|c|c|c|c|c|c|c|c|}
\hline Entrada & Alquino & $\mathbf{R}^{1}$ & $\mathbf{R}^{2}$ & $\mathbf{t}_{1}$ & $\mathbf{t}_{2}$ & Producto & Rto. $(\%)^{\mathrm{a}}$ \\
\hline 1 & 50d & $\mathrm{Ph}$ & $\mathrm{H}$ & 30 & 15 & $80 a$ & 65 \\
\hline 2 & $51 \mathrm{ac}$ & $\mathrm{Ph}$ & $5-\mathrm{OMe}^{\mathrm{b}}$ & 30 & 20 & $85 a a$ & 68 \\
\hline$--\frac{3}{4}$ & $\begin{array}{c}51 c e \\
---- \\
78\end{array}$ & $\begin{array}{c}3-\mathrm{Th}^{\mathrm{c}} \\
\mathrm{Ph}\end{array}$ & $\begin{array}{c}7-\mathrm{OMe}^{\mathrm{b}} \\
\mathrm{H}\end{array}$ & $\begin{array}{r}40 \\
-- \\
30\end{array}$ & $\begin{array}{r}10 \\
--- \\
15\end{array}$ & $\begin{array}{c}85 \mathrm{ca} \\
---- \\
81\end{array}$ & $--\frac{58}{72}$ \\
\hline
\end{tabular}

${ }^{\mathrm{a}}$ Rendimiento en producto aislado referido a los alquinos 50d, 51ac,ce y 78 . ${ }^{\mathrm{b}}$ Posición de $\mathrm{R}^{2}$ referida a la unidad de benzo[b]tiofeno. ${ }^{c} 3$-Tienilo. 


\section{c.3 Triisopropilsilil tiol (TIPS-SH) como fuente de azufre}

Por último, se decidió estudiar el TIPS-SH como equivalente sintético del $\mathrm{H}_{2} \mathrm{~S}$ con el objetivo de intentar mejorar los rendimientos moderados que se obtenían empleando tioacetato potásico.

En primer lugar, se realizaron diferentes ensayos preliminares considerando los estudios de optimización realizados con el tioacetáto potásico. Se emplearon distintos sistemas catalíticos basados en una combinación de un complejo de paladio y una fosfina. Al igual que al utilizar tioacetato potásico, el $\mathrm{Pd}_{2}(\mathrm{dba})_{3}$ resultó ser más activo que las sales de paladio (II). Con esta fuente de paladio se ensayaron distintos ligandos, obteniéndose rendimientos similares con $\mathrm{CyPF} t$-Bu y Xantphos. Sin embargo, se optó por emplear Xantphos debido a su menor coste comercial. Teniendo en cuenta estos estudios, se decidieron utilizar las siguientes condiciones de reacción: $\operatorname{Pd}_{2}(\mathrm{dba})_{3}(2.5 \mathrm{~mol} \%)$ / Xantphos ( 5 mol\%) como sistema catalítico y LiHMDS como base en tolueno a reflujo. Así, cuando se hizo reaccionar 50d con TIPS-SH (1.2 equiv.), en las condiciones previamente descritas, y la reacción se monitorizó por análisis de CG-EM, se observó conversión completa en menos de 3 horas para generar el intermedio silil protegido 86 (Esquema 3.59). A continuación, se pensó en emplear una fuente de fluoruro para llevar a cabo la desprotección del grupo sililo y poder inducir, así, la ciclación 5-endo-dig. Se comprobó que la adición de TBAF a la mezcla de reacción conducía a un 92\% del 2-fenil-4-metoxibenzo[b]tiofeno 80a tras 2 horas de agitación a temperatura ambiente (Esquema 3.59). Estas mismas condiciones también fueron ensayadas empleando el alquino 78, lo que permitió preparar el 4carbamoiloxi-2-fenilbenzo[b]tiofeno 81 con buen rendimiento (Esquema 3.59).

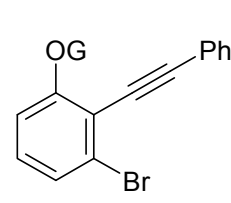

50d: $\mathrm{G}=\mathrm{Me}$ 78: $\mathrm{G}=\mathrm{CONEt}_{2}$

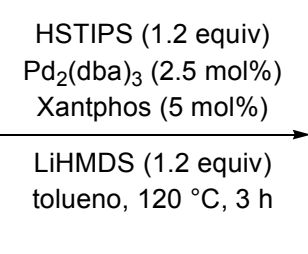

$\mathrm{Pd}_{2}(\mathrm{dba})_{3}(2.5 \mathrm{~mol} \%)$ Xantphos (5 mol\%) LiHMDS (1.2 equiv) tolueno, $120{ }^{\circ} \mathrm{C}, 3 \mathrm{~h}$

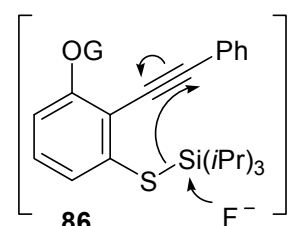

86

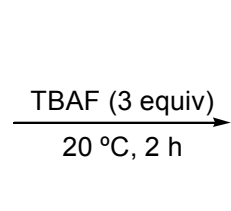

80a: $\mathrm{G}=\operatorname{Me}(92 \%)$

Esquema 3.59

81: $G=$ CONEt $_{2}(81 \%)$

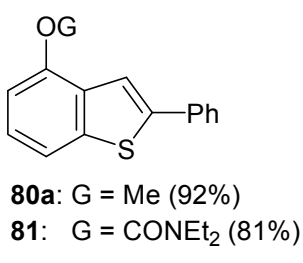

(1)

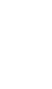

Una vez puesta a punto esta metodología para la síntesis de los 2fenilbenzo[b]tiofenos 4-oxígeno funcionalizados 80 a y 81 se decidió aplicarla para preparar otros benzo[b]tiofenos alcoxi-funcionalizados 80 y 85 . 
De esta manera, se trataron varios $o$-alquinilbromoarenos mono y dimetoxi-sustituidos 50 y 51 ac-ce, respectivamente, con TIPS-SH, bajo estas mismas condiciones de reacción, lo que permitió preparar los correspondientes metoxi y dimetoxibenzo[b]tiofenos 80 y 85 con buenos rendimientos. Esta secuencia de acoplamiento con TIPS-SH / heterociclación, llevada a cabo sobre los derivados de $o$-alquinilbromofenilo 50 y 51, es efectiva utilizando tanto alquinos con sustituyentes alifáticos (Tabla 3.8, entradas $1,4,5$ y 8), como con sustituyentes aromáticos (Tabla 3.8, entradas 2, 3 y 9) o heteroaromáticos (Tabla 3.8, entradas 6 y 7).

Además se comprobó que esta estrategia permitía obtener los 4metoxibenzo $[b]$ tiofenos con un segundo grupo metoxilo tanto en posición orto (entradas 2-4), meta (entradas 5 y 6) o para (entradas 7-9), con respecto al ya existente.

Tabla 3.8 Síntesis de benzo[b]tiofenos 4-metoxi y 4,n-dimetoxifuncionalizados $\mathbf{8 0 b}$ y $\mathbf{8 5}$
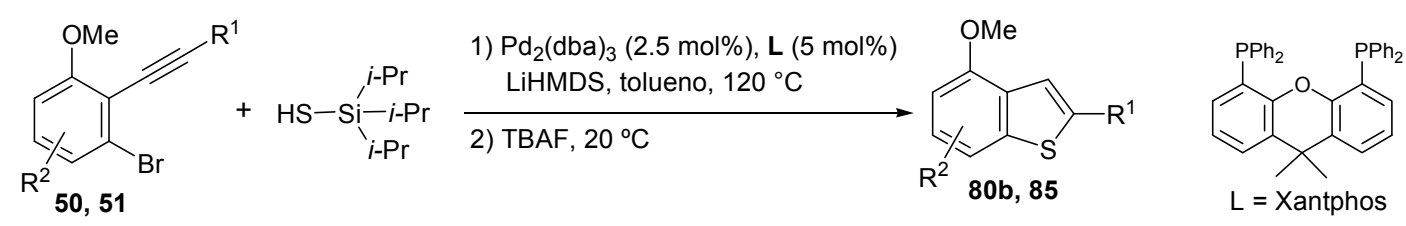

\begin{tabular}{cccccc}
\hline \hline Entrada & Alquino & $\mathbf{R}^{\mathbf{1}}$ & $\mathbf{R}^{\mathbf{2}}$ & Producto $^{\mathrm{a}}$ & ${\text { Rto. }(\mathbf{\%})^{\mathrm{b}}}^{\mathrm{b}}$ \\
\hline 1 & $\mathbf{5 0 a}$ & $n-\mathrm{C}_{5} \mathrm{H}_{11}$ & $\mathrm{H}$ & $\mathbf{8 0 b}$ & 80 \\
\hline 2 & $\mathbf{5 1 a c}$ & $\mathrm{Ph}$ & $5-\mathrm{MeO}$ & $\mathbf{8 5 a a}$ & 82 \\
3 & $\mathbf{5 1 a d}$ & $4-\mathrm{MeC}_{6} \mathrm{H}_{4}$ & $5-\mathrm{MeO}$ & $\mathbf{8 5 a b}$ & 85 \\
4 & $\mathbf{5 1 a e}$ & $n-\mathrm{Bu}$ & $5-\mathrm{MeO}$ & $\mathbf{8 5 a c}$ & 70 \\
\hline 5 & $\mathbf{5 1 b b}$ & $n-\mathrm{C}_{6} \mathrm{H}_{13}$ & $6-\mathrm{MeO}$ & $\mathbf{8 5 b a}$ & 70 \\
6 & $\mathbf{5 1 b e}$ & $3-\mathrm{Th}^{\mathrm{c}}$ & $6-\mathrm{MeO}$ & $\mathbf{8 5 b b}$ & 73 \\
\hline 7 & $\mathbf{5 1 c e}$ & $3-\mathrm{Th}^{\mathrm{c}}$ & $7-\mathrm{MeO}$ & $\mathbf{8 5 c a}$ & 71 \\
8 & $\mathbf{5 1} \mathbf{c a}$ & $n-\mathrm{C}_{5} \mathrm{H}_{11}$ & $7-\mathrm{MeO}$ & $\mathbf{8 5 c b}$ & 76 \\
9 & $\mathbf{5 1 c c}$ & $\mathrm{Ph}^{2}$ & $7-\mathrm{MeO}$ & $\mathbf{8 5 c c}$ & 90 \\
\hline
\end{tabular}

${ }^{\mathrm{a}}$ Posición de $\mathrm{R}^{2}$ referida a la unidad de benzo $[b]$ tiofeno. ${ }^{\mathrm{b}}$ Rendimiento en producto aislado referido al alquino de partida 50 ó 51. '3-Tienilo.

Podemos concluir que se han desarrollado dos rutas sintéticas eficientes para la síntesis de benzo[b]tiofenos 4-oxígeno funcionalizados basadas en una reacción tándem de 
acoplamiento C-S / heterociclación 5-endo-dig sobre derivados de 2-alquinil-3bromofenoles. Además, se ha demostrado que tanto el TIPS-SH como el tioacetato potásico se comportan como equivalentes sintéticos del $\mathrm{H}_{2} \mathrm{~S}$ para llevar a cabo el acoplamiento $\mathrm{C}-\mathrm{S}$ sobre estos sustratos de partida.

\section{d) Preparación de otros benzo[b]tiofenos 2-sustituidos}

Debido a la efectividad de estas dos secuencias de acoplamiento / heterociclación para sintetizar benzo[b]tiofenos 4-oxígeno funcionalizados, decidimos aplicar estas condiciones a una variedad representativa de $o$-alquinilbromobencenos 82 con el fin de evaluar el alcance de estos dos procedimientos "one-pot" como un nuevo método de síntesis de benzo[b]tiofenos.

Los $o$-alquinilbromobencenos 82a-k se prepararon por reacción de los 1-bromo-2yodoarenos 87 con el correspondiente alquino en presencia de $\mathrm{PdCl}_{2}\left(\mathrm{PPh}_{3}\right)_{2}(3 \mathrm{~mol} \%), \mathrm{CuI}(5$ mol\%) y $\mathrm{Et}_{2} \mathrm{NH}$ (1.5 equiv.), en DMF como disolvente a temperatura ambiente (Tabla 3.9).

Tabla 3.9 Síntesis de los $o$-alquinilbromoarenos $\mathbf{8 2 b}$-k

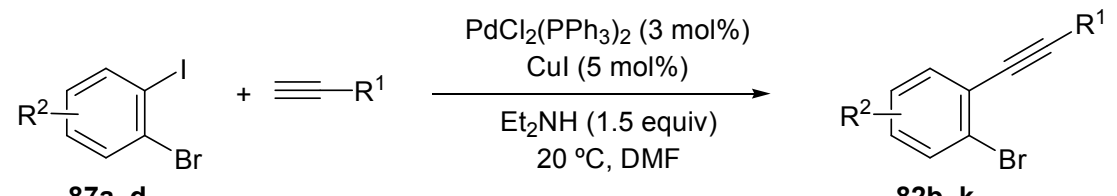

$87 a-d$

82b-k

\begin{tabular}{ccccccc}
\hline \hline Entrada & Material partida & Alquino (R) & $\mathbf{R}^{\mathbf{2}}$ & $\mathbf{t}(\mathbf{h})$ & Producto & Rto. $(\mathbf{\%})^{\mathrm{a}}$ \\
\hline 1 & $\mathbf{8 7 a}$ & $4-\mathrm{MeOC}_{6} \mathrm{H}_{4}$ & $\mathrm{H}$ & 4 & $\mathbf{8 2 b}$ & 83 \\
2 & $\mathbf{8 7 a}$ & $3-\mathrm{FC}_{6} \mathrm{H}_{4}$ & $\mathrm{H}$ & 3 & $\mathbf{8 2 c}$ & 74 \\
3 & $\mathbf{8 7 a}$ & $3-\mathrm{Th}^{\mathrm{b}}$ & $\mathrm{H}$ & 4 & $\mathbf{8 2 d}$ & 95 \\
4 & $\mathbf{8 7 a}$ & $n-\mathrm{Bu}^{\mathrm{a}}$ & $\mathrm{H}$ & 4 & $\mathbf{8 2 e}$ & 95 \\
5 & $\mathbf{8 7 a}$ & $n-\mathrm{C}_{6} \mathrm{H}_{13}$ & $\mathrm{H}$ & 3 & $\mathbf{8 2 f}$ & 89 \\
6 & $\mathbf{8 7 a}$ & $c-\mathrm{C}_{6} \mathrm{H}_{9}{ }^{\mathrm{c}}$ & $\mathrm{H}$ & 2 & $\mathbf{8 2 g}$ & 84 \\
7 & $\mathbf{8 7 a}$ & $\left(\mathrm{CH}_{2}\right)_{3} \mathrm{CN}$ & $\mathrm{H}$ & 2 & $\mathbf{8 2 h}$ & 88 \\
\hline 8 & $\mathbf{8 7 b}$ & $3-\mathrm{Th}^{\mathrm{b}}$ & $4-\mathrm{Me}^{\mathrm{d}}$ & 3 & $\mathbf{8 2 i}$ & 93 \\
9 & $\mathbf{8 7 c}$ & $\mathrm{Ph}^{\mathrm{d}}$ & $4-\mathrm{F}^{\mathrm{d}}$ & 3 & $\mathbf{8 2 j}$ & 90 \\
10 & $\mathbf{8 7 d}$ & $n-\mathrm{C}_{5} \mathrm{H}_{11}$ & $4-\mathrm{Cl}^{\mathrm{d}}$ & 5 & $\mathbf{8 2 k}$ & 85 \\
\hline
\end{tabular}

${ }^{\mathrm{a}}$ Rendimiento en producto aislado referido a los bromoyodoarenos de partida 87. ${ }^{\mathrm{b}}$ 3-Tienilo. ${ }^{\mathrm{c}}$ 1-Ciclohexenilo.

${ }^{\mathrm{d}}$ Posición del grupo $\mathrm{R}^{2}$ referida al grupo alquinilo. 
El 3-(2-bromofenil)propiolato de etilo $\mathbf{8 2 m}$ se preparó a partir de 1-bromo-2etinilbenceno 821 por adición de 1.2 equiv. de cloruro de etilmagnesio a $-78{ }^{\circ} \mathrm{C}$ en THF, evolución de la mezcla de reacción a $0{ }^{\circ} \mathrm{C}$ durante 20 minutos, y adición final de cloroformiato de etilo (Esquema 3.60).

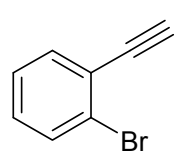

821

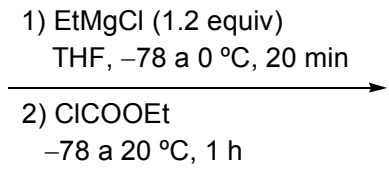

-78 a $20^{\circ} \mathrm{C}, 1 \mathrm{~h}$

Esquema 3.60

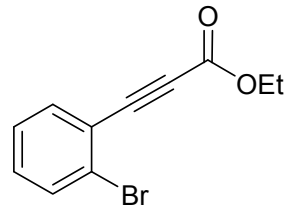

$82 \mathrm{~m}(65 \%)$

\section{d.1 Método A: Síntesis de 84 empleando tioacetato potásico}

En primer lugar, se estudió la utilización de tioacetato potásico (método A). Así, la reacción de una amplia variedad de $o$-alquinilbromoarenos $\mathbf{8 2}$ con tioacetato potásico, de acuerdo al procedimiento descrito anteriormente, permitió sintetizar los benzo[b]tiofenos $\mathbf{8 4}$.

En la Tabla 3.10 se observa que se prepararon con buenos rendimientos benzo[b]tiofenos 84 con grupos aromáticos electrón dadores y atractores, (entradas 1 y 2), heteroaromáticos (entrada 3), alquilo (entradas 4 y 5), alquenilo (entrada 6), alquilo funcionalizado (entrada 7) y éster (entrada 11), sobre la posición C-2 del anillo. Además, los $o$-alquinilbromobencenos $\mathbf{8 2 i} \mathbf{i}-\mathbf{k}$ con sustituyentes adicionales en el anillo de benceno, también fueron sustratos de partida adecuados para llevar a cabo este procedimiento (entradas 8-10).

Del análisis de los resultados presentados en la Tabla 3.10 se desprende que en el caso de emplear alquinos con sustituyentes alifáticos (entradas 4, 5 y 10) se alcanzaron rendimientos ligeramente inferiores que cuando se utilizaban alquinos con sustituyentes aromáticos o alquenilo (1, 2, 6 y 9). Por otro lado, es destacable que la existencia de un grupo éster en el alquino $\mathbf{8 2}$ es compatible con estas condiciones de reacción (Tabla 3.10, entrada 11). 
Tabla 3.10 Síntesis de los benzo[b]tiofenos 2-sustituidos $\mathbf{8 4 b}-\mathbf{m}$

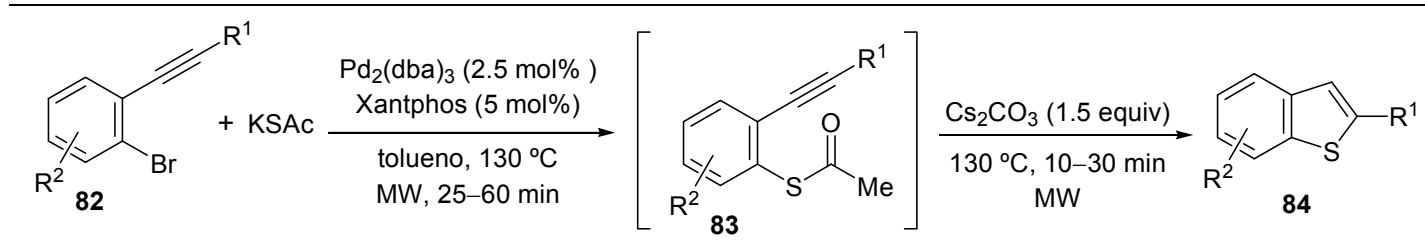

\begin{tabular}{cccccc}
\hline \hline Entrada & Alquino & $\mathbf{R}^{\mathbf{1}}$ & $\mathbf{R}^{\mathbf{2}}$ & Producto & Rto. (\%) $^{\mathrm{a}}$ \\
\hline 1 & $\mathbf{8 2 b}$ & $4-\mathrm{MeOC}_{6} \mathrm{H}_{4}$ & $\mathrm{H}$ & $\mathbf{8 4 b}$ & 64 \\
2 & $\mathbf{8 2 c}$ & $3-\mathrm{FC}_{6} \mathrm{H}_{4}$ & $\mathrm{H}$ & $\mathbf{8 4 c}$ & 62 \\
3 & $\mathbf{8 2 d}$ & $3-\mathrm{Th}^{\mathrm{b}}$ & $\mathrm{H}$ & $\mathbf{8 4 d}$ & 69 \\
4 & $\mathbf{8 2 \mathbf { e }}$ & $n-\mathrm{Bu}$ & $\mathrm{H}$ & $\mathbf{8 4} \mathbf{e}$ & 50 \\
5 & $\mathbf{8 2 f}$ & $n-\mathrm{C}_{6} \mathrm{H}_{13}$ & $\mathrm{H}$ & $\mathbf{8 4 f}$ & 53 \\
6 & $\mathbf{8 2 g}$ & $c-\mathrm{C}_{6} \mathrm{H}_{9}{ }^{\mathrm{c}}$ & $\mathrm{H}$ & $\mathbf{8 4 g}$ & 59 \\
7 & $\mathbf{8 2 h}$ & $\left(\mathrm{CH}_{2}\right)_{3} \mathrm{CN}$ & $\mathrm{H}$ & $\mathbf{8 4 h}$ & 67 \\
8 & $\mathbf{8 2 i}$ & $3-\mathrm{Th}^{\mathrm{b}}$ & $6-\mathrm{Me}^{\mathrm{d}}$ & $\mathbf{8 4 i}$ & 59 \\
9 & $\mathbf{8 2 j}$ & $\mathrm{Ph}^{\mathrm{b}}$ & $6-\mathrm{F}^{\mathrm{d}}$ & $\mathbf{8 4 j}$ & 72 \\
10 & $\mathbf{8 2 k}$ & $n-\mathrm{C}_{5} \mathrm{H}_{11}$ & $6-\mathrm{Cl}^{\mathrm{d}}$ & $\mathbf{8 4 k}$ & 54 \\
11 & $\mathbf{8 2 m}$ & $\mathrm{CO}_{2} \mathrm{Et}$ & $\mathrm{H}$ & $\mathbf{8 4 m}$ & 60 \\
\hline
\end{tabular}

${ }^{\mathrm{a}}$ Rendimiento en producto aislado referido a los alquinos 82. ${ }^{\mathrm{b}}$ 3-Tienilo. ${ }^{\mathrm{c}}$ 1-Ciclohexenilo. ${ }^{\mathrm{d}}$ Posición de $\mathrm{R}^{2}$ referida a la unidad de benzo[b]tiofeno.

Hay que destacar que, aunque no es necesario aislar el correspondiente tioacetato de $S$-2-alquinilfenilo 83 para obtener los benzo $[b]$ tiofenos 84, también se pudieron preparar y caracterizar estos intermedios 83. Para ello, se hicieron reaccionar algunos de los $o$ alquinilbromoarenos 82 con tioacetato potásico en las condiciones anteriormente descritas, y una vez finalizado el paso de acoplamiento, detectado por CG-EM, se procedió a hidrolizar la mezcla de reacción obteniéndose, tras purificación por cromatografía de columna, los tioacetatos 83 con buenos rendimientos (Tabla 3.11). 
Tabla 3.11 Síntesis de los tioacetatos de $S$-2-alquinilfenilo 83

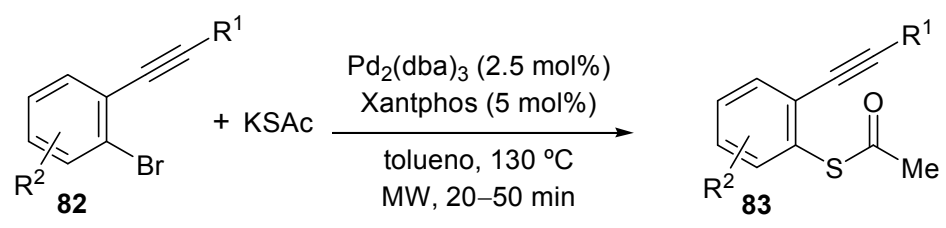

\begin{tabular}{cccccc}
\hline \hline Entrada & $\begin{array}{c}\text { Alquino } \\
\text { partida }\end{array}$ & $\mathbf{R}^{\mathbf{1}}$ & $\mathbf{R}^{\mathbf{2}}$ & Producto & Rto. (\%) $^{\mathrm{a}}$ \\
\hline 1 & $\mathbf{8 2 b}$ & $4-\mathrm{MeOC}_{6} \mathrm{H}_{4}$ & $\mathrm{H}$ & $\mathbf{8 3 b}$ & 80 \\
2 & $\mathbf{8 2 c}$ & $3-\mathrm{FC}_{6} \mathrm{H}_{4}$ & $\mathrm{H}$ & $\mathbf{8 3 c}$ & 73 \\
3 & $\mathbf{8 2 d}$ & $3-\mathrm{Th}^{\mathrm{b}}$ & $\mathrm{H}$ & $\mathbf{8 3 d}$ & 82 \\
4 & $\mathbf{8 2 e}$ & $n-\mathrm{Bu}$ & $\mathrm{H}$ & $\mathbf{8 3 e}$ & 52 \\
5 & $\mathbf{8 2 f}$ & $n-\mathrm{C}_{6} \mathrm{H}_{13}$ & $\mathrm{H}$ & $\mathbf{8 3 f}$ & 55 \\
6 & $\mathbf{8 2 g}$ & $c-\mathrm{C}_{6} \mathrm{H}_{9}{ }^{\mathrm{c}}$ & $\mathrm{H}$ & $\mathbf{8 3 g}$ & 75 \\
7 & $\mathbf{8 2 k}$ & $n-\mathrm{C}_{5} \mathrm{H}_{11}$ & $4-\mathrm{Cl}^{\mathrm{d}}$ & $\mathbf{8 3 k}$ & 57 \\
\hline
\end{tabular}

${ }^{a}$ Rendimiento en producto aislado referido a los alquinos 82. ${ }^{\mathrm{b}}$ 3-Tienilo. ${ }^{\mathrm{c}}$ 1-Ciclohexenilo. ${ }^{\mathrm{d}}$ Posición de $\mathrm{R}^{2}$ referida al grupo alquinilo.

\section{d.2 Método B: Síntesis de $\mathbf{8 4}$ empleando triisopropilsilil tiol}

A continuación, se hicieron reaccionar diferentes $o$-alquinilbromobencenos 82 con TIPS-SH (método B) bajo las condiciones de reacción previamente descritas (Esquema 3.59 y Tabla 3.8). De esta forma, se pudieron preparar los benzo[b]tiofenos 84 con buenos rendimientos (Tabla 3.12).

Como se muestra en la Tabla 3.12, alquinos con sustituyentes aromáticos (entradas 1-3), heteroaromáticos (entrada 4), alquenilo (entrada 6), alquilo (entrada 5) y alquilo funcionalizado (entrada 7) son sustratos apropiados para llevar a cabo este proceso. Además, los $o$-alquinilbromoarenos 82i-k con sustituyentes en la unidad de benceno, incluyendo halógenos, también resultaron ser sustratos de partida adecuados en esta reacción (entradas $8-10)$. En general se alcanzaron buenos rendimientos de los benzo[b]tiofenos 84, excepto para el alquino 82m que contenía un grupo éster en su estructura (entrada 11).

Por otro lado, también se comprobó que la cantidad de fosfina y catalizador de paladio, requerida en el paso de acoplamiento con el TIPS-SH, podía ser reducida hasta un 1 
mol\% mediante un incremento del tiempo de reacción de 1 a 14 horas, pero sin observarse una disminución apreciable en el rendimiento del proceso (Tabla 3.12, entrada 1). En general se observa que este método $\mathrm{B}$ conduce a mejores rendimientos de los benzo $[b]$ tiofenos $\mathbf{8 4}$ que el empleo de la primera estrategia (método A).

Tabla 3.12 Síntesis de los benzo[b]tiofenos 2-sustituidos 84a-k

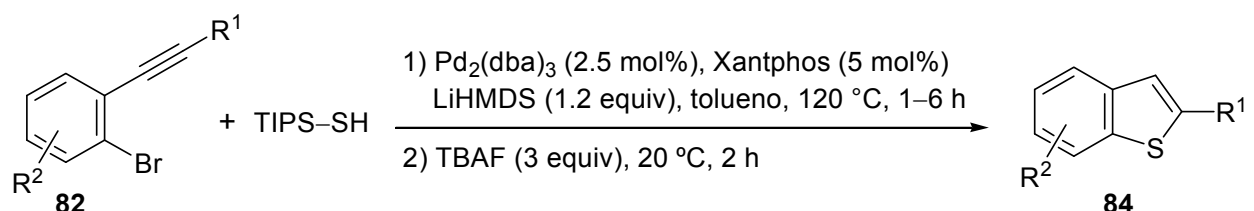

\begin{tabular}{cccccc}
\hline \hline Entrada & Alquino & $\mathbf{R}^{\mathbf{1}}$ & $\mathbf{R}^{\mathbf{2}}$ & Producto & Rto. (\%) $)^{\mathrm{a}}$ \\
\hline 1 & $\mathbf{8 2 a}$ & $\mathrm{Ph}$ & $\mathrm{H}$ & $\mathbf{8 4 a}$ & $88(87)^{\mathrm{b}}$ \\
2 & $\mathbf{8 2 b}$ & $4-\mathrm{MeOC}_{6} \mathrm{H}_{4}$ & $\mathrm{H}$ & $\mathbf{8 4 b}$ & 66 \\
3 & $\mathbf{8 2 c}$ & $3-\mathrm{FC}_{6} \mathrm{H}_{4}$ & $\mathrm{H}$ & $\mathbf{8 4 c}$ & 89 \\
4 & $\mathbf{8 2 d}$ & $3-\mathrm{Th}^{\mathrm{c}}$ & $\mathrm{H}$ & $\mathbf{8 4 d}$ & 77 \\
5 & $\mathbf{8 2 f}$ & $n-\mathrm{C}_{6} \mathrm{H}_{13}$ & $\mathrm{H}$ & $\mathbf{8 4 f}$ & 84 \\
6 & $\mathbf{8 2 g}$ & $c-\mathrm{C}_{6} \mathrm{H}_{9}{ }^{\mathrm{d}}$ & $\mathrm{H}$ & $\mathbf{8 4 g}$ & 66 \\
7 & $\mathbf{8 2 h}$ & $\left(\mathrm{CH}_{2}\right)_{3} \mathrm{CN}$ & $\mathrm{H}$ & $\mathbf{8 4 h}$ & 86 \\
8 & $\mathbf{8 2 i}$ & $3-\mathrm{Th}^{\mathrm{c}}$ & $6-\mathrm{Me}^{\mathrm{e}}$ & $\mathbf{8 4 i}$ & 75 \\
9 & $\mathbf{8 2 j}$ & $\mathrm{Ph}^{\mathrm{e}}$ & $6-\mathrm{F}^{\mathrm{e}}$ & $\mathbf{8 4 j}$ & 92 \\
10 & $\mathbf{8 2 k}$ & $n-\mathrm{C}_{5} \mathrm{H}_{11}$ & $6-\mathrm{Cl}^{\mathrm{e}}$ & $\mathbf{8 4 k}$ & 72 \\
11 & $\mathbf{8 2 m}$ & $\mathrm{CO}_{2} \mathrm{Et}$ & $\mathrm{H}$ & - & - \\
\hline
\end{tabular}

${ }^{\mathrm{a}}$ Rendimiento en producto aislado referido a los alquinos $\mathbf{8 2}$. ${ }^{\mathrm{b}}$ Reacción llevada a cabo con $1 \mathrm{~mol} \%$ de catalizador (14 h). ${ }^{\mathrm{c}}$ 3-Tienilo. ${ }^{\mathrm{d}} 1$-Ciclohexenilo. ${ }^{\mathrm{e}}$ Posición de $\mathrm{R}^{2}$ referida a la unidad de benzo[b]tiofeno.

Se puede concluir que tanto el método A: utilizando tioacetato potásico, como el método B: empleando TIPS-SH, son estrategias sintéticas adecuadas para la preparación de una gran variedad de benzo[b]tiofenos 2-sustituidos, demostrándose así la generalidad de ambos procedimientos en la síntesis de benzo[b]tiofenos. 


\section{e) Preparación de los benzo $[b]$ tiofenos 3-funcionalizados 88}

Para finalizar, consideramos estudiar la posibilidad de preparar benzo[b]tiofenos 2,3-disustituidos mediante una funcionalización selectiva de los benzo[b]tiofenos en el C-3, por adición de un electrófilo en la secuencia de reacción.

En este punto es interesante destacar que, aunque los indoles y benzo[b]furanos 2,3disustituidos se pueden sintetizar fácilmente a partir de $o$-alquinil anilinas y fenoles, respectivamente, a través de reacciones que implican especies de organopaladio (reacción de Cacchi), ${ }^{158}$ esta metodología no es aplicable a la síntesis de los correspondientes benzo $[b]$ tiofenos. ${ }^{247}$ Esto es debido a que no es posible preparar $o$-alquinilbencenotioles por la gran tendencia que presentan a ciclar a los correspondientes benzo[b]tiofenos 2-sustituidos. ${ }^{248}$

Sin embargo, considerando el carácter aniónico de las condiciones empleadas para la desprotección del grupo sililo en los $o$-alquinilsililtiobencenos intermedios $\mathbf{8 6}$, cuando se utilizaba el método B (acoplamiento con TIPS-SH), se pensó que la desprotección del grupo sililo en el intermedio $\mathbf{8 6}$ empleando una fuente de fluoruro anhidra, seguida de una reacción de ciclación en presencia de especies electrofílicas adecuadas podría permitir la preparación de los benzo[b]tiofenos 2,3-disustituidos (Esquema 3.61). Los principales requisitos para el éxito de esta idea son la presencia del reactivo electrofílico durante el paso de ciclación y la ausencia de protones en el medio de reacción. Por lo tanto, se hizo obligatoria la eliminación de los reactivos empleados en el acoplamiento $\mathrm{C}-\mathrm{S}$, principalmente el HMDS, antes de la adición de la fuente de fluoruro y el electrófilo.
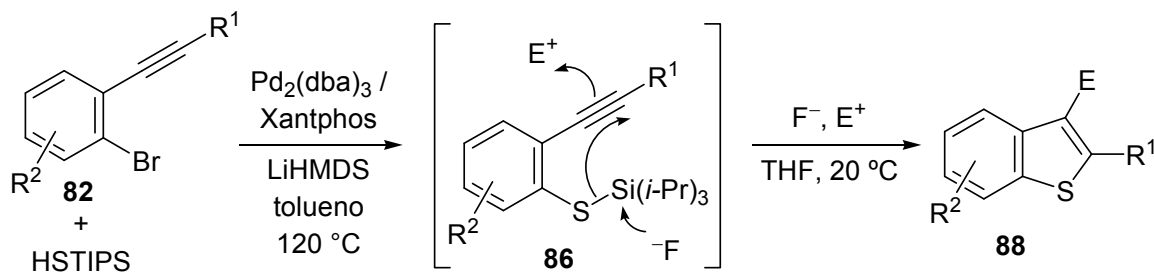

Esquema 3.61

Con este propósito, tras la formación de los sililtioderivados 86, en las condiciones descritas anteriormente, se llevó a cabo la filtración del crudo de reacción a través de una

\footnotetext{
${ }^{247}$ I. Nakamura, T. Sato, Y. Yamamoto, Angew. Chem., Int. Ed. 2006, 45, 4473.

248 A. M. Malte, C. E. Castro, J. Am. Chem. Soc. 1967, 89, 6770.
} 
columna corta de gel de alúmina neutra empleando como eluyente una mezcla hexano / éter (2 / 1), seguida de la evaporación de los disolventes. Así se obtuvieron los ariltiosilanos 86, con pureza suficiente para continuar con el proceso sintético.

A continuación, se estudió la fuente de fluoruro idónea para llevar a cabo el proceso de desprotección del grupo sililo / ciclación de los intermedios 86 en presencia de un electrófilo. En primer lugar se ensayó el TBAF, el cual habíamos empleado en la preparación de los benzo[b]tiofenos 84. Sin embargo, esta fuente de fluoruro no condujo a buenos resultados obteniéndose mayoritariamente el benzo $[b]$ tiofeno 2-sustituido. Este resultado puede ser debido a que el TBAF puede actuar, al menos parcialmente, como una fuente de protones mediante una eliminación de Hofmann. Por lo tanto se ensayó la utilización de otras fuentes de fluoruro y, tras varios ensayos, se determinó que el empleo de CsF anhidro en THF permitía la introducción de los electrófilos en la posición $\mathrm{C}-3$ del anillo de benzo[ $b]$ tiofeno.

Por último, se aplicaron estas condiciones a la síntesis de distintos benzo[b]tiofenos 2,3-disustituidos (Tabla 3.13). Así, se hicieron reaccionar los $o$-alquinilbromobencenos 50d y 82 con TIPS-SH, empleando el sistema catalítico $\mathrm{Pd}_{2}\left(\mathrm{dba}_{3} /\right.$ Xantphos y LiHMDS como base en tolueno a $120{ }^{\circ} \mathrm{C}$. Una vez comprobada la formación del correspondiente ariltiosilano 86 por CG-EM, y tras filtración por alúmina, su tratamiento con CsF anhidro y el correspondiente electrófilo en THF permitió obtener los benzo[b]tiofenos 2,3difuncionalizados $\mathbf{8 8}$.

En primer lugar, se ensayó el empleo de disulfuros como agentes electrofílicos. Así, se pudieron preparar los 3-metiltiobenzo[b]tiofenos 88a-d y el 3-ariltiobenzo[b]tiofeno 88e, al llevar a cabo la desprotección de los ariltiosilanos 86 con $\mathrm{CsF}$ en presencia del correspondiente disulfuro alifático o aromático (Tabla 3.13, entradas 1-5). Esta metodología permitió la síntesis del benzo[b]tiofeno 2,3,4-trifuncionalizado 88a, que contenía un grupo metoxilo en la posición 4 del anillo (Tabla 3.13, entrada 1). Además, también se pudieron introducir otros electrófilos basados en carbono, tales como aldehídos, permitiendo obtener los correspondientes alcoholes con buenos rendimientos (Tabla 3.13, entradas 6 y 7).

En todas estas reacciones junto con los benzo[b]tiofenos funcionalizados $\mathbf{8 8}$ se obtuvieron pequeñas cantidades de los correspondientes derivados de benzo[b]tiofeno no sustituidos en la posición C -3 del anillo. Sin embargo, estos pudieron ser separados de los benzo[$[b]$ tiofenos 3 -funcionalizados $\mathbf{8 8}$ mediante purificación por cromatografía de columna. 
Tabla 3.13 Preparación de los benzo $[b]$ tiofenos 3-funcionalizados $\mathbf{8 8}$<smiles>[R]C#Cc1cc[c-]cc1Br</smiles>

$50 \mathrm{~d}, 82$

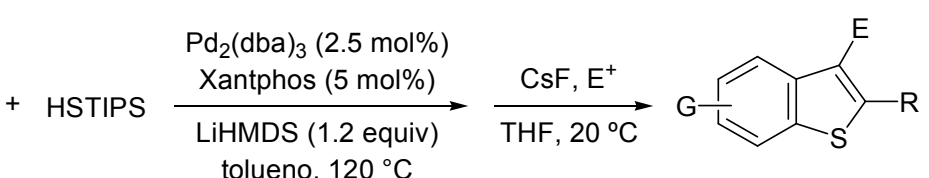
tolueno, $120^{\circ} \mathrm{C}$

88

\begin{tabular}{|c|c|c|c|c|c|c|}
\hline Entrada & Alquino & $\mathbf{R}$ & $\mathbf{G}$ & $\mathbf{E}^{+}$ & Producto & Rto. $(\%)^{a}$ \\
\hline 1 & 50d & $\mathrm{Ph}$ & $\mathrm{OMe}^{\mathrm{b}}$ & $\mathrm{Me}_{2} \mathrm{~S}_{2}$ & & 62 \\
\hline 2 & $82 a$ & $\mathrm{Ph}$ & $\mathrm{H}$ & $\mathrm{Me}_{2} \mathrm{~S}_{2}$ & & 73 \\
\hline 3 & $82 \mathbf{i}$ & $3-\mathrm{Th}^{\mathrm{c}}$ & $\mathrm{Me}^{\mathrm{d}}$ & $\mathrm{Me}_{2} \mathrm{~S}_{2}$ & & 70 \\
\hline 4 & $82 a$ & $n-\mathrm{Bu}$ & $\mathrm{H}$ & $\mathrm{Me}_{2} \mathrm{~S}_{2}$ & & 68 \\
\hline 5 & $82 a$ & $\mathrm{Ph}$ & $\mathrm{H}$ & $\left(4-\mathrm{ClC}_{6} \mathrm{H}_{4}\right)_{2} \mathrm{~S}_{2}$ & & 67 \\
\hline 6 & $82 a$ & $\mathrm{Ph}$ & $\mathrm{H}$ & $\left(4-\mathrm{ClC}_{6} \mathrm{H}_{4}\right) \mathrm{CHO}$ & & 68 \\
\hline 7 & $82 a$ & $\mathrm{Ph}$ & $\mathrm{H}$ & $\left(4-\mathrm{BrC}_{6} \mathrm{H}_{4}\right) \mathrm{CHO}$ & & 69 \\
\hline
\end{tabular}

${ }^{\mathrm{a}}$ Rendimiento en producto aislado referido a $\mathbf{5 0 d}$ y $\mathbf{8 2 a}, \mathbf{i}^{\mathrm{b}}{ }^{\mathrm{b}} \mathrm{El}$ grupo OMe se encuentra en posición orto con respecto al grupo alquinilo. ${ }^{\mathrm{c}}$ 3-Tienilo. ${ }^{\mathrm{d}} \mathrm{El}$ grupo Me se encuentra en posición para con respecto al grupo alquinilo.

Podemos concluir que con esta estrategia se han podido introducir selectivamente distintos electrófilos en la posición $\mathrm{C}-3$ del anillo de benzo[b]tiofeno, lo que ha permitido preparar benzo[b]tiofenos altamente funcionalizados de forma sencilla y eficaz. 


\subsubsection{CONCLUSIONES}

Como resumen de este Capítulo 3 se puede concluir que:

Se ha puesto a punto una ruta eficiente para la síntesis regioselectiva de benzo[b]tiofenos 7-oxígeno funcionalizados 2,3-disustituidos mediante una secuencia de $o$ litiación-acoplamiento de Sonogashira-ciclación electrofílica, partiendo de derivados de 3halofenoles. Hay que destacar la escasez de métodos existentes en la bibliografía para la preparación de 7-hidroxibenzo $[b]$ tiofenos y su presencia en el esqueleto de numerosos compuestos biológicamente activos.

Se han desarrollado dos estrategias para la síntesis de benzo[b]tiofenos oxígenofuncionalizados basadas en una reacción tándem de acoplamiento $\mathrm{C}-\mathrm{S}$ / heterociclación 5endo-dig sobre derivados de 2-alquinil-3-bromofenoles, empleando TIPS-SH o tioacetato potásico como equivalentes sintéticos del $\mathrm{H}_{2} \mathrm{~S}$.

Se ha evaluado el alcance de las dos estrategias sintéticas anteriores preparando una gran variedad de benzo[b]tiofenos 2-sustituidos con buenos rendimientos.

$>$ Se han podido sintetizar benzo[b]tiofenos 2,3-difuncionalizados a partir de $o$ alquinilbromoarenos por combinación del procedimiento de acoplamiento $\mathrm{C}-\mathrm{S}$, empleando TIPS-SH, con una reacción de ciclación en presencia del correspondiente electrófilo. 



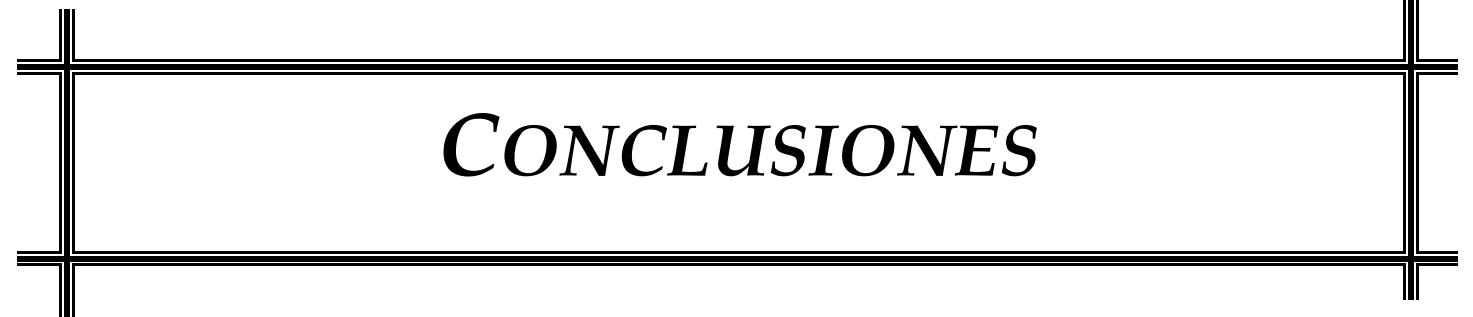

\footnotetext{
“Conclusión es el lugar donde llegaste cansado de pensar". Anónimo
} 

Se han descrito tres aproximaciones sintéticas diferentes para acceder a 2,3dihaloanilinas y se ha analizado el alcance de cada una de ellas.

Se ha puesto a punto un nuevo y eficiente método para la síntesis de 2,3dihaloanilinas a partir de 2,3-dihalofenoles empleando el reagrupamiento de Smiles como paso clave del proceso.

Se ha desarrollado una nueva metodología "one-pot" para la síntesis de $1 H$-indoles 2-sustituidos basada en una secuencia acoplamiento de Sonogashira sobre 2-yodoanilinas / heterociclación 5-endo-dig mediada por hidróxido sódico.

Se ha aplicado la estrategia anterior a las 2,3-dihaloanilidas, lo que ha permitido la síntesis de una gran variedad de 4-haloindoles con buenos rendimientos. En este contexto, también se han podido preparar 4-haloindoles 2,3-disustituidos a partir de los mismos productos de partida. Por otro lado, los 4-haloindoles sintetizados se han podido funcionalizar fácilmente mediante reacciones de acoplamiento catalizadas por complejos de paladio.

Se ha desarrollado una ruta sintética para acceder de forma regioselectiva a 4metoxi y 4,n-dimetoxibenzo[b]furanos a partir de 3-bromoanisoles mediante la combinación de reacciones de orto-metalación dirigida con acoplamientos cruzados catalizados por paladio. De esta manera, los 3-bromo-2-yodoanisoles, resultantes del proceso de $o$-zincación y posterior reacción con yodo, experimentan un acoplamiento selectivo de Sonogashira y una posterior reacción tándem de hidroxilación / heterociclación que permite acceder a los benzo[b]furanos funcionalizados.

Se han sintetizado benzo[b]tiofenos 7-oxígeno funcionalizados 2,3-disustituidos con buenos rendimientos mediante la secuencia $o$-litiación / acoplamiento de Sonogashira / ciclación electrofílica, partiendo de derivados de 3-halofenoles.

$>$ Se han descrito dos estrategias para la síntesis de benzo[b]tiofenos 4-oxígeno funcionalizados basadas en un proceso tándem acoplamiento $\mathrm{C}-\mathrm{S}$ / heterociclación 5-endo-dig sobre derivados de 2-alquinil-3-bromofenoles, comprobándose que tanto el triisopropilsilanotiol como el tioacetato potásico son equivalentes sintéticos adecuados del ácido sulfhídrico para llevar a cabo este proceso sintético. Además, se ha evaluado el alcance de estas dos estrategias y, así, se han preparado una gran variedad de benzo[b]tiofenos 2sustituidos con buenos rendimientos. 
Como conclusión general se puede decir que este trabajo de investigación se ha centrado en la preparación de diferentes heterociclos funcionalizados que presentan gran interés en Química Orgánica, al formar parte del esqueleto de numerosos compuestos con actividad biológica. En concreto se han puesto a punto procedimientos para la síntesis de diferentes indoles, benzo $[b]$ furanos y benzo $[b]$ tiofenos regioselectivamente funcionalizados, empleando, fundamentalmente, una combinación de la estrategia de orto-metalación dirigida con distintos procesos de acoplamiento cruzado catalizados por paladio.

Por último, comentar que la mayor parte de los resultados obtenidos y recogidos en la presente Memoria han aparecido publicados en las siguientes revistas científicas:

- "A Practical, One-Pot Synthesis of Highly Substituted Thiophenes and Benzo[b] thiophenes from Bromoenynes and o-Alkynylbromobenzenes"

V. Guilarte, M. A. Fernández, P. García, E. Hernando, R. Sanz, Org. Lett. 2011, 13, 5100.

- "Combined directed ortho-zincation and palladium-catalyzed strategies: Synthesis of 4,n-dimethoxy-substituted benzo[b]furans"

V. Guilarte, M. P. Castroviejo, E. Álvarez, R. Sanz, Beilstein J. Org. Chem. 2011, 7, 1255.

- "Approaches to the Synthesis of 2,3-Dihaloanilines. Useful Precursors of 4Functionalized-1H-indoles"

V. Guilarte, M. P. Castroviejo, P. García, M. A. Fernández, R. Sanz, J. Org. Chem. 2011, 76, 3416.

- "Synthesis of Regioselectively Functionalized Benzo[b]thiophenes by Combined ortho-Lithiation-Halocyclization Strategies"

R. Sanz, V. Guilarte, E. Hernando, A. M. Sanjuán, J. Org. Chem. 2010, 75, 7443.

Seleccionado en Synfacts, 2011, 143: "Directed ortho-Metalation-Halocyclization Route to Benzothiophenes"

- "Synthesis of 4-functionalized-1H-indoles from 2,3-dihalophenols"

R. Sanz, V. Guilarte, N. García, Org. Biomol. Chem. 2010, 8, 3860.

- "Straightforward selective preparation of nitro- or amino-indoles from 2halonitroanilines and alkynes. First synthesis of 7-amino-5-nitroindoles"

R. Sanz, V. Guilarte, A. Pérez, Tetrahedron Lett. 2009, 50, 4423.

- "Simple Indole Synthesis by One-Pot Sonogashira Coupling-NaOH-Mediated Cyclization"

R. Sanz, V. Guilarte, M. P. Castroviejo, Synlett 2008, 3006. 


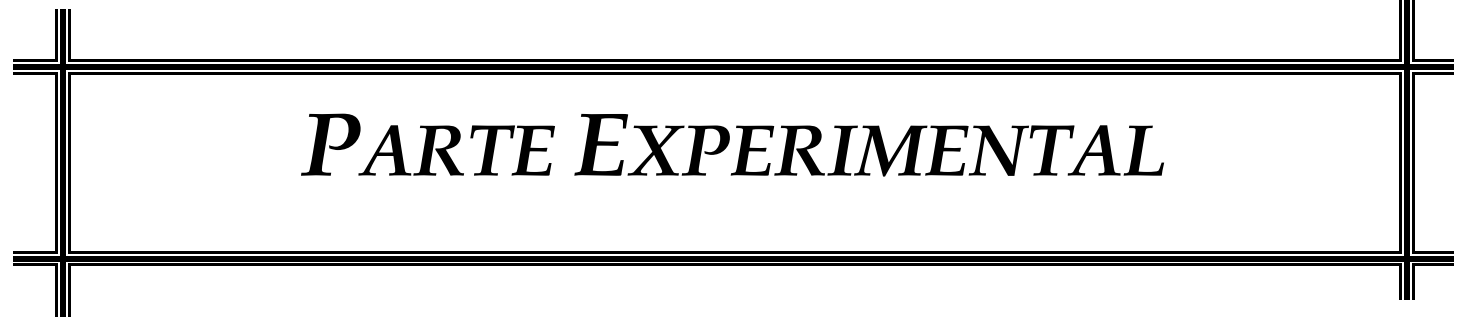

"Para mejorar nuestro conocimiento debemos aprender a contemplar más". René Descartes 



\section{Generalidades}

Todos los aparatos de vidrio se secaron y evacuaron previamente a ser utilizados. Todas las operaciones que implicaron la manipulación de reactivos organometálicos se realizaron en atmósfera inerte de nitrógeno.

Las mezclas frigoríficas utilizadas en las reacciones de baja temperatura se prepararon mezclando $\mathrm{N}_{2}$ líquido o $\mathrm{CO}_{2}$ sólido con acetona o etanol dependiendo de la temperatura de reacción. Las temperaturas de reacción indicadas en esta Memoria se refieren, en todos los casos, a las temperaturas de las mezclas frigoríficas.

El grado de deuteración de los compuestos que presentan incorporación de deuterio se determinó por resonancia magnética nuclear de ${ }^{1} \mathrm{H}$.

\section{Disolventes}

Los disolventes orgánicos volátiles se evaporaron en todos los casos a presión reducida (20 $\mathrm{mm} \mathrm{Hg}$ ) en un evaporador rotativo Heildolph Laborota 4000 o en un Buchi Rotavapor RII.

Los disolventes utilizados para las reacciones en atomósfera inerte fueron secados y destilados antes de su uso de la siguiente manera:

- THF y $\mathrm{Et}_{2} \mathrm{O}$ : reflujo sobre sodio en hilos bajo atmósfera de nitrógeno.

- $\mathrm{CH}_{2} \mathrm{Cl}_{2}$ : reflujo sobre pentóxido de fósforo bajo atmósfera de nitrógeno.

- Tolueno: reflujo sobre $\mathrm{CaH}_{2}$ bajo atmósfera de nitrógeno.

La DMF y DMA anhidras fueron adquiridas comercialmente.

\section{Reactivos de partida}

En su mayoría los reactivos de partida fueron adquiridos del mejor grado comercial asequible y se usaron sin posterior purificación.

La TMEDA fue secada mediante calentamiento sobre potasio, con benzofenona como indicador, y destilada a presión reducida bajo atmósfera de nitrógeno.

Las disoluciones de $n$-BuLi $(2.5 \mathrm{M}$ y $1.6 \mathrm{M})$ en hexano y $t$-BuLi $(1.5 \mathrm{M})$ en pentano fueron asequibles comercialmente.

\section{Cromatografía}

La cromatografía de columna fue realizada utilizando sílica gel 60 (230-400 mesh ASTM) o alúmina neutra 90 (70-230 mesh ASTM) en los casos en los que se indique como fases estacionarias. Como fase móvil se emplearon mezclas de hexano / AcOEt o hexano / $\mathrm{Et}_{2} \mathrm{O}$.

La cromatografía en capa fina fue realizada utilizando placas de sílica gel 60 F254, revelando las mismas por exposición a luz UV, al yodo o bien mediante reveladores de Ce / Mo o de ácido fosfomolíbdico y posterior calefacción.

\section{Microondas}

Las reacciones bajo radiación de microondas se realizaron en un equipo CEM Focused Microwave System, Discover S-Class con sensor de IR. Los tiempos de reacción se refieren al tiempo que la reacción se mantiene a la temperatura de trabajo fijada. La potencia máxima aplicada fue $300 \mathrm{~W}$. 


\section{Técnicas instrumentales}

$>$ Espectroscopía de resonancia magnética nuclear (RMN)

Varian Inova 400, Varian Mercury Plus 300.

Los valores de los desplazamientos químicos $(\delta)$ se dan en partes por millón (ppm) y están referenciados al tetrametilsilano (TMS), empleando como referencia interna para el ${ }^{1} \mathrm{H}-\mathrm{RMN}$ la señal del residuo del disolvente no deuterado $\left(\mathrm{CHCl}_{3}: \delta=7.26\right.$; DMSO-d ${ }_{6}: \delta=2.54$ y $\left.\left(\mathrm{CD}_{3}\right)_{2} \mathrm{CO}: \delta=2.05\right)$ y para el ${ }^{13} \mathrm{C}-\mathrm{RMN}$ la señal del disolvente deuterado $\left(\mathrm{CHCl}_{3}: \delta=77.16\right.$; DMSO-d $\mathrm{d}_{6}: \delta=39.52 \mathrm{y}$ $\left.\left(\mathrm{CD}_{3}\right)_{2} \mathrm{CO}: \delta=29.84\right)$. Las constantes de acoplamiento $(J)$ se dan en Hertzios $(\mathrm{Hz})$ en ambos casos. Las abreviaturas empleadas para designar la multiplicidad en resonancia son: s (singulete), sa (singulete ancho), d (doblete), dd (doble doblete), dt (doble triplete), ddd (doble doblete de dobletes), $\mathrm{ddt}$ (doble doblete de tripletes), dtd (doble triplete de dobletes), $\mathrm{t}$ (triplete), $\mathrm{t}$ ap (triplete aparente), $\mathrm{td}$ (triple doblete), $\mathrm{tt}$ (triple triplete), $\mathrm{q}$ (cuadruplete), m (multiplete).

$>$ Espectrometría de masas (EM)

Se realizaron espectrometrías de masas tanto de baja resolución (EMBR) como de alta resolución (EMAR). Los experimentos EMBR se realizaron en un espectrómetro Agilent 6890N / 5973 y los de EMAR en un espectrómetro Micromass Autospec.

En todos los casos se utilizaron técnicas de fragmentación por impacto electrónico (EI) a 70 eV por inyección directa o por vía indirecta (cromatógrafo de gases). Se detallan el pico base, el ión molecular y alguna de las fragmentaciones más significativas.

$>$ Análisis Elemental (CHNS)

Analizador elemental LECO CHNS-932 con VT-900 y analizador elemental Perkin-Elmer.

$>$ Espectroscopía infrarroja (IR)

Llevados a cabo en un equipo Nicolet Impact 410 con un rango de 4000 a $400 \mathrm{~cm}^{-1}$, y software de apoyo Omnic 5.2. Se empleó una dispersión del compuesto en bromuro potásico. Solo se detallan las bandas características y éstas se dan $\mathrm{en}^{-1}$.

$>$ Puntos de fusión

Aparato Büchi-Tottoli, medidos en capilar y sin corregir.

> Difracción de rayos X en monocristal

Llevada a cabo en un equipo Bruker AXS con detector SMART APEX CCD. En la representación de las estructuras moleculares y cristalinas se ha seguido el siguiente código de colores:

Azufre................amarillo
Carbono..............gris
Halógeno............verde
Hidrógeno...........rosa
Nitrógeno...........azul
Oxígeno................ojo


1. Aproximaciones a la síntesis de 2,3-dihaloanilinas. Precursores de indoles 4-funcionalizados

\section{A Sintesis de 2,3-dihaloanilinas}

\section{A.1 orto-Metalación de derivados de 3-haloanilina}

\section{A.1.1 Preparación de las trifluoroacetamidas 1 y $3 \mathbf{b c}$}

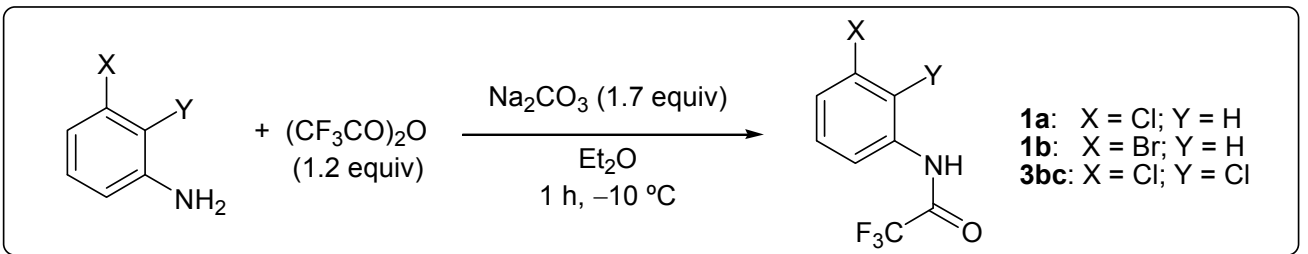

A una mezcla de la correspondiente 3-haloanilina ó de 2,3-dicloroanilina (40 mmol) y carbonato sódico $(7.21 \mathrm{~g}, 68 \mathrm{mmol})$ en $\mathrm{Et}_{2} \mathrm{O}(40 \mathrm{~mL})$ a $-10{ }^{\circ} \mathrm{C}$ se añade lentamente anhídrido trifluoroacético $(6.81 \mathrm{~mL}, 48 \mathrm{mmol})$ con ayuda de un embudo de adición. Después de 2 horas a -10 ${ }^{\circ} \mathrm{C}$ se añade hexano $(30 \mathrm{~mL})$ y la mezcla de reacción se filtra para eliminar el carbonato sódico. El filtrado se lava con agua helada, una disolución de hidrógeno carbonato sódico (10\%) y por último con una disolución de $\mathrm{NaCl}$ saturada. La fase etérea se seca sobre sulfato sódico anhidro y se elimina los disolventes mediante destilación a presión reducida $(20 \mathrm{~mm} \mathrm{Hg})$. El sólido obtenido se recristaliza en hexano.

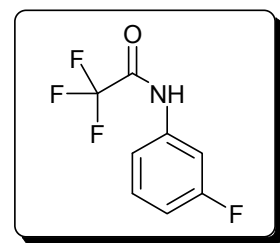

\section{2,2,2-Trifluoro- $N$-(3-fluorofenil)acetamida (1a)}

Sólido blanco.

P.f. $=67-69^{\circ} \mathrm{C}\left(\right.$ lit. $\left.^{38}=68-70{ }^{\circ} \mathrm{C}\right)$.

${ }^{1}$ H RMN $\left(300 \mathrm{MHz}, \mathrm{CDCl}_{3}\right): \delta=8.38(\mathrm{sa}, 1 \mathrm{H}), 7.48(\mathrm{dt}, J=10.2,2.1 \mathrm{~Hz}, 1 \mathrm{H}), 7.34(\mathrm{td}, J=8.2,2.1 \mathrm{~Hz}, 1 \mathrm{H})$, 7.26 (ddd, $J=8.2,2.1,1.1 \mathrm{~Hz}, 1 \mathrm{H}), 6.95$ (tdd, $J=8.2,2.5,1.1 \mathrm{~Hz}, 1 \mathrm{H})$.

${ }^{13}$ C RMN (75.4 MHz, $\left.\mathrm{CDCl}_{3}\right): \delta=162.9(\mathrm{~d}, J=246.6 \mathrm{~Hz}, \mathrm{C}), 155.3(\mathrm{q}, J=37.8 \mathrm{~Hz}, \mathrm{C}), 136.5(\mathrm{~d}, J=10.6 \mathrm{~Hz}$, C), $130.7(\mathrm{~d}, J=9.2 \mathrm{~Hz}, \mathrm{CH}), 116.2(\mathrm{~d}, J=3.2 \mathrm{~Hz}, \mathrm{CH}), 115.7(\mathrm{q}, J=288.4 \mathrm{~Hz}, \mathrm{C}), 113.5(\mathrm{~d}, J=21.2 \mathrm{~Hz}$, $\mathrm{CH}), 108.5(\mathrm{~d}, J=26.6 \mathrm{~Hz}, \mathrm{CH})$.

EMBR (IE), m/z (\%): $207\left(\mathrm{M}^{+}, 100\right), 138$ (45), 110 (36), 95 (32), 83 (18). 


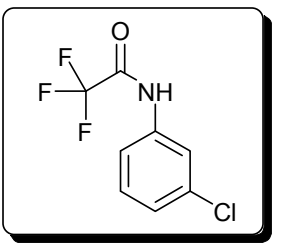

$N$-(3-Clorofenil)- 2,2,2-trifluoroacetamida (1b)

Sólido blanco.

P.f. $=68-70^{\circ} \mathrm{C}\left(\right.$ lit. $\left.^{249}=66-68^{\circ} \mathrm{C}\right)$.

${ }^{1} \mathbf{H}$ RMN $\left(300 \mathrm{MHz}, \mathrm{CDCl}_{3}\right): \delta=8.24(\mathrm{sa}, 1 \mathrm{H}), 7.66(\mathrm{t}, J=2.0 \mathrm{~Hz}, 1 \mathrm{H}), 7.42(\mathrm{ddd}, J=8.0,2.0,1.1 \mathrm{~Hz}, 1 \mathrm{H})$, $7.31(\mathrm{t}, J=8.0 \mathrm{~Hz}, 1 \mathrm{H}), 7.22(\mathrm{ddd}, J=8.0,2.0,1.1 \mathrm{~Hz}, 1 \mathrm{H})$.

${ }^{13} \mathbf{C}$ RMN (75.4 MHz, $\left.\mathrm{CDCl}_{3}\right): \delta=155.3(\mathrm{q}, J=37.8 \mathrm{~Hz}, \mathrm{C}), 136.2(\mathrm{C}), 135.2(\mathrm{C}), 130.5(\mathrm{CH}), 126.7(\mathrm{CH})$, $121.0(\mathrm{CH}), 118.8(\mathrm{CH}), 115.7(\mathrm{q}, J=288.5 \mathrm{~Hz}, \mathrm{C})$.

EMBR (IE), m/z (\%): $225\left(\mathrm{M}^{+}+2,33\right), 223\left(\mathrm{M}^{+}, 100\right), 154$ (51), 126 (19).

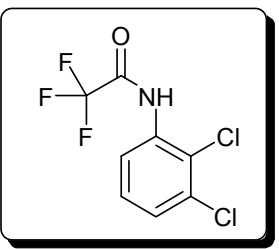

$N$-(2,3-Diclorofenil)- 2,2,2-trifluoroacetamida (3bc)

Sólido blanco.

P.f. $=54-56^{\circ} \mathrm{C}$.

${ }^{1} \mathbf{H}$ RMN (300 MHz, $\left.\mathrm{CDCl}_{3}\right): \delta=8.49(\mathrm{sa}, 1 \mathrm{H}), 8.27(\mathrm{dd}, J=8.0,1.4 \mathrm{~Hz}, 1 \mathrm{H}), 7.41-7.22(\mathrm{~m}, 2 \mathrm{H}) \mathrm{ppm}$.

${ }^{13} \mathbf{C}$ RMN (75.4 MHz, $\left.\mathrm{CDCl}_{3}\right): \delta=154.9(\mathrm{~d}, J=38.0 \mathrm{~Hz}, \mathrm{C}), 133.7(\mathrm{C}), 133.5(\mathrm{C}), 128.3(\mathrm{CH}), 127.6(\mathrm{CH})$, $122.6(\mathrm{C}), 119.9(\mathrm{CH}), 115.6(\mathrm{q}, J=288.7 \mathrm{~Hz}, \mathrm{C}) \mathrm{ppm}$.

EMBR (IE), m/z (\%): $259\left(\mathrm{M}^{+}+2,15\right), 257\left(\mathrm{M}^{+}, 23\right), 224$ (32), 222 (100), 160 (18), 69 (14).

\section{A.1.2 Procedimiento para la sintesis de las N-(3-fluoro-2-halofenil)-2,2,2-trifluoroacetamidas 3aa-ac}

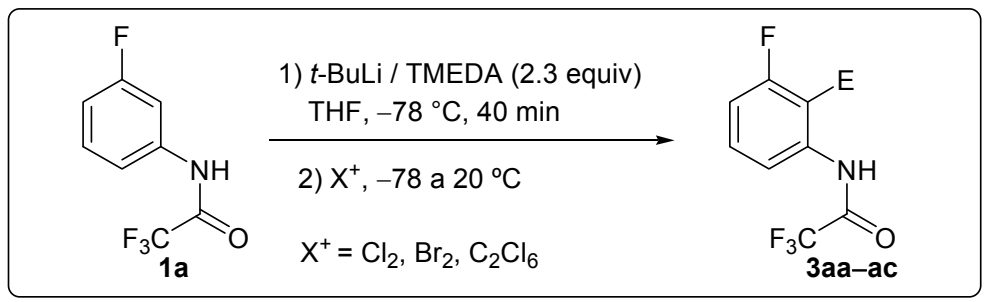

A una disolución de $N, N, N^{\prime}, N^{\prime}$-tetrametiletilendiamina (TMEDA) (2.3 equiv) en THF anhidro (3.5 $\mathrm{mL} / \mathrm{mmol}$ ) a $-80{ }^{\circ} \mathrm{C}$ se añade lentamente $t$-BuLi (2.3 equiv de una disolución $1.5 \mathrm{M}$ en hexano). Después de 5 minutos se adiciona gota a gota una disolución de 1a (1 equiv) en THF ( $1 \mathrm{~mL} / \mathrm{mmol})$ evitando que la temperatura exceda de $-70^{\circ} \mathrm{C}$. Después de 40 minutos a $-80{ }^{\circ} \mathrm{C}$, se adiciona lentamente una disolución de yodo, bromo o hexacloroetano (1.4 equiv) en THF ( $1 \mathrm{~mL} / \mathrm{mmol})$. La disolución resultante se agita durante 40 minutos a $-80^{\circ} \mathrm{C}$. A continuación, la mezcla de reacción se deja que alcance temperatura ambiente y se hidroliza con $\mathrm{H}_{2} \mathrm{O}$ (una disolución acuosa de $\mathrm{Na}_{2} \mathrm{~S}_{2} \mathrm{O}_{3}$ en el caso de usar yodo como electrofilo). La fase acuosa se extrae con $\mathrm{Et}_{2} \mathrm{O}$, y la combinación de las fases orgánicas se lava con $\mathrm{HCl}(1 \mathrm{M})$, se seca sobre $\mathrm{Na}_{2} \mathrm{SO}_{4}$ anhidro y se evapora a presión reducida. El crudo de reacción se purifica mediante cromatografía de columna (hexano / AcOEt, 8 / 1), obteniéndose los compuestos 3aa-ac.

${ }^{249}$ C. E. Stauffer, J. Am. Chem. Soc. 1972, 94, 7887. 


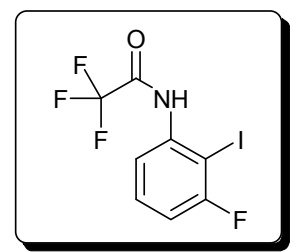

2,2,2-Trifluoro- $N$-(3-fluoro-2-yodofenil)acetamida (3aa)

Sólido rojo.

P.f. $=104-106^{\circ} \mathrm{C}$.

Reactivos: 1a (2.48 g, $12 \mathrm{mmol})$, yodo (4.26 g, $16.8 \mathrm{mmol})$.

${ }^{1}$ H RMN $\left(300 \mathrm{MHz}, \mathrm{CDCl}_{3}\right): \delta=8.39(\mathrm{sa}, 1 \mathrm{H}), 8.05(\mathrm{~d}, J=8.3 \mathrm{~Hz}, 1 \mathrm{H}), 7.40(\mathrm{td}, J=8.3,2.1 \mathrm{~Hz}, 1 \mathrm{H})$, 7.01-6.94 (m, 1H) ppm.

${ }^{13} \mathbf{C}$ RMN (75.4 MHz, $\left.\mathrm{CDCl}_{3}\right): \delta=161.9(\mathrm{~d}, J=245.6 \mathrm{~Hz}, \mathrm{C}), 155.0(\mathrm{q}, J=37.7 \mathrm{~Hz}, \mathrm{C}), 137.4(\mathrm{~d}, J=3.6 \mathrm{~Hz}$, C), $130.9(\mathrm{~d}, J=8.9 \mathrm{~Hz}, \mathrm{CH}), 117.5(\mathrm{~d}, J=3.1 \mathrm{~Hz}, \mathrm{CH}), 115.7(\mathrm{q}, J=288.5 \mathrm{~Hz}, \mathrm{C}), 113.3(\mathrm{~d}, J=23.8 \mathrm{~Hz}$ $\mathrm{CH}), 79.0(\mathrm{~d}, J=28.8 \mathrm{~Hz}, \mathrm{C}) \mathrm{ppm}$.

IR $\left(\mathrm{KBr}, \mathrm{cm}^{-1}\right): 3218,3061,1717(\mathrm{C}=\mathrm{O}), 1580,1548,1463,1207,1165,788,733$.

EMBR (IE), m/z (\%): $333\left(\mathrm{M}^{+}, 53\right), 206$ (100), 186 (26), 137 (13), 109 (22).

EMAR calculado para $\mathrm{C}_{8} \mathrm{H}_{4} \mathrm{~F}_{4} \mathrm{INO}$ : 332.9274 ; encontrado: 332.9283 .

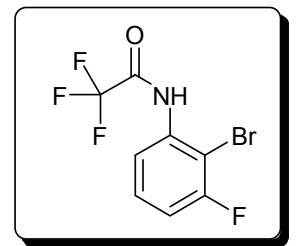

$\mathrm{N}$-(2-Bromo-3-fluorofenil)-2,2,2-trifluoroacetamida (3ab)

Sólido blanco.

P.f. $=55-57^{\circ} \mathrm{C}\left(\right.$ lit. $\left.^{38}=55-56^{\circ} \mathrm{C}\right)$.

Reactivos: 1a (414 mg, $2 \mathrm{mmol})$, bromo (447 mg, $2.8 \mathrm{mmol})$.

${ }^{1} \mathbf{H}$ RMN $\left(300 \mathrm{MHz}, \mathrm{CDCl}_{3}\right): \delta=8.48(\mathrm{sa}, 1 \mathrm{H}), 8.14(\mathrm{dt}, J=8.4,1.3 \mathrm{~Hz}, 1 \mathrm{H}), 7.38(\mathrm{td}, J=8.4,6.0 \mathrm{~Hz}, 1 \mathrm{H})$, $7.04(\operatorname{td}, J=8.4,1.3 \mathrm{~Hz}, 1 \mathrm{H}) \mathrm{ppm}$.

${ }^{13}$ C RMN (75.4 MHz, $\left.\mathrm{CDCl}_{3}\right): \delta=159.3(\mathrm{~d}, J=247.9 \mathrm{~Hz}, \mathrm{C}), 154.9(\mathrm{q}, J=37.9 \mathrm{~Hz}, \mathrm{C}), 134.8(\mathrm{C}), 129.6(\mathrm{~d}, J=$ $8.7 \mathrm{~Hz}, \mathrm{CH}), 117.3(\mathrm{~d}, J=3.3 \mathrm{~Hz}, \mathrm{CH}), 115.6(\mathrm{q}, J=288.9 \mathrm{~Hz}, \mathrm{C}), 113.8(\mathrm{~d}, J=22.0 \mathrm{~Hz}, \mathrm{CH}), 102.0(\mathrm{~d}, J$ $=24.1 \mathrm{~Hz}, \mathrm{C}) \mathrm{ppm}$.

EMBR (IE), m/z (\%): $287\left(\mathrm{M}^{+}+2,21\right), 285\left(\mathrm{M}^{+}, 21\right), 206$ (100), 186 (20), 109 (22).

EMAR calculado para $\mathrm{C}_{8} \mathrm{H}_{4} \mathrm{BrF}_{4} \mathrm{NO}$ : 284.9412; encontrado: 284.9414.

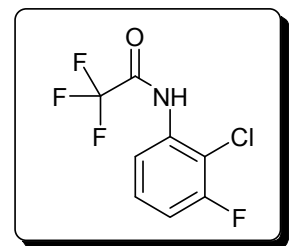

$\mathrm{N}$-(2-Cloro-3-fluorofenil)-2,2,2-trifluoroacetamida (3ac)

Sólido marrón.

P.f. $=38-40^{\circ} \mathrm{C}$.

Reactivos: 1a (1.03 g, $5 \mathrm{mmol})$, hexacloroetano (1.66 g, $7 \mathrm{mmol})$.

${ }^{1} \mathbf{H}$ RMN (300 MHz, CDCl $): \delta=8.07(\mathrm{~d}, J=8.4 \mathrm{~Hz}, 1 \mathrm{H}), 7.97(\mathrm{sa}, 1 \mathrm{H}), 7.30(\mathrm{td}, J=8.4,5.9 \mathrm{~Hz}, 1 \mathrm{H}), 7.04(\mathrm{td}$, $J=8.4,1.3 \mathrm{~Hz}, 1 \mathrm{H}) \mathrm{ppm}$.

${ }^{13} \mathbf{C}$ RMN (75.4 MHz, $\left.\mathrm{CDCl}_{3}\right): \delta=158.3(\mathrm{~d}, J=249.4 \mathrm{~Hz}, \mathrm{C}), 154.9(\mathrm{q}, J=37.9 \mathrm{~Hz}, \mathrm{C}), 133.7(\mathrm{C}), 128.5(\mathrm{~d}, J=$ $8.6 \mathrm{~Hz}, \mathrm{CH}), 117.5(\mathrm{C}), 117.4(\mathrm{~d}, J=3.5 \mathrm{~Hz}, \mathrm{CH}), 113.8(\mathrm{~d}, J=20.7 \mathrm{~Hz}, \mathrm{CH}), 112.0(\mathrm{~d}, J=20.6 \mathrm{~Hz}, \mathrm{C})$ ppm.

EMBR (IE), m/z (\%): $243\left(\mathrm{M}^{+}+2,11\right), 241$ (M+3), 206 (100), 144 (27), 117 (18), 69 (13). 


\section{A.1.3 Sintesis de 2-(trifluorometil)-7-yodobenzo[d]oxazol 4}

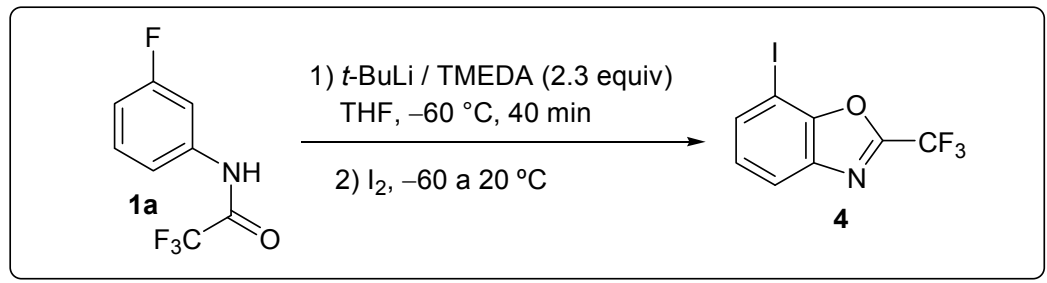

A una disolución de TMEDA $(3.8 \mathrm{~mL}, 25.3 \mathrm{mmol})$ en THF anhidro $(40 \mathrm{~mL}) \mathrm{a}-78{ }^{\circ} \mathrm{C}$ se añade lentamente $t$-BuLi (16.8 $\mathrm{mL}$ de una disolución $1.5 \mathrm{M}$ en hexano, $25.3 \mathrm{mmol})$. Después de 5 minutos, se añade gota a gota una disolución de $1 \mathbf{a}(2.27 \mathrm{~g}, 11 \mathrm{mmol})$ en THF $(10 \mathrm{~mL})$. Después de 40 minutos a $-60{ }^{\circ} \mathrm{C}$, se adiciona lentamente una disolución de yodo (3.91 g, $\left.15.4 \mathrm{mmol}\right)$ en THF (10 $\mathrm{mL})$. La mezcla resultante se agita durante 40 minutos a $-60{ }^{\circ} \mathrm{C}$. A continuación la mezcla de reacción se deja que alcance temperatura ambiente y se hidroliza con una disolución acuosa de $\mathrm{Na}_{2} \mathrm{~S}_{2} \mathrm{O}_{3}$. La fase acuosa se extrae con $\mathrm{Et}_{2} \mathrm{O}$ y la combinación de las fases orgánicas se lava con $\mathrm{HCl}$ $(1 \mathrm{M})$, se seca sobre $\mathrm{Na}_{2} \mathrm{SO}_{4}$ anhidro y se evapora a presión reducida. El crudo de reacción se purifica mediante cromatografía de columna (hexano / AcOEt, 12 / 1), obteniéndose el benzoxazol 4.

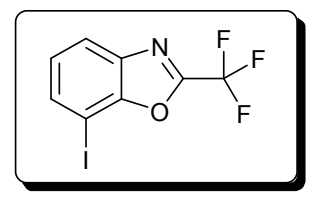

2-(Trifluorometil)-7-yodobenzo[d]oxazol 4

Sólido rojo.

P.f. $=64-66^{\circ} \mathrm{C}$.

${ }^{1} \mathbf{H}$ RMN (300 MHz, $\left.\mathrm{CDCl}_{3}\right): \delta=7.77(\mathrm{t}, J=7.6 \mathrm{~Hz}, 2 \mathrm{H}), 7.17(\mathrm{t}, J=8.0 \mathrm{~Hz}, 1 \mathrm{H}) \mathrm{ppm}$.

${ }^{13} \mathbf{C}$ RMN (75.4 MHz, $\left.\mathrm{CDCl}_{3}\right): \delta=152.3(\mathrm{C}), 151.1(\mathrm{q}, J=44.4 \mathrm{~Hz}, \mathrm{C}), 138.7(\mathrm{C}), 136.9(\mathrm{CH}), 127.5(\mathrm{CH})$, $121.7(\mathrm{CH}), 116.6(\mathrm{q}, J=272.1 \mathrm{~Hz}, \mathrm{C}), 72.9(\mathrm{C}) \mathrm{ppm}$.

EMBR (IE), m/z (\%): $313\left(\mathrm{M}^{+}, 44\right), 294$ (6), 186 (6), 127 (50), 69 (100).

EMAR calculado para for $\mathrm{C}_{8} \mathrm{H}_{3} \mathrm{~F}_{3} \mathrm{INO}: 312.9211$; encontrado: 312.9211 .

\section{A.1.4 Procedimiento general para la sintesis de las 3-fluoro-2-haloanilinas 6aa y $6 \mathbf{a b}$}

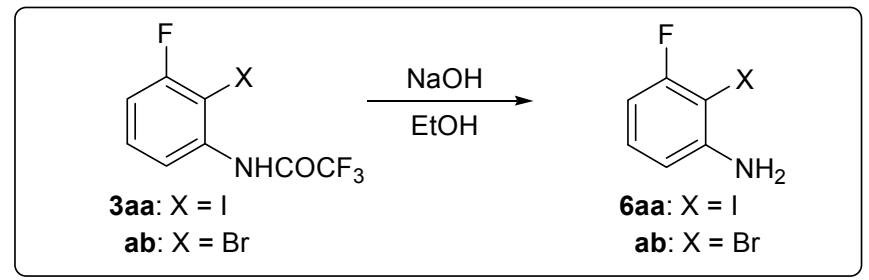

A una disolución de la correspondiente $N$-(3-fluoro-2-halofenil)-2,2,2,-trifluoroacetamida 3aa ó 3ab (2 mmol) en EtOH $(20 \mathrm{~mL})$ se añade un exceso de $\mathrm{NaOH}(800 \mathrm{mg}, 20 \mathrm{mmol})$ y la mezcla se calienta a reflujo durante 2 horas (la hidrólisis se monitoriza por CG-EM). Posteriormente, se deja enfriar la mezcla de reacción a temperatura ambiente y se elimina el EtOH a presión reducida $(20 \mathrm{~mm}$ $\mathrm{Hg})$. El residuo se diluye en AcOEt y $\mathrm{H}_{2} \mathrm{O}$. Se extrae la fase acuosa con AcOEt $(3 \times 20 \mathrm{~mL})$. Las fases orgánicas combinadas se secan sobre $\mathrm{Na}_{2} \mathrm{SO}_{4}$ anhidro y el disolvente se elimina a presión reducida (20 
$\mathrm{mm} \mathrm{Hg}$. El residuo resultante se purifica mediante cromatografía de columna (hexano / AcOEt) obteniéndose las anilinas $\mathbf{6 a a}, \mathbf{6} \mathbf{a b}$.

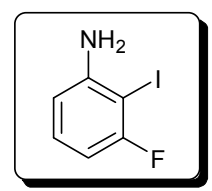

\section{3-Fluoro-2-yodoanilina (6aa)}

Sólido blanco.

P. f. $=52-54^{\circ} \mathrm{C}$.

${ }^{1} \mathbf{H}$ RMN $\left(300 \mathrm{MHz}, \mathrm{CDCl}_{3}\right): \delta=7.07(\mathrm{td}, J=8.1,1.6 \mathrm{~Hz}, 1 \mathrm{H}), 6.53-6.48(\mathrm{~m}, 1 \mathrm{H}), 6.45(\mathrm{td}, J=8.1,1.3 \mathrm{~Hz}$, $1 \mathrm{H}), 4.29$ (sa, 2H) ppm.

${ }^{13}$ C RMN (75.4 MHz, $\left.\mathrm{CDCl}_{3}\right): \delta=162.2(\mathrm{~d}, J=242.2 \mathrm{~Hz}, \mathrm{C}), 148.8(\mathrm{~d}, J=4.6 \mathrm{~Hz}, \mathrm{C}), 130.0(\mathrm{~d}, J=10.0 \mathrm{~Hz}$, $\mathrm{CH}), 109.9(\mathrm{~d}, J=2.4 \mathrm{~Hz}, \mathrm{CH}), 104.6(\mathrm{~d}, J=24.4 \mathrm{~Hz}, \mathrm{CH}), 71.8(\mathrm{~d}, J=28.2 \mathrm{~Hz}, \mathrm{C}) \mathrm{ppm}$.

IR $\left(\mathrm{KBr}, \mathrm{cm}^{-1}\right): 3399,3299,3184,1616,1553,1456,1242,1020,771$.

EMBR (IE), m/z (\%): 237 (M+100), 110 (12), 83 (12).

EMAR calculado para $\mathrm{C}_{6} \mathrm{H}_{5}$ FIN: 236.9451; encontrado: 236.9455.

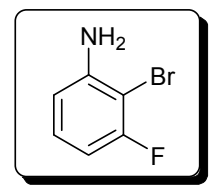

\section{2-Bromo-3-fluoroanilina (6ab)}

Sólido blanco.

P.f. $=32-34{ }^{\circ} \mathrm{C}$.

${ }^{1} \mathbf{H}$ RMN (300 MHz, $\mathrm{CDCl}_{3}$ ): $\delta=7.04$ (tdd, $\left.J=8.1,6.1,0.7 \mathrm{~Hz}, 1 \mathrm{H}\right), 6.55-6.47$ (m, 2H), 4.23 (sa, 2H) ppm.

${ }^{13} \mathbf{C}$ RMN (75.4 MHz, $\left.\mathrm{CDCl}_{3}\right): \delta=159.9(\mathrm{~d}, J=244.2 \mathrm{~Hz}, \mathrm{C}), 146.1(\mathrm{~d}, J=3.1 \mathrm{~Hz}, \mathrm{C}), 128.6(\mathrm{~d}, J=9.8 \mathrm{~Hz}$, $\mathrm{CH}), 110.8(\mathrm{~d}, J=2.7 \mathrm{~Hz}, \mathrm{CH}), 105.3(\mathrm{~d}, J=22.6 \mathrm{~Hz}, \mathrm{CH}), 96.4$ (d, $J=23.6 \mathrm{~Hz}, \mathrm{C}) \mathrm{ppm}$.

IR $\left(\mathrm{KBr}, \mathrm{cm}^{-1}\right): 3443,3317,1625,1464,763,582$.

EMBR (IE), m/z (\%): $191\left(\mathrm{M}^{+}+2,88\right), 189\left(\mathrm{M}^{+}, 100\right), 110$ (22), 90 (14), 83 (28).

EMAR calculado para $\mathrm{C}_{6} \mathrm{H}_{5} \mathrm{BrFN}$ : 188.9589; encontrado: 188.9592 .

\section{A.1.5 Procedimiento de preparación de la $\mathrm{N}$-(3-clorofenil)pivalamida 7}

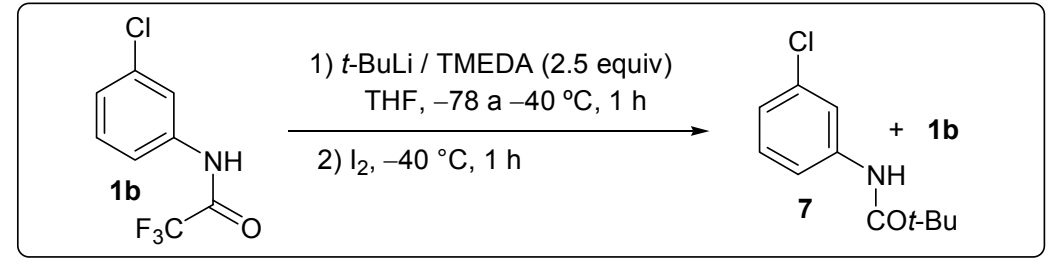

A una disolución de TMEDA $(0.38 \mathrm{~mL}, 2.52 \mathrm{mmol})$ en THF anhidro $(3 \mathrm{~mL}) \mathrm{a}-80^{\circ} \mathrm{C}$, se añade lentamente $t$-BuLi (1.6 mL de una disolución 1.6 M en pentano, $2.5 \mathrm{mmol})$. Después de 5 minutos se adiciona gota a gota una disolución de $\mathbf{1 b}(223 \mathrm{mg}, 1 \mathrm{mmol})$ en THF $(2 \mathrm{~mL})$ a esta temperatura. La mezcla de reacción se deja que alcance $-40^{\circ} \mathrm{C}$. Después de 1 hora a $-40^{\circ} \mathrm{C}$, se añade yodo $(355 \mathrm{mg}, 1.4 \mathrm{mmol})$. La disolución resultante se agita durante 1 hora a $-40{ }^{\circ} \mathrm{C}$. A continuación, se deja que la mezcla alcance temperatura ambiente y se hidroliza con una disolución acuosa de $\mathrm{Na}_{2} \mathrm{~S}_{2} \mathrm{O}_{3}$. La fase acuosa se extrae con $\mathrm{Et}_{2} \mathrm{O}(3 \times 30 \mathrm{~mL})$ y la combinación de fases orgánicas se lava con $\mathrm{HCl}(1 \mathrm{M})$, se seca sobre $\mathrm{Na}_{2} \mathrm{SO}_{4}$ anhidro y se eliminan los disolventes por destilación a presión reducida $(20 \mathrm{~mm} \mathrm{Hg})$. Se obtiene una 
mezcla 1 / 1 de 7 y 1b, comprobado por análisis de ${ }^{1} \mathrm{H}-\mathrm{RMN}$ y CG-EM. La purificación mediante cromatografía de columna (hexano / AcOEt, 10 / 1) permite aislar 7.

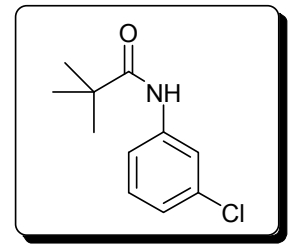

$N$-(3-Clorofenil)pivalamida (7)

Sólido blanco.

P.f. $=124-126^{\circ} \mathrm{C}\left(\right.$ lit. $\left.^{250}=124-126^{\circ} \mathrm{C}\right)$.

${ }^{1} \mathbf{H}$ RMN (300 MHz, CDCl $)$ ): $\delta=7.67(\mathrm{t}, J=2.0 \mathrm{~Hz}, 1 \mathrm{H}), 7.43(\mathrm{sa}, 1 \mathrm{H}), 7.37-7.32(\mathrm{~m}, 1 \mathrm{H}), 7.21(\mathrm{t}, J=8.0 \mathrm{~Hz}$, $1 \mathrm{H}), 7.08-7.03(\mathrm{~m}, 1 \mathrm{H}), 1.30(\mathrm{~s}, 9 \mathrm{H}) \mathrm{ppm}$.

${ }^{13}$ C RMN (75.4 MHz, $\left.\mathrm{CDCl}_{3}\right): \delta=176.9(\mathrm{C}), 139.2(\mathrm{C}), 134.6(\mathrm{C}), 130.0(\mathrm{CH}), 124.3(\mathrm{CH}), 120.3(\mathrm{CH}), 118.1$ $(\mathrm{CH}), 39.8(\mathrm{C}), 27.6\left(3 \times \mathrm{CH}_{3}\right) \mathrm{ppm}$.

EMBR (IE), m/z (\%): $213\left(\mathrm{M}^{+}+2,11\right), 211\left(\mathrm{M}^{+}, 34\right), 168$ (5), 127 (49), 57 (100).

EMAR calculado para $\mathrm{C}_{11} \mathrm{H}_{14} \mathrm{ClNO}$ : 211.0764; encontrado: 211.0764 .

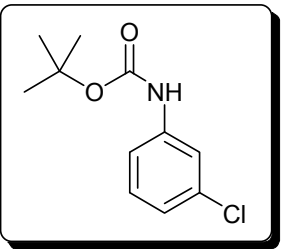

$N$-(t-Butoxicarbonil)-3-cloroanilina (8a)

Preparada de acuerdo al procedimiento publicado. ${ }^{33 a}$

Sólido blanco.

P.f. $=67-69^{\circ} \mathrm{C}\left(\right.$ lit. $\left.^{251}=69-70^{\circ} \mathrm{C}\right)$.

${ }^{1} \mathbf{H}$ RMN (300 MHz, CDCl 3$): \delta=7.51(\mathrm{sa}, 1 \mathrm{H}), 7.19-7.12(\mathrm{~m}, 2 \mathrm{H}), 6.98(\mathrm{dt}, J=7.2,1.7 \mathrm{~Hz}, 1 \mathrm{H}), 6.58(\mathrm{sa}, 1 \mathrm{H})$, $1.50(\mathrm{~s}, 9 \mathrm{H}) \mathrm{ppm}$.

${ }^{13}$ C RMN (75.4 MHz, $\left.\mathrm{CDCl}_{3}\right): \delta=152.6(\mathrm{C}), 139.7(\mathrm{C}), 134.8(\mathrm{C}), 130.0(\mathrm{CH}), 123.1(\mathrm{CH}), 118.6(\mathrm{CH}), 116.5$ $(\mathrm{CH}), 81.1(\mathrm{C}), 28.4\left(3 \times \mathrm{CH}_{3}\right) \mathrm{ppm}$.

EMBR (IE), m/z (\%): 227 (M+ , 3), 171 (16), 153 (26), 129 (33), 127 (100).

\section{A.1.6 Sintesis de la $\mathrm{N}$-(t-butoxicarbonil)anilina 9}

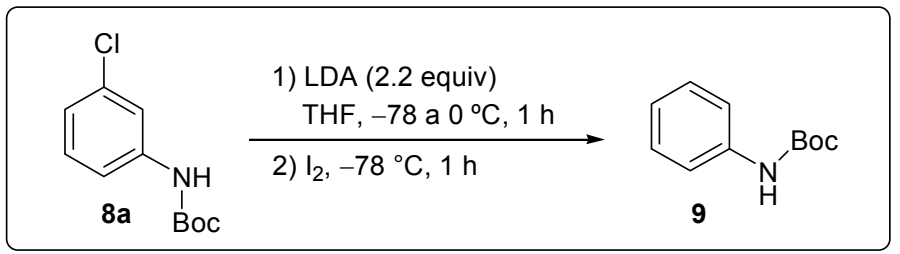

A una disolución de $i$ - $\mathrm{Pr}_{2} \mathrm{NH}(154 \mu \mathrm{L}, 1.1 \mathrm{mmol})$ en THF $(4 \mathrm{~mL})$ a $0{ }^{\circ} \mathrm{C}$ se adiciona $n$-BuLi $(0.7 \mathrm{~mL}$ de una disolución $1.6 \mathrm{M}$ en hexano, $1.1 \mathrm{mmol})$. Después de 30 minutos a $0{ }^{\circ} \mathrm{C}$, la disolución de LDA se enfría a $-78{ }^{\circ} \mathrm{C}$ y se añade $8 \mathbf{a}(114 \mathrm{mg}, 0.5 \mathrm{mmol})$. La mezcla resultante se agita durante 30 minutos a $0{ }^{\circ} \mathrm{C}$, y a continuación se adiciona yodo $(178 \mathrm{mg}, 0.7 \mathrm{mmol})$ a $-78{ }^{\circ} \mathrm{C}$. Después de 1 hora a $0{ }^{\circ} \mathrm{C}$, se deja que la mezcla de reacción alcance temperatura ambiente y se hidroliza con una disolución acuosa de $\mathrm{Na}_{2} \mathrm{~S}_{2} \mathrm{O}_{3}$. La fase acuosa se extrae con AcOEt $(3 \times 30 \mathrm{~mL})$, y la combinación de fases orgánicas se seca sobre $\mathrm{Na}_{2} \mathrm{SO}_{4}$ anhidro y el disolvente se evapora a presión reducida. El crudo

${ }^{250}$ R. J. Phipps, M. J. Gaunt, Science 2009, 323, 1593.

${ }^{251}$ S. V. Chankeshwara, A. K. Chakraborti, Tetrahedron Lett. 2006, 47, 1087. 
se purifica mediante columna de cromatografía (hexano / AcOEt, 12 / 1) en sílica gel permitiendo obtener 9.

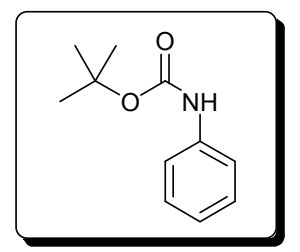

$N$-(t-Butoxicarbonil)anilina (9)

Sólido blanco.

P.f. $=135-137^{\circ} \mathrm{C}\left(\right.$ lit. $\left.^{33 \mathrm{a}}=136-137^{\circ} \mathrm{C}\right)$.

${ }^{1}$ H RMN $\left(300 \mathrm{MHz}, \mathrm{CDCl}_{3}\right): \delta=7.36(\mathrm{~d}, J=8.0 \mathrm{~Hz}, 2 \mathrm{H}), 7.31-7.25(\mathrm{~m}, 2 \mathrm{H}), 7.06-6.99(\mathrm{~m}, 1 \mathrm{H}), 6.56(\mathrm{sa}, 1 \mathrm{H})$, $1.52(\mathrm{~s}, 9 \mathrm{H}) \mathrm{ppm}$.

${ }^{13}$ C RMN (75.4 MHz, $\left.\mathrm{CDCl}_{3}\right): \delta=152.9(\mathrm{C}), 138.4(\mathrm{C}), 129.1(2 \times \mathrm{CH}), 123.1(2 \times \mathrm{CH}), 118.6(\mathrm{CH}), 80.6(\mathrm{C})$, $28.5\left(3 \times \mathrm{CH}_{3}\right) \mathrm{ppm}$.

EMBR (IE), m/z (\%): $193\left(\mathrm{M}^{+}, 5\right), 137$ (26), 119 (20), 93 (100).

\section{A.1.7 Sintesis de 2-t-butil-2-t-butoxi-7-yodobenzo[d]oxazol 10 y 2-t-butil-7-yodobenzo[d]oxazol 11}

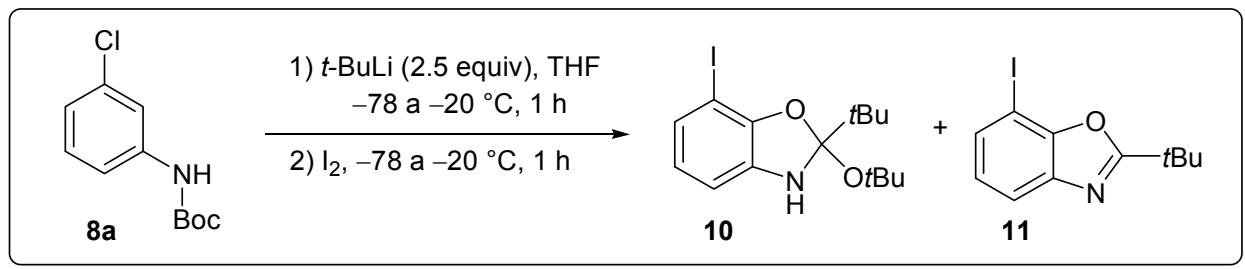

A una disolución de $8 \mathbf{a}(227 \mathrm{mg}, 1 \mathrm{mmol})$ en THF $(5 \mathrm{~mL})$ a $-78{ }^{\circ} \mathrm{C}$ se adiciona $t$-BuLi $(1.6$ $\mathrm{mL}$ de una disolución $1.6 \mathrm{M}$ en pentano, $2.5 \mathrm{mmol})$. La mezcla de reacción se deja que alcance -20 ${ }^{\circ} \mathrm{C}$ durante 1 hora. A continuación, se añade yodo $(355 \mathrm{mg}, 1.4 \mathrm{mmol}) \mathrm{a}-78{ }^{\circ} \mathrm{C}$ y la reacción se agita a $-20{ }^{\circ} \mathrm{C}$ durante 1 hora. Después de este tiempo, la mezcla de reacción se deja que alcance temperatura ambiente y se hidroliza con una disolución acuosa de $\mathrm{Na}_{2} \mathrm{~S}_{2} \mathrm{O}_{3}$. La fase acuosa se extrae con AcOEt $(3 \times 30 \mathrm{~mL})$ y la combinación de las fases orgánicas se seca sobre $\mathrm{Na}_{2} \mathrm{SO}_{4}$ anhidro. Se evaporan los disolventes a presión reducida y el crudo se purifica mediante columna de cromatografía (hexano / AcOEt, 12 / 1) obteniéndose una mezcla en proporciones $1 / 2$ de 10 (67 mg, 18\%) y 11 (114 mg, 38\%).

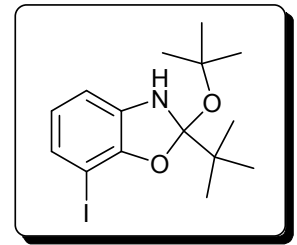

2-t-Butil-2-t-butoxi-7-yodobenzo[d]oxazol (10)

Sólido blanco.

P.f. $=134-136^{\circ} \mathrm{C}$.

${ }^{1} \mathbf{H}$ RMN $\left(300 \mathrm{MHz}, \mathrm{CDCl}_{3}\right): \delta=7.95(\mathrm{~d}, J=7.8 \mathrm{~Hz}, 1 \mathrm{H}), 7.22(\mathrm{~d}, J=7.8 \mathrm{~Hz}, 1 \mathrm{H}), 6.73(\mathrm{t}, J=7.8 \mathrm{~Hz}, 1 \mathrm{H})$, $6.30(\mathrm{sa}, 1 \mathrm{H}), 1.65(\mathrm{~s}, 9 \mathrm{H}), 1.48(\mathrm{~s}, 9 \mathrm{H}) \mathrm{ppm}$.

${ }^{13}$ C RMN (75.4 MHz, $\left.\mathrm{CDCl}_{3}\right): \delta=154.1(\mathrm{C}), 143.4(\mathrm{CH}), 136.1(\mathrm{C}), 131.1(\mathrm{C}), 127.6(2 \times \mathrm{CH}), 95.9(\mathrm{C}), 80.4$ (C), $38.2(\mathrm{C}), 32.4\left(3 \times \mathrm{CH}_{3}\right), 28.5\left(3 \times \mathrm{CH}_{3}\right) \mathrm{ppm}$.

EMBR (IE), m/z (\%): 375 (M+ , 6), 319 (99), 275 (77), 260 (99), 232 (25), 127 (67), 57 (100). 


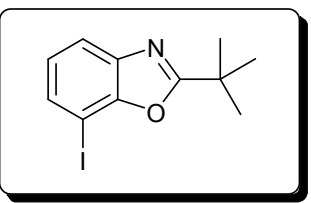

2-t-Butil-7-yodobenzo[d]oxazol (11)

Líquido incoloro.

$\mathrm{R}_{\mathrm{f}}=0.48$ (hexano / AcOEt, 7 / 1).

${ }^{1} \mathbf{H}$ RMN $\left(300 \mathrm{MHz}, \mathrm{CDCl}_{3}\right): \delta=7.61(\mathrm{dd}, J=7.9,0.9 \mathrm{~Hz}, 1 \mathrm{H}), 7.59(\mathrm{dd}, J=7.9,0.9 \mathrm{~Hz}, 1 \mathrm{H}), 7.03(\mathrm{t}, J=7.9$ $\mathrm{Hz}, 1 \mathrm{H}), 1.49(\mathrm{~s}, 9 \mathrm{H}) \mathrm{ppm}$.

${ }^{13} \mathbf{C}$ RMN (75.4 MHz, $\left.\mathrm{CDCl}_{3}\right): \delta=173.2(\mathrm{C}), 152.5(\mathrm{C}), 140.5(\mathrm{C}), 133.4(\mathrm{CH}), 125.8(\mathrm{CH}), 119.7(\mathrm{CH}), 72.3$ (C), $34.4(\mathrm{C}), 28.5\left(3 \times \mathrm{CH}_{3}\right) \mathrm{ppm}$.

EMBR (IE), m/z (\%): 301 (M+, 90), 286 (100), 259 (35), 245 (39), 127 (17).

\section{A.2 Reacción de metalación en 3-halonitrobencenos}

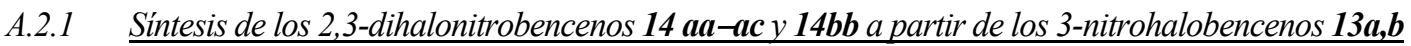

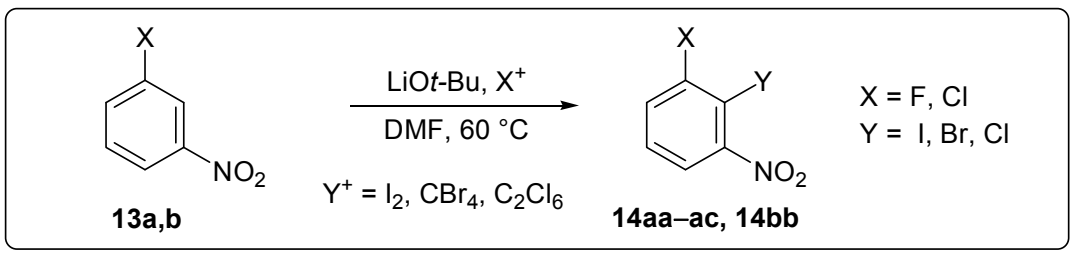

A una disolución del correspondiente 3-halonitrobenceno (1 equiv), el reactivo halogenante (1.5-2.0 equiv) y DMF anhidra ( $1 \mathrm{~mL} / \mathrm{mmol})$ se añade $\mathrm{LiO} t$-Bu $(2.5$ equiv) y la mezcla se calienta a $60{ }^{\circ} \mathrm{C}$ durante $4-17$ horas. La mezcla de reacción se deja enfriar a temperatura ambiente y se purifica mediante columna de cromatografía (hexano / AcOEt, 10 / 1) para dar los compuestos 14.

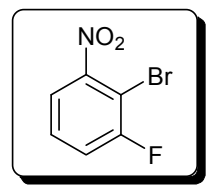

\section{2-Bromo-1-fluoro-3-nitrobenceno (14ab)}

Sólido amarillo.

P.f. $=43-45^{\circ} \mathrm{C}\left(\right.$ lit. $\left.^{141}=42-44^{\circ} \mathrm{C}\right)$.

${ }^{1} \mathbf{H}$ RMN $\left(300 \mathrm{MHz}, \mathrm{CDCl}_{3}\right): \delta=7.63(\mathrm{dt}, J=8.1,1.4 \mathrm{~Hz}, 1 \mathrm{H}), 7.47(\mathrm{td}, J=8.1,5.2 \mathrm{~Hz}, 1 \mathrm{H}), 7.36(\mathrm{td}, J=8.1$, $1.4 \mathrm{~Hz}, 1 \mathrm{H}) \mathrm{ppm}$.

${ }^{13}$ C RMN (75.4 MHz, $\left.\mathrm{CDCl}_{3}\right): \delta=159.8(\mathrm{~d}, J=251.1 \mathrm{~Hz}, \mathrm{C}), 151.0(\mathrm{C}), 129.2(\mathrm{~d}, J=8.4 \mathrm{~Hz}, \mathrm{CH}), 121.0(\mathrm{~d}, J$ $=3.5 \mathrm{~Hz}, \mathrm{CH}), 120.1(\mathrm{~d}, J=23.4 \mathrm{~Hz}, \mathrm{CH}), 103.6(\mathrm{~d}, J=25.5 \mathrm{~Hz}, \mathrm{C}) \mathrm{ppm}$.

EMBR (IE), m/z (\%): 219 (M+ 81$), 189$ (26), 175 (68), 163 (31), 94 (100).

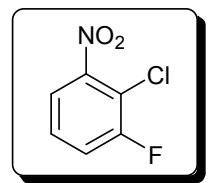

2-Cloro-1-fluoro-3-nitrobenceno (14ac) ${ }^{76 b}$

Líquido incoloro.

$\mathrm{R}_{\mathrm{f}}=0.43$ (hexano / AcOEt, $10 / 1$ ).

${ }^{1} \mathbf{H}$ RMN (300 MHz, $\left.\mathrm{CDCl}_{3}\right): \delta=7.75-7.65(\mathrm{~m}, 1 \mathrm{H}), 7.50-7.39(\mathrm{~m}, 2 \mathrm{H}) \mathrm{ppm}$.

${ }^{13} \mathbf{C}$ RMN (75.4 MHz, $\left.\mathrm{CDCl}_{3}\right): \delta=158.8(\mathrm{~d}, J=252.9 \mathrm{~Hz}, \mathrm{C}), 148.9(\mathrm{C}), 128.1(\mathrm{~d}, J=8.3 \mathrm{~Hz}, \mathrm{CH}), 121.0(\mathrm{~d}, J$ $=3.7 \mathrm{~Hz}, \mathrm{CH}), 120.5(\mathrm{~d}, J=21.9 \mathrm{~Hz}, \mathrm{CH}), 116.0(\mathrm{~d}, J=21.8 \mathrm{~Hz}, \mathrm{C}) \mathrm{ppm}$

EMBR (IE), m/z (\%): 177 (M+2, 23), 175 (M+ $\left.\mathrm{M}^{+}, 72\right), 145$ (21), 131 (35), 129 (77), 117 (36), 84 (80), 49 (100). 
EMAR calculado para $\mathrm{C}_{6} \mathrm{H}_{3} \mathrm{ClFNO}_{2}$ : 174.9836; encontrado: 174.9837 .

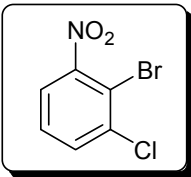

2-Bromo-1-cloro-3-nitrobenceno (14bb)

Sólido blanco.

P.f. $=83-85^{\circ} \mathrm{C}\left(\right.$ lit. $\left.^{80}=83-84^{\circ} \mathrm{C}\right)$.

${ }^{1} \mathbf{H}$ RMN $\left(300 \mathrm{MHz}, \mathrm{CDCl}_{3}\right): \delta=7.67(\mathrm{dd}, J=8.1,1.5 \mathrm{~Hz}, 1 \mathrm{H}), 7.61(\mathrm{dd}, J=8.1,1.5 \mathrm{~Hz}, 1 \mathrm{H}), 7.41(\mathrm{t}, J=8.1$ $\mathrm{Hz}, 1 \mathrm{H}) \mathrm{ppm}$.

${ }^{13}$ C RMN (75.4 MHz, $\left.\mathrm{CDCl}_{3}\right): \delta=137.6(\mathrm{C}), 133.3(\mathrm{CH}), 128.7(\mathrm{CH}), 123.1(\mathrm{CH}), 115.4(\mathrm{C}) \mathrm{ppm}$.

EMBR (IE), m/z (\%): $239\left(\mathrm{M}^{+}+4,26\right), 237\left(\mathrm{M}^{+}+2,100\right), 235\left(\mathrm{M}^{+}, 76\right), 191$ (89), 179 (63), 110 (71), 75 (74).

EMAR calculado para $\mathrm{C}_{6} \mathrm{H}_{3} \mathrm{ClBrNO}_{2}: 234.9036$; encontrado: 234.9025 .

\section{A.2.2 Sintesis de las 3-fluoro-2-haloanilinas 6 ab y 6 ac a partir de los 2,3-dihalonitrobencenos 14}

A una disolución del correspondiente 1-fluoro-2-halo-3-nitrobenceno 14 (1 mmol) en $\mathrm{HCl} /$ EtOH (1 / 7) se añade hierro en polvo $(168 \mathrm{mg}, 3 \mathrm{mmol})$ y la mezcla se calienta a reflujo durante 2 horas (la reacción se monitoriza por CG-EM). Después la mezcla de reacción se enfría a temperatura ambiente y se elimina el EtOH a presión reducida $(20 \mathrm{~mm} \mathrm{Hg})$. El residuo se diluye en AcOEt y se lava con $\mathrm{H}_{2} \mathrm{O}$. La fase acuosa se enfría a $0{ }^{\circ} \mathrm{C}$ y se neutraliza cuidadosamente con una disolución de $\mathrm{NaOH}(1 \mathrm{M})$. La fase acuosa se extrae con AcOEt $(3 \times 15 \mathrm{~mL})$. Las fases orgánicas combinadas se secan sobre $\mathrm{Na}_{2} \mathrm{SO}_{4}$ anhidro y el disolvente se elimina a presión reducida. El residuo resultante se purifica mediante cromatografía de columna (hexano / AcOEt) para dar las anilinas 6ab y 6ac. Los datos físicos y espectroscópicos de 6ab se han detallado anteriormente.

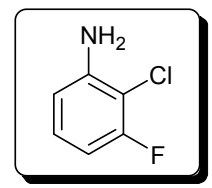

2-Cloro-3-fluroranilina (6ac) ${ }^{76 b}$

Líquido incoloro.

$\mathrm{R}_{\mathrm{f}}=0.35$ (hexano / AcOEt, $5 / 1$ ).

${ }^{1} \mathbf{H}$ RMN (300 MHz, CDCl $\left.)_{3}\right): \delta=7.00(\mathrm{td}, J=8.2,6.0 \mathrm{~Hz}, 1 \mathrm{H}), 6.57-6.49(\mathrm{~m}, 2 \mathrm{H}), 4.18$ (sa, 2H) ppm.

$\left.{ }^{13} \mathbf{C ~ R M N ~ ( 7 5 . 4 ~ M H z , ~} \mathrm{CDCl}_{3}\right): \delta=159.0(\mathrm{~d}, J=245.6 \mathrm{~Hz}, \mathrm{C}), 144.9(\mathrm{~d}, J=2.4 \mathrm{~Hz}, \mathrm{C}), 127.6(\mathrm{~d}, J=9.7 \mathrm{~Hz}$, $\mathrm{CH}), 110.8(\mathrm{~d}, J=2.8 \mathrm{~Hz}, \mathrm{CH}), 106.5(\mathrm{~d}, J=20.3 \mathrm{~Hz}, \mathrm{C}), 105.4(\mathrm{~d}, J=21.3 \mathrm{~Hz}, \mathrm{CH}) \mathrm{ppm}$.

IR $\left(\mathrm{KBr}, \mathrm{cm}^{-1}\right): 3390,1622,1470,987,767$.

EMBR (IE), m/z (\%): $147\left(\mathrm{M}^{+}+2,31\right), 145\left(\mathrm{M}^{+}, 100\right), 118$ (7), 110 (9), 83 (18).

EMAR calculado para $\mathrm{C}_{6} \mathrm{H}_{5} \mathrm{ClFN}$ : 145.0095 ; encontrado: 145.0103 .

\section{A.3 Preparación de 2,3-dihaloanilinas a partir de derivados de 2,3-dihalofenoles}

\section{A.3.1 Preparación de los N,N-dietilcarbamatos de O-2,3-dihalofenilo 17aa-ad}

A una disolución de $i$ - $\operatorname{Pr}_{2} \mathrm{NH}(1.85 \mathrm{~mL}, 13.2 \mathrm{mmol})$ en THF $(40 \mathrm{~mL})$ a $0{ }^{\circ} \mathrm{C}$ se le añade $n$-BuLi (8.25 mL de una disolución 1.6 M en hexano, $13.2 \mathrm{mmol}$ ). Después de 30 minutos a esta temperatura, la disolución de LDA formada se enfría a $-78^{\circ} \mathrm{C}$ y se añade el correspondiente $N, N$-dietilcarbamato de 3 halofenilo $^{252} 15$ (12 mmol). La disolución resultante se agita durante 30 minutos a $-78{ }^{\circ} \mathrm{C}$ y

${ }^{252}$ Los $N, N$-dietilcarbamatos de 3-halofenilo 15 se prepararon por tratamiento de los 3-halofenoles comerciales con 1.5 equiv. de $\mathrm{NaH}$ a $0{ }^{\circ} \mathrm{C}$ y posterior adición de cloruro de $N, N$-dietilcarbamó́lo, empleando THF como disolvente. 
posteriormente se adiciona directamente el correspondiente electrófilo (hexacloroetano, tetrabromuro de carbono o yodo) (14.4 mmol). Tras 30 minutos a baja temperatura, el medio de reacción se calienta a temperatura ambiente y se hidroliza con $\mathrm{H}_{2} \mathrm{O}$ o una disolución acuosa de $\mathrm{Na}_{2} \mathrm{~S}_{2} \mathrm{O}_{3}$. La fase acuosa se extrae con AcOEt $(3 \times 30 \mathrm{~mL})$ y la fase orgánica se lava con una disolución $1 \mathrm{M}$ de $\mathrm{HCl}$, se seca sobre $\mathrm{Na}_{2} \mathrm{SO}_{4}$ anhidro y se eliminan los disolventes por destilación a presión reducida $(20 \mathrm{~mm} \mathrm{Hg})$. El residuo obtenido se purifica mediante columna de cromatografía (hexano / AcOEt, 10 / 1) para dar lugar a los carbamatos 17aa-dc.<smiles>CCN(CC)C(=O)Oc1cccc(F)c1I</smiles>

$N, N$-Dietilcarbamato de $O$-3-fluoro-2-yodofenilo (17aa)

Líquido marrón.

$\mathrm{R}_{\mathrm{f}}=0.17$ (hexano / AcOEt, $10 / 1$ ).

${ }^{1} \mathbf{H}$ RMN $\left(300 \mathrm{MHz}, \mathrm{CDCl}_{3}\right): \delta=7.35-7.25(\mathrm{~m}, 1 \mathrm{H}), 7.00(\mathrm{dd}, J=8.2,1.1 \mathrm{~Hz}, 1 \mathrm{H}), 6.91(\mathrm{t}, J=8.2 \mathrm{~Hz}, 1 \mathrm{H})$, $3.52(\mathrm{q}, J=7.1 \mathrm{~Hz}, 2 \mathrm{H}), 3.39(\mathrm{q}, J=7.1 \mathrm{~Hz}, 2 \mathrm{H}), 1.32(\mathrm{t}, J=7.1 \mathrm{~Hz}, 3 \mathrm{H}), 1.20(\mathrm{t}, J=7.1 \mathrm{~Hz}, 3 \mathrm{H}) \mathrm{ppm}$.

${ }^{13}$ C RMN (75.4 MHz, $\left.\mathrm{CDCl}_{3}\right): \delta=162.4(\mathrm{~d}, J=245.7 \mathrm{~Hz}, \mathrm{C}), 153.3(\mathrm{~d}, J=4.5 \mathrm{~Hz}, \mathrm{C}), 152.6(\mathrm{C}), 129.8(\mathrm{~d}, J=$ $9.3 \mathrm{~Hz}, \mathrm{CH}), 119.0(\mathrm{~d}, J=3.2 \mathrm{~Hz}, \mathrm{CH}), 112.3(\mathrm{~d}, J=24.0 \mathrm{~Hz}, \mathrm{CH}), 80.03(\mathrm{~d}, J=26.8 \mathrm{~Hz}, \mathrm{C}), 42.4\left(\mathrm{CH}_{2}\right)$, $42.1\left(\mathrm{CH}_{2}\right), 14.4\left(\mathrm{CH}_{3}\right), 13.3\left(\mathrm{CH}_{3}\right) \mathrm{ppm}$.

IR $\left(\mathrm{KBr}, \mathrm{cm}^{-1}\right):$ 3076, 2975, 2935, $1727(\mathrm{C}=\mathrm{O}), 1460,1414,1260,1225,1153,1045,994$.

EMBR (IE), m/z (\%): 337 (M+23), 100 (100), 72 (99).

EMAR calculado para $\mathrm{C}_{11} \mathrm{H}_{13} \mathrm{FINO}_{2}$ : 336.9975; encontrado: 336.9962 .

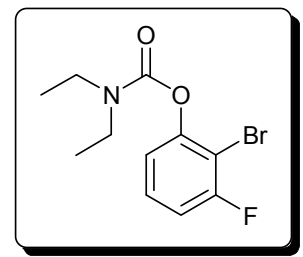

$N, N$-Dietilcarbamato de $O$-2-bromo-3-fluorofenilo (17ab)

Líquido incoloro.

$\mathrm{R}_{\mathrm{f}}=0.22$ (hexano / AcOEt, $10 / 1$ ).

${ }^{1} \mathbf{H}$ RMN (300 MHz, $\left.\mathrm{CDCl}_{3}\right): \delta=7.26(\mathrm{td}, J=8.3,6.1 \mathrm{~Hz}, 1 \mathrm{H}), 7.03(\mathrm{dt}, J=8.3,1.4 \mathrm{~Hz}, 1 \mathrm{H}), 6.97(\mathrm{td}, J=8.3,1.4 \mathrm{~Hz}$, $1 \mathrm{H}), 3.48(\mathrm{q}, J=7.1 \mathrm{~Hz}, 2 \mathrm{H}), 3.38(\mathrm{q}, J=7.1 \mathrm{~Hz}, 2 \mathrm{H}), 1.29(\mathrm{t}, J=7.1 \mathrm{~Hz}, 3 \mathrm{H}), 1.20(\mathrm{t}, J=7.1 \mathrm{~Hz}, 3 \mathrm{H}) \mathrm{ppm}$.

${ }^{13} \mathbf{C}$ RMN (75.4 MHz, $\left.\mathrm{CDCl}_{3}\right): \delta=159.8(\mathrm{~d}, J=247.6 \mathrm{~Hz}, \mathrm{C}), 152.7(\mathrm{C}), 150.3$ (d, $\left.J=2.9 \mathrm{~Hz}, \mathrm{C}\right), 128.3(\mathrm{~d}, J=$ $9.2 \mathrm{~Hz}, \mathrm{CH}), 119.6(\mathrm{~d}, J=3.3 \mathrm{~Hz}, \mathrm{CH}), 118.1(\mathrm{~d}, J=22.3 \mathrm{~Hz}, \mathrm{CH}), 104.9(\mathrm{~d}, J=22.3 \mathrm{~Hz}, \mathrm{C}), 42.5\left(\mathrm{CH}_{2}\right)$, $42.1\left(\mathrm{CH}_{2}\right), 14.2\left(\mathrm{CH}_{3}\right), 13.3\left(\mathrm{CH}_{3}\right) \mathrm{ppm}$.

IR $\left(\mathrm{KBr}, \mathrm{cm}^{-1}\right):$ 3083, 2977, 2935, $2725(\mathrm{C}=\mathrm{O}), 1468,1419,1264,1233,1151,1049,998$.

EMBR (IE), m/z (\%): 289 (M+, 3), 100 (100), 72 (38).

EMAR calculado para $\mathrm{C}_{11} \mathrm{H}_{13} \mathrm{BrFNO}_{2}: 289.0114$ encontrado: 289.0123.

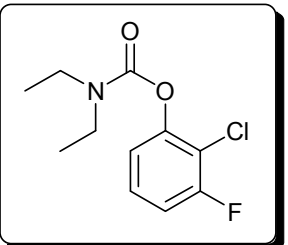

$N, N$-Dietilcarbamato de $O$-2-cloro-3-fluorofenilo (17ac)

Líquido incoloro.

$\mathrm{R}_{\mathrm{f}}=0.19$ (hexano / AcOEt, $10 / 1$ ).

${ }^{1} \mathbf{H}$ RMN $\left(300 \mathrm{MHz}, \mathrm{CDCl}_{3}\right): \delta=7.20(\mathrm{td}, J=8.3,6.0 \mathrm{~Hz}, 1 \mathrm{H}), 7.06-6.95(\mathrm{~m}, 2 \mathrm{H}), 3.46(\mathrm{q}, J=7.1 \mathrm{~Hz}, 2 \mathrm{H})$, $3.38(\mathrm{q}, J=7.1 \mathrm{~Hz}, 2 \mathrm{H}), 1.28(\mathrm{t}, J=7.1 \mathrm{~Hz}, 3 \mathrm{H}), 1.20(\mathrm{t}, J=7.1 \mathrm{~Hz}, 3 \mathrm{H}) \mathrm{ppm}$. 
${ }^{13} \mathbf{C} \mathbf{R M N}\left(75.4 \mathrm{MHz}, \mathrm{CDCl}_{3}\right): \delta=158.8(\mathrm{~d}, J=249.1 \mathrm{~Hz}, \mathrm{C}), 152.7(\mathrm{C}), 149.1(\mathrm{~d}, J=2.1 \mathrm{~Hz}, \mathrm{C}), 127.1(\mathrm{~d}, J=$ $9.1 \mathrm{~Hz}, \mathrm{CH}), 119.5(\mathrm{~d}, J=3.4 \mathrm{~Hz}, \mathrm{CH}), 115.5(\mathrm{~d}, J=18.9 \mathrm{~Hz}, \mathrm{C}), 118.2(\mathrm{~d}, J=21.0 \mathrm{~Hz}, \mathrm{CH}), 42.5\left(\mathrm{CH}_{2}\right)$, $42.2\left(\mathrm{CH}_{2}\right), 14.1\left(\mathrm{CH}_{3}\right), 13.3\left(\mathrm{CH}_{2}\right) \mathrm{ppm}$.

IR $\left(\mathrm{KBr}, \mathrm{cm}^{-1}\right):$ 3086, 2977, 2936, 1727 (C=O), 1467, 1418, 1263, 1236, 1154, 1049, 999.

EMBR (IE), m/z (\%): $210\left(\mathrm{M}^{+}-\mathrm{Cl}, 2\right), 100$ (100), 72 (47).

EMAR calculado para $\mathrm{C}_{11} \mathrm{H}_{13} \mathrm{ClFNO}_{2}$ : 245.0617; encontrado: 245.0625 .<smiles>CCCCc1c(Cl)cccc1OC(=O)N(CC)CC</smiles>

$N, N$-Dietilcarbamato de $O$-3-cloro-2-yodofenilo (17ba)

Sólido blanco.

P.f. $=69-71{ }^{\circ} \mathrm{C}$.

${ }^{1} \mathbf{H}$ RMN (300 MHz, $\left.\mathrm{CDCl}_{3}\right): \delta=7.33-7.22(\mathrm{~m}, 2 \mathrm{H}), 7.05(\mathrm{dd}, J=7.1,2.5 \mathrm{~Hz}, 1 \mathrm{H}), 3.53(\mathrm{q}, J=7.1 \mathrm{~Hz}, 2 \mathrm{H})$, $3.40(\mathrm{q}, J=7.1 \mathrm{~Hz}, 2 \mathrm{H}), 1.32(\mathrm{t}, J=7.1 \mathrm{~Hz}, 3 \mathrm{H}), 1.22(\mathrm{t}, J=7.1 \mathrm{~Hz}, 3 \mathrm{H}) \mathrm{ppm}$.

${ }^{13} \mathbf{C}$ RMN (75.4 MHz, $\left.\mathrm{CDCl}_{3}\right): \delta=153.5(\mathrm{C}), 152.8(\mathrm{C}), 139.6(\mathrm{C}), 129.6(\mathrm{CH}), 126.2(\mathrm{CH}), 121.3(\mathrm{CH}), 96.9$ (C), $42.5\left(\mathrm{CH}_{2}\right), 42.2\left(\mathrm{CH}_{2}\right), 14.5\left(\mathrm{CH}_{3}\right), 13.4\left(\mathrm{CH}_{3}\right) \mathrm{ppm}$.

IR $\left(\mathrm{KBr}, \mathrm{cm}^{-1}\right): 3075,2975,2934,1707(\mathrm{C}=\mathrm{O}), 1415,1237,1153,1041,964$.

EMBR (IE), m/z (\%): $353\left(\mathrm{M}^{+}, 0.1\right), 100$ (100), 72 (40).

Análisis elemental calculado (\%) para $\mathrm{C}_{11} \mathrm{H}_{13} \mathrm{ClINO}_{2}$ : C 37.37, H 3.71, N 3.96; encontrado: C 37.49, H 3.85, N 3.89.

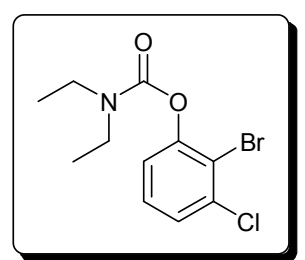

$N$, $N$-Dietilcarbamato de $O$-2-bromo-3-clorofenilo (17bb)

Sólido blanco.

P.f. $=57-59^{\circ} \mathrm{C}$.

${ }^{1} \mathbf{H}$ RMN (300 MHz, $\left.\mathrm{CDCl}_{3}\right): \delta=7.32(\mathrm{dd}, J=8.1,2.0 \mathrm{~Hz}, 1 \mathrm{H}), 7.25(\mathrm{t}, J=8.1 \mathrm{~Hz}, 1 \mathrm{H}), 7.12(\mathrm{dd}, J=8.1,2.0 \mathrm{~Hz}$, $1 \mathrm{H}), 3.50(\mathrm{q}, J=8.1 \mathrm{~Hz}, 2 \mathrm{H}), 3.39(\mathrm{q}, J=7.1 \mathrm{~Hz}, 2 \mathrm{H}), 1.30(\mathrm{t}, J=7.1 \mathrm{~Hz}, 3 \mathrm{H}), 1.21(\mathrm{t}, J=7.1 \mathrm{~Hz}, 3 \mathrm{H}) \mathrm{ppm}$.

${ }^{13} \mathbf{C}$ RMN (75.4 MHz, $\left.\mathrm{CDCl}_{3}\right): \delta=152.8(\mathrm{C}), 150.5(\mathrm{C}), 135.6(\mathrm{C}), 128.2(\mathrm{CH}), 127.2(\mathrm{CH}), 122.4(\mathrm{CH}), 118.1$ (C), $42.6\left(\mathrm{CH}_{2}\right), 42.2\left(\mathrm{CH}_{2}\right), 14.3\left(\mathrm{CH}_{3}\right), 13.4\left(\mathrm{CH}_{3}\right) \mathrm{ppm}$.

IR $\left(\mathrm{KBr}, \mathrm{cm}^{-1}\right): 3082,2984,2937,1722(\mathrm{C}=\mathrm{O}), 1419,1245,1158,963$.

EMBR (IE), m/z (\%): $307\left(\mathrm{M}^{+}+2,0.1\right), 305\left(\mathrm{M}^{+}, 0.1\right), 100(100), 72(36)$.

Análisis elemental calculado (\%) para $\mathrm{C}_{11} \mathrm{H}_{13} \mathrm{BrClNO}_{2}$ : C 43.09, H 4.27, N 4.57; encontrado: C 43.01, H 4.29, N 4.59.

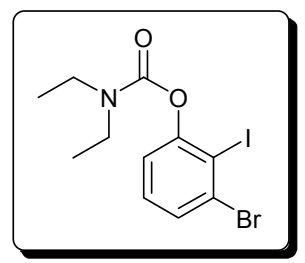

$\mathrm{N}, \mathrm{N}$-Dietilcarbamato de $\mathrm{O}$-3-bromo-2-yodofenilo (17ca)

Sólido blanco.

P.f. $=70-72^{\circ} \mathrm{C}$.

${ }^{1} \mathbf{H}$ RMN (300 MHz, CDCl $): \delta=7.45(\mathrm{~d}, J=8.0 \mathrm{~Hz}, 1 \mathrm{H}), 7.20(\mathrm{td}, J=8.0,1.0 \mathrm{~Hz}, 1 \mathrm{H}), 7.08(\mathrm{~d}, J=8.0 \mathrm{~Hz}, 1 \mathrm{H})$, $3.51(\mathrm{q}, J=7.1 \mathrm{~Hz}, 2 \mathrm{H}), 3.38(\mathrm{q}, J=7.1 \mathrm{~Hz}, 2 \mathrm{H}), 1.30(\mathrm{t}, J=7.1 \mathrm{~Hz}, 3 \mathrm{H}), 1.21(\mathrm{t}, J=7.1 \mathrm{~Hz}, 3 \mathrm{H}) \mathrm{ppm}$.

${ }^{13}$ C RMN (75.4 MHz, $\left.\mathrm{CDCl}_{3}\right): \delta=153.3(\mathrm{C}), 152.6(\mathrm{C}), 130.5(\mathrm{C}), 129.9(\mathrm{CH}), 129.5(\mathrm{CH}), 121.7(\mathrm{CH}), 99.8$ (C), $42.4\left(\mathrm{CH}_{2}\right), 42.1\left(\mathrm{CH}_{2}\right), 14.4\left(\mathrm{CH}_{3}\right), 13.3\left(\mathrm{CH}_{3}\right) \mathrm{ppm}$.

IR (KBr, cm $\left.{ }^{-1}\right): 3074,2976,2934,1777(\mathrm{C}=\mathrm{O}), 1413,1237,1151$ 1049, 960.

EMBR (IE), m/z (\%): $401\left(\mathrm{M}^{+}+2,0.1\right), 399\left(\mathrm{M}^{+}, 0.1\right), 100$ (100), 72 (38). 
Análisis elemental calculado (\%) para $\mathrm{C}_{11} \mathrm{H}_{13} \mathrm{BrINO}_{2}$ : C 33.19, H 3.29, N 3.52; encontrado: C 33.25, H 3.25, N 3.48 .

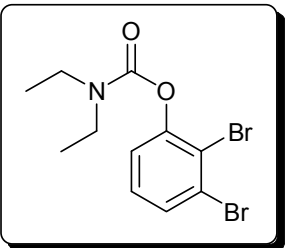

$N, N$-Dietilcarbamato de $O$-2,3-dibromofenilo (17cb)

Sólido blanco.

P.f. $=51-53^{\circ} \mathrm{C}$

${ }^{1} \mathbf{H}$ RMN $\left(300 \mathrm{MHz}, \mathrm{CDCl}_{3}\right): \delta=7.47(\mathrm{dd}, J=6.9,2.6 \mathrm{~Hz}, 1 \mathrm{H}), 7.23-7.14(\mathrm{~m}, 2 \mathrm{H}), 3.48(\mathrm{q}, J=7.1 \mathrm{~Hz}, 2 \mathrm{H})$, $3.38(\mathrm{q}, J=7.1 \mathrm{~Hz}, 2 \mathrm{H}), 1.29(\mathrm{t}, J=7.1 \mathrm{~Hz}, 3 \mathrm{H}), 1.21(\mathrm{t}, J=7.1 \mathrm{~Hz}, 3 \mathrm{H}) \mathrm{ppm}$.

${ }^{13} \mathbf{C}$ RMN (75.4 MHz, $\left.\mathrm{CDCl}_{3}\right): \delta=152.8(\mathrm{C}), 150.3(\mathrm{C}), 130.5(\mathrm{CH}), 128.7(\mathrm{CH}), 125.8(\mathrm{C}), 123.0(\mathrm{CH}), 120.3$ (C), $42.5\left(\mathrm{CH}_{2}\right), 42.2\left(\mathrm{CH}_{2}\right), 14.2\left(\mathrm{CH}_{3}\right), 13.4\left(\mathrm{CH}_{3}\right) \mathrm{ppm}$.

IR $\left(\mathrm{KBr}, \mathrm{cm}^{-1}\right): 3076,2989,2935,1715(\mathrm{C}=\mathrm{O}), 1417,1242,1149$.

EMBR (IE), m/z (\%): $353\left(\mathrm{M}^{+}+4,0.1\right), 351\left(\mathrm{M}^{+}+2,0.1\right), 349\left(\mathrm{M}^{+}, 0.1\right), 100$ (100), 72 (33).

EMAR calculado para $\mathrm{C}_{11} \mathrm{H}_{13} \mathrm{BrNO}_{2}$ : 348.9313; encontrado: 348.9319 .

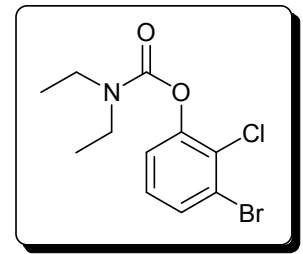

$\mathrm{N}, \mathrm{N}$-Dietilcarbamato de $\mathrm{O}$-3-bromo-2-clorofenilo (17cc)

Sólido blanco.

P.f. $=40-42{ }^{\circ} \mathrm{C}$.

${ }^{1} \mathbf{H}$ RMN $\left(400 \mathrm{MHz}, \mathrm{CDCl}_{3}\right): \delta=7.48(\mathrm{dd}, J=8.0,1.7 \mathrm{~Hz}, 1 \mathrm{H}), 7.20(\mathrm{dd}, J=8.0,1.7 \mathrm{~Hz}, 1 \mathrm{H}), 7.14(\mathrm{t}, J=8.0$ $\mathrm{Hz}, 1 \mathrm{H}), 3.49$ (q, $J=7.1 \mathrm{~Hz}, 2 \mathrm{H}), 3.40$ (q, $J=7.1 \mathrm{~Hz}, 2 \mathrm{H}), 1.30(\mathrm{t}, J=7.1 \mathrm{~Hz}, 3 \mathrm{H}), 1.22$ (t, $J=7.1 \mathrm{~Hz}$, 3H) $\mathrm{ppm}$.

${ }^{13} \mathbf{C}$ RMN (100.6 MHz, $\left.\mathrm{CDCl}_{3}\right): \delta=152.9(\mathrm{C}), 148.9(\mathrm{C}), 130.5(\mathrm{CH}), 128.6(\mathrm{C}), 127.8(\mathrm{CH}), 123.4(\mathrm{C}), 123.2$ $(\mathrm{CH}), 42.6\left(\mathrm{CH}_{2}\right), 42.2\left(\mathrm{CH}_{2}\right), 14.3\left(\mathrm{CH}_{3}\right), 13.4\left(\mathrm{CH}_{3}\right) \mathrm{ppm}$.

IR $\left(\mathrm{KBr}, \mathrm{cm}^{-1}\right): 3078,2978,2934,1716(\mathrm{C}=\mathrm{O}), 1415,1243,1156,960$.

EMBR (IE), m/z (\%): $270\left(\mathrm{M}^{+}-\mathrm{Cl}, 4\right), 100$ (100), 72 (38).

Análisis elemental calculado (\%) para $\mathrm{C}_{11} \mathrm{H}_{13} \mathrm{BrClNO}_{2}$ : C 43.09, H 4.27, N 4.57; encontrado: C 43.21, H 4.24, $\mathrm{N} 4.45$.

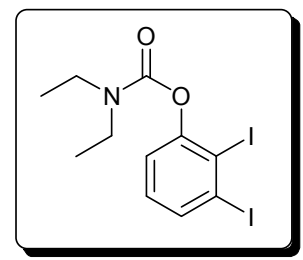

$N, N$-Dietilcarbamato de $O$-2,3-diyodofenilo (17da)

Sólido blanco.

P.f. $=76-78^{\circ} \mathrm{C}$.

${ }^{1} \mathbf{H}$ RMN (400 MHz, $\left.\mathrm{CDCl}_{3}\right): \delta=7.71(\mathrm{dd}, J=7.1,2.2 \mathrm{~Hz}, 1 \mathrm{H}), 7.13-7.05(\mathrm{~m}, 2 \mathrm{H}), 3.51(\mathrm{q}, J=7.2 \mathrm{~Hz}, 2 \mathrm{H})$, 3.39 (q, $J=7.2 \mathrm{~Hz}, 2 \mathrm{H}), 1.30$ (t, $J=7.2 \mathrm{~Hz}, 3 \mathrm{H}), 1.22(\mathrm{t}, J=7.2 \mathrm{~Hz}, 3 \mathrm{H}) \mathrm{ppm}$.

${ }^{13}$ C RMN (100.6 MHz, $\left.\mathrm{CDCl}_{3}\right): \delta=152.8(\mathrm{C}), 152.5(\mathrm{C}), 136.3(\mathrm{CH}), 130.4(\mathrm{CH}), 122.4(\mathrm{CH}), 108.7(\mathrm{C}), 106.1$ (C), $42.4\left(\mathrm{CH}_{2}\right), 42.2\left(\mathrm{CH}_{2}\right), 14.5\left(\mathrm{CH}_{3}\right), 13.4\left(\mathrm{CH}_{3}\right) \mathrm{ppm}$.

IR $\left(\mathrm{KBr}, \mathrm{cm}^{-1}\right): 3062,2973,2932,1718(\mathrm{C}=\mathrm{O}), 1415,1233,1215,1152,58,763$.

EMBR (IE), m/z (\%): $445\left(\mathrm{M}^{+}, 12\right), 100(100), 72(95)$.

Análisis elemental calculado (\%) para $\mathrm{C}_{11} \mathrm{H}_{13} \mathrm{I}_{2} \mathrm{NO}_{2}$ : C 29.69, H 2.94, N 3.15; encontrado: C 29.64, H 2.96, N 3.17. 


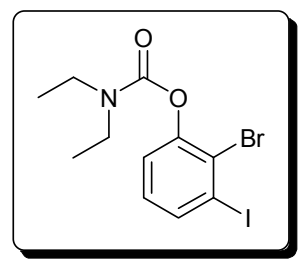

$N$, $N$-Dietilcarbamato de $O$-2-bromo-3-yodofenilo (17db)

Sólido blanco.

P.f. $=53-55^{\circ} \mathrm{C}$.

${ }^{1} \mathbf{H}$ RMN $\left(300 \mathrm{MHz}, \mathrm{CDCl}_{3}\right): \delta=7.71(\mathrm{dd}, J=8.0,1.5 \mathrm{~Hz}, 1 \mathrm{H}), 7.18(\mathrm{dd}, J=8.0,1.5 \mathrm{~Hz}, 1 \mathrm{H}), 7.04(\mathrm{t}, J=8.0 \mathrm{~Hz}$, $1 \mathrm{H}), 3.48(\mathrm{q}, J=7.1 \mathrm{~Hz}, 2 \mathrm{H}), 3.38(\mathrm{q}, J=7.1 \mathrm{~Hz}, 2 \mathrm{H}), 1.29(\mathrm{t}, J=7.1 \mathrm{~Hz}, 3 \mathrm{H}), 1.21(\mathrm{t}, J=7.1 \mathrm{~Hz}, 3 \mathrm{H}) \mathrm{ppm}$.

${ }^{13} \mathbf{C}$ RMN (75.4 MHz, $\left.\mathrm{CDCl}_{3}\right): \delta=152.9(\mathrm{C}), 149.3(\mathrm{C}), 137.0(\mathrm{CH}), 129.3(\mathrm{CH}), 124.8(\mathrm{C}), 123.9(\mathrm{CH}), 102.1$ (C), $42.5\left(\mathrm{CH}_{2}\right), 42.2\left(\mathrm{CH}_{2}\right), 14.4\left(\mathrm{CH}_{3}\right), 13.4\left(\mathrm{CH}_{3}\right) \mathrm{ppm}$.

IR $\left(\mathrm{KBr}, \mathrm{cm}^{-1}\right): 2973,2934,1706(\mathrm{C}=\mathrm{O}), 1405,1263,1238,1151,956,760$.

EMBR (IE), m/z (\%): $399\left(\mathrm{M}^{+}+2,0.1\right), 100(100), 72(32)$.

Análisis elemental calculado (\%) para $\mathrm{C}_{11} \mathrm{H}_{13} \mathrm{BrINO}_{2}$ : C 33.19, H 3.29, N 3.52; encontrado: C 33.24, H 3.26, N 3.50.

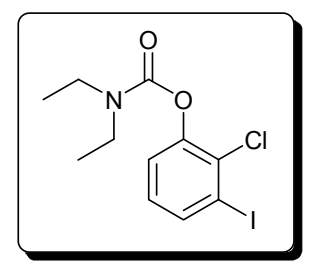

$N, N$-Dietilcarbamato de $O$-2-cloro-3-yodofenilo (17dc)

Sólido blanco.

P.f. $=50-52^{\circ} \mathrm{C}$.

${ }^{1}$ H RMN (300 MHz, $\left.\mathrm{CDCl}_{3}\right): \delta=7.70(\mathrm{dd}, J=8.0,1.4 \mathrm{~Hz}, 1 \mathrm{H}), 7.20(\mathrm{dd}, J=8.0,1.4 \mathrm{~Hz}, 1 \mathrm{H}), 6.98(\mathrm{t}, J=8.0 \mathrm{~Hz}$, $1 \mathrm{H}), 3.47(\mathrm{q}, J=7.1 \mathrm{~Hz}, 2 \mathrm{H}), 3.38(\mathrm{q}, J=7.1 \mathrm{~Hz}, 2 \mathrm{H}), 1.28(\mathrm{t}, J=7.1 \mathrm{~Hz}, 3 \mathrm{H}), 1.20(\mathrm{t}, J=7.1 \mathrm{~Hz}, 3 \mathrm{H}) \mathrm{ppm}$.

${ }^{13} \mathbf{C}$ RMN (75.4 MHz, $\left.\mathrm{CDCl}_{3}\right): \delta=152.9(\mathrm{C}), 147.8(\mathrm{C}), 136.9(\mathrm{CH}), 132.2(\mathrm{C}), 128.5(\mathrm{CH}), 124.2(\mathrm{CH}), 99.0$ (C), $42.6\left(\mathrm{CH}_{2}\right), 42.2\left(\mathrm{CH}_{2}\right), 14.2\left(\mathrm{CH}_{3}\right), 13.4\left(\mathrm{CH}_{3}\right) \mathrm{ppm}$.

IR $\left(\mathrm{KBr}, \mathrm{cm}^{-1}\right): 3069,2976,2931,1715(\mathrm{C}=\mathrm{O}), 1410,1240,1149,956,760$.

EMBR (IE), m/z (\%): $353\left(\mathrm{M}^{+}, 0.4\right), 100$ (100), 72 (31).

Análisis elemental calculado (\%) para $\mathrm{C}_{11} \mathrm{H}_{13} \mathrm{ClINO}_{2}$ : C 37.37, H 3.71, N 3.96; encontrado: C 37.31, H 3.66, N 3.92.

\section{A.3.2 Estudio de la estabilidad de los carbamatos orto-litiados $\mathbf{1 6}$}

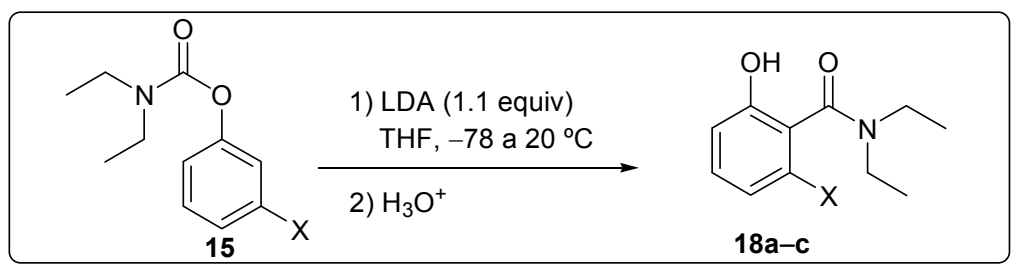

Método $A$ (Válido para $X=F, C l$ )

A una disolución de $i$ - $\operatorname{Pr}_{2} \mathrm{NH}(154 \mu \mathrm{L}, 1.1 \mathrm{mmol})$ en $\mathrm{THF}(3 \mathrm{~mL})$ a $0{ }^{\circ} \mathrm{C}$ se añade $n$-BuLi (687 $\mu \mathrm{L}$ de una disolución 1.6 M en hexano, $1.1 \mathrm{mmol})$. Después de 30 minutos a esta temperatura, la disolución de LDA formada se enfría a $-78^{\circ} \mathrm{C}$ y se adiciona el correspondiente $N, N$-dietilcarbamato de 3-halofenilo 15a ó 15b $(1 \mathrm{mmol})$. La disolución resultante se deja que evolucione hasta temperatura ambiente durante 3 horas. Se hidroliza con $\mathrm{H}_{2} \mathrm{O}$ y la fase acuosa se extrae con AcOEt (3 $\times 15 \mathrm{~mL}$ ). La combinación de las fases orgánicas se seca sobre $\mathrm{Na}_{2} \mathrm{SO}_{4}$ anhidro y se eliminan los disolventes por destilación a presión reducida $(20 \mathrm{~mm} \mathrm{Hg})$. El residuo obtenido se purifica mediante columna de cromatografía (hexano / AcOEt, 1/2) para dar lugar a los compuestos 18a y $\mathbf{1 8 b}$. 


\section{Método $B$ (Válido para $X=B r, I)$}

A una disolución de $i$ - $\operatorname{Pr}_{2} \mathrm{NH}(154 \mu \mathrm{L}, 1.1 \mathrm{mmol})$ en THF $(3 \mathrm{~mL})$ a $0{ }^{\circ} \mathrm{C}$ se añade $n$-BuLi $(687 \mu \mathrm{L}$ de una disolución $1.6 \mathrm{M}$ en hexano, $1.1 \mathrm{mmol}$ ). Después de 30 minutos a esta temperatura, la disolución de LDA formada se enfría a $-78^{\circ} \mathrm{C}$ y se adiciona el correspondiente $N, N$-dietilcarbamato de 3-halofenilo $15 \mathbf{c}$ ó $\mathbf{1 5 d}(1 \mathrm{mmol})$. Tras 30 minutos a $-78{ }^{\circ} \mathrm{C}$, se deja que la mezcla de reacción evolucione hasta temperatura ambiente durante 3 horas. Se hidroliza con $\mathrm{H}_{2} \mathrm{O}$ y la fase acuosa se extrae con AcOEt $(3 \times 15 \mathrm{~mL})$. La combinación de las fases orgánicas se seca sobre $\mathrm{Na}_{2} \mathrm{SO}_{4}$ anhidro y se eliminan los disolventes por destilación a presión reducida $(20 \mathrm{~mm} \mathrm{Hg})$. El residuo obtenido se purifica mediante columna de cromatografía (hexano / AcOEt, 1 / 2) para dar lugar a una mezcla de los compuestos 18c y $\mathbf{2 0}$, en el caso de partir del carbamato de bromo 15c. Sin embargo, en el caso de emplear el carbamato de 3-yodofenilo 15d se obtiene una mezcla de 21 y el bifenilo 22.

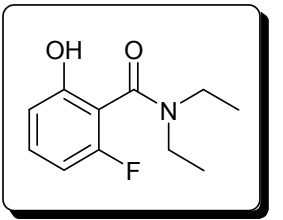

\section{$N, N$-Dietil-2-fluoro-6-hidroxibenzamida (18a)}

Sólido blanco.

$150-152^{\circ} \mathrm{C}$

${ }^{1}$ H RMN (300 MHz, DMSO-d $\left.{ }_{6}\right): \delta=10.14(\mathrm{~s}, 1 \mathrm{H}), 7.17(\mathrm{dd}, J=15.5,8.1 \mathrm{~Hz}, 1 \mathrm{H}), 6.66(\mathrm{dd}, J=18.6,8.4 \mathrm{~Hz}$, 2H), 3.41 (q, $J=7.0 \mathrm{~Hz}, 2 \mathrm{H}), 3.09$ (q, $J=7.0 \mathrm{~Hz}, 2 \mathrm{H}), 1.09$ (t, $J=7.0 \mathrm{~Hz}, 3 \mathrm{H}), 0.96$ (t, $J=7.0 \mathrm{~Hz}, 3 \mathrm{H})$ ppm.

${ }^{13}$ C RMN (75.4 MHz, DMSO-d $\left.{ }_{6}\right): \delta=162.8(\mathrm{~d}, J=1.8 \mathrm{~Hz}, \mathrm{C}), 158.8(\mathrm{~d}, J=241.9 \mathrm{~Hz}, \mathrm{C}), 154.9(\mathrm{~d}, J=8.5 \mathrm{~Hz}$, C), $130.1(\mathrm{~d}, J=10.3 \mathrm{~Hz}, \mathrm{CH}), 113.6(\mathrm{~d}, J=21.8 \mathrm{~Hz}, \mathrm{C}), 111.6(\mathrm{~d}, J=2.5 \mathrm{~Hz}, \mathrm{CH}), 105.7(\mathrm{~d}, J=21.5 \mathrm{~Hz}$, $\mathrm{CH}), 42.4\left(\mathrm{CH}_{2}\right), 38.5\left(\mathrm{CH}_{2}\right), 14.0\left(\mathrm{CH}_{3}\right), 12.9\left(\mathrm{CH}_{3}\right) \mathrm{ppm}$.

EMBR (IE), m/z (\%): $211\left(\mathrm{M}^{+}, 33\right), 192$ (24), 176 (13), 139 (100), 83 (16), 58 (40).

EMAR calculado para $\mathrm{C}_{11} \mathrm{H}_{14} \mathrm{FNO}_{2}$ : 211.1009; encontrado: 211.1009 .

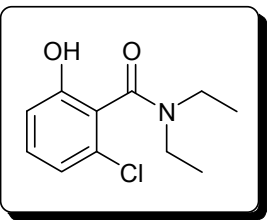

\section{2-Cloro- $N, N$-dietil-6-hidroxibenzamida (18b)}

Sólido blanco.

$168-170{ }^{\circ} \mathrm{C}$

${ }^{1}$ H RMN $\left(300 \mathrm{MHz}, \mathrm{DMSO}-\mathrm{d}_{6}\right): \delta=10.13(\mathrm{~s}, 1 \mathrm{H}), 7.16(\mathrm{t}, J=8.1 \mathrm{~Hz}, 1 \mathrm{H}), 6.87(\mathrm{dd}, J=8.1,0.7 \mathrm{~Hz}, 1 \mathrm{H}), 6.81$ $(\mathrm{dd}, J=8.1,0.7 \mathrm{~Hz}, 1 \mathrm{H}), 3.60-3.45(\mathrm{~m}, 1 \mathrm{H}), 3.36-3.23(\mathrm{~m}, 1 \mathrm{H}), 3.16-2.96(\mathrm{~m}, 2 \mathrm{H}), 1.10(\mathrm{t}, J=7.1 \mathrm{~Hz}$, $3 \mathrm{H}), 0.98$ (t, $J=7.1 \mathrm{~Hz}, 3 \mathrm{H}) \mathrm{ppm}$.

${ }^{13}$ C RMN (75.4 MHz, DMSO-d d $\left._{6}\right): \delta=164.4(\mathrm{C}), 154.6(\mathrm{C}), 130.1(\mathrm{CH}), 124.5(\mathrm{C}), 119.5(\mathrm{CH}), 114.3(\mathrm{CH})$, $42.2\left(\mathrm{CH}_{2}\right), 38.4\left(\mathrm{CH}_{2}\right), 13.9\left(\mathrm{CH}_{3}\right), 12.7\left(\mathrm{CH}_{3}\right) \mathrm{ppm}$.

EMBR (IE), m/z (\%): $227\left(\mathrm{M}^{+}, 31\right), 210$ (26), 192 (75), 155 (100), 99 (20), 72 (28), 58 (54).

EMAR calculado para $\mathrm{C}_{11} \mathrm{H}_{14} \mathrm{ClNO}_{2}$ : 227.0713; encontrado: 227.0702 .

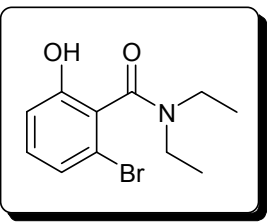

2-Bromo- $N, N$-dietil-6-hidroxibenzamida (18c)

Sólido blanco.

$167-169^{\circ} \mathrm{C}$. 
${ }^{1}$ H RMN (300 MHz, DMSO-d $\left.{ }_{6}\right): \delta=10.13(\mathrm{sa}, 1 \mathrm{H}), 7.12-6.99(\mathrm{~m}, 2 \mathrm{H}), 6.85(\mathrm{~d}, J=7.9 \mathrm{~Hz}, 1 \mathrm{H}), 3.62-3.49(\mathrm{~m}$, $1 \mathrm{H}), 3.31-3.21(\mathrm{~m}, 1 \mathrm{H}), 3.13-2.98(\mathrm{~m}, 2 \mathrm{H}), 1.11(\mathrm{t}, J=7.0 \mathrm{~Hz}, 3 \mathrm{H}), 1.00(\mathrm{t}, J=7.0 \mathrm{~Hz}, 3 \mathrm{H}) \mathrm{ppm}$.

${ }^{13}$ C RMN (75.4 MHz, DMSO-d 6 ): $\delta=165.3(\mathrm{C}), 154.6(\mathrm{C}), 130.4(\mathrm{CH}), 126.4(\mathrm{C}), 122.6(\mathrm{CH}), 119.5(\mathrm{C}), 114.8$ $(\mathrm{CH}), 42.2\left(\mathrm{CH}_{2}\right), 38.3\left(\mathrm{CH}_{2}\right), 13.8\left(\mathrm{CH}_{3}\right), 12.6\left(\mathrm{CH}_{3}\right) \mathrm{ppm}$.

EMBR (IE), m/z (\%): $273\left(\mathrm{M}^{+}+2,3\right), 271\left(\mathrm{M}^{+}, 3\right), 100(100), 72(41)$.

EMAR calculado para $\mathrm{C}_{11} \mathrm{H}_{14} \mathrm{BrNO}_{2}$ : 271.0208; encontrado: 271.0208 .

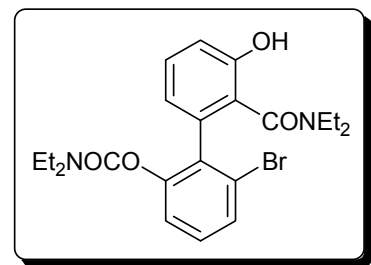

\section{2'-Bromo-2-carbamoíl-6'-carbamoiloxi-3-hidroxibifenilo (20)}

Sólido amarillo.

${ }^{1}$ H RMN $\left(400 \mathrm{MHz}, \mathrm{CDCl}_{3}\right): \delta=7.48-7.42(\mathrm{~m}, 1 \mathrm{H}), 7.33(\mathrm{dd}, J=8.3,1.1 \mathrm{~Hz}, 1 \mathrm{H}), 7.22(\mathrm{dd}, J=8.0,1.3 \mathrm{~Hz}$, 1H), 7.13-7.07 (m, 2H), 7.01 (dd, $J=8.0,1.3 \mathrm{~Hz}, 1 \mathrm{H}), 3.58-3.49(\mathrm{~m}, 1 \mathrm{H}), 3.47-3.28(\mathrm{~m}, 4 \mathrm{H}), 3.28-3.23$ (m, 1H), 3.21-3.12 (m, 2H), $1.19(\mathrm{t}, J=7.1 \mathrm{~Hz}, 6 \mathrm{H}), 1.01(\mathrm{t}, J=7.1 \mathrm{~Hz}, 3 \mathrm{H}), 0.83(\mathrm{t}, J=7.1 \mathrm{~Hz}, 3 \mathrm{H})$ ppm.

${ }^{13}$ C RMN (100.6 MHz, $\left.\mathrm{CDCl}_{3}\right): \delta=168.8(\mathrm{C}), 155.8(\mathrm{C}), 153.3(\mathrm{C}), 146.9(\mathrm{C}), 135.5(\mathrm{C}), 130.5(\mathrm{CH}), 130.3$ (C), $129.6(\mathrm{CH}), 129.5(\mathrm{C}), 129.1(\mathrm{CH}), 125.6(\mathrm{CH}), 123.8(\mathrm{C}), 122.7(\mathrm{CH}), 119.8(\mathrm{CH}), 43.4\left(\mathrm{CH}_{2}\right), 42.5$ $\left(\mathrm{CH}_{2}\right), 42.1\left(\mathrm{CH}_{2}\right), 38.4\left(\mathrm{CH}_{2}\right), 14.3\left(\mathrm{CH}_{3}\right), 13.8\left(\mathrm{CH}_{3}\right), 13.5\left(\mathrm{CH}_{3}\right), 11.9\left(\mathrm{CH}_{3}\right) \mathrm{ppm}$.

EMBR (IE), m/z (\%): $464\left(\mathrm{M}^{+}+2,7\right), 462\left(\mathrm{M}^{+}, 7\right), 447$ (4), 445 (5), 383 (32), 100 (100), 72 (44).

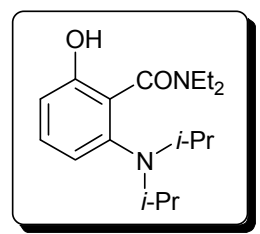

\section{2-(Diisopropilamino)- $N, N$-dietil-6-hidroxibenzamida (21)}

Sólido blanco.

${ }^{1}$ H RMN (300 MHz, DMSO-d $\left.{ }_{6}\right): \delta=9.38(\mathrm{sa}, 1 \mathrm{H}), 7.02(\mathrm{t}, J=8.0 \mathrm{~Hz}, 1 \mathrm{H}), 6.67(\mathrm{~d}, J=8.0 \mathrm{~Hz}, 1 \mathrm{H}), 6.58(\mathrm{~d}, J=$ $8.0 \mathrm{~Hz}, 1 \mathrm{H}), 3.77-3.65(\mathrm{~m}, 1 \mathrm{H}), 3.40-3.31(\mathrm{~m}, 2 \mathrm{H}), 3.14-3.01(\mathrm{~m}, 2 \mathrm{H}), 3.00-2.89(\mathrm{~m}, 1 \mathrm{H}), 1.10(\mathrm{t}, J=$ $7.0 \mathrm{~Hz}, 3 \mathrm{H}), 1.05-0.94(\mathrm{~m}, 15 \mathrm{H}) \mathrm{ppm}$.

${ }^{13}$ C RMN (75.4 MHz, DMSO-d $\left.{ }_{6}\right): \delta=167.0(\mathrm{C}), 154.3(\mathrm{C}), 149.2(\mathrm{C}), 127.9(\mathrm{CH}), 125.1(\mathrm{C}), 117.7(\mathrm{CH}), 111.3$ $(\mathrm{CH}), 50.4(2 \times \mathrm{CH}), 42.0\left(\mathrm{CH}_{2}\right), 36.9\left(\mathrm{CH}_{2}\right), 23.0\left(2 \times \mathrm{CH}_{3}\right), 21.6\left(2 \times \mathrm{CH}_{3}\right), 13.6\left(\mathrm{CH}_{3}\right), 12.6\left(\mathrm{CH}_{3}\right) \mathrm{ppm}$. EMBR (IE), m/z (\%): 292 (M+, 1), 249 (29), 219 (22), 176 (100), 162 (43).

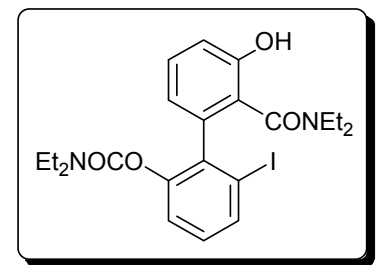

2-Carbamoíl-2'-carbamoiloxi-3-hidroxi-6'-yodobifenilo (22) Sólido amarillo.

${ }^{1}$ H RMN (400 MHz, $\left.\mathrm{CDCl}_{3}\right): \delta=9.70(\mathrm{sa}, 1 \mathrm{H}), 7.38(\mathrm{t}, J=7.9 \mathrm{~Hz}, 1 \mathrm{H}), 7.26-7.22(\mathrm{~m}, 1 \mathrm{H}), 7.21-7.16(\mathrm{~m}, 1 \mathrm{H})$, 7.04-6.98 (m, 1H), 6.92-6.86 (m, 1H), 6.85-6.81 (m, 1H), 3.51-3.42 (m, 1H), 3.36-3.16 (m, 5H), $2.98-2.76(\mathrm{~m}, 2 \mathrm{H}), 1.12-1.04(\mathrm{~m}, 6 \mathrm{H}), 0.92-0.85(\mathrm{~m}, 3 \mathrm{H}), 0.66-0.55(\mathrm{~m}, 3 \mathrm{H}) \mathrm{ppm}$.

${ }^{13} \mathbf{C}$ RMN (100.6 MHz, $\left.\mathrm{CDCl}_{3}\right): \delta=168.7$ (C), 154.8 (C), 153.2 (C), 146.7 (C), 138.7 (C), 133.9 (C), 132.3 $(\mathrm{CH}), 131.1(\mathrm{CH}), 129.7(\mathrm{CH}), 129.4(\mathrm{CH}), 129.1(\mathrm{C}), 122.7(\mathrm{CH}), 120.7(\mathrm{CH}), 100.0(\mathrm{C}), 43.8\left(\mathrm{CH}_{2}\right)$, $42.5\left(\mathrm{CH}_{2}\right), 42.0\left(\mathrm{CH}_{2}\right), 38.4\left(\mathrm{CH}_{2}\right), 14.3\left(\mathrm{CH}_{3}\right), 14.0\left(\mathrm{CH}_{3}\right), 13.4\left(\mathrm{CH}_{3}\right), 11.9\left(\mathrm{CH}_{3}\right) \mathrm{ppm}$. 


\section{A.3.3 Procedimiento general para la sintesis de las 2-ariloxi-2-metilpropanamidas 24}

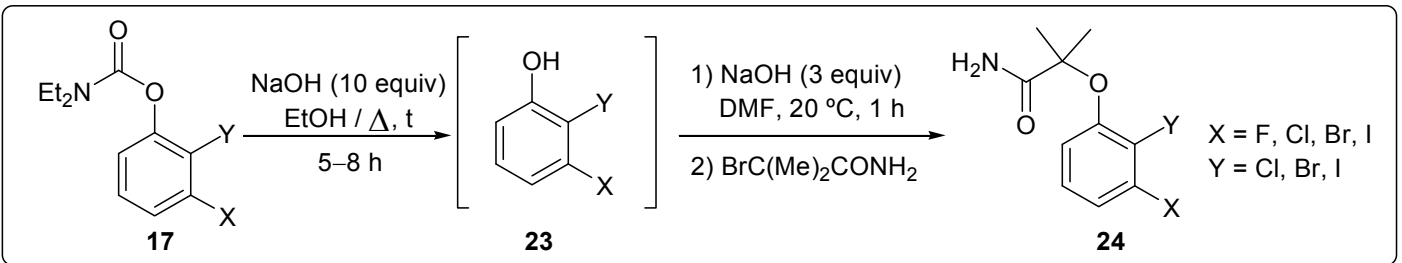

A una disolución del correspondiente carbamato $17(0.5 \mathrm{mmol})$ en EtOH $(5 \mathrm{~mL})$ se añade $\mathrm{NaOH}$ (200 mg, $5 \mathrm{mmol}$ ). La mezcla se agita a reflujo durante 5-8 horas (la reacción se sigue por CG-EM). Posteriormente, se deja enfriar la mezcla de reacción a temperatura ambiente y se elimina el EtOH a presión reducida $(20 \mathrm{~mm} \mathrm{Hg})$. El residuo se diluye en $\mathrm{Et}_{2} \mathrm{O}$ y se lava con $\mathrm{H}_{2} \mathrm{O}(3 \times 10 \mathrm{~mL})$. La fase acuosa se enfría a $0{ }^{\circ} \mathrm{C}$ y se neutraliza utilizando una disolución de $\mathrm{HCl} 1 \mathrm{M}$. La fase acuosa se extrae con $\mathrm{Et}_{2} \mathrm{O}(3 \times 10 \mathrm{~mL})$. La fase orgánica resultante de la extracción se seca sobre $\mathrm{Na}_{2} \mathrm{SO}_{4}$ anhidro y se elimina el disolvente a presión reducida. Sin una posterior purificación, el bruto de reacción se disuelve en DMF seca $(1.5 \mathrm{~mL})$ bajo atmósfera de $\mathrm{N}_{2}$ y se adiciona $\mathrm{NaOH}(60 \mathrm{mg}, 1.5$ mmol). Tras 1 hora a $20{ }^{\circ} \mathrm{C}$ se añade 2-bromo-2-metilpropanamida (250 $\left.\mathrm{mg}, 1.5 \mathrm{mmol}\right)$ y se agita 2 horas a esta temperatura (el final de la reacción se detecta mediante CG-EM). La posterior hidrólisis de la mezcla de reacción permite obtener la correspondiente 2-(2,3-dihalofenoxi)-2metilpropanamidas $\mathbf{2 4}$ como un sólido recuperado mediante filtración.

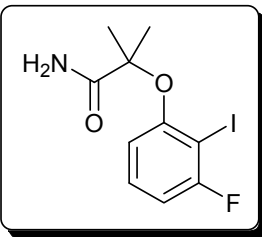

\section{2-(3-Fluoro-2-yodofenoxi)-2-metilpropanamida (24aa)}

Sólido blanco.

P.f. $=100-102^{\circ} \mathrm{C}$.

${ }^{1} \mathbf{H}$ RMN $\left(300 \mathrm{MHz}, \mathrm{CDCl}_{3}\right): \delta=7.23(\mathrm{td}, J=8.2,6.6 \mathrm{~Hz}, 1 \mathrm{H}), 6.85(\mathrm{sa}, 1 \mathrm{H}), 6.84-6.76(\mathrm{~m}, 2 \mathrm{H}), 5.84(\mathrm{sa}, 1 \mathrm{H})$, $1.65(\mathrm{~s}, 6 \mathrm{H}) \mathrm{ppm}$.

${ }^{13}$ C RMN (75.4 MHz, $\left.\mathrm{CDCl}_{3}\right): \delta=177.0(\mathrm{C}), 163.0(\mathrm{~d}, J=245.8 \mathrm{~Hz}, \mathrm{C}), 156.1(\mathrm{~d}, J=4.9 \mathrm{~Hz}, \mathrm{C}), 129.9(\mathrm{~d}, J=$ $9.6 \mathrm{~Hz}, \mathrm{CH}), 114.8(\mathrm{~d}, J=3.0 \mathrm{~Hz}, \mathrm{CH}), 110.4(\mathrm{~d}, J=24.1 \mathrm{~Hz}, \mathrm{CH}), 83.8(\mathrm{C}), 80.3(\mathrm{~d}, J=25.7 \mathrm{~Hz}, \mathrm{C})$, $25.0\left(2 \times \mathrm{CH}_{3}\right) \mathrm{ppm}$.

IR $\left(\mathrm{KBr}, \mathrm{cm}^{-1}\right): 3451,3416,1673(\mathrm{C}=\mathrm{O}), 1458,1237,1152,600$.

EMBR (IE), m/z (\%): 323 (M+, 1), 279 (41), 238 (81), 196 (60), 152 (19), 112 (19), 86 (100).

Análisis elemental calculado (\%) para $\mathrm{C}_{10} \mathrm{H}_{11} \mathrm{FINO}_{2}: \mathrm{C}, 37.17 ; \mathrm{H}, 3.43 ; \mathrm{N}, 4.34$; encontrado: $\mathrm{C}, 37.44 ; \mathrm{H}, 3.55 ; \mathrm{N}, 4.43$.

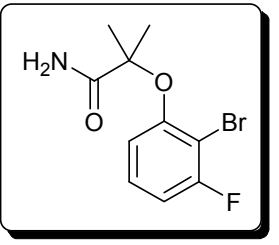

2-(2-Bromo-3-fluorofenoxi)-2-metilpropanamida (24ab)

Sólido blanco.

P.f. $=91-93^{\circ} \mathrm{C}$.

${ }^{1} \mathbf{H}$ RMN $\left(300 \mathrm{MHz}, \mathrm{CDCl}_{3}\right): \delta=7.19(\mathrm{td}, J=8.3,6.5 \mathrm{~Hz}, 1 \mathrm{H}), 6.98(\mathrm{sa}, 1 \mathrm{H}), 6.91-6.82(\mathrm{~m}, 2 \mathrm{H}), 6.48(\mathrm{sa}, 1 \mathrm{H})$, $1.60(\mathrm{~s}, 6 \mathrm{H}) \mathrm{ppm}$ 
${ }^{13} \mathbf{C}$ RMN (75.4 MHz, $\left.\mathrm{CDCl}_{3}\right): \delta=177.4(\mathrm{C}), 160.2(\mathrm{~d}, J=247.7 \mathrm{~Hz}, \mathrm{C}), 153.4(\mathrm{~d}, J=3.0 \mathrm{~Hz}, \mathrm{C}), 128.2(\mathrm{~d}, J=$ $9.5 \mathrm{~Hz}, \mathrm{CH}), 116.4(\mathrm{~d}, J=3.2 \mathrm{~Hz}, \mathrm{CH}), 111.2(\mathrm{~d}, J=22.4 \mathrm{~Hz}, \mathrm{CH}), 104.9(\mathrm{~d}, J=21.2 \mathrm{~Hz}, \mathrm{C}), 83.9(\mathrm{C})$, $24.8\left(2 \times \mathrm{CH}_{3}\right) \mathrm{ppm}$.

IR $\left(\mathrm{KBr}, \mathrm{cm}^{-1}\right): 3428,3212,1683(\mathrm{C}=\mathrm{O}), 1463,1018,794,596$.

EMBR (IE), m/z (\%): 277 (M+2, 1), 275 (M+1 1), 233 (27), 231 (28), 196 (52), 192 (39), 190 (39), 86 (100).

EMAR calculado para for $\mathrm{C}_{10} \mathrm{H}_{11} \mathrm{BrFNO}_{2}: 274.9957$; encontrado: 274.9953.

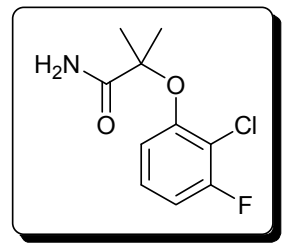

\section{2-(2-Cloro-3-fluorofenoxi)-2-metilpropanamida (24ac)}

Sólido blanco.

P.f. $=92-94{ }^{\circ} \mathrm{C}$.

${ }^{1} \mathbf{H}$ RMN $\left(300 \mathrm{MHz}, \mathrm{CDCl}_{3}\right): \delta=7.13(\mathrm{td}, J=8.3,6.3 \mathrm{~Hz}, 1 \mathrm{H}), 6.98(\mathrm{sa}, 1 \mathrm{H}), 6.92-6.84(\mathrm{~m}, 2 \mathrm{H}), 6.73(\mathrm{sa}, 1 \mathrm{H})$, $1.56(\mathrm{~s}, 6 \mathrm{H}) \mathrm{ppm}$.

${ }^{13}$ C RMN (75.4 MHz, $\left.\mathrm{CDCl}_{3}\right): \delta=177.5(\mathrm{C}), 159.2(\mathrm{~d}, J=249.2 \mathrm{~Hz}, \mathrm{C}), 152.2(\mathrm{~d}, J=2.2 \mathrm{~Hz}, \mathrm{C}), 127.1(\mathrm{~d}, J=$ $9.4 \mathrm{~Hz}, \mathrm{CH}), 117.0(\mathrm{~d}, J=3.2 \mathrm{~Hz}, \mathrm{CH}), 115.3(\mathrm{~d}, J=18.1 \mathrm{~Hz}, \mathrm{C}), 111.4(\mathrm{~d}, J=21.2 \mathrm{~Hz}, \mathrm{CH}), 83.9(\mathrm{C})$, $24.7\left(2 \times \mathrm{CH}_{3}\right) \mathrm{ppm}$.

IR $\left(\mathrm{KBr}, \mathrm{cm}^{-1}\right): 3425,3214,1684(\mathrm{C}=\mathrm{O}), 1465,1452,1140,1020,795,605$.

EMBR (IE), m/z (\%): 231 (M+1 1), 196 (20), 187 (49), 146 (53), 86 (100), 58 (29).

EMAR calculado para $\mathrm{C}_{10} \mathrm{H}_{11} \mathrm{ClFNO}_{2}$ : 231.0462; encontrado: 231.0469.

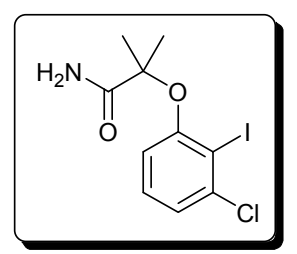

\section{2-(3-Cloro-2-yodofenoxi)-2-metilpropanamida (24ba)}

Sólido blanco.

P.f. $=101-103^{\circ} \mathrm{C}$.

${ }^{1}$ H RMN (300 MHz, CDCl $)$ ): $\delta=7.26-7.16(\mathrm{~m}, 2 \mathrm{H}), 6.89-6.82(\mathrm{~m}, 2 \mathrm{H}), 5.71(\mathrm{sa}, 1 \mathrm{H}), 1.65(\mathrm{~s}, 6 \mathrm{H}) \mathrm{ppm}$.

${ }^{13}$ C RMN (75.4 MHz, $\left.\mathrm{CDCl}_{3}\right): \delta=177.1(\mathrm{C}), 156.2(\mathrm{C}), 140.1(\mathrm{C}), 129.5(\mathrm{CH}), 124.1(\mathrm{CH}), 116.8(\mathrm{CH}), 97.3$ (C), $83.9(\mathrm{C}), 25.1\left(2 \times \mathrm{CH}_{3}\right) \mathrm{ppm}$.

IR $\left(\mathrm{KBr}, \mathrm{cm}^{-1}\right): 3453,3418,1673(\mathrm{C}=\mathrm{O}), 1563,1439,1151,1134,980,958,771,576$.

EMBR (IE), m/z (\%): 339 (M+1), 295 (12), 254 (42), 212 (44), 128 (17), 86 (100), 58 (24).

EMAR calculado para $\mathrm{C}_{10} \mathrm{H}_{11} \mathrm{ClINO}_{2}$ : 338.9523 ; encontrado: 338.9524 .

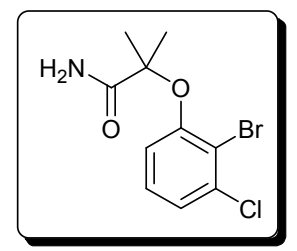

2-(2-Bromo-3-clorofenoxi)-2-metilpropanamida (24bb)

Sólido blanco.

P.f. $=84-86^{\circ} \mathrm{C}$.

${ }^{1}$ H RMN (300 MHz, $\left.\mathrm{CDCl}_{3}\right): \delta=7.26-7.13(\mathrm{~m}, 2 \mathrm{H}), 7.01-6.94(\mathrm{~m}, 2 \mathrm{H}), 6.11(\mathrm{sa}, 1 \mathrm{H}), 1.61(\mathrm{~s}, 6 \mathrm{H}) \mathrm{ppm}$.

${ }^{13} \mathbf{C}$ RMN (75.4 MHz, $\left.\mathrm{CDCl}_{3}\right): \delta=177.2(\mathrm{C}), 153.4(\mathrm{C}), 136.1(\mathrm{C}), 128.1(\mathrm{CH}), 125.1(\mathrm{CH}), 118.9(\mathrm{CH}), 118.1$ (C), 84.0 (C), $24.9\left(2 \times \mathrm{CH}_{3}\right) \mathrm{ppm}$.

IR $\left(\mathrm{KBr}, \mathrm{cm}^{-1}\right): 3467,3156,1698(\mathrm{C}=\mathrm{O}), 1570,1445,1260,1149,963,544$.

EMBR (IE), m/z (\%): $291\left(\mathrm{M}^{+}, 1\right), 249$ (12), 214 (10), 212 (33), 168 (11), 86 (100), 58 (26).

EMAR calculado para $\mathrm{C}_{10} \mathrm{H}_{11} \mathrm{BrClNO}_{2}$ : 290.9662; encontrado: 290.9650. 


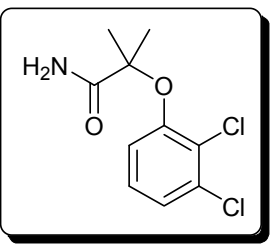

\section{2-(2,3-Diclorofenoxi)-2-metilpropanamida (24bc)}

Sólido blanco.

P.f. $=100-102^{\circ} \mathrm{C}$.

${ }^{1} \mathbf{H}$ RMN (300 MHz, $\left.\mathrm{CDCl}_{3}\right)$ : $\delta=7.26-7.09(\mathrm{~m}, 2 \mathrm{H}), 7.05-6.89(\mathrm{~m}, 2 \mathrm{H}), 6.21(\mathrm{sa}, 1 \mathrm{H}), 1.58(\mathrm{~s}, 6 \mathrm{H}) \mathrm{ppm}$.

${ }^{13}$ C RMN (75.4 MHz, $\mathrm{CDCl}_{3}$ ): $\delta=177.3(\mathrm{C}), 152.1(\mathrm{C}), 134.1(\mathrm{C}), 127.2(\mathrm{CH}), 126.7$ (C), $125.3(\mathrm{CH}), 119.8$ $(\mathrm{CH}), 84.1(\mathrm{C}), 24.8\left(2 \times \mathrm{CH}_{3}\right) \mathrm{ppm}$.

IR $\left(\mathrm{KBr}, \mathrm{cm}^{-1}\right): 3474,3155,1699(\mathrm{C}=\mathrm{O}), 1450,1264,1145,783,550$.

EMBR (IE), m/z (\%): $249\left(\mathrm{M}^{+}+2,1\right), 247\left(\mathrm{M}^{+}, 1\right), 212(23), 203$ (30), $162(50), 126(14), 86(100), 58(25)$.

Análisis elemental calculado (\%) para $\mathrm{C}_{10} \mathrm{H}_{11} \mathrm{Cl}_{2} \mathrm{NO}_{2}: \mathrm{C}, 48.41 ; \mathrm{H}, 4.47 ; \mathrm{N}, 5.65$; encontrado: $\mathrm{C}, 47.91 ; \mathrm{H}, 4.34 ; \mathrm{N}, 5.84$.

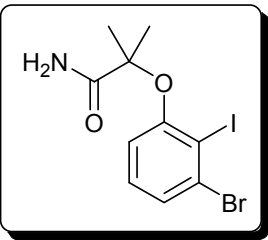

2-(3-Bromo-2-yodofenoxi)-2-metilpropanamida (24ca)

Sólido blanco.

P.f. $=114-116^{\circ} \mathrm{C}$.

${ }^{1} \mathbf{H}$ RMN $\left(300 \mathrm{MHz}, \mathrm{CDCl}_{3}\right): \delta=7.35(\mathrm{dd}, J=8.1,1.1 \mathrm{~Hz}, 1 \mathrm{H}), 7.14(\mathrm{t}, J=8.1 \mathrm{~Hz}, 1 \mathrm{H}), 6.89(\mathrm{dd}, J=8.1,1.1$ $\mathrm{Hz}, 1 \mathrm{H}), 6.83(\mathrm{sa}, 1 \mathrm{H}), 5.82(\mathrm{sa}, 1 \mathrm{H}), 1.64(\mathrm{~s}, 6 \mathrm{H}) \mathrm{ppm}$.

${ }^{13} \mathbf{C}$ RMN (75.4 MHz, $\left.\mathrm{CDCl}_{3}\right): \delta=177.3(\mathrm{C}), 156.2(\mathrm{C}), 131.2(\mathrm{C}), 129.8(\mathrm{CH}), 127.4(\mathrm{CH}), 117.2(\mathrm{CH}), 100.3$ $(\mathrm{C}), 83.9(\mathrm{C}), 25.0\left(2 \times \mathrm{CH}_{3}\right) \mathrm{ppm}$.

IR $\left(\mathrm{KBr}, \mathrm{cm}^{-1}\right): 3461,3146,1674(\mathrm{C}=\mathrm{O}), 1434,1146,966,911,575$.

EMBR (IE), m/z (\%): $339\left(\mathrm{M}^{+}-\mathrm{CONH}_{2}, 6\right), 300$ (25), 298 (25), 258 (25), 256 (26), 207 (14), 86 (100), 58 (27).

EMAR calculado para $\mathrm{C}_{10} \mathrm{H}_{11} \mathrm{BrINO}_{2}$ : 382.9018; encontrado: 382.9005 .

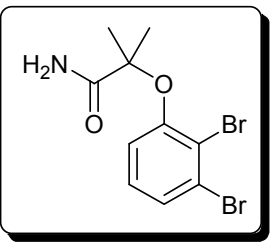

2-(2,3-Dibromofenoxi)-2-metilpropanamida (24cb)

Sólido blanco.

P.f. $=111-113^{\circ} \mathrm{C}$.

${ }^{1} \mathbf{H}$ RMN (300 MHz, $\left.\mathrm{CDCl}_{3}\right): \delta=7.35(\mathrm{~d}, J=7.8 \mathrm{~Hz}, 1 \mathrm{H}), 7.14-6.94(\mathrm{~m}, 3 \mathrm{H}), 6.42(\mathrm{sa}, 1 \mathrm{H}), 1.60(\mathrm{~s}, 6 \mathrm{H}) \mathrm{ppm}$.

${ }^{13}$ C RMN (75.4 MHz, $\left.\mathrm{CDCl}_{3}\right): \delta=177.3(\mathrm{C}), 153.2(\mathrm{C}), 128.6(\mathrm{CH}), 128.4(\mathrm{CH}), 126.3(\mathrm{C}), 120.3(\mathrm{C}), 119.5$ $(\mathrm{CH}), 84.0(\mathrm{C}), 24.9\left(2 \times \mathrm{CH}_{3}\right) \mathrm{ppm}$.

IR $\left(\mathrm{KBr}, \mathrm{cm}^{-1}\right): 3467,3147,1698(\mathrm{C}=\mathrm{O}), 1440,1260,1147,953,779,548$.

EMBR (IE), m/z (\%): $293\left(\mathrm{M}^{+}-\mathrm{CONH}_{2}+2,11\right), 291\left(\mathrm{M}^{+}-\mathrm{CONH}_{2}, 5\right), 252$ (26), 86 (100), 58 (22).

EMAR calculado para $\mathrm{C}_{10} \mathrm{H}_{11} \mathrm{Br}_{2} \mathrm{NO}_{2}$ : 334.9157 ; encontrado: 334.9150 .

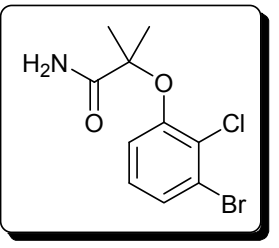

2-(3-Bromo-2-clorofenoxi)-2-metilpropanamida (24cc)

Sólido blanco.

P.f. $=117-119^{\circ} \mathrm{C}$. 
${ }^{1}$ H RMN (300 MHz, $\left.\mathrm{CDCl}_{3}\right): \delta=7.37(\mathrm{dd}, J=6.7,2.7 \mathrm{~Hz}, 1 \mathrm{H}), 7.23-7.04(\mathrm{~m}, 2 \mathrm{H}), 6.94(\mathrm{sa}, 1 \mathrm{H}), 5.67$ (sa, 1H), $1.59(\mathrm{~s}, 6 \mathrm{H}) \mathrm{ppm}$.

${ }^{13}$ C RMN (75.4 MHz, $\left.\mathrm{CDCl}_{3}\right): \delta=177.2(\mathrm{C}), 151.9(\mathrm{C}), 128.5(\mathrm{CH}), 127.7(\mathrm{CH}), 124.0(\mathrm{CH}), 120.4(\mathrm{CH}), 84.1$ (C), $24.8\left(2 \times \mathrm{CH}_{3}\right) \mathrm{ppm}$.

IR $\left(\mathrm{KBr}, \mathrm{cm}^{-1}\right): 3471,3153,1699(\mathrm{C}=\mathrm{O}), 1446,1263,1149,953,912,548$.

EMBR (IE), m/z (\%): 293 (M+2, 1), 291 (M+1), 258 (11), 249 (19), 247 (14), 208 (33), 206 (24), 86 (100), 58 (23).

EMAR calculado para $\mathrm{C}_{10} \mathrm{H}_{11} \mathrm{ClBrNO}_{2}$ : 290.9662; encontrado: 290.9667.

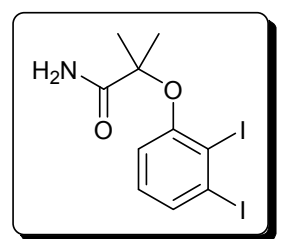

2-(2,3-Diyodofenoxi)-2-metilpropanamida (24da)

Sólido blanco.

P.f. $=131-133^{\circ} \mathrm{C}$.

${ }^{1}$ H RMN $\left(300 \mathrm{MHz}, \mathrm{CDCl}_{3}\right): \delta=7.59(\mathrm{dd}, J=7.7,1.4 \mathrm{~Hz}, 1 \mathrm{H}), 7.01(\mathrm{t}$ ap, $J=8.0 \mathrm{~Hz}, 1 \mathrm{H}), 6.91(\mathrm{dd}, J=8.2$, $1.4 \mathrm{~Hz}, 1 \mathrm{H}), 6.84(\mathrm{sa}, 1 \mathrm{H}), 6.29(\mathrm{sa}, 1 \mathrm{H}), 1.63(\mathrm{~s}, 6 \mathrm{H}) \mathrm{ppm}$.

${ }^{13}$ C RMN (75.4 MHz, $\left.\mathrm{CDCl}_{3}\right): \delta=177.2(\mathrm{C}), 155.5(\mathrm{C}), 134.1(\mathrm{CH}), 130.3(\mathrm{CH}), 117.7(\mathrm{CH}), 109.5(\mathrm{C}), 106.4$ (C), $83.9(\mathrm{C}), 25.1\left(2 \times \mathrm{CH}_{3}\right) \mathrm{ppm}$.

IR $\left(\mathrm{KBr}, \mathrm{cm}^{-1}\right): 3465,3263,1682(\mathrm{C}=\mathrm{O}), 1429,1141,953,564$.

EMBR (IE), m/z (\%): 431 (M+1 1), 387 (16), 346 (88), 304 (100), 260 (10), 218 (11), 86 (59), 58 (18).

EMAR calculado para $\mathrm{C}_{10} \mathrm{H}_{11} \mathrm{I}_{2} \mathrm{NO}_{2}$ : 430.8879 ; encontrado: 430.8891 .

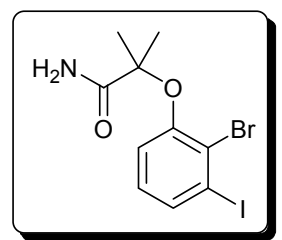

2-(2-Bromo-3-yodofenoxi)-2-metilpropanamida (24db)

Sólido blanco.

P.f. $=134-136^{\circ} \mathrm{C}$.

${ }^{1}$ H RMN (400 MHz, $\left.\mathrm{CDCl}_{3}\right): \delta=7.58(\mathrm{~d}, J=7.6 \mathrm{~Hz}, 1 \mathrm{H}), 7.02(\mathrm{~d}, J=7.9 \mathrm{~Hz}, 1 \mathrm{H}), 6.98-6.92(\mathrm{~m}, 2 \mathrm{H}), 6.27$ (sa, $1 \mathrm{H}), 1.59(\mathrm{~s}, 6 \mathrm{H}) \mathrm{ppm}$.

${ }^{13}$ C RMN (100.6 MHz, $\left.\mathrm{CDCl}_{3}\right): \delta=177.4(\mathrm{C}), 152.4(\mathrm{C}), 134.9(\mathrm{CH}), 129.2(\mathrm{CH}), 124.8(\mathrm{C}), 120.3(\mathrm{CH}), 102.8$ (C), $84.2(\mathrm{C}), 24.9\left(2 \times \mathrm{CH}_{3}\right) \mathrm{ppm}$.

IR $\left(\mathrm{KBr}, \mathrm{cm}^{-1}\right): 3444,3184,1680(\mathrm{C}=\mathrm{O}), 1566,1437,1154,966,764,584$.

EMBR (IE), m/z (\%): $385\left(\mathrm{M}^{+}+2,1\right), 383\left(\mathrm{M}^{+}, 1\right), 341$ (17), 339 (18), 304 (100), 300 (50), 298 (53), 86 (96).

EMAR calculado para $\mathrm{C}_{10} \mathrm{H}_{11} \mathrm{BrINO}_{2}$ : 382.9018; encontrado: 382.9001 .

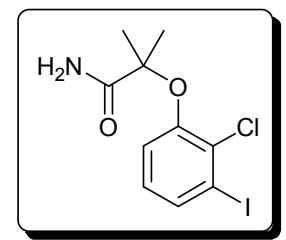

2-(2-Cloro-3-yodofenoxi)-2-metilpropanamida (24dc)

Sólido blanco.

P.f. $=130-132^{\circ} \mathrm{C}$.

${ }^{1} \mathbf{H}$ RMN (400 MHz, $\left.\mathrm{CDCl}_{3}\right): \delta=7.58(\mathrm{dd}, J=8.1,1.1 \mathrm{~Hz}, 1 \mathrm{H}), 7.06(\mathrm{dd}, J=8.1,1.1 \mathrm{~Hz}, 1 \mathrm{H}), 6.95(\mathrm{sa}, 1 \mathrm{H})$, $6.90(\mathrm{t}, J=8.1 \mathrm{~Hz}, 1 \mathrm{H}), 6.24(\mathrm{sa}, 1 \mathrm{H}), 1.57(\mathrm{~s}, 6 \mathrm{H}) \mathrm{ppm}$.

${ }^{13} \mathbf{C}$ RMN (100.6 MHz, $\left.\mathrm{CDCl}_{3}\right): \delta=177.3(\mathrm{C}), 151.0(\mathrm{C}), 134.9(\mathrm{CH}), 132.2(\mathrm{C}), 128.4(\mathrm{CH}), 121.4(\mathrm{CH}), 99.6$ (C), $84.1(\mathrm{C}), 24.9\left(2 \times \mathrm{CH}_{3}\right) \mathrm{ppm}$.

IR $\left(\mathrm{KBr}, \mathrm{cm}^{-1}\right): 3454,3175,1680(\mathrm{C}=\mathrm{O}), 1568,1442,1155,968,765,586$.

EMBR (IE), m/z (\%): $339\left(\mathrm{M}^{+}, 1\right), 304$ (38), 295 (25), 256 (19), 254 (59), 86 (100).

EMAR calculado para $\mathrm{C}_{10} \mathrm{H}_{11} \mathrm{ClINO}_{2}$ : 338.9523 ; encontrado: 338.9524 . 


\section{A.3.4 Sintesis de las N-(2,3-dihalofenil)-2-hidroxi-2-metilpropanamidas $\mathbf{2 5}$}

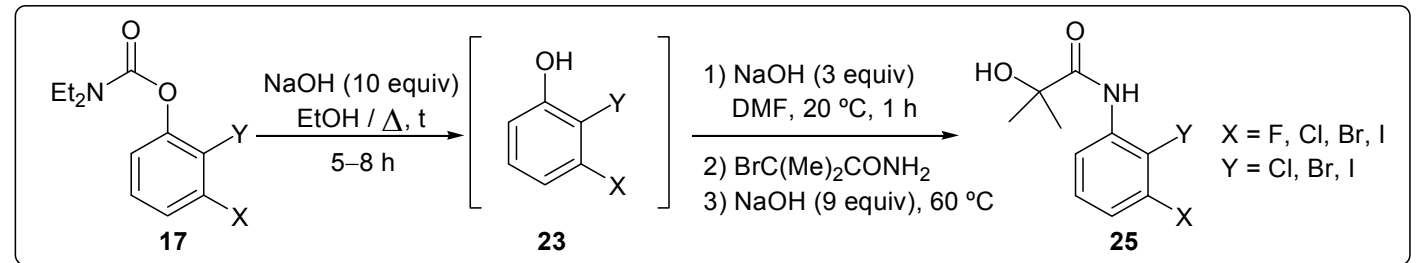

A una disolución del correspondiente carbamato $17(2 \mathrm{mmol})$ en EtOH $(20 \mathrm{~mL})$ se añade $\mathrm{NaOH}(800 \mathrm{mg}, 20 \mathrm{mmol})$. La mezcla se agita a reflujo durante 5-8 horas (la reacción se sigue por CG-EM). Posteriormente, la mezcla de reacción se deja enfriar a temperatura ambiente y se elimina el EtOH a presión reducida $(20 \mathrm{~mm} \mathrm{Hg})$. El residuo se diluye en $\mathrm{Et}_{2} \mathrm{O}$ y se lava con $\mathrm{H}_{2} \mathrm{O}(3 \times 15 \mathrm{~mL})$. La fase acuosa se enfría a $0{ }^{\circ} \mathrm{C}$ y se neutraliza utilizando una disolución de $\mathrm{HCl} 1 \mathrm{M}$. La fase acuosa se extrae con $\mathrm{Et}_{2} \mathrm{O}(3 \times 20 \mathrm{~mL})$. La fase orgánica resultante de esta extracción se seca sobre $\mathrm{Na}_{2} \mathrm{SO}_{4}$ anhidro y el disolvente se elimina a presión reducida. Sin una posterior purificación, el bruto de reacción se disuelve en DMF seca $(5 \mathrm{~mL})$ bajo atmósfera de nitrógeno y se adiciona $\mathrm{NaOH}(240 \mathrm{mg}$, $6 \mathrm{mmol}$ ). La disolución resultante se mantiene 1 hora a $20{ }^{\circ} \mathrm{C}$ seguida de la adición de 2-bromo-2metilpropanamida (990 mg, $6 \mathrm{mmol}$ ). Una vez completada la alquilación del correspondiente fenol (monitorizada por CG-EM), se adiciona $\mathrm{NaOH}(720 \mathrm{mg}, 18 \mathrm{mmol})$ y la mezcla de reacción se calienta a $60{ }^{\circ} \mathrm{C}$ durante 2 horas. La posterior hidrólisis permite obtener la correspondiente anilida $\mathbf{2 5}$ como un sólido recuperado mediante filtración.

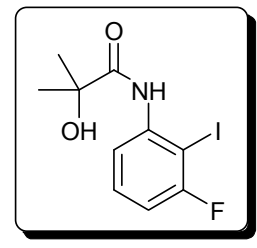

$N$-(3-Fluoro-2-yodofenil)-2-hidroxi-2-metilpropanamida (25aa)

Sólido blanco.

P.f. $=95-97^{\circ} \mathrm{C}$.

${ }^{1}$ H RMN $\left(300 \mathrm{MHz}, \mathrm{CDCl}_{3}\right): \delta=9.31(\mathrm{sa}, 1 \mathrm{H}), 8.13(\mathrm{~d}, J=8.3 \mathrm{~Hz}, 1 \mathrm{H}), 7.35-7.26(\mathrm{~m}, 1 \mathrm{H}), 6.83(\mathrm{t}, J=8.3 \mathrm{~Hz}$, $1 \mathrm{H}), 2.71(\mathrm{~s}, 1 \mathrm{H}), 1.58(\mathrm{~s}, 6 \mathrm{H}) \mathrm{ppm}$

${ }^{13} \mathbf{C}$ RMN (75.4 MHz, $\left.\mathrm{CDCl}_{3}\right): \delta=175.0(\mathrm{C}), 161.8(\mathrm{~d}, J=243.7 \mathrm{~Hz}, \mathrm{C}), 139.8(\mathrm{~d}, J=3.5 \mathrm{~Hz}, \mathrm{C}), 130.5(\mathrm{~d}, J=$ $9.0 \mathrm{~Hz}, \mathrm{CH}), 116.5$ (d, $J=2.9 \mathrm{~Hz}, \mathrm{CH}), 111.2(\mathrm{~d}, J=23.8 \mathrm{~Hz}, \mathrm{CH}), 78.1$ (d, $J=27.9 \mathrm{~Hz}, \mathrm{C}), 74.7(\mathrm{C})$, $28.1\left(2 \times \mathrm{CH}_{3}\right) \mathrm{ppm}$.

IR $\left(\mathrm{KBr}, \mathrm{cm}^{-1}\right): 3420,3368,3289,1661(\mathrm{C}=\mathrm{O}), 1462,1416,776$.

EMBR (IE), m/z (\%): 323 (M , 27), 265 (33), 237 (100), 138 (19), 59 (81).

EMAR calculado para $\mathrm{C}_{10} \mathrm{H}_{11} \mathrm{FINO}_{2}: 322.9819$; encontrado: 322.9812

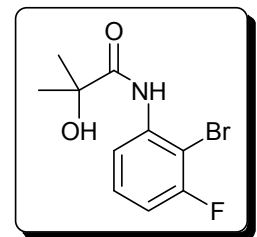

$\mathrm{N}$-(2-Bromo-3-fluorofenil)-2-hidroxi-2-metilpropanamida (25ab)

Sólido blanco.

P.f. $=102-104^{\circ} \mathrm{C}$.

${ }^{1}$ H RMN $\left(300 \mathrm{MHz}, \mathrm{CDCl}_{3}\right): \delta=9.47(\mathrm{sa}, 1 \mathrm{H}), 8.20(\mathrm{dt}, J=8.3,1.4 \mathrm{~Hz}, 1 \mathrm{H}), 7.25(\mathrm{td}, J=8.3,6.2 \mathrm{~Hz}, 1 \mathrm{H})$, $6.87(\mathrm{td}, J=8.3,1.4 \mathrm{~Hz}, 1 \mathrm{H}), 3.01(\mathrm{~s}, 1 \mathrm{H}), 1.56(\mathrm{~s}, 6 \mathrm{H}) \mathrm{ppm}$. 
${ }^{13} \mathbf{C} \mathbf{R M N}\left(75.4 \mathrm{MHz}, \mathrm{CDCl}_{3}\right): \delta=175.1(\mathrm{C}), 159.2(\mathrm{~d}, J=245.9 \mathrm{~Hz}, \mathrm{C}), 137.2(\mathrm{~d}, J=2.2 \mathrm{~Hz}, \mathrm{C}), 129.0(\mathrm{~d}, J=$ $8.8 \mathrm{~Hz}, \mathrm{CH}), 116.3(\mathrm{~d}, J=3.2 \mathrm{~Hz}, \mathrm{CH}), 111.6(\mathrm{~d}, J=22.0 \mathrm{~Hz}, \mathrm{CH}), 101.3(\mathrm{~d}, J=23.2 \mathrm{~Hz}, \mathrm{C}), 74.7(\mathrm{C})$, $28.0\left(2 \times \mathrm{CH}_{3}\right) \mathrm{ppm}$.

IR $\left(\mathrm{KBr}, \mathrm{cm}^{-1}\right): 3326,3310,1665(\mathrm{C}=\mathrm{O}), 1601,1469,1422,1252,777$.

EMBR (IE), m/z (\%): $277\left(\mathrm{M}^{+}+2,12\right), 275\left(\mathrm{M}^{+}, 13\right), 219(15), 217$ (15), 191 (61), $189(73), 59$ (100).

EMAR calculado para $\mathrm{C}_{10} \mathrm{H}_{11} \mathrm{BrFNO}_{2}$ : 274.9957; encontrado: 274.9958.

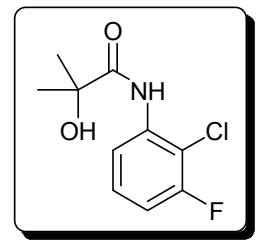

$\mathrm{N}$-(2-Cloro-3-fluorofenil)-2-hidroxi-2-metilpropanamida (25ac)

Sólido blanco.

P.f. $=106-108^{\circ} \mathrm{C}$.

${ }^{1}$ H RMN (300 MHz, $\left.\mathrm{CDCl}_{3}\right): \delta=9.44(\mathrm{sa}, 1 \mathrm{H}), 8.23(\mathrm{~d}, J=8.4 \mathrm{~Hz}, 1 \mathrm{H}), 7.27-7.16(\mathrm{~m}, 1 \mathrm{H}), 6.90(\mathrm{t}, J=8.4 \mathrm{~Hz}$, $1 \mathrm{H}), 2.84(\mathrm{~s}, 1 \mathrm{H}), 1.56(\mathrm{~s}, 6 \mathrm{H}) \mathrm{ppm}$.

${ }^{13} \mathbf{C}$ RMN (75.4 MHz, $\left.\mathrm{CDCl}_{3}\right): \delta=174.9(\mathrm{C}), 158.2(\mathrm{~d}, J=247.4 \mathrm{~Hz}, \mathrm{C}), 136.0(\mathrm{~d}, J=1.2 \mathrm{~Hz}, \mathrm{C}), 128.0(\mathrm{~d}, J=$ $8.7 \mathrm{~Hz}, \mathrm{CH}), 116.0(\mathrm{~d}, J=3.4 \mathrm{~Hz}, \mathrm{CH}), 111.5(\mathrm{~d}, J=20.7 \mathrm{~Hz}, \mathrm{CH}), 111.0(\mathrm{~d}, J=20.0 \mathrm{~Hz}, \mathrm{C}), 74.7$ (C), $28.0\left(2 \times \mathrm{CH}_{3}\right) \mathrm{ppm}$.

IR $\left(\mathrm{KBr}, \mathrm{cm}^{-1}\right): 3418,3340,1677(\mathrm{C}=\mathrm{O}), 1522,1472,1253,1132,782$.

EMBR (IE), m/z (\%): $233\left(\mathrm{M}^{+}+2,7\right), 231\left(\mathrm{M}^{+}, 21\right), 173$ (25), 147 (28), 145 (97), 59 (100).

EMAR calculado para $\mathrm{C}_{10} \mathrm{H}_{11} \mathrm{ClFNO}_{2}$ : 231.0462; encontrado: 231.0462 .

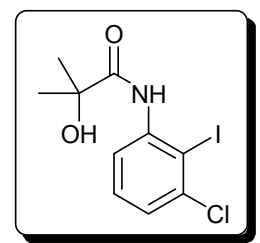

N-(3-Cloro-2-yodofenil)-2-hidroxi-2-metilpropanamida (25ba)

Sólido blanco.

P.f. $=113-115^{\circ} \mathrm{C}$.

${ }^{1}$ H RMN (300 MHz, $\left.\mathrm{CDCl}_{3}\right): \delta=9.33(\mathrm{sa}, 1 \mathrm{H}), 8.21(\mathrm{dd}, J=7.8,1.5 \mathrm{~Hz}, 1 \mathrm{H}), 7.31-7.21(\mathrm{~m}, 2 \mathrm{H}), 2.47(\mathrm{~s}, 1 \mathrm{H})$, $1.58(\mathrm{~s}, 6 \mathrm{H}) \mathrm{ppm}$.

${ }^{13} \mathbf{C}$ RMN (75.4 MHz, $\left.\mathrm{CDCl}_{3}\right): \delta=175.0(\mathrm{C}), 140.4(\mathrm{C}), 139.1(\mathrm{C}), 129.8(\mathrm{CH}), 125.1(\mathrm{CH}), 118.9(\mathrm{CH}), 95.1$ (C), $74.7(\mathrm{C}), 28.0\left(2 \times \mathrm{CH}_{3}\right) \mathrm{ppm}$.

IR $\left(\mathrm{KBr}, \mathrm{cm}^{-1}\right): 3398,3291,1662(\mathrm{C}=\mathrm{O}), 1575,1539,1444,1396,1126,776$.

EMBR (IE), m/z (\%): $341\left(\mathrm{M}^{+}+2,3\right), 339\left(\mathrm{M}^{+}, 8\right), 281$ (10), 253 (62), 194 (15), 154 (24), 59 (100).

EMAR calculado para $\mathrm{C}_{10} \mathrm{H}_{11} \mathrm{ClINO}_{2}$ : 338.9523 ; encontrado: 338.9514 .

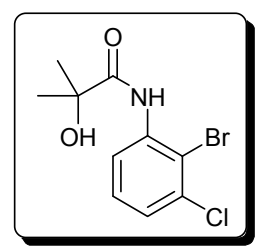

$\mathrm{N}$-(2-Bromo-3-clorofenil)-2-hidroxi-2-metilpropanamida (25bb)

Sólido blanco.

P.f. $=107-109^{\circ} \mathrm{C}$.

${ }^{1}$ H RMN (300 MHz, $\left.\mathrm{CDCl}_{3}\right): \delta=9.48(\mathrm{sa}, 1 \mathrm{H}), 8.34(\mathrm{dd}, J=7.5,2.3 \mathrm{~Hz}, 1 \mathrm{H}), 7.28-7.19(\mathrm{~m}, 2 \mathrm{H}), 2.56(\mathrm{~s}, 1 \mathrm{H})$, $1.57(\mathrm{~s}, 6 \mathrm{H}) \mathrm{ppm}$.

${ }^{13}$ C RMN (75.4 MHz, $\left.\mathrm{CDCl}_{3}\right): \delta=174.7(\mathrm{C}), 137.5(\mathrm{C}), 134.9(\mathrm{C}), 128.7(\mathrm{CH}), 125.5(\mathrm{CH}), 119.1(\mathrm{CH}), 114.4$ (C), $74.8(\mathrm{C}), 28.1\left(2 \times \mathrm{CH}_{3}\right) \mathrm{ppm}$.

IR $\left(\mathrm{KBr}, \mathrm{cm}^{-1}\right): 3390,3315,1663(\mathrm{C}=\mathrm{O}), 1582,1543,1450,1404,777$.

EMBR (IE), m/z (\%): $293\left(\mathrm{M}^{+}+2,5\right) 291\left(\mathrm{M}^{+}, 4\right), 235$ (5), 233 (5), 207 (35), 205 (27), 154 (14), 59 (100).

EMAR calculado para $\mathrm{C}_{10} \mathrm{H}_{11} \mathrm{BrClNO}_{2}$ : 290.9662; encontrado: 290.9661. 


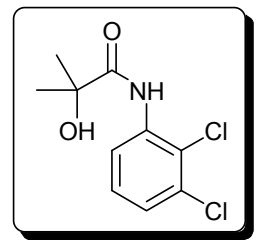

$N$-(2,3-Diclorofenil)-2-hidroxi-2-metilpropanamida (25bc)

Sólido blanco.

P.f. $=109-111^{\circ} \mathrm{C}$.

${ }^{1}$ H RMN (300 MHz, $\left.\mathrm{CDCl}_{3}\right): \delta=9.50(\mathrm{sa}, 1 \mathrm{H}), 8.37-8.29(\mathrm{~m}, 1 \mathrm{H}), 7.22-7.15(\mathrm{~m}, 2 \mathrm{H}), 3.11(\mathrm{~s}, 1 \mathrm{H}), 1.55(\mathrm{~s}, 6 \mathrm{H}) \mathrm{ppm}$.

${ }^{13}$ C RMN (75.4 MHz, $\left.\mathrm{CDCl}_{3}\right): \delta=175.1(\mathrm{C}), 136.0(\mathrm{C}), 132.8(\mathrm{C}), 127.8(\mathrm{CH}), 125.4(\mathrm{CH}), 122.0(\mathrm{C}), 118.9$ $(\mathrm{CH}), 74.6(\mathrm{C}), 27.9\left(2 \times \mathrm{CH}_{3}\right) \mathrm{ppm}$.

IR $\left(\mathrm{KBr}, \mathrm{cm}^{-1}\right): 3422,3337,1671(\mathrm{C}=\mathrm{O}), 1509,1407,1124,778,701$.

EMBR (IE), m/z (\%): 251 (M+4, 2), 249 (M+2, 12), $247\left(\mathrm{M}^{+}, 21\right), 189$ (20), 163 (56), 161 (89), 59 (100)

Análisis elemental calculado (\%) para $\mathrm{C}_{10} \mathrm{H}_{11} \mathrm{Cl}_{2} \mathrm{NO}_{2}$ : C, 48.41; H, 4.47; N, 5.65; encontrado: $\mathrm{C}, 48.49 ; \mathrm{H}, 4.47$; N, 5.76.

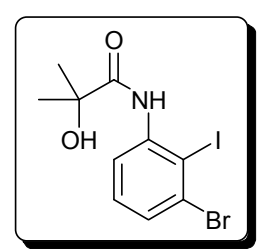

$N$-(3-Bromo-2-yodofenil)-2-hidroxi-2-metilpropanamida (25ca)

Sólido blanco.

P.f. $=118-120^{\circ} \mathrm{C}$.

${ }^{1} \mathbf{H}$ RMN (300 MHz, $\left.\mathrm{CDCl}_{3}\right): \delta=9.33(\mathrm{sa}, 1 \mathrm{H}), 8.23(\mathrm{dd}, J=8.1,1.4 \mathrm{~Hz}, 1 \mathrm{H}), 7.40(\mathrm{dd}, J=8.1,1.4 \mathrm{~Hz}, 1 \mathrm{H})$, $7.22(\mathrm{t}, J=8.1 \mathrm{~Hz}, 1 \mathrm{H}), 2.55(\mathrm{~s}, 1 \mathrm{H}), 1.57(\mathrm{~s}, 6 \mathrm{H}) \mathrm{ppm}$.

${ }^{13}$ C RMN (75.4 MHz, $\left.\mathrm{CDCl}_{3}\right): \delta=174.9(\mathrm{C}), 140.5(\mathrm{C}), 130.4(\mathrm{C}), 130.1(\mathrm{CH}), 128.5(\mathrm{CH}), 119.4(\mathrm{CH}), 98.2$ (C), $74.7(\mathrm{C}), 28.0\left(2 \times \mathrm{CH}_{3}\right) \mathrm{ppm}$.

IR $\left(\mathrm{KBr}, \mathrm{cm}^{-1}\right): 3387,3285,1652(\mathrm{C}=\mathrm{O}), 1651,1525,1392,776,693$.

EMBR (IE), m/z (\%): 385 (M+2, 3), 383 (M+1, 3), 299 (24), 297 (25), 240 (10), 238 (10), 200 (15), 59 (100).

EMAR calculado para $\mathrm{C}_{10} \mathrm{H}_{11} \mathrm{BrINO}_{2}$ : 382.9018; encontrado: 382.9012 .

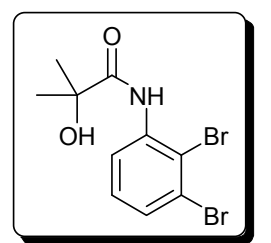

$N$-(2,3-Dibromofenil)-2-hidroxi-2-metilpropanamida (25cb)

Sólido blanco.

P.f. $=119-121^{\circ} \mathrm{C}$.

${ }^{1} \mathbf{H}$ RMN $\left(300 \mathrm{MHz}, \mathrm{CDCl}_{3}\right): \delta=9.51(\mathrm{sa}, 1 \mathrm{H}), 8.34(\mathrm{dd}, J=8.1,1.4 \mathrm{~Hz}, 1 \mathrm{H}), 7.36(\mathrm{dd}, J=8.1,1.4 \mathrm{~Hz}, 1 \mathrm{H})$, $7.15(\mathrm{t}, J=8.1 \mathrm{~Hz}, 1 \mathrm{H}), 3.01(\mathrm{sa}, 1 \mathrm{H}), 1.55(\mathrm{~s}, 6 \mathrm{H}) \mathrm{ppm}$.

${ }^{13}$ C RMN (75.4 MHz, $\left.\mathrm{CDCl}_{3}\right): \delta=175.1(\mathrm{C}), 137.4(\mathrm{C}), 129.0(\mathrm{CH}), 128.9(\mathrm{CH}), 125.2(\mathrm{C}), 119.7(\mathrm{CH}), 116.6$ (C), $74.6(\mathrm{C}), 28.0\left(2 \times \mathrm{CH}_{3}\right) \mathrm{ppm}$.

IR $\left(\mathrm{KBr}, \mathrm{cm}^{-1}\right): 3444,3224,1668(\mathrm{C}=\mathrm{O}), 1575,1567,1515,780$.

EMBR (IE), m/z (\%): 339 (M+4, 2), 337 (M+2, 5), 335 (M+, 2), 279 (6), 253 (19), 251 (38), 249 (19), 58 (100).

EMAR calculado para $\mathrm{C}_{10} \mathrm{H}_{11} \mathrm{Br}_{2} \mathrm{NO}_{2}$ : 334.9157; encontrado: 334.9165 .

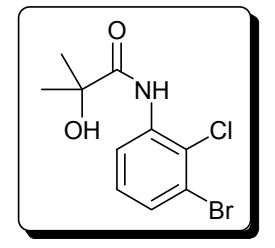

$\mathrm{N}$-(3-Bromo-2-clorofenil)-2-hidroxi-2-metilpropanamida (25cc)

Sólido blanco.

P.f. $=114-116^{\circ} \mathrm{C}$ 
${ }^{1} \mathbf{H}$ RMN $\left(300 \mathrm{MHz}, \mathrm{CDCl}_{3}\right): \delta=9.51(\mathrm{sa}, 1 \mathrm{H}), 8.36(\mathrm{dd}, J=8.2,1.1 \mathrm{~Hz}, 1 \mathrm{H}), 7.34(\mathrm{dd}, J=8.2,1.1 \mathrm{~Hz}, 1 \mathrm{H})$, $7.10(\mathrm{t}, J=8.2,1 \mathrm{H}), 3.22(\mathrm{~s}, 1 \mathrm{H}), 1.55(\mathrm{~s}, 6 \mathrm{H}) \mathrm{ppm}$.

${ }^{13} \mathbf{C}$ RMN (75.4 MHz, $\mathrm{CDCl}_{3}$ ): $\delta=175.2(\mathrm{C}), 135.9(\mathrm{C}), 128.7(\mathrm{CH}), 128.2(\mathrm{CH}), 123.8(\mathrm{C}), 122.7(\mathrm{C}), 119.6$ $(\mathrm{CH}), 74.5(\mathrm{C}), 27.9\left(2 \times \mathrm{CH}_{3}\right) \mathrm{ppm}$.

IR $\left(\mathrm{KBr}, \mathrm{cm}^{-1}\right): 3343,3323,1664(\mathrm{C}=\mathrm{O}), 1526,1406,1132,777,569$.

EMBR (IE), m/z (\%): 295 (M+4, 2), 293 (M+2, 10) 291 (M+, 9), 209 (14), 207 (60), 205 (46), 59 (100).

EMAR calculado para $\mathrm{C}_{10} \mathrm{H}_{11} \mathrm{ClBrNO}_{2}$ : 290.9662; encontrado: 290.9672.

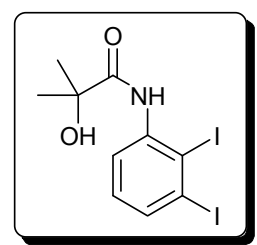

$N$-(2,3-Diyodofenil)-2-hidroxi-2-metilpropanamida (25da)

Sólido blanco.

P.f. $=144-146^{\circ} \mathrm{C}$

${ }^{1}$ H RMN $\left(300 \mathrm{MHz}, \mathrm{CDCl}_{3}\right): \delta=9.28(\mathrm{sa}, 1 \mathrm{H}), 8.24(\mathrm{dd}, J=8.2,1.4 \mathrm{~Hz}, 1 \mathrm{H}), 7.67(\mathrm{dd}, J=7.8,1.4 \mathrm{~Hz}, 1 \mathrm{H})$, 7.09 ( $\mathrm{t}$ ap $, J=8.0 \mathrm{~Hz}, 1 \mathrm{H}), 2.53(\mathrm{sa}, 1 \mathrm{H}), 1.57(\mathrm{~s}, 6 \mathrm{H}) \mathrm{ppm}$.

${ }^{13} \mathbf{C}$ RMN (75.4 MHz, $\left.\mathrm{CDCl}_{3}\right): \delta=175.1(\mathrm{C}), 140.0(\mathrm{C}), 135.4(\mathrm{CH}), 130.4(\mathrm{CH}), 120.2(\mathrm{CH}), 108.8(\mathrm{C}), 104.5$ (C), $74.5(\mathrm{C}), 28.0\left(2 \times \mathrm{CH}_{3}\right) \mathrm{ppm}$.

IR $\left(\mathrm{KBr}, \mathrm{cm}^{-1}\right): 3318,1651(\mathrm{C}=\mathrm{O}), 1568,1523,1386,773$.

EMBR (IE), m/z (\%): 431 (M+, 21), 372 (8), 345 (85), 286 (62), 246 (44), 218 (14), 91 (15), 59 (100).

EMAR calculado para $\mathrm{C}_{10} \mathrm{H}_{11} \mathrm{I}_{2} \mathrm{NO}_{2}$ : 430.8879 ; encontrado: 430.8873 .

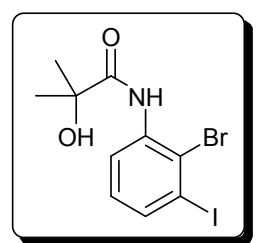

\section{N-(2-Bromo-3-yodofenil)-2-hidroxi-2-metilpropanamida (25db)}

Sólido blanco.

P.f. $=110-112^{\circ} \mathrm{C}$.

${ }^{1} \mathbf{H}$ RMN $\left(400 \mathrm{MHz}, \mathrm{CDCl}_{3}\right): \delta=9.47(\mathrm{sa}, 1 \mathrm{H}), 8.36(\mathrm{dd}, J=8.1,1.1 \mathrm{~Hz}, 1 \mathrm{H}), 7.60(\mathrm{dd}, J=8.1,1.1 \mathrm{~Hz}, 1 \mathrm{H})$, $7.01(\mathrm{t}, J=8.1 \mathrm{~Hz}, 1 \mathrm{H}), 3.01(\mathrm{sa}, 1 \mathrm{H}), 1.54(\mathrm{~s}, 6 \mathrm{H}) \mathrm{ppm}$.

${ }^{13} \mathbf{C}$ RMN (100.6 MHz, $\left.\mathrm{CDCl}_{3}\right): \delta=175.1(\mathrm{C}), 136.7(\mathrm{C}), 135.5(\mathrm{CH}), 129.5(\mathrm{CH}), 121.1(\mathrm{C}), 120.6(\mathrm{CH}), 101.5$ (C), $74.5(\mathrm{C}), 27.9\left(2 \times \mathrm{CH}_{3}\right) \mathrm{ppm}$.

IR $\left(\mathrm{KBr}, \mathrm{cm}^{-1}\right): 3334,1661(\mathrm{C}=\mathrm{O}), 1578,1529,1392,774$.

EMBR (IE), m/z (\%): 385 (M+2, 11), 383 (M+1 11), 304 (40), 299 (55), 297 (46), 246 (34), 207 (77), 59 (100).

EMAR calculado para $\mathrm{C}_{10} \mathrm{H}_{11} \mathrm{BrINO}_{2}$ : 382.9018 ; encontrado: 382.9001 .

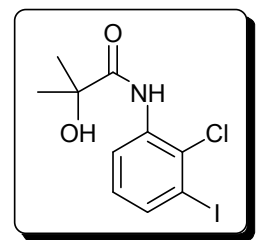

$\mathrm{N}$-(2-Cloro-3-yodofenil)-2-hidroxi-2-metilpropanamida (25dc)

Sólido blanco.

P.f. $=101-103^{\circ} \mathrm{C}$.

${ }^{1} \mathbf{H}$ RMN $\left(400 \mathrm{MHz}, \mathrm{CDCl}_{3}\right): \delta=9.40(\mathrm{sa}, 1 \mathrm{H}), 8.33(\mathrm{dd}, J=8.1,1.2 \mathrm{~Hz}, 1 \mathrm{H}), 7.52(\mathrm{dd}, J=8.1,1.2 \mathrm{~Hz}, 1 \mathrm{H})$, $6.89(\mathrm{t}, J=8.1 \mathrm{~Hz}, 1 \mathrm{H}), 2.94(\mathrm{~s}, 1 \mathrm{H}), 1.48(\mathrm{~s}, 6 \mathrm{H}) \mathrm{ppm}$.

${ }^{13} \mathbf{C}$ RMN (100.6 MHz, $\left.\mathrm{CDCl}_{3}\right): \delta=175.1(\mathrm{C}), 135.2(\mathrm{CH}), 135.1(\mathrm{C}), 128.8(\mathrm{CH}), 127.5(\mathrm{C}), 120.6(\mathrm{CH}), 98.2$ (C), $74.6(\mathrm{C}), 27.9\left(2 \times \mathrm{CH}_{3}\right) \mathrm{ppm}$.

IR $\left(\mathrm{KBr}, \mathrm{cm}^{-1}\right): 3343,3325,1662(\mathrm{C}=\mathrm{O}), 1568,1528,1397,776$.

EMBR (IE), m/z (\%): $341\left(\mathrm{M}^{+}+2,10\right), 339\left(\mathrm{M}^{+}, 30\right), 304$ (41), 281 (31), 255 (31), 253 (99), 246 (36), 59 (100).

EMAR calculado para $\mathrm{C}_{10} \mathrm{H}_{11} \mathrm{ClINO}_{2}$ : 338.9523 ; encontrado: 338.9522 . 


\section{A.3.5 Sintesis de los 3-halo-2-yodoanisoles 26}

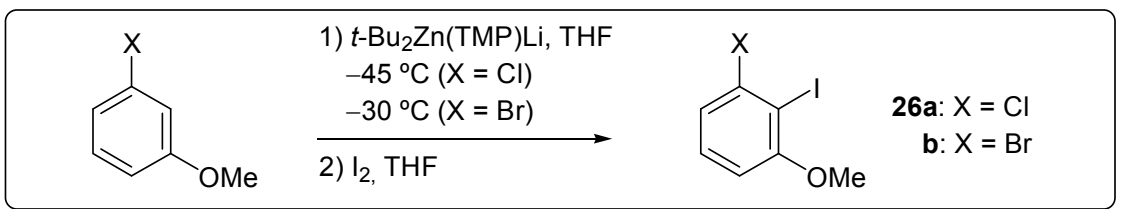

A. Se adiciona $t$-BuLi $(29.33 \mathrm{~mL}$ de una disolución $1.5 \mathrm{M}$ en pentano, $44 \mathrm{mmol})$ sobre una disolución de $\mathrm{ZnCl}_{2}(2.99 \mathrm{~g}, 22 \mathrm{mmol})$ en $30 \mathrm{~mL}$ de THF a $-78^{\circ} \mathrm{C}$. La disolución resultante (A) se agita a $20^{\circ} \mathrm{C}$ durante 30 minutos.

B. Por otro lado, a una disolución de 2,2,6,6-tetrametilpiperidina (2.82 g, $20 \mathrm{mmol}$ ) en THF (30 $\mathrm{mL}) \mathrm{a}-78^{\circ} \mathrm{C}$ se le añade $n$-BuLi (12.5 $\mathrm{mL}$ de una disolución $1.6 \mathrm{M}$ en hexano) y se deja que evolucione a $20^{\circ} \mathrm{C}$ durante 30 minutos. La mezcla preparada en el paso A se adiciona sobre esta última a $-78^{\circ} \mathrm{C}$ y se agita durante 30 minutos a $0{ }^{\circ} \mathrm{C}$. Así se genera la disolución de $t$ - $\mathrm{Bu}_{2} \mathrm{Zn}(\mathrm{TMP}) \mathrm{Li}(\mathrm{B})$.

Una vez preparado el organozincato (B), se adiciona el correspondiente 3-haloanisol 26 (10 mmol) a $-78{ }^{\circ} \mathrm{C}$ y se permite que la mezcla alcance la temperatura de $-45^{\circ} \mathrm{C}(\mathrm{X}=\mathrm{Cl})$ o de $-30{ }^{\circ} \mathrm{C}$ $(\mathrm{X}=\mathrm{Br})$. La agitación se mantiene a esa temperatura durante 12 horas, tras las cuales se adiciona yodo (17.78 g, $70 \mathrm{mmol}$ ). Después, se deja alcanzar temperatura ambiente lentamente y se continúa la agitación durante 2 horas. La mezcla de reacción resultante se hidroliza con una disolución al $10 \%$ de $\mathrm{Na}_{2} \mathrm{~S}_{2} \mathrm{O}_{3}$ y se extrae con $\mathrm{Et}_{2} \mathrm{O}(3 \times 30 \mathrm{~mL})$. La fase orgánica se seca sobre $\mathrm{Na}_{2} \mathrm{SO}_{4}$ anhidro y los disolventes se evaporan a presión reducida $(20 \mathrm{~mm} \mathrm{Hg})$. El residuo obtenido se purifica por cromatografía de columna (hexano / AcOEt). De esta forma se aislan los 3-halo-2-yodoanisoles 26.

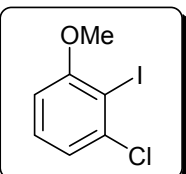

1-Cloro-3-metoxi-2-yodobenceno (26a)

Sólido blanco.

P.f. $=52-54{ }^{\circ} \mathrm{C}\left(\right.$ lit. $\left.^{253}=53.5^{\circ} \mathrm{C}\right)$.

${ }^{1} \mathbf{H}$ RMN $\left(300 \mathrm{MHz}, \mathrm{CDCl}_{3}\right): \delta=7.22(\mathrm{t}, J=8.1 \mathrm{~Hz}, 1 \mathrm{H}), 7.08(\mathrm{ddd}, J=8.1,1.3,0.5 \mathrm{~Hz}, 1 \mathrm{H}), 6.67(\mathrm{dd}, J=8.1$, $1.3 \mathrm{~Hz}, 1 \mathrm{H}), 3.87(\mathrm{~s}, 3 \mathrm{H}) \mathrm{ppm}$.

${ }^{13} \mathbf{C}$ RMN (75.4 MHz, $\left.\mathrm{CDCl}_{3}\right): \delta=159.9(\mathrm{C}), 139.8(\mathrm{C}), 129.9(\mathrm{CH}), 121.9(\mathrm{CH}), 108.5(\mathrm{CH}), 91.3(\mathrm{C}), 56.9$ $\left(\mathrm{CH}_{3}\right) \mathrm{ppm}$

IR $\left(\mathrm{KBr}, \mathrm{cm}^{-1}\right): 1568,1456,1429,1258,1044,1016,768$

EMBR (IE), m/z (\%): 270 (M+2, 31), 268 (M+1 100), 253 (23), 225 (12), 126 (24), 111 (11).

EMAR calculado para $\mathrm{C}_{7} \mathrm{H}_{6} \mathrm{ClIO}$ : 267.9152; encontrado: 267.9166 .

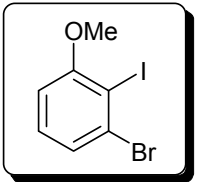

1-Bromo-3-metoxi-2-yodobenceno (26b)

Sólido blanco.

P.f. $=63-65^{\circ} \mathrm{C}\left(\right.$ lit. $\left.^{41}=62.5-64^{\circ} \mathrm{C}\right)$.

${ }^{253}$ H. H. Hodgson, A. Kershaw, J. Chem. Soc. 1929, 2917. 
${ }^{1}$ H RMN $\left(300 \mathrm{MHz}, \mathrm{CDCl}_{3}\right): \delta=7.26(\mathrm{td}, J=8.0,1.2 \mathrm{~Hz}, 1 \mathrm{H}), 7.18(\mathrm{dt}, J=8.0,1.2 \mathrm{~Hz}, 1 \mathrm{H}), 6.71(\mathrm{dd}, J=8.0$, $1.2 \mathrm{~Hz}, 1 \mathrm{H}), 3.87(\mathrm{~s}, 3 \mathrm{H}) \mathrm{ppm}$.

${ }^{13}$ C RMN (75.4 MHz, $\left.\mathrm{CDCl}_{3}\right): \delta=160.1(\mathrm{C}), 131.2(\mathrm{C}), 130.2(\mathrm{CH}), 125.2(\mathrm{CH}), 108.9(\mathrm{CH}), 94.4(\mathrm{C}), 57.0\left(\mathrm{CH}_{3}\right)$ ppm.

IR $\left(\mathrm{KBr}, \mathrm{cm}^{-1}\right): 1567,1455,1424,1260,1038,1008,823,761$.

EMBR (IE), m/z (\%): 314 (M+2, 100), 312 (M+1 100), 299 (21), 297 (20), 172 (42), 170 (40).

EMAR calculado para $\mathrm{C}_{7} \mathrm{H}_{6} \mathrm{BrIO}$ : 311.8647 ; encontrado: 311.8635 .

\section{A.3.6 Sintesis de las N-(2,3-dihalofenil)-2-hidroxi-2-metilpropanamidas 25ba,ca a partir de 26}

A una disolución del correspondiente 3-halo-2-yodoanisol 26 (4 mmol) en $\mathrm{CH}_{2} \mathrm{Cl}_{2} \mathrm{a}-78{ }^{\circ} \mathrm{C}$ se añade muy lentamente una disolución $1 \mathrm{M} \mathrm{BBr}_{3}$ en $\mathrm{CH}_{2} \mathrm{Cl}_{2}(20 \mathrm{~mL}, 20 \mathrm{mmol})$. Se permite que la mezcla de reacción alcance temperatura ambiente y se mantiene la agitación a esa temperatura durante toda la noche. A continuación, se añade $\mathrm{NaHCO}_{3}(1.68 \mathrm{~g}, 20 \mathrm{mmol})$. Se enfría la mezcla resultante a $0{ }^{\circ} \mathrm{C}$ y se adiciona lentamente $\mathrm{MeOH}(70 \mathrm{~mL})$. Después de 30 minutos a $0{ }^{\circ} \mathrm{C}$, se deja que la mezcla alcance $20^{\circ} \mathrm{C}$. Tras 1 hora de agitación, se hidroliza con $\mathrm{H}_{2} \mathrm{O}$ y la fase acuosa se extrae con $\mathrm{CH}_{2} \mathrm{Cl}_{2}(2 \times 30 \mathrm{~mL})$. La fase orgánica se seca sobre $\mathrm{Na}_{2} \mathrm{SO}_{4}$ anhidro y se elimina el disolvente a presión reducida. Sin más purificación, el correspondiente dihalofenol 23 se disuelve en DMF anhidra $(6 \mathrm{~mL})$ bajo atmósfera de $\mathrm{N}_{2}$ y se añade $\mathrm{NaOH}(480 \mathrm{mg}, 12 \mathrm{mmol})$. Después de 1 hora a 20 ${ }^{\circ} \mathrm{C}$ se adiciona 2-bromo-2-metilpropanamida (1.99 g, $\left.12 \mathrm{mmol}\right)$ y la reacción se agita a esta temperatura durante 2 horas. Una vez que se ha completado la alquilación de $\mathbf{2 3}$ (monitorizada por CG-EM), se añade $\mathrm{NaOH}(1.44 \mathrm{~g}, 36 \mathrm{mmol})$ y la reacción se calienta a $60{ }^{\circ} \mathrm{C}$ durante 2 horas. La mezcla de reacción se hidroliza con $\mathrm{H}_{2} \mathrm{O}$ y la correspondiente propanamida $25 \mathbf{b a}$ ó 25ca se recupera como un sólido tras filtración. Los datos físicos y espectroscópicos de $\mathbf{2 5 b a , c a}$ han sido detallados anteriomente.

\section{A.3.7 Obtención de las 2,3-dihaloanilinas $\mathbf{6}$ a partir de las anilidas $\mathbf{2 5}$}

Una disolución de la correspondiente anilida 25 (1 mmol) en $\mathrm{HCl}(6 \mathrm{M})$ / EtOH (1 / 1) (20 $\mathrm{mL}$ ) se calienta a reflujo durante 5-6 horas (la reacción se monitoriza por CG-EM). Después, la mezcla de reacción se enfría a temperatura ambiente y se elimina el EtOH a presión reducida $(20 \mathrm{~mm}$ $\mathrm{Hg}$ ). El residuo se diluye en AcOEt y se lava con $\mathrm{H}_{2} \mathrm{O}$. La fase acuosa se enfría a $0{ }^{\circ} \mathrm{C}$ y se neutraliza cuidadosamente con una disolución de $\mathrm{NaOH}(1 \mathrm{M})$. La fase acuosa se extrae con AcOEt $(3 \times 15$ $\mathrm{mL}$ ). Las fases orgánicas combinadas se secan sobre $\mathrm{Na}_{2} \mathrm{SO}_{4}$ anhidro y el disolvente se elimina a presión reducida. El residuo resultante se purifica mediante cromatografía de columna (hexano / AcOEt, 6 / 1) para dar la correspondiente anilina 6. Los datos físicos y espectroscópicos de $\mathbf{6 a b}$ y $\mathbf{6 a c}$ han sido detallados anteriormente.

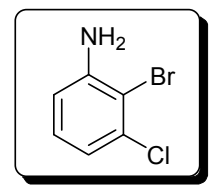

2-Bromo-3-cloroanilina (6bb) ${ }^{82}$

Sólido blanco.

P.f. $=41-43^{\circ} \mathrm{C}$.

${ }^{1} \mathbf{H}$ RMN $\left(300 \mathrm{MHz}, \mathrm{CDCl}_{3}\right): \delta=7.02(\mathrm{t}, J=8.0 \mathrm{~Hz}, 1 \mathrm{H}), 6.84(\mathrm{dd}, J=8.0,1.5 \mathrm{~Hz}, 1 \mathrm{H}), 6.63(\mathrm{dd}, J=8.0,1.5$ $\mathrm{Hz}, 1 \mathrm{H}), 4.26(\mathrm{sa}, 2 \mathrm{H}) \mathrm{ppm}$.

${ }^{13} \mathbf{C}$ RMN (75.4 MHz, $\left.\mathrm{CDCl}_{3}\right): \delta=146.1(\mathrm{C}), 135.1(\mathrm{C}), 128.4(\mathrm{CH}), 119.5(\mathrm{CH}), 113.5(\mathrm{CH}), 109.3(\mathrm{C}) \mathrm{ppm}$.

IR $\left(\mathrm{KBr}, \mathrm{cm}^{-1}\right): 3473,3381,1610,1462,1018,769$.

EMBR (IE), m/z (\%): 209 (M+4, 23), 207 (M+2, 100), 205 (M+1 , 77), 126 (16), 90 (30), 63 (12). 
EMAR calculado para $\mathrm{C}_{6} \mathrm{H}_{5} \mathrm{ClBrN}$ : 204.9294; encontrado: 204.9293.

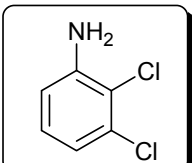

\section{2,3-Dicloroanilina (6bc)}

Sólido blanco.

P.f. $=26-28^{\circ} \mathrm{C}$

${ }^{1} \mathbf{H}$ RMN $\left(300 \mathrm{MHz}, \mathrm{CDCl}_{3}\right): \delta=6.97(\mathrm{t}, J=8.0 \mathrm{~Hz}, 1 \mathrm{H}), 6.84(\mathrm{dd}, J=8.0,1.5 \mathrm{~Hz}, 1 \mathrm{H}), 6.63(\mathrm{dd}, J=8.0,1.5$ $\mathrm{Hz}, 1 \mathrm{H}), 4.20(\mathrm{sa}, 2 \mathrm{H}) \mathrm{ppm}$.

${ }^{13}$ C RMN (75.4 MHz, $\mathrm{CDCl}_{3}$ ): $\delta=144.6(\mathrm{C}), 132.9(\mathrm{C}), 127.6(\mathrm{CH}), 119.4(\mathrm{CH}), 117.3(\mathrm{C}), 113.7(\mathrm{CH}) \mathrm{ppm}$. IR $\left(\mathrm{KBr}, \mathrm{cm}^{-1}\right): 3479,3390,1615,1464,905,768$.

EMBR (IE), m/z (\%): $165\left(\mathrm{M}^{+}+4,9\right), 163\left(\mathrm{M}^{+}+2,61\right), 161\left(\mathrm{M}^{+}, 100\right), 126(9), 90(17), 63(9)$.

EMAR calculado para $\mathrm{C}_{6} \mathrm{H}_{5} \mathrm{Cl}_{2} \mathrm{~N}$ : 160.9799; encontrado: 160.9792 .

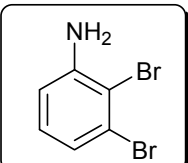

\section{2,3-Dibromoanilina (6cb)}

Sólido blanco.

P.f. $=41-43{ }^{\circ} \mathrm{C}\left(\right.$ lit. $\left.^{254}=45-46^{\circ} \mathrm{C}\right)$.

${ }^{1} \mathbf{H}$ RMN $\left(300 \mathrm{MHz}, \mathrm{CDCl}_{3}\right): \delta=7.01(\mathrm{dd}, J=7.8,1.8 \mathrm{~Hz}, 1 \mathrm{H}), 6.95(\mathrm{t}, J=7.8 \mathrm{~Hz}, 1 \mathrm{H}), 6.68(\mathrm{dd}, J=7.8,1.8$ $\mathrm{Hz}, 1 \mathrm{H}), 4.28(\mathrm{sa}, 2 \mathrm{H}) \mathrm{ppm}$.

${ }^{13} \mathbf{C}$ RMN (75.4 MHz, $\left.\mathrm{CDCl}_{3}\right): \delta=146.1(\mathrm{C}), 128.9(\mathrm{CH}), 125.7(\mathrm{C}), 122.9(\mathrm{CH}), 114.1(\mathrm{CH}), 111.5(\mathrm{C}) \mathrm{ppm}$. IR $\left(\mathrm{KBr}, \mathrm{cm}^{-1}\right): 3382,1611,1455,1287,1014,768,695$.

EMBR (IE), m/z (\%): $253\left(\mathrm{M}^{+}+4,48\right), 251\left(\mathrm{M}^{+}+2,100\right), 249\left(\mathrm{M}^{+}, 53\right), 172(12), 170(12), 90$ (43).

EMAR calculado para $\mathrm{C}_{6} \mathrm{H}_{5} \mathrm{Br}_{2} \mathrm{~N}$ : 248.8789; encontrado: 248.8777 .

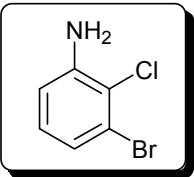

3-Bromo-2-cloroanilina (6cc)

Sólido blanco.

P.f. $=31-33^{\circ} \mathrm{C}$.

${ }^{1} \mathbf{H}$ RMN $\left(400 \mathrm{MHz}, \mathrm{CDCl}_{3}\right): \delta=6.99(\mathrm{dd}, J=8.0,1.5 \mathrm{~Hz}, 1 \mathrm{H}), 6.90(\mathrm{t}, J=8.0 \mathrm{~Hz}, 1 \mathrm{H}), 6.67(\mathrm{dd}, J=8.0,1.5$ $\mathrm{Hz}, 1 \mathrm{H}), 4.16(\mathrm{sa}, 2 \mathrm{H}) \mathrm{ppm}$.

${ }^{13} \mathbf{C}$ RMN (100.6 MHz, $\left.\mathrm{CDCl}_{3}\right): \delta=144.6(\mathrm{C}), 128.1(\mathrm{CH}), 123.2(\mathrm{C}), 122.8(\mathrm{CH}), 119.2(\mathrm{C}), 114.4(\mathrm{CH}) \mathrm{ppm}$. IR $\left(\mathrm{KBr}, \mathrm{cm}^{-1}\right): 3480,3388,1615,1462,1435,767$.

EMBR (IE), m/z (\%): 209 (M+4, 22), $207\left(\mathrm{M}^{+}+2,100\right), 205\left(\mathrm{M}^{+}, 71\right), 126$ (13), 90 (29), 63 (12).

EMAR calculado para $\mathrm{C}_{6} \mathrm{H}_{5} \mathrm{ClBrN}$ : 204.9294; encontrado: 204.9286.

${ }^{254}$ R. P. Hanzlik, P. E. Weller, J. Desai, J. Zheng, L. R. Hall, D. E. Slaughter, J. Org. Chem. 1990, 55, 2736. 


\section{B Síntesis de indoles sustituidos}

\section{B.1 Reacción de Sonogashira de las anilidas 25}

\section{B.1.1 Procedimiento general para la sintesis de las 2-alquinil-3-haloanilidas $\mathbf{2 7}$}

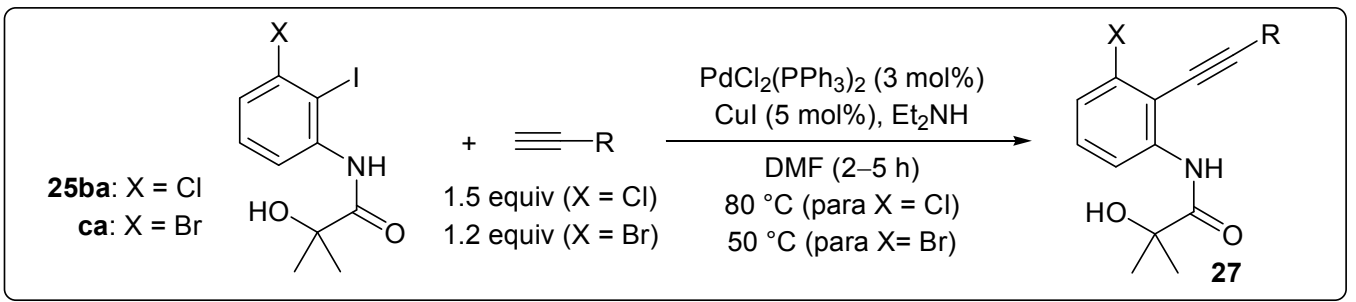

Una mezcla formada por la correspondiente $\mathrm{N}$-(3-halo-2-yodofenil) propanamida $\mathbf{2 5 b a}$ ó 25ca ( $1 \mathrm{mmol})$, alquino ( $1.5 \mathrm{mmol}$ cuando $\mathrm{X}=\mathrm{Cl}$, ó $1.2 \mathrm{mmol}$ cuando $\mathrm{X}=\mathrm{Br}), \mathrm{PdCl}_{2}\left(\mathrm{PPh}_{3}\right)_{2}(21 \mathrm{mg}$, $3 \mathrm{~mol} \%), \mathrm{CuI}(9 \mathrm{mg}, 5 \mathrm{~mol} \%)$ y Et ${ }_{2} \mathrm{NH}(156 \mu \mathrm{L}, 1.5 \mathrm{mmol})$ en DMF anhidra $(4 \mathrm{~mL})$ se agita bajo $\mathrm{N}_{2}$ a 40, 50 ó $80{ }^{\circ} \mathrm{C}$ durante el tiempo necesario para la desaparición de la anilida de partida, monitorizado por CG-EM (2-6 horas). Una vez que la mezcla de reacción alcanza temperatura ambiente se añaden $\mathrm{CH}_{2} \mathrm{Cl}_{2}(20 \mathrm{~mL})$ y $0.5 \mathrm{M} \mathrm{HCl}(20 \mathrm{~mL})$. La fase acuosa separada se extrae con $\mathrm{CH}_{2} \mathrm{Cl}_{2}(2 \times 20 \mathrm{~mL})$. La fase orgánica se lava con $\mathrm{H}_{2} \mathrm{O}(2 \times 40 \mathrm{~mL})$. La fase orgánica se seca sobre $\mathrm{Na}_{2} \mathrm{SO}_{4}$ anhidro y se concentra a presión reducida. El residuo resultante se purifica mediante columna de cromatografía de sílica gel (hexano / AcOEt, 5 / 1) permitiendo obtener las alquinil anilidas 27ba-cg.

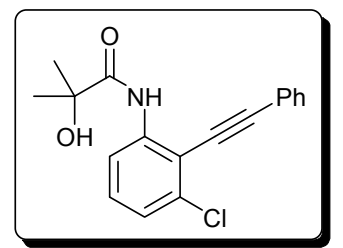

$\mathrm{N}$-[3-Cloro-2-(feniletinil)fenil]-2-hidroxi-2-metilpropanamida (27ba) Sólido blanco. P.f. $=139-141^{\circ} \mathrm{C}$.

${ }^{1} \mathbf{H}$ RMN $\left(300 \mathrm{MHz}, \mathrm{CDCl}_{3}\right): \delta=9.83(\mathrm{sa}, 1 \mathrm{H}), 8.42(\mathrm{dd}, J=8.2,1.1 \mathrm{~Hz}, 1 \mathrm{H}), 7.65-7.57(\mathrm{~m}, 2 \mathrm{H}), 7.40-7.34$ $(\mathrm{m}, 3 \mathrm{H}), 7.24$ (t, $J=8.2 \mathrm{~Hz}, 1 \mathrm{H}), 7.15(\mathrm{dd}, J=8.2,1.1 \mathrm{~Hz}, 1 \mathrm{H}), 2.35(\mathrm{sa}, 1 \mathrm{H}), 1.58(\mathrm{~s}, 6 \mathrm{H}) \mathrm{ppm}$.

${ }^{13} \mathbf{C}$ RMN (75.4 MHz, $\left.\mathrm{CDCl}_{3}\right): \delta=174.7(\mathrm{C}), 140.2(\mathrm{C}), 135.7(\mathrm{C}), 131.8(2 \times \mathrm{CH}), 129.9(\mathrm{CH}), 129.2(\mathrm{CH}), 128.7$ $(2 \times \mathrm{CH}), 124.2(\mathrm{CH}), 122.4(\mathrm{C}), 116.8(\mathrm{CH}), 112.9(\mathrm{C}), 101.7(\mathrm{C}), 81.6(\mathrm{C}), 74.8(\mathrm{C}), 28.1\left(2 \times \mathrm{CH}_{3}\right) \mathrm{ppm}$. IR $\left(\mathrm{KBr}, \mathrm{cm}^{-1}\right): 3365,3321,1665,1571,1534,1452,759,692$.

EMBR (IE), m/z (\%): 315 (M+2, 17), $313\left(\mathrm{M}^{+}, 51\right), 254$ (54), 229 (33), 227 (100), 190 (27), 59 (41).

EMAR calculado para $\mathrm{C}_{18} \mathrm{H}_{16} \mathrm{ClNO}_{2}: 313.0870$; encontrado: 313.0857 .

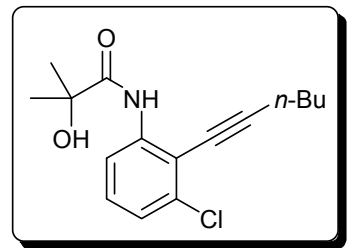

$\mathrm{N}$-[3-Cloro-2-(1-hexinil)fenil]-2-hidroxi-2-metilpropanamida (27bb)

Sólido marrón.

P.f. $=66-68^{\circ} \mathrm{C}$. 
${ }^{1} \mathbf{H}$ RMN (300 MHz, $\left.\mathrm{CDCl}_{3}\right): \delta=9.65(\mathrm{sa}, 1 \mathrm{H}), 8.37(\mathrm{~d}, J=8.1 \mathrm{~Hz}, 1 \mathrm{H}), 7.24-7.07(\mathrm{~m}, 2 \mathrm{H}), 2.55(\mathrm{t}, J=6.9 \mathrm{~Hz}$, $2 \mathrm{H}), 2.45(\mathrm{sa}, 1 \mathrm{H}), 1.70-1.46(\mathrm{~m}, 4 \mathrm{H}), 1.56(\mathrm{~s}, 6 \mathrm{H}), 0.95(\mathrm{t}, J=7.1 \mathrm{~Hz}, 3 \mathrm{H}) \mathrm{ppm}$.

${ }^{13} \mathbf{C}$ RMN (75.4 MHz, $\left.\mathrm{CDCl}_{3}\right): \delta=174.8(\mathrm{C}), 140.2(\mathrm{C}), 135.6(\mathrm{C}), 129.0(\mathrm{CH}), 124.1(\mathrm{CH}), 116.7(\mathrm{CH}), 113.5$ (C), $103.7(\mathrm{C}), 74.5(\mathrm{C}), 73.1(\mathrm{C}), 30.7\left(\mathrm{CH}_{2}\right), 28.1\left(2 \times \mathrm{CH}_{3}\right), 22.1\left(\mathrm{CH}_{2}\right), 19.6\left(\mathrm{CH}_{2}\right), 13.7\left(\mathrm{CH}_{3}\right) \mathrm{ppm}$. IR $\left(\mathrm{KBr}, \mathrm{cm}^{-1}\right): 3419,3322,1670,1572,1516,1450,981$.

EMBR (IE), m/z (\%): $295\left(\mathrm{M}^{+}+2,17\right), 293\left(\mathrm{M}^{+}, 51\right), 207$ (48), 193 (41), 178 (64), 164 (88), 59 (100).

EMAR calculado para $\mathrm{C}_{16} \mathrm{H}_{20} \mathrm{ClNO}_{2}$ : 293.1183; encontrado: 293.1184 .

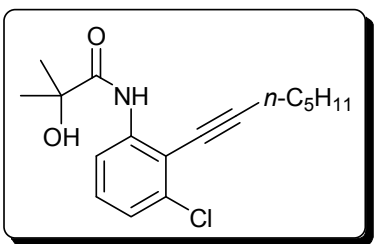

$N$-[3-Cloro-2-(1-heptinil)fenil]-2-hidroxi-2-metilpropanamida (27bc) Sólido marrón.

P.f. $=76-78^{\circ} \mathrm{C}$.

${ }^{1} \mathbf{H}$ RMN $\left(300 \mathrm{MHz}, \mathrm{CDCl}_{3}\right): \delta=9.77(\mathrm{sa}, 1 \mathrm{H}), 8.32(\mathrm{dd}, J=7.6,1.8 \mathrm{~Hz}, 1 \mathrm{H}), 7.15-7.05(\mathrm{~m}, 2 \mathrm{H}), 3.49(\mathrm{~s}, 1 \mathrm{H})$, $2.49(\mathrm{t}, J=7.1 \mathrm{~Hz}, 2 \mathrm{H}), 1.68-1.56(\mathrm{~m}, 2 \mathrm{H}), 1.53(\mathrm{~s}, 6 \mathrm{H}), 1.47-1.21(\mathrm{~m}, 4 \mathrm{H}), 0.88(\mathrm{t}, J=7.1 \mathrm{~Hz}, 3 \mathrm{H}) \mathrm{ppm}$.

${ }^{13}$ C RMN (75.4 MHz, $\left.\mathrm{CDCl}_{3}\right): \delta=175.3(\mathrm{C}), 140.0(\mathrm{C}), 135.6(\mathrm{C}), 128.8(\mathrm{CH}), 124.0(\mathrm{CH}), 116.6(\mathrm{CH}), 113.6$ (C), $103.8(\mathrm{C}), 74.2(\mathrm{C}), 73.0(\mathrm{C}), 31.1\left(\mathrm{CH}_{2}\right), 28.2\left(\mathrm{CH}_{2}\right), 27.9\left(2 \times \mathrm{CH}_{3}\right), 22.2\left(\mathrm{CH}_{2}\right), 19.7\left(\mathrm{CH}_{2}\right), 14.0$ $\left(\mathrm{CH}_{3}\right) \mathrm{ppm}$.

IR $\left(\mathrm{KBr}, \mathrm{cm}^{-1}\right): 3311,2953,1662,1569,1520,1453,1139,790,731$.

EMBR (IE), m/z (\%): 309 (M+2, 7), 307 (M+2 21), 206 (20), 180 (35), 164 (44), 59 (100).

EMAR calculado para $\mathrm{C}_{17} \mathrm{H}_{22} \mathrm{ClNO}_{2}: 307.1339$; encontrado: 307.1342 .

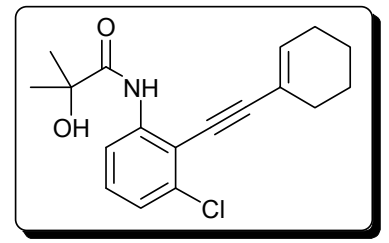

$\mathrm{N}$-[3-Cloro-2-(1-ciclohexeniletinil)fenil]-2-hidroxi-2metilpropanamida (27bd)

Sólido blanco.

P.f. $=145-147^{\circ} \mathrm{C}$.

${ }^{1} \mathbf{H}$ RMN $\left(300 \mathrm{MHz}, \mathrm{CDCl}_{3}\right): \delta=9.67(\mathrm{sa}, 1 \mathrm{H}), 8.36(\mathrm{dd}, J=8.1,1.3 \mathrm{~Hz}, 1 \mathrm{H}), 7.17(\mathrm{t}, J=8.1 \mathrm{~Hz}, 1 \mathrm{H}), 7.10(\mathrm{dd}$, $J=8.1,1.3 \mathrm{~Hz}, 1 \mathrm{H}), 6.36-6.30(\mathrm{~m}, 1 \mathrm{H}), 2.80(\mathrm{~s}, 1 \mathrm{H}), 2.30-2.22(\mathrm{~m}, 2 \mathrm{H}), 2.18-2.10(\mathrm{~m}, 2 \mathrm{H}), 1.72-1.57$ $(\mathrm{m}, 4 \mathrm{H}), 1.55(\mathrm{~s}, 6 \mathrm{H}) \mathrm{ppm}$.

${ }^{13}$ C RMN (75.4 MHz, $\left.\mathrm{CDCl}_{3}\right): \delta=174.9(\mathrm{C}), 139.7(\mathrm{C}), 137.0(\mathrm{CH}), 135.4(\mathrm{C}), 129.2(\mathrm{CH}), 124.1(\mathrm{CH}), 120.3$ $(\mathrm{C}), 116.6(\mathrm{CH}), 113.4(\mathrm{C}), 103.8(\mathrm{C}), 79.0(\mathrm{C}), 74.5(\mathrm{C}), 29.0\left(\mathrm{CH}_{2}\right), 28.0\left(2 \times \mathrm{CH}_{3}\right), 26.0\left(\mathrm{CH}_{2}\right), 22.3$ $\left(\mathrm{CH}_{2}\right), 21.5\left(\mathrm{CH}_{2}\right) \mathrm{ppm}$.

IR $\left(\mathrm{KBr}, \mathrm{cm}^{-1}\right): 3372,3320,1652,1572,1532,1450,1435,1197,1184,778,725$

EMBR (IE), m/z (\%): $319\left(\mathrm{M}^{+}+2,23\right), 317\left(\mathrm{M}^{+}, 72\right), 281$ (25), 231 (57), 207 (100), 180 (26), 59 (55).

EMAR calculado para $\mathrm{C}_{18} \mathrm{H}_{20} \mathrm{ClNO}_{2}: 317.1183$; encontrado: 317.1190 .

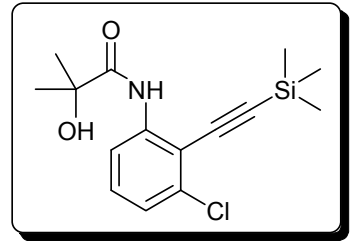

$N$-[3-Cloro-2-(trimetilsililetinil)fenil]-2-hidroxi-2-metilpropanamida (27be)

Sólido marrón.

P.f. $=144-146^{\circ} \mathrm{C}$.

Condiciones: Llevada a cabo a $40{ }^{\circ} \mathrm{C}$ debido a la volatilidad del trimetilsililacetileno.

${ }^{1}$ H RMN $\left(300 \mathrm{MHz}, \mathrm{CDCl}_{3}\right): \delta=9.66(\mathrm{sa}, 1 \mathrm{H}), 8.37(\mathrm{dd}, J=8.3,0.9 \mathrm{~Hz}, 1 \mathrm{H}), 7.21(\mathrm{t}, J=8.3 \mathrm{~Hz}, 1 \mathrm{H}), 7.09$ (dd, $J=8.3,0.9 \mathrm{~Hz}, 1 \mathrm{H}), 2.60(\mathrm{sa}, 1 \mathrm{H}), 1.55(\mathrm{~s}, 6 \mathrm{H}), 0.29(\mathrm{~d}, J=0.9 \mathrm{~Hz}, 9 \mathrm{H}) \mathrm{ppm}$. 
${ }^{13} \mathbf{C}$ RMN (75.4 MHz, $\left.\mathrm{CDCl}_{3}\right): \delta=175.0(\mathrm{C}), 140.8(\mathrm{C}), 135.8(\mathrm{C}), 130.0(\mathrm{CH}), 124.1(\mathrm{CH}), 116.8(\mathrm{CH}), 112.8$ (C), $108.1(\mathrm{C}), 96.6(\mathrm{C}), 74.5(\mathrm{C}), 28.1\left(2 \times \mathrm{CH}_{3}\right), 0.0\left(3 \times \mathrm{CH}_{3}\right) \mathrm{ppm}$.

EMBR (IE), m/z (\%): $311\left(\mathrm{M}^{+}+2,10\right), 309\left(\mathrm{M}^{+}, 29\right), 236$ (100), 208 (39).

EMAR calculado para $\mathrm{C}_{15} \mathrm{H}_{20} \mathrm{ClNO}_{2} \mathrm{Si}$ : 309.0952; encontrado: 309.0951 .

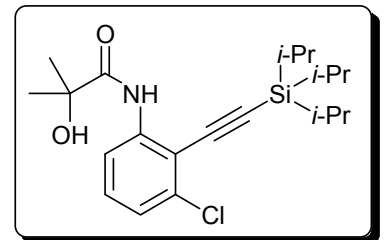

$N$-[3-Cloro-2-(triisopropilsililetinil)fenil]-2-hidroxi-2metilpropanamida (27bf)

Sólido blanco.

P.f. $=128-130^{\circ} \mathrm{C}$.

Condiciones: Llevada a cabo a $40{ }^{\circ} \mathrm{C}$ debido a la volatilidad del triisopropilsililacetileno.

${ }^{1} \mathbf{H}$ RMN (300 MHz, $\left.\mathrm{CDCl}_{3}\right): \delta=9.62(\mathrm{sa}, 1 \mathrm{H}), 8.39(\mathrm{dd}, J=8.2,1.1 \mathrm{~Hz}, 1 \mathrm{H}), 7.21(\mathrm{t}, J=8.2 \mathrm{~Hz}, 1 \mathrm{H}), 7.12(\mathrm{dd}$, $J=8.2,1.1 \mathrm{~Hz}, 1 \mathrm{H}), 2.44(\mathrm{~s}, 1 \mathrm{H}), 1.54(\mathrm{~s}, 6 \mathrm{H}), 1.18-1.12(\mathrm{~m}, 21 \mathrm{H}) \mathrm{ppm}$.

${ }^{13} \mathbf{C}$ RMN (75.4 MHz, $\left.\mathrm{CDCl}_{3}\right): \delta=175.0(\mathrm{C}), 140.6(\mathrm{C}), 136.6(\mathrm{C}), 129.8(\mathrm{CH}), 124.2(\mathrm{CH}), 116.9(\mathrm{CH}), 113.1$ (C), $104.9(\mathrm{C}), 98.5(\mathrm{C}), 74.4(\mathrm{C}), 28.1(3 \times \mathrm{CH}), 18.8\left(2 \times \mathrm{CH}_{3}\right), 11.3\left(6 \times \mathrm{CH}_{3}\right) \mathrm{ppm}$.

EMBR (IE), m/z (\%): $393\left(\mathrm{M}^{+}, 4\right), 352$ (37), 350 (100), 332 (19), 290 (7), 192 (17), 103 (40).

EMAR calculado para $\mathrm{C}_{21} \mathrm{H}_{32} \mathrm{ClNO}_{2} \mathrm{Si}$ : 393.1891; encontrado: 393.1891 .

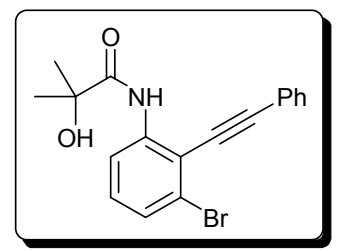

$N$-[3-Bromo-2-(feniletinil)fenil]-2-hidroxi-2-metilpropanamida (27ca)

Sólido blanco.

P.f. $=131-133^{\circ} \mathrm{C}$.

${ }^{1} \mathbf{H}$ RMN $\left(300 \mathrm{MHz}, \mathrm{CDCl}_{3}\right): \delta=9.86(\mathrm{sa}, 1 \mathrm{H}), 8.44(\mathrm{dd}, J=8.2,1.0 \mathrm{~Hz}, 1 \mathrm{H}), 7.63-7.58(\mathrm{~m}, 2 \mathrm{H}), 7.38-7.29$ $(\mathrm{m}, 4 \mathrm{H}), 7.13(\mathrm{t}, J=8.2 \mathrm{~Hz}, 1 \mathrm{H}), 2.87(\mathrm{~s}, 1 \mathrm{H}), 1.55(\mathrm{~s}, 6 \mathrm{H}) \mathrm{ppm}$.

${ }^{13} \mathbf{C}$ RMN (75.4 MHz, $\left.\mathrm{CDCl}_{3}\right): \delta=175.0(\mathrm{C}), 140.1(\mathrm{C}), 131.7(2 \times \mathrm{CH}), 130.1(\mathrm{CH}), 129.2(\mathrm{CH}), 128.6(2 \times \mathrm{CH})$, $127.3(\mathrm{CH}), 125.0(\mathrm{C}), 122.3(\mathrm{C}), 117.3(\mathrm{CH}), 115.0(\mathrm{C}), 101.1(\mathrm{C}), 83.4(\mathrm{C}), 74.7(\mathrm{C}), 28.0\left(2 \times \mathrm{CH}_{3}\right)$ ppm.

IR $\left(\mathrm{KBr}, \mathrm{cm}^{-1}\right): 3372,3312,1661,1566,1532,1446,1200,1131,752,726,689$.

EMBR (IE), m/z (\%): $359\left(\mathrm{M}^{+}+2,62\right), 357\left(\mathrm{M}^{+}, 62\right), 300$ (60), 298 (58), 273 (100), 271 (100), 165 (53), 59 (83).

EMAR calculado para $\mathrm{C}_{18} \mathrm{H}_{16} \mathrm{BrNO}_{2}$ : 357.0364 ; encontrado: 357.0368 .

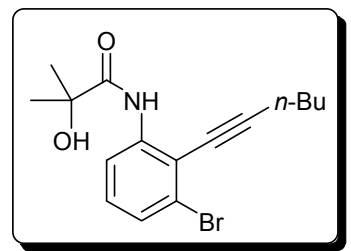

$\mathrm{N}$-[3-Bromo-2-(1-hexinil)fenil]-2-hidroxi-2-metilpropanamida (27cb)

Sólido marrón.

P.f. $=70-72^{\circ} \mathrm{C}$.

${ }^{1} \mathbf{H}$ RMN $\left(300 \mathrm{MHz}, \mathrm{CDCl}_{3}\right): \delta=9.76(\mathrm{sa}, 1 \mathrm{H}), 8.36(\mathrm{dd}, J=8.2,1.0 \mathrm{~Hz}, 1 \mathrm{H}), 7.25(\mathrm{dd}, J=8.2,1.0 \mathrm{~Hz}, 1 \mathrm{H})$, $7.05(\mathrm{t}, J=8.2 \mathrm{~Hz}, 1 \mathrm{H}), 3.42(\mathrm{~s}, 1 \mathrm{H}), 2.50(\mathrm{t}, J=7.0 \mathrm{~Hz}, 2 \mathrm{H}), 1.64-1.43(\mathrm{~m}, 4 \mathrm{H}), 1.52(\mathrm{~s}, 6 \mathrm{H}), 0.91(\mathrm{t}, J=$ $7.2 \mathrm{~Hz}, 3 \mathrm{H}) \mathrm{ppm}$.

${ }^{13}$ C RMN (75.4 MHz, $\left.\mathrm{CDCl}_{3}\right): \delta=175.3(\mathrm{C}), 140.1(\mathrm{C}), 129.2(\mathrm{CH}), 127.2(\mathrm{CH}), 125.0(\mathrm{C}), 117.1(\mathrm{CH}), 115.6$ $(\mathrm{C}), 103.1(\mathrm{C}), 74.8(\mathrm{C}), 74.2(\mathrm{C}), 30.5\left(\mathrm{CH}_{2}\right), 27.9\left(2 \times \mathrm{CH}_{3}\right), 22.1\left(\mathrm{CH}_{2}\right), 19.5\left(\mathrm{CH}_{2}\right), 13.7\left(\mathrm{CH}_{3}\right) \mathrm{ppm}$.

IR $\left(\mathrm{KBr}, \mathrm{cm}^{-1}\right): 3419,3319,1673,1567,1520,1427,980,729$.

EMBR (IE), m/z (\%): $339\left(\mathrm{M}^{+}+2,37\right), 337\left(\mathrm{M}^{+}, 36\right), 253$ (29), 251 (30), 226 (50), 210 (51), 129 (26), 59 (100).

EMAR calculado para $\mathrm{C}_{16} \mathrm{H}_{20} \mathrm{BrNO}_{2}$ : 337.0677; encontrado: 337.0676 . 


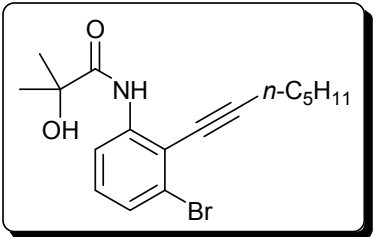

$N$-[3-Bromo-2-(1-heptinil)fenil]-2-hidroxi-2-metilpropanamida (27cc)

Sólido blanco.

P.f. $=79-81^{\circ} \mathrm{C}$.

${ }^{1}$ H RMN (300 MHz, $\left.\mathrm{CDCl}_{3}\right): \delta=9.78(\mathrm{~s}, 1 \mathrm{H}), 8.35(\mathrm{dd}, J=8.2,0.8 \mathrm{~Hz}, 1 \mathrm{H}), 7.24(\mathrm{dd}, J=8.2,0.8 \mathrm{~Hz}, 1 \mathrm{H})$, $7.03(\mathrm{t}, J=8.2 \mathrm{~Hz}, 1 \mathrm{H}), 3.58(\mathrm{~s}, 1 \mathrm{H}), 2.47(\mathrm{t}, J=7.2 \mathrm{~Hz}, 2 \mathrm{H}), 1.68-1.57(\mathrm{~m}, 2 \mathrm{H}), 1.52(\mathrm{~s}, 6 \mathrm{H}), 1.49-1.24$ $(\mathrm{m}, 4 \mathrm{H}), 0.87(\mathrm{t}, J=7.2 \mathrm{~Hz}, 3 \mathrm{H}) \mathrm{ppm}$.

${ }^{13}$ C RMN (75.4 MHz, $\left.\mathrm{CDCl}_{3}\right): \delta=175.4(\mathrm{C}), 140.1(\mathrm{C}), 129.1(\mathrm{CH}), 127.1(\mathrm{CH}), 125.0(\mathrm{C}), 117.1(\mathrm{CH}), 115.6(\mathrm{C})$, $103.2(\mathrm{C}), 74.8(\mathrm{C}), 74.2(\mathrm{C}), 31.1\left(\mathrm{CH}_{2}\right), 28.2\left(\mathrm{CH}_{2}\right), 27.8\left(2 \times \mathrm{CH}_{3}\right), 22.2\left(\mathrm{CH}_{2}\right), 19.7\left(\mathrm{CH}_{2}\right), 14.0\left(\mathrm{CH}_{3}\right)$ ppm.

IR $\left(\mathrm{KBr}, \mathrm{cm}^{-1}\right): 3295,2930,1661,1564,1520,1449,1130,981,788,730$.

EMBR (IE), m/z (\%): $353\left(\mathrm{M}^{+}+2,15\right), 351\left(\mathrm{M}^{+}, 15\right), 226$ (28), $210(30), 157$ (21), 59 (100).

EMAR calculado para $\mathrm{C}_{17} \mathrm{H}_{22} \mathrm{BrNO}_{2}$ : 351.0834; encontrado: 351.0822 .

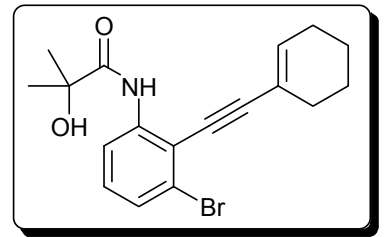

$N$-[3-Bromo-2-(1-ciclohexeniletinil)fenil]-2-hidroxi-2-metil propanamida (27cd)

Sólido blanco.

P.f. $=154-156^{\circ} \mathrm{C}$.

${ }^{1} \mathbf{H}$ RMN $\left(300 \mathrm{MHz}, \mathrm{CDCl}_{3}\right): \delta=9.65(\mathrm{sa}, 1 \mathrm{H}), 8.42(\mathrm{dd}, J=8.2,1.1 \mathrm{~Hz}, 1 \mathrm{H}), 7.29(\mathrm{dd}, J=8.2,1.1 \mathrm{~Hz}, 1 \mathrm{H})$ $7.12(\mathrm{t}, J=8.2 \mathrm{~Hz}, 1 \mathrm{H}), 6.37-6.32(\mathrm{~m}, 1 \mathrm{H}), 2.48(\mathrm{sa}, 1 \mathrm{H}), 2.32-2.22(\mathrm{~m}, 2 \mathrm{H}), 2.21-2.12(\mathrm{~m}, 2 \mathrm{H})$, $1.77-1.58(\mathrm{~m}, 4 \mathrm{H}), 1.56(\mathrm{~s}, 6 \mathrm{H}) \mathrm{ppm}$.

${ }^{13} \mathbf{C}$ RMN (100.6 MHz, $\left.\mathrm{CDCl}_{3}\right): \delta=174.7(\mathrm{C}), 139.9(\mathrm{C}), 137.0(\mathrm{CH}), 129.6(\mathrm{CH}), 127.2(\mathrm{CH}), 124.9(\mathrm{C}), 120.4$ (C), $117.2(\mathrm{CH}), 115.5(\mathrm{C}), 103.2(\mathrm{C}), 80.9(\mathrm{C}), 74.7(\mathrm{C}), 29.0\left(\mathrm{CH}_{2}\right), 28.1\left(2 \times \mathrm{CH}_{3}\right), 26.0\left(\mathrm{CH}_{2}\right), 22.3$ $\left(\mathrm{CH}_{2}\right), 21.5\left(\mathrm{CH}_{2}\right) \mathrm{ppm}$.

IR $\left(\mathrm{KBr}, \mathrm{cm}^{-1}\right): 3376,3318,2929,1653,1566,1530,1446,1433,976,775,724$.

EMBR (IE), m/z (\%): 363 (M+2, 100), $361\left(\mathrm{M}^{+}, 100\right), 277$ (53), 275 (53), 167 (34), 59 (63).

EMAR calculado para $\mathrm{C}_{18} \mathrm{H}_{20} \mathrm{BrNO}_{2}$ : 361.0677 ; encontrado: 361.0677 .

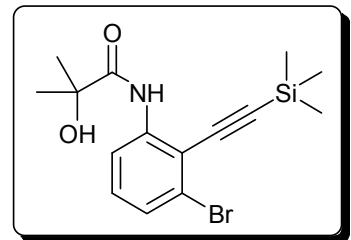

$\mathrm{N}$-[3-Bromo-2-(trimetilsililetinil)fenil]-2-hidroxi-2-metilpropanamida (27ce)

Sólido marrón.

P.f. $=150-152^{\circ} \mathrm{C}$.

Condiciones: Llevada a cabo a $40{ }^{\circ} \mathrm{C}$ debido a la volatilidad del trimetilsililacetileno.

${ }^{1} \mathbf{H}$ RMN $\left(300 \mathrm{MHz}, \mathrm{CDCl}_{3}\right): \delta=9.70(\mathrm{sa}, 1 \mathrm{H}), 8.40(\mathrm{dt}, J=8.2,0.9 \mathrm{~Hz}, 1 \mathrm{H}), 7.27(\mathrm{td}, J=8.2,0.9 \mathrm{~Hz}, 1 \mathrm{H})$, $7.12(\mathrm{t}, J=8.2 \mathrm{~Hz}, 1 \mathrm{H}), 2.83(\mathrm{~s}, 1 \mathrm{H}), 1.54(\mathrm{~d}, J=0.6 \mathrm{~Hz}, 6 \mathrm{H}), 0.28(\mathrm{~d}, J=0.8 \mathrm{~Hz}, 9 \mathrm{H}) \mathrm{ppm}$.

${ }^{13} \mathbf{C}$ RMN (75.4 MHz, $\left.\mathrm{CDCl}_{3}\right): \delta=175.1(\mathrm{C}), 140.8(\mathrm{C}), 130.3(\mathrm{CH}), 127.2(\mathrm{CH}), 125.0(\mathrm{C}), 117.3(\mathrm{CH}), 114.8$ (C), $107.5(\mathrm{C}), 98.3(\mathrm{C}), 74.4(\mathrm{C}), 28.0\left(2 \times \mathrm{CH}_{3}\right),-0.1\left(3 \times \mathrm{CH}_{3}\right) \mathrm{ppm}$.

EMBR (IE), m/z (\%): $355\left(\mathrm{M}^{+}+2,28\right), 353\left(\mathrm{M}^{+}, 27\right), 282$ (100), 280 (100), 254 (37), 252 (37), 238 (19), 236 (18).

EMAR calculado para $\mathrm{C}_{15} \mathrm{H}_{20} \mathrm{BrNO}_{2} \mathrm{Si}$ : 353.0447 ; encontrado: 353.0450 . 


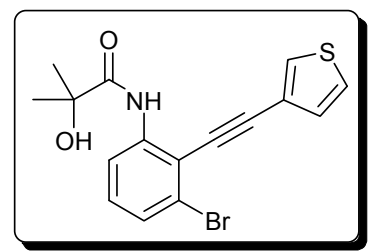

$N$-[3-Bromo-2-(3-tieniletinil)fenil]-2-hidroxi-2-metilpropanamida

\section{(27cg)}

Sólido blanco.

P.f. $=132-134^{\circ} \mathrm{C}$.

${ }^{1} \mathbf{H}$ RMN $\left(400 \mathrm{MHz}, \mathrm{CDCl}_{3}\right): \delta=9.82(\mathrm{sa}, 1 \mathrm{H}), 8.41(\mathrm{~d}, J=8.3 \mathrm{~Hz}, 1 \mathrm{H}), 7.63(\mathrm{dd}, J=2.9,1.1 \mathrm{~Hz}, 1 \mathrm{H})$, 7.31-7.27 (m, 2H), $7.24(\mathrm{dd}, J=4.9,1.1 \mathrm{~Hz}, 1 \mathrm{H}), 7.11(\mathrm{t}, J=8.3 \mathrm{~Hz}, 1 \mathrm{H}), 2.90(\mathrm{~s}, 1 \mathrm{H}), 1.53(\mathrm{~s}, 6 \mathrm{H}) \mathrm{ppm}$.

${ }^{13}$ C RMN (100.6 MHz, $\left.\mathrm{CDCl}_{3}\right): \delta=175.0(\mathrm{C}), 140.1(\mathrm{C}), 130.0(\mathrm{CH}), 129.9(\mathrm{CH}), 129.8(\mathrm{CH}), 127.3(\mathrm{CH})$, $125.9(\mathrm{CH}), 124.7(\mathrm{C}), 121.4(\mathrm{C}), 117.3(\mathrm{CH}), 115.1(\mathrm{C}), 96.3(\mathrm{C}), 83.1(\mathrm{C}), 74.7(\mathrm{C}), 28.0\left(2 \times \mathrm{CH}_{3}\right) \mathrm{ppm}$. EMBR (IE), m/z (\%): 365 (M+2, 40), 363 (M+144), 279 (61), 277 (59), 198 (29), 196 (32), 171 (23), 59 (100).

EMAR calculado para $\mathrm{C}_{16} \mathrm{H}_{14} \mathrm{BrNO}_{2} \mathrm{~S}$ : 362.9929; encontrado: 362.9928 .

\section{B.2 Síntesis de los $\mathbf{1 H}$-indoles 2 -sustituidos 30}

\section{B.2.1 Sintesis de las o-alquinilanilinas $\mathbf{2 9}$}

A una disolución de $o$-yodoanilina $(2 \mathrm{mmol})$ en DMF anhidra $(3 \mathrm{~mL})$ se añade $\mathrm{PdCl}_{2}\left(\mathrm{PPh}_{3}\right)_{2}$ (42 mg, $3 \mathrm{~mol} \%$ ), CuI (19 mg, $5 \mathrm{~mol} \%$ ), alquino (3 mmol) y $\mathrm{Et}_{2} \mathrm{NH}(310 \mu \mathrm{L}, 3 \mathrm{mmol})$. La mezcla se agita bajo $\mathrm{N}_{2}$ a temperatura ambiente durante el tiempo necesario para la desaparición de la anilina de partida, monitorizado por CG-EM (1-4 horas). La mezcla de reacción se hidroliza con $\mathrm{H}_{2} \mathrm{O}$ y se extrae con $\mathrm{Et}_{2} \mathrm{O}(3 \times 15 \mathrm{~mL})$. La fase orgánica se seca sobre $\mathrm{Na}_{2} \mathrm{SO}_{4}$ anhidro y se concentra a presión reducida. El residuo resultante se purifica mediante columna de cromatografía de sílica gel (hexano / AcOEt) para dar las alquinil anilinas 29.

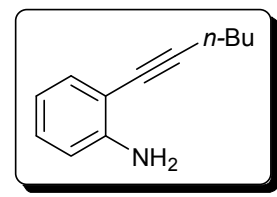

$o-(1-H e x i n i l) a n i l i n a(29 a)^{255}$

Líquido marrón.

$\mathrm{R}_{\mathrm{f}}=0.75$ (hexano / AcOEt, $\left.6 / 1\right)$.

${ }^{1}$ H RMN (300 MHz, $\left.\mathrm{CDCl}_{3}\right): \delta=7.28-7.23(\mathrm{~m}, 1 \mathrm{H}), 7.12-7.05(\mathrm{~m}, 1 \mathrm{H}), 6.71-6.64(\mathrm{~m}, 2 \mathrm{H}), 4.17(\mathrm{sa}, 2 \mathrm{H}), 2.49$ $(\mathrm{t}, J=7.1 \mathrm{~Hz}, 2 \mathrm{H}), 1.68-1.56(\mathrm{~m}, 2 \mathrm{H}), 1.55-1.43(\mathrm{~m}, 2 \mathrm{H}), 0.97(\mathrm{td}, J=7.1,1.5 \mathrm{~Hz}, 3 \mathrm{H}) \mathrm{ppm}$.

${ }^{13} \mathbf{C}$ RMN (75.4 MHz, $\left.\mathrm{CDCl}_{3}\right): \delta=147.7(\mathrm{C}), 132.1(\mathrm{CH}), 128.9(\mathrm{CH}), 117.9(\mathrm{CH}), 114.2(\mathrm{CH}), 109.0(\mathrm{C}), 95.8$ (C), $77.0(\mathrm{C}), 31.1\left(\mathrm{CH}_{2}\right), 22.2\left(\mathrm{CH}_{2}\right), 19.4\left(\mathrm{CH}_{2}\right), 13.8\left(\mathrm{CH}_{3}\right) \mathrm{ppm}$.

IR $\left(\mathrm{KBr}, \mathrm{cm}^{-1}\right): 3474,3378,2957,2930,1613,1492,1456,1306,747$.

EMBR (IE), m/z (\%): 173 (M+, 73 ), 158 (16), 144 (50), 130 (100), 77 (20).

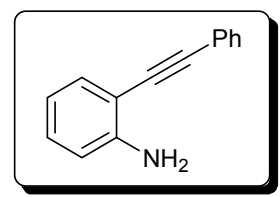

$o$-(Feniletinil)anilina (29b)

Sólido blanco.

P.f. $=87-89^{\circ} \mathrm{C}$.

${ }^{255}$ Y. Yin, W. Ma, Z. Chai, G. Zhao, J. Org. Chem. 2007, 72, 5731. 
${ }^{1}$ H RMN $\left(300 \mathrm{MHz}, \mathrm{CDCl}_{3}\right): \delta=7.66-7.61(\mathrm{~m}, 2 \mathrm{H}), 7.49(\mathrm{dd}, J=7.7,1.3 \mathrm{~Hz}, 1 \mathrm{H}), 7.45-7.39(\mathrm{~m}, 3 \mathrm{H})$, $7.26-7.19(\mathrm{~m}, 1 \mathrm{H}), 6.85-6.76(\mathrm{~m}, 2 \mathrm{H}), 4.32(\mathrm{sa}, 2 \mathrm{H}) \mathrm{ppm}$.

${ }^{13} \mathbf{C}$ RMN (75.4 MHz, $\left.\mathrm{CDCl}_{3}\right): \delta=147.8(\mathrm{C}), 132.1(\mathrm{CH}), 131.4(2 \times \mathrm{CH}), 129.8(\mathrm{CH}), 128.4(2 \times \mathrm{CH}), 128.2$ $(\mathrm{CH}), 123.2(\mathrm{C}), 117.9(\mathrm{CH}), 114.3(\mathrm{CH}), 107.8(\mathrm{C}), 94.7(\mathrm{C}), 86.0(\mathrm{C}) \mathrm{ppm}$.

EMBR (IE), m/z (\%): $193\left(\mathrm{M}^{+}, 100\right), 165$ (32), 96 (7), 89 (10).

EMAR calculado para $\mathrm{C}_{14} \mathrm{H}_{15} \mathrm{~N}$ : 197.1204; encontrado: 197.1205 .

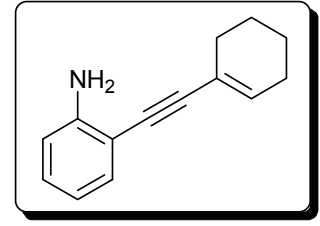

$o-(1-C i c l o h e x e n i l e t i n i l) a n i l i n a(29 c)^{256}$

Sólido blanco.

P.f. $=31-33{ }^{\circ} \mathrm{C}$.

${ }^{1} \mathbf{H}$ RMN (300 MHz, $\left.\mathrm{CDCl}_{3}\right): \delta=7.35-7.31(\mathrm{~m}, 1 \mathrm{H}), 7.16-7.10(\mathrm{~m}, 1 \mathrm{H}), 6.76-6.68(\mathrm{~m}, 2 \mathrm{H}), 6.28-6.23(\mathrm{~m}, 1 \mathrm{H})$, $4.20(\mathrm{sa}, 2 \mathrm{H}), 2.34-2.27(\mathrm{~m}, 2 \mathrm{H}), 2.24-2.15(\mathrm{~m}, 2 \mathrm{H}), 1.79-1.61(\mathrm{~m}, 4 \mathrm{H}) \mathrm{ppm}$.

${ }^{13}$ C RMN (75.4 MHz, $\left.\mathrm{CDCl}_{3}\right): \delta=147.5(\mathrm{C}), 134.7(\mathrm{CH}), 131.7(\mathrm{CH}), 129.1(\mathrm{CH}), 120.6(\mathrm{C}), 117.7(\mathrm{CH})$,

$114.1(\mathrm{CH}), 108.3(\mathrm{C}), 96.6(\mathrm{C}), 83.1(\mathrm{C}), 29.4\left(\mathrm{CH}_{2}\right), 25.7\left(\mathrm{CH}_{2}\right), 22.3\left(\mathrm{CH}_{2}\right), 21.4\left(\mathrm{CH}_{2}\right) \mathrm{ppm}$.

EMBR (IE), m/z (\%): 197 (M+100), 182 (13), 168 (57), 130 (19), 117 (19).

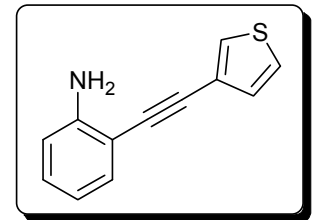

$o$-(3-Tieniletinil)anilina (29d)

Sólido marrón.

P.f. $=50-52^{\circ} \mathrm{C}$

${ }^{1} \mathbf{H}$ RMN (300 MHz, $\left.\mathrm{CDCl}_{3}\right): \delta=7.54(\mathrm{ddd}, J=3.0,1.2,0.5 \mathrm{~Hz}, 1 \mathrm{H}), 7.42(\mathrm{dd}, J=7.6,1.6 \mathrm{~Hz}, 1 \mathrm{H}), 7.32$ (ddd, $J=5.0,3.0,0.5 \mathrm{~Hz}, 1 \mathrm{H}), 7.24(\mathrm{ddd}, J=5.0,1.2,0.5 \mathrm{~Hz}, 1 \mathrm{H}), 7.18(\mathrm{tdd}, J=7.6,1.6,0.5 \mathrm{~Hz}, 1 \mathrm{H})$, $6.80-6.72(\mathrm{~m}, 2 \mathrm{H}), 4.30(\mathrm{sa}, 2 \mathrm{H}) \mathrm{ppm}$.

${ }^{13}$ C RMN (75.4 MHz, $\left.\mathrm{CDCl}_{3}\right): \delta=147.8(\mathrm{C}), 132.1(\mathrm{CH}), 129.8(\mathrm{CH}), 129.7(\mathrm{CH}), 128.4(\mathrm{CH}), 125.5(\mathrm{CH})$, $122.2(\mathrm{C}), 118.0(\mathrm{CH}), 114.4(\mathrm{CH}), 107.8(\mathrm{CH}), 89.8(\mathrm{C}), 85.5(\mathrm{C}) \mathrm{ppm}$.

EMBR (IE), m/z (\%): $199\left(\mathrm{M}^{+}, 100\right), 171$ (18), 154 (12), 127 (6).

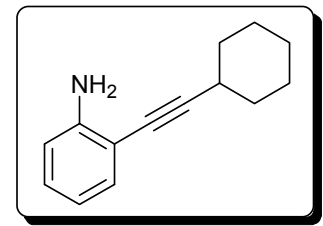

$o$-(Ciclohexiletinil)anilina (29e) $)^{256}$

Liquido amarillo.

$\mathrm{R}_{\mathrm{f}}=0.41$ (hexano / AcOEt, 7 / 1).

${ }^{1} \mathbf{H}$ RMN $\left(300 \mathrm{MHz}, \mathrm{CDCl}_{3}\right): \delta=7.28(\mathrm{dd}, J=7.9,1.6 \mathrm{~Hz}, 1 \mathrm{H}), 7.09(\mathrm{td}, J=7.9,1.6 \mathrm{~Hz}, 1 \mathrm{H}), 6.72-6.65(\mathrm{~m}$, $2 \mathrm{H}), 4.18(\mathrm{sa}, 2 \mathrm{H}), 2.74-2.63(\mathrm{~m}, 1 \mathrm{H}), 2.00-1.88(\mathrm{~m}, 2 \mathrm{H}), 1.85-1.73(\mathrm{~m}, 2 \mathrm{H}), 1.66-1.52(\mathrm{~m}, 3 \mathrm{H})$, $1.48-1.31(\mathrm{~m}, 3 \mathrm{H}) \mathrm{ppm}$.

${ }^{13}$ C RMN (75.4 MHz, $\left.\mathrm{CDCl}_{3}\right): \delta=147.6(\mathrm{C}), 132.0(\mathrm{CH}), 128.8(\mathrm{CH}), 117.8(\mathrm{CH}), 114.1(\mathrm{CH}), 108.9(\mathrm{C})$, $100.0(\mathrm{C}), 76.9(\mathrm{C}), 33.0\left(2 \times \mathrm{CH}_{2}\right), 29.9(\mathrm{CH}), 26.0\left(2 \times \mathrm{CH}_{2}\right), 25.0\left(\mathrm{CH}_{2}\right) \mathrm{ppm}$.

EMBR (IE), m/z (\%): 199 (M+ 84), 170 (92), 156 (73), 143 (100), 130 (59), 115 (92), 89 (52).

\footnotetext{
${ }^{256}$ M. Suginome, T. Fukuda, Y. Ito, Org. Lett. 1999, 1, 1977.
} 


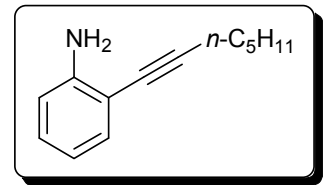

$o-(1-H e p t i n i l) a n i l i n a(29 f)^{257}$

Líquido marrón.

$\mathrm{R}_{\mathrm{f}}=0.42$ (hexano / AcOEt, $8 / 1$ ).

${ }^{1}$ H RMN (300 MHz, $\left.\mathrm{CDCl}_{3}\right): \delta=7.32(\mathrm{~d}, J=7.7 \mathrm{~Hz}, 1 \mathrm{H}), 7.17-7.09(\mathrm{~m}, 1 \mathrm{H}), 6.75-6.68(\mathrm{~m}, 2 \mathrm{H}), 4.22(\mathrm{sa}, 2 \mathrm{H})$, $2.52(\mathrm{t}, J=7.1 \mathrm{~Hz}, 2 \mathrm{H}), 1.74-1.63(\mathrm{~m}, 2 \mathrm{H}), 1.57-1.36(\mathrm{~m}, 4 \mathrm{H}), 1.00(\mathrm{t}, J=7.1 \mathrm{~Hz}, 3 \mathrm{H}) \mathrm{ppm}$.

${ }^{13} \mathbf{C}$ RMN (75.4 MHz, $\left.\mathrm{CDCl}_{3}\right): \delta=147.6(\mathrm{C}), 131.9(\mathrm{CH}), 128.7(\mathrm{CH}), 117.7(\mathrm{CH}), 114.1(\mathrm{CH}), 108.8(\mathrm{C}), 95.7$

(C), $77.0(\mathrm{C}), 31.1\left(\mathrm{CH}_{2}\right), 28.6\left(\mathrm{CH}_{2}\right), 22.2\left(\mathrm{CH}_{2}\right), 19.6\left(\mathrm{CH}_{2}\right), 14.0\left(\mathrm{CH}_{3}\right) \mathrm{ppm}$.

EMBR (IE), m/z (\%): $187\left(\mathrm{M}^{+}, 63\right), 158$ (25), 144 (51), 130 (100), 103 (21), 77 (28).

\section{B.2.2 Procedimiento general para la sintesis de los 1 H-indoles 2-sustituidos $\mathbf{3 0}$}

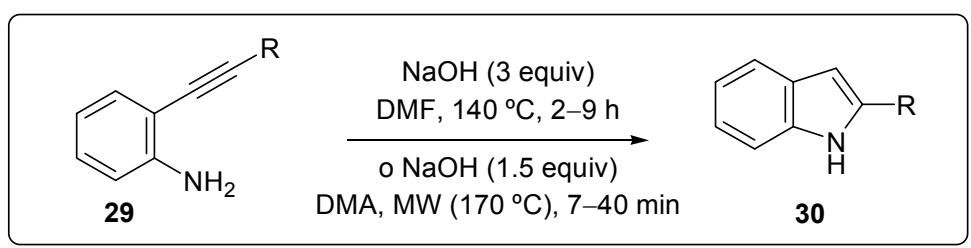

Metodo A: Calentamiento térmico.

A una disolución de la correspondiente $o$-alquinilanilina 29 (1 mmol) en DMF anhidra $(4 \mathrm{~mL}) \mathrm{se}$ añade un exceso de $\mathrm{NaOH}$ en polvo $(120 \mathrm{mg}, 3 \mathrm{mmol})$. La mezcla resultante se calienta a reflujo bajo $\mathrm{N}_{2}$ a $140{ }^{\circ} \mathrm{C}$ durante 2-9 horas (la reacción se sigue por CG-EM). Se deja que la reacción se enfríe a temperatura ambiente y se añaden $\mathrm{CH}_{2} \mathrm{Cl}_{2}(15 \mathrm{~mL})$ y $\mathrm{HCl}(15 \mathrm{~mL}$ de una disolución $0.5 \mathrm{M})$. La fase acuosa separada se extrae con $\mathrm{CH}_{2} \mathrm{Cl}_{2}(2 \times 15 \mathrm{~mL})$. La combinación de fases orgánicas se lava con $\mathrm{H}_{2} \mathrm{O}(2$ $\times 40 \mathrm{~mL}$ ). La fase orgánica se seca sobre $\mathrm{Na}_{2} \mathrm{SO}_{4}$ anhidro y se concentra a presión reducida. El residuo resultante se purifica mediante columna de cromatografía (hexano / AcOEt) obteniéndose los indoles 30.

\section{Metodo B: Calentamiento por microondas.}

A una disolución de la correspondiente $o$-alquinilanilina $29(0.5 \mathrm{mmol})$ en DMA anhidra (2 $\mathrm{mL})$ se añade un exceso de $\mathrm{NaOH}$ en polvo $(60 \mathrm{mg}, 0.75 \mathrm{mmol})$. La mezcla resultante se agita en un microondas, CEM Discover S-Class a $170{ }^{\circ} \mathrm{C}$ durante $7-40$ minutos (la reacción se sigue por CG$\mathrm{EM})$. Se deja que la reacción se enfríe a temperatura ambiente y se añaden $\mathrm{CH}_{2} \mathrm{Cl}_{2}(10 \mathrm{~mL})$ y $\mathrm{HCl}(10$ $\mathrm{mL}$ de una disolución $0.5 \mathrm{M})$. La fase acuosa separada se extrae con $\mathrm{CH}_{2} \mathrm{Cl}_{2}(2 \times 10 \mathrm{~mL})$. La combinación de fases orgánicas se lava con $\mathrm{H}_{2} \mathrm{O}(2 \times 30 \mathrm{~mL})$. La fase orgánica se seca sobre $\mathrm{Na}_{2} \mathrm{SO}_{4}$ anhidro y se concentra a presión reducida. El residuo resultante se purifica mediante columna de cromatografía de sílica gel (hexano / AcOEt) obteniéndose los indoles 30.

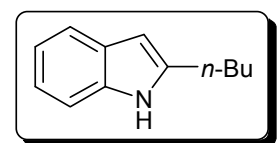

2-Butil-1H-indol (30a)

Sólido blanco.

P.f. $=29-31^{\circ} \mathrm{C}\left(\right.$ lit. $\left.^{258}=28-29.5^{\circ} \mathrm{C}\right)$.

\footnotetext{
${ }^{257}$ P. D. Woodgate, H. S. Sutherland, J. Organomet. Chem. 2001, 629, 131.

${ }^{258}$ C. E. Castro y col.; J. Org. Chem. 1966, 31, 4071.
} 
${ }^{1} \mathbf{H}$ RMN $\left(300 \mathrm{MHz}, \mathrm{CDCl}_{3}\right): \delta=7.73(\mathrm{sa}, 1 \mathrm{H}), 7.65-7.61(\mathrm{~m}, 1 \mathrm{H}), 7.33-7.29(\mathrm{~m}, 1 \mathrm{H}), 7.24-7.14(\mathrm{~m}, 2 \mathrm{H}), 6.32(\mathrm{dd}, J$ $=2.1,0.9 \mathrm{~Hz}, 1 \mathrm{H}), 2.76(\mathrm{t}, J=7.3 \mathrm{~Hz}, 2 \mathrm{H}), 1.81-1.69(\mathrm{~m}, 2 \mathrm{H}), 1.56-1.42(\mathrm{~m}, 2 \mathrm{H}), 1.04(\mathrm{t}, J=7.3 \mathrm{~Hz}, 3 \mathrm{H}) \mathrm{ppm}$.

${ }^{13} \mathbf{C}$ RMN (75.4 MHz, $\left.\mathrm{CDCl}_{3}\right): \delta=140.2(\mathrm{C}), 135.8(\mathrm{C}), 128.9(\mathrm{C}), 120.9(\mathrm{CH}), 119.8(\mathrm{CH}), 119.6(\mathrm{CH}), 110.4$ $(\mathrm{CH}), 99.4(\mathrm{CH}), 31.4\left(\mathrm{CH}_{2}\right), 28.0\left(\mathrm{CH}_{2}\right), 22.5\left(\mathrm{CH}_{2}\right), 14.0\left(\mathrm{CH}_{3}\right) \mathrm{ppm}$.

IR $\left(\mathrm{KBr}, \mathrm{cm}^{-1}\right): 3390,2951,2928,1548,1456,776,744$.

EMBR (IE), m/z (\%): $173\left(\mathrm{M}^{+}, 29\right), 144$ (6), 130 (100), 103 (6).

EMAR calculado para $\mathrm{C}_{12} \mathrm{H}_{15} \mathrm{~N}$ : 173.1204; encontrado: 173.1207 .

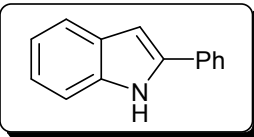

\section{2-Fenil-1H-indol (30b)}

Sólido blanco.

P.f. $=188-190{ }^{\circ} \mathrm{C}\left(\right.$ lit. $\left.^{116}=190-192^{\circ} \mathrm{C}\right)$.

${ }^{1} \mathbf{H}$ RMN (300 MHz, $\left.\mathrm{CDCl}_{3}\right): \delta=8.32(\mathrm{sa}, 1 \mathrm{H}), 7.67(\mathrm{~d}, J=7.2 \mathrm{~Hz}, 3 \mathrm{H}), 7.50-7.31(\mathrm{~m}, 4 \mathrm{H}), 7.26-7.20(\mathrm{~m}, 1 \mathrm{H})$, 7.19-7.13 (m, 1H), 6.87-6.85 (m, 1H) ppm.

${ }^{13}$ C RMN (75.4 MHz, $\left.\mathrm{CDCl}_{3}\right): \delta=138.0(\mathrm{C}), 136.9(\mathrm{C}), 132.4(\mathrm{C}), 129.3(\mathrm{C}), 129.1(2 \times \mathrm{CH}), 127.8(\mathrm{CH}), 125.3$ $(2 \times \mathrm{CH}), 122.5(\mathrm{CH}), 120.8(\mathrm{CH}), 120.4(\mathrm{CH}), 111.0(\mathrm{CH}), 100.1(\mathrm{CH}) \mathrm{ppm}$.

EMBR (IE), m/z (\%): $193\left(\mathrm{M}^{+}, 100\right), 165$ (21), 96 (10).

EMAR calculado para $\mathrm{C}_{14} \mathrm{H}_{11} \mathrm{~N}$ : 193.0891; encontrado: 193.0887 .

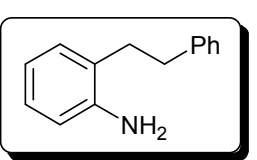

\section{2-(2-Feniletil)anilina $(33)^{259}$}

Líquido marrón.

$\mathrm{R}_{\mathrm{f}}=0.19$ (hexano / AcOEt, 8 / 1).

Aislado junto a 30b cuando se lleva a cabo la reacción en DMF como disolvente.

${ }^{1} \mathbf{H}$ RMN $\left(300 \mathrm{MHz}, \mathrm{CDCl}_{3}\right): \delta=7.43-7.34(\mathrm{~m}, 2 \mathrm{H}), 7.33-7.26(\mathrm{~m}, 3 \mathrm{H}), 7.17-7.10(\mathrm{~m}, 2 \mathrm{H}), 6.84(\mathrm{td}, J=7.4$, $1.2 \mathrm{~Hz}, 1 \mathrm{H}), 6.74(\mathrm{dd}, J=8.2,1.2 \mathrm{~Hz}, 1 \mathrm{H}), 3.56(\mathrm{sa}, 2 \mathrm{H}), 3.06-2.98(\mathrm{~m}, 2 \mathrm{H}), 2.90-2.82(\mathrm{~m}, 2 \mathrm{H}) \mathrm{ppm}$.

${ }^{13}$ C RMN (75.4 MHz, $\left.\mathrm{CDCl}_{3}\right): \delta=144.2(\mathrm{C}), 141.9(\mathrm{C}), 129.4(\mathrm{CH}), 128.53(2 \times \mathrm{CH}), 128.49(2 \times \mathrm{CH}), 127.2$ $(\mathrm{CH}), 126.1(\mathrm{CH}), 126.0(\mathrm{C}), 118.9(\mathrm{CH}), 115.7(\mathrm{CH}), 35.3\left(\mathrm{CH}_{2}\right), 33.4\left(\mathrm{CH}_{2}\right) \mathrm{ppm}$.

EMBR (IE), m/z (\%): $197\left(\mathrm{M}^{+}, 36\right), 106$ (100), 77 (9).

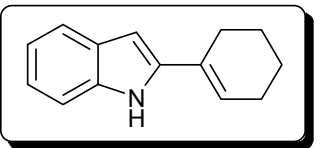

\section{2-(1-Ciclohexenil)-1H-indol (30c)}

Sólido blanco.

P.f. $=137-139^{\circ} \mathrm{C}\left(\right.$ lit. $\left.^{260}=140-141^{\circ} \mathrm{C}\right)$.

${ }^{1}$ H RMN $\left(300 \mathrm{MHz}, \mathrm{CDCl}_{3}\right): \delta=8.06(\mathrm{sa}, 1 \mathrm{H}), 7.66(\mathrm{~d}, J=7.8 \mathrm{~Hz}, 1 \mathrm{H}), 7.35(\mathrm{dd}, J=7.8,1.2 \mathrm{~Hz}, 1 \mathrm{H})$, 7.29-7.14 (m, 2H), $6.53(\mathrm{~d}, J=1.7 \mathrm{~Hz}, 1 \mathrm{H}), 6.15-6.09(\mathrm{~m}, 1 \mathrm{H}), 2.57-2.48(\mathrm{~m}, 2 \mathrm{H}), 2.36-2.27(\mathrm{~m}, 2 \mathrm{H})$, $1.92-1.82(\mathrm{~m}, 2 \mathrm{H}), 1.82-1.72(\mathrm{~m}, 2 \mathrm{H}) \mathrm{ppm}$.

${ }^{13}$ C RMN (75.4 MHz, $\mathrm{CDCl}_{3}$ ): $\delta=139.6(\mathrm{C}), 136.2(\mathrm{C}), 129.1(\mathrm{C}), 129.0(\mathrm{C}), 122.7(\mathrm{CH}), 122.0(\mathrm{CH}), 120.4$ $(\mathrm{CH}), 119.8(\mathrm{CH}), 110.5(\mathrm{CH}), 98.7(\mathrm{CH}), 26.1\left(\mathrm{CH}_{2}\right), 25.6\left(\mathrm{CH}_{2}\right), 22.6\left(\mathrm{CH}_{2}\right), 22.3\left(\mathrm{CH}_{2}\right) \mathrm{ppm}$.

EMBR (IE), m/z (\%): $197\left(\mathrm{M}^{+}, 100\right), 182$ (13), 168 (58), 130 (33).

EMAR calculado para $\mathrm{C}_{14} \mathrm{H}_{15} \mathrm{~N}$ : 197.1204; encontrado: 197.1199 .

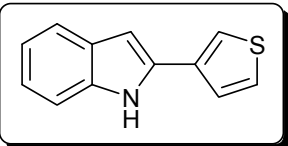

2-(3-Tienil)-1H-indol (30d)

Sólido blanco.

P.f. $=207-209^{\circ} \mathrm{C}\left(\right.$ lit. $\left.^{122 \mathrm{a}}=212-214^{\circ} \mathrm{C}\right)$.

\footnotetext{
${ }^{259}$ Schindler y col. Helv. Chim. Acta 1966, 49, 985.

${ }^{260}$ S. Kano, E. Sugino, S. Shibuya, S, Hibino, J. Org. Chem. 1981, 46, 3856.
} 
${ }^{1}$ H RMN (300 MHz, $\left.\left(\mathrm{CD}_{3}\right)_{2} \mathrm{CO}\right): \delta=10.64(\mathrm{sa}, 1 \mathrm{H}), 7.79(\mathrm{dd}, J=2.8,1.3 \mathrm{~Hz}, 1 \mathrm{H}), 7.64-7.53(\mathrm{~m}, 3 \mathrm{H}), 7.38(\mathrm{dt}$, $J=8.1,0.9 \mathrm{~Hz}, 1 \mathrm{H}), 7.14-6.98(\mathrm{~m}, 2 \mathrm{H}), 6.78(\mathrm{dd}, J=2.2,0.9 \mathrm{~Hz}, 1 \mathrm{H}) \mathrm{ppm}$.

${ }^{13} \mathbf{C}$ RMN (75.4 MHz, $\left.\left(\mathrm{CD}_{3}\right)_{2} \mathrm{CO}\right): \delta=137.8(\mathrm{C}), 135.3(\mathrm{C}), 135.1(\mathrm{C}), 130.0(\mathrm{C}), 127.4(\mathrm{CH}), 126.6(\mathrm{CH})$, $122.5(\mathrm{CH}), 121.0(\mathrm{CH}), 120.4(\mathrm{CH}), 119.9(\mathrm{CH}), 111.7(\mathrm{CH}), 99.8(\mathrm{CH}) \mathrm{ppm}$.

IR $\left(\mathrm{KBr}, \mathrm{cm}^{-1}\right): 3418,1452,1342,774,748$.

EMBR (IE), m/z (\%): 199 (M+1 100), 171 (10), 154 (8), 99 (5).

EMAR calculado para $\mathrm{C}_{12} \mathrm{H}_{9} \mathrm{NS}$ : 199.0456 ; encontrado: 199.0447.

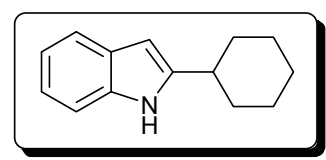

\section{2-Ciclohexil-1H-indol (30e)}

Sólido blanco.

P.f. $=99-101^{\circ} \mathrm{C}\left(\right.$ lit. $\left.^{261}=104-105^{\circ} \mathrm{C}\right)$.

${ }^{1}$ H RMN $\left(300 \mathrm{MHz}, \mathrm{CDCl}_{3}\right): \delta=7.89(\mathrm{sa}, 1 \mathrm{H}), 7.58-7.54(\mathrm{~m}, 1 \mathrm{H}), 7.31(\mathrm{dd}, J=7.6,0.6 \mathrm{~Hz}, 1 \mathrm{H}), 7.18-7.05$ $(\mathrm{m}, 2 \mathrm{H}), 6.26-6.23(\mathrm{~m}, 1 \mathrm{H}), 2.78-2.65(\mathrm{~m}, 1 \mathrm{H}), 2.15-2.04(\mathrm{~m}, 2 \mathrm{H}), 1.99-1.26(\mathrm{~m}, 8 \mathrm{H}) \mathrm{ppm}$.

${ }^{13} \mathbf{C}$ RMN (75.4 MHz, $\left.\mathrm{CDCl}_{3}\right): \delta=145.2(\mathrm{C}), 135.6(\mathrm{C}), 128.7(\mathrm{C}), 121.0(\mathrm{CH}), 120.0(\mathrm{CH}), 119.6(\mathrm{CH}), 110.5$ $(\mathrm{CH}), 97.6(\mathrm{CH}), 37.4(\mathrm{CH}), 33.1\left(2 \times \mathrm{CH}_{2}\right), 26.4\left(2 \times \mathrm{CH}_{2}\right), 26.2\left(\mathrm{CH}_{2}\right) \mathrm{ppm}$.

EMBR (IE), m/z (\%): 199 (M+1 100), 184 (7), 170 (22), 156 (53), 144 (54), 131 (59), 117 (16).

EMAR calculado para $\mathrm{C}_{14} \mathrm{H}_{17} \mathrm{~N}$ : 199.1361; encontrado: 199.1371.

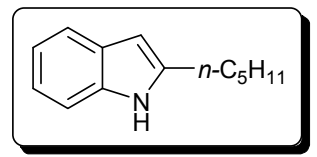

\section{2-Pentil-1H-indol (30f)}

Sólido blanco.

P.f. $=38-40{ }^{\circ} \mathrm{C}\left(\right.$ lit. $\left.^{116}=40-42^{\circ} \mathrm{C}\right)$.

${ }^{1}$ H RMN $\left(300 \mathrm{MHz}, \mathrm{CDCl}_{3}\right): \delta=7.72(\mathrm{sa}, 1 \mathrm{H}), 7.64(\mathrm{dd}, J=6.8,0.9 \mathrm{~Hz}, 1 \mathrm{H}), 7.33-7.29(\mathrm{~m}, 1 \mathrm{H}), 7.26-7.15$ $(\mathrm{m}, 2 \mathrm{H}), 6.34-6.31(\mathrm{~m}, 1 \mathrm{H}), 2.76(\mathrm{t}, J=7.6 \mathrm{~Hz}, 2 \mathrm{H}), 1.83-1.72(\mathrm{~m}, 2 \mathrm{H}), 1.52-1.40(\mathrm{~m}, 4 \mathrm{H}), 1.02(\mathrm{t}, J=$ $6.8 \mathrm{~Hz}, 3 \mathrm{H}) \mathrm{ppm}$.

${ }^{13}$ C RMN (75.4 MHz, $\left.\mathrm{CDCl}_{3}\right): \delta=140.2(\mathrm{C}), 135.9(\mathrm{C}), 128.9(\mathrm{C}), 120.9(\mathrm{CH}), 119.8(\mathrm{CH}), 119.6(\mathrm{CH}), 110.5$ $(\mathrm{CH}), 99.4(\mathrm{CH}), 31.6\left(\mathrm{CH}_{2}\right), 29.0\left(\mathrm{CH}_{2}\right), 28.3\left(\mathrm{CH}_{2}\right), 22.6\left(\mathrm{CH}_{2}\right), 14.2\left(\mathrm{CH}_{3}\right) \mathrm{ppm}$.

EMBR (IE), m/z (\%): $187\left(\mathrm{M}^{+}, 34\right), 144$ (23), 130 (100), 103 (6).

EMAR calculado para $\mathrm{C}_{13} \mathrm{H}_{17} \mathrm{~N}$ : 187.1361; encontrado: 187.1367 .

\section{B.2.3 Preparación de los 1 H-indoles 30 a partir de las o-yodoanilinas 31}

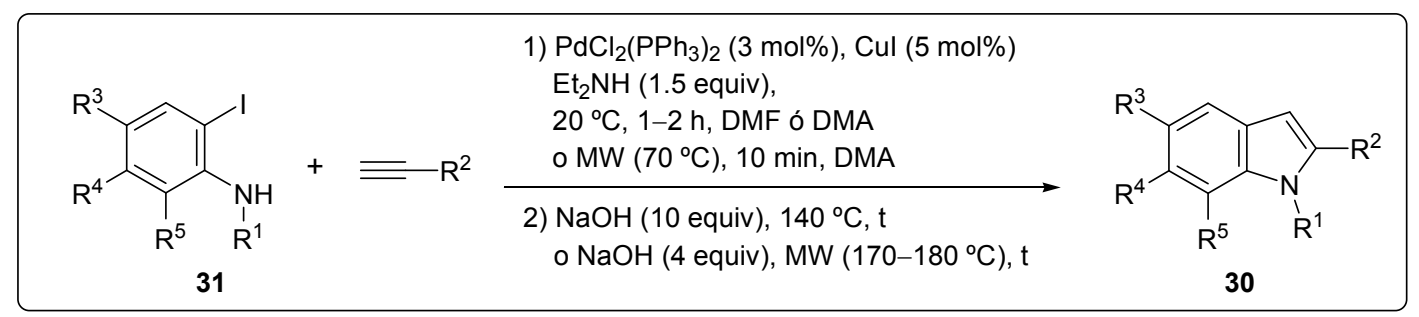

Metodo A: Calentamiento térmico.

Una mezcla de la correpondiente $o$-yodoanilina 31 (1 mmol), alquino (1.5 mmol), $\mathrm{PdCl}_{2}\left(\mathrm{PPh}_{3}\right)_{2}(3 \mathrm{~mol} \%)$, CuI $(5 \mathrm{~mol} \%)$ y Et ${ }_{2} \mathrm{NH}(156 \mu \mathrm{L}, 1.5 \mathrm{mmol})$ en DMF ó DMA $(5 \mathrm{~mL})$ se agita bajo $\mathrm{N}_{2}$ a temperatura ambiente el tiempo necesario hasta la desaparición completa de la $o$-yodoanilina 31 (la reacción se monitoriza mediante CG-EM) (1-2 h). A continuación se añade un exceso de $\mathrm{NaOH}$

${ }^{261}$ H. Adkins, H. L. Coonradt, J. Am. Chem. Soc. 1941, 63, 1563. 
en polvo (400 mg, $10 \mathrm{mmol}$ ). La mezcla resultante se calienta a reflujo bajo $\mathrm{N}_{2}$ a $140{ }^{\circ} \mathrm{C}$ durante $2-6$ horas (la reacción se sigue por CG-EM). Se deja que la reacción se enfríe a temperatura ambiente y se añaden $\mathrm{CH}_{2} \mathrm{Cl}_{2}(20 \mathrm{~mL})$ y $\mathrm{HCl}(20 \mathrm{~mL}$ de una disolución $0.5 \mathrm{M})$. La fase acuosa separada se extrae con $\mathrm{CH}_{2} \mathrm{Cl}_{2}(2 \times 20 \mathrm{~mL})$. La combinación de fases orgánicas se lava con $\mathrm{H}_{2} \mathrm{O}(2 \times 50 \mathrm{~mL})$. La fase orgánica se seca sobre $\mathrm{Na}_{2} \mathrm{SO}_{4}$ anhidro y se concentra a presión reducida. El residuo resultante se purifica mediante columna de cromatografía de sílica gel (hexano / AcOEt) obteniéndose los indoles 30. Los datos físicos y espectroscópicos de los indoles 30a-f se han detallado anteriormente.

\section{Metodo B: Calentamiento por microondas.}

Una mezcla de la correpondiente $o$-yodoanilina 31 (0.5 mmol), alquino $(0.75 \mathrm{mmol})$, $\mathrm{PdCl}_{2}\left(\mathrm{PPh}_{3}\right)_{2}(3 \mathrm{~mol} \%)$, CuI $(5 \mathrm{~mol} \%)$ y Et $\mathrm{NH}_{2}(78 \mu \mathrm{L} 0.75$ equiv) en DMA $(2 \mathrm{~mL})$ se agita en un microondas, CEM Discover S-Class a $70{ }^{\circ} \mathrm{C}$ y $70 \mathrm{~W}$ durante el tiempo necesario hasta la desaparición completa de la $o$-yodoanilina 31 de partida (10 minutos). A continuación se añade un exceso de $\mathrm{NaOH}$ en polvo ( $80 \mathrm{mg}, 2 \mathrm{mmol}$ ). La mezcla resultante se agita en el microondas a $170{ }^{\circ} \mathrm{C}$ durante $10-50$ minutos (la evolución de la reacción se sigue por CG-EM). Se deja que la reacción se enfríe a temperatura ambiente y se añaden $\mathrm{CH}_{2} \mathrm{Cl}_{2}(10 \mathrm{~mL})$ y $\mathrm{HCl}(10 \mathrm{~mL}$ de una disolución $0.5 \mathrm{M})$. La fase acuosa separada se extrae con $\mathrm{CH}_{2} \mathrm{Cl}_{2}(2 \times 10 \mathrm{~mL})$. La combinación de fases orgánicas se lava con $\mathrm{H}_{2} \mathrm{O}(2 \times 30 \mathrm{~mL})$. La fase orgánica se seca sobre $\mathrm{Na}_{2} \mathrm{SO}_{4}$ anhidro y se concentra a presión reducida. El residuo resultante se purifica mediante columna de cromatografía de sílica gel (hexano / AcOEt) obteniéndose los indoles 30. Los datos físicos y espectroscópicos de los indoles 30a-f se han detallado anteriormente.

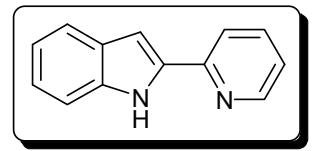

2-(2-Piridil)-1 $H$-indol (30g)

Sólido blanco.

P.f. $=149-151^{\circ} \mathrm{C}\left(\right.$ lit. $\left.^{262}=154-155^{\circ} \mathrm{C}\right)$.

${ }^{1} \mathbf{H}$ RMN $\left(300 \mathrm{MHz}, \mathrm{CDCl}_{3}\right): \delta=10.68(\mathrm{sa}, 1 \mathrm{H}), 8.65-8.61(\mathrm{~m}, 1 \mathrm{H}), 7.86(\mathrm{dd}, J=8.1,0.9 \mathrm{~Hz}, 1 \mathrm{H}), 7.77-7.69$ $(\mathrm{m}, 2 \mathrm{H}), 7.34(\mathrm{~d}, J=8.1 \mathrm{~Hz}, 1 \mathrm{H}), 7.29-7.23(\mathrm{~m}, 1 \mathrm{H}), 7.23-7.13(\mathrm{~m}, 2 \mathrm{H}), 7.11-7.08(\mathrm{~m}, 1 \mathrm{H}) \mathrm{ppm}$.

${ }^{13}$ C RMN (75.4 MHz, $\left.\mathrm{CDCl}_{3}\right): \delta=150.6(\mathrm{C}), 149.0(\mathrm{CH}), 136.95(\mathrm{C}), 136.88(\mathrm{CH}), 129.1(\mathrm{C}), 123.2(\mathrm{CH})$, $122.1(\mathrm{CH}), 121.2(\mathrm{CH}), 120.2(\mathrm{CH}), 120.1(\mathrm{CH}), 111.6(\mathrm{CH}), 100.9(\mathrm{CH}) \mathrm{ppm}$.

IR $\left(\mathrm{KBr}, \mathrm{cm}^{-1}\right): 1595,1467,1413,1303,998,809,779$.

EMBR (IE), m/z (\%): $194\left(\mathrm{M}^{+}, 100\right), 167$ (7), 139 (4), 89 (6).

EMAR calculado para $\mathrm{C}_{13} \mathrm{H}_{10} \mathrm{~N}_{2}$ : 194.0844; encontrado: 194.0842 .

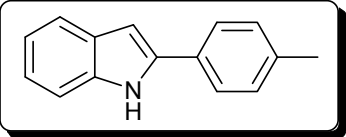

2-p-Tolil-1H-indol (30h)

Sólido blanco.

P.f. $=208-210^{\circ} \mathrm{C}\left(\right.$ lit. $\left.^{263}=212-214^{\circ} \mathrm{C}\right)$.

${ }^{1} \mathbf{H}$ RMN (300 MHz, $\left.\mathrm{CDCl}_{3}\right): \delta=8.32(\mathrm{sa}, 1 \mathrm{H}), 7.67-7.63(\mathrm{~m}, 1 \mathrm{H}), 7.59-7.54(\mathrm{~m}, 2 \mathrm{H}), 7.42-7.38(\mathrm{~m}, 1 \mathrm{H}), 7.29-7.24(\mathrm{~m}$, 2H), 7.21 (ddd, $J=8.0,7.1,1.3 \mathrm{~Hz}, 1 \mathrm{H}), 7.18-7.12(\mathrm{~m}, 1 \mathrm{H}), 6.81(\mathrm{dd}, J=2.1,0.9 \mathrm{~Hz}, 1 \mathrm{H}), 2.41(\mathrm{~s}, 3 \mathrm{H}) \mathrm{ppm}$.

${ }^{13} \mathbf{C}$ RMN (75.4 MHz, $\left.\mathrm{CDCl}_{3}\right): \delta=138.1(\mathrm{C}), 137.7(\mathrm{C}), 136.8(\mathrm{C}), 129.8(2 \times \mathrm{CH}), 129.6(\mathrm{C}), 129.4(\mathrm{C}), 125.2$ $(2 \times \mathrm{CH}), 122.2(\mathrm{CH}), 120.6(\mathrm{CH}), 120.3(\mathrm{CH}), 110.9(\mathrm{CH}), 99.4(\mathrm{CH}), 21.4\left(\mathrm{CH}_{3}\right) \mathrm{ppm}$.

IR $\left(\mathrm{KBr}, \mathrm{cm}^{-1}\right): 3439,1454,1350,1298,823,792,512$.

EMBR (IE), m/z (\%): 207 (M+100), 191 (4), 178 (7), 165 (4).

EMAR calculado para $\mathrm{C}_{15} \mathrm{H}_{13} \mathrm{~N}$ : 207.1048; encontrado: 207.1055.

${ }^{262}$ Z. Popovic, S. Wang, J. Am. Chem. Soc. 2000, 122, 3671.

${ }^{263}$ S. Cacchi, V. Carnicelli, F. Marinelli, J. Organomet. Chem. 1994, 475, 289. 


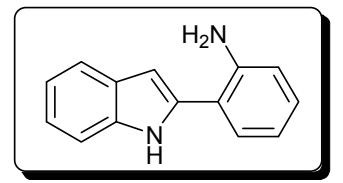

2-(2-Aminofenil)-1H-Indol (30i)

Sólido blanco-rosado.

P.f. $=149-151^{\circ} \mathrm{C}\left(\right.$ lit. $\left.^{132 \mathrm{~b}}=152-154^{\circ} \mathrm{C}\right)$.

${ }^{1} \mathbf{H}$ RMN (300 MHz, $\left.\mathrm{CDCl}_{3}\right): \delta=8.48(\mathrm{sa}, 1 \mathrm{H}), 7.66(\mathrm{~d}, J=7.6 \mathrm{~Hz}, 1 \mathrm{H}), 7.43-7.36(\mathrm{~m}, 2 \mathrm{H}), 7.26-7.12(\mathrm{~m}, 3 \mathrm{H}), 6.88$ $(\mathrm{td}, J=7.6,1.1 \mathrm{~Hz}, 1 \mathrm{H}), 6.82(\mathrm{dd}, J=8.0,0.8 \mathrm{~Hz}, 1 \mathrm{H}), 6.73(\mathrm{dd}, J=2.0,0.8 \mathrm{~Hz}, 1 \mathrm{H}), 4.10(\mathrm{sa}, 2 \mathrm{H}) \mathrm{ppm}$.

${ }^{13} \mathbf{C}$ RMN (75.4 MHz, $\left.\mathrm{CDCl}_{3}\right): \delta=144.2(\mathrm{C}), 136.2(\mathrm{C}), 136.0(\mathrm{C}), 129.3(\mathrm{CH}), 129.2(\mathrm{CH}), 129.0(\mathrm{C}), 122.2$ $(\mathrm{CH}), 120.5(\mathrm{CH}), 120.3(\mathrm{CH}), 119.2(\mathrm{CH}), 118.9(\mathrm{C}), 116.6(\mathrm{CH}), 111.0(\mathrm{CH}), 101.7(\mathrm{CH}) \mathrm{ppm}$.

EMBR (IE), m/z (\%): $208\left(\mathrm{M}^{+}, 100\right), 180$ (23), 152 (15), 104 (31), 89 (63).

EMAR calculado para $\mathrm{C}_{14} \mathrm{H}_{12} \mathrm{~N}_{2}: 208.1000$; encontrado: 208.0991 .

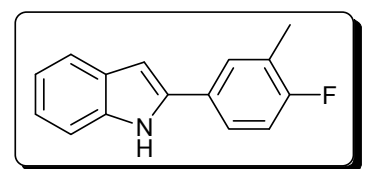

2-(4-Fluoro-3-metilfenil)-1H-indol (30j)

Sólido marrón.

P.f. $=148-150{ }^{\circ} \mathrm{C}\left(\right.$ lit. $\left.^{264}=155^{\circ} \mathrm{C}\right)$.

${ }^{1}$ H RMN (300 MHz, $\left.\left(\mathrm{CD}_{3}\right)_{2} \mathrm{CO}\right): \delta=10.63(\mathrm{sa}, 1 \mathrm{H}), 7.76(\mathrm{dd}, J=7.3,1.7 \mathrm{~Hz}, 1 \mathrm{H}), 7.72-7.65(\mathrm{~m}, 1 \mathrm{H}), 7.56(\mathrm{~d}$, $J=7.9 \mathrm{~Hz}, 1 \mathrm{H}), 7.42(\mathrm{~d}, J=7.9 \mathrm{~Hz}, 1 \mathrm{H}), 7.18-7.08(\mathrm{~m}, 2 \mathrm{H}), 7.06-6.99(\mathrm{~m}, 1 \mathrm{H}), 6.84(\mathrm{~d}, J=2.1 \mathrm{~Hz}, 1 \mathrm{H})$, $2.32(\mathrm{~d}, J=1.5 \mathrm{~Hz}, 3 \mathrm{H}) \mathrm{ppm}$.

${ }^{13}$ C RMN (75.4 MHz, $\left.\left(\mathrm{CD}_{3}\right)_{2} \mathrm{CO}\right): \delta=161.6(\mathrm{~d}, J=244.1 \mathrm{~Hz}, \mathrm{C}), 138.3(\mathrm{C}), 138.0(\mathrm{C}), 130.2(\mathrm{C}), 129.8(\mathrm{~d}, J=3.6$ $\mathrm{Hz}, \mathrm{C}), 129.2$ (d, $J=5.0 \mathrm{~Hz}, \mathrm{CH}), 125.9$ (d, $J=17.7 \mathrm{~Hz}, \mathrm{C}), 125.2$ (d, $J=8.1 \mathrm{~Hz}, \mathrm{CH}), 122.6(\mathrm{CH}), 121.0$ $(\mathrm{CH}), 120.5(\mathrm{CH}), 116.2(\mathrm{~d}, J=22.8 \mathrm{~Hz}, \mathrm{CH}), 112.0(\mathrm{CH}), 99.7(\mathrm{CH}), 14.6\left(\mathrm{~d}, J=3.5 \mathrm{~Hz}, \mathrm{CH}_{3}\right) \mathrm{ppm}$.

EMBR (IE), m/z (\%): 225 (M+, 100), 208 (5), 196 (7), 183 (12), 112 (14), 89 (29).

EMAR calculado para $\mathrm{C}_{15} \mathrm{H}_{12} \mathrm{FN}$ : 225.0954; encontrado: 225.0956

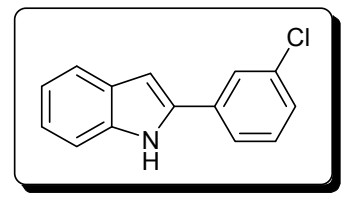

\section{2-(3-Clorofenil)-1H-indol (30k)}

Sólido marrón

P.f. $=134-136^{\circ} \mathrm{C}\left(\right.$ lit. $\left.^{265}=139-140{ }^{\circ} \mathrm{C}\right)$.

${ }^{1}$ H RMN $\left(300 \mathrm{MHz},\left(\mathrm{CD}_{3}\right)_{2} \mathrm{CO}\right): \delta=10.76(\mathrm{sa}, 1 \mathrm{H}), 7.90(\mathrm{t}, J=1.9 \mathrm{~Hz}, 1 \mathrm{H}), 7.81(\mathrm{ddd}, J=7.9,1.9,1.0 \mathrm{~Hz}$, $1 \mathrm{H}), 7.62-7.57(\mathrm{~m}, 1 \mathrm{H}), 7.48-7.40(\mathrm{~m}, 2 \mathrm{H}), 7.32(\mathrm{ddd}, J=7.9,1.9,1.0 \mathrm{~Hz}, 1 \mathrm{H}), 7.15$ (ddd, $J=7.9,7.1$, $1.0 \mathrm{~Hz}, 1 \mathrm{H}), 7.09-7.02(\mathrm{~m}, 1 \mathrm{H}), 6.99(\mathrm{dd}, J=2.3,1.0 \mathrm{~Hz}, 1 \mathrm{H}) \mathrm{ppm}$.

${ }^{13}$ C RMN (75.4 MHz, $\left.\left(\mathrm{CD}_{3}\right)_{2} \mathrm{CO}\right): \delta=138.5(\mathrm{C}), 137.1(\mathrm{C}), 135.6(\mathrm{C}), 135.3(\mathrm{C}), 131.4(\mathrm{CH}), 129.9(\mathrm{C}), 127.9$ $(\mathrm{CH}), 125.5(\mathrm{CH}), 124.3(\mathrm{CH}), 123.2(\mathrm{CH}), 121.4(\mathrm{CH}), 120.7(\mathrm{CH}), 112.1(\mathrm{CH}), 101.1(\mathrm{CH}) \mathrm{ppm}$.

IR $\left(\mathrm{KBr}, \mathrm{cm}^{-1}\right): 3428,1598,1441,1347,778,750$.

EMBR (IE), m/z (\%): 229 (M+2, 35), $227\left(\mathrm{M}^{+}, 100\right), 191$ (21), 165 (42), 113 (24), 89 (42).

EMAR calculado para $\mathrm{C}_{14} \mathrm{H}_{10} \mathrm{ClN}$ : 227.0502; encontrado: 227.0502 .

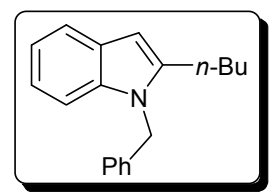

\section{$\boldsymbol{N}$-Bencil-2-butil-1 $\boldsymbol{H}$-indol (30I) ${ }^{266}$}

Líquido incoloro.

$\mathrm{R}_{\mathrm{f}}=0.58$ (hexano / AcOEt, $10 / 1$ ).

${ }^{264}$ K. C. Joshi, V. N. Pathak, R. P. Singh, Monatsh. Chem. 1980, 111, 1343.

${ }^{265}$ G. H. Chen, C. Hoechstetter, P. Knochel, Tetrahedron Lett. 1989, 30, 4795.

${ }^{266}$ Z.-Y. Tang, Q.-S. Hu, Adv. Synth. Catal. 2006, 348, 846. 
${ }^{1} \mathbf{H}$ RMN (300 MHz, $\left.\mathrm{CDCl}_{3}\right): \delta=7.82-7.74(\mathrm{~m}, 1 \mathrm{H}), 7.44-7.32(\mathrm{~m}, 4 \mathrm{H}), 7.31-7.24(\mathrm{~m}, 2 \mathrm{H}), 7.14-7.08(\mathrm{~m}, 2 \mathrm{H}), 6.55(\mathrm{~s}$, $1 \mathrm{H}), 5.43(\mathrm{~s}, 2 \mathrm{H}), 2.83(\mathrm{t}, J=7.4 \mathrm{~Hz}, 2 \mathrm{H}), 1.91-1.80(\mathrm{~m}, 2 \mathrm{H}), 1.65-1.52(\mathrm{~m}, 2 \mathrm{H}), 1.10(\mathrm{t}, J=7.4 \mathrm{~Hz}, 3 \mathrm{H}) \mathrm{ppm}$.

$\left.{ }^{13} \mathbf{C ~ R M N ~ ( 7 5 . 4 ~ M H z , ~} \mathrm{CDCl}_{3}\right): \delta=141.4(\mathrm{C}), 138.1(\mathrm{C}), 137.2(\mathrm{C}), 128.8(2 \times \mathrm{CH}), 128.2(\mathrm{C}), 127.2(\mathrm{CH}), 125.9$ $(2 \times \mathrm{CH}), 120.8(\mathrm{CH}), 119.9(\mathrm{CH}), 119.6(\mathrm{CH}), 109.4(\mathrm{CH}), 99.4(\mathrm{CH}), 46.3\left(\mathrm{CH}_{2}\right), 30.6\left(\mathrm{CH}_{2}\right), 26.5\left(\mathrm{CH}_{2}\right)$, $22.6\left(\mathrm{CH}_{2}\right), 14.0\left(\mathrm{CH}_{3}\right) \mathrm{ppm}$.

IR $\left(\mathrm{KBr}, \mathrm{cm}^{-1}\right): 3031,2956,2929,1548,1463,1454,746,727$.

EMBR (IE), m/z (\%): $263\left(\mathrm{M}^{+}, 69\right), 220$ (100), 206 (20), 130 (20) 91 (75).

EMAR calculado para $\mathrm{C}_{19} \mathrm{H}_{21} \mathrm{~N}$ : 263.1674; encontrado: 263.1690 .

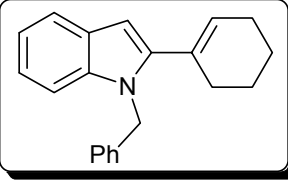

\section{$N$-Bencil-2-(1-ciclohexenil)-1H-indol (30m) ${ }^{267}$}

Líquido amarillo.

$\mathrm{R}_{\mathrm{f}}=0.59$ (hexano / AcOEt, $10 / 1$ ).

${ }^{1}$ H RMN (300 MHz, $\left.\mathrm{CDCl}_{3}\right): \delta=7.71-7.64(\mathrm{~m}, 1 \mathrm{H}), 7.38-7.27(\mathrm{~m}, 3 \mathrm{H}), 7.19-7.14(\mathrm{~m}, 3 \mathrm{H}), 7.13-7.08(\mathrm{~m}, 2 \mathrm{H}), 6.52$ $(\mathrm{s}, 1 \mathrm{H}), 5.91-5.87(\mathrm{~m}, 1 \mathrm{H}), 5.42(\mathrm{~s}, 2 \mathrm{H}), 2.41-2.33(\mathrm{~m}, 2 \mathrm{H}), 2.25-2.16(\mathrm{~m}, 2 \mathrm{H}), 1.85-1.65(\mathrm{~m}, 4 \mathrm{H}) \mathrm{ppm}$.

${ }^{13}$ C RMN (75.4 MHz, $\left.\mathrm{CDCl}_{3}\right): \delta=143.7$ (C), $138.6(\mathrm{C}), 137.9(\mathrm{C}), 129.8(\mathrm{C}), 129.2(\mathrm{CH}), 128.8(2 \times \mathrm{CH}), 128.3$ (C), $127.1(\mathrm{CH}), 126.1(2 \times \mathrm{CH}), 121.5(\mathrm{CH}), 120.3(\mathrm{CH}), 119.9(\mathrm{CH}), 110.3(\mathrm{CH}), 100.3(\mathrm{CH}), 47.9$ $\left(\mathrm{CH}_{2}\right), 29.9\left(\mathrm{CH}_{2}\right), 25.8\left(\mathrm{CH}_{2}\right), 23.0\left(\mathrm{CH}_{2}\right), 22.0\left(\mathrm{CH}_{2}\right) \mathrm{ppm}$.

IR $\left(\mathrm{KBr}, \mathrm{cm}^{-1}\right): 2922,2889,1462,1453,1339,780,735,724$.

EMBR (IE), m/z (\%): $287\left(\mathrm{M}^{+}, 37\right), 196$ (8), 180 (14), 167 (17), 91 (100).

EMAR calculado para $\mathrm{C}_{21} \mathrm{H}_{21} \mathrm{~N}$ : 287.1674; encontrado: 287.1674 .

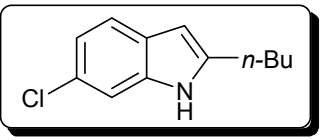

\section{2-Butil-6-cloro-1H-indol (30n)}

Sólido blanco.

P.f. $=89-91{ }^{\circ} \mathrm{C}\left(\right.$ lit $\left.^{268}=88-90{ }^{\circ} \mathrm{C}\right)$.

${ }^{1} \mathbf{H}$ RMN (300 MHz, $\mathrm{CDCl}_{3}$ ): $\delta=7.80(\mathrm{sa}, 1 \mathrm{H}), 7.43(\mathrm{dd}, J=8.4 \mathrm{~Hz}, 0.5 \mathrm{~Hz}, 1 \mathrm{H}), 7.26-7.23(\mathrm{~m}, 1 \mathrm{H}), 7.05(\mathrm{ddd}$, $J=8.4,1.9,0.5 \mathrm{~Hz}, 1 \mathrm{H}), 6.23-6.20(\mathrm{~m}, 1 \mathrm{H}), 2.73(\mathrm{t}, J=7.6 \mathrm{~Hz}, 2 \mathrm{H}), 1.75-1.64(\mathrm{~m}, 2 \mathrm{H}), 1.49-1.35(\mathrm{~m}$, $2 \mathrm{H}), 0.97(\mathrm{t}, J=7.3 \mathrm{~Hz}, 3 \mathrm{H}) \mathrm{ppm}$.

${ }^{13} \mathbf{C}$ RMN (75.4 MHz, $\mathrm{CDCl}_{3}$ ): $\delta=141.1(\mathrm{C}), 136.2(\mathrm{C}), 127.4(\mathrm{C}), 126.6(\mathrm{C}), 120.5(\mathrm{CH}), 120.2(\mathrm{CH}), 110.4$ $(\mathrm{CH}), 99.4(\mathrm{CH}), 31.2\left(\mathrm{CH}_{2}\right), 27.9\left(\mathrm{CH}_{2}\right), 22.5\left(\mathrm{CH}_{2}\right), 14.0\left(\mathrm{CH}_{3}\right) \mathrm{ppm}$.

IR $\left(\mathrm{KBr}, \mathrm{cm}^{-1}\right): 3402,2957,2938,1546,1457,1401,816,508$.

EMBR (IE), m/z (\%): 209 (M+2, 11), $207\left(\mathrm{M}^{+}, 33\right), 164$ (100), 128 (7), 102 (5).

EMAR calculado para $\mathrm{C}_{12} \mathrm{H}_{14} \mathrm{ClN}$ : 207.0815; encontrado: 207.0816.

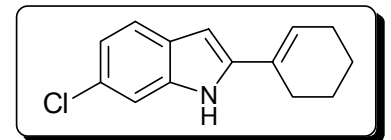

\section{2-(1-Ciclohexenil)-6-cloro-1H-indol (30o)}

Sólido blanco.

P.f. $=154-156^{\circ} \mathrm{C}$.

${ }^{1} \mathbf{H}$ RMN (300 MHz, $\left.\mathrm{CDCl}_{3}\right): \delta=8.06(\mathrm{sa}, 1 \mathrm{H}), 7.44(\mathrm{~d}, J=8.3 \mathrm{~Hz}, 1 \mathrm{H}), 7.27(\mathrm{~s}, 1 \mathrm{H}), 7.04(\mathrm{dd}, J=8.3,1.7 \mathrm{~Hz}, 1 \mathrm{H}), 6.40$ $(\mathrm{s}, 1 \mathrm{H}), 6.14-6.08(\mathrm{~m}, 1 \mathrm{H}), 2.49-2.39(\mathrm{~m}, 2 \mathrm{H}), 2.29-2.20(\mathrm{~m}, 2 \mathrm{H}), 1.84-1.75(\mathrm{~m}, 2 \mathrm{H}), 1.75-1.64(\mathrm{~m}, 2 \mathrm{H}) \mathrm{ppm}$.

${ }^{13}$ C RMN (75.4 MHz, $\left.\mathrm{CDCl}_{3}\right): \delta=140.3(\mathrm{C}), 136.6(\mathrm{C}), 128.9$ (C), 127.7 (C), 127.6 (C), $123.3(\mathrm{CH}), 121.2$ $(\mathrm{CH}), 120.5(\mathrm{CH}), 110.4(\mathrm{CH}), 98.7(\mathrm{CH}), 26.1\left(\mathrm{CH}_{2}\right), 25.6\left(\mathrm{CH}_{2}\right), 22.6\left(\mathrm{CH}_{2}\right), 22.3\left(\mathrm{CH}_{2}\right) \mathrm{ppm}$.

IR $\left(\mathrm{KBr}, \mathrm{cm}^{-1}\right): 3427,2935,1446,1340,813$.

EMBR (IE), m/z (\%): $233\left(\mathrm{M}^{+}+2,33\right), 231\left(\mathrm{M}^{+}, 100\right), 203$ (31), 164 (23), 151 (18).

EMAR calculado para $\mathrm{C}_{14} \mathrm{H}_{14} \mathrm{ClN}$ : 231.0815 ; encontrado: 231.0815 .

${ }^{267}$ K. B. Hong, Ch. W. Lee, E. K. Yum, Tetrahedron Lett. 2004, 45, 693.

${ }^{268}$ N. Suzuki, S. Yasaki, A. Yasuhara, T. Sakamoto, Chem. Pharm. Bull. 2003, 51, 1170. 


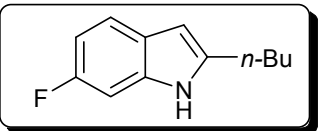

\section{2-Butil-6-fluoro-1H-indol (30p)}

Sólido blanco.

P.f. $=65-67^{\circ} \mathrm{C}$.

${ }^{1} \mathbf{H}$ RMN $\left(300 \mathrm{MHz}, \mathrm{CDCl}_{3}\right): \delta=7.79(\mathrm{sa}, 1 \mathrm{H}), 7.45(\mathrm{dd}, J=8.6,5.4 \mathrm{~Hz}, 1 \mathrm{H}), 7.00-6.94(\mathrm{~m}, 1 \mathrm{H}), 6.92-6.83(\mathrm{~m}, 1 \mathrm{H})$, $6.25-6.21(\mathrm{~m}, 1 \mathrm{H}), 2.73(\mathrm{t}, J=7.6 \mathrm{~Hz}, 2 \mathrm{H}), 1.76-1.65(\mathrm{~m}, 2 \mathrm{H}), 1.51-1.37(\mathrm{~m}, 2 \mathrm{H}), 0.98(\mathrm{td}, J=7.2,1.7 \mathrm{~Hz}, 3 \mathrm{H}) \mathrm{ppm}$.

${ }^{13} \mathbf{C}$ RMN $\left(75.4 \mathrm{MHz}, \mathrm{CDCl}_{3}\right): \delta=159.3(\mathrm{~d}, J=235.8 \mathrm{~Hz}, \mathrm{C}), 140.6(\mathrm{~d}, J=3.6 \mathrm{~Hz}, \mathrm{C}), 135.7(\mathrm{~d}, J=12.3 \mathrm{~Hz}$, C), $125.3(\mathrm{C}), 120.3(\mathrm{~d}, J=9.9 \mathrm{~Hz}, \mathrm{CH}), 108.1(\mathrm{~d}, J=24.1 \mathrm{~Hz}, \mathrm{CH}), 99.3(\mathrm{CH}), 96.9(\mathrm{~d}, J=26.1 \mathrm{~Hz}, \mathrm{CH})$, $31.3\left(\mathrm{CH}_{2}\right), 28.0\left(\mathrm{CH}_{2}\right), 22.5\left(\mathrm{CH}_{2}\right), 14.0\left(\mathrm{CH}_{3}\right) \mathrm{ppm}$.

IR $\left(\mathrm{KBr}, \mathrm{cm}^{-1}\right): 3403,2960,2929,1624,1495,1143,808$.

EMBR (IE), m/z (\%): $191\left(\mathrm{M}^{+}, 27\right), 162$ (4), 148 (100), 101 (6).

EMAR calculado para $\mathrm{C}_{12} \mathrm{H}_{14} \mathrm{FN}$ : 191.1110; encontrado: 191.1112 .

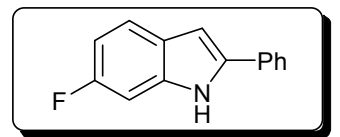

\section{2-Fenil-6-fluoro-1 $H$-indol (30q)}

Sólido blanco.

P.f. $=170-172{ }^{\circ} \mathrm{C}\left(\right.$ lit. $\left.^{269}=180-181^{\circ} \mathrm{C}\right)$.

${ }^{1} \mathbf{H}$ RMN (300 MHz, $\left.\mathrm{CDCl}_{3}\right): \delta=8.39(\mathrm{sa}, 1 \mathrm{H}), 7.67-7.61(\mathrm{~m}, 2 \mathrm{H}), 7.54(\mathrm{dd}, J=8.6,5.4 \mathrm{~Hz}, 1 \mathrm{H}), 7.48-7.40$ $(\mathrm{m}, 2 \mathrm{H}), 7.37-7.30(\mathrm{~m}, 1 \mathrm{H}), 7.09(\mathrm{dd}, J=9.6,2.2 \mathrm{~Hz}, 1 \mathrm{H}), 6.90(\mathrm{ddd}, J=9.6,8.6,2.2 \mathrm{~Hz}, 1 \mathrm{H}), 6.80(\mathrm{dd}, J$ $=2.2,0.9 \mathrm{~Hz}, 1 \mathrm{H}) \mathrm{ppm}$.

${ }^{13} \mathbf{C}$ RMN $\left(75.4 \mathrm{MHz}, \mathrm{CDCl}_{3}\right): \delta=160.1(\mathrm{~d}, J=238.1 \mathrm{~Hz}, \mathrm{C}), 138.5(\mathrm{~d}, J=3.6 \mathrm{~Hz}, \mathrm{C}), 136.8(\mathrm{~d}, J=12.5 \mathrm{~Hz}$, C), $132.2(\mathrm{C}), 129.2(2 \times \mathrm{CH}), 127.9(\mathrm{CH}), 125.9(\mathrm{C}), 125.1(2 \times \mathrm{CH}), 121.5(\mathrm{~d}, J=10.1 \mathrm{~Hz}, \mathrm{CH}), 109.1(\mathrm{~d}$, $J=24.4 \mathrm{~Hz}, \mathrm{CH}), 99.9(\mathrm{~d}, J=0.7 \mathrm{~Hz}, \mathrm{CH}), 97.4(\mathrm{~d}, J=26.2 \mathrm{~Hz}, \mathrm{CH}) \mathrm{ppm}$.

IR $\left(\mathrm{KBr}, \mathrm{cm}^{-1}\right): 3433,1542,1446,842,813,759$.

EMBR (IE), m/z (\%): $211\left(\mathrm{M}^{+}, 100\right), 191$ (3), 183 (28), 107 (24), 77 (8).

EMAR calculado para $\mathrm{C}_{14} \mathrm{H}_{10} \mathrm{FN}$ : 211.0797; encontrado: 211.0799 .

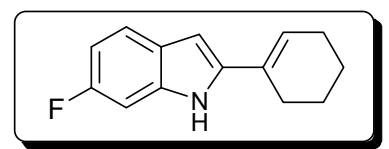

2-(1-Ciclohexenil)-6-fluoro-1H-indol (30r)

Sólido blanco.

P.f. $=128-130^{\circ} \mathrm{C}$.

${ }^{1}$ H RMN $\left(300 \mathrm{MHz}, \mathrm{CDCl}_{3}\right): \delta=8.08(\mathrm{sa}, 1 \mathrm{H}), 7.46(\mathrm{dd}, J=8.6,5.4 \mathrm{~Hz}, 1 \mathrm{H}), 6.98(\mathrm{dd}, J=9.6,2.2 \mathrm{~Hz}, 1 \mathrm{H})$, 6.85 (ddd, $J=9.6,8.6,2.2 \mathrm{~Hz}, 1 \mathrm{H}), 6.41(\mathrm{~d}, J=1.2 \mathrm{~Hz}, 1 \mathrm{H}), 6.10-6.04(\mathrm{~m}, 1 \mathrm{H}), 2.48-2.41(\mathrm{~m}, 2 \mathrm{H})$, 2.29-2.22 (m, 2H), 1.85-1.76 (m, 2H), 1.75-1.66 (m, 2H) ppm.

${ }^{13}$ C RMN (75.4 MHz, $\left.\mathrm{CDCl}_{3}\right): \delta=160.0(\mathrm{~d}, J=237.2 \mathrm{~Hz}, \mathrm{C}), 140.1(\mathrm{~d}, J=3.7 \mathrm{~Hz}, \mathrm{C}), 136.2(\mathrm{~d}, J=12.5 \mathrm{~Hz}, \mathrm{C})$, $129.0(\mathrm{C}), 125.5(\mathrm{~d}, J=0.6 \mathrm{~Hz}, \mathrm{C}), 122.6(\mathrm{CH}), 121.0(\mathrm{~d}, J=10.0 \mathrm{~Hz}, \mathrm{CH}), 108.4(\mathrm{~d}, J=24.3 \mathrm{~Hz}, \mathrm{CH}), 98.6$ $(\mathrm{d}, J=0.6 \mathrm{~Hz}, \mathrm{CH}), 97.0(\mathrm{~d}, J=26.2 \mathrm{~Hz}, \mathrm{CH}), 26.1\left(\mathrm{CH}_{2}\right), 25.6\left(\mathrm{CH}_{2}\right), 22.6\left(\mathrm{CH}_{2}\right), 22.3\left(\mathrm{CH}_{2}\right) \mathrm{ppm}$.

IR $\left(\mathrm{KBr}, \mathrm{cm}^{-1}\right): 3442,2936,1616,1497,1236,838,809$.

EMBR (IE), m/z (\%): 215 (M+1 100), 200 (14), 186 (52), 172 (13), 148 (27), 135 (19).

EMAR calculado para $\mathrm{C}_{14} \mathrm{H}_{14} \mathrm{FN}$ : 215.1110 ; encontrado: 215.1114 .

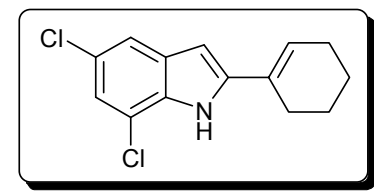

2-(1-Ciclohexenil)-5,7-dicloro-1H-indol (30s)

Sólido blanco.

P.f. $=76-78^{\circ} \mathrm{C}$.

${ }^{269}$ J. L. Rutherford, M. P. Rainka, S. L. Buchwald, J. Am. Chem. Soc. 2002, 124, 15168. 
${ }^{1} \mathbf{H} \mathbf{R M N}\left(300 \mathrm{MHz}, \mathrm{CDCl}_{3}\right): \delta=8.22(\mathrm{sa}, 1 \mathrm{H}), 7.39(\mathrm{~d}, J=1.7 \mathrm{~Hz}, 1 \mathrm{H}), 7.12(\mathrm{~d}, J=1.7 \mathrm{~Hz}, 1 \mathrm{H}), 6.37(\mathrm{~d}, J=2.2 \mathrm{~Hz}$, $1 \mathrm{H}), 6.26-6.20(\mathrm{~m}, 1 \mathrm{H}), 2.47-2.38(\mathrm{~m}, 2 \mathrm{H}), 2.31-2.22(\mathrm{~m}, 2 \mathrm{H}), 1.84-1.75(\mathrm{~m}, 2 \mathrm{H}), 1.74-1.64(\mathrm{~m}, 2 \mathrm{H}) \mathrm{ppm}$.

${ }^{13} \mathbf{C}$ RMN (75.4 MHz, $\left.\mathrm{CDCl}_{3}\right): \delta=141.6(\mathrm{C}), 132.0(\mathrm{C}), 130.8(\mathrm{C}), 128.5$ (C), 125.3 (C), $124.8(\mathrm{CH}), 121.3$ $(\mathrm{CH}), 118.5(\mathrm{CH}), 116.2(\mathrm{C}), 99.2(\mathrm{CH}), 26.1\left(\mathrm{CH}_{2}\right), 25.6\left(\mathrm{CH}_{2}\right), 22.5\left(\mathrm{CH}_{2}\right), 22.1\left(\mathrm{CH}_{2}\right) \mathrm{ppm}$.

IR $\left(\mathrm{KBr}, \mathrm{cm}^{-1}\right): 3460,2939,1567,1468,1408,830,775,756$.

EMBR (IE), m/z (\%): 269 (M+4, 11), 267 (M+2, 66), 265 (M+1 100), 237 (25), 198 (22), 185 (19), 167 (14).

EMAR calculado para $\mathrm{C}_{14} \mathrm{H}_{13} \mathrm{Cl}_{2} \mathrm{~N}$ : 265.0425; encontrado: 265.0420 .<smiles>Clc1cc(Cl)c2[nH]c(-c3ccccc3)cc2c1</smiles>

\section{5,7-Dicloro-2-pentil-1H-indol (30t)}

Líquido marrón.

$\mathrm{R}_{\mathrm{f}}=0.53$ (hexano / AcOEt, $8 / 1$ ).

${ }^{1}$ H RMN (300 MHz, $\left.\mathrm{CDCl}_{3}\right): \delta=8.07(\mathrm{sa}, 1 \mathrm{H}), 7.40(\mathrm{~d}, J=1.7 \mathrm{~Hz}, 1 \mathrm{H}), 7.13(\mathrm{~d}, J=1.7 \mathrm{~Hz}, 1 \mathrm{H}), 6.24-6.21(\mathrm{~m}$, $1 \mathrm{H}), 2.74(\mathrm{t}, J=7.7 \mathrm{~Hz}, 2 \mathrm{H}), 1.79-1.68(\mathrm{~m}, 2 \mathrm{H}), 1.44-1.34(\mathrm{~m}, 4 \mathrm{H}), 0.95(\mathrm{t}, J=6.9 \mathrm{~Hz}, 3 \mathrm{H}) \mathrm{ppm}$.

${ }^{13} \mathbf{C}$ RMN (75.4 MHz, $\left.\mathrm{CDCl}_{3}\right): \delta=142.5(\mathrm{C}), 131.7(\mathrm{C}), 130.7$ (C), $125.1(\mathrm{C}), 120.3(\mathrm{CH}), 118.0(\mathrm{CH}), 116.1$ (C), $100.4(\mathrm{CH}), 31.6\left(\mathrm{CH}_{2}\right), 28.8\left(\mathrm{CH}_{2}\right), 28.2\left(\mathrm{CH}_{2}\right), 22.6\left(\mathrm{CH}_{2}\right), 14.1\left(\mathrm{CH}_{3}\right) \mathrm{ppm}$.

IR $\left(\mathrm{KBr}, \mathrm{cm}^{-1}\right): 3437,2957,2929,1574,1468,1305,866,779,736$.

EMBR (IE), m/z (\%): $259\left(\mathrm{M}^{+}+4,4\right), 257\left(\mathrm{M}^{+}+2,24\right), 255\left(\mathrm{M}^{+}, 38\right), 212$ (30), 198 (100), 164 (13), 127 (12).

EMAR calculado para $\mathrm{C}_{13} \mathrm{H}_{15} \mathrm{Cl}_{2} \mathrm{~N}$ : 255.0582; encontrado: 255.0569 .

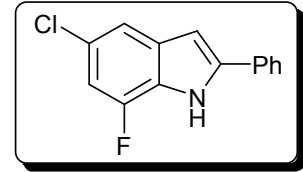

\section{5-Cloro-2-fenil-7-fluoro-1H-indol (30u)}

Sólido marrón.

P.f. $=151-153^{\circ} \mathrm{C}\left(\right.$ lit. $\left.^{270}=153-155^{\circ} \mathrm{C}\right)$.

${ }^{1} \mathbf{H}$ RMN (300 MHz, $\left.\mathrm{CDCl}_{3}\right): \delta=8.52(\mathrm{sa}, 1 \mathrm{H}), 7.66(\mathrm{~d}, J=8.0 \mathrm{~Hz}, 2 \mathrm{H}), 7.47(\mathrm{t}, J=8.0 \mathrm{~Hz}, 2 \mathrm{H}), 7.42-7.34(\mathrm{~m}$, 2H), 6.97-6.90 (m, 1H), 6.79-6.75 (m, 1H) ppm.

${ }^{13}$ C RMN (75.4 MHz, $\left.\mathrm{CDCl}_{3}\right): \delta=148.7(\mathrm{~d}, J=246.8, \mathrm{C}), 140.1(\mathrm{C}), 132.9(\mathrm{~d}, J=5.9 \mathrm{~Hz}, \mathrm{C}), 131.4(\mathrm{C}), 129.3$ $(2 \times \mathrm{CH}), 128.6(\mathrm{CH}), 125.5(2 \times \mathrm{CH}), 125.2(\mathrm{~d}, J=8.7 \mathrm{~Hz}, \mathrm{C}), 123.6(\mathrm{~d}, J=12.9 \mathrm{~Hz}, \mathrm{C}), 116.1(\mathrm{~d}, J=3.6$ $\mathrm{Hz}, \mathrm{CH}), 108.5(\mathrm{~d}, J=20.0 \mathrm{~Hz}, \mathrm{CH}), 100.2(\mathrm{~d}, J=2.4 \mathrm{~Hz}, \mathrm{CH}) \mathrm{ppm}$.

IR $\left(\mathrm{KBr}, \mathrm{cm}^{-1}\right): 3472,1579,1471,1393,1304,897,820,758,490$.

EMBR (IE), m/z (\%): $247\left(\mathrm{M}^{+}+2,32\right), 245$ (M+100), 209 (14), 190 (10), 183 (32), 122 (15), 107 (30).

EMAR calculado para $\mathrm{C}_{14} \mathrm{H}_{9} \mathrm{ClFN}$ : 245.0408; encontrado: 245.0412 .

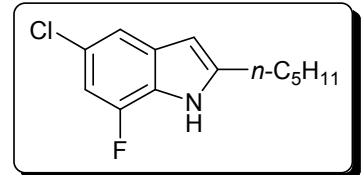

\section{5-Cloro-7-fluoro-2-pentil-1 $H$-indol (30v)}

Líquido marrón.

$\mathrm{R}_{\mathrm{f}}=0.57$ (hexano / AcOEt, $9 /$ 1).

${ }^{1} \mathbf{H}$ RMN $\left(300 \mathrm{MHz}, \mathrm{CDCl}_{3}\right): \delta=8.08(\mathrm{sa}, 1 \mathrm{H}), 7.27(\mathrm{dd}, J=1.6,0.8 \mathrm{~Hz}, 1 \mathrm{H}), 6.88-6.82(\mathrm{~m}, 1 \mathrm{H}), 6.23-6.19$ $(\mathrm{m}, 1 \mathrm{H}), 2.74(\mathrm{t}, J=7.6 \mathrm{~Hz}, 2 \mathrm{H}), 1.78-1.65(\mathrm{~m}, 2 \mathrm{H}), 1.48-1.30(\mathrm{~m}, 4 \mathrm{H}), 0.92(\mathrm{t}, J=7.0 \mathrm{~Hz}, 3 \mathrm{H}) \mathrm{ppm}$.

${ }^{13} \mathbf{C}$ RMN (75.4 MHz, $\left.\mathrm{CDCl}_{3}\right): \delta=148.4$ (d, $\left.J=245.9 \mathrm{~Hz}, \mathrm{C}\right), 142.4(\mathrm{C}), 132.7$ (d, $\left.J=6.2 \mathrm{~Hz}, \mathrm{C}\right), 124.5(\mathrm{~d}, J=$ $8.7 \mathrm{~Hz}, \mathrm{C}), 122.5(\mathrm{~d}, J=12.7 \mathrm{~Hz}, \mathrm{C}), 115.3(\mathrm{~d}, J=3.4 \mathrm{~Hz}, \mathrm{CH}), 107.2(\mathrm{~d}, J=20.1 \mathrm{~Hz}, \mathrm{CH}), 100.2(\mathrm{~d}, J=$ $2.3 \mathrm{~Hz}, \mathrm{CH}), 31.6\left(\mathrm{CH}_{2}\right), 28.8\left(\mathrm{CH}_{2}\right), 28.2\left(\mathrm{CH}_{2}\right), 22.6\left(\mathrm{CH}_{2}\right), 14.1\left(\mathrm{CH}_{3}\right) \mathrm{ppm}$.

IR $\left(\mathrm{KBr}, \mathrm{cm}^{-1}\right): 3442,2931,1583,1476,1308,895$.

EMBR (IE), m/z (\%): $241\left(\mathrm{M}^{+}+2,13\right), 239$ (M+1, 38), 196 (31), 182 (100), 161 (9), 148 (12), 127 (9).

EMAR calculado para $\mathrm{C}_{13} \mathrm{H}_{15} \mathrm{ClFN}$ : 239.0877; encontrado: 239.0875 .

${ }^{270}$ P. Saejueng, C. G. Bates, D. Venkataraman, Synthesis 2005, 10, 1706. 


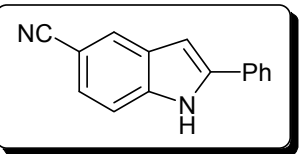

2-Fenil-1H-indol-5-carbonitrilo (30w)

Sólido blanco.

P.f. $=192-194^{\circ} \mathrm{C}\left(\right.$ lit. $\left.^{271}=195^{\circ} \mathrm{C}\right)$.

${ }^{1}$ H RMN (300 MHz, $\left.\left(\mathrm{CD}_{3}\right)_{2} \mathrm{CO}\right): \delta=11.2(\mathrm{sa}, 1 \mathrm{H}), 8.02-7.99(\mathrm{~m}, 1 \mathrm{H}), 7.91-7.84(\mathrm{~m}, 2 \mathrm{H}), 7.58(\mathrm{dt}, J=8.4,0.8$ $\mathrm{Hz}, 1 \mathrm{H}), 7.51-7.45(\mathrm{~m}, 2 \mathrm{H}), 7.45-7.34(\mathrm{~m}, 2 \mathrm{H}), 7.01(\mathrm{dd}, J=2.2,0.9 \mathrm{~Hz}, 1 \mathrm{H}) \mathrm{ppm}$.

${ }^{13}$ C RMN (75.4 MHz, $\left.\left(\mathrm{CD}_{3}\right)_{2} \mathrm{CO}\right): \delta=141.4(\mathrm{C}), 139.8(\mathrm{C}), 132.3(\mathrm{C}), 129.9(2 \times \mathrm{CH}), 129.8(\mathrm{C}), 129.1(\mathrm{CH})$, $126.3(\mathrm{CH}), 126.2(2 \times \mathrm{CH}), 125.2(\mathrm{CH}), 121.1(\mathrm{C}), 113.1(\mathrm{CH}), 103.5(\mathrm{C}), 100.3(\mathrm{CH}) \mathrm{ppm}$.

IR $\left(\mathrm{KBr}, \mathrm{cm}^{-1}\right): 3347,2221,1452,1331,756,735$.

EMBR (IE), m/z (\%): $218\left(\mathrm{M}^{+}, 100\right), 190$ (20), 164 (9), 114 (15), 88 (13).

EMAR calculado para $\mathrm{C}_{15} \mathrm{H}_{10} \mathrm{~N}_{2}: 218.0844$; encontrado: 218.0838 .

\section{B.2.4 Procedimiento general para la sintesis de 3-ariltio-1H-indoles funcionalizados $\mathbf{3 2}$}

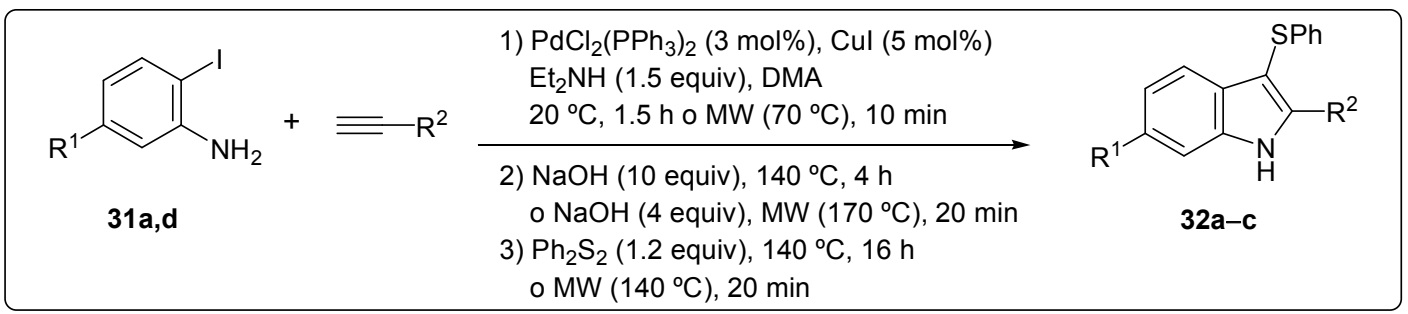

Metodo A: Calentamiento térmico.

Una mezcla de $o$-yodoanilina 31a $(220 \mathrm{mg}, 1 \mathrm{mmol})$, 1-hexino (170 $\mu \mathrm{L}, 1.5 \mathrm{mmol})$, $\mathrm{PdCl}_{2}\left(\mathrm{PPh}_{3}\right)_{2}(3 \mathrm{~mol} \%)$, CuI $(5 \mathrm{~mol} \%)$ y Et ${ }_{2} \mathrm{NH}(156 \mu \mathrm{L}, 1.5 \mathrm{mmol})$ en DMA $(5 \mathrm{~mL})$ se agita bajo $\mathrm{N}_{2}$ a temperatura ambiente el tiempo necesario hasta la desaparición completa de la $o$-yodoanilina 31a (la reacción se monitoriza mediante $\mathrm{CG}-\mathrm{EM}$ ) (1.5 horas). A continuación se añade un exceso de $\mathrm{NaOH}$ en polvo (400 mg, $10 \mathrm{mmol}$ ). La mezcla resultante se calienta a reflujo bajo $\mathrm{N}_{2}$ a $140{ }^{\circ} \mathrm{C}$ durante 3.5 horas (la reacción se sigue por CG-EM). Entonces, se añade $\mathrm{Ph}_{2} \mathrm{~S}_{2}(261 \mathrm{mg}, 1.2$ mmoles) y la reacción se agita durante toda la noche a $140{ }^{\circ} \mathrm{C}$. Se deja que la mezcla de reacción se enfríe a temperatura ambiente y se añaden $\mathrm{CH}_{2} \mathrm{Cl}_{2}(20 \mathrm{~mL})$ y $\mathrm{HCl}(20 \mathrm{~mL}$ de una disolución $0.5 \mathrm{M})$. La fase acuosa separada se extrae con $\mathrm{CH}_{2} \mathrm{Cl}_{2}(2 \times 20 \mathrm{~mL})$. La combinación de fases orgánicas se lava con $\mathrm{H}_{2} \mathrm{O}(2 \times 50 \mathrm{~mL})$. La fase orgánica se seca sobre $\mathrm{Na}_{2} \mathrm{SO}_{4}$ anhidro y se concentra a presión reducida. El residuo resultante se purifica mediante columna de cromatografía de sílica gel (hexano / AcOEt) obteniéndose el 2-butil-3feniltio- $1 H$-indol 32a.

\section{Metodo B: Calentamiento por microondas.}

Una mezcla de la correspondiente $o$-yodoanilina 31 (0.5 mmol), alquino $(0.75 \mathrm{mmol})$, $\mathrm{PdCl}_{2}\left(\mathrm{PPh}_{3}\right)_{2}(3 \mathrm{~mol} \%), \mathrm{CuI}(5 \mathrm{~mol} \%)$ y Et ${ }_{2} \mathrm{NH}(78 \mu \mathrm{L}, 0.75 \mathrm{mmol})$ en DMA $(2 \mathrm{~mL})$ se agita en un microondas, CEM Discover S-Class a $70{ }^{\circ} \mathrm{C}$ y $70 \mathrm{~W}$ durante el tiempo necesario hasta la desaparición completa de la $o$-yodoanilina 31 (10 minutos). A continuación se añade un exceso de $\mathrm{NaOH}$ en polvo $(80 \mathrm{mg}, 2 \mathrm{mmol})$. La mezcla resultante se agita en el microondas a $170{ }^{\circ} \mathrm{C}$ durante 20 minutos (la reacción se sigue por CG-EM). Entonces, se añade $\mathrm{Ph}_{2} \mathrm{~S}_{2}(131 \mathrm{mg}, 0.6 \mathrm{mmol})$ y la reacción se agita

${ }^{271}$ A. Yasuhara, Y. Kanamori, M. Kaneko, A. Numata, Y. Kondo, T. Sakamoto, J. Chem. Soc., Perkin Trans. 1, $1999,4,529$. 
durante otros 20 minutos a $140{ }^{\circ} \mathrm{C}$. Se deja que la reacción se enfríe a temperatura ambiente y se añaden $\mathrm{CH}_{2} \mathrm{Cl}_{2}(15 \mathrm{~mL})$ y $\mathrm{HCl}(15 \mathrm{~mL}$ de una disolución $0.5 \mathrm{M})$. La fase acuosa separada se extrae con $\mathrm{CH}_{2} \mathrm{Cl}_{2}$ $(2 \times 15 \mathrm{~mL})$. La combinación de fases orgánicas se lava con $\mathrm{H}_{2} \mathrm{O}(2 \times 30 \mathrm{~mL})$. La fase orgánica se seca sobre $\mathrm{Na}_{2} \mathrm{SO}_{4}$ anhidro y se concentra a presión reducida. El residuo resultante se purifica mediante columna de cromatografía (hexano / AcOEt) obteniéndose los 3-fenil-1H-indoles 2-sustituidos 32.

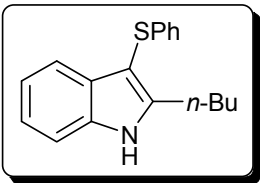

2-Butil-3-(feniltio)-1H-indol (32a)

Líquido marrón.

$\mathrm{R}_{\mathrm{f}}=0.16$ (hexano / AcOEt, $15 / 1$ ).

${ }^{1} \mathbf{H}$ RMN (300 MHz, CDCl $)$ ): $\delta=8.35(\mathrm{sa}, 1 \mathrm{H}), 7.68(\mathrm{~d}, J=7.7 \mathrm{~Hz}, 1 \mathrm{H}), 7.40(\mathrm{~d}, J=7.7 \mathrm{~Hz}, 1 \mathrm{H}), 7.34-7.27(\mathrm{~m}, 1 \mathrm{H})$, $7.27-7.09(\mathrm{~m}, 5 \mathrm{H}), 2.96(\mathrm{t}, J=7.3 \mathrm{~Hz}, 2 \mathrm{H}), 1.75-1.63(\mathrm{~m}, 2 \mathrm{H}), 1.49-1.35(\mathrm{~m}, 2 \mathrm{H}), 0.98(\mathrm{t}, J=7.3 \mathrm{~Hz}, 3 \mathrm{H}) \mathrm{ppm}$.

${ }^{13}$ C RMN (75.4 MHz, $\left.\mathrm{CDCl}_{3}\right): \delta=145.7(\mathrm{C}), 139.6(\mathrm{C}), 135.5(\mathrm{C}), 130.2(\mathrm{C}), 128.7(2 \times \mathrm{CH}), 125.4(2 \times \mathrm{CH})$, $124.5(\mathrm{CH}), 122.1(\mathrm{CH}), 120.6(\mathrm{CH}), 119.0(\mathrm{CH}), 110.9(\mathrm{CH}), 98.5(\mathrm{C}), 31.7\left(\mathrm{CH}_{2}\right), 26.2\left(\mathrm{CH}_{2}\right), 22.4$ $\left(\mathrm{CH}_{2}\right), 13.9\left(\mathrm{CH}_{3}\right) \mathrm{ppm}$.

IR $\left(\mathrm{KBr}, \mathrm{cm}^{-1}\right): 3397,2953,2928,1582,1455,742,690$.

EMBR (IE), m/z (\%): $281\left(\mathrm{M}^{+}, 76\right), 238$ (79), 204 (66), 130 (100), 117 (36), 77 (91).

EMAR calculado para $\mathrm{C}_{18} \mathrm{H}_{19} \mathrm{NS}: 281.1238$; encontrado: 281.1241 .

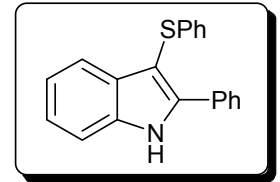

2-Fenil-3-(feniltio)-1H-indol (32b) ${ }^{272}$

Líquido marrón.

$\mathrm{R}_{\mathrm{f}}=0.25$ (hexano / AcOEt, 9 / 1).

${ }^{1} \mathbf{H}$ RMN (300 MHz, CDCl $): \delta=8.72(\mathrm{sa}, 1 \mathrm{H}), 7.81-7.75(\mathrm{~m}, 2 \mathrm{H}), 7.70(\mathrm{~d}, J=8.0 \mathrm{~Hz}, 1 \mathrm{H}), 7.48-7.39(\mathrm{~m}, 4 \mathrm{H})$, 7.31 (ddd, $J=8.0,7.1,1.3 \mathrm{~Hz}, 1 \mathrm{H}), 7.25-7.06(\mathrm{~m}, 6 \mathrm{H}) \mathrm{ppm}$.

$\left.{ }^{13} \mathbf{C ~ R M N ~ ( 7 5 . 4 ~ M H z , ~} \mathrm{CDCl}_{3}\right): \delta=142.2(\mathrm{C}), 139.4(\mathrm{C}), 135.9(\mathrm{C}), 131.4(\mathrm{C}), 131.2(\mathrm{C}), 128.9(2 \times \mathrm{CH}), 128.8$ $(2 \times \mathrm{CH}), 128.7(\mathrm{CH}), 128.2(2 \times \mathrm{CH}), 125.6(2 \times \mathrm{CH}), 124.7(\mathrm{CH}), 123.4(\mathrm{CH}), 121.2(\mathrm{CH}), 120.0(\mathrm{CH})$, $111.3(\mathrm{CH}), 99.2(\mathrm{C}) \mathrm{ppm}$.

EMBR (IE), m/z (\%): $301\left(\mathrm{M}^{+}, 69\right), 267$ (10), 223 (74), 190 (12), 121 (28), 77 (100).

EMAR calculado para $\mathrm{C}_{20} \mathrm{H}_{15} \mathrm{NS}$ : 301.0925 ; encontrado: 301.0925 .

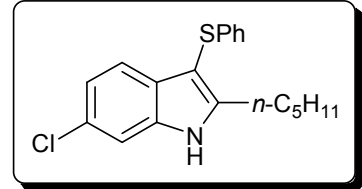

6-Cloro-3-(feniltio)-2-pentil-1H-indol (32c)

Líquido marrón.

$\mathrm{R}_{\mathrm{f}}=0.27$ (hexano / AcOEt, $15 / 1$ ).

${ }^{1} \mathbf{H}$ RMN (300 MHz, CDCl $): \delta=8.37$ (sa, $\left.1 \mathrm{H}\right), 7.47(\mathrm{~d}, J=8.4 \mathrm{~Hz}, 1 \mathrm{H}), 7.32(\mathrm{~d}, J=1.7 \mathrm{~Hz}, 1 \mathrm{H}), 7.22-7.15(\mathrm{~m}, 2 \mathrm{H})$, $7.15-7.02(\mathrm{~m}, 4 \mathrm{H}), 2.89(\mathrm{t}, J=7.5 \mathrm{~Hz}, 2 \mathrm{H}), 1.71-1.60(\mathrm{~m}, 2 \mathrm{H}), 1.36-1.25(\mathrm{~m}, 4 \mathrm{H}), 0.86(\mathrm{t}, J=6.9 \mathrm{~Hz}, 3 \mathrm{H}) \mathrm{ppm}$.

${ }^{13} \mathbf{C}$ RMN (75.4 MHz, $\left.\mathrm{CDCl}_{3}\right): \delta=146.4(\mathrm{C}), 139.2(\mathrm{C}), 135.9(\mathrm{C}), 128.9(\mathrm{C}), 128.8(2 \mathrm{xCH}), 128.0(\mathrm{C}), 125.5$ $(2 x \mathrm{CH}), 124.7(\mathrm{CH}), 121.4(\mathrm{CH}), 120.0(\mathrm{CH}), 111.0(\mathrm{CH}), 99.2(\mathrm{C}), 31.5\left(\mathrm{CH}_{2}\right), 29.2\left(\mathrm{CH}_{2}\right), 26.5\left(\mathrm{CH}_{2}\right)$, $22.4\left(\mathrm{CH}_{2}\right), 14.0\left(\mathrm{CH}_{3}\right) \mathrm{ppm}$.

IR $\left(\mathrm{KBr}, \mathrm{cm}^{-1}\right): 3411,2931,1582,1454,808,740,690$.

EMBR (IE), m/z (\%): $331\left(\mathrm{M}^{+}+2,37\right), 329$ (M+, 92$), 272$ (57), 236 (100), 204 (38), 164 (60).

EMAR calculado para $\mathrm{C}_{19} \mathrm{H}_{20}$ CINS: 329.1005; encontrado: 329.1004 .

${ }^{272}$ C. Berti, M. Colonna, M. Poloni, Gazz. Chim. Ital. 1986, 116, 181. 


\section{B.3 Preparación de los nitro y amino-indoles 35 y 36 a partir de las 2-halonitroanilinas 34}

\section{B.3.1 Procedimiento para la sintesis de las anilinas 34 c y $34 d$}

A una disolución de la 4-cloro-2-nitroanilina (2.59 g, $15 \mathrm{mmol})$ o de la 4-metil-2-nitroanilina (2.28 g, $15 \mathrm{mmol})$ y NaOAc $(1.35 \mathrm{~g}, 16.5 \mathrm{mmol})$ en $\mathrm{AcOH}$ a $80-82{ }^{\circ} \mathrm{C}$ se añade muy lentamente una disolución de $\mathrm{ICl}(838 \mu \mathrm{L}, 16.5 \mathrm{mmol})$ en $\mathrm{AcOH}(10 \mathrm{~mL})$. La mezcla resultante se agita a esta temperatura durante 15 horas. A continuación se basifica con una disolución de $\mathrm{NaOH}(20 \%)$ hasta $\mathrm{pH}=8$ y la fase acuosa se extrae con AcOEt $(3 \times 50 \mathrm{~mL})$. La combinación de fases orgánicas se seca sobre $\mathrm{Na}_{2} \mathrm{SO}_{4}$ anhidro y se concentra a presión reducida. El residuo resultante se purifica mediante columna de cromatografía de sílica gel (hexano / AcOEt) obteniéndose las anilinas 34c y 34d.

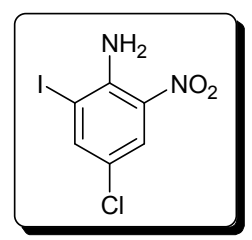

4-Cloro-2-nitro-6-yodoanilina (34c)

Sólido amarillo.

P.f. $=132-134{ }^{\circ} \mathrm{C}{ }^{\circ} \mathrm{C}\left(\right.$ lit. $\left.^{273}=132-133^{\circ} \mathrm{C}\right)$.

${ }^{1} \mathbf{H}$ RMN (300 MHz, $\left.\mathrm{CDCl}_{3}\right): \delta=8.18(\mathrm{dd}, J=2.4,0.8 \mathrm{~Hz}, 1 \mathrm{H}), 7.90(\mathrm{dd}, J=2.4,0.8 \mathrm{~Hz}, 1 \mathrm{H}), 6.66$ (sa, 2H) ppm. EMBR (IE), m/z (\%): 298 (M+ 70), 252 (29), 126 (100), 90 (44), 63 (54).

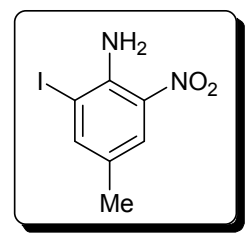

4-Metil-2-nitro-6-yodoanilina (34d)

Sólido rojo.

P.f. $=86-88^{\circ} \mathrm{C}$.

${ }^{1} \mathbf{H}$ RMN (300 MHz, $\left.\mathrm{CDCl}_{3}\right): \delta=7.96-7.93(\mathrm{~m}, 1 \mathrm{H}), 7.77-7.75(\mathrm{~m}, 1 \mathrm{H}), 6.50(\mathrm{sa}, 2 \mathrm{H}), 2.25-2.23(\mathrm{~m}, 3 \mathrm{H}) \mathrm{ppm}$. ${ }^{13}$ C RMN (75.4 MHz, $\left.\mathrm{CDCl}_{3}\right): \delta=147.0(\mathrm{CH}), 142.2(\mathrm{C}), 131.6(\mathrm{C}), 127.8(\mathrm{C}), 126.7(\mathrm{CH}), 87.4(\mathrm{C}), 19.8\left(\mathrm{CH}_{3}\right) \mathrm{ppm}$. EMBR (IE), m/z (\%): 278 (M+, 100), 232 (16), 105 (26).

\section{B.3.2 Procedimiento para la sintesis de la 4-cloro-3-nitro-2,6-diyodoanilina 34e}

Una mezcla de 4-cloro-3-nitroanilina (2.59 g, $15 \mathrm{mmol}), \mathrm{H}_{2} \mathrm{SO}_{4}(1 \mathrm{~mL}), \mathrm{HIO}_{3}(1.13 \mathrm{~g}, 6.4$ $\mathrm{mmol})$, yodo $(2.88 \mathrm{~g}, 11.35 \mathrm{mmol})$ y $\mathrm{CCl}_{4}(2.5 \mathrm{~mL})$ en $\mathrm{AcOH}(20 \mathrm{~mL})$ se agita a $80{ }^{\circ} \mathrm{C}$ durante 15 horas. La mezcla de reacción resultante se trata con una disolución al $10 \%$ de $\mathrm{Na}_{2} \mathrm{~S}_{2} \mathrm{O}_{5}$, se enfría en un baño de hielo y se filtra. El sólido se lava con $\mathrm{H}_{2} \mathrm{O}$, obteniéndose una vez seco la anilina 34e.

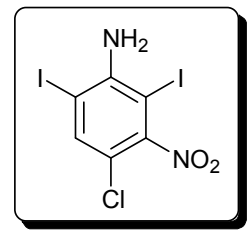

4-Cloro-3-nitro-2,6-diyodoanilina (34e)

Sólido amarillo.

P.f. $=110-112^{\circ} \mathrm{C}$.

${ }^{273}$ W. Dohle, A. Staubitz, P. Knochel, Chem. Eur. J. 2003, 9, 5323. 
${ }^{1} \mathbf{H} \mathbf{R M N}\left(300 \mathrm{MHz}, \mathrm{CDCl}_{3}\right): \delta=7.79(\mathrm{~s}, 1 \mathrm{H}), 5.00(\mathrm{sa}, 2 \mathrm{H}) \mathrm{ppm}$.

${ }^{13}$ C RMN (75.4 MHz, $\left.\mathrm{CDCl}_{3}\right): \delta=147.1(\mathrm{C}), 139.6(\mathrm{CH}), 112.7(\mathrm{C}), 81.5(\mathrm{C}), 71.9(\mathrm{C}) \mathrm{ppm}$.

EMBR (IE), m/z (\%): 424 (M+1 100), 378 (42), 257 (34), 124 (13).

\section{B.3.3 Procedimiento general para la preparación de los nitroindoles $\mathbf{3 5}$}

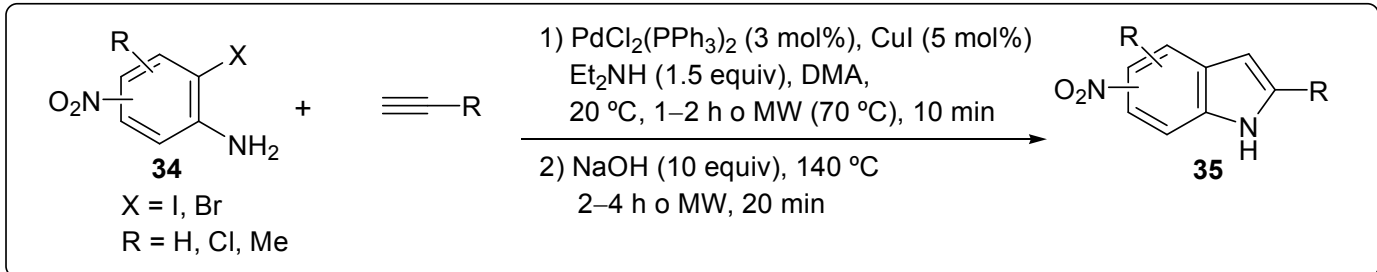

Una mezcla de la correspondiente 2-halonitroanilina 34 (1 $\mathrm{mmol})$, alquino $(1.5 \mathrm{mmol})$, $\mathrm{PdCl}_{2}\left(\mathrm{PPh}_{3}\right)_{2}(21 \mathrm{mg}, 3 \mathrm{~mol} \%)$, CuI $(9 \mathrm{mg}, 5 \mathrm{~mol} \%)$ y Et ${ }_{2} \mathrm{NH}(156 \mu \mathrm{L}, 1.5 \mathrm{mmol})$ en DMA $(3 \mathrm{~mL}) \mathrm{se}$ agita bajo $\mathrm{N}_{2}$ a temperatura ambiente durante el tiempo necesario para que el acoplamiento se complete, monitorizado por CG-EM (1-2 horas). Entonces, se añade $\mathrm{NaOH}$ (400 mg, $10 \mathrm{mmol}$ ) a la mezcla de reacción y se calienta a $140{ }^{\circ} \mathrm{C}$ hasta que la ciclación finalice (2-4 horas). La mezcla de reacción se enfría a temperatura ambiente y se añaden $\mathrm{CH}_{2} \mathrm{Cl}_{2}(20 \mathrm{~mL})$ y $\mathrm{H}_{2} \mathrm{O}(20 \mathrm{~mL})$. La fase acuosa separada se extrae con $\mathrm{CH}_{2} \mathrm{Cl}_{2}(3 \times 20 \mathrm{~mL})$. La combinación de fases orgánicas se lava con $\mathrm{H}_{2} \mathrm{O}(2 \times 50 \mathrm{~mL})$ y se seca sobre $\mathrm{Na}_{2} \mathrm{SO}_{4}$ anhidro. El disolvente se elimina a presión reducida y el residuo se purifica por cromatografía de columna (hexano / AcOEt) para obtener los correspondientes nitroindoles 35 .

Cuando la reacción se lleva a cabo bajo radiación de microondas, un tubo sellado con la mezcla de 2-halonitroanilina 34 ( $1 \mathrm{mmol})$, alquino (1.5 mmol), $\mathrm{PdCl}_{2}\left(\mathrm{PPh}_{3}\right)_{2}(3 \mathrm{~mol} \%), \mathrm{CuI}(5 \mathrm{~mol} \%)$ y $\mathrm{Et}_{2} \mathrm{NH}\left(156 \mu \mathrm{L}, 1.5\right.$ equiv) en DMA se irradia a $70^{\circ} \mathrm{C}$ en un microondas CEM Discover S-Class durante 10 minutos (acoplamiento de Sonogashira). Después de enfriarse, se añade $\mathrm{NaOH}$ en polvo (400 mg, $10 \mathrm{mmol}$ ) y la mezcla de reacción se calienta a $140{ }^{\circ} \mathrm{C}$ en el microondas durante 20 minutos (ciclación).

\section{B.3.4 Procedimiento general para la preparación de los aminoindoles 36}

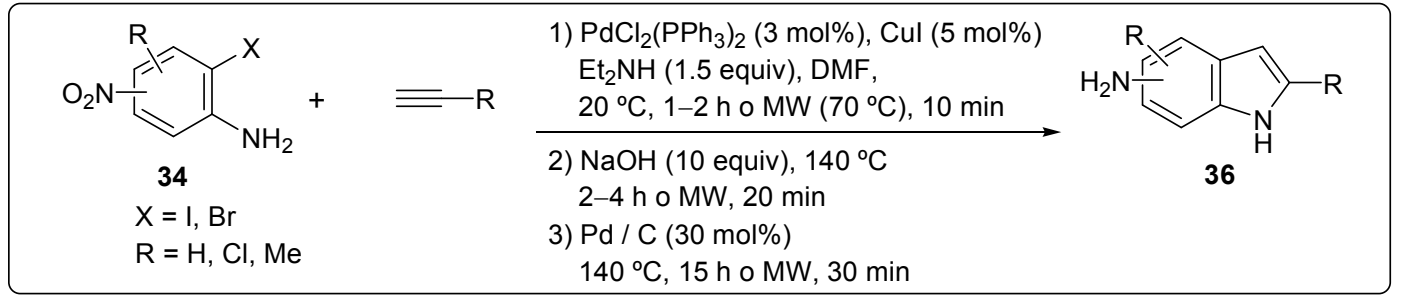

Una mezcla de la correspondiente 2-halonitroanilina (1 $\mathrm{mmol})$, alquino (1.5 mmol), $\mathrm{PdCl}_{2}\left(\mathrm{PPh}_{3}\right)_{2}(21 \mathrm{mg}, 3 \mathrm{~mol} \%)$, CuI $(9 \mathrm{mg}, 5 \mathrm{~mol} \%)$ y Et ${ }_{2} \mathrm{NH}(156 \mu \mathrm{L}, 1.5 \mathrm{mmol})$ en DMF (3 mL) se agita bajo $\mathrm{N}_{2}$ a temperatura ambiente durante el tiempo necesario para el consumo completo de la nitroanilina de partida 34, monitorizado por CG-EM (1-2 horas). Entonces, se añade $\mathrm{NaOH}$ (400 mg, $10 \mathrm{mmol})$ a la mezcla de reacción, y se calienta a $140^{\circ} \mathrm{C}$ hasta que la ciclación se completa $(2-4$ 
horas). A continuación se añade Pd / C (30 mol\%) y la reacción se agita 15 horas a $140{ }^{\circ} \mathrm{C}$. La mezcla de reacción se enfría a temperatura ambiente, se filtra a través de celita y se lava con $\mathrm{CH}_{2} \mathrm{Cl}_{2} . \mathrm{El}$ crudo se diluye con $\mathrm{H}_{2} \mathrm{O}(20 \mathrm{~mL})$ y se extrae con $\mathrm{CH}_{2} \mathrm{Cl}_{2}(3 \times 20 \mathrm{~mL})$. La combinación de fases orgánicas se lava con $\mathrm{H}_{2} \mathrm{O}(2 \times 50 \mathrm{~mL})$ y se seca sobre $\mathrm{Na}_{2} \mathrm{SO}_{4}$ anhidro. El disolvente se elimina a presión reducida y el residuo se purifica por cromatografía de columna (hexano / AcOEt) para obtener los correspondientes aminoindoles $\mathbf{3 6}$.

Cuando la reacción se lleva a cabo bajo radiación de microondas, un tubo sellado con la mezcla de 2-halonitroanilina 34 ( $1 \mathrm{mmol})$, alquino (1.5 mmol), $\mathrm{PdCl}_{2}\left(\mathrm{PPh}_{3}\right)_{2}(3 \mathrm{~mol} \%), \mathrm{CuI}(5 \mathrm{~mol} \%)$ y $\mathrm{Et}_{2} \mathrm{NH}(156 \mu \mathrm{L}, 1.5 \mathrm{mmol})$ en DMF se irradia a $70{ }^{\circ} \mathrm{C}$ en un microondas CEM Discover S-Class durante 10 minutos (acoplamiento de Sonogashira). Después de enfriarse, se añade $\mathrm{NaOH}$ en polvo (400 mg, $10 \mathrm{mmol}$ ) y la mezcla de reacción se calienta a $140{ }^{\circ} \mathrm{C}$ en el microondas durante 20 minutos (ciclación). A continuación y después de enfriarse, se añade Pd / C (30 mol\%) y la mezcla de reacción se agita a $140{ }^{\circ} \mathrm{C}$ durante 30 minutos.

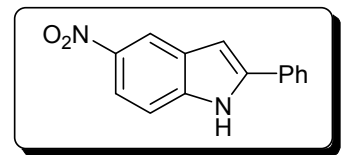

\section{2-Fenil-5-nitro-1H-indol (35aa)}

Sólido amarillo.

P.f. $=189-191^{\circ} \mathrm{C}$ (lit. $\left..^{133 b}=190-191^{\circ} \mathrm{C}\right)$.

${ }^{1} \mathbf{H}$ RMN (300 MHz, $\left.\left(\mathrm{CD}_{3}\right)_{2} \mathrm{CO}\right): \delta=11.31(\mathrm{sa}, 1 \mathrm{H}), 8.52(\mathrm{dd}, J=1.7,0.5 \mathrm{~Hz}, 1 \mathrm{H}), 8.03(\mathrm{dd}, J=8.9,2.3 \mathrm{~Hz}$, $1 \mathrm{H}), 7.89-7.83(\mathrm{~m}, 2 \mathrm{H}) .7 .56-7.51(\mathrm{~m}, 1 \mathrm{H}), 7.50-7.43(\mathrm{~m}, 2 \mathrm{H}), 7.40-7.33(\mathrm{~m}, 1 \mathrm{H}), 7.08(\mathrm{dd}, J=2.3,0.8$ $\mathrm{Hz}, 1 \mathrm{H}) \mathrm{ppm}$.

${ }^{13}$ C RMN (75.4 MHz, $\left.\left(\mathrm{CD}_{3}\right)_{2} \mathrm{CO}\right): \delta=142.6(\mathrm{C}), 142.5(\mathrm{C}), 141.3(\mathrm{C}), 132.2(\mathrm{C}), 129.9(2 \times \mathrm{CH}), 129.33(\mathrm{C})$, $129.29(\mathrm{CH}), 126.3(2 \times \mathrm{CH}), 117.9(\mathrm{CH}), 117.8(\mathrm{CH}), 112.2(\mathrm{CH}), 101.8(\mathrm{CH}) \mathrm{ppm}$.

IR $\left(\mathrm{KBr}, \mathrm{cm}^{-1}\right): 3334,1505,1470,1330,744,682$.

EMBR (IE), m/z (\%): 238 (M+ 100), 208 (16), 191 (59), 180 (38), 165 (57), 152 (19), 139 (20), 87 (27), 77 (34).

EMAR calculado para $\mathrm{C}_{14} \mathrm{H}_{10} \mathrm{~N}_{2} \mathrm{O}_{2}: 238.0742$; encontrado: 238.0742 .

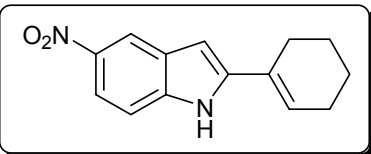

2-(1-Ciclohexenil)-5-nitro-1H-indol (35ab)

Sólido naranja.

P.f. $=171-173^{\circ} \mathrm{C}$.

${ }^{1}$ H RMN $\left(300 \mathrm{MHz}, \mathrm{CDCl}_{3}\right): \delta=8.66(\mathrm{sa}, 1 \mathrm{H}), 8.48(\mathrm{~d}, J=2.0 \mathrm{~Hz}, 1 \mathrm{H}), 8.04(\mathrm{ddd}, J=8.9,2.0,0.6 \mathrm{~Hz}, 1 \mathrm{H})$, $7.32(\mathrm{~d}, J=8.9 \mathrm{~Hz}, 1 \mathrm{H}), 6.55(\mathrm{~s}, 1 \mathrm{H}), 6.27-6.21(\mathrm{~m}, 1 \mathrm{H}), 2.50-2.40(\mathrm{~m}, 2 \mathrm{H}), 2.31-2.21(\mathrm{~m}, 2 \mathrm{H})$, $1.86-1.75(\mathrm{~m}, 2 \mathrm{H}), 1.75-1.64(\mathrm{~m}, 2 \mathrm{H}) \mathrm{ppm}$.

${ }^{13} \mathbf{C}$ RMN (75.4 MHz, $\mathrm{CDCl}_{3}$ ): $\delta=142.8$ (C), 141.8 (C), 139.5 (C), 128.5 (C), 128.4 (C), $125.1(\mathrm{CH}), 117.8$ $(\mathrm{CH}), 117.4(\mathrm{CH}), 110.4(\mathrm{CH}), 100.4(\mathrm{CH}), 26.1\left(\mathrm{CH}_{2}\right), 25.7\left(\mathrm{CH}_{2}\right), 22.5\left(\mathrm{CH}_{2}\right), 22.1\left(\mathrm{CH}_{2}\right) \mathrm{ppm}$.

IR $\left(\mathrm{KBr}, \mathrm{cm}^{-1}\right): 3351,2921,1505,1470,1317,775,750$.

EMBR (IE), m/z (\%): 242 (M+96), 207 (38), 194 (36), 184 (32), 168 (100), 153 (50), 129 (54), 115 (67), 78 (50).

EMAR calculado para $\mathrm{C}_{14} \mathrm{H}_{14} \mathrm{~N}_{2} \mathrm{O}_{2}: 242.1055$; encontrado: 242.1056 .

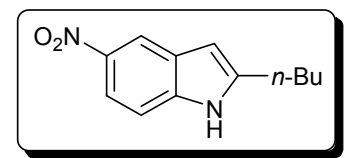

2-Butil-5-nitro-1H-indol (35ac)

Sólido marrón.

P.f. $=99-101^{\circ} \mathrm{C}\left(\right.$ lit. $\left.^{274}=99-100^{\circ} \mathrm{C}\right)$.

${ }^{274}$ L. Jiao, T. Bach, J. Am. Chem. Soc. 2011, 133, 12990. 
${ }^{1} \mathbf{H}$ RMN (300 MHz, $\left.\mathrm{CDCl}_{3}\right): \delta=8.67(\mathrm{sa}, 1 \mathrm{H}), 8.47(\mathrm{~d}, J=2.2 \mathrm{~Hz}, 1 \mathrm{H}), 8.03(\mathrm{dd}, J=8.9,2.2 \mathrm{~Hz}, 1 \mathrm{H}), 7.34(\mathrm{~d}$, $J=8.9 \mathrm{~Hz}, 1 \mathrm{H}), 6.39(\mathrm{~s}, 1 \mathrm{H}), 2.79(\mathrm{t}, J=7.6 \mathrm{~Hz}, 2 \mathrm{H}), 1.79-1.67(\mathrm{~m}, 2 \mathrm{H}), 1.49-1.36(\mathrm{~m}, 2 \mathrm{H}), 0.96(\mathrm{t}, J=$ $7.3 \mathrm{~Hz}, 3 \mathrm{H}) \mathrm{ppm}$.

${ }^{13} \mathbf{C}$ RMN (75.4 MHz, $\mathrm{CDCl}_{3}$ ): $\delta=143.9(\mathrm{C}), 141.6(\mathrm{C}), 139.3(\mathrm{C}), 128.3(\mathrm{C}), 116.9(\mathrm{CH}), 116.8(\mathrm{CH}), 110.4$ $(\mathrm{CH}), 101.6(\mathrm{CH}), 31.0\left(\mathrm{CH}_{2}\right), 28.0\left(\mathrm{CH}_{2}\right), 22.4\left(\mathrm{CH}_{2}\right), 13.9\left(\mathrm{CH}_{3}\right) \mathrm{ppm}$.

IR $\left(\mathrm{KBr}, \mathrm{cm}^{-1}\right): 3321,2925,1505,1477,1324,775,750$

EMBR (IE), m/z (\%): 218 (M+2, 21), 175 (87), 143 (13), 129 (100), 117 (22), 102 (38).

EMAR calculado para $\mathrm{C}_{12} \mathrm{H}_{14} \mathrm{~N}_{2} \mathrm{O}_{2}: 218.1055$; encontrado: 218.1055 .

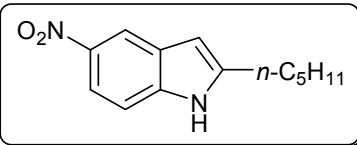

\section{5-Nitro-2-pentil-1H-indol (35ad)}

Sólido amarillo.

P.f. $=98-100{ }^{\circ} \mathrm{C}$

${ }^{1}$ H RMN (300 MHz, $\left.\left(\mathrm{CD}_{3}\right)_{2} \mathrm{CO}\right): \delta=10.7(\mathrm{sa}, 1 \mathrm{H}), 8.43(\mathrm{~d}, J=2.2 \mathrm{~Hz}, 1 \mathrm{H}), 7.96(\mathrm{dd}, J=8.9,2.2 \mathrm{~Hz}, 1 \mathrm{H}), 7.44$ $(\mathrm{d}, J=8.9 \mathrm{~Hz}, 1 \mathrm{H}), 6.45-6.42(\mathrm{~m}, 1 \mathrm{H}), 2.80(\mathrm{t}, J=7.6 \mathrm{~Hz}, 2 \mathrm{H}), 1.80-1.68(\mathrm{~m}, 2 \mathrm{H}), 1.40-1.29(\mathrm{~m}, 4 \mathrm{H})$ $0.87(\mathrm{t}, J=7.1 \mathrm{~Hz}, 3 \mathrm{H}) \mathrm{ppm}$.

${ }^{13}$ C RMN (75.4 MHz, $\left.\left(\mathrm{CD}_{3}\right)_{2} \mathrm{CO}\right): \delta=145.4(\mathrm{C}), 142.2(\mathrm{C}), 140.5(\mathrm{C}), 129.2(\mathrm{C}), 116.9(\mathrm{CH}), 116.7(\mathrm{CH})$, $111.4(\mathrm{CH}), 101.9(\mathrm{CH}), 32.2\left(\mathrm{CH}_{2}\right), 29.4\left(\mathrm{CH}_{2}\right), 28.7\left(\mathrm{CH}_{2}\right), 23.1\left(\mathrm{CH}_{2}\right), 14.3\left(\mathrm{CH}_{3}\right) \mathrm{ppm}$.

EMBR (IE), m/z (\%): $232\left(\mathrm{M}^{+}, 38\right), 189$ (25), 176 (100), 143 (13), 129 (49).

EMAR calculado para $\mathrm{C}_{13} \mathrm{H}_{16} \mathrm{~N}_{2} \mathrm{O}_{2}: 232.1212$; encontrado: 232.1213 .

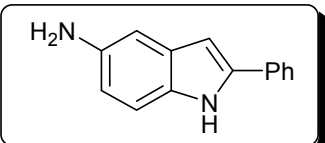

\section{5-Amino-2-fenil-1H-indol (36aa)}

Sólido marrón.

P.f. $=200-202{ }^{\circ} \mathrm{C}\left(\right.$ lit. $\left.^{275}=223-225^{\circ} \mathrm{C}\right)$.

${ }^{1}$ H RMN (300 MHz, DMSO-d $\left.{ }_{6}\right): \delta=11.05(\mathrm{sa}, 1 \mathrm{H}), 7.77(\mathrm{~d}, J=8.5 \mathrm{~Hz}, 2 \mathrm{H}), 7.39(\mathrm{t}, J=7.5 \mathrm{~Hz}, 2 \mathrm{H}), 7.28-7.19$ $(\mathrm{m}, 1 \mathrm{H}), 7.08(\mathrm{~d}, J=8.5 \mathrm{~Hz}, 1 \mathrm{H}), 6.67(\mathrm{~s}, 1 \mathrm{H}), 6.61(\mathrm{~s}, 1 \mathrm{H}), 6.50(\mathrm{~d}, J=8.5 \mathrm{~Hz}, 1 \mathrm{H}), 4.76(\mathrm{sa}, 2 \mathrm{H}) \mathrm{ppm}$.

${ }^{13}$ C RMN (75.4 MHz, DMSO-d $\left.\mathrm{d}_{6}\right): \delta=141.0(\mathrm{C}), 137.2(\mathrm{C}), 132.6(\mathrm{C}), 131.2(\mathrm{C}), 129.5(\mathrm{C}), 128.8(2 \times \mathrm{CH})$, $126.9(\mathrm{CH}), 124.6(2 \times \mathrm{CH}), 112.7(\mathrm{CH}), 111.4(\mathrm{CH}), 103.2(\mathrm{CH}), 97.5(\mathrm{CH}) \mathrm{ppm}$.

EMBR (IE), m/z (\%): 208 (M+37), 201 (25), 152 (30), 91 (100), 77 (84).

EMAR calculado para $\mathrm{C}_{14} \mathrm{H}_{12} \mathrm{~N}_{2}: 208.1000$; encontrado: 208.1009 .

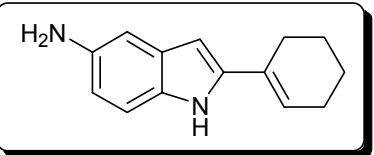

\section{5-Amino-2-(1-ciclohexenil)-1H-indol (36ab)}

Sólido blanco-rosado.

P.f. $=167-169^{\circ} \mathrm{C}$.

${ }^{1} \mathbf{H}$ RMN $\left(300 \mathrm{MHz}, \mathrm{CDCl}_{3}\right): \delta=7.96(\mathrm{sa}, 1 \mathrm{H}), 7.10(\mathrm{~d}, J=8.4 \mathrm{~Hz}, 1 \mathrm{H}), 6.86(\mathrm{~d}, J=2.1 \mathrm{~Hz}, 1 \mathrm{H}), 6.60(\mathrm{dd}, J=$ 8.4, $2.1 \mathrm{~Hz}, 1 \mathrm{H}), 6.28(\mathrm{~d}, J=1.6 \mathrm{~Hz}, 1 \mathrm{H}), 6.11-6.06(\mathrm{~m}, 1 \mathrm{H}), 3.34(\mathrm{sa}, 2 \mathrm{H}), 2.48-2.40(\mathrm{~m}, 2 \mathrm{H}), 2.26-2.19$ (m, 2H), 1.82-1.63 (m, 4H) ppm.

${ }^{13}$ C RMN (75.4 MHz, $\left.\mathrm{CDCl}_{3}\right): \delta=140.2$ (C), 139.5 (C), $131.2(\mathrm{C}), 129.9$ (C), 129.3 (C), $122.4(\mathrm{CH}), 112.8$ $(\mathrm{CH}), 111.0(\mathrm{CH}), 105.5(\mathrm{CH}), 97.9(\mathrm{CH}), 26.1\left(\mathrm{CH}_{2}\right), 25.6\left(\mathrm{CH}_{2}\right), 22.7\left(\mathrm{CH}_{2}\right), 22.3\left(\mathrm{CH}_{2}\right) \mathrm{ppm}$.

EMBR (IE), m/z (\%): $212\left(\mathrm{M}^{+}, 100\right), 183$ (24), 169 (16), 145 (10), 132 (9).

EMAR calculado para $\mathrm{C}_{14} \mathrm{H}_{16} \mathrm{~N}_{2}: 212.1313$; encontrado: 212.1310 .

${ }^{275}$ S. Taliani, E. Da Pozzo, M. Bellandi, S. Bendinelli, I. Pugliesi, F. Simorini, C. La Motta, S. Salerno, A. M. Marini, F. Da Settimo, B. Cosimelli, G. Greco, E. Novellino, C. Matini, J. Med. Chem. 2010, 53, 4085. 


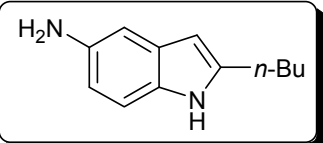

\section{5-Amino-2-butil-1H-indol (36ac)}

Sólido marrón.

P.f. $=150-152^{\circ} \mathrm{C}$.

${ }^{1}$ H RMN $\left(300 \mathrm{MHz}, \mathrm{CDCl}_{3}\right): \delta=7.75(\mathrm{sa}, 1 \mathrm{H}), 7.08(\mathrm{~d}, J=8.2 \mathrm{~Hz}, 1 \mathrm{H}), 6.85(\mathrm{~s}, 1 \mathrm{H}), 6.58(\mathrm{~d}, J=8.2 \mathrm{~Hz} 1 \mathrm{H})$, $6.07(\mathrm{~s}, 1 \mathrm{H}), 3.31(\mathrm{sa}, 2 \mathrm{H}), 2.69(\mathrm{t}, J=7.6 \mathrm{~Hz}, 2 \mathrm{H}), 1.75-1.58(\mathrm{~m}, 2 \mathrm{H}), 1.49-1.33(\mathrm{~m}, 2 \mathrm{H}), 0.96$ (t, $J=7.3$ $\mathrm{Hz}, 3 \mathrm{H}) \mathrm{ppm}$.

$\left.{ }^{13} \mathbf{C ~ R M N ~ ( 7 5 . 4 ~ M H z , ~} \mathrm{CDCl}_{3}\right): \delta=140.8(\mathrm{C}), 139.3(\mathrm{C}), 130.8(\mathrm{C}), 129.9(\mathrm{C}), 111.6(\mathrm{CH}), 110.9(\mathrm{CH}), 105.2$ $(\mathrm{CH}), 98.6(\mathrm{CH}), 31.4\left(\mathrm{CH}_{2}\right), 28.1\left(\mathrm{CH}_{2}\right), 22.5\left(\mathrm{CH}_{2}\right), 14.0\left(\mathrm{CH}_{3}\right) \mathrm{ppm}$.

EMBR (IE), m/z (\%): $188\left(\mathrm{M}^{+}, 25\right), 145$ (100), 128 (12), 117 (18).

EMAR calculado para $\mathrm{C}_{12} \mathrm{H}_{16} \mathrm{~N}_{2}$ : 188.1313; encontrado: 188.1316 .

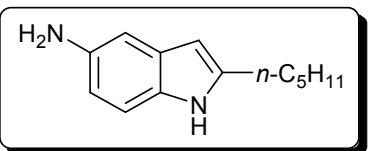

\section{5-Amino-2-pentil-1H-indol (36ad)}

Sólido marrón.

P.f. $=148-150^{\circ} \mathrm{C}$.

${ }^{1}$ H RMN (300 MHz, $\left.\mathrm{CDCl}_{3}\right): \delta=7.76(\mathrm{sa}, 1 \mathrm{H}), 7.08(\mathrm{~d}, J=8.4 \mathrm{~Hz}, 1 \mathrm{H}), 6.86(\mathrm{~s}, 1 \mathrm{H}), 6.58(\mathrm{dd}, J=8.4,2.1 \mathrm{~Hz}$, $1 \mathrm{H}), 6.08(\mathrm{~s}, 1 \mathrm{H}), 3.38(\mathrm{sa}, 2 \mathrm{H}), 2.68(\mathrm{t}, J=7.6 \mathrm{~Hz}, 2 \mathrm{H}), 1.75-1.63(\mathrm{~m}, 2 \mathrm{H}), 1.42-1.31(\mathrm{~m}, 4 \mathrm{H}), 0.92(\mathrm{t}, J$ $=6.8 \mathrm{~Hz}, 3 \mathrm{H}) \mathrm{ppm}$.

${ }^{13} \mathbf{C}$ RMN (75.4 MHz, $\left.\mathrm{CDCl}_{3}\right): \delta=140.9(\mathrm{C}), 139.3(\mathrm{C}), 130.8(\mathrm{C}), 129.9(\mathrm{C}), 111.6(\mathrm{CH}), 110.8(\mathrm{CH}), 105.2$ $(\mathrm{CH}), 98.6(\mathrm{CH}), 31.6\left(\mathrm{CH}_{2}\right), 29.0\left(\mathrm{CH}_{2}\right), 28.4\left(\mathrm{CH}_{2}\right), 22.6\left(\mathrm{CH}_{2}\right), 14.1\left(\mathrm{CH}_{3}\right) \mathrm{ppm}$.

EMBR (IE), m/z (\%): $202\left(\mathrm{M}^{+}, 100\right), 159$ (15), 145 (100), 117 (15).

EMAR calculado para $\mathrm{C}_{13} \mathrm{H}_{18} \mathrm{~N}_{2}: 202.1470$; encontrado: 202.1477 .

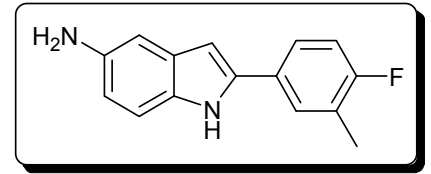

5-Amino-2-(4-fluoro-3-metilfenil)-1H-indol (36ae)

Sólido marrón.

P.f. $=188-190^{\circ} \mathrm{C}$.

${ }^{1}$ H RMN (300 MHz, DMSO-d $\left.{ }_{6}\right): \delta=11.01(\mathrm{sa}, 1 \mathrm{H}), 7.71(\mathrm{~d}, J=7.2 \mathrm{~Hz}, 1 \mathrm{H}), 7.64-7.57(\mathrm{~m}, 1 \mathrm{H}), 7.16(\mathrm{t}, J=8.4 \mathrm{~Hz}$, $1 \mathrm{H}), 7.08(\mathrm{~d}, J=8.4 \mathrm{~Hz}, 1 \mathrm{H}), 6.66(\mathrm{~s}, 1 \mathrm{H}), 6.55(\mathrm{~s}, 1 \mathrm{H}), 6.53-6.48(\mathrm{~m}, 1 \mathrm{H}), 4.57$ (sa, 2H), 2.27 (s, 3H) ppm.

${ }^{13}$ C RMN (75.4 MHz, DMSO-d ${ }_{6}$ ): $\delta=159.9(\mathrm{~d}, J=243.2 \mathrm{~Hz}, \mathrm{C}), 141.4(\mathrm{C}), 136.5$ (C), 131.1 (C), 129.6 (C), 129.0 (d, $J=3.2 \mathrm{~Hz}, \mathrm{C}), 127.9$ (d, $J=4.9 \mathrm{~Hz}, \mathrm{CH}), 124.6$ (d, $J=17.5 \mathrm{~Hz}, \mathrm{C}), 123.9$ (d, $J=7.9 \mathrm{~Hz}, \mathrm{CH}), 115.3$ (d, $J$ $=22.4 \mathrm{~Hz}, \mathrm{CH}), 112.5(\mathrm{CH}), 111.4(\mathrm{CH}), 103.1(\mathrm{CH}), 97.4(\mathrm{CH}), 14.4\left(\mathrm{~d}, J=3.1 \mathrm{~Hz}, \mathrm{CH}_{3}\right) \mathrm{ppm}$.

EMBR (IE), m/z (\%): $240\left(\mathrm{M}^{+}, 100\right), 207$ (11), 152 (4).

EMAR calculado para $\mathrm{C}_{15} \mathrm{H}_{13} \mathrm{FN}_{2}$ : 240.1063; encontrado: 240.1063 .

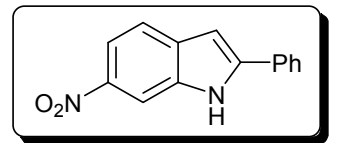

\section{2-Fenil-6-nitro-1 $H$-indol (35ba)}

Sólido amarillo.

P.f. $=204-206^{\circ} \mathrm{C}\left(\right.$ lit. $\left.^{133 \mathrm{~b}}=211-212^{\circ} \mathrm{C}\right)$

${ }^{1}$ H RMN (300 MHz, DMSO-d $\left.{ }_{6}\right): \delta=12.34$ (sa, 1H), 8.27 (s, 1H), 7.96-7.86 (m, 3H), $7.69(\mathrm{~d}, J=8.8 \mathrm{~Hz}, 1 \mathrm{H})$, $7.55-7.48(\mathrm{~m}, 2 \mathrm{H}), 7.42(\mathrm{~d}, J=7.3 \mathrm{~Hz}, 1 \mathrm{H}), 7.15-7.12(\mathrm{~m}, 1 \mathrm{H}) \mathrm{ppm}$.

${ }^{13}$ C RMN (75.4 MHz, DMSO-d $\left.{ }_{6}\right): \delta=144.2(\mathrm{C}), 141.9(\mathrm{C}), 135.5(\mathrm{C}), 133.7(\mathrm{C}), 130.8(\mathrm{C}), 129.2(2 \times \mathrm{CH})$, $129.0(\mathrm{CH}), 125.8(2 \times \mathrm{CH}), 120.2(\mathrm{CH}), 114.9(\mathrm{CH}), 107.8(\mathrm{CH}), 99.9(\mathrm{CH}) \mathrm{ppm}$.

EMBR (IE), m/z (\%): 238 (M , 100), 208 (57), 192 (34), 191 (34), 165 (24).

EMAR calculado para $\mathrm{C}_{14} \mathrm{H}_{10} \mathrm{~N}_{2} \mathrm{O}_{2}$ : 238.0742; encontrado: 238.0747 . 


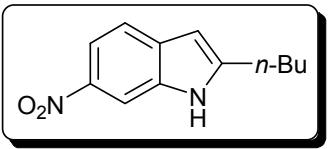

\section{2-Butil-6-nitro-1H-indol (35bc)}

Sólido marrón.

P.f. $=64-66^{\circ} \mathrm{C}$.

${ }^{1}$ H RMN (300 MHz, DMSO-d $\left.)_{6}\right): \delta=11.74(\mathrm{sa}, 1 \mathrm{H}), 8.18-8.16(\mathrm{~m}, 1 \mathrm{H}), 7.82(\mathrm{dd}, J=8.7,2.2 \mathrm{~Hz}, 1 \mathrm{H}), 7.55(\mathrm{~d}$, $J=8.7 \mathrm{~Hz}, 1 \mathrm{H}), 6.37(\mathrm{~s}, 1 \mathrm{H}), 2.77(\mathrm{t}, J=7.4 \mathrm{~Hz}, 2 \mathrm{H}), 1.73-1.60(\mathrm{~m}, 2 \mathrm{H}), 1.40-1.28(\mathrm{~m}, 2 \mathrm{H}), 0.89(\mathrm{t}, J=$ $7.4 \mathrm{~Hz}, 3 \mathrm{H}) \mathrm{ppm}$.

${ }^{13}$ C RMN (75.4 MHz, $\left.\mathrm{CDCl}_{3}\right): \delta=147.0(\mathrm{C}), 142.4(\mathrm{C}), 134.4(\mathrm{C}), 134.2(\mathrm{C}), 119.4(\mathrm{CH}), 115.6(\mathrm{CH}), 107.4$ $(\mathrm{CH}), 101.0(\mathrm{CH}), 31.1\left(\mathrm{CH}_{2}\right), 28.3\left(\mathrm{CH}_{2}\right), 22.5\left(\mathrm{CH}_{2}\right), 14.0\left(\mathrm{CH}_{3}\right) \mathrm{ppm}$

EMBR (IE), m/z (\%): $218\left(\mathrm{M}^{+}, 36\right), 176$ (46), 156 (23), 145 (100), 129 (57), 102 (70), 76 (46), 51 (49).

EMAR calculado para $\mathrm{C}_{12} \mathrm{H}_{14} \mathrm{~N}_{2} \mathrm{O}_{2}: 218.1055$; encontrado: 218.1051 .

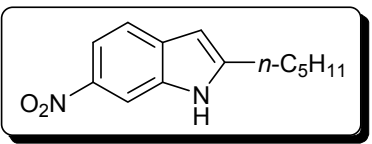

\section{6-Nitro-2-pentil-1H-indol (35bd)}

Sólido amarillo.

P.f. $=64-66^{\circ} \mathrm{C}$.

${ }^{1} \mathbf{H}$ RMN (300 MHz, $\left.\mathrm{CDCl}_{3}\right): \delta=8.85(\mathrm{sa}, 1 \mathrm{H}), 8.33(\mathrm{~d}, J=1.6 \mathrm{~Hz}, 1 \mathrm{H}), 7.99(\mathrm{dd}, J=8.8,2.0 \mathrm{~Hz}, 1 \mathrm{H}), 7.52(\mathrm{~d}$, $J=2.0 \mathrm{~Hz}, 1 \mathrm{H}), 6.35(\mathrm{~s}, 1 \mathrm{H}), 2.81(\mathrm{t}, J=7.6 \mathrm{~Hz}, 2 \mathrm{H}), 1.83-1.70(\mathrm{~m}, 2 \mathrm{H}), 1.41-1.32(\mathrm{~m}, 4 \mathrm{H}), 0.91(\mathrm{t}, J=$ $7.0 \mathrm{~Hz}, 3 \mathrm{H}) \mathrm{ppm}$.

${ }^{13}$ C RMN (75.4 MHz, $\left.\mathrm{CDCl}_{3}\right): \delta=147.5(\mathrm{C}), 142.1(\mathrm{C}), 134.4(\mathrm{C}), 134.3(\mathrm{C}), 119.3(\mathrm{CH}), 115.5(\mathrm{CH}), 107.6$ $(\mathrm{CH}), 100.8(\mathrm{CH}), 31.5\left(\mathrm{CH}_{2}\right), 28.6\left(\mathrm{CH}_{2}\right), 28.5\left(\mathrm{CH}_{2}\right), 22.5\left(\mathrm{CH}_{2}\right), 14.1\left(\mathrm{CH}_{3}\right) \mathrm{ppm}$.

EMBR (IE), m/z (\%): 232 (M+ 41), 207 (48), 189 (27), 176 (100), 145 (64), 129 (46).

EMAR calculado para $\mathrm{C}_{13} \mathrm{H}_{16} \mathrm{~N}_{2} \mathrm{O}_{2}: 232.1212$; encontrado: 232.1220 .

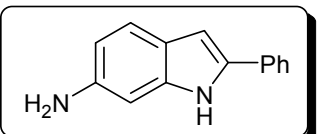

\section{6-Amino-2-fenil-1H-indol (36ba) ${ }^{276}$}

Sólido marrón.

P.f. $=200-202{ }^{\circ} \mathrm{C}$.

${ }^{1}$ H RMN (300 MHz, DMSO-d 6 ): $\delta=10.95(\mathrm{~s}, 1 \mathrm{H}), 7.76(\mathrm{~d}, J=7.9 \mathrm{~Hz}, 2 \mathrm{H}), 7.38$ (t, $\left.J=7.5 \mathrm{~Hz}, 2 \mathrm{H}\right), 7.29-7.14$ $(\mathrm{m}, 3 \mathrm{H}), 6.67(\mathrm{~d}, J=9.4 \mathrm{~Hz}, 1 \mathrm{H}), 6.46(\mathrm{~d}, J=8.3 \mathrm{~Hz}, 1 \mathrm{H}), 4.85(\mathrm{sa}, 2 \mathrm{H}) \mathrm{ppm}$.

${ }^{13}$ C RMN (75.4 MHz, DMSO-d $\left.{ }_{6}\right): \delta=144.5(\mathrm{C}), 139.1(\mathrm{C}), 134.4(\mathrm{C}), 132.9(\mathrm{C}), 128.8(2 \times \mathrm{CH}), 126.2(\mathrm{CH})$, $124.1(2 \times \mathrm{CH}), 120.7(\mathrm{C}), 120.4(\mathrm{CH}), 110.4(\mathrm{CH}), 99.0(\mathrm{CH}), 94.9(\mathrm{CH}) \mathrm{ppm}$.

EMBR (IE), m/z (\%): $208\left(\mathrm{M}^{+}, 100\right), 180$ (8), 104 (18), 91 (16).

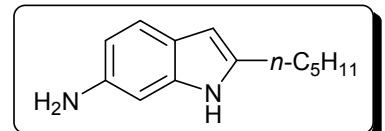

\section{6-Amino-2-pentil-1H-indol (36bd)}

Líquido marrón.

$\mathrm{R}_{\mathrm{f}}=0.23$ (hexano / AcOEt, $1 / 1$ )

${ }^{1} \mathbf{H}$ RMN $\left(300 \mathrm{MHz}, \mathrm{CDCl}_{3}\right): \delta=7.72(\mathrm{sa}, 1 \mathrm{H}), 7.32-7.25(\mathrm{~m}, 1 \mathrm{H}), 6.59(\mathrm{~s}, 1 \mathrm{H}), 6.53(\mathrm{dd}, J=8.3,1.8 \mathrm{~Hz}, 1 \mathrm{H})$, 6.11-6.08 (m, 1H), $3.34(\mathrm{sa}, 2 \mathrm{H}), 2.67(\mathrm{t}, J=7.6 \mathrm{~Hz}, 2 \mathrm{H}), 1.74-1.62(\mathrm{~m}, 2 \mathrm{H}), 1.40-1.30(\mathrm{~m}, 4 \mathrm{H})$, $0.94-0.85(\mathrm{t}, J=7.6 \mathrm{~Hz}, 3 \mathrm{H}) \mathrm{ppm}$.

${ }^{13} \mathbf{C}$ RMN (75.4 MHz, $\left.\mathrm{CDCl}_{3}\right): \delta=141.2(\mathrm{C}), 138.1(\mathrm{C}), 137.2(\mathrm{C}), 122.3(\mathrm{C}), 120.3(\mathrm{CH}), 110.3(\mathrm{CH}), 99.1$ $(\mathrm{CH}), 96.7(\mathrm{CH}), 31.6\left(\mathrm{CH}_{2}\right), 29.0\left(\mathrm{CH}_{2}\right), 28.3\left(\mathrm{CH}_{2}\right), 22.6\left(\mathrm{CH}_{2}\right), 14.2\left(\mathrm{CH}_{3}\right) \mathrm{ppm}$.

EMBR (IE), m/z (\%): $202\left(\mathrm{M}^{+}, 35\right), 158$ (4), 145 (100), 117 (5).

EMAR calculado para $\mathrm{C}_{13} \mathrm{H}_{18} \mathrm{~N}_{2}: 202.1470$; encontrado: 202.1468 .

${ }^{276}$ F. Gallou, N. Yee, F. Qiu, C. Senanayake, G. Linz, J. Schnaubelt, R. Soyka, Synlett 2004, 5, 883. 


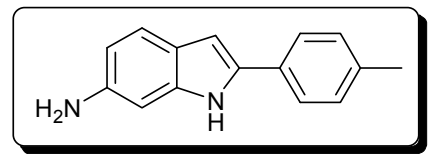

6-Amino-2-(p-tolil)-1H-indol (36bf)

Sólido marrón.

P.f. $=192-194{ }^{\circ} \mathrm{C}$.

${ }^{1}$ H RMN (400 MHz, DMSO-d ${ }_{6}$ ): $\delta=10.80(\mathrm{sa}, 1 \mathrm{H}), 7.61(\mathrm{~d}, J=7.0 \mathrm{~Hz}, 2 \mathrm{H}), 7.19-7.11(\mathrm{~m}, 3 \mathrm{H}), 6.56(\mathrm{~d}, J=$ $7.0 \mathrm{~Hz}, 2 \mathrm{H}), 6.36(\mathrm{~d}, J=8.3 \mathrm{~Hz}, 1 \mathrm{H}), 4.84(\mathrm{sa}, 2 \mathrm{H}), 2.28(\mathrm{~s}, 3 \mathrm{H}) \mathrm{ppm}$.

${ }^{13}$ C RMN (100.6 MHz, DMSO-d $\left.{ }_{6}\right): \delta=144.2(\mathrm{C}), 138.8(\mathrm{C}), 135.4(\mathrm{C}), 134.6(\mathrm{C}), 130.2(\mathrm{C}), 129.3(2 \times \mathrm{CH})$, $124.0(2 \times \mathrm{CH}), 120.6(\mathrm{C}), 120.1(\mathrm{CH}), 110.2(\mathrm{CH}), 98.1(\mathrm{CH}), 94.9(\mathrm{CH}), 20.8\left(\mathrm{CH}_{3}\right) \mathrm{ppm}$.

EMBR (IE), m/z (\%): $222\left(\mathrm{M}^{+}, 100\right), 207$ (36), 111 (7).

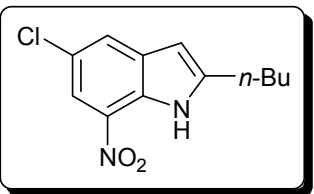

\section{2-Butil-5-cloro-7-nitro-1 $H$-indol (35cc)}

Sólido amarillo.

P.f. $=98-100^{\circ} \mathrm{C}$.

${ }^{1} \mathbf{H}$ RMN $\left(300 \mathrm{MHz},\left(\mathrm{CD}_{3}\right)_{2} \mathrm{CO}\right): \delta=11.11(\mathrm{sa}, 1 \mathrm{H}), 7.95(\mathrm{~d}, J=1.9 \mathrm{~Hz}, 1 \mathrm{H}), 7.90(\mathrm{~d}, J=1.9 \mathrm{~Hz}, 1 \mathrm{H})$, 6.47-6.44 (m, 1H), $2.91(\mathrm{t}, J=7.6 \mathrm{~Hz}, 2 \mathrm{H}), 1.82-1.70(\mathrm{~m}, 2 \mathrm{H}), 1.49-1.35(\mathrm{~m}, 2 \mathrm{H}), 0.94(\mathrm{t}, J=7.4 \mathrm{~Hz}$, 3H) $\mathrm{ppm}$.

${ }^{13}$ C RMN (75.4 MHz, $\left.\left(\mathrm{CD}_{3}\right)_{2} \mathrm{CO}\right): \delta=147.3(\mathrm{C}), 135.2(\mathrm{C}), 133.1(\mathrm{C}), 128.8(\mathrm{C}), 127.2(\mathrm{CH}), 124.1(\mathrm{C}), 117.4$ $(\mathrm{CH}), 101.0(\mathrm{CH}), 32.0\left(\mathrm{CH}_{2}\right), 28.2\left(\mathrm{CH}_{2}\right), 23.1\left(\mathrm{CH}_{2}\right), 14.2\left(\mathrm{CH}_{3}\right) \mathrm{ppm}$.

EMBR (IE), m/z (\%): 222 (M+, 57), 207 (34), 179 (100), 145 (12).

EMAR calculado para $\mathrm{C}_{12} \mathrm{H}_{13} \mathrm{~N}_{2} \mathrm{O}_{2}: 252.0666$; encontrado: 252.0663 .

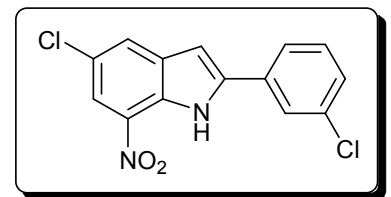

5-Cloro-2-(3-clorofenil)-7-nitro-1 $H$-indol (35cg)

Sólido amarillo.

P.f. $=198-200^{\circ} \mathrm{C}$.

${ }^{1}$ H RMN (400 MHz, DMSO-d R $_{6}: \delta=11.89$ (s, 1H), $8.12(\mathrm{~s}, 1 \mathrm{H}), 8.05(\mathrm{~s}, 1 \mathrm{H}), 7.98(\mathrm{~d}, J=1.9 \mathrm{~Hz}, 1 \mathrm{H}), 7.89$ (d, $J$ $=7.5 \mathrm{~Hz}, 1 \mathrm{H}), 7.49-7.39(\mathrm{~m}, 2 \mathrm{H}), 7.14(\mathrm{~s}, 1 \mathrm{H}) \mathrm{ppm}$.

${ }^{13}$ C RMN (100.6 MHz, DMSO-d ${ }_{6}$ ): $\delta=141.4(\mathrm{C}), 133.6(\mathrm{C}), 133.5(\mathrm{C}), 132.7$ (C), $132.4(\mathrm{C}), 130.5$ (CH), 128.5 $(\mathrm{CH}), 128.4(\mathrm{C}), 127.3(\mathrm{CH}), 126.4(\mathrm{CH}), 125.5(\mathrm{CH}), 123.3(\mathrm{C}), 118.2(\mathrm{CH}), 101.8(\mathrm{CH}) \mathrm{ppm}$.

EMBR (IE), m/z (\%): $306\left(\mathrm{M}^{+}, 100\right), 276$ (15), 260 (19), 225 (47), 207 (20).

EMAR calculado para $\mathrm{C}_{14} \mathrm{H}_{8} \mathrm{Cl}_{2} \mathrm{~N}_{2} \mathrm{O}_{2}$ : 305.9963 ; encontrado: 305.9969 .

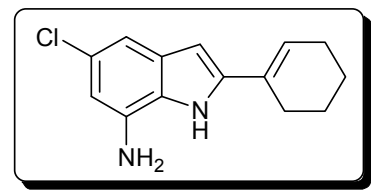

7-Amino-2-(1-ciclohexenil)-5-cloro-1H-indol (36cb)

Líquido marrón.

$\mathrm{R}_{\mathrm{f}}=0.34$ (hexano / AcOEt, 2 / 1).

${ }^{1}$ H RMN (300 MHz, $\left.\mathrm{CDCl}_{3}\right): \delta=8.18(\mathrm{sa}, 1 \mathrm{H}), 7.02(\mathrm{~s}, 1 \mathrm{H}), 6.49$ (s, 1H), $6.32(\mathrm{~s}, 1 \mathrm{H}), 6.15$ (s, $\left.1 \mathrm{H}\right), 3.60$ (sa, $2 \mathrm{H}), 2.46-2.36(\mathrm{~m}, 2 \mathrm{H}), 2.25-2.16(\mathrm{~m}, 2 \mathrm{H}), 1.82-1.57(\mathrm{~m}, 4 \mathrm{H}) \mathrm{ppm}$.

${ }^{13} \mathbf{C}$ RMN (75.4 MHz, $\left.\mathrm{CDCl}_{3}\right): \delta=140.6(\mathrm{C}), 131.4(\mathrm{C}), 130.5(\mathrm{C}), 129.0(\mathrm{C}), 125.6(\mathrm{C}), 125.4(\mathrm{C}), 123.3(\mathrm{CH})$,

$111.5(\mathrm{CH}), 109.0(\mathrm{CH}), 99.2(\mathrm{CH}), 26.2\left(\mathrm{CH}_{2}\right), 25.6\left(\mathrm{CH}_{2}\right), 22.6\left(\mathrm{CH}_{2}\right), 22.3\left(\mathrm{CH}_{2}\right) \mathrm{ppm}$.

EMBR (IE), m/z (\%): 246 (M $\left.\mathrm{M}^{+}, 100\right), 207$ (26), 183 (13), 166 (12).

EMAR calculado para $\mathrm{C}_{14} \mathrm{H}_{15} \mathrm{ClN}_{2}$ : 246.0924; encontrado: 246.0926. 


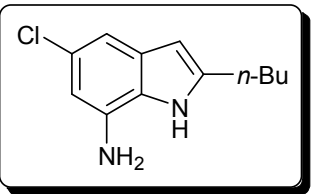

\section{7-Amino-2-butil-5-cloro-1H-indol (36cc)}

Sólido marrón.

P.f. $=120-122^{\circ} \mathrm{C}$

${ }^{1}$ H RMN $\left(300 \mathrm{MHz}, \mathrm{CDCl}_{3}\right): \delta=8.04(\mathrm{sa}, 1 \mathrm{H}), 7.03(\mathrm{~d}, J=1.7 \mathrm{~Hz}, 1 \mathrm{H}), 6.47(\mathrm{~d}, J=1.7 \mathrm{~Hz}, 1 \mathrm{H}), 6.11(\mathrm{~d}, J=$ $1.0 \mathrm{~Hz}, 1 \mathrm{H}), 3.56(\mathrm{sa}, 2 \mathrm{H}), 2.61(\mathrm{t}, J=7.6 \mathrm{~Hz}, 2 \mathrm{H}), 1.66-1.54(\mathrm{~m}, 2 \mathrm{H}), 1.42-1.28(\mathrm{~m}, 2 \mathrm{H}), 0.92(\mathrm{t}, J=7.3$ $\mathrm{Hz}, 3 \mathrm{H}) \mathrm{ppm}$.

${ }^{13} \mathbf{C}$ RMN (75.4 MHz, $\left.\mathrm{CDCl}_{3}\right): \delta=141.3(\mathrm{C}), 131.0(\mathrm{C}), 130.6(\mathrm{C}), 125.4(\mathrm{C}), 125.0(\mathrm{C}), 111.3(\mathrm{CH}), 108.3$ $(\mathrm{CH}), 100.1(\mathrm{CH}), 31.3\left(\mathrm{CH}_{2}\right), 28.0\left(\mathrm{CH}_{2}\right), 22.5\left(\mathrm{CH}_{2}\right), 14.0\left(\mathrm{CH}_{3}\right) \mathrm{ppm}$.

EMBR (IE), m/z (\%): $222\left(\mathrm{M}^{+}, 56\right), 179(100), 145$ (13).

EMAR calculado para $\mathrm{C}_{12} \mathrm{H}_{15} \mathrm{ClN}_{2}$ : 222.0924; encontrado: 222.0923.

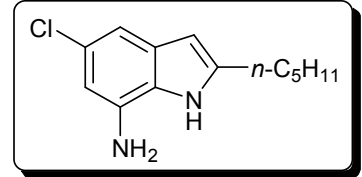

7-Amino-5-cloro-2-pentil-1H-indol (36cd)

Sólido marrón.

P.f. $=74-76^{\circ} \mathrm{C}$.

${ }^{1} \mathbf{H}$ RMN (400 MHz, CDCl $): \delta=7.98(\mathrm{sa}, 1 \mathrm{H}), 7.01(\mathrm{~d}, J=1.6 \mathrm{~Hz}, 1 \mathrm{H}), 6.47(\mathrm{~d}, J=1.6 \mathrm{~Hz}, 1 \mathrm{H}), 6.13-6.11(\mathrm{~m}$, $1 \mathrm{H}), 3.65(\mathrm{sa}, 2 \mathrm{H}), 2.67(\mathrm{t}, J=7.6 \mathrm{~Hz}, 2 \mathrm{H}), 1.71-1.62(\mathrm{~m}, 2 \mathrm{H}), 1.36-1.30(\mathrm{~m}, 4 \mathrm{H}), 0.90-0.86(\mathrm{~m}, 3 \mathrm{H}) \mathrm{ppm}$.

${ }^{13} \mathbf{C}$ RMN (100.6 MHz, $\left.\mathrm{CDCl}_{3}\right): \delta=141.1(\mathrm{C}), 131.1(\mathrm{C}), 130.6(\mathrm{C}), 125.6(\mathrm{C}), 125.0(\mathrm{C}), 111.3(\mathrm{CH}), 108.3$ $(\mathrm{CH}), 100.2(\mathrm{CH}), 31.6\left(\mathrm{CH}_{2}\right), 29.0\left(\mathrm{CH}_{2}\right), 28.4\left(\mathrm{CH}_{2}\right), 22.6\left(\mathrm{CH}_{2}\right), 14.1\left(\mathrm{CH}_{3}\right) \mathrm{ppm}$.

EMBR (IE), m/z (\%): $236\left(\mathrm{M}^{+}, 61\right), 207$ (12), 193 (25), 179 (100).

EMAR calculado para $\mathrm{C}_{13} \mathrm{H}_{17} \mathrm{ClN}_{2}: 236.1080$; encontrado: 236.1082 .

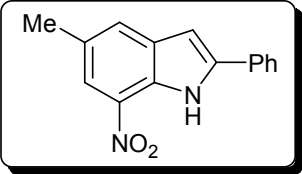

\section{2-Fenil-5-metil-7-nitro-1H-indol (35da)}

Sólido amarillo.

P.f. $=174-176^{\circ} \mathrm{C}$.

${ }^{1} \mathbf{H}$ RMN (400 MHz, $\left.\left(\mathrm{CD}_{3}\right)_{2} \mathrm{CO}\right): \delta=10.8(\mathrm{sa}, 1 \mathrm{H}), 7.98(\mathrm{t}, J=1.7 \mathrm{~Hz}, 1 \mathrm{H}), 7.97-7.92(\mathrm{~m}, 2 \mathrm{H}), 7.85-7.82(\mathrm{~m}$, 1H), 7.53-7.46 (m, 2H), 7.44-7.37 (m, 1H), $7.04(\mathrm{~d}, J=2.3 \mathrm{~Hz}, 1 \mathrm{H}), 2.52-2.48(\mathrm{~m}, 3 \mathrm{H}) \mathrm{ppm}$.

${ }^{13} \mathbf{C}$ RMN $\left(100.6 \mathrm{MHz},\left(\mathrm{CD}_{3}\right)_{2} \mathrm{CO}\right): \delta=142.2(\mathrm{C}), 134.2(\mathrm{C}), 132.1(\mathrm{CH}), 130.1(\mathrm{C}), 129.7(2 \times \mathrm{CH}), 129.5(\mathrm{C})$, $129.3(2 \times \mathrm{CH}), 128.9(\mathrm{C}), 128.8(\mathrm{C}), 126.9(\mathrm{CH}), 120.2(\mathrm{CH}), 101.1(\mathrm{CH}), 20.9\left(\mathrm{CH}_{3}\right) \mathrm{ppm}$.

EMBR (IE), m/z (\%): $252\left(\mathrm{M}^{+}, 100\right), 206$ (36), 191 (15), 178 (10).

EMAR calculado para $\mathrm{C}_{15} \mathrm{H}_{12} \mathrm{~N}_{2} \mathrm{O}_{2}$ : 252.0899; encontrado: 252.0894 .

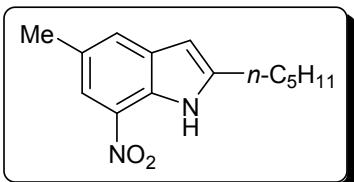

5-Metil-7-nitro-2-pentil-1H-indol (35dd)

Sólido amarillo.

P.f. $=70-72^{\circ} \mathrm{C}$.

${ }^{1}$ H RMN (300 MHz, $\left.\left(\mathrm{CD}_{3}\right)_{2} \mathrm{CO}\right): \delta=10.82(\mathrm{sa}, 1 \mathrm{H}), 7.84(\mathrm{~s}, 1 \mathrm{H}), 7.71(\mathrm{~s}, 1 \mathrm{H}), 6.38-6.36(\mathrm{~m}, 1 \mathrm{H}), 2.89(\mathrm{t}, J=$ $7.5 \mathrm{~Hz}, 2 \mathrm{H}), 2.47(\mathrm{~s}, 3 \mathrm{H}), 1.84-1.73(\mathrm{~m}, 2 \mathrm{H}), 1.42-1.35(\mathrm{~m}, 4 \mathrm{H}), 0.93-0.86(\mathrm{~m}, 3 \mathrm{H}) \mathrm{ppm}$.

${ }^{13} \mathbf{C}$ RMN (75.4 MHz, $\left.\left(\mathrm{CD}_{3}\right)_{2} \mathrm{CO}\right): \delta=145.3(\mathrm{C}), 134.3(\mathrm{C}), 132.9(\mathrm{C}), 129.2(\mathrm{C}), 128.7(\mathrm{C}), 128.6(\mathrm{CH}), 118.7$ $(\mathrm{CH}), 100.8(\mathrm{CH}), 32.3\left(\mathrm{CH}_{2}\right), 28.5\left(\mathrm{CH}_{2}\right), 23.2\left(\mathrm{CH}_{2}\right), 21.0\left(\mathrm{CH}_{2}\right), 14.4\left(\mathrm{CH}_{3}\right) \mathrm{ppm}$.

EMBR (IE), m/z (\%): 246 (M , 36), 203 (29), 190 (100), 143 (31).

EMAR calculado para $\mathrm{C}_{14} \mathrm{H}_{18} \mathrm{~N}_{2} \mathrm{O}_{2}$ : 246.1368; encontrado: 246.1369 . 


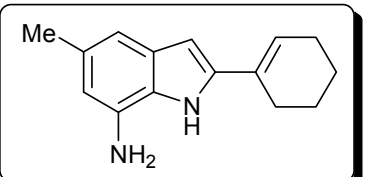

7-Amino-2-(1-ciclohexenil)-5-metil-1H-indol (36db)

Sólido marrón.

P.f. $=98-100^{\circ} \mathrm{C}$.

${ }^{1}$ H RMN (300 MHz, DMSO-d $\left.\mathrm{d}_{6}\right): \delta=10.28(\mathrm{sa}, 1 \mathrm{H}), 6.46(\mathrm{~s}, 1 \mathrm{H}), 6.23(\mathrm{~s}, 1 \mathrm{H}), 6.13(\mathrm{~s}, 1 \mathrm{H}), 6.08(\mathrm{~s}, 1 \mathrm{H}), 4.99$ (sa, 2H), 2.50-2.45 (m, 2H), 2.39-2.32 (m, 2H), $2.18(\mathrm{~s}, 3 \mathrm{H}), 1.75-1.55(\mathrm{~m}, 4 \mathrm{H}) \mathrm{ppm}$.

${ }^{13}$ C RMN (75.4 MHz, DMSO-d $)_{6}$ : $\delta$ = $138.2(\mathrm{C}), 132.9(\mathrm{C}), 129.1(\mathrm{C}), 129.0(\mathrm{C}), 128.2(\mathrm{C}), 124.2(\mathrm{C}), 121.2(\mathrm{CH})$, $108.2(\mathrm{CH}), 106.8(\mathrm{CH}), 97.9(\mathrm{CH}), 25.5\left(\mathrm{CH}_{2}\right), 24.8\left(\mathrm{CH}_{2}\right), 22.3\left(\mathrm{CH}_{2}\right), 21.9\left(\mathrm{CH}_{2}\right), 21.6\left(\mathrm{CH}_{3}\right) \mathrm{ppm}$.

EMBR (IE), m/z (\%): 226 (M+1 100), 207 (20), 199 (24), 152 (11).

EMAR calculado para $\mathrm{C}_{15} \mathrm{H}_{18} \mathrm{~N}_{2}: 226.1470$; encontrado: 226.1467 .<smiles>CCCCCCc1cc2cc(Cl)c([N+](=O)[O-])cc2[nH]1</smiles>

\section{2-Butil-5-cloro-6-nitro-1 $H$-indol (35ec)}

Sólido amarillo.

${ }^{1}$ H RMN (300 MHz, DMSO-d $\left.{ }_{6}\right): \delta=11.80(\mathrm{~s}, 1 \mathrm{H}), 8.04(\mathrm{~s}, 1 \mathrm{H}), 7.68(\mathrm{~s}, 1 \mathrm{H}), 6.31(\mathrm{~s}, 1 \mathrm{H}), 2.75(\mathrm{t}, J=7.5 \mathrm{~Hz}$, $2 \mathrm{H}), 1.72-1.58(\mathrm{~m}, 2 \mathrm{H}), 1.38-1.24(\mathrm{~m}, 2 \mathrm{H}), 0.88(\mathrm{t}, J=7.2 \mathrm{~Hz}, 3 \mathrm{H}) \mathrm{ppm}$.

${ }^{13}$ C RMN (75.4 MHz, DMSO-d 6 ): $\delta=148.7(\mathrm{C}), 140.0(\mathrm{C}), 132.7(\mathrm{C}), 132.3(\mathrm{C}), 120.8(\mathrm{CH}), 115.6(\mathrm{C}), 109.5$ $(\mathrm{CH}), 99.4(\mathrm{CH}), 30.5\left(\mathrm{CH}_{2}\right), 27.4\left(\mathrm{CH}_{2}\right), 21.8\left(\mathrm{CH}_{2}\right), 13.7\left(\mathrm{CH}_{3}\right) \mathrm{ppm}$.

EMBR (IE), m/z (\%): 252 (31), 210 (100), 179 (52), 163 (35), 128 (28).

EMAR calculado para $\mathrm{C}_{12} \mathrm{H}_{13} \mathrm{ClN}_{2} \mathrm{O}_{2}$ : 252.0666; encontrado: 252.0668 .

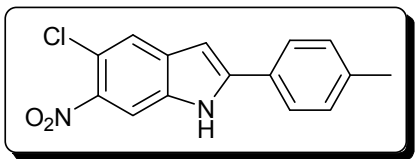

5-Cloro-6-nitro-2-p-tolil-1H-indol (35ef)

Sólido marrón.

P.f. $=260-262^{\circ} \mathrm{C}$.

${ }^{1}$ H RMN (300 MHz, DMSO-d $\left.{ }_{6}\right): \delta=11.01(\mathrm{sa}, 1 \mathrm{H}), 7.62(\mathrm{~d}, J=8.0 \mathrm{~Hz}, 2 \mathrm{H}), 7.32(\mathrm{~s}, 1 \mathrm{H}), 7.22-7.16(\mathrm{~m}, 2 \mathrm{H})$, $6.79(\mathrm{~s}, 1 \mathrm{H}), 6.59(\mathrm{~s}, 1 \mathrm{H}), 2.29(\mathrm{~s}, 3 \mathrm{H}) \mathrm{ppm}$.

${ }^{13}$ C RMN (75.4 MHz, DMSO-d 6 ): $\delta=139.8$ (C), 137.5 (C), 136.3 (C), $136.1(\mathrm{C}), 129.6(\mathrm{C}), 129.4(2 \times \mathrm{CH})$, $124.3(2 \times \mathrm{CH}), 121.5(\mathrm{C}), 119.4(\mathrm{CH}), 113.2(\mathrm{C}), 97.5(\mathrm{CH}), 96.2(\mathrm{CH}), 20.8\left(\mathrm{CH}_{3}\right) \mathrm{ppm}$.

EMBR (IE), m/z (\%): $256\left(\mathrm{M}^{+}, 100\right), 207$ (18), 128 (7), 110 (9).

EMAR calculado para $\mathrm{C}_{15} \mathrm{H}_{13} \mathrm{ClN}_{2} \mathrm{O}_{2}: 286.0509$; encontrado: 256.0501 .

\section{B.4 Reducción selectiva de 5,7-dinitroindoles 2-sustituidos 38}

B.4.1 Procedimiento general para la síntesis de los 5,7-dinitroindoles 2-sustituidos 38

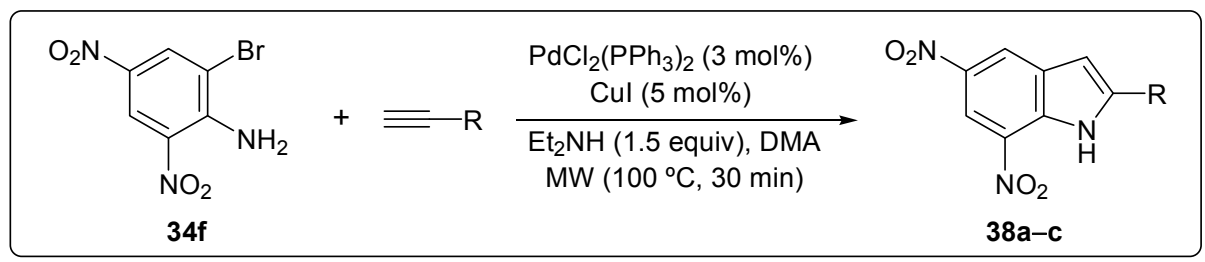


En un tubo sellado se añade una mezcla de 2-bromo-4,6-dinitroanilina (262 $\mathrm{mg}, 1 \mathrm{mmol}$ ), alquino (1.5 mmoles), $\mathrm{PdCl}_{2}\left(\mathrm{PPh}_{3}\right)_{2}(21 \mathrm{mg}, 0.03 \mathrm{mmol}), \mathrm{CuI}(9.5 \mathrm{mg}, 0.05 \mathrm{mmol})$ y Et ${ }_{2} \mathrm{NH}(156 \mu \mathrm{L}$, $1.5 \mathrm{mmol}$ ) en DMA (3 mL). La mezcla se calienta a $100{ }^{\circ} \mathrm{C}$ y $80 \mathrm{~W}$ en un microondas (CEM, Discover S-Class) durante 30 minutos. La mezcla de reacción se enfría a temperatura ambiente y se añaden $\mathrm{CH}_{2} \mathrm{Cl}_{2}(20 \mathrm{~mL})$ y una disolución de $\mathrm{HCl}(20 \mathrm{~mL}$ de una disolución $0.5 \mathrm{M})$. La fase acuosa separada se extrae con $\mathrm{CH}_{2} \mathrm{Cl}_{2}(2 \times 20 \mathrm{~mL})$, y la combinación de fases orgánicas se lava con $\mathrm{H}_{2} \mathrm{O}(3 \times$ $50 \mathrm{~mL}$ ). La fase orgánica se seca sobre $\mathrm{Na}_{2} \mathrm{SO}_{4}$ anhidro y se concentra a presión reducida. El crudo de reacción se purifica mediante columna de cromatografía de sílica gel (hexano / AcOEt) obteniéndose los 5,7-dinitroindoles 38.<smiles>O=[N+]([O-])C1=CC2=Cc3cc(cc([N+](=O)[O-])c3)NC2=C1</smiles>

\section{2-Fenil-5,7-dinitro-1H-indol (38a)}

Sólido naranja.

P.f. $=220-222^{\circ} \mathrm{C}$.

${ }^{1}$ H RMN $\left(300 \mathrm{MHz}, \mathrm{DMSO}_{\mathrm{d}}\right): \delta=12.25(\mathrm{sa}, 1 \mathrm{H}), 8.86(\mathrm{~d}, J=2.0 \mathrm{~Hz}, 1 \mathrm{H}), 8.68(\mathrm{~d}, J=2.0 \mathrm{~Hz}, 1 \mathrm{H}), 7.96(\mathrm{~d}, J$ $=6.9 \mathrm{~Hz}, 2 \mathrm{H}), 7.55-7.35(\mathrm{~m}, 4 \mathrm{H}) \mathrm{ppm}$.

${ }^{13}$ C RMN (75.4 MHz, DMSO-d ${ }_{6}$ ): $\delta=144.7$ (C), 139.8 (C), 132.4 (C), 131.9 (C), 131.7 (C), 129.9 (C), 129.3 $(\mathrm{CH}), 128.8(2 \times \mathrm{CH}), 127.1(2 \times \mathrm{CH}), 122.6(\mathrm{CH}), 113.5(\mathrm{CH}), 103.3(\mathrm{CH}) \mathrm{ppm}$.

EMBR (IE), m/z (\%): 283 (M+100), 237 (23), 207 (27), 191 (49), 163 (9).

EMAR calculado para $\mathrm{C}_{14} \mathrm{H}_{9} \mathrm{~N}_{3} \mathrm{O}_{4}$ : 283.0593; encontrado: 283.0588 .

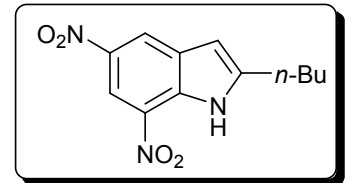

\section{2-Butil-5,7-dinitro-1 $H$-indol (38b)}

Sólido amarillo.

P.f. $=140-142^{\circ} \mathrm{C}$

${ }^{1}$ H RMN (400 MHz, DMSO-d $\left.)_{6}\right): \delta=12.25(\mathrm{~s}, 1 \mathrm{H}), 8.72(\mathrm{~s}, 1 \mathrm{H}), 8.60(\mathrm{~s}, 1 \mathrm{H}), 6.63(\mathrm{~s}, 1 \mathrm{H}), 2.80(\mathrm{t}, J=7.6 \mathrm{~Hz}$, 2H), $1.69-1.59(\mathrm{~m}, 2 \mathrm{H}), 1.39-1.28(\mathrm{~m}, 2 \mathrm{H}), 0.89(\mathrm{t}, J=7.3 \mathrm{~Hz}, 3 \mathrm{H}) \mathrm{ppm}$.

${ }^{13}$ C RMN (100.6 MHz, DMSO-d ${ }_{6}$ ): $\delta$ = 148.2 (C), 139.1 (C), 132.4 (C), 130.8 (C), 130.6 (C), 121.6 (CH), 112.3 $(\mathrm{CH}), 102.5(\mathrm{CH}), 30.6\left(\mathrm{CH}_{2}\right), 26.9\left(\mathrm{CH}_{2}\right), 21.8\left(\mathrm{CH}_{2}\right), 13.6\left(\mathrm{CH}_{3}\right) \mathrm{ppm}$.

EMBR (IE), m/z (\%): $263\left(\mathrm{M}^{+}, 18\right), 221$ (100), 220 (65), 207 (56), 174 (21), 128 (27).

EMAR calculado para $\mathrm{C}_{12} \mathrm{H}_{13} \mathrm{~N}_{3} \mathrm{O}_{4}$ : 263.0906; encontrado: 263.0909.

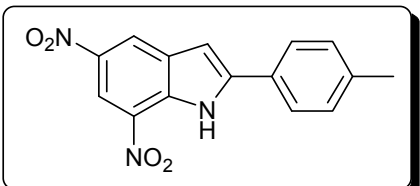

\section{5,7-Dinitro-2-(p-tolil)-1H-indol (38c)}

Sólido amarillo.

P.f. $=228-230^{\circ} \mathrm{C}$.

${ }^{1}$ H RMN (300 MHz, DMSO-d $\left.)_{6}\right): \delta=12.22(\mathrm{sa}, 1 \mathrm{H}), 8.88-8.86(\mathrm{~m}, 1 \mathrm{H}), 8.70-8.68(\mathrm{~m}, 1 \mathrm{H}), 7.90(\mathrm{~d}, J=1.7 \mathrm{~Hz}$, $1 \mathrm{H}), 7.88-7.86(\mathrm{~m}, 1 \mathrm{H}), 7.32(\mathrm{~s}, 1 \mathrm{H}), 7.30(\mathrm{~d}, J=1.7 \mathrm{~Hz}, 2 \mathrm{H}), 2.36(\mathrm{~s}, 3 \mathrm{H}) \mathrm{ppm}$.

${ }^{13}$ C RMN (75.4 MHz, DMSO-d ${ }_{6}$ ): $\delta=144.9$ (C), 139.8 (C), 139.0 (C), 132.6 (C), 131.9 (C), 131.7 (C), 129.4 $(2 \times \mathrm{CH}), 127.1(\mathrm{C}), 127.0(2 \times \mathrm{CH}), 122.4(\mathrm{CH}), 113.3(\mathrm{CH}), 102.7(\mathrm{CH}), 21.0\left(\mathrm{CH}_{3}\right) \mathrm{ppm}$.

EMBR (IE), m/z (\%): 297 (100), 267 (5), 251 (24), 205 (41).

EMAR calculado para $\mathrm{C}_{15} \mathrm{H}_{11} \mathrm{~N}_{3} \mathrm{O}_{4}$ : 297.0750; encontrado: 297.0748 . 


\section{B.4.2 Procedimiento general para la síntesis de los 7-amino-5-nitroindoles 2-sustituidos 39}

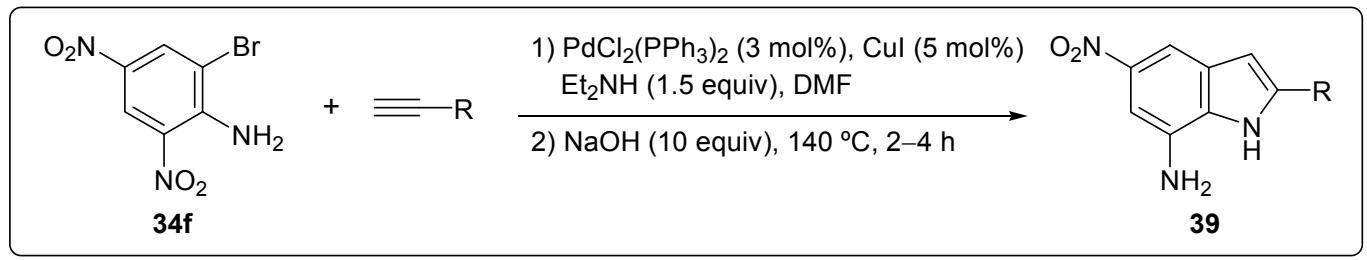

Una mezcla de 2-bromo-4,6-dinitroanilina (262 mg, $1 \mathrm{mmol})$, alquino (1.5 mmol), $\mathrm{PdCl}_{2}\left(\mathrm{PPh}_{3}\right)_{2}(21 \mathrm{mg}, 0.03 \mathrm{mmol}), \mathrm{CuI}(9.5 \mathrm{mg}, 0.05 \mathrm{mmol}) \mathrm{y} \mathrm{Et}_{2} \mathrm{NH}(156 \mu \mathrm{L}, 1.5 \mathrm{mmol})$ en DMF (3 $\mathrm{mL}$ ) se agita bajo $\mathrm{N}_{2}$ a $70{ }^{\circ} \mathrm{C}$ durante 2 horas. La reacción se monitoriza por CG-EM. A continuación se añade $\mathrm{NaOH}$ en polvo (400 mg, $10 \mathrm{mmol}$ ) y la mezcla de reacción se calienta a $140{ }^{\circ} \mathrm{C}$ hasta que la ciclación se completa (2-4 horas), monitorizada por CG-EM. La mezcla de reacción se enfría a temperatura ambiente y se añaden $\mathrm{H}_{2} \mathrm{O}(20 \mathrm{~mL})$ y $\mathrm{CH}_{2} \mathrm{Cl}_{2}(20 \mathrm{~mL})$. La fase acuosa separada se extrae con $\mathrm{CH}_{2} \mathrm{Cl}_{2}(3 \times 20 \mathrm{~mL})$ y la combinación de fases orgánicas se lava con $\mathrm{H}_{2} \mathrm{O}(2 \times 50 \mathrm{~mL})$ y se seca sobre $\mathrm{Na}_{2} \mathrm{SO}_{4}$ anhidro. El disolvente se elimina a presión reducida y el residuo se purifica mediante columna de cromatografía (hexano / AcOEt) permitiendo obtener los 7-amino-5-nitroindoles 39.

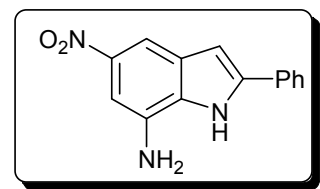

\section{7-Amino-2-fenil-5-nitro-1 $H$-indol (39a)}

Sólido marrón.

P.f. $=244-246^{\circ} \mathrm{C}$.

${ }^{1}$ H RMN (300 MHz, DMSO-d $\left.{ }_{6}\right): \delta=11.58(\mathrm{~s}, 1 \mathrm{H}), 7.88-7.79(\mathrm{~m}, 3 \mathrm{H}), 7.48(\mathrm{t}, J=7.5 \mathrm{~Hz}, 2 \mathrm{H}), 7.39-7.31(\mathrm{~m}$, $1 \mathrm{H}), 7.24(\mathrm{~d}, J=2.0 \mathrm{~Hz}, 1 \mathrm{H}), 7.02(\mathrm{~s}, 1 \mathrm{H}), 5.82(\mathrm{sa}, 2 \mathrm{H}) \mathrm{ppm}$.

${ }^{13}$ C RMN (75.4 MHz, DMSO-d 6 ): $\delta=142.5$ (C), 139.5 (C), 134.4 (C), $131.4(\mathrm{C}), 129.4(\mathrm{C}), 129.1(2 \times \mathrm{CH})$, $128.1(\mathrm{CH}), 127.8(\mathrm{C}), 125.1(2 \times \mathrm{CH}), 105.8(\mathrm{CH}), 101.5(\mathrm{CH}), 98.6(\mathrm{CH}) \mathrm{ppm}$.

EMBR (IE), m/z (\%): 253 (M , 100), 207 (46), 195 (13), 180 (13).

EMAR calculado para $\mathrm{C}_{14} \mathrm{H}_{11} \mathrm{~N}_{3} \mathrm{O}_{2}: 253.0851$; encontrado: 253.0854 .

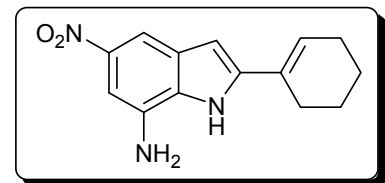

7-Amino-2-(1-ciclohexenil)-5-nitro-1H-indol (39b)

Sólido marrón rojizo.

P.f. $=218-220^{\circ} \mathrm{C}$.

${ }^{1}$ H RMN (400 MHz, DMSO-d $\left.)_{6}\right): \delta=11.05(\mathrm{~s}, 1 \mathrm{H}), 7.71(\mathrm{~d}, J=2.1 \mathrm{~Hz}, 1 \mathrm{H}), 7.15(\mathrm{dd}, J=2.1,1.2 \mathrm{~Hz}, 1 \mathrm{H}), 6.49$ $(\mathrm{d}, J=1.8 \mathrm{~Hz}, 1 \mathrm{H}), 6.36(\mathrm{~s}, 1 \mathrm{H}), 5.71(\mathrm{~s}, 2 \mathrm{H}), 2.39-2.32(\mathrm{~m}, 2 \mathrm{H}), 2.25-2.17(\mathrm{~m}, 2 \mathrm{H}), 1.75-1.57(\mathrm{~m}, 4 \mathrm{H})$ ppm.

${ }^{13}$ C RMN (100.6 MHz, DMSO-d $\left.\mathrm{d}_{6}\right): \delta=141.9$ (C), 141.3 (C), 133.8 (C), 128.9 (C), 128.4 (C), $127.3(\mathrm{C}), 123.8$ $(\mathrm{CH}), 105.6(\mathrm{CH}), 100.4(\mathrm{CH}), 98.5(\mathrm{CH}), 25.4\left(\mathrm{CH}_{2}\right), 24.8\left(\mathrm{CH}_{2}\right), 22.0\left(\mathrm{CH}_{2}\right), 21.7\left(\mathrm{CH}_{2}\right) \mathrm{ppm}$.

EMBR (IE), m/z (\%): 257 (100), 227 (15), 207 (80), 183 (11).

EMAR calculado para $\mathrm{C}_{14} \mathrm{H}_{15} \mathrm{~N}_{3} \mathrm{O}_{2}$ : 259.1164; encontrado: 259.1175 . 


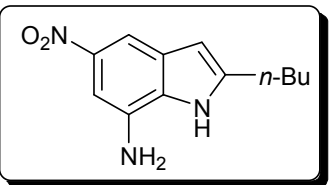

7-Amino-2-butil-5-nitro-1H-indol (39c)

Líquido marrón.

$\mathrm{R}_{\mathrm{f}}=0.38$ (hexano / AcOEt, $1 / 1$ ).

${ }^{1}$ H RMN (300 MHz, DMSO-d $\left.\mathrm{d}_{6}\right): \delta=11.05(\mathrm{~s}, 1 \mathrm{H}), 7.69(\mathrm{~d}, J=2.1 \mathrm{~Hz}, 1 \mathrm{H}), 7.13(\mathrm{~d}, J=2.1 \mathrm{~Hz}, 1 \mathrm{H}), 6.26(\mathrm{~d}, J$ $=2.1 \mathrm{~Hz}, 1 \mathrm{H}), 5.51(\mathrm{sa}, 2 \mathrm{H}), 2.70(\mathrm{t}, J=7.6 \mathrm{~Hz}, 2 \mathrm{H}), 1.68-1.59(\mathrm{~m}, 2 \mathrm{H}), 1.37-1.28(\mathrm{~m}, 2 \mathrm{H}), 0.89(\mathrm{t}, J=$ $7.3 \mathrm{~Hz}, 3 \mathrm{H}) \mathrm{ppm}$.

${ }^{13}$ C RMN (75.4 MHz, DMSO-d $\mathrm{d}_{6}$ ): $\delta=142.2(\mathrm{C}), 141.8(\mathrm{C}), 133.6(\mathrm{C}), 128.5(\mathrm{C}), 127.4(\mathrm{CH}), 105.4(\mathrm{CH}), 101.3$ $(\mathrm{CH}), 97.9(\mathrm{CH}), 30.7\left(\mathrm{CH}_{2}\right), 27.3\left(\mathrm{CH}_{2}\right), 21.8\left(\mathrm{CH}_{2}\right), 13.8\left(\mathrm{CH}_{3}\right) \mathrm{ppm}$.

EMBR (IE), m/z (\%): $233\left(\mathrm{M}^{+}, 73\right), 191$ (100), 144 (46), 117 (12).

EMAR calculado para $\mathrm{C}_{12} \mathrm{H}_{15} \mathrm{~N}_{3} \mathrm{O}_{2}: 233.1164$; encontrado: 233.1164 .<smiles>Nc1cc([N+](=O)[O-])cc2cc(-c3ccccc3)[nH]c12</smiles>

7-Amino-5-nitro-2-pentil-1H-indol (39d)

Líquido marrón.

$\mathrm{R}_{\mathrm{f}}=0.40$ (hexano / AcOEt, $\left.1 / 1\right)$.

${ }^{1} \mathbf{H}$ RMN (300 MHz, $\left.\mathrm{CDCl}_{3}\right): \delta=10.63(\mathrm{sa}, 1 \mathrm{H}), 7.92(\mathrm{~d}, J=1.9 \mathrm{~Hz}, 1 \mathrm{H}), 7.26-7.24(\mathrm{~m}, 1 \mathrm{H}), 6.25(\mathrm{~s}, 1 \mathrm{H}), 4.57$ $(\mathrm{sa}, 2 \mathrm{H}), 2.69(\mathrm{t}, J=7.6 \mathrm{~Hz}, 2 \mathrm{H}), 1.74-1.62(\mathrm{~m}, 2 \mathrm{H}), 1.34-1.26(\mathrm{~m}, 4 \mathrm{H}), 0.86(\mathrm{t}, J=7.0 \mathrm{~Hz}, 3 \mathrm{H}) \mathrm{ppm}$.

${ }^{13} \mathbf{C}$ RMN (75.4 MHz, $\left.\mathrm{CDCl}_{3}\right): \delta=142.7(\mathrm{C}), 142.2(\mathrm{C}), 132.0(\mathrm{C}), 129.4(\mathrm{C}), 128.2(\mathrm{C}), 107.9(\mathrm{CH}), 101.6$ $(\mathrm{CH}), 100.1(\mathrm{CH}), 31.5\left(\mathrm{CH}_{2}\right), 28.8\left(\mathrm{CH}_{2}\right), 28.4\left(\mathrm{CH}_{2}\right), 22.5\left(\mathrm{CH}_{2}\right), 14.1\left(\mathrm{CH}_{3}\right) \mathrm{ppm}$.

EMBR (IE), m/z (\%): 247 (M+ 68), 204 (23), 191 (100), 158 (14), 144 (46).

EMAR calculado para $\mathrm{C}_{13} \mathrm{H}_{17} \mathrm{~N}_{3} \mathrm{O}_{2}: 247.1321$; encontrado: 247.1317 .

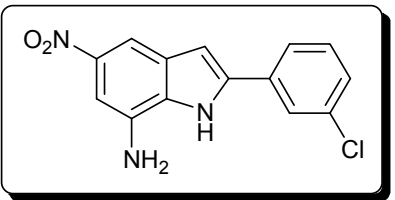

7-Amino-2-(3-clorofenil)-5-nitro-1H-indol (39e)

Sólido marrón rojizo.

P.f. $=260-262^{\circ} \mathrm{C}$.

${ }^{1}$ H RMN $\left.(300 \mathrm{MHz}, \text { DMSO-d })_{6}\right): \delta=11.62(\mathrm{~s}, 1 \mathrm{H}), 7.91-7.88(\mathrm{~m}, 1 \mathrm{H}), 7.83-7.77(\mathrm{~m}, 2 \mathrm{H}), 7.51(\mathrm{t}, J=7.9 \mathrm{~Hz}$, 1H), $7.41(\mathrm{~d}, J=7.9 \mathrm{~Hz}, 1 \mathrm{H}), 7.23(\mathrm{~d}, J=2.1 \mathrm{~Hz}, 1 \mathrm{H}), 7.14(\mathrm{~d}, J=2.1 \mathrm{~Hz}, 1 \mathrm{H}), 5.79$ (sa, 2H) ppm.

${ }^{13}$ C RMN (75.4 MHz, DMSO-d $\left.{ }_{6}\right): \delta=142.6(\mathrm{C}), 137.8(\mathrm{C}), 134.5(\mathrm{C}), 134.0(\mathrm{C}), 133.5$ (C), $131.0(\mathrm{CH}), 129.6$ (C), $127.8(\mathrm{CH}), 127.6(\mathrm{C}), 124.5(\mathrm{CH}), 123.8(\mathrm{CH}), 105.9(\mathrm{CH}), 102.7(\mathrm{CH}), 98.8(\mathrm{CH}) \mathrm{ppm}$.

EMAR calculado para $\mathrm{C}_{14} \mathrm{H}_{10} \mathrm{ClN}_{3} \mathrm{O}_{2}$ : 287.0462; encontrado: 287.0470 .

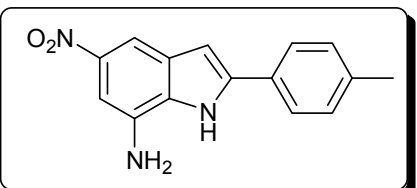

7-Amino-5-nitro-2-(p-tolil)-1H-indol (39f)

Sólido marrón rojizo.

P.f. $=272-274^{\circ} \mathrm{C}$.

${ }^{1}$ H RMN (300 MHz, DMSO-d d $_{6}: \delta=11.49$ (sa, 1H), 7.78 (d, $\left.J=2.1 \mathrm{~Hz}, 1 \mathrm{H}\right), 7.72(\mathrm{~d}, J=8.2 \mathrm{~Hz}, 2 \mathrm{H}), 7.30$ (d, $J$ $=8.2 \mathrm{~Hz}, 2 \mathrm{H}), 7.19(\mathrm{~d}, J=2.1 \mathrm{~Hz}, 1 \mathrm{H}), 6.97(\mathrm{~d}, J=2.1 \mathrm{~Hz}, 1 \mathrm{H}), 5.79(\mathrm{sa}, 2 \mathrm{H}), 2.33(\mathrm{~s}, 3 \mathrm{H}) \mathrm{ppm}$.

${ }^{13}$ C RMN (75.4 MHz, DMSO-d 6 ): $\delta=142.4$ (C), 139.7 (C), 137.7 (C), $134.3(\mathrm{C}), 129.7(2 \times \mathrm{CH}), 129.3(\mathrm{C})$, 128.6 (C), $127.9(\mathrm{C}), 125.0(2 \times \mathrm{CH}), 105.6(\mathrm{CH}), 100.9(\mathrm{CH}), 98.5(\mathrm{CH}), 20.9\left(\mathrm{CH}_{3}\right) \mathrm{ppm}$.

EMBR (IE), m/z (\%): $267\left(\mathrm{M}^{+}, 1\right), 234$ (95), 219 (100), 204 (38), 189 (6), 142 (11), 105 (26).

EMAR calculado para $\mathrm{C}_{15} \mathrm{H}_{13} \mathrm{~N}_{3} \mathrm{O}_{2}$ : 267.1008; encontrado: 267.1001 . 


\section{B.4.3 Sintesis del 2-(1-ciclohexenil)-1-metil-7-(N,N-dimetilamino)-5-nitro-1H-indol 40a}

A una disolución de 7-amino-2-(1-ciclohexenil)-5-nitro-1H-indol (128 mg, $0.5 \mathrm{mmol})$ en $\mathrm{CH}_{3} \mathrm{CN}(4 \mathrm{~mL})$ se añaden $\mathrm{K}_{2} \mathrm{CO}_{3}(207 \mathrm{mg}, 1.5 \mathrm{mmol})$ y MeI $(124 \mu \mathrm{L}, 2 \mathrm{mmol})$. La mezcla resultante se agita a reflujo durante 6 horas (la reacción se monitoriza mediante CG-EM). El crudo se filtra para eliminar el $\mathrm{K}_{2} \mathrm{CO}_{3}$, y el $\mathrm{CH}_{3} \mathrm{CN}$ se elimina a presión reducida. El residuo se diluye en AcOEt y $\mathrm{H}_{2} \mathrm{O}$. La fase acuosa separada se extrae con AcOEt $(2 \times 15 \mathrm{~mL})$ y la combinación de fases orgánicas se seca sobre $\mathrm{Na}_{2} \mathrm{SO}_{4}$ anhidro. El disolvente se evapora por destilación a presión reducida. El crudo se purifica mediante columna de cromatografía (hexano / AcOEt, 8 / 1) permitiendo obtener 40a.

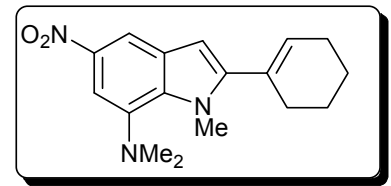

2-(1-Ciclohexenil)-1-metil-7-( $N, N$-dimetilamino)-5-nitro-1 $H$-indol (40a) Sólido marrón. P.f. $=99-101^{\circ} \mathrm{C}$.

${ }^{1} \mathbf{H}$ RMN (400 MHz, $\left.\mathrm{CDCl}_{3}\right): \delta=8.19(\mathrm{~d}, J=2.0 \mathrm{~Hz}, 1 \mathrm{H}), 7.70(\mathrm{~d}, J=2.0 \mathrm{~Hz}, 1 \mathrm{H}), 6.45(\mathrm{~s}, 1 \mathrm{H}), 5.98(\mathrm{sa}, 1 \mathrm{H}), 3.98$ $(\mathrm{s}, 3 \mathrm{H}), 2.80(\mathrm{~s}, 6 \mathrm{H}), 2.36-2.30(\mathrm{~m}, 2 \mathrm{H}), 2.28-2.22(\mathrm{~m}, 2 \mathrm{H}), 1.83-1.76(\mathrm{~m}, 2 \mathrm{H}), 1.75-1.67(\mathrm{~m}, 2 \mathrm{H}) \mathrm{ppm}$.

${ }^{13}$ C RMN (100.6 MHz, $\left.\mathrm{CDCl}_{3}\right): \delta=148.5(\mathrm{C}), 141.9(\mathrm{C}), 140.9(\mathrm{C}), 135.6(\mathrm{C}), 131.1(\mathrm{CH}), 129.4(\mathrm{C}), 129.0$ (C), $113.1(\mathrm{CH}), 107.0(\mathrm{CH}), 103.0(\mathrm{CH}), 44.9\left(2 \times \mathrm{CH}_{3}\right), 33.3\left(\mathrm{CH}_{3}\right), 29.3\left(\mathrm{CH}_{2}\right), 25.8\left(\mathrm{CH}_{2}\right), 22.9\left(\mathrm{CH}_{2}\right)$, $22.0\left(\mathrm{CH}_{2}\right) \mathrm{ppm}$.

EMBR (IE), m/z (\%): 299 (M+1 100), 284 (28), 253 (12), 209 (7).

EMAR calculado para $\mathrm{C}_{17} \mathrm{H}_{21} \mathrm{~N}_{3} \mathrm{O}_{2}$ : 299.1634; encontrado: 299.1630 .

\section{B.4.4 Síntesis del 5-nitro-2-p-tolil-7-(N-tosilamino)-1H-indol $40 \mathrm{~b}$}

A una disolución de 7-amino-5-nitro-2-p-tolil-1H-indol ( $85 \mathrm{mg}, 0.32 \mathrm{mmol}$ ) en piridina anhidra $(2 \mathrm{~mL})$ a $0{ }^{\circ} \mathrm{C}$ se adiciona lentamente durante 30 minutos una disolución de cloruro de tosilo (100 mg, 0.52 mmol). La mezcla resutante se agita a $20^{\circ} \mathrm{C}$ durante 15 horas y se hidroliza con $\mathrm{H}_{2} \mathrm{O}$. Se adiciona $\mathrm{CH}_{2} \mathrm{Cl}_{2}$ $(15 \mathrm{~mL})$. La fase acuosa separada se extrae con $\mathrm{CH}_{2} \mathrm{Cl}_{2}(3 \times 15 \mathrm{~mL})$ y la combinación de fases orgánicas se seca sobre $\mathrm{Na}_{2} \mathrm{SO}_{4}$ anhidro. Se evapora el disolvente a presión reducida y el crudo de la reacción se purifica mediante columna de cromatografía (hexano / AcOEt, 1/1).

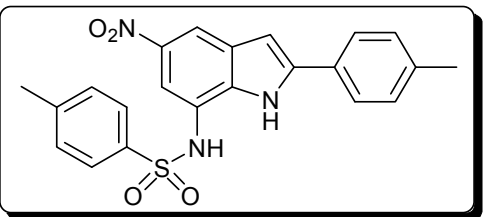

5-Nitro-2-p-tolil-7-( $N$-tosilamino)-1H-indol (40b)

Sólido marrón.

${ }^{1} \mathbf{H}$ RMN $\left(300 \mathrm{MHz},\left(\mathrm{CD}_{3}\right)_{2} \mathrm{CO}\right): \delta=10.97(\mathrm{sa}, 1 \mathrm{H}), 8.34(\mathrm{~d}, J=2.1 \mathrm{~Hz}, 1 \mathrm{H}), 7.90(\mathrm{~d}, J=2.1 \mathrm{~Hz}, 1 \mathrm{H})$, 7.77-7.68 (m, 4H), 7.35-7.26 (m, 5H), $7.08(\mathrm{~s}, 1 \mathrm{H}), 2.38(\mathrm{~s}, 3 \mathrm{H}), 2.29(\mathrm{~s}, 3 \mathrm{H}) \mathrm{ppm}$.

${ }^{13}$ C RMN (75.4 MHz, $\left.\left(\mathrm{CD}_{3}\right)_{2} \mathrm{CO}\right): \delta=145.1(\mathrm{C}), 142.8(\mathrm{C}), 142.7(\mathrm{C}), 139.7(\mathrm{C}), 137.2(\mathrm{C}), 134.8(\mathrm{C}), 130.73$ (C), $130.66(2 \times \mathrm{CH}), 130.59(2 \times \mathrm{CH}), 129.2(\mathrm{C}), 128.2(2 \times \mathrm{CH}), 126.4(2 \times \mathrm{CH}), 122.8(\mathrm{C}), 115.1(\mathrm{CH})$, $111.0(\mathrm{CH}), 102.1(\mathrm{CH}), 21.4\left(\mathrm{CH}_{3}\right), 21.3\left(\mathrm{CH}_{3}\right) \mathrm{ppm}$.

EMBR (IE), m/z (\%): 421 (M+ , 83), 391 (12), 281 (33), 266 (100), 207 (98), 236 (28), 91 (27). 


\section{Síntesis regioselectiva de 4-haloindoles 28}

\section{C.1 Preparación de los 4-haloindoles 28 a partir de las alquinilanilidas 27}

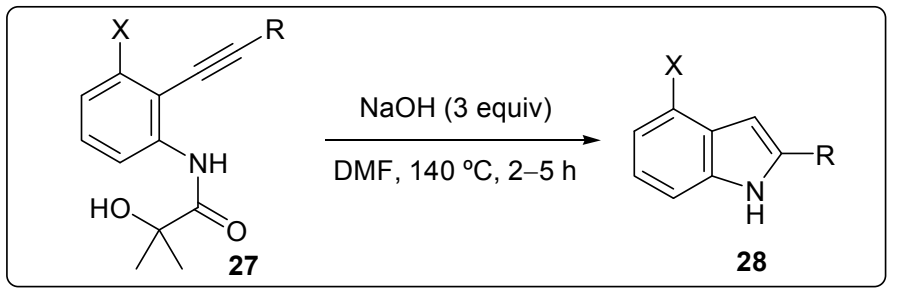

A una disolución de la correspondiente 3-halo-2-alquinilpropanamida 27 (1 equiv) en DMF anhidra ( $3 \mathrm{~mL} / \mathrm{mmol})$ se añade un exceso de $\mathrm{NaOH}$ en polvo (3 equiv). La mezcla resultante se calienta a reflujo bajo $\mathrm{N}_{2}$ a $140{ }^{\circ} \mathrm{C}$ durante 2-5 horas (la reacción se sigue por CG-EM). Se deja que la reacción se enfríe a temperatura ambiente y se añaden $\mathrm{CH}_{2} \mathrm{Cl}_{2}(20 \mathrm{~mL} / \mathrm{mmol})$ y $\mathrm{HCl}(20 \mathrm{~mL} /$ mmol de una disolución $0.5 \mathrm{M})$. La fase acuosa separada se extrae con $\mathrm{CH}_{2} \mathrm{Cl}_{2}(2 \times 20 \mathrm{~mL} / \mathrm{mmol})$. La combinación de fases orgánicas se lava con $\mathrm{H}_{2} \mathrm{O}(2 \times 40 \mathrm{~mL} / \mathrm{mmol})$. La fase orgánica se seca sobre $\mathrm{Na}_{2} \mathrm{SO}_{4}$ anhidro y se concentra a presión reducida. El residuo resultante se purifica mediante columna de cromatografía de sílica gel (hexano / AcOEt) obteniéndose los indoles 28.

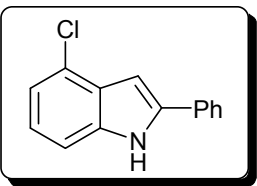

\section{4-Cloro-2-fenil-1 $H$-indol (28ba)}

Sólido blanco.

P.f. $=73-75^{\circ} \mathrm{C}\left(\right.$ lit. $\left.^{121}=76-77^{\circ} \mathrm{C}\right)$.

${ }^{1}$ H RMN (300 MHz, $\left.\mathrm{CDCl}_{3}\right): \delta=8.43(\mathrm{sa}, 1 \mathrm{H}), 7.70-7.63(\mathrm{~m}, 2 \mathrm{H}), 7.50-7.43(\mathrm{~m}, 2 \mathrm{H}), 7.39-7.33(\mathrm{~m}, 1 \mathrm{H})$, 7.31-7.27 (m, 1H), 7.17-7.08 (m, 2H), $6.94(\mathrm{dd}, J=2.2,0.8 \mathrm{~Hz}, 1 \mathrm{H}) \mathrm{ppm}$.

${ }^{13}$ C RMN (75.4 MHz, $\left.\mathrm{CDCl}_{3}\right): \delta=138.6(\mathrm{C}), 137.4(\mathrm{C}), 131.8(\mathrm{C}), 129.2(2 \times \mathrm{CH}), 128.3(\mathrm{CH}), 128.2(\mathrm{C}), 125.9$ (C), $125.4(2 \times \mathrm{CH}), 122.9(\mathrm{CH}), 120.1(\mathrm{CH}), 109.6(\mathrm{CH}), 98.5(\mathrm{CH}) \mathrm{ppm}$.

IR $\left(\mathrm{KBr}, \mathrm{cm}^{-1}\right): 3449,2961,2924,1452,1261,1098,803,756,688$.

EMBR (IE), m/z (\%): $229\left(\mathrm{M}^{+}+2,33\right), 227\left(\mathrm{M}^{+}, 100\right), 191(10), 165(16), 113$ (10).

EMAR calculado para $\mathrm{C}_{14} \mathrm{H}_{10} \mathrm{ClN}$ : 227.0502; encontrado: 227.0501 .

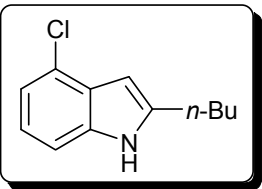

\section{2-Butil-4-cloro-1H-indol (28bb)}

Líquido incoloro.

$\mathrm{R}_{\mathrm{f}}=0.46$ (hexano / AcOEt, $6 / 1$ ).

${ }^{1} \mathbf{H}$ RMN $\left(300 \mathrm{MHz}, \mathrm{CDCl}_{3}\right): \delta=7.90(\mathrm{sa}, 1 \mathrm{H}), 7.18(\mathrm{dt}, J=7.7,1.0 \mathrm{~Hz}, 1 \mathrm{H}), 7.12(\mathrm{dd}, J=7.7,1.0 \mathrm{~Hz}, 1 \mathrm{H})$, $7.05(\mathrm{t}, J=7.7 \mathrm{~Hz}, 1 \mathrm{H}), 6.38(\mathrm{dd}, J=2.2,0.9 \mathrm{~Hz}, 1 \mathrm{H}), 2.74(\mathrm{t}, J=7.6 \mathrm{~Hz}, 2 \mathrm{H}), 1.77-1.66(\mathrm{~m}, 2 \mathrm{H})$, $1.51-1.38(\mathrm{~m}, 2 \mathrm{H}), 0.99(\mathrm{t}, J=7.3 \mathrm{~Hz}, 3 \mathrm{H}) \mathrm{ppm}$.

${ }^{13} \mathbf{C}$ RMN (75.4 MHz, $\left.\mathrm{CDCl}_{3}\right): \delta=141.0(\mathrm{C}), 136.5(\mathrm{C}), 127.6(\mathrm{C}), 125.0(\mathrm{C}), 121.6(\mathrm{CH}), 119.4(\mathrm{CH}), 109.1$ $(\mathrm{CH}), 98.1(\mathrm{CH}), 31.2\left(\mathrm{CH}_{2}\right), 28.0\left(\mathrm{CH}_{2}\right), 22.5\left(\mathrm{CH}_{2}\right), 14.0\left(\mathrm{CH}_{3}\right) \mathrm{ppm}$.

IR $\left(\mathrm{KBr}, \mathrm{cm}^{-1}\right): 3417,2957,2929,1575,1548,1433,1330,1182,941,765$.

EMBR (IE), m/z (\%): $209\left(\mathrm{M}^{+}+2,10\right), 207\left(\mathrm{M}^{+}, 33\right), 164$ (100), 128 (8), 101 (6).

EMAR calculado para $\mathrm{C}_{12} \mathrm{H}_{14} \mathrm{ClN}$ : 207.0815; encontrado: 207.0822. 


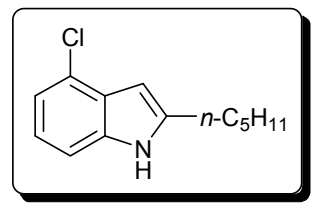

\section{4-Cloro-2-pentil-1H-indol (28bc)}

Sólido marrón.

P.f. $=24-26^{\circ} \mathrm{C}$.

${ }^{1} \mathbf{H}$ RMN (300 MHz, CDCl $\left.)_{3}\right): \delta=7.96(\mathrm{sa}, 1 \mathrm{H}), 7.19(\mathrm{dd}, J=7.6,0.9 \mathrm{~Hz}, 1 \mathrm{H}), 7.11-7.00(\mathrm{~m}, 2 \mathrm{H}), 6.36(\mathrm{~d}, J=$ $0.9 \mathrm{~Hz}, 1 \mathrm{H}), 2.75(\mathrm{t}, J=7.6 \mathrm{~Hz}, 2 \mathrm{H}), 1.79-1.68(\mathrm{~m}, 2 \mathrm{H}), 1.43-1.25(\mathrm{~m}, 4 \mathrm{H}), 0.93(\mathrm{t}, J=6.7 \mathrm{~Hz}, 3 \mathrm{H}) \mathrm{ppm}$.

${ }^{13} \mathbf{C}$ RMN (75.4 MHz, $\mathrm{CDCl}_{3}$ ): $\delta=141.0(\mathrm{C}), 136.5(\mathrm{C}), 127.7(\mathrm{C}), 125.0(\mathrm{C}), 121.6(\mathrm{CH}), 119.4(\mathrm{CH}), 109.0$ $(\mathrm{CH}), 98.1(\mathrm{CH}), 31.6\left(\mathrm{CH}_{2}\right), 28.8\left(\mathrm{CH}_{2}\right), 28.3\left(\mathrm{CH}_{2}\right), 22.6\left(\mathrm{CH}_{2}\right), 14.1\left(\mathrm{CH}_{3}\right) \mathrm{ppm}$.

IR $\left(\mathrm{KBr}, \mathrm{cm}^{-1}\right): 3417,2956,2928,1547,1433,1329,1182,939,765$.

EMBR (IE), m/z (\%): 223 (M+2, 11), 221, (M+1, 34), 178 (24), 164 (100), 128 (9), 101 (6).

EMAR calculado para $\mathrm{C}_{13} \mathrm{H}_{16} \mathrm{ClN}$ : 221.0971; encontrado: 221.0980 .

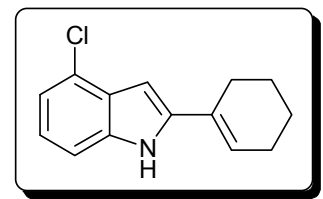

2-(1-Ciclohexenil)-4-cloro-1 $H$-indol (28bd)

Líquido marrón.

$\mathrm{R}_{\mathrm{f}}=0.70$ (hexano / AcOEt, $6 / 1$ ).

${ }^{1}$ H RMN (300 MHz, $\left.\mathrm{CDCl}_{3}\right): \delta=8.21(\mathrm{sa}, 1 \mathrm{H}), 7.21-7.17(\mathrm{~m}, 1 \mathrm{H}), 7.09-7.02(\mathrm{~m}, 2 \mathrm{H}), 6.54(\mathrm{~d}, J=2.0 \mathrm{~Hz}, 1 \mathrm{H})$, 6.17-6.12 (m, 1H), 2.51-2.44 (m, 2H), 2.29-2.21 (m, 2H), 1.85-1.76 (m, 2H), 1.75-1.65 (m, 2H) ppm.

${ }^{13} \mathbf{C}$ RMN (75.4 MHz, $\left.\mathrm{CDCl}_{3}\right): \delta=140.1(\mathrm{C}), 136.8(\mathrm{C}), 128.8(\mathrm{C}), 127.8(\mathrm{C}), 125.6(\mathrm{C}), 123.8(\mathrm{CH}), 122.5$ $(\mathrm{CH}), 119.5(\mathrm{CH}), 109.1(\mathrm{CH}), 97.1(\mathrm{CH}), 26.0\left(\mathrm{CH}_{2}\right), 25.6\left(\mathrm{CH}_{2}\right), 22.5\left(\mathrm{CH}_{2}\right), 22.2\left(\mathrm{CH}_{2}\right) \mathrm{ppm}$.

IR $\left(\mathrm{KBr}, \mathrm{cm}^{-1}\right): 3433,2928,1569,1432,1334,1184,947,764,731$.

EMBR (IE), m/z (\%): $233\left(\mathrm{M}^{+}+2,32\right), 231\left(\mathrm{M}^{+}, 100\right), 203$ (35), 164 (34), 151 (29).

EMAR calculado para $\mathrm{C}_{14} \mathrm{H}_{14} \mathrm{ClN}$ : 231.0815; encontrado: 231.0814 .

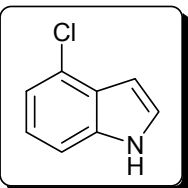

4-Cloro-1H-indol (28be)

Líquido marrón.

$\mathrm{R}_{\mathrm{f}}=0.33$ (hexano / AcOEt, 5 / 1).

${ }^{1} \mathbf{H}$ RMN (300 MHz, $\left.\mathrm{CDCl}_{3}\right): \delta=8.25(\mathrm{sa}, 1 \mathrm{H}), 7.31-7.21(\mathrm{~m}, 2 \mathrm{H}), 7.16-7.08(\mathrm{~m}, 2 \mathrm{H}), 6.70-6.62(\mathrm{~m}, 1 \mathrm{H}) \mathrm{ppm}$.

${ }^{13} \mathbf{C}$ RMN (75.4 MHz, $\left.\mathrm{CDCl}_{3}\right): \delta=136.6(\mathrm{C}), 126.9(\mathrm{C}), 126.2(\mathrm{C}), 124.9(\mathrm{CH}), 122.7(\mathrm{CH}), 119.7(\mathrm{CH}), 109.8$ $(\mathrm{CH}), 101.4(\mathrm{CH}) \mathrm{ppm}$.

EMBR (IE), m/z (\%): $153\left(\mathrm{M}^{+}+2,31\right), 151\left(\mathrm{M}^{+}, 100\right), 116(18), 89(27)$.

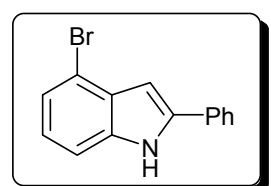

4-Bromo-2-fenil-1 $H$-indol (28ca)

Sólido blanco.

P.f. $=100-102^{\circ} \mathrm{C}$

${ }^{1} \mathbf{H}$ RMN (300 MHz, $\left.\mathrm{CDCl}_{3}\right): \delta=8.42(\mathrm{sa}, 1 \mathrm{H}), 7.65(\mathrm{dd}, J=8.4,1.0 \mathrm{~Hz}, 2 \mathrm{H}), 7.49-7.42(\mathrm{~m}, 2 \mathrm{H}), 7.40-7.29$ $(\mathrm{m}, 3 \mathrm{H}), 7.06(\mathrm{t}, J=7.9 \mathrm{~Hz}, 1 \mathrm{H}), 6.91-6.89(\mathrm{~m}, 1 \mathrm{H}) \mathrm{ppm}$.

${ }^{13} \mathbf{C}$ RMN (75.4 MHz, $\left.\mathrm{CDCl}_{3}\right): \delta=138.5(\mathrm{C}), 137.0(\mathrm{C}), 131.7(\mathrm{C}), 130.1(\mathrm{C}), 129.2(2 \times \mathrm{CH}), 128.3(\mathrm{CH}), 125.3$ $(2 \times \mathrm{CH}), 123.2(\mathrm{CH}), 114.6(\mathrm{C}), 110.2(\mathrm{CH}), 100.2(\mathrm{CH}) \mathrm{ppm}$.

IR $\left(\mathrm{KBr}, \mathrm{cm}^{-1}\right): 3445,1475,1452,1352,1289,1181,916,758,691$.

EMBR (IE), m/z (\%): 273 (M+2, 98), $271\left(\mathrm{M}^{+}, 100\right), 191$ (27), 165 (34), 136 (11).

EMAR calculado para $\mathrm{C}_{14} \mathrm{H}_{10} \mathrm{BrN}$ : 270.9997; encontrado: 270.9995. 


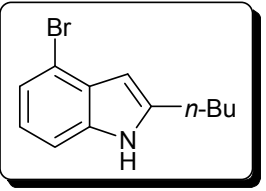

4-Bromo-2-butil-1H-indol (28cb)

Sólido blanco.

P.f. $=29-31^{\circ} \mathrm{C}$.

${ }^{1} \mathbf{H}$ RMN $\left(300 \mathrm{MHz}, \mathrm{CDCl}_{3}\right): \delta=7.95(\mathrm{sa}, 1 \mathrm{H}), 7.26(\mathrm{dd}, J=7.8,0.8 \mathrm{~Hz}, 1 \mathrm{H}), 7.22(\mathrm{dt}, J=7.8,0.8 \mathrm{~Hz}, 1 \mathrm{H})$, $6.99(\mathrm{t}, J=7.8 \mathrm{~Hz}, 1 \mathrm{H}), 6.32(\mathrm{dd}, J=2.2,0.9 \mathrm{~Hz}, 1 \mathrm{H}), 2.74(\mathrm{t}, J=7.6 \mathrm{~Hz}, 2 \mathrm{H}), 1.77-1.66(\mathrm{~m}, 2 \mathrm{H})$, $1.50-1.37(\mathrm{~m}, 2 \mathrm{H}), 0.98(\mathrm{t}, J=7.3 \mathrm{~Hz}, 3 \mathrm{H}) \mathrm{ppm}$.

${ }^{13}$ C RMN (75.4 MHz, $\left.\mathrm{CDCl}_{3}\right): \delta=141.0(\mathrm{C}), 136.0(\mathrm{C}), 129.6(\mathrm{C}), 122.5(\mathrm{CH}), 121.9(\mathrm{CH}), 113.7(\mathrm{C}), 109.6$ $(\mathrm{CH}), 99.8(\mathrm{CH}), 31.2\left(\mathrm{CH}_{2}\right), 28.0\left(\mathrm{CH}_{2}\right), 22.5\left(\mathrm{CH}_{2}\right), 14.0\left(\mathrm{CH}_{3}\right) \mathrm{ppm}$.

IR $\left(\mathrm{KBr}, \mathrm{cm}^{-1}\right): 3407,2958,2929,1539,1430,1329,1178,917,763,729$.

EMBR (IE), m/z (\%): $253\left(\mathrm{M}^{+}+2,37\right), 251\left(\mathrm{M}^{+}, 37\right), 210$ (100), 208 (98), 129 (32).

EMAR calculado para $\mathrm{C}_{12} \mathrm{H}_{14} \mathrm{BrN}$ : 251.0310; encontrado: 251.0309.

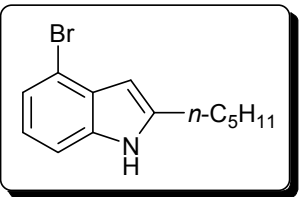

\section{4-Bromo-2-pentil-1H-indol (28cc)}

Líquido marrón.

$\mathrm{R}_{\mathrm{f}}=0.42$ (hexano / AcOEt, $6 / 1$ ).

${ }^{1} \mathbf{H}$ RMN (300 MHz, $\left.\mathrm{CDCl}_{3}\right): \delta=7.97(\mathrm{sa}, 1 \mathrm{H}), 7.28-7.20(\mathrm{~m}, 2 \mathrm{H}), 6.98(\mathrm{t}, J=8.0 \mathrm{~Hz}, 1 \mathrm{H}), 6.31(\mathrm{dd}, J=2.2$, $0.8 \mathrm{~Hz}, 1 \mathrm{H}), 2.74(\mathrm{t}, J=7.7 \mathrm{~Hz}, 2 \mathrm{H}), 1.79-1.68(\mathrm{~m}, 2 \mathrm{H}), 1.43-1.34(\mathrm{~m}, 4 \mathrm{H}), 0.93(\mathrm{t}, J=7.0 \mathrm{~Hz}, 3 \mathrm{H}) \mathrm{ppm}$.

${ }^{13} \mathbf{C}$ RMN (75.4 MHz, $\left.\mathrm{CDCl}_{3}\right): \delta=141.0(\mathrm{C}), 136.1(\mathrm{C}), 129.6(\mathrm{C}), 122.5(\mathrm{CH}), 121.9(\mathrm{CH}), 113.7(\mathrm{C}), 109.6$ $(\mathrm{CH}), 99.9(\mathrm{CH}), 31.6\left(\mathrm{CH}_{2}\right), 28.9\left(\mathrm{CH}_{2}\right), 28.3\left(\mathrm{CH}_{2}\right), 22.6\left(\mathrm{CH}_{2}\right), 14.1\left(\mathrm{CH}_{3}\right) \mathrm{ppm}$.

IR $\left(\mathrm{KBr}, \mathrm{cm}^{-1}\right): 3411,2956,2928,1548,1430,1327,1178,917,763$.

EMBR (IE), m/z (\%): 267 (M+2, 41), 265 (M+, 42), 224 (19), 210 (100), 208 (98), 129 (32).

EMAR calculado para $\mathrm{C}_{13} \mathrm{H}_{16} \mathrm{BrN}$ : 265.0466; encontrado: 265.0467.

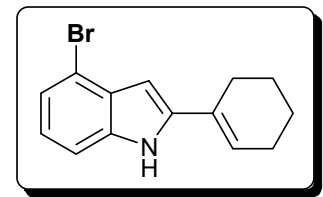

4-Bromo-2-(1-ciclohexenil)-1H-indol (28cd)

Líquido incoloro.

$\mathrm{R}_{\mathrm{f}}=0.50$ (hexano / AcOEt, $\left.6 / 1\right)$.

${ }^{1} \mathbf{H}$ RMN $\left(300 \mathrm{MHz}, \mathrm{CDCl}_{3}\right): \delta=8.27(\mathrm{sa}, 1 \mathrm{H}), 7.27-7.20(\mathrm{~m}, 2 \mathrm{H}), 6.99(\mathrm{t}, J=7.8 \mathrm{~Hz}, 1 \mathrm{H}), 6.48(\mathrm{~d}, J=1.9 \mathrm{~Hz}$, $1 \mathrm{H}), 6.17-6.12(\mathrm{~m}, 1 \mathrm{H}), 2.51-2.43(\mathrm{~m}, 2 \mathrm{H}), 2.28-2.20(\mathrm{~m}, 2 \mathrm{H}), 1.84-1.75(\mathrm{~m}, 2 \mathrm{H}), 1.75-1.65(\mathrm{~m}, 2 \mathrm{H}) \mathrm{ppm}$.

${ }^{13}$ C RMN (75.4 MHz, $\left.\mathrm{CDCl}_{3}\right): \delta=140.2(\mathrm{C}), 136.4(\mathrm{C}), 129.7(\mathrm{C}), 128.9(\mathrm{C}), 123.8(\mathrm{CH}), 122.8(\mathrm{CH}), 122.7$ $(\mathrm{CH}), 114.3(\mathrm{C}), 109.7(\mathrm{CH}), 98.9(\mathrm{CH}), 26.1\left(\mathrm{CH}_{2}\right), 25.6\left(\mathrm{CH}_{2}\right), 22.6\left(\mathrm{CH}_{2}\right), 22.2\left(\mathrm{CH}_{2}\right) \mathrm{ppm}$.

IR $\left(\mathrm{KBr}, \mathrm{cm}^{-1}\right): 3427,2927,1568,1524,1429,1332,1179,917,762,730$.

EMBR (IE), m/z (\%): $277\left(\mathrm{M}^{+}+2,98\right), 275\left(\mathrm{M}^{+}, 100\right), 247$ (24), 195 (23), 167 (38).

EMAR calculado para $\mathrm{C}_{14} \mathrm{H}_{14} \mathrm{BrN}$ : 275.0310; encontrado: 275.0314 .

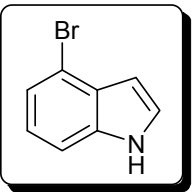

\section{4-Bromo-1H-indol (28ce)}

Líquido incoloro.

$\mathrm{R}_{\mathrm{f}}=0.29$ (hexano / AcOEt, $6 / 1$ ).

${ }^{1}$ H RMN $\left(300 \mathrm{MHz}, \mathrm{CDCl}_{3}\right): \delta=8.28(\mathrm{sa}, 1 \mathrm{H}), 7.37-7.23(\mathrm{~m}, 3 \mathrm{H}), 7.06(\mathrm{t}, J=7.9 \mathrm{~Hz}, 1 \mathrm{H}), 6.64-6.60(\mathrm{~m}, 1 \mathrm{H}) \mathrm{ppm}$.

${ }^{13} \mathbf{C}$ RMN (75.4 MHz, $\left.\mathrm{CDCl}_{3}\right): \delta=136.1(\mathrm{C}), 128.8(\mathrm{C}), 124.8(\mathrm{CH}), 123.0(\mathrm{CH}), 122.9(\mathrm{CH}), 114.9(\mathrm{C}), 110.4$ $(\mathrm{CH}), 103.2(\mathrm{CH}) \mathrm{ppm}$. 
EMBR (IE), m/z (\%): $197\left(\mathrm{M}^{+}+2,100\right), 195\left(\mathrm{M}^{+}, 100\right), 184$ (7), 116 (77), 89 (44).

EMAR calculado para $\mathrm{C}_{8} \mathrm{H}_{6} \mathrm{BrN}$ : 194.9684; encontrado: 194.9679.

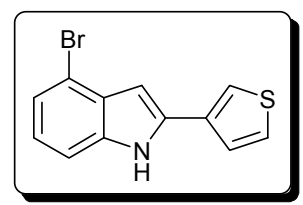

\section{4-Bromo-2-(3-tienil)-1 $H$-indol (28cg)}

Sólido marrón.

P.f. $=44-46^{\circ} \mathrm{C}$.

${ }^{1}$ H RMN (300 MHz, $\left.\mathrm{CDCl}_{3}\right): \delta=8.35(\mathrm{sa}, 1 \mathrm{H}), 7.47-7.38(\mathrm{~m}, 3 \mathrm{H}), 7.29(\mathrm{~d}, J=7.7 \mathrm{~Hz}, 2 \mathrm{H}), 7.07-7.00(\mathrm{~m}, 1 \mathrm{H})$, $6.75(\mathrm{~d}, J=2.1 \mathrm{~Hz}, 1 \mathrm{H}) \mathrm{ppm}$.

${ }^{13} \mathbf{C}$ RMN (75.4 MHz, $\left.\mathrm{CDCl}_{3}\right): \delta=136.6(\mathrm{C}), 134.6(\mathrm{C}), 133.5(\mathrm{C}), 129.9(\mathrm{C}), 127.0(\mathrm{CH}), 125.7(\mathrm{CH}), 123.25$ $(\mathrm{CH}), 123.18(\mathrm{CH}), 119.9(\mathrm{CH}), 114.5(\mathrm{C}), 110.0(\mathrm{CH}), 100.2(\mathrm{CH}) \mathrm{ppm}$.

EMBR (IE), m/z (\%): $281\left(\mathrm{M}^{+}+2,100\right), 279\left(\mathrm{M}^{+}, 96\right), 198$ (38), 171 (61), 154 (27), 126 (32).

EMAR calculado para $\mathrm{C}_{12} \mathrm{H}_{8}$ BrNS: 276.9561; encontrado: 276.9576 .

\section{C.2 Preparación de los 4-haloindoles 28 a partir de las 2,3-dihaloanilidas 25}

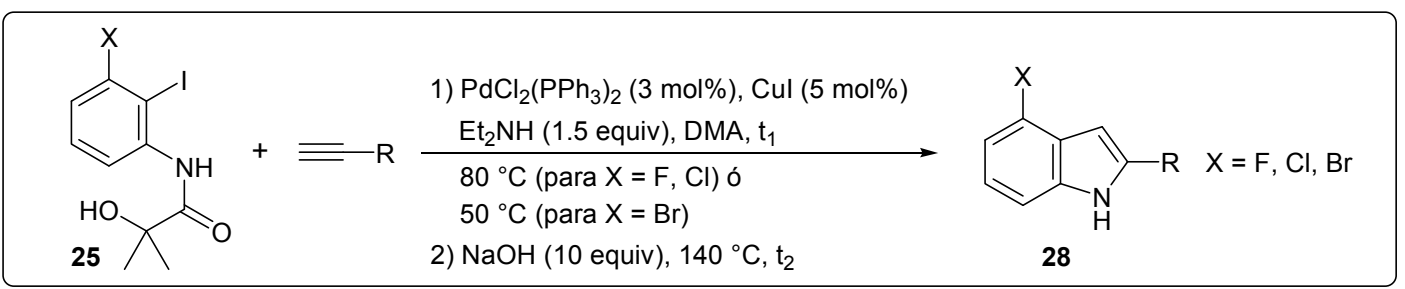

Una mezcla de la correspondiente 2,3-dihaloanilida $25(0.5 \mathrm{mmol})$, alquino $(0.75 \mathrm{mmol}$ cuando $\mathrm{X}=\mathrm{F}, \mathrm{Cl}$, ó $0.6 \mathrm{mmol} \mathrm{si} \mathrm{X}=\mathrm{Br}), \mathrm{PdCl}_{2}\left(\mathrm{PPh}_{3}\right)_{2}(11 \mathrm{mg}, 3 \mathrm{~mol} \%), \mathrm{CuI}(5 \mathrm{mg}, 5 \mathrm{~mol} \%)$ y Et $\mathrm{NH}_{2}(78 \mu \mathrm{L}$, $0.75 \mathrm{mmol}$ ) en DMA $(2 \mathrm{~mL})$ se agita bajo $\mathrm{N}_{2}$ a $80{ }^{\circ} \mathrm{C}$ (para 25aa y 25ba), a $50{ }^{\circ} \mathrm{C}$ (para 25ca), o a 40 ${ }^{\circ} \mathrm{C}$ (cuando se emplea trimetilsililacetileno como alquino) el tiempo necesario hasta la desaparición completa de la anilida 25 de partida (la reacción se monitoriza mediante CG-EM) (2-6 h). A continuación se añade un exceso de $\mathrm{NaOH}$ en polvo $(200 \mathrm{mg}, 5 \mathrm{mmol})$. La mezcla resultante se calienta a reflujo bajo $\mathrm{N}_{2}$ a $140{ }^{\circ} \mathrm{C}$ durante $2-12$ horas (la reacción se sigue por CG-EM). Se deja que la reacción se enfríe a temperatura ambiente y se añaden $\mathrm{CH}_{2} \mathrm{Cl}_{2}(10 \mathrm{~mL})$ y $\mathrm{HCl}(10 \mathrm{~mL}$ de una disolución $0.5 \mathrm{M})$. La fase acuosa separada se extrae con $\mathrm{CH}_{2} \mathrm{Cl}_{2}(2 \times 10 \mathrm{~mL})$. La combinación de fases orgánicas se lava con $\mathrm{H}_{2} \mathrm{O}(2 \times 30 \mathrm{~mL})$. La fase orgánica se seca sobre $\mathrm{Na}_{2} \mathrm{SO}_{4}$ anhidro y se concentra a presión reducida. El residuo resultante se purifica mediante columna de cromatografía de sílica gel (hexano / AcOEt) obteniéndose los indoles $\mathbf{2 8}$. Los datos físicos y espectroscópicos de $\mathbf{2 8 b a - b e , ~ y ~} \mathbf{2 8 c a - c g}$ han sido detallados anteriormente.

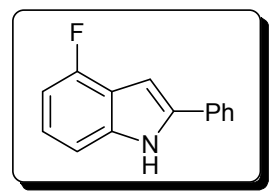

2-Fenil-4-fluoro-1H-indol (28aa)

Sólido marrón.

P.f. $=62-64^{\circ} \mathrm{C}\left(\right.$ lit. $\left.^{122 \mathrm{a}}=65-67^{\circ} \mathrm{C}\right)$.

${ }^{1}$ H RMN (300 MHz, $\left.\mathrm{CDCl}_{3}\right): \delta=8.45(\mathrm{sa}, 1 \mathrm{H}), 7.70-7.63(\mathrm{~m}, 2 \mathrm{H}), 7.51-7.43(\mathrm{~m}, 2 \mathrm{H}), 7.41-7.33(\mathrm{~m}, 1 \mathrm{H})$, $7.21-7.09(\mathrm{~m}, 2 \mathrm{H}), 6.93(\mathrm{dd}, J=2.2,0.7 \mathrm{~Hz}, 1 \mathrm{H}), 6.84(\mathrm{ddd}, J=10.3,7.4,1.2 \mathrm{~Hz}, 1 \mathrm{H}) \mathrm{ppm}$. 
${ }^{13} \mathbf{C} \mathbf{R M N}\left(75.4 \mathrm{MHz}, \mathrm{CDCl}_{3}\right): \delta=156.5(\mathrm{~d}, J=246.8 \mathrm{~Hz}, \mathrm{C}), 139.3(\mathrm{~d}, J=11.2 \mathrm{~Hz}, \mathrm{C}), 138.0(\mathrm{C}), 131.9$ (C), $129.2(2 \times \mathrm{CH}), 128.1(\mathrm{CH}), 125.3(2 \times \mathrm{CH}), 122.8(\mathrm{~d}, J=7.6 \mathrm{~Hz}, \mathrm{CH}), 118.6(\mathrm{~d}, J=22.4 \mathrm{~Hz}, \mathrm{C}), 107.1(\mathrm{~d}, J$ $=3.6 \mathrm{~Hz}, \mathrm{CH}), 105.1(\mathrm{~d}, J=18.9 \mathrm{~Hz}, \mathrm{CH}), 95.8(\mathrm{CH}) \mathrm{ppm}$.

EMAR calculado para $\mathrm{C}_{14} \mathrm{H}_{10} \mathrm{FN}$ : 211.0797; encontrado: 211.0787 .

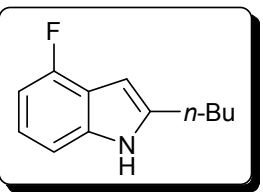

2-Butil-4-fluro-1H-indol (28ab)

Líquido marrón.

$\mathrm{R}_{\mathrm{f}}=0.50$ (hexano / AcOEt, 4 / 1).

${ }^{1} \mathbf{H}$ RMN (300 MHz, $\mathrm{CDCl}_{3}$ ): $\delta=7.92(\mathrm{sa}, 1 \mathrm{H}), 7.11-7.00(\mathrm{~m}, 2 \mathrm{H}), 6.78(\mathrm{ddd}, J=10.4,6.9,1.7 \mathrm{~Hz}, 1 \mathrm{H}), 6.35(\mathrm{dd}, J=$ $2.2,0.8 \mathrm{~Hz}, 1 \mathrm{H}), 2.75(\mathrm{t}, J=7.6 \mathrm{~Hz}, 2 \mathrm{H}), 1.77-1.66(\mathrm{~m}, 2 \mathrm{H}), 1.51-1.38(\mathrm{~m}, 2 \mathrm{H}), 0.99(\mathrm{t}, J=7.3 \mathrm{~Hz}, 3 \mathrm{H}) \mathrm{ppm}$.

${ }^{13}$ C RMN (75.4 MHz, $\left.\mathrm{CDCl}_{3}\right): \delta=155.9(\mathrm{~d}, J=245.2 \mathrm{~Hz}, \mathrm{C}), 140.1(\mathrm{C}), 138.6(\mathrm{~d}, J=11.8 \mathrm{~Hz}, \mathrm{C}), 121.4(\mathrm{~d}, J=$ $7.6 \mathrm{~Hz}, \mathrm{CH}), 117.8(\mathrm{~d}, J=22.4 \mathrm{~Hz}, \mathrm{C}), 106.5(\mathrm{~d}, J=3.4 \mathrm{~Hz}, \mathrm{CH}), 104.5(\mathrm{~d}, J=19.1 \mathrm{~Hz}, \mathrm{CH}), 95.4(\mathrm{CH})$, $31.3\left(\mathrm{CH}_{2}\right), 27.9\left(\mathrm{CH}_{2}\right), 22.5\left(\mathrm{CH}_{2}\right), 14.0\left(\mathrm{CH}_{3}\right) \mathrm{ppm}$.

EMAR calculado para $\mathrm{C}_{12} \mathrm{H}_{14} \mathrm{FN}$ : 191.1110; encontrado: 191.1106 .

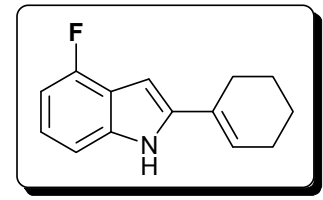

2-(1-Ciclohexenil)-4-fluoro-1 $H$-indol (28ad)

Sólido marrón.

P.f. $=90-92^{\circ} \mathrm{C}$.

${ }^{1}$ H RMN (300 MHz, CDCl $)$ ) $\delta=8.24(\mathrm{sa}, 1 \mathrm{H}), 7.13-7.00(\mathrm{~m}, 2 \mathrm{H}), 6.79-6.69(\mathrm{~m}, 1 \mathrm{H}), 6.51(\mathrm{~d}, J=1.7 \mathrm{~Hz}, 1 \mathrm{H})$, 6.17-6.11 (m, 1H), 2.50-2.42 (m, 2H), 2.29-2.21 (m, 2H), 1.85-1.75 (m, 2H), 1.74-1.64 (m, 2H) ppm.

${ }^{13}$ C RMN (75.4 MHz, $\left.\mathrm{CDCl}_{3}\right): \delta=156.4(\mathrm{~d}, J=246.2 \mathrm{~Hz}, \mathrm{C}), 139.6(\mathrm{C}), 138.8$ (d, $\left.J=11.5 \mathrm{~Hz}, \mathrm{C}\right), 128.9$ (C), $123.5(\mathrm{CH}), 122.4(\mathrm{~d}, J=7.7 \mathrm{~Hz}, \mathrm{CH}), 118.1(\mathrm{~d}, J=22.3 \mathrm{~Hz}, \mathrm{C}), 106.6(\mathrm{~d}, J=3.5 \mathrm{~Hz}, \mathrm{CH}), 104.6(\mathrm{~d}, J=$ 19.0 Hz, $\mathrm{CH}), 94.6(\mathrm{CH}), 26.1\left(\mathrm{CH}_{2}\right), 25.6\left(\mathrm{CH}_{2}\right), 22.6\left(\mathrm{CH}_{2}\right), 22.3\left(\mathrm{CH}_{2}\right) \mathrm{ppm}$.

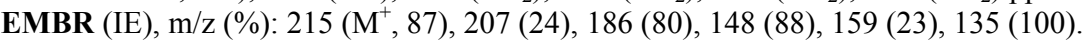

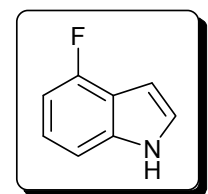

\section{4-Fluoro-1 $H$-indol (28ae)}

Líquido marrón.

$\mathrm{R}_{\mathrm{f}}=0.40$ (hexano / AcOEt, 5 / 1).

${ }^{1}$ H RMN (300 MHz, $\left.\mathrm{CDCl}_{3}\right): \delta=8.24(\mathrm{sa}, 1 \mathrm{H}), 7.21-7.09(\mathrm{~m}, 3 \mathrm{H}), 6.83(\mathrm{ddd}, J=10.3,7.3,1.0 \mathrm{~Hz}, 1 \mathrm{H}), 6.67(\mathrm{t}$, $J=2.6 \mathrm{~Hz}, 1 \mathrm{H}) \mathrm{ppm}$

${ }^{13} \mathbf{C}$ RMN (75.4 MHz, CDCl $)$ ): $\delta=156.6(\mathrm{~d}, J=246.5 \mathrm{~Hz}, \mathrm{C}), 138.5(\mathrm{~d}, J=11.5 \mathrm{~Hz}, \mathrm{C}), 124.2(\mathrm{CH}), 122.6(\mathrm{~d}, J=7.7$

$\mathrm{Hz}, \mathrm{CH}), 117.2(\mathrm{~d}, J=22.6 \mathrm{~Hz}, \mathrm{C}), 107.2(\mathrm{~d}, J=3.6 \mathrm{~Hz}, \mathrm{CH}), 104.6(\mathrm{~d}, J=19.0 \mathrm{~Hz}, \mathrm{CH}), 98.8(\mathrm{CH}) \mathrm{ppm}$.

EMBR (IE), m/z (\%): $135\left(\mathrm{M}^{+}, 100\right), 127$ (9), 107 (41).

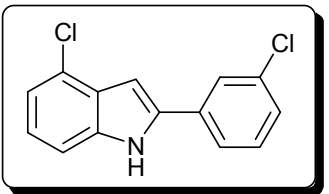

4-Cloro-2-(3-clorofenil)-1 $H$-indol (28bh)

Sólido marrón.

P.f. $=80-82^{\circ} \mathrm{C}$.

${ }^{1} \mathbf{H}$ RMN $\left(300 \mathrm{MHz}, \mathrm{CDCl}_{3}\right): \delta=8.44(\mathrm{sa}, 1 \mathrm{H}), 7.62(\mathrm{t}, J=1.6 \mathrm{~Hz}, 1 \mathrm{H}), 7.50(\mathrm{dt}, J=7.5,1.6 \mathrm{~Hz}, 1 \mathrm{H}), 7.36(\mathrm{t}, J$ $=7.5 \mathrm{~Hz}, 1 \mathrm{H}), 7.32-7.24(\mathrm{~m}, 2 \mathrm{H}), 7.17-7.08(\mathrm{~m}, 2 \mathrm{H}), 6.92(\mathrm{dd}, J=2.2,0.7 \mathrm{~Hz}, 1 \mathrm{H}) \mathrm{ppm}$. 
${ }^{13} \mathbf{C}$ RMN (75.4 MHz, $\mathrm{CDCl}_{3}$ ): $\delta=137.5(\mathrm{C}), 136.9(\mathrm{C}), 135.1(\mathrm{C}), 133.5(\mathrm{C}), 130.4(\mathrm{CH}), 128.1(\mathrm{CH}), 128.0$ (C), $126.1(\mathrm{C}), 125.3(\mathrm{CH}), 123.40(\mathrm{CH}), 123.38(\mathrm{CH}), 120.3(\mathrm{CH}), 109.7(\mathrm{CH}), 99.4(\mathrm{CH}) \mathrm{ppm}$.

EMBR (IE), m/z (\%): $265\left(\mathrm{M}^{+}+4,13\right), 263\left(\mathrm{M}^{+}+2,62\right), 261\left(\mathrm{M}^{+}, 100\right), 226$ (13), 199 (30), 190 (35), 89 (49).

EMAR calculado para $\mathrm{C}_{14} \mathrm{H}_{9} \mathrm{Cl}_{2} \mathrm{~N}$ : 261.0112; encontrado: 261.0112 .

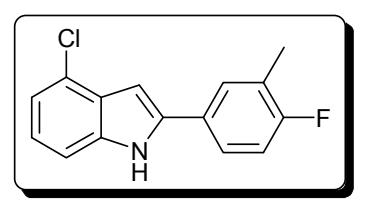

4-Cloro-2-(4-fluoro-3-metilfenil)-1 $H$-indol (28bi)

Sólido marrón.

P.f. $=114-116^{\circ} \mathrm{C}$.

${ }^{1}$ H RMN $\left(300 \mathrm{MHz}, \mathrm{CDCl}_{3}\right): \delta=8.41(\mathrm{sa}, 1 \mathrm{H}), 7.49(\mathrm{~d}, J=7.1 \mathrm{~Hz}, 1 \mathrm{H}), 7.46-7.39(\mathrm{~m}, 1 \mathrm{H}), 7.29-7.24(\mathrm{~m}, 1 \mathrm{H})$, $7.15-7.03(\mathrm{~m}, 3 \mathrm{H}), 6.84(\mathrm{~d}, J=0.9 \mathrm{~Hz}, 1 \mathrm{H}), 2.34(\mathrm{sa}, 3 \mathrm{H}) \mathrm{ppm}$.

${ }^{13} \mathbf{C}$ RMN (75.4 MHz, $\left.\mathrm{CDCl}_{3}\right): \delta=161.4(\mathrm{~d}, J=247.0 \mathrm{~Hz}, \mathrm{C}), 138.0(\mathrm{C}), 137.4(\mathrm{C}), 128.6(\mathrm{~d}, J=5.3 \mathrm{~Hz}, \mathrm{CH})$, 128.2 (C), 127.8 (d, $J=3.7 \mathrm{~Hz}, \mathrm{C}), 125.9$ (d, $J=7.2 \mathrm{~Hz}, \mathrm{C}), 125.7$ (C), 124.4 (d, $J=8.2 \mathrm{~Hz}, \mathrm{CH}), 122.9$ $(\mathrm{CH}), 120.1(\mathrm{CH}), 115.8(\mathrm{~d}, J=22.9 \mathrm{~Hz}, \mathrm{CH}), 109.6(\mathrm{CH}), 98.2(\mathrm{CH}), 14.8\left(\mathrm{~d}, J=3.4 \mathrm{~Hz}, \mathrm{CH}_{3}\right) \mathrm{ppm}$.

EMBR (IE), m/z (\%): $261\left(\mathrm{M}^{+}+2,49\right), 259\left(\mathrm{M}^{+}, 100\right), 223$ (14), 208 (13), 197 (14), 129 (16), 111 (23).

EMAR calculado para $\mathrm{C}_{15} \mathrm{H}_{11} \mathrm{ClFN}$ : 259.0564; encontrado: 259.0561 .

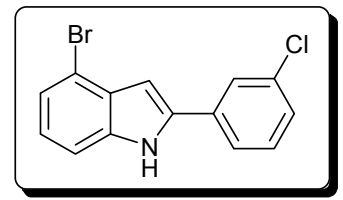

4-Bromo-2-(3-clorofenil)-1H-indol (28ch)

Sólido marrón.

P.f. $=89-91^{\circ} \mathrm{C}$.

${ }^{1} \mathbf{H}$ RMN $\left(300 \mathrm{MHz}, \mathrm{CDCl}_{3}\right): \delta=8.47(\mathrm{sa}, 1 \mathrm{H}), 7.67-7.64(\mathrm{~m}, 1 \mathrm{H}), 7.55(\mathrm{ddd}, J=7.6,2.8,1.3 \mathrm{~Hz}, 1 \mathrm{H})$, $7.43-7.27(\mathrm{~m}, 4 \mathrm{H}), 7.06(\mathrm{td}, J=8.1,1.2 \mathrm{~Hz}, 1 \mathrm{H}), 6.90-6.87(\mathrm{~m}, 1 \mathrm{H}) \mathrm{ppm}$.

${ }^{13} \mathbf{C}$ RMN (75.4 MHz, $\left.\mathrm{CDCl}_{3}\right): \delta=137.1(\mathrm{C}), 137.0(\mathrm{C}), 135.2(\mathrm{C}), 133.6(\mathrm{C}), 130.5(\mathrm{CH}), 129.9(\mathrm{C}), 128.2$ $(\mathrm{CH}), 125.4(\mathrm{CH}), 123.8(\mathrm{CH}), 123.5(\mathrm{CH}), 123.4(\mathrm{CH}), 114.9(\mathrm{C}), 110.3(\mathrm{CH}), 101.2(\mathrm{CH}) \mathrm{ppm}$.

EMBR (IE), m/z (\%): 309 (M+4, 23), $307\left(\mathrm{M}^{+}+2,100\right), 305\left(\mathrm{M}^{+}, 80\right), 226$ (16), $199(34), 190$ (74), 163 (60).

EMAR calculado para $\mathrm{C}_{14} \mathrm{H}_{9} \mathrm{BrClN}$ : 304.9607 ; encontrado: 304.9620 .

\section{C.3 Síntesis de los 4-fluoro-1 $H$-indoles 28aa,aj y 41 a partir de la trifluoroacetamida 3aa \\ C.3.1 Procedimiento para la preparación de los 4-fluoro-1H-indoles 28aa,aj a partir de 3aa}

Una mezcla de 3aa $(0.5 \mathrm{mmol})$, el correspondiente alquino $(0.75 \mathrm{mmol}), \mathrm{PdCl}_{2}\left(\mathrm{PPh}_{3}\right)_{2}(11$ $\mathrm{mg}, 3 \mathrm{~mol} \%$ ), $\mathrm{CuI}(5 \mathrm{mg}, 5 \mathrm{~mol} \%)$ y $\mathrm{Et}_{2} \mathrm{NH}(78 \mu \mathrm{L}, 0.75 \mathrm{mmol})$ en DMA anhidra $(2 \mathrm{~mL})$ se calienta bajo $\mathrm{N}_{2}$ a $80{ }^{\circ} \mathrm{C}$ durante 4 horas (la reacción se monitoriza por CG-EM). Se deja enfriar la mezcla de reacción a temperatura ambiente y se añaden $\mathrm{CH}_{2} \mathrm{Cl}_{2}(10 \mathrm{~mL})$ y $\mathrm{H}_{2} \mathrm{O}(10 \mathrm{~mL})$. La fase acuosa separada se extrae con $\mathrm{CH}_{2} \mathrm{Cl}_{2}(2 \times 10 \mathrm{~mL})$. La combinación de fases orgánicas se lava con $\mathrm{H}_{2} \mathrm{O}(2 \times$ $30 \mathrm{~mL}$ ). La fase orgánica se seca sobre $\mathrm{Na}_{2} \mathrm{SO}_{4}$ anhidro y se concentra a presión reducida. El residuo resultante se purifica mediante columna de cromatografía (hexano / AcOEt, 10 / 1) obteniéndose los 4-fluoro- $1 H$-indoles 28aa,aj. Los datos físicos y espectroscópicos de 28aa han sido detallados anteriormente. 


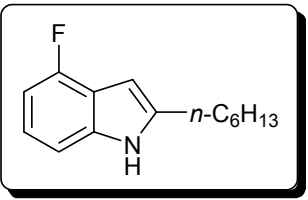

4-Fluoro-2-hexil-1H-indol (28aj)

Líquido marrón.

$\mathrm{R}_{\mathrm{f}}=0.45$ (hexano / AcOEt, $5 / 1$ ).

${ }^{1}$ H RMN (300 MHz, CDCl $)$ ): $\delta=7.93$ (sa, 1H), 7.15-6.93 (m, 2H), 6.79 (ddd, $\left.J=10.4,6.9,1.7 \mathrm{~Hz}, 1 \mathrm{H}\right), 6.35$ (dd, $J=$ 2.2, $0.8 \mathrm{~Hz}, 1 \mathrm{H}), 2.74(\mathrm{t}, J=7.5 \mathrm{~Hz}, 2 \mathrm{H}), 1.80-1.62(\mathrm{~m}, 2 \mathrm{H}), 1.47-1.21(\mathrm{~m}, 6 \mathrm{H}), 0.94(\mathrm{t}, J=6.9 \mathrm{~Hz}, 3 \mathrm{H}) \mathrm{ppm}$.

${ }^{13} \mathbf{C}$ RMN (75.4 MHz, $\left.\mathrm{CDCl}_{3}\right): \delta=155.8(\mathrm{~d}, J=245.1 \mathrm{~Hz}, \mathrm{C}), 140.2(\mathrm{C}), 138.5(\mathrm{~d}, J=11.9 \mathrm{~Hz}, \mathrm{C}), 121.3(\mathrm{~d}, J=$

$7.7 \mathrm{~Hz}, \mathrm{CH}), 117.8$ (d, $J=22.4 \mathrm{~Hz}, \mathrm{C}), 106.5(\mathrm{~d}, J=3.4 \mathrm{~Hz}, \mathrm{CH}), 104.5$ (d, $J=19.1 \mathrm{~Hz}, \mathrm{CH}), 95.4(\mathrm{CH})$,

$31.7\left(\mathrm{CH}_{2}\right), 29.14\left(\mathrm{CH}_{2}\right), 29.08\left(\mathrm{CH}_{2}\right), 28.2\left(\mathrm{CH}_{2}\right), 22.7\left(\mathrm{CH}_{2}\right), 14.2\left(\mathrm{CH}_{3}\right) \mathrm{ppm}$.

EMBR (IE), m/z (\%): 219 (M+27), 162 (32), 148 (100), 101 (9).

EMAR calculado para $\mathrm{C}_{14} \mathrm{H}_{18} \mathrm{FN}$ : 219.1423; encontrado: 219.1418 .

\section{C.3.2 Procedimiento para la sintesis de los 3-aril-4-fluoro-1H-indoles 2-sustituidos 41a-h}

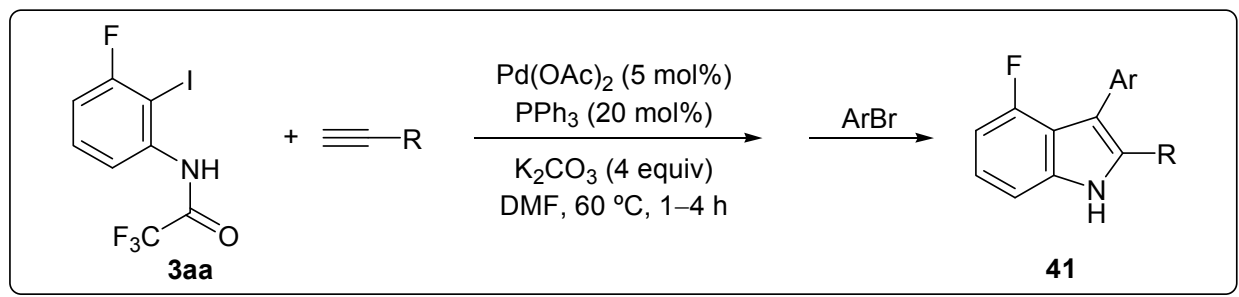

Una mezcla de 3aa (166 mg, 0.5 mmoles), $\mathrm{Pd}(\mathrm{OAc})_{2}(6 \mathrm{mg}, 5 \mathrm{~mol} \%), \mathrm{PPh}_{3}(26 \mathrm{mg}, 20$ mol\%), $\mathrm{K}_{2} \mathrm{CO}_{3}(276 \mathrm{mg}, 2 \mathrm{mmol})$ y el correspondiente alquino $(0.6 \mathrm{mmol})$ en DMF (3 $\left.\mathrm{mL}\right)$ se agita bajo $\mathrm{N}_{2}$ a $60{ }^{\circ} \mathrm{C}$ hasta la formación completa de la 2-alquinilacetamida (monitorizada por CG-EM). A continuación se adiciona el correspondiente bromuro de arilo $(0.6 \mathrm{mmol})$ y la mezcla de reacción se agita durante 15 horas a $60{ }^{\circ} \mathrm{C}$. Para la síntesis de 41c y 41d, el correspondiente bromuro de arilo se añade desde el principio de la reacción y la mezcla se agita bajo $\mathrm{N}_{2}$ a $60{ }^{\circ} \mathrm{C}$ hasta que la formación del correspondiente 4-fluoroindol 2,3-disustituido se completa (monitorizada por CG-EM). En ambos casos la mezcla de reacción resultante se hidroliza con $\mathrm{H}_{2} \mathrm{O}$ y la fase acuosa se extrae con AcOEt $(3 \times$ $15 \mathrm{~mL})$. La combinación de fases orgánicas se lava con $\mathrm{H}_{2} \mathrm{O}(2 \times 30 \mathrm{~mL})$ y se seca sobre $\mathrm{Na}_{2} \mathrm{SO}_{4}$ anhidro. El disolvente se elimina a presión reducida y el residuo se purifica mediante columna de cromatografía (hexano / AcOEt) para obtener los compuestos 41a-h.

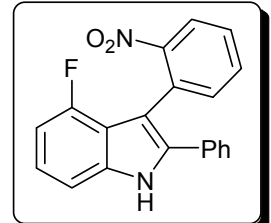

\section{2-Fenil-4-fluoro-3-(2-nitrofenil)-1H-indol (41a)}

Sólido naranja.

P.f. $=177-179^{\circ} \mathrm{C}$

${ }^{1} \mathbf{H}$ RMN $\left(300 \mathrm{MHz}, \mathrm{CDCl}_{3}\right): \delta=8.47(\mathrm{sa}, 1 \mathrm{H}), 8.10-8.05(\mathrm{~m}, 1 \mathrm{H}), 7.52-7.42(\mathrm{~m}, 2 \mathrm{H}), 7.38-7.34(\mathrm{~m}, 1 \mathrm{H}), 7.29$ $(\mathrm{s}, 4 \mathrm{H}), 7.16(\mathrm{t}, J=8.2 \mathrm{~Hz}, 2 \mathrm{H}), 7.13-7.06(\mathrm{~m}, 1 \mathrm{H}), 6.74(\mathrm{dd}, J=11.7,7.7 \mathrm{~Hz}, 1 \mathrm{H}) \mathrm{ppm}$.

${ }^{13}$ C RMN (75.4 MHz, $\left.\mathrm{CDCl}_{3}\right): \delta=156.7$ (d, $\left.J=247.1 \mathrm{~Hz}, \mathrm{C}\right), 150.0(\mathrm{C}), 138.2(\mathrm{~d}, J=10.4 \mathrm{~Hz}, \mathrm{C}), 135.2(\mathrm{~d}, J=$ $0.9 \mathrm{~Hz}, \mathrm{C}), 134.6(\mathrm{CH}), 132.6(\mathrm{CH}), 131.4(\mathrm{C}), 130.7(\mathrm{~d}, J=0.6 \mathrm{~Hz}, \mathrm{C}), 129.0(2 \times \mathrm{CH}), 128.4(\mathrm{CH})$, $128.13(2 \times \mathrm{CH}), 128.06(\mathrm{CH}), 124.8(\mathrm{CH}), 123.3(\mathrm{~d}, J=8.0 \mathrm{~Hz}, \mathrm{CH}), 116.9(\mathrm{~d}, J=18.6 \mathrm{~Hz}, \mathrm{C}), 108.4(\mathrm{~d}, J$ $=1.7 \mathrm{~Hz}, \mathrm{C}), 107.5(\mathrm{~d}, J=3.7 \mathrm{~Hz}, \mathrm{CH}), 105.9(\mathrm{~d}, J=19.2 \mathrm{~Hz}, \mathrm{CH}) \mathrm{ppm}$. 
EMBR (IE), m/z (\%): $332\left(\mathrm{M}^{+}, 44\right), 285$ (15), 105 (100), 77 (16).

EMAR calculado para $\mathrm{C}_{20} \mathrm{H}_{13} \mathrm{FN}_{2} \mathrm{O}_{2}: 332.0961$; encontrado: 332.0949 .

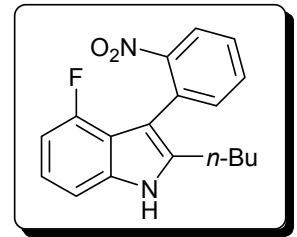

2-Butil-4-fluoro-3-(2-nitrofenil)-1H-indol (41b)

Sólido naranja.

P.f. $=85-87^{\circ} \mathrm{C}$.

${ }^{1}$ H RMN (300 MHz, $\left.\mathrm{CDCl}_{3}\right): \delta=8.19(\mathrm{sa}, 1 \mathrm{H}), 8.08-8.03(\mathrm{~m}, 1 \mathrm{H}), 7.65-7.58(\mathrm{~m}, 1 \mathrm{H}), 7.52-7.45(\mathrm{~m}, 2 \mathrm{H})$, $7.12-7.08(\mathrm{~m}, 1 \mathrm{H}), 7.08-7.00(\mathrm{~m}, 1 \mathrm{H}), 6.70(\mathrm{ddd}, J=11.1,7.5,1.2 \mathrm{~Hz}, 1 \mathrm{H}), 2.71-2.54(\mathrm{~m}, 2 \mathrm{H})$, $1.64-1.53(\mathrm{~m}, 2 \mathrm{H}), 1.36-1.21(\mathrm{~m}, 2 \mathrm{H}), 0.84(\mathrm{t}, J=7.3 \mathrm{~Hz}, 3 \mathrm{H}) \mathrm{ppm}$.

${ }^{13} \mathbf{C} \mathbf{R M N}\left(75.4 \mathrm{MHz}, \mathrm{CDCl}_{3}\right): \delta=156.2(\mathrm{~d}, J=245.7 \mathrm{~Hz}, \mathrm{C}), 150.0(\mathrm{C}), 137.8(\mathrm{~d}, J=11.0 \mathrm{~Hz}, \mathrm{C}), 137.2(\mathrm{C})$, 134.2 (CH), $132.3(\mathrm{CH}), 130.5(\mathrm{C}), 127.8(\mathrm{CH}), 124.5(\mathrm{CH}), 122.1(\mathrm{~d}, J=7.8 \mathrm{~Hz}, \mathrm{CH}), 116.2(\mathrm{~d}, J=18.8$ $\mathrm{Hz}, \mathrm{C}), 107.6$ (d, $J=1.6 \mathrm{~Hz}, \mathrm{C}), 107.0$ (d, $J=3.5 \mathrm{~Hz}, \mathrm{CH}), 105.3$ (d, $J=19.3 \mathrm{~Hz}, \mathrm{CH}), 31.5\left(\mathrm{CH}_{2}\right), 25.8$ $\left(\mathrm{CH}_{2}\right), 22.3\left(\mathrm{CH}_{2}\right), 13.8\left(\mathrm{CH}_{3}\right) \mathrm{ppm}$.

IR $\left(\mathrm{KBr}, \mathrm{cm}^{-1}\right): 3411,2953,2927,1519,1351,1046,779,753,740$.

EMBR (IE), m/z (\%): $312\left(\mathrm{M}^{+}, 100\right), 253$ (86), 228 (71), 199 (25).

EMAR calculado para $\mathrm{C}_{18} \mathrm{H}_{17} \mathrm{FN}_{2} \mathrm{O}_{2}: 312.1274$; encontrado: 312.1276 .

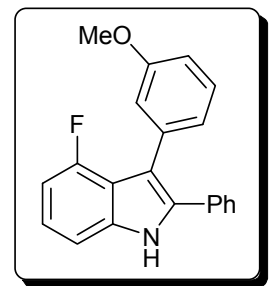

2-Fenil-4-fluoro-3-(3-metoxifenil)-1H-indol (41c)

Sólido marrón.

P.f. $=120-122^{\circ} \mathrm{C}$.

${ }^{1}$ H RMN (300 MHz, $\left.\mathrm{CDCl}_{3}\right): \delta=8.39$ (s, 1H), 7.41-7.24 (m, 5H), 7.24-7.10 (m, 3H), 7.03 (s, 2H), 6.92-6.77 $(\mathrm{m}, 2 \mathrm{H}), 3.76(\mathrm{~s}, 3 \mathrm{H}) \mathrm{ppm}$.

${ }^{13}$ C RMN (75.4 MHz, $\left.\mathrm{CDCl}_{3}\right): \delta=159.2(\mathrm{C}), 157.1$ (d, $\left.J=249.0 \mathrm{~Hz}, \mathrm{C}\right), 138.3(\mathrm{~d}, J=10.8 \mathrm{~Hz}, \mathrm{C}), 136.3$ (C), $134.7(\mathrm{C}), 132.2(\mathrm{C}), 128.9(\mathrm{CH}), 128.7(2 \times \mathrm{CH}), 128.4(2 \times \mathrm{CH}), 128.0(\mathrm{CH}), 123.6(\mathrm{~d}, J=1.9 \mathrm{~Hz}, \mathrm{CH})$, $123.0(\mathrm{~d}, J=8.0 \mathrm{~Hz}, \mathrm{CH}), 117.2(\mathrm{~d}, J=18.0 \mathrm{~Hz}, \mathrm{C}), 116.3(\mathrm{~d}, J=2.6 \mathrm{~Hz}, \mathrm{CH}), 113.1(\mathrm{~d}, J=3.0 \mathrm{~Hz}, \mathrm{C})$, $112.6(\mathrm{CH}), 107.1(\mathrm{~d}, J=3.7 \mathrm{~Hz}, \mathrm{CH}), 105.9(\mathrm{~d}, J=20.1 \mathrm{~Hz}, \mathrm{CH}), 55.2\left(\mathrm{CH}_{3}\right) \mathrm{ppm}$.

EMBR (IE), m/z (\%): $317\left(\mathrm{M}^{+}, 100\right), 285$ (10), 272 (20), 259 (4).

EMAR calculado para $\mathrm{C}_{21} \mathrm{H}_{16} \mathrm{FNO}$ : 317.1216 ; encontrado: 317.1216 .

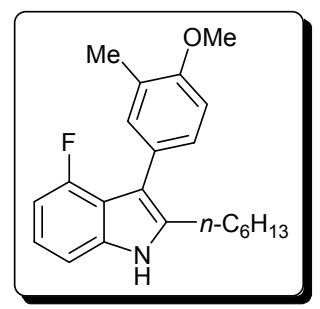

4-Fluoro-2-hexil-3-(3-metil-4-metoxifenil)-1 $H$-indol (41d)

Sólido marrón.

P.f. $=211-213^{\circ} \mathrm{C}$.

${ }^{1}$ H RMN (300 MHz, $\left.\mathrm{CDCl}_{3}\right): \delta=8.06(\mathrm{sa}, 1 \mathrm{H}), 7.27(\mathrm{~s}, 2 \mathrm{H}), 7.15-7.02(\mathrm{~m}, 2 \mathrm{H}), 6.92(\mathrm{~d}, J=8.6 \mathrm{~Hz}, 1 \mathrm{H}), 6.77$ $(\mathrm{dd}, J=10.0,7.3 \mathrm{~Hz}, 1 \mathrm{H}), 3.91(\mathrm{~s}, 3 \mathrm{H}), 2.76(\mathrm{t}, J=7.7 \mathrm{~Hz} 2 \mathrm{H}), 2.32(\mathrm{~s}, 3 \mathrm{H}), 1.71-1.61(\mathrm{~m}, 2 \mathrm{H})$, $1.40-1.20(\mathrm{~m}, 6 \mathrm{H}), 0.90(\mathrm{t}, J=6.6 \mathrm{~Hz}, 3 \mathrm{H}) \mathrm{ppm}$.

${ }^{13} \mathbf{C}$ RMN (75.4 MHz, $\left.\mathrm{CDCl}_{3}\right): \delta=156.6(\mathrm{~d}, J=247.4 \mathrm{~Hz}, \mathrm{C}), 156.4(\mathrm{C}), 137.9$ (d, $\left.J=11.4 \mathrm{~Hz}, \mathrm{C}\right), 136.3$ (C), $132.9(\mathrm{~d}, J=1.9 \mathrm{~Hz}, \mathrm{CH}), 130.5(\mathrm{~d}, J=2.1 \mathrm{~Hz}, \mathrm{C}), 128.8$ (d, $J=1.9 \mathrm{~Hz}, \mathrm{CH}), 127.9(\mathrm{C}), 127.1(\mathrm{C}), 125.8$ 
$(\mathrm{CH}), 121.6(\mathrm{~d}, J=8.0 \mathrm{~Hz}, \mathrm{CH}), 116.6(\mathrm{~d}, J=18.1 \mathrm{~Hz}, \mathrm{C}), 112.4(\mathrm{~d}, J=2.6 \mathrm{~Hz}, \mathrm{C}), 109.5(\mathrm{CH}), 106.5(\mathrm{~d}$, $J=3.5 \mathrm{~Hz}, \mathrm{CH}), 105.2(\mathrm{~d}, J=20.2 \mathrm{~Hz}, \mathrm{CH}), 55.4\left(\mathrm{CH}_{3}\right), 31.6\left(\mathrm{CH}_{2}\right), 29.9\left(\mathrm{CH}_{2}\right), 29.1\left(\mathrm{CH}_{2}\right), 26.1\left(\mathrm{CH}_{2}\right)$, $22.7\left(\mathrm{CH}_{2}\right), 16.5\left(\mathrm{CH}_{3}\right), 14.2\left(\mathrm{CH}_{3}\right) \mathrm{ppm}$.

EMBR (IE), m/z (\%): 339 (M+1 100), 295 (21), 268 (43), 253 (12), 237 (23), 224 (36).

EMAR calculado para $\mathrm{C}_{22} \mathrm{H}_{26} \mathrm{FNO}$ : 339.1998; encontrado: 339.1996.

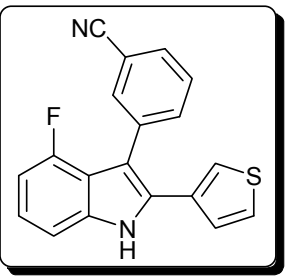

3-[4-Fluoro-2-(3-tienil)-1 $H$-indol-3-il]benzonitrilo (41e)

Sólido marrón.

${ }^{1}$ H RMN (300 MHz, DMSO-d $\left.{ }_{6}\right): \delta=11.95(\mathrm{sa}, 1 \mathrm{H}), 7.82-7.73(\mathrm{~m}, 2 \mathrm{H}), 7.69$ (ddd, $\left.J=7.8,3.1,1.6 \mathrm{~Hz}, 1 \mathrm{H}\right)$, $7.62-7.49(\mathrm{~m}, 3 \mathrm{H}), 7.27(\mathrm{~d}, J=8.0 \mathrm{~Hz}, 1 \mathrm{H}), 7.11(\mathrm{td}, J=8.0,5.1 \mathrm{~Hz}, 1 \mathrm{H}), 6.92(\mathrm{dd}, J=3.9,2.6 \mathrm{~Hz}, 1 \mathrm{H})$, $6.77(\mathrm{dd}, J=11.8,7.3 \mathrm{~Hz}, 1 \mathrm{H}) \mathrm{ppm}$.

${ }^{13}$ C RMN (75.4 MHz, DMSO-d $\left.{ }_{6}\right): \delta=155.9(\mathrm{~d}, J=245.2 \mathrm{~Hz}, \mathrm{C}), 138.3(\mathrm{~d}, J=10.8 \mathrm{~Hz}, \mathrm{C}), 136.7(\mathrm{C}), 135.7$ (C), $134.0(\mathrm{~d}, J=1.9 \mathrm{~Hz}, \mathrm{C}), 132.0(\mathrm{CH}), 131.3(\mathrm{C}), 130.4(\mathrm{CH}), 129.3(\mathrm{CH}), 127.0(\mathrm{CH}), 126.8(\mathrm{CH})$, $123.8(\mathrm{CH}), 122.5(\mathrm{~d}, J=7.9 \mathrm{~Hz}, \mathrm{C}), 118.9(\mathrm{CH}), 116.0(\mathrm{~d}, J=17.7 \mathrm{~Hz}, \mathrm{C}), 111.2(\mathrm{CH}), 108.9(\mathrm{~d}, J=2.7$ $\mathrm{Hz}, \mathrm{C}), 108.0$ (d, $J=3.4 \mathrm{~Hz}, \mathrm{CH}), 104.9(\mathrm{~d}, J=19.4 \mathrm{~Hz}, \mathrm{CH}) \mathrm{ppm}$.

EMBR (IE), m/z (\%): $318\left(\mathrm{M}^{+}, 100\right), 285$ (11), 273 (9).

EMAR calculado para $\mathrm{C}_{19} \mathrm{H}_{11} \mathrm{FN}_{2} \mathrm{~S}: 318.0627$; encontrado: 318.0621 .

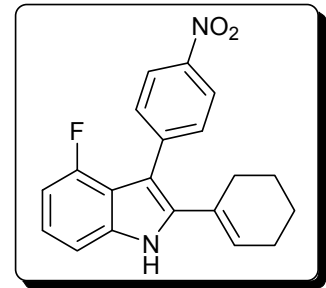

\section{2-(1-Ciclohexenil)-4-fluoro-l-3-(4-nitrofenil)-1H-indol (41f)}

Sólido naranja.

P.f. $=239-241^{\circ} \mathrm{C}$.

${ }^{1}$ H RMN (300 MHz, DMSO-d $\left.{ }_{6}\right): \delta=11.7(\mathrm{~s}, 1 \mathrm{H}), 8.19(\mathrm{~d}, J=8.1 \mathrm{~Hz}, 2 \mathrm{H}), 7.62(\mathrm{~d}, J=7.5 \mathrm{~Hz}, 2 \mathrm{H}), 7.21(\mathrm{~d}, J=$ $8.1 \mathrm{~Hz}, 1 \mathrm{H}), 7.07(\mathrm{dd}, J=12.7,7.7 \mathrm{~Hz}, 1 \mathrm{H}), 6.76(\mathrm{dd}, J=11.9,7.7 \mathrm{~Hz}, 1 \mathrm{H}), 5.88(\mathrm{~s}, 1 \mathrm{H}), 2.19-1.96(\mathrm{~m}$, $4 \mathrm{H}), 1.65-1.46(\mathrm{~m}, 4 \mathrm{H}) \mathrm{ppm}$.

${ }^{13}$ C RMN (75.4 MHz, DMSO-d $\left.)_{6}\right): \delta=155.7$ (d, $\left.J=245.0 \mathrm{~Hz}, \mathrm{C}\right), 145.3(\mathrm{C}), 143.4(\mathrm{C}), 139.2(\mathrm{C}), 138.0(\mathrm{~d}, J=$ $11.0 \mathrm{~Hz}, \mathrm{C}), 131.1(\mathrm{~d}, J=3.0 \mathrm{~Hz}, 2 \times \mathrm{CH}), 130.7(\mathrm{CH}), 129.0(\mathrm{CH}), 122.9(2 \times \mathrm{CH}), 122.2(\mathrm{~d}, J=8.0 \mathrm{~Hz}$, C), $115.1(\mathrm{~d}, J=17.7 \mathrm{~Hz}, \mathrm{C}), 108.3(\mathrm{~d}, J=2.8 \mathrm{~Hz}, \mathrm{C}), 108.0(\mathrm{~d}, J=3.2 \mathrm{~Hz}, \mathrm{CH}), 105.0(\mathrm{~d}, J=20.0 \mathrm{~Hz}$, $\mathrm{CH}), 27.5\left(\mathrm{CH}_{2}\right), 25.2\left(\mathrm{CH}_{2}\right), 22.2\left(\mathrm{CH}_{3}\right), 21.4\left(\mathrm{CH}_{3}\right) \mathrm{ppm}$.

EMBR (IE), m/z (\%): $336\left(\mathrm{M}^{+}, 100\right), 290$ (35), 261 (24), 248 (29), 235 (21), 222 (10).

EMAR calculado para $\mathrm{C}_{20} \mathrm{H}_{17} \mathrm{FN}_{2} \mathrm{O}_{2}: 336.1274$; encontrado: 336.1274 .

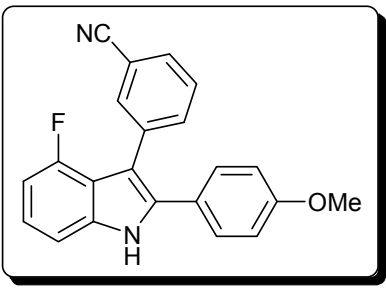

3-[4-Fluoro-2-(4-metoxifenil)-1 $H$-indol-3-il]benzonitrilo (41g) Sólido marrón.

P.f. $=186-188^{\circ} \mathrm{C}$. 
${ }^{1}$ H RMN $\left(300 \mathrm{MHz}, \mathrm{CDCl}_{3}\right): \delta=8.43(\mathrm{sa}, 1 \mathrm{H}), 7.69(\mathrm{~d}, J=1.7 \mathrm{~Hz}, 1 \mathrm{H}), 7.67-7.62(\mathrm{~m}, 1 \mathrm{H}), 7.56-7.52(\mathrm{~m}, 1 \mathrm{H})$, $7.43(\mathrm{t}, J=7.8 \mathrm{~Hz}, 1 \mathrm{H}), 7.25-7.19(\mathrm{~m}, 3 \mathrm{H}), 7.18-7.10(\mathrm{~m}, 1 \mathrm{H}), 6.87(\mathrm{~d}, J=8.9 \mathrm{~Hz}, 2 \mathrm{H}), 6.83-6.78(\mathrm{~m}$, $1 \mathrm{H}), 3.82(\mathrm{~s}, 3 \mathrm{H}) \mathrm{ppm}$.

${ }^{13}$ C RMN (75.4 MHz, $\left.\mathrm{CDCl}_{3}\right): \delta=159.9(\mathrm{C}), 156.7(\mathrm{~d}, J=248.0 \mathrm{~Hz}, \mathrm{C}), 138.2(\mathrm{~d}, J=10.7 \mathrm{~Hz}, \mathrm{C}), 136.7$ (C), $135.6(\mathrm{~d}, J=2.4 \mathrm{~Hz}, \mathrm{CH}), 134.4(\mathrm{~d}, J=2.6 \mathrm{~Hz}, \mathrm{CH}), 130.0(\mathrm{CH}), 129.8(2 \times \mathrm{CH}), 128.8(\mathrm{CH}), 123.7(\mathrm{C})$, $123.1(\mathrm{~d}, J=8.0 \mathrm{~Hz}, \mathrm{CH}), 119.3(\mathrm{C}), 116.8(\mathrm{~d}, J=18.1 \mathrm{~Hz}, \mathrm{C}), 114.6(2 \times \mathrm{CH}), 112.1(\mathrm{C}), 110.1(\mathrm{C}), 107.2$ $(\mathrm{d}, J=3.7 \mathrm{~Hz}, \mathrm{CH}), 106.2(\mathrm{~d}, J=20.0 \mathrm{~Hz}, \mathrm{CH}), 55.4\left(\mathrm{CH}_{3}\right) \mathrm{ppm}$.

EMBR (IE), m/z (\%): $342\left(\mathrm{M}^{+}, 100\right), 297$ (17), 272 (4).

EMAR calculado para $\mathrm{C}_{22} \mathrm{H}_{15} \mathrm{FN}_{2} \mathrm{O}: 342.1168$; encontrado: 342.1172 .

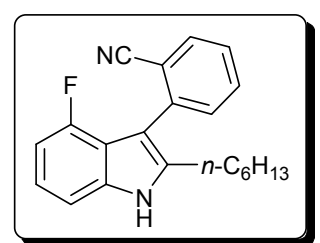

\section{2-[4-Fluoro-2-hexil-1 H-indol-3-il]benzonitrilo (41h)}

Sólido marrón.

P.f. $=100-102^{\circ} \mathrm{C}$.

${ }^{1}$ H RMN $\left(300 \mathrm{MHz}, \mathrm{CDCl}_{3}\right): \delta=8.39(\mathrm{sa}, 1 \mathrm{H}), 7.76(\mathrm{~d}, J=7.5,1.4 \mathrm{~Hz}, 1 \mathrm{H}), 7.62(\mathrm{td}, J=7.5,1.4 \mathrm{~Hz}, 1 \mathrm{H})$, $7.56-7.49(\mathrm{~m}, 1 \mathrm{H}), 7.43(\mathrm{td}, J=7.5,1.4 \mathrm{~Hz}, 1 \mathrm{H}), 7.14-7.00(\mathrm{~m}, 2 \mathrm{H}), 6.76(\mathrm{ddd}, J=11.2,7.5,1.1 \mathrm{~Hz}, 1 \mathrm{H})$, $2.80-2.57(\mathrm{~m}, 2 \mathrm{H}), 1.73-1.46(\mathrm{~m}, 2 \mathrm{H}), 1.34-1.08(\mathrm{~m}, 6 \mathrm{H}), 0.82(\mathrm{t}, J=6.9 \mathrm{~Hz}, 3 \mathrm{H}) \mathrm{ppm}$.

${ }^{13} \mathbf{C}$ RMN (75.4 MHz, $\left.\mathrm{CDCl}_{3}\right): \delta=156.2(\mathrm{~d}, J=246.6 \mathrm{~Hz}, \mathrm{C}), 139.7(\mathrm{C}), 138.1(\mathrm{C}), 137.8(\mathrm{~d}, J=10.9 \mathrm{~Hz}, \mathrm{C})$, $132.7(\mathrm{CH}), 132.4(\mathrm{~d}, J=1.7 \mathrm{~Hz}, \mathrm{CH}), 132.1(\mathrm{CH}), 127.1(\mathrm{CH}), 122.3(\mathrm{~d}, J=7.9 \mathrm{~Hz}, \mathrm{CH}), 119.1(\mathrm{C})$, $116.4(\mathrm{~d}, J=18.5 \mathrm{~Hz}, \mathrm{C}), 114.2(\mathrm{C}), 108.8(\mathrm{~d}, J=2.0 \mathrm{~Hz}, \mathrm{C}), 107.0(\mathrm{~d}, J=3.6 \mathrm{~Hz}, \mathrm{CH}), 105.6(\mathrm{~d}, J=19.5$ $\mathrm{Hz}, \mathrm{CH}), 31.5\left(\mathrm{CH}_{2}\right), 29.3\left(\mathrm{CH}_{2}\right), 28.9\left(\mathrm{CH}_{2}\right), 26.4\left(\mathrm{CH}_{2}\right), 22.6\left(\mathrm{CH}_{2}\right), 14.1\left(\mathrm{CH}_{3}\right) \mathrm{ppm}$.

EMBR (IE), m/z (\%): $320\left(\mathrm{M}^{+}, 74\right), 263$ (22), 249 (100), 229 (22), 84 (18).

EMAR calculado para $\mathrm{C}_{21} \mathrm{H}_{21} \mathrm{FN}_{2}: 320.1689$; encontrado: 320.1691 .

\section{C.3.3 Procedimiento para la sintesis de los 3-aril-4-fluoro-1H-indoles 2-sustituidos 41i,j}

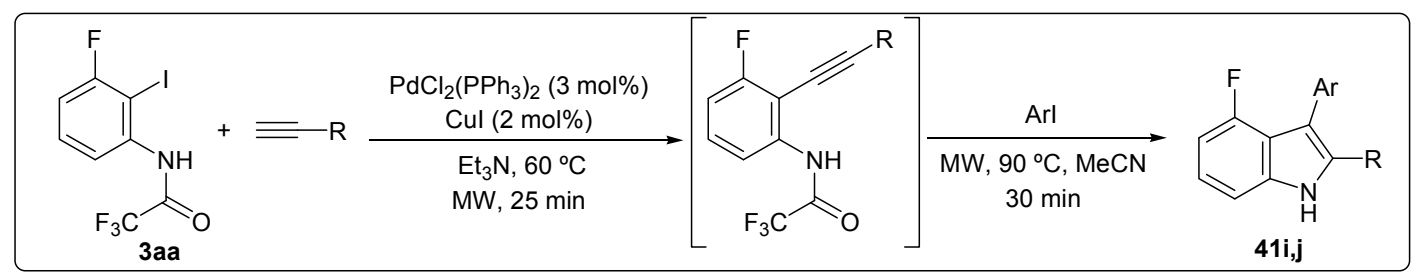

En un tubo sellado bajo $\mathrm{N}_{2}$ se adiciona una mezcla de 3aa (100 mg, 0.3 mmoles), $\mathrm{PdCl}_{2}\left(\mathrm{PPh}_{3}\right)_{2}(6.3 \mathrm{mg}, 3 \mathrm{~mol} \%)$, CuI (1.4 mg, $\left.2 \mathrm{~mol} \%\right)$ y el correspondiente alquino $(0.36 \mathrm{mmol}) \mathrm{en}$ $\mathrm{Et}_{3} \mathrm{~N}(1.5 \mathrm{~mL})$. La mezcla resultante se calienta a $60^{\circ} \mathrm{C}$ en un microondas (CEM, Discover S-Class) durante 25 minutos. A continuación se adiciona el correspondiente yoduro de arilo $(0.36 \mathrm{mmoles}) \mathrm{y}$ $\mathrm{MeCN}(1.5 \mathrm{~mL})$ y la mezcla se irradia durante 30 minutos a $90{ }^{\circ} \mathrm{C}$. La reacción se enfría a temperatura ambiente y se adiciona $\operatorname{AcOEt}(10 \mathrm{~mL})$ y $\mathrm{H}_{2} \mathrm{O}(10 \mathrm{~mL})$. La fase acuosa separada se extrae con AcOEt $(2 \times 10 \mathrm{~mL})$. La combinación de fases orgánicas se seca sobre $\mathrm{Na}_{2} \mathrm{SO}_{4}$ anhidro y el disolvente se elimina a presión reducida. El crudo de reacción se purifica mediante columna de cromatografía (hexano / AcOEt, 10 / 1) para obtener los compuestos 41i,j. 


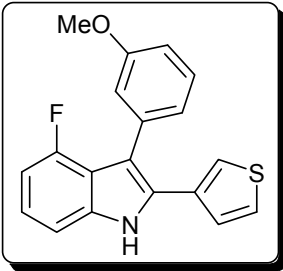

4-Fluoro-3-(3-metoxifenil)-2-(3-tienil)-1H-indol (41i)

Líquido marrón.

$\mathrm{R}_{\mathrm{f}}=0.50$ (hexano / AcOEt, 5 / 1).

${ }^{1} \mathbf{H}$ RMN (400 MHz, $\left.\mathrm{CDCl}_{3}\right): \delta=8.45(\mathrm{sa}, 1 \mathrm{H}), 7.31(\mathrm{~d}, J=8.0 \mathrm{~Hz}, 1 \mathrm{H}), 7.26-7.22(\mathrm{~m}, 2 \mathrm{H}), 7.18-7.05(\mathrm{~m}, 4 \mathrm{H})$, 6.98 (ddd, $J=4.2,2.2,0.5 \mathrm{~Hz}, 1 \mathrm{H}), 6.95-6.90(\mathrm{~m}, 1 \mathrm{H}), 6.84-6.77(\mathrm{~m}, 1 \mathrm{H}), 3.79(\mathrm{~s}, 3 \mathrm{H}) \mathrm{ppm}$.

${ }^{13}$ C RMN (100.6 MHz, $\left.\mathrm{CDCl}_{3}\right): \delta=159.3(\mathrm{C}), 157.0(\mathrm{~d}, J=248.9 \mathrm{~Hz}, \mathrm{C}), 138.1$ (d, $\left.J=10.7 \mathrm{~Hz}, \mathrm{C}\right), 136.4(\mathrm{C})$, $132.9(\mathrm{C}), 130.5(\mathrm{C}), 129.0(\mathrm{CH}), 127.0(\mathrm{CH}), 126.1(\mathrm{C}), 126.0(\mathrm{CH}), 123.6(\mathrm{~d}, J=1.7 \mathrm{~Hz}, \mathrm{CH}), 123.0(\mathrm{~d}$, $J=7.9 \mathrm{~Hz}, \mathrm{CH}), 122.4(\mathrm{CH}), 117.4(\mathrm{~d}, J=18.0 \mathrm{~Hz}, \mathrm{C}), 116.3(\mathrm{~d}, J=2.1 \mathrm{~Hz}, \mathrm{CH}), 112.9(\mathrm{CH}), 107.0(\mathrm{~d}, J$ $=3.7 \mathrm{~Hz}, \mathrm{CH}), 105.8(\mathrm{~d}, J=19.9 \mathrm{~Hz}, \mathrm{CH}), 55.3\left(\mathrm{CH}_{3}\right) \mathrm{ppm}$.

EMBR (IE), m/z (\%): 323 (M+100), 291 (14), 280 (17), 246 (9), 235 (8).

EMAR calculado para $\mathrm{C}_{19} \mathrm{H}_{14}$ FNOS: 323.0780; encontrado: 323.0789 .

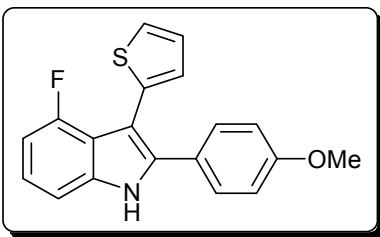

4-Fluoro-2-(4-metoxifenil)-3-(2-tienil)-1H-indol (41j)

Sólido marrón.

P.f. $=96-98^{\circ} \mathrm{C}$

${ }^{1} \mathbf{H}$ RMN $\left(300 \mathrm{MHz}, \mathrm{CDCl}_{3}\right): \delta=8.35(\mathrm{sa}, 1 \mathrm{H}), 7.61-7.54(\mathrm{~m}, 2 \mathrm{H}), 7.39-7.24(\mathrm{~m}, 1 \mathrm{H}), 7.20-7.03(\mathrm{~m}, 3 \mathrm{H}), 6.98$ $(\mathrm{d}, J=8.8 \mathrm{~Hz}, 2 \mathrm{H}), 6.87-6.75(\mathrm{~m}, 2 \mathrm{H}), 3.85(\mathrm{~s}, 3 \mathrm{H}) \mathrm{ppm}$.

${ }^{13}$ C RMN (75.4 MHz, $\left.\mathrm{CDCl}_{3}\right): \delta=159.6(\mathrm{C}), 156.3(\mathrm{~d}, J=246.3 \mathrm{~Hz}, \mathrm{C}), 139.2(\mathrm{~d}, J=11.4 \mathrm{~Hz}, \mathrm{C}), 138.1(\mathrm{C})$, $129.6(\mathrm{~d}, J=4.6 \mathrm{~Hz}, \mathrm{CH}), 128.0(\mathrm{C}), 126.7(2 \times \mathrm{CH}), 126.1(\mathrm{C}), 124.7(\mathrm{C}), 122.3(\mathrm{~d}, J=7.6 \mathrm{~Hz}, \mathrm{CH}), 118.6$ $(\mathrm{d}, J=22.4 \mathrm{~Hz} \mathrm{C}), 114.6(2 \times \mathrm{CH}), 114.2(\mathrm{CH}), 107.0(\mathrm{~d}, J=3.5 \mathrm{~Hz}, \mathrm{CH}), 105.0(\mathrm{~d}, J=19.0 \mathrm{~Hz}, \mathrm{CH}), 94.7$ $(\mathrm{CH}), 55.5\left(\mathrm{CH}_{3}\right) \mathrm{ppm}$.

EMAR calculado para $\mathrm{C}_{19} \mathrm{H}_{14} \mathrm{FNOS}$ : 323.0780; encontrado: 323.0792.

\section{C.4 Síntesis de los 3-feniltio-4-halo-1H-indoles 43}

C.4.1 Procedimiento general para la sintesis de 3-(feniltio)-4-halo-1H-indoles 2-sustituidos $\mathbf{4 3 a , b}$ a partir de 25aa,ba

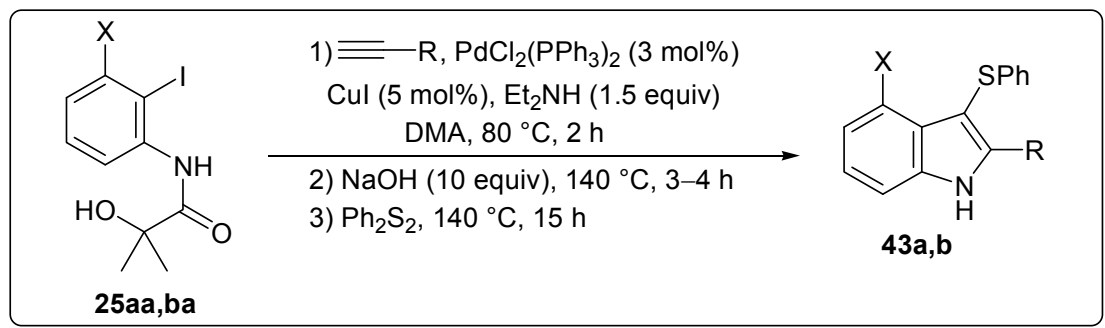

Una mezcla de la correspondiente anilida 25aa ó 25ba $(0.4 \mathrm{mmol})$, alquino $(0.6 \mathrm{mmol})$, $\mathrm{PdCl}_{2}\left(\mathrm{PPh}_{3}\right)_{2}(8 \mathrm{mg}, 3 \mathrm{~mol} \%)$, CuI (4 mg, $\left.5 \mathrm{~mol} \%\right)$ y Et ${ }_{2} \mathrm{NH}(63 \mu \mathrm{L}, 0.6 \mathrm{mmol})$ en DMA $(2 \mathrm{~mL}) \mathrm{se}$ agita bajo $\mathrm{N}_{2}$ a $80^{\circ} \mathrm{C}$ durante 2 horas. A continuación, se añade un exceso de $\mathrm{NaOH}$ en polvo (160 
$\mathrm{mg}, 4 \mathrm{mmol}$ ). La mezcla resultante se calienta a reflujo bajo $\mathrm{N}_{2}$ a $140{ }^{\circ} \mathrm{C}$ durante 3 horas (hasta que la ciclación se completa monitorizada por CG-EM). Entonces, se añade $\mathrm{Ph}_{2} \mathrm{~S}_{2}(105 \mathrm{mg}, 0.48 \mathrm{mmol})$ a la mezcla y la reacción se agita durante toda la noche a $140{ }^{\circ} \mathrm{C}$. Se deja que la reacción se enfríe a temperatura ambiente y se añaden $\mathrm{CH}_{2} \mathrm{Cl}_{2}(10 \mathrm{~mL})$ y $\mathrm{HCl}(10 \mathrm{~mL}$ de una disolución $0.5 \mathrm{M})$. La fase acuosa separada se extrae con $\mathrm{CH}_{2} \mathrm{Cl}_{2}(2 \times 10 \mathrm{~mL})$. La combinación de fases orgánicas se lava con $\mathrm{H}_{2} \mathrm{O}(2 \times 30 \mathrm{~mL})$. La fase orgánica se seca sobre $\mathrm{Na}_{2} \mathrm{SO}_{4}$ anhidro y se concentra a presión reducida. El residuo resultante se purifica mediante columna de cromatografía de sílica gel (hexano / AcOEt) obteniéndose los compuestos 43a,b.

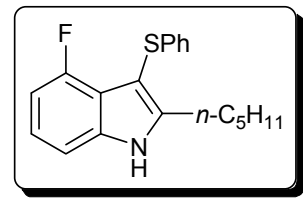

3-(Feniltio)-4-fluoro-2-pentil-1 $H$-indol (43a)

Sólido marrón.

P.f. $=78-80^{\circ} \mathrm{C}$.

${ }^{1} \mathbf{H}$ RMN (300 MHz, CDCl $\left.)_{3}\right): \delta=8.50(\mathrm{sa}, 1 \mathrm{H}), 7.26-7.02(\mathrm{~m}, 7 \mathrm{H}), 6.76(\mathrm{ddd}, J=10.9,7.5,1.1 \mathrm{~Hz}, 1 \mathrm{H}), 2.89(\mathrm{t}$, $J=7.5 \mathrm{~Hz}, 2 \mathrm{H}), 1.70-1.60(\mathrm{~m}, 2 \mathrm{H}), 1.34-1.24(\mathrm{~m}, 4 \mathrm{H}), 0.84(\mathrm{t}, J=7.0 \mathrm{~Hz}, 3 \mathrm{H}) \mathrm{ppm}$.

${ }^{13} \mathbf{C}$ RMN (75.4 MHz, $\left.\mathrm{CDCl}_{3}\right): \delta=156.4(\mathrm{~d}, J=248.9 \mathrm{~Hz}, \mathrm{C}), 146.1(\mathrm{C}), 140.3(\mathrm{C}), 138.2(\mathrm{C}), 128.7(2 \times \mathrm{CH})$, $125.8(2 \times \mathrm{CH}), 124.7(\mathrm{CH}), 122.5(\mathrm{~d}, J=7.8 \mathrm{~Hz}, \mathrm{CH}), 118.7(\mathrm{~d}, J=17.3 \mathrm{~Hz}, \mathrm{C}), 107.1(\mathrm{~d}, J=3.9 \mathrm{~Hz}$, $\mathrm{CH}), 106.4(\mathrm{~d}, J=19.2 \mathrm{~Hz}, \mathrm{CH}), 97.0(\mathrm{~d}, J=2.3 \mathrm{~Hz}, \mathrm{C}), 31.5\left(\mathrm{CH}_{2}\right), 29.3\left(\mathrm{CH}_{2}\right), 26.2\left(\mathrm{CH}_{2}\right), 22.5\left(\mathrm{CH}_{2}\right)$, $14.0\left(\mathrm{CH}_{3}\right) \mathrm{ppm}$.

EMBR (IE), m/z (\%): 313 (M+, 100), 256 (48), 222 (16), 148 (24), 69 (16).

EMAR calculado para $\mathrm{C}_{19} \mathrm{H}_{20}$ FNS: 313.1300; encontrado: 313.1291 .

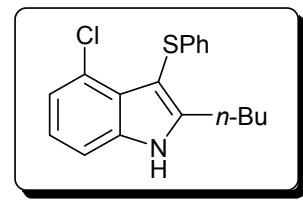

\section{2-Butil-4-cloro-3-(feniltio)-1H-indol (43b)}

Sólido blanco.

P.f. $=76-78^{\circ} \mathrm{C}$.

${ }^{1} \mathbf{H}$ RMN (300 MHz, $\mathrm{CDCl}_{3}$ ): $\delta=8.47$ (sa, 1H), 7.25 (ddd, $\left.J=6.5,2.4,0.4 \mathrm{~Hz}, 1 \mathrm{H}\right), 7.22-7.15(\mathrm{~m}, 2 \mathrm{H}), 7.12-7.03$ (m, $5 \mathrm{H}), 2.91(\mathrm{t}, J=7.6 \mathrm{~Hz}, 2 \mathrm{H}), 1.68-1.56(\mathrm{~m}, 2 \mathrm{H}), 1.41-1.27(\mathrm{~m}, 2 \mathrm{H}), 0.99(\mathrm{t}, J=7.3 \mathrm{~Hz}, 3 \mathrm{H}) \mathrm{ppm}$.

${ }^{13} \mathbf{C}$ RMN (75.4 MHz, $\left.\mathrm{CDCl}_{3}\right): \delta=147.5(\mathrm{C}), 141.3(\mathrm{C}), 136.9(\mathrm{C}), 128.7(2 \times \mathrm{CH}), 126.3(\mathrm{C}), 126.1(\mathrm{C}), 125.4$ $(2 \times \mathrm{CH}), 124.4(\mathrm{CH}), 122.6(\mathrm{CH}), 122.2(\mathrm{CH}), 109.8(\mathrm{CH}), 98.6(\mathrm{C}), 31.6\left(\mathrm{CH}_{2}\right), 26.2\left(\mathrm{CH}_{2}\right), 22.5\left(\mathrm{CH}_{2}\right)$, $13.9\left(\mathrm{CH}_{3}\right) \mathrm{ppm}$.

EMBR (IE), m/z (\%): 317 (M+2, 39), 315 (M+1, 83), 272 (22), 236 (100), 204 (50), 164 (96), 119 (23), 77 (59).

EMAR calculado para $\mathrm{C}_{18} \mathrm{H}_{18}$ CINS: 315.0848 ; encontrado: 315.0849 .

\section{C.4.2 Procedimiento para la sintesis de 3-(feniltio)-4-halo-1H-indoles $43 \boldsymbol{c}-$ fa partir de $27 \boldsymbol{b a}, \boldsymbol{c a}$-cb}

A una disolución de la correspondiente 2-alquinil-3-halopropanamida 27ba, 27ca ó 27cb $(0.3 \mathrm{mmol})$ en DMA $(1 \mathrm{~mL})$ se añade un exceso de $\mathrm{NaOH}$ en polvo $(120 \mathrm{mg}, 3 \mathrm{mmol})$. La mezcla resultante se calienta a reflujo bajo $\mathrm{N}_{2}$ a $140^{\circ} \mathrm{C}$ durante 2-3 horas (la reacción se monitoriza por CGEM). Entonces, se añade $\mathrm{Ph}_{2} \mathrm{~S}_{2}(78 \mathrm{mg}, 0.36 \mathrm{mmol})$ a la mezcla y la reacción se agita durante toda la noche a $140^{\circ} \mathrm{C}$. Se deja que la reacción se enfríe a temperatura ambiente y se añaden $\mathrm{CH}_{2} \mathrm{Cl}_{2}(10 \mathrm{~mL})$ y $\mathrm{HCl}(10 \mathrm{~mL}$ de una disolución $0.5 \mathrm{M})$. La fase acuosa separada se extrae con $\mathrm{CH}_{2} \mathrm{Cl}_{2}(2 \times 10 \mathrm{~mL})$. La combinación de fases orgánicas se lava con $\mathrm{H}_{2} \mathrm{O}(2 \times 30 \mathrm{~mL})$. La fase orgánica se seca sobre $\mathrm{Na}_{2} \mathrm{SO}_{4}$ anhidro y se concentra a presión reducida. El residuo resultante se purifica mediante columna de cromatografía de sílica gel (hexano / AcOEt, 6 / 1) obteniéndose los compuestos 43c-f. 


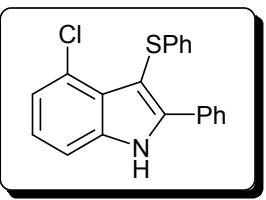

\section{4-Cloro-2-fenil-3-(feniltio)-1 $H$-indol (43c)}

Sólido blanco.

P.f. $=131-133^{\circ} \mathrm{C}$.

${ }^{1} \mathbf{H}$ RMN $\left(300 \mathrm{MHz}, \mathrm{CDCl}_{3}\right): \delta=8.70(\mathrm{sa}, 1 \mathrm{H}), 7.66(\mathrm{dd}, J=6.6,2.9 \mathrm{~Hz}, 2 \mathrm{H}), 7.43-7.38(\mathrm{~m}, 3 \mathrm{H}), 7.36-7.29$ $(\mathrm{m}, 1 \mathrm{H}), 7.26-7.05(\mathrm{~m}, 7 \mathrm{H}) \mathrm{ppm}$.

${ }^{13}$ C RMN (75.4 MHz, $\left.\mathrm{CDCl}_{3}\right): \delta=144.3(\mathrm{C}), 141.4(\mathrm{C}), 137.3(\mathrm{C}), 131.0(\mathrm{C}), 129.2(\mathrm{CH}), 128.9(2 \times \mathrm{CH}), 128.7$ $(4 \times \mathrm{CH}), 127.0(\mathrm{C}), 126.8(\mathrm{C}), 125.3(2 \times \mathrm{CH}), 124.6(\mathrm{CH}), 123.7(\mathrm{CH}), 122.8(\mathrm{CH}), 110.2(\mathrm{CH}), 98.8(\mathrm{C})$ ppm.

EMBR (IE), m/z (\%): 337 (M+2, 22), 335 (M+1 51), 299 (16), 267 (15), 223 (100), 190 (12), 77 (86), 51 (67).

EMAR calculado para $\mathrm{C}_{20} \mathrm{H}_{14} \mathrm{ClNS}$ : 335.0535; encontrado: 335.0534 .

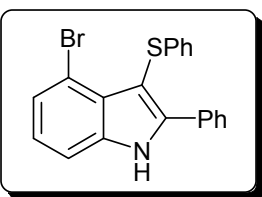

4-Bromo-2-fenil-3-(feniltio)-1 $H$-indol (43d)

Sólido blanco.

P.f. $=154-156^{\circ} \mathrm{C}$.

${ }^{1} \mathbf{H}$ RMN $\left(300 \mathrm{MHz}, \mathrm{CDCl}_{3}\right): \delta=8.65(\mathrm{sa}, 1 \mathrm{H}), 7.69-7.63(\mathrm{~m}, 2 \mathrm{H}), 7.44-7.38(\mathrm{~m}, 4 \mathrm{H}), 7.37-7.35(\mathrm{~m}, 1 \mathrm{H})$, 7.26-7.18 (m, 2H), 7.13-7.05 (m, 4H) ppm.

${ }^{13}$ C RMN (75.4 MHz, $\left.\mathrm{CDCl}_{3}\right): \delta=144.7(\mathrm{C}), 141.6(\mathrm{C}), 137.2(\mathrm{C}), 131.1(\mathrm{C}), 129.2(\mathrm{CH}), 128.9(2 \times \mathrm{CH})$, $128.80(2 \times \mathrm{CH}), 128.78(2 \times \mathrm{CH}), 127.8(\mathrm{C}), 126.4(\mathrm{CH}), 125.3(2 \times \mathrm{CH}), 124.5(\mathrm{CH}), 124.1(\mathrm{CH}), 114.9$ (C), $110.8(\mathrm{CH}), 99.7(\mathrm{C}) \mathrm{ppm}$.

EMBR (IE), m/z (\%): $381\left(\mathrm{M}^{+}+2,25\right), 379\left(\mathrm{M}^{+}, 17\right), 299$ (22), 223 (100), 195 (24), 121 (31), 77 (76).

EMAR calculado para $\mathrm{C}_{20} \mathrm{H}_{14}$ BrNS: 379.0030 ; encontrado: 379.0029 .

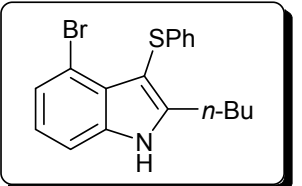

4-Bromo-2-butil-3-(feniltio)-1H-indol (43e)

Sólido marrón.

P.f. $=86-88^{\circ} \mathrm{C}$.

${ }^{1} \mathbf{H}$ RMN $\left(300 \mathrm{MHz}, \mathrm{CDCl}_{3}\right): \delta=8.42(\mathrm{sa}, 1 \mathrm{H}), 7.30(\mathrm{tdd}, J=8.0,4.4,0.9 \mathrm{~Hz}, 2 \mathrm{H}), 7.22-7.15(\mathrm{~m}, 2 \mathrm{H})$, $7.09-6.99(\mathrm{~m}, 4 \mathrm{H}), 2.92(\mathrm{t}, J=7.7 \mathrm{~Hz}, 2 \mathrm{H}), 1.67-1.56(\mathrm{~m}, 2 \mathrm{H}), 1.41-1.26(\mathrm{~m}, 2 \mathrm{H}), 0.89(\mathrm{td}, J=7.1,0.7$ $\mathrm{Hz}, 3 \mathrm{H}) \mathrm{ppm}$.

${ }^{13}$ C RMN (75.4 MHz, $\left.\mathrm{CDCl}_{3}\right): \delta=147.9(\mathrm{C}), 141.5(\mathrm{C}), 136.7(\mathrm{C}), 128.7(2 \times \mathrm{CH}), 127.3(\mathrm{C}), 125.7(\mathrm{CH}), 125.3$ $(2 \times \mathrm{CH}), 124.4(\mathrm{CH}), 123.0(\mathrm{CH}), 113.9(\mathrm{C}), 110.4(\mathrm{CH}), 99.4(\mathrm{C}), 31.6\left(\mathrm{CH}_{2}\right), 26.3\left(\mathrm{CH}_{2}\right), 22.5\left(\mathrm{CH}_{2}\right)$, $13.9\left(\mathrm{CH}_{3}\right) \mathrm{ppm}$.

EMBR (IE), m/z (\%): $361\left(\mathrm{M}^{+}+2,25\right), 359$ (M+2 25), 236 (100), 223 (27), 208 (30), 77 (60), 51 (59).

EMAR calculado para $\mathrm{C}_{18} \mathrm{H}_{18}$ BrNS: 359.0343; encontrado: 359.0346 .

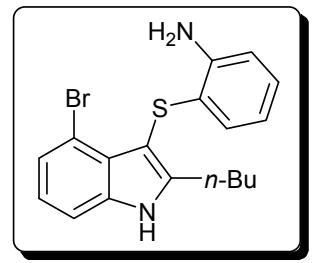

3-(2-Aminofeniltio)-4-bromo-2-butil-1 $\mathrm{H}$-indol (43f)

Sólido marrón.

P.f. $=114-116^{\circ} \mathrm{C}$ 
${ }^{1} \mathbf{H}$ RMN $\left(300 \mathrm{MHz}, \mathrm{CDCl}_{3}\right): \delta=8.55(\mathrm{sa}, 1 \mathrm{H}), 7.28(\mathrm{~d}, J=7.7 \mathrm{~Hz}, 1 \mathrm{H}), 7.21(\mathrm{~d}, J=8.0 \mathrm{~Hz}, 1 \mathrm{H}), 7.00-6.92(\mathrm{~m}$, $2 \mathrm{H}), 6.77(\mathrm{~d}, J=7.7 \mathrm{~Hz}, 1 \mathrm{H}), 6.70(\mathrm{~d}, J=7.7 \mathrm{~Hz}, 1 \mathrm{H}), 6.60(\mathrm{t}, J=7.7 \mathrm{~Hz}, 1 \mathrm{H}), 4.17(\mathrm{sa}, 2 \mathrm{H}), 2.87-2.80$ $(\mathrm{m}, 2 \mathrm{H}), 1.62-1.49(\mathrm{~m}, 2 \mathrm{H}), 1.38-1.24(\mathrm{~m}, 2 \mathrm{H}), 0.87(\mathrm{t}, J=7.3 \mathrm{~Hz}, 3 \mathrm{H}) \mathrm{ppm}$.

${ }^{13} \mathbf{C}$ RMN (75.4 MHz, $\mathrm{CDCl}_{3}$ ): $\delta=147.8(\mathrm{C}), 143.3(\mathrm{C}), 136.7(\mathrm{C}), 128.4(\mathrm{CH}), 127.0(\mathrm{C}), 126.1(\mathrm{CH}), 125.6$ $(\mathrm{CH}), 125.0(\mathrm{C}), 122.8(\mathrm{CH}), 119.3(\mathrm{CH}), 115.5(\mathrm{CH}), 113.7(\mathrm{C}), 110.5(\mathrm{CH}), 98.9(\mathrm{C}), 31.5\left(\mathrm{CH}_{2}\right), 26.4$ $\left(\mathrm{CH}_{2}\right), 22.5\left(\mathrm{CH}_{2}\right), 13.9\left(\mathrm{CH}_{3}\right) \mathrm{ppm}$.

EMBR (IE), m/z (\%): 374 (M+ , 28), 297 (18), 252 (73), 238 (34), 210 (100), 129 (32), 93 (37), 80 (40), 65 (76).

EMAR calculado para $\mathrm{C}_{18} \mathrm{H}_{19} \mathrm{BrN}_{2} \mathrm{~S}$ : 374.0452 ; encontrado: 374.0457.

\section{C.5 Síntesis de $1 H$-indoles funcionalizados en la posición 4}

\section{C.5.1 Síntesis de los 4-alquinil-1H-indoles 2-sustituidos 45a-d a partir de la anilida 25 bc}

- $\quad$ Procedimiento general para la preparación de las 2,3-dialquinilanilidas $44 a-d$

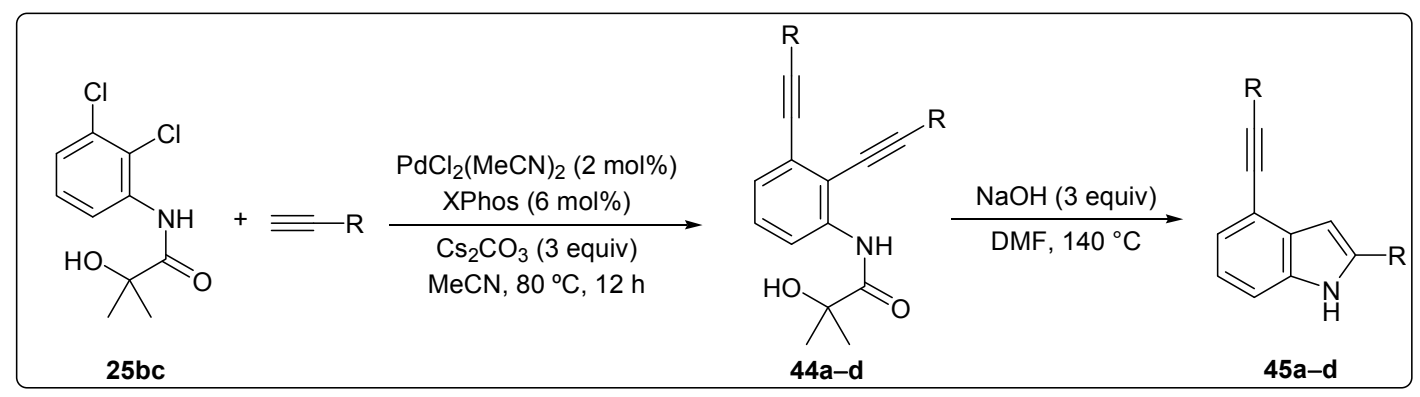

Una mezcla de 25bc (148 mg, $0.6 \mathrm{mmol}), \mathrm{PdCl}_{2}\left(\mathrm{CH}_{3} \mathrm{CN}\right)_{2}(3 \mathrm{mg}, 2 \mathrm{~mol} \%)$, XPhos (17 mg, 3 mol\%) and $\mathrm{Cs}_{2} \mathrm{CO}_{3}(586 \mathrm{mg}, 1.8 \mathrm{mmol})$ en $\mathrm{MeCN}$ anhidro $(2 \mathrm{~mL})$ se agita bajo $\mathrm{N}_{2}$ a $20{ }^{\circ} \mathrm{C}$ durante 25 minutos. A continuación se añade el correspondiente alquino $(1.8 \mathrm{mmol})$ y la mezcla de reacción se agita a reflujo durante 12 horas. Después de que la mezcla se ha enfriado a temperatura ambiente se adiciona $\mathrm{H}_{2} \mathrm{O}$ y AcOEt. La fase acuosa separada se extrae con AcOEt $(3 \times 15 \mathrm{~mL})$. La fase orgánica se seca sobre $\mathrm{Na}_{2} \mathrm{SO}_{4}$ anhidro y se concentra a presión reducida. El residuo obtenido se purifica mediante columna de cromatografía (hexano / AcOEt) permitiendo obtener 44.

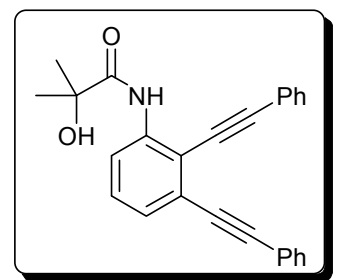

$N$-[2,3-Bis(feniletinil)fenil]-2-hidroxi-2-metilpropanamida (44a)

Sólido marrón.

P.f. $=162-164^{\circ} \mathrm{C}$.

${ }^{1}$ H RMN (300 MHz, $\left.\mathrm{CDCl}_{3}\right): \delta=9.84(\mathrm{sa}, 1 \mathrm{H}), 8.53-8.45(\mathrm{~m}, 1 \mathrm{H}), 7.65-7.54(\mathrm{~m}, 4 \mathrm{H}), 7.41-7.33(\mathrm{~m}, 6 \mathrm{H})$, $7.34-7.27(\mathrm{~m}, 2 \mathrm{H}), 2.45(\mathrm{~s}, 1 \mathrm{H}), 1.60(\mathrm{~s}, 6 \mathrm{H}) \mathrm{ppm}$.

${ }^{13}$ C RMN (75.4 MHz, $\left.\mathrm{CDCl}_{3}\right): \delta=174.7(\mathrm{C}), 139.0(\mathrm{C}), 131.8(2 \times \mathrm{CH}), 131.6(2 \times \mathrm{CH}), 129.1(\mathrm{CH}), 129.0(\mathrm{CH})$, $128.7(3 \times \mathrm{CH}), 128.6(2 \times \mathrm{CH}), 127.0(\mathrm{CH}), 125.8(\mathrm{C}), 123.2(\mathrm{C}), 122.8(\mathrm{C}), 118.5(\mathrm{CH}), 115.1(\mathrm{C}), 100.8$ (C), $93.7(\mathrm{C}), 88.2(\mathrm{C}), 83.6(\mathrm{C}), 74.8(\mathrm{C}), 28.1\left(2 \times \mathrm{CH}_{3}\right) \mathrm{ppm}$.

EMBR (IE), m/z (\%): 379 (M+, 61), 361 (73), 321 (61), 292 (58), 265 (56), 189 (20), 59 (100).

EMAR calculado para $\mathrm{C}_{26} \mathrm{H}_{21} \mathrm{NO}_{2}: 379.1572$; encontrado: 379.1569 . 


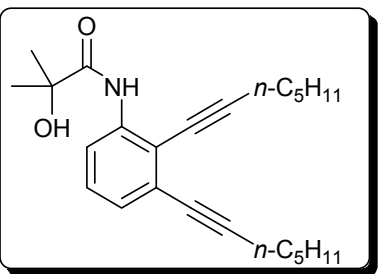

$N$-[2,3-Di(1-heptinil)fenil]-2-hidroxi-2-metilpropanamida (44b)

Líquido marrón.

$\mathrm{R}_{\mathrm{f}}=0.48$ (hexano / AcOEt, 3 / 1).

${ }^{1}$ H RMN (400 MHz, $\left.\mathrm{CDCl}_{3}\right): \delta=9.59(\mathrm{~s}, 1 \mathrm{H}), 8.34(\mathrm{dd}, J=7.9,1.3 \mathrm{~Hz}, 1 \mathrm{H}), 7.15(\mathrm{t}, J=7.9 \mathrm{~Hz}, 1 \mathrm{H}), 7.08(\mathrm{dd}$, $J=7.9,1.3 \mathrm{~Hz}, 1 \mathrm{H}), 2.72(\mathrm{~s}, 1 \mathrm{H}), 2.51(\mathrm{t}, J=7.1 \mathrm{~Hz}, 2 \mathrm{H}), 2.43(\mathrm{t}, J=7.1 \mathrm{~Hz}, 2 \mathrm{H}), 1.68-1.57(\mathrm{~m}, 4 \mathrm{H})$, $1.53(\mathrm{~s}, 6 \mathrm{H}), 1.49-1.41(\mathrm{~m}, 4 \mathrm{H}), 1.39-1.30(\mathrm{~m}, 4 \mathrm{H}), 0.90(\mathrm{td}, J=7.2,3.8 \mathrm{~Hz}, 6 \mathrm{H}) \mathrm{ppm}$.

${ }^{13}$ C RMN (100.6 MHz, $\left.\mathrm{CDCl}_{3}\right): \delta=174.8(\mathrm{C}), 138.9(\mathrm{C}), 128.1(\mathrm{CH}), 127.0(\mathrm{CH}), 126.6(\mathrm{C}), 117.7(\mathrm{CH}), 115.8$ (C), $101.8(\mathrm{C}), 94.4(\mathrm{C}), 79.5(\mathrm{C}), 75.0(\mathrm{C}), 74.4(\mathrm{C}), 31.23\left(\mathrm{CH}_{2}\right), 31.17\left(\mathrm{CH}_{2}\right), 28.58\left(\mathrm{CH}_{2}\right), 28.56\left(\mathrm{CH}_{2}\right)$, $28.0\left(2 \times \mathrm{CH}_{3}\right), 22.4\left(2 \times \mathrm{CH}_{2}\right), 19.9\left(\mathrm{CH}_{2}\right), 19.7\left(\mathrm{CH}_{2}\right), 14.11\left(\mathrm{CH}_{3}\right), 14.09\left(\mathrm{CH}_{3}\right) \mathrm{ppm}$.

EMBR (IE), m/z (\%): 367 (M+20), 320 (37), 296 (87), 278 (100), 167 (29), 59 (40).

EMAR calculado para $\mathrm{C}_{24} \mathrm{H}_{33} \mathrm{NO}_{2}: 367.2511$; encontrado: 367.2518 .

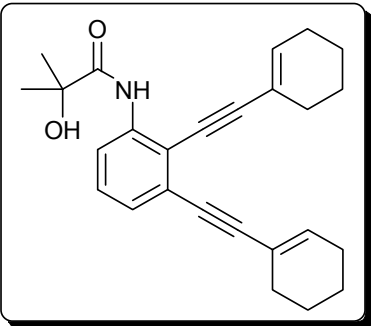

$N$-[2,3-Bis(1-ciclohexeniletinil)fenil]-2-hidroxi-2-metilpropanamida (44c)

Sólido amarillo.

P.f. $=156-158^{\circ} \mathrm{C}$

${ }^{1}$ H RMN $\left(300 \mathrm{MHz}, \mathrm{CDCl}_{3}\right): \delta=9.60(\mathrm{sa}, 1 \mathrm{H}), 8.38(\mathrm{dd}, J=8.0,1.3 \mathrm{~Hz}, 1 \mathrm{H}), 7.27-7.19(\mathrm{~m}, 1 \mathrm{H}), 7.17-7.12$ $(\mathrm{m}, 1 \mathrm{H}), 6.33-6.27(\mathrm{~m}, 1 \mathrm{H}), 6.27-6.22(\mathrm{~m}, 1 \mathrm{H}), 2.50(\mathrm{sa}, 1 \mathrm{H}), 2.30-2.21(\mathrm{~m}, 4 \mathrm{H}), 2.20-2.11(\mathrm{~m}, 4 \mathrm{H})$, $1.72-1.59(\mathrm{~m}, 8 \mathrm{H}), 1.56(\mathrm{~d}, J=1.1 \mathrm{~Hz}, 6 \mathrm{H}) \mathrm{ppm}$.

${ }^{13}$ C RMN (75.4 MHz, $\left.\mathrm{CDCl}_{3}\right): \delta=174.7(\mathrm{C}), 138.5(\mathrm{C}), 136.3(\mathrm{CH}), 135.9(\mathrm{CH}), 128.4(\mathrm{CH}), 126.8(\mathrm{CH})$, $126.0(\mathrm{C}), 120.9(\mathrm{C}), 120.7(\mathrm{CH}), 117.9(\mathrm{C}), 115.3(\mathrm{C}), 102.6(\mathrm{C}), 95.4(\mathrm{C}), 85.7(\mathrm{C}), 81.0(\mathrm{C}), 74.6(\mathrm{C})$, $29.3\left(\mathrm{CH}_{2}\right), 29.2\left(\mathrm{CH}_{2}\right), 28.1\left(2 \times \mathrm{CH}_{3}\right), 26.03\left(\mathrm{CH}_{2}\right), 25.98\left(\mathrm{CH}_{2}\right), 22.5\left(\mathrm{CH}_{2}\right), 22.4\left(\mathrm{CH}_{2}\right), 21.6\left(\mathrm{CH}_{2}\right)$, $21.5\left(\mathrm{CH}_{2}\right) \mathrm{ppm}$

EMBR (IE), m/z (\%): 387 (M+ , 92), 369 (32), 328 (38), 300 (36), 207 (100), 59 (83).

EMAR calculado para $\mathrm{C}_{26} \mathrm{H}_{29} \mathrm{NO}_{2}: 387.2198$; encontrado: 387.2198 .

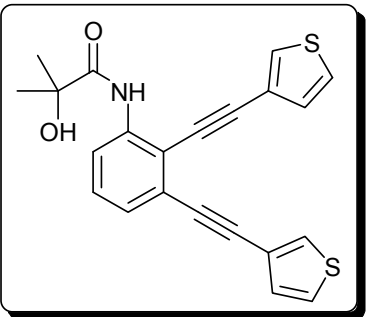

$N$-[2,3-Bis(3-tieniletinil)fenil]-2-hidroxi-2-metilpropanamida (44d)

Sólido marrón.

P.f. $=206-208^{\circ} \mathrm{C}$.

${ }^{1} \mathbf{H}$ RMN $\left(400 \mathrm{MHz},\left(\mathrm{CD}_{3}\right)_{2} \mathrm{CO}\right): \delta=10.1(\mathrm{~s}, 1 \mathrm{H}), 8.56(\mathrm{dd}, J=8.3,1.2 \mathrm{~Hz}, 1 \mathrm{H}), 7.83(\mathrm{dd}, J=3.0,1.2 \mathrm{~Hz}, 1 \mathrm{H})$, $7.81(\mathrm{dd}, J=3.0,1.2 \mathrm{~Hz}, 1 \mathrm{H}), 7.57(\mathrm{dd}, J=5.0,3.0 \mathrm{~Hz}, 2 \mathrm{H}), 7.39(\mathrm{t}, J=8.0 \mathrm{~Hz}, 1 \mathrm{H}), 7.32(\mathrm{dd}, J=5.0,1.2$ $\mathrm{Hz}, 1 \mathrm{H}), 7.30(\mathrm{dd}, J=2.2,1.2 \mathrm{~Hz}, 1 \mathrm{H}), 7.28(\mathrm{dd}, J=1.2,0.4 \mathrm{~Hz}, 1 \mathrm{H}), 5.41(\mathrm{~s}, 1 \mathrm{H}), 1.51(\mathrm{~s}, 6 \mathrm{H}) \mathrm{ppm}$.

${ }^{13}$ C RMN $\left(100.6 \mathrm{MHz},\left(\mathrm{CD}_{3}\right)_{2} \mathrm{CO}\right): \delta=176.0(\mathrm{C}), 140.6(\mathrm{C}), 130.7(\mathrm{CH}), 130.6(\mathrm{CH}), 130.5(\mathrm{CH}), 130.4(\mathrm{CH})$, $129.9(\mathrm{CH}), 127.3(\mathrm{CH}), 127.2(\mathrm{CH}), 127.0(\mathrm{CH}), 126.2(\mathrm{C}), 122.8(\mathrm{C}), 122.4(\mathrm{C}), 118.8(\mathrm{CH}), 115.3(\mathrm{C})$, $96.8(\mathrm{C}), 89.6(\mathrm{C}), 88.1(\mathrm{C}), 83.6(\mathrm{C}), 74.6(\mathrm{C}), 28.1\left(2 \times \mathrm{CH}_{3}\right) \mathrm{ppm}$. 
EMBR (IE), m/z (\%): 391 (M+ , 82), 372 (20), 345 (100), 305 (76), 277 (57), 245 (23), 207 (78), 59 (47).

EMAR calculado para $\mathrm{C}_{22} \mathrm{H}_{17} \mathrm{NO}_{2} \mathrm{~S}_{2}: 391.0701$; encontrado: 391.0701 .

- $\quad$ Síntesis de los 4-alquinil-1H-indoles 2-sustituidos 45a-d

A una disolución de la correspondiente 2,3-dialquinilpropanamida 44 (1 equiv) en DMF (3 $\mathrm{mL} / \mathrm{mmol}$ ) se adiciona $\mathrm{NaOH}$ (3 equiv). La mezcla resultante se calienta bajo $\mathrm{N}_{2}$ a $140{ }^{\circ} \mathrm{C}$ hasta que la ciclación finaliza (6 horas, monitorizado por CG-EM). Se adiciona $\mathrm{CH}_{2} \mathrm{Cl}_{2}(10 \mathrm{~mL})$ y $\mathrm{HCl} 0.5 \mathrm{M}$ $(10 \mathrm{~mL})$. La fase acuosa separada se extrae con $\mathrm{CH}_{2} \mathrm{Cl}_{2}(2 \times 10 \mathrm{~mL})$. La combinación de fases orgánicas se lava con $\mathrm{H}_{2} \mathrm{O}(2 \times 30 \mathrm{~mL})$. La fase orgánica se seca sobre $\mathrm{Na}_{2} \mathrm{SO}_{4}$ anhidro y se concentra a presión reducida. El residuo obtenido se purifica mediante columna de cromatografía (hexano / AcOEt) obteniéndose los 4-alquinilindoles 45a-d.

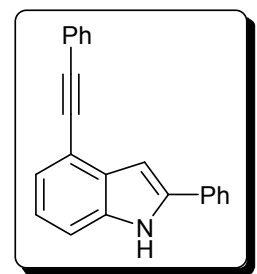

2-Fenil-4-(feniletinil)-1 $H$-indol (45a)

Sólido marrón.

P.f. $=132-134^{\circ} \mathrm{C}$.

${ }^{1}$ H RMN (300 MHz, $\left.\mathrm{CDCl}_{3}\right): \delta=8.49(\mathrm{sa}, 1 \mathrm{H}), 7.73-7.57(\mathrm{~m}, 4 \mathrm{H}), 7.50-7.34(\mathrm{~m}, 8 \mathrm{H}), 7.19(\mathrm{t}, J=7.7 \mathrm{~Hz}, 1 \mathrm{H})$, $7.10(\mathrm{~d}, J=2.2 \mathrm{~Hz}, 1 \mathrm{H}) \mathrm{ppm}$.

${ }^{13}$ C RMN (75.4 MHz, $\left.\mathrm{CDCl}_{3}\right): \delta=138.6(\mathrm{C}), 136.5(\mathrm{C}), 132.1(\mathrm{C}), 131.8(2 \times \mathrm{CH}), 130.9(\mathrm{C}), 129.1(2 \times \mathrm{CH})$, $128.5(2 \times \mathrm{CH}), 128.2(\mathrm{CH}), 128.1(\mathrm{CH}), 125.4(2 \times \mathrm{CH}), 124.2(\mathrm{CH}), 123.9(\mathrm{C}), 122.2(\mathrm{CH}), 114.7(\mathrm{C})$, $111.6(\mathrm{CH}), 99.8(\mathrm{CH}), 92.1(\mathrm{C}), 88.5(\mathrm{C}) \mathrm{ppm}$.

IR $\left(\mathrm{KBr}, \mathrm{cm}^{-1}\right): 3427,3056,1597,1487,1451,1422,1283,753,687$

EMBR (IE), m/z (\%): $293\left(\mathrm{M}^{+}, 100\right), 207$ (12), 189 (10), 146 (12).

EMAR calculado para $\mathrm{C}_{22} \mathrm{H}_{15} \mathrm{~N}$ : 293.1204; encontrado: 293.1205.

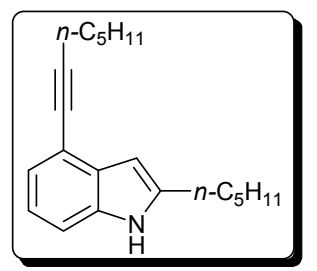

4-(1-Heptinil)-2-pentil-1 $H$-indol (45b)

Líquido marrón.

$\mathrm{R}_{\mathrm{f}}=0.50$ (hexano / AcOEt, 5 / 1).

${ }^{1}$ H RMN $\left(300 \mathrm{MHz}, \mathrm{CDCl}_{3}\right): \delta=7.88(\mathrm{sa}, 1 \mathrm{H}), 7.24-7.13(\mathrm{~m}, 2 \mathrm{H}), 7.03(\mathrm{t}, J=7.6 \mathrm{~Hz}, 1 \mathrm{H}), 6.40(\mathrm{dd}, J=1.5$, $0.6 \mathrm{~Hz}, 1 \mathrm{H}), 2.74$ (t, $J=7.6 \mathrm{~Hz}, 2 \mathrm{H}), 2.52(\mathrm{t}, J=7.0 \mathrm{~Hz}, 2 \mathrm{H}), 1.81-1.61(\mathrm{~m}, 4 \mathrm{H}), 1.61-1.45(\mathrm{~m}, 2 \mathrm{H})$, $1.45-1.26(\mathrm{~m}, 6 \mathrm{H}), 0.94(\mathrm{dt}, J=9.2,7.2 \mathrm{~Hz}, 6 \mathrm{H}) \mathrm{ppm}$.

${ }^{13} \mathbf{C}$ RMN (75.4 MHz, $\mathrm{CDCl}_{3}$ ): $\delta=140.6(\mathrm{C}), 135.4(\mathrm{C}), 130.6(\mathrm{C}), 123.2(\mathrm{CH}), 120.8(\mathrm{CH}), 114.7(\mathrm{C}), 110.2$ (CH), $99.3(\mathrm{CH}), 92.5(\mathrm{C}), 79.6(\mathrm{C}), 31.6\left(\mathrm{CH}_{2}\right), 31.3\left(\mathrm{CH}_{2}\right), 28.95\left(\mathrm{CH}_{2}\right), 28.86\left(\mathrm{CH}_{2}\right), 28.4\left(\mathrm{CH}_{2}\right), 22.6$ $\left(\mathrm{CH}_{2}\right), 22.4\left(\mathrm{CH}_{2}\right), 19.8\left(\mathrm{CH}_{2}\right), 14.22\left(\mathrm{CH}_{3}\right), 14.16\left(\mathrm{CH}_{3}\right) \mathrm{ppm}$.

EMBR (IE), m/z (\%): $281\left(\mathrm{M}^{+}, 89\right), 238$ (24), 224 (100), 167 (53).

EMAR calculado para $\mathrm{C}_{20} \mathrm{H}_{27} \mathrm{~N}$ : 281.2143; encontrado: 281.2141 . 


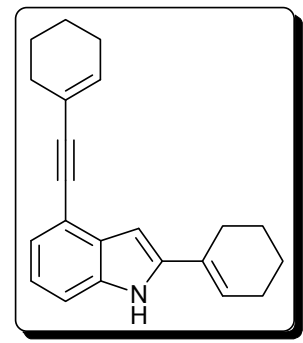

\section{2-(1-Ciclohexenil)-4-(1-ciclohexeniletinil)-1 $H$-indol (45c)}

Líquido incoloro.

$\mathrm{R}_{\mathrm{f}}=0.40$ (hexano / AcOEt, 5 / 1).

${ }^{1}$ H RMN $\left(300 \mathrm{MHz}, \mathrm{CDCl}_{3}\right): \delta=8.15(\mathrm{sa}, 1 \mathrm{H}), 7.23(\mathrm{dt}, J=7.9,1.0 \mathrm{~Hz}, 1 \mathrm{H}), 7.16(\mathrm{dd}, J=7.4,1.0 \mathrm{~Hz}, 1 \mathrm{H})$, 7.09-7.03 (m, 1H), $6.58(\mathrm{~d}, J=1.8 \mathrm{~Hz}, 1 \mathrm{H}), 6.29-6.25(\mathrm{~m}, 1 \mathrm{H}), 6.17-6.12(\mathrm{~m}, 1 \mathrm{H}), 2.52-2.45(\mathrm{~m}, 2 \mathrm{H})$, $2.37-2.22(\mathrm{~m}, 4 \mathrm{H}), 2.21-2.14(\mathrm{~m}, 2 \mathrm{H}), 1.84-1.76(\mathrm{~m}, 2 \mathrm{H}), 1.75-1.60(\mathrm{~m}, 6 \mathrm{H}) \mathrm{ppm}$.

${ }^{13} \mathbf{C}$ RMN (75.4 MHz, $\mathrm{CDCl}_{3}$ ): $\delta=140.0(\mathrm{C}), 135.8(\mathrm{C}), 134.7(\mathrm{CH}), 130.5(\mathrm{C}), 130.0(\mathrm{C}), 129.2(\mathrm{C}), 123.5$ $(\mathrm{CH}), 123.3(\mathrm{CH}), 121.9(\mathrm{CH}), 121.3(\mathrm{C}), 115.0(\mathrm{C}), 110.5(\mathrm{CH}), 98.7(\mathrm{CH}), 93.8(\mathrm{C}), 85.9(\mathrm{C}), 29.7$ $\left(\mathrm{CH}_{2}\right), 26.2\left(\mathrm{CH}_{2}\right), 26.0\left(\mathrm{CH}_{2}\right), 25.7\left(\mathrm{CH}_{2}\right), 22.7\left(\mathrm{CH}_{2}\right), 22.6\left(\mathrm{CH}_{2}\right), 22.3\left(\mathrm{CH}_{2}\right), 21.7\left(\mathrm{CH}_{2}\right) \mathrm{ppm}$.

EMBR (IE), m/z (\%): 301 (M+100), 273 (9), 230 (6), 204 (8), 191 (6).

EMAR calculado para $\mathrm{C}_{22} \mathrm{H}_{23} \mathrm{~N}$ : 301.1830; encontrado: 301.1835 .

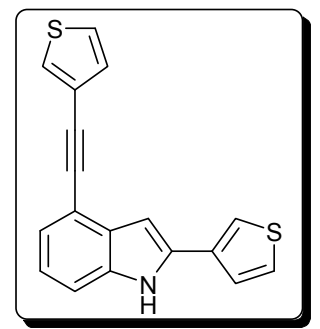

\section{2-(3-Tienil)-4-(3-tieniletinil)-1 $H$-indol (45d)}

Sólido blanco.

P.f. $=200-202{ }^{\circ} \mathrm{C}$.

${ }^{1} \mathbf{H}$ RMN (300 MHz, $\left.\left(\mathrm{CD}_{3}\right)_{2} \mathrm{CO}\right): \delta=10.92(\mathrm{~s}, 1 \mathrm{H}), 7.88(\mathrm{dd}, J=2.9,1.3 \mathrm{~Hz}, 1 \mathrm{H}), 7.80(\mathrm{dd}, J=2.9,1.3 \mathrm{~Hz}, 1 \mathrm{H}), 7.69$ $(\mathrm{dd}, J=5.0,1.3 \mathrm{~Hz}, 1 \mathrm{H}), 7.59$ (ddd, $J=6.7,5.0,2.9 \mathrm{~Hz}, 2 \mathrm{H}), 7.42(\mathrm{dt}, J=8.0,1.0 \mathrm{~Hz}, 1 \mathrm{H}), 7.33(\mathrm{dd}, J=5.0,1.3$ $\mathrm{Hz}, 1 \mathrm{H}), 7.22(\mathrm{dd}, J=7.4,1.0 \mathrm{~Hz}, 1 \mathrm{H}), 7.12(\mathrm{dd}, J=8.0,7.4 \mathrm{~Hz}, 1 \mathrm{H}), 7.03(\mathrm{dd}, J=2.3,1.0 \mathrm{~Hz}, 1 \mathrm{H}) \mathrm{ppm}$.

${ }^{13}$ C RMN (75.4 MHz, $\left.\left(\mathrm{CD}_{3}\right)_{2} \mathrm{CO}\right): \delta=137.5(\mathrm{C}), 136.1(\mathrm{C}), 134.9(\mathrm{C}), 131.4(\mathrm{C}), 130.7(\mathrm{CH}), 129.4(\mathrm{CH})$, $127.6(\mathrm{CH}), 126.9(\mathrm{CH}), 126.8(\mathrm{CH}), 124.1(\mathrm{CH}), 123.6(\mathrm{C}), 122.4(\mathrm{CH}), 120.8(\mathrm{CH}), 114.8(\mathrm{C}), 112.5$ $(\mathrm{CH}), 99.4(\mathrm{CH}), 88.8(\mathrm{C}), 87.4(\mathrm{C}) \mathrm{ppm}$.

EMBR (IE), m/z (\%): 305 (M+100), 281 (27), 253 (12), 207 (98), 191 (10).

EMAR calculado para $\mathrm{C}_{18} \mathrm{H}_{11} \mathrm{NS}_{2}$ : 305.0333; encontrado: 305.0333 .

\section{C.5.2 Sintesis de los 4-alquinil-1H-indoles 2-sustituidos 45e,f}

A una mezcla de 3bc (231 mg, $0.9 \mathrm{mmol}), \mathrm{PdCl}_{2}\left(\mathrm{CH}_{3} \mathrm{CN}\right)_{2}(5 \mathrm{mg}, 2 \mathrm{~mol} \%)$, XPhos (26 mg, $3 \mathrm{~mol} \%$ ) y $\mathrm{Cs}_{2} \mathrm{CO}_{3}(880 \mathrm{mg}, 2.7 \mathrm{mmol})$ en $\mathrm{MeCN}$ anhidro $(3 \mathrm{~mL})$ se agita bajo $\mathrm{N}_{2}$ a $20^{\circ} \mathrm{C}$ durante 25 minutos. A continuación se adiciona el correspondiente alquino $(2.7 \mathrm{mmol})$ y la mezcla de reacción se calienta a reflujo durante 12 horas. Se adiciona AcOEt $(15 \mathrm{~mL})$ y $\mathrm{H}_{2} \mathrm{O}(15 \mathrm{~mL})$. La fase acuosa separada se extrae con AcOEt $(3 \times 15 \mathrm{~mL})$. La fase orgánica se seca sobre $\mathrm{Na}_{2} \mathrm{SO}_{4}$ anhidro y se concentra a presión reducida. El residuo obtenido se purifica mediante columna de cromatografía (hexano / AcOEt) obteniéndose los 4-alquinilindoles 45e,f. 


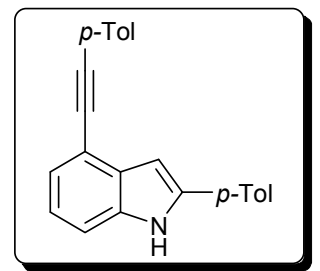

\section{2-p-Tolil-4-(p-toliletinil)-1 $H$-indol (45e)}

Líquido marrón.

$\mathrm{R}_{\mathrm{f}}=0.40$ (hexano / AcOEt, 5 / 1).

${ }^{1} \mathbf{H}$ RMN (400 MHz, $\left.\mathrm{CDCl}_{3}\right): \delta=8.42(\mathrm{sa}, 1 \mathrm{H}), 7.59(\mathrm{~d}, J=8.2 \mathrm{~Hz}, 2 \mathrm{H}), 7.53(\mathrm{~d}, J=8.2 \mathrm{~Hz}, 2 \mathrm{H}), 7.36-7.30(\mathrm{~m}$, $2 \mathrm{H}), 7.25(\mathrm{~d}, J=7.9 \mathrm{~Hz}, 2 \mathrm{H}), 7.18(\mathrm{~d}, J=7.9 \mathrm{~Hz}, 2 \mathrm{H}), 7.14(\mathrm{t}, J=7.9 \mathrm{~Hz}, 1 \mathrm{H}), 7.02(\mathrm{~d}, J=1.3 \mathrm{~Hz}, 1 \mathrm{H})$, $2.39(\mathrm{~d}, J=1.8 \mathrm{~Hz}, 6 \mathrm{H}) \mathrm{ppm}$.

${ }^{13} \mathbf{C}$ RMN (100.6 MHz, $\left.\mathrm{CDCl}_{3}\right): \delta=138.8(\mathrm{C}), 138.3(\mathrm{C}), 138.1(\mathrm{C}), 136.4(\mathrm{C}), 131.7(2 \times \mathrm{CH}), 131.0(\mathrm{C}), 129.9$ $(2 \times \mathrm{CH}), 129.4(\mathrm{C}), 129.2(2 \times \mathrm{CH}), 125.3(2 \times \mathrm{CH}), 124.1(\mathrm{CH}), 122.0(\mathrm{CH}), 120.9(\mathrm{C}), 114.8(\mathrm{C}), 111.3$ $(\mathrm{CH}), 99.3(\mathrm{CH}), 92.2(\mathrm{C}), 87.9(\mathrm{C}), 21.7\left(\mathrm{CH}_{3}\right), 21.4\left(\mathrm{CH}_{3}\right) \mathrm{ppm}$.

EMBR (IE), m/z (\%): $321\left(\mathrm{M}^{+}, 100\right), 281$ (10), 207 (31), 160 (7).

EMAR calculado para $\mathrm{C}_{24} \mathrm{H}_{19} \mathrm{~N}$ : 321.1517 ; encontrado: 321.1518 .

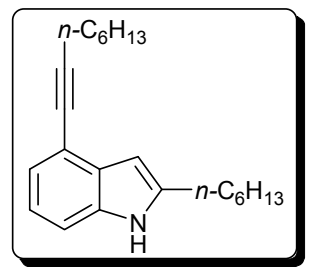

\section{2-Hexil-4-(1-octinil)-1H-indol (45f)}

Líquido marrón.

$\mathrm{R}_{\mathrm{f}}=0.50$ (hexano / AcOEt, 5 / 1).

${ }^{1} \mathbf{H}$ RMN (400 MHz, $\left.\mathrm{CDCl}_{3}\right): \delta=7.90(\mathrm{sa}, 1 \mathrm{H}), 7.19(\mathrm{dt}, J=8.1,0.9 \mathrm{~Hz}, 1 \mathrm{H}), 7.15(\mathrm{dd}, J=7.4,0.9 \mathrm{~Hz}, 1 \mathrm{H})$, $7.02(\mathrm{dd}, J=8.1,7.4 \mathrm{~Hz}, 1 \mathrm{H}), 6.39(\mathrm{dd}, J=2.2,0.9 \mathrm{~Hz}, 1 \mathrm{H}), 2.73(\mathrm{t}, J=7.7 \mathrm{~Hz}, 2 \mathrm{H}), 2.51(\mathrm{t}, J=7.0 \mathrm{~Hz}$, 2H), 1.77-1.63 (m, 4H), 1.57-1.48 (m, 2H), 1.44-1.18 (m, 10H), 0.96-0.87 (m, 6H) ppm.

${ }^{13} \mathbf{C}$ RMN (100.6 MHz, $\left.\mathrm{CDCl}_{3}\right): \delta=140.6(\mathrm{C}), 135.5(\mathrm{C}), 130.7(\mathrm{C}), 123.2(\mathrm{CH}), 120.8(\mathrm{CH}), 114.8(\mathrm{C}), 110.2$ $(\mathrm{CH}), 99.4(\mathrm{CH}), 92.5(\mathrm{C}), 79.7(\mathrm{C}), 31.8\left(\mathrm{CH}_{2}\right), 31.6\left(\mathrm{CH}_{2}\right), 29.25\left(\mathrm{CH}_{2}\right), 29.18\left(\mathrm{CH}_{2}\right), 29.15\left(\mathrm{CH}_{2}\right), 28.8$ $\left(\mathrm{CH}_{2}\right), 28.5\left(\mathrm{CH}_{2}\right), 22.8\left(\mathrm{CH}_{2}\right), 22.7\left(\mathrm{CH}_{2}\right), 19.9\left(\mathrm{CH}_{2}\right), 14.23\left(\mathrm{CH}_{3}\right), 14.23\left(\mathrm{CH}_{3}\right) \mathrm{ppm}$.

EMBR (IE), m/z (\%): 309 (M+1 100), 281 (19), 252 (27), 238 (84), 207 (46), 167 (56).

EMAR calculado para $\mathrm{C}_{22} \mathrm{H}_{31} \mathrm{~N}$ : 309.2457 ; encontrado: 309.2456 .

\section{C.5.3 Preparación del 2-fenil-4-(feniletinil)-1H-indol $45 a$ a partir de 25 ca}

Una mezcla de $25 \mathrm{ca}$ (383 mg, $1 \mathrm{mmol}$ ), fenilacetileno (408 mg, $4 \mathrm{mmol}), \mathrm{PdCl}_{2}\left(\mathrm{PPh}_{3}\right)_{2}(70$ $\mathrm{mg}, 10 \mathrm{~mol} \%)$, y TBAF $3 \mathrm{H}_{2} \mathrm{O}(947 \mathrm{mg}, 3 \mathrm{mmol})$ se agita bajo $\mathrm{N}_{2}$ a $60{ }^{\circ} \mathrm{C}$ hasta que la anilida de partida desaparece ( 5 horas), monitorizando la reacción mediante CG-EM. El crudo se lava con agua, se extrae con $\mathrm{Et}_{2} \mathrm{O}(3 \times 20 \mathrm{~mL})$, y se evapora el disolvente a presión reducida. Para eliminar las sales de $\mathrm{Pd}$, el crudo se filtra a través de una corta columna de sílica gel. A continuación, el residuo se trata con $\mathrm{NaOH}$ (120 mg, $3 \mathrm{mmol}$ ) en DMA ( $3 \mathrm{~mL}$ ) bajo $\mathrm{N}_{2}$ a $140{ }^{\circ} \mathrm{C}$ durante 8 horas. Se adiciona $\mathrm{CH}_{2} \mathrm{Cl}_{2}$ $(20 \mathrm{~mL})$ y $\mathrm{HCl} 0.5 \mathrm{M}(20 \mathrm{~mL})$ sobre la mezcla de reacción fría. La fase acuosa separada se extrae con $\mathrm{CH}_{2} \mathrm{Cl}_{2}(2 \times 20 \mathrm{~mL})$. La combinación de fases orgánicas se lava con $\mathrm{H}_{2} \mathrm{O}(2 \times 30 \mathrm{~mL})$. La fase orgánica se seca sobre $\mathrm{Na}_{2} \mathrm{SO}_{4}$ anhidro y se concentra a presión reducida. El residuo resultante se purifica mediante columna de cromatografía (hexano / AcOEt, 10 / 1) obteniéndose 45a cuyos datos físicos y espectroscópicos han sido detallados anteriormente. 


\section{C.5.4 Sintesis del 2-fenil-4-(1-hexinil)-1H-indol 45g}

A una disolución del 4-bromo-2-fenil- $1 H$-indol 28ca (81 mg, $0.3 \mathrm{mmol})$ en DMF anhidra (2 $\mathrm{mL}$ ) se adicionan $\mathrm{PdCl}_{2}\left(\mathrm{PPh}_{3}\right)_{2}(12 \mathrm{mg}, 6 \mathrm{~mol} \%)$, CuI (6 mg, $\left.10 \mathrm{~mol} \%\right)$, 1-hexino (36 mg, 0.45 mmol) y $\mathrm{Et}_{2} \mathrm{NH}(33 \mathrm{mg}, 0.45 \mathrm{mmol})$ y la mezcla se agita bajo $\mathrm{N}_{2}$ a $80{ }^{\circ} \mathrm{C}$ durante 17 horas. Una vez que la disolución se enfría a temperatura ambiente, se añaden $\mathrm{CH}_{2} \mathrm{Cl}_{2}(10 \mathrm{~mL})$ y $\mathrm{HCl} 0.5 \mathrm{M}(10 \mathrm{~mL})$. La fase acuosa separada se extrae con $\mathrm{CH}_{2} \mathrm{Cl}_{2}(3 \times 10 \mathrm{~mL})$. La fase orgánica se seca sobre $\mathrm{Na}_{2} \mathrm{SO}_{4}$ anhidro y se concentra a presión reducida. El residuo resultante se purifica mediante columna de cromatografía de sílica gel (hexano / AcOEt, 8 / 1) para obtener 45g.

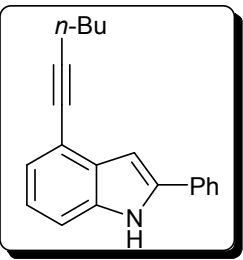

2-Fenil-4-(1-hexinil)-1 $H$-indol (45g)

Sólido marrón.

P.f. $=33-35^{\circ} \mathrm{C}$.

${ }^{1}$ H RMN (300 MHz, $\left.\mathrm{CDCl}_{3}\right): \delta=8.39(\mathrm{sa}, 1 \mathrm{H}), 7.69(\mathrm{~d}, J=7.3 \mathrm{~Hz}, 2 \mathrm{H}), 7.45(\mathrm{t}, J=7.7 \mathrm{~Hz}, 2 \mathrm{H}), 7.33(\mathrm{~d}, J=$ $7.3 \mathrm{~Hz}, 2 \mathrm{H}), 7.21(\mathrm{~d}, J=7.3 \mathrm{~Hz}, 1 \mathrm{H}), 7.11(\mathrm{t}, J=7.7 \mathrm{~Hz}, 1 \mathrm{H}), 6.99-6.97(\mathrm{~m}, 1 \mathrm{H}), 2.55(\mathrm{t}, J=6.9 \mathrm{~Hz}, 2 \mathrm{H})$, $1.75-1.63(\mathrm{~m}, 2 \mathrm{H}), 1.62-1.50(\mathrm{~m}, 2 \mathrm{H}), 1.00(\mathrm{t}, J=7.2 \mathrm{~Hz}, 3 \mathrm{H}) \mathrm{ppm}$.

${ }^{13} \mathbf{C}$ RMN (75.4 MHz, $\left.\mathrm{CDCl}_{3}\right): \delta=138.2(\mathrm{C}), 136.5(\mathrm{C}), 132.3(\mathrm{C}), 131.1(\mathrm{C}), 129.2(2 \times \mathrm{CH}), 128.0(\mathrm{CH}), 125.3$ $(2 \times \mathrm{CH}), 123.9(\mathrm{CH}), 122.3(\mathrm{CH}), 115.8(\mathrm{C}), 110.7(\mathrm{CH}), 99.9(\mathrm{CH}), 93.2(\mathrm{C}), 79.3(\mathrm{C}), 31.2\left(\mathrm{CH}_{2}\right), 22.2$ $\left(\mathrm{CH}_{2}\right), 19.6\left(\mathrm{CH}_{2}\right), 13.9\left(\mathrm{CH}_{3}\right) \mathrm{ppm}$.

EMBR (IE), m/z (\%): 273 (M+ , 89), 258 (16), 244 (38), 230 (100), 202 (29), 127 (23).

EMAR calculado para $\mathrm{C}_{20} \mathrm{H}_{19} \mathrm{~N}$ : 273.1517; encontrado: 273.1511 .

\section{C.5.5 Procedimiento para la preparación de los 4-(2-furanil)-1H-indoles 2-sustituidos 46}

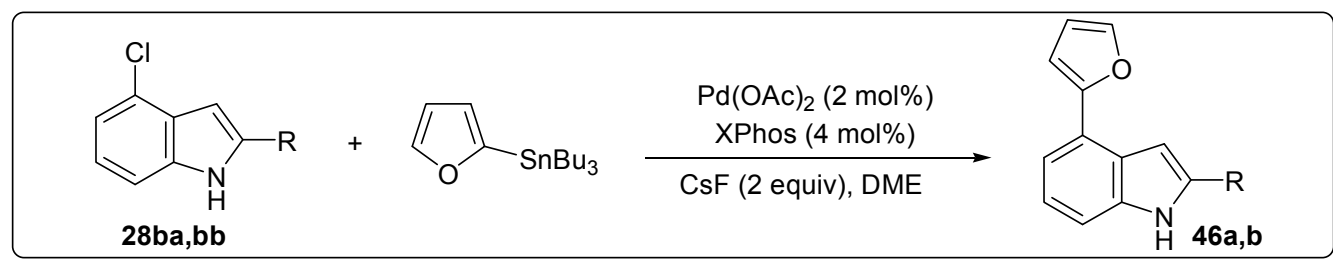

$\mathrm{Pd}(\mathrm{OAc})_{2}(1.3 \mathrm{mg}, 2 \mathrm{~mol} \%)$ y XPhos $(5.7 \mathrm{mg}, 4 \mathrm{~mol} \%)$ previamente mezclados, CsF (100 mg, $0.66 \mathrm{mmol})$, el correspondiente 4-cloroindol $28 \mathrm{ba}$ ó $28 \mathrm{bb}(0.3 \mathrm{mmol})$ y tributil-(2-furanil)estannano $(118 \mathrm{mg}, 0.33 \mathrm{mmol})$ en DME $(0.8 \mathrm{~mL})$ se agitan bajo $\mathrm{N}_{2}$ a $80^{\circ} \mathrm{C}$ durante 3 horas (el acoplamiento se monitoriza por CG-EM). Una vez que la reacción alcanza temperatura ambiente, el crudo se filtra a través de celita y se lava con AcOEt $(20 \mathrm{~mL})$. El filtrado se concentra a presión reducida y el residuo se purifica mediante columna de cromatografía (hexano / AcOEt) obteniéndose 46.

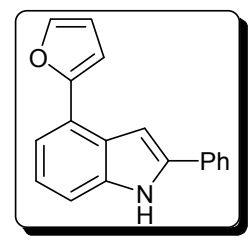

2-Fenil-4-(2-furanil)-1H-indol (46a)

Líquido incoloro.

$\mathrm{R}_{\mathrm{f}}=0.31$ (hexano / AcOEt, $8 / 1$ ). 
${ }^{1} \mathbf{H}$ RMN (300 MHz, $\left.\mathrm{CDCl}_{3}\right): \delta=8.43(\mathrm{sa}, 1 \mathrm{H}), 7.73-7.64(\mathrm{~m}, 3 \mathrm{H}), 7.58(\mathrm{dd}, J=6.7,1.6 \mathrm{~Hz}, 1 \mathrm{H}), 7.47(\mathrm{t}, J=7.6 \mathrm{~Hz}$, 2H), 7.40-7.35 (m, 2H), 7.31-7.24 (m, 2H), $6.92(\mathrm{~d}, J=3.3 \mathrm{~Hz}, 1 \mathrm{H}), 6.63(\mathrm{dd}, J=3.3,1.8 \mathrm{~Hz}, 1 \mathrm{H}) \mathrm{ppm}$.

${ }^{13} \mathbf{C}$ RMN (75.4 MHz, $\left.\mathrm{CDCl}_{3}\right): \delta=154.6(\mathrm{C}), 141.8(\mathrm{CH}), 138.5(\mathrm{C}), 137.6(\mathrm{C}), 132.1(\mathrm{C}), 129.0(2 \times \mathrm{CH}), 127.9$ $(\mathrm{CH}), 125.3(2 \times \mathrm{CH}), 124.9(\mathrm{C}), 123.0(\mathrm{C}), 122.4(\mathrm{CH}), 116.9(\mathrm{CH}), 111.7(\mathrm{CH}), 110.5(\mathrm{CH}), 106.5(\mathrm{CH})$, $100.2(\mathrm{CH}) \mathrm{ppm}$.

EMBR (IE), m/z (\%): 259 (M+, 100), 230 (40), 202 (8), 127 (8).

EMAR calculado para $\mathrm{C}_{18} \mathrm{H}_{13} \mathrm{NO}$ : 259.0997; encontrado: 259.0994 .

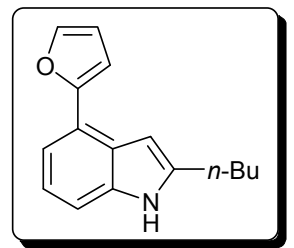

2-Butil-4-(2-furanil)-1 $H$-indol (46b)

Sólido blanco.

P.f. $=50-52^{\circ} \mathrm{C}$.

${ }^{1}$ H RMN $\left(300 \mathrm{MHz}, \mathrm{CDCl}_{3}\right): \delta=7.85(\mathrm{sa}, 1 \mathrm{H}), 7.61(\mathrm{~d}, J=1.8 \mathrm{~Hz}, 1 \mathrm{H}), 7.56-7.52(\mathrm{~m}, 1 \mathrm{H}), 7.23-7.20(\mathrm{~m}, 2 \mathrm{H})$, $6.85(\mathrm{~d}, J=3.3 \mathrm{~Hz}, 1 \mathrm{H}), 6.75(\mathrm{~s}, 1 \mathrm{H}), 6.60(\mathrm{ddd}, J=3.3,1.8,0.6 \mathrm{~Hz}, 1 \mathrm{H}), 2.76(\mathrm{t}, J=7.6 \mathrm{~Hz}, 2 \mathrm{H})$, $1.79-1.68(\mathrm{~m}, 2 \mathrm{H}), 1.52-1.39(\mathrm{~m}, 2 \mathrm{H}), 1.01(\mathrm{t}, J=7.3 \mathrm{~Hz}, 3 \mathrm{H}) \mathrm{ppm}$.

${ }^{13} \mathbf{C}$ RMN (75.4 MHz, $\mathrm{CDCl}_{3}$ ): $\delta=154.8(\mathrm{C}), 141.5(\mathrm{CH}), 141.0(\mathrm{C}), 136.6(\mathrm{C}), 124.4(\mathrm{C}), 122.1(\mathrm{C}), 121.0(\mathrm{CH}), 116.4$ $(\mathrm{CH}), 111.6(\mathrm{CH}), 110.0(\mathrm{CH}), 106.2(\mathrm{CH}), 99.6(\mathrm{CH}), 31.4\left(\mathrm{CH}_{2}\right), 28.1\left(\mathrm{CH}_{2}\right), 22.5\left(\mathrm{CH}_{2}\right), 14.0\left(\mathrm{CH}_{3}\right) \mathrm{ppm}$.

EMBR (IE), m/z (\%): $239\left(\mathrm{M}^{+}, 56\right), 196(100), 167$ (14), 154 (4).

EMAR calculado para $\mathrm{C}_{18} \mathrm{H}_{17} \mathrm{NO}$ : 239.1310; encontrado: 239.1319 .

\section{C.5.6 Sintesis de los 4-aril-1H-indoles 2-sustituidos 47 mediante reacción de Suzuki}

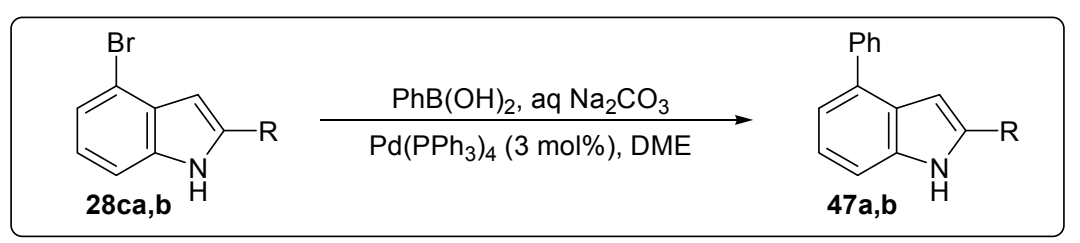

A una mezcla del 4-bromo- $1 H$-indol 28ca ó 28cb (1 equiv), ácido fenilborónico (1.5 equiv) y $\mathrm{Pd}\left(\mathrm{PPh}_{3}\right)_{4}(3 \mathrm{~mol} \%)$ en DME $(15 \mathrm{~mL} / \mathrm{mmol})$ bajo $\mathrm{N}_{2}$ se añade $\mathrm{Na}_{2} \mathrm{CO}_{3}$ (1.5 equiv) en $\mathrm{H}_{2} \mathrm{O}(7 \mathrm{~mL} /$ mmol). La mezcla de reacción se agita a $80^{\circ} \mathrm{C}$ durante 15 horas (el progreso de la reacción se monitoriza por CG-EM). A continuación se añaden $\mathrm{CH}_{2} \mathrm{Cl}_{2}(10 \mathrm{~mL})$ y $\mathrm{H}_{2} \mathrm{O}$ a la mezcla de reacción fría. La fase acuosa separada se extrae con $\mathrm{CH}_{2} \mathrm{Cl}_{2}(3 \times 20 \mathrm{~mL})$. La combinación de fases orgánicas se seca sobre $\mathrm{Na}_{2} \mathrm{SO}_{4}$ anhidro y se evapora a presión reducida. El residuo se purifica mediante columna de cromatografía (hexano / AcOEt, 8 / 1) para dar los indoles 47.

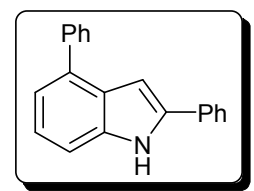

2,4-Difenil-1H-indol (47a)

Sólido blanco.

P.f. $=205-207^{\circ} \mathrm{C}\left(\right.$ lit. $\left.^{277}=209^{\circ} \mathrm{C}\right)$.

${ }^{1}$ H RMN $\left(300 \mathrm{MHz}, \mathrm{CDCl}_{3}\right): \delta=8.42(\mathrm{sa}, 1 \mathrm{H}), 7.89-7.82(\mathrm{~m}, 2 \mathrm{H}), 7.67(\mathrm{~d}, J=8.1 \mathrm{~Hz}, 2 \mathrm{H}), 7.61(\mathrm{t}, J=7.7 \mathrm{~Hz}$, 2H), 7.53-7.44 (m, 3H), 7.43-7.25 (m, 4H), $7.12(\mathrm{~d}, J=2.2 \mathrm{~Hz}, 1 \mathrm{H}) \mathrm{ppm}$.

${ }^{277}$ C. F. Allen, M. R. Gilbert, D. M. Young, J. Org. Chem. 1937, 2, 235. 
${ }^{13} \mathbf{C}$ RMN (75.4 MHz, $\left.\mathrm{CDCl}_{3}\right): \delta=141.3(\mathrm{C}), 138.3(\mathrm{C}), 137.3(\mathrm{C}), 134.5$ (C), $132.2(\mathrm{C}), 129.1(2 \times \mathrm{CH}), 128.9$ $(2 \times \mathrm{CH}), 128.7(2 \times \mathrm{CH}), 127.8(\mathrm{CH}), 127.6(\mathrm{C}), 127.1(\mathrm{CH}), 125.2(2 \times \mathrm{CH}), 122.7(\mathrm{CH}), 120.2(\mathrm{CH}), 110.2$ $(\mathrm{CH}), 99.6(\mathrm{CH}) \mathrm{ppm}$.

EMBR (IE), m/z (\%): 269 (M+1 100), 190 (10), 165 (53), 133 (11), 77 (28).

EMAR calculado para $\mathrm{C}_{20} \mathrm{H}_{15} \mathrm{~N}: 269.1204$; encontrado: 269.1204 .

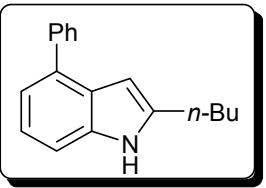

\section{2-Butil-4-fenil-1H-indol (47b)}

Líquido incoloro.

$\mathrm{R}_{\mathrm{f}}=0.64$ (hexano / AcOEt, $6 /$ 1).

${ }^{1} \mathbf{H}$ RMN $\left(400 \mathrm{MHz}, \mathrm{CDCl}_{3}\right): \delta=7.88-7.83(\mathrm{~m}, 3 \mathrm{H}), 7.60(\mathrm{t}, J=7.6 \mathrm{~Hz}, 2 \mathrm{H}), 7.48(\mathrm{t}, J=7.6 \mathrm{~Hz}, 1 \mathrm{H})$, 7.33-7.30 (m, 3H), $6.56(\mathrm{~d}, J=1.7 \mathrm{~Hz}, 1 \mathrm{H}), 2.77$ (t, $J=7.6 \mathrm{~Hz}, 2 \mathrm{H}), 1.81-1.71(\mathrm{~m}, 2 \mathrm{H}), 1.54-1.44(\mathrm{~m}$, $2 \mathrm{H}), 1.05$ (t, $J=7.3 \mathrm{~Hz}, 3 \mathrm{H}) \mathrm{ppm}$.

${ }^{13}$ C RMN (100.6 MHz, $\left.\mathrm{CDCl}_{3}\right): \delta=141.6(\mathrm{C}), 140.6(\mathrm{C}), 136.3(\mathrm{C}), 133.4(\mathrm{C}), 128.8(2 \times \mathrm{CH}), 128.5(2 \times \mathrm{CH})$, $127.0(\mathrm{C}), 126.8(\mathrm{CH}), 121.3(\mathrm{CH}), 119.6(\mathrm{CH}), 109.7(\mathrm{CH}), 98.9(\mathrm{CH}), 31.4\left(\mathrm{CH}_{2}\right), 28.0\left(\mathrm{CH}_{2}\right), 22.5$ $\left(\mathrm{CH}_{2}\right), 14.0\left(\mathrm{CH}_{3}\right) \mathrm{ppm}$.

EMBR (IE), m/z (\%): $249\left(\mathrm{M}^{+}, 23\right), 206$ (100), 178 (15), 165 (16).

EMAR calculado para $\mathrm{C}_{18} \mathrm{H}_{19} \mathrm{~N}: 249.1517$; encontrado: 249.1528 .

\section{C.5.7 Sintesis del 4-bromo-2-fenil-3-[(Z)-1,3-difenil-4-metil-penta-1,3-dienil)-1H-indol 48}

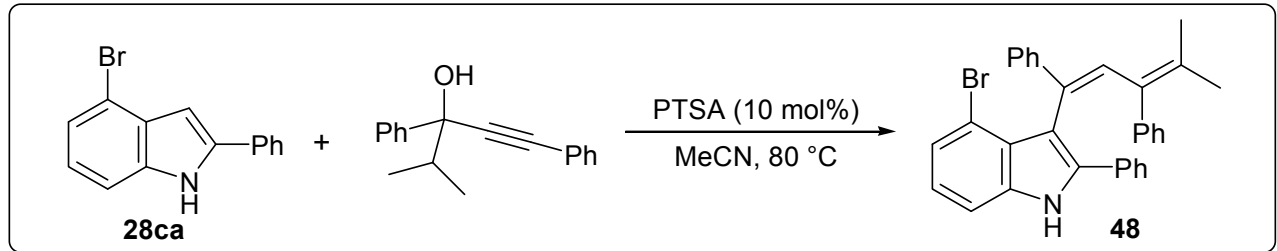

A una disolución de 4-bromo-2-fenil- $1 H$-indol (42 mg, $0.155 \mathrm{mmol})$ y 1,3-difenil-4-metilpent1-in-3-ol (42 mg, $0.17 \mathrm{mmol})$ en $\mathrm{MeCN}(2 \mathrm{~mL})$ se añade ácido $p$-toluensulfónico monohidrato (13 mg, $10 \mathrm{~mol} \%$ ). La mezcla resultante se calienta a $80{ }^{\circ} \mathrm{C}$ durante 5.5 horas (el progreso de la reacción se monitoriza por CG-EM). Se evapora el disolvente a presión reducida. El residuo resultante se purifica mediante columna de cromatografía (hexano / AcOEt, 10 / 1) para obtener 48.

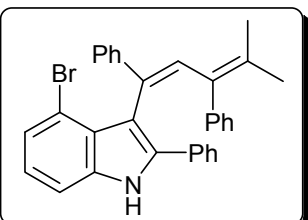

4-Bromo-2-fenil-3-[(Z)-1,3-difenil-4-metilpenta-1,3-dienil]-1H-indol (48) Sólido blanco.

P.f. $=72-74{ }^{\circ} \mathrm{C}$

${ }^{1} \mathbf{H}$ RMN (300 MHz, $\left.\mathrm{CDCl}_{3}\right): \delta=7.98(\mathrm{sa}, 1 \mathrm{H}), 7.55-7.48(\mathrm{~m}, 4 \mathrm{H}), 7.39-7.23(\mathrm{~m}, 7 \mathrm{H}), 7.05(\mathrm{~d}, J=7.8 \mathrm{~Hz}, 1 \mathrm{H}), 6.95$ $(\mathrm{d}, J=7.8 \mathrm{~Hz}, 1 \mathrm{H}), 6.82(\mathrm{t}, J=7.8 \mathrm{~Hz}, 1 \mathrm{H}), 6.77-6.64(\mathrm{~m}, 4 \mathrm{H}), 6.50(\mathrm{t}, J=7.1 \mathrm{~Hz}, 1 \mathrm{H}), 1.43(\mathrm{~s}, 6 \mathrm{H}) \mathrm{ppm}$.

${ }^{13}$ C RMN (75.4 MHz, $\mathrm{CDCl}_{3}$ ): $\delta=144.2$ (C), 141.3 (C), 136.91 (C), 136.89 (C), 134.9 (C), 134.5 (C), 134.1 (C), $133.3(\mathrm{CH}), 132.8(\mathrm{C}), 128.55(2 \times \mathrm{CH}), 128.53(2 \times \mathrm{CH}), 128.4(2 \times \mathrm{CH}), 127.8(\mathrm{CH}), 127.2(2 \times \mathrm{CH}), 126.94$ $(2 \times \mathrm{CH}), 126.87(\mathrm{C}), 126.8(\mathrm{CH}), 126.2(2 \times \mathrm{CH}), 124.3(\mathrm{CH}), 124.0(\mathrm{CH}), 122.7(\mathrm{CH}), 115.1(\mathrm{C}), 113.3$ (C), $109.4(\mathrm{CH}), 22.2\left(\mathrm{CH}_{3}\right), 21.0\left(\mathrm{CH}_{3}\right) \mathrm{ppm}$

EMBR (IE), m/z (\%): 505 (M+2, 37), $503\left(\mathrm{M}^{+}, 36\right), 424$ (41), 409 (72), 207 (100)

EMAR calculado para $\mathrm{C}_{32} \mathrm{H}_{26} \mathrm{BrN}$ : 503.1249; encontrado: 503.1255 . 


\section{Reacciones de orto-zincación en derivados de 3-bromoanisoles.} Aplicación a la síntesis de benzo[b]furanos alcoxi-funcionalizados.

A Síntesis de alcoxi y dialcoxibenzo $[b]$ furanos a partir de derivados de 2,3dihalofenoles

\section{A.1 Preparación de 3-bromo-2-yodoanisoles}

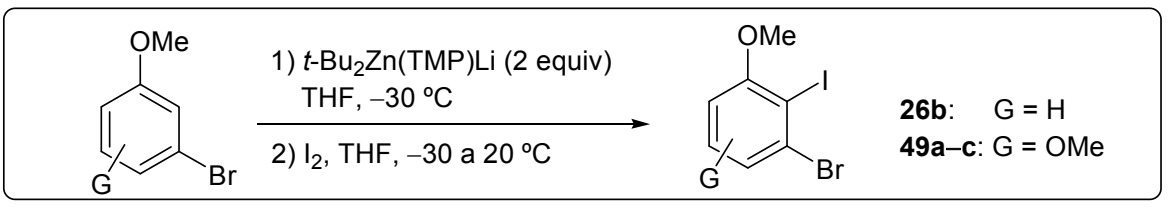

A una disolución del amiduro de litio de la 2,2,6,6-tetrametilpiperidina (20 mmol) en THF (30 $\mathrm{mL}) \mathrm{a}-78^{\circ} \mathrm{C}$, se le añade una disolución de di-t-butilzinc $(22 \mathrm{mmol})$ en THF $(30 \mathrm{~mL})$ y se mantiene la agitación a $0{ }^{\circ} \mathrm{C}$ durante 30 minutos. Posteriormente a $-78^{\circ} \mathrm{C}$, a la disolución de TMP-zincato se le adiciona el correspondiente 3 -bromoanisol $(10 \mathrm{mmol})$ y se permite alcanzar la temperatura de $-30^{\circ} \mathrm{C}$. La agitación se mantiene a esa temperatura durante 12 horas, tras las cuales se adiciona yodo (17.78 g, $70 \mathrm{mmol}$ ). Después de 30 minutos, se deja alcanzar temperatura ambiente lentamente y se continúa la agitación durante 2 horas. La mezcla de reacción resultante se hidroliza con una disolución al 10\% de $\mathrm{Na}_{2} \mathrm{~S}_{2} \mathrm{O}_{3}$ y se extrae con $\mathrm{Et}_{2} \mathrm{O}(3 \times 30 \mathrm{~mL})$. La fase orgánica se seca sobre $\mathrm{Na}_{2} \mathrm{SO}_{4}$ anhidro y los disolventes se evaporan a presión reducida $(20 \mathrm{~mm} \mathrm{Hg})$. El residuo obtenido se purifica por cromatografía de columna (hexano / AcOEt). De esta forma se aislan los 3-bromo-2-yodoanisoles 26b y 49a-c. Los datos físicos y espectroscópicos de 26b han sido detallados en el Capítulo 1.

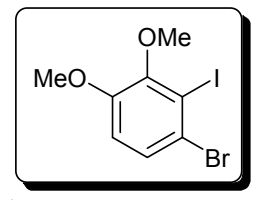

1-Bromo-3,4-dimetoxi-2-yodobenceno (49a)

Sólido blanco.

P.f. $=44-46^{\circ} \mathrm{C}$.

${ }^{1} \mathbf{H}$ RMN $\left(300 \mathrm{MHz}, \mathrm{CDCl}_{3}\right): \delta=7.32(\mathrm{~d}, J=8.8 \mathrm{~Hz}, 1 \mathrm{H}), 6.78(\mathrm{~d}, J=8.8 \mathrm{~Hz}, 1 \mathrm{H}), 3.83(\mathrm{~s}, 3 \mathrm{H}), 3.80(\mathrm{~s}, 3 \mathrm{H})$ ppm.

${ }^{13} \mathbf{C}$ RMN (75.4 MHz, $\left.\mathrm{CDCl}_{3}\right): \delta=151.4(\mathrm{C}), 150.6(\mathrm{C}), 127.9(\mathrm{CH}), 120.2(\mathrm{C}), 113.7(\mathrm{CH}), 101.0(\mathrm{C}), 60.4$ $\left(\mathrm{CH}_{3}\right), 56.3\left(\mathrm{CH}_{3}\right) \mathrm{ppm}$.

EMBR (IE), m/z (\%): 344 (M+2, 98\%), 342 (M+1 100), 329 (29), 327 (31), 172 (22).

EMAR calculado para $\mathrm{C}_{8} \mathrm{H}_{8} \mathrm{BrIO}_{2}: 341.8752$; encontrado: 341.8754 . 


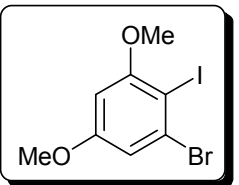

1-Bromo-3,5-dimetoxi-2-yodobenceno (49b)

Sólido blanco.

P.f. $=95-97^{\circ} \mathrm{C}\left(\right.$ lit. $\left.{ }^{278}=93-95^{\circ} \mathrm{C}\right)$.

${ }^{1} \mathbf{H}$ RMN $\left(300 \mathrm{MHz}, \mathrm{CDCl}_{3}\right): \delta=6.85(\mathrm{~d}, J=2.6 \mathrm{~Hz}, 1 \mathrm{H}), 6.32(\mathrm{~d}, J=2.6 \mathrm{~Hz}, 1 \mathrm{H}), 3.83(\mathrm{~s}, 3 \mathrm{H}), 3.78(\mathrm{~s}, 3 \mathrm{H})$ ppm.

${ }^{13}$ C RMN (75.4 MHz, $\left.\mathrm{CDCl}_{3}\right): \delta=161.3(\mathrm{C}), 160.4(\mathrm{C}), 131.0(\mathrm{C}), 131.0(\mathrm{C}), 109.7(\mathrm{CH}), 97.8(\mathrm{CH}), 83.5(\mathrm{C})$, $56.8\left(\mathrm{CH}_{3}\right), 55.8\left(\mathrm{CH}_{3}\right) \mathrm{ppm}$.

EMBR (IE), m/z (\%): 344 (M+2, 100), 342 (M+1 100), 301 (10), 299 (11), 187 (16), 185 (17).

EMAR calculado para $\mathrm{C}_{8} \mathrm{H}_{8} \mathrm{BrIO}_{2}: 341.8752$; encontrado: 341.8758 .

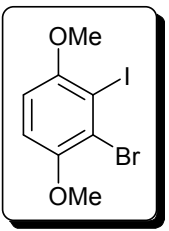

2-Bromo-1,4-dimetoxi-3-yodobenceno (49c)

Sólido blanco.

P.f. $=153-155^{\circ} \mathrm{C}$.

${ }^{1} \mathbf{H}$ RMN (300 MHz, $\left.\mathrm{CDCl}_{3}\right): \delta=6.89(\mathrm{~d}, J=8.8 \mathrm{~Hz}, 1 \mathrm{H}), 6.77(\mathrm{~d}, J=8.8 . \mathrm{Hz}, 1 \mathrm{H}), 3.84(\mathrm{~s}, 3 \mathrm{H}), 3.83(\mathrm{~s}, 3 \mathrm{H})$ ppm.

${ }^{13}$ C RMN (75.4 MHz, $\left.\mathrm{CDCl}_{3}\right): \delta=154.1(\mathrm{C}), 151.2(\mathrm{C}), 121.0(\mathrm{C}), 112.1(\mathrm{CH}), 109.9(\mathrm{CH}), 96.6(\mathrm{C}), 57.3$ $\left(\mathrm{CH}_{3}\right), 57.2\left(\mathrm{CH}_{3}\right) \mathrm{ppm}$.

EMBR (IE), m/z (\%): $344\left(\mathrm{M}^{+}+2,98\right), 342\left(\mathrm{M}^{+}, 100\right), 329$ (64), 327 (65).

EMAR calculado para $\mathrm{C}_{8} \mathrm{H}_{8} \mathrm{BrIO}_{2}: 341.8752$; encontrado: 341.8750 .

\section{A.2 Procedimiento general para la preparación de los o-alquinilhaloarenos 50 y 51}

\section{A.2.1 Sintesis de los o-alquinilbromoanisoles 50a-e empleando fluoruro de tetrabutil amonio}

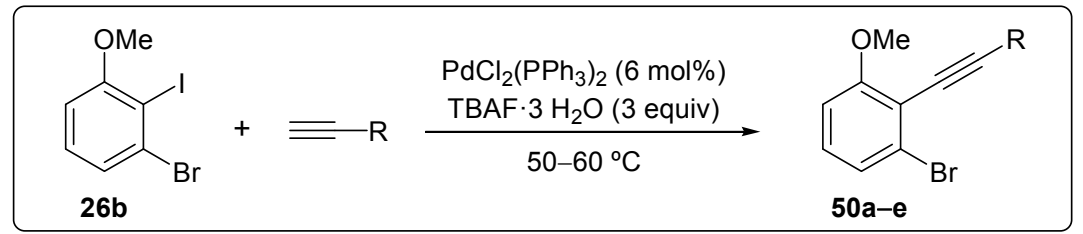

Una mezcla formada por 1-bromo-2-yodoanisol (780 mg, $2.5 \mathrm{mmol})$, alquino (3 $\mathrm{mmol})$, $\mathrm{PdCl}_{2}\left(\mathrm{PPh}_{3}\right)_{2}(105 \mathrm{mg}, 0.15 \mathrm{mmol})$ y TBAF$\cdot 3 \mathrm{H}_{2} \mathrm{O}(2.37 \mathrm{~g}, 7.5 \mathrm{mmol})$ se calienta bajo atmósfera de $\mathrm{N}_{2}$ a $50-60{ }^{\circ} \mathrm{C}$ durante el tiempo necesario hasta la completa desaparición de $\mathbf{2 6 \mathbf { b }}$, monitorizando la reacción por CG-EM. Posteriormente, se deja que la mezcla alcance temperatura ambiente, se hidroliza con $\mathrm{H}_{2} \mathrm{O}$ y se extrae con $\mathrm{Et}_{2} \mathrm{O}(3 \times 20 \mathrm{~mL})$. La fase orgánica se seca sobre $\mathrm{Na}_{2} \mathrm{SO}_{4}$ anhidro y se elimina el disolvente a presión reducida $(20 \mathrm{~mm} \mathrm{Hg})$. La purificación del residuo resultante por cromatografía de columna (hexano / AcOEt) da lugar a los compuestos 50a-e.

${ }^{278}$ S. Fuse, S. Sugiyama, T. Takahashi, Chem. Asian J. 2010, 5, 2459. 


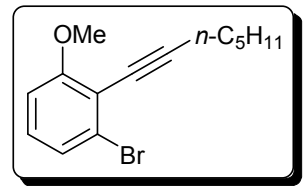

1-Bromo-2-(1-heptinil)-3-metoxibenceno (50a)

Líquido marrón.

$\mathrm{R}_{\mathrm{f}}=0.58$ (hexano / AcOEt, $8 / 1$ ).

${ }^{1} \mathbf{H}$ RMN $\left(300 \mathrm{MHz}, \mathrm{CDCl}_{3}\right): \delta=7.16(\mathrm{~d}, J=8.2 \mathrm{~Hz}, 1 \mathrm{H}), 7.04(\mathrm{t}, J=8.2 \mathrm{~Hz}, 1 \mathrm{H}), 6.76(\mathrm{~d}, J=8.2 \mathrm{~Hz}, 1 \mathrm{H})$, $3.84(\mathrm{~s}, 3 \mathrm{H}), 2.52(\mathrm{t}, J=6.9 \mathrm{~Hz}, 2 \mathrm{H}), 1.72-1.61(\mathrm{~m}, 2 \mathrm{H}), 1.56-1.44(\mathrm{~m}, 2 \mathrm{H}), 1.43-1.29(\mathrm{~m}, 2 \mathrm{H}), 0.92(\mathrm{t}, J$ $=7.1 \mathrm{~Hz}, 3 \mathrm{H}) \mathrm{ppm}$.

${ }^{13}$ C RMN (75.4 MHz, $\left.\mathrm{CDCl}_{3}\right): \delta=161.1(\mathrm{C}), 128.9(\mathrm{CH}), 127.0(\mathrm{C}), 124.5(\mathrm{CH}), 115.6(\mathrm{C}), 109.1(\mathrm{CH}), 100.1$ (C), $75.6(\mathrm{C}), 56.2\left(\mathrm{CH}_{3}\right), 31.1\left(\mathrm{CH}_{2}\right), 28.4\left(\mathrm{CH}_{2}\right), 22.3\left(\mathrm{CH}_{2}\right), 20.0\left(\mathrm{CH}_{2}\right), 14.1\left(\mathrm{CH}_{3}\right) \mathrm{ppm}$.

EMBR (IE), m/z (\%): 282 (M+2, 39), 280 (M+, 41), 253 (13), 251 (13), 211 (53), 209 (54), 146 (100), 144 (84).

EMAR calculado para $\mathrm{C}_{14} \mathrm{H}_{17} \mathrm{BrO}$ : 280.0463; encontrado: 280.0472 .

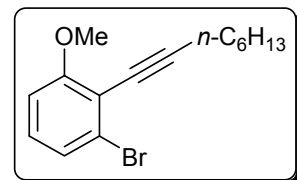

1-Bromo-3-metoxi-2-(1-octinil)benceno (50b)

Líquido amarillo.

$\mathrm{R}_{\mathrm{f}}=0.67$ (hexano / AcOEt, $6 / 1$ ).

${ }^{1} \mathbf{H}$ RMN $\left(300 \mathrm{MHz}, \mathrm{CDCl}_{3}\right): \delta=7.15(\mathrm{dd}, J=8.2,0.8 \mathrm{~Hz}, 1 \mathrm{H}), 7.03(\mathrm{t}, J=8.2 \mathrm{~Hz}, 1 \mathrm{H}), 6.76(\mathrm{dd}, J=8.2,0.8$ $\mathrm{Hz}, 1 \mathrm{H}), 3.83(\mathrm{~s}, 3 \mathrm{H}), 2.52(\mathrm{t}, J=6.9 \mathrm{~Hz}, 2 \mathrm{H}), 1.70-1.60(\mathrm{~m}, 2 \mathrm{H}), 1.58-1.47(\mathrm{~m}, 2 \mathrm{H}), 1.38-1.27(\mathrm{~m}, 4 \mathrm{H})$, $0.90(\mathrm{t}, J=6.9 \mathrm{~Hz}, 3 \mathrm{H}) \mathrm{ppm}$.

${ }^{13} \mathbf{C}$ RMN (75.4 MHz, $\left.\mathrm{CDCl}_{3}\right): \delta=161.1(\mathrm{C}), 128.8(\mathrm{CH}), 126.9(\mathrm{C}), 124.4(\mathrm{CH}), 115.6(\mathrm{C}), 109.1(\mathrm{CH}), 100.1$ (C), $75.6(\mathrm{C}), 56.1\left(\mathrm{CH}_{3}\right), 31.4\left(\mathrm{CH}_{2}\right), 28.65\left(\mathrm{CH}_{2}\right), 28.56\left(\mathrm{CH}_{2}\right), 22.7\left(\mathrm{CH}_{2}\right), 20.0\left(\mathrm{CH}_{2}\right), 14.1\left(\mathrm{CH}_{3}\right) \mathrm{ppm}$.

EMBR (IE), m/z (\%): $296\left(\mathrm{M}^{+}+2,39\right), 294\left(\mathrm{M}^{+}, 43\right), 253$ (14), 151 (15), 227 (25), 225 (34), 211 (57), 209 (60), 201 (44), 199 (54), 146 (100), 144 (81).

EMAR calculado para $\mathrm{C}_{15} \mathrm{H}_{19} \mathrm{BrO}$ : 294.0619; encontrado: 294.0610.

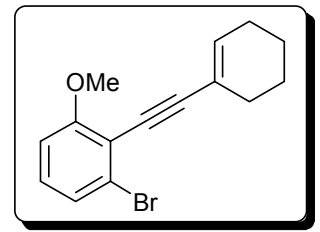

1-Bromo-2-(1-ciclohexeniletinil)-3-metoxibenceno (50c)

Líquido marrón.

$\mathrm{R}_{\mathrm{f}}=0.28$ (hexano / AcOEt, $20 / 1$ ).

${ }^{1}$ H RMN $\left(300 \mathrm{MHz}, \mathrm{CDCl}_{3}\right): \delta=7.20-7.14(\mathrm{~m}, 1 \mathrm{H}), 7.07(\mathrm{t}, J=8.2 \mathrm{~Hz}, 1 \mathrm{H}), 6.79(\mathrm{~d}, J=8.2 \mathrm{~Hz}, 1 \mathrm{H})$, 6.33-6.24 (m, 1H), $3.86(\mathrm{~s}, 3 \mathrm{H}), 2.33-2.24(\mathrm{~m}, 2 \mathrm{H}), 2.19-2.09(\mathrm{~m}, 2 \mathrm{H}), 1.74-1.54(\mathrm{~m}, 4 \mathrm{H}) \mathrm{ppm}$.

${ }^{13} \mathbf{C}$ RMN (75.4 MHz, $\left.\mathrm{CDCl}_{3}\right): \delta=160.7(\mathrm{C}), 135.7(\mathrm{CH}), 129.1(\mathrm{CH}), 126.7(\mathrm{C}), 124.4(\mathrm{CH}), 120.8(\mathrm{C}), 115.3$ (C), 109.1 (CH), 100.2 (C), $81.9(\mathrm{C}), 56.1\left(\mathrm{CH}_{3}\right), 29.1\left(\mathrm{CH}_{2}\right), 25.8\left(\mathrm{CH}_{2}\right), 22.3\left(\mathrm{CH}_{2}\right), 21.5\left(\mathrm{CH}_{2}\right) \mathrm{ppm}$.

EMBR (IE), m/z (\%): $292\left(\mathrm{M}^{+}+2,49\right), 290\left(\mathrm{M}^{+}, 55\right), 139$ (98), 115 (100), 79 (95).

EMAR calculado para $\mathrm{C}_{15} \mathrm{H}_{15} \mathrm{BrO}$ : 290.0306; encontrado: 290.0310 .

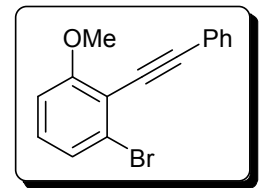

1-Bromo-2-(feniletinil)-3-metoxibenceno (50d)

Líquido marrón.

$\mathrm{R}_{\mathrm{f}}=0.19$ (hexano / AcOEt, 20 / 1).

${ }^{1} \mathbf{H}$ RMN $\left(300 \mathrm{MHz}, \mathrm{CDCl}_{3}\right): \delta=7.66-7.60(\mathrm{~m}, 2 \mathrm{H}), 7.40-7.33(\mathrm{~m}, 3 \mathrm{H}), 7.24(\mathrm{dd}, J=8.2,1.1 \mathrm{~Hz}, 1 \mathrm{H}), 7.14(\mathrm{t}$, $J=8.2 \mathrm{~Hz}, 1 \mathrm{H}), 6.84(\mathrm{dd}, J=8.2,1.1 \mathrm{~Hz}, 1 \mathrm{H}), 3.91(\mathrm{~s}, 3 \mathrm{H}) \mathrm{ppm}$.

${ }^{13}$ C RMN (75.4 MHz, $\left.\mathrm{CDCl}_{3}\right): \delta=161.1(\mathrm{C}), 131.8(2 \times \mathrm{CH}), 129.8(\mathrm{CH}), 128.6(\mathrm{CH}), 128.4(2 \times \mathrm{CH}), 127.1(\mathrm{C})$, 124.6 (CH), $123.3(\mathrm{C}), 115.0(\mathrm{C}), 109.4(\mathrm{CH}), 98.3(\mathrm{C}), 84.7(\mathrm{C}), 56.3\left(\mathrm{CH}_{3}\right) \mathrm{ppm}$. 
EMBR (IE), m/z (\%): 288 (M+2, 99), $286\left(\mathrm{M}^{+}, 100\right), 211$ (41), 182 (82), 163 (93).

EMAR calculado para $\mathrm{C}_{15} \mathrm{H}_{11} \mathrm{BrO}$ : 285.9993; encontrado: 285.9991 .

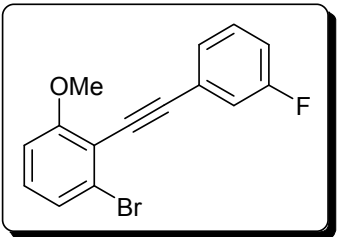

1-Bromo-2-(3-fluorofeniletinil)-3-metoxibenceno (50e)

Líquido marrón.

$\mathrm{R}_{\mathrm{f}}=0.45$ (hexano / AcOEt, $8 / 1$ ).

${ }^{1}$ H RMN $\left(300 \mathrm{MHz}, \mathrm{CDCl}_{3}\right): \delta=7.40(\mathrm{dt}, J=7.8,1.2 \mathrm{~Hz}, 1 \mathrm{H}), 7.35-7.29(\mathrm{~m}, 2 \mathrm{H}), 7.23(\mathrm{dd}, J=8.2,1.0 \mathrm{~Hz}, 1 \mathrm{H})$, $7.14(\mathrm{t}, J=8.2 \mathrm{~Hz}, 1 \mathrm{H}), 7.05(\mathrm{tdd}, J=8.5,2.6,1.0 \mathrm{~Hz}, 1 \mathrm{H}), 6.83(\mathrm{dd}, J=8.2,1.0 \mathrm{~Hz}, 1 \mathrm{H}), 3.89(\mathrm{~s}, 3 \mathrm{H}) \mathrm{ppm}$.

${ }^{13} \mathbf{C}$ RMN (75.4 MHz, $\left.\mathrm{CDCl}_{3}\right): \delta=162.4(\mathrm{~d}, J=246.3 \mathrm{~Hz}, \mathrm{C}), 161.2(\mathrm{C}), 130.2(\mathrm{CH}), 130.0(\mathrm{~d}, J=8.7 \mathrm{~Hz}, \mathrm{CH})$,

$127.7(\mathrm{~d}, J=3.0 \mathrm{~Hz}, \mathrm{CH}), 127.1(\mathrm{C}), 125.2(\mathrm{~d}, J=9.6 \mathrm{~Hz}, \mathrm{C}), 124.6(\mathrm{CH}), 118.4(\mathrm{~d}, J=22.8 \mathrm{~Hz}, \mathrm{CH})$,

115.8 (d, $J=21.2 \mathrm{~Hz}, \mathrm{CH}), 114.5(\mathrm{C}), 109.4(\mathrm{CH}), 96.8$ (d, $J=3.4 \mathrm{~Hz}, \mathrm{C}), 85.7(\mathrm{C}), 56.2\left(\mathrm{CH}_{3}\right) \mathrm{ppm}$.

EMBR (IE), m/z (\%): $306\left(\mathrm{M}^{+}+2,91\right), 304\left(\mathrm{M}^{+}, 100\right), 262$ (67), $196(37), 183$ (47).

EMAR calculado para $\mathrm{C}_{15} \mathrm{H}_{10} \mathrm{BrFO}$ : 303.9899; encontrado: 303.9907 .

\section{A.2.2 Síntesis de los o-alquinilbromoarenos 50a,d y 51 empleando catálisis $\mathrm{Pd} / \mathrm{Cu}$}

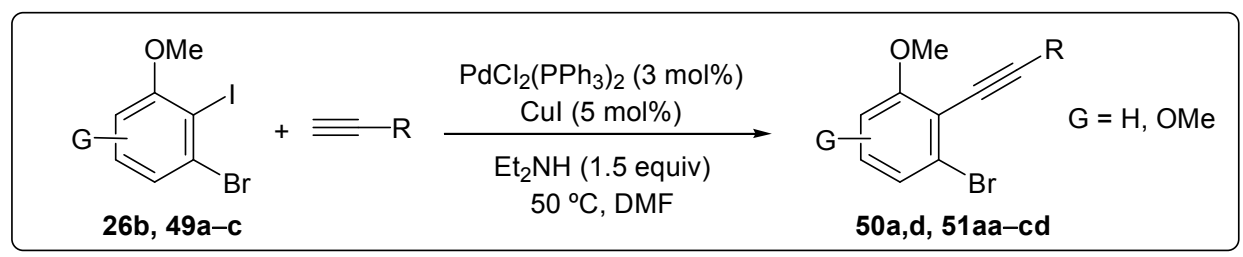

Una mezcla formada por el derivado de yodobenceno $26 b$ ó 49 (1 equiv), alquino (1.2 equiv), $\mathrm{PdCl}_{2}\left(\mathrm{PPh}_{3}\right)_{2}(3 \mathrm{~mol} \%)$, CuI $(5 \mathrm{~mol} \%)$ y Et ${ }_{2} \mathrm{NH}$ (1.5 equiv) en DMF anhidra (4 mL $\left./ \mathrm{mmol}\right)$ se agita bajo $\mathrm{N}_{2}$ a $50{ }^{\circ} \mathrm{C}$ durante el tiempo necesario hasta la completa desaparición del anisol de partida, monitorizado por CG-EM (2-4 horas). Una vez que la mezcla de reacción alcanza temperatura ambiente, se añaden $\mathrm{CH}_{2} \mathrm{Cl}_{2}(20 \mathrm{~mL} / \mathrm{mmol})$ y $0.5 \mathrm{M} \mathrm{HCl}(20 \mathrm{~mL} / \mathrm{mmol})$. La fase acuosa separada se extrae con $\mathrm{CH}_{2} \mathrm{Cl}_{2}(2 \times 20 \mathrm{~mL})$. La fase orgánica se lava con $\mathrm{H}_{2} \mathrm{O}(2 \times 40 \mathrm{~mL})$, se seca sobre $\mathrm{Na}_{2} \mathrm{SO}_{4}$ anhidro y se concentra a presión reducida. El residuo resultante se purifica mediante columna de cromatografía de sílica gel (hexano / AcOEt) permitiendo obtener los alquinil anisoles 50a,d y 51. Los datos físicos y espectroscópicos de 50a,d han sido detallados anteriormente.

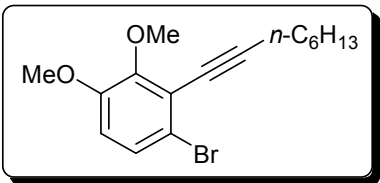

1-Bromo-3,4-dimetoxi-2-(1-octinil)benceno (51aa)

Líquido marrón.

$\mathrm{R}_{\mathrm{f}}=0.57$ (hexano / AcOEt, 7 / 1).

Reactivos: 49a (513 mg, $1.5 \mathrm{mmol})$, 1-octino $(265 \mu \mathrm{L}, 1.8 \mathrm{mmol})$.

${ }^{1} \mathbf{H}$ RMN $\left(300 \mathrm{MHz}, \mathrm{CDCl}_{3}\right): \delta=7.19(\mathrm{~d}, J=8.9 \mathrm{~Hz}, 1 \mathrm{H}), 6.66(\mathrm{~d}, J=8.9 \mathrm{~Hz}, 1 \mathrm{H}), 3.86(\mathrm{~s}, 3 \mathrm{H}), 3.78(\mathrm{~s}, 3 \mathrm{H}), 2.49(\mathrm{t}, J$ $=6.9 \mathrm{~Hz}, 2 \mathrm{H}), 1.68-1.57(\mathrm{~m}, 2 \mathrm{H}), 1.54-1.44(\mathrm{~m}, 2 \mathrm{H}), 1.33-1.25(\mathrm{~m}, 4 \mathrm{H}), 0.87(\mathrm{t}, J=6.9 \mathrm{~Hz}, 3 \mathrm{H}) \mathrm{ppm}$.

${ }^{13}$ C RMN (75.4 MHz, $\left.\mathrm{CDCl}_{3}\right): \delta=151.9(\mathrm{C}), 151.3(\mathrm{C}), 127.2(\mathrm{CH}), 121.1(\mathrm{C}), 116.3(\mathrm{C}), 112.6(\mathrm{CH}), 99.8(\mathrm{C})$, $75.4(\mathrm{C}), 60.7\left(\mathrm{CH}_{3}\right), 55.9\left(\mathrm{CH}_{3}\right), 31.3\left(\mathrm{CH}_{2}\right), 28.5\left(2 \times \mathrm{CH}_{2}\right), 22.6\left(\mathrm{CH}_{2}\right), 19.8\left(\mathrm{CH}_{2}\right), 14.1\left(\mathrm{CH}_{3}\right) \mathrm{ppm}$.

EMBR (IE), m/z (\%): $326\left(\mathrm{M}^{+}+2,58\right), 324\left(\mathrm{M}^{+}, 60\right), 241$ (32), 239 (34), 216 (24), 176 (100).

EMAR calculado para $\mathrm{C}_{16} \mathrm{H}_{21} \mathrm{BrO}_{2}: 324.0725$; encontrado: 324.0721 . 


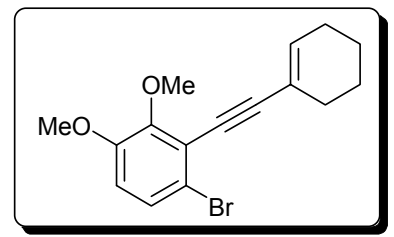

1-Bromo-2-(1-ciclohexeniletinil)-3,4-dimetoxibenceno (51ab)

Líquido marrón.

$\mathrm{R}_{\mathrm{f}}=0.23$ (hexano / AcOEt, $9 / 1$ ).

Reactivos: 49a (857 mg, $2.5 \mathrm{mmol})$, 1-etinilciclohexenilo $(352 \mu \mathrm{L}, 3 \mathrm{mmol})$.

${ }^{1} \mathbf{H}$ RMN $\left(300 \mathrm{MHz}, \mathrm{CDCl}_{3}\right): \delta=7.20(\mathrm{~d}, J=8.9 \mathrm{~Hz}, 1 \mathrm{H}), 6.68(\mathrm{~d}, J=8.9 \mathrm{~Hz}, 1 \mathrm{H}), 6.27(\mathrm{tt}, J=4.0,1.8 \mathrm{~Hz}$, $1 \mathrm{H}), 3.88(\mathrm{~s}, 3 \mathrm{H}), 3.79(\mathrm{~s}, 3 \mathrm{H}), 2.29-2.22(\mathrm{~m}, 2 \mathrm{H}), 2.16-2.08(\mathrm{~m}, 2 \mathrm{H}), 1.70-1.52(\mathrm{~m}, 4 \mathrm{H}) \mathrm{ppm}$.

${ }^{13} \mathbf{C}$ RMN (75.4 MHz, $\left.\mathrm{CDCl}_{3}\right): \delta=151.9(\mathrm{C}), 151.0(\mathrm{C}), 136.0(\mathrm{CH}), 127.3(\mathrm{CH}), 120.9(\mathrm{C}), 120.7(\mathrm{C}), 116.2$ (C), $112.9(\mathrm{CH}), 100.2(\mathrm{C}), 81.8(\mathrm{C}), 60.9\left(\mathrm{CH}_{3}\right), 56.1\left(\mathrm{CH}_{3}\right), 28.9\left(\mathrm{CH}_{2}\right), 25.8\left(\mathrm{CH}_{2}\right), 22.2\left(\mathrm{CH}_{2}\right), 21.5$ $\left(\mathrm{CH}_{2}\right) \mathrm{ppm}$.

EMBR (IE), m/z (\%): $322\left(\mathrm{M}^{+}+2,100\right), 320\left(\mathrm{M}^{+}, 100\right), 307$ (20), 305 (20), 211 (29).

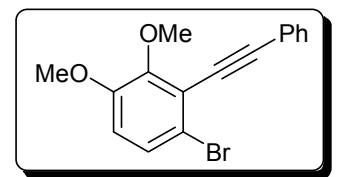

1-Bromo-2-(feniletinil)-3,4-dimetoxibenceno (51ac)

Líquido marrón.

$\mathrm{R}_{\mathrm{f}}=0.40$ (hexano / AcOEt, $9 / 1$ ).

Reactivos: 49a (686 mg, $2 \mathrm{mmol})$, fenilacetileno $(264 \mu \mathrm{L}, 2.4 \mathrm{mmol})$.

${ }^{1} \mathbf{H}$ RMN $\left(300 \mathrm{MHz}, \mathrm{CDCl}_{3}\right): \delta=7.64-7.58(\mathrm{~m}, 1 \mathrm{H}), 7.60(\mathrm{~d}, J=2.3 \mathrm{~Hz}, 1 \mathrm{H}), 7.39-7.34(\mathrm{~m}, 3 \mathrm{H}), 7.29(\mathrm{~d}, J=$ $8.8 \mathrm{~Hz}, 1 \mathrm{H}), 6.76(\mathrm{~d}, J=8.8 \mathrm{~Hz}, 1 \mathrm{H}), 3.99(\mathrm{~s}, 3 \mathrm{H}), 3.84(\mathrm{~s}, 3 \mathrm{H}) \mathrm{ppm}$.

${ }^{13} \mathbf{C}$ RMN (75.4 MHz, $\left.\mathrm{CDCl}_{3}\right): \delta=152.1(\mathrm{C}), 151.3(\mathrm{C}), 131.7(2 \times \mathrm{CH}), 128.7(\mathrm{CH}), 128.4(2 \times \mathrm{CH}), 127.5(\mathrm{CH})$,

$123.1(\mathrm{C}), 120.5(\mathrm{C}), 116.4(\mathrm{C}), 113.5(\mathrm{CH}), 98.0(\mathrm{C}), 84.4(\mathrm{C}), 61.2\left(\mathrm{CH}_{3}\right), 56.2\left(\mathrm{CH}_{3}\right) \mathrm{ppm}$.

EMBR (IE), m/z (\%): $318\left(\mathrm{M}^{+}+2,98\right), 316\left(\mathrm{M}^{+}, 100\right), 179$ (45), 165 (43), 150 (30).

EMAR calculado para $\mathrm{C}_{16} \mathrm{H}_{13} \mathrm{BrO}_{2}: 316.0099$; encontrado: 316.0093 .

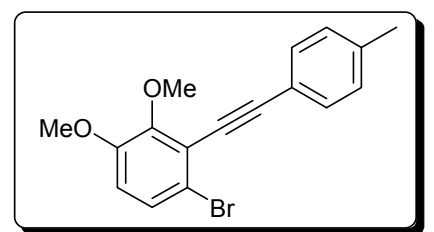

1-Bromo-3,4-dimetoxi-2-(p-toliletinil)benceno (51ad)

Sólido marrón.

P.f. $=65-67^{\circ} \mathrm{C}$

Reactivos: 49a (513 mg, $1.5 \mathrm{mmol}), p$-tolilacetileno $(228 \mu \mathrm{L}, 1.8 \mathrm{mmol})$.

${ }^{1}$ H RMN (300 MHz, $\left.\mathrm{CDCl}_{3}\right): \delta=7.55-7.50(\mathrm{~m}, 2 \mathrm{H}), 7.29(\mathrm{~d}, J=8.8 \mathrm{~Hz}, 1 \mathrm{H}), 7.19(\mathrm{~d}, J=7.9 \mathrm{~Hz}, 2 \mathrm{H}), 6.75(\mathrm{~d}$, $J=8.8 \mathrm{~Hz}, 1 \mathrm{H}), 4.00(\mathrm{~s}, 3 \mathrm{H}), 3.84(\mathrm{~s}, 3 \mathrm{H}), 2.39(\mathrm{~s}, 3 \mathrm{H}) \mathrm{ppm}$.

${ }^{13} \mathbf{C}$ RMN (75.4 MHz, $\left.\mathrm{CDCl}_{3}\right): \delta=152.0(\mathrm{C}), 151.2(\mathrm{C}), 138.9(\mathrm{C}), 131.6(2 \times \mathrm{CH}), 129.1(2 \times \mathrm{CH}), 127.5(\mathrm{CH})$, $120.7(\mathrm{C}), 120.0(\mathrm{C}), 116.3(\mathrm{C}), 113.3(\mathrm{CH}), 98.3(\mathrm{C}), 83.8(\mathrm{C}), 61.1\left(\mathrm{CH}_{3}\right), 56.1\left(\mathrm{CH}_{3}\right), 21.6\left(\mathrm{CH}_{3}\right) \mathrm{ppm}$.

EMBR (IE), m/z (\%): $332\left(\mathrm{M}^{+}+2,96\right), 330\left(\mathrm{M}^{+}, 100\right), 317$ (16), 315 (16), 236 (19), 207 (29), 193 (47), 165 (41).

EMAR calculado para $\mathrm{C}_{17} \mathrm{H}_{15} \mathrm{BrO}_{2}$ : 330.0255 ; encontrado: 330.0254 .

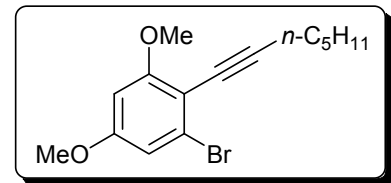

1-Bromo-2-(1-heptinil)-3,5-dimetoxibenceno (51ba)

Sólido blanco.

P.f. $=42-44^{\circ} \mathrm{C}$.

Reactivos: 49b (514 mg, $1.5 \mathrm{mmol})$, 1-heptino (236 $\mu \mathrm{L}, 1.8 \mathrm{mmol})$. 
${ }^{1} \mathbf{H}$ RMN $\left(300 \mathrm{MHz}, \mathrm{CDCl}_{3}\right): \delta=6.72(\mathrm{~d}, J=2.3 \mathrm{~Hz}, 1 \mathrm{H}), 6.36(\mathrm{~d}, J=2.3 \mathrm{~Hz}, 1 \mathrm{H}), 3.83(\mathrm{~s}, 3 \mathrm{H}), 3.78(\mathrm{~s}, 3 \mathrm{H})$, $2.50(\mathrm{t}, J=7.0 \mathrm{~Hz}, 2 \mathrm{H}), 1.70-1.60(\mathrm{~m}, 2 \mathrm{H}), 1.54-1.44(\mathrm{~m}, 2 \mathrm{H}), 1.42-1.30(\mathrm{~m}, 2 \mathrm{H}), 0.91(\mathrm{t}, J=7.2 \mathrm{~Hz}$, 3H) $\mathrm{ppm}$.

${ }^{13}$ C RMN (75.4 MHz, $\left.\mathrm{CDCl}_{3}\right): \delta=161.8(\mathrm{C}), 159.9(\mathrm{C}), 127.5(\mathrm{C}), 109.0(\mathrm{CH}), 108.6(\mathrm{C}), 98.2(\mathrm{C}), 97.8(\mathrm{CH})$, $75.4(\mathrm{C}), 56.3\left(\mathrm{CH}_{3}\right), 55.7\left(\mathrm{CH}_{3}\right), 31.2\left(\mathrm{CH}_{2}\right), 28.6\left(\mathrm{CH}_{2}\right), 22.4\left(\mathrm{CH}_{2}\right), 20.0\left(\mathrm{CH}_{2}\right), 14.2\left(\mathrm{CH}_{3}\right) \mathrm{ppm}$.

EMBR (IE), m/z (\%): $312\left(\mathrm{M}^{+}+2,84\right), 310\left(\mathrm{M}^{+}, 84\right), 257$ (52), 255 (75), 231 (52), 229 (41), 176 (100), 159 (99).

EMAR calculado para $\mathrm{C}_{15} \mathrm{H}_{19} \mathrm{BrO}_{2}: 310.0568$; encontrado: 310.0571 .

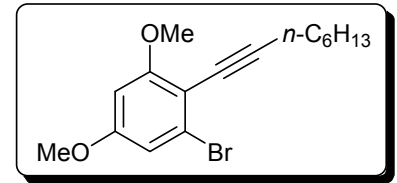

1-Bromo-3,5-dimetoxi-2-(1-octinil)benceno (51bb)

Líquido marrón.

$\mathrm{R}_{\mathrm{f}}=0.39$ (hexano / AcOEt, $10 / 1$ ).

Reactivos: 49b (342 mg, $1 \mathrm{mmol})$, 1-octino (177 $\mu \mathrm{L}, 1.2 \mathrm{mmol})$.

${ }^{1} \mathbf{H}$ RMN $\left(300 \mathrm{MHz}, \mathrm{CDCl}_{3}\right): \delta=6.70(\mathrm{~d}, J=2.3 \mathrm{~Hz}, 1 \mathrm{H}), 6.33(\mathrm{~d}, J=2.3 \mathrm{~Hz}, 1 \mathrm{H}), 3.81(\mathrm{~s}, 3 \mathrm{H}), 3.76(\mathrm{~s}, 3 \mathrm{H})$, $2.49(\mathrm{t}, J=6.9 \mathrm{~Hz}, 2 \mathrm{H}), 1.68-1.57(\mathrm{~m}, 2 \mathrm{H}), 1.55-1.44(\mathrm{~m}, 2 \mathrm{H}), 1.36-1.25(\mathrm{~m}, 4 \mathrm{H}), 0.88(\mathrm{t}, J=6.7 \mathrm{~Hz}$, 3H) $\mathrm{ppm}$.

${ }^{13}$ C RMN (75.4 MHz, $\left.\mathrm{CDCl}_{3}\right): \delta=161.7(\mathrm{C}), 159.9(\mathrm{C}), 127.4(\mathrm{C}), 108.9(\mathrm{CH}), 108.5(\mathrm{C}), 98.0(\mathrm{C}), 97.7(\mathrm{CH})$, $75.4(\mathrm{C}), 56.1\left(\mathrm{CH}_{3}\right), 55.6\left(\mathrm{CH}_{3}\right), 31.5\left(\mathrm{CH}_{2}\right), 28.8\left(\mathrm{CH}_{2}\right), 28.6\left(\mathrm{CH}_{2}\right), 22.7\left(\mathrm{CH}_{2}\right), 20.0\left(\mathrm{CH}_{2}\right), 14.2\left(\mathrm{CH}_{3}\right)$ ppm.

EMBR (IE), m/z (\%): $326\left(\mathrm{M}^{+}+2,50\right.$

), $324\left(\mathrm{M}^{+}, 50\right), 255$ (75), 231 (56), 229 (64), 176 (100), 159 (83).

EMAR calculado para $\mathrm{C}_{16} \mathrm{H}_{21} \mathrm{BrO}_{2}$ : 324.0725 ; encontrado: 324.0724 .

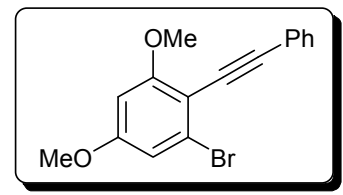

1-Bromo-2-(feniletinil)-3,5-dimetoxibenceno (50bc)

Sólido marrón.

P.f. $=93-95^{\circ} \mathrm{C}$.

Reactivos: 49b (686 mg, $2 \mathrm{mmol})$, fenilacetileno $(264 \mu \mathrm{L}, 2.4 \mathrm{mmol})$.

${ }^{1} \mathbf{H}$ RMN (300 MHz, $\left.\mathrm{CDCl}_{3}\right): \delta=7.63-7.57(\mathrm{~m}, 2 \mathrm{H}), 7.39-7.30(\mathrm{~m}, 3 \mathrm{H}), 6.78(\mathrm{~d}, J=2.3 \mathrm{~Hz}, 1 \mathrm{H}), 6.40(\mathrm{~d}, J=$ $2.3 \mathrm{~Hz}, 1 \mathrm{H}), 3.88(\mathrm{~s}, 3 \mathrm{H}), 3.81(\mathrm{~s}, 3 \mathrm{H}) \mathrm{ppm}$.

${ }^{13} \mathbf{C}$ RMN (75.4 MHz, $\left.\mathrm{CDCl}_{3}\right): \delta=161.8(\mathrm{C}), 160.7(\mathrm{C}), 131.6(2 \times \mathrm{CH}), 128.3(2 \times \mathrm{CH}), 128.2(\mathrm{CH}), 127.6(\mathrm{C})$, $123.7(\mathrm{C}), 109.2(\mathrm{CH}), 107.9(\mathrm{C}), 97.8(\mathrm{CH}), 96.5(\mathrm{C}), 84.7(\mathrm{C}), 56.2\left(\mathrm{CH}_{3}\right), 55.8\left(\mathrm{CH}_{3}\right) \mathrm{ppm}$.

EMBR (IE), m/z (\%): $318\left(\mathrm{M}^{+}+2,98\right), 316\left(\mathrm{M}^{+}, 100\right), 179$ (92), 165 (99), 150 (79).

EMAR calculado para $\mathrm{C}_{16} \mathrm{H}_{13} \mathrm{BrO}_{2}: 316.0099$; encontrado: 316.0099 .

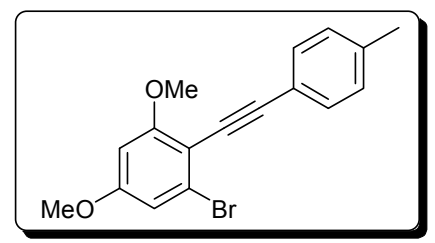

\section{1-Bromo-3,5-dimetoxi-2-(p-toliletinil)benceno (51bd)} Sólido marrón.

P.f. $=104-106^{\circ} \mathrm{C}$.

Reactivos: 49b (342 mg, $1 \mathrm{mmol})$, $p$-tolilacetileno $(152 \mu \mathrm{L}, 1.2 \mathrm{mmol})$.

${ }^{1} \mathbf{H}$ RMN $\left(300 \mathrm{MHz}, \mathrm{CDCl}_{3}\right): \delta=7.51(\mathrm{~d}, J=8.0 \mathrm{~Hz}, 2 \mathrm{H}), 7.16(\mathrm{~d}, J=8.0 \mathrm{~Hz}, 2 \mathrm{H}), 6.78(\mathrm{~d}, J=2.2 \mathrm{~Hz}, 1 \mathrm{H})$, $6.39(\mathrm{~d}, J=2.2 \mathrm{~Hz}, 1 \mathrm{H}), 3.86(\mathrm{~s}, 3 \mathrm{H}), 3.79(\mathrm{~s}, 3 \mathrm{H}), 2.37(\mathrm{~s}, 3 \mathrm{H}) \mathrm{ppm}$.

${ }^{13}$ C RMN (75.4 MHz, $\left.\mathrm{CDCl}_{3}\right): \delta=161.6(\mathrm{C}), 160.5(\mathrm{C}), 138.2(\mathrm{C}), 131.4(2 \times \mathrm{CH}), 129.0(2 \times \mathrm{CH}), 127.4(\mathrm{C})$, $120.5(\mathrm{C}), 109.1(\mathrm{CH}), 108.0(\mathrm{C}), 97.6(\mathrm{CH}), 96.7(\mathrm{C}), 84.0(\mathrm{C}), 56.1\left(\mathrm{CH}_{3}\right), 55.6\left(\mathrm{CH}_{3}\right), 21.5\left(\mathrm{CH}_{3}\right) \mathrm{ppm}$. EMBR (IE), m/z (\%): $332\left(\mathrm{M}^{+}+2,100\right), 330\left(\mathrm{M}^{+}, 99\right), 317$ (12), 315 (15), 207 (65), 193 (38).

EMAR calculado para $\mathrm{C}_{17} \mathrm{H}_{15} \mathrm{BrO}_{2}: 330.0255$; encontrado: 330.0266 . 


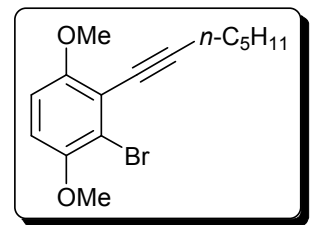

2-Bromo-3-(1-heptinil)-1,4-dimetoxibenceno (51 ca)

Líquido marrón.

$\mathrm{R}_{\mathrm{f}}=0.38$ (hexano / AcOEt, $9 / 1$ ).

Reactivos: 49c (514 mg, $1.5 \mathrm{mmol})$, 1-heptino $(236 \mu \mathrm{L}, 1.8 \mathrm{mmol})$.

${ }^{1}$ H RMN $\left(300 \mathrm{MHz}, \mathrm{CDCl}_{3}\right): \delta=6.78-6.73(\mathrm{~m}, 2 \mathrm{H}), 3.83(\mathrm{~s}, 3 \mathrm{H}), 3.82(\mathrm{~s}, 3 \mathrm{H}), 2.53(\mathrm{t}, J=7.0 \mathrm{~Hz}, 2 \mathrm{H})$, $1.72-1.61(\mathrm{~m}, 2 \mathrm{H}), 1.55-1.44(\mathrm{~m}, 2 \mathrm{H}), 1.42-1.30(\mathrm{~m}, 2 \mathrm{H}), 0.91(\mathrm{t}, J=7.2 \mathrm{~Hz}, 3 \mathrm{H}) \mathrm{ppm}$.

${ }^{13}$ C RMN (75.4 MHz, $\left.\mathrm{CDCl}_{3}\right): \delta=155.2(\mathrm{C}), 150.6(\mathrm{C}), 117.2(\mathrm{C}), 116.8(\mathrm{C}), 111.4(\mathrm{CH}), 109.9(\mathrm{CH}), 100.6$ (C), $75.8(\mathrm{C}), 56.9\left(\mathrm{CH}_{3}\right), 56.7\left(\mathrm{CH}_{3}\right), 31.2\left(\mathrm{CH}_{2}\right), 28.4\left(\mathrm{CH}_{2}\right), 22.3\left(\mathrm{CH}_{2}\right), 20.1\left(\mathrm{CH}_{2}\right), 14.2\left(\mathrm{CH}_{3}\right) \mathrm{ppm}$.

EMBR (IE), m/z (\%): $312\left(\mathrm{M}^{+}+2,87\right), 310\left(\mathrm{M}^{+}, 86\right), 241$ (33), 239 (36), 202 (33), 176 (100).

EMAR calculado para $\mathrm{C}_{15} \mathrm{H}_{19} \mathrm{BrO}_{2}: 310.0568$; encontrado: 310.0566 .

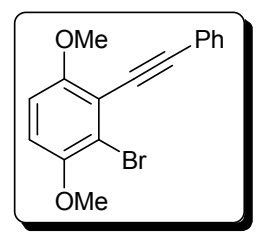

\section{2-Bromo-3-(feniletinil)-1,4-dimetoxibenceno $(51 \mathrm{cb})$}

Sólido marrón.

P.f. $=66-68^{\circ} \mathrm{C}$.

Reactivos: 49c (686 mg, $2 \mathrm{mmol})$, fenilacetileno $(264 \mu \mathrm{L}, 2.4 \mathrm{mmol})$

${ }^{1} \mathbf{H}$ RMN (300 MHz, CDCl 3$): \delta=7.69-7.59(\mathrm{~m}, 2 \mathrm{H}), 7.40-7.32(\mathrm{~m}, 3 \mathrm{H}), 6.84-6.74(\mathrm{~m}, 2 \mathrm{H}), 3.85(\mathrm{~s}, 3 \mathrm{H}), 3.83(\mathrm{~s}, 3 \mathrm{H}) \mathrm{ppm}$.

${ }^{13} \mathbf{C}$ RMN (75.4 MHz, $\left.\mathrm{CDCl}_{3}\right): \delta=155.2(\mathrm{C}), 150.7(\mathrm{C}), 131.8(2 \times \mathrm{CH}), 128.6(\mathrm{CH}), 128.4(2 \times \mathrm{CH}), 123.3(\mathrm{C})$, $116.7(\mathrm{C}), 116.5(\mathrm{C}), 112.3(\mathrm{CH}), 110.1(\mathrm{CH}), 98.5(\mathrm{C}), 84.8(\mathrm{C}), 57.0\left(\mathrm{CH}_{3}\right), 56.7\left(\mathrm{CH}_{3}\right) \mathrm{ppm}$.

EMBR (IE), m/z (\%): $318\left(\mathrm{M}^{+}+2,98\right), 316\left(\mathrm{M}^{+}, 100\right), 303$ (30), 301 (32), 179 (28), 165 (29), 151 (22).

EMAR calculado para $\mathrm{C}_{16} \mathrm{H}_{13} \mathrm{BrO}_{2}: 316.0099$; encontrado: 316.0097 .

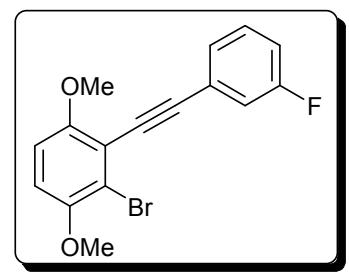

2-Bromo-3-(3-fluorofeniletinil)-1,4-dimetoxibenceno (51cc)

Sólido marrón rojizo.

P.f. $=84-86^{\circ} \mathrm{C}$.

Reactivos: 49c ( $857 \mathrm{mg}, 2.5 \mathrm{mmol})$, 3-fluorofenilacetileno (347 $\mu \mathrm{L}, 3 \mathrm{mmol})$.

${ }^{1} \mathbf{H}$ RMN $\left(300 \mathrm{MHz}, \mathrm{CDCl}_{3}\right): \delta=7.39(\mathrm{~d}, J=7.5 \mathrm{~Hz}, 1 \mathrm{H}), 7.35-7.26(\mathrm{~m}, 2 \mathrm{H}), 7.04(\mathrm{ddt}, J=8.3,2.3,1.1 \mathrm{~Hz}$, $1 \mathrm{H}), 6.85-6.75(\mathrm{~m}, 2 \mathrm{H}), 3.85(\mathrm{~s}, 3 \mathrm{H}), 3.83(\mathrm{~s}, 3 \mathrm{H}) \mathrm{ppm}$.

${ }^{13}$ C RMN (75.4 MHz, $\left.\mathrm{CDCl}_{3}\right): \delta=162.3(\mathrm{~d}, J=246.4 \mathrm{~Hz}, \mathrm{C}), 155.2(\mathrm{C}), 150.5(\mathrm{C}), 129.9(\mathrm{~d}, J=8.6 \mathrm{~Hz}, \mathrm{CH})$, $127.6(\mathrm{CH}), 125.1(\mathrm{~d}, J=9.5 \mathrm{~Hz}, \mathrm{C}), 118.4(\mathrm{~d}, J=22.8 \mathrm{~Hz}, \mathrm{CH}), 116.6(\mathrm{C}), 115.8(\mathrm{~d}, J=21.2 \mathrm{~Hz}, \mathrm{CH})$, $115.83(\mathrm{C}), 112.6(\mathrm{CH}), 110.0(\mathrm{CH}), 96.9(\mathrm{~d}, J=3.5 \mathrm{~Hz}, \mathrm{C}), 85.8(\mathrm{C}), 56.8\left(\mathrm{CH}_{3}\right), 56.5\left(\mathrm{CH}_{3}\right) \mathrm{ppm}$.

EMBR (IE), m/z (\%): $336\left(\mathrm{M}^{+}+2,97\right), 334\left(\mathrm{M}^{+}, 100\right), 321$ (35), 319 (36), 278 (12), 276 (12), 225 (18), 197 (29). EMAR calculado para $\mathrm{C}_{16} \mathrm{H}_{12} \mathrm{BrFO}_{2}$ : 334.0005; encontrado: 334.0005 .

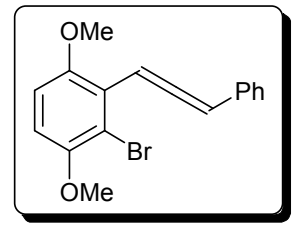

2-Bromo-3-(3-fenilpropa-1,2-dienil)-1,4-dimetoxibenceno (51cd)

Sólido amarillo. P.f. $=87-89^{\circ} \mathrm{C}$. 
Reactivos: 49c (342 mg, $1 \mathrm{mmol})$, 1-propinilbenceno (149 $\mu \mathrm{L}, 1.2 \mathrm{mmol})$.

${ }^{1} \mathbf{H}$ RMN $\left(300 \mathrm{MHz}, \mathrm{CDCl}_{3}\right): \delta=7.46-7.41(\mathrm{~m}, 2 \mathrm{H}), 7.37-7.30(\mathrm{~m}, 2 \mathrm{H}), 7.26-7.19(\mathrm{~m}, 1 \mathrm{H}), 7.00(\mathrm{~d}, J=6.7$ $\mathrm{Hz}, 1 \mathrm{H}), 6.80(\mathrm{~d}, J=2.5 \mathrm{~Hz}, 2 \mathrm{H}), 6.41(\mathrm{~d}, J=6.7 \mathrm{~Hz}, 1 \mathrm{H}), 3.87(\mathrm{~s}, 3 \mathrm{H}), 3.71(\mathrm{~s}, 3 \mathrm{H}) \mathrm{ppm}$.

${ }^{13}$ C RMN (75.4 MHz, $\left.\mathrm{CDCl}_{3}\right): \delta=210.6(\mathrm{C}), 152.5(\mathrm{C}), 150.8(\mathrm{C}), 134.5(\mathrm{C}), 128.6(2 \times \mathrm{CH}), 127.3(2 \times \mathrm{CH})$, $126.9(\mathrm{CH}), 124.3(\mathrm{C}), 114.2(\mathrm{C}), 110.7(\mathrm{CH}), 110.6(\mathrm{CH}), 95.0(\mathrm{CH}), 92.6(\mathrm{CH}), 57.0\left(\mathrm{CH}_{3}\right), 56.7\left(\mathrm{CH}_{3}\right)$ ppm.

EMBR (IE), m/z (\%): $332\left(\mathrm{M}^{+}+2,17\right), 320\left(\mathrm{M}^{+}, 18\right), 317$ (95), 315 (100), 236 (28), 221 (24), 165 (37).

EMAR calculado para $\mathrm{C}_{17} \mathrm{H}_{15} \mathrm{BrO}_{2}$ : 330.0255; encontrado: 330.0254 .

\section{A.3 Procedimiento general para la preparación de los alcoxibenzo[b]furanos 52-55}

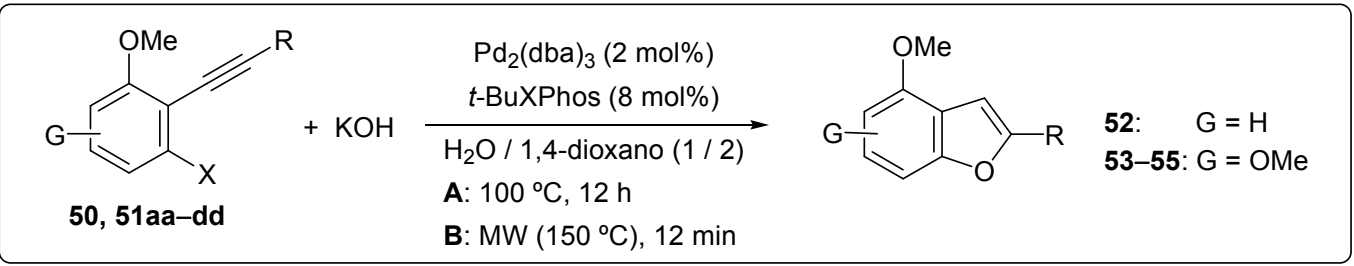

\section{Método A}

Sobre una disolución de $\mathrm{Pd}_{2}(\mathrm{dba})_{3}(9.2 \mathrm{mg}, 0.01 \mathrm{mmol}, 2 \mathrm{~mol} \%), t$-BuXPhos $(17 \mathrm{mg}, 0.04$ mmol, $8 \mathrm{~mol} \%)$ y $\mathrm{KOH}(0.84 \mathrm{~g}, 1.5 \mathrm{mmol})$ en $\mathrm{H}_{2} \mathrm{O}(0.5 \mathrm{~mL})$ y 1 ,4-dioxano $(1 \mathrm{~mL})$ se añade el correspondiente alquino 50 ó $51(0.5 \mathrm{mmol})$ y se calienta a $100^{\circ} \mathrm{C}$ durante 12 horas. Posteriormente se deja que la mezcla alcance temperatura ambiente, se hidroliza con $\mathrm{H}_{2} \mathrm{O}$ y se extrae con $\mathrm{Et}_{2} \mathrm{O}(3 \times$ $15 \mathrm{~mL}$ ). La combinación de fases orgánicas se seca sobre $\mathrm{Na}_{2} \mathrm{SO}_{4}$ anhidro y se elimina el disolvente a presión reducida $(20 \mathrm{~mm} \mathrm{Hg})$. La purificación del residuo resultante por cromatografía de columna (hexano / AcOEt) da lugar a los compuestos 52-55.

\section{Método B}

Sobre una disolución de $\mathrm{Pd}_{2}(\mathrm{dba})_{3}(9.2 \mathrm{mg}, 0.01 \mathrm{mmol}, 2 \mathrm{~mol} \%), t$-BuXPhos $(17 \mathrm{mg}, 0.04$ mmol, $8 \mathrm{~mol} \%)$ y $\mathrm{KOH}(0.84 \mathrm{~g}, 1.5 \mathrm{mmol})$ en $\mathrm{H}_{2} \mathrm{O}(0.5 \mathrm{~mL})$ y 1 ,4-dioxano $(1 \mathrm{~mL})$ se añade el correspondiente alquino 50 ó $51(0.5 \mathrm{mmol})$. La mezcla se calienta mediante radiación de MW a 150 ${ }^{\circ} \mathrm{C}$ durante 12 minutos. Posteriormente se deja que alcance temperatura ambiente, se hidroliza con $\mathrm{H}_{2} \mathrm{O}$ y se extrae con $\mathrm{Et}_{2} \mathrm{O}(3 \times 15 \mathrm{~mL})$. La combinación de fases orgánicas se seca sobre $\mathrm{Na}_{2} \mathrm{SO}_{4}$ anhidro y se elimina el disolvente a presión reducida $(20 \mathrm{~mm} \mathrm{Hg})$. La purificación del residuo resultante por cromatografía de columna (hexano / AcOEt) da lugar a los compuestos 52-55.

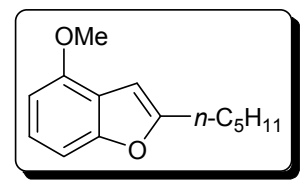

4-Metoxi-2-pentilbenzo[b]furano (52a)

Líquido amarillo.

$\mathrm{R}_{\mathrm{f}}=0.56$ (hexano / AcOEt, $10 / 1$ ).

${ }^{1} \mathbf{H}$ RMN $\left(300 \mathrm{MHz}, \mathrm{CDCl}_{3}\right): \delta=7.23-7.11(\mathrm{~m}, 2 \mathrm{H}), 6.67(\mathrm{~d}, J=7.6 \mathrm{~Hz}, 1 \mathrm{H}), 6.55(\mathrm{~s}, 1 \mathrm{H}), 3.97(\mathrm{~s}, 3 \mathrm{H}), 2.80(\mathrm{t}$, $J=7.6 \mathrm{~Hz}, 2 \mathrm{H}), 1.85-1.75(\mathrm{~m}, 2 \mathrm{H}), 1.47-1.40(\mathrm{~m}, 4 \mathrm{H}), 0.98(\mathrm{t}, J=7.0 \mathrm{~Hz}, 3 \mathrm{H}) \mathrm{ppm}$.

${ }^{13}$ C RMN (75.4 MHz, $\left.\mathrm{CDCl}_{3}\right): \delta=158.4(\mathrm{C}), 156.0(\mathrm{C}), 152.9(\mathrm{C}), 123.7(\mathrm{CH}), 119.0(\mathrm{C}), 104.3(\mathrm{CH}), 103.1$ $(\mathrm{CH}), 99.1(\mathrm{CH}), 55.5\left(\mathrm{CH}_{3}\right), 31.4\left(\mathrm{CH}_{2}\right), 28.4\left(\mathrm{CH}_{2}\right), 27.5\left(\mathrm{CH}_{2}\right), 22.6\left(\mathrm{CH}_{2}\right), 14.1\left(\mathrm{CH}_{3}\right) \mathrm{ppm}$.

EMBR (IE), m/z (\%): $218\left(\mathrm{M}^{+}, 35\right), 161$ (100), 146 (19).

EMAR calculado para $\mathrm{C}_{14} \mathrm{H}_{18} \mathrm{O}_{2}: 218.1307$; encontrado: 218.1307 . 


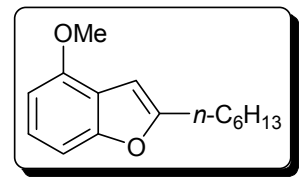

\section{2-Hexil-4-metoxibenzo[b]furano (52b)}

Líquido amarillo.

$\mathrm{R}_{\mathrm{f}}=0.62$ (hexano / AcOEt, $10 / 1$ ).

${ }^{1} \mathbf{H}$ RMN $\left(400 \mathrm{MHz}, \mathrm{CDCl}_{3}\right): \delta=7.12(\mathrm{t}, J=8.0 \mathrm{~Hz}, 1 \mathrm{H}), 7.05(\mathrm{dd}, J=8.0,0.7 \mathrm{~Hz}, 1 \mathrm{H}), 6.62(\mathrm{~d}, J=8.0 \mathrm{~Hz}$, $1 \mathrm{H}), 6.47-6.45(\mathrm{~m}, 1 \mathrm{H}), 3.92(\mathrm{~s}, 3 \mathrm{H}), 2.74(\mathrm{t}, J=7.5 \mathrm{~Hz}, 2 \mathrm{H}), 1.76-1.68(\mathrm{~m}, 2 \mathrm{H}), 1.41-1.34(\mathrm{~m}, 2 \mathrm{H})$, $1.34-1.28(\mathrm{~m}, 4 \mathrm{H}), 0.88(\mathrm{t}, J=7.0 \mathrm{~Hz}, 3 \mathrm{H}) \mathrm{ppm}$.

${ }^{13} \mathbf{C}$ RMN (100.6 MHz, $\left.\mathrm{CDCl}_{3}\right): \delta=158.5(\mathrm{C}), 156.0(\mathrm{C}), 153.0(\mathrm{C}), 123.8(\mathrm{CH}), 119.1(\mathrm{C}), 104.3(\mathrm{CH}), 103.2$ $(\mathrm{CH}), 99.1(\mathrm{~d}, J=2.0 \mathrm{~Hz}, \mathrm{CH}), 55.7\left(\mathrm{~d}, J=1.6 \mathrm{~Hz}, \mathrm{CH}_{3}\right), 31.7\left(\mathrm{CH}_{2}\right), 29.0\left(\mathrm{CH}_{2}\right), 28.5\left(\mathrm{CH}_{2}\right), 27.8\left(\mathrm{CH}_{2}\right)$, $22.7\left(\mathrm{CH}_{2}\right), 14.2\left(\mathrm{CH}_{3}\right) \mathrm{ppm}$.

EMBR (IE), m/z (\%): $232\left(\mathrm{M}^{+}, 35\right), 161$ (100), 146 (16), 137 (11).

EMAR calculado para $\mathrm{C}_{15} \mathrm{H}_{20} \mathrm{O}_{2}: 232.1463$; encontrado: 232.1468 .

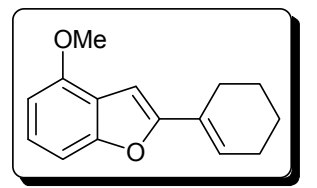

\section{2-(1-Ciclohexenil)-4-metoxibenzo[b]furano (52c)}

Líquido amarillo.

$\mathrm{R}_{\mathrm{f}}=0.37$ (hexano / AcOEt, $30 / 1$ ).

${ }^{1}$ H RMN (300 MHz, $\left.\mathrm{CDCl}_{3}\right): \delta=7.15(\mathrm{t}, J=8.0 \mathrm{~Hz}, 1 \mathrm{H}), 7.08-7.04(\mathrm{~m}, 1 \mathrm{H}), 6.62(\mathrm{~d}, J=8.0 \mathrm{~Hz}, 1 \mathrm{H}), 6.60(\mathrm{~s}$, $1 \mathrm{H}), 6.60-6.54(\mathrm{~m}, 1 \mathrm{H}), 3.93(\mathrm{~s}, 3 \mathrm{H}), 2.42-2.34(\mathrm{~m}, 2 \mathrm{H}), 2.31-2.22(\mathrm{~m}, 2 \mathrm{H}), 1.83-1.74(\mathrm{~m}, 2 \mathrm{H})$, $1.72-1.63(\mathrm{~m}, 2 \mathrm{H}) \mathrm{ppm}$.

${ }^{13} \mathbf{C}$ RMN (75.4 MHz, $\mathrm{CDCl}_{3}$ ): $\delta=156.4(\mathrm{C}), 155.7(\mathrm{C}), 153.3(\mathrm{C}), 127.2(\mathrm{C}), 125.6(\mathrm{CH}), 124.6(\mathrm{CH}), 119.4$ (C), $104.3(\mathrm{CH}), 103.1(\mathrm{CH}), 97.5(\mathrm{CH}), 55.7\left(\mathrm{CH}_{3}\right), 25.5\left(\mathrm{CH}_{2}\right), 25.0\left(\mathrm{CH}_{2}\right), 22.5\left(\mathrm{CH}_{2}\right), 22.3\left(\mathrm{CH}_{2}\right) \mathrm{ppm}$. EMBR (IE), m/z (\%): $228\left(\mathrm{M}^{+}, 100\right), 213$ (23), 200 (41), 185 (19).

EMAR calculado para $\mathrm{C}_{15} \mathrm{H}_{16} \mathrm{O}_{2}: 228.1150$; encontrado: 228.1153 .

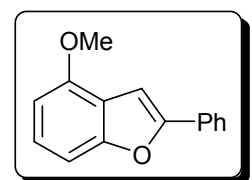

\section{2-Fenil-4-metoxibenzo[b]furano $(\mathbf{5 2 d})^{279}$}

Sólido blanco.

P.f. $=59-61{ }^{\circ} \mathrm{C}$.

${ }^{1}$ H RMN (300 MHz, $\left.\mathrm{CDCl}_{3}\right): \delta=7.92-7.87(\mathrm{~m}, 2 \mathrm{H}), 7.51-7.44(\mathrm{~m}, 2 \mathrm{H}), 7.40-7.33(\mathrm{~m}, 1 \mathrm{H}), 7.29-7.17$ (m, 3H), $6.69(\mathrm{dd}, J=7.3,1.4 \mathrm{~Hz}, 1 \mathrm{H}), 3.99(\mathrm{~s}, 3 \mathrm{H}) \mathrm{ppm}$.

${ }^{13}$ C RMN (75.4 MHz, $\left.\mathrm{CDCl}_{3}\right): \delta=156.1(\mathrm{C}), 154.7(\mathrm{C}), 153.5(\mathrm{C}), 130.6(\mathrm{C}), 128.9(\mathrm{CH}), 128.4(\mathrm{CH}), 125.1$ $(\mathrm{CH}), 124.8(\mathrm{CH}), 119.6(\mathrm{C}), 104.6(\mathrm{CH}), 103.4(\mathrm{CH}), 98.9(\mathrm{CH}), 55.7\left(\mathrm{CH}_{3}\right) \mathrm{ppm}$.

EMBR (IE), m/z (\%): 224 (M+, 100), 209 (92), 152 (23), 105 (10), 77 (10).

EMAR calculado para $\mathrm{C}_{15} \mathrm{H}_{12} \mathrm{O}_{2}$ : 224.0837; encontrado: 224.0841 .

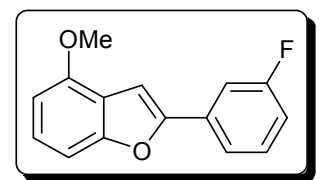

2-(3-Fluorofenil)-4-metoxibenzo[b]furano (52e)

Sólido blanco.

P.f. $=100-102^{\circ} \mathrm{C}$.

${ }^{1} \mathbf{H}$ RMN (300 MHz, $\left.\mathrm{CDCl}_{3}\right): \delta=7.62(\mathrm{ddd}, J=8.0,1.5,1.0 \mathrm{~Hz}, 1 \mathrm{H}), 7.55(\mathrm{ddd}, J=10.0,2.4,1.5 \mathrm{~Hz}, 1 \mathrm{H}), 7.39$ $(\mathrm{td}, J=8.0,5.9 \mathrm{~Hz}, 1 \mathrm{H}), 7.25(\mathrm{t}, J=8.0 \mathrm{~Hz}, 1 \mathrm{H}), 7.19-7.15(\mathrm{~m}, 2 \mathrm{H}), 7.03(\mathrm{tdd}, J=8.4,2.6,1.0 \mathrm{~Hz}, 1 \mathrm{H})$, $6.68(\mathrm{~d}, J=8.0 \mathrm{~Hz}, 1 \mathrm{H}), 3.97(\mathrm{~s}, 3 \mathrm{H}) \mathrm{ppm}$.

${ }^{279}$ M. Watanabe, M. Date, K. Kawanishi, T. Hori, S. Furukawa, Chem. Pharm. Bull. 1991, 39, 41. 
${ }^{13}$ C RMN (75.4 MHz, $\left.\mathrm{CDCl}_{3}\right): \delta=163.2(\mathrm{~d}, J=245.4 \mathrm{~Hz}, \mathrm{C}), 156.2(\mathrm{C}), 153.6(\mathrm{C}), 153.3(\mathrm{~d}, J=3.1 \mathrm{~Hz}, \mathrm{C}), 132.7$ $(\mathrm{d}, J=8.5 \mathrm{~Hz}, \mathrm{C}), 130.5(\mathrm{~d}, J=8.4 \mathrm{~Hz}, \mathrm{CH}), 125.6(\mathrm{CH}), 120.4(\mathrm{~d}, J=3.0 \mathrm{~Hz}, \mathrm{CH}), 119.4(\mathrm{C}), 115.1(\mathrm{~d}, J=$ $21.4 \mathrm{~Hz}, \mathrm{CH}), 111.7(\mathrm{~d}, J=23.6 \mathrm{~Hz}, \mathrm{CH}), 104.6(\mathrm{CH}), 103.5(\mathrm{CH}), 100.0(\mathrm{CH}), 55.7\left(\mathrm{CH}_{3}\right) \mathrm{ppm}$.

EMBR (IE), m/z (\%): $242\left(\mathrm{M}^{+}, 100\right), 227$ (95), 170 (25), 123 (17).

EMAR calculado para $\mathrm{C}_{15} \mathrm{H}_{11} \mathrm{FO}_{2}$ : 242.0743; encontrado: 242.0749 .

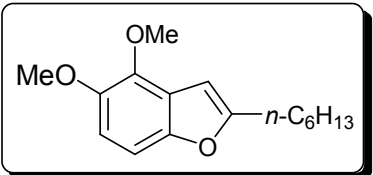

\section{2-Hexil-4,5-dimetoxibenzo[b]furano (53a)}

Líquido amarillo.

$\mathrm{R}_{\mathrm{f}}=0.44$ (hexano / AcOEt, 10 / 1).

${ }^{1} \mathbf{H}$ RMN (300 MHz, $\left.\mathrm{CDCl}_{3}\right): \delta=7.05(\mathrm{~d}, J=8.7 \mathrm{~Hz}, 1 \mathrm{H}), 6.84(\mathrm{~d}, J=8.7 \mathrm{~Hz}, 1 \mathrm{H}), 6.49(\mathrm{~s}, 1 \mathrm{H}), 4.03(\mathrm{~s}, 3 \mathrm{H})$, $3.88(\mathrm{~s}, 3 \mathrm{H}), 2.72(\mathrm{t}, J=7.6 \mathrm{~Hz}, 2 \mathrm{H}), 1.78-1.67(\mathrm{~m}, 2 \mathrm{H}), 1.44-1.26(\mathrm{~m}, 6 \mathrm{H}), 0.89(\mathrm{t}, J=6.5 \mathrm{~Hz}, 3 \mathrm{H}) \mathrm{ppm}$.

${ }^{13} \mathbf{C}$ RMN (75.4 MHz, $\left.\mathrm{CDCl}_{3}\right): \delta=159.9(\mathrm{C}), 151.0(\mathrm{C}), 146.6(\mathrm{C}), 141.3(\mathrm{C}), 122.2(\mathrm{C}), 110.0(\mathrm{CH}), 105.0$ $(\mathrm{CH}), 99.7(\mathrm{CH}), 60.5\left(\mathrm{CH}_{3}\right), 57.6\left(\mathrm{CH}_{3}\right), 31.7\left(\mathrm{CH}_{2}\right), 29.0\left(\mathrm{CH}_{2}\right), 28.6\left(\mathrm{CH}_{2}\right), 27.7\left(\mathrm{CH}_{2}\right), 22.7\left(\mathrm{CH}_{2}\right)$, $14.2\left(\mathrm{CH}_{3}\right) \mathrm{ppm}$.

EMBR (IE), m/z (\%): $262\left(\mathrm{M}^{+}, 100\right), 247$ (33), 191 (59), 147 (22).

EMAR calculado para $\mathrm{C}_{16} \mathrm{H}_{22} \mathrm{O}_{3}: 262.1569$; encontrado: 262.1565 .

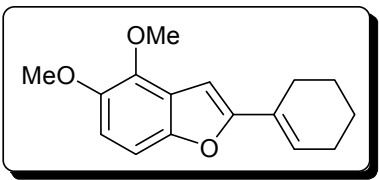

\section{2-(1-Ciclohexenil)-4,5-dimetoxibenzo[b]furano (53b)}

Sólido amarillo.

P.f. $=48-50^{\circ} \mathrm{C}$.

${ }^{1} \mathbf{H}$ RMN $\left(300 \mathrm{MHz}, \mathrm{CDCl}_{3}\right): \delta=7.06(\mathrm{~d}, J=8.8 \mathrm{~Hz}, 1 \mathrm{H}), 6.86(\mathrm{~d}, J=8.8 \mathrm{~Hz}, 1 \mathrm{H}), 6.61(\mathrm{~s}, 1 \mathrm{H}), 6.60-6.54(\mathrm{~m}$, $1 \mathrm{H}), 4.04(\mathrm{~s}, 3 \mathrm{H}), 3.89(\mathrm{~s}, 3 \mathrm{H}), 2.43-2.34(\mathrm{~m}, 2 \mathrm{H}), 2.30-2.22(\mathrm{~m}, 2 \mathrm{H}), 1.84-1.73(\mathrm{~m}, 2 \mathrm{H}), 1.72-1.61(\mathrm{~m}$, 2H) $\mathrm{ppm}$.

${ }^{13} \mathbf{C}$ RMN (75.4 MHz, $\left.\mathrm{CDCl}_{3}\right): \delta=157.6(\mathrm{C}), 150.7(\mathrm{C}), 146.6(\mathrm{C}), 141.6(\mathrm{C}), 127.1(\mathrm{C}), 126.4(\mathrm{CH}), 122.5(\mathrm{C})$, $110.6(\mathrm{CH}), 105.0(\mathrm{CH}), 97.9(\mathrm{CH}), 60.7\left(\mathrm{CH}_{3}\right), 57.5\left(\mathrm{CH}_{3}\right), 25.5\left(\mathrm{CH}_{2}\right), 25.0\left(\mathrm{CH}_{2}\right), 22.4\left(\mathrm{CH}_{2}\right), 22.2$ $\left(\mathrm{CH}_{2}\right) \mathrm{ppm}$.

EMBR (IE), m/z (\%): $258\left(\mathrm{M}^{+}, 100\right), 243$ (34), 230 (10).

EMAR calculado para $\mathrm{C}_{16} \mathrm{H}_{18} \mathrm{O}_{3}: 258.1256$; encontrado: 258.1264 .

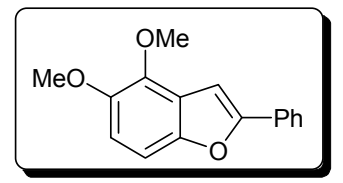

\section{2-Fenil-4,5-dimetoxibenzo[b]furano (53c)}

Sólido amarillo.

P.f. $=68-70^{\circ} \mathrm{C}$.

${ }^{1} \mathbf{H}$ RMN (300 MHz, $\left.\mathrm{CDCl}_{3}\right): \delta=7.87-7.82(\mathrm{~m}, 2 \mathrm{H}), 7.48-7.41(\mathrm{~m}, 2 \mathrm{H}), 7.39-7.31(\mathrm{~m}, 1 \mathrm{H}), 7.18(\mathrm{dd}, J=8.8$, $0.9 \mathrm{~Hz}, 1 \mathrm{H}), 7.14(\mathrm{~d}, J=0.9 \mathrm{~Hz}, 1 \mathrm{H}), 6.94(\mathrm{~d}, J=8.8 \mathrm{~Hz}, 1 \mathrm{H}), 4.10(\mathrm{~s}, 3 \mathrm{H}), 3.92(\mathrm{~s}, 3 \mathrm{H}) \mathrm{ppm}$.

${ }^{13} \mathbf{C}$ RMN (75.4 MHz, $\left.\mathrm{CDCl}_{3}\right)$ : $\delta=156.0(\mathrm{C}), 151.1(\mathrm{C}), 147.0(\mathrm{C}), 141.8(\mathrm{C}), 130.4(\mathrm{C}), 128.9(2 \times \mathrm{CH}), 128.7$ $(\mathrm{CH}), 125.0(2 \times \mathrm{CH}), 122.8(\mathrm{C}), 111.3(\mathrm{CH}), 105.5(\mathrm{CH}), 99.2(\mathrm{CH}), 60.8\left(\mathrm{CH}_{3}\right), 57.6\left(\mathrm{CH}_{3}\right) \mathrm{ppm}$.

EMBR (IE), m/z (\%): $254\left(\mathrm{M}^{+}, 100\right), 239$ (42), 196 (24), 165 (15), 105 (17).

EMAR calculado para $\mathrm{C}_{16} \mathrm{H}_{14} \mathrm{O}_{3}: 254.0943$; encontrado: 254.0950 .

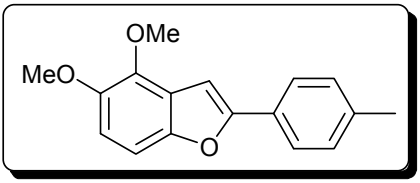

4,5-Dimetoxi-2-p-tolilbenzo $[b]$ furano $(53 \mathrm{~d})$

Sólido rojizo.

P.f. $=72-74^{\circ} \mathrm{C}$. 
${ }^{1} \mathbf{H}$ RMN (300 MHz, $\left.\mathrm{CDCl}_{3}\right): \delta=7.74(\mathrm{~d}, J=8.2 \mathrm{~Hz}, 2 \mathrm{H}), 7.29-7.23(\mathrm{~m}, 2 \mathrm{H}), 7.16(\mathrm{dd}, J=8.7,0.8 \mathrm{~Hz}, 1 \mathrm{H})$, $7.09(\mathrm{~s}, 1 \mathrm{H}), 6.92(\mathrm{~d}, J=8.7 \mathrm{~Hz}, 1 \mathrm{H}), 4.09(\mathrm{~d}, J=0.6 \mathrm{~Hz}, 3 \mathrm{H}), 3.91(\mathrm{~s}, 3 \mathrm{H}), 2.40(\mathrm{~s}, 3 \mathrm{H}) \mathrm{ppm}$.

${ }^{13}$ C RMN (75.4 MHz, $\left.\mathrm{CDCl}_{3}\right): \delta=156.3(\mathrm{C}), 151.0(\mathrm{C}), 146.9(\mathrm{C}), 138.8(\mathrm{C}), 131.6(\mathrm{C}), 129.6(2 \times \mathrm{CH}), 129.2(\mathrm{C})$, $127.7(\mathrm{C}), 124.9(2 \times \mathrm{CH}), 111.0(\mathrm{CH}), 105.4(\mathrm{CH}), 98.5(\mathrm{CH}), 60.8\left(\mathrm{CH}_{3}\right), 57.6\left(\mathrm{CH}_{3}\right), 21.5\left(\mathrm{CH}_{3}\right) \mathrm{ppm}$.

EMBR (IE), m/z (\%): $268\left(\mathrm{M}^{+}, 100\right), 253$ (50), 210 (31).

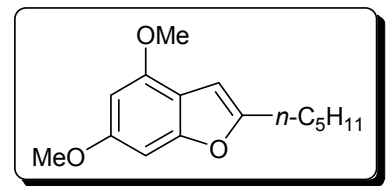

\section{4,6-Dimetoxi-2-pentilbenzo[b]furano (54a)}

Líquido amarillo.

$\mathrm{R}_{\mathrm{f}}=0.56$ (hexano / AcOEt, $10 / 1$ ).

${ }^{1}$ H RMN $\left(300 \mathrm{MHz}, \mathrm{CDCl}_{3}\right): \delta=6.61(\mathrm{~s}, 1 \mathrm{H}), 6.37(\mathrm{~s}, 1 \mathrm{H}), 6.30(\mathrm{~d}, J=1.9 \mathrm{~Hz}, 1 \mathrm{H}), 3.89(\mathrm{~s}, 3 \mathrm{H}), 3.83(\mathrm{~s}, 3 \mathrm{H})$, $2.71(\mathrm{t}, J=7.4 \mathrm{~Hz}, 2 \mathrm{H}), 1.76-1.66(\mathrm{~m}, 2 \mathrm{H}), 1.40-1.31(\mathrm{~m}, 4 \mathrm{H}), 0.90(\mathrm{t}, J=7.0 \mathrm{~Hz}, 3 \mathrm{H}) \mathrm{ppm}$.

${ }^{13} \mathbf{C}$ RMN (75.4 MHz, $\left.\mathrm{CDCl}_{3}\right): \delta=158.3(\mathrm{C}), 157.3(\mathrm{C}), 156.3(\mathrm{C}), 152.9(\mathrm{C}), 112.6(\mathrm{C}), 98.8(\mathrm{CH}), 93.9(\mathrm{CH})$, $88.3(\mathrm{CH}), 55.9\left(\mathrm{CH}_{3}\right), 55.6\left(\mathrm{CH}_{3}\right), 31.4\left(\mathrm{CH}_{2}\right), 28.4\left(\mathrm{CH}_{2}\right), 27.6\left(\mathrm{CH}_{2}\right), 22.6\left(\mathrm{CH}_{2}\right), 14.1\left(\mathrm{CH}_{3}\right) \mathrm{ppm}$.

EMBR (IE), m/z (\%): $248\left(\mathrm{M}^{+}, 29\right), 191$ (100), 176 (5).

EMAR calculado para $\mathrm{C}_{15} \mathrm{H}_{20} \mathrm{O}_{3}: 248.1412$; encontrado: 248.1411 .

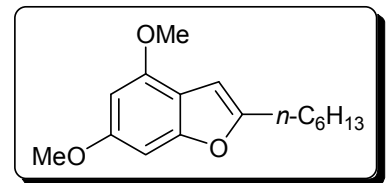

\section{2-Hexil-4,6-dimetoxibenzo[b]furano (54b)}

Sólido blanco.

P.f. $=40-42^{\circ} \mathrm{C}$.

${ }^{1} \mathbf{H}$ RMN $\left(300 \mathrm{MHz}, \mathrm{CDCl}_{3}\right): \delta=6.61(\mathrm{dd}, J=1.9,0.9 \mathrm{~Hz}, 1 \mathrm{H}), 6.37(\mathrm{~d}, J=0.9 \mathrm{~Hz}, 1 \mathrm{H}), 6.30(\mathrm{~d}, J=1.9 \mathrm{~Hz}$, $1 \mathrm{H}), 3.89(\mathrm{~s}, 3 \mathrm{H}), 3.83(\mathrm{~s}, 3 \mathrm{H}), 2.71(\mathrm{t}, J=7.5 \mathrm{~Hz}, 2 \mathrm{H}), 1.76-1.65(\mathrm{~m}, 2 \mathrm{H}), 1.42-1.27(\mathrm{~m}, 6 \mathrm{H}), 0.89(\mathrm{t}, J=$ $7.0 \mathrm{~Hz}, 3 \mathrm{H}) \mathrm{ppm}$.

${ }^{13} \mathbf{C}$ RMN (75.4 MHz, $\left.\mathrm{CDCl}_{3}\right): \delta=158.3(\mathrm{C}), 157.3(\mathrm{C}), 156.3(\mathrm{C}), 152.9(\mathrm{C}), 112.6(\mathrm{C}), 98.8(\mathrm{CH}), 93.9(\mathrm{CH})$, $88.3(\mathrm{CH}), 55.9\left(\mathrm{CH}_{3}\right), 55.6\left(\mathrm{CH}_{3}\right), 31.7\left(\mathrm{CH}_{2}\right), 29.0\left(\mathrm{CH}_{2}\right), 28.5\left(\mathrm{CH}_{2}\right), 27.9\left(\mathrm{CH}_{2}\right), 22.7\left(\mathrm{CH}_{2}\right), 14.2$ $\left(\mathrm{CH}_{3}\right) \mathrm{ppm}$.

EMBR (IE), m/z (\%): $262\left(\mathrm{M}^{+}, 33\right), 191$ (100), 176 (4).

EMAR calculado para $\mathrm{C}_{16} \mathrm{H}_{22} \mathrm{O}_{3}: 262.1569$; encontrado: 262.1565 .

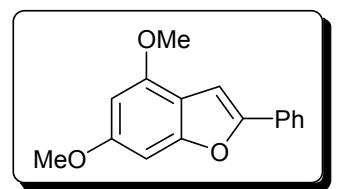

\section{2-Fenil-4,6-dimetoxibenzo[b]furano (54c)}

Sólido blanco.

P. f. $=69-71^{\circ} \mathrm{C}$.

${ }^{1}$ H RMN $\left(300 \mathrm{MHz}, \mathrm{CDCl}_{3}\right): \delta=7.85-7.78(\mathrm{~m}, 2 \mathrm{H}), 7.47-7.39(\mathrm{~m}, 2 \mathrm{H}), 7.35-7.25(\mathrm{~m}, 1 \mathrm{H}), 7.05(\mathrm{~s}, 1 \mathrm{H})$, $6.72-6.70(\mathrm{~m}, 1 \mathrm{H}), 6.34(\mathrm{~d}, J=1.9 \mathrm{~Hz}, 1 \mathrm{H}), 3.93(\mathrm{~s}, 3 \mathrm{H}), 3.87(\mathrm{~s}, 3 \mathrm{H}) \mathrm{ppm}$.

${ }^{13} \mathbf{C}$ RMN (75.4 MHz, $\mathrm{CDCl}_{3}$ ): $\delta=159.3$ (C), 156.7 (C), 153.8 (C), 153.6 (C), 130.9 (C), $128.9(2 \times \mathrm{CH}), 127.9$ $(\mathrm{CH}), 124.3(2 \times \mathrm{CH}), 113.3(\mathrm{C}), 98.9(\mathrm{CH}), 94.4(\mathrm{CH}), 88.3(\mathrm{CH}), 55.9\left(\mathrm{CH}_{3}\right), 55.7\left(\mathrm{CH}_{3}\right) \mathrm{ppm}$.

EMBR (IE), m/z (\%): $254\left(\mathrm{M}^{+}, 76\right), 239$ (100), 152 (48), 127 (47), 105 (48), 77 (74).

EMAR calculado para $\mathrm{C}_{16} \mathrm{H}_{14} \mathrm{O}_{3}: 254.0943$; encontrado: 254.0943 .

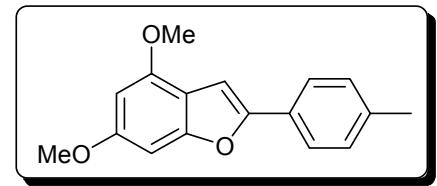

4,6-Dimetoxi-2-p-tolilbenzo[b]furano (54d)

Sólido marrón.

P.f. $=97-99^{\circ} \mathrm{C}$. 
${ }^{1} \mathbf{H} \mathbf{R M N}\left(300 \mathrm{MHz}, \mathrm{CDCl}_{3}\right): \delta=7.71(\mathrm{~d}, J=8.0 \mathrm{~Hz}, 2 \mathrm{H}), 7.25(\mathrm{~d}, J=8.0 \mathrm{~Hz}, 2 \mathrm{H}), 7.01(\mathrm{~s}, 1 \mathrm{H}), 6.72(\mathrm{~d}, J=1.8$ $\mathrm{Hz}, 1 \mathrm{H}), 6.35$ (d, $J=1.8 \mathrm{~Hz}, 1 \mathrm{H}), 3.93(\mathrm{~s}, 3 \mathrm{H}), 3.87$ (s, 3H), $2.40(\mathrm{~s}, 3 \mathrm{H}) \mathrm{ppm}$.

${ }^{13} \mathbf{C}$ RMN (75.4 MHz, $\left.\mathrm{CDCl}_{3}\right): \delta=159.1(\mathrm{C}), 156.5(\mathrm{C}), 154.0(\mathrm{C}), 153.4(\mathrm{C}), 137.8(\mathrm{C}), 129.5(2 \times \mathrm{CH}), 128.1$ (C), $124.3(2 \times \mathrm{CH}), 113.4(\mathrm{C}), 98.1(\mathrm{CH}), 94.3(\mathrm{CH}), 88.3(\mathrm{CH}), 55.8\left(\mathrm{CH}_{3}\right), 55.6\left(\mathrm{CH}_{3}\right), 21.4\left(\mathrm{CH}_{3}\right) \mathrm{ppm}$.

EMBR (IE), m/z (\%): $268\left(\mathrm{M}^{+}, 100\right), 253$ (86), 210 (11).

EMAR calculado para $\mathrm{C}_{17} \mathrm{H}_{16} \mathrm{O}_{3}: 268.1099$; encontrado: 268.1097.

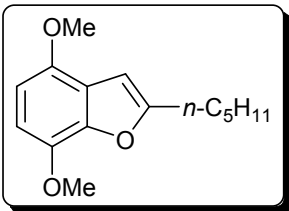

\section{4,7-Dimetoxi-2-pentilbenzo[b]furano (55a)}

Líquido amarillo.

$\mathrm{R}_{\mathrm{f}}=0.53$ (hexano / AcOEt, 8 / 1).

${ }^{1} \mathbf{H}$ RMN $\left(300 \mathrm{MHz}, \mathrm{CDCl}_{3}\right): \delta=6.62(\mathrm{~d}, J=8.6 \mathrm{~Hz}, 1 \mathrm{H}), 6.50(\mathrm{~d}, J=8.6 \mathrm{~Hz}, 1 \mathrm{H}), 6.48-6.46(\mathrm{~m}, 1 \mathrm{H}), 3.96(\mathrm{~s}$, $3 \mathrm{H}), 3.88(\mathrm{~s}, 3 \mathrm{H}), 2.77$ (t, $J=7.6 \mathrm{~Hz}, 2 \mathrm{H}), 1.80-1.69(\mathrm{~m}, 2 \mathrm{H}), 1.40-1.33(\mathrm{~m}, 4 \mathrm{H}), 0.90(\mathrm{t}, J=7.0 \mathrm{~Hz}, 3 \mathrm{H})$ ppm.

${ }^{13}$ C RMN (75.4 MHz, $\left.\mathrm{CDCl}_{3}\right): \delta=159.0$ (C), $147.0(\mathrm{C}), 144.6(\mathrm{C}), 140.0(\mathrm{C}), 120.8$ (C), $105.2(\mathrm{CH}), 102.7$ $(\mathrm{CH}), 99.6(\mathrm{CH}), 56.5\left(\mathrm{CH}_{3}\right), 55.9\left(\mathrm{CH}_{3}\right), 31.5\left(\mathrm{CH}_{2}\right), 28.4\left(\mathrm{CH}_{2}\right), 27.6\left(\mathrm{CH}_{2}\right), 22.5\left(\mathrm{CH}_{2}\right), 14.1\left(\mathrm{CH}_{3}\right)$ ppm.

EMBR (IE), m/z (\%): 248 (M+ , 79), 233 (100), 191 (31), 176 (17), 161 (18).

EMAR calculado para $\mathrm{C}_{15} \mathrm{H}_{20} \mathrm{O}_{3}: 248.1412$; encontrado: 248.1415 .

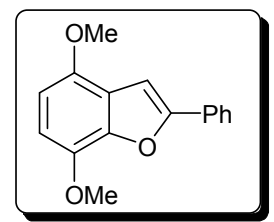

\section{2-Fenil-4,7-dimetoxibenzo[b]furano (55b)}

Sólido amarillo.

P.f. $=75-77^{\circ} \mathrm{C}$.

${ }^{1}$ H RMN (300 MHz, $\left.\mathrm{CDCl}_{3}\right): \delta=7.92-7.88(\mathrm{~m}, 2 \mathrm{H}), 7.48-7.40(\mathrm{~m}, 2 \mathrm{H}), 7.38-7.31(\mathrm{~m}, 1 \mathrm{H}), 7.14(\mathrm{~s}, 1 \mathrm{H}), 6.70$ $(\mathrm{d}, J=8.5 \mathrm{~Hz}, 1 \mathrm{H}), 6.54(\mathrm{~d}, J=8.5 \mathrm{~Hz}, 1 \mathrm{H}), 4.01(\mathrm{~s}, 3 \mathrm{H}), 3.92(\mathrm{~s}, 3 \mathrm{H}) \mathrm{ppm}$.

${ }^{13}$ C RMN (75.4 MHz, $\left.\mathrm{CDCl}_{3}\right): \delta=155.2(\mathrm{C}), 147.5(\mathrm{C}), 145.0(\mathrm{C}), 140.2(\mathrm{C}), 130.4(\mathrm{C}), 128.8(2 \times \mathrm{CH}), 128.5$ $(\mathrm{CH}), 125.0(2 \times \mathrm{CH}), 121.3(\mathrm{C}), 106.9(\mathrm{CH}), 102.9(\mathrm{CH}), 99.3(\mathrm{CH}), 56.7\left(\mathrm{CH}_{3}\right), 55.9\left(\mathrm{CH}_{3}\right) \mathrm{ppm}$.

EMBR (IE), m/z (\%): $254\left(\mathrm{M}^{+}, 79\right), 239$ (100), 224 (32), 139 (11).

EMAR calculado para $\mathrm{C}_{16} \mathrm{H}_{14} \mathrm{O}_{3}: 254.0943$; encontrado: 254.0936 .

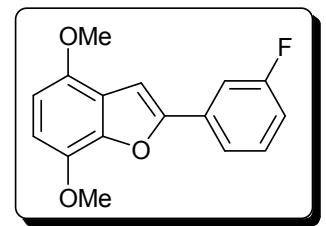

\section{2-(3-Fluorofenil)-4,7-dimetoxibenzo[b]furano (55c)}

Sólido blanco.

P.f. $=104-106^{\circ} \mathrm{C}$

${ }^{1}$ H RMN $\left(300 \mathrm{MHz}, \mathrm{CDCl}_{3}\right): \delta=7.64(\mathrm{~d}, J=7.8 \mathrm{~Hz}, 1 \mathrm{H}), 7.60-7.54(\mathrm{~m}, 1 \mathrm{H}), 7.38(\mathrm{td}, J=8.0,5.9 \mathrm{~Hz}, 1 \mathrm{H})$, $7.14(\mathrm{~s}, 1 \mathrm{H}), 7.02(\mathrm{td}, J=8.3,2.4 \mathrm{~Hz}, 1 \mathrm{H}), 6.71(\mathrm{~d}, J=8.5 \mathrm{~Hz}, 1 \mathrm{H}), 6.53(\mathrm{~d}, J=8.5 \mathrm{~Hz}, 1 \mathrm{H}), 4.00(\mathrm{~s}, 3 \mathrm{H})$, $3.91(\mathrm{~s}, 3 \mathrm{H}) \mathrm{ppm}$.

${ }^{13}$ C RMN (75.4 MHz, $\left.\mathrm{CDCl}_{3}\right): \delta=163.2(\mathrm{~d}, J=245.5 \mathrm{~Hz}, \mathrm{C}), 153.8(\mathrm{~d}, J=3.1 \mathrm{~Hz}, \mathrm{C}), 147.6(\mathrm{C}), 145.0(\mathrm{C})$, 140.2 (C), 132.5 (d, $J=8.4 \mathrm{~Hz}, \mathrm{C}), 130.4$ (d, $J=8.4 \mathrm{~Hz}, \mathrm{CH}), 121.1(\mathrm{C}), 120.6$ (d, $J=2.9 \mathrm{~Hz}, \mathrm{CH}), 115.2$ $(\mathrm{d}, J=21.3 \mathrm{~Hz}, \mathrm{CH}), 111.8(\mathrm{~d}, J=23.6 \mathrm{~Hz}, \mathrm{CH}), 107.3(\mathrm{CH}), 103.0(\mathrm{CH}), 100.4(\mathrm{CH}), 56.7\left(\mathrm{CH}_{3}\right), 55.9$ $\left(\mathrm{CH}_{3}\right) \mathrm{ppm}$.

EMBR (IE), m/z (\%): $272\left(\mathrm{M}^{+}, 68\right), 257$ (100), 242 (29), 214 (9).

EMAR calculado para $\mathrm{C}_{16} \mathrm{H}_{13} \mathrm{FO}_{3}: 272.0849$; encontrado: 272.0849 . 


\section{A.4 Transformaciones sintéticas de los metoxibenzo[b]furanos}

\section{A.4.1 Síntesis de los hidroxibenzo/b]furanos 56, 57 y 58}

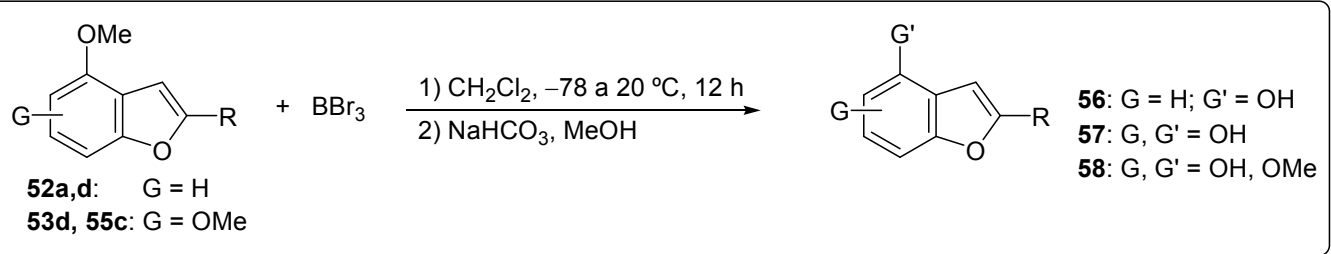

A una disolución del correspondiente benzofurano 52a,d, 53d, 55c $(0.3 \mathrm{mmol})$ en $\mathrm{CH}_{2} \mathrm{Cl}_{2}$ a $-78{ }^{\circ} \mathrm{C}$ se le añade muy lentamente una disolución $1 \mathrm{M} \mathrm{BBr}_{3}$ en $\mathrm{CH}_{2} \mathrm{Cl}_{2}(1.20 \mathrm{~mL}, 1.2 \mathrm{mmol}$ para 52a,d, 53 y $0.54 \mathrm{~mL}, 0.54 \mathrm{mmol}$ para 55c). Se permite que la mezcla de reacción alcance temperatura ambiente y se mantiene la agitación a esa temperatura durante toda la noche. Se le añade entonces $\mathrm{NaHCO}_{3}(100 \mathrm{mg}, 1.2 \mathrm{mmol}$ para 52a,d, 53 y $45 \mathrm{mg}, 0.54 \mathrm{mmol}$ para 55c). Se enfría la mezcla resultante a $0{ }^{\circ} \mathrm{C}$ y se adiciona lentamente $\mathrm{MeOH}(6 \mathrm{~mL})$. Después de 30 minutos a $0{ }^{\circ} \mathrm{C}$, se deja que la mezcla alcance $20^{\circ} \mathrm{C}$. Tras 1 hora de agitación, se eliminan los disolventes a presión reducida. El residuo obtenido se hidroliza con $\mathrm{H}_{2} \mathrm{O}$ y la fase acuosa se extrae con $\mathrm{CH}_{2} \mathrm{Cl}_{2}(2 \times 10 \mathrm{~mL})$. La fase orgánica se seca sobre $\mathrm{Na}_{2} \mathrm{SO}_{4}$ anhidro y se elimina el disolvente a presión reducida. La purificación del residuo por cromatografía de columna (hexano / AcOEt) da lugar a los compuestos 56-58.

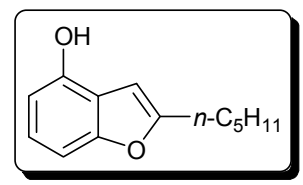

4-Hidroxi-2-pentilbenzo[b]furano (56a)

Líquido marrón.

$\mathrm{R}_{\mathrm{f}}=0.44$ (hexano / AcOEt, $2 / 1$ ).

${ }^{1} \mathbf{H}$ RMN $\left(300 \mathrm{MHz}, \mathrm{CDCl}_{3}\right): \delta=7.09-7.01(\mathrm{~m}, 2 \mathrm{H}), 6.59(\mathrm{dd}, J=5.9,2.7 \mathrm{~Hz}, 1 \mathrm{H}), 6.43(\mathrm{~s}, 1 \mathrm{H}), 5.12(\mathrm{sa}, 1 \mathrm{H})$, $2.74(\mathrm{t}, J=7.6 \mathrm{~Hz}, 2 \mathrm{H}), 1.79-1.68(\mathrm{~m}, 2 \mathrm{H}), 1.43-1.33(\mathrm{~m}, 4 \mathrm{H}), 0.91(\mathrm{t}, J=7.0 \mathrm{~Hz}, 3 \mathrm{H}) \mathrm{ppm}$.

${ }^{13}$ C RMN (75.4 MHz, $\left.\mathrm{CDCl}_{3}\right): \delta=158.8(\mathrm{C}), 156.4(\mathrm{C}), 148.5(\mathrm{C}), 123.8(\mathrm{CH}), 118.0(\mathrm{C}), 107.8(\mathrm{CH}), 104.2$ $(\mathrm{CH}), 98.4(\mathrm{CH}), 31.5\left(\mathrm{CH}_{2}\right), 28.5\left(\mathrm{CH}_{2}\right), 27.5\left(\mathrm{CH}_{2}\right), 22.6\left(\mathrm{CH}_{2}\right), 14.1\left(\mathrm{CH}_{3}\right) \mathrm{ppm}$.

EMBR (IE), m/z (\%): $204\left(\mathrm{M}^{+}, 28\right), 147(100), 123(8)$.

EMAR calculado para $\mathrm{C}_{13} \mathrm{H}_{16} \mathrm{O}_{2}: 204.1150$; encontrado: 204.1158 .

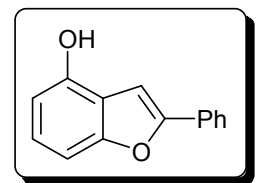

2-Fenil-4-hidroxibenzo[b]furano $(56 \mathbf{b})^{280}$

Sólido blanco.

P.f. $=157-159^{\circ} \mathrm{C}$.

${ }^{1}$ H RMN (300 MHz, $\left.\left(\mathrm{CD}_{3}\right)_{2} \mathrm{CO}\right): \delta=8.87(\mathrm{sa}, 1 \mathrm{H}), 7.85-7.80(\mathrm{~m}, 2 \mathrm{H}), 7.42-7.35(\mathrm{~m}, 2 \mathrm{H}), 7.31-7.24(\mathrm{~m}, 2 \mathrm{H})$, $7.09-6.96(\mathrm{~m}, 2 \mathrm{H}), 6.62(\mathrm{dd}, J=7.6,1.1 \mathrm{~Hz}, 1 \mathrm{H}) \mathrm{ppm}$.

$\left.{ }^{13} \mathbf{C ~ R M N ~ ( 7 5 . 4 ~ M H z , ~}\left(\mathrm{CD}_{3}\right)_{2} \mathrm{CO}\right): \delta=157.3(\mathrm{C}), 154.9(\mathrm{C}), 152.0(\mathrm{C}), 131.3(\mathrm{C}), 129.7(2 \times \mathrm{CH}), 129.2(\mathrm{CH})$, $126.2(\mathrm{CH}), 125.3(2 \times \mathrm{CH}), 119.4(\mathrm{C}), 108.8(\mathrm{CH}), 103.6(\mathrm{CH}), 99.7(\mathrm{CH}) \mathrm{ppm}$.

EMBR (IE), m/z (\%): 210 (M+100), 181 (9), 153 (17), 105 (14).

EMAR calculado para $\mathrm{C}_{14} \mathrm{H}_{10} \mathrm{O}_{2}: 210.0681$; encontrado: 210.0678 .

${ }^{280}$ N. Takeda, O. Miyata, T. Naito, Eur. J. Org. Chem. 2007, 1491. 


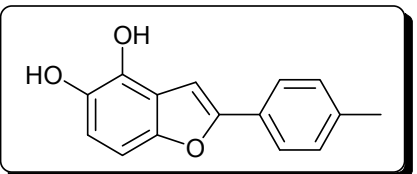

4,5-Dihidroxi-2-p-tolilbenzo[b]furano (57)

Sólido rojo.

P.f. $=130-132^{\circ} \mathrm{C}$.

${ }^{1} \mathbf{H}$ RMN $\left(300 \mathrm{MHz}, \mathrm{CDCl}_{3}\right): \delta=7.72(\mathrm{~d}, J=7.9 \mathrm{~Hz}, 2 \mathrm{H}), 7.29-7.21(\mathrm{~m}, 2 \mathrm{H}), 7.02(\mathrm{~s}, 1 \mathrm{H}), 6.97(\mathrm{~d}, J=8.6 \mathrm{~Hz}$, $1 \mathrm{H}), 6.82(\mathrm{~d}, J=8.6 \mathrm{~Hz}, 1 \mathrm{H}), 5.54(\mathrm{sa}, 1 \mathrm{H}), 4.84(\mathrm{sa}, 1 \mathrm{H}), 2.39(\mathrm{~s}, 3 \mathrm{H}) \mathrm{ppm}$.

${ }^{13}$ C RMN (75.4 MHz, $\left.\mathrm{CDCl}_{3}\right): \delta=156.4(\mathrm{C}), 151.0(\mathrm{C}), 138.8(\mathrm{C}), 137.6(\mathrm{C}), 136.6(\mathrm{C}), 130.1(\mathrm{C}), 129.7$ $(2 \times \mathrm{CH}), 127.9(\mathrm{C}), 125.0(2 \times \mathrm{CH}), 119.4(\mathrm{C}), 113.0(\mathrm{CH}), 103.1(\mathrm{CH}), 97.7(\mathrm{CH}), 21.6\left(\mathrm{CH}_{3}\right) \mathrm{ppm}$.

EMBR (IE), m/z (\%): $238\left(\mathrm{M}^{+}-2,86\right), 207$ (100), 191 (11), 153 (16), 119 (24).

EMAR calculado para $\mathrm{C}_{15} \mathrm{H}_{12} \mathrm{O}_{3}: 240.0786$; encontrado: 240.0785 .

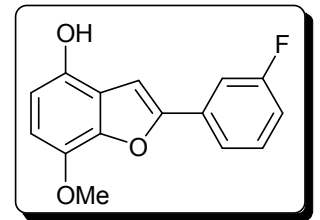

2-(3-Fluorofenil)-4-hidroxi-7-metoxibenzo[b]furano (58a)

Sólido rojo.

${ }^{1}$ H RMN (300 MHz, DMSO-d $\left.{ }_{6}\right): \delta=9.64(\mathrm{~s}, 1 \mathrm{H}), 7.85-7.75(\mathrm{~m}, 2 \mathrm{H}), 7.65-7.53(\mathrm{~m}, 2 \mathrm{H}), 7.29-7.21(\mathrm{~m}, 1 \mathrm{H})$, $6.73(\mathrm{~d}, J=8.5 \mathrm{~Hz}, 1 \mathrm{H}), 6.62(\mathrm{~d}, J=8.5 \mathrm{~Hz}, 1 \mathrm{H}), 3.86(\mathrm{~s}, 3 \mathrm{H}) \mathrm{ppm}$.

${ }^{13}$ C RMN (75.4 MHz, DMSO-d $\left.{ }_{6}\right): \delta=162.5(\mathrm{~d}, J=243.2 \mathrm{~Hz}, \mathrm{C}), 152.4(\mathrm{~d}, J=3.1 \mathrm{~Hz}, \mathrm{C}), 145.7(\mathrm{C}), 143.8(\mathrm{C})$, 136.7 (C), 132.1 (d, $J=8.7 \mathrm{~Hz}, \mathrm{C}), 131.1$ (d, $J=8.6 \mathrm{~Hz}, \mathrm{CH}), 120.4$ (d, $J=2.6 \mathrm{~Hz}, \mathrm{CH}), 120.1$ (C), 115.2 $(\mathrm{d}, J=21.3 \mathrm{~Hz}, \mathrm{CH}), 111.0(\mathrm{~d}, J=23.7 \mathrm{~Hz}, \mathrm{CH}), 110.8(\mathrm{CH}), 104.1(\mathrm{CH}), 101.3(\mathrm{CH}), 55.5\left(\mathrm{CH}_{3}\right) \mathrm{ppm}$.

EMAR calculado para $\mathrm{C}_{15} \mathrm{H}_{11} \mathrm{FO}_{3}$ : 258.0692; encontrado: 258.0702 .

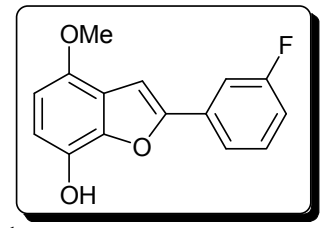

\section{2-(3-Fluorofenil)-7-hidroxi-4-metoxibenzo[b]furano (58b)}

Sólido rojo.

${ }^{1} \mathbf{H}$ RMN $\left(400 \mathrm{MHz}, \mathrm{CDCl}_{3}\right): \delta=7.62(\mathrm{~d}, J=7.9 \mathrm{~Hz}, 1 \mathrm{H}), 7.55(\mathrm{~d}, J=9.8 \mathrm{~Hz}, 1 \mathrm{H}), 7.37(\mathrm{td}, J=7.9,5.9 \mathrm{~Hz}$, $1 \mathrm{H}), 7.11(\mathrm{~s}, 1 \mathrm{H}), 7.01(\mathrm{td}, J=8.4,2.6 \mathrm{~Hz}, 1 \mathrm{H}), 6.66(\mathrm{~d}, J=8.4 \mathrm{~Hz}, 1 \mathrm{H}), 6.54(\mathrm{~d}, J=8.4 \mathrm{~Hz}, 1 \mathrm{H}), 5.32$ (sa, 1H), $3.99(\mathrm{~s}, 3 \mathrm{H}) \mathrm{ppm}$.

${ }^{13} \mathbf{C}$ RMN (100.6 MHz, CDCl $): \delta=163.2(\mathrm{~d}, J=245.6 \mathrm{~Hz}, \mathrm{C}), 154.1(\mathrm{C}), 145.3(\mathrm{C}), 143.3(\mathrm{C}), 140.1(\mathrm{C}), 132.4$ $(\mathrm{d}, J=8.1 \mathrm{~Hz}, \mathrm{C}), 130.5(\mathrm{~d}, J=7.6 \mathrm{~Hz}, \mathrm{CH}), 120.7(\mathrm{CH}), 120.4(\mathrm{C}), 115.4(\mathrm{~d}, J=21.4 \mathrm{~Hz}, \mathrm{CH}), 112.0(\mathrm{~d}$, $J=23.5 \mathrm{~Hz}, \mathrm{CH}), 107.9(\mathrm{~d}, J=12.5 \mathrm{~Hz}, \mathrm{CH}), 99.9(\mathrm{CH}), 56.9\left(\mathrm{CH}_{3}\right) \mathrm{ppm}$.

EMAR calculado para $\mathrm{C}_{15} \mathrm{H}_{11} \mathrm{FO}_{3}$ : 258.0692; encontrado: 258.0705 .

\section{B Intentos de síntesis de 4-halobenzo[b]furanos 3-funcionalizados}

B.1 Preparación de los 1-halo-3-metoxi-2-vinilbencenos 60

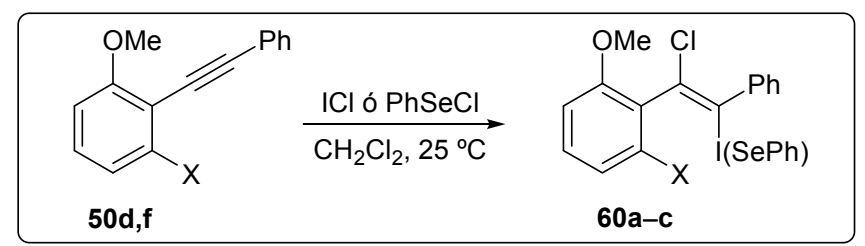


Sobre una disolución del alquino $\mathbf{5 0 d}$ ó $\mathbf{5 0 f}(0.3 \mathrm{mmol})$ en $\mathrm{CH}_{2} \mathrm{Cl}_{2}(3 \mathrm{~mL})$ se añade lentamente el correspondiente electrófilo $(0.6 \mathrm{mmol})$ disuelto en $\mathrm{CH}_{2} \mathrm{Cl}_{2}(2 \mathrm{~mL})$. Se agita la mezcla a temperatura ambiente hasta la completa desaparición del sustrato de partida, monitorizando la reacción por CG-EM. Después de 3 horas, la mezcla de reacción se hidroliza con $\mathrm{H}_{2} \mathrm{O}$ y se extrae con $\mathrm{CH}_{2} \mathrm{Cl}_{2}(2 \times 10 \mathrm{~mL})$. La combinación de fases orgánicas se seca sobre $\mathrm{Na}_{2} \mathrm{SO}_{4}$ anhidro y se evapora el disolvente a presión reducida $(20 \mathrm{~mm} \mathrm{Hg})$. El residuo se purifica por cromatografía de columna en sílica gel (hexano / AcOEt, 20 / 1) obteniéndose los compuestos 60a-c.

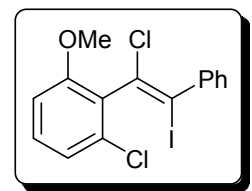

1-Cloro-2-[(E)-1-cloro-2-fenil-2-yodovinil]-3-metoxibenceno (60a) Sólido blanco. P.f. $=132-134^{\circ} \mathrm{C}$.

${ }^{1}$ H RMN (300 MHz, $\left.\mathrm{CDCl}_{3}\right): \delta=7.54(\mathrm{~d}, J=8.1 \mathrm{~Hz}, 2 \mathrm{H}), 7.41(\mathrm{t}, J=7.6 \mathrm{~Hz}, 2 \mathrm{H}), 7.36-7.28(\mathrm{~m}, 2 \mathrm{H}), 7.10(\mathrm{~d}$, $J=8.1 \mathrm{~Hz}, 1 \mathrm{H}), 6.90(\mathrm{~d}, J=8.4 \mathrm{~Hz}, 1 \mathrm{H}), 3.95(\mathrm{~s}, 3 \mathrm{H}) \mathrm{ppm}$.

${ }^{13} \mathbf{C}$ RMN (75.4 MHz, $\left.\mathrm{CDCl}_{3}\right): \delta=157.5(\mathrm{C}), 141.7(\mathrm{C}), 134.0(\mathrm{C}), 130.9(\mathrm{CH}), 130.0(\mathrm{C}), 129.0(2 \times \mathrm{CH}), 128.9$ (C), $128.7(\mathrm{CH}), 128.4(2 \times \mathrm{CH}), 125.5(\mathrm{C}), 121.8(\mathrm{CH}), 109.8(\mathrm{CH}), 99.1(\mathrm{C}), 56.6\left(\mathrm{CH}_{3}\right) \mathrm{ppm}$.

EMBR (IE), m/z (\%): $406\left(\mathrm{M}^{+}+2,4\right), 404\left(\mathrm{M}^{+}, 6\right), 277$ (39), 262 (100), 242 (21), 199 (15), 178 (11), 163 (19).

EMAR calculado para $\mathrm{C}_{15} \mathrm{H}_{11} \mathrm{Cl}_{2} \mathrm{IO}$ : 403.9232; encontrado: 403.9233 .

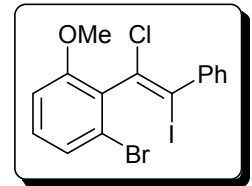

1-Bromo-2-[(E)-1-cloro-2-fenil-2-yodovinil]-3-metoxibenceno (60b) Sólido blanco.

P.f. $=138-140^{\circ} \mathrm{C}$.

${ }^{1}$ H RMN (300 MHz, CDCl $\left.)_{3}\right): \delta=7.60-7.53(\mathrm{~m}, 2 \mathrm{H}), 7.46-7.39(\mathrm{~m}, 2 \mathrm{H}), 7.38-7.31(\mathrm{~m}, 1 \mathrm{H}), 7.31-7.21(\mathrm{~m}, 2 \mathrm{H})$, $6.94(\mathrm{dd}, J=7.7,1.6 \mathrm{~Hz}, 1 \mathrm{H}), 3.94(\mathrm{~s}, 3 \mathrm{H}) \mathrm{ppm}$.

${ }^{13}$ C RMN (75.4 MHz, $\left.\mathrm{CDCl}_{3}\right): \delta=157.5(\mathrm{C}), 141.6(\mathrm{C}), 131.7(\mathrm{C}), 131.3(\mathrm{CH}), 129.0(2 \times \mathrm{CH}), 128.7(\mathrm{CH})$, $128.4(2 \times \mathrm{CH}), 127.1(\mathrm{C}), 124.9(\mathrm{CH}), 123.9(\mathrm{C}), 110.4(\mathrm{CH}), 99.0(\mathrm{C}), 56.6\left(\mathrm{CH}_{3}\right) \mathrm{ppm}$.

EMBR (IE), m/z (\%): $452\left(\mathrm{M}^{+}+4,2\right), 450\left(\mathrm{M}^{+}+2,5\right), 448\left(\mathrm{M}^{+}, 5\right), 310(25), 308$ (100), 306 (79), 163 (36).

EMAR calculado para $\mathrm{C}_{15} \mathrm{H}_{11}$ BrClIO: 447.8726; encontrado: 447.8727.

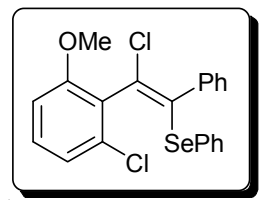

1-Cloro-2-[(E)-1-cloro-2-fenil-2-(fenilselanil)vinil]-3-metoxibenceno (60c)

Líquido marrón.

$\mathrm{R}_{\mathrm{f}}=0.28$ (hexano / AcOEt, $\left.20 / 1\right)$.

${ }^{1}$ H RMN (300 MHz, $\left.\mathrm{CDCl}_{3}\right): \delta=7.46-7.41(\mathrm{~m}, 2 \mathrm{H}), 7.35-7.28(\mathrm{~m}, 3 \mathrm{H}), 7.28-7.21(\mathrm{~m}, 2 \mathrm{H}), 7.20-7.16(\mathrm{~m}, 1 \mathrm{H})$, $7.16-7.03(\mathrm{~m}, 4 \mathrm{H}), 6.89(\mathrm{~d}, J=8.4 \mathrm{~Hz}, 1 \mathrm{H}), 3.93(\mathrm{~d}, J=0.6 \mathrm{~Hz}, 3 \mathrm{H}) \mathrm{ppm}$.

${ }^{13} \mathbf{C}$ RMN (75.4 MHz, $\left.\mathrm{CDCl}_{3}\right): \delta=157.8(\mathrm{C}), 138.2(\mathrm{C}), 134.8(\mathrm{C}), 134.3(2 \times \mathrm{CH}), 134.1(\mathrm{C}), 130.6(\mathrm{CH}), 129.8$ $(2 \times \mathrm{CH}), 129.2(\mathrm{C}), 128.7(2 \times \mathrm{CH}), 128.0(\mathrm{C}), 127.8(\mathrm{CH}), 127.7(2 \times \mathrm{CH}), 127.6(\mathrm{CH}), 123.2(\mathrm{C}), 121.8$ $(\mathrm{CH}), 109.5(\mathrm{CH}), 56.4\left(\mathrm{CH}_{3}\right) \mathrm{ppm}$.

EMBR (IE), m/z (\%): $438\left(\mathrm{M}^{+}+4,6\right), 436\left(\mathrm{M}^{+}+2,24\right), 434\left(\mathrm{M}^{+}, 34\right), 401$ (22), 399 (49), 364 (28), 264 (65), 262 (100), 241 (45), 163 (33).

EMAR calculado para $\mathrm{C}_{21} \mathrm{H}_{16} \mathrm{Cl}_{2} \mathrm{OSe}$ : 433.9743; encontrado: 433.9743. 


\section{Reacciones de orto-metalación combinadas con acoplamientos catalizados por paladio. Síntesis de benzo $[b]$ tiofenos regioselectivamente funcionalizados.}

\section{A Síntesis de benzo[b]tiofenos 7-oxígeno-funcionalizados}

\section{A.1 Preparación de los $N, N$-dietilcarbamatos de $O$-3-halo-2-sulfanilfenilo 61}

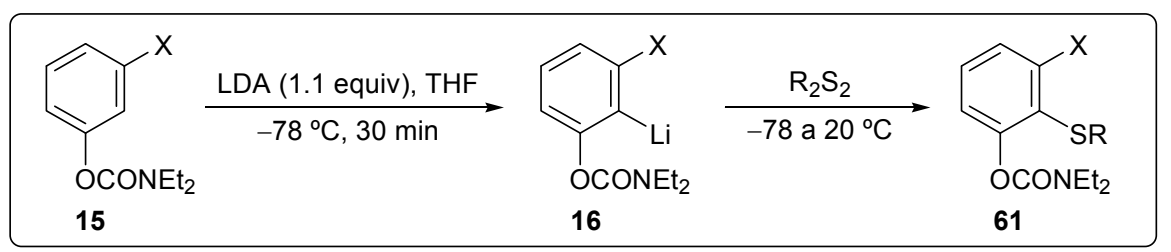

A una disolución de $i$ - $\operatorname{Pr}_{2} \mathrm{NH}(463 \mu \mathrm{L}, 3.3 \mathrm{mmol})$ en THF $(12 \mathrm{~mL})$ a $0{ }^{\circ} \mathrm{C}$ se adiciona $n$-BuLi (2.1 $\mathrm{mL}$ de una disolución $1.6 \mathrm{M}$ en hexano, $3.3 \mathrm{mmol}$ ). Después de 30 minutos a $0{ }^{\circ} \mathrm{C}$, la disolución de LDA se enfría a $-78^{\circ} \mathrm{C}$, y se añade $15(3 \mathrm{mmol})$. La mezcla resultante se agita durante 30 minutos a $0{ }^{\circ} \mathrm{C}$, y a continuación se adiciona el correspondiente electrófilo (3.6 mmol) a $-78{ }^{\circ} \mathrm{C}$. Después de 30 minutos a $-78{ }^{\circ} \mathrm{C}$, se deja que la mezcla de reacción alcance temperatura ambiente y se hidroliza con $\mathrm{H}_{2} \mathrm{O}$. La fase acuosa se extrae con $\mathrm{Et}_{2} \mathrm{O}(3 \times 20 \mathrm{~mL})$. La combinación de fases orgánicas se seca sobre $\mathrm{Na}_{2} \mathrm{SO}_{4}$ anhidro y el disolvente se evapora a presión reducida. El crudo se purifica mediante columna de cromatografía (hexano / AcOEt) en sílica gel permitiendo obtener $6 \mathbf{6 1}$.

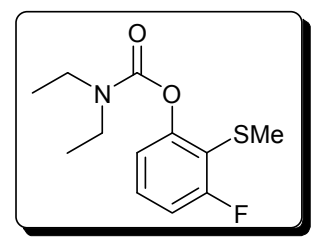

$\mathrm{N}, \mathrm{N}$-Dietilcarbamato de $\boldsymbol{O}$-3-fluoro-2-(metiltio)fenilo (61aa)

Líquido incoloro.

$\mathrm{R}_{\mathrm{f}}=0.42$ (hexano / AcOEt, $5 / 1$ ).

${ }^{1} \mathbf{H}$ RMN $\left(300 \mathrm{MHz}, \mathrm{CDCl}_{3}\right): \delta=7.24(\mathrm{td}, J=8.2,6.2 \mathrm{~Hz}, 1 \mathrm{H}), 6.99-6.92(\mathrm{~m}, 2 \mathrm{H}), 3.53-3.44(\mathrm{~m}, 2 \mathrm{H})$, $3.43-3.33(\mathrm{~m}, 2 \mathrm{H}), 2.37(\mathrm{~d}, J=0.6 \mathrm{~Hz}, 3 \mathrm{H}), 1.29(\mathrm{t}, J=7.1 \mathrm{~Hz}, 3 \mathrm{H}), 1.20(\mathrm{t}, J=7.1 \mathrm{~Hz}, 3 \mathrm{H}) \mathrm{ppm}$.

${ }^{13} \mathbf{C}$ RMN (75.4 MHz, $\left.\mathrm{CDCl}_{3}\right): \delta=163.5(\mathrm{~d}, J=246.5 \mathrm{~Hz}, \mathrm{C}), 153.7(\mathrm{C}), 153.2(\mathrm{~d}, J=4.3 \mathrm{~Hz}, \mathrm{C}), 129.1(\mathrm{~d}, J=$ $10.1 \mathrm{~Hz}, \mathrm{CH}), 118.8(\mathrm{~d}, J=3.3 \mathrm{~Hz}, \mathrm{CH}), 113.0(\mathrm{~d}, J=23.7 \mathrm{~Hz}, \mathrm{CH}), 42.4\left(\mathrm{CH}_{2}\right), 42.2\left(\mathrm{CH}_{2}\right), 17.9(\mathrm{~d}, J=$ $\left.4.9 \mathrm{~Hz}, \mathrm{CH}_{3}\right), 14.2\left(\mathrm{CH}_{3}\right), 13.3\left(\mathrm{CH}_{3}\right) \mathrm{ppm}$.

EMBR (IE), m/z (\%): $257\left(\mathrm{M}^{+}, 30\right), 158(6), 143$ (6), 114 (9), 100 (100), 72 (51).

EMAR calculado para $\mathrm{C}_{12} \mathrm{H}_{16} \mathrm{FNO}_{2} \mathrm{~S}: 257.0886$; encontrado: 257.0877 . 


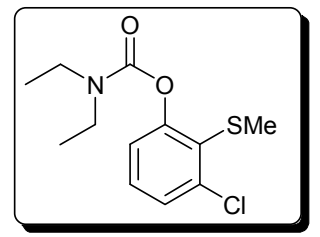

\section{$\mathrm{N}, \mathrm{N}$-Dietilcarbamato de $\mathrm{O}$-3-cloro-2-(metiltio)fenilo (61ba)}

Líquido incoloro.

$\mathrm{R}_{\mathrm{f}}=0.45$ (hexano / AcOEt, 5 / 1).

${ }^{1} \mathbf{H}$ RMN $\left(300 \mathrm{MHz}, \mathrm{CDCl}_{3}\right): \delta=7.32(\mathrm{dd}, J=8.1,1.5 \mathrm{~Hz}, 1 \mathrm{H}), 7.24(\mathrm{t}, J=8.1 \mathrm{~Hz}, 1 \mathrm{H}), 7.06(\mathrm{dd}, J=8.1,1.5$ $\mathrm{Hz}, 1 \mathrm{H}), 3.58-3.48(\mathrm{~m}, 2 \mathrm{H}), 3.47-3.37(\mathrm{~m}, 2 \mathrm{H}), 2.36(\mathrm{~s}, 3 \mathrm{H}), 1.30(\mathrm{t}, J=7.1 \mathrm{~Hz}, 3 \mathrm{H}), 1.21(\mathrm{t}, J=7.1 \mathrm{~Hz}$, 3H) $\mathrm{ppm}$.

${ }^{13} \mathbf{C}$ RMN (75.4 MHz, $\left.\mathrm{CDCl}_{3}\right): \delta=154.3(\mathrm{C}), 153.9(\mathrm{C}), 140.5(\mathrm{C}), 129.7(\mathrm{CH}), 129.6(\mathrm{C}), 127.2(\mathrm{CH}), 121.9$ $(\mathrm{CH}), 42.5\left(\mathrm{CH}_{2}\right), 42.2\left(\mathrm{CH}_{2}\right), 18.1\left(\mathrm{CH}_{3}\right), 14.3\left(\mathrm{CH}_{3}\right), 13.4\left(\mathrm{CH}_{3}\right) \mathrm{ppm}$.

EMBR (IE), m/z (\%): $275\left(\mathrm{M}^{+}+2,4\right), 273\left(\mathrm{M}^{+}, 12\right), 226$ (4), 131 (4), 100 (100), 72 (51).

EMAR calculado para $\mathrm{C}_{12} \mathrm{H}_{16} \mathrm{ClNO}_{2} \mathrm{~S}$ : 273.0590; encontrado: 273.0591 .

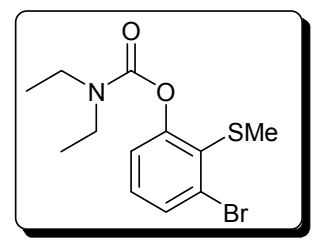

$N, N$-Dietilcarbamato de $O$-3-bromo-2-(metiltio)fenilo (61 ca)

Sólido blanco.

P.f. $=45-47^{\circ} \mathrm{C}$.

${ }^{1} \mathbf{H}$ RMN $\left(300 \mathrm{MHz}, \mathrm{CDCl}_{3}\right): \delta=7.51-7.47(\mathrm{~m}, 1 \mathrm{H}), 7.16(\mathrm{t}, J=7.9 \mathrm{~Hz}, 1 \mathrm{H}), 7.12-7.07(\mathrm{~m}, 1 \mathrm{H}), 3.48(\mathrm{q}, J=$ $7.1 \mathrm{~Hz}, 2 \mathrm{H}), 3.37$ (q, $J=7.1 \mathrm{~Hz}, 2 \mathrm{H}), 2.35(\mathrm{~d}, J=0.6 \mathrm{~Hz}, 3 \mathrm{H}), 1.29$ (t, $J=7.1 \mathrm{~Hz}, 3 \mathrm{H}), 1.19$ (t, $J=7.1 \mathrm{~Hz}$, 3H) $\mathrm{ppm}$.

${ }^{13} \mathbf{C}$ RMN (75.4 MHz, $\left.\mathrm{CDCl}_{3}\right): \delta=154.2(\mathrm{C}), 153.8(\mathrm{C}), 131.5(\mathrm{C}), 131.3(\mathrm{C}), 130.4(\mathrm{CH}), 130.2(\mathrm{CH}), 122.6$ $(\mathrm{CH}), 42.4\left(\mathrm{CH}_{2}\right), 42.2\left(\mathrm{CH}_{2}\right), 18.4\left(\mathrm{CH}_{3}\right), 14.2\left(\mathrm{CH}_{3}\right), 13.3\left(\mathrm{CH}_{3}\right) \mathrm{ppm}$.

EMBR (IE), m/z (\%): $319\left(\mathrm{M}^{+}+2,10\right), 317\left(\mathrm{M}^{+}, 9\right), 270$ (4), 138 (6), 100 (100), 72 (38).

EMAR calculado para $\mathrm{C}_{12} \mathrm{H}_{16} \mathrm{BrNO}_{2} \mathrm{~S}: 317.0085$; encontrado: 317.0085 .

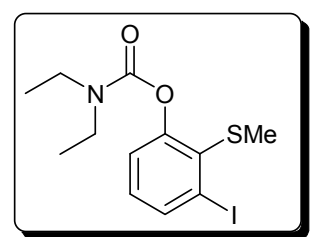

$N, N$-Dietilcarbamato de $O$-2-(metiltio)-3-yodofenilo (61da)

Sólido blanco.

P.f. $=66-68^{\circ} \mathrm{C}$.

${ }^{1} \mathbf{H}$ RMN $\left(300 \mathrm{MHz}, \mathrm{CDCl}_{3}\right): \delta=7.77(\mathrm{~d}, J=7.9 \mathrm{~Hz}, 1 \mathrm{H}), 7.14(\mathrm{~d}, J=7.9 \mathrm{~Hz}, 1 \mathrm{H}), 7.01(\mathrm{td}, J=7.9,0.7 \mathrm{~Hz}$, $1 \mathrm{H}), 3.53-3.44(\mathrm{~m}, 2 \mathrm{H}), 3.43-3.34(\mathrm{~m}, 2 \mathrm{H}), 2.34(\mathrm{~d}, J=0.7 \mathrm{~Hz}, 3 \mathrm{H}), 1.29(\mathrm{t}, J=7.1 \mathrm{~Hz}, 3 \mathrm{H}), 1.20(\mathrm{t}, J=$ $7.1 \mathrm{~Hz}, 3 \mathrm{H}) \mathrm{ppm}$.

${ }^{13}$ C RMN (75.4 MHz, $\left.\mathrm{CDCl}_{3}\right): \delta=154.0(\mathrm{C}), 153.3(\mathrm{C}), 137.0(\mathrm{CH}), 134.9(\mathrm{C}), 131.0(\mathrm{CH}), 123.7(\mathrm{CH}), 109.9$ (C), $42.4\left(\mathrm{CH}_{2}\right), 42.2\left(\mathrm{CH}_{2}\right), 19.2\left(\mathrm{CH}_{3}\right), 14.4\left(\mathrm{CH}_{3}\right), 14.2\left(\mathrm{CH}_{3}\right), 13.5\left(\mathrm{CH}_{3}\right), 13.4\left(\mathrm{CH}_{3}\right) \mathrm{ppm}$.

EMBR (IE), m/z (\%): 365 (M+, 20), 318 (16), 138 (10), 123 (11), 100 (100), 72 (44).

EMAR calculado para $\mathrm{C}_{12} \mathrm{H}_{16} \mathrm{INO}_{2} \mathrm{~S}: 364.9947$; encontrado: 364.9944. 


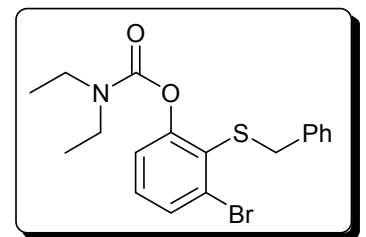

$N, N$-Dietilcarbamato de $O$-2-(benciltio)-3-bromofenilo (61 cb)

Líquido incoloro.

$\mathrm{R}_{\mathrm{f}}=0.35$ (hexano / AcOEt, 4 / 1).

${ }^{1} \mathbf{H}$ RMN $\left(300 \mathrm{MHz}, \mathrm{CDCl}_{3}\right): \delta=7.54(\mathrm{dd}, J=7.7,1.6 \mathrm{~Hz}, 1 \mathrm{H}), 7.31-7.16(\mathrm{~m}, 6 \mathrm{H}), 7.13(\mathrm{dd}, J=7.7,1.6 \mathrm{~Hz}$, $1 \mathrm{H}), 4.08(\mathrm{~s}, 2 \mathrm{H}), 3.45-3.36(\mathrm{~m}, 4 \mathrm{H}), 1.30-1.19(\mathrm{~m}, 6 \mathrm{H}) \mathrm{ppm}$.

${ }^{13} \mathbf{C}$ RMN (75.4 MHz, $\mathrm{CDCl}_{3}$ ): $\delta=154.4(\mathrm{C}), 153.5(\mathrm{C}), 137.2(\mathrm{C}), 132.0(\mathrm{C}), 130.3(\mathrm{CH}), 130.2(\mathrm{CH}), 129.5$ (C), $128.9(2 \times \mathrm{CH}), 128.2(2 \times \mathrm{CH}), 127.0(\mathrm{CH}), 122.5(\mathrm{CH}), 42.1\left(\mathrm{CH}_{2}\right), 41.8\left(\mathrm{CH}_{2}\right), 39.7\left(\mathrm{CH}_{2}\right), 14.1$ $\left(\mathrm{CH}_{3}\right), 13.3\left(\mathrm{CH}_{3}\right) \mathrm{ppm}$.

EMBR (IE), m/z (\%): $395\left(\mathrm{M}^{+}+2,14\right), 393\left(\mathrm{M}^{+}, 13\right), 213$ (4), 100 (100), 72 (37).

EMAR calculado para $\mathrm{C}_{18} \mathrm{H}_{20} \mathrm{BrNO}_{2} \mathrm{~S}$ : 393.0398; encontrado: 393.0406 .

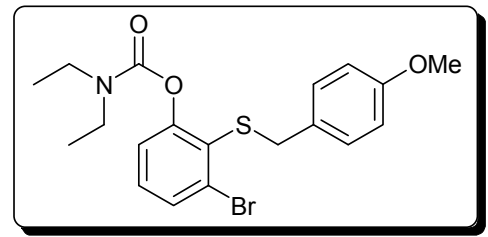

$N, N$-Dietilcarbamato de $O$-3-bromo-2-(4-metoxibenciltio) fenilo (61 cc)

Líquido incoloro.

$\mathrm{R}_{\mathrm{f}}=0.37$ (hexano / AcOEt, 4 / 1).

${ }^{1} \mathbf{H}$ RMN (300 MHz, $\left.\mathrm{CDCl}_{3}\right): \delta=7.51(\mathrm{~d}, J=7.8 \mathrm{~Hz}, 1 \mathrm{H}), 7.22-7.06(\mathrm{~m}, 4 \mathrm{H}), 6.77(\mathrm{~d}, J=8.3 \mathrm{~Hz}, 2 \mathrm{H}), 4.01(\mathrm{~s}$, $2 \mathrm{H}), 3.75(\mathrm{~s}, 3 \mathrm{H}), 3.47-3.34(\mathrm{~m}, 4 \mathrm{H}), 1.31-1.16(\mathrm{~m}, 6 \mathrm{H}) \mathrm{ppm}$.

${ }^{13}$ C RMN (75.4 MHz, $\left.\mathrm{CDCl}_{3}\right): \delta=158.7(\mathrm{C}), 154.5(\mathrm{C}), 153.7(\mathrm{C}), 132.1(\mathrm{C}), 130.34(\mathrm{CH}), 130.31(\mathrm{CH}), 130.1$ $(2 \times \mathrm{CH}), 129.7(\mathrm{C}), 129.3(\mathrm{C}), 122.6(\mathrm{CH}), 113.7(2 \times \mathrm{CH}), 55.2\left(\mathrm{CH}_{3}\right), 42.2\left(\mathrm{CH}_{2}\right), 41.9\left(\mathrm{CH}_{2}\right), 39.3\left(\mathrm{CH}_{2}\right)$, $14.3\left(\mathrm{CH}_{3}\right), 13.4\left(\mathrm{CH}_{3}\right) \mathrm{ppm}$.

EMBR (IE), m/z (\%): $425\left(\mathrm{M}^{+}+2,1\right), 423\left(\mathrm{M}^{+}, 1\right), 121$ (100), 100 (22), 72 (15).

EMAR calculado para $\mathrm{C}_{19} \mathrm{H}_{22} \mathrm{BrNO}_{3} \mathrm{~S}$ : 423.0504; encontrado: 423.0506 .

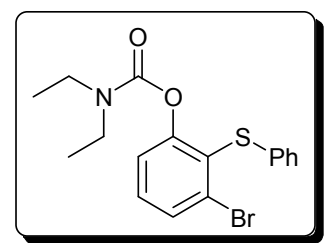

$\mathrm{N}, \mathrm{N}$-Dietilcarbamato de $\mathrm{O}$-3-bromo-2-(feniltio)fenilo (61 cd)

Líquido incoloro.

$\mathrm{R}_{\mathrm{f}}=0.35$ (hexano / AcOEt, 4 / 1).

${ }^{1}$ H RMN $\left(300 \mathrm{MHz}, \mathrm{CDCl}_{3}\right): \delta=7.57(\mathrm{dd}, J=7.3,1.7 \mathrm{~Hz}, 1 \mathrm{H}), 7.33-7.15(\mathrm{~m}, 5 \mathrm{H}), 7.15-7.05(\mathrm{~m}, 2 \mathrm{H})$, $3.33-3.17(\mathrm{~m}, 4 \mathrm{H}), 1.14-1.04(\mathrm{~m}, 6 \mathrm{H}) \mathrm{ppm}$.

${ }^{13}$ C RMN (75.4 MHz, $\left.\mathrm{CDCl}_{3}\right): \delta=154.4(\mathrm{C}), 153.3(\mathrm{C}), 136.4(\mathrm{C}), 131.9(\mathrm{C}), 131.0(\mathrm{CH}), 130.8(\mathrm{CH}), 129.0$ $(2 \times \mathrm{CH}), 127.9(\mathrm{C}), 127.2(2 \times \mathrm{CH}), 125.7(\mathrm{CH}), 123.1(\mathrm{CH}), 42.3\left(\mathrm{CH}_{2}\right), 41.9\left(\mathrm{CH}_{2}\right), 14.1\left(\mathrm{CH}_{3}\right), 13.3$ $\left(\mathrm{CH}_{3}\right) \mathrm{ppm}$.

EMBR (IE), m/z (\%): $381\left(\mathrm{M}^{+}+2,15\right), 379$ (M+1 15), 272 (4), 270 (4), 200 (16), 171 (27), 100 (100), 72 (40).

EMAR calculado para $\mathrm{C}_{17} \mathrm{H}_{18} \mathrm{BrNO}_{2} \mathrm{~S}$ : 379.0242; encontrado: 379.0259. 


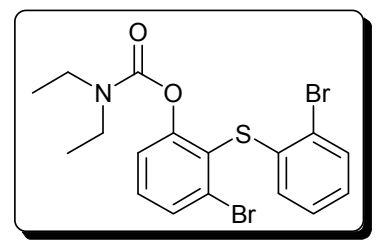

$N, N$-Dietilcarbamato de $O$-3-bromo-2-(2-bromofeniltio)fenilo (61ce)

Sólido blanco.

P.f. $=68-70^{\circ} \mathrm{C}$.

${ }^{1} \mathbf{H}$ RMN $\left(300 \mathrm{MHz}, \mathrm{CDCl}_{3}\right): \delta=7.61(\mathrm{dd}, J=7.4,1.4 \mathrm{~Hz}, 1 \mathrm{H}), 7.48(\mathrm{~d}, J=7.9 \mathrm{~Hz}, 1 \mathrm{H}), 7.38-7.27(\mathrm{~m}, 2 \mathrm{H})$, $7.08(\mathrm{td}, J=7.9,0.9 \mathrm{~Hz}, 1 \mathrm{H}), 6.95(\mathrm{td}, J=7.4,1.3 \mathrm{~Hz}, 1 \mathrm{H}), 6.59(\mathrm{dd}, J=7.9,1.3 \mathrm{~Hz}, 1 \mathrm{H}), 3.31-3.16(\mathrm{~m}$, $4 \mathrm{H}), 1.10-1.00(\mathrm{~m}, 6 \mathrm{H}) \mathrm{ppm}$.

${ }^{13}$ C RMN (75.4 MHz, $\left.\mathrm{CDCl}_{3}\right): \delta=154.7(\mathrm{C}), 153.1(\mathrm{C}), 137.7(\mathrm{C}), 132.6(\mathrm{CH}), 132.1(\mathrm{C}), 131.6(\mathrm{CH}), 130.8$ $(\mathrm{CH}), 127.8(\mathrm{CH}), 126.9(\mathrm{C}), 126.7(\mathrm{CH}), 126.3(\mathrm{CH}), 123.3(\mathrm{CH}), 120.4(\mathrm{C}), 42.3\left(\mathrm{CH}_{2}\right), 42.0\left(\mathrm{CH}_{2}\right)$, $14.0\left(\mathrm{CH}_{3}\right), 13.2\left(\mathrm{CH}_{3}\right) \mathrm{ppm}$.

EMBR (IE), m/z (\%): $461\left(\mathrm{M}^{+}+4,38\right), 459\left(\mathrm{M}^{+}+2,74\right), 457\left(\mathrm{M}^{+}, 36\right), 280$ (32), 278 (31), 171 (62), 100 (100), $72(49)$.

EMAR calculado para $\mathrm{C}_{17} \mathrm{H}_{17} \mathrm{Br}_{2} \mathrm{NO}_{2} \mathrm{~S}$ : 456.9347; encontrado: 456.9346.

\section{A.2 Síntesis de los $N, N$-dietilcarbamatos de $O$-3-alquinil-2-(metiltio)fenilo 62}

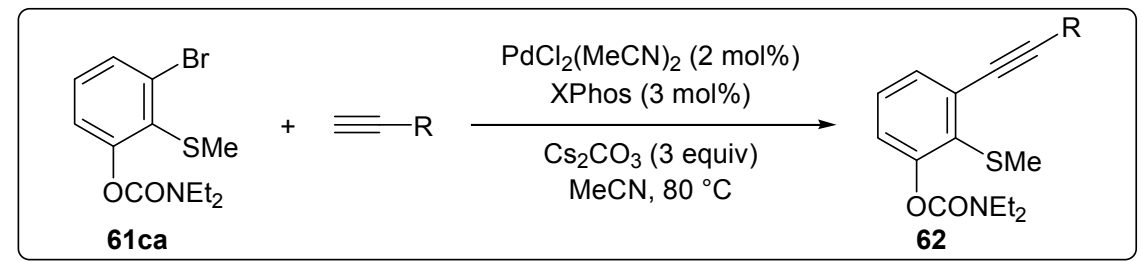

Una mezcla de 61ca (1 equiv), $\mathrm{PdCl}_{2}\left(\mathrm{CH}_{3} \mathrm{CN}\right)_{2}(2 \mathrm{~mol} \%), \mathrm{XPhos}(3 \mathrm{~mol} \%)$ and $\mathrm{Cs}_{2} \mathrm{CO}_{3}(3$ equiv) en MeCN anhidro ( $2 \mathrm{~mL} / \mathrm{mmol})$ se agita bajo $\mathrm{N}_{2}$ a $20{ }^{\circ} \mathrm{C}$ durante 25 minutos. A continuación, se añade el correspondiente alquino (1.5 equiv) y la mezcla de reacción se agita a reflujo durante $2-3$ horas (la reacción se monitoriza mediante CG-EM). Cuando el alquino es etiniltriisopropilsilano, la reacción se lleva a cabo a $45^{\circ} \mathrm{C}$ durante 45 horas. Después de que la mezcla de reacción se ha enfriado a temperatura ambiente, se adiciona $\mathrm{H}_{2} \mathrm{O}$ y AcOEt. La fase acuosa separada se extrae con AcOEt $(3 \times 15$ $\mathrm{mL}$ ). La fase orgánica se seca sobre $\mathrm{Na}_{2} \mathrm{SO}_{4}$ anhidro y se concentra a presión reducida. El residuo obtenido se purifica mediante columna de cromatografía (hexano / AcOEt) permitiendo obtener 62.

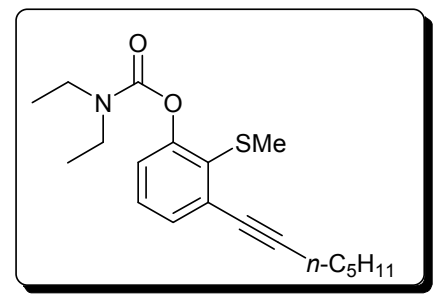

$N, N$-Dietilcarbamato de $O$-3-(1-heptinil)-2-(metiltio)fenilo (62a)

Líquido marrón.

$\mathrm{R}_{\mathrm{f}}=0.38$ (hexano / AcOEt, 5 / 1).

Reactivos: 61ca (318 mg, $1 \mathrm{mmol}), \mathrm{PdCl}_{2}\left(\mathrm{CH}_{3} \mathrm{CN}\right)_{2}(5.2 \mathrm{mg}, 0.02 \mathrm{mmol}), \mathrm{XPhos}(14.3 \mathrm{mg}, 0.03 \mathrm{mmol}), \mathrm{Cs}_{2} \mathrm{CO}_{3}$ (977 mg, $3 \mathrm{mmol})$ y 1-heptino $(197 \mu \mathrm{L}, 1.5 \mathrm{mmol})$.

${ }^{1}$ H RMN $\left(300 \mathrm{MHz}, \mathrm{CDCl}_{3}\right): \delta=7.30(\mathrm{dd}, J=7.8,1.4 \mathrm{~Hz}, 1 \mathrm{H}), 7.19(\mathrm{t}, J=7.8 \mathrm{~Hz}, 1 \mathrm{H}), 7.04(\mathrm{dd}, J=7.8,1.4$ $\mathrm{Hz}, 1 \mathrm{H}), 3.53-3.44(\mathrm{~m}, 2 \mathrm{H}), 3.43-3.33(\mathrm{~m}, 2 \mathrm{H}), 2.47(\mathrm{t}, J=7.0 \mathrm{~Hz}, 2 \mathrm{H}), 2.41(\mathrm{~s}, 3 \mathrm{H}), 1.69-1.58(\mathrm{~m}, 2 \mathrm{H})$, $1.53-1.41(\mathrm{~m}, 2 \mathrm{H}), 1.40-1.26(\mathrm{~m}, 5 \mathrm{H}), 1.20(\mathrm{t}, J=7.1 \mathrm{~Hz}, 3 \mathrm{H}), 0.91(\mathrm{t}, J=7.1 \mathrm{~Hz}, 3 \mathrm{H}) \mathrm{ppm}$. 
${ }^{13} \mathbf{C}$ RMN (75.4 MHz, $\left.\mathrm{CDCl}_{3}\right): \delta=154.1(\mathrm{C}), 153.0(\mathrm{C}), 131.9(\mathrm{C}), 130.6(\mathrm{C}), 130.4(\mathrm{CH}), 128.6(\mathrm{CH}), 122.6$ $(\mathrm{CH}), 95.9(\mathrm{C}), 79.2(\mathrm{C}), 42.4\left(\mathrm{CH}_{2}\right), 42.2\left(\mathrm{CH}_{2}\right), 31.2\left(\mathrm{CH}_{2}\right), 28.4\left(\mathrm{CH}_{2}\right), 22.3\left(\mathrm{CH}_{2}\right), 19.7\left(\mathrm{CH}_{2}\right), 18.2$ $\left(\mathrm{CH}_{3}\right), 14.3\left(\mathrm{CH}_{3}\right), 14.1\left(\mathrm{CH}_{3}\right), 13.4\left(\mathrm{CH}_{3}\right) \mathrm{ppm}$.

EMBR (IE), m/z (\%): $333\left(\mathrm{M}^{+}, 1\right), 318$ (8), 277 (10), 163 (4), 100 (100), 72 (30).

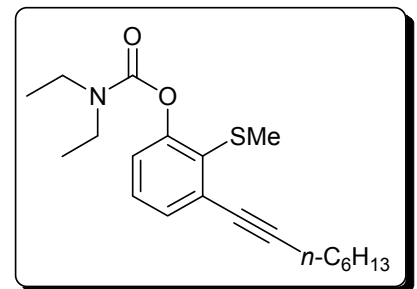

$N, N$-Dietilcarbamato de $O$-2-(metiltio)-3-(1-octinil)fenilo (62b)

Líquido amarillo.

$\mathrm{R}_{\mathrm{f}}=0.50$ (hexano / AcOEt, 4 / 1).

Reactivos: 61ca (254 mg, $0.8 \mathrm{mmol}), \mathrm{PdCl}_{2}\left(\mathrm{CH}_{3} \mathrm{CN}\right)_{2}(4.1 \mathrm{mg}, 0.016 \mathrm{mmol})$, XPhos (11.4 mg, $\left.0.024 \mathrm{mmol}\right)$, $\mathrm{Cs}_{2} \mathrm{CO}_{3}(782 \mathrm{mg}, 2.4 \mathrm{mmol})$ y 1 -octino $(140 \mu \mathrm{L}, 1.2 \mathrm{mmol})$.

${ }^{1} \mathbf{H}$ RMN $\left(300 \mathrm{MHz}, \mathrm{CDCl}_{3}\right): \delta=7.30(\mathrm{dd}, J=7.9,1.5 \mathrm{~Hz}, 1 \mathrm{H}), 7.19(\mathrm{t}, J=7.9 \mathrm{~Hz}, 1 \mathrm{H}), 7.04(\mathrm{dd}, J=8.0,1.5$ $\mathrm{Hz}, 1 \mathrm{H}), 3.53-3.44(\mathrm{~m}, 2 \mathrm{H}), 3.42-3.33(\mathrm{~m}, 2 \mathrm{H}), 2.47(\mathrm{t}, J=7.0 \mathrm{~Hz}, 2 \mathrm{H}), 2.41(\mathrm{~s}, 3 \mathrm{H}), 1.69-1.57(\mathrm{~m}, 2 \mathrm{H})$, $1.54-1.43(\mathrm{~m}, 2 \mathrm{H}) 1.36-1.26(\mathrm{~m}, 7 \mathrm{H}), 1.20(\mathrm{t}, J=7.0 \mathrm{~Hz}, 3 \mathrm{H}), 0.89(\mathrm{t}, J=7.0 \mathrm{~Hz}, 3 \mathrm{H}) \mathrm{ppm}$.

${ }^{13} \mathbf{C}$ RMN (75.4 MHz, $\left.\mathrm{CDCl}_{3}\right): \delta=154.1(\mathrm{C}), 153.0(\mathrm{C}), 131.9(\mathrm{C}), 130.6(\mathrm{C}), 130.4(\mathrm{CH}), 128.6(\mathrm{CH}), 122.6$ $(\mathrm{CH}), 95.9(\mathrm{C}), 79.2(\mathrm{C}), 42.4\left(\mathrm{CH}_{2}\right), 42.2\left(\mathrm{CH}_{2}\right), 31.5\left(\mathrm{CH}_{2}\right), 28.7\left(\mathrm{CH}_{3}\right), 22.7\left(\mathrm{CH}_{2}\right), 19.8\left(\mathrm{CH}_{2}\right), 18.2$ $\left(\mathrm{CH}_{3}\right), 14.3\left(\mathrm{CH}_{3}\right), 14.2\left(\mathrm{CH}_{2}\right), 13.4\left(\mathrm{CH}_{3}\right) \mathrm{ppm}$.

EMBR (IE), m/z (\%): $347\left(\mathrm{M}^{+}, 1\right), 332$ (6), 300 (6), 277 (9), 100 (100), 72 (27).

EMAR calculado para $\mathrm{C}_{20} \mathrm{H}_{29} \mathrm{NO}_{2} \mathrm{~S}$ : 347.1919; encontrado: 347.1912 .

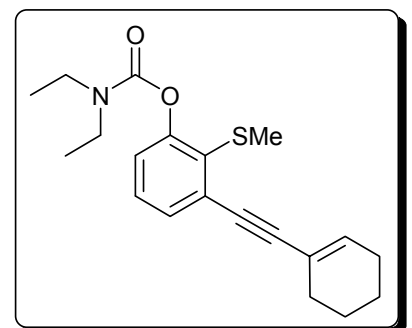

$N, N$-Dietilcarbamato de $O$-3-(1-ciclohexeniletinil)-2-(metiltio)fenilo (62c)

Líquido amarillo.

$\mathrm{R}_{\mathrm{f}}=0.42$ (hexano / AcOEt, 5 / 1).

Reactivos: 61 ca (318 mg, $1 \mathrm{mmol}), \mathrm{PdCl}_{2}\left(\mathrm{CH}_{3} \mathrm{CN}\right)_{2}(5.2 \mathrm{mg}, 0.02 \mathrm{mmol}), \mathrm{XPhos}(14.3 \mathrm{mg}, 0.03 \mathrm{mmol}), \mathrm{Cs}_{2} \mathrm{CO}_{3}$ (977 mg, $3 \mathrm{mmol})$ y 1-etinilciclohexeno $(176 \mu \mathrm{L}, 1.5 \mathrm{mmol})$.

${ }^{1} \mathbf{H} \mathbf{R M N}\left(300 \mathrm{MHz}, \mathrm{CDCl}_{3}\right): \delta=7.31(\mathrm{dd}, J=7.9,1.4 \mathrm{~Hz}, 1 \mathrm{H}), 7.20(\mathrm{t}, J=7.9 \mathrm{~Hz}, 1 \mathrm{H}), 7.04(\mathrm{dd}, J=7.9,1.4$ $\mathrm{Hz}, 1 \mathrm{H}), 6.26-6.20(\mathrm{~m}, 1 \mathrm{H}), 3.53-3.43(\mathrm{~m}, 2 \mathrm{H}), 3.42-3.33(\mathrm{~m}, 2 \mathrm{H}), 2.43(\mathrm{~s}, 3 \mathrm{H}), 2.29-2.21(\mathrm{~m}, 2 \mathrm{H})$, 2.19-2.11 (m, 2H), 1.72-1.56 (m, 4H), $1.29(\mathrm{t}, J=7.0 \mathrm{~Hz}, 3 \mathrm{H}), 1.20(\mathrm{t}, J=7.0 \mathrm{~Hz}, 3 \mathrm{H}) \mathrm{ppm}$.

${ }^{13} \mathbf{C}$ RMN (75.4 MHz, $\left.\mathrm{CDCl}_{3}\right): \delta=154.0(\mathrm{C}), 153.0(\mathrm{C}), 135.8(\mathrm{CH}), 131.9(\mathrm{C}), 130.2(\mathrm{C}), 130.1(\mathrm{CH}), 128.6$ $(\mathrm{CH}), 122.7(\mathrm{CH}), 120.8(\mathrm{C}), 96.4(\mathrm{C}), 85.4(\mathrm{C}), 42.4\left(\mathrm{CH}_{2}\right), 42.2\left(\mathrm{CH}_{2}\right), 29.0\left(\mathrm{CH}_{2}\right), 25.9\left(\mathrm{CH}_{2}\right), 22.3$ $\left(\mathrm{CH}_{2}\right), 21.5\left(\mathrm{CH}_{2}\right), 18.2\left(\mathrm{CH}_{3}\right), 14.3\left(\mathrm{CH}_{3}\right), 13.4\left(\mathrm{CH}_{3}\right) \mathrm{ppm}$.

EMBR (IE), m/z (\%): 343 (M+ 46), 296 (10), 100 (100), 72 (26).

EMAR calculado para $\mathrm{C}_{20} \mathrm{H}_{25} \mathrm{NO}_{2} \mathrm{~S}: 343.1606$; encontrado: 343.1621 . 


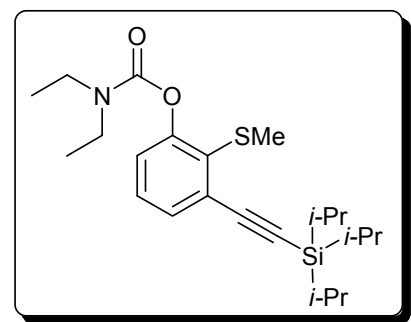

$N, N$-Dietilcarbamato de $O$-3-(triisopropilsililetinil)-2-(metiltio)fenilo (62d)

Líquido marrón.

$\mathrm{R}_{\mathrm{f}}=0.58$ (hexano / AcOEt, 4 / 1).

Reactivos: 61 ca (318 mg, $1 \mathrm{mmol}), \mathrm{PdCl}_{2}\left(\mathrm{CH}_{3} \mathrm{CN}\right)_{2}(5.2 \mathrm{mg}, 0.02 \mathrm{mmol}), \mathrm{XPhos}(14.3 \mathrm{mg}, 0.03 \mathrm{mmol}), \mathrm{Cs}_{2} \mathrm{CO}_{3}$ $(977 \mathrm{mg}, 3 \mathrm{mmol})$ y 1-etiniltriisopropilsilano $(336 \mu \mathrm{L}, 1.5 \mathrm{mmol})$.

${ }^{1}$ H RMN (300 MHz, $\left.\mathrm{CDCl}_{3}\right): \delta=7.40(\mathrm{dd}, J=7.8,0.8 \mathrm{~Hz}, 1 \mathrm{H}), 7.22(\mathrm{td}, J=7.8,0.8 \mathrm{~Hz}, 1 \mathrm{H}), 7.09$ (dd, $J=7.8$, $0.8 \mathrm{~Hz}, 1 \mathrm{H}), 3.57-3.48(\mathrm{~m}, 2 \mathrm{H}), 3.47-3.38(\mathrm{~m}, 2 \mathrm{H}), 2.43(\mathrm{~d}, J=0.8 \mathrm{~Hz}, 3 \mathrm{H}), 1.30$ (t, $J=7.1 \mathrm{~Hz}, 3 \mathrm{H}), 1.26$ $(\mathrm{t}, J=7.1 \mathrm{~Hz}, 3 \mathrm{H}), 1.15(\mathrm{~s}, 21 \mathrm{H}) \mathrm{ppm}$.

${ }^{13}$ C RMN (75.4 MHz, $\left.\mathrm{CDCl}_{3}\right): \delta=154.1(\mathrm{C}), 153.1(\mathrm{C}), 132.6(\mathrm{C}), 131.1(\mathrm{CH}), 130.2(\mathrm{C}), 128.7(\mathrm{CH}), 123.4$ $(\mathrm{CH}), 104.8(\mathrm{C}), 96.3(\mathrm{C}), 42.4\left(\mathrm{CH}_{2}\right), 42.2\left(\mathrm{CH}_{2}\right), 18.8\left(6 \times \mathrm{CH}_{3}\right), 18.3\left(\mathrm{CH}_{3}\right), 14.3\left(\mathrm{CH}_{3}\right), 13.4\left(\mathrm{CH}_{3}\right)$, $11.5(3 \times \mathrm{CH}) \mathrm{ppm}$.

EMBR (IE), m/z (\%): 419 (M+, 1), 404 (25), 376 (64), 362 (20), 348 (11), 100 (100), 72 (32).

EMAR calculado para $\mathrm{C}_{23} \mathrm{H}_{37} \mathrm{NO}_{2} \mathrm{SSi}$ : 419.2314; encontrado: 419.2329 .

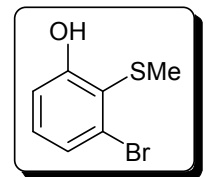

\section{3-Bromo-2-(metiltio)fenol}

Líquido incoloro.

$\mathrm{R}_{\mathrm{f}}=0.60$ (hexano / AcOEt, 4 / 1).

${ }^{1} \mathbf{H}$ RMN $\left(400 \mathrm{MHz}, \mathrm{CDCl}_{3}\right): \delta=7.16(\mathrm{dd}, J=7.9,1.4 \mathrm{~Hz}, 1 \mathrm{H}), 7.13(\mathrm{~s}, 1 \mathrm{H}), 7.09(\mathrm{t}, J=7.9 \mathrm{~Hz}, 1 \mathrm{H}), 6.93(\mathrm{dd}$, $J=7.9,1.4 \mathrm{~Hz}, 1 \mathrm{H}), 2.31(\mathrm{~s}, 3 \mathrm{H}) \mathrm{ppm}$.

${ }^{13} \mathbf{C}$ RMN (100.6 MHz, $\left.\mathrm{CDCl}_{3}\right): \delta=158.2(\mathrm{C}), 131.7(\mathrm{CH}), 130.7(\mathrm{C}), 124.9(\mathrm{CH}), 121.7(\mathrm{C}), 113.9(\mathrm{CH}), 18.5$ $\left(\mathrm{CH}_{3}\right) \mathrm{ppm}$

EMBR (IE), m/z (\%): 220 (M+2, 100), 218 (M+1 100), 205 (44), 203 (43), 177 (34), 175 (34), 123 (17), 69 (25).

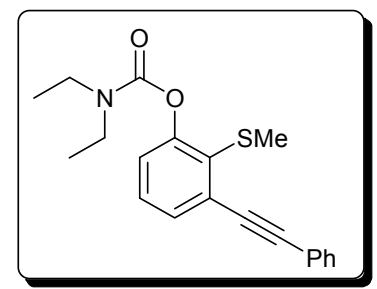

$N, N$-Dietilcarbamato de $O$-3-(feniletinil)-2-(metiltio)fenilo (62e)

Líquido marrón.

$\mathrm{R}_{\mathrm{f}}=0.20$ (hexano / AcOEt, $\left.20 / 1\right)$.

Reactivos: 61ca $(1.27 \mathrm{~g}, 4 \mathrm{mmol}), \mathrm{PdCl}_{2}\left(\mathrm{CH}_{3} \mathrm{CN}\right)_{2}(21 \mathrm{mg}, 0.08 \mathrm{mmol}), \mathrm{XPhos}(57 \mathrm{mg}, 0.12 \mathrm{mmol}), \mathrm{Cs}_{2} \mathrm{CO}_{3}$ $(3.91 \mathrm{~g}, 12 \mathrm{mmol})$ y fenilacetileno $(659 \mu \mathrm{L}, 6 \mathrm{mmol})$.

${ }^{1}$ H RMN (300 MHz, $\left.\mathrm{CDCl}_{3}\right): \delta=7.60-7.55(\mathrm{~m}, 2 \mathrm{H}), 7.45(\mathrm{dd}, J=7.7,1.4 \mathrm{~Hz}, 1 \mathrm{H}), 7.38-7.33(\mathrm{~m}, 3 \mathrm{H}), 7.27(\mathrm{t}$, $J=7.9 \mathrm{~Hz}, 1 \mathrm{H}), 7.13(\mathrm{dd}, J=8.1,1.4 \mathrm{~Hz}, 1 \mathrm{H}), 3.56-3.46(\mathrm{~m}, 2 \mathrm{H}), 3.45-3.36(\mathrm{~m}, 2 \mathrm{H}), 2.51(\mathrm{~s}, 3 \mathrm{H}), 1.32$ (t, $J=7.0 \mathrm{~Hz}, 3 \mathrm{H}), 1.22(\mathrm{t}, J=7.0 \mathrm{~Hz}, 3 \mathrm{H}) \mathrm{ppm}$.

${ }^{13}$ C RMN (75.4 MHz, CDCl $): \delta=154.0(\mathrm{C}), 153.1(\mathrm{C}), 132.3(\mathrm{C}), 131.6(2 \times \mathrm{CH}), 130.3(\mathrm{CH}), 129.7(\mathrm{C}), 128.7$ $(\mathrm{CH}), 128.6(\mathrm{CH}), 123.3(\mathrm{CH}), 128.4(2 \times \mathrm{CH}), 123.2(\mathrm{C}), 94.3(\mathrm{C}), 88.0(\mathrm{C}), 42.4\left(\mathrm{CH}_{2}\right), 42.2\left(\mathrm{CH}_{2}\right), 18.4$ $\left(\mathrm{CH}_{3}\right), 14.3\left(\mathrm{CH}_{3}\right), 13.4\left(\mathrm{CH}_{3}\right) \mathrm{ppm}$.

EMBR (IE), m/z (\%): 339 (M+ , 35), 292 (7), 221 (6), 100 (100), 72 (33).

EMAR calculado para $\mathrm{C}_{20} \mathrm{H}_{21} \mathrm{NO}_{2} \mathrm{~S}$ : 339.1293; encontrado: 339.1289 . 


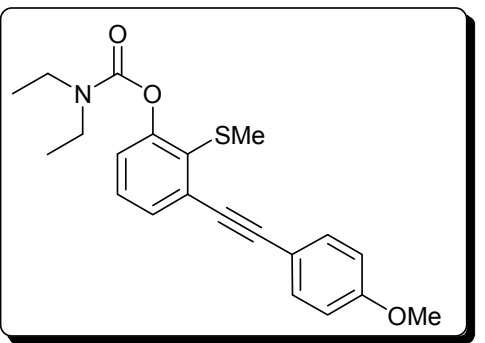

$N, N$-Dietilcarbamato de $O$-2-(metiltio)-3-(p-metoxifeniletinil) fenilo (62f)

Líquido marrón.

$\mathrm{R}_{\mathrm{f}}=0.34$ (hexano / AcOEt, 4 / 1).

Reactivos: 61 ca (318 mg, $1 \mathrm{mmol}), \mathrm{PdCl}_{2}\left(\mathrm{CH}_{3} \mathrm{CN}\right)_{2}(5.2 \mathrm{mg}, 0.02 \mathrm{mmol})$, XPhos (14.3 mg, $\left.0.03 \mathrm{mmol}\right), \mathrm{Cs}_{2} \mathrm{CO}_{3}$ (977 mg, $3 \mathrm{mmol})$ y 4-metoxifenilacetileno $(194 \mu \mathrm{L}, 1.5 \mathrm{mmol})$.

${ }^{1}$ H RMN $\left(300 \mathrm{MHz}, \mathrm{CDCl}_{3}\right): \delta=7.55-7.48(\mathrm{~m}, 2 \mathrm{H}), 7.42(\mathrm{dd}, J=7.7,1.4 \mathrm{~Hz}, 1 \mathrm{H}), 7.26(\mathrm{t}, J=7.7 \mathrm{~Hz}, 1 \mathrm{H})$, $7.10(\mathrm{dd}, J=7.7,1.4 \mathrm{~Hz}, 1 \mathrm{H}), 6.93-6.86(\mathrm{~m}, 2 \mathrm{H}), 3.82(\mathrm{~s}, 3 \mathrm{H}), 3.60-3.50(\mathrm{~m}, 2 \mathrm{H}), 3.49-3.40(\mathrm{~m}, 2 \mathrm{H})$, $2.50(\mathrm{~s}, 3 \mathrm{H}), 1.32(\mathrm{t}, J=7.0 \mathrm{~Hz}, 3 \mathrm{H}), 1.22(\mathrm{t}, J=7.0 \mathrm{~Hz}, 3 \mathrm{H}) \mathrm{ppm}$.

${ }^{13}$ C RMN (75.4 MHz, $\left.\mathrm{CDCl}_{3}\right): \delta=159.8(\mathrm{C}), 153.9(\mathrm{C}), 153.0(\mathrm{C}), 133.1(2 \times \mathrm{CH}), 132.0(\mathrm{C}), 130.01(\mathrm{CH})$, $129.97(\mathrm{C}), 128.6(\mathrm{CH}), 122.9(\mathrm{CH}), 115.2(\mathrm{C}), 114.0(2 \times \mathrm{CH}), 94.5(\mathrm{C}), 86.7(\mathrm{C}), 55.3\left(\mathrm{CH}_{3}\right), 42.3\left(\mathrm{CH}_{2}\right)$, $42.1\left(\mathrm{CH}_{2}\right), 18.3\left(\mathrm{CH}_{3}\right), 14.2\left(\mathrm{CH}_{3}\right), 13.4\left(\mathrm{CH}_{3}\right) \mathrm{ppm}$.

EMBR (IE), m/z (\%): 369 (M+27), 322 (5), 207 (12), 100 (100), 72 (31).

EMAR calculado para $\mathrm{C}_{21} \mathrm{H}_{23} \mathrm{NO}_{3} \mathrm{~S}$ : 369.1399 ; encontrado: 369.1400 .

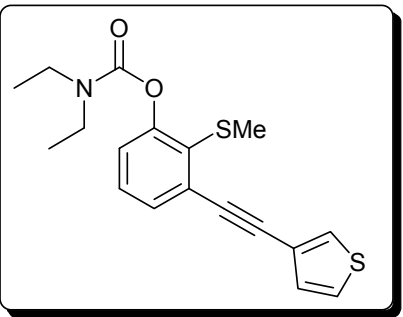

$N, N$-Dietilcarbamato de $O$-2-(metiltio)-3-(3-tieniletinil)fenilo (62h) Líquido amarillo. $\mathrm{R}_{\mathrm{f}}=0.30$ (hexano / AcOEt, 4 / 1).

Reactivos: 61ca $(254 \mathrm{mg}, 0.8 \mathrm{mmol}), \mathrm{PdCl}_{2}\left(\mathrm{CH}_{3} \mathrm{CN}\right)_{2}(4.1 \mathrm{mg}, 0.016 \mathrm{mmol})$, XPhos (11.4 mg, $\left.0.024 \mathrm{mmol}\right)$, $\mathrm{Cs}_{2} \mathrm{CO}_{3}(782 \mathrm{mg}, 2.4 \mathrm{mmol})$ y 3 -etiniltiofeno $(129 \mu \mathrm{L}, 1.2 \mathrm{mmol})$.

${ }^{1} \mathbf{H}$ RMN $\left(300 \mathrm{MHz}, \mathrm{CDCl}_{3}\right): \delta=7.56(\mathrm{dd}, J=2.9,1.1 \mathrm{~Hz}, 1 \mathrm{H}), 7.42(\mathrm{dd}, J=7.9,1.4 \mathrm{~Hz}, 1 \mathrm{H}), 7.33-7.28(\mathrm{~m}$, $1 \mathrm{H}), 7.27-7.21(\mathrm{~m}, 2 \mathrm{H}), 7.11(\mathrm{dd}, J=7.9,1.4 \mathrm{~Hz}, 1 \mathrm{H}), 3.57-3.46(\mathrm{~m}, 2 \mathrm{H}), 3.45-3.35(\mathrm{~m}, 2 \mathrm{H}), 2.48(\mathrm{~d}, J$ $=0.9 \mathrm{~Hz}, 3 \mathrm{H}), 1.31(\mathrm{t}, J=7.0 \mathrm{~Hz}, 3 \mathrm{H}), 1.22(\mathrm{t}, J=7.0 \mathrm{~Hz}, 3 \mathrm{H}) \mathrm{ppm}$.

${ }^{13} \mathbf{C}$ RMN (75.4 MHz, $\left.\mathrm{CDCl}_{3}\right): \delta=153.9(\mathrm{C}), 153.0(\mathrm{C}), 132.1(\mathrm{C}), 130.2(\mathrm{CH}), 129.8(\mathrm{CH}), 129.6(\mathrm{C}), 128.9$ $(\mathrm{CH}), 128.7(\mathrm{CH}), 125.5(\mathrm{CH}), 123.2(\mathrm{CH}), 122.2(\mathrm{C}), 89.5(\mathrm{C}), 87.4(\mathrm{C}), 42.3\left(\mathrm{CH}_{2}\right), 42.1\left(\mathrm{CH}_{2}\right), 18.3$ $\left(\mathrm{CH}_{3}\right), 14.2\left(\mathrm{CH}_{3}\right), 13.4\left(\mathrm{CH}_{3}\right) \mathrm{ppm}$.

EMBR (IE), m/z (\%): $345\left(\mathrm{M}^{+}, 20\right), 298$ (4), 201 (3), 100 (100), 72 (40).

EMAR calculado para $\mathrm{C}_{18} \mathrm{H}_{19} \mathrm{NO}_{2} \mathrm{~S}_{2}: 345.0857$; encontrado: 345.0856 .

A.3 Síntesis de los benzo[b]tiofenos 7-oxígeno-funcionalizados 2,3-disustituidos 63-66

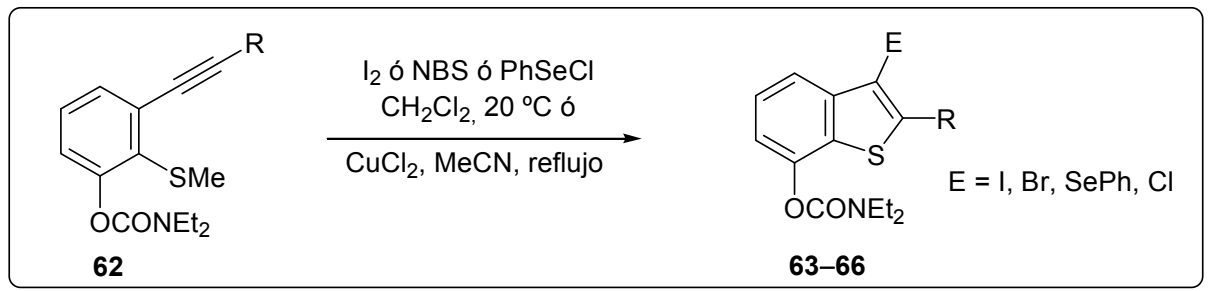


A una disolución del correspondiente carbamato 62 (1 equiv) en $\mathrm{CH}_{2} \mathrm{Cl}_{2}$ anhidro $(5 \mathrm{~mL} / \mathrm{mmol})$ se añade un exceso del electrófilo ( 2 equiv para $\mathrm{CuCl}_{2}, 1.5$ equiv para yodo y 1.2 equiv para $\mathrm{NBS}$ ó $\mathrm{PhSeCl}$ ). La disolución resultante se agita a $20^{\circ} \mathrm{C}$ hasta que la ciclación se complete (2.5-16 horas), monitorizada por CG-EM. Cuando se emplea $\mathrm{CuCl}_{2}$ como electrófilo se utiliza $\mathrm{MeCN}$ como disolvente y la mezcla se calienta a reflujo durante 2.5 horas. A continuación, a la mezcla de reacción se añade $\mathrm{CH}_{2} \mathrm{Cl}_{2}(10 \mathrm{~mL}) \mathrm{y}$ $\mathrm{H}_{2} \mathrm{O}$ o una disolución de $\mathrm{Na}_{2} \mathrm{~S}_{2} \mathrm{O}_{3}$ (cuando se emplea yodo como electrófilo). La fase acuosa separada se extrae con $\mathrm{CH}_{2} \mathrm{Cl}_{2}(2 \times 10 \mathrm{~mL})$. La combinación de fases orgánicas se seca sobre $\mathrm{Na}_{2} \mathrm{SO}_{4}$ anhidro y se concentra a presión reducida. El residuo resultante se purifica por columna de cromatografia (hexano / AcOEt) permitiendo obtener los benzo[b]tiofenos 7-oxígeno-funcionalizados 2,3-disustituidos 63-66.

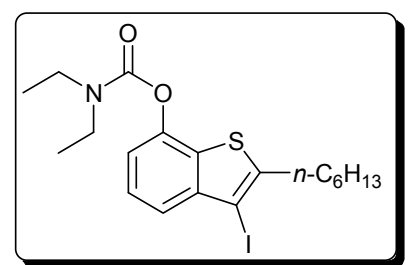

7-(N,N-Dietilcarbamoiloxi)-2-hexil-3-yodobenzo/b/tiofeno (63b)

Líquido marrón.

$\mathrm{R}_{\mathrm{f}}=0.44$ (hexano / AcOEt, 5 / 1).

${ }^{1} \mathbf{H}$ RMN (300 MHz, $\left.\mathrm{CDCl}_{3}\right): \delta=7.54(\mathrm{dd}, J=8.0,0.9 \mathrm{~Hz}, 1 \mathrm{H}), 7.42(\mathrm{t}, J=8.0 \mathrm{~Hz}, 1 \mathrm{H}), 7.24(\mathrm{dd}, J=8.0,0.9$ $\mathrm{Hz}, 1 \mathrm{H}), 3.56-3.47(\mathrm{~m}, 2 \mathrm{H}), 3.47-3.38(\mathrm{~m}, 2 \mathrm{H}), 2.94(\mathrm{t}, J=7.6 \mathrm{~Hz}, 2 \mathrm{H}), 1.80-1.68(\mathrm{~m}, 2 \mathrm{H}), 1.49-1.29$ $(\mathrm{m}, 9 \mathrm{H}), 1.24(\mathrm{t}, J=7.4 \mathrm{~Hz}, 3 \mathrm{H}), 0.91(\mathrm{t}, J=7.0 \mathrm{~Hz}, 3 \mathrm{H}) \mathrm{ppm}$.

${ }^{13}$ C RMN (75.4 MHz, $\left.\mathrm{CDCl}_{3}\right): \delta=153.1(\mathrm{C}), 145.7$ (C), $145.1(\mathrm{C}), 143.3(\mathrm{C}), 130.7$ (C), 125.7 (CH), 121.9 $(\mathrm{CH}), 117.3(\mathrm{CH}), 80.0(\mathrm{C}), 42.6\left(\mathrm{CH}_{2}\right), 42.2\left(\mathrm{CH}_{2}\right), 33.0\left(\mathrm{CH}_{2}\right), 31.6\left(\mathrm{CH}_{2}\right), 30.6\left(\mathrm{CH}_{2}\right), 28.9\left(\mathrm{CH}_{2}\right), 22.6$ $\left(\mathrm{CH}_{2}\right), 14.4\left(\mathrm{CH}_{3}\right), 14.2\left(\mathrm{CH}_{3}\right), 13.5\left(\mathrm{CH}_{3}\right) \mathrm{ppm}$.

EMBR (IE), m/z (\%): 459 (M+27), 359 (3), 260 (8), 100 (100), 72 (25).

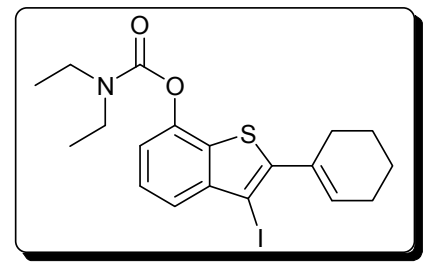

2-(1-Ciclohexenil)-7-( $N, N$-dietilcarbamoiloxi)-3yodobenzo $[b]$ tiofeno $(63 \mathrm{c})$

Líquido incoloro.

$\mathrm{R}_{\mathrm{f}}=0.33$ (hexano / AcOEt, 5 / 1).

${ }^{1} \mathbf{H}$ RMN $\left(300 \mathrm{MHz}, \mathrm{CDCl}_{3}\right): \delta=7.59(\mathrm{dd}, J=8.0,0.8 \mathrm{~Hz}, 1 \mathrm{H}), 7.43(\mathrm{t}, J=8.0 \mathrm{~Hz}, 1 \mathrm{H}), 7.25(\mathrm{dd}, J=8.0,0.8$ $\mathrm{Hz}, 1 \mathrm{H}), 6.20-6.16(\mathrm{~m}, 1 \mathrm{H}), 3.57-3.47(\mathrm{~m}, 2 \mathrm{H}), 3.47-3.37(\mathrm{~m}, 2 \mathrm{H}), 2.51-2.41(\mathrm{~m}, 2 \mathrm{H}), 2.30-2.20(\mathrm{~m}$, $2 \mathrm{H}), 1.85-1.76(\mathrm{~m}, 2 \mathrm{H}), 1.76-1.66(\mathrm{~m}, 2 \mathrm{H}), 1.34(\mathrm{t}, J=7.1 \mathrm{~Hz}, 3 \mathrm{H}), 1.23(\mathrm{t}, J=7.1 \mathrm{~Hz}, 3 \mathrm{H}) \mathrm{ppm}$.

${ }^{13} \mathbf{C}$ RMN (75.4 MHz, $\left.\mathrm{CDCl}_{3}\right): \delta=153.1(\mathrm{C}), 145.6(\mathrm{C}), 145.5(\mathrm{C}), 143.7(\mathrm{C}), 132.8(\mathrm{CH}), 132.2(\mathrm{C}), 130.7(\mathrm{C})$, $125.9(\mathrm{CH}), 122.7(\mathrm{CH}), 117.5(\mathrm{CH}), 77.3(\mathrm{C}), 42.6\left(\mathrm{CH}_{2}\right), 42.3\left(\mathrm{CH}_{2}\right), 29.9\left(\mathrm{CH}_{2}\right), 25.7\left(\mathrm{CH}_{2}\right), 22.9$ $\left(\mathrm{CH}_{2}\right), 21.8\left(\mathrm{CH}_{2}\right), 14.5\left(\mathrm{CH}_{3}\right), 13.5\left(\mathrm{CH}_{3}\right) \mathrm{ppm}$.

EMBR (IE), m/z (\%): $455\left(\mathrm{M}^{+}, 30\right), 281$ (5), 171 (5), 100 (100), 72 (25).

EMAR calculado para $\mathrm{C}_{19} \mathrm{H}_{22} \mathrm{NNO}_{2} \mathrm{~S}$ : 455.0416; encontrado: 455.0421 .

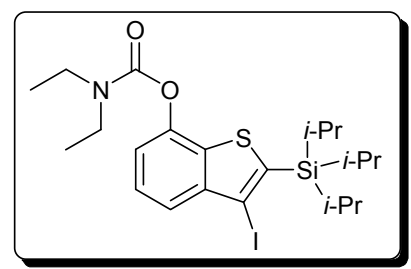

7-(N,N-Dietilcarbamoiloxi)-2-(triisopropilsilil)-3yodobenzo $[b]$ tiofeno $(63 \mathrm{~d})$

Sólido blanco.

P.f. $=94-96^{\circ} \mathrm{C}$. 
${ }^{1} \mathbf{H}$ RMN $\left(300 \mathrm{MHz}, \mathrm{CDCl}_{3}\right): \delta=7.72(\mathrm{dd}, J=8.1,0.9 \mathrm{~Hz}, 1 \mathrm{H}), 7.47(\mathrm{t}, J=8.1 \mathrm{~Hz}, 1 \mathrm{H}), 7.31(\mathrm{dd}, J=8.1,0.9$ $\mathrm{Hz}, 1 \mathrm{H}), 3.59-3.50(\mathrm{~m}, 2 \mathrm{H}), 3.49-3.40(\mathrm{~m}, 2 \mathrm{H}), 1.88-1.72(\mathrm{~m}, 3 \mathrm{H}), 1.36(\mathrm{t}, J=7.1 \mathrm{~Hz}, 3 \mathrm{H}), 1.30-1.15$ $(\mathrm{m}, 21 \mathrm{H}) \mathrm{ppm}$.

${ }^{13}$ C RMN (75.4 MHz, $\mathrm{CDCl}_{3}$ ): $\delta=153.2$ (C), 145.5 (C), 145.3 (C), 138.0 (C), 134.0 (C), $125.6(\mathrm{CH}), 122.6$ $(\mathrm{CH}), 117.4(\mathrm{CH}), 88.2(\mathrm{C}), 42.6\left(\mathrm{CH}_{2}\right), 42.3\left(\mathrm{CH}_{2}\right), 19.1\left(6 \times \mathrm{CH}_{3}\right), 14.4\left(\mathrm{CH}_{3}\right), 13.5\left(\mathrm{CH}_{3}\right), 12.8(3 \times \mathrm{CH})$ ppm.

EMBR (IE), m/z (\%): $531\left(\mathrm{M}^{+}, 29\right), 488$ (65), 446 (19), 418 (15), 318 (18), 100 (100), 72 (36).

EMAR calculado para $\mathrm{C}_{22} \mathrm{H}_{34} \mathrm{INO}_{2} \mathrm{SSi}$ : 531.1124; encontrado: 531.1104 .

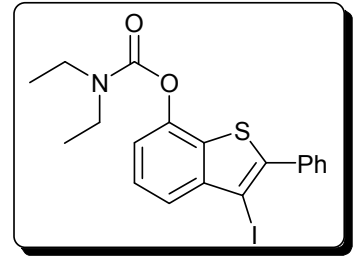

7-( $N, N$-Dietilcarbamoiloxi)-2-fenil-3-yodobenzo/b/tiofeno (63e)

Sólido blanco.

P.f. $=74-76^{\circ} \mathrm{C}$.

${ }^{1}$ H RMN $\left(300 \mathrm{MHz}, \mathrm{CDCl}_{3}\right): \delta=7.75-7.66(\mathrm{~m}, 3 \mathrm{H}), 7.58-7.43(\mathrm{~m}, 4 \mathrm{H}), 7.34(\mathrm{dd}, J=7.8,0.9 \mathrm{~Hz}, 1 \mathrm{H})$, $3.58-3.49(\mathrm{~m}, 2 \mathrm{H}), 3.48-3.38(\mathrm{~m}, 2 \mathrm{H}), 1.35(\mathrm{t}, J=7.0 \mathrm{~Hz}, 3 \mathrm{H}), 1.25(\mathrm{t}, J=7.0 \mathrm{~Hz}, 3 \mathrm{H}) \mathrm{ppm}$.

${ }^{13} \mathbf{C}$ RMN (75.4 MHz, $\left.\mathrm{CDCl}_{3}\right): \delta=153.1$ (C), $145.6(\mathrm{C}), 143.9$ (C), 142.5 (C), 134.5 (C), 131.8 (C), 130.1 $(2 \times \mathrm{CH}), 129.1(\mathrm{CH}), 128.6(2 \times \mathrm{CH}), 126.2(\mathrm{CH}), 123.2(\mathrm{CH}), 118.0(\mathrm{CH}), 79.4(\mathrm{C}), 42.7\left(\mathrm{CH}_{2}\right), 42.3$ $\left(\mathrm{CH}_{2}\right), 14.4\left(\mathrm{CH}_{3}\right), 13.5\left(\mathrm{CH}_{3}\right) \mathrm{ppm}$.

EMBR (IE), m/z (\%): $451\left(\mathrm{M}^{+}, 26\right), 323$ (6), 195 (10), 152 (14), 100 (100), 72 (30).

EMAR calculado para $\mathrm{C}_{19} \mathrm{H}_{18} \mathrm{INO}_{2} \mathrm{~S}$ : 451.0103; encontrado: 451.0106.

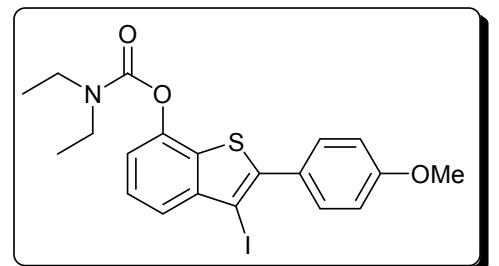

7-(N,N-Dietilcarbamoiloxi)-2-(4-metoxifenil)-3yodobenzo $[b]$ tiofeno $(63 f)$

Líquido marrón.

$\mathrm{R}_{\mathrm{f}}=0.32$ (hexano / AcOEt, 4 / 1).

${ }^{1} \mathbf{H}$ RMN $\left(300 \mathrm{MHz}, \mathrm{CDCl}_{3}\right): \delta=7.69-7.62(\mathrm{~m}, 3 \mathrm{H}), 7.49(\mathrm{t}, J=7.9 \mathrm{~Hz}, 1 \mathrm{H}), 7.33(\mathrm{dd}, J=7.9,0.9 \mathrm{~Hz}, 1 \mathrm{H})$, $7.03-6.98(\mathrm{~m}, 2 \mathrm{H}), 3.86(\mathrm{~s}, 3 \mathrm{H}), 3.57-3.48(\mathrm{~m}, 2 \mathrm{H}), 3.48-3.39(\mathrm{~m}, 2 \mathrm{H}), 1.35(\mathrm{t}, J=7.0 \mathrm{~Hz}, 3 \mathrm{H}), 1.25(\mathrm{t}, J$ $=7.0 \mathrm{~Hz}, 3 \mathrm{H}) \mathrm{ppm}$.

${ }^{13} \mathbf{C}$ RMN (75.4 MHz, $\mathrm{CDCl}_{3}$ ): $\delta=160.1$ (C), 153.0 (C), 145.5 (C), 143.9 (C), 142.4 (C), 131.5 (C), 131.3 $(2 \times \mathrm{CH}), 126.6(\mathrm{C}), 126.0(\mathrm{CH}), 122.9(\mathrm{CH}), 117.7(\mathrm{CH}), 113.9(2 \times \mathrm{CH}), 78.8(\mathrm{C}), 55.4\left(\mathrm{CH}_{3}\right), 42.6\left(\mathrm{CH}_{2}\right)$, $42.2\left(\mathrm{CH}_{2}\right), 14.4\left(\mathrm{CH}_{3}\right), 13.4\left(\mathrm{CH}_{3}\right) \mathrm{ppm}$.

EMBR (IE), m/z (\%): 481 (M+25), 353 (4), 207 (10), 139 (6), 100 (100), 72 (32).

EMAR calculado para $\mathrm{C}_{20} \mathrm{H}_{20} \mathrm{INO}_{3} \mathrm{~S}$ : 481.0209; encontrado: 481.0208 .

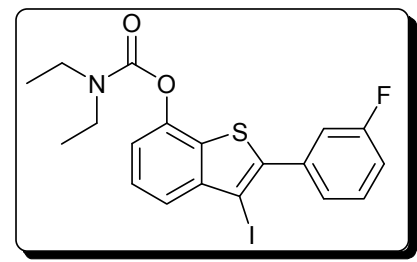

7-( $N, N$-Dietilcarbamoiloxi)-2-(3-fluorofenil)-3-yodobenzo[b]tiofeno (63g)

Líquido incoloro.

$\mathrm{R}_{\mathrm{f}}=0.47$ (hexano / AcOEt, 5 / 1). 
${ }^{1} \mathbf{H}$ RMN $\left(300 \mathrm{MHz}, \mathrm{CDCl}_{3}\right): \delta=7.68(\mathrm{dd}, J=8.0,1.0 \mathrm{~Hz}, 1 \mathrm{H}), 7.51(\mathrm{~d}, J=8.0 \mathrm{~Hz}, 1 \mathrm{H}), 7.48-7.44(\mathrm{~m}, 2 \mathrm{H})$, $7.43-7.38(\mathrm{~m}, 1 \mathrm{H}), 7.33(\mathrm{dd}, J=8.0,1.0 \mathrm{~Hz}, 1 \mathrm{H}), 7.19-7.11(\mathrm{~m}, 1 \mathrm{H}), 3.58-3.47(\mathrm{~m}, 2 \mathrm{H}), 3.47-3.37(\mathrm{~m}$, $2 \mathrm{H}), 1.34(\mathrm{t}, J=7.0 \mathrm{~Hz}, 3 \mathrm{H}), 1.24(\mathrm{t}, J=7.0 \mathrm{~Hz}, 3 \mathrm{H}) \mathrm{ppm}$.

${ }^{13} \mathbf{C}$ RMN (75.4 MHz, $\mathrm{CDCl}_{3}$ ): $\delta=162.6$ (d, $\left.J=247.1 \mathrm{~Hz}, \mathrm{C}\right), 153.1$ (C), 145.7 (C), 143.9 (C), 140.9 (C), 136.5 $(\mathrm{d}, J=8.3 \mathrm{~Hz}, \mathrm{C}), 131.8(\mathrm{C}), 130.2(\mathrm{~d}, J=8.5 \mathrm{~Hz}, \mathrm{CH}), 126.4(\mathrm{CH}), 126.0(\mathrm{~d}, J=3.0 \mathrm{~Hz}, \mathrm{CH}), 123.4$ (CH), $118.3(\mathrm{CH}), 117.2(\mathrm{~d}, J=22.8 \mathrm{~Hz}, \mathrm{CH}), 116.1(\mathrm{~d}, J=21.0 \mathrm{~Hz}, \mathrm{CH}), 80.0(\mathrm{C}), 42.7\left(\mathrm{CH}_{2}\right), 42.4$ $\left(\mathrm{CH}_{2}\right), 14.5\left(\mathrm{CH}_{3}\right), 13.5\left(\mathrm{CH}_{3}\right) \mathrm{ppm}$.

EMBR (IE), m/z (\%): $469\left(\mathrm{M}^{+}, 10\right), 341$ (3), $170(9), 100$ (100), 72 (33).

EMAR calculado para $\mathrm{C}_{19} \mathrm{H}_{17} \mathrm{FINO}_{2} \mathrm{~S}: 469.0009$; encontrado: 469.0020 .

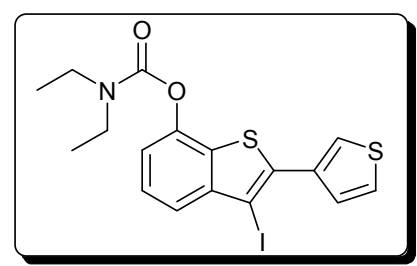

7-(N,N-Dietilcarbamoiloxi)-2-(3-tienil)-3-yodobenzo[b]tiofeno (63h) Líquido incoloro. $\mathrm{R}_{\mathrm{f}}=0.37$ (hexano / AcOEt, 5 / 1).

${ }^{1} \mathbf{H}$ RMN $\left(300 \mathrm{MHz}, \mathrm{CDCl}_{3}\right): \delta=7.84(\mathrm{dd}, J=3.0,1.3 \mathrm{~Hz}, 1 \mathrm{H}), 7.66(\mathrm{dd}, J=8.0,0.8 \mathrm{~Hz}, 1 \mathrm{H}), 7.56(\mathrm{dd}, J=5.0$, $1.3 \mathrm{~Hz}, 1 \mathrm{H}), 7.49(\mathrm{~d}, J=8.0 \mathrm{~Hz}, 1 \mathrm{H}), 7.45-7.41(\mathrm{~m}, 1 \mathrm{H}), 7.31(\mathrm{dd}, J=8.0,0.8 \mathrm{~Hz}, 1 \mathrm{H}), 3.57-3.48(\mathrm{~m}$, 2H), 3.48-3.39 (m, 2H), $1.35(\mathrm{t}, J=7.1 \mathrm{~Hz}, 3 \mathrm{H}), 1.25(\mathrm{t}, J=7.1 \mathrm{~Hz}, 3 \mathrm{H}) \mathrm{ppm}$.

${ }^{13} \mathbf{C}$ RMN (75.4 MHz, $\left.\mathrm{CDCl}_{3}\right): \delta=153.0(\mathrm{C}), 145.6(\mathrm{C}), 144.1(\mathrm{C}), 137.5(\mathrm{C}), 134.5(\mathrm{C}), 130.9(\mathrm{C}), 128.4(\mathrm{CH})$, $126.2(\mathrm{CH}), 126.0(\mathrm{CH}), 125.6(\mathrm{CH}), 123.0(\mathrm{CH}), 118.0(\mathrm{CH}), 78.6(\mathrm{C}), 42.6\left(\mathrm{CH}_{2}\right), 42.3\left(\mathrm{CH}_{2}\right), 14.4$ $\left(\mathrm{CH}_{3}\right), 13.5\left(\mathrm{CH}_{3}\right) \mathrm{ppm}$.

EMBR (IE), m/z (\%): $457\left(\mathrm{M}^{+}, 17\right), 329$ (4), 158 (6), 100 (100), 72 (36).

EMAR calculado para $\mathrm{C}_{17} \mathrm{H}_{16} \mathrm{INO}_{2} \mathrm{~S}_{2}$ : 456.9667; encontrado: 456.9674.

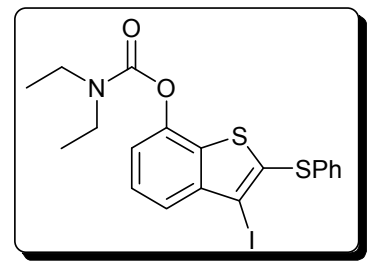

7-(N,N-Dietilcarbamoiloxi)-2-(feniltio)-3-yodobenzo/b/tiofeno (63j) Sólido amarillo.

P.f. $=84-86^{\circ} \mathrm{C}$.

${ }^{1} \mathbf{H}$ RMN $\left(300 \mathrm{MHz}, \mathrm{CDCl}_{3}\right): \delta=7.59(\mathrm{~d}, J=8.0 \mathrm{~Hz}, 1 \mathrm{H}), 7.47(\mathrm{t}, J=8.0 \mathrm{~Hz}, 1 \mathrm{H}), 7.41-7.23(\mathrm{~m}, 6 \mathrm{H})$, $3.52-3.43(\mathrm{~m}, 2 \mathrm{H}), 3.43-3.35(\mathrm{~m}, 2 \mathrm{H}), 1.29(\mathrm{t}, J=7.1 \mathrm{~Hz}, 3 \mathrm{H}), 1.22(\mathrm{t}, J=7.1 \mathrm{~Hz}, 3 \mathrm{H}) \mathrm{ppm}$.

${ }^{13}$ C RMN (75.4 MHz, $\left.\mathrm{CDCl}_{3}\right): \delta=152.8$ (C), $145.4(\mathrm{C}), 143.4$ (C), 136.2 (C), 134.7 (C), 134.0 (C), 129.8 $(2 \times \mathrm{CH}), 129.4(2 \times \mathrm{CH}), 127.5(\mathrm{CH}), 126.2(\mathrm{CH}), 123.0(\mathrm{CH}), 118.5(\mathrm{CH}), 91.5(\mathrm{C}), 42.6\left(\mathrm{CH}_{2}\right), 42.2$ $\left(\mathrm{CH}_{3}\right), 14.4\left(\mathrm{CH}_{3}\right), 13.4\left(\mathrm{CH}_{3}\right) \mathrm{ppm}$.

EMBR (IE), m/z (\%): $483\left(\mathrm{M}^{+}, 2\right), 355$ (5), 227 (12), 100 (100), 72 (61).

EMAR calculado para $\mathrm{C}_{19} \mathrm{H}_{18} \mathrm{INO}_{2} \mathrm{~S}_{2}: 482.9824$; encontrado: 482.9823.

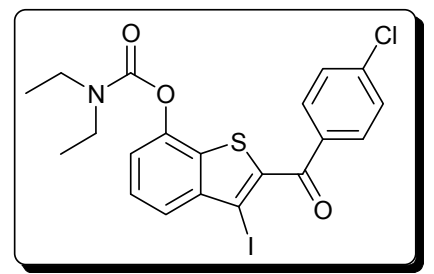

2-(4-Clorobenzoil)-7-( $N, N$-dietilcarbamoiloxi)-3-yodo benzo $[b]$ tiofeno $(63 \mathrm{k})$

Líquido amarillo.

$\mathrm{R}_{\mathrm{f}}=0.64$ (hexano / AcOEt, $1 / 1$ ). 
${ }^{1} \mathbf{H}$ RMN $\left(300 \mathrm{MHz}, \mathrm{CDCl}_{3}\right): \delta=7.89-7.82(\mathrm{~m}, 2 \mathrm{H}), 7.78(\mathrm{dd}, J=8.1,0.9 \mathrm{~Hz}, 1 \mathrm{H}), 7.56(\mathrm{t}, J=8.1 \mathrm{~Hz}, 1 \mathrm{H})$, 7.52-7.42 (m, 3H), 3.60-3.50 (m, 2H), 3.50-3.40 (m, 2H), $1.32(\mathrm{t}, J=7.1 \mathrm{~Hz}, 3 \mathrm{H}), 1.23(\mathrm{t}, J=7.1 \mathrm{~Hz}$, 3H) ppm.

${ }^{13}$ C RMN (75.4 MHz, $\mathrm{CDCl}_{3}$ ): $\delta=189.4$ (C), 152.9 (C), 146.1 (C), 143.5 (C), 140.4 (C), 135.6 (C), 132.7 (C), $131.9(2 \times \mathrm{CH}), 129.2(2 \times \mathrm{CH}), 128.4(\mathrm{C}), 127.1(\mathrm{CH}), 124.5(\mathrm{CH}), 120.1(\mathrm{CH}), 85.2(\mathrm{C}), 42.9\left(\mathrm{CH}_{2}\right), 42.5$ $\left(\mathrm{CH}_{2}\right), 14.6\left(\mathrm{CH}_{3}\right), 13.6\left(\mathrm{CH}_{3}\right) \mathrm{ppm}$.

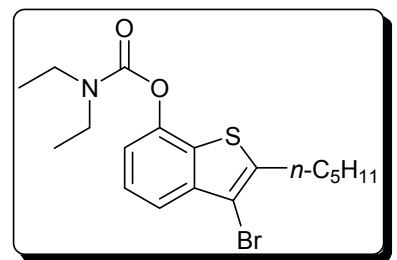

\section{3-Bromo-7-( $N, N$-dietilcarbamoiloxi)-2-pentilbenzo/b/tiofeno (64a)} Líquido incoloro. $\mathrm{R}_{\mathrm{f}}=0.46$ (hexano / AcOEt, 5 / 1).

${ }^{1} \mathbf{H}$ RMN $\left(300 \mathrm{MHz}, \mathrm{CDCl}_{3}\right): \delta=7.58(\mathrm{dd}, J=8.0,0.8 \mathrm{~Hz}, 1 \mathrm{H}), 7.42(\mathrm{t}, J=8.0 \mathrm{~Hz}, 1 \mathrm{H}), 7.24(\mathrm{dd}, J=8.0,0.8$ $\mathrm{Hz}, 1 \mathrm{H}), 3.57-3.48(\mathrm{~m}, 2 \mathrm{H}), 3.47-3.38(\mathrm{~m}, 2 \mathrm{H}), 2.93(\mathrm{t}, J=7.5 \mathrm{~Hz}, 2 \mathrm{H}), 1.81-1.68(\mathrm{~m}, 2 \mathrm{H}), 1.45-1.30$ $(\mathrm{m}, 7 \mathrm{H}), 1.24(\mathrm{t}, J=7.1 \mathrm{~Hz}, 3 \mathrm{H}), 0.92(\mathrm{t}, J=7.1 \mathrm{~Hz}, 3 \mathrm{H}) \mathrm{ppm}$.

${ }^{13}$ C RMN (75.4 MHz, $\left.\mathrm{CDCl}_{3}\right): \delta=153.1$ (C), $145.8(\mathrm{C}), 141.3(\mathrm{C}), 140.5(\mathrm{C}), 129.8(\mathrm{C}), 125.8(\mathrm{CH}), 119.5$ $(\mathrm{CH}), 117.4(\mathrm{CH}), 105.9(\mathrm{C}), 42.6\left(\mathrm{CH}_{2}\right), 42.3\left(\mathrm{CH}_{2}\right), 31.3\left(\mathrm{CH}_{2}\right), 30.1\left(\mathrm{CH}_{2}\right), 30.0\left(\mathrm{CH}_{2}\right), 22.5\left(\mathrm{CH}_{2}\right)$, $14.4\left(\mathrm{CH}_{3}\right), 14.1\left(\mathrm{CH}_{3}\right), 13.5\left(\mathrm{CH}_{3}\right) \mathrm{ppm}$.

EMBR (IE), m/z (\%): $399\left(\mathrm{M}^{+}+2,6\right), 397\left(\mathrm{M}^{+}, 5\right), 214$ (3), 100 (100), 72 (27).

EMAR calculado para $\mathrm{C}_{18} \mathrm{H}_{24} \mathrm{BrNO}_{2} \mathrm{~S}$ : 397.0711; encontrado: 397.0715 .

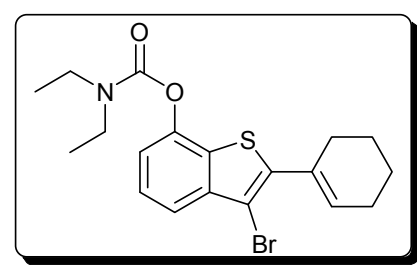

3-Bromo-2-(1-ciclohexenil)-7-( $N, N$-dietilcarbamoiloxi) benzo $[b]$ tiofeno $(64 c)$

Líquido incoloro.

$\mathrm{R}_{\mathrm{f}}=0.46$ (hexano / AcOEt, 5 / 1).

${ }^{1} \mathbf{H}$ RMN $\left(300 \mathrm{MHz}, \mathrm{CDCl}_{3}\right): \delta=7.69-7.60(\mathrm{~m}, 1 \mathrm{H}), 7.45(\mathrm{td}, J=8.0,0.6 \mathrm{~Hz}, 1 \mathrm{H}), 7.35-7.25(\mathrm{~m}, 1 \mathrm{H})$, 6.33-6.28 (m, 1H), 3.57-3.47 (m, 2H), 3.47-3.36 (m, 2H), 2.61-1.99 (m, 6H), 1.93-1.73 (m, 2H), $1.34(\mathrm{t}$, $J=7.0 \mathrm{~Hz}, 3 \mathrm{H}), 1.24(\mathrm{t}, J=7.0 \mathrm{~Hz}, 3 \mathrm{H}) \mathrm{ppm}$.

${ }^{13} \mathbf{C}$ RMN (75.4 MHz, $\left.\mathrm{CDCl}_{3}\right): \delta=153.0(\mathrm{C}), 145.8(\mathrm{C}), 140.5(\mathrm{C}), 138.1(\mathrm{C}), 137.1(\mathrm{CH}), 132.3(\mathrm{C}), 130.1(\mathrm{C})$, $126.1(\mathrm{CH}), 120.2(\mathrm{CH}), 118.1(\mathrm{CH}), 105.8(\mathrm{C}), 50.5\left(\mathrm{CH}_{2}\right), 42.6\left(\mathrm{CH}_{2}\right), 42.3\left(\mathrm{CH}_{2}\right), 32.6\left(\mathrm{CH}_{2}\right), 25.8$ $\left(\mathrm{CH}_{2}\right), 17.0\left(\mathrm{CH}_{2}\right), 14.5\left(\mathrm{CH}_{2}\right), 13.5\left(\mathrm{CH}_{3}\right) \mathrm{ppm}$.

EMBR (IE), m/z (\%): $409\left(\mathrm{M}^{+}+2,6\right), 407\left(\mathrm{M}^{+}, 6\right), 171$ (4), 100 (100), 72 (30).

EMAR calculado para $\mathrm{C}_{19} \mathrm{H}_{22} \mathrm{BrNO}_{2} \mathrm{~S}$ : 407.0555; encontrado: 407.0538 .

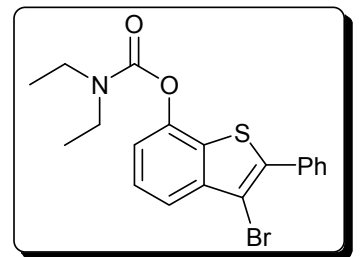

3-Bromo-7-( $N, N$-dietilcarbamoiloxi)-2-fenilbenzo/b/tiofeno (64e)

Líquido incoloro.

$\mathrm{R}_{\mathrm{f}}=0.41$ (hexano / AcOEt, 5 / 1).

${ }^{1} \mathbf{H}$ RMN $\left(300 \mathrm{MHz}, \mathrm{CDCl}_{3}\right): \delta=7.80-7.75(\mathrm{~m}, 2 \mathrm{H}), 7.73(\mathrm{dd}, J=7.9,1.0 \mathrm{~Hz}, 1 \mathrm{H}), 7.54-7.42(\mathrm{~m}, 4 \mathrm{H}), 7.34$ $(\mathrm{dd}, J=7.9,1.0 \mathrm{~Hz}, 1 \mathrm{H}), 3.58-3.49(\mathrm{~m}, 2 \mathrm{H}), 3.49-3.40(\mathrm{~m}, 2 \mathrm{H}), 1.36(\mathrm{t}, J=7.1 \mathrm{~Hz}, 3 \mathrm{H}), 1.26(\mathrm{t}, J=7.1$ $\mathrm{Hz}, 3 \mathrm{H}) \mathrm{ppm}$. 
${ }^{13} \mathbf{C ~ R M N ~ ( 7 5 . 4 ~ M H z , ~} \mathrm{CDCl}_{3}$ ): $\delta=153.0$ (C), 145.8 (C), 141.2 (C), 138.6 (C), 132.9 (C), 130.5 (C), 129.7 $(2 \times \mathrm{CH}), 129.0(\mathrm{CH}), 128.7(2 \times \mathrm{CH}), 126.2(\mathrm{CH}), 120.5(\mathrm{CH}), 118.1(\mathrm{CH}), 105.1(\mathrm{C}), 42.7\left(\mathrm{CH}_{2}\right), 42.3$ $\left(\mathrm{CH}_{2}\right), 14.4\left(\mathrm{CH}_{3}\right), 13.5\left(\mathrm{CH}_{3}\right) \mathrm{ppm}$.

EMBR (IE), m/z (\%): $405\left(\mathrm{M}^{+}+2,6\right), 403\left(\mathrm{M}^{+}, 6\right), 277$ (4), 195 (6), 152 (9), 100 (100), 72 (35).

EMAR calculado para $\mathrm{C}_{19} \mathrm{H}_{18} \mathrm{BrNO}_{2} \mathrm{~S}$ : 403.0242; encontrado: 403.0245 .

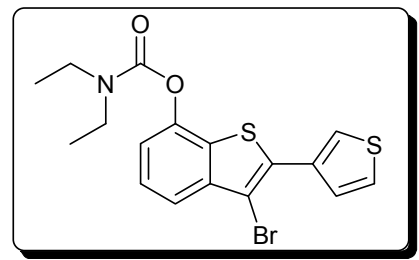

3-Bromo-7-( $N, N$-dietilcarbamoiloxi)-2-(3-tienil)benzo[b]tiofeno (64h)

Líquido incoloro.

$\mathrm{R}_{\mathrm{f}}=0.49$ (hexano / AcOEt, 5 / 1).

${ }^{1} \mathbf{H}$ RMN $\left(300 \mathrm{MHz}, \mathrm{CDCl}_{3}\right): \delta=7.91(\mathrm{ddd}, J=3.0,1.3,0.6 \mathrm{~Hz}, 1 \mathrm{H}), 7.69(\mathrm{~d}, J=8.0 \mathrm{~Hz}, 1 \mathrm{H}), 7.60(\mathrm{ddd}, J=$ $5.0,1.3,0.6 \mathrm{~Hz}, 1 \mathrm{H}), 7.48(\mathrm{td}, J=8.0,0.6 \mathrm{~Hz}, 1 \mathrm{H}), 7.41(\mathrm{ddd}, J=5.0,3.0,0.6 \mathrm{~Hz}, 1 \mathrm{H}), 7.33(\mathrm{~d}, J=8.0$ $\mathrm{Hz}, 1 \mathrm{H}), 3.57-3.49(\mathrm{~m}, 2 \mathrm{H}), 3.48-3.40(\mathrm{~m}, 2 \mathrm{H}), 1.36(\mathrm{t}, J=7.1 \mathrm{~Hz}, 3 \mathrm{H}), 1.26(\mathrm{t}, J=7.1 \mathrm{~Hz}, 3 \mathrm{H}) \mathrm{ppm}$.

${ }^{13} \mathbf{C}$ RMN (75.4 MHz, $\mathrm{CDCl}_{3}$ ): $\delta=152.8(\mathrm{C}), 145.6(\mathrm{C}), 141.2(\mathrm{C}), 133.5(\mathrm{C}), 133.0(\mathrm{C}), 129.5(\mathrm{C}), 127.8(\mathrm{CH})$, $126.2(\mathrm{CH}), 125.9(\mathrm{CH}), 125.0(\mathrm{CH}), 120.2(\mathrm{CH}), 118.0(\mathrm{CH}), 104.5(\mathrm{C}), 42.6\left(\mathrm{CH}_{2}\right), 42.2\left(\mathrm{CH}_{2}\right), 14.4$ $\left(\mathrm{CH}_{3}\right), 13.4\left(\mathrm{CH}_{3}\right) \mathrm{ppm}$.

EMBR (IE), m/z (\%): $411\left(\mathrm{M}^{+}+2,20\right), 409$ (M+1, 20), 283 (11), 281 (10), 201 (9), 158 (13), 100 (100), 72 (39).

EMAR calculado para $\mathrm{C}_{17} \mathrm{H}_{16} \mathrm{BrNO}_{2} \mathrm{~S}_{2}$ : 408.9806; encontrado: 408.9816.

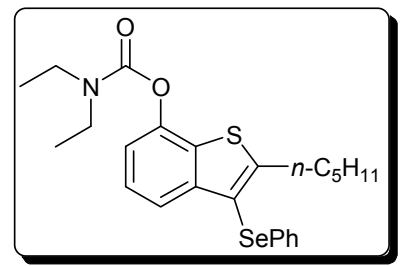

7-(N,N-Dietilcarbamoiloxi)-3-(fenilselanil)-2-pentilbenzo/b/tiofeno (65a)

Sólido blanco.

P.f. $=40-42{ }^{\circ} \mathrm{C}$.

${ }^{1} \mathbf{H}$ RMN $\left(300 \mathrm{MHz}, \mathrm{CDCl}_{3}\right): \delta=7.67(\mathrm{dd}, J=7.9,1.0 \mathrm{~Hz}, 1 \mathrm{H}), 7.36(\mathrm{t}, J=7.9 \mathrm{~Hz}, 1 \mathrm{H}), 7.24(\mathrm{dd}, J=7.9,1.0$ $\mathrm{Hz}, 1 \mathrm{H}), 7.19-7.11(\mathrm{~m}, 5 \mathrm{H}), 3.60-3.51(\mathrm{~m}, 2 \mathrm{H}), 3.51-3.42(\mathrm{~m}, 2 \mathrm{H}), 3.22-3.08(\mathrm{~m}, 2 \mathrm{H}), 1.79-1.67(\mathrm{~m}$, $2 \mathrm{H}), 1.44-1.32(\mathrm{~m}, 7 \mathrm{H}), 1.28(\mathrm{t}, J=7.0 \mathrm{~Hz}, 3 \mathrm{H}), 0.88(\mathrm{t}, J=7.0 \mathrm{~Hz}, 3 \mathrm{H}) \mathrm{ppm}$.

${ }^{13}$ C RMN (75.4 MHz, $\left.\mathrm{CDCl}_{3}\right): \delta=153.2$ (C), 152.8 (C), 145.9 (C), 143.8 (C), 132.5 (C), 131.0 (C), 129.2 $(2 \times \mathrm{CH}), 129.0(2 \times \mathrm{CH}), 126.0(\mathrm{CH}), 125.7(\mathrm{CH}), 120.9(\mathrm{CH}), 117.2(\mathrm{CH}), 116.3(\mathrm{C}), 42.6\left(\mathrm{CH}_{2}\right), 42.2$ $\left(\mathrm{CH}_{2}\right), 31.4\left(\mathrm{CH}_{2}\right), 31.3\left(\mathrm{CH}_{2}\right), 31.0\left(\mathrm{CH}_{2}\right), 22.4\left(\mathrm{CH}_{2}\right), 14.4\left(\mathrm{CH}_{3}\right), 14.0\left(\mathrm{CH}_{3}\right), 13.5\left(\mathrm{CH}_{3}\right) \mathrm{ppm}$.

EMBR (IE), m/z (\%): $476\left(\mathrm{M}^{+}+5,3\right), 475\left(\mathrm{M}^{+}+4,12\right), 473\left(\mathrm{M}^{+}+2,6\right), 100$ (100), 72 (27).

EMAR calculado para $\mathrm{C}_{24} \mathrm{H}_{29} \mathrm{NO}_{2} \mathrm{SSe}$ : 475.1084; encontrado: 475.1078 .

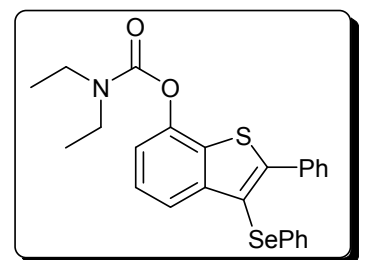

7-( $N, N$-Dietilcarbamoiloxi)-2-fenil-3-(fenilselanil)benzo/b/tiofeno (65e) Líquido amarillo.

$\mathrm{R}_{\mathrm{f}}=0.33$ (hexano / AcOEt, 5 / 1).

${ }^{1}$ H RMN (300 MHz, $\left.\mathrm{CDCl}_{3}\right): \delta=7.77-7.73(\mathrm{~m}, 1 \mathrm{H}), 7.69-7.66(\mathrm{~m}, 1 \mathrm{H}), 7.66-7.63(\mathrm{~m}, 1 \mathrm{H}), 7.48-7.40(\mathrm{~m}, 4 \mathrm{H})$, $7.33-7.29(\mathrm{~m}, 1 \mathrm{H}), 7.22-7.11(\mathrm{~m}, 5 \mathrm{H}), 3.61-3.52(\mathrm{~m}, 2 \mathrm{H}), 3.52-3.42(\mathrm{~m}, 2 \mathrm{H}), 1.39(\mathrm{t}, J=7.0 \mathrm{~Hz}, 3 \mathrm{H})$, $1.28(\mathrm{t}, J=7.0 \mathrm{~Hz}, 3 \mathrm{H}) \mathrm{ppm}$. 
${ }^{13} \mathbf{C}$ RMN (75.4 MHz, $\mathrm{CDCl}_{3}$ ): $\delta=153.2(\mathrm{C}), 149.3$ (C), 145.8 (C), 144.2 (C), $134.0(\mathrm{C}), 132.7(\mathrm{C}), 131.9$ (C), $130.2(2 \times \mathrm{CH}), 129.3(2 \times \mathrm{CH}), 129.1(2 \times \mathrm{CH}), 129.0(\mathrm{CH}), 128.4(2 \times \mathrm{CH}), 126.11(\mathrm{CH}), 126.09(\mathrm{CH}), 122.0$ $(\mathrm{CH}), 117.8(\mathrm{CH}), 115.9(\mathrm{C}), 42.7\left(\mathrm{CH}_{2}\right), 42.3\left(\mathrm{CH}_{2}\right), 14.5\left(\mathrm{CH}_{3}\right), 13.5\left(\mathrm{CH}_{3}\right) \mathrm{ppm}$.

EMBR (IE), m/z (\%): 481 (M+25), 275 (6), 208 (3), 195 (6), 100 (100).

EMAR calculado para $\mathrm{C}_{25} \mathrm{H}_{23} \mathrm{NO}_{2} \mathrm{SSe}: 481.0581$; encontrado: 481.0582 .

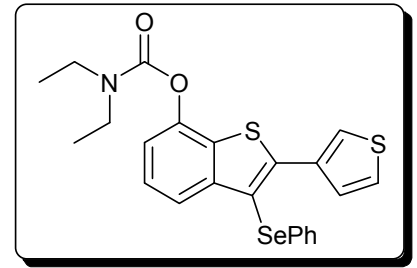

7-(N,N-Dietilcarbamoiloxi)-3-(fenilselanil)-2-(3-tienil) benzo $[b]$ tiofeno $(65 \mathrm{~h})$

Líquido incoloro.

$\mathrm{R}_{\mathrm{f}}=0.41$ (hexano / AcOEt, $5 / 1$ ).

${ }^{1} \mathbf{H}$ RMN $\left(300 \mathrm{MHz}, \mathrm{CDCl}_{3}\right): \delta=7.80(\mathrm{dd}, J=3.0,1.3 \mathrm{~Hz}, 1 \mathrm{H}), 7.77(\mathrm{dd}, J=7.9,1.0 \mathrm{~Hz}, 1 \mathrm{H}), 7.56(\mathrm{dd}, J=5.1$, $1.3 \mathrm{~Hz}, 1 \mathrm{H}), 7.43-7.34(\mathrm{~m}, 2 \mathrm{H}), 7.29(\mathrm{dd}, J=7.9,1.0 \mathrm{~Hz}, 1 \mathrm{H}), 7.23-7.10(\mathrm{~m}, 5 \mathrm{H}), 3.62-3.52(\mathrm{~m}, 2 \mathrm{H})$, $3.52-3.42(\mathrm{~m}, 2 \mathrm{H}), 1.39(\mathrm{t}, J=7.0 \mathrm{~Hz}, 3 \mathrm{H}), 1.28(\mathrm{t}, J=7.0 \mathrm{~Hz}, 3 \mathrm{H}) \mathrm{ppm}$.

${ }^{13} \mathbf{C}$ RMN (75.4 MHz, $\left.\mathrm{CDCl}_{3}\right): \delta=153.1(\mathrm{C}), 145.8(\mathrm{C}), 144.6(\mathrm{C}), 143.9$ (C), 134.2 (C), $132.5(\mathrm{C}), 131.1$ (C), $129.4(2 \times \mathrm{CH}), 128.9(2 \times \mathrm{CH}), 128.6(\mathrm{CH}), 126.1(2 \times \mathrm{CH}), 125.7(2 \times \mathrm{CH}), 121.8(\mathrm{CH}), 117.9(\mathrm{CH}), 115.2$ (C), $42.7\left(\mathrm{CH}_{2}\right), 42.3\left(\mathrm{CH}_{2}\right), 14.5\left(\mathrm{CH}_{3}\right), 13.5\left(\mathrm{CH}_{3}\right) \mathrm{ppm}$.

EMBR (IE), m/z (\%): 487 (M+1 12), 281 (3), 158 (4), 100 (100), 72 (34).

EMAR calculado para $\mathrm{C}_{23} \mathrm{H}_{21} \mathrm{NO}_{2} \mathrm{~S}_{2} \mathrm{Se}$ : 487.0179; encontrado: 487.0173 .

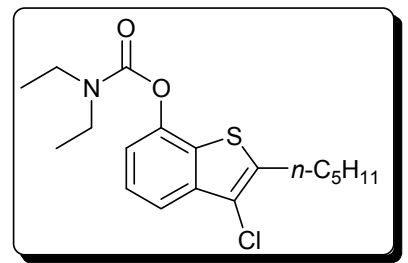

3-Cloro-7-( $N, N$-dietilcarbamoiloxi)-2-pentilbenzo/b/tiofeno (66a) Líquido marrón. $\mathrm{R}_{\mathrm{f}}=0.44$ (hexano / AcOEt, 5 / 1).

${ }^{1} \mathbf{H}$ RMN $\left(300 \mathrm{MHz}, \mathrm{CDCl}_{3}\right): \delta=7.59(\mathrm{dd}, J=8.0,0.9 \mathrm{~Hz}, 1 \mathrm{H}), 7.42(\mathrm{td}, J=8.0,0.9 \mathrm{~Hz}, 1 \mathrm{H}), 7.25(\mathrm{dd}, J=8.0$, $0.9 \mathrm{~Hz}, 1 \mathrm{H}), 3.57-3.48(\mathrm{~m}, 2 \mathrm{H}), 3.47-3.37(\mathrm{~m}, 2 \mathrm{H}), 2.98-2.89(\mathrm{~m}, 2 \mathrm{H}), 1.80-1.68(\mathrm{~m}, 2 \mathrm{H}), 1.47-1.30(\mathrm{~m}$, $7 \mathrm{H}), 1.25(\mathrm{t}, J=7.1 \mathrm{~Hz}, 3 \mathrm{H}), 0.93(\mathrm{t}, J=7.1 \mathrm{~Hz}, 3 \mathrm{H}) \mathrm{ppm}$.

${ }^{13} \mathbf{C}$ RMN (75.4 MHz, $\left.\mathrm{CDCl}_{3}\right): \delta=153.0(\mathrm{C}), 145.9(\mathrm{C}), 139.4(\mathrm{C}), 139.2(\mathrm{C}), 129.0(\mathrm{C}), 125.8(\mathrm{CH}), 118.2$ $(\mathrm{CH}), 117.6(\mathrm{C}), 117.4(\mathrm{CH}), 42.6\left(\mathrm{CH}_{2}\right), 42.2\left(\mathrm{CH}_{2}\right), 31.3\left(\mathrm{CH}_{2}\right), 30.0\left(\mathrm{CH}_{2}\right), 28.3\left(\mathrm{CH}_{2}\right), 22.4\left(\mathrm{CH}_{2}\right)$, $14.4\left(\mathrm{CH}_{3}\right), 14.0\left(\mathrm{CH}_{3}\right), 13.4\left(\mathrm{CH}_{3}\right) \mathrm{ppm}$.

EMBR (IE), m/z (\%): $355\left(\mathrm{M}^{+}+2,1\right), 353\left(\mathrm{M}^{+}, 3\right), 255$ (2), 253 (5), 168 (14), 100 (100), 72 (41).

EMAR calculado para $\mathrm{C}_{18} \mathrm{H}_{24} \mathrm{ClNO}_{2} \mathrm{~S}$ : 353.1216; encontrado: 353.1215 .

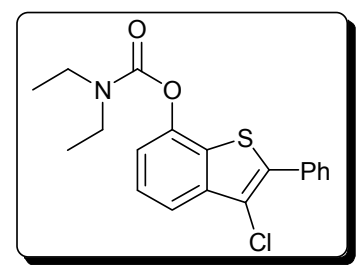

3-Cloro-7-( $N, N$-dietilcarbamoiloxi)-2-fenilbenzo/b/tiofeno (66e)

Líquido incoloro.

$\mathrm{R}_{\mathrm{f}}=0.44$ (hexano / AcOEt, 5 / 1)

${ }^{1} \mathbf{H}$ RMN $\left(300 \mathrm{MHz}, \mathrm{CDCl}_{3}\right): \delta=7.84-7.79(\mathrm{~m}, 2 \mathrm{H}), 7.73(\mathrm{dd}, J=8.0,0.9 \mathrm{~Hz}, 1 \mathrm{H}), 7.54-7.41(\mathrm{~m}, 4 \mathrm{H}), 7.35$ $(\mathrm{dd}, J=8.0,0.9 \mathrm{~Hz}, 1 \mathrm{H}), 3.59-3.50(\mathrm{~m}, 2 \mathrm{H}), 3.49-3.40(\mathrm{~m}, 2 \mathrm{H}), 1.37(\mathrm{t}, J=7.0 \mathrm{~Hz}, 3 \mathrm{H}), 1.27(\mathrm{t}, J=7.0$ $\mathrm{Hz}, 3 \mathrm{H}) \mathrm{ppm}$. 
${ }^{13} \mathbf{C ~ R M N ~ ( 7 5 . 4 ~ M H z , ~} \mathrm{CDCl}_{3}$ ): $\delta=153.0$ (C), 145.9 (C), 139.9 (C), 136.7 (C), 132.2 (C), 129.6 (C), 129.3 $(2 \times \mathrm{CH}), 128.9(\mathrm{CH}), 128.7(2 \times \mathrm{CH}), 126.2(\mathrm{CH}), 119.1(\mathrm{CH}), 118.2(\mathrm{CH}), 116.9(\mathrm{C}), 42.6\left(\mathrm{CH}_{2}\right), 42.3$ $\left(\mathrm{CH}_{2}\right), 14.4\left(\mathrm{CH}_{3}\right), 13.5\left(\mathrm{CH}_{3}\right) \mathrm{ppm}$.

EMBR (IE), m/z (\%): 359 (M+1, 3), 259 (3), 233 (7), 231 (14), 195 (13), 152 (12), 100 (100), 72 (45).

EMAR calculado para $\mathrm{C}_{19} \mathrm{H}_{18} \mathrm{ClNO}_{2} \mathrm{~S}: 359.0747$; encontrado: 359.0745 .

\section{A.3.1 Preparación del etinilcarbamato 62 y del 3-yodobenzo[b]tiofeno 63 i}

A una disolución de 62i ó 63i $(0.25 \mathrm{mmol})$ en THF anhidro $(3 \mathrm{~mL})$ se añade un exceso de $\mathrm{Bu}_{4} \mathrm{NF}(0.5 \mathrm{~mL}$ de una disolución $1 \mathrm{M}, 0.5 \mathrm{mmol})$. La mezcla resultante se agita a $20^{\circ} \mathrm{C}$ hasta que la correspondiente desililación ha terminado ( 2 horas), monitorizada por CG-EM. A continuación se añade $\mathrm{H}_{2} \mathrm{O}$ y AcOEt. La fase acuosa separada se extrae con AcOEt $(2 \times 10 \mathrm{~mL})$. La combinación de fases orgánicas se seca sobre $\mathrm{Na}_{2} \mathrm{SO}_{4}$ anhidro y se concentra a presión reducida. El residuo resultante se purifica por columna de cromatografía (hexano / AcOEt) permitiendo obtener los correspondientes compuestos desililados $62 \mathbf{i}$ y $63 \mathbf{i}$.

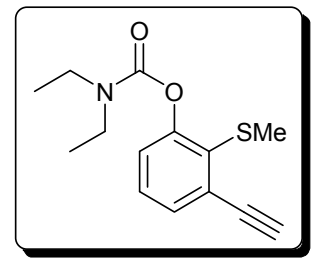

$N, N$-Dietilcarbamato de $O$-3-etinil-2-(metiltio)fenilo (62i)

Líquido incoloro.

$\mathrm{R}_{\mathrm{f}}=0.42$ (hexano / AcOEt, 5 / 1).

${ }^{1} \mathbf{H}$ RMN $\left(300 \mathrm{MHz}, \mathrm{CDCl}_{3}\right): \delta=7.39(\mathrm{~d}, J=7.9 \mathrm{~Hz}, 1 \mathrm{H}), 7.24(\mathrm{t}, J=7.9 \mathrm{~Hz}, 1 \mathrm{H}), 7.12(\mathrm{~d}, J=7.9 \mathrm{~Hz}, 1 \mathrm{H})$, $3.57-3.47(\mathrm{~m}, 2 \mathrm{H}), 3.46-3.36(\mathrm{~m}, 3 \mathrm{H}), 2.42(\mathrm{~d}, J=0.4 \mathrm{~Hz}, 3 \mathrm{H}), 1.29(\mathrm{t}, J=7.1 \mathrm{~Hz}, 3 \mathrm{H}), 1.19(\mathrm{t}, J=7.1$ $\mathrm{Hz}, 3 \mathrm{H}) \mathrm{ppm}$.

${ }^{13} \mathbf{C}$ RMN (75.4 MHz, $\left.\mathrm{CDCl}_{3}\right): \delta=154.0(\mathrm{C}), 153.2(\mathrm{C}), 132.7(\mathrm{C}), 131.2(\mathrm{CH}), 128.9(\mathrm{CH}), 128.8(\mathrm{C}), 124.1$ $(\mathrm{CH}), 82.3(\mathrm{CH}), 81.9(\mathrm{C}), 42.5\left(\mathrm{CH}_{2}\right), 42.3\left(\mathrm{CH}_{2}\right), 18.5\left(\mathrm{CH}_{3}\right), 14.3\left(\mathrm{CH}_{3}\right), 13.5\left(\mathrm{CH}_{3}\right) \mathrm{ppm}$.

EMBR (IE), m/z (\%): $263\left(\mathrm{M}^{+}, 20\right), 216$ (7), 134 (21), 120 (15), 100 (100), 72 (63).

EMAR calculado para $\mathrm{C}_{14} \mathrm{H}_{17} \mathrm{NO}_{2} \mathrm{~S}$ : 263.0980; encontrado: 263.0973 .

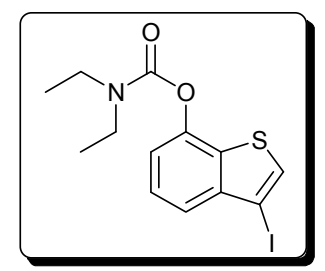

7-(N,N-Dietilcarbamoiloxi)-3-yodobenzo/b/tiofeno (63i)

Sólido blanco.

P.f. $=128-130^{\circ} \mathrm{C}$.

${ }^{1} \mathbf{H}$ RMN $\left(300 \mathrm{MHz}, \mathrm{CDCl}_{3}\right): \delta=7.62-7.57(\mathrm{~m}, 2 \mathrm{H}), 7.49(\mathrm{t}, J=7.9 \mathrm{~Hz}, 1 \mathrm{H}), 7.34(\mathrm{~d}, J=7.9 \mathrm{~Hz}, 1 \mathrm{H})$, $3.57-3.47(\mathrm{~m}, 2 \mathrm{H}), 3.47-3.37(\mathrm{~m}, 2 \mathrm{H}), 1.34(\mathrm{t}, J=7.1 \mathrm{~Hz}, 3 \mathrm{H}), 1.24(\mathrm{t}, J=7.1 \mathrm{~Hz}, 3 \mathrm{H}) \mathrm{ppm}$.

${ }^{13} \mathbf{C}$ RMN (75.4 MHz, $\left.\mathrm{CDCl}_{3}\right): \delta=152.9(\mathrm{C}), 145.9(\mathrm{C}), 142.4(\mathrm{C}), 131.1(\mathrm{C}), 129.2(\mathrm{CH}), 126.0(\mathrm{CH}), 122.1$

$(\mathrm{CH}), 117.6(\mathrm{CH}), 78.3(\mathrm{C}), 42.6\left(\mathrm{CH}_{2}\right), 42.3\left(\mathrm{CH}_{2}\right), 14.4\left(\mathrm{CH}_{3}\right), 13.5\left(\mathrm{CH}_{3}\right) \mathrm{ppm}$.

EMBR (IE), m/z (\%): 375 (M+, 24), 275 (4), 247 (12), 120 (14), 100 (100), 72 (42).

EMAR calculado para $\mathrm{C}_{13} \mathrm{H}_{14} \mathrm{INO}_{2} \mathrm{~S}: 374.9790$; encontrado: 374.9781 .

\section{A.3.2 Síntesis de los $N, N$-dietilcarbamatos de O-3-alquinil-2-(metiltio)fenilo $62 \mathrm{j}-\mathrm{I}$}

A una disolución de $\mathbf{6 2 i}(131 \mathrm{mg}, 0.5 \mathrm{mmol})$ en THF seco $(3 \mathrm{~mL})$ a $-78^{\circ} \mathrm{C}$ se adiciona $n$ $\operatorname{BuLi}(0.35 \mathrm{~mL}$ de una disolución 1.6 $\mathrm{M}$ en hexano, $0.55 \mathrm{mmol})$. Después de 10 minutos a $-78^{\circ} \mathrm{C}$, se 
deja que la mezcla alcance $0{ }^{\circ} \mathrm{C}$ durante 15 minutos. A continuación, se enfría la mezcla a $-78{ }^{\circ} \mathrm{C}$ y se adiciona el correspondiente electrófilo $(0.6 \mathrm{mmol})$. La disolución resultante se agita a temperatura ambiente durante 2 horas y se hidroliza con $\mathrm{H}_{2} \mathrm{O}$ o una disolución de $\mathrm{Na}_{2} \mathrm{~S}_{2} \mathrm{O}_{3}$ (cuando se emplea yodo como electrófilo). La fase acuosa se extrae con AcOEt $(3 \times 10 \mathrm{~mL})$, se seca sobre $\mathrm{Na}_{2} \mathrm{SO}_{4}$ anhidro y se concentra a presión reducida. El residuo resultante se purifica por columna de cromatografía (hexano / AcOEt, 12 / 1) permitiendo obtener los $\mathrm{N}, \mathrm{N}$-dietilcarbamatos de $\mathrm{O}$-3alquinil-2-(metiltio)fenilo $\mathbf{6 2} \mathbf{j}-\mathbf{l}$.<smiles>CCN(CC)C(=O)Oc1cccc(C#Cc2ccccc2)c1C</smiles>

$N, N$-Dietilcarbamato de $O$-3-(feniltioetinil)-2-(metiltio)fenilo (62j) Líquido incoloro.

$\mathrm{R}_{\mathrm{f}}=0.39$ (hexano / AcOEt, 5 / 1).

${ }^{1}$ H RMN (300 MHz, $\left.\mathrm{CDCl}_{3}\right): \delta=7.64-7.59(\mathrm{~m}, 2 \mathrm{H}), 7.41-7.33(\mathrm{~m}, 3 \mathrm{H}), 7.31-7.23(\mathrm{~m}, 2 \mathrm{H}), 7.12(\mathrm{dd}, J=8.0$, $1.5 \mathrm{~Hz}, 1 \mathrm{H}), 3.56-3.47(\mathrm{~m}, 2 \mathrm{H}), 3.45-3.36(\mathrm{~m}, 2 \mathrm{H}), 2.43(\mathrm{~s}, 3 \mathrm{H}), 1.32(\mathrm{t}, J=7.1 \mathrm{~Hz}, 3 \mathrm{H}), 1.23(\mathrm{t}, J=7.1$ $\mathrm{Hz}, 3 \mathrm{H}) \mathrm{ppm}$.

${ }^{13}$ C RMN (75.4 MHz, $\mathrm{CDCl}_{3}$ ): $\delta=153.9$ (C), 153.2 (C), 132.8 (C), 131.7 (C), $129.8(\mathrm{CH}), 129.7$ (C), 129.3 $(2 \times \mathrm{CH}), 129.0(\mathrm{CH}), 126.6(\mathrm{CH}), 126.3(2 \times \mathrm{CH}), 123.4(\mathrm{CH}), 96.7(\mathrm{C}), 80.7(\mathrm{C}), 42.4\left(\mathrm{CH}_{2}\right), 42.2\left(\mathrm{CH}_{2}\right)$, $18.6\left(\mathrm{CH}_{3}\right), 14.3\left(\mathrm{CH}_{3}\right), 13.4\left(\mathrm{CH}_{3}\right) \mathrm{ppm}$.

EMBR (IE), m/z (\%): $370\left(\mathrm{M}^{+}-1,3\right), 227$ (10), 121 (13), 100 (100), 72 (49).

EMAR calculado para $\mathrm{C}_{20} \mathrm{H}_{21} \mathrm{NO}_{2} \mathrm{~S}_{2}: 371.1014$; encontrado: 371.1014 .

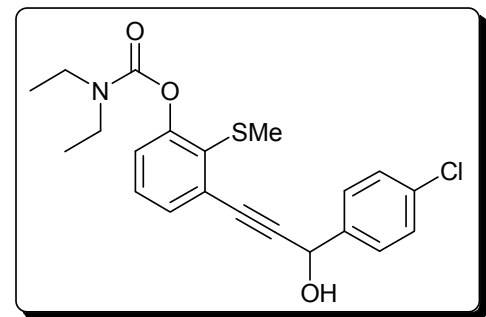

$N, N$-Dietilcarbamato de $O$-3-[3-(4-clorofenil)-3-hidroxi-1propinil]-2-(metiltio)fenilo (62k)

Líquido incoloro.

$\mathrm{R}_{\mathrm{f}}=0.24$ (hexano / AcOEt, $3 / 1$ ).

${ }^{1}$ H RMN (300 MHz, $\left.\mathrm{CDCl}_{3}\right): \delta=7.59-7.53(\mathrm{~m}, 2 \mathrm{H}), 7.37-7.29(\mathrm{~m}, 3 \mathrm{H}), 7.23(\mathrm{t}, J=7.9 \mathrm{~Hz}, 1 \mathrm{H}), 7.10(\mathrm{dd}, J=$ 8.0, $1.5 \mathrm{~Hz}, 1 \mathrm{H}), 5.64(\mathrm{sa}, 1 \mathrm{H}), 3.54-3.43(\mathrm{~m}, 3 \mathrm{H}), 3.41-3.32(\mathrm{~m}, 2 \mathrm{H}), 2.31(\mathrm{~s}, 3 \mathrm{H}), 1.29(\mathrm{t}, J=7.1 \mathrm{~Hz}$, $3 \mathrm{H}), 1.19(\mathrm{t}, J=7.1 \mathrm{~Hz}, 3 \mathrm{H}) \mathrm{ppm}$.

${ }^{13}$ C RMN (75.4 MHz, $\left.\mathrm{CDCl}_{3}\right): \delta=154.0(\mathrm{C}), 153.1(\mathrm{C}), 139.2(\mathrm{C}), 134.0(\mathrm{C}), 132.5(\mathrm{C}), 130.6(\mathrm{CH}), 129.0(\mathrm{C})$, $128.9(\mathrm{CH}), 128.7(2 \times \mathrm{CH}), 128.3(2 \times \mathrm{CH}), 123.8(\mathrm{CH}), 93.4(\mathrm{C}), 85.0(\mathrm{C}), 64.3(\mathrm{CH}), 42.5\left(\mathrm{CH}_{2}\right), 42.2$ $\left(\mathrm{CH}_{2}\right), 18.5\left(\mathrm{CH}_{3}\right), 14.2\left(\mathrm{CH}_{3}\right), 13.4\left(\mathrm{CH}_{3}\right) \mathrm{ppm}$.

EMAR calculado para $\mathrm{C}_{21} \mathrm{H}_{22} \mathrm{ClNO}_{3} \mathrm{~S}$ : 403.1009; encontrado: 403.1000 .

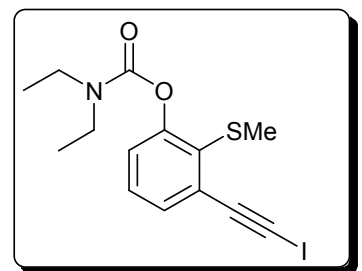

$\mathrm{N}, \mathrm{N}$-Dietilcarbamato de $\mathrm{O}$-3-(yodoetinil)-2-(metiltio)fenilo (62I)

Líquido incoloro.

$\mathrm{R}_{\mathrm{f}}=0.27$ (hexano / AcOEt, 5 / 1). 
${ }^{1} \mathbf{H}$ RMN $\left(400 \mathrm{MHz}, \mathrm{CDCl}_{3}\right): \delta=7.34(\mathrm{dd}, J=7.8,1.4 \mathrm{~Hz}, 1 \mathrm{H}), 7.22(\mathrm{td}, J=7.8,1.4 \mathrm{~Hz}, 1 \mathrm{H}), 7.09(\mathrm{dd}, J=7.8$, $1.4 \mathrm{~Hz}, 1 \mathrm{H}), 3.53-3.43(\mathrm{~m}, 2 \mathrm{H}), 3.42-3.32(\mathrm{~m}, 2 \mathrm{H}), 2.42(\mathrm{~d}, J=1.0 \mathrm{~Hz}, 3 \mathrm{H}), 1.29(\mathrm{t}, J=7.0 \mathrm{~Hz}, 3 \mathrm{H}), 1.20$ $(\mathrm{t}, J=7.0 \mathrm{~Hz}, 3 \mathrm{H}) \mathrm{ppm}$.

${ }^{13} \mathbf{C}$ RMN (100.6 MHz, $\left.\mathrm{CDCl}_{3}\right): \delta=153.9(\mathrm{C}), 152.9(\mathrm{C}), 133.2(\mathrm{C}), 131.4(\mathrm{CH}), 129.7(\mathrm{C}), 128.6(\mathrm{CH}), 124.0$ $(\mathrm{CH}), 92.5(\mathrm{C}), 42.5\left(\mathrm{CH}_{2}\right), 42.2\left(\mathrm{CH}_{2}\right), 18.5\left(\mathrm{CH}_{3}\right), 14.3\left(\mathrm{CH}_{3}\right), 13.4\left(\mathrm{CH}_{3}\right), 12.1(\mathrm{C}) \mathrm{ppm}$.

EMAR calculado para $\mathrm{C}_{14} \mathrm{H}_{16} \mathrm{INO}_{2} \mathrm{~S}$ : 388.9947 ; encontrado: 388.9935 .

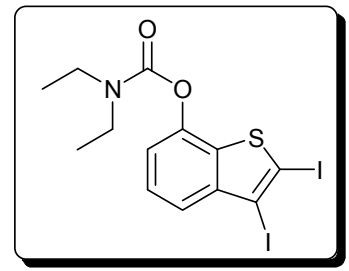

7-(N,N-Dietilcarbamoiloxi)-2,3-diyodobenzo/b/tiofeno (63I)

Sólido blanco.

P.f. $=120-122^{\circ} \mathrm{C}$.

${ }^{1} \mathbf{H}$ RMN $\left(300 \mathrm{MHz}, \mathrm{CDCl}_{3}\right): \delta=7.52(\mathrm{dd}, J=8.0,1.0 \mathrm{~Hz}, 1 \mathrm{H}), 7.40(\mathrm{t}, J=8.0 \mathrm{~Hz}, 1 \mathrm{H}), 7.25(\mathrm{dd}, J=8.0,1.0$ $\mathrm{Hz}, 1 \mathrm{H}), 3.55-3.46(\mathrm{~m}, 2 \mathrm{H}), 3.46-3.36(\mathrm{~m}, 2 \mathrm{H}), 1.33(\mathrm{t}, J=7.1 \mathrm{~Hz}, 3 \mathrm{H}), 1.23(\mathrm{t}, J=7.1 \mathrm{~Hz}, 3 \mathrm{H}) \mathrm{ppm}$.

${ }^{13}$ C RMN (75.4 MHz, $\left.\mathrm{CDCl}_{3}\right): \delta=152.8(\mathrm{C}), 144.9(\mathrm{C}), 143.5(\mathrm{C}), 136.4(\mathrm{C}), 126.6(\mathrm{CH}), 123.4(\mathrm{CH}), 118.0$ $(\mathrm{CH}), 95.1(\mathrm{C}), 89.4(\mathrm{C}), 42.7\left(\mathrm{CH}_{2}\right), 42.3\left(\mathrm{CH}_{2}\right), 14.5\left(\mathrm{CH}_{3}\right), 13.5\left(\mathrm{CH}_{3}\right) \mathrm{ppm}$.

EMBR (IE), m/z (\%): $501\left(\mathrm{M}^{+}, 2\right), 401$ (3), 373 (9), 246 (3), 119 (11), 100 (100), 72 (50).

EMAR calculado para $\mathrm{C}_{13} \mathrm{H}_{13} \mathrm{I}_{2} \mathrm{NO}_{2} \mathrm{~S}$ : 500.8757; encontrado: 500.8754.

\section{A.4 Síntesis de los 7-hidroxibenzo[b]tiofenos 2,3-disustituidos 67 y del 7-hidroxi-2- pentil-3-yodobenzo[b]selenofeno 72}

A una disolución del correspondiente 7-(N,N-dietilcarbamoiloxi)benzo[b]tiofeno 2,3disustituido 63b, 64e, 66a, ó del 7-(N,N-dietilcarbamoiloxi)-2-pentil-3-yodobenzo[b]selenofeno 70b $(0.3 \mathrm{mmol})$ en etanol $(3 \mathrm{~mL})$ se añade un exceso de $\mathrm{NaOH}(120 \mathrm{mg}, 3 \mathrm{mmol})$ y la mezcla se agita a reflujo durante 3-5 horas (la reacción se monitoriza por CG-EM). Posteriormente se deja enfriar la mezcla de reacción a temperatura ambiente y se elimina el EtOH a presión reducida $(20 \mathrm{~mm} \mathrm{Hg})$. El residuo se diluye en $\mathrm{Et}_{2} \mathrm{O}$ y $\mathrm{H}_{2} \mathrm{O}$. La fase acuosa se extrae con $\mathrm{Et}_{2} \mathrm{O}(3 \times 10 \mathrm{~mL})$. Las fases orgánicas combinadas se secan sobre $\mathrm{Na}_{2} \mathrm{SO}_{4}$ anhidro y el disolvente se elimina a presión reducida ( $20 \mathrm{mmHg}$ ). El residuo resultante se purifica mediante cromatografía de columna (hexano / AcOEt) obteniéndose el correspondiente 7-hidroxibenzo[b]tiofeno 67 o el 7-hidroxibenzo[b]selenofeno $\mathbf{7 2}$.

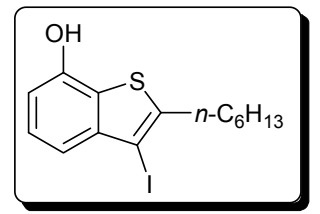

\section{2-Hexil-7-hidroxi-3-yodobenzo[b]tiofeno (67a)}

Sólido blanco.

P.f. $=78-80^{\circ} \mathrm{C}$.

Condiciones de reacción: 3 horas, $90^{\circ} \mathrm{C}$.

${ }^{1} \mathbf{H}$ RMN $\left(400 \mathrm{MHz}, \mathrm{CDCl}_{3}\right): \delta=7.33(\mathrm{~d}, J=7.8 \mathrm{~Hz}, 1 \mathrm{H}), 7.27(\mathrm{t}, J=7.8 \mathrm{~Hz}, 1 \mathrm{H}), 6.73(\mathrm{~d}, J=7.8 \mathrm{~Hz}, 1 \mathrm{H})$, $5.50(\mathrm{~s}, 1 \mathrm{H}), 2.98-2.93(\mathrm{~m}, 2 \mathrm{H}), 1.79-1.70(\mathrm{~m}, 2 \mathrm{H}), 1.49-1.40(\mathrm{~m}, 2 \mathrm{H}), 1.39-1.29(\mathrm{~m}, 4 \mathrm{H}), 0.91(\mathrm{t}, J=$ $6.9 \mathrm{~Hz}, 3 \mathrm{H}) \mathrm{ppm}$.

${ }^{13}$ C RMN (100.6 MHz, $\left.\mathrm{CDCl}_{3}\right): \delta=149.8(\mathrm{C}), 145.4(\mathrm{C}), 143.6(\mathrm{C}), 126.1(\mathrm{CH}), 125.5(\mathrm{C}), 118.2(\mathrm{CH}), 109.5$ $(\mathrm{CH}), 80.3(\mathrm{C}), 33.1\left(\mathrm{CH}_{2}\right), 31.7\left(\mathrm{CH}_{2}\right), 30.6\left(\mathrm{CH}_{2}\right), 28.9\left(\mathrm{CH}_{2}\right), 22.7\left(\mathrm{CH}_{2}\right), 14.2\left(\mathrm{CH}_{3}\right) \mathrm{ppm}$.

EMBR (IE), m/z (\%): $360\left(\mathrm{M}^{+}, 41\right), 289$ (94), 163 (100), 134 (44).

EMAR calculado para $\mathrm{C}_{14} \mathrm{H}_{17} \mathrm{IOS}$ : 360.0045 ; encontrado: 360.0041 . 


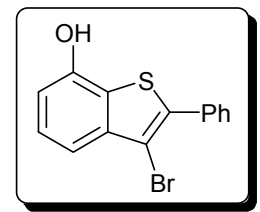

3-Bromo-3-fenil-7-hidroxibenzo[b]tiofeno (67b)

Líquido incoloro.

$\mathrm{R}_{\mathrm{f}}=0.33$ (hexano / AcOEt, 5 / 1).

Condiciones de reacción: 3 horas, $90^{\circ} \mathrm{C}$.

${ }^{1} \mathbf{H} \mathbf{R M N}\left(400 \mathrm{MHz}, \mathrm{CDCl}_{3}\right): \delta=7.78(\mathrm{~d}, J=7.9 \mathrm{~Hz}, 2 \mathrm{H}), 7.56-7.40(\mathrm{~m}, 4 \mathrm{H}), 7.35(\mathrm{t}, J=7.9 \mathrm{~Hz}, 1 \mathrm{H}), 6.81(\mathrm{~d}$, $J=7.9 \mathrm{~Hz}, 1 \mathrm{H}), 5.50(\mathrm{~s}, 1 \mathrm{H}) \mathrm{ppm}$.

${ }^{13}$ C RMN (100.6 MHz, $\left.\mathrm{CDCl}_{3}\right): \delta=149.9(\mathrm{C}), 141.5(\mathrm{C}), 138.9(\mathrm{C}), 133.2(\mathrm{C}), 129.8(2 \times \mathrm{CH}), 129.0(\mathrm{CH})$, $128.7(2 \times \mathrm{CH}), 126.6(\mathrm{CH}), 125.4(\mathrm{C}), 116.8(\mathrm{CH}), 110.2(\mathrm{CH}), 105.3(\mathrm{C}) \mathrm{ppm}$.

EMBR (IE), m/z (\%): $306\left(\mathrm{M}^{+}+2,100\right), 304\left(\mathrm{M}^{+}, 98\right), 281$ (14), 207 (88), 165 (14), 152 (27).

EMAR calculado para $\mathrm{C}_{14} \mathrm{H}_{9}$ BrOS: 303.9557 ; encontrado: 303.9551 .

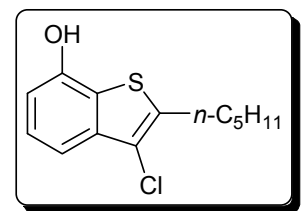

\section{3-Cloro-7-hidroxi-2-pentilbenzo $[b]$ tiofeno $(67 c)$}

Sólido blanco.

P.f. $=68-70^{\circ} \mathrm{C}$.

Condiciones de reacción: 4 horas, $90^{\circ} \mathrm{C}$.

${ }^{1} \mathbf{H} \mathbf{R M N}\left(300 \mathrm{MHz}, \mathrm{CDCl}_{3}\right): \delta=7.37(\mathrm{~d}, J=7.9 \mathrm{~Hz}, 1 \mathrm{H}), 7.28(\mathrm{t}, J=7.9 \mathrm{~Hz}, 1 \mathrm{H}), 6.75(\mathrm{~d}, J=7.9 \mathrm{~Hz}, 1 \mathrm{H})$, $5.84(\mathrm{sa}, 1 \mathrm{H}), 2.95(\mathrm{t}, J=7.6 \mathrm{~Hz}, 2 \mathrm{H}), 1.85-1.67(\mathrm{~m}, 2 \mathrm{H}), 1.52-1.33(\mathrm{~m}, 4 \mathrm{H}), 0.93(\mathrm{t}, J=6.7 \mathrm{~Hz}, 3 \mathrm{H})$ ppm.

${ }^{13}$ C RMN (75.4 MHz, $\mathrm{CDCl}_{3}$ ): $\delta=150.2(\mathrm{C}), 139.7(\mathrm{C}), 139.4(\mathrm{C}), 126.2(\mathrm{CH}), 123.9$ (C), $117.7(\mathrm{C}), 114.2$ $(\mathrm{CH}), 109.6(\mathrm{CH}), 31.3\left(\mathrm{CH}_{2}\right), 30.1\left(\mathrm{CH}_{2}\right), 28.4\left(\mathrm{CH}_{2}\right), 22.5\left(\mathrm{CH}_{2}\right), 14.1\left(\mathrm{CH}_{3}\right) \mathrm{ppm}$.

EMAR calculado para $\mathrm{C}_{13} \mathrm{H}_{15} \mathrm{ClOS}$ : 254.0532; encontrado: 254.0535.

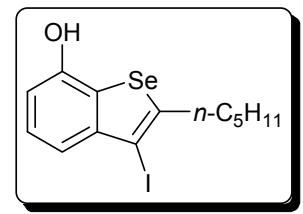

7-Hidroxi-2-pentil-3-yodobenzo[b]selenofeno (72)

Sólido morado.

P.f. $=90-92^{\circ} \mathrm{C}$.

Condiciones de reacción: 5 horas, $90^{\circ} \mathrm{C}$.

${ }^{1} \mathbf{H}$ RMN $\left(300 \mathrm{MHz}, \mathrm{CDCl}_{3}\right): \delta=7.44(\mathrm{~d}, J=7.9 \mathrm{~Hz}, 1 \mathrm{H}), 7.31(\mathrm{td}, J=7.9,1.0 \mathrm{~Hz}, 1 \mathrm{H}), 6.70(\mathrm{dd}, J=7.9,1.0$ $\mathrm{Hz}, 1 \mathrm{H}), 5.48(\mathrm{~s}, 1 \mathrm{H}), 3.03-2.97(\mathrm{~m}, 2 \mathrm{H}), 1.82-1.70(\mathrm{~m}, 2 \mathrm{H}), 1.51-1.33(\mathrm{~m}, 4 \mathrm{H}), 0.93(\mathrm{t}, J=6.7 \mathrm{~Hz}, 3 \mathrm{H})$ ppm.

${ }^{13}$ C RMN (75.4 MHz, $\left.\mathrm{CDCl}_{3}\right): \delta=151.7(\mathrm{C}), 148.6(\mathrm{C}), 145.2(\mathrm{C}), 126.6(\mathrm{CH}), 125.8(\mathrm{C}), 120.6(\mathrm{CH}), 109.6$ $(\mathrm{CH}), 83.2(\mathrm{C}), 35.9\left(\mathrm{CH}_{2}\right), 31.4\left(\mathrm{CH}_{2}\right), 31.2\left(\mathrm{CH}_{2}\right), 22.6\left(\mathrm{CH}_{2}\right), 14.1\left(\mathrm{CH}_{3}\right) \mathrm{ppm}$.

EMBR (IE), m/z (\%): $394\left(\mathrm{M}^{+}, 33\right), 337$ (52), 211 (79), 182 (33), 127 (70), 102 (100), 57 (65).

EMAR calculado para $\mathrm{C}_{13} \mathrm{H}_{15} \mathrm{IOSe}$ : 393.9333 ; encontrado: 393.9338 .

\section{A.5 Síntesis de los 3-halobenzo[b]selenofenos 7-oxígeno-funcionalizados 2-sustituidos 70 y 71}

\section{A.5.1 Preparación del N,N-dietilcarbamato de O-3-bromo-2-(metilseleno)fenilo 68}

La preparación de $\mathbf{6 8}$ se llevó a cabo de acuerdo con el procedimiento general para la síntesis de los $N, N$-dietilcarbamatos de $O$-3-halo-2-sulfanilfenilo 61. 


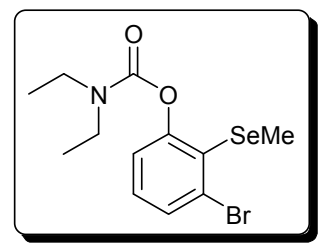

$N, N$-Dietilcarbamato de $O$-3-bromo-2-(metilseleno)fenilo (68)

Líquido incoloro.

$\mathrm{R}_{\mathrm{f}}=0.32$ (hexano / AcOEt, 5 / 1).

${ }^{1} \mathbf{H}$ RMN (300 MHz, $\left.\mathrm{CDCl}_{3}\right): \delta=7.47(\mathrm{dd}, J=7.9,1.4 \mathrm{~Hz}, 1 \mathrm{H}), 7.15(\mathrm{t}, J=7.9 \mathrm{~Hz}, 1 \mathrm{H}), 7.07(\mathrm{dd}, J=7.9,1.4$ $\mathrm{Hz}, 1 \mathrm{H}), 3.52-3.42(\mathrm{~m}, 2 \mathrm{H}), 3.41-3.31(\mathrm{~m}, 2 \mathrm{H}), 2.26(\mathrm{~s}, 3 \mathrm{H}), 1.28(\mathrm{t}, J=7.1 \mathrm{~Hz}, 3 \mathrm{H}), 1.19(\mathrm{t}, J=7.1 \mathrm{~Hz}$ 3H) $\mathrm{ppm}$.

${ }^{13} \mathbf{C}$ RMN (75.4 MHz, $\mathrm{CDCl}_{3}$ ): $\delta=154.1(\mathrm{C}), 153.7(\mathrm{C}), 131.8(\mathrm{C}), 130.2(\mathrm{CH}), 130.0(\mathrm{CH}), 127.5(\mathrm{C}), 122.0$ $(\mathrm{CH}), 42.3\left(\mathrm{CH}_{2}\right), 42.0\left(\mathrm{CH}_{2}\right), 14.2\left(\mathrm{CH}_{3}\right), 13.3\left(\mathrm{CH}_{3}\right), 9.2\left(\mathrm{CH}_{3}\right) \mathrm{ppm}$.

EMBR (IE), m/z (\%): 367 (M+2, 5), 365 (M+1, 6), 272 (3), 270 (4), 185 (11), 117 (10), 100 (100), 72 (70).

EMAR calculado para $\mathrm{C}_{12} \mathrm{H}_{16} \mathrm{BrNO}_{2} \mathrm{Se}$ : 364.9530 ; encontrado: 364.9528 .

\section{A.5.2 Preparación de los $N, N$-dietilcarbamatos de O-3-alquinil-2-(metilseleno)fenilo 69}

La preparación de 69 se llevó a cabo de acuerdo al procedimiento general para la síntesis de los alquinil carbamatos 62 .

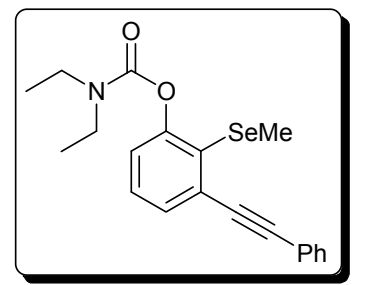

$\mathrm{N}, \mathrm{N}$-Dietilcarbamato de $\mathrm{O}$-3-(feniletinil)-2-(metilseleno)fenilo (69a)

Líquido marrón.

$\mathrm{R}_{\mathrm{f}}=0.44$ (hexano / AcOEt, 5 / 1).

${ }^{1} \mathbf{H}$ RMN (300 MHz, $\left.\mathrm{CDCl}_{3}\right): \delta=7.62-7.56(\mathrm{~m}, 2 \mathrm{H}), 7.45(\mathrm{dd}, J=7.9,1.3 \mathrm{~Hz}, 1 \mathrm{H}), 7.41-7.33(\mathrm{~m}, 3 \mathrm{H}), 7.29(\mathrm{t}$, $J=7.9 \mathrm{~Hz}, 1 \mathrm{H}), 7.12(\mathrm{dd}, J=7.9,1.3 \mathrm{~Hz}, 1 \mathrm{H}), 3.60-3.51(\mathrm{~m}, 2 \mathrm{H}), 3.50-3.40(\mathrm{~m}, 2 \mathrm{H}), 2.39(\mathrm{~d}, J=0.9 \mathrm{~Hz}$, $3 \mathrm{H}), 1.33(\mathrm{t}, J=7.0 \mathrm{~Hz}, 3 \mathrm{H}), 1.24(\mathrm{t}, J=7.0 \mathrm{~Hz}, 3 \mathrm{H}) \mathrm{ppm}$.

${ }^{13} \mathbf{C}$ RMN (75.4 MHz, $\left.\mathrm{CDCl}_{3}\right): \delta=153.9(\mathrm{C}), 153.0(\mathrm{C}), 131.6(2 \times \mathrm{CH}), 130.2(\mathrm{C}), 130.1(\mathrm{CH}), 128.8(\mathrm{CH})$, $128.5(\mathrm{CH}), 128.4(2 \times \mathrm{CH}), 127.7(\mathrm{C}), 123.2(\mathrm{C}), 122.9(\mathrm{CH}), 93.6(\mathrm{C}), 89.1(\mathrm{C}), 42.3\left(\mathrm{CH}_{2}\right), 42.1\left(\mathrm{CH}_{2}\right)$, $14.3\left(\mathrm{CH}_{3}\right), 13.4\left(\mathrm{CH}_{3}\right), 8.7\left(\mathrm{CH}_{3}\right) \mathrm{ppm}$.

EMBR (IE), m/z (\%): 387 (M+ , 2), 292 (8), 243 (6), 163 (12), 100 (100), 72 (53).

EMAR calculado para $\mathrm{C}_{20} \mathrm{H}_{21} \mathrm{NO}_{2} \mathrm{Se}$ : 387.0738; encontrado: 387.0742 .

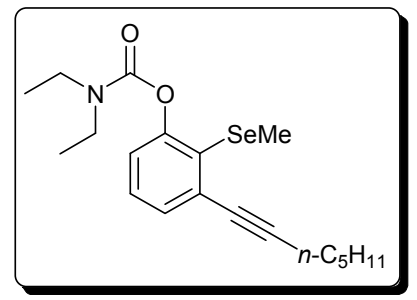

$N, N$-Dietilcarbamato de $O$-3-(1-heptinil)-2-(metilseleno)fenilo (69b)

Líquido incoloro.

$\mathrm{R}_{\mathrm{f}}=0.36$ (hexano / AcOEt, 5 / 1).

${ }^{1} \mathbf{H}$ RMN $\left(300 \mathrm{MHz}, \mathrm{CDCl}_{3}\right): \delta=7.29(\mathrm{~d}, J=7.8 \mathrm{~Hz}, 1 \mathrm{H}), 7.20(\mathrm{t}, J=7.8 \mathrm{~Hz}, 1 \mathrm{H}), 7.03(\mathrm{~d}, J=7.8 \mathrm{~Hz}, 1 \mathrm{H})$, 3.54-3.44 (m, 2H), 3.43-3.33 (m, 2H), $2.47(\mathrm{t}, J=7.0 \mathrm{~Hz}, 2 \mathrm{H}), 2.30(\mathrm{~d}, J=0.7 \mathrm{~Hz}, 3 \mathrm{H}), 1.69-1.58(\mathrm{~m}$, $2 \mathrm{H}), 1.53-1.41(\mathrm{~m}, 2 \mathrm{H}), 1.41-1.33(\mathrm{~m}, 2 \mathrm{H}), 1.29(\mathrm{t}, J=7.0 \mathrm{~Hz}, 3 \mathrm{H}), 1.20(\mathrm{t}, J=7.0 \mathrm{~Hz}, 3 \mathrm{H}), 0.91(\mathrm{t}, J=$ $7.2 \mathrm{~Hz}, 3 \mathrm{H}) \mathrm{ppm}$. 
${ }^{13} \mathbf{C}$ RMN (75.4 MHz, $\left.\mathrm{CDCl}_{3}\right): \delta=154.0(\mathrm{C}), 152.9(\mathrm{C}), 131.1(\mathrm{C}), 130.2(\mathrm{CH}), 128.7(\mathrm{CH}), 127.3(\mathrm{C}), 122.2$ $(\mathrm{CH}), 95.3(\mathrm{C}), 80.3(\mathrm{C}), 42.3\left(\mathrm{CH}_{2}\right), 42.1\left(\mathrm{CH}_{2}\right), 31.2\left(\mathrm{CH}_{2}\right), 28.4\left(\mathrm{CH}_{2}\right), 22.3\left(\mathrm{CH}_{2}\right), 19.7\left(\mathrm{CH}_{3}\right), 14.3$ $\left(\mathrm{CH}_{3}\right), 14.1\left(\mathrm{CH}_{2}\right), 13.4\left(\mathrm{CH}_{3}\right), 8.5\left(\mathrm{CH}_{3}\right) \mathrm{ppm}$.

EMBR (IE), m/z (\%): $366\left(\mathrm{M}^{+}, 1\right), 308$ (1), 211 (2), 129 (3), 115 (6), 100 (100), 72 (42).

EMAR calculado para $\mathrm{C}_{19} \mathrm{H}_{27} \mathrm{NO}_{2} \mathrm{Se}: 381.1207$; encontrado: 381.1208 .

\section{A.5.3 Preparación de los 7-(N,N-dietilcarbamoiloxi)-3-halobenzo[b]selenofenos-2-sustituidos 70 y $7 \mathbf{1}$}

La preparación de $\mathbf{7 0}$ y $\mathbf{7 1}$ se llevó a cabo de acuerdo al procedimiento general empleado en la síntesis de los 7-(N,N-dietilcarbamoiloxi)-3-halobenzo[ $b]$ tiofenos-2-sustituidos 63 у 64.

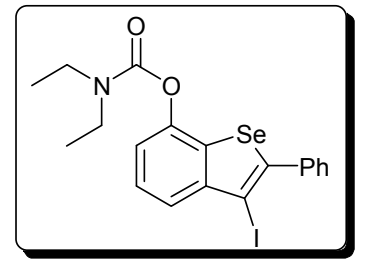

7-(N,N-Dietilcarbamoiloxi)-2-fenil-3-yodobenzo/b/selenofeno (70a) Sólido amarillo. P.f. $=102-104^{\circ} \mathrm{C}$.

${ }^{1} \mathbf{H}$ RMN (300 MHz, CDCl 3$): \delta=7.79(\mathrm{dd}, J=8.0,0.9 \mathrm{~Hz}, 1 \mathrm{H}), 7.67-7.60(\mathrm{~m}, 2 \mathrm{H}), 7.57-7.41(\mathrm{~m}, 4 \mathrm{H}), 7.32(\mathrm{dd}, J=$ 8.0, $0.9 \mathrm{~Hz}, 1 \mathrm{H}), 3.56-3.48(\mathrm{~m}, 2 \mathrm{H}), 3.47-3.38(\mathrm{~m}, 2 \mathrm{H}), 1.34(\mathrm{t}, J=7.0 \mathrm{~Hz}, 3 \mathrm{H}), 1.25(\mathrm{t}, J=7.0 \mathrm{~Hz}, 3 \mathrm{H}) \mathrm{ppm}$.

${ }^{13}$ C RMN (75.4 MHz, $\left.\mathrm{CDCl}_{3}\right): \delta=153.0$ (C), 147.7 (C), 145.4 (C), 144.6 (C), 136.7 (C), 133.0 (C), 130.0 $(2 \times \mathrm{CH}), 128.9(\mathrm{CH}), 128.5(2 \times \mathrm{CH}), 126.7(\mathrm{CH}), 125.6(\mathrm{CH}), 117.9(\mathrm{CH}), 82.5(\mathrm{C}), 42.6\left(\mathrm{CH}_{2}\right), 42.3$ $\left(\mathrm{CH}_{2}\right), 14.5\left(\mathrm{CH}_{3}\right), 13.5\left(\mathrm{CH}_{3}\right) \mathrm{ppm}$.

EMBR (IE), m/z (\%): $499\left(\mathrm{M}^{+}, 1\right), 243$ (3), 163 (6), 100 (100), 72 (47).

EMAR calculado para $\mathrm{C}_{19} \mathrm{H}_{18} \mathrm{INO}_{2} \mathrm{Se}$ : 498.9548 ; encontrado: 498.9548.

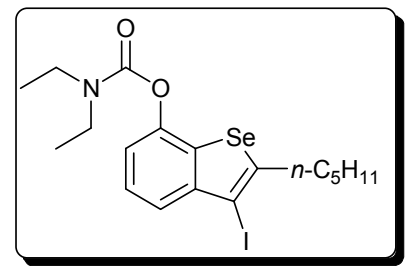

7-( $N, N$-Dietilcarbamoiloxi)-2-pentil-3-yodobenzo/b/selenofeno (70b) Líquido incoloro.

$\mathrm{R}_{\mathrm{f}}=0.29$ (hexano / AcOEt, 5 / 1).

${ }^{1} \mathbf{H}$ RMN $\left(300 \mathrm{MHz}, \mathrm{CDCl}_{3}\right): \delta=7.64(\mathrm{dd}, J=8.0,0.9 \mathrm{~Hz}, 1 \mathrm{H}), 7.45(\mathrm{t}, J=8.0 \mathrm{~Hz}, 1 \mathrm{H}), 7.22(\mathrm{dd}, J=8.0,0.9$ $\mathrm{Hz}, 1 \mathrm{H}), 3.55-3.46(\mathrm{~m}, 2 \mathrm{H}), 3.45-3.36(\mathrm{~m}, 2 \mathrm{H}), 3.03-2.96(\mathrm{~m}, 2 \mathrm{H}), 1.81-1.69(\mathrm{~m}, 2 \mathrm{H}), 1.49-1.37$ (m, $4 \mathrm{H}), 1.33(\mathrm{t}, J=7.1 \mathrm{~Hz}, 3 \mathrm{H}), 1.24(\mathrm{t}, J=7.1 \mathrm{~Hz}, 3 \mathrm{H}), 0.93(\mathrm{t}, J=7.1 \mathrm{~Hz}, 3 \mathrm{H}) \mathrm{ppm}$.

${ }^{13}$ C RMN (75.4 MHz, $\left.\mathrm{CDCl}_{3}\right): \delta=153.0$ (C), 148.1 (C), 147.8 (C), 144.9 (C), $131.3(\mathrm{C}), 126.2(\mathrm{CH}), 124.2$ $(\mathrm{CH}), 117.3(\mathrm{CH}), 82.9(\mathrm{C}), 42.6\left(\mathrm{CH}_{2}\right), 42.2\left(\mathrm{CH}_{2}\right), 35.8\left(\mathrm{CH}_{2}\right), 31.3\left(\mathrm{CH}_{2}\right), 31.1\left(\mathrm{CH}_{2}\right), 22.5\left(\mathrm{CH}_{2}\right), 14.5$ $\left(\mathrm{CH}_{3}\right), 14.1\left(\mathrm{CH}_{3}\right), 13.5\left(\mathrm{CH}_{3}\right) \mathrm{ppm}$.

EMBR (IE), m/z (\%): $493\left(\mathrm{M}^{+}, 2\right), 393$ (2), 308 (3), 115 (3), 100 (100), 72 (42).

EMAR calculado para $\mathrm{C}_{18} \mathrm{H}_{24} \mathrm{INO}_{2} \mathrm{Se}: 493.0017$; encontrado: 493.0025.

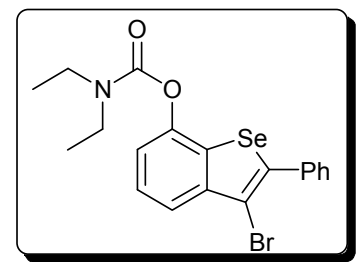

3-Bromo-7-( $N, N$-dietilcarbamoiloxi)-2-fenilbenzo/b/selenofeno (71) Líquido incoloro.

$\mathrm{R}_{\mathrm{f}}=0.39$ (hexano / AcOEt, 5 / 1). 
${ }^{1} \mathbf{H}$ RMN (300 MHz, $\left.\mathrm{CDCl}_{3}\right): \delta=7.78(\mathrm{dd}, J=8.0,0.9 \mathrm{~Hz}, 1 \mathrm{H}), 7.73-7.66(\mathrm{~m}, 2 \mathrm{H}), 7.57-7.38(\mathrm{~m}, 4 \mathrm{H}), 7.31$ $(\mathrm{dd}, J=8.0,0.9 \mathrm{~Hz}, 1 \mathrm{H}), 3.57-3.48(\mathrm{~m}, 2 \mathrm{H}), 3.47-3.37(\mathrm{~m}, 2 \mathrm{H}), 1.34(\mathrm{t}, J=6.9 \mathrm{~Hz}, 3 \mathrm{H}), 1.25(\mathrm{t}, J=6.9$ $\mathrm{Hz}, 3 \mathrm{H}) \mathrm{ppm}$.

${ }^{13}$ C RMN (75.4 MHz, $\left.\mathrm{CDCl}_{3}\right): \delta=153.0$ (C), 147.8 (C), 142.9 (C), 141.0 (C), 134.8 (C), 131.5 (C), 129.9 $(2 \times \mathrm{CH}), 128.9(\mathrm{CH}), 128.7(2 \times \mathrm{CH}), 126.7(\mathrm{CH}), 122.8(\mathrm{CH}), 118.2(\mathrm{CH}), 106.8(\mathrm{C}), 42.7\left(\mathrm{CH}_{2}\right), 42.3$ $\left(\mathrm{CH}_{2}\right), 14.5\left(\mathrm{CH}_{3}\right), 13.5\left(\mathrm{CH}_{3}\right) \mathrm{ppm}$.

EMBR (IE), m/z (\%): $453\left(\mathrm{M}^{+}+2,2\right), 451\left(\mathrm{M}^{+}, 2\right), 323$ (2), 241 (4), 163 (5), 100 (100), 72 (47).

EMAR calculado para $\mathrm{C}_{19} \mathrm{H}_{18} \mathrm{BrNO}_{2} \mathrm{Se}$ : 450.9686 ; encontrado: 450.9688 .

\section{A.6 Aplicaciones sintéticas de los 7-(N,N-dietilcarbamoiloxi)-3-halobenzo[b]tiofenos 63 y 64}

\section{A.6.1 Preparación de los benzo[b]tiofenos 3-deuterados 73}

A una disolución de $63(0.3 \mathrm{mmol})$ en THF ó $\mathrm{Et}_{2} \mathrm{O}$ seco $(3 \mathrm{~mL})$ a $-78{ }^{\circ} \mathrm{C}$ se adiciona $n$-BuLi (206 $\mu \mathrm{L}$ de una disolución $1.6 \mathrm{M}$ en hexano, $0.33 \mathrm{mmol}$ ). Después de 1 hora a esta temperatura se adiciona MeOD y la mezcla resultante se agita 1 hora a $-78^{\circ} \mathrm{C}$. Se deja que la mezcla alcance temperatura ambiente durante 2 horas y se hidroliza con $\mathrm{H}_{2} \mathrm{O}$. La fase acuosa se extrae con AcOEt (3 $\times 10 \mathrm{~mL}$ ), se seca sobre $\mathrm{Na}_{2} \mathrm{SO}_{4}$ anhidro y se concentra a presión reducida. El residuo resultante se purifica por columna de cromatografía (hexano / AcOEt) permitiendo obtener los benzo[b]tiofenos 3deuterados 73 .

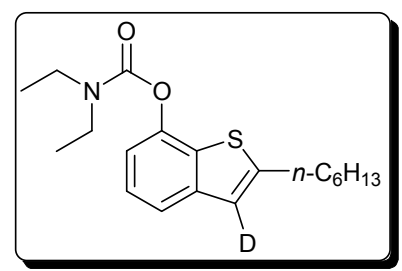

3-Deuterio-7-( $N, N$-dietilcarbamoiloxi)-2-hexilbenzo/b/tiofeno (73a)

Líquido incoloro.

$\mathrm{R}_{\mathrm{f}}=0.47$ (hexano / AcOEt, 5 / 1).

${ }^{1} \mathbf{H}$ RMN $\left(300 \mathrm{MHz}, \mathrm{CDCl}_{3}\right): \delta=7.49(\mathrm{dd}, J=7.9,0.9 \mathrm{~Hz}, 1 \mathrm{H}), 7.31(\mathrm{t}, J=7.9 \mathrm{~Hz}, 1 \mathrm{H}), 7.14(\mathrm{dd}, J=7.9,0.9$ $\mathrm{Hz}, 1 \mathrm{H}), 3.61-3.52(\mathrm{~m}, 2 \mathrm{H}), 3.52-3.42(\mathrm{~m}, 2 \mathrm{H}), 2.91-2.85(\mathrm{~m}, 2 \mathrm{H}), 1.82-1.71(\mathrm{~m}, 2 \mathrm{H}), 1.46-1.29(\mathrm{~m}$, 9H), $1.24(\mathrm{t}, J=7.1 \mathrm{~Hz}, 3 \mathrm{H}), 0.90(\mathrm{t}, J=7.1 \mathrm{~Hz}, 3 \mathrm{H}) \mathrm{ppm}$.

${ }^{13}$ C RMN (75.4 MHz, $\left.\mathrm{CDCl}_{3}\right): \delta=153.3(\mathrm{C}), 147.1(\mathrm{C}), 146.0(\mathrm{C}), 142.5(\mathrm{C}), 131.9(\mathrm{C}), 125.1(\mathrm{CH}), 120.8(\mathrm{C})$, $119.5(\mathrm{CH}), 116.1(\mathrm{CH}), 42.5\left(\mathrm{CH}_{2}\right), 42.2\left(\mathrm{CH}_{2}\right), 31.7\left(\mathrm{CH}_{2}\right), 31.2\left(\mathrm{CH}_{2}\right), 30.8\left(\mathrm{CH}_{2}\right), 28.9\left(\mathrm{CH}_{2}\right), 22.7$ $\left(\mathrm{CH}_{2}\right), 14.4\left(\mathrm{CH}_{3}\right), 14.2\left(\mathrm{CH}_{3}\right), 13.5\left(\mathrm{CH}_{3}\right) \mathrm{ppm}$.

EMBR (IE), m/z (\%): $334\left(\mathrm{M}^{+}, 28\right), 333\left(\mathrm{M}^{+}-1,4\right), 234$ (5), 164 (10), 135 (20), 100 (100), 72 (37).

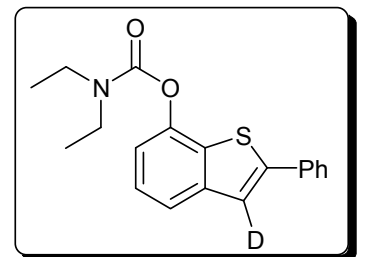

3-Deuterio-7-( $N, N$-dietilcarbamoiloxi)-2-fenilbenzo/b/tiofeno (73b)

Sólido blanco.

P.f. $=88-90^{\circ} \mathrm{C}$.

${ }^{1} \mathbf{H}$ RMN (300 MHz, $\mathrm{CDCl}_{3}$ ): $\delta=7.77-7.68(\mathrm{~m} \mathrm{2H}), 7.61$ (dd, $\left.J=7.8,0,8 \mathrm{~Hz}, 1 \mathrm{H}\right), 7.48-7.32(\mathrm{~m}, 4 \mathrm{H}), 7.24$ (ddd, $J=7.8$, $1.6,0.8 \mathrm{~Hz}, 1 \mathrm{H}), 3.62-3.52(\mathrm{~m}, 2 \mathrm{H}), 3.51-3.42(\mathrm{~m}, 2 \mathrm{H}), 1.39(\mathrm{t}, J=6.9 \mathrm{~Hz}, 3 \mathrm{H}), 1.27(\mathrm{t}, J=6.9 \mathrm{~Hz}, 3 \mathrm{H}) \mathrm{ppm}$.

${ }^{13}$ C RMN (75.4 MHz, $\mathrm{CDCl}_{3}$ ): $\delta=153.3$ (C), 146.1 (C), 144.5 (C), 142.8 (C), 134.1 (C), 132.2 (C), 129.0 $(2 \times \mathrm{CH}), 128.5(\mathrm{CH}), 126.6(2 \times \mathrm{CH}), 125.6(\mathrm{CH}), 120.5(\mathrm{CH}), 117.1(\mathrm{CH}), 42.6\left(\mathrm{CH}_{2}\right), 42.3\left(\mathrm{CH}_{2}\right), 14.5$ $\left(\mathrm{CH}_{3}\right), 13.6\left(\mathrm{CH}_{3}\right) \mathrm{ppm}$. 
EMBR (IE), m/z (\%): 326 (M+, 15), 325 (1), 226 (8), 198 (61), 166 (28), 100 (100), 72 (53).

EMAR calculado para $\mathrm{C}_{19} \mathrm{H}_{18} \mathrm{DNO}_{2} \mathrm{~S}$ : 326.1199 ; encontrado: 326.1193 .

\section{A.6.2 Sintesis del 7-(N,N-dietilcarbamoiloxi)-2,3-difenilbenzo[b]tiofeno 74}

A una mezcla de 64e $(121 \mathrm{mg}, 0.3 \mathrm{mmol})$, ácido fenilborónico (56 $\mathrm{mg}, 0.45 \mathrm{mmol})$ y $\mathrm{Pd}\left(\mathrm{PPh}_{3}\right)_{4}(11 \mathrm{mg}, 3 \mathrm{~mol} \%)$ en DME $(5 \mathrm{~mL})$ bajo $\mathrm{N}_{2}$ se añade $\mathrm{Na}_{2} \mathrm{CO}_{3}(48 \mathrm{mg}, 0.45 \mathrm{mmol})$ en $\mathrm{H}_{2} \mathrm{O}(2$ $\mathrm{mL}$ ). La mezcla de reacción se agita a $80^{\circ} \mathrm{C}$ durante 15 horas (el progreso de la reacción se monitoriza por CG-EM). A continuación se añade $\mathrm{CH}_{2} \mathrm{Cl}_{2}(10 \mathrm{~mL})$ y $\mathrm{H}_{2} \mathrm{O}$ a la mezcla de reacción fría. La fase acuosa separada se extrae con $\mathrm{CH}_{2} \mathrm{Cl}_{2}(3 \times 15 \mathrm{~mL})$. La combinación de fases orgánicas se seca sobre $\mathrm{Na}_{2} \mathrm{SO}_{4}$ anhidro y se evapora a presión reducida. El residuo se purifica mediante columna de cromatografía (hexano / AcOEt, 10 / 1) para dar 74.

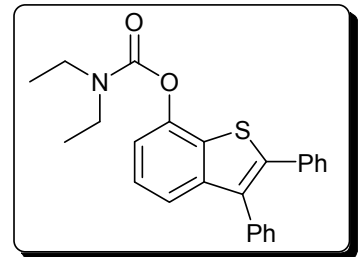

7-(N,N-Dietilcarbamoiloxi)-2,3-difenilbenzo/b/tiofeno (74)

Sólido blanco.

P.f. $=118-120^{\circ} \mathrm{C}$.

${ }^{1} \mathbf{H}$ RMN (300 MHz, $\left.\mathrm{CDCl}_{3}\right): \delta=7.48(\mathrm{dd}, J=7.9,1.1 \mathrm{~Hz}, 1 \mathrm{H}), 7.45-7.33(\mathrm{~m}, 8 \mathrm{H}), 7.31-7.24(\mathrm{~m}, 4 \mathrm{H})$, 3.64-3.55 (m, 2H), 3.54-3.45 (m, 2H), $1.42(\mathrm{t}, J=6.9 \mathrm{~Hz}, 3 \mathrm{H}), 1.30$ (t, $J=6.9 \mathrm{~Hz}, 3 \mathrm{H}) \mathrm{ppm}$.

${ }^{13}$ C RMN (75.4 MHz, $\left.\mathrm{CDCl}_{3}\right): \delta=153.3$ (C), 145.9 (C), 143.1 (C), 139.9 (C), 135.4 (C), 134.1 (C), 133.7 (C), $131.7(\mathrm{C}), 130.4(2 \times \mathrm{CH}), 129.7(2 \times \mathrm{CH}), 128.7(2 \times \mathrm{CH}), 128.4(2 \times \mathrm{CH}), 127.9(\mathrm{CH}), 127.5(\mathrm{CH}), 125.6$ $(\mathrm{CH}), 120.4(\mathrm{CH}), 117.4(\mathrm{CH}), 42.6\left(\mathrm{CH}_{2}\right), 42.3\left(\mathrm{CH}_{2}\right), 14.5\left(\mathrm{CH}_{3}\right), 13.5\left(\mathrm{CH}_{3}\right) \mathrm{ppm}$

EMBR (IE), m/z (\%): $401\left(\mathrm{M}^{+}, 23\right), 271$ (6), 239 (7), 100 (100), 72 (33)

EMAR calculado para $\mathrm{C}_{25} \mathrm{H}_{23} \mathrm{NO}_{2} \mathrm{~S}$ : 401.1450; encontrado: 401.1437.

\section{A.6.3 Procedimiento para la sintesis del 7-(N,N-dietilcarbamoiloxi)-2-fenil-3-(2-furanil) benzo[b] tiofeno 75}

$\mathrm{Pd}(\mathrm{OAc})_{2}(1.3 \mathrm{mg}, 2 \mathrm{~mol} \%)$ y XPhos $(5.7 \mathrm{mg}, 4 \mathrm{~mol} \%)$ previamente mezclados, CsF (100 mg, $0.66 \mathrm{mmol}), 64 \mathrm{e}(121 \mathrm{mg}, 0.3 \mathrm{mmol})$ y tributil-(2-furanil)estannano $(118 \mathrm{mg}, 0.33 \mathrm{mmol})$ en DME $(2$ $\mathrm{mL}$ ) se agitan bajo $\mathrm{N}_{2}$ a $80{ }^{\circ} \mathrm{C}$ durante 4 horas (el final del acoplamiento se monitoriza por CG-EM). A continuación, se permite que la mezcla de reacción alcance temperatura ambiente y el crudo se filtra a través de celita y se lava con AcOEt $(20 \mathrm{~mL})$. El filtrado se concentra a presión reducida y el residuo se purifica mediante columna de cromatografía (hexano / AcOEt, 10 / 1) obteniéndose 75.

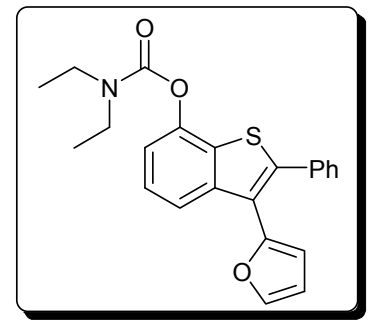

7-( $N, N$-Dietilcarbamoiloxi)-2-fenil-3-(2-furanil)benzo[b]tiofeno (75)

Líquido amarillo.

$\mathrm{R}_{\mathrm{f}}=0.31$ (hexano / AcOEt, 5 / 1). 
${ }^{1} \mathbf{H}$ RMN (300 MHz, $\left.\mathrm{CDCl}_{3}\right): \delta=7.88(\mathrm{dd}, J=8.0,0.9 \mathrm{~Hz}, 1 \mathrm{H}), 7.53-7.34(\mathrm{~m}, 7 \mathrm{H}), 7.31(\mathrm{dd}, J=8.0,0.9 \mathrm{~Hz}$, $1 \mathrm{H}), 6.49-6.45(\mathrm{~m}, 1 \mathrm{H}), 6.32(\mathrm{dd}, J=3.3,0.7 \mathrm{~Hz}, 1 \mathrm{H}), 3.60-3.51(\mathrm{~m}, 2 \mathrm{H}), 3.50-3.41(\mathrm{~m}, 2 \mathrm{H}), 1.37(\mathrm{t}, J=$ $6.9 \mathrm{~Hz}, 3 \mathrm{H}), 1.26(\mathrm{t}, J=6.9 \mathrm{~Hz}, 3 \mathrm{H}) \mathrm{ppm}$.

${ }^{13}$ C RMN (75.4 MHz, $\left.\mathrm{CDCl}_{3}\right): \delta=153.2(\mathrm{C}), 148.7(\mathrm{C}), 145.8(\mathrm{C}), 142.0(\mathrm{CH}), 141.8(\mathrm{C}), 141.5(\mathrm{C}), 134.2(\mathrm{C})$, $131.7(\mathrm{C}), 129.4(2 \times \mathrm{CH}), 128.6(2 \times \mathrm{CH}), 128.5(\mathrm{CH}), 125.9(\mathrm{CH}), 123.2(\mathrm{C}), 120.6(\mathrm{CH}), 117.4(\mathrm{CH})$, $111.1(\mathrm{CH}), 109.7(\mathrm{CH}), 42.6\left(\mathrm{CH}_{2}\right), 42.3\left(\mathrm{CH}_{2}\right), 14.5\left(\mathrm{CH}_{3}\right), 13.5\left(\mathrm{CH}_{3}\right) \mathrm{ppm}$.

EMAR calculado para $\mathrm{C}_{23} \mathrm{H}_{21} \mathrm{NO}_{3} \mathrm{~S}: 391.1242$; encontrado: 391.1248 .

\section{A.6.4 Preparación de los 3-alquinilbenzo[b]tiofenos $\mathbf{7 6}$}

Una mezcla de 63b ó 63f (0.3 mmol), alquino (0.45 mmol), $\mathrm{PdCl}_{2}\left(\mathrm{PPh}_{3}\right)_{2}(6 \mathrm{mg}, 3 \mathrm{~mol} \%), \mathrm{CuI}$ ( $3 \mathrm{mg}, 5 \mathrm{~mol} \%)$ y Et ${ }_{2} \mathrm{NH}(47 \mu \mathrm{L}, 0.45 \mathrm{mmol})$ en $\mathrm{DMF}(1.5 \mathrm{~mL})$ se agita bajo $\mathrm{N}_{2}$ a $50{ }^{\circ} \mathrm{C}$ el tiempo necesario hasta la desaparición del sustrato de partida, monitorizado mediante CG-EM. A continuación se adiciona $\mathrm{HCl}(10 \mathrm{~mL}$ de una disolución $0.5 \mathrm{M})$ y $\mathrm{CH}_{2} \mathrm{Cl}_{2}(10 \mathrm{~mL})$ a la mezcla de reacción fría. La fase acuosa separada se extrae con $\mathrm{CH}_{2} \mathrm{Cl}_{2}(3 \times 15 \mathrm{~mL})$. La combinación de fases orgánicas se lava con $\mathrm{H}_{2} \mathrm{O}(2 \times 20 \mathrm{~mL})$. La fase orgánica se seca sobre $\mathrm{Na}_{2} \mathrm{SO}_{4}$ anhidro y se concentra a presión reducida. El residuo resultante se purifica mediante columna de cromatografía (hexano / AcOEt) obteniéndose 76.

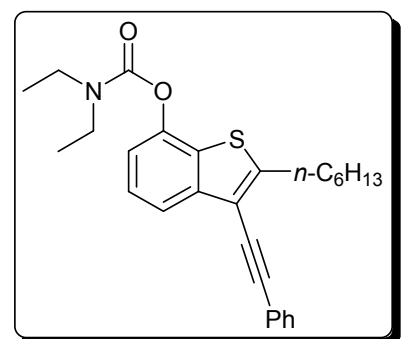

7-(N,N-Dietilcarbamoiloxi)-3-(feniletinil)-2-hexilbenzo[b]tiofeno

\section{(76a)}

Líquido incoloro.

$\mathrm{R}_{\mathrm{f}}=0.38$ (hexano / AcOEt, 5 / 1).

${ }^{1} \mathbf{H}$ RMN (300 MHz, $\left.\mathrm{CDCl}_{3}\right): \delta=7.77(\mathrm{dd}, J=7.9,0.9 \mathrm{~Hz}, 1 \mathrm{H}), 7.64-7.59(\mathrm{~m}, 2 \mathrm{H}), 7.47-7.36(\mathrm{~m}, 4 \mathrm{H}), 7.25$ $(\mathrm{dd}, J=7.9,0.9 \mathrm{~Hz}, 1 \mathrm{H}), 3.59-3.49(\mathrm{~m}, 2 \mathrm{H}), 3.49-3.40(\mathrm{~m}, 2 \mathrm{H}), 3.12(\mathrm{t}, J=7.5 \mathrm{~Hz}, 2 \mathrm{H}), 1.82(\mathrm{~m}, 2 \mathrm{H})$, $1.54-1.32(\mathrm{~m}, 9 \mathrm{H}), 1.26(\mathrm{t}, J=6.4 \mathrm{~Hz}, 3 \mathrm{H}), 0.91(\mathrm{t}, J=7.0 \mathrm{~Hz}, 3 \mathrm{H}) \mathrm{ppm}$.

${ }^{13} \mathbf{C}$ RMN (75.4 MHz, $\left.\mathrm{CDCl}_{3}\right): \delta=153.2(\mathrm{C}), 151.1(\mathrm{C}), 146.0(\mathrm{C}), 142.1(\mathrm{C}), 131.6(2 \times \mathrm{CH}), 130.1(\mathrm{C}), 128.5$ $(2 \times \mathrm{CH}), 128.3(\mathrm{CH}), 125.7(\mathrm{CH}), 123.5(\mathrm{C}), 119.4(\mathrm{CH}), 117.2(\mathrm{CH}), 115.6(\mathrm{C}), 94.5(\mathrm{C}), 82.7(\mathrm{C}), 42.6$ $\left(\mathrm{CH}_{2}\right), 42.2\left(\mathrm{CH}_{2}\right), 31.6\left(\mathrm{CH}_{2}\right), 31.1\left(\mathrm{CH}_{2}\right), 30.0\left(\mathrm{CH}_{2}\right), 28.9\left(\mathrm{CH}_{2}\right), 22.7\left(\mathrm{CH}_{2}\right), 14.4\left(\mathrm{CH}_{3}\right), 14.2\left(\mathrm{CH}_{3}\right)$, $13.5\left(\mathrm{CH}_{3}\right) \mathrm{ppm}$.

EMBR (IE), m/z (\%): 433 (M+18), 234 (7), 207 (17), 100 (100), 72 (29).

EMAR calculado para $\mathrm{C}_{27} \mathrm{H}_{31} \mathrm{NO}_{2} \mathrm{~S}$ : 433.2075; encontrado: 433.2070 .

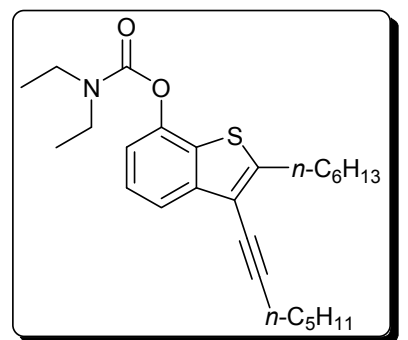

7-(N,N-Dietilcarbamoiloxi)-3-(1-heptinil)-2-hexilbenzo[b]tiofeno

(76b)

Líquido marrón.

$\mathrm{R}_{\mathrm{f}}=0.49$ (hexano / AcOEt, 4 / 1).

${ }^{1} \mathbf{H}$ RMN (300 MHz, $\mathrm{CDCl}_{3}$ ): $\delta=7.64(\mathrm{dd}, J=7.9,0.9 \mathrm{~Hz}, 1 \mathrm{H}), 7.38(\mathrm{dt}, J=7.9,0.9 \mathrm{~Hz}, 1 \mathrm{H}), 7.19(\mathrm{dd}, J=7.9,0.9$ $\mathrm{Hz}, 1 \mathrm{H}), 3.56-3.47(\mathrm{~m}, 2 \mathrm{H}), 3.47-3.38(\mathrm{~m}, 2 \mathrm{H}), 3.01(\mathrm{t}, J=7.6 \mathrm{~Hz}, 2 \mathrm{H}), 2.53$ (t, $J=7.0 \mathrm{~Hz}, 2 \mathrm{H}), 1.81-1.62$ $(\mathrm{m}, 4 \mathrm{H}), 1.57-1.47(\mathrm{~m}, 2 \mathrm{H}), 1.45-1.29(\mathrm{~m}, 11 \mathrm{H}), 1.24(\mathrm{t}, J=7.1 \mathrm{~Hz}, 3 \mathrm{H}), 0.99-0.85(\mathrm{~m}, 6 \mathrm{H}) \mathrm{ppm}$. 
${ }^{13} \mathbf{C}$ RMN (75.4 MHz, $\left.\mathrm{CDCl}_{3}\right): \delta=153.2(\mathrm{C}), 149.6(\mathrm{C}), 145.9(\mathrm{C}), 142.5(\mathrm{C}), 130.0(\mathrm{C}), 125.4(\mathrm{CH}), 119.3$ $(\mathrm{CH}), 116.9(\mathrm{CH}), 116.3(\mathrm{C}), 95.5(\mathrm{C}), 73.8(\mathrm{C}), 42.6\left(\mathrm{CH}_{2}\right), 42.2\left(\mathrm{CH}_{2}\right), 31.6\left(\mathrm{CH}_{2}\right), 31.2\left(\mathrm{CH}_{2}\right), 31.0$ $\left(\mathrm{CH}_{2}\right), 29.9\left(\mathrm{CH}_{2}\right), 28.9\left(\mathrm{CH}_{2}\right), 28.8\left(\mathrm{CH}_{2}\right), 22.7\left(\mathrm{CH}_{2}\right), 22.4\left(\mathrm{CH}_{2}\right), 19.7\left(\mathrm{CH}_{2}\right), 14.4\left(\mathrm{CH}_{3}\right), 14.22\left(\mathrm{CH}_{3}\right)$, $14.16\left(\mathrm{CH}_{3}\right), 13.5\left(\mathrm{CH}_{3}\right) \mathrm{ppm}$.

EMBR (IE), m/z (\%): 427 (M+19), 171 (3), 100 (100), 72 (21).

EMAR calculado para $\mathrm{C}_{26} \mathrm{H}_{37} \mathrm{NO}_{2} \mathrm{~S}$ : 427.2545 ; encontrado: 427.2544 .

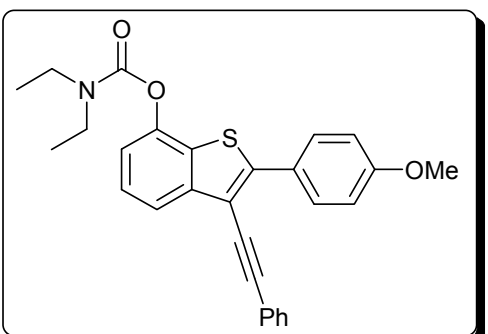

7-(N,N-Dietilcarbamoiloxi)-3-(feniletinil)-2-(4-metoxifenil) benzo $[b]$ tiofeno (76c)

Sólido marrón.

P.f. $=92-94^{\circ} \mathrm{C}$.

${ }^{1} \mathbf{H}$ RMN $\left(300 \mathrm{MHz}, \mathrm{CDCl}_{3}\right): \delta=8.09-8.00(\mathrm{~m}, 2 \mathrm{H}), 7.87(\mathrm{~d}, J=7.9 \mathrm{~Hz}, 1 \mathrm{H}), 7.64-7.58(\mathrm{~m}, 2 \mathrm{H}), 7.49$ (td, $J=$ $7.9,0.6 \mathrm{~Hz}, 1 \mathrm{H}), 7.44-7.35(\mathrm{~m}, 3 \mathrm{H}), 7.30(\mathrm{~d}, J=7.9 \mathrm{~Hz}, 1 \mathrm{H}), 7.05-7.00(\mathrm{~m}, 2 \mathrm{H}), 3.87(\mathrm{~s}, 3 \mathrm{H}), 3.60-3.51$ $(\mathrm{m}, 2 \mathrm{H}), 3.51-3.42(\mathrm{~m}, 2 \mathrm{H}), 1.39(\mathrm{t}, J=7.0 \mathrm{~Hz}, 3 \mathrm{H}), 1.28(\mathrm{t}, J=7.0 \mathrm{~Hz}, 3 \mathrm{H}) \mathrm{ppm}$.

${ }^{13} \mathbf{C}$ RMN (75.4 MHz, $\left.\mathrm{CDCl}_{3}\right): \delta=160.2(\mathrm{C}), 153.1(\mathrm{C}), 146.5$ (C), $145.9(\mathrm{C}), 143.2(\mathrm{C}), 131.6(2 \times \mathrm{CH}), 129.9(\mathrm{C})$, $129.8(2 \times \mathrm{CH}), 128.5(2 \times \mathrm{CH}), 128.4(\mathrm{CH}), 126.3(\mathrm{C}), 126.0(\mathrm{CH}), 123.4(\mathrm{C}), 119.9(\mathrm{CH}), 117.7(\mathrm{CH}), 114.1$ $(2 \times \mathrm{CH}), 112.8(\mathrm{C}), 94.5(\mathrm{C}), 84.3(\mathrm{C}), 55.4\left(\mathrm{CH}_{3}\right), 42.6\left(\mathrm{CH}_{2}\right), 42.3\left(\mathrm{CH}_{2}\right), 14.4\left(\mathrm{CH}_{3}\right), 13.5\left(\mathrm{CH}_{3}\right) \mathrm{ppm}$.

EMBR (IE), m/z (\%): $455\left(\mathrm{M}^{+}, 49\right), 327$ (16), 282 (12), 207 (42), 100 (100), 72 (36).

EMAR calculado para $\mathrm{C}_{28} \mathrm{H}_{25} \mathrm{NO}_{3} \mathrm{~S}$ : 455.1555 ; encontrado: 455.1564 .

\section{A.6.5 Preparación del 3-ciano-7-(N,N-dietilcarbamoiloxi)-2-fenilbenzo[b]tiofeno 77}

Una mezcla de 63e (113 mg, $0.25 \mathrm{mmol}), \mathrm{Pd}(\mathrm{OAc})_{2}(1 \mathrm{mg}, 5 \mathrm{~mol} \%), \mathrm{K}_{4}\left[\mathrm{Fe}(\mathrm{CN})_{6}\right] \cdot 3 \mathrm{H}_{2} \mathrm{O}(28$ $\mathrm{mg}, 0.066 \mathrm{mmol})$ y $\mathrm{Na}_{2} \mathrm{CO}_{3}(26 \mathrm{mg}, 0.25 \mathrm{mmol})$ en DMA $(1 \mathrm{~mL})$ se agita bajo $\mathrm{N}_{2}$ a $120{ }^{\circ} \mathrm{C}$ durante 3 horas. A continuación se añade AcOEt $(10 \mathrm{~mL})$ y $\mathrm{H}_{2} \mathrm{O}(10 \mathrm{~mL})$ sobre la mezcla de reacción fría. La fase acuosa separada se extrae con AcOEt $(3 \times 15 \mathrm{~mL})$. La combinación de fases orgánicas se seca sobre $\mathrm{Na}_{2} \mathrm{SO}_{4}$ anhidro y se concentra a presión reducida. El residuo resultante se purifica mediante columna de cromatografía (hexano / AcOEt, 6/1) para dar 77.

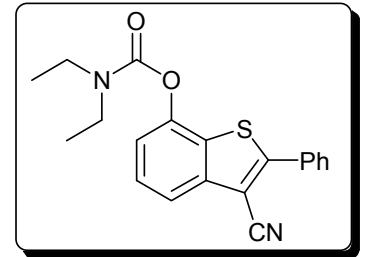

3-Ciano-7-( $N, N$-dietilcarbamoiloxi)-2-fenilbenzo/b/tiofeno (77)

Líquido incoloro.

$\mathrm{R}_{\mathrm{f}}=0.28$ (hexano / AcOEt, 5 / 1).

${ }^{1}$ H RMN $\left(300 \mathrm{MHz}, \mathrm{CDCl}_{3}\right): \delta=7.93-7.86(\mathrm{~m}, 2 \mathrm{H}), 7.79(\mathrm{~d}, J=8.0 \mathrm{~Hz}, 1 \mathrm{H}), 7.59-7.47(\mathrm{~m}, 4 \mathrm{H}), 7.35(\mathrm{~d}, J=$ $8.0 \mathrm{~Hz}, 1 \mathrm{H}), 3.58-3.49(\mathrm{~m}, 2 \mathrm{H}), 3.48-3.39(\mathrm{~m}, 2 \mathrm{H}), 1.35(\mathrm{t}, J=7.1 \mathrm{~Hz}, 3 \mathrm{H}), 1.25(\mathrm{t}, J=7.1 \mathrm{~Hz}, 3 \mathrm{H}) \mathrm{ppm}$.

${ }^{13} \mathbf{C}$ RMN (75.4 MHz, $\mathrm{CDCl}_{3}$ ): $\delta=155.4$ (C), 152.7 (C), 146.1 (C), 141.0 (C), 131.3 (C), 130.7 (CH), 130.5 (C), $129.4(2 \times \mathrm{CH}), 128.3(2 \times \mathrm{CH}), 127.3(\mathrm{CH}), 119.3(\mathrm{CH}), 118.8(\mathrm{CH}), 115.0(\mathrm{C}), 102.4(\mathrm{C}), 42.7\left(\mathrm{CH}_{2}\right), 42.3$ $\left(\mathrm{CH}_{2}\right), 14.4\left(\mathrm{CH}_{3}\right), 13.4\left(\mathrm{CH}_{3}\right) \mathrm{ppm}$.

EMBR (IE), m/z (\%): 350 (M+, 2), 250 (3), 222 (19), 190 (6), 100 (100), 72 (42).

EMAR calculado para for $\mathrm{C}_{20} \mathrm{H}_{18} \mathrm{~N}_{2} \mathrm{O}_{2} \mathrm{~S}$ : 350.1089 ; encontrado: 350.1104 . 


\section{B Síntesis de benzo[b]tiofenos a partir de o-alquinilbromobencenos}

\section{B.1 Preparación de los derivados de 2-alquinil-3-bromofenoles 51, 78 y 82}

Método A (Válido para los o-alquinilbromobencenos 51ae-ce y 78)

Una mezcla del correspondiente bromoyodobenceno 49a-c ó 17ca (1 mmol), alquino (1.2 $\mathrm{mmol}), \mathrm{PdCl}_{2}\left(\mathrm{PPh}_{3}\right)_{2}(21 \mathrm{mg}, 3 \mathrm{~mol} \%)$, CuI $(9 \mathrm{mg}, 5 \mathrm{~mol} \%)$ y Et ${ }_{2} \mathrm{NH}(156 \mu \mathrm{L}, 1.5 \mathrm{mmol})$ en DMF (4 $\mathrm{mL}$ ) se agita bajo $\mathrm{N}_{2}$ a $50{ }^{\circ} \mathrm{C}$ el tiempo necesario hasta la desaparición del sustrato de partida (3-7 horas), monitorizado por CG-EM. A continuación se adiciona $\mathrm{H}_{2} \mathrm{O}(20 \mathrm{~mL})$ y $\mathrm{CH}_{2} \mathrm{Cl}_{2}(20 \mathrm{~mL})$ a la mezcla de reacción fría. La fase acuosa separada se extrae con $\mathrm{CH}_{2} \mathrm{Cl}_{2}(3 \times 15 \mathrm{~mL})$. $\mathrm{La}$ combinación de fases orgánicas se lava con $\mathrm{H}_{2} \mathrm{O}(2 \times 30 \mathrm{~mL})$. La fase orgánica se seca sobre $\mathrm{Na}_{2} \mathrm{SO}_{4}$ anhidro y se concentra a presión reducida. El residuo resultante se purifica mediante columna de cromatografia (hexano / AcOEt) obteniendose los compuestos 51ae-ce, 78.

Método B (Válido para los o-alquinilbromobencenos $82 \boldsymbol{a}-\boldsymbol{k}$ )

El procedimiento empleado es igual que el método A pero la reacción se lleva a cabo a temperatura ambiente (1-5 horas). Condiciones: bromoyodobenceno 87a-d (3 mmol), alquino (3.6 mmol), $\mathrm{PdCl}_{2}\left(\mathrm{PPh}_{3}\right)_{2}(63 \mathrm{mg}, 3 \mathrm{~mol} \%)$, CuI (28 mg, $5 \mathrm{~mol} \%$ ) y Et ${ }_{2} \mathrm{NH}(469 \mu \mathrm{L}, 4.5 \mathrm{mmol})$ en DMF $(12 \mathrm{~mL})$.

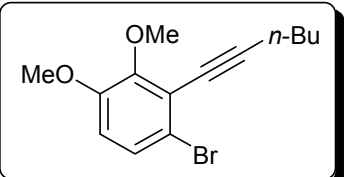

1-Bromo-2-(1-hexinil)-3,4-dimetoxibenceno (51ae)

Líquido incoloro.

$\mathrm{R}_{\mathrm{f}}=0.40$ (hexano / AcOEt, 20 / 1).

${ }^{1}$ H RMN (300 MHz, $\left.\mathrm{CDCl}_{3}\right): \delta=7.21(\mathrm{~d}, J=8.8 \mathrm{~Hz}, 1 \mathrm{H}), 6.69(\mathrm{~d}, J=8.8 \mathrm{~Hz}, 1 \mathrm{H}), 3.87(\mathrm{~s}, 3 \mathrm{H}), 3.80(\mathrm{~s}, 3 \mathrm{H})$, $2.51(\mathrm{t}, J=6.8 \mathrm{~Hz}, 2 \mathrm{H}), 1.69-1.46(\mathrm{~m}, 4 \mathrm{H}), 0.94(\mathrm{t}, J=7.2 \mathrm{~Hz}, 3 \mathrm{H}) \mathrm{ppm}$.

${ }^{13} \mathbf{C}$ RMN (75.4 MHz, $\left.\mathrm{CDCl}_{3}\right): \delta=152.0(\mathrm{C}), 151.4(\mathrm{C}), 127.3(\mathrm{CH}), 121.2(\mathrm{C}), 116.5(\mathrm{C}), 112.8(\mathrm{CH}), 100.0$ (C), $75.4(\mathrm{C}), 60.9\left(\mathrm{CH}_{3}\right), 56.1\left(\mathrm{CH}_{3}\right), 30.7\left(\mathrm{CH}_{2}\right), 22.0\left(\mathrm{CH}_{2}\right), 19.6\left(\mathrm{CH}_{2}\right), 13.7\left(\mathrm{CH}_{3}\right) \mathrm{ppm}$.

EMBR (IE), m/z (\%): $298\left(\mathrm{M}^{+}+2,65\right), 296\left(\mathrm{M}^{+}, 60\right), 239$ (76), 187 (55), 174 (64), 158 (44), 131 (73), 115 (100).

EMAR calculado para $\mathrm{C}_{14} \mathrm{H}_{17} \mathrm{BrO}_{2}: 296.0412$; encontrado: 296.0413 .

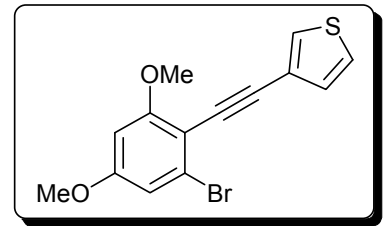

1-Bromo-2-(3-tieniletinil)-3,5-dimetoxibenceno (51be)

Sólido rojo.

${ }^{1} \mathbf{H}$ RMN $\left(300 \mathrm{MHz}, \mathrm{CDCl}_{3}\right): \delta=7.56(\mathrm{dd}, J=2.9,1.1 \mathrm{~Hz}, 1 \mathrm{H}), 7.31-7.22(\mathrm{~m}, 2 \mathrm{H}), 6.76(\mathrm{~d}, J=2.3 \mathrm{~Hz}, 1 \mathrm{H})$, $6.38(\mathrm{~d}, J=2.3 \mathrm{~Hz}, 1 \mathrm{H}), 3.85(\mathrm{~s}, 3 \mathrm{H}), 3.79(\mathrm{~s}, 3 \mathrm{H}) \mathrm{ppm}$.

${ }^{13}$ C RMN (75.4 MHz, $\left.\mathrm{CDCl}_{3}\right): \delta=161.7(\mathrm{C}), 160.6(\mathrm{C}), 130.0(\mathrm{CH}), 128.5(\mathrm{CH}), 127.4(\mathrm{C}), 125.2(\mathrm{CH}), 122.6$ (C), $109.2(\mathrm{CH}), 107.7(\mathrm{C}), 97.7(\mathrm{CH}), 91.5(\mathrm{C}), 84.1(\mathrm{C}), 56.2\left(\mathrm{CH}_{3}\right), 55.7\left(\mathrm{CH}_{3}\right) \mathrm{ppm}$.

EMBR (IE), m/z (\%): 324 (M+2, 98), 322 (M+1 100), 308 (22), 200 (33), 185 (57), 171 (48), 113 (43), 69 (66).

EMAR calculado para $\mathrm{C}_{14} \mathrm{H}_{11} \mathrm{BrO}_{2} \mathrm{~S}: 321.9663$; encontrado: 321.9666 . 


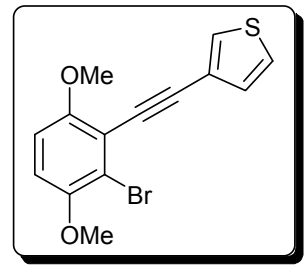

\section{2-Bromo-3-(3-tieniletinil)-1,4-dimetoxibenceno (51ce)}

Sólido blanco.

P.f. $=100-102^{\circ} \mathrm{C}$

${ }^{1} \mathbf{H}$ RMN (300 MHz, $\left.\mathrm{CDCl}_{3}\right): \delta=7.60(\mathrm{~m}, 1 \mathrm{H}), 7.31-7.24(\mathrm{~m}, 2 \mathrm{H}), 6.83-6.73(\mathrm{~m}, 2 \mathrm{H}), 3.83(\mathrm{~s}, 3 \mathrm{H}), 3.83(\mathrm{~s}, 3 \mathrm{H}) \mathrm{ppm}$.

${ }^{13}$ C RMN (75.4 MHz, $\left.\mathrm{CDCl}_{3}\right): \delta=155.0(\mathrm{C}), 150.5(\mathrm{C}), 130.0(\mathrm{CH}), 129.1(\mathrm{CH}), 125.4(\mathrm{CH}), 122.2(\mathrm{C}), 116.4$ (C), $116.2(\mathrm{C}), 112.1(\mathrm{CH}), 109.9(\mathrm{CH}), 93.5(\mathrm{C}), 84.2(\mathrm{C}), 56.8\left(\mathrm{CH}_{3}\right), 56.5\left(\mathrm{CH}_{3}\right) \mathrm{ppm}$.

EMBR (IE), m/z (\%): 324 (M+2, 67), 322 (M+ $\left.\mathrm{M}^{+}, 67\right), 309$ (19), 307 (21), 266 (27), 264 (26), 185 (100), 171 (78), 157 (61), $113(57)$.

EMAR calculado para $\mathrm{C}_{14} \mathrm{H}_{11} \mathrm{BrO}_{2} \mathrm{~S}: 321.9663$; encontrado: 321.9665 .

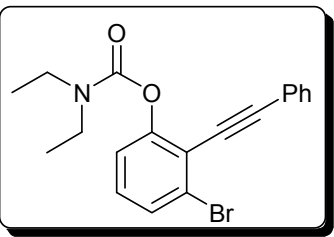

$N, N$-Dietilcarbamato de $O$-3-bromo-2-(feniletinil)fenilo (78)

Sólido rojo.

${ }^{1} \mathbf{H}$ RMN $\left(300 \mathrm{MHz}, \mathrm{CDCl}_{3}\right): \delta=7.74-7.41(\mathrm{~m}, 3 \mathrm{H}), 7.41-7.24(\mathrm{~m}, 3 \mathrm{H}), 7.24-7.04(\mathrm{~m}, 2 \mathrm{H}), 3.50(\mathrm{q}, J=7.0 \mathrm{~Hz}$, $2 \mathrm{H}), 3.39$ (q, $J=7.0 \mathrm{~Hz}, 2 \mathrm{H}), 1.29(\mathrm{t}, J=7.0 \mathrm{~Hz}, 3 \mathrm{H}), 1.17(\mathrm{t}, J=7.0 \mathrm{~Hz}, 3 \mathrm{H}) \mathrm{ppm}$.

${ }^{13}$ C RMN (75.4 MHz, $\left.\mathrm{CDCl}_{3}\right): \delta=153.0(\mathrm{C}), 131.5(2 \times \mathrm{CH}), 129.3(\mathrm{CH}), 129.1(\mathrm{CH}), 128.7(\mathrm{CH}), 128.3(2 \times \mathrm{CH}), 126.0$ (C), $122.8(\mathrm{C}), 121.6(\mathrm{CH}), 120.1(\mathrm{C}), 98.1(\mathrm{C}), 83.8(\mathrm{C}), 42.4\left(\mathrm{CH}_{2}\right), 42.0\left(\mathrm{CH}_{2}\right), 14.2\left(\mathrm{CH}_{3}\right), 13.3\left(\mathrm{CH}_{3}\right) \mathrm{ppm}$.

EMBR (IE), m/z (\%): $373\left(\mathrm{M}^{+}+2,17\right), 371\left(\mathrm{M}^{+}, 18\right), 163(26), 100(100)$.

EMAR calculado para $\mathrm{C}_{19} \mathrm{H}_{18} \mathrm{BrNO}_{2}: 371.0521$; encontrado: 371.0225 .

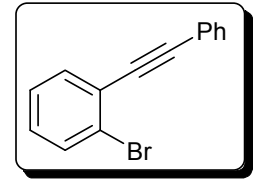

1-Bromo-2-(feniletinil)benceno $(82 a)^{281}$

Líquido incoloro.

$\mathrm{R}_{\mathrm{f}}=0.52$ (hexano / AcOEt, $10 / 1$ ).

${ }^{1} \mathbf{H}$ RMN (300 MHz, $\left.\mathrm{CDCl}_{3}\right): \delta=7.67-7.54(\mathrm{~m}, 4 \mathrm{H}), 7.43-7.34(\mathrm{~m}, 3 \mathrm{H}), 7.31(\mathrm{td}, J=7.6,1.2 \mathrm{~Hz}, 1 \mathrm{H}), 7.19$ (td, $J=7.6,1.7 \mathrm{~Hz}, 1 \mathrm{H}) \mathrm{ppm}$.

${ }^{13}$ C RMN (75.4 MHz, $\left.\mathrm{CDCl}_{3}\right): \delta=133.3(\mathrm{CH}), 132.6(\mathrm{C}), 132.5(\mathrm{CH}), 131.8(2 \times \mathrm{CH}), 129.5(\mathrm{CH}), 1288(\mathrm{CH})$, $128.55(\mathrm{C}), 128.49(2 \times \mathrm{CH}), 127.1(\mathrm{CH}), 125.7(\mathrm{C}), 125.5(\mathrm{C}), 123.0(\mathrm{C}) \mathrm{ppm}$.

EMBR (IE), m/z (\%): $258\left(\mathrm{M}^{+}+2,51\right), 256$ (M+ 49$), 176$ (100), 150 (53), 126 (27), 98 (39), 50 (67).

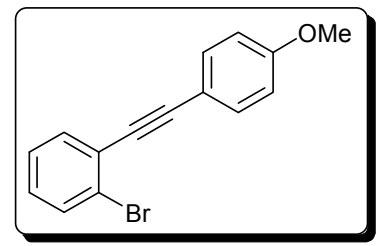

1-Bromo-2-(4-metoxifeniletinil)benceno (82b)

Sólido blanco.

P.f. $=88-90^{\circ} \mathrm{C}\left(\right.$ lit. $\left.^{282}=87^{\circ} \mathrm{C}\right)$.

${ }^{281}$ R. L. Letsinger, T. E. Feare, T. J. Savereide, J. R. Nazy, J. Org. Chem. 1961, 26, 1271.

${ }^{282}$ A. K. Verma, T. Kersharwani, J. Singh, V. Tandon, R. C. Larock, Angew. Chem., Int. Ed. 2009, 48, 1138. 
${ }^{1} \mathbf{H}$ RMN (300 MHz, $\left.\mathrm{CDCl}_{3}\right): \delta=7.61(\mathrm{~d}, J=8.0 \mathrm{~Hz}, 1 \mathrm{H}), 7.57-7.49(\mathrm{~m}, 3 \mathrm{H}), 7.28(\mathrm{t}, J=7.5 \mathrm{~Hz}, 1 \mathrm{H}), 7.16(\mathrm{t}, J$ $=7.5 \mathrm{~Hz}, 1 \mathrm{H}), 6.90(\mathrm{~d}, J=8.7 \mathrm{~Hz}, 2 \mathrm{H}), 3.83(\mathrm{~s}, 3 \mathrm{H}) \mathrm{ppm}$.

${ }^{13} \mathbf{C}$ RMN (75.4 MHz, $\left.\mathrm{CDCl}_{3}\right): \delta=160.0(\mathrm{C}), 133.3(2 \times \mathrm{CH}), 133.1(\mathrm{CH}), 132.5(\mathrm{CH}), 129.1(\mathrm{CH}), 127.1(\mathrm{CH})$, $125.8(\mathrm{C}), 125.5(\mathrm{C}), 115.1(\mathrm{C}), 114.1(2 \times \mathrm{CH}), 94.2(\mathrm{C}), 87.0(\mathrm{C}), 55.4\left(\mathrm{CH}_{3}\right) \mathrm{ppm}$.

EMBR (IE), m/z (\%): $288\left(\mathrm{M}^{+}+2,27\right), 286\left(\mathrm{M}^{+}, 27\right), 273$ (10), 271 (13), 163 (100), 137 (21).

EMAR calculado para $\mathrm{C}_{15} \mathrm{H}_{11} \mathrm{BrO}$ : 285.9993; encontrado: 285.9989 .

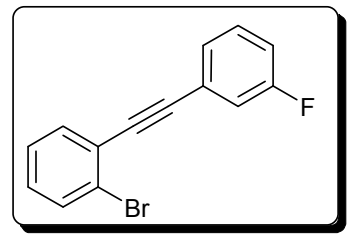

1-Bromo-2-(3-fluorofeniletinil)benceno (82c)

Líquido incoloro.

$\mathrm{R}_{\mathrm{f}}=0.56$ (hexano / AcOEt, $10 / 1$ ).

${ }^{1}$ H RMN (300 MHz, $\left.\mathrm{CDCl}_{3}\right): \delta=7.63(\mathrm{dd}, J=8.0,1.3 \mathrm{~Hz}, 1 \mathrm{H}), 7.57(\mathrm{dd}, J=7.7,1.7 \mathrm{~Hz}, 1 \mathrm{H}), 7.40(\mathrm{dt}, J=7.7$, $1.3 \mathrm{~Hz}, 1 \mathrm{H}), 7.35-7.26(\mathrm{~m}, 3 \mathrm{H}), 7.19(\mathrm{td}, J=7.7,1.7 \mathrm{~Hz}, 1 \mathrm{H}), 7.13-7.04(\mathrm{~m}, 1 \mathrm{H}) \mathrm{ppm}$.

${ }^{13}$ C RMN (75.4 MHz, $\left.\mathrm{CDCl}_{3}\right): \delta=162.4(\mathrm{~d}, J=246.7 \mathrm{~Hz}, \mathrm{C}), 133.3(\mathrm{CH}), 132.5(\mathrm{CH}), 130.0(\mathrm{~d}, J=8.6 \mathrm{~Hz}$, $\mathrm{CH}), 129.8(\mathrm{CH}), 127.6(\mathrm{~d}, J=3.1 \mathrm{~Hz}, \mathrm{CH}), 127.1(\mathrm{CH}), 125.8(\mathrm{C}), 125.0(\mathrm{C}), 124.8(\mathrm{~d}, J=9.5 \mathrm{~Hz}, \mathrm{C})$, $118.5(\mathrm{~d}, J=22.8 \mathrm{~Hz}, \mathrm{CH}), 116.0(\mathrm{~d}, J=21.2 \mathrm{~Hz}, \mathrm{CH}), 92.6$ (d, $J=3.5 \mathrm{~Hz}, \mathrm{C}), 89.0(\mathrm{C}) \mathrm{ppm}$.

EMBR (IE), m/z (\%): $276\left(\mathrm{M}^{+}+2,91\right), 274\left(\mathrm{M}^{+}, 100\right), 168$ (40), 144 (18), 50 (48).

EMAR calculado para $\mathrm{C}_{14} \mathrm{H}_{8} \mathrm{BrF}$ : 273.9793; encontrado: 273.9785 .

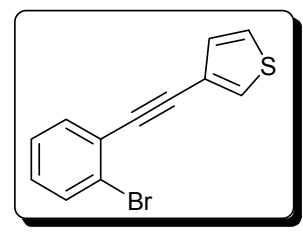

1-Bromo-2-(3-tieniletinil)benceno (82d) ${ }^{282}$

Sólido marrón.

P.f. $=36-38^{\circ} \mathrm{C}$.

${ }^{1} \mathbf{H}$ RMN $\left(300 \mathrm{MHz}, \mathrm{CDCl}_{3}\right): \delta=7.67-7.59(\mathrm{~m}, 2 \mathrm{H}), 7.55(\mathrm{dd}, J=7.6,1.7 \mathrm{~Hz}, 1 \mathrm{H}), 7.35-7.24(\mathrm{~m}, 3 \mathrm{H})$, 7.22-7.14 (m, 1H) ppm.

${ }^{13} \mathbf{C}$ RMN (75.4 MHz, $\left.\mathrm{CDCl}_{3}\right): \delta=133.3(\mathrm{CH}), 132.5(\mathrm{CH}), 129.9(\mathrm{CH}), 129.4(\mathrm{CH}), 129.3(\mathrm{CH}), 127.1(\mathrm{CH})$, $125.6(\mathrm{CH}), 125.5(\mathrm{C}), 125.4(\mathrm{C}), 122.0(\mathrm{C}), 89.2(\mathrm{C}), 87.6(\mathrm{C}) \mathrm{ppm}$.

EMBR (IE), m/z (\%): $264\left(\mathrm{M}^{+}+2,68\right), 262\left(\mathrm{M}^{+}, 59\right), 225$ (16), 182 (14), 139 (100), 63 (33).

EMAR calculado para $\mathrm{C}_{12} \mathrm{H}_{7} \mathrm{BrS}: 261.9452$; encontrado: 261.9445 .

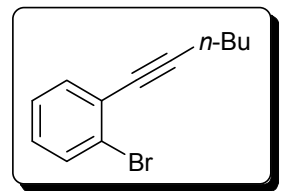

1-Bromo-2-(1-hexinil)benceno (82e $)^{283}$

Líquido incoloro.

$\mathrm{R}_{\mathrm{f}}=0.65$ (hexano / AcOEt, $\left.10 / 1\right)$.

${ }^{1} \mathbf{H}$ RMN (300 MHz, $\left.\mathrm{CDCl}_{3}\right): \delta=7.56(\mathrm{dd}, J=8.0,1.2 \mathrm{~Hz}, 1 \mathrm{H}), 7.44(\mathrm{dd}, J=7.7,1.7 \mathrm{~Hz}, 1 \mathrm{H}), 7.22(\mathrm{td}, J=7.7,1.2$ $\mathrm{Hz}, 1 \mathrm{H}), 7.10(\mathrm{td}, J=7.7,1.7 \mathrm{~Hz}, 1 \mathrm{H}), 2.48(\mathrm{t}, J=6.8 \mathrm{~Hz}, 2 \mathrm{H}), 1.68-1.48(\mathrm{~m}, 4 \mathrm{H}), 0.97(\mathrm{t}, J=7.2 \mathrm{~Hz}, 3 \mathrm{H}) \mathrm{ppm}$.

${ }^{13} \mathbf{C}$ RMN (75.4 MHz, $\left.\mathrm{CDCl}_{3}\right): \delta=133.3(\mathrm{CH}), 132.3(\mathrm{CH}), 128.7(\mathrm{CH}), 126.9(\mathrm{CH}), 126.1(\mathrm{C}), 125.5(\mathrm{C}), 95.6$ (C), $79.4(\mathrm{C}), 30.7\left(\mathrm{CH}_{2}\right), 22.1\left(\mathrm{CH}_{2}\right), 19.4\left(\mathrm{CH}_{2}\right), 13.7\left(\mathrm{CH}_{3}\right) \mathrm{ppm}$.

EMBR (IE), m/z (\%): 238 (M+2, 16), 236 (M+16), 223 (13), 221 (12), 195 (28), 193 (32), 142 (77), 115 (100).

EMAR calculado para $\mathrm{C}_{12} \mathrm{H}_{13} \mathrm{Br}$ : 236.0201; encontrado: 236.0201.

${ }^{283}$ C. Körner, P. Starkov, T. D. Sheppard, J. Am. Chem. Soc. 2010, 132, 5968. 


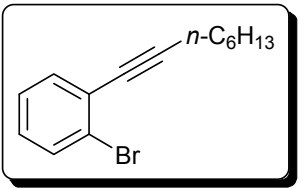

1-Bromo-2-(1-octinil)benceno (82f) ${ }^{244 a}$

Líquido incoloro.

$\mathrm{R}_{\mathrm{f}}=0.61$ (hexano / AcOEt, $10 / 1$ ).

${ }^{1} \mathbf{H}$ RMN $\left(300 \mathrm{MHz}, \mathrm{CDCl}_{3}\right): \delta=7.56(\mathrm{dd}, J=8.0,1.2 \mathrm{~Hz}, 1 \mathrm{H}), 7.44(\mathrm{dd}, J=7.7,1.7 \mathrm{~Hz}, 1 \mathrm{H}), 7.22(\mathrm{td}, J=7.7$, $1.2 \mathrm{~Hz}, 1 \mathrm{H}), 7.14-7.07(\mathrm{~m}, 1 \mathrm{H}), 2.47(\mathrm{t}, J=6.9 \mathrm{~Hz}, 2 \mathrm{H}), 1.71-1.59(\mathrm{~m}, 2 \mathrm{H}), 1.58-1.45(\mathrm{~m}, 2 \mathrm{H})$, $1.42-1.28(\mathrm{~m}, 4 \mathrm{H}), 0.93(\mathrm{t}, J=6.9 \mathrm{~Hz}, 3 \mathrm{H}) \mathrm{ppm}$.

${ }^{13} \mathbf{C}$ RMN (75.4 MHz, $\left.\mathrm{CDCl}_{3}\right): \delta=133.3(\mathrm{CH}), 132.3(\mathrm{CH}), 128.7(\mathrm{CH}), 127.0(\mathrm{CH}), 126.2(\mathrm{C}), 125.5(\mathrm{C}), 95.7$ (C), $79.5(\mathrm{C}), 31.5\left(\mathrm{CH}_{2}\right), 28.7\left(\mathrm{CH}_{2}\right), 28.6\left(\mathrm{CH}_{2}\right), 22.7\left(\mathrm{CH}_{2}\right), 19.7\left(\mathrm{CH}_{2}\right), 14.2\left(\mathrm{CH}_{3}\right) \mathrm{ppm}$.

EMBR (IE), m/z (\%): $266\left(\mathrm{M}^{+}+2,12\right), 264$ (M+1 13), 221 (21), 195 (36), 142 (68), 129 (84), 115 (100), 55 (32).

EMAR calculado para $\mathrm{C}_{14} \mathrm{H}_{17} \mathrm{Br}$ : 264.0514; encontrado: 264.0508 .

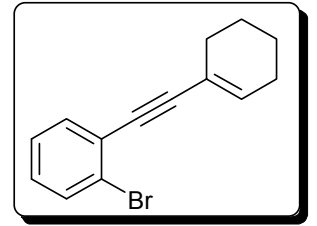

1-Bromo-2-(1-ciclohexeniletinil)benceno (82g)

Líquido incoloro.

$\mathrm{R}_{\mathrm{f}}=0.65$ (hexano).

${ }^{1} \mathbf{H}$ RMN $\left(300 \mathrm{MHz}, \mathrm{CDCl}_{3}\right): \delta=7.57(\mathrm{dd}, J=8.0,1.0 \mathrm{~Hz}, 1 \mathrm{H}), 7.48-7.42(\mathrm{~m}, 1 \mathrm{H}), 7.22(\mathrm{tt}, J=7.7,1.0 \mathrm{~Hz}$, $1 \mathrm{H}), 7.10(\mathrm{tdd}, J=8.0,1.7,1.0 \mathrm{~Hz}, 1 \mathrm{H}), 6.34-6.26(\mathrm{~m}, 1 \mathrm{H}), 2.33-2.24(\mathrm{~m}, 2 \mathrm{H}), 2.20-2.05(\mathrm{~m}, 2 \mathrm{H})$, $1.75-1.56(\mathrm{~m}, 4 \mathrm{H}) \mathrm{ppm}$.

${ }^{13} \mathbf{C}$ RMN (75.4 MHz, $\left.\mathrm{CDCl}_{3}\right): \delta=136.0(\mathrm{CH}), 132.9(\mathrm{CH}), 132.2(\mathrm{CH}), 128.8(\mathrm{CH}), 126.9(\mathrm{CH}), 125.8(\mathrm{C})$, $125.4(\mathrm{C}), 120.6(\mathrm{C}), 95.9(\mathrm{C}), 85.6(\mathrm{C}), 29.0\left(\mathrm{CH}_{2}\right), 25.8\left(\mathrm{CH}_{2}\right), 22.3\left(\mathrm{CH}_{2}\right), 21.5\left(\mathrm{CH}_{2}\right) \mathrm{ppm}$.

EMBR (IE), m/z (\%): $262\left(\mathrm{M}^{+}+2,19\right), 260\left(\mathrm{M}^{+}, 32\right), 217$ (16), 196 (18), 165 (100), 151 (46), 63 (80), 51 (60).

EMAR calculado para $\mathrm{C}_{14} \mathrm{H}_{13} \mathrm{Br}$ : 260.0201; encontrado: 260.0195 .

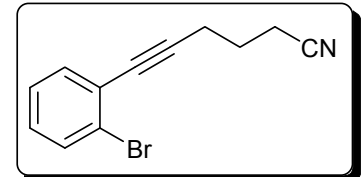

6-(2-Bromofenil)-5-hexinonitrilo (82h)

Líquido incoloro.

$\mathrm{R}_{\mathrm{f}}=0.36$ (hexano / AcOEt, 5 / 1).

${ }^{1} \mathbf{H}$ RMN (300 MHz, $\left.\mathrm{CDCl}_{3}\right): \delta=7.57-7.49(\mathrm{~m}, 1 \mathrm{H}), 7.45-7.33(\mathrm{~m}, 1 \mathrm{H}), 7.27-7.17(\mathrm{~m}, 1 \mathrm{H}), 7.17-7.06(\mathrm{~m}, 1 \mathrm{H})$, $2.67-2.54(\mathrm{~m}, 4 \mathrm{H}), 2.03-1.88(\mathrm{~m}, 2 \mathrm{H}) \mathrm{ppm}$.

${ }^{13} \mathbf{C}$ RMN (75.4 MHz, $\left.\mathrm{CDCl}_{3}\right): \delta=133.3(\mathrm{CH}), 132.3(\mathrm{CH}), 129.2(\mathrm{CH}), 127.1(\mathrm{CH}), 125.5(\mathrm{C}), 125.2(\mathrm{C})$, $119.3(\mathrm{C}), 92.0(\mathrm{C}), 81.1(\mathrm{C}), 24.5\left(\mathrm{CH}_{2}\right), 18.7\left(\mathrm{CH}_{2}\right), 16.2\left(\mathrm{CH}_{2}\right) \mathrm{ppm}$.

EMBR (IE), m/z (\%): 249 (M+2, 20), 247 (M+1 20), 208 (20), 193 (41), 167 (56), 128 (88), 52 (100).

EMAR calculado para $\mathrm{C}_{12} \mathrm{H}_{10} \mathrm{BrN}$ : 246.9997; encontrado: 246.9998 .

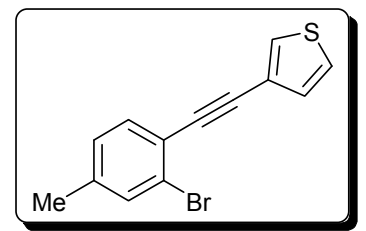

2-Bromo-4-metil-1-(3-tieniletinil)benceno (82i)

Sólido blanco.

P.f. $=48-50^{\circ} \mathrm{C}$.

${ }^{1} \mathbf{H}$ RMN $\left(400 \mathrm{MHz}, \mathrm{CDCl}_{3}\right): \delta=7.57(\mathrm{dd}, J=3.0,1.1 \mathrm{~Hz}, 1 \mathrm{H}), 7.47(\mathrm{~d}, J=8.2 \mathrm{~Hz}, 1 \mathrm{H}), 7.36(\mathrm{~d}, J=1.8 \mathrm{~Hz}$, $1 \mathrm{H}), 7.30(\mathrm{ddd}, J=5.0,3.0,1.1 \mathrm{~Hz}, 1 \mathrm{H}), 7.23(\mathrm{dd}, J=5.0,1.1 \mathrm{~Hz}, 1 \mathrm{H}), 6.99-6.95(\mathrm{~m}, 1 \mathrm{H}), 2.29(\mathrm{~s}, 3 \mathrm{H})$ ppm. 
${ }^{13}$ C RMN (100.6 MHz, $\left.\mathrm{CDCl}_{3}\right): \delta=137.1(\mathrm{C}), 133.8(\mathrm{CH}), 132.2(\mathrm{CH}), 130.5(\mathrm{CH}), 130.0(\mathrm{CH}), 129.2(\mathrm{CH})$, $125.5(\mathrm{CH}), 125.1(\mathrm{C}), 122.20(\mathrm{C}), 122.18(\mathrm{C}), 88.8(\mathrm{C}), 87.8(\mathrm{C}), 20.8\left(\mathrm{CH}_{3}\right) \mathrm{ppm}$.

EMBR (IE), m/z (\%): 278 (M+2, 78), 276 (M+ 76$), 251$ (31), 234 (26), 195 (39), 152 (89), 58 (100).

EMAR calculado para $\mathrm{C}_{13} \mathrm{H}_{9} \mathrm{BrS}: 275.9608$; encontrado: 275.9609 .

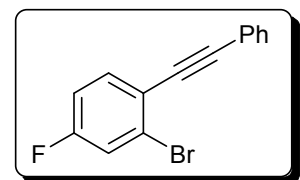

2-Bromo-1-(feniletinil)-4-fluorobenceno (82j)

Sólido blanco.

P.f. $=54-56^{\circ} \mathrm{C}$.

${ }^{1}$ H RMN (300 MHz, $\left.\mathrm{CDCl}_{3}\right): \delta=7.67-7.49(\mathrm{~m}, 3 \mathrm{H}), 7.44-7.30(\mathrm{~m}, 4 \mathrm{H}), 7.03(\mathrm{td}, J=8.3,2.6 \mathrm{~Hz}, 1 \mathrm{H}) \mathrm{ppm}$.

${ }^{13} \mathbf{C}$ RMN (75.4 MHz, $\left.\mathrm{CDCl}_{3}\right): \delta=161.8(\mathrm{~d}, J=253.8 \mathrm{~Hz}, \mathrm{C}), 134.3(\mathrm{~d}, J=8.7 \mathrm{~Hz}, \mathrm{CH}), 131.8(2 \times \mathrm{CH}), 128.8$ $(\mathrm{CH}), 128.5(2 \times \mathrm{CH}), 126.3(\mathrm{~d}, J=9.6 \mathrm{~Hz}, \mathrm{C}), 122.8(\mathrm{C}), 121.9$ (d, $J=3.6 \mathrm{~Hz}, \mathrm{C}), 120.1$ (d, $J=25.0 \mathrm{~Hz}$, $\mathrm{CH}), 114.8(\mathrm{~d}, J=21.8 \mathrm{~Hz}, \mathrm{CH}), 93.7(\mathrm{C}), 87.1(\mathrm{C}) \mathrm{ppm}$.

EMBR (IE), m/z (\%): 276 (M+2, 94), 274 (M+1 100), 194 (69), 174 (29), 137 (16), 51 (42).

EMAR calculado para $\mathrm{C}_{14} \mathrm{H}_{8} \mathrm{BrF}: 273.9793$; encontrado: 273.9796.

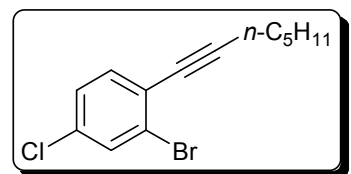

2-Bromo-4-cloro-1-(1-heptinil)benceno (82k)

Líquido incoloro.

$\mathrm{R}_{\mathrm{f}}=0.60$ (hexano / AcOEt, $20 / 1$ ).

${ }^{1} \mathbf{H}$ RMN $\left(300 \mathrm{MHz}, \mathrm{CDCl}_{3}\right): \delta=7.56(\mathrm{dd}, J=2.1,1.0 \mathrm{~Hz}, 1 \mathrm{H}), 7.34(\mathrm{~d}, J=8.3 \mathrm{~Hz}, 1 \mathrm{H}), 7.20(\mathrm{ddd}, J=8.3,2.1$, $1.0 \mathrm{~Hz}, 1 \mathrm{H}), 2.45(\mathrm{t}, J=7.0 \mathrm{~Hz}, 2 \mathrm{H}), 1.72-1.56(\mathrm{~m}, 2 \mathrm{H}), 1.56-1.26(\mathrm{~m}, 4 \mathrm{H}), 0.93(\mathrm{t}, J=7.2 \mathrm{~Hz}, 3 \mathrm{H}) \mathrm{ppm}$. ${ }^{13}$ C RMN (75.4 MHz, $\left.\mathrm{CDCl}_{3}\right): \delta=133.9(\mathrm{CH}), 133.7(\mathrm{C}), 132.1(\mathrm{CH}), 127.4(\mathrm{CH}), 126.0(\mathrm{C}), 124.8(\mathrm{C}), 96.8$ (C), $78.6(\mathrm{C}), 31.2\left(\mathrm{CH}_{2}\right), 28.3\left(\mathrm{CH}_{2}\right), 22.3\left(\mathrm{CH}_{2}\right), 19.7\left(\mathrm{CH}_{2}\right), 14.2\left(\mathrm{CH}_{3}\right) \mathrm{ppm}$.

EMBR (IE), m/z (\%): 286 (M+2, 33), 284 (M+2 , 26), 257 (40), 229 (44), 176 (50), 150 (100), 128 (49), 113 (44). EMAR calculado para $\mathrm{C}_{13} \mathrm{H}_{14} \mathrm{BrCl}$ : 283.9967; encontrado: 283.9965 .

\section{B.1.1 Procedimiento para la síntesis del 3-(2-bromofenil)propiolato de etilo $\mathbf{8 2 m}$}

A una disolución de 1-bromo-2-etinilbenceno (450 mg, $2.5 \mathrm{mmol})$ en THF $(10 \mathrm{~mL}) \mathrm{a}-78{ }^{\circ} \mathrm{C}$ se añade $\mathrm{Et}_{2} \mathrm{MgCl}(1.5 \mathrm{~mL}$ de una disolución $2 \mathrm{M}$ en THF, $3 \mathrm{mmol})$. La mezcla resultante se agita durante 10 minutos a esta temperatura y a continuación se deja que alcance $0{ }^{\circ} \mathrm{C}$ durante 20 minutos. Se enfría la mezcla a $-78{ }^{\circ} \mathrm{C}$ y se adiciona el cloroformiato de etilo $(380 \mathrm{mg}, 3.5 \mathrm{mmol})$. La disolución resultante se agita a temperatura ambiente durante 2 horas y se hidroliza con $\mathrm{H}_{2} \mathrm{O}$. La fase acuosa se extrae con $\mathrm{Et}_{2} \mathrm{O}(3 \times 20 \mathrm{~mL})$. La combinación de fases orgánicas se seca sobre $\mathrm{Na}_{2} \mathrm{SO}_{4}$ anhidro y se concentra a presión reducida. El residuo resultante se purifica por columna de cromatografía (hexano / AcOEt, 30 / 1) permitiendo obtener $82 \mathbf{m}$

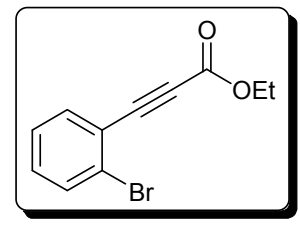

3-(2-Bromofenil)propiolato de etilo $(82 \mathrm{~m})^{284}$

Líquido incoloro.

$\mathrm{R}_{\mathrm{f}}=0.39$ (hexano / AcOEt, $10 / 1$ ).

${ }^{284}$ H. Rao, H. Fu, Y. Jiang, Y. Zhao, Adv. Synth. Catal. 2010, 352, 458. 
${ }^{1} \mathbf{H}$ RMN (300 MHz, $\left.\mathrm{CDCl}_{3}\right): \delta=7.58-7.50(\mathrm{~m}, 2 \mathrm{H}), 7.30-7.20(\mathrm{~m}, 2 \mathrm{H}), 4.31-4.21(\mathrm{~m}, 2 \mathrm{H}), 1.31(\mathrm{t}, J=7.1 \mathrm{~Hz}$, $3 \mathrm{H}) \mathrm{ppm}$.

${ }^{13}$ C RMN (75.4 MHz, $\left.\mathrm{CDCl}_{3}\right): \delta=153.6(\mathrm{C}), 134.7(\mathrm{CH}), 132.7(\mathrm{CH}), 131.7(\mathrm{CH}), 127.2(\mathrm{CH}), 126.3(\mathrm{C})$, $122.0(\mathrm{C}), 84.3(\mathrm{C}), 83.7(\mathrm{C}), 66.2\left(\mathrm{CH}_{2}\right), 14.1\left(\mathrm{CH}_{3}\right) \mathrm{ppm}$.

EMBR (IE), m/z (\%): 254 (M+2, 21), $252\left(\mathrm{M}^{+}, 19\right), 209$ (79), 207 (78), 182 (98), 180 (100), 128 (27), 74 (48).

EMAR calculado para $\mathrm{C}_{11} \mathrm{H}_{9} \mathrm{BrO}_{2}: 251.9786$; encontrado: 251.9790 .

\section{B.2 Procedimiento general para la síntesis de los tioacetatos de $S$-2-alquinilfenilo 83}

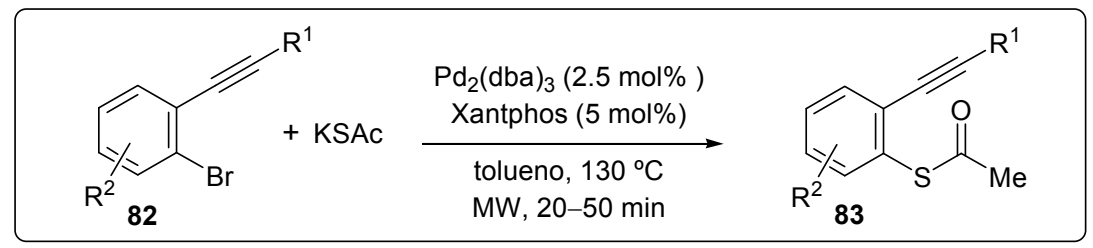

Una disolución del correspondiente 1-alquinil-2-bromobenceno 82 (0.5 mmol), $\mathrm{Pd}_{2} \mathrm{dba}_{3}(12$ $\mathrm{mg}, 2.5 \mathrm{~mol} \%$ ), 4,5-bis(difenilfosfino)-9,9-dimetilxanteno (Xantphos) (15 $\mathrm{mg}, 5 \mathrm{~mol} \%$ ) y tioacetato potásico $(85.5 \mathrm{mg}, 0.75 \mathrm{mmol})$ en tolueno seco $(1.5 \mathrm{~mL})$ se agita bajo atmósfera de $\mathrm{N}_{2}$ en un microondas, CEM Discover S-Class, a $130{ }^{\circ} \mathrm{C}$ y $300 \mathrm{~W}$ durante el tiempo necesario hasta la desaparición del sustrato de partida, determinado por CG-EM. A continuación se adiciona AcOEt (10 $\mathrm{mL})$ y $\mathrm{H}_{2} \mathrm{O}(10 \mathrm{~mL})$ a la mezcla de reacción fría. La fase acuosa separada se extrae con AcOEt $(2 \times 10$ $\mathrm{mL}$ ). La combinación de fases orgánicas se seca sobre $\mathrm{Na}_{2} \mathrm{SO}_{4}$ y se concentra a presión reducida. El residuo se purifica mediante columna de cromatografía (hexano / AcOEt) para dar los tioacetatos 83.

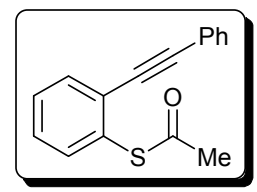

Tioacetato de $S$-2-(feniletinil)fenilo (83a)

Líquido incoloro.

$\mathrm{R}_{\mathrm{f}}=0.41$ (hexano / AcOEt, $\left.10 / 1\right)$.

${ }^{1} \mathbf{H}$ RMN (300 MHz, $\left.\mathrm{CDCl}_{3}\right): \delta=7.69-7.65(\mathrm{~m}, 1 \mathrm{H}), 7.58-7.52(\mathrm{~m}, 3 \mathrm{H}), 7.43-7.34(\mathrm{~m}, 5 \mathrm{H}), 2.47$ (s, 3H) ppm.

${ }^{13}$ C RMN (75.4 MHz, $\left.\mathrm{CDCl}_{3}\right): \delta=193.2(\mathrm{C}), 135.5(\mathrm{CH}), 133.1(\mathrm{CH}), 131.7(2 \times \mathrm{CH}), 130.4(\mathrm{C}), 129.6(\mathrm{CH})$, $128.8(\mathrm{CH}), 128.7(\mathrm{CH}), 128.5(2 \times \mathrm{CH}), 128.1(\mathrm{C}), 123.0(\mathrm{C}), 94.5(\mathrm{C}), 87.5(\mathrm{C}), 30.4\left(\mathrm{CH}_{3}\right) \mathrm{ppm}$.

EMBR (IE), m/z (\%): 252 (M+2 28), 251 (30), 237 (95), 210 (100), 165 (85), 139 (23).

EMAR calculado para $\mathrm{C}_{16} \mathrm{H}_{12} \mathrm{OS}$ : 252.0609; encontrado: 252.0605 .

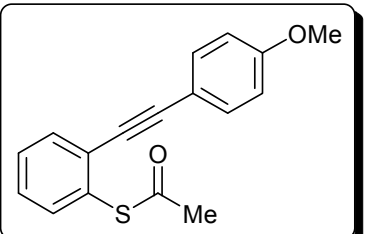

Tiacetato de $S$-2-(4-metoxifeniletinil)fenilo (83b)

Sólido blanco.

P.f. $=92-94^{\circ} \mathrm{C}$.

${ }^{1} \mathbf{H}$ RMN (300 MHz, $\left.\mathrm{CDCl}_{3}\right): \delta=7.64(\mathrm{dd}, J=7.4,1.6 \mathrm{~Hz}, 1 \mathrm{H}), 7.53(\mathrm{dd}, J=7.0,1.2 \mathrm{~Hz}, 1 \mathrm{H}), 7.47(\mathrm{~d}, J=8.3 \mathrm{~Hz}$, 2H), 7.43-7.31 (m, 2H), $6.89(\mathrm{~d}, J=8.3 \mathrm{~Hz}, 2 \mathrm{H}), 3.82(\mathrm{~d}, J=0.6 \mathrm{~Hz}, 3 \mathrm{H}), 2.45(\mathrm{~d}, J=0.6 \mathrm{~Hz}, 3 \mathrm{H}) \mathrm{ppm}$.

${ }^{13}$ C RMN (75.4 MHz, $\left.\mathrm{CDCl}_{3}\right): \delta=193.3(\mathrm{C}), 159.9(\mathrm{C}), 135.4(\mathrm{CH}), 133.2(2 \times \mathrm{CH}), 132.8(\mathrm{CH}), 130.2(\mathrm{C}), 129.6$

$(\mathrm{CH}), 128.5(\mathrm{C}), 128.4(\mathrm{C}), 115.1(\mathrm{C}), 114.1(2 \times \mathrm{CH}), 94.7(\mathrm{C}), 86.3(\mathrm{C}), 55.4\left(\mathrm{CH}_{3}\right), 30.4\left(\mathrm{CH}_{3}\right) \mathrm{ppm}$.

EMBR (IE), m/z (\%): $282\left(\mathrm{M}^{+}, 69\right), 267$ (100), 240 (26), 225 (62), 195 (24), 152 (19).

EMAR calculado para $\mathrm{C}_{17} \mathrm{H}_{14} \mathrm{O}_{2} \mathrm{~S}$ : 282.0715; encontrado: 282.0715 . 


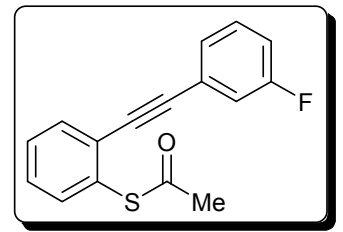

Tioacetato de $S$-2-(3-fluorofeniletinil)fenilo (83c)

Líquido incoloro.

$\mathrm{R}_{\mathrm{f}}=0.33$ (hexano / AcOEt, $10 / 1$ ).

${ }^{1} \mathbf{H}$ RMN $\left(300 \mathrm{MHz}, \mathrm{CDCl}_{3}\right): \delta=7.68-7.63(\mathrm{~m}, 1 \mathrm{H}), 7.56-7.52(\mathrm{~m}, 1 \mathrm{H}), 7.44-7.38(\mathrm{~m}, 2 \mathrm{H}), 7.34-7.29(\mathrm{~m}, 2 \mathrm{H})$, 7.25-7.19 (m, 1H), 7.10-7.01 (m, 1H), $2.47(\mathrm{~d}, J=0.6 \mathrm{~Hz}, 3 \mathrm{H}) \mathrm{ppm}$.

${ }^{13} \mathbf{C}$ RMN (75.4 MHz, $\left.\mathrm{CDCl}_{3}\right): \delta=193.1(\mathrm{C}), 162.5(\mathrm{~d}, J=246.7 \mathrm{~Hz}, \mathrm{C}), 135.6(\mathrm{CH}), 133.2(\mathrm{CH}), 130.6(\mathrm{C})$, $130.1(\mathrm{~d}, J=8.6 \mathrm{~Hz}, \mathrm{CH}), 129.7(\mathrm{CH}), 129.2(\mathrm{CH}), 127.6(\mathrm{~d}, J=3.2 \mathrm{~Hz}, \mathrm{CH}), 124.9(\mathrm{~d}, J=9.5 \mathrm{~Hz}, \mathrm{C})$, $118.5(\mathrm{~d}, J=22.8 \mathrm{~Hz}, \mathrm{CH}), 116.1(\mathrm{~d}, J=21.2 \mathrm{~Hz}, \mathrm{CH}), 93.0(\mathrm{~d}, J=3.5 \mathrm{~Hz}, \mathrm{C}), 88.3(\mathrm{C}), 30.5\left(\mathrm{CH}_{3}\right) \mathrm{ppm}$.

EMBR (IE), m/z (\%): 270 (M+, 20), 269 (23), 255 (43), 228 (100), 183 (70).

EMAR calculado para $\mathrm{C}_{16} \mathrm{H}_{11}$ FOS: 270.0515; encontrado: 270.0512 .

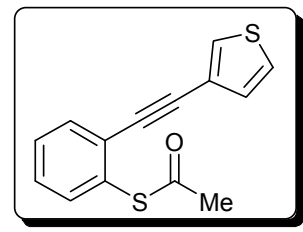

Tioacetato de $S$-2-(3-tieniletinil)fenilo (83d)

Líquido incoloro.

$\mathrm{R}_{\mathrm{f}}=0.35$ (hexano / AcOEt, $15 / 1$ ).

${ }^{1} \mathbf{H}$ RMN (300 MHz, $\left.\mathrm{CDCl}_{3}\right): \delta=7.67-7.62(\mathrm{~m}, 1 \mathrm{H}), 7.56-7.52(\mathrm{~m}, 2 \mathrm{H}), 7.42-7.35(\mathrm{~m}, 2 \mathrm{H}), 7.31(\mathrm{dd}, J=5.0$, $3.0 \mathrm{~Hz}, 1 \mathrm{H}), 7.20(\mathrm{dd}, J=5.0,1.1 \mathrm{~Hz}, 1 \mathrm{H}), 2.45(\mathrm{~s}, 3 \mathrm{H}) \mathrm{ppm}$.

${ }^{13}$ C RMN (75.4 MHz, $\left.\mathrm{CDCl}_{3}\right): \delta=193.1(\mathrm{C}), 135.5(\mathrm{CH}), 133.0(\mathrm{CH}), 130.3(\mathrm{C}), 129.9(\mathrm{CH}), 129.5(\mathrm{CH})$, $129.1(\mathrm{CH}), 128.7(\mathrm{CH}), 128.0(\mathrm{C}), 125.6(\mathrm{CH}), 122.0(\mathrm{C}), 89.6(\mathrm{C}), 87.0(\mathrm{C}), 30.4\left(\mathrm{CH}_{3}\right) \mathrm{ppm}$.

EMBR (IE), m/z (\%): $258\left(\mathrm{M}^{+}, 24\right), 243$ (100), 216 (81), 171 (97), 127 (22), 69 (48).

EMAR calculado para $\mathrm{C}_{14} \mathrm{H}_{10} \mathrm{OS}_{2}$ : 258.0173 ; encontrado: 258.0184 .

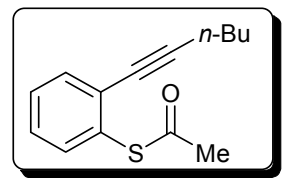

Tioacetato de $S$-2-(1-hexinil)fenilo (83e)

Líquido marrón.

$\mathrm{R}_{\mathrm{f}}=0.49$ (hexano / AcOEt, $10 / 1$ ).

${ }^{1} \mathbf{H}$ RMN $\left(300 \mathrm{MHz}, \mathrm{CDCl}_{3}\right): \delta=7.51(\mathrm{dd}, J=7.3,1.8 \mathrm{~Hz}, 1 \mathrm{H}), 7.47(\mathrm{dd}, J=7.3,1.8 \mathrm{~Hz}, 1 \mathrm{H}), 7.37-7.25(\mathrm{~m}$, $2 \mathrm{H}), 2.47-2.40(\mathrm{~m}, 5 \mathrm{H}), 1.65-1.42(\mathrm{~m}, 4 \mathrm{H}), 0.95(\mathrm{t}, J=7.2 \mathrm{~Hz}, 3 \mathrm{H}) \mathrm{ppm}$.

${ }^{13}$ C RMN (75.4 MHz, $\left.\mathrm{CDCl}_{3}\right): \delta=193.5(\mathrm{C}), 135.4(\mathrm{CH}), 133.2(\mathrm{CH}), 130.1(\mathrm{C}), 129.5(\mathrm{CH}), 129.0(\mathrm{C}), 128.1$ $(\mathrm{CH}), 96.1(\mathrm{C}), 78.8(\mathrm{C}), 30.8\left(\mathrm{CH}_{2}\right), 30.4\left(\mathrm{CH}_{3}\right), 22.0\left(\mathrm{CH}_{2}\right), 19.4\left(\mathrm{CH}_{2}\right) 13.8\left(\mathrm{CH}_{3}\right) \mathrm{ppm}$.

EMBR (IE), m/z (\%): $232\left(\mathrm{M}^{+}, 10\right), 217$ (12), 190 (14), 147 (100), 115 (15), 69 (13).

EMAR calculado para $\mathrm{C}_{14} \mathrm{H}_{16} \mathrm{OS}: 232.0922$; encontrado: 232.0921.

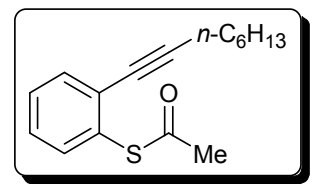

Tiacetato de $S$-2-(1-octinil)fenilo (83f)

Líquido incoloro.

$\mathrm{R}_{\mathrm{f}}=0.51$ (hexano / AcOEt, $10 / 1$ ).

${ }^{1}$ H RMN (300 MHz, $\left.\mathrm{CDCl}_{3}\right): \delta=7.56-7.44(\mathrm{~m}, 2 \mathrm{H}), 7.37-7.25(\mathrm{~m}, 2 \mathrm{H}), 2.47-2.39(\mathrm{~m}, 5 \mathrm{H}), 1.65-1.54(\mathrm{~m}, 2 \mathrm{H})$, $1.53-1.42(\mathrm{~m}, 2 \mathrm{H}), 1.40-1.28(\mathrm{~m}, 4 \mathrm{H}), 0.91(\mathrm{t}, J=6.6 \mathrm{~Hz}, 3 \mathrm{H}) \mathrm{ppm}$.

${ }^{13}$ C RMN (75.4 MHz, $\left.\mathrm{CDCl}_{3}\right): \delta=193.4(\mathrm{C}), 135.4(\mathrm{CH}), 133.2(\mathrm{CH}), 130.1(\mathrm{C}), 129.5(\mathrm{CH}), 128.9(\mathrm{C}), 128.1(\mathrm{CH})$, 96.2 (C), $78.8(\mathrm{C}), 31.5\left(\mathrm{CH}_{2}\right), 30.4\left(\mathrm{CH}_{3}\right), 28.72\left(\mathrm{CH}_{2}\right), 28.67\left(\mathrm{CH}_{2}\right), 22.7\left(\mathrm{CH}_{2}\right), 19.7\left(\mathrm{CH}_{2}\right), 14.2\left(\mathrm{CH}_{3}\right) \mathrm{ppm}$. EMBR (IE), m/z (\%): 260 (M+ , 4), 245 (5), 203 (9), 161 (10), 147 (100), 128 (14), 115 (17). 
EMAR calculado para $\mathrm{C}_{16} \mathrm{H}_{20} \mathrm{OS}: 260.1235$; encontrado: 260.1235 .

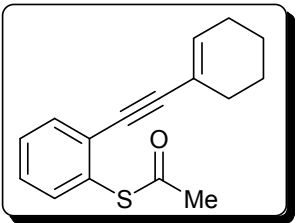

Tiacetato de $S$-2-(1-ciclohexeniletinil)fenilo (83g)

Sólido blanco.

P.f. $=74-76^{\circ} \mathrm{C}$.

${ }^{1} \mathbf{H}$ RMN $\left(300 \mathrm{MHz}, \mathrm{CDCl}_{3}\right): \delta=7.55-7.46(\mathrm{~m}, 2 \mathrm{H}), 7.38-7.25(\mathrm{~m}, 2 \mathrm{H}), 6.25-6.19(\mathrm{~m}, 1 \mathrm{H}), 2.42(\mathrm{~d}, J=0.4$ $\mathrm{Hz}, 3 \mathrm{H}), 2.26-2.18(\mathrm{~m}, 2 \mathrm{H}), 2.18-2.10(\mathrm{~m}, 2 \mathrm{H}), 1.72-1.56(\mathrm{~m}, 4 \mathrm{H}) \mathrm{ppm}$.

${ }^{13} \mathbf{C}$ RMN (75.4 MHz, $\left.\mathrm{CDCl}_{3}\right): \delta=193.1(\mathrm{C}), 135.9(\mathrm{CH}), 135.2(\mathrm{CH}), 132.7(\mathrm{CH}), 130.0(\mathrm{C}), 129.4(\mathrm{CH}), 128.5(\mathrm{C})$, $128.2(\mathrm{CH}), 120.6(\mathrm{C}), 96.5(\mathrm{C}), 84.9(\mathrm{C}), 30.3\left(\mathrm{CH}_{3}\right), 29.0\left(\mathrm{CH}_{2}\right), 25.8\left(\mathrm{CH}_{2}\right), 22.3\left(\mathrm{CH}_{2}\right), 21.5\left(\mathrm{CH}_{2}\right) \mathrm{ppm}$.

EMBR (IE), m/z (\%): 256 (M+1 14), 227 (27), 214 (40), 185 (100), 171 (45), 147 (45), 134 (48), 115 (42).

EMAR calculado para $\mathrm{C}_{16} \mathrm{H}_{16} \mathrm{OS}: 256.0922$; encontrado: 256.0931 .

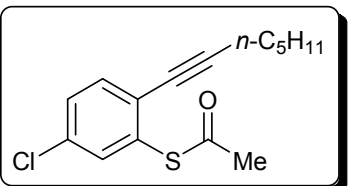

Tiacetato de $S$-5-cloro-2-(1-heptinil)fenilo (83k)

Líquido incoloro.

$\mathrm{R}_{\mathrm{f}}=0.30$ (hexano / AcOEt, $10 / 1$ ).

${ }^{1} \mathbf{H}$ RMN $\left(300 \mathrm{MHz}, \mathrm{CDCl}_{3}\right): \delta=7.48(\mathrm{~d}, J=2.2 \mathrm{~Hz}, 1 \mathrm{H}), 7.43(\mathrm{~d}, J=8.4 \mathrm{~Hz}, 1 \mathrm{H}), 7.29$ (ddd, $J=8.4,2.2,0.6$ $\mathrm{Hz}, 1 \mathrm{H}), 2.47-2.38(\mathrm{~m}, 5 \mathrm{H}), 1.65-1.54(\mathrm{~m}, 2 \mathrm{H}), 1.50-1.28(\mathrm{~m}, 4 \mathrm{H}), 0.92(\mathrm{t}, J=7.1 \mathrm{~Hz}, 3 \mathrm{H}) \mathrm{ppm}$.

${ }^{13} \mathbf{C}$ RMN (75.4 MHz, $\left.\mathrm{CDCl}_{3}\right): \delta=192.4(\mathrm{C}), 134.9(\mathrm{CH}), 133.9(\mathrm{CH}), 133.4(\mathrm{C}), 131.7(\mathrm{C}), 129.7(\mathrm{CH}), 127.3$ (C), $97.2(\mathrm{C}), 77.9(\mathrm{C}), 31.1\left(\mathrm{CH}_{2}\right), 30.4\left(\mathrm{CH}_{3}\right), 28.3\left(\mathrm{CH}_{2}\right), 22.3\left(\mathrm{CH}_{2}\right), 19.7\left(\mathrm{CH}_{2}\right), 14.1\left(\mathrm{CH}_{3}\right) \mathrm{ppm}$.

EMBR (IE), m/z (\%): $282\left(\mathrm{M}^{+}+2,5\right), 280\left(\mathrm{M}^{+}, 11\right), 238$ (32), 209 (13), 181 (100), 171 (7), 115 (8).

EMAR calculado para $\mathrm{C}_{15} \mathrm{H}_{17} \mathrm{ClOS}$ : 280.0689; encontrado: 280.0685 .

\section{B.3 Síntesis de los benzo[b]tiofenos 80a, 81, 84 y 85 mediante acoplamientos $\mathrm{C}-\mathrm{S}$} catalizados por complejos de paladio

\section{B.3.1 Método A: Empleando tioacetato potásico como fuente de azufre}

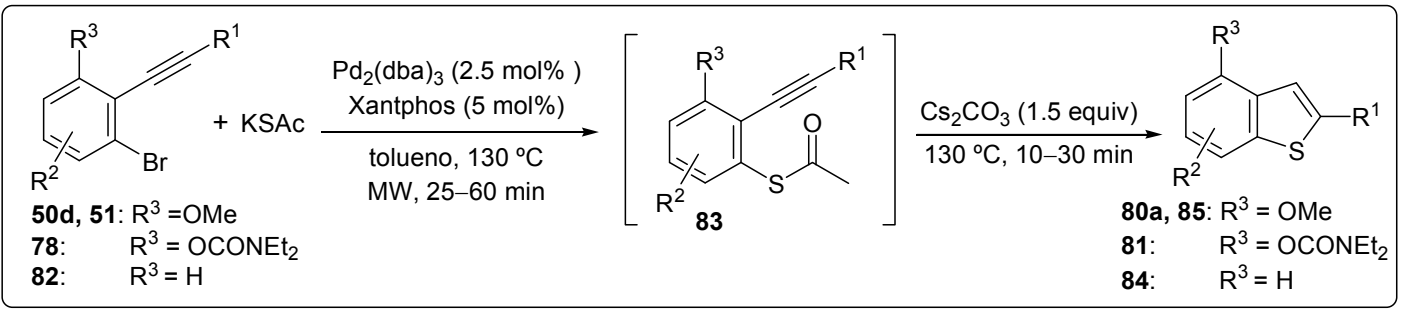

Una disolución del correspondiente 1-alquinil-2-bromobenceno (0.5 mmol), $\mathrm{Pd}_{2} \mathrm{dba}_{3}(12 \mathrm{mg}$, $2.5 \mathrm{~mol} \%)$, Xantphos (15 mg, $5 \mathrm{~mol} \%$ ) y tioacetato potásico $(85.5 \mathrm{mg}, 0.75 \mathrm{mmol})$ en tolueno seco $(1.5 \mathrm{~mL})$ se agita bajo atmósfera de $\mathrm{N}_{2}$ en un microondas, CEM Discover S-Class, a $130{ }^{\circ} \mathrm{C}$ y $300 \mathrm{~W}$ hasta la desaparición del bromuro de arilo, monitorizado por CG-EM (Paso 1, 25-60 minutos). A continuación se añade $\mathrm{Cs}_{2} \mathrm{CO}_{3}(244 \mathrm{mg}, 1.5 \mathrm{mmol})$ y la mezcla de reacción se irradia con energía de microondas hasta que la ciclación se completa (Paso 2, 10-30 minutos). Una vez fría la mezcla de reacción, se añade AcOEt $(10 \mathrm{~mL})$ y $\mathrm{H}_{2} \mathrm{O}(10 \mathrm{~mL})$, y la fase acuosa separada se extrae con AcOEt (2 
$\times 10 \mathrm{~mL}$ ). La combinación de fases orgánicas se seca sobre $\mathrm{Na}_{2} \mathrm{SO}_{4}$ anhidro y se concentra a presión reducida. El residuo resultante se purifica por columna de cromatografía en sílica gel (hexano / AcOEt) para obtener los correpondientes benzo $[b]$ tiofenos 80a, 81, 84 y 85 .

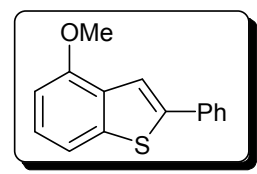

2-Fenil-4-metoxibenzo $[b]$ tiofeno (80a)

Líquido marrón.

$\mathrm{R}_{\mathrm{f}}=0.42$ (hexano / AcOEt, 9 / 1).

${ }^{1} \mathbf{H}$ RMN $\left(300 \mathrm{MHz}, \mathrm{CDCl}_{3}\right): \delta=7.85-7.82(\mathrm{~m}, 1 \mathrm{H}), 7.82-7.77(\mathrm{~m}, 2 \mathrm{H}), 7.52-7.43(\mathrm{~m}, 3 \mathrm{H}), 7.39(\mathrm{dt}, J=4.6$, $1.9 \mathrm{~Hz}, 1 \mathrm{H}), 7.31(\mathrm{t}, J=8.0 \mathrm{~Hz}, 1 \mathrm{H}), 6.79(\mathrm{~d}, J=8.0 \mathrm{~Hz}, 1 \mathrm{H}), 4.01(\mathrm{~s}, 3 \mathrm{H}) \mathrm{ppm}$.

${ }^{13}$ C RMN (75.4 MHz, $\left.\mathrm{CDCl}_{3}\right): \delta=155.0(\mathrm{C}), 142.6(\mathrm{C}), 141.0(\mathrm{C}), 134.5(\mathrm{C}), 131.5(\mathrm{C}), 129.0(2 \times \mathrm{CH}), 128.1$ $(\mathrm{CH}), 126.4(2 \times \mathrm{CH}), 125.5(\mathrm{CH}), 116.2(\mathrm{CH}), 114.8(\mathrm{CH}), 104.3(\mathrm{CH}), 55.5\left(\mathrm{CH}_{3}\right) \mathrm{ppm}$.

EMBR (IE), m/z (\%): $240\left(\mathrm{M}^{+}, 100\right), 225$ (81), 197 (56), 165 (33), 120 (11), 77 (18).

EMAR calculado para: $\mathrm{C}_{15} \mathrm{H}_{12} \mathrm{OS}: 240.0609$; encontrado: 240.0600 .

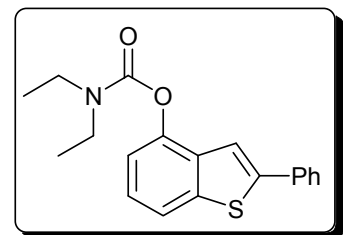

4-(N,N-Dietilcarbamoiloxi)-2-fenilbenzo $[b]$ tiofeno (81)

Líquido rojo.

$\mathrm{R}_{\mathrm{f}}=0.36$ (hexano / AcOEt, 5 / 1).

${ }^{1}$ H RMN $\left(300 \mathrm{MHz}, \mathrm{CDCl}_{3}\right): \delta=7.76-7.71(\mathrm{~m}, 2 \mathrm{H}), 7.68(\mathrm{dd}, J=7.9,0.8 \mathrm{~Hz}, 1 \mathrm{H}), 7.52(\mathrm{~s}, 1 \mathrm{H}), 7.48-7.41(\mathrm{~m}$, $2 \mathrm{H}), 7.40-7.30(\mathrm{~m}, 2 \mathrm{H}), 7.20(\mathrm{dd}, J=7.9,0.8 \mathrm{~Hz}, 1 \mathrm{H}), 3.58(\mathrm{q}, J=6.9 \mathrm{~Hz}, 2 \mathrm{H}), 3.48(\mathrm{q}, J=6.9 \mathrm{~Hz}, 2 \mathrm{H})$, $1.38(\mathrm{t}, J=6.9 \mathrm{~Hz}, 3 \mathrm{H}), 1.29(\mathrm{t}, J=6.9 \mathrm{~Hz}, 3 \mathrm{H}) \mathrm{ppm}$.

${ }^{13}$ C RMN (75.4 MHz, $\mathrm{CDCl}_{3}$ ): $\delta=153.9$ (C), 146.3 (C), 144.5 (C), 141.0 (C), 134.5 (C), 134.1 (C), 128.9 $(2 \times \mathrm{CH}), 128.4(\mathrm{CH}), 126.6(2 \times \mathrm{CH}), 124.9(\mathrm{CH}), 119.3(\mathrm{CH}), 117.2(\mathrm{CH}), 115.4(\mathrm{CH}), 42.5\left(\mathrm{CH}_{2}\right), 42.1$ $\left(\mathrm{CH}_{2}\right), 14.5\left(\mathrm{CH}_{3}\right), 13.5\left(\mathrm{CH}_{3}\right) \mathrm{ppm}$.

EMBR (IE), m/z (\%): 325 (M+ , 59), 100 (68), 72 (100).

EMAR calculado para $\mathrm{C}_{19} \mathrm{H}_{19} \mathrm{NO}_{2} \mathrm{~S}: 325,1136$; encontrado: 325.1136 .

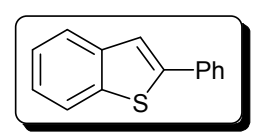

\section{2-Fenilbenzo $[b]$ tiofeno (84a)}

Sólido blanco.

P.f. $=164-166^{\circ} \mathrm{C}\left(\right.$ lit. $\left.^{285}=168-169^{\circ} \mathrm{C}\right)$.

${ }^{1}$ H RMN (300 MHz, $\left.\mathrm{CDCl}_{3}\right): \delta=7.89-7.83(\mathrm{~m}, 1 \mathrm{H}), 7.82-7.78(\mathrm{~m}, 1 \mathrm{H}), 7.77-7.71(\mathrm{~m}, 2 \mathrm{H}), 7.57(\mathrm{~s}, 1 \mathrm{H})$, 7.49-7.41 (m, 2H), 7.41-7.30 (m, 3H) ppm.

${ }^{13}$ C RMN (75.4 MHz, $\left.\mathrm{CDCl}_{3}\right): \delta=144.3(\mathrm{C}), 140.8(\mathrm{C}), 139.6(\mathrm{C}), 134.4(\mathrm{C}), 129.1(2 \times \mathrm{CH}), 128.4(\mathrm{CH}), 126.6$ $(2 \times \mathrm{CH}), 124.6(\mathrm{CH}), 124.4(\mathrm{CH}), 123.7(\mathrm{CH}), 122.4(\mathrm{CH}), 119.6(\mathrm{CH}) \mathrm{ppm}$.

EMBR (IE), m/z (\%): $210\left(\mathrm{M}^{+}, 100\right), 179(9), 165(16), 104(23), 51$ (9).

EMAR calculado para $\mathrm{C}_{14} \mathrm{H}_{10} \mathrm{~S}: 210.0503$; encontrado: 210.0507 .

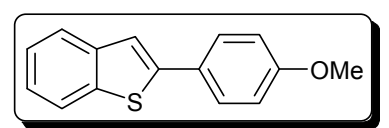

2-(4-Metoxifenil)benzo[b]tiofeno (84b)

Sólido blanco.

P.f. $=188-190^{\circ} \mathrm{C}\left(\right.$ lit. $\left.{ }^{286}=188-190^{\circ} \mathrm{C}\right)$.

${ }^{285}$ A. B. Bíró, A. Kotschy, Eur. J. Org. Chem. 2007, 1364.

${ }^{286}$ H. Baghbanzadeh, C. Pilger, C. O. Kappe, J. Org. Chem. 2011, 76, 8138. 
${ }^{1} \mathbf{H}$ RMN $\left(300 \mathrm{MHz}, \mathrm{CDCl}_{3}\right): \delta=7.81(\mathrm{~d}, J=7.8 \mathrm{~Hz}, 1 \mathrm{H}), 7.74(\mathrm{~d}, J=7.8 \mathrm{~Hz}, 1 \mathrm{H}), 7.65(\mathrm{~d}, J=8.5 \mathrm{~Hz}, 2 \mathrm{H})$, $7.43(\mathrm{~s}, 1 \mathrm{H}), 7.38-7.23(\mathrm{~m}, 2 \mathrm{H}), 6.96(\mathrm{~d}, J=8.5 \mathrm{~Hz}, 2 \mathrm{H}), 3.86(\mathrm{~s}, 3 \mathrm{H}) \mathrm{ppm}$.

${ }^{13}$ C RMN (75.4 MHz, $\left.\mathrm{CDCl}_{3}\right)$ : $\delta=159.9(\mathrm{C}), 144.3(\mathrm{C}), 141.0(\mathrm{C}), 139.3(\mathrm{C}), 127.9(2 \times \mathrm{CH}), 127.2(\mathrm{C}), 124.6$ $(\mathrm{CH}), 124.1(\mathrm{CH}), 123.4(\mathrm{CH}), 122.3(\mathrm{CH}), 118.3(\mathrm{CH}), 114.5(2 \times \mathrm{CH}), 55.5\left(\mathrm{CH}_{3}\right) \mathrm{ppm}$.

EMBR (IE), m/z (\%): $240\left(\mathrm{M}^{+}, 100\right), 225$ (53), 197 (43), 165 (27), 152 (23), 69 (16).

EMAR calculado para $\mathrm{C}_{15} \mathrm{H}_{12} \mathrm{OS}: 240.0609$; encontrado: 240.0617 .

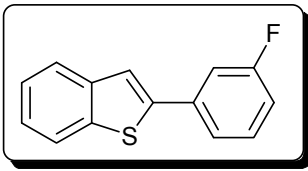

2-(3-Fluorofenil)benzo[b]tiofeno (84c)

Sólido blanco.

P.f. $=126-128^{\circ} \mathrm{C}$

${ }^{1}$ H RMN (300 MHz, $\left.\mathrm{CDCl}_{3}\right): \delta=7.88-7.76(\mathrm{~m}, 2 \mathrm{H}), 7.56(\mathrm{~s}, 1 \mathrm{H}), 7.53-7.47(\mathrm{~m}, 1 \mathrm{H}), 7.47-7.32(\mathrm{~m}, 4 \mathrm{H}), 7.06$ $(\mathrm{td}, J=8.4,2.5 \mathrm{~Hz}, 1 \mathrm{H}) \mathrm{ppm}$.

${ }^{13} \mathbf{C}$ RMN (75.4 MHz, $\left.\mathrm{CDCl}_{3}\right): \delta=163.2(\mathrm{~d}, J=246.2 \mathrm{~Hz}, \mathrm{C}), 142.8(\mathrm{~d}, J=2.8 \mathrm{~Hz}, \mathrm{C}), 140.5(\mathrm{C}), 139.6(\mathrm{C})$, $136.5(\mathrm{~d}, J=8.2 \mathrm{~Hz}, \mathrm{C}), 130.6(\mathrm{~d}, J=8.5 \mathrm{~Hz}, \mathrm{CH}), 124.82(\mathrm{CH}), 124.78(\mathrm{CH}), 123.9(\mathrm{CH}), 122.4(\mathrm{CH})$, $122.3(\mathrm{~d}, J=2.9 \mathrm{~Hz}, \mathrm{CH}), 120.4(\mathrm{CH}), 115.1(\mathrm{~d}, J=21.3 \mathrm{~Hz}, \mathrm{CH}), 113.4$ (d, $J=22.9 \mathrm{~Hz}, \mathrm{CH}) \mathrm{ppm}$.

EMBR (IE), m/z (\%): $228\left(\mathrm{M}^{+}, 100\right), 183$ (51), 163 (17), 120 (30), 69 (76).

EMAR calculado para $\mathrm{C}_{14} \mathrm{H}_{9} \mathrm{FS}: 228.0409$; encontrado: 228.0415 .

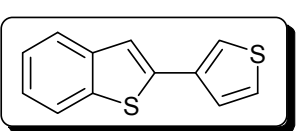

2-(3-Tienil)benzo $[b]$ tiofeno $(\mathbf{8 4 d})^{206}$

Sólido blanco.

P.f. $=178-180^{\circ} \mathrm{C}$.

${ }^{1} \mathbf{H}$ RMN (300 MHz, $\left.\mathrm{CDCl}_{3}\right): \delta=7.85-7.73(\mathrm{~m}, 2 \mathrm{H}), 7.52(\mathrm{dd}, J=2.8,1.4 \mathrm{~Hz}, 1 \mathrm{H}), 7.46-7.38(\mathrm{~m}, 3 \mathrm{H})$, 7.37-7.31 (m, 2H) ppm.

${ }^{13} \mathbf{C}$ RMN (75.4 MHz, $\left.\mathrm{CDCl}_{3}\right): \delta=140.6(\mathrm{C}), 139.1(\mathrm{C}), 139.0(\mathrm{C}), 135.8(\mathrm{C}), 126.7(\mathrm{CH}), 126.2(\mathrm{CH}), 124.7$ $(\mathrm{CH}), 124.4(\mathrm{CH}), 123.5(\mathrm{CH}), 122.3(\mathrm{CH}), 121.4(\mathrm{CH}), 119.5(\mathrm{CH}) \mathrm{ppm}$.

EMBR (IE), m/z (\%): $216\left(\mathrm{M}^{+}, 100\right), 184$ (7), 171 (32), 108 (14), 69 (20).

EMAR calculado para $\mathrm{C}_{12} \mathrm{H}_{8} \mathrm{~S}_{2}: 216.0067$; encontrado: 216.0069 .

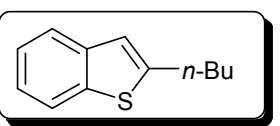

2-Butilbenzo $\left[b \mid\right.$ tiofeno $(84 e)^{287}$

Líquido incoloro.

$\mathrm{R}_{\mathrm{f}}=0.45$ (hexano).

${ }^{1} \mathbf{H}$ RMN $\left(400 \mathrm{MHz}, \mathrm{CDCl}_{3}\right): \delta=7.77(\mathrm{dd}, J=7.8,0.7 \mathrm{~Hz}, 1 \mathrm{H}), 7.67(\mathrm{~d}, J=7.2 \mathrm{~Hz}, 1 \mathrm{H}), 7.35-7.22(\mathrm{~m}, 2 \mathrm{H})$, $7.01(\mathrm{~d}, J=0.7 \mathrm{~Hz}, 1 \mathrm{H}), 2.92(\mathrm{t}, J=7.6 \mathrm{~Hz}, 2 \mathrm{H}), 1.82-1.68(\mathrm{~m}, 2 \mathrm{H}), 1.53-1.36(\mathrm{~m}, 2 \mathrm{H}), 0.97$ (t, $J=7.3$ $\mathrm{Hz}, 3 \mathrm{H}) \mathrm{ppm}$.

${ }^{13} \mathbf{C}$ RMN (100.6 MHz, $\left.\mathrm{CDCl}_{3}\right): \delta=147.0(\mathrm{C}), 140.4(\mathrm{C}), 139.4(\mathrm{C}), 124.1(\mathrm{CH}), 123.4(\mathrm{CH}), 122.8(\mathrm{CH}), 122.2$ $(\mathrm{CH}), 120.5(\mathrm{CH}), 33.4\left(\mathrm{CH}_{2}\right), 30.6\left(\mathrm{CH}_{2}\right), 22.4\left(\mathrm{CH}_{2}\right), 14.0\left(\mathrm{CH}_{3}\right) \mathrm{ppm}$.

EMBR (IE), m/z (\%): $190\left(\mathrm{M}^{+}, 34\right), 147(100), 115$ (8).

EMAR calculado para $\mathrm{C}_{12} \mathrm{H}_{14} \mathrm{~S}: 190.0816$; encontrado: 190.0815 .

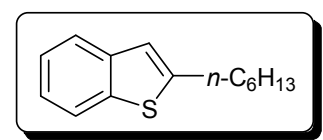

\section{2-Hexilbenzo $\left[b \mid\right.$ tiofeno $(84 f)^{244 a}$}

Líquido incoloro.

$\mathrm{R}_{\mathrm{f}}=0.44$ (hexano)

${ }^{1} \mathbf{H}$ RMN $\left(300 \mathrm{MHz}, \mathrm{CDCl}_{3}\right): \delta=7.78(\mathrm{~d}, J=7.6 \mathrm{~Hz}, 1 \mathrm{H}), 7.68(\mathrm{~d}, J=7.6 \mathrm{~Hz}, 1 \mathrm{H}), 7.37-7.23(\mathrm{~m}, 2 \mathrm{H}), 7.02(\mathrm{~s}$, $1 \mathrm{H}), 2.92(\mathrm{t}, J=7.6 \mathrm{~Hz}, 2 \mathrm{H}), 1.83-1.71(\mathrm{~m}, 2 \mathrm{H}), 1.49-1.28(\mathrm{~m}, 6 \mathrm{H}), 0.93(\mathrm{t}, J=6.8 \mathrm{~Hz}, 3 \mathrm{H}) \mathrm{ppm}$.

${ }^{287}$ O. Vechorkin, V. Proust, X. Hu, Angew. Chem., Int. Ed. 2010, 49, 3061. 
${ }^{13} \mathbf{C}$ RMN (75.4 MHz, $\left.\mathrm{CDCl}_{3}\right): \delta=147.0(\mathrm{C}), 140.3(\mathrm{C}), 139.4(\mathrm{C}), 124.1(\mathrm{CH}), 123.4(\mathrm{CH}), 122.8(\mathrm{CH}), 122.2$ $(\mathrm{CH}), 120.5(\mathrm{CH}), 31.7\left(\mathrm{CH}_{2}\right), 31.2\left(\mathrm{CH}_{2}\right), 30.9\left(\mathrm{CH}_{2}\right), 28.9\left(\mathrm{CH}_{2}\right), 22.7\left(\mathrm{CH}_{2}\right), 14.2\left(\mathrm{CH}_{3}\right) \mathrm{ppm}$.

EMBR (IE), m/z (\%): $218\left(\mathrm{M}^{+}, 12\right), 161(5), 147$ (100), 115 (11).

EMAR calculado para $\mathrm{C}_{14} \mathrm{H}_{18} \mathrm{~S}: 218.1129$; encontrado: 218.1129 .

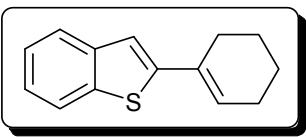

\section{2-(1-Ciclohexenil)benzo[b]tiofeno (84g)}

Sólido blanco.

P.f. $=84-86^{\circ} \mathrm{C}$.

${ }^{1} \mathbf{H}$ RMN (300 MHz, $\left.\mathrm{CDCl}_{3}\right): \delta=7.76-7.70(\mathrm{~m}, 1 \mathrm{H}), 7.66(\mathrm{dd}, J=6.7,2.3 \mathrm{~Hz}, 1 \mathrm{H}), 7.32-7.22(\mathrm{~m}, 2 \mathrm{H}), 7.11(\mathrm{~s}$ $1 \mathrm{H}), 6.33-6.28(\mathrm{~m}, 1 \mathrm{H}), 2.55-2.45(\mathrm{~m}, 2 \mathrm{H}), 2.29-2.19(\mathrm{~m}, 2 \mathrm{H}), 1.85-1.76(\mathrm{~m}, 2 \mathrm{H}), 1.73-1.63(\mathrm{~m}, 2 \mathrm{H}) \mathrm{ppm}$.

${ }^{13}$ C RMN (75.4 MHz, $\left.\mathrm{CDCl}_{3}\right): \delta=146.9(\mathrm{C}), 140.6(\mathrm{C}), 138.4(\mathrm{C}), 131.7(\mathrm{C}), 127.2(\mathrm{CH}), 124.3(\mathrm{CH}), 124.2$ $(\mathrm{CH}), 123.3(\mathrm{CH}), 122.1(\mathrm{CH}), 117.9(\mathrm{CH}), 27.1\left(\mathrm{CH}_{2}\right), 26.0\left(\mathrm{CH}_{2}\right), 22.8\left(\mathrm{CH}_{2}\right), 22.2\left(\mathrm{CH}_{2}\right) \mathrm{ppm}$.

EMBR (IE), m/z (\%): $214\left(\mathrm{M}^{+}, 100\right), 210$ (24), 185 (72), 171 (30), 147 (25), 134 (48), 115 (29).

EMAR calculado para $\mathrm{C}_{14} \mathrm{H}_{14} \mathrm{~S}: 214.0816$; encontrado: 214.0812 .

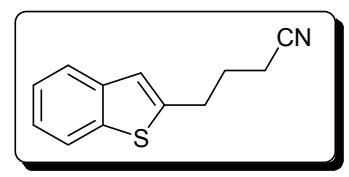

4-(Benzo $[b]$ tiofen-2-il)butanonitrilo $(84 h)^{288}$

Sólido blanco.

P.f. $=66-68^{\circ} \mathrm{C}$

${ }^{1} \mathbf{H}$ RMN $\left(300 \mathrm{MHz}, \mathrm{CDCl}_{3}\right): \delta=7.79(\mathrm{~d}, J=7.9 \mathrm{~Hz}, 1 \mathrm{H}), 7.71(\mathrm{dd}, J=7.1,1.4 \mathrm{~Hz}, 1 \mathrm{H}), 7.39-7.27(\mathrm{~m}, 2 \mathrm{H}), 7.07$ $(\mathrm{d}, J=0.7 \mathrm{~Hz}, 1 \mathrm{H}), 3.07(\mathrm{td}, J=7.1,0.7 \mathrm{~Hz}, 2 \mathrm{H}), 2.37(\mathrm{t}, J=7.1 \mathrm{~Hz}, 2 \mathrm{H}), 2.07(\mathrm{t}, J=7.1 \mathrm{~Hz}, 2 \mathrm{H}) \mathrm{ppm}$.

${ }^{13}$ C RMN (75.4 MHz, $\left.\mathrm{CDCl}_{3}\right): \delta=143.0(\mathrm{C}), 139.9(\mathrm{C}), 139.4(\mathrm{C}), 124.4(\mathrm{CH}), 123.9(\mathrm{CH}), 123.0(\mathrm{CH}), 122.2$ $(\mathrm{CH}), 121.9(\mathrm{CH}), 119.2(\mathrm{C}), 29.3\left(\mathrm{CH}_{2}\right), 26.5\left(\mathrm{CH}_{2}\right), 16.2\left(\mathrm{CH}_{2}\right) \mathrm{ppm}$.

EMBR (IE), m/z (\%): 201 (M+ , 49), 172 (26), 162 (36), 147 (100), 93 (38).

EMAR calculado para $\mathrm{C}_{12} \mathrm{H}_{11} \mathrm{NS}$ : 201.0612; encontrado: 201.0615 .

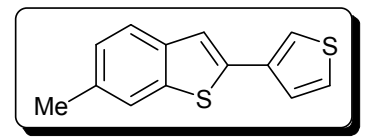

6-Metil-2-(3-tienil)benzo[b]tiofeno (84i)

Sólido blanco.

P.f. $=168-170{ }^{\circ} \mathrm{C}$.

${ }^{1} \mathbf{H}$ RMN $\left(400 \mathrm{MHz}, \mathrm{CDCl}_{3}\right): \delta=7.67(\mathrm{~d}, J=8.2 \mathrm{~Hz}, 1 \mathrm{H}), 7.53(\mathrm{~s}, 1 \mathrm{H}), 7.49(\mathrm{dd}, J=2.9,1.2 \mathrm{~Hz}, 1 \mathrm{H})$, $7.42-7.39(\mathrm{~m}, 1 \mathrm{H}), 7.39-7.36(\mathrm{~m}, 1 \mathrm{H}), 7.33(\mathrm{~s}, 1 \mathrm{H}), 7.13(\mathrm{ddd}, J=8.2,1.2,0.4 \mathrm{~Hz}, 1 \mathrm{H}), 2.45(\mathrm{~s}, 3 \mathrm{H}) \mathrm{ppm}$. ${ }^{13}$ C RMN (75.4 MHz, $\left.\mathrm{CDCl}_{3}\right): \delta=140.9$ (C), 139.1 (C), 136.3 (C), 136.0 (C), 134.4 (C), $126.6(\mathrm{CH}), 126.2$ $(\mathrm{CH}), 126.1(\mathrm{CH}), 123.6(\mathrm{CH}), 121.9(\mathrm{CH}), 121.2(\mathrm{CH}), 119.2(\mathrm{CH}), 21.6\left(\mathrm{CH}_{3}\right) \mathrm{ppm}$.

EMBR (IE), m/z (\%): 230 (M+100), 214 (22), 184 (29), 58 (83).

EMAR calculado para $\mathrm{C}_{13} \mathrm{H}_{10} \mathrm{~S}_{2}: 230.0224$; encontrado: 230.0225 .

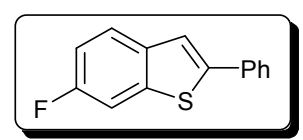

\section{2-Fenil-6-fluorobenzo[b]tiofeno $(\mathbf{8 4} \mathbf{j})^{289}$}

Sólido blanco.

P.f. $=176-178^{\circ} \mathrm{C}$.

${ }^{1} \mathbf{H}$ RMN (400 MHz, $\left.\mathrm{CDCl}_{3}\right): \delta=7.73-7.65(\mathrm{~m}, 3 \mathrm{H}), 7.53-7.47(\mathrm{~m}, 2 \mathrm{H}), 7.45-7.39(\mathrm{~m}, 2 \mathrm{H}), 7.37-7.30(\mathrm{~m}, 1 \mathrm{H})$, $7.10(\mathrm{td}, J=8.9,2.4 \mathrm{~Hz}, 1 \mathrm{H}) \mathrm{ppm}$.

${ }^{13} \mathbf{C}$ RMN (100.6 MHz, $\left.\mathrm{CDCl}_{3}\right): \delta=160.6(\mathrm{~d}, J=244.4 \mathrm{~Hz}, \mathrm{C}), 144.1(\mathrm{~d}, J=3.9 \mathrm{~Hz}, \mathrm{C}), 140.6(\mathrm{C}), 137.3(\mathrm{C})$, $134.2(\mathrm{C}), 129.1(2 \times \mathrm{CH}), 128.5(\mathrm{CH}), 126.5(2 \times \mathrm{CH}), 124.7(\mathrm{~d}, J=9.0 \mathrm{~Hz}, \mathrm{CH}), 118.9(\mathrm{CH}), 113.6(\mathrm{~d}, J=$ $24.2 \mathrm{~Hz}, \mathrm{CH}), 108.6$ (d, $J=25.5 \mathrm{~Hz}, \mathrm{CH}) \mathrm{ppm}$.

${ }^{288}$ H. Cho, Y. Iwama, K. Sugimoto, S. Mori, H. Tokuyama, J. Org. Chem. 2010, 75, 627.

${ }^{289}$ L.-L. Sun, C.-L. Deng, R.-Y. Tang, X.-G. Zhang, J. Org. Chem. 2011, 76, 7546. 
EMBR (IE), m/z (\%): 228 (M+100), 196 (14), 183 (27), 113 (21), 51 (72).

EMAR calculado para $\mathrm{C}_{14} \mathrm{H}_{9} \mathrm{FS}: 228.0409$; encontrado: 228.0403 .

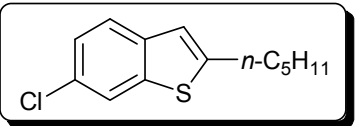

6-Cloro-2-pentilbenzo[b]tiofeno (84k)

Líquido incoloro.

$\mathrm{R}_{\mathrm{f}}=0.54$ (hexano).

${ }^{1} \mathbf{H}$ RMN (300 MHz, CDCl $): \delta=7.75-7.74(\mathrm{~m}, 1 \mathrm{H}), 7.56(\mathrm{~d}, J=8.5 \mathrm{~Hz}, 1 \mathrm{H}), 7.28(\mathrm{dd}, J=8.5,1.9 \mathrm{~Hz}, 1 \mathrm{H})$, $6.96(\mathrm{~d}, J=0.9 \mathrm{~Hz}, 1 \mathrm{H}), 2.88(\mathrm{t}, J=7.6 \mathrm{~Hz}, 2 \mathrm{H}), 1.82-1.69(\mathrm{~m}, 2 \mathrm{H}), 1.45-1.33(\mathrm{~m}, 4 \mathrm{H}), 0.94(\mathrm{t}, J=7.1$ $\mathrm{Hz}, 3 \mathrm{H}) \mathrm{ppm}$

${ }^{13}$ C RMN (75.4 MHz, $\left.\mathrm{CDCl}_{3}\right): \delta=147.7(\mathrm{C}), 140.4(\mathrm{C}), 138.7(\mathrm{C}), 129.4(\mathrm{C}), 124.9(\mathrm{CH}), 123.5(\mathrm{CH}), 121.8$ $(\mathrm{CH}), 120.0(\mathrm{CH}), 31.4\left(\mathrm{CH}_{2}\right), 30.8\left(2 \times \mathrm{CH}_{2}\right), 22.5\left(\mathrm{CH}_{2}\right), 14.1\left(\mathrm{CH}_{3}\right) \mathrm{ppm}$.

EMBR (IE), m/z (\%): $240\left(\mathrm{M}^{+}+2,9\right), 238\left(\mathrm{M}^{+}, 24\right), 180$ (89), 115 (54), 102 (100), 63 (68).

EMAR calculado para $\mathrm{C}_{13} \mathrm{H}_{15} \mathrm{ClS}: 238.0583$; encontrado: 238.0582 .

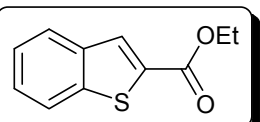

\section{(2-Benzo $[b]$ tiofenil)carboxilato de etilo $(84 \mathrm{~m})$} Sólido blanco. P.f. $=34-36^{\circ} \mathrm{C}\left(\right.$ lit. $\left.{ }^{197 b}=36-38^{\circ} \mathrm{C}\right)$

${ }^{1}$ H RMN $\left(300 \mathrm{MHz}, \mathrm{CDCl}_{3}\right): \delta=8.06(\mathrm{~s}, 1 \mathrm{H}), 7.90-7.82(\mathrm{~m}, 2 \mathrm{H}), 7.49-7.35(\mathrm{~m}, 2 \mathrm{H}), 4.46-4.35(\mathrm{~m}, 2 \mathrm{H}), 1.42$ $(\mathrm{td}, J=7.1,0.5 \mathrm{~Hz}, 3 \mathrm{H}) \mathrm{ppm}$.

${ }^{13} \mathbf{C}$ RMN (75.4 MHz, $\mathrm{CDCl}_{3}$ ): $\delta=162.9(\mathrm{C}), 142.3(\mathrm{C}), 138.8(\mathrm{C}), 134.0(\mathrm{C}), 130.5(\mathrm{CH}), 127.0(\mathrm{CH}), 125.6$ $(\mathrm{CH}), 125.0(\mathrm{CH}), 122.8(\mathrm{CH}), 61.7\left(\mathrm{CH}_{2}\right), 14.4\left(\mathrm{CH}_{3}\right) \mathrm{ppm}$.

EMBR (IE), m/z (\%): $206\left(\mathrm{M}^{+}, 23\right), 178$ (29), 161 (71), 133 (37), 89 (100), 63 (30)

EMAR calculado para $\mathrm{C}_{11} \mathrm{H}_{10} \mathrm{O}_{2} \mathrm{~S}$ : 206.0402; encontrado: 206.0400.

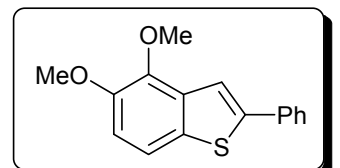

\section{2-Fenil-4,5-dimetoxibenzo $[b]$ tiofeno (85aa)}

Sólido blanco.

P.f. $=98-100^{\circ} \mathrm{C}$.

${ }^{1} \mathbf{H}$ RMN (300 MHz, $\left.\mathrm{CDCl}_{3}\right): \delta=7.78-7.72(\mathrm{~m}, 2 \mathrm{H}), 7.70(\mathrm{~s}, 1 \mathrm{H}), 7.53-7.32(\mathrm{~m}, 4 \mathrm{H}), 7.04(\mathrm{~d}, J=8.7 \mathrm{~Hz}, 1 \mathrm{H})$, $4.05(\mathrm{~s}, 3 \mathrm{H}), 3.95(\mathrm{~s}, 3 \mathrm{H}) \mathrm{ppm}$.

${ }^{13}$ C RMN (75.4 MHz, $\mathrm{CDCl}_{3}$ ): $\delta=148.9$ (C), 144.9 (C), 143.6 (C), 136.3 (C), 134.3 (C), 133.3 (C), 129.0 $(2 \times \mathrm{CH}), 128.4(\mathrm{CH}), 126.5(2 \times \mathrm{CH}), 117.7(\mathrm{CH}), 115.9(\mathrm{CH}), 112.6(\mathrm{CH}), 61.4\left(\mathrm{CH}_{3}\right), 57.0\left(\mathrm{CH}_{3}\right) \mathrm{ppm}$.

EMBR (IE), m/z (\%): 270 (M+1 100), 255 (44), 227 (19), 212 (57), 194 (33), 77 (69).

EMAR calculado para $\mathrm{C}_{16} \mathrm{H}_{14} \mathrm{O}_{2} \mathrm{~S}$ : 270.0715; encontrado: 270.0712 .

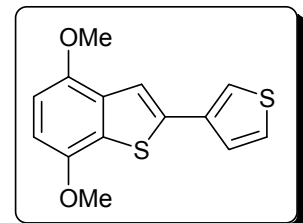

\section{4,7-Dimetoxi-2-(3-tienil)benzo $[b]$ tiofeno (85ca)}

Sólido blanco.

P.f. $=114-116^{\circ} \mathrm{C}$.

${ }^{1} \mathbf{H}$ RMN $\left(300 \mathrm{MHz}, \mathrm{CDCl}_{3}\right): \delta=7.58(\mathrm{~s}, 1 \mathrm{H}), 7.51(\mathrm{dd}, J=2.8,1.3 \mathrm{~Hz}, 1 \mathrm{H}), 7.45-7.42(\mathrm{~m}, 1 \mathrm{H}), 7.39-7.35(\mathrm{~m}$, $1 \mathrm{H}), 6.66(\mathrm{~s}, 2 \mathrm{H}), 3.96(\mathrm{~d}, J=1.2 \mathrm{~Hz}, 3 \mathrm{H}), 3.93(\mathrm{~d}, J=1.2 \mathrm{~Hz}, 3 \mathrm{H}) \mathrm{ppm}$.

${ }^{13}$ C RMN (75.4 MHz, $\left.\mathrm{CDCl}_{3}\right): \delta=149.4(\mathrm{C}), 148.6(\mathrm{C}), 138.3(\mathrm{C}), 135.9(\mathrm{C}), 132.6(\mathrm{C}), 129.1(\mathrm{C}), 126.6(\mathrm{CH})$, $126.2(\mathrm{CH}), 121.1(\mathrm{CH}), 116.7(\mathrm{CH}), 104.9(\mathrm{CH}), 104.5(\mathrm{CH}), 56.0\left(\mathrm{CH}_{3}\right), 55.9\left(\mathrm{CH}_{3}\right) \mathrm{ppm}$.

EMBR (IE), m/z (\%): 276 (M+ 92), 261 (100), 246 (52), 218 (35), 190 (19), 108 (31), 69 (31).

EMAR calculado para $\mathrm{C}_{14} \mathrm{H}_{12} \mathrm{O}_{2} \mathrm{~S}_{2}: 276.0279$; encontrado: 276.0285 . 


\section{B.3.2 Método B: Empleando triisopropilsilil tiol (TIPS-SH) como fuente de azufre}

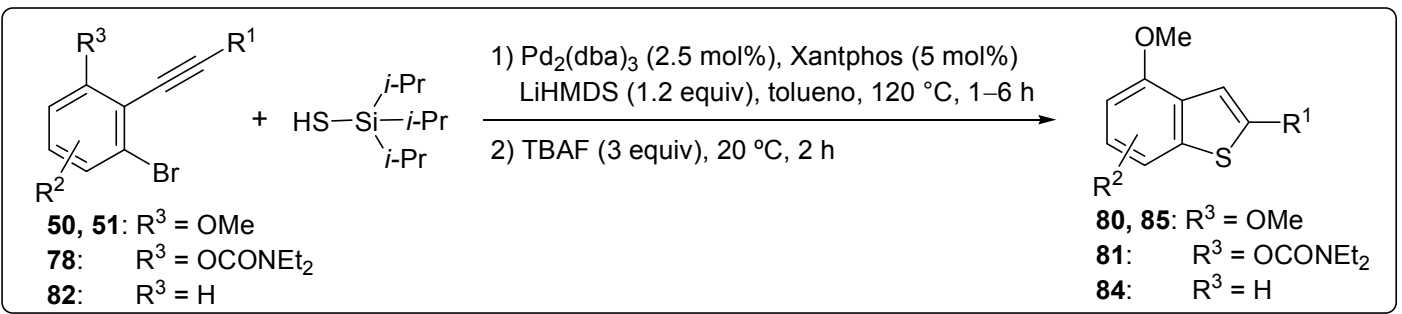

Una disolución del correspondiente 1-alquinil-2-bromobenceno (0.5 mmol), $\mathrm{Pd}_{2} \mathrm{dba}_{3}(12 \mathrm{mg}$, $2.5 \mathrm{~mol} \%)$, Xantphos (15 mg, $5 \mathrm{~mol} \%)$ y LiHMDS (600 $\mu \mathrm{L}$ de una disolución $1 \mathrm{M}$ en tolueno, 0.6 mmol) en tolueno seco $(1.5 \mathrm{~mL})$ se agita bajo atmósfera de $\mathrm{N}_{2}$ durante 2 minutos. Entonces se añade TIPS-SH $(129 \mu \mathrm{L}, 0.6 \mathrm{mmol})$ y la disolución resultante se calienta a $120^{\circ} \mathrm{C}$ hasta la desaparición del bromuro de arilo (1-6 horas), la cual se determina por CG-EM. A continuación se deja que la mezcla de reacción alcance temperatura ambiente y se adiciona $\mathrm{NBu}_{4} \mathrm{~F}(1.5 \mathrm{~mL}$ de una disolución $1 \mathrm{M}$ en THF, $1.5 \mathrm{mmol})$ y la mezcla se agita a $20^{\circ} \mathrm{C}$ durante 2 horas. Se añade AcOEt $(10 \mathrm{~mL})$ y $\mathrm{H}_{2} \mathrm{O}(10$ $\mathrm{mL})$. La fase acuosa separada se extrae con AcOEt $(2 \times 10 \mathrm{~mL})$. La fase orgánica se seca sobre $\mathrm{Na}_{2} \mathrm{SO}_{4}$ anhidro y se concentra a presión reducida. El residuo resultante se purifica mediante columna de cromatografía (hexano / AcOEt) obteniéndose los benzo $[b]$ tiofenos 80, 81, 84 ó 85. Los datos físicos y espectroscópicos de los compuestos 80a, 81, 84a-k, 85aa y 85ca han sido detallados anteriormente.

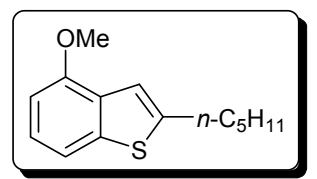

4-Metoxi-2-pentilbenzo[b]tiofeno (80b)

Líquido incoloro.

$\mathrm{R}_{\mathrm{f}}=0.44$ (hexano / AcOEt, 20 / 1).

${ }^{1}$ H RMN (300 MHz, $\left.\mathrm{CDCl}_{3}\right): \delta=7.39(\mathrm{~d}, J=8.1 \mathrm{~Hz}, 1 \mathrm{H}), 7.25-7.17(\mathrm{~m}, 2 \mathrm{H}), 6.73(\mathrm{~d}, J=8.1 \mathrm{~Hz}, 1 \mathrm{H}), 3.96(\mathrm{~s}$, $3 \mathrm{H}), 2.91(\mathrm{t}, J=7.6 \mathrm{~Hz}, 2 \mathrm{H}), 1.83-1.71(\mathrm{~m}, 2 \mathrm{H}), 1.43-1.35(\mathrm{~m}, 4 \mathrm{H}), 0.93(\mathrm{t}, J=7.0 \mathrm{~Hz}, 3 \mathrm{H}) \mathrm{ppm}$.

${ }^{13} \mathbf{C}$ RMN (75.4 MHz, $\left.\mathrm{CDCl}_{3}\right): \delta=154.3(\mathrm{C}), 145.4(\mathrm{C}), 140.8(\mathrm{C}), 130.8(\mathrm{C}), 124.4(\mathrm{CH}), 117.0(\mathrm{CH}), 114.7$ $(\mathrm{CH}), 104.0(\mathrm{CH}), 55.4\left(\mathrm{CH}_{3}\right), 31.4\left(\mathrm{CH}_{2}\right), 31.0\left(\mathrm{CH}_{2}\right), 30.8\left(\mathrm{CH}_{2}\right), 22.6\left(\mathrm{CH}_{2}\right), 14.1\left(\mathrm{CH}_{3}\right) \mathrm{ppm}$.

EMBR (IE), m/z (\%): 234 (M+ 38), 177 (100), 162 (30), 147 (14), 134 (23).

EMAR calculado para $\mathrm{C}_{14} \mathrm{H}_{18} \mathrm{OS}: 234.1078$; encontrado: 234.1081 .

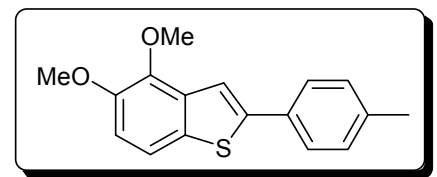

4,5-Dimetoxi-2-p-tolilbenzo $[b]$ tiofeno (85ab)

Sólido blanco.

P.f. $=86-88^{\circ} \mathrm{C}$.

${ }^{1}$ H RMN $\left(300 \mathrm{MHz}, \mathrm{CDCl}_{3}\right): \delta=7.69-7.60(\mathrm{~m}, 3 \mathrm{H}), 7.49(\mathrm{~d}, J=8.7 \mathrm{~Hz}, 1 \mathrm{H}), 7.30-7.20(\mathrm{~m}, 2 \mathrm{H}), 7.03(\mathrm{~d}, J=$ $8.7 \mathrm{~Hz}, 1 \mathrm{H}), 4.05(\mathrm{~s}, 3 \mathrm{H}), 3.96(\mathrm{~s}, 3 \mathrm{H}), 2.41(\mathrm{~s}, 3 \mathrm{H}) \mathrm{ppm}$.

${ }^{13} \mathbf{C}$ RMN (75.4 MHz, $\left.\mathrm{CDCl}_{3}\right): \delta=148.9$ (C), 145.1 (C), 143.5 (C), 138.4 (C), 136.4 (C), $133.2(\mathrm{C}), 131.5$ (C), $129.7(2 \times \mathrm{CH}), 126.4(2 \times \mathrm{CH}), 117.7(\mathrm{CH}), 115.3(\mathrm{CH}), 112.3(\mathrm{CH}), 61.4\left(\mathrm{CH}_{3}\right), 57.0\left(\mathrm{CH}_{3}\right), 21.3\left(\mathrm{CH}_{3}\right) \mathrm{ppm}$.

EMBR (IE), m/z (\%): 284 (M+1 100), 269 (42), 226 (87), 208 (42), 197 (23), 165 (18), 135 (23), 91 (37).

EMAR calculado para $\mathrm{C}_{17} \mathrm{H}_{16} \mathrm{O}_{2} \mathrm{~S}: 284.0871$; encontrado: 284.0870. 


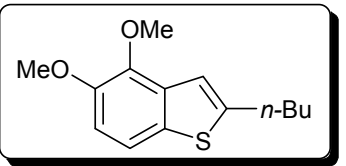

2-Butil-4,5-dimetoxibenzo[b]tiofeno (85ac)

Sólido blanco.

P.f. $=38-40{ }^{\circ} \mathrm{C}$.

${ }^{1} \mathbf{H}$ RMN $\left(300 \mathrm{MHz}, \mathrm{CDCl}_{3}\right): \delta=7.42(\mathrm{~d}, J=8.7 \mathrm{~Hz}, 1 \mathrm{H}), 7.10(\mathrm{~s}, 1 \mathrm{H}), 6.97(\mathrm{~d}, J=8.7 \mathrm{~Hz}, 1 \mathrm{H}), 3.97(\mathrm{~s}, 3 \mathrm{H})$, $3.92(\mathrm{~s}, 3 \mathrm{H}), 2.88(\mathrm{t}, J=7.6 \mathrm{~Hz}, 2 \mathrm{H}), 1.79-1.65(\mathrm{~m}, 2 \mathrm{H}), 1.50-1.36(\mathrm{~m}, 2 \mathrm{H}), 0.96(\mathrm{t}, J=7.3 \mathrm{~Hz}, 3 \mathrm{H}) \mathrm{ppm}$.

${ }^{13} \mathbf{C}$ RMN (75.4 MHz, $\left.\mathrm{CDCl}_{3}\right): \delta=148.7$ (C), 147.7 (C), $143.0(\mathrm{C}), 135.7(\mathrm{C}), 133.3$ (C), $117.6(\mathrm{CH}), 116.9$ $(\mathrm{CH}), 111.5(\mathrm{CH}), 61.3\left(\mathrm{CH}_{3}\right), 57.1\left(\mathrm{CH}_{3}\right), 33.3\left(\mathrm{CH}_{2}\right), 30.8\left(\mathrm{CH}_{2}\right), 22.3\left(\mathrm{CH}_{2}\right), 13.9\left(\mathrm{CH}_{3}\right) \mathrm{ppm}$.

EMBR (IE), m/z (\%): $250\left(\mathrm{M}^{+}, 100\right), 235$ (45), 207 (43), 163 (38), 149 (66), 134 (10), 121 (12).

EMAR calculado para $\mathrm{C}_{14} \mathrm{H}_{18} \mathrm{O}_{2} \mathrm{~S}: 250.1028$; encontrado: 250.1022 .

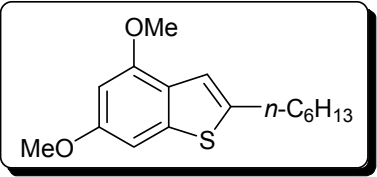

2-Hexil-4,6-dimetoxibenzo $[b]$ tiofeno (85ba)

Sólido blanco.

P.f. $=32-34^{\circ} \mathrm{C}$.

${ }^{1}$ H RMN $\left(300 \mathrm{MHz}, \mathrm{CDCl}_{3}\right): \delta=7.07(\mathrm{~s}, 1 \mathrm{H}), 6.86(\mathrm{~d}, J=1.9 \mathrm{~Hz}, 1 \mathrm{H}), 6.40(\mathrm{~d}, J=1.9 \mathrm{~Hz}, 1 \mathrm{H}), 3.91(\mathrm{~s}, 3 \mathrm{H})$, $3.85(\mathrm{~s}, 3 \mathrm{H}), 2.86(\mathrm{t}, J=7.5 \mathrm{~Hz}, 2 \mathrm{H}), 1.79-1.68(\mathrm{~m}, 2 \mathrm{H}), 1.45-1.28(\mathrm{~m}, 6 \mathrm{H}), 0.92(\mathrm{t}, J=6.9 \mathrm{~Hz}, 3 \mathrm{H}) \mathrm{ppm}$.

${ }^{13} \mathbf{C}$ RMN (75.4 MHz, $\left.\mathrm{CDCl}_{3}\right): \delta=158.1(\mathrm{C}), 154.7(\mathrm{C}), 142.4(\mathrm{C}), 141.4(\mathrm{C}), 125.1(\mathrm{C}), 116.5(\mathrm{CH}), 96.4(\mathrm{CH})$, 95.7 $(\mathrm{CH}), 55.7\left(\mathrm{CH}_{3}\right), 55.4\left(\mathrm{CH}_{3}\right), 31.7\left(\mathrm{CH}_{2}\right), 31.3\left(\mathrm{CH}_{2}\right), 30.8\left(\mathrm{CH}_{2}\right), 28.9\left(\mathrm{CH}_{2}\right), 22.7\left(\mathrm{CH}_{2}\right), 14.2$ $\left(\mathrm{CH}_{3}\right) \mathrm{ppm}$.

EMBR (IE), m/z (\%): $278\left(\mathrm{M}^{+}, 32\right), 207$ (100), 177 (4), 164 (7), 149 (8), 134 (13), 121 (8).

EMAR calculado para $\mathrm{C}_{16} \mathrm{H}_{22} \mathrm{O}_{2} \mathrm{~S}: 278.1341$; encontrado: 278.1339 .

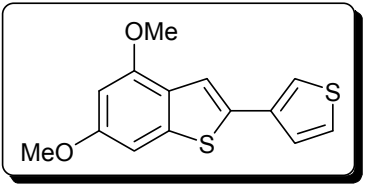

\section{4,6-Dimetoxi-2-(3-tienil)benzo[b]tiofeno (85bb)}

Sólido blanco.

P.f. $=106-108^{\circ} \mathrm{C}$.

${ }^{1}$ H RMN (300 MHz, $\left.\mathrm{CDCl}_{3}\right): \delta=7.49(\mathrm{~s}, 1 \mathrm{H}), 7.43-7.39(\mathrm{~m}, 2 \mathrm{H}), 7.38-7.34(\mathrm{~m}, 1 \mathrm{H}), 6.87(\mathrm{~d}, J=1.8 \mathrm{~Hz}, 1 \mathrm{H})$, $6.41(\mathrm{~d}, J=1.8 \mathrm{~Hz}, 1 \mathrm{H}), 3.93(\mathrm{~s}, 3 \mathrm{H}), 3.87(\mathrm{~s}, 3 \mathrm{H}) \mathrm{ppm}$.

${ }^{13} \mathbf{C}$ RMN $\left(75.4 \mathrm{MHz}, \mathrm{CDCl}_{3}\right): \delta=158.9$ (C), $155.3(\mathrm{C}), 141.2(\mathrm{C}), 136.1(\mathrm{C}), 134.8(\mathrm{C}), 126.4(\mathrm{CH}), 126.0$ $(\mathrm{CH}), 125.6(\mathrm{C}), 1201(\mathrm{CH}), 115.9(\mathrm{CH}), 96.3(\mathrm{CH}), 96.1(\mathrm{CH}), 55.7\left(\mathrm{CH}_{3}\right), 55.5\left(\mathrm{CH}_{3}\right) \mathrm{ppm}$.

EMBR (IE), m/z (\%): 276 (M $\left.\mathrm{M}^{+}, 100\right), 261$ (68), 218 (74), 190 (23), 145 (11), 127 (15), 69 (16).

EMAR calculado para $\mathrm{C}_{14} \mathrm{H}_{12} \mathrm{O}_{2} \mathrm{~S}_{2}$ : 276.0279; encontrado: 276.0279 .

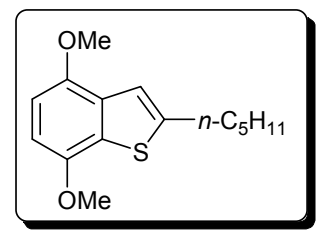

\section{4,7-Dimetoxi-2-pentilbenzo $[b]$ tiofeno $(85 \mathrm{cb})$}

Sólido blanco.

P.f. $=52-54^{\circ} \mathrm{C}$.

${ }^{1} \mathbf{H}$ RMN (300 MHz, CDCl$\left.)_{3}\right): \delta=7.19(\mathrm{t}, J=0.9 \mathrm{~Hz}, 1 \mathrm{H}), 6.67-6.59(\mathrm{~m}, 2 \mathrm{H}), 3.95(\mathrm{~s}, 3 \mathrm{H}), 3.92(\mathrm{~s}, 3 \mathrm{H}), 2.92(\mathrm{t}$, $J=7.5 \mathrm{~Hz}, 2 \mathrm{H}), 1.83-1.72(\mathrm{~m}, 2 \mathrm{H}), 1.44-1.36(\mathrm{~m}, 4 \mathrm{H}), 0.93(\mathrm{t}, J=7.0 \mathrm{~Hz}, 3 \mathrm{H}) \mathrm{ppm}$.

${ }^{13} \mathbf{C}$ RMN (75.4 MHz, $\left.\mathrm{CDCl}_{3}\right)$ : $\delta=148.8(\mathrm{C}), 148.6(\mathrm{C}), 146.1(\mathrm{C}), 132.2(\mathrm{C}), 129.3(\mathrm{C}), 117.6(\mathrm{CH}), 104.5(\mathrm{CH})$, $103.4(\mathrm{CH}), 55.9\left(\mathrm{CH}_{3}\right), 55.8\left(\mathrm{CH}_{3}\right), 31.3\left(\mathrm{CH}_{2}\right), 31.0\left(\mathrm{CH}_{2}\right), 30.8\left(\mathrm{CH}_{2}\right), 22.5\left(\mathrm{CH}_{2}\right), 14.1\left(\mathrm{CH}_{3}\right) \mathrm{ppm}$.

EMBR (IE), m/z (\%): 264 (M+ 75 ), 249 (100), 207 (54), 192 (44), 177 (82), 149 (35), 121 (13).

EMAR calculado para $\mathrm{C}_{15} \mathrm{H}_{20} \mathrm{O}_{2} \mathrm{~S}$ : 264.1184; encontrado: 264.1181 . 


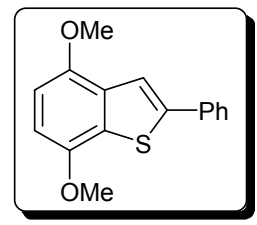

2-Fenil-4,7-dimetoxibenzo[b]tiofeno (85cc)

Sólido blanco.

P.f. $=126-128^{\circ} \mathrm{C}$.

${ }^{1}$ H RMN (300 MHz, $\left.\mathrm{CDCl}_{3}\right): \delta=7.81-7.74(\mathrm{~m}, 3 \mathrm{H}), 7.45(\mathrm{~m}, 2 \mathrm{H}), 7.35(\mathrm{~m}, 1 \mathrm{H}), 6.67(\mathrm{~d}, J=0.8 \mathrm{~Hz}, 2 \mathrm{H}), 3.97$ $(\mathrm{s}, 3 \mathrm{H}), 3.94(\mathrm{~s}, 3 \mathrm{H}) \mathrm{ppm}$.

${ }^{13}$ C RMN (75.4 MHz, $\left.\mathrm{CDCl}_{3}\right): \delta=149.4$ (C), 148.5 (C), 143.5 (C), 134.5 (C), 132.8 (C), 129.6 (C), 129.0 $(2 \times \mathrm{CH}), 128.1(\mathrm{CH}), 126.4(2 \times \mathrm{CH}), 116.7(\mathrm{CH}), 104.8(\mathrm{CH}), 104.5(\mathrm{CH}), 56.0\left(\mathrm{CH}_{3}\right), 55.8\left(\mathrm{CH}_{3}\right) \mathrm{ppm}$.

EMBR (IE), m/z (\%): 270 (M+ 75 ), 255 (100), 240 (40), 212 (46), 184 (19), 158 (22), 102 (36).

EMAR calculado para $\mathrm{C}_{16} \mathrm{H}_{14} \mathrm{O}_{2} \mathrm{~S}: 270.0715$; encontrado: 270.0712 .

\section{B.4 Procedimiento general para la síntesis de los benzo[b]tiofenos 3-funcionalizados 88}

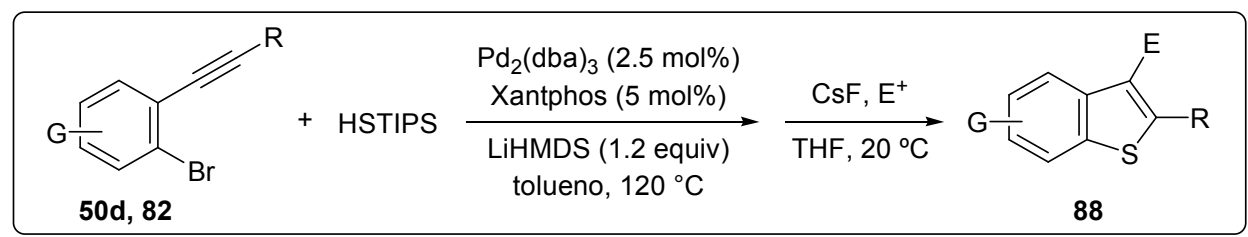

Una disolución del correspondiente 1-alquinil-2-bromobenceno ( $0.5 \mathrm{mmol}), \mathrm{Pd}_{2} \mathrm{dba}_{3}(12 \mathrm{mg}$, $2.5 \mathrm{~mol} \%)$, Xantphos (15 mg, $5 \mathrm{~mol} \%)$ y LiHMDS $(600 \mu \mathrm{L}$ de una disolución $1 \mathrm{M}$ en tolueno, 0.6 mmol) en tolueno seco $(1.5 \mathrm{~mL})$ se agita bajo atmósfera de $\mathrm{N}_{2}$ durante 2 minutos. Entonces se añade TIPS-SH $(129 \mu \mathrm{L}, 0.6 \mathrm{mmol})$ y la disolución resultante se calienta a $120^{\circ} \mathrm{C}$, hasta la desaparición del bromuro de arilo (1-3 horas), la cual se determina por CG-EM. La mezcla de reacción se filtra a través de una columna corta de alúmina neutra, empleando $50 \mathrm{~mL}$ de una mezcla (hexano / $\mathrm{Et}_{2} \mathrm{O}, 2$ / 1) como eluyente. Los disolventes se evaporan a vacío, bajo $\mathrm{N}_{2}$. Sin más purificación, el crudo de reacción se disuelve en THF seco $(2 \mathrm{~mL})$ bajo atmósfera de $\mathrm{N}_{2}$ y se añade el correspondiente electrófilo (1.5 mmol). La mezcla de reacción se transfiere a un Schlenck que contiene CsF (228 mg, $1.5 \mathrm{mmol}$ ) y tamiz molecular activado (200-250 mg, $4 \AA$ ), precalentado a $140{ }^{\circ} \mathrm{C}$ durante $2-4$ horas bajo vacío y enfriado bajo atmosfera de $\mathrm{N}_{2}$. La mezcla de reacción se agita a temperatura ambiente durante 12 horas (la ciclación se monitoriza por CG-EM). A continuación se añade AcOEt $(10 \mathrm{~mL})$ y $\mathrm{H}_{2} \mathrm{O}(10 \mathrm{~mL})$. La fase acuosa separada se extrae con AcOEt $(2 \times 10 \mathrm{~mL})$. La fase orgánica se seca sobre $\mathrm{Na}_{2} \mathrm{SO}_{4}$ anhidro y se concentra a presión reducida. El residuo resultante se purifica mediante columna de cromatografía (hexano / AcOEt) obteniéndose los benzo[b]tiofenos 3-funcionalizados 88.

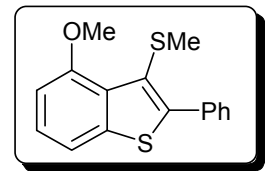

2-Fenil-3-(metiltio)-4-metoxibenzo[b]tiofeno (88a)

Sólido blanco.

P.f. $=105-107^{\circ} \mathrm{C}$.

${ }^{1}$ H RMN (300 MHz, $\mathrm{CDCl}_{3}$ ): $\delta=7.67-7.57(\mathrm{~m}, 2 \mathrm{H}), 7.51-7.39(\mathrm{~m}, 3 \mathrm{H}), 7.33-7.26(\mathrm{~m}, 2 \mathrm{H}), 6.87(\mathrm{~d}, J=7.8 \mathrm{~Hz}$, $1 \mathrm{H}), 4.02(\mathrm{~s}, 3 \mathrm{H}), 2.35(\mathrm{~s}, 3 \mathrm{H}) \mathrm{ppm}$.

${ }^{13} \mathbf{C}$ RMN (75.4 MHz, $\left.\mathrm{CDCl}_{3}\right): \delta=156.3$ (C), 144.5 (C), 140.6 (C), 134.5 (C), $130.54(2 \times \mathrm{CH}), 130.47$ (C), 128.5 $(\mathrm{CH}), 128.3(2 \times \mathrm{CH}), 125.7(\mathrm{CH}), 123.3(\mathrm{C}), 115.2(\mathrm{CH}), 106.3(\mathrm{CH}), 56.0\left(\mathrm{CH}_{3}\right), 21.1\left(\mathrm{CH}_{3}\right) \mathrm{ppm}$.

EMBR (IE), m/z (\%): $286\left(\mathrm{M}^{+}, 100\right), 256(61), 240$ (38). 
EMAR calculado para $\mathrm{C}_{16} \mathrm{H}_{14} \mathrm{OS}_{2}$ : 286.0486; encontrado: 286.0489 .

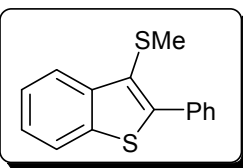

2-Fenil-3-(metiltio)benzo[b]tiofeno (88b)

Sólido blanco.

P.f. $=88-90^{\circ} \mathrm{C}$.

${ }^{1} \mathbf{H}$ RMN $\left(300 \mathrm{MHz}, \mathrm{CDCl}_{3}\right): \delta=8.06(\mathrm{~d}, J=7.9 \mathrm{~Hz}, 1 \mathrm{H}), 7.86(\mathrm{~d}, J=7.9 \mathrm{~Hz}, 1 \mathrm{H}), 7.82-7.72(\mathrm{~m}, 2 \mathrm{H})$, 7.57-7.32 (m, 5H), $2.27(\mathrm{~s}, 3 \mathrm{H}) \mathrm{ppm}$.

${ }^{13}$ C RMN (75.4 MHz, $\left.\mathrm{CDCl}_{3}\right): \delta=146.2(\mathrm{C}), 141.3(\mathrm{C}), 138.4(\mathrm{C}), 134.0(\mathrm{C}), 130.0(2 \times \mathrm{CH}), 128.7(\mathrm{CH}), 128.5$ $(2 \times \mathrm{CH}), 125.0(\mathrm{CH}), 124.9(\mathrm{CH}), 123.6(\mathrm{CH}), 122.4(\mathrm{CH}), 19.1\left(\mathrm{CH}_{3}\right) \mathrm{ppm}$.

EMBR (IE), m/z (\%): 256 (M+, 76), 240 (100), 208 (23), 163 (22), 120 (82), 69 (58).

EMAR calculado para $\mathrm{C}_{15} \mathrm{H}_{12} \mathrm{~S}_{2}$ : 256.0380; encontrado: 256.0372 .

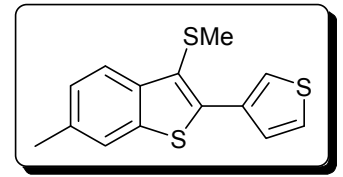

6-Metil-3-(metiltio)-2-(3-tienil)benzo[b]tiofeno (88c)

Sólido blanco.

P.f. $=78-80^{\circ} \mathrm{C}$.

${ }^{1} \mathbf{H}$ RMN $\left(300 \mathrm{MHz}, \mathrm{CDCl}_{3}\right): \delta=8.01(\mathrm{dd}, J=2.9,1.2 \mathrm{~Hz}, 1 \mathrm{H}), 7.87(\mathrm{~s}, 1 \mathrm{H}), 7.73(\mathrm{dd}, J=5.0,1.2 \mathrm{~Hz}, 1 \mathrm{H}), 7.70(\mathrm{~d}, J$ $=8.2 \mathrm{~Hz}, 1 \mathrm{H}), 7.42(\mathrm{dd}, J=5.0,2.9 \mathrm{~Hz}, 1 \mathrm{H}), 7.23(\mathrm{dd}, J=8.2,0.9 \mathrm{~Hz}, 1 \mathrm{H}), 2.57(\mathrm{~s}, 3 \mathrm{H}), 2.33(\mathrm{~s}, 3 \mathrm{H}) \mathrm{ppm}$.

${ }^{13} \mathbf{C}$ RMN (75.4 MHz, $\mathrm{CDCl}_{3}$ ): $\delta=141.8(\mathrm{C}), 141.2(\mathrm{C}), 134.8(\mathrm{C}), 134.7$ (C), 134.5 (C), $128.4(\mathrm{CH}), 126.8$ $(\mathrm{CH}), 125.6(\mathrm{CH}), 124.8(\mathrm{CH}), 123.3(\mathrm{CH}), 122.5(\mathrm{C}), 122.0(\mathrm{CH}), 21.7\left(\mathrm{CH}_{3}\right), 18.80\left(\mathrm{CH}_{3}\right) \mathrm{ppm}$.

EMBR (IE), m/z (\%): $276\left(\mathrm{M}^{+}, 100\right), 261$ (69), 246 (72).

EMAR calculado para $\mathrm{C}_{14} \mathrm{H}_{12} \mathrm{~S}_{3}: 276.0101$; encontrado: 276.0092 .

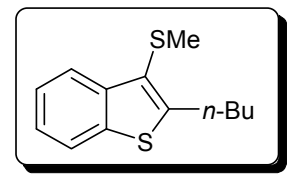

\section{2-Butil-3-(metiltio)benzo[b]tiofeno (88d)}

Líquido incoloro.

$\mathrm{R}_{\mathrm{f}}=0.44$ (hexano / AcOEt, 50 / 1).

${ }^{1} \mathbf{H}$ RMN (300 MHz, $\left.\mathrm{CDCl}_{3}\right): \delta=7.92(\mathrm{~d}, J=7.9 \mathrm{~Hz}, 1 \mathrm{H}), 7.78(\mathrm{~d}, J=8.1 \mathrm{~Hz}, 1 \mathrm{H}), 7.44-7.39(\mathrm{~m}, 1 \mathrm{H}), 7.36-7.28$ $(\mathrm{m}, 1 \mathrm{H}), 3.14(\mathrm{t}, J=7.6 \mathrm{~Hz}, 2 \mathrm{H}), 2.30(\mathrm{~s}, 3 \mathrm{H}), 1.72(\mathrm{~m}, 2 \mathrm{H}), 1.44(\mathrm{~m}, 2 \mathrm{H}), 0.97(\mathrm{t}, J=7.4 \mathrm{~Hz}, 3 \mathrm{H}) \mathrm{ppm}$.

${ }^{13} \mathbf{C}$ RMN (75.4 MHz, $\left.\mathrm{CDCl}_{3}\right): \delta=150.9(\mathrm{C}), 140.7(\mathrm{C}), 138.0(\mathrm{C}), 124.6(\mathrm{CH}), 124.3(\mathrm{CH}), 123.4(\mathrm{C}), 122.7$ $(\mathrm{CH}), 122.5(\mathrm{CH}), 33.8\left(\mathrm{CH}_{2}\right), 29.3\left(\mathrm{CH}_{2}\right), 22.5\left(\mathrm{CH}_{2}\right), 18.7\left(\mathrm{CH}_{3}\right), 14.0\left(\mathrm{CH}_{3}\right) \mathrm{ppm}$.

EMBR (IE), m/z (\%): $236\left(\mathrm{M}^{+}, 100\right), 193$ (99), 179 (40), 147 (43).

EMAR calculado para $\mathrm{C}_{13} \mathrm{H}_{16} \mathrm{~S}_{2}$ : 236.0693; encontrado: 236.0692 .

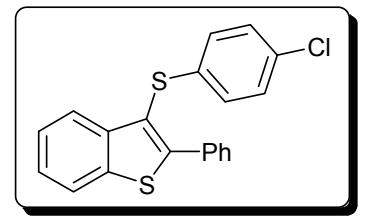

3-(4-Clorofeniltio)-2-fenilbenzo[b]tiofeno (88e)

Sólido marrón.

P.f. $=110^{\circ} \mathrm{C}($ descomposición $)$.

${ }^{1} \mathbf{H}$ RMN (300 MHz, $\left.\mathrm{CDCl}_{3}\right): \delta=7.93-7.86(\mathrm{~m}, 1 \mathrm{H}), 7.84-7.77(\mathrm{~m}, 1 \mathrm{H}), 7.75-7.63(\mathrm{~m}, 2 \mathrm{H}), 7.50-7.36(\mathrm{~m}, 5 \mathrm{H})$, $7.15(\mathrm{~d}, J=8.5 \mathrm{~Hz}, 2 \mathrm{H}), 6.98(\mathrm{~d}, J=8.5 \mathrm{~Hz}, 2 \mathrm{H}) \mathrm{ppm}$.

${ }^{13} \mathbf{C}$ RMN (75.4 MHz, $\mathrm{CDCl}_{3}$ ): $\delta=150.1$ (C), 140.8 (C), 138.5 (C), 136.3 (C), 133.3 (C), 133.2 (C), 129.9 $(2 \times \mathrm{CH}), 129.21(2 \times \mathrm{CH}), 129.17(\mathrm{CH}), 128.6(2 \times \mathrm{CH}), 127.5(2 \times \mathrm{CH}), 125.4(\mathrm{CH}), 125.3(\mathrm{CH}), 123.8$ $(\mathrm{CH}), 122.4(\mathrm{CH}), 118.0(\mathrm{C}) \mathrm{ppm}$.

EMBR (IE), m/z (\%): $334\left(\mathrm{M}^{+}+2,33\right), 332\left(\mathrm{M}^{+}, 100\right), 289$ (37), 254 (80), 221 (36).

EMAR calculado para $\mathrm{C}_{20} \mathrm{H}_{13} \mathrm{ClS}_{2}: 352.0147$; encontrado: 352.0143 . 


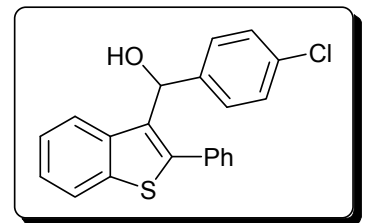

(4-Clorofenil)(2-fenil-3-benzo[b]tiofenil)metanol (88f)

Sólido blanco.

P.f. $=88-90^{\circ} \mathrm{C}$.

${ }^{1} \mathbf{H}$ RMN $\left(300 \mathrm{MHz}, \mathrm{CDCl}_{3}\right): \delta=7.84(\mathrm{~d}, J=8.0 \mathrm{~Hz}, 1 \mathrm{H}), 7.64(\mathrm{~d}, J=8.0 \mathrm{~Hz}, 1 \mathrm{H}), 7.55-7.50(\mathrm{~m}, 2 \mathrm{H})$, 7.47-7.41 (m, 3H), 7.40-7.25 (m, 5H), 7.25-7.18 (m, 1H), $6.21(\mathrm{~s}, 1 \mathrm{H}), 2.56(\mathrm{sa}, 1 \mathrm{H}) \mathrm{ppm}$.

${ }^{13} \mathbf{C}$ RMN (75.4 MHz, $\left.\mathrm{CDCl}_{3}\right): \delta=142.6(\mathrm{C}), 140.9(\mathrm{C}), 139.6(\mathrm{C}), 138.1(\mathrm{C}), 133.6(\mathrm{C}), 133.0(\mathrm{C}), 132.2(\mathrm{C})$, $129.8(2 \times \mathrm{CH}), 128.93(2 \times \mathrm{CH}), 128.88(\mathrm{CH}), 128.6(2 \times \mathrm{CH}), 127.6(2 \times \mathrm{CH}), 124.7(\mathrm{CH}), 124.6(\mathrm{CH}), 124.4$ $(\mathrm{CH}), 122.3(\mathrm{CH}), 69.3(\mathrm{CH}) \mathrm{ppm}$.

EMBR (IE), m/z (\%): 350 (M , 4), 334 (26), 332 (71), 295 (29), 221 (84), 176 (34), 111 (55), 75 (100).

EMAR calculado para $\mathrm{C}_{21} \mathrm{H}_{15}$ ClOS: 350.0532 ; encontrado: 350.0535 .

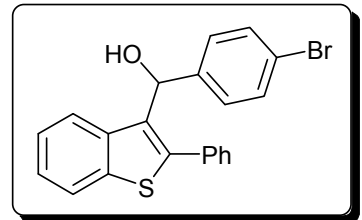

(4-Bromofenil)(2-fenil-3-benzo[b]tiofenil)metanol (88g)

Sólido marrón.

P.f. $=120^{\circ} \mathrm{C}$ (descomposición).

${ }^{1} \mathbf{H}$ RMN $\left(300 \mathrm{MHz}, \mathrm{CDCl}_{3}\right): \delta=7.83(\mathrm{~d}, J=8.0 \mathrm{~Hz}, 1 \mathrm{H}), 7.63(\mathrm{~d}, J=8.0 \mathrm{~Hz}, 1 \mathrm{H}), 7.57-7.37(\mathrm{~m}, 7 \mathrm{H}), 7.35$ $7.15(\mathrm{~m}, 4 \mathrm{H}), 6.19(\mathrm{~s}, 1 \mathrm{H}), 2.29(\mathrm{sa}, 1 \mathrm{H}) \mathrm{ppm}$.

${ }^{13}$ C RMN (75.4 MHz, $\left.\mathrm{CDCl}_{3}\right): \delta=142.7$ (C), $141.4(\mathrm{C}), 139.6$ (C), 138.0 (C), 133.6 (C), 132.1 (C), 131.5 $(2 \times \mathrm{CH}), 129.8(2 \times \mathrm{CH}), 129.0(2 \times \mathrm{CH}), 128.9(\mathrm{CH}), 128.0(2 \times \mathrm{CH}), 124.65(\mathrm{CH}), 124.59(\mathrm{CH}), 124.4$ $(\mathrm{CH}), 122.3(\mathrm{CH}), 121.2(\mathrm{C}), 69.3(\mathrm{CH}) \mathrm{ppm}$.

EMBR (IE), m/z (\%): $396\left(\mathrm{M}^{+}+2,67\right), 394\left(\mathrm{M}^{+}, 67\right), 211$ (100).

EMAR calculado para $\mathrm{C}_{21} \mathrm{H}_{15}$ BrOS: 394.0027; encontrado: 394.0028 . 